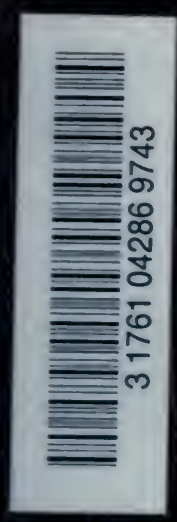




\section{THE LIBRARY FACULTY OF PHARMACY UNIVERSITY OF TOFOAYC OCT 141959}




\section{-}




SUPPLEMENT TO THE PHARMACOPOEIA,

\section{AND \\ T R E A T I S \\ COLLEGE \\ ox \\ PHARMACÓLOGY \\ IN GENERAL;}

INCLUDING NOT ONLY THE.

1) RUGS AND PREPARATIONS USED BY

PRAC'TITIONERS OF MEDICINE,

BUT ALSO

MOST OF THOSE EMPLOYED IN THE CHEMICAL ARTS; TOGETHER WITH

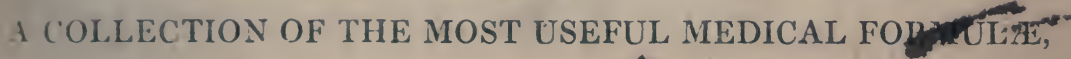

VETERINARY DRUGS, PATENT MEDICINEs, A other cómpounds;

An Explanation of the Contractions used by Physicians and Asuggists;

$$
\text { AND ALSO }
$$

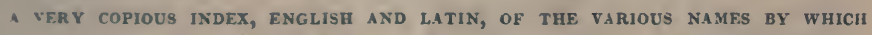
THE ARTICLES HAVE BEEN KNOWN AT DIFFERENT PERIODS:

$$
\text { BEING A }
$$

COMPLETE DISPEXSATORY, AND BOOK FORMULE, FOR CONSTANT REFERENCE IN MEDICAL AND VETERINARY PRACTICE, AND MANUAL FOR RETAIL DRUGGISTS.

TIE SIXTH EDITION, CONSIDERABLY ENLARGED:

$$
\text { INCLUDING THE NEW FRENCH MEDICINEA, }
$$

AND SELFCTIONB FROM FOREIGN PHARMACOPGIAS, AND FROM THE FORMULE OF BRITISH $\triangle N D$ FOREIGN HOSPITALS.

By SAMUEL FREDERIC GRAY,

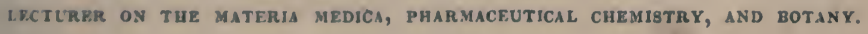

\section{LONDON :}

I,ONGMAN, REES, ORME, BROWN, GREEN, AND LONGMAN ; SIMPKIN,

MARSHALL, AND CO.; SHERWOOD, GILBERT, AND PIPER;

HENIRY RENSHAW; JOHN CHUICHHLL, \& E. COX. 

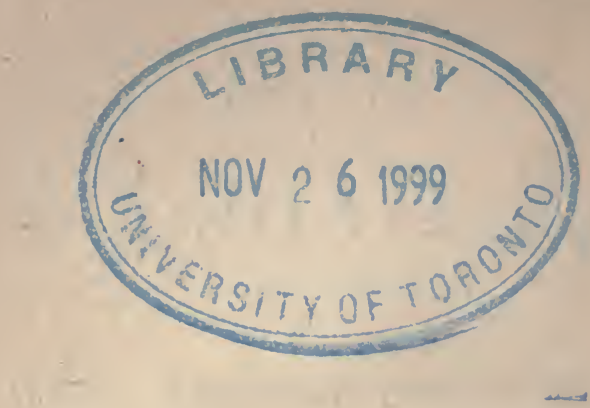

$\cdot$

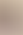

\section{PHAEMACY LBRAPY UNIVERSTYY OF TOAONJO}

LONDON :

BRADBURY AND FVANS, PRINTFR:, WHITFFRIAS. 


\section{ONTARIO \\ COLLEGE OF PHARIIACY \\ 44 GERRARD ST. E. \\ TORONTO.}

\section{NOTE BY EDITOR.}

THE improvements made in the present Edition are, - several directions for Pharmaceutical and Chemical Manipulation have been prefixed, the importance and advantage of which will be readily acknowledged; several new Medicines and Formulæ have been added, so as to bring the work up to the present improved state of Medical and Pharmaceutical Science. The Officinal Preparations of the principal articles of the Materia Medica, as adopted in the three British Pharmacopœias, as well as their medical uses, have been introduced, wherever it appeared necessary.

Los dos, July 27, 1836. 
P 1

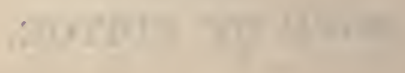

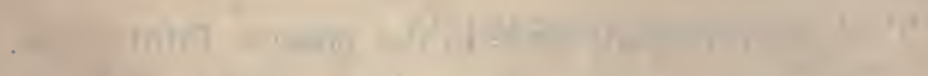

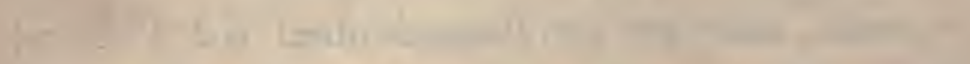

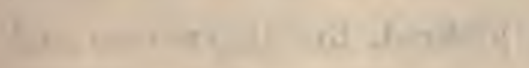

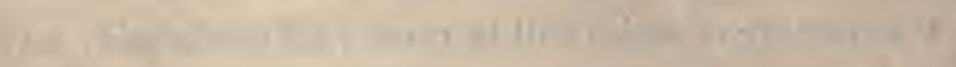

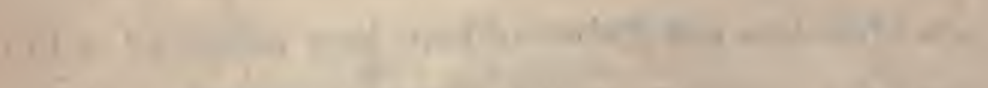

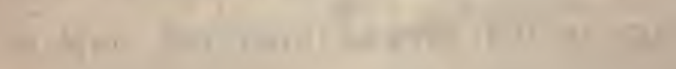

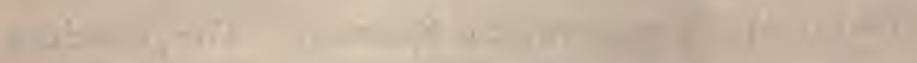

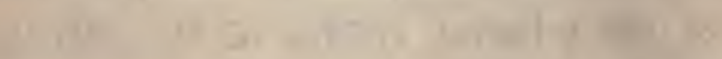

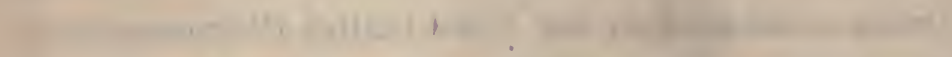

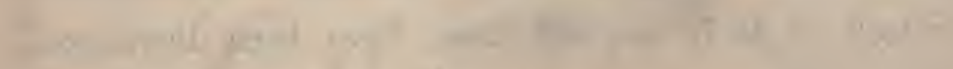

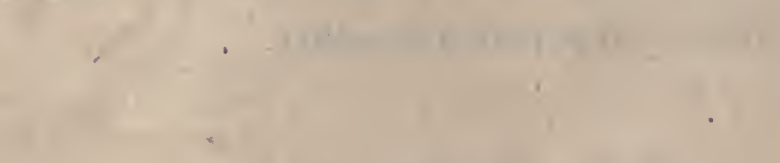

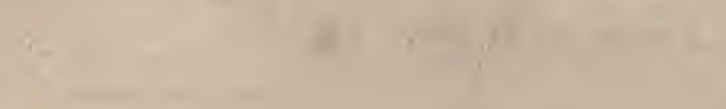




\section{O N T E N T S.}

Note by the Editor of this \begin{tabular}{l|l} 
PAGE & Fermented doughs and ferments 174
\end{tabular}

Edition . . . v

Preface . . . . ix

Pharmacopœia . . . xii

Apothecaries Act $\quad$ xxii

English Weights . . $\mathbf{x x x v}$

French Weights $\quad$ xxxviii

English Measures . $\quad$. $\quad x l$

French Measures . xli

Specific gravity and Hydrometers . . . xlii

Thermometers and Temperatures

Contractiuns used in prescribing, and in medical writings xlviii
A. Organic bodies, or their parts.

I. Vegetables

II. Aximals

B. Substances not organized.

I11. Compound Combustibles not or an olly Nature.

(a) Of vegetable origin.

\begin{tabular}{|c|c|c|c|}
\hline Sugars & • & - & . 148 \\
\hline Gums & . & & .152 \\
\hline Gum resins & . & • & . 154 \\
\hline Watery juices & . & & . 158 \\
\hline Watery extracts & - & - & . 160 \\
\hline Mixed extracts & • & & .164 \\
\hline Farinas and Feculas & & . & .165 \\
\hline Spirituous liquors & • & & .169 \\
\hline
\end{tabular}

Roasted vegetable substances $\quad 176$

(b) Of animal origin.

Animal secretions and excretions 177 Morbid concretions . . 181

Gelatinous extracts $\quad . \quad 182$

(c) Of mineral origin. $\quad 182$

IV. Compound Combustibles of aN OILY Nature.

(a) Of vegetable origin.

Mucilaginous oils $\quad . \quad 183$

Vegetable butters . . . 188

Essential oils . . $\quad . \quad 189$

Distilled vegetable oils . 195

Camphire . . . 198

Ethers . . . . 199

Turpentines and Balsams $\quad .200$

Rosins . . 20:3

Resinous extracts $\quad$. 209

Glutinous matters . . . 214

(b) Of animal origin.

Animal oils and fats . $\quad .215$

Bees'wax . . . . 218

Animal resins $\quad . \quad 218$

Distilled animal oils $\quad . \quad 220$

(c) Of mineral origin.

Mineral oils $\quad . \quad \ldots \quad .220$ 


V. Simple Combustibles.
Charcoal
Sulphurs

VI. Metals.

Metallic sulphurets, \&c. $\quad .226$ Metals . . . . 230 Metallic oxides . . . 235 Metallic subsalts . . . 243 Metallic salts . . $\quad 252$

VII. Earths and Atralies.

Earths and clays $\quad . \quad 261$ Stones and glasses . $\quad . \quad 268$ Alkalies and their carbonates . 272 Neutral Salts . . . 279 Salts of the vegetable alkalies . 290

\section{AcIDs.}

Of vegetable origin $\quad . \quad .293$

Of animal origin $\quad . \quad$. $\quad .300$

Of mineral origin $\quad$. 302

IX. WATERY Liquids.

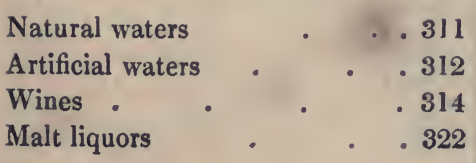

X. Gages and Fumigatiuns.

Gases ·
Fumigations
-

XI. Liquid Compounds, not oily.

Distilled waters $\quad . \quad .325$

Infusions . . . 331

Decoctions . . . 334

Mucilages and jellies $\quad . \quad 336$

Emulsions and Lohochs . 339

Iced creams, orgeats, \&c. . $\quad .340$

Watery mixtures . . 341

Impregnated wines $\quad . \quad .364$

Impregnated vinegars . $\quad .367$

Ammoniata . . .370

Compound spirits $\quad$. $\quad .374$

Tinctures $\quad$. . . 382

Syrups and liqueurs . $\quad 405$

XII. CoMpodnds, NeITHER LIQUid NOR OILY.

Conserves, \&c. $\quad$. $\quad . \quad .418$

Electuaries and linctuses $\quad .420$

Pills and pill masses _. .433

Boluses and balls $\quad . \quad .442$

Hard confections, \&c. . . .446

Powders, stones, \&c. . . . 453

XIII. Oily or greasy ComPOUNDS.

Compound oils . $\quad . \quad .477$

Soaps . . . . 484

Ointments . . . . 488

Plasters . . . . 502

Xiv. Apparatus and Chests.

Apparatus, \&c. . $\quad$. $\quad .513$

Index. 


\section{ONTARIO \\ COLLEGE OF PHARPGACY \\ 44 GERRARD ST. E. \\ TORONTO.}

P R E F A C E.

As physicians do not themselves prepare the medicines they exhibit to their patients, it is very convenient for them to intimate to the neighbouring retailers, whom the sick employ for th is purpose, the medicines they are likely to order, and the mode in which they wish certain compounds, that require time for their preparation, should be kept ready in the shops: this, and this alone, is the true office of a Pharmacopoia. And indèed the Faculty of Medicine in Paris, in the Preface to their Codex Medicamentarius, or Pharmacopoia, expressly disclaim any intention of hindering practitioners from using other remedies, or shopkeepers from keeping other articles, besides what are mentioned by them; and further observe, that they have inserted several popular medicines, although not likely to be ordered by the faculty themselves, in order that they may be uniformly prepared, and of course uniform in their action.

Before the publication of local Pharmacopoias, the apothecaries kept in their shops the six following books: Avicenna on Simples; Serapion on the same subject; Simon Januensis De Synonymis, and his Quid pro Quo on Substitutes; the Liber Servitoris of Bulchasim Ben Aberazerin, treating of the preparation of minerals, plants, and animals, similar to the chemical part of the modern Pharmacopocias; the Antidotarium of Johannes Damascenus or Mesue, arranged in classes like the Galenical part of our present Pharmacopœias; and the Antidotarium of Nicolaus de Salerno, containing these Galenical compounds, arranged alphabetically, of which there were two editions in use: in the common edition, or Nicolaus Parvus, as it was called, several of the compositions of the Nicolaus Magnus were 
omitted, and those that were retained were directed to be made upon a smaller scale than in the other.

The London College of Physicians first published, or rather distributed aniongst the apothecaries, a Pharmacopoia of their own in May 1618, selected from the two latter of these works, with a few additions from the modern authors then in repute; but this work was found so full of errors, that it was obliged to be called in immediately, the whole impression cancelled, and a new edition published in December following. This Pharmacopœia was published, like all the succeeding ones, in Latin; being intended, in the language of the preface, for the fili Apollinis only. Indeed, the college appear to have been very angry with Culpeper for translating it and the works of the principal authors on medicine into the vulgar tongue, refusing him, as it should seem, although educated at Cambridge, a licence to practise, and thus converting him into a bitter enemy. Unfortunately, the great popularity of his writings, still considered as classical amongst the common people, gave a currency to his opinions, and exposed the college to much obloquy.

The difficulties placed upon an admission into the college, originally with a view to confine the members to a small number, like the contemporaneous monopoly of the proctors of the civil and canon law, naturally led those who found themselves excluded to endeavour to evade its powers, at first by merely advising their patients to buy some medicine which had been prescribed by a member of the college for a similar complaint: a practice which some physicians, as Daffy, Goddard, \&c., in Charles the Second's reign, endeavoured to counteract, by ordering a nostrum, which could only be had at their.own house, or that of a confidential apothecary, in most of their prescriptions, communicating, however, the preparation to their fellow-members of the college under the seal of secrecy for their life; while others, as Merrett, Mortimer, \&c., furnished their patients with the necessary medicines, without any other charge than their usual fee.

Afterwards the unlicensed practitioners, or apothecaries, did not think it necessary to confine themselves to recommending the prescriptions of physicians, but acted upon their own judgments, especially when the House of Lords decided the case of 
the College $x$. Rose, for selling medicines not ordered by a physician to a patient, in their favour. Hence that preferable mode of the practice of medicine, resting entirely in the hands of prescribers, was altered, by the college confining their licences exclusively to those bred up in academical learning, which, however ornamental to its possessor, is certainly not essential to success in practice; not considering how much better it were to have had unlearned physicians for their brethren, than to convert the dispensers into rivals. It seems as if the college were afterwards sensible of their error, by their publishing a statute, inviting unlearned practitioners to be examined in the vulgar tongue, in any part of physic they might choose, and offering to license them for whatever department they might be found qualified.

Whether the state of medical practice, produced by the difficulties thus laid upon practising as a prescriber, is of advantage to the public, may be doubted; as, from the mode adopted to cvade the laws respecting it, by the practitioner pretending only to sell medicine, patients are frequently obliged to swallow more medicines than are necessary, that the apothecary, or dispensing practitioner, may be compensated for his attendance. Those medicines must, in most cases, be made unpalatable, lest the patient should conceive himself to be furnished with mere slops for the sake of a charge being made. And, as the medicines are prepared by the practitioner himself, a patient standing in some peculiar circumstances may be poisoned without much danger of detection. It is but a few years since a respectable practitioner, in the west of England, was tried for this crime, to which he was supposed to be impelled by the desire of hastening the receipt of the patient's, his mother-in-law, property; and several similar cases have occurred both in England and France. Against all these disadvantages the public have only the convenience of having medical attendance and medicines upon credit. It is singular that the House of Lords did not, in their decision upon Rose's case, perceive the great danger that arose from allowing the compatibility of medical practice with the dispensing of medicines, which has long been forbidden in some of the best regulated continental states; in order that the dispenser may serve as a check upon the prescriber, advise with him if any accidental error is suspected to occur in the prescriptions, and by keeping the pre- 
scriptions themselves, enable them to be exhibited in case of any untoward event occurring.

'I'his danger has been greatly increased of late by the almost universal junction of midwifery with apothecary practice, since midwifery accustoms the general practitioner to consider the saving or destruction of a human life as a mere matter of calculation; as also by the recent extension of our knowledge respecting vegetable poisons, and by the great attention which is now called to the subject by the present fashionable study of medical jurisprudence; there being reason to apprehend, from the imitative habits of mankind, that reading detailed accounts of crimes rouses in some cases the latent sparks of vice, and at the best serves to perfect badly-inclined persons in devising the securest modes of effecting their purpose.

To the original Pharmacopoia some additions were made in 1627 and 1635 ; and in 1650 an improved edition came forth, to which further additions were made in 1677. No alterations of much consequence, however were made until 1720, when a new edition was published under the anmpices of Sir Hans Sloane. He being a botanist, the botanical names of the platitswere added to the officinal names, which was a great improvement.

In a new edition, published in 1745 , the system of curtailment, begun by the Edinburgh College in 1738, was pursued to a considerable extent, no compound being admitted but what had a majority of voices in favour of its insertion: it was also at first proposed to omit the drugs entirely, then to give only a list of those used in making up the compounds in the work; and at last a list was made out of those which the majority of the committee supposed to be the most efficacious, and the botanical names were omitted. In this edition, the college first began the practice of changing the names of articles, on account of the alleged impropriety of their significations-a practice which has since been carried to the greatest excess.

Respecting the curtailments that were thus made in this edition, and which have occasioned the decline of pharmacological knowledge among the profession, it may be observed, that the object of a Pharmacopoia being to fix the composition of whatever medicines physicians might be likely to order, it is evident that the very contrary course to that pursued by the committee 
ought to have been adopted : the real duty of these committees seeming to be confined to correcting any defects in the standing medicines of the shops, to the rejection of those entirely obsolete, and the addition of whatever new compositions may be proposed by any of the members, after the best general mode of preparing them has been discussed; nor does it seem necessary to wait for a new edition for the regulation of these additions, which, when very active, as Prussic acid, vinum colchici, and the like, require an uniformity of preparation to be speedily instituted; as an official communication might be made to the society of apothecaries, the different medical journals, and the teachers of materia medica, for the information of the profession.

As the edition of 1745 excelled in Galenic pharmacy, the next, of 1788 , may be regarded as the best compendium of chemical pharmacy the college has produced. Some new names were, indeed, introduced from Bergmann, but they were only such as the improved state of that science called for. In the Galenical compositions simplicity was pursued to the utmost, and probably to an injurious extent; since it is well known, that a mixture of drugs will frequently have more effect than the same quantity of either of them separately, and a mixture of spices is more agreeable than any of them alone.

The edition of 1809 is chiefly remarkable for the entire adoption of the chemical nomenclature of Lavoisier and his coadjutors. It does not appear that any necessity existed for this adoption of Lavoisier's names; since, although our experimental chemists had adopted this innovation, as being more conversant with the French authors, than with the 1788 edition of the Pharmacopœia, in which Bergmann's nomenclature of salts had been reduced to actual use, yet even the French school of mineralogy, little as that nation is inclined to prefer foreign usages, still follow the nomenclature of Bergmann, and therefore the retention of those names would not have been without precedent, even in Paris itself.

A preference was evidently given, in ordering the chemical preparations, to the moist way, with the idea of enabling the apothecaries to prepare this class of medicines themselves; but in fact the college might more properly have put the whole of them into the drugs, merely noticing the strength of some of them, as they have done with oil of vitriol and spirit of wine; and, following 
the old models of Mesue and Nicolaus, have confined their directions to the Galenic department, since the chemicals are usually prepared in the country, where house-room, labour, and fuel are cheap, by manufacturers, who totally disregard the directions of the college. This being the case, the chemicals are not likely ever to be prepared by the apothecaries themselves; besides, much of the merit of chemical processes depends upon their concatenation with others carried on in the same laboratory, to make the waste of one process serve as the ingredient for another, a circumstance that cannot be considered by the college as depending upon an infinite variety of circumstances, but which has a most material influence upon the price at which the articles can be brought into the market; and it may be added, that the chemicals are always identical, or nearly so, in whatever manner they are prepared.

The Pharmacopœia printed in 1815 is only a corrected impression of the edition of 1809 ; and the new Pharmacopœia of 1824 is very slightly altered, in a few points, from its predecessor.

To enforce the performance of the directions of the Pharmacopœia, the censors of the college, and the wardens of the apothecaries, were, on the separation of the society of apothecaries from the company of grocers, empowered to search the shops of apothecaries in and about London, to destroy all they found unfaithfully prepared, and even fine the parties. The ill-will occasioned by this separation, and by the examination being referred to the apothecaries, was so great, that it was made one of the grievances complained of by the House of Commons in 1627; and from the answer made to this petition of grievances, by King James, in his last notice from the throne, a few months before his death, we learn that this separation was devised by our British Solomon himself *.

- Petition of the Commons (in 1621) to the King, complaining of divers grievances.-[Cobbett's Parliamentary History, vol. i. col. 1491.]

"Apothecaries.] Whereas the apothecaries of the city of London have been anciently members of the Company of Grocers of the same city, and whereas the said grocers did and do far exceed the number of apothecaries, and did even buy and sell all manner of drugs as well as apothecaries, which drugs, at several times of the year, were by the President and Censors of the College of the Physicians searched out and viewed whether the same were useful or not; and whereas as well the said grocers, as others, did use to distil all kinds of waters, a great part whereof was transported beyond the sea, to your Majesty's great and yearly benefit. The said apothecaries, without the consent of the said grocers, obtained letters patent, bearing date 6 th December, in the 15 th year of your reign, whereby the said apothecaries are incorporated and divided from 
While the apotheearies were only dispensers, this regulation could be strictly enforced; but when they changed into dispensing practitioners, and chemists and druggists opened shops under the sanction of the physicians, to supply the place of the old apothecaries for dispensing, and also sold perfumery, dye stuffs, paints, Sc., this power of examination, when not employed as a means of vexation, as in Goodwin's case and some others*, dwindled of ne-

the Company of Grocers; by colour of which letters patent the apothecaries have appropriated to themselves the whole buying and selling of all drugs, and the whole distillation and selling of all waters within the said city, and seven miles thereabout. Which division from the grocers, without their consent, and the appropriating of the distillation of the said waters unto the apothecaries, and the sole selling thereof by them, is against the law, to the impoverishing of many persons and their families. Your loyal subjects, therefore, humbly pray your Niajesty graciously to be pleased to declare the said letters patent to be void, and that the same shall not hereafter be put into execution."

It appears from the pamphlets published on this subject, that the number of apothecaries in London, and within seven miles thereof, was at this time about 140.

The King's answer to such part of the Commons' petition as related to the apothecaries, in which he thus retaliates on them:

"Another grievance of mine is, that you have condemned the patents of the apothecaries in London. I myself did devise that corporation, and do allow it. The grocers who complain of it are but merchants; the mystery of these apothecaries were belonging to apothecaries, wherein the grocers are unskilful; and therefore I think it fitting they should be a corporation of themselves. They bring home rotten wares from the Indies, Persia, and Greece, and here with these mixtures make waters, and sell such as belong to apothecaries, and think no man must control them, because they are not apothecaries."

These quarrels between the apothecaries and grocers, respecting the distilling and selling of spirituous liquors and cordial compounds, were settled in 1639 , by the distillors, rectifiers, and compounders being then made a separate company.

* The following is a history of the cases here referred to, as far as can be collected from the pamphlets preserved by Sir Hans Sloane, and now in the British Museum:-

The A pothecaries Company, soon after the subscription of a joint stock for trade, memorialized the Lord Iligh $\Lambda$ dmiral, that the surgeons' chests fitted up by the London chemists were defective and furnished with bad articles: whiereupon the Prince of Denmark, Iord High Admiral, ordered, 30th June, 1703, the surgeons of her Majesty's ships to furnish and provide their chests at the Common hall of the Company of Apothecaries, "the said Company liaving asourch me that they will furnish both good and cheap." 'They next endeavoured to obtain the supply of the East India Company, and obtained an order for that purpose; but the Company appointing a special committee of members having some knowledge in drugs and medicines to ilepect their invoices, the e were dissatisfied with both quantity and price, and called in two eminent wholesale apothecaries to join in a report to the getieral cominittee to this effect.

Upon this reluuff, the $\Lambda$ pothecaries Company attempted to condemn wine chests which had been fitted out by these two apothecaries; but not wocesling, they visited the sliop of one of them (Mr. Lawrence), when the 
cessity into a mere recommendation to use better articles; as the retailer can assert that his customers require the deterioration of the article, being unwilling to give more than a certain

owner was absent, and took samples of his goods for examination at the hall. Foreseeing the result, he sent some of his particular friends to the shops of the managers of the Company, to purchase the same articles. On answering to the summons about his medicines, he said, that the samples were not fairly taken from his shop, as the medicines were not finished making, but that he had brought some with him, which he would stand by. He then produced the samples bought out of their own shops, which they immediately condemned. Upon this decision, he offered to bring forward the parties, who were waiting at the door, to swear that these very medicines had been bought at their own shops; but they immediately made the matter up.

The Company also wished to supply the Royal Household; but being disappointed, and Mr. Malthus being appointed, they immediately visited his shop, and condemned his medicines.

Mr. Goodwin's case was different: he was a wholesale apothecary, and manufacturing chemist; he also supplied the Royal African Company with medicines for their forts, after much opposition from the Company of Apothecaries. Dr. Shadwell having bought some small articles from him, which were booked, the collecting clerk, at Cliristmas, inserted the amount in his list, and called several times on the Doctor for the money, which was only a few shillings; vexed at the trouble given him for such a trifle, the collecting clerk got into a passion, and the Doctor threatened vengeance. Upon which, on the 10th June, 1727, the visiters came to Goodwin's house at Charing-Cross, during his absence on 'Change, and burnt many of his articles in the street; told a person who came to buy some oleum anisi, that it was not good, nor anything in the shop; and carried off, to justify their proceedings, some emplastrum meliloti, which had been two or three years in Africa, and had come back in a chest brought to be refitted. They then went to another shop of his in Charles.street, Westminster, and condemned the goods there, taking away a chest of articles to be examined. Mr. Goodwin did not sit down quietly under this injurious treatment, but appealed to the law, and recovered, I believe, $600 \%$. damages.

It further appears from these pamphlets, that after supplying the East India Company for some years, the Apothecaries Company lost the supply, which was given to Bevin and Company, of Lombard-street, and Johnson of Fenchurch-street. Upon which they procured a pamphlet to be written, entitled, "Frauds detected in Drugs," of which I have not been able to obtain a sight. This appeal seems to have been successful, for they again obtained the supply of the East India Company, which they still retain, although they have lately lost that of the Navy, in consequence of the discussions, it is said, that took place upon their unsuccessful attempt to procure the supply of the Army also. It is probably on account of this loss, that Mr. Brande, the superintending chemical operator, has published " The Origin of the various Establishments for conducting Chemical Processes, and other Medicinal Preparations, at Apothecaries' Hall ;" and inserted the whole in the Quarterly Journal, as being that which is most read among the higher classes of society, of authority in the State. Whether this puff oblique will be as effectual as the former pamphlet, remains to be seen.

The pamphlets alluded to are, -

1. Mionopoly made a Property; or, the Navy Surgeon's Memorial to the managing Apothecaries in Black Friars. 1708. 8vo. pp. 76.

2. The Case of James Goodwin, Chymist and Apothecary. 1727. Folio, pp. 4 
price-a plea which is much facilitated by the changes in the names of the compositions, so that the articles asked for by retail customers can seldom be legally considered as those now ordered by the college; or that in practising medicine he conceives the alteration to be of advantage to his own patients ; or that they are not designed for medical use, but for some other purpose: luence the present mode of examination is of necessity confined to asking for the articles used by him in dispensing prescriptions; and this admits of an easy evasion, by keeping a small stock of choice articles. This power of examining drugs, Sic. being lodged in the Society of Apothecaries, has also excited much ill will among themselves: for, although the real dispensers have no objection to any examination by the College of Physicians, or would even court it, as being their patrons; yet since some of the apothecaries have subscribed a stock to supply the public with drugs, compounds, and even lately to make up prescriptions, it has been suggested, that it is contrary to the general principles of British legislation, that fellow-tradesmen, and still less the stockholders of a corporation, trading themselves on a common joint stock in any articles, should be constituted examiners of them when kept for sale by others, especially as it has been asserted that there is an intention to oblige all licensed apothecaries to purchase their medicines at the Society's hall; but this is said to be a mere surmise, the offspring of the opposition with which the late Apothecaries' Act has been received.

The original idea of this Act certainly arose from the ancient and interminable dispute, respecting the comparative merit of a public or private education-or, as applied to medicine, between the methodics, who acquire their knowledge by attending the public schools of medicine, and practise upon the general principles there promulgated; and the empirics, who acquire their knowledge at home by the practical instruction of their parent, a private master, or solitary study, in every case for a much longer period than any apprenticeship, or course of academical study. But the immediate origin of the $\Lambda$ ct was a mecting

S. The Apothecary displayed; or, an Answer to the Apothecary's Pamphlet, called Frauds detected in Drugs; wherein lis Profession and important Character is truly considered. 1748.8vo. pp. 48. Extremely well written. 
convened on the 3rd July, 1812, to consider the high price of glass, in consequence of the duty levied upon it. The trade being thus called together for the redress of one grievance, others were thought on; and after several meetings, they addressed, on the 5th December, in that year, a letter to the Colleges of Physicians and Surgeons, and to the Society of Apothecaries, that they conceived it necessary that a fourth privileged body should be established to license practising apothecaries and surgeon-apothecaries, and that the apothecary ' should possess a legal claim to moderate remuneration for his attendance and professional skill, under such modification as may hereafter be judged necessary.' As the three medical corporations declined joining in the proposed application to Parliament, the associated apothecaries themselves presented a petition to Parliament, 12th January, 1813, stating that several persons practised without any regular medical education, and that in consequence they could obtain few apprentices; whence they begged leave to introduce a bill, for regulating the practice of apothecaries, surgeon-apothecaries, midwives, and dispensing chemists. This was, in all probability, the first time in which the complaint of being able to obtain few apprentices was ever made to Parliament, although it was common for it to have petitions against masters taking too many apprentices. An unprejudiced observer could not be mistaken in the meaning of this petition to be the enhancing the price of apprentice fees; or in a just estimate of the double dealing, in professing one main object in their letter to the old corporations, and another to the Parliament.

That the apprentice fees should form so prominent a feature in the grievances of the apothecaries, arises from their being, in most instances, the means of a young apothecary discharging the debt incurred for his stock, \&c., on setting up in business; and also forming a considerable part of his profits even when established. In consequence of these high fees, there are not wanting some notorious instances, even in London, of masters, whose principal trade is in apprentices; and as soon as they have received the fee, they use the apprentices so ill, that they are taken away by their friends; or, if this resource is denied them, the unhappy victims of this nefarious practice are at length driven to run away.

Accordingly a bill was prepared (as it should seem by Dr., 
then Mr. Burrowes, who had five hundred guineas presented to him for his gratuitous services in this affair), providing, that a fourth nedical corporation of apothecaries and surgeon-apothecaries should be formed, the superior officers of which should be chosen by the majority of votes of the practitioners in London and its neighbourhood, with power to appoint subordinate committees in the country; that in future no person should practise as an apothecary, surgeon-apothecary, midwife, or dispensing druggist, unless they were members of the College of Surgeons, or Society of Apothecaries, without being examined by this body, under a penalty for each offence; that apothecaries and surgeonapothecaries should either serve an apprenticeship, or attend some accredited school of medicine in England, Scotland, or: Ireland, and undergo an examination of their proficiency; that if they practise surgery, they should also take a diploma from the College of Surgeons. Besides certain fees for the certificate of this examination, all these persons, and even those now practising as such, to pay certain sums for an annual licence, with power in the superintending body to refuse this licence in case of infamous or immoral behaviour. In consequence of this superintendence, apothecaries and surgeon-apothecaries to claim reasonable charges for their attendances, visits, and journeys ; the penalties for practising as an apothecary, surgeon-apothecary, midwife, or dispensing druggist, to be recoverable by common informers, who were to have half the penalty ; that apprentices should also pay a certain sum, part of which should be applied to the giving of lectures at the hall of the corporation.

It is a singular instance of the delusion under which the mind often labours, when self-interest is strongly excited, that the associated apothecaries should imagine a bill of this kind to pass without the strongest opposition from all classes, both of the profession and of the public in general. The College of Physicians could not see without jealousy the associated apothecaries placed upon a better footing than themselves, and allowed to sue for their attendance, which neither physicians nor surgeons can do. The Society of Apothecaries regulated their motions by those of the Physicians, yet could not but be jealous of a new corporation, formed upon a basis of contributions, and usurping their place. The College of Surgeons were apparently to be benefited by this 
Act, which extended their authority over the whole kingdom; but as the gorernors are mostly lecturers in the hospitals, these must have been interested against the formation of a rival school; especially as this being connected with the examining body, must naturally have been preferred by the students: while the public could not but be alarmed at the encouragement given to that hateful class, common informers, and the inquisitorial idea of refusing an annual license, on the ground of such an undefinable thing as moral character, by which a person who had spent his life in the profession might have been ruined in his old age, upon some pique taken against him by the committee. Even the country committees could not be well pleased with their great subjection to the London superintending body.

In consequence of the opposition experienced in respect to this bill, it was amended, and much art was certainly displayed in attempting to interest all the opposing parties, except those who were in fact the two parties against which it was originally levelled, namely, the female midwives and the chemists and druggists*; although, from the language held out to the public in general, they were led to suppose it was intended a grainst advertising quacks and nostrum-mongers. An attempt was made to interest the government in the bill, by offering that the indentures of apprenticeship should have a stamp of $25 l$. on them; and if the party had not served an apprenticeship by indenture, that his certificate of examination should bear the same stamp: a proceeding singularly at variance with the preamble of the bill, which stated, that in the present depressed state of medicine, the apothecaries and surgeon-apothecaries could not obtain a sufficient number of apprentices to supply his Majesty's naval and military services with medical practitioners. And, aware of the influence of the female sex, their interest was attempted to be

* The English apothecaries are desirous of securing to themselves the dispensing of physicians' prescriptions, as being a very profitable branch of their business, and thus to restrain the chemist and druggist to the retailing of simple articles only. It is singular, that in Paris, although a similar difference between these two branches of the profession exists, yet the circumstances are entirely reversed. There the chemist and druggist (apothecaries) complain of the dispensing practitioncrs (herbalistes) selling the preparations of the Codex, making up prescriptions, and even visiting the sick, which is rigorously forbidden to the French apoticaire; but for which the herbalistc gets a licence, by attending the schools of medicine, and undergoing an examination. 
secured by a proposal made in the committee, but not appearing in the bill, that the licensing money should be appropriated to the use of the widows and orphans of medical men.

In spite of these manœurres of the associated apothecaries, it was speedily discovered, that even in this amended state the bill was not likely to pass into an act. They therefore gave notice, that they meant to expunge everything relative to the compounding chemist and druggist, to the erecting of a medical school, or to the uniting of the heads of the already constituted medical bodies with the superintending body; and, indeed, confined their views entirely to causing apothecaries and surgeon-apothecaries to be examined as to their proficiency, and to obtaining for them a different mode of recompence for their visits and professional skill : but not a word about the original object, the procuring of apprentices. Feeling, however, that the hostility against the bill was still too active for them to encounter, the idea of forming a fourth medical corporation was given up by the associated apothecaries; but as more than a thousand of the apothecaries had thus agreed to a taxation of their apprentices, and urged the necessity of their attending certain courses of lectures before setting up in business, although they had, in signing the indentures of their own apprentices, covenanted to teach them the whole art and mystery of an apothecary; by which these men proclaimed to the world their own remissness in performing their engagements, the Society of Apothecaries seized the opportunity of extending their controul from London and its neighbourhood, to one over the whole kingdom, and of raising a revenue for their own members by taxing the apprentices, not only of their own members, hut also of all apothecaries, when they should wish to sct up in business. Accordingly, a new bill was brought into Parliament by this Society, which, after some opposition, passed on the third reading, by a single vote, at the moment the House was breaking up for the session.

'This Act, repealing the power of the Society of Apothecaries of examining medicines in shops, houses, cellars, \&c., in and about Iondon, substitutes for it the power of examining the medicines in the "shop or shops" of apothecaries through Eng" land and Wales, with power of fining the party if the medicines are not found good; the first time 51 ., the second 10l., and every 
succeeding offence 20l. It is expressly declared, $\S 5$, to be " the duty of every person using or exercising the art and mystery of an apothecary, to prepare with exactness, and to dispense such nuedicines as may be directed for the sick by any pluysician larefully licensed to practise pliysic;" and it directs apothecaries refusing to compound, or unlawfully compounding such medicines, to be fined upon the complaint of a physician, the first time $5 l$., the second $10 l$, and the third to be rendered incapable of practising " as an apothecary," unless he promises, and gives sufficient security, not to offend in future. Persons not already in practice on August 1, 1815, to be examined by twelve persons, appointed by the Society of Apothecaries, " to ascertain the skill and abilities of stuch person or persons in the science and practice of medicine, and his or their fitness and qualification to practise as an apothecary:" who are " empowered either to reject such person, or to grant a certificate of his qualification." None to be allowed but those who are twentyone years old, who have served an apprenticeship of not less than five years to an apothecary, and who shall produce testimonials of a sufficient medical education and of good moral conduct. Assistants who have not served a five years apprenticeship to be examined either by the Society, or by apothecaries to be appointed in each county for that purpose. Each apothecary to pay $10 l .10 s$. for a licence for London and ten miles round, or $6 l .6 s$. for a country licence, and $4 l .4 s$. in addition, if he moves to London, and each assistant 2l. $2 s$. Apothecaries acting without licence to forfeit $20 l$. for each offence, and assistants 57 ., and not to recover charges in any court of law, unless it is first proved on the trial that he is duly licensed, or was in practice before August 1, 1815. If the examiners refuse a licence to a person, he may apply again in not less than six months for an apothecary's licence, or three months for an assistant's; and "if on such re-examination he" appears "to be properly qualified," the examiners to grant a licence. (No mention is made of rejection on this re-examination, nor of any other than this second application.) A list to be published annually of those licensed in that preceding year, with their respectire residences. This part of the Act has not been complied with, nor indeed would it afford much information, as the resi- 
dence of the parties examined is most commonly a temporary lodging near the hospital at which they attend. The money for licences to belong to the Society of Apothecaries; but the penalties for offences to be given, half to the informers and half to the Society. Penalties above 57. recoverable by action, in the name of the master, Sc., of the Society, in any court of record; and under 57 . by distress, by warrant from any justice of the peace; and if not sufficient distress, the person to be imprisoned without bail for a time not exceeding a calendar month. (How a penalty of exactly 5l. is to be recovered does not appear on the Act.) "Not to prejudice or in any way affect the trade or business of a chemist and druggist in the buying, preparing, compounding, dispensing, and vending drugs, medicines, and medicinal compounds, wholesale and retail; but all persons using and exercising the same trade or business, shall and may use, exercise, and carry on the same trade and business in such manner as fully and amply, to all intents and purposes, as the same trade or business was used, exercised, or carried on by chemists and druggists before the passing of this Act." The rights and privileges of the Universities, and the Colleges of Physicians and of Surgeons, and the Society of Apothecaries, are fully reserved; and all actions limited to six months next after the fact committed, or the ceasing thereof if there was a continuation.

The associated Apothecaries and Surgeon-apothecaries did not oppose this bill; yet they objected strongly, and still object, to the clause which obliges a licensed apothecary to compound faithfully the prescriptions of physicians, as keeping them still in the rank of tradesmen, by obliging them to be sellers of medicines, whether they would or not.

This Act has had the singular fortune of being violently opposed, as insufficient, by those who were its original promoters, of being esteemed as a burden by many of those whom it was rneant to benefit, and of being looked upon with indifference by those against whom it was intended to act, since the Act was altered and restricted to those who "practise as apothecaries," with an express declaration that it did not extend to the chemists and druggists, whose shops are in general confounded with those of the apothecaries, and whose business differs no other- 
wise than that, with the dispensing physician, or modern apothecary, medical practice is the principal object, retail and dispensing the secondary; while, with the chemist and druggist, or old apothecary, retail and dispensing are the principal, and medical practice, mostly confined to the counter or to a few personal acquaintance, the secondary; $\grave{a}$ fortiori, the midwives, herbalists, cuppers, barbers, electricians, galvanisers, dentists, farriers, veterinary surgeons, village wisemen, and cow-leeches, are left in full possession of their ancient practice, and may be employed by those who place confidence in them, as they cannot be confounded with apothecaries, though the chemist and druggist may.

The originators of the Bill were displeased with the supposed ambiguity of the words "6 to practise as an apothecary." It is true that it took one hundred and fifty years of litigation, to determine the meaning of the phrase "to practise physic," as used in the statute of 15 Henry VIII. For the Court of King's Bench always adjudged, that this expression did not allow a seller or dispenser of medicines, that is to say, an apothecary, to give his advice to sick persons, as to what medicines it might be advantageous for them to take; and even went so far as to give verdicts, at the instance of the College of Physicians, against persons for selling articles accompanied with a printed description of their virtues, as coming within the legal meaning of this phrase. Yet, when in the case of the King $v$. Rose, an apothecary, for practising physic by selling a patient such medicine as he judged proper for his disorder, a more determined stand was made, and the matter carried into the House of Lords, as the dernier resort of law, they determined the matter in favour of the sellers of medicine; and this decision is the authority by which all dispensing practitioners now practise physic, as sellers only of medicines. Whether "to practise as an apothecary" will take as long to determine, must be left to time. The question will probably remain in this undetermined state, until the parties whom the Society of Apothecaries, or rather their neighbours who are licentiates of that society, prosecute for practising as apothecaries, although they disclaim that title, shall unite for their mutual defence, and follow the example set by the apothecaries themselves in 1721, by an appeal to the definitive sentence 
of the House of Lords, whether all dealer's in medicines have not the same right to recommend the use of them to purchasers, and to go to their houses to rcceive orders, in the same manner as the dealers in other commoditics. It were to be wished that the Barbers' Company of London would form a point of union for those practitioners to whom it is inconvenient to apply to the Society of Apothecaries for a licence.

The use of the licence of the College of Physicians being certainly to assure the public that if a patient should send for a licentiate, who is not known to him or his friends, there is a moral probability that this person, practising under the title of a physician, will be found deserving of their confidence; so it should seem that the object of the Apothecaries Act is certainly to give the public a similar assurance, that a person who exercises the medical profession under the title of an apothecary, has gone through a certain routine of education, and may therefore be reasonably judged capable of performing what is required from him in that profession; whereas, in committing themselves to the care of those who practise under other titles, patients do it at their own peril, and are guarded only by the general responsibility of all practitioners to the common law of the land, which gives damages to those injured through their gross neglect. As the privileges of the College of Physicians do not hinder apothecaries, according to the above decision of the House of Lords, from practising under a different title, in order that the public may not mistake the proper rank of the practitioner, so it seems probable, especially since the repeated rejection of the Surgeons' Bill, that although the courts of law, sticking to the letter and neglecting the spirit of the law, may grant verdicts in many cases against retailers who have incautiously visited sick persons, the legislature neither does nor will become a party to establish a medical monopoly throughout the country, but intends to leave the practice of medicine and surgery open to free and honourable competition, only preventing persons from practising under the cover of titles by which they are liable to be confounded with others who have gone through a certain course of study. Indeed, the obliging persons who have a strong natural genius for medicine to transport themselves to some foreign clime, because the poverty or waywardness of their parents prevented them from 
being brought up in the profession, would deprive the country of many ingenious persons; since the history of medicine, like that of other arts, exhibits instances of persons, as Sydenham, Boerhaave, and others, who were originally bred in other professions, and some, as Thomas Willis, and Verheyen, in the most humble, who have yet proved the ornaments of the medical faculty, and gradually attained to its highest honours.

Many apothecaries themselves are averse to the provisions of this Act, considering some of them as hardships, and are moreover apprehensive of the consequences that may arise from these burdens. For the restraint laid upon that mode of practising physic, which is most advantageous to both the public and the practitioner himself, namely, as a physician, inasmuch as his prescriptions are open to investigation, by the College requiring the party to have been educated for a certain time at some particular schools, has eventually and gradually led to the prevalence of a different state of medical practice, by obliging those persons, who had not been educated in the prescribed manner, to evade the restraints, and, however desirous of joining the College, to become the rivals of the physicians; while the mode of evasion, by imposing on these persons a commercial character, has led to their giving credit for the medicines they supply, and thus procured for them a preference amongst the middling classes. Hence, it is supposed, there is some danger, lest the operation of the burdens imposed by this Act should throw the present business of the apothecaries into other channels, as the cuppers, who already begin to increase in number, or the chemists and druggists.

The first hardship complained of is that which obliges all country apothecaries, from even the smallest villages, after their apprenticeship is expired, to go up to London, and stop there for six months and upwards, which is a heavy expense, totally out of the power of many, and in some cases attended with the hazard of another practitioner settling, during their absence, in the place: hence these must of necessity evade the Act by setting up as surgeons, or as chemists and druggists, trusting to the confidence their friends and acquaintance may repose in them; and thus, as their apprentices cannot in either case be received as apothecaries, the number of the profession is gradually lessened, 
and that of its rivals increased. In this respect the Act goes beyond the 5th of Elizabeth, which only required the mechanics of corporation and market towns to serve an apprenticeship, but left the villages free from this restriction. 'The experience of two centuries has shown the impolicy of this Act, in the decay, or at least the stunted prosperity, of the towns subject to this law, and the rapid progress of Manchester, and many other villages, in consequence of their being free for the exertion of genius in whatever line a person chooses to employ limself, and in the improvement made in the manufactures of those places, by allowing the free competition of all. It is, therefore, singular that so many members of a profession justly esteemed liberal, and from whom we might, therefore, expect a correspondent liberality of sentiment, with these examples before their eyes, should have been so blinded by the interested measures of a few artful leaders, as to lend their support to the application of this Act, in less than thirteen months after the mechanics had procured (18th July, 1814) a repeal of the apprentice law of Elizabeth, except so far as regards the city of London, or the bye-laws of those corporations, or companies, who may choose to impose those fetters on their own freemen. It must be allowed, that the original bill, proposed by the asso. ciated apcthecaries, was more liberal in this one respect; for it allowed persons to apply for a certificate who produced either their indentures of apprenticeship, or testimonials of a regular inedical education, or of proper attendance in some accredited school of medicine; whereas the present Act positively requires an apprenticeship of not less than five years to an apothecary, and thus goes beyond the education required by the College for a physician, which is only two years' study in the university in which they take their degree. This evidently shows that it is not the public good of obliging apothecaries to have undergone a certain course of studies previous to practising, but the private good of securing apprentice fees, as stated by the associated apothecaries in their original letter. It seems also necessary that the apprenticeship should be served in England or Wales.

It is also considered as an aggravation of this hardship, that although a person, after serving a regular apprenticeship of five, or even eight years, may have also practised as a visiting assis- 
tant for years, to the satisfaction of the patients of his master, yet he is prevented from even offering himself for examination, previous to setting up in business for himself, without pursuing, at a great expense, a second course of study, certainly of an inferior nature to apprenticeship when the master does his duty ; since no one can suppose that much can be learned by a few hour's' attendance on the most celebrated lectures in London, especially as the necessary attention to pecuniary matters obliges the pupils to hurry from one lecture to another, without first digesting what they have just heard.

As to the examination itself, although no person, intending to set up in business, ought to object to this test of his abilities, if fairly conducted, without any private predilection to the interest of particular teachers, by favouring their scholars, and endeavouring to remand those of other teachers; yet it is alleged that, however advantageous examinations may be in public schools, to create an artificial interest among young men of property, who have no other stimulus to excite their exertions; or however proper it may be for the superior medical officers of the military and naval services, to examine the qualifications of those seeking medical or surgical employment in those departments, or even the examination of candidates for the fellowship or licence of the College of Physicians, or for becoming a member of the College of Surgeons, considering these as honorary testimonies of superior abilities and education to the ordinary practitioners; yet the examination of an apprentice in favour of the public is a novel measure and useless, since he has the stimulus of profit to lead him to perfect himself in his art. It is, indeed, true that similar examinations take place in other countries, but they are in favour of the apprentice against his late master; if the apprentice be not found competent, the master is fined so much as the wardens of the trade think it reasonable he should give to another master to be fully instructed. May it not admit of some doubt, whether the covenant to instruct the apprentice fully in the mystery of his business, does not enable a person, remanded for insufficiency, to recover by law, from his former master, the expenses incurred by such rejection, for deficient instruction in his art?

It is also objected to this Act, that the monies levied from the 
licentiates is not applied to any public use, as was intended by the associated apothecaries, but that it is taken to the use of a private London society. It has been answered, that this society keep a botanic garden, have botantic excursions and demonstrations, and even lectures on materia medica; but these are not open, either to the licentiates or their apprentices, being confined to the apprentices of the members of the society.

However much the totally unprecedented extension of the Apothecaries' Act to villages may be deprecated by every liberalminded person, it is certain that this Act, by the Society of Apothecaries rendering the examination as efficient as the time will allow, and making it necessary that three of the examiners should sign the certificate, or seven of them vote for the person under examination being remanded, has already had the effect of obliging a few careless youths to be more attentive to their studies than heretofore, through the fear of being remanded. The prevailing error, and which is fostered by this Act, is to consider the mere passing of the examination as the great object to be obtained, rather than the acquirement of that general knowledge; without which an apothecary cannot perform the duties of his profession with honour to himself, and with benefit to his patiersts. Some teachers of medicine, knowing the importance attached by students to passing examination at the Hall, undertake to cram their pupils for an additional hour daily, under the name of examination; and so much does the taste for this parrot-like instruction prevail, that the majority of pupils would rather absent themselves from any other, or even all their other pursuits, than be absent from this mock examination by these grinders.

Whether the public will be ultimately benefited by these attempted restrictions upon medical practice, is even already doubtful. The licensed practitioners, it appears from the public papers, presuming upon their freedom from competition, often refuse to give medical assistance to the poor in accidents, until their remuneration is guaranteed to them: they have even taken the opinion of counsel, whether they might not disobey, unless their expenses are tendered them, the coroner's warrant to give their evidence in cases of murder, \&c. although all other persons, of whatever rank, are obliged to attend, as a personal duty owing 
to the state; and they have further proposed, that the bodies of the poor who die friendless, or of unknown travellers dying on their journey, shall be delivered to them for dissection. This last proposal is a nefarious one, in a country where dissection forms a part of the criminal law, as a punishment for the most heinous crimes; and which is thus to be inflicted upon innocent persons, provided they are friendless in the place where they happen to die. 'The first object of anatomists should be, to get this punishment set aside, as the greatest obstacle in the way; and then, as to the supply of subjects, the practice of the German and Swedish Universities, in carrying the bodies of the professors and servants of the University to the anatomical theatre for inspection before burial, is the most rational, and might be extended to the whole medical faculty, their wives, and children under age and unmarried, by an Act ordering their bodies to be carried to the nearest hospital, or the senior surgeon of the hundred, \&c. for dissection. If the medical faculty set the example, by soliciting an act to this effect, and thus showing that they do not ask to treat the bodies of others any otherwise than they are willing their own corpse and those of their families should be treated, after the performance of funeral rites over them, there can be little doubt, but that the friends of other deceased persons would, in a very short time, allow the examination of the bodies, or even sell them for complete dissection. Thus those who are benefited by the practice of dissection would alone be forced to contribute their bodies to this purpose, and not the poor and friendless. If the supply thus obtained was not sufficient, the bodies of the beneficed clergy, and of the holders of offices under government, with those of their wives and children, would surely suffice; and the tacking this condition to the acceptance of these charges and offices in future, would injure none.

As to the forcible suppression of home-bred, or even unlearned empirics altogether, the trouble and expenses of a law-suit, and the obloquy that attends those who attempt to deprive a man of the fruits of his industry and skill, through the want of technical formalities, are so great, that it is only the strong stimulus of personal enmity, or a feeling that the licentiate's interest is deeply involved in getting rid of a popular neighbour, that 
would occasion prosecution. 'The grossest ignorance and real unskilfulness, therefore, escapes when clothed in the garb of poverty, and especially considering the facility with which the poor slip from the fangs of the law, by changing their residence, as it would never be worth while in such case to hunt them out, even if it were possible. Hence it is only the active and intelli. gent practitioner, like Sutton the inoculator, that is likely to be prosecuted, because by such as him alone can the neighbouring licentiates be seriously injured.

In this respect, the present Act is far preferable to that contenıplated by the associated apothecaries: namely, that it does not make the practising as an apothecary unlicensed a public crime; but by directing the prosecution to be carried on in the name of the Master, \&c. of the Society, moderates the extreme severity of the penalties, which have been adopted from the former Bill, of $20 l$. for each separate act of practising as an apothecary, which may bring it to several hundred pounds a day; whereas, the penalty for practising as a physician, even in London, is only 5l. a month, and practising for less time than a month is not cognizable by the College. Indeed, the Society of Apothecaries seem so sensible that a jury would never find a verdict to the full amount, that in all the prosecutions hitherto undertaken, they have constantly declared for one penalty only ; and they are charged by their licentiates, and particularly by those in the country, with not sufficiently securing to them, by prosecutions, the monopoly of the practice in their neighbourhoods. But the Society appears to be perfectly aware that the want of success in any one lawsuit, or even the expenses of many, although they were successful in all of them, would outweigh any possible benefit which could arise from a rigid exercise of their power, and the instant prosecution of all unlicensed practitioners; which, by creating a great sensation in the country, would probably lead to a repeal of the Act itself, which was procured with such difficulty, and deprive the Society of the profits they now derive from it.

Moreover, as to the real justicc of attempting the forcible suppression of empirics, or home-bred practitioners, however mortifying it must be to the pride of the plilosopher, or the intense labours of the scholar, truth will oblige the bistorian of the prac- 
tice of medicine to confess, with a sigh over the vanity of human learning, that our choicest remedies, and our most approved modes of cure, are generally, if not universally, derived from empirics, and those the most unlearned; and that, however the methodics, or school-bred practitioners, have laboured to explain the modes of action, and the reasons for the effects produced, they have done little or nothing towards the improvement of the practice.

It must be owned, indeed, that it is not a little mortifying to a practitioner educated in the best medical schools, to see himself cast off for the advice of an empiric, especially as this rejection is not confined to the soldier or the ploughman, but happens even in the palace, where although on the first accession of disease the school-bred methodic, who practices in a general way, is consulted; yet, if the disease proves tedious, the confidence of the patient is shaken, the school-bred attendant is dismissed, and the patient throws himself into the power of some homebred empiric, of known experience in the medical art, although, in other respects, perhaps the rudest and most ignorant of his neighbours, whose medicines are taken and his directions followed with that implicit obedience and faith, which had they been given in the first instance to the original practitioner might have had the desired success.

And it may be finally remarked, that the home-bred practitioner, although he is frequently ignorant, notwithstanding his thirst for knowledge, because his poverty obliges him to content himself with any old medical books that may accidentally fall in his way, yet he is not the enemy of the school-bred practitioner, and in general a paltry rival, because he scarcely practises, except in remote villages, or upon the poor, who cannot afford the attendance of a regular-bred man, or in chronic cases which have been previously treated by the school-bred practitioner until the patience of the sick is exhausted.

The real enemies of the fair practitioner are those persons who, impelled by a commercial rather than a philosophic spirit, become nostrum-mongers, and frequently in defiance of their better knowledge, recommend, in pompcus terms, some inert or dangerous medicine to the notice of the sick, and thus encourage them to practise upon themselves. A practice of the most 
hazardous kind; to which, indeed, the rashest trials of the most ignorant village empiric, who derives the whole of his booklearning from a well-thumbed copy of some old black-letter herbal, are comparatively safe; since, in the latter case, there is some chance that his own experience may enable him to perceive his error in time to retrieve it, and at the worst a salutary caution would be inculcated, and a repetition of the trial avoided.

The true method of combating the enemies of the fair practitioner, is not by soliciting harsh penal laws against practitioners who have studied at certain schools, or who have not been apprenticed to medicine by their parents. For as the sick, disregarding the existing jealousies between the several ranks of the medical profession, will solicit the advice of those persons in whose knowledge they place confidence, the attempt only leads both practitioners and patients to invent modes of evasion, and widens the breach between the different branches of the profession. If we reflect upon the existence of smuggling in spite of the whole power of government arrayed against it, and the great rewards offered to discover offenders, we shall be convinced that no legal restraints, however strictly worded, can forcibly restrain the practice of medicine to any set of monopolists, as long as both patients and unlicensed practitioners have a common interest to elude them: while the attempt only produces irritation on both sides, and prevents persons, having a common study and interest, from meeting in good fellowship together, and is thus highly derogatory to that enlargement of mind which ought to distinguish the members of a scientific profession. The right mode is, surely, to rest content with securing their proper distinctions to those who have gone through the trouble and expense of obtaining them, and on the other hand, bestowing these honorary distinctions only on those that merit them; but leaving the sick and their friends perfectly at liberty to search for relief wherever they think it most likely to be found-thus creating an honourable competition and rivalry, instead of that continual bickering which at present pervades the different branches of the medical profession; as they may be well assured that the mass of mankind are not so blind as to be incapable of judging in a matter that so nearly concerris them as their health, or so inattentive to their own interest, as not to 
prefer those practitioners whose greater success in practice shall attest their superior skill; while the attempt to establish a monopoly, if we may speak the truth, only tends to render those licentiates, who thus procure the prosecution of their home-bred neighbours, to be suspected of real ignorance, and afraid of the collision of open and fair competition. 


\section{WEIGHTS AND MEASURES.}

MEDrcives, except a few hereafter mentioned, were formerly sold, and the prescriptions of physicians made up, by the common English weight, called Avoirdupois. The ounce of that weight being then, as appears by all the old authors on arithmetic, subdivided into 8 drams, 24 scruples, and 480 English grains; the medical pound differing from the common by its containing only twelve ounces, while the Troy ounce had for its fractions pennyweights and Troy grains. The College of Physicians having at length, in the 1720 edition of the Pharmacopœia, ordered the drams, scruples, and grains to be acljusted to the 'Troy ounce, hence, as the dispensers of medicines were the only persons who used these small weights, those adjusted to the Avoirdupois ounce went out of use, and were no longer made, and the quarter ounce was the smallest Avoidupois weight in common use, as it still continues; but as the Italian rotolo for raw silk has been adjusted to the Avoirdupois weight, and made 24 ounces a pound; a smaller weight, the Spanish adarme, equal to the 16th part of the Avoirdupois ounce, was used under the name of a dram, for weighing silk, and this has now become an established fraction of this ounce, but it is scarcely used by any other persons than haberdashers, and for all weights less than the quarter of an ounce 'Troy, Apothecaries' weights are employed, although, as the Avoirdupois pound is established by statute at 7000 Troy grains, the quarter ounce containing 109 gr. 375 , and the dram $27 \mathrm{gr} .34375$, are most inconvenient numbers for reduction.

TABLE OF AVOIRDUPOIS WEIGH'.

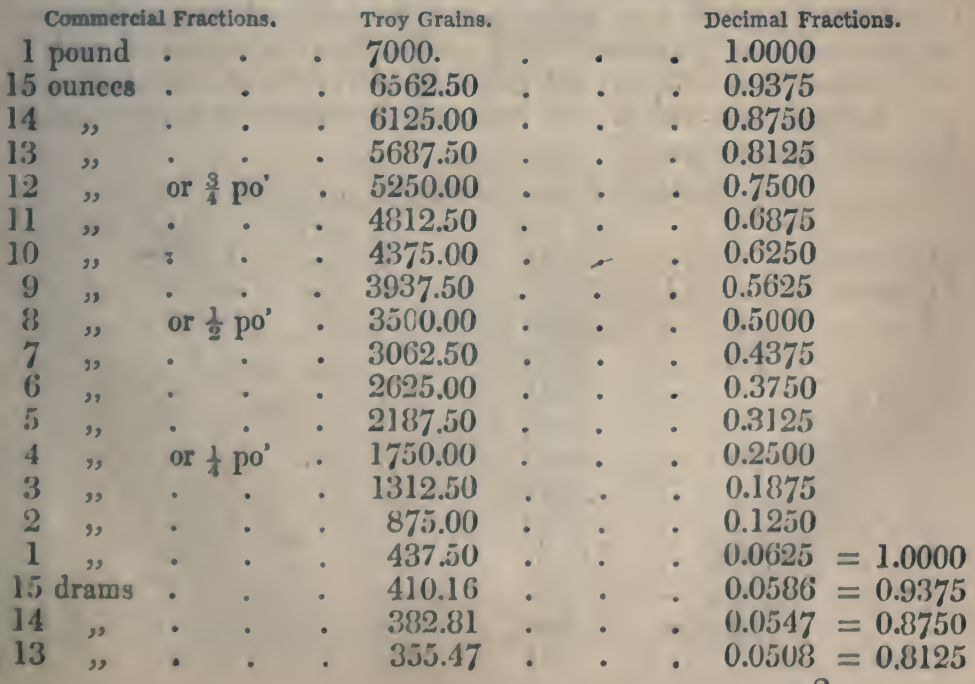




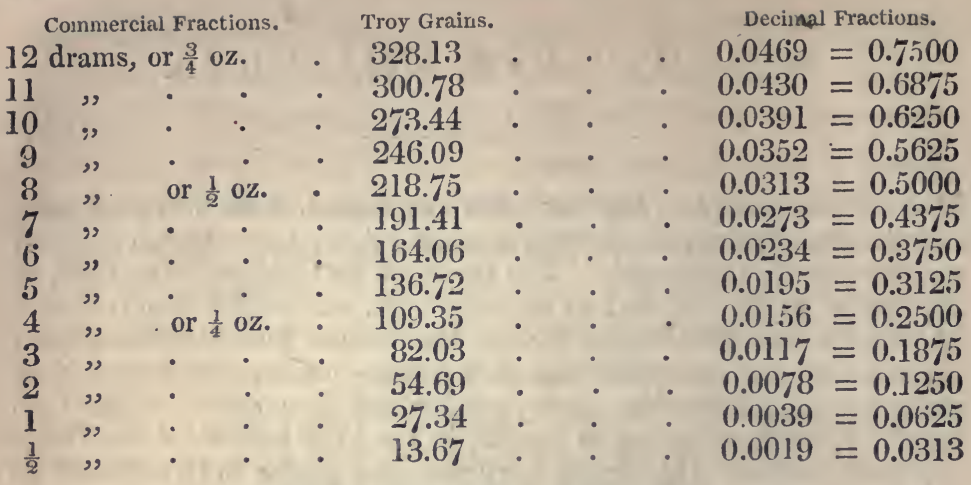

\section{APOTHECARIES' WEIGHT.}

A few choice articles of the Materia Medica, as lapis bezoar, seed pearl, white amber, balm of Mecca, oil of cinnamon, and some electaries, high in popular estimation, and imported from Italy, as Venice treacle and orvietan, were always weighed by the Troy ounce, and its subdivisions into pennyweights and grains, and still pay duties at the Custom-house by that weight, as may be scen in the Book of Rates. But it was not until the directions given in the London Pharmacopœia, edition of 1720 , that the Troy ounce was divided into the same fractions of drams, scruples, and grains as the Avoirdupois, for the purpose of dispensing all such drugs as were ordered by weight. This alteration must have been, and is still, productive of very great confusion, by obliging the same person to have two sets of weights-one for buying and selling, the other for preparing the officinal preparations and compounds, and for making up prescriptions. It does not clearly appear why this alteration was made in respect only to drugs ordered by weight, by which their proportion in the ofticinal preparations and compositions was increased 1-10th; as the Avoirdupois ounce, with its old divisions into 2 drams, and drops, 60 of which were presumed equal to the dram, was, and is still retained, in respect to drugs that are dispensed by measure.

'TABLE OF APO'THECARIES' WEIGH'.

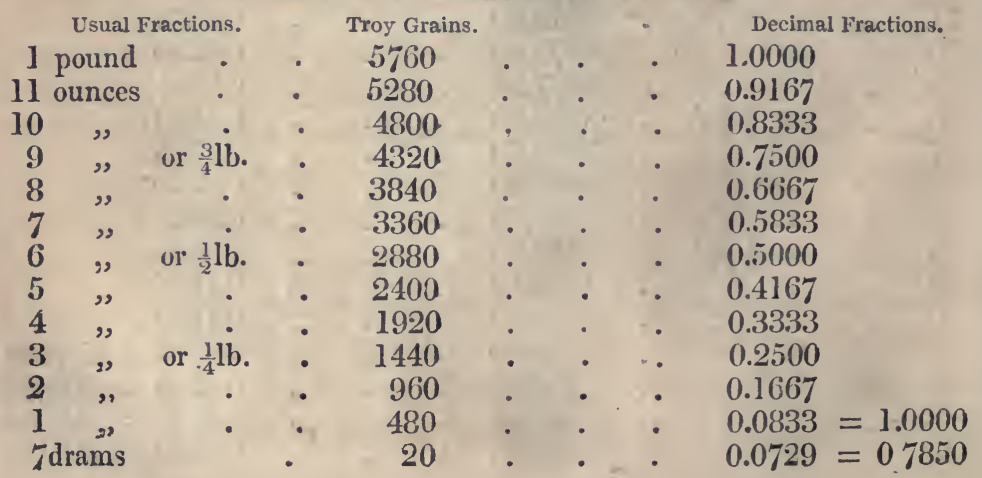


WEIGHTS AND MEASURES.

\begin{tabular}{|c|c|c|}
\hline \multicolumn{3}{|c|}{ Vsual Fractions. } \\
\hline ", & • & - \\
\hline " & & \\
\hline , , & or $\frac{1}{2}$ oume & \\
\hline " & - & \\
\hline " & - & \\
\hline scruples & - & \\
\hline & $\cdot$ & \\
\hline cruple & - & \\
\hline " & - & \\
\hline
\end{tabular}

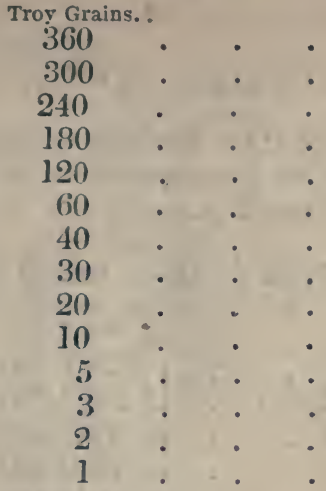

Decimal Fractions.

$0.0625=0.7500$

$0.0521=0.6250$

$0.0417=0.5000$

$0.0315=0.3750$

$0.0208=0.2500$

$0.0104=0.1250$

$0.0070=0.0833$

$0.0052=0.0625$

$0.0035=0.0416$

$0.0017=0.0212$

$0.0008=0.0106$

$0.0005=0.0062$

$0.0003=0.0041$

$0.0002=0.0021$

As apothecaries or chemists seldom keep Troy weight beyond 4 or 8 ounces, the relation between the Apothecary or Troy pounds and ounces and the common weight, is often required in preparing the officinal preparations, and is here given; the quarter ounce being used instead of the Avoirdupois dram, as the latter weight is seldom or never kept by chemists or dispensers.

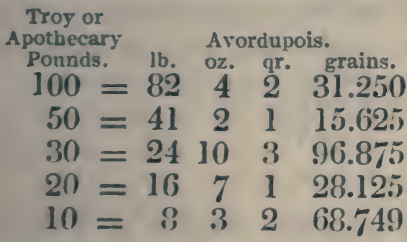

\begin{tabular}{|c|c|c|c|}
\hline $\begin{array}{l}\text { Troy or } \\
\text { Apothecary }\end{array}$ & & Aro & dupoi \\
\hline $\begin{array}{l}\text { Pounds. } \\
5=4\end{array}$ & oz. & $\mathrm{q1}^{4}$ & $\begin{array}{l}\text { grains. } \\
34.375\end{array}$ \\
\hline $3=2$ & 7 & 1 & 108.125 \\
\hline $2=1$ & 10 & 1 & 35.625 \\
\hline $1=$ & 13 & 0 & 72.500 \\
\hline
\end{tabular}

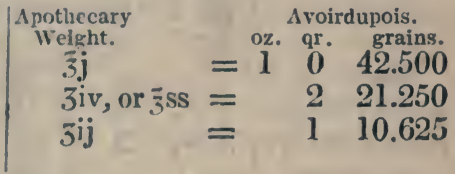

\begin{tabular}{|c|c|c|c|c|c|c|}
\hline thecary & & Avoirdupois. & Apothecary & & Avoi & upois. \\
\hline iv & $=9$ & 54.375 & $j$ & & qr. & $\begin{array}{l}\text { grains. } \\
42.500\end{array}$ \\
\hline r lbss & $=6$ & 236.5 & Ziv, or इss & $=$ & 2 & 21.250 \\
\hline iii & $=3$ & 18.1 & $3 \mathrm{ij}$ & $=$ & 1 & 10.625 \\
\hline & $=2$ & $\begin{array}{ll}0 & 85.000\end{array}$ & & & & \\
\hline
\end{tabular}

Although the quarter ounce is only 109 grains 375 , it will be convenient, in adding two or more of these reductions together, to take the even 110 grains as its value.

The Scotch pound trone is equal to 9600 grains Scotch Troy weight, or $527 \mathrm{gr}$. English 225 : the Scotch Dutch Troy pound is equal to 7680 Scotch grains, or $7620 \mathrm{gr}$. Engl. 8: both pounds are divided into 16 ounces, the ounce Dutch equal to $476 \mathrm{gr}$. Engl. 3.

Besides the regular weights, articles are sometimes quoted by the weight of seeds or kernels, as the weight of a nutmeg, or of so many black pepper-corns. In India they use the paddy weight, or that of the grains of rough rice, each of which is equal to about 2-5ths of a grain ; the gulivindum weight, or that of a jumble bead, cqual to about I grain 5-16ths; the retti weight, equal to about 2 grains 3-16ths. Gold coins are sometimes used, as the gold fanam weight, equal to 8 grains; the star pagoda weight, equal to about 84 gxains. 


\section{FRENCH WEIGHTS.}

Before the Revolution there was only one pile of weights in common use: in endeavouring to introduce one upon philosophical principles, there are now no less than four.

The old French Poids de Marc, established by Charlemagne.

livre, ponch weight.

livre, poids de marc

o médicine

1 marc, or 8 ounces

4 ounces

2 ounces

1 ounce

6 gros or dragmes

$\frac{1}{4}$ ounce, or 4 gros

2 gros

$\frac{1}{2} \%$ or $3 \dot{6}$ grains

$\frac{1}{4}$, or 18 grains

12 grains

6 "

3 ",

2

1 grain

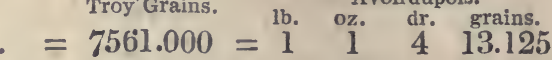

$$
\begin{aligned}
& \begin{array}{lllll}
. & =5670.750= & 12 & 15 & 10.594
\end{array} \\
& \text {. }=3780.500= \\
& \text {. }=1890.250= \\
& \text {. }=945.125= \\
& \text {. }=472.562= \\
& \text {. }=344.421= \\
& \text {. }=236.281= \\
& \text {. }=118.140= \\
& \text {. }=59.070= \\
& \text { - }=29.535= \\
& \text {. }=14.767 \\
& \text {. }=9.843 \\
& \text {. }=4.922 \\
& \text {. }= \\
& 2.461 \\
& 1.640 \\
& 0.820
\end{aligned}
$$

\begin{tabular}{|c|c|c|c|c|c|c|c|c|c|}
\hline Metrical Weights. & & & ch & ht & & & & & \\
\hline amme. & 20 & 6 & 6 & 63.500 & & 2 & 1 & 0 & 2.450 \\
\hline me, or kilo & 2 & 0 & 5 & 35.150 & . & 2 & 3 & 4 & 22.125 \\
\hline ogramme & - & 3 & 2 & 10.710 & - & & 3 & 8 & 2.152 \\
\hline agramme & & & 2 & 44.270 & & & & 5 & 17.7 \\
\hline & - & & & 18.320 & & & & & 15.444 \\
\hline nme & $\bullet$ & & & 1.880 & & & & & 1. \\
\hline mme. & 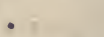 & & & 0.180 & & & & & 0. \\
\hline nilligramme , & & & & 0.018 & • & & & & 0.015 \\
\hline
\end{tabular}

The Revolutionists, misled by the apparent facility of a decimal scale, introduced the metrical system in 1795 .

A metrical quintal is 10 myriogrammes.

A millier is 1000 kilos.

The academicians complain much that the great government departments of the navy and artillery have never adopted this weight, not considering the great expense that it would occasion to recast all the artillery and balls.

The faculty of medicine at Paris, in translating their Codex Medicamentorum, or Pharmacopœia, into this new system of weights, did not esteem it necessary to use the exact reduction, but adopted a system of round numbers, and in some parts quoted both the old and 
the new weights, that the preparers might use either: thus a third system of weights was established.

\begin{tabular}{|c|c|c|c|c|}
\hline Old French Weight. & & $\begin{array}{l}\text { Exact Metric } \\
\text { Weight. Gram }\end{array}$ & & $\begin{array}{l}\text { Round Numbers of the } \\
\text { Codex. Grammes. }\end{array}$ \\
\hline $2 \mathrm{lb}$. & . & 970.02 & . & 1000. \\
\hline ] lb. . & - & 489.51 & . & 500. \\
\hline$\frac{1}{2} \mathrm{lb}$. & - & 244.75 & - & 250. \\
\hline 4 ounces & . & 122.376 & . & 128. \\
\hline $2-$ & . & 61.188 & . & 64. \\
\hline 1 ounce & . & 30.594 & . & 32. \\
\hline$\frac{1}{2}-$ & . & 15.297 & . & 16. \\
\hline$\overline{2}$ gros & . & 7.6485 & . & 8. \\
\hline $1-$ & . & 3.82 & . & 4. \\
\hline 36 grains & . & 1.91 & . & 2. \\
\hline $20-$ & . & 1.062 & . & 1. \\
\hline $10-$ & . & 0.531 & . & 0.5 \\
\hline $2-$ & 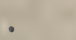 & 0.1062 & . & 0.1 \\
\hline 1 grain & . & 0.0531 & . & 0.05 \\
\hline$\frac{1}{2}-$ & & 0.0265 & . & 0.0 \\
\hline
\end{tabular}

It is not a little singular, that the medical faculty of Paris should, like that of London, prefer creating a new pile of weights, rather than employ the same as are used by all other persons.

In 1812 , the metrical system was abandoned ; but instead of reverting to the old pound of Charlemagne, a new pound was decreed; and thus four systems of weights are in common use, including that of the Codex.

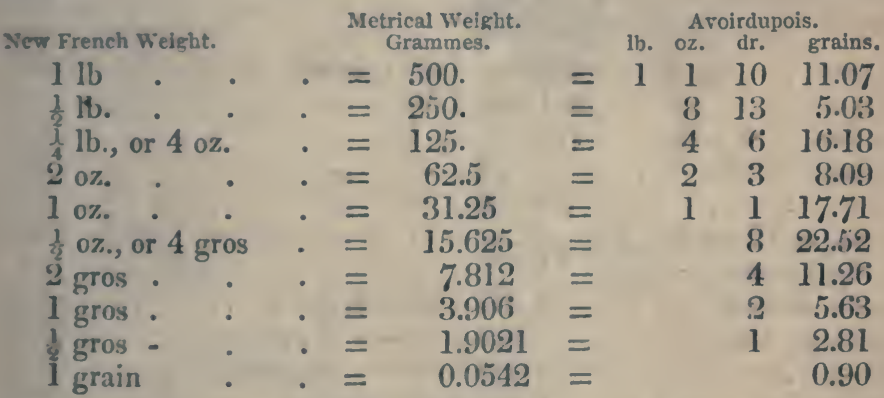

The franc piece of silver, with 1-10th of copper, wesghs 5 granmes. The sous of copper also weighs is grammes.

The confusion thus introduced by continual alteratıms may be easily conceired. The same confusion exists even in their linenr measures, fo that persons are obliged to carry a triangular rule, containing on one side the old royal foot equal to 12 inches. 792 linglish, with its inches, lines, and points; on a second, the decimetres centimetres of the metrical system; and on the third, the new font of 1812, being the third part of the metre, and equal to 13 inclies .123 English. 


\section{ENGLISH MEASURES.}

In the old editions of the London Pharmacopœia, the liquids were compounded by Avoirdupois weight; and the following terms were used for expressing a determinate number of ounces.

The Cyathus, or Cup $\quad . \quad$ for $1 \frac{1}{2}$ oz.
Hemina, or Cotyle
$\begin{aligned} & \text { Libra, or pint } \\ & \text { Sextarius, or 1-6th of a Congius - } 18- \\ & \text { Congius, or Gallon }\end{aligned}$

In 1720, when the Pharmacopœia was improved by Sir Hans Sloane and Dr. Quincy, the liquids were ordered by measure, and the gallon adopted by the London College was that just enacted for wine and spirituous liquors, containing 231 cubic inches, divided into 8 pints; they divided the pint which holds 16 Avoirdupois ounces, 10 drachms, 17 grains of water, into 16 ounces, and these into 8 drachms. Smaller quantities were ordered by drops, supposed to be equal to grains; but now the drachm measure is divided into 60 minims, and graduated tubes used to measure them, so that the old divisions of the Avoirdupois ounce were, and are still, retained in respect to liquids.

Aëriform fluids are measured by cubic inches.

The relation hetween wine measure, with the College divisions, and cubic inches, is thus expressed.

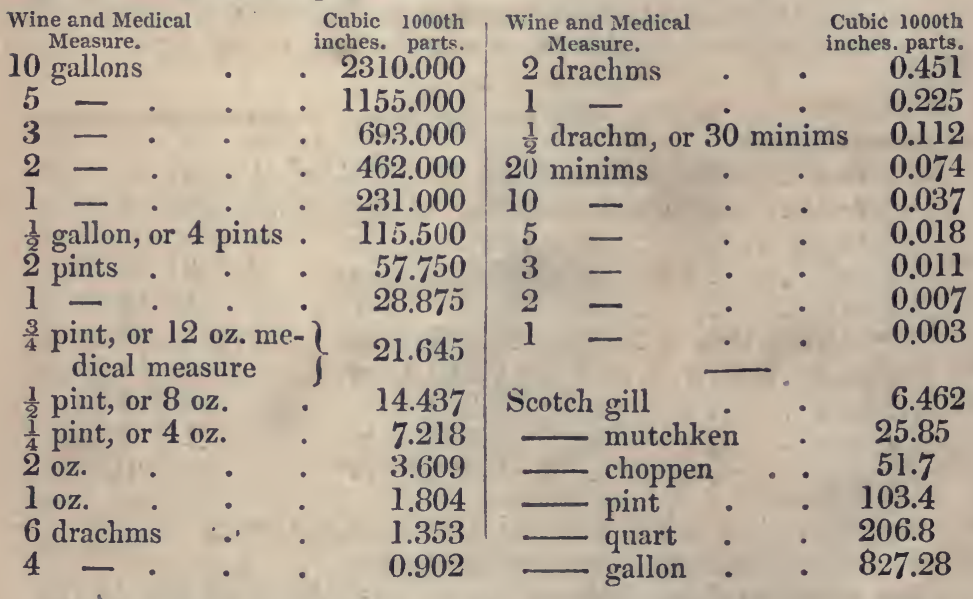

The Scotch pint is equal to $41 \mathrm{oz}$. trone of Tay water, or $55 \mathrm{oz}$. Troy of Leith water: specific gravity of Tay water 100, of Leith water 103.

Ale and beer measure is seldom mentioned by medical or chemical writers: the gallon contains 282 cubic inches; 32 gallons are a London barrel of ale, 34 a country barrel of either ale or beer, and 36 a Lonton barrel of beer. Nor is dry measure often used; the Winchester bushel, of 8 gallons, measures 2150 cubic inches .4 , or 1 cubic foot 822 , and the quarter 8 bushels. 
The imperial gallon, lately added to the others in use, is established by the weight of distilled water it will hold at $62 \mathrm{deg}$. Fahr., the barometer standing at 30 inches.

The gallon is to hold 10 Avoird. pounds of water, and must consequently measure 277 cubic inches .274 .

The pint is to hold 20 Avoird. ounces, and should of course measure 34 cubic inches .659 .

The Avoird. ounce measure of water is therefore 1 cubic inch .73298.

The Troy ounce of water measures 1 cubic inch .9013214 .

The weight of a cubic inch of water is 252 grains .456; and that of a cubic foot is 62 Avoirdupois pounds .3206 .

$\Lambda$ cubic foot of air, or 1728 cubic inches, weighs 528 Troy grains .367 , or 1 Avoird. oz., 3 dr., 8 grains .23 .

Besides these measures, other irregular measures of uncertain content, are used :-

A table spoonful, cochlearium magnum, of syrop $\bar{j}$ ss.

of distilled waters 3 iijss to $\overline{\bar{j}} \mathrm{ss}$

of spirits and tinctures $3 \mathrm{ij}$ to $3 \mathrm{iij}$.

A desert spoonful, cochlearium mediocre, of water $3 \mathrm{ij}$.

A tea or coffee spoonful, cochlearium parvum, of syrop $3 \mathrm{j}$ to $3 \mathrm{ij}$. of distilled waters Эjss to $\mathrm{Yij}$

of spirit and tinctures $\mathrm{Oj}$ to $\mathrm{Oj}$ js

of a light powder, as magnesia, Oss to $\mathrm{\jmath j}$

of a heavy powder, as sulphur, Эjss to Эij

of a metallic oxide $3 \mathrm{j}$ to $\mathrm{Giiij}$.

A thimbleful, clypcola melallica pro digitis, is usually the same as tea spoonful.

A tea-cup, vasculum pro thea, $\tilde{3}$ iij to $\overline{3}$ iv.

A wine-glass, scyphus pro vino, cyathus, zjss.

\section{FRENCH MEASURES.}

In the Codex the liquids are used by weight, and the chemists do the same; so that it is only in common affairs that measures are employed.

\begin{tabular}{|c|c|c|c|c|}
\hline $\begin{array}{l}\text { Id French } \\
\text { Moasure. } \\
\text { L1 }\end{array}$ & & $\begin{array}{l}\text { English } \\
\text { Cubic laches. } \\
\text { A U R E. }\end{array}$ & Metrical Measure of 1795 . & eet. \\
\hline Poisson & & 3.6 & or $1 \mathrm{me}$ & \\
\hline Pinte & & 58.1 & Sto & 35.31 \\
\hline DRY & MEAS & SURF. & H & 3.5377 \\
\hline $\begin{array}{l}\text { Litro } \\
\text { Boiss }\end{array}$ & & $\begin{array}{r}48 \\
\cdot 793\end{array}$ & rcoul. & \\
\hline & & & De & \\
\hline & & & 1 decimetre cube & \\
\hline & & & & \\
\hline 1 & & 66. & & \\
\hline ch: & & 7.8 & e, or 1 .centin & 0.0610 \\
\hline & & 6.5. & & \\
\hline
\end{tabular}


In the new French measures, decreed in 1812, the pinte is to be the same as the metrical litre, and the boisseau is to be 12 litres and a half, equal to 763 English cubic inches .35 .

\author{
Une verre a vin, 3 viij \\ Une verre d'un seul traite, $\overline{3} \mathrm{~V}$ \\ Une verre au liqueur, $3 \mathrm{vj}$ \\ Une cuiller a bouche, $3 \mathrm{v}$ \\ Une cuiller a café, 5 -4ths of a dram \\ Un seau, 48lb., of 16 ounces. \\ Un bassin, $4 \mathrm{lb}$.
}

\title{
SPECIFIC GRAVI'TY.
}

This is usually quoted in England by a reference to water as unity; but the great convenience of Baume's lyydrometer, and the ease with which it may be constructed and graduated, have brought it into universal use on the continent.

There are two of these hydrometers usually employed; one for liquids lighter than water, the other for those which are heavier. In both of them the same fixed points are used, namely, the floating point of the instrument in distilled water, or in a brine or solution of one ounce of dry common salt in nine ounces of water.

The correspondence between these hydrometers and the common expression of specific gravity, as given by Drs. Brugmans, Driessen, Vrolick, and Deiman, in the Pharmacopoia Batava, is here exhibited. The temperature of the liquor being between 56 and 60 degrees of Fahrenheit; for as the lydrometers are at best but a mere approximation to the truth, it is needless to be more particular.

In Baume's hydrometer for liquids lighter than water, the instrument is poised, so that the $\mathbf{0}$ of the scale is at the bottom of the stem, when it is floating in the saline solution, and the depth to which it sinks in distilled water shows the 10th degree; the space between these fixed points being equally divided. His graduation was continued upwards to the 50 th degree, but should be now continued further.

IXYDROMETER FOR IIGITT FLUIDS, OR PESE-ESPRIT.

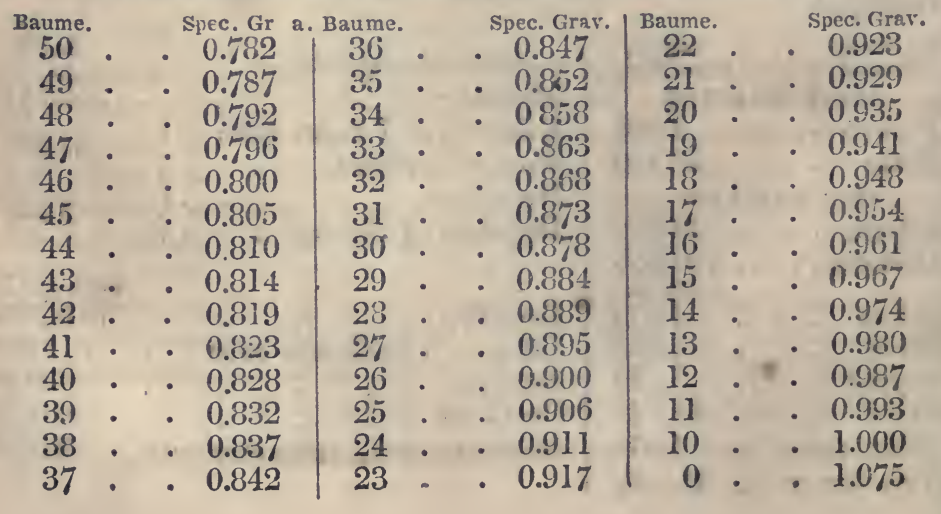


In the hydrometer for liquids heavier than water, the position of the fixed points is reversed; for the 0 is at the top of the stem, and denotes the level to which the hydrometer sinks in distilled water: the 10th degree is lower down, and shows the level to which sinks in the saline solution, and the graduation is continued downwards to the 75th degree.

\section{IIYDROMETER FOR HEAVY FLUIDS, OR PFSE-ACID.}

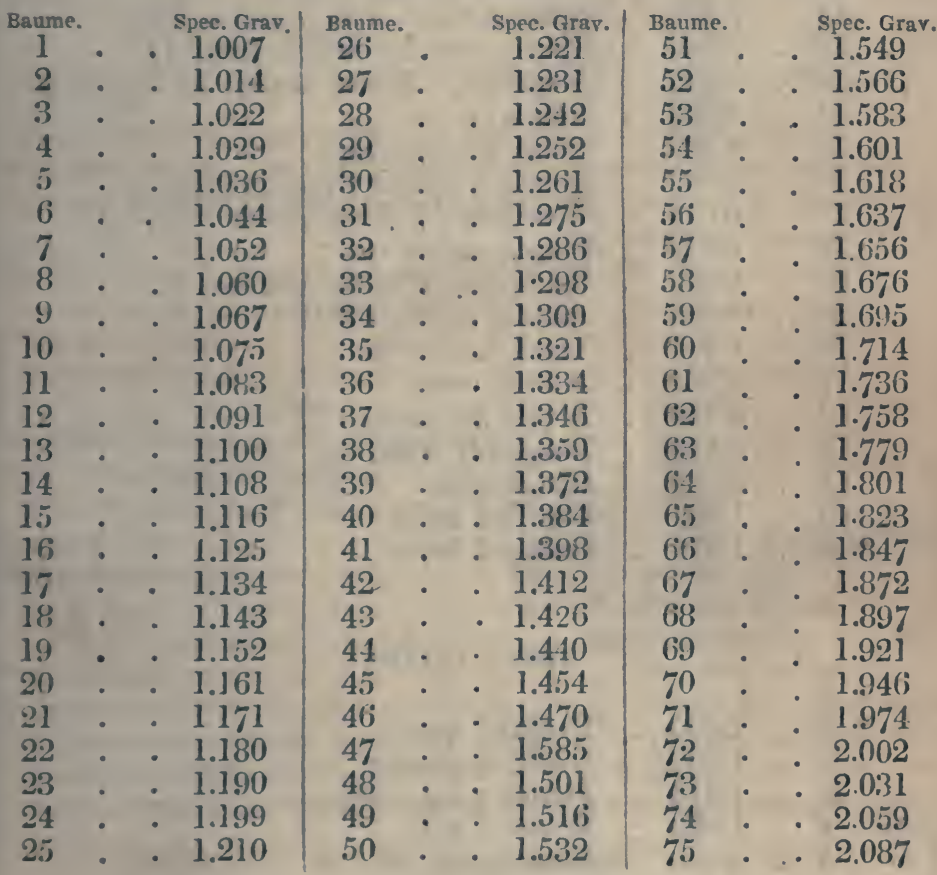

The only inconvenience of Baume's hydrometers, is, that they require several ounces of liquor to float them, and hence they cannot be used for small quantities of liquids. In this case recourse may most conveniently be had to a statical examination, by first ascertaining how many grains of water is held by a very small, light bottle, with one neck of the ordinary dimensions (or, which is better, two very slender necks, that the air may escape by the one, while the liquid is poured in by the other,) when filled to a mark in the neck, and again how many grains the bottle will hold of the liquid under examination. For then as the weight of the water it holds is to that of the liquid, so is the specific gravity of water to that of the liquid.

The following are the specific gravities and degrees of Baume of some of the most usual liquids. 


\section{LIGHT FLUIDS.}

0.700 . Gay Lussac's pure hydrocyanic acid.

0.715 . Purest ether.

0.742 . Very pure ether.

48 . 0.792 . Ether and alcohol, p. æq.

43 - 0.815 . Alcohol. P.L. and P.D.

42 - 0.835 - Spiritus rectif. P.L. Alcohol. P.E.

37 . 0.840 . Spiritus vinośus rectificatus P.D.

36 . 0.847 . Naphtha. Purest alcohol by distillation.

33 . 0.863 . Esprit de vin, $\frac{3}{6}$.

32 - 0.868 . Spirit of turpentine.

26 - 0.900 . Scheele's acid of Prussian blue.

23.0 .915 . Strongest liquid ammonia. Olive oil.

22 - 0.933 . Strong eau de vie.

20 - 0.930 . Sp. tenuis, P.L. Sp. vin. ten. P.D.

20 - 0.935 . Alcohol dilutum P.E.

18 . 0.948 . Weak eau de vie.

$17 \cdot 0.958$. Boiling water.

16 . 0.960 . Liquid ammonia.

13.0 .980 . Burgundy wine.

11.0 .993 . Claret wine.

10 . 1.000 . Distilled water.

* 0 . 1.075 . Standard brine.

HEAVY FLUINS.

* 0.1 .000 . Distilled water.

1.1 .007 . Distilled vinegar.

2 . 1.014. French wine vinegar.

below 4 . 1.029 . Watered milk.

4 to 5 . - Good milk.

above

$5 \cdot 1.036$

$7 \cdot 1.046$

$8 \cdot 1.060$

$* 10 \quad 1.075$

$13 \cdot 1.100$

Skimmed milk.

- Acidum aceticum fortius P.L.

- Wort for table ale, or malt spirít.

Standard brine.

20 . 1.160

$\int$ Wort for strong ale.

Any liquid floating a new-laid egg.

$22 \cdot 1.187$

Acidum muriaticum P.L.

$30 \cdot 1.261$

$35 \cdot 1.231$

$41 \cdot 1.398$

$48 \cdot 1.500$ Single aquafortis.

Boiling saturated syrup.

- Cold saturated syrup. Double aq. fort.

- Common nitric acid.

Acidum nitricum P.L.

51 - 1.550 . Solut. of subcarbon. of potass.

66 . 1.847 . Rectified oil of vitriol.

67 . 1.850 . Acidum sulphuricum P.L. 
Table of Specific Gravities indicated in the different British Pharmacopaias.

Sulphuric ether

Alcohol

Spirit of nitrous ether

Nitrous ether
Rectified spirit (alcohol forlius)

Dub. 182\%. Lond. Edin. 765

810

810

835

835

850

900

919

950

998

Solution of ammonia

Prussic acid

Oxymuriatic acid, Dub. 1807 . $\quad$. 1.003

Distilled vinegar

1.005

Tincture of muriate of iron (red.) Dub. $1807 \quad 1.050$

Acetic acid

Solution of oxymuriate of potass, Dub. 1807

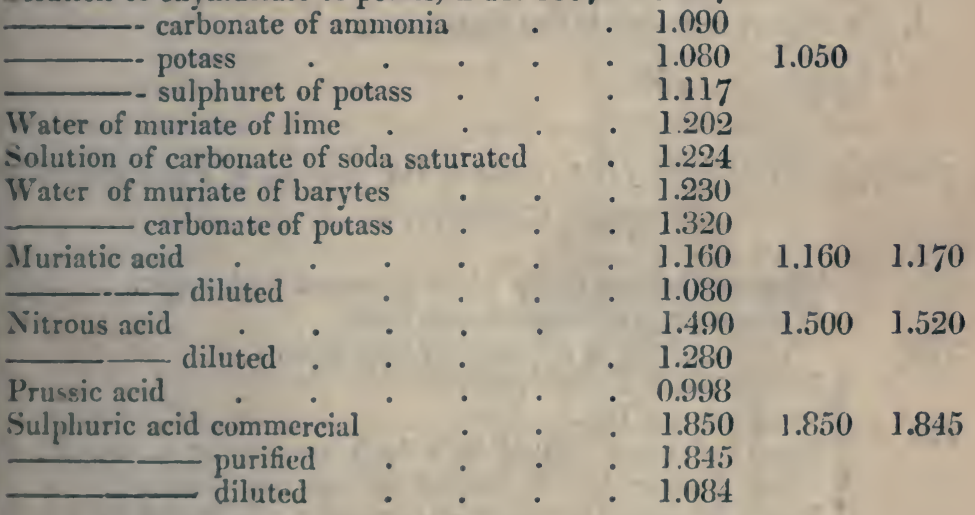

\section{THERMOME'TERS.}

Abridged Table of the correspondence between Celsius' or the Centigrade Sicale, or Reaumur's or I)e Luc's Scale and Fahrenheil's Scale; for every 5 deg. of 'Celsius' and every 4 deg. of Reaumur's.

\begin{tabular}{|c|c|c|c|c|c|c|c|c|}
\hline Cert: & $\begin{array}{c}\text { Reau. } \\
80\end{array}$ & $\begin{array}{l}\text { Yahr. } \\
212\end{array}$ & $\begin{array}{c}\text { Cent. } \\
50\end{array}$ & $\begin{array}{c}\text { Reau. } \\
40)\end{array}$ & $\begin{array}{l}\text { Falir. } \\
122\end{array}$ & Cent. & $\begin{array}{r}\text { Rean. } \\
0\end{array}$ & $\begin{array}{r}F^{\prime}{ }^{\prime}, r . \\
32\end{array}$ \\
\hline (15) & $76 ;$ & 203 & 45 & 36 & 133 & -5 & -4 & 23 \\
\hline 90 & 72 & 194 & 40 & 32 & 104 & -10 & -8 & 14 \\
\hline 85 & (i) 3 & 185 & 35 & 28 & 95 & -15 & -12 & 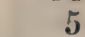 \\
\hline 80 & 64 & 176 & 30 & 24 & 86 & -20 & -16 & -4 \\
\hline 75 & 60 & 167 & $2 \pi$ & 20 & 77 & -25 & -20 & -13 \\
\hline-0 & 56 & 158 & 20 & 16 & 68 & -30 & -24 & -22 \\
\hline (i.j) & 52 & 149 & 15 & 12 & 59 & -35 & -23 & -31 \\
\hline 60 & 48 & 140 & 10 & 8 & 50 & -40 & -32 & -40 \\
\hline 30 & 44 & 131 & 5 & 4 & 41 & & & \\
\hline
\end{tabular}


The degrees of Celsius', or the Centigrade, scale which are not quoted, may be found by adding or subtracting for every degree 1.8 deg. to or from the deg. of Fahrenheit; and those of Reaumur's or De Luc's scale, by adding or subtracting $2.25 \mathrm{deg}$. to or from Fahrenheit's.

1. To reduce Centigrade degrees to those of Fahrenheit, multiply by 9 , and divide by 5 , and to the quotient add 32 , that is,

$$
\frac{\mathrm{C} \times 9}{5}+32=\mathrm{F} \text {. }
$$

-2. 'To reduce Fahrenheit's degrees to Centigrade,

F. $\frac{-32 \times 5}{9}=$ C.

3. To reduce Reaumur's to Fahrenheit's,

$\frac{\text { R. } \times 9}{4} \quad 32=\mathrm{F}$.

4. To convert Fahrenheit's to Reaumur's, $\frac{\text { F. }-32 \times 4}{9}=R$.

Temperatures which are to be noted in the practice of Pharmaceutical Chemistry.

Fahr.

221

$218 \frac{s}{4}$

$216 \frac{1}{2} \quad, \quad, \quad \frac{4}{10}$ of muriatic of lime boils.

'Temp. of boiling syrup when saturated witlı sugar.

Water cont. $\frac{1}{5}$ of common salt boils.

Boiling point of pure water.

212

Calor fervens, P.L.

Temp. of water heated by a bath containing $\frac{1}{5}$ of salt: 6 deg. $\frac{3}{4}$ being lost in passing through the vessel. $207 \frac{x}{2}\left\{\begin{array}{c}\text { Temp. of water (or olive oil, or castor oil) heated by a bath } \\ \text { of pure water : } 4 \mathrm{deg} \cdot \frac{\mathrm{x}}{2} \text { being lost. }\end{array}\right.$

$178 \cdot\{$ Water begins to simmer.

$173 \frac{3}{4} \quad$ Alcohol, 22 deg. Baume, boils in a

$1725, \quad 36$ ditto.

$171 \frac{1}{9} \quad 40$ ditto.

$167^{2}$ - Very pure ether distils in a bath.

122 Highest temp. for drying vegetables.

$110 \frac{3}{4}\{$ Temp. at which tea, coffee, or other hot liquors are usually

$100 \frac{x}{2} \quad$ Greatest heat of a bath that the feet will bear without pain? 100 to 90 Calor lenis, P.L. Temp. for digestions.

$77\{$ Lowest temp. for drying fruits, herbs, and the like.

$67 \quad$ Highest temp. for fermentation. $63 \frac{1}{2} \quad\left\{\begin{array}{c}\text { Temp. used in France for taking specific gravities by Baume's } \\ \text { hydrometers. }\end{array}\right.$ 
60 to $5 j$ Temp. used in Belgium for that purpose.

55 Temp. used in the P.L. for taking spec. grav.

32 f Temp. of melting ice, used for taking spec. grav. of ether and $\{$ other very volatile liquids.

\section{Cases of Mutual Decomposition.}

\section{From Simple Affinity}

\begin{tabular}{|c|c|c|c|}
\hline \multirow{4}{*}{$\begin{array}{l}\text { Sulphate of potass } \\
\text { soda } \\
\text { ammonia } \\
\text { magnesia }\end{array}$} & & with & Muriate of baryta. \\
\hline & & - & Nitrate of potass. \\
\hline & & - & Muriate of potass. \\
\hline & & . & Carbonate of potass. \\
\hline Supersulphate of alumin & & - & Muriate of lime. \\
\hline Nitrate of potass & • & - & - baryta. \\
\hline $\begin{array}{l}\text { Muriate of baryta } \\
\text { Mania }\end{array}$ & & - & Phosphate of soda. \\
\hline Muriate of baryta & - & - & ulphates and nitrates. \\
\hline - - lime & & $\dot{0}$ & Subborate of soda. \\
\hline - ammonia & & & Carbonate of potass. \\
\hline Phosphate of soda & - & - & Muriate of ammonia. \\
\hline Subborate of soda & & - & Carbonate of potass. \\
\hline Nitrate of silver & * & . & Muriate of soda. \\
\hline Acetate of lead & . & . & Citrate of potass. \\
\hline Sulphate of mercury & . & . & Muriate of soda. \\
\hline $\begin{array}{l}\text { Soap of potass } \\
\\
\text { sodia }\end{array}$ & & $\dot{.}$ & $\begin{array}{l}\text { Sulphate of lime. } \\
\text { Soda. }\end{array}$ \\
\hline
\end{tabular}

\section{From Compound Affinity.}

Sulphate of baryta

$$
\begin{aligned}
& \hline \text { baryta } \\
& \hline \text { potass } \\
& \text { Muriate of baryta } \\
& \text { Ditto } \\
& \text { Ditto : } \\
& \text { Ditto : } \\
& \text { Ditto } \\
& \text { Muriate of lime } \\
& \text { Phosphate of soda }
\end{aligned}
$$

A 


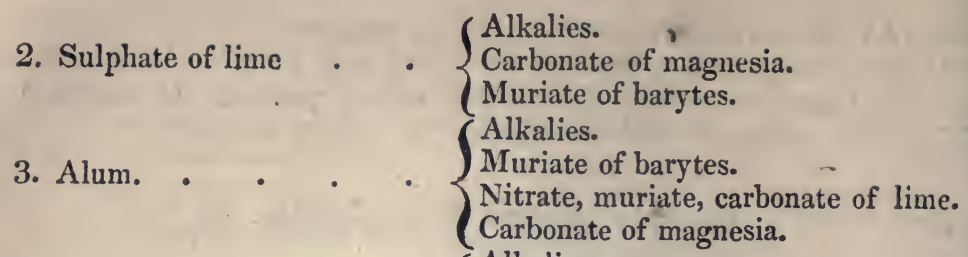

4. Sulphate of magnesia $\quad\left\{\begin{array}{l}\text { Alkalies. } \\ \text { Muriate of barytes. } \\ \text { Nitrate a mat }\end{array}\right.$

Nitrate and muriate of lime.

5. Sulphate of iron . . $\left\{\begin{array}{l}\text { Alkalies. } \\ \text { Muriate of barytes. }\end{array}\right.$

Earthy carbonates.

Sulphates.

6. Muriate of barytes . Alkaline carbonates.

(Earthy carbonates.

Sulphates, except of lime.

7. Muriate of lime . $\cdot\left\{\begin{array}{l}\text { Alkaline carbonates. } \\ \text { Carbonate of magnesia }\end{array}\right.$

8. Muriate of magnesia $\quad\left\{\begin{array}{l}\text { Alkaline carbonates. } \\ \text { sulphates. }\end{array}\right.$

9. Nitrate of lime. . . $\left\{\begin{array}{l}\text { Alkaline carbonates! } \\ \text { Carbonates of magnesia and alumina. }\end{array}\right.$ Sulphates, except of limc.

\section{CONTRACTIONS.}

\section{COMMONLY USED IN PRESCRIPTIONS, ETC.}

A. Aa. Ana, of each ingredient.-Abdom. Abdomen, the belly; abdominis, of the belly; abdomini, to the belly.-Abs. febr. Absente febre, in the absence of the fever.-Ad. 2 vic. Ad duas vices, at twice taking.-Ad. gr. acid. Ad gratam aciditatem, to an agreeable sourness.-Ad. libit. Ad libitum, at pleasure.-Add. Adde, or addantur, add; addendus, to be added; addendo, by adding.-Admov. Admoveatur, or admoveantur, apply.-Adst. febr. Adstante febre, when the fever is on.-Aggred. febre. Aggrediente febre, while the fever is coming on.-Altern. horis. Alternis horis, every other hour.-Alvo adst. Alvo adstricta, when the belly is bound.-Aq. bull. Aqua bulliens, boiling water.-Aq. ferv. Aqua fervêns, boiling water.

$B$ is ind. Bis in dies, twice a day.-B. B. Bbds. Barbadensis, Barbadoes. - B. M. Balneum maris, a water bath.-Bull. Bulliat, 'it should boil; bulliant, they should boil. $-B . V$. Balneum vaporis, a steam heat.

Corul. Coruleus, blue.-Cap. Capiat, take.-C.m. Cras mane, to-morrow morning.-Coch. ampl. Cochleare amplum, a large spoon. - Coch. infant. Cochleare infantis, a child's spoon.-Coch. magn. Cochleare magnum, a large spoon.-C'och. mod. Cochleare modicum, a dessert spoon.-Coch. parv. Cochleare parvum, a small spoon.- 
Col. Colatus, strained.-Colal. Coletur, it should be strained ; colaturæ, of or to the strained liquor.-Colent. Colentur, they should be strained.-Comp. Compositus, compounded.-Cont. rem. Continuentur remedia, the medicines should be continued.-Contr. Contritus, ground to a fine powder.-Coq. Coque, boil; coquantur, they should be boiled.-C. P. Codex of Paris.-Crast. Crastinus, to-morrow.Cuj. Cujus, of which.-Cujusl. Cujuslibet, of any.-Cyath. thea. Cyatho theæ, in a cup of tea.

Deur. pil. Deurentur pilulæ, the pills should be gilt.-Deb. spis.s. Debita spissitudo, a proper consistence.-Decub. Decubitus, of lying down-De d. in $d$. De die in diem, from day to day.-Dej.alvi. Dejectiones alvi, stools. - Det. Detur, it should be given.-Dieb. alt. Diebus alternis, every other day.-Dieb. tert. Diebus tertiis, every third day.-Dim. Dimidius, one-half.-Dir. prop. Directione propria, with a proper direction.-Donec alv. bis dej. Donec alvus bis lejiciat, until two stools have been obtained.-Donec alv. sol. fuer. Donec alvus soluta fuerit, until a stool has been obtained.

Ejusd. Ejusdem, of the same-Enem. Enema (en-e-ma), a clyster; enemata, clysters.-Ext. sup. alut. Extende super alutam, spread upon leather.

F. pil. $x i j$. Fac pilulas duodecim, make 12 pills.-Feb. dur. Febre durante, during the fever.-Fem. intern. Femoribus internis, to the inner part of the thighs.-F. vences. Fiat venæsectio, bleed.Fist. arm. Fistula armata, a clyster pipe and bladder fitted for use. - Fl. Fluidus, liquid; also by measure.

Gcl. quav. Gelatinâ quâvis, in any kind of jelly.-G.G.G. Gummi guttæ Gambiæ, gambooge.-Gr. Granum, a grain ; grana, grains.(ill. Gutta, a drop; guttre, drops.-Gutt. quibusd. Guttis quibusdam, with a few drops.

Har. pil. sum. iij. Harum pilularum sumantur tres, three of these pills should be taken.-Hor. decub. Hora decubitus, at going to bed. - IIor. som. Hora somni, just before going to sleep; or on retiring to rest.-IIor. un. spatio. Horm unius spatio, at the expiration of an hour.-Hor. interm. Horis intermediis, at the intermediate hours between what has been ordered at stated times.

Ind. Indies, from day to day, or daily.-In pulm. In pulmento, in gruel.-Inj. enem. Injiciatur enema, a clyster should be given.

I.at. dol. Lateri dolenti, to the side that is affected.-Lb. Libra, a pound ; or libra, weight, or a wine pint; when preceded by Arabic figures, Avoirdupois weight is generally meant; but when succeeded ly Roman numerals, Troy weight, or pint measures.

M. Misce, mix; mensura, by measure; manipulus, a handful.Mane pr. Mane primo, very early in the morning.-Min. Minimum, the 60th part of a drachm measure--Mill. Mitte, send; mittatur, or mittantur, there should be sent.-Mill. sang. ad. zxij sallem. Mittatur sanguis ad uncias dundecim saltem, blood should be taken uway to 12 ounces at least.-Mod. presc. Modo prascripto, in the nanner directed._Mor. sol. More solito, in the usual manner. 
Ne.tr. s. num. Ne tradas sine nummo, you should not deliver it without the money: as a caution to the shopman, when the presence of the customer prevents the master giving a verbal direction. $-N . M$. Nux moschata, a nutmeg.

$O$. Octarius, a wine pint, being 1-8th of a gallon.-Ol. lini s $i$. Oleum lini sine igne, cold drawn linseed oil.-Omn. hor. Omni hora, every hour.-Omn. bid. Omni biduo, every two days.-Omn. bih. Omni bihorio, every two hours.-Omn. man. Omni mane, every morning.-Omn. noct. Omni nocte, every night.-Omn. quadr. hor. Omni quadrante horæ, every quarter of an hour.-O. O. O. Oleum olivæ optimum, best olive oil.-Oz. The ounce Avoirdupois, or common weight, as distinguished from that prescribed by physicians in their orders.

$P$. Pondere, by weight.-P. Bat. Pharmacopoia Batava.- $P$. Belg. Pharmacopoia Belgica.-P. D. Pharmacopoia Dublinensis. -P. E. Pharmacopœia Edinensis.-P.L. Pharmacopœia Londinensis.-P. L. V. Pharmacopœia Londinensis, before 1745.-P.U.S. Pharmacopœia of the United States.-Part. vic. Partitis vicibus, to be given in divided doses, instead of all at once.-Per. op. emet. Peracta operatione emetici, when the operation of the emetic is finished. -Post sing. sed. liq. Post singulas sedes liquidas, after every loose stool.- $P . r . n$. Pro re nata, according as circumstances occur.P. rat.al. Pro ratione rtatis, according to the age of the patient. - Pug. Pugillus, a gripe between the finger and thumb.

Q.p. Quantum placet, as much as you please.-Q.s. Quantum sufficit, as much as may suffice.-Quor. Quorum, of which.

R. Recipe, take; but for this the old authors, and the French to this day, use this sign $\mathcal{\psi}$, being the old heathen invocation to Jupiter, seeking his blessing upon the formula, equivalent to the usual invocation of the poets and of Mahommedan authors, or the Laus Deo with which book-keepers' and merchants' clerks formerly began their books of account and invoices, a practice not yet quite extinct.-Red. in pulv. Redactus in pulverem, powdered.-Redig. in pulv. Redigatur in pulverem, it should be reduced to powder.-Reg. umbil. Regio umbilici, the parts near the navel.-Repet. Repetatur, it should be continued; repetantur, they should be continued.

S. A. Secundum artem, according to art.-Semidr. Semidrachma, half a drachm.- Semih. Semihora, half an hour.-Sesunc. Sesuncia, an ounce and a half.-Sesquih. Sesquihora, an hour and a half.-Si n. val. Si non valeat, if it does not answer. $-S i$ op. sit. Si opus sit, if need shall be.-Si vir. perm. Si vires permittant, if the strength will allow.-Sign. $n$. $p r$. Signetur nomine proprio, write upon it the usual name, not the trade name.-Sing. Singulorum, singularum, of each. $-S$. S. S. Stratum super stratum, layer upon layer. $-S s$. Semi, a half.-St. Stet, it should stand; stent, they should stand.-Sub fin. coct. Sub finem coctionis, when the boiling is nearly finished.-Sum. tal. Sumat talem, the patient should take one like this.-S. $V$. Spiritus vinosus, ardent spirit of any strength. $-S . V . R$. Spiritus vinosus 
rectificatus, spirit of wine. $-S . V . T$. Spiritus vinosus tenuis, proof spirit, or half and half spirit of wine and water.

Temp. dext. Tempori dextro, to the right temple.-T. $O$. 'Tinctura opii, tincture of opium; generally confounded with laudanum, which is properly the wine of opium.-T. O.C. Tinctura opii camphorata, paregoric elixir.-Trit. Tritus, ground to powder.

Ult. prescr. Ultimo præscriptus, the last ordered.

$V$. O.S. Vitello ovi solutus, dissolved in the yelk of an egg.Vom. urg. Vomitione urgente, when the romiting begins.

Z. A mark in writing that a word is contracted, as in oz. for ounce.-Zz. Zingiber, ginger.

Э. Scrupulum, a scruple, equal to 20 grains Troy. - 3. Drachma, a drachm, equal to 3 scruples; or in liquids the $8 \mathrm{th}$ part of an ounce inensure.- $\overline{3}$. Uncia, an ounce Troy; or in liquids the 16th part of a wise pint.

In labelling bottles, boxes, drawers, or pots in a shop, the name of the drug should be left predominant; while a single letter is sufticient for denoting the technical terms, as radix, pulvis, pilulæ, compositus, volatilis, \&c.; simple powders also speak for themselves to the eye, and do not require the addition of pulvis.

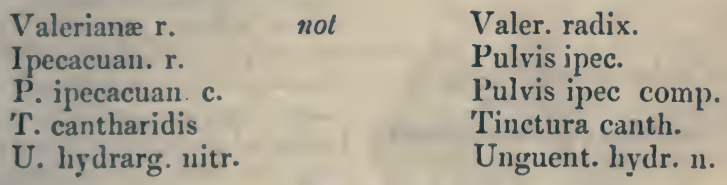

It is still more proper, and less liable to error, to denote the powdered simples as the College itself does, by the adjectives, trilus, or contritus, and not by the substantive pulvis, which renders them liable to be confounded with the compound powders : tritus being used when the sulsstance is easily powdered, and contritus when it requires great labour, or is reduced to a particular fine powder; the con being used as an intensive adjection.

And here it may be noted, that for reducing acrid substances as euphorbium, and the like, to powder, the method used by the firework makers in powdering charcoal may be advantageously employed. They put the charcoal into a strong leather bag, and having tied the opening very tight, beat it with a mallet: then leaving it for some time to setile, the bag is opened, and the powder run into a drum sieve with as little disturbance as possible. 


\section{TABLE OF VEGE'TABLE SUBSTANCES.}

The following Table from Professor Kane's Elements of Pharmacy shows the Vegretable Substances of the British Materia Medica to be collected in each Month of the Year.

January and February.

No vegetable, with the exception of a few cryptogamic plants, collected in these months.

\section{- March.}

Flowers of tussilago farfara. Leaves of ditto.

Flowers of viola odorata.

$$
\text { April. }
$$

Flowers of viola odorata.

Leaves of asarum Europæun. narcissus pseudo-narcissus. - laminum.

\section{May.}

Tops of artemisia absinthium. - juniperus communis. Herb of cochlearia officinalis. Leaves of conium maculatum. Petals of the rosa gallica. prunus lauro-cerasus. _ — rosa centifolia.

\section{June.}

Tops of artemisia absinthium. - spartium scoparium. Leaves of althæa officinalis.

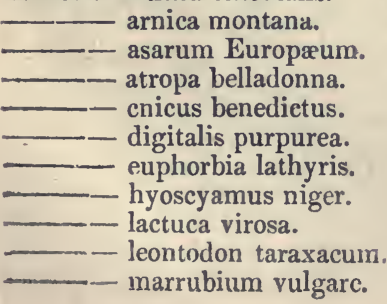

July.

Flower of the anthemis nobilis, and in July.

Flower of the sambucus niger.

Petals of the papaver rhoas. rosa centifolia. gallica.

Seeds of colchicum autumnale. Tops of artemisia absinthium. - rosmarinus officinalis. Herb of origanum marjorana. melissa officinalis.

$$
\begin{gathered}
\text { melissa officinalis. } \\
- \text { mentha piperita. } \\
\hline- \text { viridis. } \\
\hline \text { lythrum salegium. } \\
\hline
\end{gathered}
$$

Leaves of erythrea centaureum. - nicotiana tabacum. - ranunculus acris.

- ruta graveolens.

- ruinex acetosa.

- juniperus sabfna.

- salvia officinalis.

_ - scrophularia nodosa.

r. rhus toxicodendron.

Flowers of borago officinalis.

- - arnica montana.

- _ lavandula spica.

Bulbs of colchicum antumnale.

$$
\text { August. }
$$

Bulbs of colchicum autumnale. Stems of solanum dulcamara. Herb of datura stramonium. Flowers of punica granatum. Strobiles of the humulus lupulus. Fruit of the momordica elaterium.

- morus nigra.

Capsules of the papaver somniferum.

Seeds of the carum carui.

__ coriandrum sativum.

- - anethum graveolens. fœeniculum. 


\section{VEGETABLE SUBSTANEESGERRAR liii \\ September.}

Fruit of the rosa caniria.

$$
\text { rhamnus catharticus. }
$$

sambucus niger

Seeds of ditto.

punicum granatum.

datura stramonium.

Roots of angelica archangelica.

aspidium filix mas.

arnica montana.

althæa officinalis.

Seeds of calamus aromaticus.

cochlearia aromatica.

- glycirrhiza glabra.

— florentia iris.

leontodon taraxacuin. orchis mascula.

- polygonum bistorta.

rumex aquatica.

tormentilla erecta.

valeriana officinalis.

veratrum album.
Berries of juniperus communis.

Bark of œsculus hippocastanum. dapline mezereon. gnidium.

Roots of quercus robur.

ulmus campestris.

Fruit of the vitis vinifera.

Seeds of the pyrus cydonia. ricinus communis.

Roots of the inula helenium.

-

- - bryonia alba. rheum palmatum.

- - undulatum. rubia tinctorum.

Stamens of the crocus sativus.

November and December.

Boletus igniarius.

Cetronia Islandica.

Rouella tinctoria. 


\section{CORRECTION.}

Page 439. Lockyer's Pills. Omit "The formula for pauacea antimonii, additions." This sentence has been retained through inadvertence from the preceding edition, in which the formula for the panacea antimonii was omitted. That formula is now inserted in the present edition: sce page 241 . 


\section{A \\ S U P P L E M E N T,}

$\& c$.

\section{VEGETABLES.}

VEGETABLES form in every country the greatest number of remedies employed by practitioners in medicine: not being so remote, in respect to their chemical composition, from the solids and fluids of the human body, as to refuse to assimilate with them; and yet sufficiently so, as to have, in general, a decidedly marked action upon them.

The number of vegetables which are possessed of medicinal virtues, and which are sold in the shops of druggists and herbalists, or used by private practitioners, being so great, it is absolutely necessary to adopt some mode of arrangement. Of the two methods now in common use, that of Jussieu, as amended by the latest writers, is here followed, as being more conformable to nature than the sexual system of Linnæus. The preference thus given to a natural system is also justifiable on the ground that most of the orders have some common medicinal qualities, which are the more distinctly marked, as the order itself is more distinct from others in its botanical characters.

The plants are designated by their common English names, the officinal Latin names by which they are known throughout Europe, and finally, by those given them by Linnæus and his followers, when they differ from those last mentioned, in order that references may be made with facility to the works of the old botanists, who were particularly studious of the medieinal uses of plants.

The plants included in this synopsis are not only those mentioned in the several successive Pharmacopœias of the College of Physicians, and in the two provincial Pharmacopœias of Dublin and Edinburgh, but also most of the plants which have ever been detcribed as possessing any medicinal virtues or used in the chemical arts.

Roots are best taken up in the beginning of spring, unless 
otherwise ordered. They, as well as woods and barks, are the better for being fresh, although many will keep a long time without any perceptible decay. Many kinds of roots may be kept fresh in dry sand in a cellar.

Roots to be dried should be rubbed in water to get rid of the dirt, and also some of the mucous substance that would otherwise render them mouldy. The larger are then to be cut, split, or peeled: but in most aromatic roots, as those of the umbelliferous plants, the odour residing in the bark, they must not be peeled. They are then to be spread on sieves or hurdles, and dried in a heat of about $120 \mathrm{deg}$. Fahr. either on the top of an oven, in a stove, or a steam-closet, taking care to shake them occasionally to change the surfaces exposed to the air. Thick and juicy roots, as those of rhubarb, briony, piony, water lily, \&c., are cut in slices, strung upon a thread, and hung in garlands in a heat of about 90 to $100 \mathrm{deg}$. Fahr. We may here observe that it is not always the same part of the root which it is desirable to preserve: in some, as Arctium lappa, \&c., it is the bark which is to be retained, and the meditullium to be rejected; this is done by splitting up the root, and cutting out the inert portion; in others, as the Althæa officinalis, the bark is to be removed, and the meditullium retained.

The drying of woods requires little attention; but the silver grain is liable to the attack of insects. Buffon advised trees intended for timber to be barked a year before they were felled, as in that time the silver grain becomes as hard as the heart of the wood. Timber for ship-building is sometimes soaked in a solution of arsenic, to hinder it from affording a lodgment to marine worms. By floating timber for some time in water, it loses part of its extractive and saccharine juices, and becomes harder, so as to be less liable to be attacked by insects or worms: by soaking in alum-water, it is rendered less combustible.

Dried barks, for medical purposes, require the outer skin to be peeled off, as it is usually coarse and inefficacious. The ordinary heat of the atmosphere is in general sufficient.

Herbs, for medical purposes, ought to be collected when they begin to flower, and gathered on a dry day, as soon as the dew is off; they should be spread thin, dried as quickly as possible by a gentle heat, and kept in a dry dark place.

Tops, leaves, or whole herbs, should be cleansed from discoloured and rotten leaves, screened from earth or dust, placed on hurdles, covered with blotting-paper, and exposed to the sun or the heat of a stuve, in a dry airy place. 'The quicker they are dried the better, as they have less time to ferment or grow mouldy; hence they should be spread thin, and frequently turned: when dried, they should be shaken in a large-meshed sieve to get rid of the 
eggs of any insects that would otherwise be hatched amongst them. Aromatic herbs ought to be dried quickly with a moderate heat, that their odour may not be lost. Almost all plants, after they have been dried so as to become brittle, give a little, and become more odorous, as melilot, red roses, oak of Jerusalem, lesser centaury. Some persons have proposed to dry herbs in a water-bath; but this occasions them to be as it were half-boiled in their own water, especially as the evaporation goes on slowly in close vessels. With respect to the collection of the leaves of the biennial narcotic plants, Mr. Houlton has made the very important remark that they do not possess medicinal activity until their second year, and that a great part of the leaves of hyoscyamus collected for sale are of the first year's growth, mucilaginous and inert. The mixture of these in unknown quantities with the active leaves, and their being sometimes even used alone, must render the extract or tincture prepared from them of very variable strength and power.

Flowers should in general be gathered in full bloom, and dried as speedily as possible, the calyces, claws, \&c., being previously taken off: when the flowers are very small, the calyx is left, or even the whole flowering spike, as in the greatest portion of the labiate flowers. Compound flowers, with pappous seeds, as coltsfoot, ought to be dried very high before they are entirely opened, otherwise the slight moisture that remains would develope the pappi, and these would form a kind of cottony nap, which would be very hurtful in infusions, by leaving irritating particles in the throat. Flowers of little or no smell may be dried in a heat of 75 to $100 \mathrm{deg}$. Fahr. The succulent petals of the liliaceous plants, whose odour is very fugacious, cannot well be dried, as their mucilaginous substance rots and grows black. Several sorts of flowering tops, as those of lesser centaury, lily of the valley, wormwood, melilot, water germander, \&c., are tied in small parcels, and hung up, or else exposed to the sun, wrapped in paper cornets, that they may not be discoloured.

After some time, blue flowers, as those of violets, bugloss, or borage, grow yellow, and even become entirely discoloured, especially if they are kept in glass vessels that admit the light; if, however, they are dipped for a moment in boiling water, and slightly pressed before they are put into the drying stove, the blue colour is rendered permanent.

Fruits, unless their efficacy depends upon the acerbity of their juice, ought to be gathered when they are ripe, and kept upon a layer of straw, in order to ripen, in a cool, dry, shady place. The fruits ought not to touch one another, lest they should grow rotten for want of free evaporation at the place where they touch. 
Many nutritive fruits of warm climates, as figs, dates, jubebs, sebestens, myrobalans, are dried in the sun upon hurdles.

Dried peels of fruits, as those of pomegranates, oranges, or lemons. In this case, the outer peel should be separated with an ivory or silver knife from the greatest part of the white fungous substance, and it should not be squeezed or moistened with the juice of the fruit.

Dried seeds require, in general, but little attention. The farinaceous and leguminous sorts may be dried in a stove; oily seeds, fit for making emulsions, must not be dried by heat, but only in the free air, and even then they are liable to become rancid. In general, all seeds keep best in their shells or other integuments. Horny seeds, although highly dried, retain their germinative faculty for a long time.

$V$ egetables and their juices may also be preserved lny heating in well-closed vessels. The substances to be preserved are to be put into strong glass bottles, with necks of a proper size, corked with the greatest care, luted with a mixture of lime and soft cheese, spread on rags, and the whole bound down with wires across it. The bottles are then inclosed separately in canvass bags, and put into a copper of water, which is gradually heated till it boils, and thus kept until it is presumed that the substances are, as it were, boiled in their own water: the whole is then left to cool, and the bottles are taken out and carefully examined before they are laid by, lest they should have cracked, or the lute given way.

The preservation of fruit in water is, in some measure, similar to the preceding. The fruit not quite ripe, pulse, or other substance, is put into wide-necked bottles, which are placed in a copper of water nearly up to their mouths, and they are lightly corked; the water is then heated till it is very hot, but does not scald, and this heat is kept up for half an hour; the bottles are then taken out, and immediately filled with boiling water to the very brim, carefully corked, wired, placed on their sides, and turned at first every week, but afterwards seldomer, to prevent any part, in consequence of the bubble of air that forms in them, from getting dry, and thus becoming mouldy. Some attempt to preserve fruits, \&c., without water, by heating the water-bath to boiling, and corking the bottles while in the boiling water, but this does not succeed so well, unless the fruit is very greerı; and the water is at any rate useful to put into pies.

To pickle vegetables in brine. A brine is made of bay-salt, or rather London's solid salt, thoroughly saturated, so that some of the salt remains undissolved, and kept floating upon it by a frame, or bung: this requires about 4 pounds of salt to the gallon of water; into this brine the substances to be preserved are plunged, 
and kept entirely covered with it. French beans, artichokes, olives, and the different sorts of samphire are thus preserved.

Some swicet-scented flowers, as rose or elder flewers, are preserved by dry salt. Two pounds of brown or bay salt are added to each eight gallons of flowers, and the whole beaten to a paste, which is kept in a close vessel. By this means, the chemists and perfumers are not only enabled to distil rose or elder flowerwater at any time of the year, but the scent is also much improved.

Many vegetables are pickled in vinegar, and kept in the shops. The vegetables are usually soaked in salt and water for some hours, then drained, spices added to counteract the coldness of the vinegar, and boiling vinegar poured upon them; in a few days the vinegar is poured off, boiled a little with the spices, and then poured on again : if the vinegar is good, and the substances are not too moist, it is sufficient to pour it cold upon them, and keep the vessel closely covered. The white vinegar, or pyroligneous acid, much diluted, may be used still more advantageously.

In preserving fruits in symup, it is necessary to consider the manner in which the several degrees of strength in syrup is judged of in boiling. If moist sugar is used, the syrup must be clarified with white of eggs; but if refined sugar is used, it need only be melted over the fire in a quarter, or at most one third its weight of water, and as the water evaporates, the syrup must be taken up with a large slice, and let to fall into the pan again. If, during this manipulation, it forms a broad sheet as it falls, it is said to be boiled to a candy height, and will exhibit when taken from the fire, but still warm, $36 \mathrm{deg}$. of Baume's hydrometer : if it has not been boiled quite so far, the sheet is formed but imperfectly, and it exhibits a smaller number of degrees; it is then said to be boiled to a weak candy height. In shaking the slice of syrup, when in this state, it runs over in the form of the feathers of a quill, or drops in the manner of pearls, which being received in a glass of water, ought to fall to the bottom in solid and brittle globules. If the boiling is continued a little longer, these effects are produced in a more perfect manner, and the syrup exhibits $37 \mathrm{deg}$. by the hydrometer; it is then said to be boiled to a full candy height: if it be now stirred until it is cold, it forms a dry powdery mass. As all the water is now evaporated, if the sugar is continued on the fire, it will turn red, and acquire a burnt taste. 'The powdering of the sugar renders the syrup made from it thick and turbid; it should therefore be put into the water in a single lump.

To preserve fruits, then, the syrup is boiled to a weak candy height, and poured hot upon the fruit so as to cover it; the juice of the fruit of course weakens the syrup, which must, therefore, 
the next day be poured off the fruit, and reboiled to the former height, and then poured on the fruit again; and this must be repeated, if the fruit is very juicy, a third or fourth time, until the syrup is no longer weakened by the juice of the fruit, when it is left in it.

To preserve fruits in sugar. 'The fruit, if very succulent, is first soaked for some hours in very hard water, or in weak alum water, to harden it, and then drained. Upon the fruit, either prepared or not, syrup boiled to a candy height, and half cold, is to be poured: after some hours, the syrup, weakened by the juice of the fruit, is poured off, reboiled, and poured on again, and this repeated sometimes a third time. When the syrup is judged to be no longer weakened, the fruit is taken out of it, and drained.

Seeds and fruits may be preserved by being put into honey; and on being taken out, washed, and planted, they will vegetate.

Fruits are also preserved in brandy, or other spirits. Juicy fruits, as plums, apricot, cherries, peaches, ought to be gathered before they are perfectly ripe, and soaked for some hours in very hard water, or in alum water to make them firm. As the moisture of the fruit weakens the spirit, it ought to be strong, and five oz. of sugar should be added to each quart of the spirit.

A few vegetables, as truffles, are preserved in olive oil, the jars being closely luted, to prevent the oil from turning rank by the access of air, but this mode is more practised with animals.

Bees' wax has been used to preserve seeds for carriage to other distant countries, without any injury to the future germination ; but brown sugar offers a preferable mode, and this agent is only used for animal substances, as caviar.

The doses of such vegetables as exert a very powerful action on the human frame are mentioned under each article; or, if not properly known, a caution is given, lest any unlucky accident should occur. The generality, however, of plants, having no very marked action, are taken in powder, in doses of a drachm night and morning; or a sufficient quantity to give a strong taste or colour to water, is infused or boiled in it, usually an ounce to a pint; and the doses are so regulated, that the soluble parts of about a drachm of the vegetable are contained in each; and these doses are exlibited three or four times in a day.

The plants that are marked with an asterisk grow wild, or are largely cultivated, in the British islands; and are described in my Natural Arrangement of British Plants; and the chemical history of those contained in the London Pharmacopœia is detailed in my Elements of Pharmacy. 


\section{ORDER 1. ALGE.}

* Sea lentils, Vitis marina, Lenticula marina, Fucus natans. Used by the Portuguese and Dutch in dysuria.

"Bladder wrack, Quercus marina, Fucus vesiculosus. Burnt to a charcoal is the vegetable Ethiops of the shops; its ashes yield a considerable quantity of alkali; other species of fuci furnish this salt, but generally in a less quantity, therefore this is most usually burned for that purpose. This substance, when burnt, is supposed to possess some deobstruent powers, and as such, has been given in bronchocele and scrofulous affections. Its efficacy depends on the iodine which it contains. The principal use to which the plant has been applied, however, is in the manufacture of kelp.

*Fucus nodosus; - ${ }^{*}$ F. sericatus. Used for the same purposes as bladder wrack.

*Pepper dulse, Fucus pinnatifidus. Biting, aromatic taste, eaten as a salad.

- Da berlocks, Fucus esculentus, F. teres, F. fimbriatus. Eaten in Scotland.

"Gulk WeEd, Laver, Fucus natans, F. bacciferus. Eaten raw as a salad: also pickled, as samphire; aperient, diuretic, and anti-scorbutic.

"SweEt fucus, Fucus saccharinus. Washed in warm water and hung up, a saccharine substance exudes from it: some eat it without washing.

Durse, Dills, Dulesh, Fucus palmatus. Eaten either raw, boiled, or dried, but is very tough.

"R Rd Durse, Fucus edulis. Eaten while raw, also after being pinced with hot irons, in which case it tastes like roasted oysters. A red lake is prepared from it.

"SFa girdeE-ANd-hangers, Fucus digitatus. Contain a nutritive jelly, more or less saccharine, eaten both by man and beast; also burned for kelp.

"Shietd raver, Ulea umbilicalis. Esculent, but requires baking for some hours to render it eatable.

- Icrlasid sea-grass, Ulva latissima;-"Oyster green, Lichen murinus. U. Lactucu. Are also eaten.

Motss: de Corse, Helminthocorton, Conferva dichotoma, Fucus IJelminthocorton, Corsican worm-moss. 'This usually contains also wereral kinds of geniculated thread-like algx: vermifuge, taken in the form of a jelly or thick mucilage. Imported from France.

"Crow silk, Hairy river-weed, Conferva rivularis. This 
green fibrous plant, found in stagnant water, smells marshy, is used as a vermifuge by some country people; it is as difficult to burn as Fontinalis antipyretica; adheres firmly to glass or paper, and was used by the ancients to bind up broken limbs, keeping it constantly moist.

Coraluine, Sea moss, Corallina, C. officinalis. Vermifuge, 3 ss to $3 \mathrm{j}$, in coarse powder.

* Star shoot, Nostoch, N. commune, Tremella Nostoc. A greenish jelly, eatable; infused in brandy, it causes a disgust to that liquor in those who drink of it.

Sponge, Spongia, S. officinalis. Externally to stop hæmorrhages, or dipped in melted wax and squeezed, as a tent to dilate cavities, by its expansion.

\section{FUNGI.}

Frequently poisonous: the best remedy in this case, after immediate vomiting, by tickling the fauces, and the exhibition of clysters, is ether $3 \mathrm{j}$. in a glass of water, with tincture of capsicum. The Russians, however, eat almost every species that are of any size, only stewing them thoroughly, and drinking a glass of brandy after them; and the ancients stewed suspected mushrooms with some twigs of the pear-tree, as an antidote to their bad effects.

*Morect, Morchella esculenta;-M. gigas. Wholesome and agreeable, as are all the other morchellæ. Principally imported dry from Italy; used as a sauce.

*Truffles, Trubs, Tuber cibarium, T. gulosorum, Tubera terra, Lycoperdon tuber; - *T. moschatum;- * T. album; Bianchetti, T. albidum;-Rossetti, T. rufiem;-BLACK TRUFFLE with white Flesh;-Piednont truffle, T.griseum, which has a slight odour of garlic. Are all used as delicate sauces to soups, and the like. The truffles grow under ground, and are turned up, or pointed out by hogs or dogs trained for that purpose. Imported from France and Italy, either dry, or preserved in olive oil.

*Puff balls, Bull fists, Mollipuffs, Crepitus lupi, Lycoperdon Bovista. Narcotic; its smoke stupifies bees, but does not kill them; its very subtile seminal dust is used as a styptic.

* Deer balls, Boletus, Lycoperdon cervinum. Aphrodisiac, and increases the milk.

*Stink horns, Fungus phalloides, Phallus impudicus. Intolerably fœtid at a distance, so that it is oftener smelt than seen, being supposed to be some carrion, and therefore avoided; when near, it has only the pungency of volatile salts. Its odour soon fills a whole house. Applied externally to painful limbs. 
*Helvella esculenta; - $H$. Mitra. Are eaten abroad.

*Goats-beard mushroom, Clavaria coralloides; - * Grey goAts-beard, C. cinerea. Are eaten, and very safely, as from their coralline appearance they have not the least resemblance to any poisonous kinds; but their flesh is rather cottony, and their flavour very slight.

*Hedge-Hoc mushroom, Hydnum erinaceum; - ${ }^{*} H$. coralloides:- * Chevrette, $H$. repandum; - ${ }^{*}$ Brouquichons, $H$. Auriscalpium. Are all eaten.

* Chanterelle, Merulius Cantharellus. Is not a delicate species, but safe, as being unlike any poisonous kind.

*Boletus rRe, B. Chrysenteron, is eaten, at least while young.

${ }^{*}$ Cepatelli, Boletus edulis; - ${ }^{*}$ Black champignon, $B$. areus;-- ${ }^{*}$ Leccino, B. scaber;- ${ }^{*} B$. aurantiacus. Are eaten on the continent, particularly by the Tuscans.

*Bult's liver, Bull's tongue, Hypodrys, Boletus hepaticus, Fistularia hepatica. Almost the only parasitic mushroom that is usually eaten.

Boletus suaveolexs, Dedalea suaveolens. Used in phthisis, ${ }_{\mathrm{j}} \mathrm{j}$ in powder four times a day, made up into an electuary.

Agaric of tie latich, Male agaric, Agaricus, Boletus laricis. Grows in Tartary on the larch: the interior part is friable, light, and used as a drastic purge; dose $3 j$ to $3 \mathrm{ij}$, in powder, with some ginger; or an infusion of double that weight. Imported from Turkey.

*Touchwood, Spunk, German tinder, Amadou, Boletus ignarius; $-B$. fomentarius; $-B$. ungulatus. These, when softened by beating, are used for stopping blood; soaked in a ley of saltpetre, and dried, they are used as tinder: imported from Germany.

*Boletus sulphureus. On drying, evolves needle-like crystals of oxalic acid, nearly pure, and is consequently poisonous.

Blewits, Agaricus violaceus. Used for making ketchup.

"Сомmоn musuroom, Agaricus edulis. Under which name several species of agarici pratelli are supposed to be confounded; is that mostly eaten in England; all are wholesome.

Chassignox, Scotch bonnets, Agaricus pratensis. Dried and used to flavour sauces.

-Mugsaio, Agaricus elurneus;-*Motsseron de Diefpe, A. tortilis, and many others, are sold for food in the markets of Tuscany.

Pivoliade dF saul.e, Agaricus translucens. Eaten by the poor in France along with other agarici with the footstalk on the side, or totally wanting; but most are suspicious.

Agaricus deliciosus. Has yellow milk, and is of exquisite 
flavour, but must not be confounded with $A$. necator, or $A$. theiogalus, both which have also yellow milk, and are very poisonous.

*A. subdulcis ; - $*$ A piperatus; (an ingredient in the opiatum antituberculosum, which loses its acrid taste when dressed) are eaten.

*A. procerus. Is the best and most usually eaten of those whose footstalk is furnished with a moveable collar, and whose gills do not melt into a black liquid; none are known to be poisonous.

*A. muscarrus. Infused in milk, kills flies; juice rubbed on bedsteads expels bugs: dried and powdered, gr. $\mathrm{x}$ to $\mathbf{x x x}$ with vinegar, cathartic, sudorific : applied externally to ulcers and gangrenes.

*A. Bulbosus, is a very active poison.

*Jews ear, Auricula Juda, Fungus sambuci, Peziza Auricula. Grows on the elder; used, soaked in milk or vinegar, as a gargle in the quinsey, \&c.

* OAK LEA TIIE R ; Xylostroma giganteum. Found in the cracks of oaks; used in Ireland as a dressing for ulcers, and in Virginia to spread plasters upon.

\section{LICHENES.}

The softer kinds are slightly bitter, and used in affections of the lungs: those resembling a chalky crust are used in dyeing.

*Tree liver-wort, Lichen arboreus pullus, L. olivaceus. Roborant, used in hæmorrhages and old coughs.

* Oar lungs, Tree lung-vort, Hazel crottles, Pulmonaria arborea, Muscus pulmonarius, Lichen arborum, L. pulmonarius. Slightly bitter, opening, detersive, useful in diseases of the lungs; dyes wool of a durable orange colour; yields a gum similar to gum Arabic.

*Iextand moss, Lichen, Muscus Islandicus, M. catharticus, $L$. Islandicus, Cladonia Islandica, Cetraria Islandica, P. Dub. Slightly bitter, used as food in Iceland, either made into bread or boiled in water, the first water being rejected. The bitterness of this substance is removed by maceration in cold water; demulcent, and nutritious, it is easy of digestion, hence has been recommended in phthisis.

*Lichen velleus. Has the same qualities.

*Muscus cumutalis, Lichen aphthosus. A drastic vermifuge.

*Hairy tree-moss, Muscus, M. arboreus, Lichen plicatus. Astringent. 
*Lichen rangiferines. This, as well as the last, has an agreeable smell; used for making Cyprus powder, or French scent bags.

*Cup Moss, Muscus pyxidatus, Lichen coccineus, L. pyxidatus. Used in hooping cough, and other complaints of the lungs; dose a tea-cup of the infusion, which is generally slightly emetic.

*Lichex cocciferus. Used for the same purposes, and in intermittent fevers.

"Mrescus arboreus, L. prunastri. Astringent, pulmonary; very retentive of odours; used as a basis for perfumed powders.

"Ash-coloured grouxd liver-wort, Muscus caninus, Lichen terrestris, $L$. cinereus terrestris, $L$. caninus. Used in hydrophobia.

*Lichen pustulatus. May be substituted for allspice, dyes a fine red.

"Canary archer, Chinney weed, Herb archel, Rocella tinctorum, Fucus, L. Rocella. Allays the tickling cough attendant upon phthisis; and from it is manufactured litmus.

"Lichex calcareus. Dried, powdered, and steeped in urine, dyes a fine scarlet.

"Stone crottles, Arcell, Lichen caperatus. Dyes wool of an orange colour; but if the wool is previously boiled in urine, of a russet brown.

LicheN farinaceus. Yields, like many other species of lichen, a mucilage with water, similar to gum Arabic.

Conk, Corker, Arcell, Kenkerig, L. omphalodes. Styptic; dyes wool reddish brown, made into balls.

"Auvergae archer, Ground archel, L. parellus. Used, like the Canary archel, in large quantities to make litmus.

- Lichex tartareus. Dyes purple, collected in large quantities for the dyers.

"Lichex velirises. Used to poison wolves, dyes wool yellow.

LICHEN, L. arboreus pullus, L. pullus. Slightly astringent, used in asthma and old coughs.

USNEA, L. saxatilis. Astringent; used in hæmorrhages.

4. HEPATICAE.

'Liver-wort, Hepatica vulgaris, Marchantia conica;-"Star I.iver-wort, Hepatica stellata, H. fontana, H. polymorpha. A peritive, acrid, astringent; used in diseases of the liver.

\section{MUSCI.}

-Moss of a dead man's skUt.L, Usnea cranii lumani, Hypnum sericeum, Leskia sericea. Used in hæmorrhages. 
*Goldex locks, Adiantum aureum, Polytrichum, P. vulgare. Sudorific, pulmonary.

*Bog moss, Old wives' tow, Sphagnum palustre, S. commune. Scarcely combustible, used to stop cracks in chimneys : very retentive of moisture, used to pack up plants for exportation to distant countries.

\section{FILICES.}

Sweetish, astringent, and pectoral. A ley of the ashes of most of the species has been used as a wash to promote the growth of the hair, from the alkali contained in them stimulating the skin; whence they have been called capillary herbs.

*True maiden-hair, Adiantum vulgare, $A$. verum, Capillus $V$ eneris, $A$. Capillus Veneris. A fine pectoral, slightly astringent ; the decoction is a powerful emetic.

Canada mainen-hair, Capillus Veneris Canadensis, Adiantum pedatum. Used for maiden-hair.

Cape of Good Hope maiden-hair, Adiantum Aithiopicum. Used as an aromatic astringent.

Peacock's tall maiden-Hair, Adiantum melanocaulon, used in India for maiden-hair.

*Black Matuen-hark, Oak fern, Adiantum nigrum. Asplenium ad. nigrum;- COMMON MAIDEN-HAIR, Trichomanes ad. rubrum, Aspl. trichomanes;-*W ALL RuE, Tent wort, Ad. album Ruta muraria, Salvia vita, Aspl. ruta muraria, Aspl. murale. These have all nearly the same qualities as the true maiden-hair.

*Spleen-wort, Milt waste, Loradilla, Ceterach, Asplenium scolopendria, Aspl. ceterach, Blechnum squamosum, C. officinalis ;Mules fern, Hemionitis, Aspl. hemionitis. Astringent.

*Hart's tongue, Phyllitis, Lingua cervina, Scolopendrium, Asplenium scolopendrium, Blechnum lignifolium, S. vulgare. Astringent, vulnerary, pectoral, and used in spitting of blood, fluxes, and swelling of the spleen.

Rough spleen-wort, Lonchitis, Blechnum boreale. Root aperient and diuretic.

*Female fern, Common brakes, Filix, F. foemina, Pteris aquilina. Root vermifuge; and, in time of scarcity, has been manufactured into a coarse kind of bread.

*Male fern, Filix mas, Polypodium filix mas, Nephrodium crenatum. Root slightly bitter, astringent, a good vermifuge in doses of $3 j$ to $z^{i i i j}$; expelling the tænia, either by the assistance of a strong purge, or by repeating the powdered root for some time; it is also boiled in ale, to flavour ic. 
Calaguala, Polypodium calaguala. Root sudorific.

*Pulypod of the oak, Polypodium quercinum, $P$. vulgare. Ront saccharine, and slightly purgative; an infusion $5^{\mathrm{vj}}$ in half a pint of hot water may be taken at twice; by long boiling becomes bitter.

*Siall oak fern, Dryopteris, Polypodium dryopteris. Acrid, septic.

*White oAk ferx, Adiantum Album, P. Rhaticum, Cyclopteris Rhatica. Used for maiden-hair.

*Brittre cup fern, Ad. album, Cyathea fragilis, $P$. fragile, Cycl. fragilis. Used for maiden-hair.

* Flowerinc Fern, Filix florida, Oplioglossum osmunda, Osmunda regalis. The young shoots, made into a conserve, are a specific for the rickets; root boiled in water makes a kind of starch, used to stiffen linen.

*Moov wort, Lunaria, Osm. lunaria, Oph. lunaria. Leaves astringent.

"Adder's tosgue, Oph. vulyatum, Oph. spicatum. Used to form a celebrated ointment for wounds.

\section{LYCOPODINEA.}

*Club soss, Muscus clavatus, Lycopodium, L. clavatum. Herb astringent, restores ropy wine in a few days : pollen very inflaminable, used in theatres to imitate lightning, by its being thrown across the flame of a candle; repels water so strongly, that if it be strewed upon a basin of that fluid, the hand may be plunged to the bottom, without being wetted: hence females employed in delicate works use it to keep their hands free from sweat; used also to roll up boluses and pills, in the plica Polonica.

"Upricirt fir moss, Selago, Muscus erectus, Lycopodium selago. Violently emetic and purgative, fit only for robust constitutions which can bear rough medicines; used by the country girls in the north to procure abortion; the decoction is employed as a wash to destroy lice in swine and cattle.

\section{EQUISE'TACEA.}

"Duтch rushes, Equisetum mrijus, E. hyemale. Epidermis is formed of silica: used to polish wood and metals. Imported from Holland.

"Cors house-tan, Caneda equina minor, Equiselum arvense, E. minor;- Marsir horse-tail, L. palustre;- Honse-tail, Equisetum, C'auda equina, E. fluviatile. Astringent and vulnerary. 


\section{FLUVIATILES.}

*Pond weed, Potamogeton, $P$. natans. Cooling: used in itchings, and against old ulcers.

\section{ZOSTEREAE.}

*Grass wrack, Alga, Zostera marina, Z. trinerva, Z. Oceanica. Cooling; used in inflammations, and the gout. The charcoal used in strumous tumours.

\section{AROIDEE.}

*Wake robin, Cuckow pint, Barba Aaronis, Serpentaria minor, Zingiber album, Z. Germanicum, Arum, A. maculatum. Root acrid, incisive, detersive; gr. x. to Эj of the fresh root made into an emulsion with gum Arabic and spermaceti, taken three or four times a day, useful in obstinate rheumatisms : has been used in washing, instead of soap; but unless the juice is well separated, it frets and chaps the hands of the laundresses.

Arum nracontium, Dracontium pertusum. Dropsical patients are covered with the fresh leaves, which produce a slight, but universal vesication.

InDIAN TURnir, Arum tryplyllum, A. ringens. Root.

Dragon воот, Arum, P. U.S. Boiled in milk used in phthisis.

Arum peregrinum: $-A$. macrorhizon;- $A$. Virginicum;Arisarum Amboinum, A. trilobatum;-Nelenschena, Arum divaricatum;-Calcas, Kachoo, Colocasia, Arum colocasia;-Frian's Cowr, Arisarum, A. tenuifolium;-Dragons, Dracontium, Arum dracunculus;-Maun Kachoo, Arum Indicum;-Ol, Bol, A. campanulatum;-A. cordifolium;-Rumphal, A. Pentaplyyllum;A. mucronatum;-Water Dragons, Calla palustris. Roots used as food.

Srunk Cabbage, Pothos fretida, Dracontium foetidum, Ictodes foetidus, Symplocarpus foetidus. Root, Dracontium, P. U. S. antispasmodic, used in the asthma and hooping cough; the root of Veratrum viride is sometimes gathered for it by mistake.

Indian Kale, Black cacao, Arum peltatum, Caladium esculentum. Roots and petioles esculent.

Eddoes, Toyos, Arum sagittcefolium, Caladium sagittafolium. Roots imported from the West Indies, eaten boiled, the rough coat being slit, and the pulp squeezed out, it tastes like soap.

Dumb Cane, Arum regnium, Caladium seguinum. Roots used in fomentation for the gout, or bruised with lard to rub on dropsical limbs; expressed juice of the stem and root with one fourth 
of rum is diuretic, but it can scarcely be swallowed.- $A_{0}$ violaceum, C. violaceum. Roots esculent.

\section{TYPHACEA.}

*Burr reed, Sparganium, S. ramosum. Root given with wine for the bites of the viper.

*Cats rail, Reed mace, Typha, T. palustris, T. latifolia. Flowers mixed with hog's lard to cure burns.

\section{CY PERACEA.}

Long-rooted cyperus, English galangale, Cyperus longus;Round-Rooted cyperus, $C$. rotundus, $C$. odoratus. Roots sweet-scented, heating, dose $3 j$ s to $3 j$, equal to the foreign aromatics; when first powdered the scent is weak, but by keeping it becomes stronger.-C.hexastichos. Used for the true Cyperus rotundus.

ADRUE, Cyperus articulatus. Root aromatic, stimulant, used for Virginia snake-root: infusion good in vomiting and fluxes.

Rush Nut, Cyperus esculentus. Root eatable, and when roasted makes good coffee.

Bull rusir, Holoschanos, Scirpus lacustris. Seed astringent, cmmenagogue, diuretic, hypnotic.

-Sea-sedge, Carex arenaria;-"Wond sedge, C. sylvatica; - Bastard Sarsaparilla, German sarsaparilla, Carex villosa; - C. hirta;- ${ }^{*}$. disticha;-*C. intermedia. Roots used for sarsaparilla.

\section{GRAMINEA.}

Seeds nutritive, the basis of bread; and, in general, form the most usual food of man, and several animals. They are almost universally wholesome; some few possess an aromatic quality; the bran of most contains an acrid rosin, to get rid of which, the seeds are husked, or pearled, by being steamed, dried, and ground in mills for that purpose. The stems contain a saccharine juice.

Whiте wheat, Siligo, Triticum hybernum;-Red wheat, $T$. hybernum;-Calbigia, T.hybernum granis rubescentibus;-Bearded rheat, Bled llanc, Brance, T. astivum hybernum, 'T: aristatum liybernum:-Spring wheat, Gom, Froment de Mars, Bled rouge, iernello, T. astivim; - Cone wheat, T' turgidum, T' pyramidale; Square gray wheat, Graiy pollard, Duch-bill wheat, T. turgidum;Egyptian wheat, Many-cared whicat, T. compositum ;-Polish wheat, Danizic echeat, Forty days' wheat, 'Two months' wheat, 'T. foliaceum, T. Polnicum;-13 rent Banlex, Saint P'eter's corn, Zca, Briza, Spelta minor, F'rumentum barbatum, 'T' monococcum;-Spelt wheat, Gran farro, Far, Ador, Spelta major, Zca dicoccos, T. Spelta;Cascola bianca. T. Chalepense spica breviore nitidissima alba, seu 
T. Josephi, and several other species, are cultivated for grinding into a flour to make the best bread or other farinaceous food; the seeds also serve to make starch, farro and semolino; the Cascola bianca is cultivated principally for its brilliant slender straw, used in making hats, although it makes very good bread. - The ears of wheat are occasionally eaten parched, but if used for any time are very hurtful.-Farro, usually made from spelt wheat, steamed, dried, and pearled as in making pearl barley.-Soojec, Semolino, Semola, Urena : 'The heart of the grain, that resists the action of the mill, the stones being soft, blunt, and not set close, remaining in granules like coarse sand, mostly made from red wheat: imported from Italy. - Semoletta, Semola rarita. A still smaller kind of pearled wheat separated from the preceding by sifting.All of these are used for making gruel, and thickening soups and milk: the two latter for making vermicelli and other Italian pastes.-Bran, Furfur. Mixed with fine white bread to render it laxative; a decoction of it, white drink, common mash, used as a restorative, and alterative for horses.

Couch Grass, Gramen officinarum, Triticum repens. Root used in pectoral decoctions.

Whrte oats, Avena sativa alba;-Black oats, A. s. nigra;Naked oats, Pill, Pilcorn, A. nuda;-Spanish oat, A. striyosa.Grain used to feed horses; fourteen pounds by the day being the usual allowance: but hard worked horses must not be stinted. A great part passes through them unchanged, unless the oats are bruised, or wetted with salt water, in which case they are completely digested: it is also made into grits and flour.-Grits, Gruan d'avoine, Avence semina, P. L. Grutellım, C. P. Oats cut into two or three pieces, and the husks separated by a mill: used for making a heating, stimulant gruel.

Barley, Spring barley, Jow, Grudum, Hordeum, Hordeum distichum;-Turkey barley, H. d. mudum;-Square barley, Bere, H. vulgare, H. tetrastichum, H. polystichum vernum;-Naked barley, Black barley, Barley wheat, H. coleste, H. vulgare coeleste, H. tetrastichum nudum, Zeopyrum, Triticospeltum;-Full barley, Six-sided barley, Bigy, Round barley, Winter barley, Greek barley, Escourgeon, H. hexastichum, H. h. hybernum; - Sprat barley, Battledore barley, German rice, $H$. zeocriton, H. distichum $\beta$, Zeocriton commune;-All of these are cultivated for making pearled barley or malt.-Pearl barley, Hordeum mundatum, H. perlatum, Hordeum, P. U. S., Hordei semina, P. L., the seeds of spring barley steamed to soften the skin, then dried and ground in a mill to separate the husk, except that lodged in the deep furrow of the seed;-Scotch pearl barley, French barley,Hordeum perlatum, the seeds ground smaller than the last into spherical granules, generally made from bigg or bere:-Farro di orzo, made from 
sprat barley:-All these pearl barleys are used to make a cooling gruel, to thicken soups, and as ingredients in pectoral and anti-febrile drinks.

Malt, Maltum, Bina, is made from any of the species of barley soaked in water for two or three days, or until the water turns reddish, then drained, spread about two feet thick on a floor where it heats, and emits its root or spike: it is then spread thinner for two or three days, then heaped up again until it heats again, finally dried on a kiln, and the roots separated by screening. Five pounds of spring barley produce about four of malt. Malt is used to make an alterative, analeptic infusion, and its decoction is fermented to form beer and ale.-Grains. The exhausted malt left from brewing, used in London as a food for cows, to whose milk it communicates a peculiar flavour, and tendency to putrescence.

$R_{Y E}$, Secale, S. cereale hybernum;-Spring Rye, S. c. astivum. Sceds malted and manufactured into rye spirit, also ground to flour.-Spurred rye, Ergot, S. cornutum, P. U. S. Diseased grains of rye, which, when ground with healthy rye and made into bread, produces gangrene of the limbs; now in use as an emmenagogue in small doses; and to accelerate the contraction of the womb in protracted labour, and passive uterine hæmorrhage; duse 10 to $15 \mathrm{gr}$. powdered every ten minutes, or as an infusion.

Marze, Indian Corn, Turkey Corn, Formentone, Melicone, Bhoota Mukka, Zea, Z. mays. Yourg ears roasted for food; ripe grain made into flour; used by biscuit-bakers.

IxDIAN RICE, Oryza, O. Indica, O. sativa;-Seeds, rough rice, Dalun, Paddy, used to feed birds; a spirit is distilled from it called arrack. Husked seeds, rice, boiled for food, and to make an astringent decoction;-Ground rice, used for puddings.

Milrex, Milium Panicum miliaceum, M. esculentum, P. milium. Husked seeds, $M$. mundatum, used to make gruel, also ground for flour;-Panic, P. glaucum, Setaria glauca. Seeds used to feed poultry, and sometimes for gruel ;-Miglio panico, Cognee, P. Italicum, Setaria Italica. Seeds small, very delicate and wholesome, added in India to beer to make it more intoxicating; -Chinna, P. pilosum;-Saumah, $P$. frumentaceum. Sceds used in India as grain.

Innun Corx, Natchenny, Morhua, Sesame, Sesamum, Cynosurus coracimnes. Seeds size of a mustard-seed, dark coloured, fine flavoured, made into milk gruel, or ground into flour.

- Sprisio Grass, Anthoxanthum odoratum. Nearly resembles camel's hay and Indian nard; dried herb used as a substitute for tea : the very agrecable odour of new hay is owing to this grass; root aromatic. 12lb. of hay, or at most $14 \mathrm{lb}$. is the full quantity 
that ought to be allowed to a horse that works regularly and moderately.

*Frote grass, Manna grass, Gramen manna, Ulva, Typha, Festuca fluitans.-Husked seeds, Russia seeds, manna seeds, nutritive, sweet, eaten.

Sugar Cane, Arundo sacharina, Saccharum officinale;Chinese sugar cane, S. Sinense. Juice yields sugar.-* Reed, Arundo vallatoria, A. phragmites. Root diuretic, depurative; panicles dye wool green.-Bamboo cane, A. tabaxifera, A. bambos, Bambusa arundinacea;-B. baccifera. Yield tabasheer.

*Reed grass, Gramen arundinaceum, Arundo calamagrostis ;Great reed, $A$.donax. Roots diuretic and emmenagogue.

* Canary Grass, Phalaris, P. Canariensis. Juice of the herb drank in pain of the bladder: seed used to feed small birds, and ground to make flour paste.

Warnoogo, Paspalum frumentaceum. Seeds used for food.

Job's tears, Lachryma Jobi, Coix lachryma, C. ovata. Seeds diuretic, and used to make anodyne necklaces for teething children.

Canada rice, Zizania aquatica. Bears the cold better than any other species of grain, and would probably become the breadcorn of the north, beyond the latitudes in which oats grow freely, from its productiveness, but that its seeds do not ripen all at one time.

Lemon grass, Camel's hay, Sweet rush, Schonanthus, Juncus odoratus, Andropogon schonanthus. Stalk and leaves aromatic, sharp-tasted, heating, attenuant, discussive, tonic ; contains a resin analogous to myrrh: a species in Mithridate and Venice treacle. The infusion of it drank in India by those with whom Chinese tea does not agree.

Ginger grass, Nard Syriaque? Andropoyon parancura. An essential oil is distilled from it in India.

Indian spikenard, Nardus Indica, Andropogon nardus. Bitter, smells like cyperus, and has the qualities of camel's hay; a species in Mithridate and Venice treacle.

Turkey mil ce t, Indian millet, Jooar, Durra, Milium Indicum, Holcus sorghum, Sorghum commune. Grain black, yields little flour, used to feed poultry.-White flat-seeded sorgho, S. album, H. sorghum;-Saggina rubra, Sorghum vulgare rubens, S. Arduini, $H$. rubens;-Black-seeded sorgho, $H$. niger;-Guinea corn, Barbadoes millet, Milium Sabceum, S. vulgare bicolor, H. bicolor;Couscous, Bajorah, Panicum Americanum, H. spicatus, Pennisetum spiculum, Pennicillaria spicata;-Yellow-seeded Indian millet, $H$. dachna, S. saccharatus, H. saccharatus. Seeds used as bieadcorn, 
or made into gruel.-H. Cafer. Stalk very saccharine, juice made into sugar.

*Drank, Iild oat grass, Bromus, B. steritis. Seed drying, corrects stinking breath; decoction vermifuge.

Guilso, Bromus catharticus. Seed? purgative.

\section{JUNCEA.}

"Common soft rush, Juncus vulgaris, J. effusus;-*Pricking large searush, Oxyschœenos, J. acutus. Astringent.

*Swret Flag, Calamus aromaticus, Acorus calamus, A. undulatus. Root, calami radix, broad, few-jointed, a sweet-scented agreeable stomachic, which might be used for the foreign spices; dose from $3 j$ to $3 j$; used to flavour Prussian rye spirit and French snuff. Green root is candied.-A. verus, $A$. Indicus, $A$. Asiaticus. Root slender, many-jointed; aromatic.

\section{1\%. PALMA.}

By tapping many of these trees they yield a juice called toddy, which when drank fresh in the cool of the morning is a mild aperient; when the day gets warm it begins to ferment and is converted into wine, and lastly, vinegar, unless boiled down for a coarse brown sugar, jaggery. The pith of the trunk of many palms yields by washing a fecula, sago; and the kernels of their nuts yield by expression a butter-like oil.

Date tree, Palma, Phœnix dactyliferc. Fruit, dates, dactylus, saccharine, fleshy, emollient, slightly astringent, and pectoral.

Sago palm, Sego, Sagou, Sagus genuina, S. palma pinus, S. vinifera. Yields the best sago.

Saguaster major, Caryota urens. Yields toddy and sago; juice of the fruit used to poison wells; kernel made into a sweetmeat.

Guinea pala, Oil palm, Palma oleosa, Elais Guinensis. Yiclds palm oil.

Prickly pole, Cocos Guinensis, Bactris rotunda, B. minor. Fruit oily.

Cocon tree, Palma cocos, Cocos nucifera. Yields the best toddy; fruit bud crbbage, used for food; nuts, cocoa nuts, contain a milky juice, very refreshing; flesh strong-tasted, very nutritive, fattening, used in stews, rubbed down with water used as milk; yield an oil by boiling or expression. Confounded with cacao nut.

Butrarenut tree, Cocos butyracel. Fruit yields a solid oil.

Nipa Parar. Cocos Nypa. Yields toddy.

Great Macaw trex, Black cbony trce, Ebenus Rithiopica, Cocos aculeatus, C'. fusiformis. Yiclds macaw fat. 
Calamus draco. Fruit yields dragon's blood.

Sugar palm, Borassus gomutus, Arenga saccharifera. Yields sago and excellent toddy.

Chamarops. A species of this genus appears to yield gum caranna.

Dwarf palu, Chameriphes, Palma prunifera, Phonix humilis, Chamcerops humilis. Said to yield bdellium: fruit, wild dates, astringent.

Maldivian cocoa-nut tree, Borassus Sechellensis, Lodicea Sechellarum, L. Maldivica. Fruit, sea cocoa-nut, but indifferent eating, used in typhus fever.

W 4 X Pal, Ceroxylon audicola. Trunk covered two inches thick with wax and rosin.

Paliry ra tree, Lontarus domestica, Borassus flabelliformis. Yields toddy, and also bdellium.

Cabbage palir, Areca oleracea. Flowering bud, or cabbage, is highly esteemed; yields an oil.

Betel nut tree, Areca, Faufel, A. Fanfel, A. Catechu;-A. globulifera. Husk of the fruit pinany, chewed with betel and a little lime as a sialagogue and stomachic, reddens the spittle: catechu is extracted from the wood.

Caleza de Negro, Phytelephas macrocarpa;-P. microcarpa. Milk of the fruits becomes hard like ivory, and of a fine taste.

Grass tree, Acaroides resinifera, Xanthorrheu resinosa, $\mathbf{X}$. hastilis, and other species; stem yields yellow gum.

Ouvirandra fenestralis, Hydrogeton fenestralis;-Saururus natans, Aponogeton monostachyon;-A. distachyon. Roots bulbous, eaten when roasted.

WILD DATE TREE, Elate sylvestris. Yields a pleasant toddy.

Broad-leaved sago pala, Cycas circinalis;-Libby tree, $C$. revoluta;-C. inermis;-Great fan palm, Corypha umbraculifera; -Zamia cycadis, Z. lanuginosa. All yield sago.

\section{COMMELINEXE.}

American spider wort, Tradescantia Virginiaca. Leaves used as a pot-herb, aperient.

\section{COLCHICACE $\not E$.}

Almost all the parts of these plants are so active as to be really poisonous.

*Meadow saffron, Colchicum, C'. autumnale. Bulb, colchici radix, taken up towards the end of July, sliced transversely immediately to prevent its growth, and dried without heat, is a very powerful sedative, cathartic, diuretic, and expectorant; but is 
inert in the autumn, or when dried by heat; dose of the bulb, gr. ss to gr. iij, made into a pill. Seeds, colchici semina, milder than the root. The Dublin College indicate the bulb as the part used in medicine. The active properties of colchicum have been discovered to depend on an alkaline principle called veratria. Officinal preparations of the bulb.-Vinum colchici, $L$. Acetum colchici, L. D. Oxymel colchici, D. Syrupus colchici autumnalis, E. Of the seed. - Tinctura seminum colchici, $D$.

Colchicum hermodactylus. Roots, true hermodactyles, hermodactyli, incisive and purgative, in doses of Эss to 3ss.

White heliebore, Elleborus albus, Veratrum, $V$. album. Root, veratri radix, a drastic emetic, in doses of gr. ss to gr. iij; for horses, $\overline{3} s \mathrm{ss}$ to $\overline{\mathrm{j}} \mathrm{j}$, in farcy; also used as a sternutatory, and in itch ointments; juice used to poison weapons for war or hunting. Officinal preparations.-Unguentum veratri, L. D. Decoctum veratri, $D$.

American hellebore, Veratrum viride. Root emetic.Indian caustic barley, Cevadilla, $\boldsymbol{V}$. sabadilla. Capsules and grains caustic: powder used by monks to kill fleas and lice.

Methonica superba. Root, a very active purgative.

Heronius diorca. Infusion of the root anthelmintic; tincture is bitter and tonic.

\section{TULIPACEA.}

'Tulıp, Tulipa, T. Gesneriana. Root nutritive.

Dog's-тооти violet, Dens caninus, Erythronium dens caninus. Root eases the colic, and is used in epilepsy and tinea.

Eryturoxium Americanum, Erythronium, P. U. S.;-East Indian squill, E. Indicum. Roots used for squills.

RED LII.Y, Hemerocallis, Lilium bulbiferum. Root cathartic; leaves cooling.

Terx's cap, Martagon, Lilium martagon. Root diuretic and emmenagogue.

WHITE LILY, Lilium album, L. candidum. Bulb roasted is emollient and ripening.

Indian-BrEad PLANT, Yucca, Yucca gloriosa. Root yields cassava, or Indian bread.

\section{BROMELIA.}

PINr APPs.rs, Ananas, Bromelia ananas. Fruit highly odoriferous, esculent, astringent.

Agave Americana. Sap of the leaves saccharine, used as honey, and to make a wine, pulque.

Curatoe, Agave vivipera. Juice of the leaf, mixed with limejuice and treacle, a good dressing for ulcers; the inspissated juice 
used as a plaster in gout; roots chewed in diarrhœa.-Tillandsia usneoides. Used in hæmorrhoids.

Prtcairnia crystallina, Pouretia lameinosa. Exudes a crystalline gum from every part.

\section{ASPHODELI.}

Aloe siricata. Said to yield Socotrine and Cape aloes.Aloe perfoliata, now broke up into eighteen species, some of the inferior kinds of aloes. A nutritive fecula is extracted from some species.

Spider wort, Phalangium, Anthericum liliastrum. Leaves, flower, seeds, used against bites of scorpions : roots similar to those of squills.-A. planifolium;-A. bicolor. Bulbs purgative, may be used for jalap.

King's spear, Asphodelus verus luteus, Hasta regia, Asphodeluś luteus; - White asphodel, Asphodelus verus allus, A. ramosus. Roots diuretic.

Alstremeria peregrina;-A. ligtu;-A. revoluta. Roots yield an esculent farina called liuta.

*Musk-grape Flower, Bulbus vomitorius, Hyacinthus Muscari. Root emetic, used in diseases of the bladder.

*Hare bells, Hyacinthus, H. non-scriptus. Root astringent, yields a gum.

*Star of Bethlehem, Ornithogalon, O. umbellatum. Root eaten raw and dressed: seeds used to season bread.

Squilu, Scilla, S. maritima. Bulb, scilla radix, acrid, bitter, nauseous, and emetic, powerfully incisive, diuretic, and expectorant; dose of the fresh root, gr. v. to gr. $x v$; of the dried, gr. $j$ to gr. iij, twice a day. Officinal preparations.-Pulvis Scillæ; D. E. Tinctura Scillæ, D. E. L. Acetum scillæ, D. L. E. Pulvis scillæ comp. D. L. E.

Scilla lilio-hyacintuus. Bulb used as a purgative.

Leeks, Porrum, Allium porrum. Bulb, porri radix, expectorant, stimulant, and contains a little sulphur: juice a powerful diuretic, dissolving the calculi formed of the earthy phosphates.

*Wild LEeks, Scorodoprasum, Allium Ampeloprasum. Leaves partake the properties of garlic and leeks.

*Vine le exs, Porrum vitigineum, $A$. arenarium. Leaves more heating than leeks; diuretic and emmenagogue.

Moly of Homer, Allium nigrum;-Moly of Dioscorides, $A$. hirsutum. Root in a pessary, used in prolapsus of the womb.

Onions, Cepa, Allium cepa. Root esculent; the juice, when fermented, forms vinegar holding manna in solution. 
GA RLIC, Allium, A. sativum. Bulbs, allii radix, esculent, strong tasted, stimulant ; used in sauces.

Roca мвоц, I Iiper's garlic, Allium contortum. Bulbous heads used in sauces: milder than garlic.

* Crow garlic, $A$. vineale. Roots diuretic.

Shallots, A. Ascalonicum. Root used as a sauce.

"Wild garlic, $A$. oleraceum. Roots diuretic.

Welsh ontos, $A$. fistulosum. Bulbs and young leaves used in salads.

*Crves, A. schcenoprasum. Young leaves used in salads.

-Spotted ramsons, Victoralis, A. magicum. Roots heating; used also as an amulet preserving against spectres and infected air, probably inspiring courage by their stimulant qualities.

* Rassons, $A$. ursinum. Infused in brandy, used in gravelly complaints.

\section{TRILLIACEAE.}

Trillium cernudm. Root violently emetic; berry nauseous and poisonous.

\section{ASPARAGI.}

Drac.exa terminatis. Root used in diarrhæa.-D. draco. Yields, by incision, the purest dragon's blood.

"Herb Paris, True love, One berry, Herba Paris, Paris quadrifolia. Alexiterial, recommended by Boerhaave in maniacal cases, dose $3 \mathrm{j}$ a day; leaves and berries narcotic; root emetic, dose Эij.

* Asparagus, Asparagus officinalis. Diuretic; one of the five opening roots; sloots eaten as a dainty, but produce, in some, bloody urine, and accelerate the fits of the gout.

Rock sparkow-grass, Asparagus petrca, Corruda, A. cutifolia. Root opening, diuretic, lithontriptic ; shoots nutritive.

"Solomox's seat, Polygonatum, Sigillum Salomonis, Convallaria polygonatum. Root vulnerary, astringent, diuretic, but may be added to flour in time of scarcity; used in a recent state as a cataplasm to take away the marks of bruises; berries, flowers and leaves, acrid and poisonous.

"Lily of the vallxr, Lilium convallium, Convallium majalis. Flowers cephalic, in doses of $3 \mathbf{j}$; or dried and used as a sternutatory.

ONE BLADE, Monophyllon, Convallaria bifolia. Flowers alexiterial.

-Bvтcher's в воом, Knee holly, Ruscrus, Bruscus, Ruscus aculeatus. Root and berries opening: seeds roasted for coffee. 
Horse-tongue, Hippoglossum, Bislingua, Ruscus hypoglossum ; -Alexandrian bay, Laurus Alexandrina, R. hypophyllum. Roots cathartic.

Medeola Virginica. Root diuretic.

China, Tsinaw, Smilax china. Roots yield half their weight of a reddish sago; imported from the East Indies.

Rough BINDweEd, Smilax aspera;-Wild yam, Bastard ipecacuanha, Bastard china, S. Pseudochina.

Sarsaparilla, Smilax syphilitica. Root sudorific, used as sarsaparilla.

Sairsaparilla vine, Smilax sarsaparilla. Root, sarsaparille radix, gently tonic, and a cleansing sudorific, used in syphilis, chronic eruptions, the cachexiæ, and rheumatism, in powder, $\mathrm{jj}$ to $3 \mathrm{j}$, and in decoction. It is administered in the form of infusion, decoction, or of fluid extract. Officinal preparations. Infus. sarsap. comp. D. Decoctum sarsap. D. L. E. Decoct. sarsap. comp. L. D. Syrupus sarsap. D. Extract. sarsap. D. L. Extract. sarsap. fluidum, $D$. The roots of aralia are mixed with it, and those of several species of carex sold for it.

*Black Briony, Brionia nigra, Tamus communis. Root diuretic, incisive, and opening ; externally resolvent, young shoots eaten as asparagus.

\section{DIOSCOREA.}

Wrud yam, Dioscorea sativa;-White dry yam, Negro yam, D. alata;-Yam pee, D. triphylla;-Ceylon white yam, D. bulbifera;-Purple yam, D. purpurea;-Oncus esculentus, Oncorhiza esculenta. Roots very large, tuberous, farinaceous, esculent; and made also into sago.

\section{NARCISSI.}

*Narcissus, Narcissus poeticus ;- Daffodil, $N$. pseudonarcissus;-Tuberose, Polyanthes tuberosa. Roots emetic; used also as a dressing to burns.

\section{IRIDES.}

Florentine Orrice, Iris Florentina. Fresh root a drastic hydragogue, dose $9 \mathrm{j}$ to $3 \mathrm{j}$; when dried sialogogue, errhine; used to give a violet scent to oils, cut into peas to keep open issues; juice of the root, $3 j$ for a dose, has been used in dropsy.

*Yellow water ficur de luce, Acorus adulterinus, Pseudacorus, Gladiolus luteus, Iris pseudacorus. Root a nauseous drastic purgative, but used in dropsy when other medicines fail, dose gtt. Ixxx of its juice every hour or two in syrup of buckthorn; seeds roasted make coffee. 
Commox fleur de luce, Iris vulgaris, I. Germanica. Fresh root hydragogue, errhine; externally, repels eruptions.

BLUE FLAG, Iris versicolor, P. U. S. Root hydragogue. $-I$. tuberosa. Roots incisive and purgative, in doses of Эss to 3ss; considered by some as hermodactyles.

*Stinking gladwrin, Iris foetidissima. Juice of the root sternutatory, useful also in dropsy and scrofula.

\section{GLADIOLIDE E.}

Corn flag, Gladiolus communis. Root has the same qualities as that of iris pseud-acorus, but is weaker.

"Croces, Crocus sativus. Root has been proposed to be made into bread in times of scarcity; summits of the pistils dried, hay saffrom, crocus in focno, croci stigmata, in doses of gr. v. to $3 \mathrm{ss}$, cordial, emmenagogue, anodyne, and exhilarant; dyes a fine yellow, used in cookery to colour rice, \&c.

CAKE SAFFroN, crocus in placenta, formerly, and still in some countries, esteemed the best, being now reduced with marygold flowers, and those of bastard saffion, or safflower; which is perhaps the true explanation of the very different effects ascribed to saffron by medical practitioners.

\section{MUSA.}

Plantaix tree, Musa, Musa Paradisaica;-Banana, Musa sapientum. Fruit very nutritive, supposed to be the original and proper food of man; eaten either baked whole, or with milk and sugar, or sliced and stewed.

\section{CANNAE.}

Roots and seeds mostly aromatic, and used as spices.

Азомез zingiвеR. Roots, ginger, zingiber, zingiberis radix, in powder, gr. x. to $3 j$, heating, aromatic, stomachic, cordial ; in infusion, diaphoretic; used also as a spice.-Black ginger, the roots merely scalded and dried in the sun;-Preserved ginger, the fresh root, preserved in sugar-cane juice. Ginger enters into a great many officinal preparations : as Tinctura zingib. Syrup. zingib. Confectio opii. Pulv. aromat. electuarium scammonii. Infus. Sennæe compos., \&ic. \&c.

Broad-leaved Gingri, White zedoary, Amomum zerumbet, C'urcuma zenumbet. Roots, Bengalee, risagon, zerumbet, cassamunar radix.

KGMPFERTA RoteNDa. Roots, round zedoary, zedoaria rotunda; -Turmeric zedoary, Ammmum zedoaria, Curcuma zedoaria. Roots, zedoaria longa, z. flara, zedoarice radix.-Are all fragrant, stimu- 
lant, stomachic, gr. $\mathrm{x}$ to $3 \mathrm{ss}$, and used as spices. The yellow zedoary dyes a pale yellow.

Amomum verum, A. racemosum. Capsules, great cardamoms, amomum in the bunch, cardamomum majus;-A. cardamomum, Elettaria cardamomum. Capsules, lesser cardamoms, cardamomum minus. Seeds, cardamomi semina; stimulant, drying, assisting digestion, emmenagogue.

Amomum grana Paradisi. Seeds, grains of Paradise, Guinea grains, grana Paradisi, cardamomum maximum; aromatic, stimulant, tastes very hot and biting like pepper; used by some in large doses to cure agues: also to give a false strength to wine, beer, vinegar, and other liquors.

Maranta Indica;-M. arundinacea. Roots yield Indian arrow-root.

Great gatang ale, Galanga major, Amomum galanga, Maranta galanga, Alpinia galanga. Root tuberous, covered with rings, brownish, inside dirty white, a faint aromatic smell, tastes like pepper and ginger mixed.

Small galangale, Galanga minor, Costus,....? Amomum,....? Root warmer and more fragrant than galanga major, outside brown, inside red. In India is ten times the price of the other. Both are warm stomachics, and emmenagogues.

Indian cane, Canna Indica.' Seeds, Indian shot, cordial, vulnerary.

Costus Arabicus. Root, sweet costus, aromatic, rather acrid; with the smell of orrice, stomachic, tonic, discussive. Becomes bitter by keeping.

Curcuma, C. longa. Roots, turmeric, imported from the East Indies in tubers, about the size of the little finger; aromatic, tonic, discussive, and heating ; used especially in the jaundice and the itch, dose $3 \mathrm{j}$ to $3 \mathrm{ij}$ : dyes a deep yellow, and is used as a seasoning in Indian cookery.

Curcuma angustifolia. Root nutritive, excellent for sick persons, ground to a flour; yields, by washing, East Indian arrow root.

Almina Chinensis ; - Stissera curcuma ;-Dietrichia minor ;D. major;-Emdlia supersonata;-Thalia cannceformis ;-Buekia. Root used as spices.

\section{ORCHIDE $A$.}

These plants are esteemed as highly aphrodisiac.

Epidendron Vanilla, Vanilla aromatica. Pods, banilloes, vanilla, brown, as thick as a quill, covered with an efflorescence, in bundles of $5 \mathrm{oz}$. each, dipped in oil ; cephalic, stomachic, used 
to scent chocolate and liqueurs;-Vanillon. From the Brazils in iron chests, dark coloured;-Pompova. From the Spanish colonies, thick;-Simarouba. From St. Domingo, has scarcely any smell: are probably from different vines.

Grees witue, Epidendron claviculatum. Expressed juice, in doses of a table spoonful, cathartic, vermifuge, and diuretic.

-Tway BLAde, Bifolium, Ophrys ovata;-**Bastard hellebore, Helleborine, Serapias latifolia ;-French satyrion, Satyrium, Orchis, O. militaris ;- Butter-fly satyrion, Satyrium, Orchis bifolia;*Dog stones, Cynosorchis, Orchis pyramidalis ;-Goat stones, Tragurchis, Satyrium hircinum, O. hircina;-*'Triple lady's traces, Triorchis, Ophrys spiralis;-**Male satyrion royal, Orchis palmata, O. latifulia;-*Fools stones, O. Morio;-**Male fools stones, $O$. mascula. Roots washed and baked, salep, are nutritive, restorative, and aphrodisiac; Salep forms a stiff jelly with potash, ammonia, or magnesia.

* Large military goatstones, $O$. fusca. Dried leaves have the same scent as Tonca bean, and are used to scent snuff, as are also those of some other species of orchis.

\section{PANDANEAE.}

BrEAD nUt, Brocimum alicastrum. Fruits eatable.

Vaquors, Pandanus.... Seeds esculent.

\section{ALISMACE $A$.}

"Great water pla n tain, Plantago aquatica, Alisma plantago uquatica. Root used in hydrophobia.

-Ar row head, Sagitta aquatica, Sagittaria sagittifolia. Herb acrid, opening, and incisive; root bulbous, very nutritive.

\section{HYDROCHARIDES.}

- Frog bit, Morsus rana, Hydrocharis morsus rance. Root astringent, cooling.

Fresh water soldirn, Aloe palustris, Stratiotes aloides. Used in wound drinks._* Watersengreen, Stratiotes, Pistia aloides, refrigerant.

- Ducks Mra t, Lens palustris, Lemna major;-L. minor. Are used externally as coolers.

37. CYCADEA.

Mear, ванк тиед, Cycas Caffraa;-C. circinalis;-C. revoluta. Pith of the trunk made into sago. 
pectoral, are eaten raw or preserved, used in emulsions, yield oil by expression.

Aphernousli pine, Pinus cembra. Yields Briançon turpentine: nuts, cembro nuts, eatable, yield oil: shoots yield true Riga balsam by distillation.

* Common fir, Silver fir tree, Pitch tree, Abies Pinus picea. Yields Strasburgh turpentine, by puncturing the small vesicles of the bark in which it is contained, and fir rosin, by larger incisions.

Nonway spruce fir, Yew-leaved fir, Abies mibra, Pinus abies. Exudes common frankincense, and yields Burgundy pitch by incision; tops used to make spruce beer.

Balm of Giread Fir, Pinus balsamea. Yields Canada balsam.

*Spruce fir, Pinus Canadensis. Young shoots, turiones pini, in beer, antiscorbutic, cooling, antiseptic, and tonic.

* La RCh, Larix, Pinus larix. Exudes larch gum and Briançon manna ; yields, by boring, larch turpentine.

Cedar of Lebanon, Pinus cedrus. Wood astringent, antiseptic.

Mountarn pine, Mugho pine, Pinus pumilio. Exudes Hun. garian balsam.

*Scotcr FIr, Pinus sylvestris. Exudes white rosin; yields, by incision, common turpentine; inner bark eaten raw, or made into cakes and baked; tar is distilled from it, and lamp-black obtained by burning its refuse branches in tents.

Swamp pine, Pitch pine, Pinus palustris. Yields American turpentine.

Pinus maritima. Yields French or Bordeaux turpentine.

Prnus dammara, Agathis loranthifolia. Yields Ava dammar.

Sula PINE, Saul tree, Shorea robusta. Yields Nepaul dainmar. Arbor vite, Thuja occidentalis. Leaves alexiterial.-T. quadrivalvis ;-T. Articulata. Yield gum sandarach.

Cypress, Cupressus, C. sempervirens. Wood and berries astringent, vermifuge; nuts, strobiles, nuces cupressus, astringent.

Virginia cypress, Cupressus disticha. Leaves dye cinnamon colour.

*Juniper, Juniperus, J. communis. Tops, juniperi cacumina, diuretic, sudorific, antisyphilitic, may be substituted for guaiacum; berries, juniperi bacce, incisive, discussive, very stomachic; infusion drank as tea; if the seeds are broken, they communicate 
a bitter tart flavour. Officinal preparations.-Oleum juniperi and Spirit. jun. comp. D. L. E.

Berby-bearing cedar, Oxycedrus, Juniperus Phœnicea. Wood diaphoretic, by distillation yields huile de cade ; berries discutient; exudes American olibanum.

Savine, Sabina, Juniperus sabina. Leaves, sabince folia, emmenagogue, producing abortion, diuretic, vermifuge; dose, in powder, gr. xv to $\ni j$ or $3 j$, twice or thrice a day : externally escharotic, applied to warts, \&c., once a day.

JaMAICA CEDAR, Juniperus Bermudiana. Wood used for inclosing crayons.

RED CEDAK, Juniperus Virginiana. Wood, Carolina cedar, used for inclosing crayons: leaves used as savinc.

Rosa mala, Altingia excelsa. Yields liquid storax.

39. TAXIDEA.

"Yew, Tuxus, T. baccata. Wood very hard, thought to be poisonous, as were also the berries, glob berries, but they may be eaten; leaves poisonous to cattle; pollen may be substituted for that of lycopodium.

JAPAN YEw, Taxus mucifera. Berries eatable, aromatic.

Yellow wood, Taxus elongatus. Wood scentless; sold for yellow sanders, but of little value.

Gingrio, Gingko biloba. Seeds yield oil.

Survbв nonse-tail, Ephedra distachya. Berries sweet, eatable; used in lientery and menorrhagia, given in wine.

40. SALICEAE.

"White willow, Salix S. alba. (Bark, salicis cortex, P. D.) "Cвack Willow, Salix fragilis. (Bark, salicis cortex, P. D.)- Yrilow dwarf willow, Rose villou, S. helix, S. monandra; - Nonfolk purple willow, $S$. purpurea;-*Ozien, $S$. viminalis. (13ark, salicis cortex, P. L.)- 'SALLow, S. caprea;"Al.MOND-I.EAF WILLOW, S. amygdalina;-IVEEING W1LLOW, S. Balyylonira;-S. eriocephata. (Bark, Salix, P. U. S.)-Salix herbacen. Barks very bitter, febrifuge, substituted for Peruvian bark, $0 j$ to $3 \mathrm{j}$; leaves astringent, used in tamning.

-Swret willow, Bry willou, Salix lanrea, S. pentandra. Bark, the original willow bark recommended as a febrifuge; leaves aromatic, yicld prussic acid by distillation, when dried, with 1-30th of potash; dye silk, linen, and woollen, impregnated with alum, of a fine yellow.

Carorixa Porran, P'opulus balsamifern. Yields tacamahaca in the lump; buds very resinous, infused in oil to form a vulnerary balsam. 
*Black poplar, Populus nigra. Buds resinous.

*Abere, White poplar, Populus alba;-*Aspen, Trembling poplar, $P$. tremula. Barks useful in strangury.

Lombardy Poplar, Populus pyramidalis. With nitromuriate of tin, dyes a fine yellow.

*Italian Poflar, Populus fastigiata. Bark dyes mordore colour.

Populus tremuloides. Bark tonic and stomachic.

\section{BETULIDEA.}

*Brrch, Betula, B. alba. Leaves used in itch and dropsy.

*Alder, Alnus, A. glutinosa, Betula alnus. Bark and leaves very astringent, vulnerary.

\section{CORYLIDE $A$.}

*Hazel, Nut tree, Avellana, Corylus avellana. Nuts imported from Barcelona; kernel of the nut oily, pectoral, used in emulsions, yields oil.

*OAK TREe, Quercus, Q. Robur. Bark, quercûs cortex, chiefly used for tanning leather; astringent, febrifuge, gr. xv to $3 \mathrm{ss}$, every two hours, also externally in fomentation; a decoction of the bark, with some alum, very useful in relaxations of the uvula: seeds, oke-corn, acorns, glandes quercince, and their calyces, cups, cupula, as also the wood, leaves, and the excrescences produced by the bite of insects, oak-apples, are equally astringent, and of great use in tanning and dyeing.-Tanner's bark. The exhausted bark left after tanning leather, used by gardeners to produce a slight equable heat by its fermentation.-Tan balls. The muddy sediment of tanpits, used for summer fuel. Officinal preparations. - Decoctum quercus, D. L. Extractum quercus, $D$.

White oAk, Quercus alba. Bark emetic.

Quercus castanea;-Q. Castillana;-Q. esculus. Acorns eatable.

BLACK OAK, Quercitron, Quercus nigra, Q. tinctoria. Bark used in dyeing yellow; imported from America.

Holm OAK, Quercus agylops. Cups, valonia, very large, used in dyeing instead of nut-galls, imported from Greece.

QUERCUS INFECTORIA. Excrescences, mut-galls, galla, galla, very astringent, tonic, antiseptic; those from which the insect has not escaped, blue galls, are the most esteemed: imported from Aleppo. 
CORK TREE, Quercus suber. Bark, cork, suber, very light, elastic, astringent, more used in stopping vessels than in medicine.

Ever-green oAk, Quercus ilex. Astringent, mole so than the common oak. On this live the kermes insects.

Quercus ballota. Acorns used as food; yield oil.

Quercus Falcata. Leaves used externally in gangrene.

*BeEch, Fagus, $F$. sylvatica. Seeds, becch mast, useful in gravelly complaints, yield oil by expression.

*Spanish chestrut, Castanea, Fagies castanea. Bark astringent; fruit, dried upon hurdles over a clear fire, nutritive, pectoral.

Chrveuapin, Castanea pumila. Bark, castanea P. U. S., astringent.

\section{PLATANIDEAE.}

Liquidambar styraciflua. Bark odoriferous in funigations; yields, by incision or decoction, liquid storax.-L. orientalis. Thought to yield storax.

Planf. tree, Platanus orientalis. Leaves ophthalmic in wine; bark antiscorbutic infused in vinegar.

Virginia Plane tree, Platanus occidentalis. Root vulnerary, dyes red.

\section{MYRICEA.}

"SweEt willow, Dutch myrtle, Gale frutex, Myrica gale. Strong smelling, driving away insects; leaves astringent, substituted for tea, vermifuge, used as spice.

CANdieberRy wyrtle, Myrica cerifera. Roots in infusion very astringent; berries yield green wax.

Myrica Penssylvanica;-M. Carolinensis. Yield green wax.

\section{ULMIDEAE.}

"Els, Ulmus, U. campestris. Exudes ulmine; inner tough bark, ulmi cortex, astringent, febrifuge, in doses of $\exists j$ to $3 \mathrm{j}$; leaves vulnerary.

SI.IPPERY ELM, Ulmus fulva. Inner bark, ulmus, P. U. S. febrifuge.

Urmus Chinessis. Leaves used as tea.

Nettle TREE, Celtis anstralis. Berries astringent, esculent; kernels yield an oil; wood dyes brown.

\section{PIPERIDEA.}

Herbs aromatic; seeds hot, used as spices.

Black PePper vine, Piper nigrum. Herb acrid, aromatic, stimulant, sialogogue; bẹry, black pepper, mellaghoo, piper 
nigrum, piperis nigri bacce, the same: also much used in cookery as a spice, particularly in pilaus, mellaghootanies, and curries, and in preserving lampreys and ormiers; dose gr. $v$ to $\ni j$, and in larger doses in intermittent fevers; also used to drive away insects ; - white pepper, piper album. Made by soaking black pepper in salt water, and rubbing off the outside skin, or by merely rubbing the over-ripe berries that fall from the vines, is milder. Officinal preparations. - Confectio piperis nigri. Conserva rutæ, and Unguentum pip. nigr. $D$.

Long pepper vine, Piper longum. Unripe fruit, long pepper, piper longum, piperis longi fructus, opening, attenuant, stimulant, in doses similar to the former;-Elephant pepper, is a larger variety of this species.

Smalt American long pepper, Mecaxochitle, Piper obtusifolium. Leaves used to flavour chocolate.

Beter, Piper betele. Leaves bitter, stomachic, tonic, highly aphrodisiac; used as a masticatory with areka nut. $-P$. siriboa. Leaves used for those of betel.

Jabor And, Piper reticulatum. Juice an antidote against the poison of mushrooms and cassada.

Cuвев, Piper cubeba. Berry, cabob pepper, tailed pepper, cubebce, cubeba, the same quality as the other peppers; used in cookery as a spice, and to ornament boiled poultry, stuck in rows on the sides; also in gonorrhœa 3 ss to 3 jss three times a-day; but in India, ziij six or eight times a-day. Officinal preparation.Tinct. cubebæ. $D$.

Santa Maria Leaf, Piper umbellatum. Herb, in syrup, used in colds and coughs.

Pepper elder, Piper amalago. Used externally in baths and fomentations.

Carpapiga, Piper carpapiga. Leaves used in dyspepsia, and to preserve stuffed animals from insects.

Narrow leaved peprer, Piper angustifolium. Decoction used in venereal diseases.-P. peltatum. Fruit used externally in swallings and dropsy.-P. cordifolium. Acrid.

Piper inebrians. Green herb used to make an inebriating drink, as may indeed be most of this genus. $-P$. crystallinum, Peperomia crystallina. Has the odour of anise, and may be used for it.

Matruskea, Saururus vernus. Root fresh and roasted, used as an emollient poultice, and to allay inflammation.

4\%. ARTOCARPEAE.

Stem milky, containing elastic gum. 
*FIg TREE, Ficus vulgaris, F. carica. Dricd fruit, carica, carica fructus, emollient, laxative, pectoral, used as a suppurative poultice; milk of the tree caustic, consumes warts; leaves kept long upon the skin, inflame it.

Sycamore FIG, Ficus sycamorus. Fruit less agrecable and less digestible than the other.

Ficus taricaria. Used to impoison weapons.

Ficus septica. A powerful vermifuge; milky juice very acrid.

JAMAICA FIG TREE, Ficus Benghalensis. Milky juice used against the poison of manchineal.

Indian fig tree, Ficus Indica. Milky juice glutinous, and becomes a soft kind of Indian rubber.

Lisbon contrayenva, Contrayerva Drakena, Dorstenia contrayeria. Root, contrajerve radix, imported from the West Indies, in pieces about two inches long, packed in bales. When fresh, acrid; when dry, aromatic, stimulant, antiseptic, diaphoretic; dose, gr. $\mathbf{x}-\mathbf{x x x}$; in decoction or infusion to $3 \mathrm{ij}$. The roots of yarrow, or of button snake weed, may be used as substitutes.

CA A PIA, Dorstenia Brasiliensis;-D. Drakena;-D. Houstoni. Roots diaphoretic: are all sold as contrayerva.

Braad frutt tree, Artocarpus incisa. Fruit, meat fruit, bread fruit, when unripe, contains a farinaceous pulp); before the seeds fill the fruit is very pulpy and pleasant.

JACK tREe, Artocarpus jaca. Fruit eatable; juice yielded by incision, elastic like Indian rubber; bark said to make Chinese rice paper, used for flower painting; others ascribe this paper to Nelumbium speciosum.

Woxtay, Artocarpus Benghalensis. Fruit preserved in salt, used in cookery instead of tamarinds.

Antraris toxicaria, Ipo toxicaria. Milky juice, upas antiar, used to poison instruments.

Bagassa. 'Tree lactescent; fruit eatable.

-White nutberry, Morus alba;-*Red mulberry, M. rubra. Fruits esculent.

-Black mul berry, Momis nigra. Bark of the root cathartic,

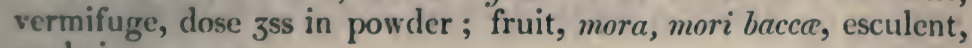
made into a syrup.

Festic, Morus tinctoria, M. xanthoxylum. Abounds with a sulphureous milk; wood, old fustic, bois janene, bois d' Angleterre; sulphur-coloured, in large blocks: with alum dyes a very durable yellow colour, with iron liquor drab colours, and with both mordants, an olive. 
ThoA urens. Bark yields gum; seed edible.

TroA E dulis; - Hedycarya dentata. Seeds sweet, eatable.

\section{URTICE $Æ$.}

*Common netrile, Urtica, U. dioica;-*Roman nettle, $U$. Romana, U. pilulifera. Roots astringent; seeds pectoral.

* Small stinging nettle, Urtica urens. Roots astringent, diuretic, depurative; plant used in palsy and lethargy' as an irritant, producing a crop of small blisters on the skin; the young shoots boiled as potherbs.

Hemp, Ganja, Cannabis, C. sativa, C. Indica. Juice made into an agreeable inebriating drink; seeds oily, cooling, antiaphrodisiac, pectoral, aperitive, but inebriating, and producing fatuity; leaves used as tobacco.

JEEA, Cannabis Jeea. Yields the gum resin, cherris.

*Pellitory of the wall, Parietaria, Helxine, P. officinalis. Herb cooling, opening, diuretic, pectoral, antiasthmatic.

*Hop, Lupulus, Humulus lupulus. Young shoots eaten as a depurative; flowers, hops, humuli strobili, bitter, inebriating, diuretic, also sedative; used to flavour beer, and the only legal substance for that purpose vellow powder sifted from the strobiles, lupuline, lupulinum, qualities same as the strobiles, but much stronger; yields an essential oil. Marsh trefoil leaves, wood sage, fringed bog bean, Geum montanum, Carolina shrub trefoil, and Momordica charantia, are used as substitutes for hops. Officinal preparations. - Tinctura humuli, D. L. Extractum humuli, D. $L$.

\section{EUPHORBIACEE.}

The milky juice is caustic, nauseous, and purgative. Embryo, or corculum of the seeds usually riolently emetic or purgative.

*French mercury, Mercurialis mas et fomina, M. annua. Herb detersive, purgative, resolvent, and emmenagogue.

*Dog's mercury, Cynocrambe, Mercurialis perennis. Herb used instead of French mercury, but has produced fatal accidents.

Children's mercury, Phyllon, Mercurialis tomentosa. Herb used by the Moors in female diseases, decoction recommended in hydrophobia.

'Triangular spurge, Euphorbia antiquorum;-E. Canariensis; $-E$. officinarum. Yield gum euphorbium; are cathartic. -E. heptagona. Juice used to poison weapons. $-E$. edulis. A kitchen herb.

Euphorbia tirucalli. Cathartic, emetic, antisyphilitic; 
exhalations affect the eyes. $-E$. canescens; $-E$. pilulifera. Antisyphilitic, useful in venomous bites.

"Garden spurge, Cataputia minor, Lathyris, Euphorbia lathyris. Seeds, no. 12 or 14, purge and vomit violently, useful in dropsy ; as they yield a fine oil, have been proposed for cultivation for that purpose; the oil purgative in doses of five or six drops: leaves inebriate fish; milk corrodes warts; decoction depilatory.

Rovgh FRUITED SPURG, Luphorbia verncosa;-Knobbed rooted spurge, Apios, E. apios. Caustic.-Petty spurge, Peplus, E. peplus;-Tree spurge, 'Tithymalus dendroides, E. dendroides; -Thyme spurge, Chamasyce, E. chamæsyce;-Myrtle spurge, Tithymalus myrsinites, E. myrsinites ;-* Wood spurge, Tithymalus characias, E. characias. All violently cathartic.

* Sun spurge, Wartucort, Euphorbia helioscopia. Juice applied to warts.- Purple sea spurge. Reveillematin, E. peplis. Purgative; milk acrid; the eyelids being touched with it, itch so as to hinder sleep.

Gieat spurge, Esula major, Euphorbia palustris. Cathartic. -Lesser spurge, Esula minor, Euphorbia pithynsa. Milk purgative, corrected by acids. - Euphorbia Gerardiana;-Largeflocered spurge, E. corollata;-Ipecacuanha spurge, E. ipecacuanha. Roots emetic, mixed with true ipecacuanha, and used for it.

CAlaca, Creeping hairy spurge, Fuphorbia hirta. Dried plant, jj, purgative, used in dry belly-ach.

*Errorbia cyparissias. Juice may be used for scammony ; is also emetic. - Broad-leaved spurge, I. platyphylla:-E. piscatoria. Used to inebriate fish.-E. ophthalmica. Used in blindness._- Evergreen wood spurge, Tithymalus sylvaticus lunato flore, T. sylraticus, Euphorbia amygdaloides. Emetic-Narrow-leaved icnorl spurge, Tithymalus amygdaloides angustifolius, E. segetalis ; -Sea spurge, Tithymalus paralias, E. paralias. Are all used as purgatives and for the other uses of spurge.

Cicca racemosa. Berry acid, eatable.

Phyldantius emblica. Fruit, myrobalanus emblica, purgative, acidulous, rather austere; when pickled excites the appetite; root astringent, used in dyeing.

Phiclaxthus niruri; $-P$. urinaria. Febrifuge, diuretic, astringent.

Puyllaxthus virosa. Bark astringent, deleterious to fish.

"Box тв1:, Buxus, B. sempervirens. Wood sudorific.

Palsa Cinristi, Oil bush, Ricinus communis, R. c. minor. Sceds, Mexico seeds, castor seeds, ricini semina, purgative; yield 1) 2 
oil, by boiling or expression ; root, in decoction, diuretic ; leaves, with lard, used externally, as an emollient poultice.

Ricinus communis major, $R$. viridis. Seeds, lamp oil seeds. Yield oil.

Croton tiglium. Seeds, Molucca grains, purging nuts, grana tiglia, gr. ss with catechu gr. $\mathrm{j}$, very liydragogue, emetic, emmenagogue, corrected by acids, or roasting, yield oil ; wood, lignum pavana, has the same qualities, but weaker, sudorific in a small dose.

Cascairlla, C. cascarilla. C. Eleuteria. Clutia Eleuteria? Bark, Eleuteria bark, narcaphte, thymiama, cortex thuris, cascarille cortex, imported from Eleutheria, in the Bahama Islands: bitter, very febrifuge, stops vomiting, the dysentery, and menorrhagia, dose gr. $x v$ to $3 \mathrm{j}$; aromatic when burnt, and used to scent tobacco for smoking, but inebriates; dyes a fine black. Officinal preparations.-Tinct. and infus. Cascarillæ, D. L.

CASCARILla BalsamiferUM; - $C$. aromaticum, and some other species, are used to aromatise distilled liqueurs in the West Indies.-C. lineare. A specific in cholic.-C. Moluccanum. Seeds, having the corculum taken out, esculent.-C. humile. Used in baths for nervous weaknesses.

Tallow tree of China, Cascarilla sebiferum, Sapium sebiferum. Seeds yield tallow.-C. lacciferum. YYields Ceylon lac.'

*Turnsol, Heliotropium, Cascarilla tinctorium. Juice blue, easily changed red by acids, and green by alkalies; used to dye rags and paper.-C.tricuspidatum. Juice blue, resembles turnsol.

Barbadoes nut tree, Jatropha curcas. Seeds, common physic nut, very violently purgative and emetic, no. 2 or 3 , carefully peeled; yield an oil : shrub yields, on incision, a lactescent and caustic juice which dyes linen black; leaves rubefacient.- $J$. glauca. Seeds pressed for their oil.

Jatropha glandulosa ; - Wild cassada, J.gossipifolia. Young leaves, no. 6 , boiled as greens, a powerful purge; no. 15-20, in decoction, with some castor oil, used as a clyster in dry bellyach; the powder of the gland contained in the stem is an errhine.

French PHysic nut, Jatropha multifida. Seed, avellana purgatrix, no. 1, a violent purge, yield oil.

Bitter cassava, Jatropha manihot. Root full of an acrid, poisonous, milky juice, separable by expression, or corrected by roasting, thus yielding a nutritive farina; also by boiling the juice, which is used as a sauce, and made into soy.

Sweet Cassavi, Jatropha janipha. Roots, meal roots, soaked in water, dried and powdered are nutritive.-Hycna poison, $J$. globosa, Hyananche globosa, Toxicodendron Capense. Fruit in 
powder used to poison hyænas.-Elastic gum tree, $J$. elastica, Siphonia elastica, Havea Guianensis. Yields, by incision, elastic gum.- Vernicia montana. Kernels yield oil.

Excecaria agallocha. Wood, aloes wood, eagle wood, bois daloes, lignum aloes, lignum aquilinum, cordial, useful in rheumatism and gout, odoriferous; exhalation so acrid as to attack the eyes.

Poonag, Rottleria tinctoria. The outside of the capsules yields a yellow dye, wassunta gunda.-Sapium aucuparium;-Hippomane biglandulosa. Yield birdlime.

Manchinear, Hippomane mancinella. Fruit beautiful, but so caustic as to corrode the mouth and occasion vomiting; juice of the tree used to poison weapons.-Ficarium Cochinchinense. Fruit edible.

\section{ARISTOLOCHIÆ.}

The plants of this order are emmenagogue.

Long-rooted Birth-wort, Aristolochia longa;-Round birthzcort, $A$. roticnda. Roots taken to 3 jss, hot, odorous, powerfully incisive.

*Upright birth-wort, Aristolochia clematitis;-A. pistolochia. Roots emmenagogue.

Ja malca contrayerva, Aristolochia odorata. Root, in infusion, diuretic, purgative, stomachic, and emmenagogue.

Virginia swake root, Serpentaria Virginiana, Aristolochia serpentaria. Root, serpentarice radix, antiseptic, heating, alexiterial, diaphoretic; an active medicine, given in doses of gr. $x$ to 3 ss of the powder, or an infusion of $3 \hat{j}$, every four hours, against the bites of snakes and canine madness. Imported from America, in bales of 200 to $500 \mathrm{lbs}$. ; frequently mixed with the roots of Collinsonia pracox. The roots of Cyperus articulatus, used as substitutes. Officinal preparation.-Tinct. in all the colleges.

Canada snakz root, Asarum Canadense. Root, Asarum, P. U. S. ; - Black snake weed, Serpentaria nigra, Asarum Virginianum. Roots are mixed with those of Virginia snake root, and lave the sarne qualities.

Hriocistes, Asorum hypocistus, ('ytinus hypocistus. Very astringent.

- Asara bacca, Asarum vulgare, A. Europaum. Root a drastic purge, working, in doses of $3 \mathrm{j}$ to $3 \mathrm{j}$, if finely powdered, upwards ; but if coarsely powdered, downwards ; it is also used as a sternutatory, from gr. j to gr. iij : leaves, asari folia, milder, and were the usual emetic before the introduction of ipccacuanha, no. 6 to 9 in whey; they are also applied to wounds. 


\section{SANTALACE $\approx$.}

? Sandal tree of Tecamez. Yields a rosin; leaves rubbed between the hands, and applied to the temples, used to take off the headach occasioned by severe drinking.

SANDAL TREE, Sirium myrtifolium. The outside of the wood, white sanders, santalum album; the heart of the tree, yellow sanders, santalum citrinum; aromatic, slightly bitter and sweetish, cordial, cephalic.

*Thesium linophyllum. Astringent.

\section{EL $\mathrm{EAGNE}$ E.}

*Sallow thorn, Sea buckthorn, Hippophae rhànoïles. Leaves purgative ; berries, made into a sauce.

*NarRow Leaved Wild olive, Elceagnus angustifolia. Vermifuge.

\section{THYMEL EAE.}

Plants of this order are caustic, particularly their bark.

*Evergreen spurge laurei, Lanteola, Chamadaphne, Daphne Laureola. Usually sold for mezereon.

* Mezereon, Spurgé olive, Chamalca, Laureola fiemina, Mezereum, Daphne Mezereum. Bark, mezerei cortex. Officinal preparations.-Decoctum mezerei, D. E. Decoct. sarsap. comp. D. E. L.

Rock rose, Cneomum niger, Daphne cneorum;-* Spurge flax, Thymelcea, D. Gnidium. Have all similar qualities, but the latter seems the most efficacious. Bark of all these serves as a vesicatory, and ulcerates the parts to which it is applied; it has been chewed in palsy of the tongue with success; taken internally, in doses of only a few grains, it is a dangerous drastic, working both upwards and downwards. Berries, grana Gnidia, equally drastic, added to vinegar to give it apparent strength; herb used to dye yellow. Both the bark and berries are steeped in vinegar, and dried to render them milder.

$\because$ Heatr spurge, Sanamunda, Daphne tarton-rairi. Leaves caustic.

Poet's rosemary, Cassia veterum spuria, Osyris, O. alba. Astringent.

Passerina tinctoria. Used to dye yellow.

Leather-wood, Dircaa palustris. Bark acrid, emetic, gr. v to $\mathrm{x}$, externally produces blisters. 


\section{PRO'TEACE压.}

Guenvina Aveldana, Quadria heterophylla. Kernels esculent, very pleasant.

Persoonia laurina, $P$. salicina. Fruit esculent.-Persoonia lenceolatu, Linkia lavis; $-P$. linearis; $-P$. hirsuta. Fruits esculent.

Persoonia gutareoides. Bark used for the Peruvian bark; nuts yield oil.

\section{MYRISTICEA.}

NUtMeg tree, Myristica officinalis, $M$. moschata. The kernel of the fruit, nutmeg, nux moschata, myristice nuclei, myristice moschate fructûs nucleus. Membrane enclosing the seed, mace, macis. Are stomachic, cephalic, uterine, and cordial; in an over dose, say 3ij, the nutmeg is soporific and produces delirium. By distillation they yield an essential oil, and by expression a concrete oil. Officinal preparations.-Spiritus nucis moschatæ, $D . L$. E. Spirit. ammon, arom., D. Spt. armoracia comp., $D$. Spt. lavand. comp., D. L. E. Confectio aromatica, D. L. Electuarium catechu, $E$.

Mrristica sebifera, Virola sebifera;-Barabee. Kernels pressed for their oil.

\section{LAURINE.}

Very aromatic, fruits or berries oily and odoriferous.

"BAy tREe, Laurus, L. nobilis. Berries, lauri bacca, 3ss to 3 jss, very heating and emmenagogue; yield oil by decoction or by the press. Leaves, lauri folia, aromatic: prepared by soaking in vinegar and drying. Officinal preparations of the berries.Conserva rutæ, $D$ ). L. Emplastrum cumini, $L$.

A vocado tear tree, Lautus persea; $-L$. glauca. Fruits yield oil.

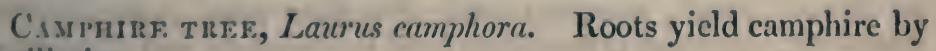
distillation.

Cixмasos твеE, Laurus cinnamomam. Bark of the first quality, breaking shivery, with a warm flavour, cimamon, canelle de Ceylon, cinnamomum, cinnamomi cortex, lauri cinnamomi cortex. Imported from Ceylon, in bales of about 92lb. :-Chinese cinnamon, Canelle de (\%ina, cinnamomum e China. In smaller bundles, often only a single quill, dark coloured, slightly aromatic, yields much oil, contains starch; - - bark of an inferior quality, breaking short, with a slimy mucilaginous taste, cassia, cassia lignea, cassice lignece cortex, laniri cassia cortex, cussia cortex. Canelle de Cayenne, cinnamomum Cayennensis. Pale, with a very slimy taste;-bark of the trunk of old wild trees, Bastard cassia, pepper 
bark? canelle matte? cassia cinnamomea, cinnamomum Indicum;twigs with the bark left on, xylocasia, cassia lignea of the ancients;-dried leaves, cassia leaves, folium Indicum, folium Indum, malabathrum; oblong, ovate, shining, with three ribs;dried receptacle of the seeds, cassia buds, cabob china, bacce cassice, flores cassia, cassice lignece flores nondum expliciti, lauri cassice flos nondum explicitus; imported in chests of different sizes, mostly from China. All these are stomachic, tonic, and cordial, in doses of $\mathrm{gr} . \mathrm{v}$ to $\mathrm{Bj}$, and are much used in cookery as spices : the bark that is not fit for sale, even under the name of cassia, is distilled for its oil. Officinal preparations, very numerous: the principal are-Aqua cinnam., L. E. D. Spirit. cinn. L. E. D. Spir. lavand. comp. L.E.D. Tinct. card. comp. L. D. Tinct. cinn. L. E. D. Vinum opii. L. D. Pulv, cretæ comp. L. E. D. Confectio aromatica, $L . D$.

Wild CINNAMON TREE, Laurus cassia, L. myrrha. Leaves bitter, narrow, pointed, elliptical, sold for folium Indicum.-L. Japonica. Leaves sold for folium Indicum, but very different in taste.

SASSAFras TREe, Laurus sassafras. Root, sassafras radix; wood, cinnamon wood, sassafras lignum; imported from the West Indies in logs : sudorific, heating, and drying; yield essential oil. Officinal preparations. - Oleum sassafras, D. E. L. Decoct. guaiaci comp. D. E. Decoct. sarsap. comp. $D . L$.

Laurus benzoin. Bark used for cinnamon.-L. culilaban. Bark, culilawan, cortex caryophylloides, brownish red, flat, thick, odour strong between clove bark and sassafras; leaves resemble those of raventsara : both are heating, stimulant, and stomachic.

Isle of France cinsamon, Laurus capularis;-Peruvian cinnamon, L. Quixos. Barks aromatic, astringent.

Laurus Parvifolia;-L. globosa;-L. foetens;-L. caustica. Barks contain an acrid principle.

Lauraster Amboynensis, Laurus . . ... Tetranthera pichurim. Seeds, sassafras nuts, Brazilian bean, faba pichurim, stomachic, astringent, anodyne, used in diarrhœea and dysentery ; yield oil.

JACK IN A Box. Hernandia sonora. Fruit astringent; seeds oily, purgative. - American myrobalans, H. ovigera. Fruit astringent.

Litsa sebifera. Sebifera glutinosa. Berries yield oil.Litsca cubeba, Laurus piperita. Berries carminative.

Chloromyron verticillatum. Yields by incision balsamum viride.

Mroschilos oblonga. Leaves used for those of senna.

Plegorhiza astringens. Root vulnerary, astringent. 


\section{POLYGONEE.}

Herbs acid or astringent, containing oxalic acid; contain also a red colouring matter, and may be used in tanning; leaves may be made to yield woad.

"Rheum Palmatum. Roots, Turkey rhubarb, Russian rhubarb, rhubarbe de Bucharie, rhabarbarum vern, rhabarbarum Turcicum, rhabarbarum Rossicum, rhei radix. In oblong pieces, roundish or flattened, broad, with a large hole through them. East Indian rhubarb, rhubarbe de China, rhubarbarum Indicum, rhabarbarum e Chinâ. In large pieces, outside yellowish, inside marbled. The difference is supposed to arise from the time of gathering.Dutch trimmed rhubarb.-British rhubarb, rhubarbe de France. In small short sticks, wrinkled lengthways, scarcely crackling between the teeth as containing much less oxalate of lime than the foreign rhubarb, as also of the red colouring material. Rhubarb is purgative and astringent, stomachic, vernifuge, gr. $x$ to $g^{i j}$; used as a tooth-powder, and in dyeing yellow. Officinal preparations : the principal are Infus. rhei, $L . D$. Tinct. rhei, $L . E$. Extractum rhei, $D$. Pil. rhei comp. $E$.

Rheuar undulatus; $-R$. compactum; $-R$. hybridum. Roots are supposed to be mixed with those of R. palmatum.-Malabar rhubarb. Plant not determined, root coarse, acrid, and very nauseous.

"RheUa riaponticum. Root, rhapontic, rhaponticum, used as rhubarb, which when carefully dried it resembles, but is much lighter, bitterer, and has not so strong a smell; radical leaf stalks peeled used in pies instead of gooseberries.

*Blood wort, Bloody doch, Lapathum sanguineum, Rumex sanguineus;-Garden patience, Patientia, Lapathum sativum, Rumex putientia ;- Dock, Great water dock, Hydrolapathum, R. aquaticus, R. Mydrolapathum;-Water dock, R. Britannicus, R. xanthorrhiza ;- "Sharp-pointed dock, L. acutum, Oxylapathum, R. umutus ;-* Monks' rhulbarb, Blunt-leaved dock, Rhabarbarum monachorum, Rumex obtusifolius ;- Bastard monks' rhubarb, Hippolaputhum, $R$. alpinus. Roots have the same qualities as foreign rhubarb, but the dose must be nearly doubled: used in powders, tinctures, and infusions, instead of rhubarb ; are eaten whilst young as potherbs, and used in dyeing.

"Curled dock, Lapathum crispum, Rumex crispus. Seeds anti-dysenteric; roots bruised and made into an ointment cure the itch.

-Sorrfi, Acetosa, Rumex acetosa. Leaves, acetosa folia. - French Sorrel, Acetosa Romana, R. scutatus;-"Sheep's sorrel, A. 
arvensis, Acetosella, R. acetosella. Root cooling purges; leaves contain much oxalate of potash, very cooling, antiscorbutic, eaten in salads; make excellent whey by boiling a few in milk.

SEA-sIDE GRAPE, Coccoloba uvifera. Fruit very astringent, yields Jamaica kino.- - Common knot grass, Centinodia, Polygonum, $P$. aviculare. Herb vulnerary, astringent; seeds nauseously aromatic, emetic, sometimes purgative.

*Buck wheat, Fagopyrum, Polygonum fagopyrum. Seeds nutritive, fattening, well-flavoured, made into bread, yield an oil.

*Black BIND-weed, Volubilis nigra, Polygonum convolvulus. Seeds equally nutritive as buck wheat, and much easier to cultivate.

*Bistort, Snake weed, Bistorta, Polygonum bistorta. Root, bistortce radix, very astringent, dose $\vartheta_{j}$ to $3 j$; tans leather very well; young shoots eaten as greens.

*Dead arse-smart, Persicaria, Polygonum persicaria;* Arse smart, Persicaria urens, Polygonum hydropiper. Vulnerary, detersive, and diuretic; dye wool yellow ; juice acidulous, acrid, sharp.

\section{ATRIPLICES.}

*SpInach, Spinachia oleracea. Leaves emollient, opening, boiled as greens.

*Root of scarcity, Mangel wurzel, Beta hybrida. Root red outside, white inside, very nutritive; yields sugar; leaves eaten as spinage.

*White BeEt, Beta vulgaris alba. Root yields sugar; leaves eaten as spinage.

* Red BeEt, Beta vulgaris rubra. Root red, nutritive; yields sugar.

*Strawberry spinach, Blitum capitatum. Laxative.

*Common sea fursiane, Portulaca marina, Atriplex portula. coides. Leaves and shoots pickled used to procure an appetite, warming; also cosmetic.

*Orach E, Atriplex hortensis. Emollient; seeds emetic.-Sea purslane, $A$. halimus.

*Sea orache, Atriplex littoralis. Leaves and young shoots pickled, and eaten in the manner of samphire.

*Narrow-leaved wild orache, Atriplex angustifolia, $A$. patula. Seeds emetic, sudorific, antidysenteric; a substitute for ipecacuanha.

Basella cordifolia;-B. rubra. Esculent.

*English mercury, Allgood, Mercurialis, Tota bona, Cheno- 
podium bonus Henricus;-*Goose foot, Pes anserinus, C. murale. Herb laxative, eaten as spinage, the shoots as asparagus.

*IVild orache, Atriplex sylvestris, Chenopodium viride. Herb laxative, discusses whitlows; seeds used in the jaundice.

Qurvos, Chenopodium Quinoa. Used as a pot herb; seeds a substitute for rice.

"Stinking onache, Atriplex olida, Chenopodium vulvaria;* Oak of Jerusalem, Botrys, Ambrosia, Chenopodium botrys. Stinking plants, used, beat up with sugar, as emmenagogues, antihysterics, and vermifuges; their decoction is used externally in eruptions.

Worm goose-Foot, Worm seed, Chenopodium, P. U. S. C. anthelminticum. Expressed juice vermifuge.

Mexicax tea, Chenopodium ambrosioides. Stomachic, antiasthmatic, used as tea.

Herbe aux charpentiers, Rivina humilis. Pectoral.

Struming ground Pine, Camphorata, Camphorosma Monspeliacum. Nervine, cephalic, antarthritic.

*Grass-wort, Saltwort, Kali, Salsola kali. Emmenagogue, diuretic, and hydragogue; yields barilla by being burned.

Gr.Ass-wort, Kali, Salsola sorla;-Alicant glass-vort, Kali Hispanicum, S. sativa;-S. Arabica;-S. aphylla;-S. mudiflora;S. eluta ;-S. Indica;-S. tragne;-Anabasis aphylla;- - Saltuort, Salicurnia fructicosa. All yield barilla by burning.

* Marsir Sampuire, Salsola herbacea. Pickled is eaten as samphire.

?'Scarlet mushroom, Cynomorium coccineum. Styptic, Đj in wine.

*American poke-weed, Poke, Jucato calleloe, Phytolacca decomulru. Root, pliytolacca, P. U. S. emetic, infusing $1 \mathrm{oz}$. in a pint of wine, and taking two spoonfuls; juice red, a very common domestic purge in America; leaves bruised, very detersive, of great use in cancerous cases as a poultice; young shoots eaten as asparagus; berries yicld a red dyc, but which does not stand; used to colour wine.

\section{AMARAN'THACEE.}

-Uprighr blitri, All seed, Blitum minus, Amaranthus blitum. Refrigerant, slightly astringent ; used as a potherb.

- Fisower gentre, Amaranthus, Flos amoris, A. caudatus. Flowers slightly astringent.

-Griat white blite, Blitum album, Amaranthus viridis;- Red blite, Blitum rubrum, A. viridis; $-\Lambda$. oleraceus ; $-\Lambda$. furinaceus. Used as potherbs. 
Achryanthes repens, Gomphrena polygonoides. Root and flower narcotic.-Amaranthus obtusifolia. Diuretic.

\section{NYCTAGINE $A$.}

* Marvel of Peru, Mirabilis jalapa, Nyctago jalapa ;-Nyctago longiflora, M. longiflora;-N. dichotoma, M. dichotoma;Herba purgativa, Boerhaavia tuberosa. Roots purgative.

\section{PLANTAGINE王.}

*Plantain, Waybread, Plantago major ; - *Lamb's lettuce, Hoary plantain, P. media; - ${ }^{*}$ Rib-wort, Rib grass, P. lanceolata. Roots 3 iij to vj, once a day, useful in vernal agues; leaves astringent, vulnerary, used whole as a dressing for wounds; juice of the leaves used as a collyrium, and internally, ${ }^{\mathrm{j}} \mathrm{j}$ to $3 \mathrm{ij}$ in fevers.

*Bucks-hor s plantain, Cornu cervinum, Plantago coronopus. Roots and leaves beaten up with bay salt, are applied as a poultice to the wrists in agues; a decoction of the leaves is given in disorders of the eyes.

Flea-wort, Psyllum pulicaria, Plantago psyllium, P. arenaria. Seeds mucilaginous, purgative.-Spanish plantain, Holostium, $\boldsymbol{P}$. albicana. Herb vulnerary, used in herniæ.

\section{PLUMBAGINE $\mathrm{E}$.}

Plumbago Zeylanica; $-P$. rosea. Used as vesicatories.

Tooth-wort, Dentarix, Dentillaria, Plumbago Europæa. Caustic, corrosive; used by beggars to produce ulcers, in order to excite pity; and in tooth-ache as a masticatory; may be used for ipecacuanha.-Herbe au diable, P. scandens. Used in the itch.

\section{STATICE $A$.}

*Red behen, Sea lavender, Behen rubrum, Limonium maritimum, Statice limonium. Root astringent, used in loosenesses, \&c. ; seeds also astringent. Druggists sell, under this name, round transverse slices of a root resembling jalap, of a reddish brown colour.

Marsh rosemary, Statice Caroliniana. Root, statice, P. U. S.; used in dysentery.

\section{GLOBULARI 2 .}

Montpelier turbith, Globularia alypum. Root purgative; leaves used for senna.

\section{LYSIMACHI}

*Prmperner, Anagallis terrestris mas, A. arvensis. Used in mania and against hydrophobia; flower used in epilepsy, gr. xx, quater in die.- - Blue-flowered pimpernel, Anagallis foemina, A. coerulea. Is of similar qualities. 
*Primrose, Primula veris vulgaris, P.v. acaulis;-* Ox lip, Great couslips, $P$. v. elatior. Roots emetic; herbs anodyne.

Yellow bears-ear, Auricula ursi, Primula auricula. Herb vulnerary and expectorant.

*Cowslips, Pagils, P. v. officinalis, Paralysis vulgaris. Flowers used to flavour wine, and render it narcotic.

Bears-ear saxicle, Cortusa Matthioli, Cephalic, anodýnc, expectorant.

*Yellow roosf. STRIFE, Willow herb, Lysimachia vulgaris;

*Money-wort, Herb two-pence, Nummularia, Lysimachia nummularia. Astringent.

Anvul navel-wort. Androsace maxima. Diuretic.

"Butте к wовт, Yorkshire sanicle, Pinguicula vulgaris. Leaves heal wounds and chaps of the skin ; made into a purging syrup; used to thicken milk, turn it sour, and make it keep for any length of time.

* Watrir pimperner, Samolus valerandi. Has similar qualities.

*Sow bread, Artanita, Cyclamen, C. Europceum;-Soldanella Alpina. Roots drastic, emmenagogue, errhine; leaves bruised and made into a pessary are emmenagogue, and cause abortion ; an ointment is made from it, which, when rubbed on the navel, purges and kills worms.

\section{ACANTHACEE.}

Wit. BRANK uRsine, Acanthus sylvestris, A. spinosus. Herb diuretic, astringent.

Ben as breEch, Branca ursina, Acanthus, A. mollis. Leaves diuretic, externally maturative; dye a fine yellow.

Malabar nut tree, Justicia adhatoda. Leaves purgative.

Crfats, Justicia paniculata. Root and herb externally bitter, stomachic.

BaLsAM, Justicia pectoralis. Vulnerary, resolvent; a syrup is made from it, and used in diseases of the chest.

Samcocolla surub, Penca sarcocolla;-P. mucronata. Said to yield gum salcocol.

Reellia tuberosa. Used instead of ipecacuanha.

Barleria loNgifotia. Root diuretic.

68. PYRENACEA:.

Agnes castus, Vitex agnus custus. Flowering tops cooling, drying; and looked upon as anaphrodisiac, whence they were used to strew the beds of the Vestal virgins and Christian nuns.

TECTONIA GRANDis. Leaves used against the thrush and dropsy ; and also to purify water.

-Vervain, Verbena, V. officinalis. Febrifuge, vulnerary; used 
externally as a rubefacient in rheumatism and other pains of the joints. Root worn round the neck cures scrofulous and scorbutic affections.-Jamaica vervain, Verbena Jamaicensis. Juice, cochl. maj. j. to ij, cathartic, deobstruent, emmenagogue-Volkameria inermis, Clerodendrum inerme ;-Avicennia resinifera, $A$. tomentosa. Exude rosins.

\section{LABIATÆ.}

Aromatic and heating.

SAGE of virtue, Small garden sage, Salvia virtutis, S. hortensis minor, $S$. officinalis. Heating, sudorific, used in palsy and trembling of the nerves; also cordial, stomachic, stops night sweats, and the flow of milk after weaning: galls, baisonge, eaten.

Great GARDEN SAGE, Salvia hortensis major, S. officinalis.* Clary, Sclarea, Salvia sclarea. Added to wine to give the flavour of muscadel. $-S$. Indica. Herb put in Hindustan into the country beer to improve its flavour.

Purlle-top clary, Horminum, Salvia horminum.-Sage of Crete, S. Cretica;-Ethiopian sage, Salvia Athiopica. Excite the nervous system, produce a slight intoxication, used in disorders of the eyes, and are aphrodisiac.

Wild clarr, Oculus Christi, Salvia verbenaca;-Wild clary, Horminum sylvestre, S. verticillata. Seeds put in the eye become mucilaginous, and thus facilitate the extraction of anything that has got into it.

Cancer weed, Salvia lyrata. Root leaves bruised used to destroy warts, and in cancerous cases.

*Rosemary, Rosmarinus, R. officinalis. Flowers, anthos, rorismarini cacumina, cephalic, nervine, cordial, heating, emmenagogue, and strengthening: infusion promotes the growth of the hair, and gives it a healthy appearance.

Canadian snake-root, Collinsonia procox. Root used for Virginia snake-root.- * LAvandER, Lavandule angustijolia, $L$. spica :- Spike lavander, L. latifolia, Spica vulgaris, L. spica. Flowering tops, lavandula flores, very odoriferous, yield essential oil ; are nervine, antispasmodic, and cephalic. French lavander, Stoechas Arabica, L. stochas. Has the same qualities, and is also diuretic.

Curi, Ed-LEAVED mint, Mentha crispa; - * Bergamot mint, Mentha odorata; - * Pepper mint, M. piperis sapore, M. piperita; - Horse mint, Menthastrum, Mentha sylvestris;- Water mint, Sisymbrium sylvestre, M. aquatica;-* Penny royal, Pulegium, $P$. vulgare, M. pulegium;-* Water calamint, Calamintha aquatica, $M$. arvensis;-*Spear mint, M. viridis, M. sativa;-**Bushy red mint, M. balsamina, M. gentilis; - ${ }^{*}$ Round-leaved horse mint, Mentha sylvestris, M. rotundifolia;-Harts penny royal, Pulegium 
cervinum, M. cervina. Are all stomachic, promoting digestion, diuretic, and approved emmenagogues, either in powder or infusion; they all yield, on distillation, oil.

* Cerlonian plant, Ear wort, Marlow, Auricularia, Mentha sylvestris, M. villosa. Used for deafness.

*Balm, Melissa, M. officinalis ;-*Common Calamint, Calamintha vulgaris, C. montana, Mentha calamintha;-Mountain calamint, Calamintha magno flore, Melissa grandiflora;-* Lesser calamint, $C$. odore pulegii, Mentha nepeta. Cephalic; used in nervous and hysteric cases.

*Bastard bali, Melissa Fuchsii, Melittis melissophyllum. Diuretic, opening.

*Sweet basil, Basilicum, Ocymum basilicum. Strong-scented, emmenagogue; gave the peculiar flavour to the original Fetterlane sausages.

Java potatoes, Ocymum tuberosum. Tubers eaten.-Toolsie tea, O. album. Leaves used as tea.

SUmmer savory, Satureja hortensis. More acrid, and hotter than sweet basil, dyes a yellow colour.

Wister savory, Satureja durior, S. frutescens, S. montana. Used as spice.

* Rock savory, Satureja spicata, S. Juliani. Herb agrees with other savories.

Твек Tинчмва, Thrymba vera, S. thrymba. Herb emmenagogue, used with honey in coughs.

*Tиче тичме, Thymum verum, Satureja capitata;-Mountain liyssop, Thymbra spicata. Vermifuge.

"Hyssop, Hyssopus, H. officinalis. Leaves emmenagogue, pectoral, used as tea; soaked in water or wine, and applied as a cataplasm, used as a discutient for black eyes and other contusions.

"'Yuxмe, Thymus, T. vulgaris ;-*Mother of thyme, Wila thyme, Iemon thyme, Serpyllum, T' serpyllum;-Herb mastich, Marum, T. mastichum;-Wild thyme, T. sylvestris, T. zygis;Wils busil, I'oiny mountain, Acinos, 'T' acinos; - *'Pot marjoram, Majoranr oleracea, Origanum onites;-Bastard marjoram, Origanum Heraclenticum;- Winter marjoram, Origanum, O. vulgare (the tops of which dye purple); - "Siveet marjoram, Mujorana, Amaracus, Sranipsucus, Origanum majorana; - Dittany of Crete, Dictronnus C'reticus, O. dictammus; - Ground ivy, Hedera terrestris, Chamacissus, Glechoma herleracea ; - "Cat mint, Nepeta, Mentha cataria, N. catoria (highly alluring to cats);- "Wood betnny, Befonica sylvestris, B. vulyaris, B. officinalis;-Dead nettle, While archanyel, Urtica mortua, Lamium allnam;-"Great wild brssil, Ocymum sylvestre, Clinopodium vulyare;-P'urple archangel, Iamium orvala; - Red archangel, L. purpureum. All of these have analogous qualities, being heating and strengthening; made 
into tea with honey, they are diaphoretic, discussive, expectorant: some are. slightly astringent; ground ivy is the most commonly used; dittany of Crete was a celebrated vulnerary and astringent among the old physicians : several are used as spice.

*Spotted archanger, Milzadella, Urtica lactea, Lamium maculatum. Herb esteemed specific in scrofula and fluor albus.

J AMAICA wild Hops, Clinopodium rugosum. Used as a gargle with honey and alum.

Moldavian mist, Dracocephalum Moldavica. Similar in quality to mint.

*Horehound, Prassium, Marrubium, M. allum, M. vulgare. Pectoral, used in coughs and colds, $3 \mathrm{j}$ of the leaves powdered, or zij of the expressed juice, or Mss. infused for tea.

Bastard dittany, Marrubium pseudodictamnus; - Galen's mad wort, Alyssum Galeni, M. alyssum;-*Black horehound, M. nigrum, Ballote nigrum;-Jamaica spike-nard, Ballote suaveolens (infusion used in dropsy and gravel);- ${ }^{*}$ Clowns all-heal, Panax coloni, Stachys palustris;- - Stinking dead-nettle, S. sylvatica;* Smooth-leaved iron-wort, Sideritis arvensis latifolia glabra, Stachys arvensis ;-* Common hemp-nettle, Bastard hemp, Galeopsis tetrahit (the seeds of which yield oil);-* Narrow-leaf all-heal, G. ladanum; - Yellow archangel, Lamium luteum, G. galeobdolon;- W Water horehound, Marribium aquaticum, Lycopus Europaus ;-* Mother wort, Cardiaca, Leonurus cardiaca;-Bastard horehound, L. marrubiastrum; - Sage-leaf mullein, Phlomis lychnitis. All of these are strong-scented plants, more or less disagreeable, emmenagogue, antihysteric, antiepileptic, expectorant, and, for the most part, vernifuge; externally they are vulnerary.

Virginia Penny royal, Cunila Mariana, Ziziphora Mariana. Leaves, cunila, P. U. S., diaphoretic, distilled for their oil.

Monarda pUnctata. Root, monarda, P. U. S., emmenagogue.

Oswego tea, Monardo Kalmiana. Leaves used as those of tea.

*Germander, Scordium, Teucrium scordium;-*Wood sage, scorodonia, Salvia agrestis, T. scorodonia. Used instead of hops.

JAGGED GERMANDER, Teucrium botrys;-Syrian herb-mastich, Cat thyme, Marum Syriacum, T. marum. Have similar qualities: this last plant is emmenagogue, $\partial_{j}$ to $3 \mathrm{ss}$; cats are very fond of it.

* Creeping germander, Chamadrys, Trissago, Teucrium chamcedrys;-Ground pine, Chamæpitys, Iva arthritica, Teucrium chamapitys. Bitter, tonic, febrifuge.

Poly-modntain, Polium montanum, Teucrium capitatum. Lavender-leaf poly, T. montanum ;-Cretan poly-mountain, Polium 
Creticum, T. Creticum. Have all the same alexiterial heating qualities.

Yeliow poly-mountain, $P . m$. flavum, Teucrium polium; - White poly-mountain, P. m. allum, Teucrium teuthrion;-Tree germander, Teucrium, T. flavum. Leaves used in diseases of the liver and spleen.

Base horenound, Stachys, Sideritis Syriaca. Leaves acrid, emmenagogue, fetid.

InoN-wort, Sideritis, S. hirsuta. Herb cures wounds by the first inteution.

Genjan IRON-wort, Sideritis flore luteolo, S. scordioides; -Mountain iron-uort, S. montana;- Common bugle, Bugula, Ajuga reptans;-**Mountain bugle, Ajuga pyramidalis;-*Selfheal, Prunella, P. vulgaris; - * Hooded willow-herb, Lysimachia galericulata, Scutellaria galericulata. Bitter, astringent, nearly inodorous; the English ones are substituted for bark.

\section{PEDICUI.AREÆ.}

*Eyr: bright, Euphragia, Euphrasia officinalis. Cephalic, ophthalmic.

*Speedwelr, Fluellin, Veronica mas, Betonica Pauli, V. officinalis. Leaves slightly astringent, bitter ; substituted for tea, but is more astringent and less grateful.

*Siralest fluellin, Veronica spicata;-Mountain mad-wort, $V$. montana; Speed-well chickweed, $V$. arvensis. Vulncrary, incisive, diaphoretic, antiphthisic.

*Wild germander, Chamadrys sylvestris, Veronica Chamadrys. Leaves a better substitute for tea than those of speedwell.

Virginia speedweld, Veronica Virginica. Root, veronica, P. U. S., astringent.

* Broок r.rme, Anagallis aquatica, Beccabunga, Veronica beccabunga. Leaves, when fresh, diuretic, antiscorbutic, eaten as salad; juice, in a full dose, an easy purge.

* Red iatrle, Louse-zoort, Pedicularis palustris. Nauseous, acrid; its juice, or a decoction, used externally in old ulcers; kills lice, yet said to breed lice in cattle that feed on it.

Yellow rattre, Cock's comb, Crista galli, Rhinanthus crista galli. Is used to kill lice.- ${ }^{*}$ Cow wheat, Triticum vaccinum, Melampirum arvense;-* Wild cow-uheat, Crataogonum, M. pratense. Seeds aphrodisiac; herb fattens cows.

\section{OROBANCHIDEA.}

"Tооти-wort, Squamaria, Lathraa squamaria. Herb consolidating, astringent, used in hernix and wounds. 
* Broour rape, Orobanche, O. major. Herb in powder gives relief in the colic; used in hypochondriasis, externally resolvent.

\section{SCROPHULARIN E.}

*KNotted FIG-wort, Scrophularia nodosa ;-* Water fig-wort, Water betony, S. aquatica, Betonica aquatica. Incisive, attenuating, used in scrofula and cancer. Officinal preparations.-Unguentum scrophulariæ.

Hedge Hyssop, Gratiola, G. officinalis. Very acrid, drastic, vermifuge, used also in dropsy and jaundice; dose gr. $v$ to $9 j 5 s$, beginning with a small one; inspissated juice gr. $\mathrm{xx}$ to $\mathbf{x x x}$ is purgative and diuretic.

Sweet woop, Capraria bifolia. Flowers used instead of tea.

*Fox-glove, Digitalis, D. purpurea. Leaves, digitalis folia, used externally as vulnerary and antiscrofulous; and internally, in doses of gr. ss to gr. $\ddot{\mathrm{ij}}$, as a sedative, and particularly as a diuretic; but great caution is required in using it, because it accumulates in the system; and the practitioner may be surprised at the sudden demise of his patient, even after he has left off its use. Seeds, digitalis semina, used for the same purposes, less uncertain. Officinal preparations.-Infus. digit. D. L. E. Tinct. digit. D. L. $E$.

Yexlow FoX-Glove, Digitalis lutea. May be used as the former.

*Snap Dragon, Antirrhinum majus. Antihysteric, and used externally in ophthalmia.

*Toad-Fuax, Linaria, Antirrhinum linaria, L. vulgaris. Deobstruent, diuretic.

*Small toad-flax, Antirrhinum minus;- - Ivy-leaved toadflax, Cymbalaria, A. cymbalaria, Linaria cymbalaria;-*Fluellin, Female speed-well, Elatine, Veronica foemina, A. elatine. Are all anticancerous, especially the last, the juice of which is used in foul ulcers and cutaneous eruptions.

*Calves' Snout, Orontium arvense, Antirrhinum orontium. Herb poisonous.-Hemimeris caulialata. Stomachic, anodyne.Diceros Cochinchinensis. Eaten in salads.-Picria felterre. Intensely bitter.-Besleria violacea. Berry edible.

\section{SOLANE E.}

More or less poisonous.

*White mulleiv, High taper, Cons lung-wort, Verbascum, Tapsus barbatus, $V$. thapsus. Anodyne and pectoral; the down has been used as moxa for the actual cautery; a decoction of $3 \mathrm{ij}$ of the leaves in a quart of water, given in doses of 3iiij every three hours in diarrhœas. 
*Yellow motir mullern, Blattaria, Verbascum blattaria. Has the same qualities; attracts moths; seeds inebriate fish.

*Black a ullein, Verbascum nigrum. Root astringent; leaves and flowers anodyne and pectoral.

*White-flowered Mullein, $V$. album, $V$. lychnitis. Leaves pulmonary.

*Hen-Baise, Hyoscyamus, H. niger. Leaves, hyoscyami, folia, a very powerful narcotic, in doses of gr. $\mathrm{ijj}$ to gr. $\mathrm{x}$; externally is anodyne or resolvent ; seeds, hyoscyami semina, narcotic, gr. iij to gr. $x$, less uncertain than the leaves; their smoke, applied by a funnel, is used in toothach. Officinal preparations.- Succus spissatus hyoscyami, $E$. D. Extract. hyoscyami, $L$. 'Tinct. hyos. L. E. D.

Great white hen-Bane, Hyoscyamus albus. Milder than the black; seeds used in spitting of blood.

Toвacco, Nicotiana, Petum, Tabacum, N. tabacum. Leaves, tabaci folia, when green, detersive, acrid, narcotic, and apophlegmatizant; used externally in diseases of the skin, and as a dressing to verminous sores; and internally as an emetic, gr. iij to gr. $x$ in water Jiiij, and in dropsy and palsy; their smoke is used as a pleasant mode of losing time, and as a stimulating clyster in apoplexy, inveterate costiveness, and apparent death by drowning or hanging ; in which last case, however, it is sometimes improper; as, if it does not immediately succeed, it exhausts the patient so much as to render other means ineffectual; imported from Anerica and the West Indian islands.-English tobacco, Nicotiana minor, N. rustica. Leaves narcotic; sometimes sold as those of mandrake. Officinal preparations.-Infus. tabaci, L. D. Vinum tabaci, $E$.

* Thorxy apple, Stramonium, Datura stramonium. Herb a strong narcotic, even when mixed with tobacco and smoked; much used lately in asthma; cxternally the leaves, stramonii folia, are anodyne, and used in headach and the gout; seeds, stramonii semina, may be given in powder to $\mathrm{gr}$. $\mathrm{x}$; expressed juice made into an ointment with hog's lard, used for irritable ulcers, burns, and scalds. Officinal preparations.-Extractum stramonii, $D$.

Metel, Datura metel. Seeds narcotic, more powerful than the last, produce temporary idiotcy, used for frauds.

Masinake, Mandragora, Atropa mandragora. Formerly supposed to be aphrodisiac, root gr. iij narcotic, or it may be steeped in wine: leaves externally used as anodynes and resolvents, as also the powder of the root to indurated glands.

"Dfadly Nigit-snade, Dwale, Solenum lethale, S. maniacum, S. furiosum, Belladonna, Atropa belladonna. Leaves belladonnce E 2 
folia, applied to the eye, paralyse the iris; they are useful in cancer and scrofula, either applied as poultices, or sprinkled over the sores; used also internally in doses of $\mathrm{gr}$. $\mathrm{j}$ to iij in obstinate diseases, acting as a narcotic, diaphoretic, diuretic, and sialogogue. Berries eaten in an over-dose, that is, more than three or four, are poisonous; vinegar is the best antidote, as emetics, even tartar emetic Oss, have, in this case, scarcely any action; juice of the berries cosmetic, rendering the cheeks pale, made into syrup, in doses of coch. parv. $\mathrm{j}$, has been given as an anodyne in dysentery. The narcotic properties of this substance depend on its containing the alkaloid atropia.

Winter cherry, Alkekengi, Halicacabum, Physalis alkekengi. Berries antinephritic, lithontriptic, and diuretic; if in gathering they are rubbed against the calyx, they acquire a nauseous taste, and become purgative.

Jamaica winter cherry, Physalis angulosa. Juice of the plant, with Cayenne pepper, diuretic; eases the colic.

*Common NIGHT-sHade, Solanum vulgare, S. nigrum. Leares used externally as anodyne in erysipelas; young shoots, bredes, laman, eaten as spinage; berries produce mania, somnambulism, and death.

* Bitter sweet, Woody night-shade, Solanum lignosum, Dulcamara, S. dulcamara. Twigs, dulcamarce caules, diuretic, depurative, in chronic eruptions; its taste being covered with milk. The form in which it has been used is chiefly that of decoction; two or three ounces of that of the London Pharmacopœia may be given thrice a day. Officinal preparation.-Decoct. dulc. $D . L$.

Lycopersicon, Solanum lycopersicon. Berries, love-apple, tomatoes; used to make a sauce.

Melongena, Solanum melongena. Leaves narcotic; berries, mad apples, mala insana, boiled and eaten in the warmer countries. S. incanum. Leaves applied to cancers.

Solanum tuberosum. Tubers of the root, potatoes, batatas, appear to yield a vast quantity of food upon a small extent of ground, and with little labour, but only one-seventh part of the weight is nutritive; the remainder is an acrid, poisonous juice. When it first began to be used, it was supposed to be narcotic, diuretic, and aphrodisiac.

Salep powder, French salep. Potatoes peeled, cut in slices, baked until brittle, hornlike and breaking like glass, then ground to a whitish powder.

Solanum ovigerum, distinguishable from the egg-like variety of S. melongena, by its acrid pulp, which being removed by the scoop or pressure, the flesh is dressed and eaten, $-S$. vespertilio. 
Berries deep lake-red, used to colour the cheeks. -S. montanum ; -S. valenzuele. 'Tubers farinaceous.-Tree night-shade, Amomum Plinii, Solanum pseudocapsicum. Fruit anodyne.

SLEEPY Night-snade, Solanum somniferum, Physalis somniferum. Root hypnotic, milder than opium ; fruit very diuretic; decoction of the herb used in toothach.

Natre, Solamum crispum. Shrub very bitter; berry in infusion used in inflammatory fevers. $-S$. muricatum;-S. anguivi. 'Fruits eatable.-S. scabrum;-S. gnaphaloides. Berries saponaceous.

Capsicum, C. annum. Berries, Spanish pepper, Pepper pods, Guinea pepper, Capsici bacce, Capsicum, P. U. S., which are fleshless, are of a burning heat, irritating, attenuant ; used as sauce, or to give a false strength to vinegar, spirits, \&c. ; infused in vinegar, used as a gargle; the powder is given in doses of gr. iij to viij; externally they are rubefacient; with hog's lard, form a liniment for paralytic limbs. Officinal preparations.-Tinct. capsici. D. L. E.

Piper Ixdicum, Capsicum frutescens. Berries, Bird pepper, Red pepper, Cayenne pepper, Guinea pods, Tschilies, used for the former.-Coffrée tschilie, C.grossum. Flesh of the berry pickled.

Calabash tree, Crescentia cujete and $C$. lagenaria. Pulp used in diarrhœa, dropsy, headach; also externally in burns and in coups de soleil; expressed juice of the pulp 3iiij is purgative: a pectoral syrup is also made from it, which is sent over to Europe.

\section{SEBESTENEA.}

Cordia MYXA, and C. sebesten. Fruit, sebestens, myxa, is esculent, laxative; bird-lime is made from it: wood tough, solid, used for procuring fire by friction.-C. geras-canthus. Wood, Jamaica rosewood, fine-scented, used by the cabinet-makers, and distilled for its oil.

\section{7\%. BORAGINE E.}

'The plants of this order are refreshing.

*Borage, Borago officinalis ;-*Garden bugloss, Ox tongue, Buglossum hortense, Anchusa officinalis. Flower cordial; the tops were formerly used in cool tankards; leaves refreshing, moistening; contain nitre.

"Spotted Luxg-wort, Spotted comfrey, Sage of Jerusulem, Corcs lips of Jerusalem, Pulmonaria maculosa, P. officinalis;- Small veild borage, Great gonse-grass, German mad wort, Asperugo procumbens ; - Wall lugloss, Lycopsis, A. Asyptiaca. Root sudorific, also used with oil as a dressing for wounds.

* Mouse f.ar, Scorpion grass, Myosotis scorpioides a, M.arvensis; - Water scorpion grass, M. scorpioides $\beta$, M. palustris ;-*Small 
wild bugloss, Lycopsis arvensis;-Creeping bugloss, L. vesicularia. Are all pectoral plants.

Alкanet, Anchusa tinctoria. Mostly brought from France; -Anchusa Virginica. Root used as alkanet.-Small yellow alkanet, Onosma echioides;-*Gromivell, Bastard alkanet, Milium Solis, Lithospermum, L. officinale;-Dyer's bugloss, L. tinctorium;-L. arvense.

True alkanet, Echium mibrum. Bark of the root colours oily substances red, used in lipsalves; juice of the fresh roots used to redden the cheeks : colouring matter extracted by ether.

Stone Bugloss, Onosma, Echium Italicum. Leaves in wine facilitate delivery.

*Vipers bugloss, Echium, E. vulgare. Root opening and slightly astringent.

Smalt Turnsol, Heliotropium minus, H. supinum. Herb laxative; seeds emmenagogue.

Turnsol, Heliotropium Europæum. Softens warts, and makes them fall off; taken internally it opens the belly; flowers used as a blue colour, when altered by ammonia as a purple, and by acids as a red.- ${ }^{*}$ Jamaica turnsol, $\boldsymbol{H}$. Jamaicense. Plant in decoction diuretic.

*Comfrex, Great consound, Symphytum, Consolida major, $S$. officinale. Root astringent, glutinous: leaves used to flavour cakes; young shoots esculent.

*Hounds tongue, Cynoglossum, C. officinale. Roots astringent and sedative; used externally, and internally in decoction, in scrofula: the herb bruised drives away mice.

78. CONVOLVULACEA.

These are generally purgative.

Convolvulus Jalapa. Root jalap, jalapium, jalapa, mechoacanna nigra, jalapce radix, a very active purgative, in doses of 3 ss to $3 \mathrm{j}$, in powder. In hypochondriacal disorders and bilious temperaments it gripes violently, and seldom acts properly as a purge, unless combined with the potassæ supertartras and a little ginger; from South America. Sea colewort root, white briony root, root of Thapsa villosa, root and leaves of spurting cucumber, hemp agrimony root, root of Anthericum planifolium, petals of the dog rose may be used as substitutes. Officinal preparations.-Tinct. jal. L. D. E. Extractum jalapæ, L. D. E. Pulv. jal. comp. D. E. Tinct. sennæ comp. $E$.

Convolvulus turpethum. Root, turbith, turbeth, turpethum, similar to jalap, rougher in its operation.

Rock rose, Cneorum album, Dorycnium, Convolvulus cneorum. Root purgative. 
Lavander bixd-weed, Cantabrica, Convolvulus minimus, $C$. Cantabrica. Herb vermifuge.

Convolvolt's mechoacanna. Root, mechoacan, mechoacanna $a l b a$, less active than jalap, and not so fatiguing.

*SEA Cole-wort, Scotch scurvy-grass, Soldanella, Brassica marina, Convolvulus soldanella. Root purgative.

Aleppo scamony plant, Convolvulus scammonium. Roots yield, by incision, Aleppo scammony.

Convolvulus florides. Root used as an errhine; wood, rosencood, of good quality.-C. edulis. Root eaten.-C.althæooides. Root purgative, may also be substituted for jalap.

*BIND-WeEn, Convolvulus sepium;-C. arvensis. Juices purgative.

Sea-side potato-slip, Convolvulus Brasiliensis. Root, in decoction, purgative; yields scammony.-Convolvulus BATATAS. Root, sucet potatoes, Spanish potatocs, nutritive.

Coxvolvulus scoparius. Wood, rosewood, hard, used by the fan-makers, shavings have the scent of roses; brought from the Canary Islands.

Convolvulus papirin;-C. tuberosus;-Wild potatoes, C. panduratus;-C. macrorhizos;-C. macrocarpus;-C. maritimus. Roots purgative.

*Dodder or thyme, Epithymum, Cuscuta epithymum :* Great dodder, Hell weed, Cuscuta Europæa. Juice purgative, deobstruent; externally used against the itch.

IFOMEA QUAMOCLIT. Root used as a sternutatory.

79. POLEMONIDE/E.

-Greek valerian, Jacol's ladder, Polemonium coruleum. Root astringent, antidysenteric, and vulnerary.

\section{BIGNONIACE $A$.}

Gingetry, Jugeoline, Guiggiolana, Vangloe, Sesamum orientale. Seeds parched and ground, eaten, or mixed whole with bread, yield oil.

Bigxonia radicaxs;-B. sempervirens;-B. cclinata. Roots vulnerary, sudorific, employed in America against the bites of venomous animals.

WutTE CEDAR, B. leucoxylon. Alexiterial, used against the poison of the manchineel apple.

Bignosia Brasiliensis, Jacaranda Brasiliensis. Wood, green ebony, used in dyeing. 


\section{GENTIANEÆ.}

The roots are generally bitter, tonic, and febrifuge.

Great yellow gentian, Gentiana, G. lutea. Root, gentiance radix, very bitter, febrifuge, vermifuge, antiseptic, carminative, dose in powder gr. $\mathbf{x}$ to $\mathrm{g}_{\mathrm{ij}}$; contains saccharine matter; fermented yields a spirit; from Germany. Officinal preparations. - Infus. gent. comp., D. L.E. Tinct. gentianæ, D. L. E. Extract. gentianæ, D. L. E.

Gentiana campestris;-Cachen, G. Peruviana;- ${ }^{*}$ Yellow centaury, $G$. perfoliata, Chlora perfoliata;-Blue gentian, $G$. Catesbei. Roots bitter, tonic.

*Gentianel, Gentianella verna, G. verna; - *Fell wort, Bastard gentian, Gentianella autumnalis, Gentiana amarella;Chirayit, Creata, G. chirayita (highly esteemed in India, and recently used with advantage in this country).-Gentiana cruciata; -G. rubra;-G. purpurea;-*Marsh gentian, Calathian violet, G. pneumonanthe;-Gentiana grandiflora, G. acaulis. Herbs bitter, used as tonics.

*Lessir centaurr, Centaurium minus, Gentiana centaurium, Chironia centaurium. Flowering tops, centaurii cacumina, bitter, febrifuge, and vermifuge; used against obstructions, jaundice, weaknesses, hydrophobia; sometimes cathartic; externally in decoction destroys lice and cures the itch. Roots more powerful than the flowers.

Worm Grass, Carolina pink, Spigelia Marylandica;-S. an. thelmia. Herbs bitter, used to expel lumbrici from children: dose of the powdered root or herb, gr. $x$ to $3 \mathrm{j}$, night and morning; expressed juice, cochl. maj. $j$ to children of four or five years old: infusion of the herb coch. maj. ij, for the same age.

Ophiorihiza mungos;-O. lanceolata. Roots bitter, alexiterial, used against the bite of venomous serpents, analogous to serpentaria.

Coutoubea alba;-C. purpurea. Febrifuge and stomachic:

American centaury, Chironia angularis, Sabbatia angularis, Sabbatia, P. U. S. ;-C. decussata. Roots extremely bitter, used as tonics.

Marsh trefoil, Bog bean, Trifolium paludosum, Menyanthes, M. trifoliata.- * Fringed bog bean, Dwarf water lily, Nymphea lutea minor, Menyanthes nymphoides, Villarsia nymphoides. These are very bitter, astringent : root mixed with meal, in scarcities of bread: leaves dried and powdered, $3 \mathrm{j}$, purge and vomit, used as a vermifuge; an infusion is extremely bitter, and useful in 
rheumatism and dropsy; substituted for hops in brewing, $2 \mathrm{oz}$. being equal to a lb. of hops.

Frasera Walteri, Muretta columbo. Root, American columbo, Frasera, P. U. S., used as calumba root.

Potalia AmanA. Bitter, acrid, and vomitive.

\section{APOCYNEA.}

Rose BAY, South Sea rose, Nerium oleander. Internally poisonous; externally astringent, antipsoric, and sternutatory; wood used to clear muddy water; leaves acrid, appear to contain free gallic acid, poisonous, infused in oil, used in itch.

BELA-AYE, Nerium antidysentericum, Echites antidysenterica. Bark, Tellicherry bark, Conessi bark, Codaga pala. Bitter, used in dysentery : seeds vermifuge and antispasmodic, used in cholera. - Echites syphilitica. Used in syphilis.

Ophoxylon SERPENTINUM: root, radix mustela, purgative, bitter, tonic, febrifuge : used in the bites of serpents.

Alchorsia latifolia: bark, alcomocco cabarro, in thick, flat, long pieces, rather spongy, reddish yellow, covered with yellowish lichens: from Jamaica; used in phthisis, $\vartheta_{j}$ in powder, or in decoction.

Swallow wort, Hirundinaria, Asclepias vincetoxicum : root, German contraycrva, irritating, forcing out a sweat, alexiterial and antihydropic.

Common silk ween, Apocynum Syriacum, Asclepias Syriaca. Milk of the plant a drastic poison; leaves resolvent, root emetic. - A. lactifera. Milk used as food.

Ericu, Asclepias giguntea. Milk inspissated, used in lepra; inner rind of the root, madar, mudar, in syphilis and tapeworm, gr. v. twice a day.

Bastard ipecacuanha, Red head, Asclepias Curassavica. Root whitish, mixed with ipecacuanha, less active; expressed juice of the plant emetic, coch. maj. $\mathrm{j}$ to $\mathrm{ij}$; or as a clyster in bleeding piles: bruised leaves applied to fresh wounds.

Fresh-coloured asclepias, Asclepias incarnata. Root diuretic.-A. stipitacea;-A. aphylla. Young shoots esculent.

Betrferfly Weed, Asclepias tuberosa. Root diuretic, purgative. $-A$. decumbens. Root, butterfly root, diaphoretic, slightly stimulant; also purgative.

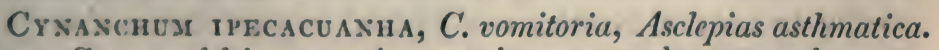
Root, Coromandel ipecacuanha, emetic; young shoots esculent.

Crinanchum Maunitinum. Ront, Isle of France ipecacuanta; -C. lavigatum, C. rindera, Rindera lavigata, R. tetraspis, Mattia 
lavigata. Root, White Bengal ipecacuanha;-C. tomentosum. Root, Ceylon ipecacuanha, emetic.

Ferigulea edulis. Young shoots eatable.

European scammony, Cynanchum monspeliacum. Yields French scammony.

Periploca scammonium. Root yields by incision Smyrna scammony. $-P$. emetica. Root used for ipecacuanha. ative.

Periploca Indica. Root, East Indian sarsaparilla, alter-

Scammony senna, Periploca Graca. Leaves mixed with senna, more pointed, and longer. $P$. esculenta. Young shoots esculent.

Venetian dog's BANe, Apocynum Venetum. Leaves mixed up with grease used to poison animals.-A. Indicum. Young shoots eatable.

American Dogs' BANe, Apocynum androscemifolium. Root, apocynum, P. U. S., emetic.

*Periwinkle, Vinca pervinca, V. minor;- * Greater periwinkle, $V$. major. Leaves astringent, used in tanning, antidysenteric, contracting and strengthening the sexual organs: in hot climates the plants of this genus acquire poisonous qualities.

Theophrasta Americana. Pulp of the fruit esculent.

Cerbera manghas. Bark purgative.-C. Thevetia, $C$. ahouai. Seeds, nux ahouai, violently emetic.

BoHon upas, Cerbera oppositifolia. The famous Molucca poison-tree.

Tabernemontana arcuata. Stem lactescent; exudes rosin.

Stapelia incarnata. Herb esculent.

Urceola elastica;-Vahea. Yield elastic gum.

\section{STRYCHNEAE.}

Strychnos nux vomica. Ripe pulp eatable in small quantity. Seeds, nux vomica, horny, require rasping or roasting, very bitter, emetic, and poisonous to most animals; they act as an excitant upon the nervous system, producing tetanus : used in paralysis with some success, and in chronic diarrhœa and chronic dysentery; said to render persons insensible to the poison of serpents. The active principles of it are Strychnia and Brucea. Its action appears to be directed towards the spinal cord, and to have no influence on the brain. It is found useful in paralytic affections of the voluntary muscles. Officinal preparations.-Extractum nucis vomicæ, $D$.

Ignatia amara, Strychnos Ignatia. Seed, faba sancti Ignatii, Saint Ignatius's bean, has the form of a nut, excessively bitter, 
occasions giddiness, convulsions, and vomiting, but has been used in small doses to cure agues.

Strichios coldbrixum. Wood, snake wood, lignum colubrinum, occasions tremblings, is emetic, vermifuge, very bitter, and serviceable in stubborn intermittents, and chronic diarrhœa.

Titan cotte, Strychnos potatorum. Wood and seeds very bitter, used to render muddy water clear ; flowers aromatic; ripe fruit emetic; young fruit preserved used as a sweetmeat.

\section{JASMINEE.}

Flowers odorous, and leaves slightly astringent.

Jasmine, Jasminum, J. officinale. Flowers recommended in shortness of breath, and in schirrus of the womb.-J.grandiflomum. Yields essential oil.

*Privet, Ligustrum, L. vulgare. Leaves bitter and slightly astringent ; flowers astringent and temperant, used in washes and gargles for ulcers; berries have a dry spongy pulp, from which a rose-coloured paint may be obtained.

SAjвAC, Targorium sambac. Yields essential oil.

\section{OLEINEAE.}

Mock privet, Phillyrea, $P$. media. Leaves astringent, cleansing ulcers of the mouth.

Orive Tree, Olea, O. Europea. Unripe fruit preserved in brine, oily, astringent. Ripe fruit yields oil ; leaves astringent; bark substituted for the Peruvian bark.-O. fragrans. Flowers used to scent tea.

*Ash tree, Fraxinus excelsior. Bark febrifuge and diuretic; seeds acrid, bitter; leaves 3 vj to $\bar{j}$ jss in infusion a good purge; and a decoction of the same has been used to cure agues; exudes a small quantity of manna from the leaves in hot weather.- $F$. rutundifolia;-F. ornus;-F. parvifolia. Exude manna.

\section{TERNSTROMIEA.}

Köleho, Scaphr ... Fruit acidulous, eaten.

88. SIMPLOCINER.

Alstowia . . . Leaves astringent, used as tea.

Hopea tixctoria, Symplocos Martinicensis. Leaves used to dye yellow.

Cane storax tree, Styrax officinale. Yields, by incision, storax.

Brazoin laurex, Styrax benzoin. Yields, by incision, benzoin. 


\section{EBENACE E.}

Pishamin, Persimmon, Diospyros Virginiana. Berries eatable when rotten-ripe ; bark, diospyros, febrifuge, P. U. S. $-D$. sapota nigra; $-K i, K a k i, D$. kaki; $-D$. decandra; $-D$. chloroxylon. Berries esculent. - D. embryopteris, Embryopteris peregrina, $E$. ghutinifera. Fruit used as glue, yields gaub; seeds yield oil.

\section{SAPOTE}

Inocarpus edulis;-Mimusops elengi;-Imbricaria Malabarica. Pulp of the fruit eatable.

Butter-nut tree, Mava, Maduca, Bassia butyracea;-B. longifolia. Seeds yield oil.

Achras lacuma. Seeds resemble chestnuts. A. caimito. Tree milky: fruit eatable.

Neese Berry, Achras sapota. Diuretic: bark used for the Peruvian bark.

Sapodilla Tree, Achras mammosa. Kernel bitter, makes a strengthening emulsion.

Star apPle, Chrysophyllum cainito. Juice of the unripe fruit, with orange juice, very astringent.-C. microcarpum ; $-C$. $J a-$ maicense;-C. oliviforme; -C. macoucou. Fruits esculent.? Butter tree. Yields oil. ? Cow tree. Yields cow-tree milk.

\section{ERICINEA.}

Roots and leaves mostly astringent; sometimes narcotic; berries often esculent. The brown powder that adheres to the petioles of almost every species of kalmia, andromeda, and rhododendron, is used, in America, as snuff.

\section{*Strawberry tree, Arbutus unedo. Fruit astringent: yields sugar.}

*BeAR' berry, Uva ursi, Arbutus uva ursi. Leaves, uvce ursi folia, bitter, astringent, used in disorders of the urinary passages, and thought to be lithontriptic; in powder, gr. $x$ to $y^{i j}$ three or four times a day, and in infusion; boiled with an acid dye brown, used to tan leather; leaves of red whorts sold for them.

Strawberry bay, Andrachne, Arbutus andrachne. Fruit acerb and austere, but esculent. - Arbutus Alpina ; - A. integrifolia;-A. mucronata. Berries esculent.

*Heatrs. Various species of Erica, as E. vulgaris; $-E$. herbacea; $-E$. purpurascens. Used in fomentations and baths, against rheumatism and paralytic affections, causing a sweat: dye a fine yellow, and tan leather. 
*Rosemary-leaved Annomeda, Andromeda polifolia. Has the same qualities as the preceding.- $A$. Mariana. Decoction used as a narcotic.

*Iinter-green, Pyrola, $P$. rotundifolia. Vulnerary.

Small winter-Green, Pyrola altera, $P$. secunda. Herb cooling, drying; leaves diuretic : used in dropsy.

American winter-green, Pyrola umbellata, Chimaphylla umbellata. An infusion of the leaves has been found efficacious as a diuretic in dropsy.

Partridgf berry, Gualtheria procumbens. Leaves, gualtheria, P. U. S., used for tea.

Rhododendron maximum; $R$. Ponticum;-Duarf rosebay, R. fermigineun;-Yellow rhododendron, R. chrysanthum. Leaves austere, astringent, bitter, stimulant; diaphoretic and narcotic; used against the rheumatism and gout; $3 \mathrm{ij}$ of the dried leaves, infused in half a pint of water, kept hot all night, and drank in the morning : root astringent.

Marsh cistus, Wild rosemary, Ledum palustre. Gives an agreeable odour to beer, but renders it heady : root astringent.

LABRADOR TEA, Wishecumpuouare, Wiserpukki, Ledum latifolium. Leaves used for tea.

Azalea procumbens. Bark and leaves astringent.

Bross.ea coccinea;-Riche's support, Styphelia Richei. Berries esculent.

\section{VACCINIE玉.}

*VAccivia, Myrtillus, V. myrtillus. Berries, black whortle berries, bilberries, acidulous, refreshing, useful in fevers, also antiscorbutic; would make wine: dried berries, berry dye, imported from Germany to colour wines.

"Great Briberry, Vaccinia uliginosum;-*Red whort, $V$. vitis Idca. (Leaves sold for those of uva ursi, but are veined in a network above, dotted underneath, and their infusion precipitates neither isinglass, jelly, nor a solution of green vitriol.)$\boldsymbol{V}$. glaucum;- $\boldsymbol{V}$. meridionale; berries esculent.

Americas cranberry, Vaccinium mactocarpum, Oxycoccos erythrocarpus. (Berries imported in large quantities from North A merica preserved in water.)-White cranberry, O. hispidulus;- Cranberry, $V$. oxycoccus, $O$. palustris. Berries esculent, used in tarts.

\section{CUCURBITACEA.}

Fruits mostly esculent, but a few have the laxative power so increased as to become drastic purgatives. 
*White bryony, Bryonia alba, B. dioica. Root, $9 j$ to $3 j$, in powder, or coch. $\mathrm{j}$ of its juice, nauseous, violently emetic and purgative; externally resolvent : yields fæcula.-Brionia callosa. Seeds vermifuge; yield an oil.

Abyssinian Bryony, Bryonia ...... Root esculent when boiled.

*Wild cucomber, Spurting cucumber, Cucumis agrestis, C. asininus, Momordica elaterium. Root and herb hydragogue, vermifuge; leaves, used externally, detersive and resolvent : fruit, elaterii poma, yields elaterium; juice of the fruit hydragogue.

Balsam apple, Cerasse, Momordica balsamina. Root purgative, $\rightarrow \mathrm{ij}$ in powder; plant vulnerary, balsamic, refreshing; leaves used in decoctions for clysters; fruit, infused in oil, makes a vulnerary balsam; the juice that exudes upon cutting the ripe fruit, used for fresh wounds.-Momordica chanantia. Very bitter, vermifuge, used in brewing in the East Indies.-M. luffa. Used to rub the body in cutaneous eruptions ; fruit eatable.

Trichosanthes amara. Fruit very bitter, purgative, emetic; used to destroy rats.

Coloquintida, Colocynthis, Cucumis colocynthis. Fruit, shell colocynth, imported from the Levant; pulp of the dry fruit, bitter apple, peeled colocynth, colocynthidis pulpa, also imported; purgative, in powder, gr. iij-viij, well rubbed with some gummy or farinaceous substance, or in clysters, $3 j$; mixed with paste or other cements, to keep away insects by its extreme bitterness: seeds ground used for the pith. Officinal preparations.-Extract. col. L. D. Extr. col. comp. L. E. D. Pil. col. comp. E. D.

*Cucumber, Cucumis hortensis, C. sativus. Fruit eaten, cooling; young fruit, gerkins, pickled for a sauce; salted cucumbers, imported from Russia; seeds yield oil.-C. chate. Fruit has a sweet refreshing juice.

Water melon, Cucumis anguria. Fruit eatable, refreshing.

*Melon, Melo, Cucumis melo. Fruit very refreshing; much eaten in France, where it takes the place of our potatoes.

*Gourd, Calebash, Cucurbita, C. lagenaria. Seeds cooling; leaves, no. 15-20, in decoction, form a purgative clyster.

*Pumpion, Pepo, Cucurbita pepo. The same qualities as the preceding; applied externally in burns, erysipelas, \&c.

Squash, Cucurbita melopepo. Fruit better tasted than the preceding, but of the same quality.

Citrux, Water melon, Citrullus, Cucurbita citrullus. Flesh of the fruit saccharine and watery.

*Vegetable marrow, Cucurbita succada. Fruit an excellent potherb, coming into use in England. 
Coccoon Axtidote, Feuillea cordifolia. Alexiterial, febrifuge, used in venomous bites; kernel of the fruit, called, in St. Domingo, noix de serpente, infused in rum or water, used against sedative poisons.

Calabash coccoon-antidote, Feuillea scandens. Seeds bitter and laxative; a large dose vomits.

\section{LOBELIACE $F$.}

Lobelia urens;-L. circiifolia. Very active, reputed a poison.

Cardinal flower, Lobelia cardinalis. Root vermifuge.

Blue cardinal rlower, Lobelia syphilitica. Root depurative, anti-venereal.

Lobelia tupa. Plant and root poisonous in the extreme; acts as an emetic simply by smelling the flowers : juice caustic.

Indian товасco, Lobelia inflata. Root, lobelia, P. U. S. used in leucorrhœa.-L. longiflora. Juice corrosive.

\section{CAMPANULACE E.}

Syrian Bell-flower, Medium, Campanula laciniata. Roots restrain the menses; seeds stimulate their expulsion.

"Field bell-flower, Campanula patula. Leaves lactescent, bitter.

- Raypioxs, Rapunculus esculentus, Campanula rapunculus. Rout esculent, far more delicate than turnips or radishes; juice odontalgic; seeds ophthalmic.

*Great throat-wort, Canterbury bells, Trachelium, Campanula trachelium. Root eaten in salads; herb astringent, recommended in quinsey, tumours, and inflammation of the mouth.

- Coventry bells, Viola Mariana Campanula medium. Root used as a potherb, cooling.

-Horned ramplons, Rapunculus corniculatus, Phyteuma orbiculare. Herb used in syphilis. SpIKed rampions, Phyteuma spicata. Root astringent, used in quinsey.

- Hatry sueeps-scabious, Scabiosa ovilla, Jasione montana. Herb astringent, used in inflammations of the mouth and neighbouring parts.

\section{CICHORACEAE.}

-Exurve, Cichorium, Seris, C. endivia. Roots used as a potherb; blanched stems as a salad and potherb.

"Wind succory, Cichorium agreste, C. intybus. Aperitive, hepatic, attenuant, used in fevers; root used for coffec.

- Nipple wort, Lampsana, Lapsana communis. Used for healing sore nipples. 
WART sUCCory, Zacintha, Cichorium verrucarium, Lapsana zacintha. Herb diuretic, edulcorant; takes off warts.

Blue gum-succory, Catananche cerulea. Similar to wild succory.

*Spanisir cardoons, Scolymus Hispanicus. Root and young shoots esculent.

Golden thistre, Scolymus maculatus. Root used instead of eryngo.

*Italian LetTuce, Scariola, Lactuca scariola.

*Lettuce, Lactuca, L. sativa. Many varieties. Has been substituted for opium in checking diarrhoea, allaying cough and diminishing pain in rheumatism. An inspissated juice is made of it ; dose, gr. ij, iv, or viij, in pills. Leaves refreshing, slightly anodyne, laxative, and antiphrodisiac.

*Strong-scented wild-LetTuce, Lactuca sylvestris major odore opii, L. virosa. The inspissated juice has been given in dropsies arising from visceral obstructions; gently laxative, very diuretic and somewhat diaphoretic. Narcotic and anodyne, occasions giddiness; inspissated juice resembles opium.

GuM succory, Chondrilla prima, Lactuca perennis. Herb restrains the menses.

Wild LetTuce, Lactuca elongata. Herb narcotic.

VEJuco, Prenanthes serpentaria. Persons inoculated with its juice are insensible to the poison of serpents.

Rushy gum-succory, Chrondrilla juncea. Laxative, diuretic; used in dropsy, gr. xviij to 3 iij, in twenty-four hours.

Sonchus Plumieri. Calyx exudes resinous drops.

*Great hawk-weed, Hieracium, H. majus, Sonchus arvensis; - ${ }^{*}$ Smooth sow-thistle, Hare's lettuce, Sonchus lavis, S. oleraceus lavis;-* Prickly sow-thistle, S. asper, S. oleraceus asper. These and the other species of this genus, as well as those of picris, crepis, prenanthes, hyoseris, \&c., possess similar qualities with lettuce.

*Golden lung-wont, Pulmonaria Gallica, Hieracium murorum. Herb cordial and pulmonary.

* Common mousf-enr, Auricula muris, Hieracium pilosella. Leaves sternutatory, vulnerary, astringent.-H. Gronovii. Leaves bruised, used to destroy warts.

*Hungarian hawk-weed, Herba costa, Hypocheris maculata ;-* Long-rooted hawk-weed, Hieracium officinale, Hypochæris radicata. Used in pulmonary affections and pains of the side.

*Smalt Hawk-weed, Hieracium minus, Leontodon autumnale. Leaves sharpen the sight, laxative. 
*Davdelios, Piss-a-bed, Dens leonis, Taraxacum, Leontodon taraxacum. Root, taraxaci radix, diuretic, roasted and used as coffee; blanched leaves used in salads; inspissated juice and extract much used, or a strong decoction of the roots, $3 j-i v$, two or three times a day, detergent, aperitive, and deobstruent.

LEONTOdon bulbosus. Root anodyne.

Scorzonera, Fiper's grass, Scorzonera Hispanica. Eaten.

HUdgariax viper's grass, Scorzonera subccrulea, S. purpurea.

*Yellow goats-Beard, Go-to-bed-at-noon, Tragopogon pratense.- SAlsafy, T. purpureum, T. porrifolium. Roots eaten as pot-herbs, opening, and supposed to be useful in affections of the chest ; young shoots also esculent.

99. CINAROCEPHALEA.

*Great buR-dock, Lappa, Bardana major, Arctium lappa. Young shoots stripped eaten as asparagus; root used in disorders of the skin, diaphoretic, diuretic, also useful in dropsy, $3 \mathrm{ij}$ of the fresh root boiled in three pints of water to two, and the whole drank in a day and night; seeds diuretic, diaphoretic, and slightly purgative.

*Oer Lady's tuistie, Milk thistle, Carduns Maria, C. Marianus. Pectoral, antipleuritic, aperitive.

Artichoke, Cincura, Scolymus, C. scolymus. Receptacle and base of the calyx scales eaten as a pot-herb; the bottoms are preserved in brine; infusion of the flowers used as rennet.

Сuarnoon, ('imara cardunculus. Aperitive, diuretic, and aphrodisiac; flowers used to curdle milk; petioles and ribs of the leaves eaten as potherbs.

Fisir thistre, Acarna, Carduus casabona.-Theophrastus's тиistle, Acarmus, Cirduns Syriacus. Eaten as potherbs while young.

Meinacholy tuistie, Cirsium, Cardiens Monspeliacus. Root bound on varices to assuage the pain of them.

WOOLIY-IIEADED THISTL, Friar's crown, Carduns eriophorus. Receptacle eaten as artichokes.

Carline thistres, Carlina, Chumaleon allus, Carlina acaulis. Root restorative, useful after great fatigue, when proper refreshments cannot be procured : formerly in common use with military men and foot travellers.

"Prickly camine thistre, Carlina vulyaris. Diuretic and diaphoretic; the dried calyx may serve as a hygrometer; in fine weather it opens horizontally, and is even sometimes reflexpd; on the contrary, in wet weatler it is closed.-Curlina acanthifolia. Receptacle esculent. 
* Common cotron-thistre. Acanthium, Onopordum acanthium. Flowers used to coagulate milk; receptacle eaten as artichokes.

Caicus ertophorus. Used in scirrhous tumours.

Bastard saffron, Dyer's saffron, Carthamus, Cnicus, $C$. tinctorius. Flowers, safflower, used to colour broths, also in dyeing, and to adulterate saffron; East Indian oiled; seeds, parrots' corn, purgative, emetic, yield oil.

Atractylis humilis;- $A$. gummifera. Analogous to Carduus benedictus; flowers coagulate milk.

Distafy thistre, Atractylis, Cnicus lanatus. Root depurative.

*SAw wort, Serratula, S. tinctoria. Vulnerary; dyes yellow with alum, but is inferior to weld.

*Way thistre, Carduus arvensis, Serratula arvensis. Useful in scirrhous tumours; yields a sort of galls.

Pacourina edulis. Receptacle and whole plant edible.

* Blue bottle, Cyanus segetum, Centaurea cyanus;-Great blue-bottle, Cyanus major, Centaurea montana. Flowers cooling, astringent, make a fine blue wash colour.

* Knap weed, Matfellon, Jacea nigra, Centaurea Jacea;-C. stobe. Flowers cooling, astringent.

Great centaury, Centaurium majus, C. centaurium. Root vulnerary, astringent, anti-dysenteric.

* Star thistre, Calcitrappa, Carduus stellatus, Centaurea calcitrapa;-Carduus benedictus, C. benedicta. Root diuretic, deobstruent, lithontriptic; leaves alexiterial in infusion; seeds diaphoretic.

*St. Barnaby's thistle, Calcitrapa, Centaurea solstitialis. Herb and seed opening, deobstruent.

Centaurea behen. Root, white ben, ben album, rhapontic blanc, rhubarbe indigène, rhaponticum behen; used for rhubarb, very astringent.

Grobe thistle, Crocodilion, Echinops spharocephalus. Root used internally in bleeding of the nose; seed diuretic.

Little globe thistle, Ritro, Echinops Ritro. Root astringent.

Echrnops strigosus. Down of the flower, Spanish tinder, used as amadou.

100. CORYMBIFER死.

Cacalia alpina;-C. Saracenica. Used in coughs; the juice allays the tickling in the throat. 
I. VEGETABLES.-CORYMBIFERE.

Cacalia antiuphorbium. Serves as an antidote to euphorbiun.

*Hemp agrimont, Eupatorium Avicenna, $E$. cannabinum. Herb bitter, hepatic, aperitive, useful in catarrh, cough, and cachexy, also diuretic and vulnerary; root purgative, used for jalap.

Arapana, Eupatorium ayapana;-Guaco, Huaco, E. saturejafolium? Sudorific, alexiterial, used in bites of serpents and hydrophobia.-E. purpureum. Root, gravel root, lithontriptic.E. perfoliatum. Root, thorough root.

WILD horenouxd, Eupatorium teucrifolium. Astringent.

Mountain cudweed, Cat's foot, Gnaphalium montanum, G. dioicum;-G. tomentosum. Flowers used in the violent running of the nose in children, slightly astringent and diaphoretic.

*Jersey cud-weed, Gnaphalium luteo-album; - Eternal flower, Stcchas citrina, G. stochas. Tops used in obstructions and colds.

Geibsan Golden-locks, Stochas citrina Germanica, Gnaphalium arenarium. Herb and tops stimulant, used in palsy.

Orienta golden-locks, Chrysocome, Gnaphalizem orientale. Root astringent.

*Cud-weed, Herb impious, Gnaphalium, Filago Germanica ;- LEAST CUD-WEED;-Gnaphalium minimum, Fillago montana;$F$. arvensis ; $-F$. leontopodium. Roots astringent and discussive.

CoNYZa sERICEA. Bark and wood used against the toothach. "Ploughman's spike-Nard, Baccharis, Conyza, C. squarrosa. Root and leaves used in ointments against the itch and farcy, and in wine against the jaundice.

German golden-Locks, Chrysocoma linosyris. Anthelmintic, deobstruent.

Frea-bane, Erigeron acre;-Pliladelphia flea-bane, E. Philadelplicum;-"Canadian flea-bane, E. Canadense. Are diuretic, lithontriptic, and vulnerary.

Great plea-Bane, Comyza major, Erigeron viscosum. Herb suppurative.

Sanali, flea-bane, Conyza minor vera, Erigeron graveolens. Herb diuretic.

-Star-wort, Aster amellus. Leavez discussive, vulnerary, resolvent; and useful in angina.

SEA stak-wort, Tripolium, Aster tripolium. Root hydragogue.

"Goldex mon, Virga aurea, Solidago virga aurea. Herb vulnerary, diuretic, useful in spitting of blood; infusion used in fevers. 
AMErICAN Golden-rod, Solidago odora. Leaves, solidago, P. U. S., carminative, nervine, used as tea, and even exported in large quantities from America to China.

Canada goldei-rod, Solidago Canadensis. With alum, dyes wool, silk, and cotton, a beautiful yellow.

* Elicampane, Helenium, Enula campana, Inula helenium. Root aromatic, slightly bitter, tonic, diaphoretic, stomachic, useful in asthma, hooping cough, and in uterine and exanthematous diseases, usually given in infusion, $3 \mathbf{j}$ for a dose; externally antipsoric : a decoction of the root cures the scab in sheep.

SweEt-rooted STAR-Wort, Inula odora. Root aromatic.

*Middle size flea-bane, Conyza media, Inula dysenterica. Tonic, used in diarrhœa.

*Flea-bane, Pulicaria, Conyza, Inula pulicaria. Drives away insects by its smell.

* Coltsfoot, Tussilago, Farfara, T. farfara. Leaves form the basis of most of the British herb toloaccos; used also externally to diminish inflammation; an infusion of the dried leaves is much used as an expectorant in coughs and shortness of breath as tea, or the steam is inhaled for the same purpose: a strong decoction of them is of considerable service in scrofulous cases; the downy substance on the under side of the leaf, dipped in a solution of saltpetre, and dried, is used as tinder; juice drank liberally serviceable in calculous complaints.

Alpine coltsfoot, Tussilago Alpina. Has the same qualities.

*Butter bur, Petasites, Tussilago petasites. Leaves used to dress ulcers; flowers strongly diaphoretic, diuretic, useful in asthma; root used against the tape-worm.

*Groundsel, Erigeron, Senecio vulgaris. Weak infusion a common purge; strong infusion, or juice, used as an emetic, and also given to horses to free them from botts; leaves externally suppurative; flowers given to song-birds as a cooler.

* RAG wort, Seggrum, Jacobca, S. jacobaa. Used in poultices and cholic pains; also as a gargle in sore throat.

Alpine ground-sei, Senecio doronicum. Infusion and steam of the infusion used in asthma.

Donin's wound-wort, Herba doria, Senecio doria;-Saracen's wound-wort, Consolida Saracenica, Senecio Saracenicus. Leaves used internally and externally in wounds and malignant ulcers.

French marygold, Tagetes patula. Dried juice used in disorders of the eyes; flowers dye yellow.

German leopard's-Bane, Arnica montana. Root discussive, leaves attenuant, diaphoretic, and diuretic, in doses of gr. v to gr. 
$\mathrm{x}$; in large doses they induce vomiting until the stomach is used to them. The emetic action of arnica was found by M. Dupuytren to depend on particles of down, which remain suspended in the infusion: hence the necessity of filtering. Much used in bruises from falls; flowers may be substituted for Peruvian bark, in intermittents and gangrenes, $\$ j$ to be taken in two days, beat up with honey into an electuary; in their effects the flowers are stimulating, and when administered in small doses they are very beneficial in raising the pulse, in exciting the action of the entire sanguiferous system, in checking diarrhœas, and particularly in removing paralytic affections of the voluntary muscles. They have also been recommended in chronic rheumatism, in retention of urine from paralysis of the bladder and in amaurosis. They are best exhibited in the form of infusion.

Creeping leoparis's-bane, Doronicum radice dulci, Arnica scorpioides;- - Leopard's bane, D. Romanum, D. pardalianches ;Small leopard's bane, D. minus,'D. plantagineum. Roots aromatic, used by sportsmen in alpine countries against giddiness.

MABY-Gord, Calendula officinalis. Flowers cordial, hepatic, diaphoretic, and emmenagogue.

*Wild MARY-Gold, Calendula caltha, C. arvensis. Herb cordial.

-Darsx, Day's eye, Small daisy, Bellis minor, Consolida minima, Sympliytum minimum, B. perennis. Root antiscrofulous; leaves in salads open the body, used in vulnerary fomentations.

Dioscorides' corn marygold, Chrysanthemum, C. coronarium. Flowers used to discuss steatomatous tumours.

"Griat daisy, Ox eye daisy, Bellis major, Chrysanthemum leucanthemum.

"Corn arary-gold, Chrysanthemum segetum. Discussive and attenuant, when used externally ; and given against the jaundice, asthma, and shortness of breath.

- Feverfew, Matricaria, Parthenium, M. parthenium.

* Comson camomile, Chamamichum vulgare, M. chamomilla. Emmenagogue, stomachic, carminative, anticolic; and used externally as a fomentation in nephritic pains.

Cosт mary, Tanacetum balsamita. Leaves stomachic, cordial, cephalic, uterine, supposed to diminish the narcotic power of opium; seed vermifuge.

"Tasser, Tanacetum vulgare. Vermifuge, uterinc, diuretic; used in colic pains and in gout; dose in substance $3 \mathrm{j}$, or more, usually drank as tea; sceds vermifuge, substituted for worm sees or santolina.

GoLdEx cUD-WEed, Heliochrysum, Tanacetum anmum. Herb emmenagogue, used in dyeing, and rheumatism. 
*Mug wort, Artemisia, A. vulgaris. Tops active uterines in decoction as a bath; mixed with rice and sugar, are, by the Chinese women, used as a pessary.

Artemisia Sinensis;-A. lanuginosa;-Madras worm-uood, A. Maderaspatana. Down of the leaves, moxa, formed into small cones, is burned on the place affected in gout, rheumatism, diseases of the joints, \&c.

*Souther wood, Abrotanum mas, Artemisia abrotanum. Tops discussive, antiseptic, vermifuge, and tonic.

Santonicum, Artemisia santonica?-A. contra?-A. Judaica? The seeds, worm seed, semen contra, s. cince, used as a vernifuge, in doses of gr. x. to 3 ss. three or four times a day; they are also stomachic; tansey seeds are substituted for them.

*Worm-wood, Absinthium vulgare, Artemisia absinthium ;True Roman worm-wood, Abs. Romanum, Art. Pontica;-Alpine worm-wood, Art. rupestris;worm-wood, Abs. maritimum, Art. maritima. Stomachic, excites the appetite, promotes digestion, antiseptic, and vermifuge; made into conserve, used to prevent dropsy.

Tarragon, Dracunculus hortensis, Artemisia dracunculus. Excites the appetite and the menses, heating, carminative; eaten as a pot herb, and communicates a peculiar fine flavour to vinegar and to mustard.

*Fine-reaved mug-wort, Artemisia, A. campestris. Herb astringent, antiseptic, discutient.

Santolina tinctoria. Affords a yellow dye.

*Cotton weed, Gnaphalium, Athanasia maritima, Santonica maritima; - Lavander cotton, Abrotanum fremina, Chamiceyparissus, Santolina chamacyparissus. Vermifuge, used to drive away insects from wardrobes.

* Ox Eye camomile, Anthemis tinctoria. Flowers dye a good yellow.

*Wild camomile, Anthemis arvensis;- Camomile, Chamcemelum, A. nobilis. Flowers of the latter, anthemidis flores, used in flatulent colic, and spasmodic affections, diuretic, laxative, and diaphoretic; they are equal to bark in curing intermittent fevers, giving $3 s s$ to $3 \mathrm{j}$, in powder, several times during the intermission, and avoiding their laxative effect, by joining an opiate or an astringent; used also externally in resolvent fomentations and poultices.

*Stinkrag camomile, Mayweed, Cotula, C. foetida, Anthemis cotula. Used in hysteric fits; and the juice in the king's evil.

Pellitory of Spain, Pyrethrum, Anthemis pyrethrum. Root', pyrethri.radix, imported from Turkey and Barbary, in bales; 
acrid, pickled while young for a sauce, sialogogue, and used as a masticatory in the toothach, and in powder, in the cure of intermittents, or as a sternutatory.

Ox Exe, Buphthalmum, Anthemis valentima. Vulnerary, aperitive; dyes a good yellow.

Yellow star-wort, Aster Atticus, Inguinalis, Buphthalmum spinosum. Vulnerary, and used in buboes, and other swellings of the groin.

MADI, Madia sativa. Seeds yield oil.

*Yar row, Milfoil, Millefolium, Achillea millefolium;-Achillea nobilis. Astringent, tonic, and vulnerary, used in hæmorrhages; and externally in headach, tumours, \&c.; added to beer to render. it more intoxicating, and lately recommended to smokers, in lieu of tobacco: root warm, used for contrayerva. Dr. Stoker of Dublin has found milfoil serviceable in dropsies.

*S.neze wort, Bastard pellitory, Ptarmica, Achillea ptarmica. Leaves sternutatory; root acrid.

Swret maudin, Ageratum, Eupatorium Mesues, Achillea ageratum. Stomachic, cordial, cephalic.

*WATER heMP-AGRIMONY, Eupatorium cannabinum foeminum, Bidens tripartita. Strong smelling, hepatic, vulnerary.

Spilantuus acmella. Diuretic, diaphoretic, attenuant, and anodyne; leaves and seeds used as tea.-Spilanthus tinctorius. Leaves juicy; when bruised yield an excellent azure colour. $-S$. oleraceus. When masticated irritates the interior of the mouth, and provokes a copious flow of saliva.

Baccharss concava. Leaves dye a black colour,-B. cmarginata;-B. dependens;-B. oblongifolia. Vulnerary and conso-. lidañt.-B. prostrata. Decoction used in dysury.

SeN yLowr: Helianthus annuus. Seeds oily, used in emul. sions; young shoots boiled are aphrodisiac; flowers yield turpentine.

JerUsalem artichoke, Helianthus tuberosus. Roots nourishing, diuretic, give the smell of turpentine to the urine; flowers yield turpentine.

Places tomrntosus;-P. lavis. Juices used to give a smell to cakes.

Cinfraria meterophyida. Bark yellow, powerfully anthelnintic.

Eclipta erfacta. Juice used to dye the hair black.

Verbesina Boswfolia. Esculent, having the smell and taste of fennel. Gur' ellu, Huts ellu, V. sativa. Seeds pressed for oil. 
Galinsoga parviflora. Vulnerary and antiscorbutic.

- Ambrosia maritima. Cardiac, cephalic, astringent.

* Small Burdock, Xanthium Lappa minor, Bardana minor, X. strumarium. Root bitter, antiscrofulous, and anticancerous.

101. DIPSACE 2 .

* Scabious, Scabiosa, S. arvensis. Leaves depurative, used in diseases of the skin, of the lungs, and in quinsy.

*Devil's bit, Succisa, Morsus Diaboli, Scabiosa succisa. Root used in syphilis and scrofula.

: 'Teaser, Fullers' thistle, Dipsacus sativus, Carduus fullonum, D. fullonum. Root bitter and tonic.

*Wild Teasex, Dipsacus sylvestris, Labrum Veneris, D. fullonum. Roots antiscrofulous, and in wine diuretic.

\section{VALERIANE E.}

*Wild valerian, Valeriana sylvestris, $V$. officinalis. Root, valeriance radix, very sudorific, diuretic, antiseptic, strengthening the sight, vermifuge, anti-epileptic ; given in powder, in doses of 3j to $3 \mathrm{j}$, mace covers its unpleasant flavour; plant allures cats and rats to the place. Officinal preparation.-Tinct. and tinct. valer. ammoniata, D.L.E.

*Smali valerian, Phu minus, Valeriana dioica.-Great valerian, Phu, Valeriana major, V.phu. Root an active tonic, exhibited in spasmodic diseases.

Celtic nard, Nardus Celtica, Valeriana Celtica;-Indian Nard, Nardus Indica, Valeriana Jatamensi,-Mountain valeRIAN, Valeriana montana. Roots aromatic, used 'in hysteria and epilepsy.

*Corn salad, Valeriana locusta; - $V$. rubra. Young shoots eaten as a salad.

\section{RUBIACE}

*Woodroof, Asperula, A. odorata. Hepatic and deobstruent internally; antipsoric externally.

*Squinancy wort, Rubia cynanchica, Asperula cymanclica. Used externally in quinsy.

Asperula arvensis; - $A$. tinctoria; - *Wild madder, Rubia sylvestris lavis, Galium mollugo;-Galium sylvaticum. Roots dye red, herbs opening.

*Small mountain bastard madder, Mollugo montana. Galium uliginosum; - *LADIEs' BED-STRAW, Cheese renning Galium, G.verum;- - ${ }^{*}$ cheavers, Goose grass, Aparine, Galium aparine. Vulnerary, infusion used to curdle milk; roots dye a red colour. 
"Maduer, Rubia tinctorum. Root, madder, grappe, meekrappe, lizuri, rubice rudix, slightly astringent, diuretic, emmenagogue, and aperitive, used in the rickets, dose in powder $3 \mathrm{j}$ to $3 \mathrm{ss}$, or of the decoction $\overline{3}$ ij ter die: it dyes red.

RuBia мaкjтн. Root, Bengal madder, munject;-Danais fragrans;-Oldenlandia umbellata. Root, chay root. These roots are all used for dyeing.

*Cross-wort, Cmiciatu, Valantia cruciata ; - Litit lefieid MADDER, Sherardiu arvensis. Qualities the same as those of ladies' bed-straw.

Psychotria sulphurea. Extremely bitter, yields a fine yellow tincture; used as a tonic.

Psychotoria herbacea. Roots emetic.-P. emetica. Root, broun ipecacuanha, ipecacuanha noir, ipec. non annelé, emetic; contains 9 per cent. of emetine.

Callicocca ipecacuanha, Cephaelis ipecacuanha. Root, ipecacuanha, ipéc. Urun, ipéc. cannelé gris noiratre, ipecacuanhe radix, emetic $\partial_{j}$; outside contains sixteen per cent. of emetine, woody fibre in the centre only one quarter per cent. ; from Brazil; the brown and white ipecacuanha are frequently mixed with it. Seeds of orache, narrow-leaved wild orache, leaves of wood betony, or of asarabacca, roots of primrose, oxlip, and tooth-wort may be used for it. The roots of Asclepias Curassavica, A. asthmatica, Secamine emetica, A pocynum androsæmifolium, Euphorbia Gerardiana, E. ipecacuanha, Canthium coronatum, Gymnema sylvestre, Periploca Mauritiana, Cynanchum tomentosum, Gillenia trifoliata, and Cymoglossum lavigatum are also employed as substitutes.-Ipécacuanha cannelé gris rouge. A variety: contains fourteen per cent. of emetine.-Ipéc. gris blanc. Another variety. Officinal preparation.-Vinum ipec. and pulvis ipec. comp.

Gardenia longiflora. Berry eatable.-G. gummifera. Exudes a gun resin like elemi, perhaps cancame.

Gardenia demetolum, C'anthium coronatum. Root, Malabar ipecacuanha, emetic.

Cалthium parvifonum, Webera tetrandra. Root bitter, red.

Macronemus corrabosum. Bark bitter, viscid, inside white, often mixed with that of cinchona.

VActeria EDUis. Seeds like almonds.

Pisknea pubescens. Bark febrifuge, used the same as that of cinchona.

Genipa Americana. Berry eatable.

Nauclea gambeer, Uncuria gambeer. Gutta gambir is made from it.

Guettarda coccinea. Bark very bitter. 
Peruvian bark trees, Loxa trees. These are here placed as they appear in the work of Rœmer and Schutze, the discontinuance of which is so much to be regretted.

Loxa TrEe, Jesuit's bark tree, Cinchona officinalis of Linnæus, Cinchona Condaminea. Bark, Jesuit's bark, Peruvian bark, grey bark, pale bark, cascarilla fina, quinquina gris, C. P. kinakina cinericea, cortex pallidus, cinchona officinalis cortex communis, $c$. lancifolice cortex, P. L. cinchona pallida, P. U.S. Thin, very fine, much rolled, inside rusty fawn, aromatic, breaks clean between the teeth, tonic, resinous, middling bitter, very rich in cinchonine, yields but little quinine.

Cinchona rosea. Bark, kinkina nova, thick, woody, long, straight, flat, smooth coat, whitish, inside pale red or flesh colour, mawkish, then acrid, nauseous, infusion and tincture astringent, not bitter, slightly febrifuge.

Cinchona F Usca. Bark, cascarilla asmonich, chocolate colour on the inside, very styptic, a variety of C. rosea.-Cascarilla pardo, Cinchona aharquillado, brown with white spots, extremely bitter; another variety.

Cinchona lancifocia, Cinchona lanceolata, $C$. glabra, $C$. officinalis of Vahl. Bark; crown bark, quinquina orangé, C. P. rather large, inside fawn, coat brown, rugged, sometimes peeled, split transversely; smells rather spicy, very bitter, tonic, grows darker in water or alcohol, highly esteemed in America, yields much more quinine than cinchonine.-C. nitida. A variety highly esteemed in America. C. angustifolia. A variety; bark, pale red bark, coat whiter, less rugged, and neither so bitter nor astringent.-Cascarilla lampigna. A variety of the bark: very thick, woody, in large pieces, not rolled, taste very slight, contains no rosin.

Cinchona conmirolia, Cinchona officinalis of Gmelin, $C$. pubescens, C. tenuis, C. pallescens, C. ovata. Bark, ycllow bark, quinquina jaune, $q$. jaune royal, $q$. calisaga, C. P. cortex flavus, cinchone cordifolice cortex, cinchone officinalis cortex flavus, cinchona flava, P. U. S. in large pieces, slightly rolled, fine grained, fibres fine, coat thick, and may be separated in flakes, sometimes peeled, inside deep yellow, very bitter and astringent, decoction peach bloom colour; yields much more quinine than cinchonine:- $C$. micrantha. A variety: bark, new Carthagena bark, yellow, flat, thin, thready, brittle, coat silvery white, not cracked, decoction pale, slightly bitter and astringent, yields little or no precipitate with infusion of gall nuts, feebly febrifuge.-C. hirsuta. A variety: bark, kinkina Loxa delgada, cascarilla delgadilla, febrifuge, power strong.-C. purpurea. A variety: bark, mulberry leaf bark, yellowish brown, in good esteem in America.

Cinchona oblongrfolia, Cinchona magnifolia of Ruiz, not 
of Humboldt and Bonpland, C. lutescens, C. grandifolia. Bark, red bark, quinquina rouge, C. P. cascarilla amarilla, cortex ruber, cinchonce officinalis cortex muber, cinchone oblongifolice cortex, cinchona rubra, P. U. S. thick, fibrous, brown red or dark fawn, coat rugged, and cracked in various directions, fibrous, antiseptic, used in gangrenous cases, contains quinine and cinchonine in nearly equal quantities.

Crimciona Hemboldiana, $C$. nealifolic of Humboldt. Bark, cascarillu peluda, resembles that of Cosmibuena obtusifolia, cracked lengthwise, inside clear yellow, bitter, astringent, resinous, is usually mixed with that of $C$. glandulifera.

Cinchona gianidulfera. Bark, Havannah bark, huanuco, in larger pieces than that of $C$. Humboldtiana, outside dark fawn, warty and knobby, with perpendicular cracks, inside fawn, fibrous, slightly resinous, bitter, slightly aromatic; frequently mixed with that of C'osmibuena obtusifolia.-Black huanuco, cascarilla negrilla. $A$ darker variety of the bark.

Cinchona triflora. Bark, Jamaica bark, in a full dose emetic.-Cinchona laccafera. Fresh bark, scraped on the inside, yields a red lake, dried bark, socchi, thick, red, slightly rolled, spongy.

Cosmbena obtusifolia, Cinchona macrocarpa, C. grandiflora, C. nvalifolia of Mutis. Bark, pale bark, female Loxa, Lima bark, quinquina blane, C. P. outside whitish grey, cracked transversely, inside pale fawn, breaks clean, not very resinous nor aromatic, mixed with other bark, especially that of myroxylon pedicellatum, Cinchona longiflora. A variety: bark, Guaiana inark, in long pieces, thick, bitter, scentless.

Exostemma Cary в.eum, Cinchona Caribca, C. Jamaicensis. Bark, Cariblee bark, quinquina des Antilles, cinnamon colour, bitter, scentless, cheap.-Exostemma brachycarpum. Bark emetic in a full dose: from Jamaica.-E. floribundum, Cinchona florilundr, C. montana, C. Sancta Luzia, C. Luziana. Bark, Sainte Lurie larls, quinquina piton, thick, brown, rugged, inside rusty fawn, mostly used externally, being apt to excite vomiting and purging.- L. coriuceum, $C$. coriacea, $C$. niticla. Bark highly esteemed in America.

In the generality of Pharmacopocias the grey, yellow, and red barks are enumerated; the Paris Codex adds to them Quinquina lulane, Q. piton, Q. des Antilles, and Q. orangé: some of the other. barks are used for grinding with these, and reducing their price. 'The bark of Macrncnenum corymbosum, of the Weinmannia, called red tan bark, and that of Funis fellens, are mixed with these barks. - The chemical habits of these several barks are very different, but they cannot well be examined in Europe. The infusion of some kinds precipitates the infusion of nut galls, as 
well as isinglass jelly; others, only one or other of these tests ; but the chemists vary in their accounts, owing to the mixture of the barks of several species, and their sale under one common name. Medically considered, they are all tonic and febrifuge, and may be given in powder, from $9 \mathrm{j}$ to $3^{\mathrm{ij}}$ every two or four hours, so as to get down an ounce between each fit of intermittent fevers; of great use in stopping the progress of gangrene: they are also given in infusion and decoction.-The roots of bistort, Calamus aromaticus, avens, water avens, and tormentil, oak bark, that of several kinds of willow, horsechestnut, ash, and the sloe bush, mahogany saw-dust, the dried herbs of yellow loosestrife, bugle, water horehound, and self-heal, are used either as substitutes or to reduce the price of the ground bark, as is also the root of Geum montanum. The barks of Pinknea pubescens, Unnona febrifuga, Swietenia febrifuga, Cedrela tuna, Magnolia glauca, M. acuminata, M. tripetala, Achras sapota, Rubus trivialis, and $R$. villosus are also used as substitutes.

Coffee shrub, Coffe, Coffea Arabica. The fresh seeds are febrifuge, diuretic, and tonic; decoction used for that of Peruvian bark.

Iron wood, Siderodendrum triflorum. Bark diuretic, stomachic.

Nonatelia officinalis. Pectoral in infusion.

Cada pilava, Bancudus latifolius, Morinda citrifolia; $-M$. umbellata;-Hydrophylax maritima;-Pattibea coccinea. Fibres of the roots, muddi, aul, imported from the East Indies, used for dyeing reds and browns.

\section{LORANTHEAE.}

Bark astringent; berries contain a principle analogous to caoutchouc, called bird-lime.

*Misseltoe, Viscum, $V$. album. Berries very purgative, used to make bird-lime; leaves antiepileptic in doses of $9 \mathrm{j}$ to $3 \mathrm{j}$, twice a day.

*Miśsertoe of the oAK, Viscum quercinum, Loranthus Europaus. Esteemed a sacred plant by our ancestors, hence extirpated by them, but still found plentifully on the oaks in those parts of Europe where the druidical religion was not established: the common misseltoe, viscum album, which scarcely, if ever, grows on the oak, is still used as a substitute for it in medicine, and also to deck our churches, and preserve our houses from evil spirits.

MANGRove, Rhizophora mangle. Fruit and bark used in tanning; imported from the West Indies.

Brugulera gymnorhiza. Fruit, leaves, and even bark eaten. 


\section{CAPRIFOLIACEE.}

*LiNsea borealis. Used in rheumatism and gout; astringent and diuretic.

*Wood-bine, Periclymenum, Caprifolium, Matrisylva, Lonicera, periclymenum;- - HoNeY sucki, Lonicera caprifolium. Leaves used in detersive gargles; flowers antiasthmatic.

*IVayfarixg tree, Pliant mealy tree, Viburnum lantana. Berries drying, astringent ; bark of the root made into bird-lime.

Cashio-berri bush, Perygua, Cassine peragua, Viburnum cassinoides. Leaves purgative, sometimes emetic or diaphoretic, used as a specific in diabetes.

WII.D BAY, Laurus timus, Viburnum tinus. Berries purge violently.

*Geld Res rose, Viburmum opulus. Leaves and berries refreshing, and used in astringent gargles.

*Elder, Sambucus, S. nigra. Second bark, gr. v to $\vartheta_{\mathrm{j}}$, very active, antihydropic; leaves a nauseous purgative; flowers diaphoretic, useful in disorders of the chest, discussive and attenuant ; berries used to flavour sugar wine, poisonous to poultry; dry berries, grana actes, useful in dropsy.

White-berried elder, Sambucus nigra virescens. Flowers used to give wine the flavour of Frontignac.

Americin elder, Sambucus Canadensis. Berries, Sambucus, P. U. S. used as the former.

*Dwali Elder, Ebulus, Sambucus cluchus. Root, Jjss, a strong purge; leaves used in poultices for the gout and piles; berries used to dye blue, and also to make wine.

Modxtarn elder, Sambucus racemosu. Narcotic.

- Ivy, hedera arborea, H. helix. Leaves used internally in atrophy, and to dress issues; also boiled in wine as a wash to kill verıin; berries purge; the trunk yields a gum resin.

Cornelian cinerry, Comus, $C$. mascula. Fruit very astringent, useful in loosenesses.

-Dor-wood, Gatter tree, Female cornel trec, Cormus formina, C. sunguiner. Seeds yield oil, like those of the former species; wood used for making charcoal for gunpowder.

Rount)-LEaven Dos-Wood, Cormes circinata;-Sweamp dogwood, Comus sericea;-Americun don-unood, C. floridu. Barks of the roots used as poultices.

Triosted PERfolitum. Root, ferer root, triosteum, P. U.S., emetic and cathartic; bark of the root bitter, tonic. 


\section{ARALIACE $\approx$.}

False sarsaparilita, Aralia nudicàulis; - A. racemosa. Roots bitter, mixed with those of sarsaparilla.

Angelica tree, Aralia spinosa. Bark astringent; berries used in rheumatism and cholic.

Ginseng. Panax quinquefolium. Root cordial, alexiterial, and aphrodisiac; dose $3 \mathrm{j}-\mathrm{ij}$, chewed, or sliced and made into tea: often confounded with nin sing. From North America.

Panax undurata. Woods, barks, leaves, flowers, and fruit aromatic.-Panax fruticosa. Herb diuretic.

\section{0\%. UMBELLIFER $\mathbb{E}$.}

Aromatic, and if they grow in water, poisonous ; roots of many contain a saccharine principle; an essential oil is generally contained in the vittæ of the seeds.

Anise, Anisum, Pimpinella anisum. Seeds one of the four great hot ones, cephalic, stomachic, carminative, diuretic, and emmenagogue. Our summers not being sufficiently warm to ripen the seeds, they are usually imported.

*Bunnet saxifrage, Pimpinella saxifraga. Root chewed relieves the toothach; seeds are opening, detersive, and lithontriptic; $9 j$ in powder, or $\ni i j$ in infusion.

*Herb Gerard, Gout wort, Ash weed, REgopodium podagraria. Root and leaves used in the gout : young leaves used in salads.

*Caraway, Carui, Carum, Carum carui. Seeds, caraway seeds, carui semina, stomachic, carminative; root sweet, nourishing, and better eating than parsneps.

*Smallage, Celery, Apium, Eleoselinum, Apium graveolens. Root opening, diuretic, used in jaundice and the gravel; seeds more active; blanched stalks eaten in salads.

*Parslex, Petroselinum vulgare, Apium petroselinum. Root diuretic; leaves used as a seasoning to meat, resolve coagulated milk in the breasts, but supposed to produce epilepsy and inflammation of the eyes; seeds carminative.

*Fennel, Foeniculum vulgare, Anethum foeniculum. Seeds aromatic, hot, carminative; roots opening; leaves diuretic, used as seasoning to fish.

Sweet Fennex, Foeniculum dulce, Anethum segetum. Blanched stem used as a potherb; seeds, finocchio, foniculi semina, carminative, used in soups; imported from Italy.

*Dill, Anethum, A. graveolens. Seeds discussive, galactopoietic, stopping vomiting and the hiccough ; leaves ripen tumours.

Wonum, Anethum sowa. Seeds carminative. 
*Alexanders, Smyrnium, Hipposelinum, S. olusatrum. Root and herb opening, emmenagogue.

Common bishops-weed, Ammi vulgare, $A$. majus. Seeds sold for those of ammi verum.

* Parsnep, Pastinaca hortensis, $P$. sativa. Root nutritive, but its strong smell renders it disagreeable to many; sugar and wine are made from it; seeds aromatic.

Gum parsnep, Pastinaca opopanax. Root yields, by incision, opopanax.

Thapsia villosa. Root purgative; may be used for jalap.

Thapsia Ascleprum;-T. garganica;-Seseli turbith. Roots acrid, and purge upwards and downwards very violently.

Seseli saxifraguar;-Bastard spignel, Seseli montanum;S. glaucum. Roots purgative, not so acrid as $S$. turbith, or the Thapsia. $-S$. leucospermum. Root resinous, aromatic.

French hart wort, Seseli tortuosum;-S. hippomarathrum. Seeds stomachic, aperitive; roots anti-asthmatic.

* Master wort, Imperatoria, Astrantia, Imperatoria obstruthium. Root very restorative after fatigue; formerly chewed by military officers and soldiers in forced marches and other fatiguing duties.

*Wild cicery, Cou-wced, Cicutaria vulgaris, Charophyllum sylvestre. Strong smelling, acrid, diuretic, dyes woollen yellow and green.

Chervil, Cherophyllum sativum. Plant used as a potherb.

Hemlock chervir, Chcerophyllum cicutaria. Root poisonous, as well as the leaves.

"Mesk chervil, Charophyllum aromaticum;-* Chervil, Cherefolium, Scandix cerefolium - -SweEt CICELy, Myrrhis, Scandix odorata. Very resolving, diuretic, lithontriptic.

- Vevus сомв, Shepherd's needle, Pecten Veneris, Scandix pecten. Young shoots eaten raw or boiled.

* Coriander, Coriandrum sativum. Herb eaten as a salad too frequently occasions fatuity; seeds, coriandri semina, stomachic ; cover the taste and prevent the griping of senna. Scmina coriandri prapuratu. Seeds steeped in vinegar for a day and night, then dried, are milder.

*Spignel, Men, Meum, Athamanta meum, Aithusa meum. Root gummy, resinous, carminative.

"I.esspr Hemtock, Fools' parsley, Cicutaria fatua, Rithusa cynapium. Poisonous, liable to be mistaken for parsley, but is inodorous and insipid.

- Long-leaved water parsnep, Sium erucafolia, Cicuta virosa;-*Marsh uesLock, Water hemlock, Phillandrium, $P$. 
aquaticum;-P. mutellina;- *Water drop-wort, Enanthe aquatica, CE. fistulosa;- * HEMLOCK DROP-WORT, $C$. cicuta facia, $\mathscr{C E}$. crocata. Acrid, poisonous, especially the roots, emetic, and act upon the nervous system: used externally are powerfully resolvent, anodyne, and used in scrofulous and scirrhous tumours, and in inflammation of the penis; juices yellow, poisonous.

* Enanthe peUcedanifolia;-* Parsley water drop-wort, Enanthe pimpinelloides. Roots used as potherbs.

*Hewlock, Cicuta, Conium maculatum. Very poisonous in warm countries, but less active in cold ones, powerfully narcotic, used in many obstinate disorders, as scirrhous cancer, chronic rheumatism, ill-conditioned ulcers, and glandular tumours; dose of the dried leaves, cicutce folia, conii folia, in powder, gr. j, gradually increased to $Э \mathrm{j}$, every four hours, to be exhibited with caution, especially when a fresh parcel of powder is used : seeds, conii semina, less uncertain in their effects. Officinal preparation.-Tinct. conii, D. Succus spissatus con., D. E. Extractum conii, $L$. Unguentum conii, $D$. Cataplasma conii, $D$.

Cumrs, Cyminum, Cuminum cyminum. Seeds, cumini semina, aromatic, carminative; imported from Sicily and Malta.

Wrod cumin, Cuminum sylvestre, Lagoccia cuminoides;-Macedonian parsley, Petroselinum Macedonicum, Bubon Macedonicum. Seeds carminative.

Bubon galbanum; - $B$. gummiferum. Yields galbanum. Officinal preparation.-Pil. galb. comp., L. D. Tinct. galb., $D$. Pil. fotid. comp., $E$.

Ammi verum, Sison ammi;-* Сommon amonum, Bastard stone parsley, Amomum vulgare, Sison amomum. Seeds warm, aromatic; used in Venice treacle.

*Corn hone-wort, Sison segetum. Useful in indolent tumours.

SkrrRer, Sisarum, Sium sisarum. Root used as a potherb, stomachic; a specific against the bad effects of quicksilver; sugar is made from it.

Nin sing, Ninzen, Nisi, Sium Ninsi. Alexiterial and aphrodisiac, and thought to lengthen life; frequently confounded with ginseng, as in the Pharm. Lond. 1720.

*Great water parsnep, Pastinaca aquatica, Sium latifolium:-Urright water Parsnep, Sium berula. Roots poisonous; leaves aperitive, diuretic, antiscorbutic.

* Creeping water paissep, Sium nodiflorum. Juice used in cutaneous diseases ; dose for children iij tea-spoonfuls twice a-day, and for adults 3iij every morning.

*Angelica, $A$. archangelica. Root stomachic, carminative, aperitive, diaphoretic, useful in typhus fever. Seeds aromatic. 
CANDIED ANGeliCA, caules angelice conditi. The fresh stalks are boiled in water to take away the bitterness, and some of the strong scent, then put into syrup boiled to a candy height till quite dry, takien out and dried ; cordial, aphrodisiac.

America.i a vgelica, Angelica, P.U.S., $A$. atropurpureum;- Vild angelica, A. sylvestris. The same, but weaker.

*Lovage, Levisticum, Ligusticum levisticum. Root, leaves, and seeds aromatic, stomachic, and diaphoretic; stem yields English opopanax.

Great biroad-leaved hemlock, Seseli Peloponnense, Ligusticum Peloponnesiacum. Root and seeds used in nervous diseases.

"Cornish lovage, Ligusticum aquilegifolium, L. Cornubiense. Root exudes a resin.

Hart wort, Seseli, Siler montanum, Laserpitium siler, $-L$. Latifolium;-L. angustifolium;-L. chironium. Roots used in scrofula, spitting of blood, and piles.

*Cow Parsiep, Sphondylium, Heracleum sphondylium. 1Ront and leaves emollient; seeds a specific in hysteric spasms; juice of the head renders the hair curly; young shoots substituted for asparagus: exudes sugar.

Master wort, Heracleum lanatum. Root, heracleum, P.U.S. emollient.-Heracleum panax, and some other species, are added to fermented liquors, and distilled by the northern nations.

HERACLEUM GUMMIFERU. Yields gum ammoniac.

Fexiel giast, Ferula, $F$. communis. Seeds carminative; grcen pith of the stem used in spitting of blood.

Small Fendel giant, Ferula, $F$. galbanifera, $F$. Ferulago. Seeds found in galbanum produced this plant.

FrRula ASSAFETIDA. Old roots yield assafœetida, young roots roasted and eaten ; leaves eaten as greens. Some seeds found in sagapenum produced an unknown fecula.

Ferula Persica. Also said to yield gum ammoniac.

- Hogs Fenvet, Sulphur wort, Hore strange, Peucedanum, P. nfficinale. Root very diuretic, attenuant, expectorant, aperitive; wounded it exudes a gum resin.

- Meadow saxifrage, Saxifraga vulgaris, Peucedanum silaus. Root aperitive, used in calculous cases.

Cachrys mвanotys. Root very heating and detersive; used externally in piles.-Colontalyica. Used in toothach.

-Sлмрипе, Critlımun, Fneniculum maritimum, Herba Sancti Petri, Crithmum maritimum. Excites the appetite.-P'ickled sumphire. Used for sauce.

Mountais pansiero, I'etrosclinum montanum, Athamanta oreo- 
selinum;-*Black gentian, Gentrana nigra, $A$. libanotis. Diaphoretic, diuretic, used in calculus.

Daucus Crexicus', Athamanta Cretensis.' 'Seeds odorous, car. minative, diuretic, antihysteric, and nervine.

Selinum caruifolia;-Milky parsley, S. sylvestre. Roots alexiterial.

*Bulbocastanum, Bunium bulbocastanum. Tubers, earth nut, kipper nut, pig nut, haugh nut, very nourishing, stimulant; useful in bloody urine and spitting of blood: sold for salep roots.

* Carrot, Daucus nostras, D. vulgaris, D. carota. Roots dauci radix, saccharine, alimentary; externally to carcinomatous and foul ulcers : a sugar is made from them.

Wiln Carrot, Daucus sylvestris, D. visnaga, Ammi visnaga, $V$. daucoides. Seeds, dauci semina, P.L. diuretic, antipleuritic; rays of the umbel Spanish toothpicks.

Daucus gummifer. Yields one sort of opopanax.

Adjowaen, Ammi Copticum, Daucus Copticus, Bubon Copticum. Seeds carminative; imported from the East Indies.

*Great bastard parsley, Caucalis latifolia;-* Fine-leaned bastard parsley, Caucalis daucoides;-C. leptophylla;-C. grandiflora. Are all diuretic.

*Hedge parsley, Hens foot, Caucalis minor, Tordylium anthriscus;-*Harts wort, Tordylium officinale. Roots and seeds diuretic.

Oriental pick-тоoтh, Gingidium, Artedia squamata. Leaves diuretic, stomachic, used as a potherb, or eaten raw : rays of the umbel used as toothpicks.

*Thorough wax, Perfoliata, Bupleurum perfoliatum. Vulnerary, used externally in tumours.

*Hares ear, Auricula leporis, Bupleurum rotundifolium, and the other species of the same genus, are aperitive, discussive, and diuretic.

Shrubby Hart-wort, Seseli Aithiopicum, Bupleurum fruticosum. Seeds carminative, very acrid and odorous.

Black master-wort, Astrantia major;-A. minor. Roots used in scirrhus of the spleen, and mania.

* Sanicle, Sanicula Europcea. Leaves vulnerary, cleansing.

* Marsh PENNy-wort, White rot, Hydrocotyle vulgaris;BUTTON SNAKE-WEED, Eryngium aquaticum: (root, eryngium, P.U.S.) - * Common ERYNGo, Erymgium campestre;- ERYNGo, Sea holly, E. maritimum. (Shoots boiled eaten as asparagus.)Three-leaved eryngo, E. tricuspidatum. Roots aphrodisiac, diuretic, sudorific, may be used for contrayerva.-Candied eryngo, Radix eryngii condita. Roots slit, washed in cold water, and then put into the syrup. 
STrNosg weEd, Eryngizm foetidum. Leaves, in infusion, anti-hysteric, either internally or in clysters.

\section{CUNONIACEA.}

RED TAN, Weinmannia .... Bark astringent, frequently mixed with that of the Loxa tree, or Peruvian bark.

\section{SAXIFRAGEA.}

*White Saxifrage, Saxifraga alba, S. granulata;-*Rueleaved uhitlow-grass, Paronychia, Saxifraga trydactylites;-Narrow-leaved suxifrage, S. cotyledon;- *London pride, S. geum, and most other species of this genus, are aperitive, diuretic; useful in jaundice, obstructions, and scrofula.

Cirrisosplenium oppositifolium; - *Golden saxifrage, Saxifiaga aurea, Chrysosplenum alternifolium. Aperitive, diuretic, anti-asthmatic, and pectoral.

"Tuberous moschatel, Adoxa moschatellina. Has nearly the same qualities.

Heuchera Americaxa: Root, alum root, heuchera, P. U. S. astringent, used externally in cancer.

\section{CRASSULACE $A$.}

The thick juicy leaves are used outwardly as cooling and astringent. Many of them contain malate of lime.

- Navel wort, Uinbilicus Veneris, Cotyledon, C. umbilicus. Refreshing, detersive, cooling, very diuretic, useful in inflammations of the skin.

"Rose wort, Rose root, Rhodia radix, Rhodiola rosea. Root cephalic, astringent.

- Orpise, Live long, Telephium, Crassula, Fabaria, Sedum tepplium. Astringent, easing pain in fresh wounds or in old ulcers; eaten as a potherb, leaves a slight but disagreable irritation in the throat.

Evergreen lesser house-leek, Sedum anacampseros;Annual white house-leck, Sedum cepcea. Equally cooling, astringent, and diuretic.

-Lesser nousf-Lerk, Prick madam, Sedum minus, S. album. Qualitics the same; used in salads.

- War. pe.pper, Stone crop, Scdum minimum, Illecebra, /Sedum acre. Emetic, cathartic, detersive in cancers and scrofula, antikorbutic : externally rubcfacient.

-Comaron great house-lezk, Serlum majus, Sempervivum, Semp. tectorum. Cooling, astringent ; used externally to corns. 


\section{GROSSULARIE.}

The fruits of this order are eatable, acidulous, and cooling.

*RIBes, Ribesia, Ribes rubrum. Fruit, red currants, garnet berries, acid, cooling; juice of the fruit with sugar drank as lemonade or orgeat; and made into wine.-White currants. A variety; fruit less acid, juice made into wine.

*Black currants, Quinsey berries, Ribes nigrum. Odour similar to that of bugs; leaves, in infusion, aperitive, diuretic, used in gargles, young leaves substituted for tea; fruit aperitive, used in calculous affections; the juice boiled made into wine.

*Grossularia, Uva crispa, Ribes grossularia, R. uva crispa. Berries, gooseberries, berries, used as sauce for mackerel and other fish; astringent, but when very ripe, laxative; make wine and vinegar; seeds washed and roasted, substituted for coffee.Ribes triste. Berry black, used to colour wines. $-R$. punctatum; $-R$. Alpinum; $-R$. fragrans; $-R$. viscosum $;-R$. macrobotrys; $-R$. albinervium. Fruit eaten.

\section{NOPALE E.}

Indian fig, Prickly pear, Cactus opuntia, Opuntia vulgaris. Fruit sweetish, diuretic; plants very cooling; juice contains a red colouring principle, which colours the urine of those that eat the fruit.-Cactus coccinillifer, Opuntia coccinillifer. The food of the grana fina cochineal.

Cactus ficus Indica, O. fic. Indica. The food of the grana sylvestria cochineal.

\section{TAMARISCINEE.}

*Tamarisc, Tamariscus, T. Gallica;-German tamarisk, Tamariscus Germanica;-T. Africana. Ashes contain sulphate of soda. A species of tamarisk affords Arabian manna.

\section{PARONYCHICE .}

*Sea chickweed, Arenaria, Polycarpon tetraphyllon. Herb applied to whitlows.

*Verticillate knot-grass, Corrigiola, Illecebrum verticillatum. Refrigerant and astringent.

*Rupture wont, Herniaria glabra. Rather saltish, astringent, diuretic; juice removes specks in the eye.

* Strap wort, Corrigiola littoralis. Herb cooling.

*Axpual knawei.i, German knot-grass, Scleranthus annuus. Diuretic, astringent, the vapour arising from a decoction of it is used in the toothach. 
*Perexwial Kxawel, Scleranthus peremis. Coccus Polonicus is found upon its roots.

Achryanthes aspera. Herb diuretic.

\section{PORTULACEA.}

Pursine, Portulaca, $P$. oleracea. Used as a potherb, cooling, useful in scurvy, heat of urine, and bilious disorders; seeds vermifuge.

Jamaica pursiane, Portulaca pilosa. In salads, diuretic; as also its expressed juice.

Telinum umbellatus. Flowers used as a cosinetic.

Claytonia perfoliata, $C$. Cubensis. Used both as a salad and a potherb.

\section{FICOIDEE.}

ICE PLANT, Mesembryanthemum crystallinum. Contains acetate of potash; like the other species of this genus it is very mucilaginous, and useful in inflammatory and bilious fevers.-M. edule. Esculent.-M. Copticum. Burned for barilla,-M. nodiflorum. Used in the preparation of Morocco leather; and burned for barilla.

'Гetragonia expansa, Demidovia tetragonoides. Antiscorbutic, cooling, used as a potherb.

Sestrium portulacastrus. Used as a potherb.

Reaumeria vermiculata. Exudes common salt mixed with saltpetre.

\section{ONAGRARIA.}

"Tree primrose, QEnothera biennis. Root cleanses foul ulcers, and is eaten in salads.

Rose-bay wrllow-herb, Persian willow, French willow, Epilobium angustifolium. Suckers eatable; an infusion of the plant intoxicates; down of the seeds, mixed with cotton or fur, has been woven or felted.

- Broad shooth-reaved willow-Herb, Epilobium montanum ; - Square-stalked willow-herb, E. tetragonum. And the foreign species are used to cleanse foul ulcers.

Jussieva Peruviana. Leaves emollient.

"Exchanters' vight-shade, Circaa Lutetiana. Resolvent, vulnerary; formerly supposed to possess wonderful properties in regard to magic and sorcery.

Water caltrops, Tribulus aquaticus, Trapa natans. Herb cooling: nuts, nuces aquatica, farinaceous and nourishing.

Escationia resinosa. Twigs covered with resin. 


\section{COMBRETACE TE.}

Bark generally astringent.

Terminalia chebula. Fruit, hurr nut, ink nut, chebulic myrobalans, Myrobalani chebuli. Galls, on the leaves, aldecay, excellent for dyeing.

Terminalia bellerica. Fruit, belleric myrobalans, myrobalani bellerici. Taken from 3 vj to 3 jss, are astringent.

Yellow myobatans, Myrobalani citrini; - Pickled myrobalans. The yellow myrobalans preserved in brine.

Indian BLACK Myrobalans, Myrobalani Indici. Fruits of the same genus of plants, but are rather purgative.

Varnish tree of China, Terminalia vernix. Produces the resin used in varnishing the Indian cabinets.-T. benzoe. Shrub milky, yields benzoin.

Apamaram, Terminalia catappa. Fruit, Indian almond, nourishing, used by the sick; yields an oil. The kernels of several other species are eaten.

\section{MYRTINEE.}

Are generally aromatic.

Guava tree, Bay plum, psidium pyriferum. Young leaves, buds, and fruit, in decoction, astringent: marmalade of the fruit the same.- $P$. pomiferum. Fruit esculent.

Ky a putty tree, Melaleuca leucodendron. Leaves yield an essential oil (cajeput oil).

Myrtis, Myrtus communis. Leaves odoriferous, cephalic, astringent; bark and leaves used in tanning: berries used in dyeing, and to form an extract; flowers and leaves yield an essential oil by distillation; and the berries a fixed oil, myrteum.

Musk MYRTLE, Myrtus ugni. Root used in dysentery; leaves used as tea.-M. luma. Berries used to make wine; leaves make a very cordial tea; root astringent.-M. cheken. Juice, from the green wood, used in glaucoma.

Alispice TRee, Myrtus pimenta. Fruit dried before it is thoroughly ripe, allspice, Jamaica pepper, clove pepper, Piper - Jamaicense, Pimenta, Pimentce bacce, Piper odoratum, P. caryophyllatum, is heating, aromatic ; used as a sauce, and in liqueurs; yields an essential oil. Lichen pustulatus may be used to reduce the ground spice.

Clove berRy treE, Myrtus caryophyllata. Bark, clove bark, canelle giroflée, Canella caryophyllata, Cassia caryophyllata, aromatic, cephalic; fruit, carpobalsamum, amomum, agree in 
qualities with cloves. - M. acris;-M. fragrans. Fruit aromatic, used for spice.

Clove tree, Eugenia caryophyllata. Flower buds of the tree before they open, dried and smoked, cloves, girofle Anglais, Caryophyllus aromaticus, Caryophylli, hot, stimulating, and aromatic, dose gr. $v$ to gr.x. Imported from the West Indies, in chests. An inferior kind, from Cayenne, girofle de Cayenne.-Preserved cloves are also imported.-The ripe fruit, mother cloves, fusses, antophylli, large, less aromatic.-Preserved mother cloves. Stomachic and antispasmodic. The footstalks, Griffes de girofe, used to flavour distilled spirit. Officinal preparations.-Infus. caryophyll., $D$. $L$. Infus. aurant. comp., $D$. Mist. ferri aromat., D. Vinum opii., L. D. Confect. aromatica, D. L. Electuarium scammonii, $D$. $L$.

Jasros. Eugenia jambos. Fruit eatable, aromatic.

Leptosperaus scoparium. Leaves used as tea.

Pomegranate tree, Punica granatum. Fruit, pomegranate, mala Punica, granata, very cooling, antibilious, astringent, cordial. Rind of the fruit, pomegranate peel, granati cortex, malacorium, astringent, detersive; vermifuge ; in powder, 3ss to $3 \mathrm{j}$, in infusion to 3 ss; used in tanning: from the south of Europe; double flowers of the wild trees, balaustic ; of the cultivated trees, cytini, tonic, astringent.

Syrring, Moch orange, Philadelphus coronarius. Flowers strong scented; leaves detersive, used as tea.

Alaxgium decapetalum; - A. hexapetalum. Roots aromatic, cathartic.

Lecyturs zabucago. Seeds, Brazil nuts, kernels eatable.

Robinsoxia Meliantufolia, Touroulin Guajanensis. Berry edible.

Browx GUM TREF, Eucalyptus resinifera, Metrosideros gummifera. Yields the brown gum or Botany-bay kino.-Eucalyptus Mialaccensis. Bark used in dysentery.

\section{MELAS'TOM 2 .}

Mfíastosia mirta. Leaves powdered used to sprinkle on ulcers; berries yield a juice like that of myrtle berries; also used for ulecrs.

Melastoma succosa;- M. alata. Juice used to wash wounds. The berries of various species of melastoma dye a black, which is very lasting, and are many of them eatable.

Tococa Guainnensis. Berries eatable.

122. SAI,ICARIEA.

-PURPLe-spikt.d Willow IIERB, Lysimachia purpurea spicata, 
Lythrum salicaria. Ophthalmic, astringent, used in the winter diarrhœas of northern countries; also as tea, and to make beer.

Henna, Lawsonia inermis. Used to colour the nails of females of a reddish colour.

Calyplectus acuminatus. Leaves bitter, affording a yellow dye.

Hanchrol, Ginoria ..... Juice, ziiij, is diaphoretic, diuretic, and cathartic: is used in syphilis.

\section{POMACEA.}

Fruit edible, but some require to become rotten ripe, as other. wise their astringency is too predominant.

Apple tree, Malus, Pyrus malus. Fruit of the wild crab, malus sylvestris, rough to the taste, contains an astringent principle, and much malic acid: fruit of the cultivated apple, malus, sweet, eatable.

RENNetT APPLE, poma renettia, C. P. the sort to be used in pharmacy.

Poma nivalis. Fruit, when ripe, extremely sweet.

*Pear tree, Pyrus, $P$. communis. Fruit, pear, pyrus, nearly the same as that of the apple, but becomes much sweeter by cultivation: yields sugar.

Quince tree, Cotonea, Cydonia, Pyrus cydonia. Fruit, quince, cydonia, rough, astringent, binding, very stomachic ; seeds, cydonice semina, very mucilaginous.

*White вEAM, Wild pear, Cratagus aria;-* Wild service tree, Sorb tree, Cratcegus torminalis. Fruit, wild service, sorb, sorbus, ripened upon straw until soft, eatable, astringent, useful in fluxes.

Azarole, Cratcegus azarolus. Fruit of a sharpish taste, saccharine, refreshing.

*Hawtrorn, White thorn, May, Spina alba, Cratcegus oxyacantha. Flowers odoriferous; fruit, haws, cenella, yields by fermentation a refreshing acidulous liquor.

*Dutch Medlar, Mespilus Germanica. Fruit extremely astringent, even when ripe; leaves and seeds used in detersive gargles.

BASTARD QUINCE, Mespilus cotoneaster;-Evergreen thorn, M. pyracantha. Fruits astringent.

* Service tree, Sorbus domestica. Fruit rough, very astringent, even when softened.

Mountain ash, Quicken, Roan, Fraxinus sylvestris, Sorbus aucuparia. Fruit astringent, dried and powdered makes a kind 
of bread; infusion acidulous ; seeds yield oil ; bark tans better than oak bark.

\section{ROSACEA.}

* Pale red rose bush, Rosa rubra P. L. Rosa pallida C. P. R. Gallica. Petals, flores rosarum rubrarum, rosce Gallice petala, less odoriferous than those of the Provins rose, powder $3 \mathrm{j}$ laxative. Officinal Preparations.-Mel. rosæ, D. L. Conserva rosæ, D. L. E Infus. rosæ, L. F. D.

*Dog rose bush, Wild briar, Cynorrhodon, Rosa canina. Root has been recommended in hydrophobia, a decoction of it used in dysentery ; fruit, hips, cynosbatos, lithontriptic, opening ; the pulp, rosce canince pulpa, makes a fine conserve; excrescences made by an insect, bedeguar, spongia rosce, used in calculous diseases; petals cathartic, used for jalap. Officinal preparation.Conserva rosæ caninæ, $L$.

* Rosa systyla;-R. arvensis. Hips fine flavoured.

*Sweet briar, Rosa eglanteria, $R$. rubiginosa. Leaves odoriferous; substituted for tea.

*Hundred-leaved rose, Rosa flore albo pleno, R. centifolia. Petals, flores rosarum allorum, rose centifolia petala, astringent, purgative, yield an odoriferous distilled water, and butter of roses. Officinal preparations.-Aqua rosæ, D. L. E. Syrup. rosæ, D. L.

* Evergreen rose, Rosa sempervirens. Petals musky, very purgative; used for distilling attar of roses.

White rose bush, Rosa alba vulgaris major, $R$. alba. Petals smell less agreeable than those of the hundred-leaf rose, more purgative.

Damask rose bush, Rosa moschata, R. Damascena. Petals, flores rosarum Damascenarum, pale red, good scent, more purgative than the other.

Provins rose, Rose de Provins, Rosa mubra, C. P. R. Provincialis. Petals deep red, scent powerful, which they preserve after drying; astringent, tonic, cephalic ; may be kept for a year or eighteen months, by being closely pressed together ; some prefer iron vessels for this purpose. -1 . mollissima. Fruit edible.

\section{SANGUISORBEE.}

-Ssall burnet, Pimpinella, Sanguisorba, Poterium sanguisorba. Used in salads; cordial.

-Agrimony, Eupatorium Gracorum, Agrimonia, A. eupatorium. Herb used in gargles; also as tea.

- Parsley plert, Aplianes arvensis. Diuretic.

"Ladirs' mantle, Bear's foot, Alchemilla vulgaris;-*Alpine 
ladies' mantle, A. Alpina. Very astringent, used in decoction as a bath to render women's breasts firm.

\section{POTENTILLEA.}

*Tormentin, Septfoil, Tormentilla, Hetaphyllum, Tormentilla erecta. Root, tormentilla radix, very astringent, febrifuge, and not stimulant; dose $Э \mathrm{j}$ to $Э \mathrm{ij}$.

*Cinq-Forl, Five-leaved grass, Pentaphyllum, Quinquefolium, Potentilla reptans. Bark of the root used as a gargle for loose teeth; leaves febrifuge, taken as tea.

*Wild tansie, Silver weed, Argentina, Potentilla anserina; - Hoary cinq-foil, Potentilla argentea;-*Purple marsh cinqfoil, Pentaphyllum rubrum palustre, Comarum palustre. Febrifuge; root of this last dyes a dirty red.

*Strawberry Plant, Fragaria, F. vesca. Róots aperitive; fruit, strawberries, cooling, opening, diuretic, dissolves the tartar off the teeth, diaphoretic, used in calculous gout and consumption.

*Barren strawberry, Fragaria sterilis. Root astringent; dyes red.

*Avens, Herb bennet, Caryophyllata, Geum uirbanum;*Water avens, Geum rivale. Roots scented like cloves, sudorific, tonic, antipodagric, stomachic, febrifuge ; may be substituted for bark: when young, they give a pleasant flavour to ale, and prevent it from growing sour.-Geum montanum. Root, pink root, imported from the south of Europe; used for the same purposes as avens.

* Raspberry busil, Rubus Idaus. Fruit, raspberry, hindberry, cooling, cordial, communicates a fine flavour to liqueurs: leaves form astringent and detersive gargles.

*Dewberry bush, Small bramble, Rubus casius. The same but sourish.

* Knotberry Bush, Chamamome, Rubus chamamorus. Fruit, cloudberry, knotberry, acerb, astringent, dyes a bluish purple; leaves and tops astringent.

* Blackberry bush, Bramble, Rubus vulgaris, $R$. fruticosus. Fruit, blackberry, rather acerb; eatable; but soon sickening; green twigs used in dyeing black; root used in chincough.

American DEWBerRY, Rubus trivialis;-American blackberry, Rubus villosus. Bark of the roots febrifuge, used for bark. lent.

*Stone bramble, Chamcerubus, Rubus saxatilis. Berry escu- 


\section{2\%. ULMARIE E.}

*Meadow sweet, Queen of the meadows, Ulmaria, Regina prati, Spircea ulmaria. Herb sudorific, astringent, antispasmodic; flowers give a fine flavour to warm water.

"Drop wontr, Filipendula. Spirca filipendula. Herb astringent, diuretic; roots dried and powdered, used for bread in famines.

SpIKEd willow, Spirca, S. salicifolia. Seed astringent.Hard hack, Spirca tomentosa. Root, spircea, P. U. S.

Amrrican ipecacuanira, Indian physic, Gillenia trifoliata, Spircea trifoliata. Bark of the root, Gillenia, P. U. S. gr. xx, enetic, tonic.

Mauritius ipecacuania, Sudia heterophylla. Bark emetic.

\section{AMYGDALE EE.}

Noet.A-Tali, Antidesma alexitera. Fruit cooling; leaves antiseptic.

Brasilletro, Psendo-brasilium, Picramnia triandra, P. antidesma. Wood used to dye red.

Lecania incana, Hedycroa;-Chrysobalanus purpurea;C. oblongifolius;-Icaco, C. icaco. Fruits eaten.

* Cinerri, Gee, Cerasus, Prumus cerasus. Many varieties; fruit, red cherries, cerasa rubra, cooling, nutritive, laxative; leaves used as tea in fevers. - Brantly cherries. Morello cherries preserved in brandy.

* Bird cherry, Iild cluster cherry, Cerasus avium, Prumus padus. Fruit, black cherries, cerasa nigra, astringent, nauseous, but gives an agreeable flavour to wine or brandy.

Sour cherri, Amarelle, Prumus cerasus acida. Fruit esculent, acidulous.

Perfumfo cherry-tree, Prunus mahaleb. Wood, Saint Lucie wood, odoriferous, sudorific; kernels, macanet grains, used to scent washballs.

Laur r.r., Laurocerasus, Prunus laurocerasus. Leaves have been used in cookery for those of the bay tree, but are less aromatic, and communicate the flavour of bitter almonds: as they contain Prussic acid, they act on the nervous system, and are dangeorus; distilled oil of the leaves poisonous to animals. Officinal preparatim.-A Aqua lauro-cerasi, $D$.

Whid cherry trex, Prunus Virginianu. Bark febrifuge; plum and leaves poisonous to many animals.-P'runus aspera Fruit edible. $-P$. hyemalis. Fruit acerb, edible in winter.

PluM, Prunus domestica. Many varieties; fruit laxative, 
French plums, pruna Gallica, black, acidulous, cooling, laxative, apt to purge.

Prunelloes; Imperial plums, pruna Brignoliensa. Yellow, not apt to purge.--Prunes, pruna Damascena, black, purgative.

Sloe tree, Black thorn, Prunus sylvestris, P. spinosa. Leaves substituted for tea; bark powdered, $3 \mathrm{ij}$ used in intermittent fevers ; flowers $z j$, infused in water or whey, are a pleasant purge; fruit, sloes, prina sylvestria, gives a pleasant flavour and red colour to wine; juice of the fruit stains linen of an indelible colour.

Apricock tree, Prunis Armeniaca. Fruit, apricocks, Arme. niaca mala, prcecocia, nourishing, laxative, febrile; seeds bitter, saponaceous.

Briançon apricocks, Armeniaca Brigantiaca. Fruit acid; kernels yield oil.

Pench tree, Nectarine, Amygdalus Persica. Leaves and flowers purgative; fruit, Persica mala, in hot countries, the same : wood used in dyeing, sold in chips and ground.

Dwarf almond, Amygdahis pumila. Flowers purgative.

Almond tree, Amygdalus communis. Kernels, sweet almonds, amygdala dulces, pectoral and cooling, but mawkish; imported from the south of Europe and the Barbary coast; Mogadore. Blanched almonds. Almonds thrown into boiling water until the skin comes off by pressing between the fingers, the hot water is then strained away, the almonds flung into cold water, peeled, and dried either in a stove or the sun until they are brittle.Burnt almonds; used to colour and flavour liqueurs. - Bitter almonds, amygdala amarce. A variety, imported from Mogadore, used to relieve the flavour of the sweet, and to clear muddy water; both pressed for oil.-Almond cake, amygdalce placenta, left on pressing the oil, used for washing the hands. Principal officinal preparations.-Amygd. dulces. Oleum amygd., and Conamygd. D. L. Mist. amygd. I).

Aquilaria ovata, Aloexylum agallochum. Wood, aloes wood, calambac, eagle wood, lignum aloes; white, buried for some time becomes dark and resinous, cordial, alexiterial; used in fumigations and pastilles.-Aghilcuttay, Lignum aspalathi. Reddish, resinous, added to sandal wood to increase its fragrancy.

Calycanthus floridus. Root emetic, seed poisonous.

\section{LEGUMINOSE.}

Egyptian thonn, Acacia, Mimosa Nilotica. Exudes white gum Arabic, juice of its pods is made into acacia vera.-Mimosa Senegal; - M. Farnesiana. Exudes gum. Principal officinal 
preparations.-Mucil. acaciæ, L. Emulsio Arab., D. Mist. cornu usti., $L$. Confectio amygd., $L$. D.

Mimosa catechu. Yields terra Japonica. Principal officinal preparations.-Infus. catechu comp., and tinct. catechu, $L$.

Coccoor, Mimosa scandens. Seeds eatable.

CAts' claw, Mimosa unguis cati. In decoction, diuretic.

Creeping and prickly sensitive plants, Mimosa . .... Roots cleaned and barked, about gr. xv, in red wine, used against poisons; leaves poisonous. - M. inga; $-M$. fagifolia ; $-M$. ferox. Seeds purgative, but eaten.

Mrmosa Natans. Eaten as a salad herb.

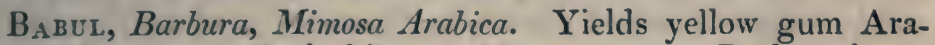
bic.-M. amara. Bark bitter.-M. saponaria. Bark makes a kind of suap.

Triple-thorned acacia, Gleditsia triacanthos. Seeds used to feed animals; sap yields sugar.

Санов тrfe, St. John's bread, Siliqua dulcis, Caroba, Ceratia, Ceratonia siliqua. Pod used as food for man and beast, and by singers to improve the voice.

Tamarivd, Tamarindus, T. Indica. Pulp acidulous, cooling, laxative; stones baked, soaked in water to get off the skins, and the kernels boiled or fried, used for food.

'Tamarixds in trie pod, Tamarindi fructus naturalis. From Egypt, in bags of six cwt. each.-RED TAMARINDs, Tamarindi rubri, Tamarindi proparati. The shells broken off, and syrup added to preserve the pulp.-BIACK TAMARINDS, Tamarindi nigri. The shell broken off, and salt added to preserve the pulp.Eastern Islands tamarinds. The shell broken off, and the pulp dried in the sun. Officinal preparations.-Infus. sennæ cum Tamarindis, D.E. Eleetuarium sennæ, D. E. L. Elect. cassia, D. E.

Scotra specioss, Guaiacum Afrum. Seeds eaten.

C.ıssia sтіск твеE, Cathartocarpus fistula, Cassia fistularis. Fruit, cassia fistula, two feet long, size of the thumb, imported from the West Indies; pulp purgative, cooling.

Horse cassis, Cassia Brasiliensis, C. mollis, C. Javanica. Pulp purgative, bitter.

Strnkrsc WeEd, Jamenira piss-a-berl, Cassia occidcntalis. Expressed juice used in eruptions; root diuretic.

Wfast Inda sexwa, Cissia emarginata. Pulp of the pods laxative; leaves purgative, used for senna.

American slinsa, Cassir Maryiandica. Leaves purgative.

Cassia oniextaris, C. acutifolice. Leaves, Mccca senna, pilgrim senna, senun, senna. Alexandrina, senna folia, lanceolate, equal sided, with glands above the basc of the petiole, $\exists j$ to $3 \mathbf{j}$, or in 
infusion, purgative, nauseous and apt to gripe, best corrected with ginger or coriander seeds. The leaves of Cynanche arguel, and Coriaria myrtifolia are mixed with senna; the leaves of Pleriploca Græca, Globularia alypum, of several other species of Cassia and of Colutea, and those of Coronilla emerus, are substituted for senna: pods, sennce folliculi, less purgative than the leaves, but also less bitter, and seldom gripe. Officinal preparations.-Iinct. sennæ comp. $D$. Electuarium sennæ, D. E. Confectio sennæ, $L$. Infus. sennæ, L. $E$. Infus. sennæ comp. $D$. Pulv. sennæ comp. $L$.

Cassia absus. Leaves reverse ovate, two awl-shape glands at the base of the petiole; mixed with those of the preceding plant : seeds, tschischim semina, applied with sugar to the eyes in the Egyptian ophthalmia.

Cassia senna. Leaves, Italian senna, Coromandel scnna, country senna, nearly ovate, petiole not glandular, more nauseous and less active than the Alexandrian: used in the East Indies for senna.

Cassia lanceorata. Leaves, Mocho senna, East Indian senna, senna Arabica, very long, lanceolate, equal sided, smell weak. -Cassia . . . Leaves, Tripoli senna, senna Tripolitana, large, blunt, rough, darkish green.

Cane-piece sensitive plant, Cassia chamcecrista. Used against the poison of nightshade.-C. alata. Flowers used to cure tetters.

Ringworm bush, Cassia herpetica. Bruised leaves and expressed juice used against itch, tetters, and ringworms.

Smooth вonduc tree, Guilandina moringa, Hyperanthera moringa, Moringa Zeylanica, M. oleifera. Root, moorunghy root, East Indian country horse-radish, acrid, used as a sauce: wood, lignum nephriticum, diuretic, used for dyeing blue; nuts, ben nuts, pois queniques, nuces behen, balanus myrepsica, glans unguentaria, yield oil by pressure; pods, leaves, and flowers, eaten as potherbs.

Yellow mickar tree, Guilandina bonduc. Nuts, yellow nickars, astringent, used in gonorrhœa, yaws, and convulsions.

Grey nickar tree, Guilandina bonducella. Nuts, grey nickars, pressed for oil.

Gullandina sappan, Casalpinia sappan. Wood, Chappungham wood, Sappan, bois d'Inde, bresillet des Indes. - From the East Indies; used to dye red, scentless.

Logwood treE, Hcmatoxylon Campechianum. Exudes a gum: wood, logwood, lignum Campechense, hamatoxyli lignum, in large logs, without any bark, solid, inside pale reddish brown, sweetish; astringent $\mathrm{Bj}$ to $3 \mathrm{j}$, used to dye red or purple.

asAlipINIA CRIsta. Wood, Brazil wood, ligmum Brasiliense, 
very hard, sinks in water, pale when fresh cut, but turns nearly black by exposure to air; used to dye red, and for ink; from South America,-Casalpinia Brasiliensis, C. Bahamensis. Wood, Bahama brazilletto, used to dye red, gives a deep colour to water. -C. echinata. Wood, Nicaragua wood, bresil de St. Marthe, stockrisch hout, in short logs with a thin bark, much split, very hard and heavy, smells like salt fish; used to dye red.- $C$. vesicaria, C. bijuga, Poinciana bijuga. Wood, bastard Nicaragua wood, brown, dyes red; from Jamaica. - C. corinria. Pods, libidibi, used in tanning.

Barbadoes flower fence, Barbadoes pride, Spanish carnations, Casalpinia putcherrima, Poinciana pulcherrima. Tea of the leaves and flowers, and syrup of the flowers, purgative, and cmmenagogue; also the seeds in powder, dose $3 \mathrm{j}$, in common use with the negro slave girls to procure abortion.

Butea frondosa. Yields, by incision, gummi rubrum astringens.

Adenanthera pavonia. Wood substituted for red sanders.

Lotus courbaril, Hymenia courbaril. Exudes gum anime, pods contain an acidulous nutritive farina.

Podalyia tinctoria. Root dyes black.

JUDAS TREE, Cercis siliquastrum. Flowèrs piquant, antiscorbutic, in salads.

Stinking bean trefoll, Anagyris foetida. Leaves emmenagogue, cephalic; seeds emetic.

*Furze, Whins, Gorse, Genista spinosa, Ulex Europæus. Plant attenuant, diuretic, determining to the skin, occasioning nausea.

Canary rose wood, Genista Canariensis. Root, lignum rhodium, ycllowish, with red veins, has the scent of roses: used for fumigation, is cordial and cephalic.

"Dyeis' вroom, Green weed. Wood waxen, Sereque, Genista tinctoria. Flowers and leaves aperitive, diuretic; used to dye yellow.

Genista ovata, used to dye yellow.

Spartium purgans. Leaves and seeds purgative.

- Bвоом, Gmista, Spartium scoparium. 'Tops, spartii cacumina, diuretic, even to animals who browse on them; flowers used as a pickle for the table; seeds emetic, cathartic ; roasted and used as coffee. Officinal preparation.-Extract. scoparii, $D$.

Siaxisn вroor, Spartium junceum. Qualities the same as common broom.

T'REFoll ACACIA, Aspalathus, Spartium spinosum. Yields Italian acacia. 
Laburnum, Cytisus laburnum. Leaves diuretic, resolvent.C. cajan. Seeds, pigeon pea, Angola pea, orror, used as food, strong tasted; young shoots pectoral ; roots aromatic.

Hairy shrub-trefoll, Pseudo-cytisus, Cytisus hirsutus. Leaves cooling, diuretic.

White LuPINE, lupinus, L. albus. Seeds rather bitter, emmenagogue, vermifuge ; used as food, and externally in resolvent poultices.

WrLd LUPINe, Lupinus sylvestris, L. varius. Seeds bitterish, but nutritive.

*Rest-hakrow, Cammock, Petty whin, Ononis, Anonis, Resta bovis, Ononis spinosa. Root diuretic, detersive, aperient; used in decoction.

Arachis Hy Pogra. Seeds, earth peas, pindars, ground nuts, nourishing; yield oil, made into chocolate; root sweet.

* Kidney vetch, Anthyllis vulneraria;-Dalea enneaphylla. Dye yellow.

Paraguay tea, Psoralia glandulosa. Leaves stomachic, vulnerary, vermifuge.

Strnking treforl, Trifolium bituminosum, Psoralia bituminosa. Leaves diuretic, anticancerous; seeds yield oil.- $P$. pentaphylla. Root, Spanish contrayerva. contrayerva, slightly aromatic, taste sharp, used in typhoid fevers.

Mountain Lrquorice, Alpine trefoil, Trifolium Alpinum. Root sweet.

*Hare's foot, Lagopus, Pes leporinus, Trifolium arvense. Leaves pectoral, antidysenteric.

Field treforl, Lotus urbana, Trifolium odoratum, T. caruleum. Herb diuretic, vulnerary, anodyne.

*Common treforl, Trifolium, Lotus herba sylvestris, T.pratense. Herb laxative.

*Melilot, Melilotus, Trifolium melilotus officinalc. Herb pectoral, discussive, causes the peculiar flavour of the schab-ziger, or scraped cheese of Germany.

Itamian melilot, Melilotus vera, Trifolium melilotus Italica. Herb suppurative.

*Lucerne, Medicago sativa. Seeds dye yellow.

* Lrttale yellow treforl, Melilot trefoil, Trifolium luteum minimum, Medicago lupulina. Herb lenifying.

Sea kidey veтch, Anthyllis, Medicago circinata. Herb used in dysury.

Fenugreek, Maytee, Fonum Gracum, Trigonella foenum 
Grecum. Seed odoriferous, mucous, resolvent, stomachic, roasted for coffee; dye yellow.

Pile rotus, Trifolium hemorrhoidale, Lotus hirsutus;-Ihite lotus, Lotus dorycnium. Seerds useful in piles.

*Yellow lotus, Lotus corniculata. Anodyne, emollient; used in burns: leares turn green in drying.

Black Eerptian bean, Lablab, Dolichos lablab. Șeeds nutritive.

Dolichos pruriens. Pods, siliqua hirsuta, eaten when young, imported from the West Indies; the hair of the pods, corchage, dolichi pubes, occasions violent itching, to be allayed by a solution of green vitriol or oil; vermifuge, by scraping the hair off a pod into treacle or syrup for a morning dose, and giving a brisk purge after two or three doses of the cowhage; root, in decoction, diuretic, and very useful in dropsy.

Barвatr, Dolichos catjang; $-D$. soya. Seeds used to make soy, eaten in soup.

Cooltri, Dolichos biflorus;-D. Sinensis. Seeds eaten. $-D$. tuberosus;-D. bulbosus. Roots eatable.

Frescil bean, Kidney bean, Fève de Rome, Haricot, Phaseolus vulgaris;-Scarlet bean, Phaseolus coccineus;-Dwarf hidney berin, $P$. namus. Pods eatable, nourishing; flour of the seed emollient, diuretic, nourishing.

Mexco, Halli moog, Phaseolus mungo. Seeds made into sago. -P. tuberosis. Root esculent.

Vellore Bean, Duffin bean, Phaseolus lunatus;-East India country bean, a variety;-Soria moog, $P$. aureus;-Krishna moog, $P$. max ;-Mash cally, $P$. racliatus;-Moot, $P$. aconitifolius;- $P$. Tunkinensis. Seeds eaten as pulse.

Eryturisa monosplera. Yiclds a kind of lac.

Gr.ycive apios, Apios tuberosa. Root farinaceous.

Grycine abisus, Abrus precatorine. Root, Jamaica wild liquorice, yields an extract like liquorice; herb diaphoretic, pectoral, demulcent; seeds, jumble beads, sold at the china shops, ophthalmic, cephalic.

Dog Wood, Piscidia erytherince. Bark of the root thrown into ponds, or still water, stupifies the larger fish, without rendering them unwholesome, and kills the smaller ones; used to cleanse foul ulcers.

robina caracana. Seeds oleaginous, catable.

Astragateus Creticus;- $A$. gummifer. Exude gum tragaeantl. 
Milk vetcr, Astragalus, A. Syriacus. Root astringent, diuretic。

*Wild Liquorice, Liquorice vetch, Astragalus glycyphyllos. Root sweet, used for liquorice; leaves used in retention of urine.

Bladder senna, Colutea cruenta;-C. arborescens. Leaves and pods purgative, used for senna.

Liquorice, Glycyrrhiza, G. glabra. Root, stick liquorice, liquiritia, glycyrrhize radix, sweet, opening, expectorant, pectoral, diuretic; chewed, it extinguishes thirst; its infusion covers the taste of unpalatable drugs more effectually than sugar: 1 s. $8 d$. the $1 \mathrm{~b}$.; ground, $2 s$. $8 d$.

Prickly liquorice, Glycyrrhiza echinata. Root sweet, juice is used in tetters and ringworms.

GoATs rUE, Galega, Ruta capraria, Glycyrrhiza officinalis. Sudorific, vermifuge, alexiterial, useful in epilepsy and convulsions.-G. piscatoria; G. tinctoria. Intoxicates fish.

INDigo PI.ANT, Anil, Indigofera tinctoria, and several other species, yield indigo.

TuBERous vetch, Lathyrus tuberosus. Root tuberous, sweet, yields fecule; they are sold for salep roots.

CHICK PEA, Keessari, Lathyrus sativus. Seeds nutritive.

*Verch, Vicia, $V$ : sativa. Seeds, tare, detersive, astringent. The Canadian variety makes good bread.

Vicia FABA. Seeds, garden bean, faba major, nourishing, difficult of digestion, flatulent.-Vicia faba $\beta$. Seeds, horse bean, faba minor, f. equina, nourishing, roasted for coffee.

*Bastard vetch, Orobus sylvaticus;-O. luteus;-O. vernus; -O. niger. Seeds yield a resolvent farina.

* Bitter vetch, Heath pea, Orobus, Ervum, O. tuberosus. Roots nutritive; farina of the seed resolvent.

Ervum Lens. Seeds, lentil, lens vulgaris, mussoor, difficult of digestion, astringent, hurtful to the eyes.

Ervom envilia. Farina maturative and resolvent.

PeA, Motor, Pisum, P. sativum. Green pods used in the scurvy: fresh seeds saccharine, nutritive; dry seeds heavy and flatulent.

CHick peA, Cicer, C. arietinum. Seeds, calavanches, bhoot, horse gram; heavy, but wholesome, roasted for coffee ; farina resolvent.

Milk vetch, Polygala vera, Coronilla juncea. Herb in decoction increases the milk.

*SMall BIRDS-Foot, Ornithopus perpusitlus. Herb lithontriptic, and used in ruptures. 
Scorpion wort, Scorpioides, Ornithopus scorpioides. Herb stimulant, applied externally to bites of venomous animals.

*Horseshor vetch, Ferrum equinum comosum, Hippocrepis comosa :-Scorpion sema, Coronilla emerus. Leaves purgative; used instead of senna by the country people.

Securidaca, Coronilla securidaca. Seed extremely bitter, purgative.-C. varia. Juice emetic.

* Sainforn, Cochshead, Onobrychis, Hedlysarnom onobrychis. Herb ripening, discussive, useful in strangury.

Alhagr, Hedysarum alhagi. Yields Persian manna.

Sesban, Aschinomene sesban. Seeds stomachic, cmmenagogue.

Bastard sensitive-plant, Aischinomene grandiflora. Seeds catable; yield gum agaty; used in dyeing.

Cabbage tree, Worm-bark tree, Geoffroea inermis;-G. Surinamensis. Barks bitter, astringent, febrifuge, and vermifuge, in doses of $\mathrm{Yj}$ to $\mathrm{3j}$; but the dose should be less at first, and gradually increased, 1 est it should occasion vomiting, delirium, and fever: gr. xv, with as much jalap, a good purgative; or $\overline{3}$ jss, boiled in water, dose coch. maj. ij-iv, omni mane, for three or four days, and afterwards a dose of oil.

Pterocarieus santalinus. Wood, red sanders, bresille, rood caliatour hout, santalum rubrum, pterocarpi.lignum, resinous, odoriferous, austere, astringent, tonic: used as a red colouring ingrcdient in spirituous tinctures, yields a rosin analogous to dragon's blood.-Pterocarpus draco;-P. Indicus. Yield dragon's blood. -P. dahlbergioides. Wood, Andaman red wood, rood.hout, used in dyeing. - P. erinaceus. Yields common gum kino.

Copaifera officinalis. Yields balsam of copaiba.

Original Jesuit's bark tree, Kina kina, Myrospermum pedicellatum, Myroxylon pedicellatum. The first kind of Peruvian bark brought to Europe; speckled on the outside, resinous when held to the sun, odoriferous, not so bitter or astringent as the present sorts from the Loxa tree; yields a rosin.

Mrrospersum penuifenum, Myroxylon peruiferum, Toluifera. bulsamum. Yields, by incision, balsam of Peru and balsam of 'Tolu.

Dipterix odorata, Coumarouna odorata, Baryosma tonga. Kernel, Tonca bean, odoriferous, used to scent snuff; contains coumarine, which exudes between the lobes.

DERRIS PINSATA. Root used for areca nut.

Stizolobium uRens. Legume irritating; hairs of the pods of all the species are used as anthelmintics; powdered seeds are applied externally as an antidote against the stings of insects and reptiles. 
Prosopis spicigera. Pod esculent.

Tespesia? Cercis? Wood, cam wood, red wood, bois de cham, pao gaban, red, with black veins, more porous, lighter, and smoother than either logwood, brasilletto, or Nicaragua wood; from Africa.

\section{POLYGALEE.}

*Mrlx wort, Polygala vulgaris;-P. amara;-P. sanguinea; - Bitter polygala, P. rubella. Roots may be substituted for rattlesnake root, dose in powder is 3 ss to $3 \mathrm{j}$, useful in pleurisy; herbs bitter, diaphoretic, in infusion 3 iiij taken daily, promote expectoration, and are used in catarrhous coughs.

Polygala senega. Root, rattlesnake root, Scneka snake root, senega, senegce radix, diaphoretic, diuretic, used in America against the bite of the rattlesnake, either in powder $\mathrm{Oi}_{\mathrm{i}}$ to $\mathrm{ij}$, or $3 \mathrm{j}$ boiled in $\mathrm{lb}$. jss of water to $\mathrm{lb} . \mathrm{j}$, and given by $3 \mathrm{ij}$ at a time; from North America. Black snake root is used for it. Officinal preparation. -Decoctum senegæ, D. E.

Polygala theezans. Mixed with tea in Japan.

Krameria Ixina; $-K$. triandra. Root, ratany, rhatania, Krameria radix, astringent and tonic.

\section{TEREBINTACEAE.}

Cashew-nut tree, Cassuvium occidentale, Anacardium occidentale. Peduncle of the nut astringent, eatable; juice astringent, made into a kind of wine; kernel of the nut aphrodisiac, used to increase the memory, as also to quicken the genius; shell of the nut contains an acrid oil : exudes gum.

Malacca bean tree, Anacardium orientale, Semecarpus anacardium. Nut, Malacca bean, boiled for the oil, contain a caustic, black, oily mucilage, and then a sweet white kernel, which is cephalic, and increases the memory; the mucilage is used externally in disorders of the skin ; green fruit used for marking, eatable.

Mangoe, Mangifera Indica. Fruit eaten raw;-Pickled mangoes. Used as sauce;--Preserved mangoes. The fruits peeled, and pressed into sheets like brown paper.

Sumach, Rhus obsoniorum, $R$. coriaria. Bark, leaves, flowers, and fruits acidulous, very astringent; shoots and leaves imported and sold ground, for dyeing.

Venice sumacir, Red sumach, Rhus cotinus. Equally astringent; wood, young fustick, yellow, dyes coffee-colour, and with nitromuriate of tin an orange; fruit, sumach berries, astringent.

Porson oak, Rhus toxicodendron. Juice caustic, dyes linen, \&c., black, raises blisters on the skin, and is poisonous taken 
internally ; leaves, toxicodendron, P.U.S. toxicodendrifolia, stimulant, narcotic, used in palsy ; dose gr. ss to gr. iv, twice or thrice a-day.

Common Pennsyluanian sumach, Rhus glabrum. Bark febrifuge, used in dyeing red.-Rhus copallinum. Yields West India copal.-R. vernix. Yields, by incision, Japanese varnish ; milky juice dyes linen, \&c., black.

Virginian sumach, Rhus Virginianum, R. typhinum. Berries astringent, used in fluxes of different kinds; juice of the stem raises blisters on the skin.

Hog guar treE, Rhus metopium. Yields hog gum.-R. Javanicum. Berries boiled in water yield rosin. $-R$. striatum. Juice of the bark yields a black colour. $-R$. radicans. Juice vesicatory.

Mrrten-Leaved sumach, Coriaria myrtifotia. Leaves used in tanning and dyeing the same as sumach ; mixed with senna.

Wrdow warl, Cneorum tricoccum. Acrid, caustic, drastic, a powerful detersive, but dangerous.

Comocladia nentata. Wood, bastard brasil, dark red, dyes like Brasil wood; juice dyes the skin of a nearly indelible black colour.-Comocladia angulosa. Wood, Saint Domingo braziletto, used in dyeing.-C. illicifolia. Juice dyes the skin black.

Balm of Gilead tree, Amyris Gileadensis, $A$. opobalsamum. Yields, by incision, the true balm of Gilead in very small quantities, generally at the rate of three or four drops a-day from a branch; even the most resinous trees not yielding more than sixty, whence arises its value: fruit, carpobalsamum, and branches, xylolalsamum, vulnerary, antiseptic, and used against barrenness.

Amyris elemifera. Yields, by incision, gum elemi; wood, bois de chandclle noir, split in laths, and burned for lights.

Amyris balsamifeica. Wood, Jamaica rose wood, lignum rhodium, used in eephalic fumigations, burning with a scent of roses; leaves, in infusion, diaphoretic, aromatic, cephalic ; berries used for balsam of capivi. From undescribed trees of this genus, Amyris, are produced true or male frankincense, myrrh, opocalpasum, bdellium, and liquid myrrh.

A MYrIS TOXIFErA. Yields a rosin used as a poison in war and hunting, which is, perhaps, that called ticuna.- $A$. ambrosiace. Yiclds coumia.- $A$. proteum. Shells of the fruit yield an essential oil.-A. acuchina, Icica acuchina. Yields balsam acouchi.

ICICA HF.PTAPUYLIA. Yiclds woorali poison, and, according to some, gum elenii.

Mrrodendrum houmiri. Yields balsam houmiri; bark resinous. 
Canarium balsamiferum. Yields a kind of incense.- $C$. commune. Nuts, Java almonds, eaten, and made into bread; kernels yield an oil.

Schinus Molle. Yields Peruvian mastich : wood purgative, detersive, astringent : fruits make a kind of wine, rather acrid, soon turning into vinegar.

Pistachia, $P$. vera. Kernel oily, sweeter than those of almonds, forms a green emulsion, cooling.

Turpentine tree, Pistachia terebinthus. Yields, by incision, Scio turpentine; fruit styptic, pickled for eating; bark resinous, substituted for narcaphte.

Mastich tree, Lentiscus vulgaris, Pistachia lentiscus. Yields, by incision, mastich ; berries yield oil; wood used in dyspeptic affections, gout, and dysentery.- $P$. Atlantica. Yields Barbary mastich; fruit acidulous.-P. trifolia. Fruit eatable.

JAMAICA BIRCH TREe, Bursera gummifera. Yields resina chibou; bark has the qualities of simarouba; root astringent.Bursera orientalis. Also yields a tonic styptic resin.

Spondias citherea. Fruit acid, cooling.

Moмвгn, Spondius myrobalanus. Yields rosin; fruit acerb, acidulous, laxative.

Hog puUm, Spondius entra. Bark, externally, as a fomentation in anasarca. -Otaheite apple, S. dulcis. Fruit edible.

False angostura, Wooginoos, Brucea antidysenterica, B. fermuginea. Inner bark astringent; used to make brucine.

Aver rhoa carambola;-A.bilimbi;-A. acidissima. Fruits acid, made into preserves with sugar.

Boswellia serrata, Libanus thurifera. Yields olibanum.B. glabra. Exudes koondricum, and, by incision, yields gugul.

\section{JUGLANDEAE.}

WALnut, Juglans, J. regia. Sap yields sugar; kernels of the seeds cooling, but are difficult of digestion; when old, acrid; yields half their weight of oil by expression; peel of the fruit used in dyeing brown colours; leaves detersive, diaphoretic, antiarthritic, anti-syphilitic; inner bark emetic, and also cathartic when given in pills; spongy substance inside the nut astringent.

American hiccory, Juglans alba. Bark, green leaves, and rind of the fruit used in dyeing, with alum, a bright yellow colour.

Pennysylvania walnut, Butter nut, Juglans cinerea. Inner bark of the root, juglans, P. U. S. cathartic, and used against worms. 


\section{PITTOSPORE E.}

Pittospones tobira. Seeds surrounded by a kind of resinous birdlime.

? Billardiera scandens. Flesh of the berry eatable.

136. CELASTRINE E.

Blander nut-tree, Staphylea trifolia. Kernels eaten.

*SPINDle tree, Prick wood, Fusain, Evonymus Europœus. Seeds, three or four, emetic and purgative; externally used as a powder to kill lice, \&c.; wood makes good charcoal; fruits dye a yellowish red or rusty colour.

Celastrus macrocarpus. Seeds oily.-C. maytenus. Decoction of the young twigs used as a wash, in the swellings produced by the shadow of the tree called lithi.

\section{3\%. ILICIDE E.}

Cassine Peragua, Ilex vomitaria. Leaves, Paraguay tea, diuretic in infusion, and diminish hunger; but if too much is used, emetic ; an infusion of the high-dried leaves is drank as an exhilarant.

"Holty, Ilex, I. aquifolium. Root, bark, berries acrid, purgative, and externally used emollient and resolvent; berries roasted used for coffee; bark yields birdlime.

\section{FRANGULACE压.}

- Buck thors, Spina cervina, Rhamnus catharticus. Berries, rhamni bacce, no. $\mathrm{xx}$, or $3 \mathrm{jss}$, when dried, very purgative, usually made into a syrup; juice made into sap-green; bark dyes yellow; inner bark is cathartic.

Rinames infectorius. Berries purgative; unripe berries, dried, French berrics, grana Avenionensia, dye yellow.-Turkey berries, preferred by the dyers, are a larger variety.

Rhamnus theezans. Leaves used to reduce tea.

"Black alder tree, Alnus nigra, Frangula, Rhamnus frangula. Unripe berries used to make sap-green ; ripe berries purgative; bark bitter, emetic, detersive, aperitive, and dyes yellow; bark of the root violently purgative; wood, black dog wood, makes the best charcoal for gunpowder.

Evergregn PRivet, Rhammus alatemus. Some sap-green is made from it; laxative.

JUJEBE, тHEE, Rhamnus ziziphus. Fruit, jujubes, jujuo®, nourishing, mawkish, mucilaginous, pectoral. 
Lotus, Rhamnus lotus. Fruit eatable, makes a pleasant wine. -R. jujuba. Fruit styptic. - R. soporifera. Fruit anodyne, soporific; used in decoction, $-R$. paliums. Seeds diuretic ; root and leaves astringent, detersive; fruit incisive.- $R$. Siculus, Elceodendrum argan. Nuts pressed for their oil.

Great jujubes, Anoplia, Rhamnus onoplia. Unripe fruit stomachic, astringent; juice of the ripe fruit laxative.

Black ram thonN, Rhamnus niger, R. lycioides. Fruit, in decoction, relieves the pain of the gout.- $R$. sanguineus. Bark, boiled in milk, used for the itch.

Hovenia dulcis. Peduncle fleshy, sweet tasted, esculent.

New Jersey tea, Ceanothus Americanus. Leaves used for tea.

Apalachian tea, Prinos glaber. Leaves used as tea.

Black alder, Prinos verticillatus. Bark, prinos, P. U. S., febrifuge.

? Aristotelia macqui, $A$. glandulosa. Fruit eaten with sugar, or rubbed down with water for a drink.

\section{BERBERIDE $A$.}

*Berberis Oxycantha, B. vulgaris. Berries, berberries, pipperidges, very acid, incisive, astringent, hepatic; bark useful in jaundice as an aperitive; root very bitter: root, wood, and bark give wool a yellow colour destructible by air and soap.

*Alpine barren wort, Epimedium Alpinum. Roots and leaves astringent.

Black turnip, Leontopetalon, Leontice leontopetalon. Root stomachic.

RED TURNip, Chrysogonum, Leontice chrysogonum. Root stomachic.

\section{NYMPHEACE $A$.}

*Yellow water IILY, Nymphcea lutea. Root astringent, contains a quantity of fecula.

*White water-Lily, Nymphcea alba. Root astringent, refrigerant; a weak infusion useful in leprosy, dose a pint night and morning.

Egyptian bean, Jamaica water-lily, Faba Agyptiaca, Nymphæa nelumbo, Nelumbium speciosum. Root used as food; liquor that runs out of the footstalk when cut, used in loosenesses and vomitings, also diuretic and cooling; seeds nutritive; bark is said to form Chinese rice paper, others ascribe it to artocarpus jaca. 


\section{PAPAVERACE}

*White poppy, Papaver album, P. somniferum. Seeds, mav seed, put into cakes, used in emulsions, better tasted than almonds, yield oil; capsules without the seed, poppy heads, papaveris capsula, used in anodyne fomentations; yields, by incision, the best opium, and, by expression, a coarser sort: cultivated by the Lincolnshire cottagers, for the purpose of distilling a narcotic water from the flowers. Officinal preparations.-The principal are, Extractum opii aquosum, D. L. Tinctura opii, D.E. L. Tinct. opii camph. D. L. Acetum opii and vinum opii D. Pulv. ipecac. comp. D. E. $L$. Pulv. cornu usti cum opio., $L$. Pulv. cretæ comp. cum opio, D. L. Confectio opii, $L$. Emplastrum opii.

Black Poppy, Papaver nigrum. A variety of the last.

* Red poppr, Com rose, Papaver mubrum, Rhoeas, P. erraticum, $P$. rhoeas. Petals, rhocados petala, pectoral, slightly anodyne; used also as a red colouring ingredient in medicines.

*Loxg-headed bastard pOPpy, Argemone capitulo longiori, Papaver argemone. I.eaves used outwardly in inflammations; the yellow expressed juice takes off spots on the cornea.

Jamaica Yellow thistle, Argemone Mexicana. Juice and leaves used in ophthalmia ; seeds emetic, yield an oil.

"Yendow horned poppy, Chelidonium glaucum. Seeds and juice analogous to the preceding.

"Great celandine, Chelidonium majus. Root detersive, acrid, purgative; herb ophthalmic.

Blood root, Puccoon, Sanguinaria Cunadensis. Juice blood red, gr. $\mathrm{vx}$ to $\mathrm{xx}$, used in dyeing; fruit narcotic; root, sanguinaria, P. U.S. emetic, purgative.

MaY aPple, Podophyllum pedatum. Root, podophylhum, P. U. S. purgative.-Bocconia frutescens. Juice red, used in dyeing.

JEFFERSONIA DIPHYLLA. Root purgative.

\section{FUMARIDEE.}

"Fusitony, Fumaria officinalis; - * Bulbous-rooted fumitory, F. Inellosa, F. solida ;- Yellow fumitory, I'. lutea. Very opening, refreshing: of use in cutaneous disorders, boiled in milk; or their expressed juice, taken daily to $\overline{3} \mathrm{ij}$, twice a day ; infusion removes freckles and clears the skin; dyes yellow.

Horned wit. cemix, Hypecoon, Hypecoum procumbens; CODDED WILD cUsin, Cuminum soliquosum, Hypecoon pendulum. Narcotic ; yields cumin opium, 


\section{CRUCIFERA.}

Contain azote (nitrogen) in their composition, and therefore easily putrify and furnish volatile alkali by distillation; they are generally stimulant, but when dried lose their antiscorbutic quality; seeds soon lose their vitality, unless kept moist in a cool place: these plants are always the first that are attacked by insects, and soon destroyed by them when kept in a hortus siccus.

*Wild MUSTARD, Charlock, Rhaphanus rhaphanistrum;RADIsH, Raphanus hortensis, $R$. sativus. Aperitive, diuretic, and excite the appetite; seed attenuant, pressed for oil.

*Mustard, Sinapi, Sinapis nigra. Seeds, sinapis semina, unbruised, coch. maj.j, stimulant, and generally laxative, cure vernal agues : farina of the seeds used as a rubefacient, and as seasoning; when mixed with water or vinegar has a bitter flavour, which, after some time, goes off : hull of the seed sold for ground pepper, under the name of P.D. i. e. pepper dust, and pressed for oil.

*White mustard, Sinapi album, Sinapis alba. Seeds ground for mustard, but is not so stimulant.

*Yellow charlock, Sinapis arvensis. Seed detersive and digestive; when given to birds instead of rape, heats and kills them ; ground for mustard, but its flavour is inferior.

Sersoon,"Sinapis dichotoma;-Rai, S. ramosa;-Sheta sersha, S. glauca;-Chinese mustard, S. Sinensis;-Tori, S. . . . . . . Seeds pressed for oil.

*Cole wort, Cabbage, Cauliflower, Brocoli, \&c. \&c. Brassica, Caulis, B. oleracea. Afford a copious source of aliment to man and beast; juice a good pectoral, discussive, diuretic, and opens the belly; leaves vulnerary, opening.

* Red cabBage, Brassica oleracea rubra. Leaves used to make a test liquor for acids and alkalies.-Pickled red cabbage. The leaves sliced and preserved with vinegar and spices, used as a sauce.

Saur kraut, Brassica acidulata. Large white cabbages cut into thin horizontal slices, and placed in a barrel with a layer of salt at top and bottom, and between each layer of cabbages. A board with some weights on it is then put on the top, and it is kept in a cool place for some weeks : a kind of fermentation takes place, and vinegar is formed. Some add juniper berries, coriander seeds, tops of anise, or caraway seeds to the salt as a kind of spice. It may be dried in an oven without any loss of its flavour.

*Turnip, Rapum, Brassica rapa. Root nourishing. 
Navetre de Dauphine, Brassica rapa oleifera. Seeds pressed for the oil.

- "Narew, French turnip, Napus dulcis, Brassica napus. Roots nourishing, containing a sweet juice, which is very pectoral, and of great use in coughs, asthma, colds, and consumptions.

${ }^{*} \mathrm{R}_{\mathrm{APE}}$, Cole, Navette dhiver, Colsa d'hiver, Napus sylvestris, Brassica napus oleifera; -Navette de printems, Colsa de printems, Brassica campestris oleifera. Seeds pressed for their oil.

Rоскет, Eruca, Brassica eruca ;-Wild rocket, Eruca sylvestris, Brassica erncastrum. Antiscorbutic, diuretic, flatulent, seeds acrid, stimulant, exciting the appetite.

*Tower mustard, Turritis hirsuta;-Bastard tower mustard, Arabis turrita. Juices kill worms, and cures the thrush.

Dames viou et, Rocket, Hesperis matronalis. Incisive; used in dysury, strangury, and dyspnœa.

* iVall flower, Cheiri, Leucojum luteum, Cheiranthus cheiri. Flowers cordial, emmenagogue, used in palsy.

Stock gildiflower, Leucojum album, Cheiranthus incanus. Flowers used in inflammation, and to cleanse ulcers.

Treacle worm-Seev, Camelina, Erysimum cheiranthoides. Herb vermifuge, stomachic.

Broad-LeAved hedge-Mustard. Erysimum latifolium, Sisymbrium irio. Herb used as a heating potherb.

"Hedge mustard, Erysimum, Erysimum officinale;-“-Jack by the hedge, Sauce alone, Alliaria, E. alliaria;-W Winter cresses, Winter rocket, E. barbarea. Antiscorbutic; used in coughs; externally detersive; seeds acrid, lithontriptic.

* Earla winter cress, Erysimum precox, Barbarea precox; - IVater radish, Raphanus aquaticus, Sisymbrium amphibium. Herbs acrid, used in scurvy ; eaten in salads.

"Fltx weed, Sophia chirurgorum, Sisymbrium sophia. Vulnerary, astringent, detersive.

W ATER cresses, Nasturtium aquaticum, Sisymbrium nasturtium. Depurative and antiscorbutic; used in obstructions and calculous cases.

"Ladirs' smocks, Cuchow flower, Cardamine pratensis. Qualities of the preceding; flowers, cardamines flores, antispasmodic, in doses of $3 \mathrm{j}$ to $3 \mathrm{ij}$, twice or thrice a day; flowering tops are still more successfully used in epileptic fits.

Dentaria diphylia. Dried roots used as mustard.-D. heptaphylla. Root astringent, attenuant.

Satin plower, Honesty, Moon wort, Lunaria rediviva; $-L$. annua. Roots detersive; leaves diuretic; seeds extremely acrid, used in epilepsy. 
*Alysson, Alyssum campestre. Seeds, with honey, take away freckles, used in mania.

* Common whitlow grass, Paronychia vulgaris, Draba verna; - Draba muralis. Opening, detersive; seed, English pepper, hot, used for pepper.

*Horse radish, Raphanus sylvestris, R. rusticanus, Armoracia, Cochlearia armoracia. Root, armoracice radix, powerfully antiscorbutic, antirheumatic, acrid ; taken, cut into small pieces, without chewing, coch. j., every morning, incisive; used as a sauce.

*Swire's cresses, Coronopus Ruelli, Cochlearia coronopus; - ${ }^{*}$ Scurvy grass, Cochlearia Batava, C. hortensis, C. officinalis; - Sea scurvy grass, C. Britannica marina, C. Anglica. These herbs abound in volatile principles, which are dissipated by heat; they are the most valuable of antiscorbutics eaten raw, or only their juice, $\overline{3}$, to ziiij : an excellent whey may be made from them.

*Lesser shepherds'-purse, Bursa pastoris minor, Iberis nudicaulis;- ${ }^{*}$ I. amara. Antiscorbutic, may be eaten in salads.

* Shepherds'-purse, Bursa pastoris, Thlaspi Bursa pastoris ; - - Treacle mustard, Penny cress, Thlaspi arvense. (Seeds, 10s. the lb.)-**Mithridate mustard, Bastard cress, T. campestre. Seeds acrid, detersive, astringent.

Garden cresses, Nasturtium hortense, Lepidium sativum; -Ambrosia Lepidium procumbens. Seeds opening, incisive, antiscorbutic.

* Dittander, Pepper wort, Lepidium, Piperitis, L. latifolium. Acrid, irritative, useful in sciatica; infused in beer, facilitates delivery ; sialogogue.

Sciatica Cress, Iberis, Lepidium iberis. Made into a poultice with lard, used in sciatica.

*Wild gold of pleasure, Myagrum sativum. Vermifuge; seeds, sesamum seeds, useful in palsy, yield oil.

Bunias erucago. Acrid, diuretic.

*Sea rocket, Eruca marina, Bunias cakile. Antiscorbutic, useful in the colic.

*Sra Cole-wort, Sea cabbage, Brassica marina Anglica, Crambe maritima. An excellent potherb when blanched.

Chara, C. Tatarica. Roots good tasted, nutritive.

*WoAd, Isatis, Glastum, Isatis tinctoria. Desiccative, astringent; used as a blue dye; and indigo is said to have been manufactured from it.-Isatis Lusitanica. Used in dyeing. 


\section{CAPPARIDER.}

Caper tree, Capparis spinosa. Bark of the root acerb, discussive, splenic, useful in the gout.-Pickled capers. The unopened flowers used as a sauce.

Bastard mustard, Cleome dodecandra. Root vermifuge. C. icosandra. Used as a sauce, and also for sinapisms.

\section{RESEDACER.}

*Wend, Yellowo weed, Dyers' weed, Luteola, Reseda luteola. Used in dyeing yellow and green.-French weld. Stem much tiner than the English.

*Wild rocket, Reseda vulgaris, R. lutea. Discussive; used externally to dissipate inflammations and tumours; dyes yellow.

\section{DROSERACE}

"Sun DEw, Rosa solis, Ros solis, Rosella, Drosera rotundifolia. Acrid, anti-arthritic, detersive, externally rubefacient.

\section{PARNASSIEX.}

"Grass of Pannassus, Gramen Parnassi, Parnassia palustris. Juice ophthalmic; seeds diuretic, aperitive.

\section{SAPINDACE 1 .}

Sosp-berry tree, Saponaria, Sapindus saponaria. Fruit used with rum, as an embrocation in rheumatism; tops, leaves, and seed-vessels form a lather with water, and cleanse linen, \&c.; plant intoxicates and kills fish.

Liт sсиi, Euphoria puniceu, Dimocarpus, Sapindus eclutis Fruit esculent.

Camiosíenaum Halicacabuar. Juice used as an emollient in gonorrhoea; herb used as food.

Genip tree, Melicocca bijuga. Sceds oily, esculent.

Paclinis subrotuxda. Arillus esculent.

Liane. a PERsir, Seriana triternata. Used to poison fish.

Rиzовоu, pésea, R. tuberculosa, Pekea tuberculosa, Caryncar tomentosum. Secds, Giviana almonds, Brazil muts, esculent; imported from the Brazils. Rhizobolus butyrosus, Pelea butyracer, Caryocar butyrosum. Secd, surahwah nut, esculent.

\section{ACERINER.}

Common mapli, Acer mimus, A. campestre. Root useful in liver complaints. 
Vikginia maple, Acer rubrum. Inner bark used, in decoction, as. an astringent eye-water.

Sugar maple, Acer saccharinum;-*Greater maple, Sycamore, A. majus, A. pseudoplatanus;-Norvay maple, Acer platanoides. The sap of these trees, as well as that of the common maple, is used for making sugar and wine.

\section{HIPPOCASTANIDEÆ.}

Horse chestnut, Hippocastanum, Asculus hippocastanum. Bark and skin of the fruit febrifuge, astringent, used for Peruvian bark in doses of $3 \mathrm{ss}$ to $3 \mathrm{j}$, also errhine: seeds farinaceous, but must be soaked in an alkaline ley to take off their bitterness.

SCARLET-FLOWERED HoRse CHestNut, AEsculus pavia. Bark febrifuge; root used for soap; seeds, buck eyes, used to poison fish.

\section{MALPIGHIACEÆ.}

SWItch sornel, Triopteris Jamaicensis. Acerb, bitterish.

Barbadoes cherry, Cerasus Jamaicensis, Malpighia glabra. Fruit subacid, carminative, stomachic.-M. mourelia. Bark used as a febrifuge.

\section{HIPPOCRATICE $A$.}

Hiprocratea comosa, $H$. multiflora. Nuts white, sweetish.

\section{HYPERICINEÆ.}

*St. JoHs's wort, Hypericum, H. perforatum. Resolvent, attenuant, nervine; in maniacal cases; contains rosin; leaves give a good red dye to wool, and oil.

*St. Peter's wort, Ascyron, Hypericum ascyrum. Seeds purgative; useful in sciatica.

Bastarn St. John's wort, Coris, Hypericum coris. Seeds diuretic, antispasmodic.

*Tutsan, Park leaves, Androscmum, Clymenum Italorum, Hypericum androsémum. Resolvent, attenuant. $-H$. parviflorum, Vismia guttifera; $-V$. sessilifolia, $H$. sessilifolium. Yield Mexican gamboge.

\section{GUTTIFERE.}

Ponna maram, Poon wood tree, Alexandrian laurel, Calophyllum inophyllum, Balsamaria inophyllum. Seeds yield oil.

Santa Maria tree, Calophyllum calaba. Yields oleum Sanctæ Marix.-C. tacamahaca, C. inophyllum. Yields Mauritius tacamahac.

Tsi Xu, Augia Sinensis. Yields black China varnish. 
Stalagmis cambogia;-Cambooge tree, Cambogia gutta, Garcinia cambogia;-G. morella. Produce gamboge.

Clesia ALBA;-C. rosea. Juices used as pitch.

Mammea Americana. Fruit eaten.-M. Asiatica, Barringtonia speciosa, Butonica speciosa. Kernels mixed with baits, and flung into the sea, used to intoxicate fish.

Grias cauliflora. Half-ripe fruits, preserved in syrup or brine, used as food.

Dryobalanors camprora. Trunk contains cells filled with camphire, or oil of camphire.

\section{GERANIEAE.}

Herbs slightly acrid, or acid, vulnerary, and astringent.

*Cranes' bill, Geranium cicutarium;-*Musk cranes' bill, G. moschatum ;- Herb Robert, Gratia Dei, Geranium Robertianum;- Doves' foot, Geranium columbinum, Pes columbinus, G. rotundifolium; - *Bloody cranes' bill, G. sanguineum; - Blue doves' foot, G. batrachyoides. Astringent and detersive; used in poultices.

American cranes' bill, Geranium maculatum. Root, geranium, P. U. S. boiled in milk, used in the cholera of infants.

Bulbous-rooted cranes' bill, Geranium tuberosum. Root in wine used as a wash in inflammation of the vulva.

Nasturtium, Indian cress, Tropcolum majus; Smaller nasturtium, T. minus.-Eaten in salads, antiscorbutic, excite the appetite, assist digestion; externally used in stubborn itch.-T. tuberosum. Root eaten.

"Yellow Balsam, Touch me not, Impatiens noli tangere. Herb diuretic, capable of producing a diabetes; but extremely uncertain in its operation.

"Green sauce, Wood sorrel, Alleluja, Lujula, Acetosella, Trifolinem Acidum, Oxalis acetosella;-*O. corniculata. Herbs in salads very refreshing, acidulous, antiputrescent; make a very pleasant whey; used for the extraction of salt of sorrel.

JasAica WOOD-sorREL, Oxalis stricta;-O. compressa;-O. frutescens;-O. dodecandra. Acid, cooling.-O. tuberosa. Root like potatoes; herb acid.

\section{SARMENTACE 2 .}

Grape vine, Vitis, $V$. vinifera. Numerous varieties of this plant are cultivated; fruits, grapes, uva, esculent, juice made into a variety of wincs, also inspissated, and made into sugar.-Dried grupes, Uva siccata. From Barbary, in jars.-Raisins of the sun, 
Uva passa majores. These and the other raisins are prepared by being left to wither a little on the vine, the stalk being cut half way through, then gathered and dipped in a ley of wood ash, and barilla at 12 to $15 \mathrm{deg}$. Baume, or spec. gr. $1 \cdot 094$ to $1 \cdot 116$, to every four gallons of which are added a handful of salt, and a pint of oil or a pound and half of butter, and then drying them in the sun; they lose about two-thirds of their weight, and become covered with a saccharine exudation;-Denia raisins, Malaga raisins;-Valencia raisins;-Belvidere raisins;-Lexia raisins;Muscatcl raisins;-Bloom raisins ;-Sultana raisins, Uvce apyrerce. (Small, yellowish red, without stones);-Black Smyrna raisins ;Red Smyrna raisins;-Currants, Uva minores Corinthiacce;-East Indian raisins, Kishmish. From the small Shiraz grapes.-All these dried grapes are used for food, or fermented with water and made into wine. - Rape, Vinacea. The cake left on pressing grapes; it is fermented with water, and distilled for brandy. Officinal preparations. -Decoctum altheæ, D. E. Decoct. guaiaci comp., E. Decoct. hordei comp., D. L. 'I'inct. cardam. comp., $L$. Tinct. sennæ, $L$.

\section{5\%. MELIACEE.}

Wintera canelia. Beriy aromatic, used as a spice; bark, white cinnamon, canella alba, canella cortex, rolled, peeled, whitish, thicker than cinnamon, pungent, and sweet smelling; warm, stimulant, antiscorbutic; dose gr. $\mathrm{x}$ to $3 \mathrm{ss}$; used also as a sternutatory; alouchi is said to be the produce of this tree.

Azedaracir, Bead tree, Melia azedarachta. Seeds yield oil ; bark, azedarachta, P. U.S. used for the Peruvian; leaves vulnerary, vermifuge, diuretic: pulp of the fruit poisonous; trees yield gum, and also toddy.

RED wood TREF, Swietenia febrifuga. Bark astringent, tonic, used as a substitute for Peruvian bark; dose, in powder, 3ss.

MaHog Any, Swietenia mahogani. Wood astringent, an extract is made from it.

Barbadoes. cedar, Cedrela odorata; - Cedrela rosmarinus. Wood slightly odoriferous, anti-rheumatic ; yields a resin.

Toona, Poma, Cedrela Toona. Bark used as a febrifuge.

T'richilia spondordes. Wood, bastard brasil, used in dyeing.-T. spinosa. Berries boiled for their oil.

Guarea trichilioides. Bark emetic and purgative.

\section{HESPERIDE $A$.}

Fruits generally acidulous, refreshing.

Citron tree, Citrus medica, C. vulgaris. Fruit, citria malus, 
ritrus, excites the appetite, stops vomiting, is acidulous, antiseptic, antiscorbutic, and used along with cordials as an antidote to the manchineel poison ; rind of the fruit, citri cortex, aromatic, tonic, yields essence de cedrat; seeds bitter, vermifuge.-Candied citron peel, cortex citri conditu. Soak the peels in water frequently changed, until their bitterness is exhausted, put them into syrup, until they become soft and transparent, then take them out and drain them; stomachic, and used as a swectmeat.

Lemon tree, Citrus medica acida, C. limonum. Fruit, lemon, limonia malus, imported from Malaga and Lisbon in chests, each lemon in a separate paper; juice of the fruit more acid than that of the citron; rind of the fruit, limonum cortex, aromatic, not so hot as orange peel; yields essence of lemons;-Candicd lemon peel, cortex limonum condita. Prepared as candied citron peel; a stomachic sweet meat.

Seville orange tree, Aurantium Hispalense, Citrus aurantium. Leaves and flowers antispasmodic, cordial, 3 ss to $3 \mathrm{j}$, bis terve in die, or in a decoction; fruit, Seville orange, aurantia malus, aurantice bacca; imported from Seville; rind of the fruit, aurantii cortex, bitter, stomachic: unripe fruit, orange peas, Curasso aranges, burce aurantice, aurantia C'uraslavensia, aurantia Curassoventilu, used to flavour liqueurs, and for issue peas.-Candied. orange peel, cortex anrantiorum condita. Made the same way as candied citron peel; stomachic.

Orange tree, Aurantium Climense, Citrus Sinensis. Fruit, siceet orange, Clina orange, sweet; imported from Faro, Lisbon, Port St. Michael's; price very variable; juice of the fruit contains a saccharine, as well as an acid matter; mixed with salt is a common purge in the West Indies; flowers, naphr, sweet scented, used to make orange-flower water; are collected every moining in May and June, for thirty miles round Paris, from both public and private gardens; buds, currantice flores, that fall from the trees, used to make orange-flowcr water.-Candied mange flowers, 1.7ores untantiorum conditi. Orange flowers, freed from their cups, stamina and pistils, four ounces are put into lb. ij of sugar. boiled to a candy height, and poured on a slab, so as to be formed into cakes; stomachic, antispasmodic.-Malta orange. Pulp red, juice very sweet.-E East Ludiun small clove mange, Chota chia. Rind used to nuke the best orange marmalade.-East Indian country orange, Koula. Pulp austere and coarse; rind added in small quantity to orange marmalade to give it an agrecable bitterness.

Bergamot onaNof tref, Bergamot lemon tree, Citrus medica Bergumottu, Limon Bergamottu, C. limettu Beryamium. Rinds of the fruit very thick, yield essence of Bergamotte. 
Shaddock, Pampelmus, Citrus decumana. Fruit very large, esculent.

Lime tree, Citrus medica acida, C. acida, C. limetta. Fruit, lime, limetta, used to rub floors to cleanse them and also scent the rooms; juice of the fruit very acid, and even acrid, used to acidu. late spirituous drinks.

\section{THEACE E.}

Thea oleosa. Seeds expressed yield a fine limpid oil.BLACK TEA, Thea bohea. Leaves, in weak infusion, stomachic, favour digestion, raise the spirits, an excellent diluent.

Des Guignes gives the following characters of the different kinds of black tea, as he observed them in China, using the common English orthography, with their usual price at Canton: they are supposed to be picked from old trees, and are dried in shallow pans over charcoal fires.

1. Bohea tea, (Vo he, the name of a place, ) is of a black cast, and yields a deep yellowish infusion; sells in China for 12 to 15 taels.

2. Congou TEA, (cong fou, great care,) the infusion is lighter than that of bohea, rather green, and seldom of an agreeable smell; preferred by the Chinese and. Indian islanders for their own use.

3. Soutchong tea, (se ow chong, a very little sort,) the infusion is a fine green, smells agreeably; the leaves ought to have no spots on them.

4. PeKao TEA, (pe kow, white leaf bud,) the infusion is light and rather green, has a violet scent, and a very fine perfume in the mouth.

5. Imperial tea (mao tcha, has a green cast, the infusion is also green; the leaves large and of a fine green; has a slight smell of soap.-To these may be added, Campoi tea, which is intermediate between congou and soutchong.

6. Padre teA, (pou chong tcha, a very fine soutchong, imported in pound papers, for presents ; being the best and most delicious.-Caper tea, made into balls with gum, and scented, imported only in small boxes.

Green tea, Thea viridis. Doubtful whether a distinct species, or only the young leaves of the bohea, slowly dried in the shade: the infusion narcotic in a small dose, and appeases the qualms of intoxication, but taken largely brings on watchfulness, nervous agitation, and is even emetic: this irritability is best allayed by butter-milk. - The green teas of Des Guignes are,

1. Songlo TEA, (from the place where it is grown,) has a 
leaden cast, the infusion is green, the leaves are longer, and more pointed than the black teas; the inferior sorts have yellow leaves and a smell of sprats.

2. Hyson TEA, (he tchune, first crop,) is of a leaden cast, the infusion is a fine green, the leaves are handsome, without spots, and open quite flat; it has a strong taste, and a slight smell of ronsted chesnuts.

3. Tchu tcha, of which he gires no characters.-Besides these, there are imported into England, these green teas : Hyson skin, or bloom tea, being the large loose leaves of the hyson; a faint delicate smell; infusion a pale green ; the bloom is given by means of indigo heated under it.-Superior hyson skin, intermediate between hyson and hyson skin.-Gunpowder tea, a superior hyson in small round grains, of a blooming greenish hue.-Chelium, or corcslip hyson, a scented hyson, mixed with small berries, that give it a cowslip flavour.-The Ankoy teas, obtained from An Khe, have the same appearance as the Canton teas, but are inferior in Havour, and generally sell from $4 d$. to $1 s$. a lb. lower. They are supposed to be picked from wild tea plants. The leaves of tea having little or no smell, they are rendered fragrant by mixing with them the leaves of Olea fragrans, and Camellia sesanqua. The leaves of Polygala theezans, and of Rhamnus theezans, are also mixed with China tea.

China tea is not turned black by being put into water impregnated with sulphuretted hydrogen gas, nor does it tinge spirit of hartshorn blue. The infusion is amber coloured, and is not reddened by adding a few drops of oil or spirit of vitriol to it. The leaves of speedwell, wild germander, black currants, syringa or mock orange, purple-spiked willow herb, sweetbriar, cherry tree, sloe, are all substituted for tea, either singly or mixed. In foreign countries a variety of plants are used instead of Chinese tea, as Capraria bifulia, Alstonia theanformis, Gualtheria procumbens, Myrtus uyni, Leptospermum scoparium, Ceanothus Americanus, Prinos glaber, Lerhum latifolium, Chenopodium ambrosioides, Monurda kolmiana, Psorulia ylandulosa, Cassine perague. Zenopoms there Sinensis is beginning to be cultivated in France as a substitute for Chinese tea. In Hindustan, those with whom the common tea does not agree use an infusion of lemon grass, or of $\mathrm{Ocy}$ mum allum.

Ja Paxesp. Cameiria, Camellia Japonica. Leaves frequently mixed with those of tea by the Chinese.-C. sesanqua. Leaves used for those of tea, are odoriferous, and are also added to tea to scent it; seeds expressed for their oil.-C. drupifera. Nuts expressed for their oil. 


\section{PASSIFLORE $A$.}

Passion-flower, Passiflora carulea;-Wild passion-flower, Contrayerva, $P$. normalis;-Red passion-flower, $P$. incarnata. Roots sudorific.

Bul h hoof, Dutchman's laudanum, Passiflora murucuja. Herb made into a syrup, or flowers infused in rum, narcotic, used for laudanuin.

Water lemon, Passiflora maliformis:-Sweet calibash, $P$. laurifolia;-Granadilla, $P$. hexangularis. Fruit esculent.

Papaw, Carica Papaya. Fruit nutritive; seed an excellent vermifuge; leaves saponaceous; milky juice corrosive, is mixed with water, and used to wash meat to make it tender.

\section{VIOLACE $A$.}

Pomboma ipecacuanin, Inodium ipecacuanha, Viola ipecacuanha. Root, white ipecacuantu, emetic, milder than the false kinds, but mostly adulterated with then ; dose gr. v to Эij; in sınall doses, gr. ss to gr. ij, given frequently, it is diaphoretic, expectorant, and stomachic. In both methods it is antidysenteric; gr. v, or enough to excite nausea, given an hour before the fit, has been successful in intermittents.

Viоla гволвоч; $-V$. parviflora. Roots emetic.

*Dog violet, March violet, Viola canina;-*Purple violet, Viola odorata, (petals made into syrup) - Hearts ease, Pensée, Viola tricolor. Flowers moistening, pectoral; seeds diuretic; roots expectorant, slightly emetic, and in doses of $3 \mathrm{j}$, cathartic.

American violet, viola. P.U.S. Viola pedata. Root emetic.

\section{CISTINEA.}

'The plants of this order are astringent or pectoral.

*Dwary cistus, Little sun-flower, Helianthemum Anglicum huteum, Cistus helianthemum;-Cistus pumana ;-* ${ }^{*}$.guttatus, and the other species are astringent. The parasitic plant hypocistus, Cytinus luypocistus, grows chiefly on the Cistus incanus. $-C$. Creticus, C. Laurifolins. Yields labdanum. - C. ladaniferus. Yields the inferior sort of labdanum.

Male holly rose, Cistus mas, C. villosus;- Female holly rose, $C$. fomina, C. salvifolius. Leaves and flowers are astringent.

\section{LINEA.}

*Flax, Linum, L. usitatissimum. Seeds, lini usitatissimi semina, linseed, emollient, diuretic; yicld oil; imported from Russia, 
Poland, and North America.-Linseed cake, lini placenta. Left after the oil has been pressed out; used for feeding cattle and broken winded horses. - *Dwarf wild flax, Mill mountain, $L$. catharticum. Purgative in doses of 3 ss to $3 \mathrm{j} .-L$. selaginoides. Herb bitter, and aperitive.

\section{CARYOPHYLLEAE.}

*FIEld PINk, Caryophyllus arvensis, Holosterm umbellatum;*Chick weed, Alsine, A. media;-A. mucronata;-" Spurry, Spergula arvensis;- - Mouse-EAR CHICK WEED, Alsine hirsuta myosotis, Cerastum vulgatum; - * BROAD-LEAVED MOUSE-EAR CHICK-WEED, Alsine hirsuta altera viscosa, Cerastum viscosum;"Great marsh chick-weed, A. aquatica major, C. aquaticum; - Corn mouse-Ear, $C$. arvense; - $C$. repens. All cooling, moistening herbs, nourishing cattle, used as spinach.

*Saxd wort, Arenaria media. Externally used in whitlows and other inflammations. $-A$. peploides. Herb fermented and made into Iceland beer.

*Sea spur ry, Arenaria marina. Very succulent.-Pickled sea spurry. Sold for samphire.

"Great stitchi-wort, Stellaria holostea;-S. alsine. Cooling, moistening, used as spinach.

Gypsophila saxifraga ; - G. struthium;-G. muralis. Lithontriptic; and used for soap-wort in lues.

Cow BASIL, Vaccaria, Saponaria vaccaria. Seed heating, diuretic.

"Soap-wort, Saponaria, S. officinalis. Attenuating, opening, antivenereal.

"Clove pink, Clove gillyflower, Caryophyllus ruber, I'eronica, Dianthus caryophyllus. Flowers, tunica, cephalic, cordial, antispasmodic, nervine, in doses of $3 \mathrm{j}$ to $3 \mathrm{j}$; useful in heartburn and contagious fevers: the odour is improved by drying.-OEILLET des Cilartreux, Dianthus Carthusianus;-DEeptrond link, Caryophlyllus pratensis, Dianthus armeria;-SWEET Wildisam, D. barbatus;-Fringed PINK, D. superbus;- "STONe PINK, Maiden pinh, D. arenarins, and the other species of dianthus, have similar qualities but weaker.

Great saxifrage, Saxifraga antiquorum, Silene suxifraga. Herb used in calculous disorders. - "Lobel's catch-fly, Behen album, Silene armeria;-Red crtch-fly, Silene muscipula;-S. behen. Roots cordial._S. Virginica. Root in decoction vermifuge.

-Spatrixg, poppy, White bottle, White behen, Behen album, Cuculvalus behen;- "Campion, Bachelor's button, Lychnis clioica ;'Catchfly, L. viscaria ;-"Cuchoo flower, Meadow-pink, L. flos cuculi. Roots cordial. 
* Cockle, Agrostemma githago;-Rose campion, A. coronaria; -A. flos Jovis;-A. coli-rosa. Roots vulnerary, astringent; seeds purgative.

\section{CUSPARIE正.}

Cusparia febrifuga, Bomplandia trifoliata. Bark, angostura bark, cusparia cortex, in pieces of different lengths, aromatic, intensely bitter, tonic, stimulant, very useful in dyspepsia, diarrhoea, and dysentery; dose gr. $\mathrm{v}$ to xx. Imported from Cadiz and the West Indies, in casks.

? Carolina shrub treforl, Ptelea trifoliata. Fruit bitter, aromatic, used as a substitute for hops.

\section{ZANTHOPHYLLE $\mathbb{E}$.}

Japan pepper, Piper Japonicum, Fagara piperita. Bark, leaves, and fruit aromatic, used as spice.

Cacatin, Fagara Guianensis. Used as spice.-F. octandra. Yields tacamahaca in the shell:

Тоотн-Асн тREE, Zanthoxylum clava Herculis. Leaves sudorific, diuretic, sialogogue, even taken internally, used in rheumatism and palsy; expressed juice of the roots, coch. ij, antispasmodic; roots, in infusion, used as a collyrium, powder of the bark of the roots useful in dressing putrid sores.

Prickly ash, Prickly yellow wood, zanthoxylum Caribbaum, z. fraxineum. Bark, zanthoxylon, P. U. S. febrifuge, dyes yellow.

Raventsara, Evodia aromatica, Agathophyllum aromaticum, E. ravensara, Ravensara aromatica. Bark aromatic, red; nut resembles both cloves and pimento; kernel extremely hot, biting, with a strong spicy smell; leaves an excellent tonic cordial spice, form an agreeable cordial, yield an oil.

Bastard dittany, Fraxinella, Dictaminus albus. Root rather bitter, cordial, cephalic, alexiterial, uterine, anti-epileptic, vermifuge, in powder $\vartheta_{\mathrm{j}}$, twice a day.

\section{6\%. DIOSME正.}

Buскно, Diosma Crenata. Powder of the leaves strong smelling, tonic, astringent, and diuretic. In gleet, and other diseases of the urinary passages. Also in dyspepsia and chronic diarrhoea. Officinal preparations.-Tinct. et infus. buchu, $D$.

168. RUTACEE.

*RoE, Ruta hortensis, R. graveolens. Leaves, ruta folia, 
powerfully resolvent, emmenagogue, carminative, diuretic; also alexiterial, nervine, cephalic, antispasmodic, and anaphrodisiac; dose gr. xv to $\mathrm{gij}$; externally rubefacient.

Narrow-Leaved rue. Ruta angustifolia. Vermifuge.

Wild rue, Harmel, Ruta sylvestris, Peganum harmala. Seeds very inebriating, soporific, causing a happy forgetfulness and pleasant delirium.

\section{ZYGOPHYLIEA.}

Cartrors, Tribulus terrestris. Herb detersive, astringent, vermifuge; seeds cordial.

BEAN CAPER, ̃ygophyllum fubago. Vermifuge.

Lignum vite tree, Guaiacum, G. officinale;-Lignum sanctum, G. sanctum. Wood, guaiaci lignum, resinous, hot, aromatic, diaphoretic, diuretic, when used in dropsy, gout, and especially in the venereal disease in warm climates; yields gum guaiacum; leaves detergent, used in scouring floors, and washing printed linens. Officinal preparations of the wood.-Aqua calcis comp., $D$. Decoctum guaiaci comp., D. E.

Porliera itygrometra. Wood sudorific, antirheumatic.

170. SIMAROUBER.

Bark and wood intensely bitter, and devoid of astringency.

Stave wood, Mountain damson, Simarouba, Quassia simarouba. Bark, simaroube cortex, inodorous, bitter, astringent, useful in dysentery, intermittent fever, dyspepsia, the whites; dose $\ni j$ to 3ss. From the West Indies. Officinal preparation. - Infus. simaroubx, D. $L$.

Quassia, Coissi, Quassia amara. Wood of the root, quassia lignum, very bitter, febrifuge, stomachic, used in gout; dose gr. $\mathbf{x}$ to $3 \mathrm{j}$, three or four times a day, or in infusion: used by brewers instead of hops; and pastry-cooks, \&cc. put a few chips into a plate of water, as a poison for flies: bark of the root esteemed in Surinam the most powerful, but not to be had in Europe.

Quassia excelsa. The same qualities, but weaker. Officinal prepuration.-Infus. quassiæ, D. L. 'Tinct. quassiæ, $D . \dot{E}$.

Bıттв wooD, Quassia polygama. Wood makes a good bitter infusion, $3^{i j-i v}$ to $11 \mathrm{~b}$. cold water; or the powder, gr. xv, may be taken.

171. OCHNACEA.

Walrema serrata, Meesia serrata. Root and leaves bitter, tonic, stomachic, and anti-emetic. 


\section{ELAOCARPE}

Ganistrum, Dicera serrata, Elcoocarpus serratus;-Ganistrum oblongum, Elcoocarpis integrifolius. Fruit eaten, either raw, or preserved in sugar or salt and vinegar, strengthening.

Penoe, Vateria Indica, Elcoocarpus copalliferus. Yields Moschat rosin, pænoe tallow, and pænoe varnish.

\section{TILIACE $\AA$.}

Lime, Linden, Bast, Tilia Europea. Flowers anti-spasmodic, cephalic; bark and leaves drying, astringent, diuretic, emmenagogue; berries astringent; slime of the bark used in burns and wounds.

Jews' mallow, Bhungee paut, Corchorus olitorius;-Ghee naltha paut, C. capsularis. Leaves emollient, eaten as spinach in hot countries.

- Annotto plant, Bixa Orellana. Yields annotto.

Grewia orientalis. Fruits and leaves boiled in water to make a kind of drink.

Schageri cottan, Grewia microcos, Microcos paniculata. Juice with sugar used as an astringent gargle, also internally in dysentery.

Brandewyn bosch, Grewia flava, G. orientalis. Berries make a spirituous liquor.

Couror Moen li, Flacourtia sepiaria. Fruit delicious, eatable; a decoction of the bark in oil used against gout; a decoction of the leaves and root in cows' milk used as an antidote against the bite of serpents. - Flacourtia ramontchi ; - F. sapida ; -Spina spinarum, Jamgornas, Stigmarota jamgornas. Fruits eaten.

Valisa cordifolia. Leaves dye cloth yellow.

Abatia rugosa, A. parviflora. Leaves dye black.

\section{STERCULIACEA.}

Kola, Sterculia acuminata. Fruit, kola nuts, much esteemed in Africa, as brackish water tastes well after eating them. $-S$. urens. Yields gum kuteera.

Cavalani, Clompanos minor, Sterculia balanghas. Pulp of the fruit esculent, kernels toasted and eaten.

KariL, Clompanos major, Sterculia digitifolia, S. foetida. Root, leaves, and fruit, in decoction, useful in pains of the joints. $-S$. platanifolia. Seeds pressed for their oil.

\section{MALVACEE.}

*Common mallow, Malva communis, M. sylvestris;- - Dwarf 
mallow, Malva rotundifolia;-Curl-leaved mallow, Malva crispa; -*Verrain mallow, Alcea, Malva alcea.-**Musk mallow, Malva moschata. All these herbs are eninently emollient and moistening, proper to cool and open the belly; flowers pectoral.

*Marsh mallows, Althcea, Bismalva, Itiscus, Althcea officinalis. Roots, althree radix, and leaves, althreer folia, very emollient, particularly useful in diseases of the bladder; flowers pectoral. Officinal preparation.-Decoct. althææ, D.E. Syrup. althiex, $L$.

A trifea hirsuta; - Holly hock, Malva arborea, Alcea rosea;

*Tree mallove, M. arborea, Lavatera arborea;-L. triloba;L.Thuringiaca;-Sida rhomboidea;-Indian mallow, Sida abutilon. Leaves emollient, cleansing to ulcers ; seeds opening, diuretic.Sida cordifolia. Mixed with rice, used in dysentery.

Mu's Mailow. Musk ochra, Bamia moschata. Hibiscus abelmoschus. Seeds, musk seeds, grains d'ambrette, smell like musk, are cordial, cephalic, stomachic, and emetic; used in coffee; and mixed with hair powder.

Oкra, Hibiscus esculentus. Uuripe pod used as a pot-herb, contains a kind of gelatine; decoction of the leaves and pods demulcent, pectoral.

Guinea sorrel, Red sorrel, Hibiscus sabdariffu. Herb acid, refreshing, diuretic. $-H$. rosa Sinensis. Flower's astringent. $-H$. Suratensis; $-H$. cannatinus. Acidulous.

Соттом, Bombax, Gossypium herbaceum. Seeds pectoral, antiasthmatic ; down of the seeds used as a caustic, instead of moxa; young buds very mucilaginous, pectoral._Gossypium Barbadense. Seeds pressed for oil._Bombax pentandrum. Y Yelds cotton-tree gum.

Cacao, Theolroma cacao. Seeds, chocolate nut, island cacao, cacao des Antilles, cacao des isles, cacao Antillamum, flattened, covered with a red paper-like envelope, kernel brown, fat, taste agreeable, slightly acrid; yields oil; chocolate and cacao are made from it.-Caracca cacao, Cacao Caraque, Cucao Caraccense. Seed larger, round, covering reddish brown, kernel pale brown, friable, dry and strong tasted, is often mouldy, as having been buried for thirty or forty days, to get rid of some of their acridness.

Wurti cacan, Serjeant, Pachera aquatica, Carolinea princeps. Seeds esculent, similar to almonds.

ВАОв в Adlmsona digitata. Emollient; fruit acidulous, used in pulmonary affections, and for tanarinds.

BUTTNERIA cordata. Leaves applied to the bites of spiders. Muchucuxda, Pentapetes...... Flowers, expressed, yield a mucilaginous and refrigerant juice, used in gonorrhoea. 


\section{MENISPERME T.}

Саватнa, Menispermum edule. Berry esculent, but acrid, producing an intoxicating liquor by fermentation.

Cocculus Indicus, Menispermum cocculus. Capsules acrid, used to intoxicate fish, and to destroy vermin; also by brewers, to give a false strength to beer.

Kalumb, Menispermum hirsutum, M. columba. Root, colombo root, calumboe radix, bitter, aromatic, stomachic, anti-emetic, astringent; dose 3 ss frequently in a day : in transverse slices, one or two inches diameter, and not half an inch thick, covered with a bark : imported from Mozambique in bags or cases. Officinal preparations.-Tinct. et infus. calumbæ, D. L. E.

Red columbo, Menispermum palmatum. Root stomachic, bitter.-M. cordifolium. Tonic and febrifuge.-M. lacunosum. Fruit used to intoxicate fish and birds.

White pariera brava, Velvet leaf, Cissampelos pariera. Trunk or root, in powder, $\mathrm{gj}_{\mathrm{j}}$ to $\mathrm{gij}$; or in infusion, 3iij to $\mathrm{lb} . \mathrm{j}$ water, for three doses; diuretic, very useful in obstructions, dropsy, or gravelly complaints.

Liane a glacer l'eau, Timac? Cissampelos caapela. A very powerful diuretic, in use among the negroes in Martinique against bites of serpents.

Brown pariera brava, Menispermum abuta, Abuta rufescens. The same qualities as the white pariera brava.-BItTer PARIERA, Abuta amara. Root bitter.-Liane amere, A. candicans. Root bitter.

\section{Lardizabala biternata. Berry esculent.}

Funis felleus. Menispermum crispum, $M$. tuberculatum. Bark esteemed equal to that of the Loxa or Peruvian bark tree.

Epibaterium tomentosum. Bark extrenely bitter.

\section{ANNONACEE.}

Uvalia tripetaloidea. Yields a gum by incision.

Uvaria aromatica, Unona EEthiopica. Capsules, Monkey pepper, Grains de zelim, Ethiopian pepper, Piper Bthiopicum, very aromatic, heating, used to flavour liqueurs.

UNoNA FEBRIFUga. Bark chininincha bark, febrifuge, superior to Peruvian bark.-Unona discreta. Fruit aromatic.

Canagna virgata, and some other species. Fruits aromatic, very heating.

Asimina triloba. Fruit fleshy, juice very acid. 
Sour sop, Annona muricata. Root, in decoction, used against fish poison; fruit eatable; inner bark made into bast.

Nettle custard apple, Annona reticulata;-Sweet sop, $A$. squamosa;-Water apple, Alligator apple, A. palustris. Fruits esculent; imported from the West Indies, preserved in syrup.

Bitter wood, Hylopia glabra, Xylopicrum, Picroxylon .... Fruit eatable.

Porcelia nitidrfolia. Fruit grateful, leaves yield a yellow colour.

Mollinfota repanda. Fruit yields a purple colour.- $M$. ovata. Fruit yields a violet colour.

\section{MAGNOLIACE $Æ$.}

Bark of these trees is bitter, astringent, or aromatic.

Winterana aromatica, Drymis Winteri. Bark, Winter's cinnamon, Winter's bark, cortex Winteranus, thick, channelled across on the outside, grey, much cracked; on the inside solid, iron grey ; sharp-tasted, aromatic, very fragrant ; used in scurvy, vomiting, and palsy ; rare at present, being not in such esteem as canella alba; dose, in powder, gr. $x$ to $\partial_{j}$; from America.C.Nelo, Drynis magnolicefolia;-Drymis granatensis, and two other species, not well known. Bark slightly bitter, very acrid, leating, and aromatic.

Drrmis? Bark, melambo bark, febrifuge; contains the bitter principle without any tannin or gallic acid.

Star anise, Anisum stellatum, Illicium anisatum. Seeds fine scented, stomachic, make excellent liqueurs; also burnt as incense ; yield an essential oil; capsules, East Indian.

Virinia tUlip-TREe, Liriodendron tulipifera. Root and bark smell like essence of bergamot, and are used to flavour liqueurs, bark of the root, liriodendron, P. U. S., used in fevers, contains only the bitter principle without tannin or gallic acid.

Erephaxt wood, Magnolia Plumieri, Annona dodecupetala, Falenna Plumieri. Flowers distilled with spirit into a spirituous liqueur.-Magnolia glauca;-M. grandiflora;-M. auriculnta;H. acominata;-M. tripetula. Bark febrifuge; used for the Peruvian; flowers strongly scented, causing nausea, headach, and even fever.

Tsix-צ, Yu-len, Marmolia precia, M. Yu-lan. Seeds bitter, febrifuge; flowers used in perfumery.

Crampac, Micholia Champsaca, M. suaveolens. Flowers used in perfumery. 


\section{DILLENIACE $Æ$.}

Dillenia speciosa,,$D$. elliptica. Fruits used to acidulate cooling drinks.

\section{RANUNCULACEA.}

Plants acrid; many are poisonous.

Clematis Mauritiana. Used as a vesicatory.

Wild travelier's-Joy, Clematis vitalba. Bark and herb caustic, raising blisters, ophthalmic ; young shoots eaten as a potherb.-C. flammula;-C. erecta. Caustic, burning; used for issues and venereal ulcers; seeds drastic; leaves used outwardly in leprosy, internally, $3 \mathrm{ij}$ or iij in lbj boiling water, the infusion to be drunk in a day and night, in inveterate syphilis.

Virgin's bower, Clematis, C. viticella;-Atragene Alpina. Leaves used as a poultice in leprosy; seeds purgative.

*Lesser Meadow-RUE, Thalictrum minus; -T. aquilegifolium; -T. angustifolium. Roots and herbs bitter, purgative, diuretic, useful in old ulcers and the jaundice.

*Spanish meadow-rue, Pseudo-rhabarbarum, Thalictrum flavum;-*Meadow-rue, English rhubarb, T. majus. Roots substituted for thubarb, requires a double dose.

Yeldow anemone, Anemone vernalis ; - A. pratensis ; - Woodanemone, Wood-crowfoot, A. nemorosa; - Ihite wood-anemone, A. sylvestris. Plants acrid, caustic, exulcerating, used in gout and rheumatism; being chewed, they act as sialogogues; flowers poisonous.

*Pasque flower, Pulsatilla, Anemone pulsatilla. Root acrid, sternutatory; leaves detersive.

Garden anemone, Anemone coronaria. I.ess caustic.

Hepatica, Hepatica nobilis, Trifolium aureum, Anemone hepatica. Aperitive, vulnerary, useful in diabetes and dysentery; leaves detergent in diseases of the skin, or in gargles.

* Lesser celandine, Pilewort, Chelidonium minus, Ramunculus ficaria. Juice of the root acrid, styptic, useful in piles, being weakened with wine or beer: leaves caustic, but mild, and eaten in Sweden, according to Linnæus.

*Lesser spear-wort, Ramunculus flammeus minor, R. flammula; - *Great spear-wort, R. flammeus major, R. lingua;Alpine crow-foot, Thora, Ranunculus thora. Very acrid, cauterises the skin; poisonous to man and horse.

*UPRight MEAdOW CROW-FOOT, Buttercups, Ranunculus acris. 
Equally caustic; root used, when dry, as a febrifuge in intermittents.

*Rouxd-Roот crow-Foot, Ranunculus, P. U. S., R. bulbosus. Very acrid, kills rats, but not sheep; root used as a vesicatory; yields a nutritive fæcula.

*Marsh crow-Foot, Ramenculus palustris, R. scleratus;* Water crou-foot, $R$. aquatilis;- ${ }^{*}$ Com crou-foot, R. arvensis. Very acrid and poisonous, but eaten by animals in some countries.

*IVood cRow-Foot, Ranunculus, auricomus. - Less acrid, used while young as a potherb. By drying, most of the ranunculi lose their acridness.

*Crow-Foot, Ranunculus, $R$. repens. Herb used as a potherb while young.- White-flowered crow-foot, Ranunculus montanus, $R$. aconitifolius. Herb used to cure intermittents, by being applied to the wrists.

* Marsh Marigord, Caltha palustris. Herb acrid, caustic, useful externally in diseases of the reins or loins.

*Peonr Pconia officinalis. Root and seeds anti-epileptic, emmenagogue.

*Mouse tail, Myosumus minimus;-Bird's eye, Adonis vernalis :- Pheasant's eye, Red morocco, A. antumnalis. Astringent ; roots bitter.

*Herb Cinristophen, Bane berries, Christophoriana, Actca spicata. Vulnerary, astringent; juice of the berries affords a deep black dye. $-A$. racemosa. Root, infused in spirit, used in rheumatic pains; used also in astringent gargles.

ZaxтHoRriza A PHFolia. Root, ycllow root, zanthorrhiza, I. U. S., extremely bitter ; bitterness very permanent; makes a yellow lake.

Hydrastis Canadensis. Root, Canadu ycllow root, bitter, used for calumbo; gives out a most beautiful yellow colour.

Вцаск иеццвове, Cleristmas rose, Elleborus niger, Melampodium, Hellelorus niger. Root, hellebori nigri radix, nauseous, violently purgative both to man and horse, anthelmintic, diuretic and enmenagogue, also used as an exutory in cattle to keep open issues; dose in powder, gr. $x$ to $\partial j$. Officinal preparations.'Tinct. helleb. nig., L. E. D. Extr. helleb. nig., E. D.

Goin) tunend, Coptis trifoliata, Helleborus trifolius. Root a pure bitter, used in thrush; leaves dye yellow.

"WHiD BLACK HЕLLEBORE, Bear's-font;-Helleborus viridis, H. liyemalis. Qualities the same as black hellebore.

EAst INDAN BLACK IFE,teBORE, Hellelorus orientalis? Roots very different in appearance from the European; qualities the sane. 
*Great bastard bear's-Foot, Setter wort, Helleboraster maximus, Helleborus foetidus. Leaves, hellebori foetidi folia, vermifuge, in powder, gr. $\mathrm{x}$ to 3 ss or a decoction of $3 \mathrm{j}$; the juice (a little vinegar being added to moisten the bruised leaves) made into a syrup, is also used with advantage, a tea spoonful at night, and one or two in the morning.

*Globe crow-Foot, Locker gowlons, Ranunculus globosus, Trollius Europaus;-T. Asiaticus. Equally acrid, and must be used with caution.

Fenner, flower, Devil in a bush, Nigella, Gith, Nigella sativa $-N$. Indica; $-N$. arvensis. Seeds acrid, oily, attenuant, opening, used as a spice.

*Columbine, Aquilegia sylvestris, A. vulgaris. Herb, flower, and seeds opening, acrid, diuretic, and used in detersive gargles.

Cimicifuga fotida. Root antispasmodic.

Black sNake root, Cimicifuga serpentaria. Root, cimicifuga, P. U. S., used for rattle-snake root.

Lark's spur, Delphinium, Consolida regalis, Delphinium consolida. Root, delphinium. P. U. S., vulnerary, consolidating wounds, ophthalmic.

UPRIGHT LARK's-SPUR, Delphinium Ajacis,-Siberian bee lark'sspur, D. elatum. The same qualities as lark's-spur.

Stavesacre, Staphisagria, Delphinium staphisagria. Seeds, staphisagria semina, acrid, nauseous, imported from Turkey ; kill lice and rats, purging violently in doses of gr. iij to gr. $\mathrm{x}$; used as a masticatory in toothach, and also in apophlegmatizant gargles.

Wolfsbane, Aconitum lycoctonum. Root poisonous, occasioning vertigo, stupor, and spasm; used to kill wolves.

Purple monk's-Hood, Aconitum, $A$. Neomontanum. Leaves, aconiti folia, narcotic, powerfully diaphoretic and diuretic, in doses of gr. j, gradually increased.

Early blue wolfsbane, Aconitum napellus;-Greater monkshood, $A$. cammarum;-A. Tauricum. Are used indiscriminately for one another, and the leaves sold for those of aconitum.

Wholesome worfsbane, Yellow helmet flower, Anthora, Antithora, Aconitum anthora. Roots cordial.

Knowltonia vesicaria. Used as a vesicatory.

\section{PARTS OF PLANTS NOT KNOWN.}

There are several roots, barks, and other parts of vegetables common in the shops of the native druggists in the Englisn dominions in the East Indies, whose origin is unknown; some of 
which are occasionally brought to Europe. They are enumerated by Dr. W. Ainslie in his very valuable Materia Indica, that they may be further investigated; for, as he justly observes, it is better that many things should be brought forward, although sonie may ultimately prove of little value, than that any one should be omitted which might become a valuable acquisition to medicine. Some of these which have been brought to Europe are here enumerated, and to these are added some African and American drugs and woods of unknown origin.

BARKS.

J UвABA. Taste and smell of vanilla, antispasmodic.

Massoy bark. Tonic.

Autour bark. Is it not the macer grœcorum of the old physicians? Resembles coarse cassia, used in making fine carmine; from Turkey.

Angelince cortex. Vermifuge, used in Granada.

Kilioorum puttay. Stomachic; resembles Canella alba in appearance and properties.

Vaymbadum puttay. Used as a red dye.

Pocgereba cortex. Used in dysentery; brought from America.

Unquentrius cortex. Slimy, used in ulcerous cases; brought from South America, perhaps from Ulmus Americana.

Chinese rice paper. Texture excellently adapted for flower painting; doubtful whether from an Artocarpus or a Nelumbium.

IIERBS AND LEAVE.S.

Letchicutlay elley, folia de bunkood. Used in rheumatism, much esteemed by the Portuguese.

Agal arjal. A mucilaginous alga, used to stiffen Chinese silks and paper.

Roots.

Lopezka jaur, radix Indica Lopezina, used in colliquative diarrhcea, and the last stage of consumption.

P'ooda carapan puttay, Pan de merda, Pan sujo. Smells like human excrements; used in a liniment against inveterate itch.

Put chuck. Burned in China as a perfume.

Pcepul mul, Pimple mool, Pipla more. Aromatic.

Behen alloum. Ascribed to Cucubalus beken; but this is doubted.

Behen rubrum. Ascribed to Statice limonum; but this is still more doubtful. 


\section{from India.}

Gentiana Indica. Bitter, aronatic; brought by the Portuguese

Sanctce Helence radix. Aromatic, odour between galangale and cardamoms : brought from America.

Ikan. Similar to salep; brought from China.

Matalista. P'urgative, $3 \mathrm{ij}$; from America.

Pefaulina radix. Similar to scorzonera, rather sweetish; brought from China.

\section{SEEDS.}

Chouan. Resembles semen santonicum, used in making fine carmine.

Kanari nuts. Kernels taste like filberts, beat up with sago are made into cakes, and eaten as bread; yield a fine oil.

WOODS.

Bar wood. Red, used in dyeing; from Gaboon.

Bois de calambac de Mexique. Greenish brown, in large logs, sweet-scented, bitter, used by the French cabinet-makers; said to be brought also from Timor and Solor.

Pao aquila. Black, compact, heavy, resembles black ebony, sweet-scented, bitter.

Lignum rodium, Bois de rose du Levant, Bois de Chypre. Brought from Turkey, shavings sweet-scented, distilled for its oil.

Bois tapire. Veined red and yellow, sweet-scented; supposed to be a variety of Sideroxylum inerme; brought from Cayenne, in large logs.

Violet wood, Palisanten liout, Bois violet, Bois de palexandre. Dark violet, close-grained, takes a fine polish, used by the cabinetmakers and violin-makers, for bows for stringed instruments; brought from the Dutch colonies in South America in large logs; perhaps Acacia hrematoxylon.

Bois de la Chino. Reddish, liable to split, does not keep its polish; obtained by the French cabinet-makers from Holland.

Japans hout. Sold by the cwt.-Nagel hout. Sold by the single $\mathrm{lb}$-Sacradaans hout. Sold by the cwt.-St. Marten's hout;-Salmoni hout. From Amboyna.-Rood eben hout. From Mauritius._Cocus wood;-King wood;-Snake wood;-Tulip wood;-Brazil beef wood;-Botany-bay wood. Probably Evania resinifera.

East India satin wood;-Carabouca uood. From a species of palm, finely veined and spotted. 


\section{SPECIES.}

\section{DENOMINATIONS COMPRISING SEVERAL VEGETABLES.}

Four gheater carminativf: hot seens, Quatuor semina calida majora carminativa. Anise, Carui, Cummin, and Fennel.

Four Lesser hot seeds, Quatuor semina calida minora. Bishop's weed, Stone parsley, Smallage, and Wild carrot.

Four cold seeds, Quatuor semina frigida. Cucumber, Gourd, Melon, and Watermelon.

Focr resser cold seeds, Quatuor semina frigidu minora. Endive, Lettuce, Purslain and Succory.

Five opening roots, Quinque radices aperientes. Asparagus, Butcher's broom, Fennel, Parsley, and Smallage.

Five lesser opening roots, Quinque radices aperientes minores. Caper, Dandelion, Eryngo, Madder, and Restharrow.

Five emolliext helis, Quinque herbe emollientes. Beet, Mallow, Marsh mallow, French Mercury, and Violet.

Fivf, captilary ueris, Quinque herbe capillares. Hart's tongue, Black, White, and Golden maidenhair, and Spleen wort.

Four sudorific woods, Quatuor ligna sudorifica. Guaiacum, Perfumed cherry, Sarsaparilla, and Sassafias.

Four condat Fiowens, Quatuor flores cordiales. Borage, Bugloss, Roses, and Violets.

Four carminative rlowers, Quatuor flores carminativi. Camomile, Dill, Feverfew, and Melilot.

Fuer resolvent meals, Quatuor farince resolventes. Barley, Bean, Linseed, and Ryc.

The FIve ayrobai.ANs, Myrobalani quinque. Belleric, Chebulic, Emblic the most purgative, Indian, and Yellow the most astringent.

Glyster herbs, Herbe pro enemate. Mallow leaves two parts, and camomile flowers one part: an ounce and a half to a pint of water.

Fonfatation herbs, Herbe pro fotu. Leaves of southeruwood, tops of sea wormwood, and camomile flowers, each two parts, bay leaves one part: thrce ounces and a half to six pints of water.

CAKF: SAFrron, Crocus in placenta. Hay saffron one part, petals of marigolds or safflower nine parts, made into thin cakes with a little oil.

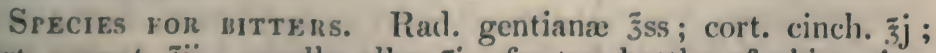
cort. aurant. $3 i j$; canellax albe $3 \mathbf{j}$; for two bottles of white winc. 
2. Rad. gent. $z^{i j}$; cort. aurant. $\xi_{j}$; cardam. minor. $z^{\mathrm{ss}}$; for a quart of brandy.

3. Rad. gent, -cort. aurant. sicc. ana $3 \mathrm{ij}$; cort. limon. recent. zss; for a pint and a half of boiling water.

SPECIES Yor DIET DRINk, Species pro decoctu lignorum. Lign. guaiaci ऊjss ; rad. chinæ, -rad. sarsa. ana $\jmath^{i j}$; lign. sassafr. 3iij ; rad. glycyrrh. sicc. 3iv; for three quarts of water.

2. Lign. guaiaci, -rad. sarsa. -rad. chinæ, ana $3 \mathrm{j}$; sennæ electæ zss ; rad. rhæi $3 \mathrm{ij}$; for four quarts of water ; to which add, before it is boiled, subcarb. potassæ $3 \mathrm{j}$; antimonii crudi ziiij : used in gonorrhœa and syphilis for common drink.

British her b tobacco, Species sternutatorice. Thyme, two oz.; coltsfoot, three oz. ; betony and eyebright, of each four oz. ; marjoram and hyssop, ana, two oz.; rosemary and lavender, ana, eight oz., mixed.

Imitation tea. The leaves which have been found in the possession of the manufacturers, are those of the sloe tree, ash tree, elder bush, and white thorn. They are described as having been boiled, in some cases, with logwood, or scalded, then rolled up and dried, the green bloom being given to them by Dutch pink, or verditer. The use of sheeps' dung, verdigris, or copperas, seems a mere slander.

Russian tea. Composed of the leaves of Saxifraga crassifolia, Pyrola rotundifolia or winter green, Clematis alba, Pyrola uniflora, Prunus padus or bird cherry, Spiræ coronata, Ulmus campestris or common elm, Polypodium fragrans, and Rosa canina, or dog-rose.

Bowles's HER B TEA. Wood betony, wood sage, and ground pine, equal parts of each. Very useful in gout, headach, and nervolis disorders.

Mongul tea, Tea in tiles, Ziegel thee. Made by the Mongul Tartars and Baritoes, from leaves which resemble those of Cerasus avium, made into flat cakes with the blood of animals; the leaves of Ulmus pumila and Prunus padus are also used.

Semilla DEL GUACharo. Various sorts of hard and dry fruits, found in the stomachs of the young guacharoes. A celebrated South American remedy against intermittent fevers.

Graverle, Gravellee Clavelli. Lees of wine mixed with vine twigs, and the cake of grapes, being the refuse of the vineyards and vinegar-makers; dried for sale to make a pure kind of alkali.

Piccalrluy, Indian pickle. White cabbages sliced, cauliflowers pulled to pieces and scalded, radishes topped and tailed, French beans, celery in three-inch lengths, shoots of elder peeled, clusters of elder flowers unopened, all salted for two or three days, 
then mixed with apples and cucumbers sliced, and a large proportion of ginger, garlic, turmeric, long pepper, and mustard seed, as the pickle is expected to be very warm; the vinegar must also be the strongest that can be procured, and just sufficient to float the articles: any other vegetables may be used at pleasure.

\section{A N I A L S.}

Avimal substances are often preserved by drying in a stove, or oven, which should be heated as high as possible, provided the heat is not such as to scorch the external parts, nor operate any other change in the substance than the evaporation of the water.

The action of frost is also used in the northern countries to preserve animal substances, as rein-deer tongues and many kinds of fish: this requires no other care than to guard them against the attacks of living animals.

The brine of common salt is one of the most casy and effectual methods of preservation. To employ it in the most advantageous manner, a saturated solution of salt in water is first made : as 100 parts of the brine are composed of about 28 parts of dry salt and 72 of water, it will require rather more than three pounds and a quarter of salt to be added to each wine gallon of water to form it, or four pounds to each imperial gallon. The meat, or other substance, is to be put into this brine, and a board placed upon them, loaded with a lump of solid salt, or at least with the largest grained salt that can be procured, so as to kecp the substances under the brine, and also to keep the brine at its full strength, as the juices of the meat or fish of course weaken the original brine. After the meat or other substance has remained in the brine for two or three days, it is taken out, and either dried by rubbing it with bran or pollard for present use, or packed in barrels with large grained salt for long keeping, or hung up in a smoking room. When the brine gets loaded with the juices of the meat or fish, it is to be boiled in an iron pot, carefully scummed, and then strained through a canvass or flannel bag, a sufficient quantity of water being added in the boiling to take up nearly all the salt that has settled at the bottom. Different sorts of meat or fish ought not to be put into the same brine, but by this boiling and scumming the same brine will last a lorg time. The addition of an ounce of saltpetre to each pound of salt that is used, will preserve the red colour of the meat, and the same quantity of brown sugar will improve its flavour.

Animals are also preserved by packing in dry salt, for which purpose salting-tubs with double bottoms, the upper having 
several small holes bored through it, are preferable. A layer of large-grained salt is laid upon this, the pieces of meat or fish packed along with the same kind of salt, and covered at top with another layer of salt. In about a week, or rather sooner, the substances are taken out and repacked in small vessels with the same coarse-grained salt; some add a little spirit of salt in this repacking to improve the flavour. Cutting out the bones of meat that is to be salted in this manner, and splitting large fish, is of advantage. In some places the boned meat is also pressed by heavy stones laid upon a plank, or by a screw before it is put into the salt.

Preservation of animal substances by merely rubbing in of salt is practised when and where salt is dear. The meat is laid on a table or bank of brickwork which has a gentle slope, and well rubbed with salt, to which a little saltpetre and coarse sugar may be added with great advantage; a small quantity of salt or dry mixture is then strewed over the meat. As the moisture of the meat melts some of the sait; it runs off the table or bank. If only a single piece of meat is thus salted in a dish, a smaller dish should be placed, bottom upwards, in the larger dish, to allow the brine to drain away from the meat. This method is less efficacious than pickling in brine or packing in dry salt, and frequently fails : it also cannot be well applied to fish, on account of their tenderness not bearing the necessary rubbing. The brine that drains from the meat may be made boiling hot, scummed, boiled down nearly to dryness, and the salt thus obtained used again.

The preservation of animal substances in strong vinegar is seldom practised; but a mixture of common vinegar, small beer, and water, in equal quantities, is used to pickle some fish, as salmon, for present use, as it will not keep them more than a few days.

Olive oil is also used to preserve fish, as salmon and tunny, the jars being filled to the brim, well closed, and the joints secured with mortar or plaster of Paris to keep out the air, which would turn the oil rank.

Small birds, as quails, and fish, as char, are also preserved by potting them, that is, by pouring clarified butter over them, so as to fill the vessel, which is then kept closely covered, and paper pasted over the joints. Meat and fish, previously dressed, are also chopped, and pounded to a paste along with spices, pressed into pots, and clarified butter poured over the paste to the thickness of a quarter of an inch, to keep it from the air.

For preserving meat and fish by smoking them, in perfection, proper rooms are necessary. These rooms are on the two uppermost floors in the house, as high from the ground floor as possible. 
The fire-place is placed in the cellar, where the previous salting is performed, in order that the smoke may deposit its soot in the flues, of which there are usually two, placed side by side, and arrive cool in the lower smoking room, in which the pieces of meat or fish are hung as close as possible, yet so that they may not touch one another. From this lower room the smoke passes through one or two openings cut in the ceiling into the upper room, which is mostly used for smoking sausages or fish. The fuel used is very diy oak, as moist wood would be apt to produce mouldiness, and turn the meat rank. Meat or sausages about five or six inches thick require six weeks to be smoked properly, thinner and slenderer pieces a less time in proportion. The smoke penetrates quicker in cold weather than in warm; hence the manufacturers seldom smoke in summer. The skins of animals are also prepared in this manner instead of by tanning; the leather thus prepared is, when well made, semitransparent, like horn.

The buccaning of meat is a rucie kind of smoking, practised by hunters in forests. Forked branches of wood are stuck in the ground, and by these means a grating of rods is formed between two and three feet high from the surface of the earth. The flesh of the animals that are killed is cut into thick slices, or merely scored very deep, placed on this grating, a fire lighted under it, and the meat rendered fit for keeping, partly by the drying, and partly by the smoking.

Another method of preserving animal substances used in hot countries is called charqui, or jerking. The lean of meat is cut into as thin slices as possible, and exposed to the full action of the sun to dry it, the slices being turned when necessary. The meat thus dried is pounded in a mortar into a uniform paste, which is pressed into jars for use. If the meat is prepared for travelling, it is beaten up with maize meal, and pressed into leather bags, so that it does not require to be eaten with bicad, or any further dressing by fire.

Animal substances, particularly the skins, are preserved by tanning them; for this they are immersed in water along with scveral kinds of bark, mostly oak or larch, for several days, or even weeks. Other astringent substances, as terra Japonica, are also employed for this purpose, by which the time is shortened, but the sulsstance is rendered hard and brittle.

Another method of preservation mostly applied to skins is by tunving them. For this they are soaked in water with fresh slaked lime, and left in it for six weeks, the water being changed twice, then rinsed, soaked afresh in water mixed with wheat bran, until they first float in the water, and when beaten down do not rise again; the bran is then scraped off; after this a paste is thus prepared,-for 100 sheep's skins 8lb. of alum and 3lb. of salt are 
dissolved in warm water, and this is added to 20lb. of fine wheat flour and 96 yolks of eggs, so as to form a liquid paste. A ladle full of this paste is put into a trough of warm water along with twelve of the skins, where they remain for some time, and are then pulled and stretched. This is repeated twice, and they are then left for five or six days at the most, after which they are dried,-the quicker the better.

Dipping in pyroligneous acid is an effectual method of preservation. When the substance is intended for food, it must not be left in the acid for more than two or three minutes. If rough pyroligneous acid is used, it communicates the taste of smoked meats to the substance; and for this purpose it is sufficient merely to smear it over the substance with a feather or sponge.

The solution of corrosive sublimate in water is used to preserve objects of natural history, with a view of preventing their being destroyed by insects, but it renders them as hard as a board.

Alcohol diluted with water is more commonly used: this also hardens the finer parts, unless some liquor ammoniæ is added to the alcohol.

The several kinds of flesh, fish, and white of egg, contain twelve or even thirteen oz, of water in the lb.; the three or four oz. of solid matter is composed of about one o\%. of gelatine, and the remainder is albumen, which is left undissolved when the solid matter (obtained either by drying with heat, or by oil of vitriol in a vacuum) is boiled in water.

\section{MAMMALIA.}

Man, Homo; - Mummy, Mumia. Procured from Egypt, made by impregnating the subject with bitumen, or, according to Dr. Granville, with bees' wax ; formerly used in bruises, epilepsy, asthma, phthisis, 3 ss to $3 \mathbf{j}$ at night in wine.

Hair. Prepared by baking in a crust of flour and water ; that of different nations judged by their smell, the Scotch and Irish hair having the strongest scent; hair with a natural curl rare, not above $301 \mathrm{lb}$. in a bale of $140 \mathrm{lb}$; f fine long white hair is 21 . or more the oz.-Subcutaneous fat and excrements used.

Monkey. An unknown species yields Borneo oriental bezoar.

Neat cattle, Kine, Bos taurus. Flesh of the young animal, veal, caro vitulina, nutritive, easily digested. Flesh of the adult animal, beef, caro bovina, nutritive, strengthening.-Pickled beef. The flesh rubbed with salt, and packed with it.-Hung beef. Flesh salted and smoked. - German sausages. The muscular flesh chopped in small pieces, salted, packed in intestines, and smoked. -Pickled tripe. The stomach preserved in brine.-Pickled tongues. Packed in salt.-Dried tongues. Pickled tongues smoked.- 
Rennet, calves' maus, coagulum. The stomachs of calves washed, and preserved either in brine or dry salt; used to curdle milk, two square inches from the bottom usually sufficient for a cheese of 60lb. - Brains. Boiled, used by the vermicelli-makers to grease the screws of their presses. - Skulls, canards; -inside of the horns, cornillons; - remains of the rib bones left by the button-mould makers, dentelle des boutonniers, escafillottes; - The tails, ox tails. All used to make glue and portable soup.-Shavings of calves' shin bones, ossa vitulina. Sold for hartshorn shavings.-Brochettes, the thin parings cut by the currier from skins;-Buenos Ayres, the trinmmings of foreign hides, and the raw-hide thongs used to tie the hides together;-Patins, the tendons of the legs attached to the small hind hoofs; - Nerf de boenf, the genitals of the male; - The ears and skins of calves' heads are all used to make glue and size.-Cow heels, the feet from which the hoofs have been separated, used to make hatmaker's glue.-Outside of the horns ;Hoofs, used for making steel and Prussian blue, will not make glue or soup.-Teeth, distilled for subcarbonate of ammonia.Hides, made into leather, either by tawing, tanning, or smoking, -Refise bones of butcheries and kitchens, boiled for bone grease, and made into bone black.-Horns from Brazil, $2 l$. to $2 l .5 s$. by the 123. - Hides, foreign, $5 d$. to $8 d$. the $\mathrm{lb}$.

Goldbeater's skin, prepared from the peritoneal membrane of the cæcum, which, as soon as it is detached, is pulled out to the extent of two feet or upwards, then dried. The dried membrane, which has the appearance of a piece of packthread, is then soaked in a very weak solution of potash, and spread out flat on a frame; another membrane is then taken and applied to the other, so that the two surfaces which adhered to the muscular membrane of the intestine may adhere together; they unite perfectly, and soon dry. The skins are then glued on a hollow frame, washed with alum water, dried, washed with a solution of isinglass in white wine, to which spices, such as cloves, nutmegs, ginger, or camphire, have been added, and varnished with white of egg. Used to separate the leaves of gold while being beat thinner, and as a defensive for cuts.-Allantoides of calves, prepared in the same manner; used to make air balloons for lectures.-Blown up intestines, prepared by cutting off the fat and part of the peritoneal membrane, turning them inside out, macerating in water for a few days, until about one-third of the mucous membrane can be removed in strips by the nail, blowing them up, drying them, pressing out the air, exposing them to the fumes of burning brimstone, and finally packing them in boxes or bags, along with a small quantity of pepper, camphire, and other aromatics. Lately the water in which the intestines are macerated has two pails of water, to each of which twelve ounces of Javelle bleaching liquid 
at 12 or $13 \mathrm{deg}$. Baume, are added for every 50 sets of intestines : this addition not only corrects the fetid scent immediately, but also allows the mucous membrane to be removed after a single night's maceration : used for packing German sausages and black puddings. - Ox bladders, prepared nearly in the same way: used for packages, and for covering bottles.-Druggists' gut skins, the blind gut prepared in the same coarse manner: used for wrapping up extracts, pill masses, as also the fetid gums, $3 s$. the gross.Gelatine brut, from the skulls of oxen, the spongy insides of ox horns and the ribs, by washing them, soaking them in an equal weight of weak muriatic acid, at $6 \mathrm{deg}$. Baume in the winter, and 5 or only 4 in summer, for about ten days; pouring off the acid, soaking them afresh in acid at only 1 deg. Baume for a day and night, steeping them in water for some hours, renewing it five or six times until all the acid is washed out, and finally steeping them in a very weak solution of subcarbonate of soda. $100 \mathrm{lbs}$. of bones yield about 25 or $27 \mathrm{lbs}$. of gelatine brut : used for making carpenters' glue, as the fat in the bones gives it a bad taste, and renders it unfit for soup.-Abdominal fat, marrow of the thigh bone, milk, gall, cystic calculus, urine, and dung, collected for use.

Buffar.o, Bos bubalus. Flesh coarse, nutritive, but preferred to that of neat cattle in summer, as they preserve themselves from the teasing of insects by remaining most of the day under water, leaving only their nostrils above it. Skin tanned, buff leather; epidermis of the skin removed in preparing buff leather, effleurures, used to make glue; hoofs sold as elk hoofs, but want the sweet smell when scraped.-Horns from the East Indies.

Sheep, Ovis aries. Flesh of the yourg animal, lamb, nutritive, easily digestible;-flesh of the adult animal, mutton, nutritive, strong tasted;-mutton hams, legs salted and smoked, or dipped in pyroligneous acid for two or three minutes, and dried;-skins tawed, white leather, tanned, basil skins, also made into parchment; -abdominal fat, raw mutton suet, sevum ovinum, sevum P. L. 1809, adeps ovis arietis, eaten raw as a pectoral medicine;-shulls, blade bones, omoplates, used to make portable soup and bone glue;stomachs, ewe rennet, used to coagulate milk:-the parings of parchment; - sheep's trotters; the trimmings of sheep-skins cut off by the tanners, used to make glue. -- Horns, rubbed upon heated iron or steel tools to varnish them. - German sausage skins, prepared from the intestines, by soaking them until the peritoneal membrane can be detached by a knife, that of the half next the small end of the intestine comes off in strips of three or four inches long, the remainder follows in the whole remaining length of the intestine, provided the detachment is begun at the 
small end; these long strips are called filundre, and used as thread to sew the guts: the mucous membrane is then removed, and the thick end of the intestine cut off for this use in the length of about eight feet. If these skins are to be sent to a distance, they are salted for two or three days, and then repacked with fresh salt.Comdonus, Armour, Baudruches, Redingotes Anglaises. 'The intestina ceeca of sheep soakcd for some hours in water, turned inside out, macerated again in weak alkaline ley changed every twelve hours, scraped carefully to abstract the mucous membrane, leaving the peritoneal and muscular coats; then exposed to the vapour of burning brimstone, and afterwards washed with soap and water; they are then blown up, dried, cut to the length of seven or eight inches, and bordered at the open end with a riband: used to prevent venereal infection, or pregnancy.-Bandinches fines. The blind guts are soaked in weak ley, then turned inside out, and dressed as before: soaked again in ley, brimstoned, drawn smooth upon oiled moulds of a proper size, observing that the external coat of the gut is next the mould, and dried.-B. superfines. The baudruches fines are washed in two soapy waters, after soaking twenty-four hours in them, and very carefully dressed with the knife; then soaked in hard water for three days, the water being often changed; dried with a clean cloth, scented with essences, and being stretched on a glass mould, rubbed with a glass to polish them.-B. supperfines doubles. The baudruche in its moist state being on the mould, another is drawn over it also moist, when the two insides adhere together.-C'unepin. The flower, or epidermis, torn from the skins, after soaking in water, to make chamois leather; larger pieces used to make gloves, French chicken skin glores, packed and sold in a gilt walnut shell, also fans and some other toys; middling pieces used to wipe fine cutlery; small to rub out pencil lines, which it takes out cleaner than Indian rubber.

Coarse catgnt. From the intestines, by removing the mucous and peritoneal membranes, then soaking them in water, to each gallon of which is added an oz. of potash and another of pearlash, then scraping them with a copper plate having a semicircular notch, twisting thein according to their uses, sometimes colouring them, as for whips, with ink, red ink, or sap green, and exposing them to the fumes of burning brimstone for two or three times: used for tennis rackets, whips, hatmakers' bows, and clock-work.-Fine catgut. 'The mucous and peritoneal membranes are removed with great care, they are then soaked for a day or two in water to which potash is added, then removed to water impregnated with burnt lees of wine, which is made stronger by degrees, scraping them carefully to separate the fat. As soon as the intestines begin to float, they are immediately taken out, twisted, brimstoned, again twisted, and dried; when sufficiently dried, the catgut is rubbed 
over with olive oil, and kept as long as convenient, as it improves by age: used for musical instruments; the finest are still made only at Naples.

Gelatine brut fin. From the skulls, blade bones, and shank bones, the ends being cut off, and the bones cut down the middle to remove the fat, steeping them in muriatic acid, as the gelatine brut of ox bones, then in boiling water for a few minutes, wiping them carefully, drying them, shaking them together in a bag to remove the internal pellicle, cutting them across or into dice to disguise them, and finally dipping them in a hot solution of gelatine to varnish them. Used to make soup, keeps better than the cakes of portable soup; and when less carefully prepared, used also to make carpenters' glue for fine work. The muriatic acid obtained by distilling salt with oil of vitriol in iron cylinders is less fit for this purpose than that of the manufacturers of subcarbonate of soda, as being apt to give it a bad taste. Their milk and subcutaneous fat are also used, and their dung by the dyers.

Camer, Camelus Bactrianus;-Dromedary, C. dromedarius. Stomach, camel rennet, used to curdle milk: their milk, cystic calculus, and dung are used.

Gost, Capra hircus. Flesh of the young animal, hid, nutritive; stomach, East Indian rennet, goat rerinet, used to curdle milk: skins tanned, Morocco leather, yields milk: hair from Italy.-C. ibex. The blood is used.-Gazelle, $C$. gazella;-C. agragus.

Antelope oryx. Yield Persian oriental bezoar.

Musk DEer, Moschus moschiferus. Follicle near the navel, musk in the pod, moschus in vesica;-Tonquin pods, China pods, M. Tunquinensis. M. Chinensis, thin, round, size of a pigeon's egg, covered with short red hair, lined with a thin brown skin, imported in bags of 20 to $100 \mathrm{oz}$.- Thibet pods, musc kebardin, m. Thibetinus, smaller, of a silvery white colour, imported from Bengal and Russia.-Musk bags, exuvice moschi. Those from which the musk has been extracted; used to scent liquids.

Rein deer, Cervus tarandus. Tongues preserved by freezing, imported from Norway as a delicacy.

Buck, Doe, Fallow deer, Cervus dama. Flesh, venison, highly esteemed; horns, English horns, round, white; shavings, rasura cornu cervi, used to make jelly and burnt hartshorn; abdominal fat used, also the hair, mohair.

Stag, Hart, Hind, Red deer, Cervus elaphus. Flesh, venison, less esteemed; horns, flat, dark brown, foreign horns, cornua, P. L. used by the cutlers for handles of knives, ordered by the college to be used in medicire for the former. 
Eık, Cervus alce. Hoof, ungula alcis, smells very sweet when scraped, made into necklaces in France for, teething children; shavings, $3 j$ in powder, in epileptic fits.

Honse, Equus caballus. Flesh of the young animal nutritive, strong smelling, eaten in some countries, smoked for keeping by the 'Tartars; tongues salted and dried, sold for neats' tongues; bones boiled for bone grease, and distilled for bone black; 'skins tawed for thongs of whips, also tanned and smoked, shagreen, very tough, particularly the croup.

Catgut. From the intestines, which are soaked in water, with a pailful of weakened Javelle bleaching liquid for each eight or ten sets; the mucous membrane is then separated, the intestine cut into four strips by forcing a ball with four knives placed crosswise along them, these strips twisted, and when dry, any slight inequalities removed by fish skin; used for turning-lathes and other machinery. Stomach of the foal, horse rennet, used to curdle mares' milk; hair of the tail twisted round wooden cylinders and baked, used to make elastic cushions.

Ass, Asinus, Equus asinus. Flesh eaten, and esteemed a delicacy; skins made into shagreen; intestines made into coarse catgut; yield milk.-Mule, E. mulus. Skin made into shagreen; intestines made into coarse catgut.

Brown bear, Ursus Europæus. Abdominal fat used.White bear, $U$. maritimus. Gall used.

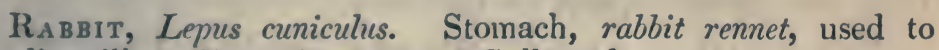
curdle milk.-Hare, L. timidus. Gall used.

Civet cat, Viverra zibetha. Dried glandular follicle from beneath the tail, zivet perfume, poollughoo shuttum, sold in the Indian bazars, contains civet.- $V$. Indica;-Pole cat, Mustela putorius. Yield civet.

Braver, Castor fiber. Large follicles near the genitals, castor pods, custoreum in vesicis, contains castor.-Russian castor, Castoreum Rossicum, C. Siberinum, in large pods, contents friable, not quite dry, liver colour, strong peculiar smell, taste acrid, bitter. The pods are prepared by boiling them for ten minutes in a ley of wood ashes, then drying and smoking them for an hour over a fire upon which some birch bark is laid; ordered by the London college to be alone used in medicine, but it is scarcely to be procured at any price.-New England castor, C. Novœ Anglia, C. Anglicumum. Pods smaller, smell very different from the Russian : imported from North America.

Elephant, Eleplas Capensis. Tusks, ivory, ebur, dens elpphantis, shavings, rasura eboris; used to make jelly and ivory black; from Africa. 
Hog, Sus scrofa. Flesh, pork, caro suilla, extremely nutritive and easily digested; of the adult animal, bacon hog, salted in brine or with dry salt, and then either kept moist, pickled pork, or merely dried, white bacon, or dried and smoked, bacon, that of the hind legs, ham, equally nutritive, but less easily digested; skin, rind, eaten with the flesh if not smoked, also tanned for saddle seats; bladders prepared as ox bladders: the abdominal fat, pig's flare, adeps suillus, adeps P. L. is used, as also the blood for food, and it yields a bezoar.

Sea horse, Bottle-nose seal, Sea lion, Phoca leonina. Flesh, beef, nutritive; yields blubber, and about two hhds. of blood.

Ursine seat, Sea bear, Phoca ursina. Flesh of the young animal has the taste of lamb and sucking pig; that of the adult is coarse, black, and unpalatable : fat about four inches thick, unpalatable.

Leonine seal, Sea lion, Phoca jubata. Flesh of the young nutritive ; skin used as leather, yields fat.

Seat, Sea calf, Sea dog, Phoca vitulina. Flesh delicate, hide and fur used; yield oil.

Arctic watuus, Morse, Sea cov, Trichecus rosmarus. Blubber four inches thick, white, firm; teeth a foot long, weigh $4 \mathrm{lb}$. to 10lb., not equally sound throughout, some parts superior to ivory, others inferior; skin forms excellent leather.

Indrax walrus, Sea cov, Dugong, Trichecus dugong. Teeth, Lapis manati, very white, used as ivory.

Whaic-tailed manati, Manatus borealis. Flesh of the young animal like veal, of the adult like coarse beef, and requires long boiling; blubber has the taste of oil of almonds, grows yellow in the sun, substituted for butter, keeps sweet all the summer; skin used for shoes, and covering boats.

River horse, Hippopotamus amphibius. Subcutaneous fat, weighs from $1000 \mathrm{lb}$. to $2000 \mathrm{lb}$., particularly delicious; tongues preserved by drying, delicious; teeth, morse teeth, harder and whiter than ivory, not so apt to turn yellow, used to make artificial teeth.

Brack wirale, Greenland whale, Balana mysticcetus. Teeth, whalebone, whale fins, lamince balcnarum, elastic, used for flexible probes : yields subcutaneous fat, Llubber.-Iceland whale, B. nordcaper;-Fin-fish, Balcnoptera gibbar;-Sea suord, Delphinus gladiator;-Porpoise, D. phocena. Yield subcutaneous fat, blubber.

Great spermaceti whale, Physeter macrocephahe; - Bluntheaded cacholot, P. trumpo ;-Small-eyed cacholot, P. microps. Yield subcutaneous fat, blubber, and head matter, from whence spermaceti is extracted. 
Narwha, Unicorn fish, Monodon vulgaris. 'Tusk, unicorn's horn, cornu unicomu, C. monoceratis. A very fine ivory; yields blubber.

Friss. The membranous remains of blubber, from whence fish oil has been drained; made into animal charcoal.

\section{AVES.}

Flesh and eggs uutritive.

*Common row t, Phusiamus gallus, Gallus domesticus, G. yallinaceus. Flesh restorative, delicate; eggs, ova gallinacea, kept in a cellar, in a pan with water and slaked lime, or in brine, or covered with a coat of oil or butter.

"TURKey, Melearyris gallopavo. Rough inner skin of the gi\%zard salted and dried, turkey rennet, gallino, used to curdle milk for chcese, makes a finer curd than calves' rennet.

Quall, Tetrao coturnix. Inported from 'Turkey preserved in oil, and from Cagliari potted with clarified butter.

Carolina PIGeons, Columba migratoria. Yield an oil.

"RAvEs, Corvus corax. Pen feathers of the wings, crouv quills.

Ostricr, Struthio camelus. Feathers preserved by dipping in a mixture of one gallon of lime water with five of clear spring water, and drying or stoving them; from Africa.

* Goose, Anas anser, Anser domesticus. Flesh nutritive, pen feathers of the wings, quills, prepared with lime water, hardened by fire, barrels coloured with dilute nitric acid; from Germany. Its fat is used.

*Solaxd coosk, Anas sula, Sulu alba. Salted and dried for foorl, sulted geese, very fisliy to the taste.

\section{REPTILIA.}

Greex turten, Chelonia mydas. Flesh highly nutritive, and restorative; has succeeded to the place of viper brotl.

HawKS-BILL TURTLE. Flesh produces fever and dysentery; egrgs estecmed as food ; scales of the shell, tortoise shell, turtle slicll, prepared by softening, in warm water, and pressing between hot iron plates, used in cabinct.work; from the East Indies, $1 l$. 16s. to $2 l$. the lb.

Logrernead tURtif, Merliterranean turtle. Flesh coarse, rank, but eaten; scales very thin, but used in cabinet-work; fat melted into oil.

Mcd tortorse, Testudo lutaria, Testudo, C. P. Flesh restorative; the best summer meat in warm countries, the cattle being thin from the irritation of insects, and poultry rank from the quantity of worms they pick up.-Fierce tortoise, 'T' ferox. 
Flesh not inferior to that of the green turtle-LLand tortoise, $T$. Graca ;-Guiana dragon, Draccena Guianensis. Flesh and eggs used as food.

Guana, Iguana delicatissima. Flesh delicious, antivenereal, preserved by salting.

Skink, Scincus officinalis. Flesh dried, salted, and powdered, alexiterial.

Hyla tinctoria. Blood used to rub on the skin of paroquets to cause the growth of various coloured feathers.

Gibious Frog, Green frog, Rana esculenta. Flesh of the hind thighs used as restorative food.

Surinam Frog. Rana paradoxa. Tadpole, frog fish, jackie, flesh used as food.

Toad, Bufo vulgaris. Flesh of the hind thighs sold for that of the green frog.

\section{SERPENTES.}

Bite of many of these animals mortal; the best remedy is a bottle of Madeira wine drank at two doses, with only a few minutes' interval, or an equally large dose of any strong spirituous or fermented liquor; "or camphor and ammonia with Cayenne pepper. Also ligatures should be applied above the bites, or cupping glasses over them. Repeated suction with the mouth preferable to both." Inoculation with the juice of vejuco, Prenanthes serpentaria, renders persons insensible to this poison.

Viper, Vipera, Coluber berus. Flesh along with the heart, liver, and blood, in all about four oz. with three quarters of a pint of water, made into a restorative decoction; has given way in England to turtle soup; dried vipers, viperce sicce, headed, gutted, skinned, abdominal fat removed for separate use, and dried, made into lozenges.

\section{PISCES.}

Some of these are poisonous at all times, others only occasionally; but the greater number are eaten with safety: the nature of this fish poison is unknown.

SeA lamprey, Lampar eel, Petromyzon marinus;-Lesser lamprey, Nine-eyed eel, $P$. fuviatilis;-Pride, Lampern, P. branchialis. Flesh glutinous, preserved, potted lampreys, by peppering so highly that it often produces an access of fever, as Henry II. found, and paid for his luxury with his life.

Sкате, Flare, Blue skate, Grey skate, Raia batis ;-White skate, Friar skate, May skate, $R$. oxyrinchus;-Thornback, $R$. clavata. Flesh nutritive, salted, and dried for exportation. 
Sthagreen ray, Raia tuberculata. Skin dried, shark's skin, shagreen, knobby, used to cover boxes.

Rousette, Raia sephen. Skin dressed, galuchat, fish skin, transparent, used to cover boxes, cemented on green stained paper, the tubercles filed down, polished, and the skin stained with verdigris, spots, circular, large, very beautiful.

*Rougil Hound, Squalus catulus (the male), Spotted dog fish, S. canicula (the female), Chien de ner. Skin dressed, shark skin, rough, used for polishing wood and ivory.-Sugre, Aiguillat, Squalus spinax;-Porc, $S$.....;-Melandre, S. galens. Skins dried, and used either as fish skin for covering, or for polishing wood.

* IVhite shark, Squalus carcharias. Liver pressed for the oil.

* Sturgeon, Acipenser sturio. Flesh pickled in brine, or sliced and frozen, runckel; the back bone soft, fat, preserved by smoking, chinolia, spinachia; sounds made into isinglass; roe of the female, which sometimes weighs 200 lbs., made into caviare; skin dressed for leather, those of the young fish transparent, used for windows; fat collected.

Bezuga, Acipenser huso. Sounds make the greatest part of the isinglass that is sold.

Tetraodon ocelatus; $-T$. sceleratus; $-T$. lineatus. Flesh poisonous.

Drodon atrisa. Sounds made into isinglass; gall poisonous.

*Eer, Murcena anguilla. Skins dried, used as leather; liver, hepar anguilla, used to facilitate labour, $\vartheta_{\mathrm{j}}$ in a glass of wine; fat collected by roasting them.- ${ }^{*}$ Conger, M. conger. Flesh, after the fat has dropped from it, salted; fat collected for use.

*Co D, Gadus morhua. Three fins on the back; flesh split and dried, stock fish, salted, salt fish; sounds pickled in brine, also made into isinglass; liver boiled for its oil; spawn made into caviare.

"HАдроск, Gaclus aglefinus. Flesh split and dried; small bones in the head, tooth shells; sold at the china shops, used as a stimulant to warts, with vinegar.- ${ }^{*}$ Whiting, G. merlangus. Flesh split, and dried.

"Lise, Gadus molva. Two fins on the back; flesh split and dried, stock fish, salted, salt fish.

*'Torsk, Gadus brosme. One fin on the back; flesh split and dried, stock fish, salted, salt fish.

* Macka rel, Scomber scombrus. Flesh preserved whole in brine, pickled mackarel; also cut in slices, and preserved with vinegar and spices, cavcach, coratch, used as a sauce. 
* Father lasuer, Cottus scorpio. Pressed for oil.

*Tunvy, Scomber thynmus. Preserved whole in oil ; imported from Italy.

* Strickleback, Gasterosteus aculeatus. This extremely small fish is in some places so plentiful as to be pressed for its oil, the remainder used as manure.

Lunulated gilt head, Sparus aurata. Flesh salted.Sparus pagurus. Flesh poisonous, used for suicide.-Perca .... Skins prepared as isinglass.

* Salmon, Salmo salar. Flesh preserved in half lengths, pickled salmon, with vinegar, small beer, and water, three fish in a kit; or split, salted, and smoked, kipper salmon; or whole in oil.

Char, Salmo alpinus. Flesh preserved by potting, potted char.

*Mu cLet, Mugil cephalus. Spawn salted, dried, and dipped in melted wax, botargo, used as sauce.

*Herring, Clupea harengus. Belly fin six rayed; flesh. pickled in brine, and repacked with salt, white herrings, pickled herrings. - Scotch herrings, Dutch herrings, caught off the Scottish coast after the 24th June, large, fat, full bellied, rich flavoured, but do not keep in hot climates. - Yarmouth pickled herrings. Caught off Yarmouth in September and October, lank, mostly without roe, keep well, exported to the West Indies for the negroes.-Red herrings. The Scotch herrings salted and smoked with dry oak-wood smoke; also pressed for oil.

Anchovies, Clupea cncrasicolus. Flesh pickled with vinegar; used as sauce, the bones dissolve during the boiling; imported from Italy and France. Gorgona anchovies.

* Srrats, Clupea sprattus. Belly fin nine rayed; flesh dry; whole fish, not gutted, salted in brine; headed, gutted and pickled in vinegar, used for anchovies.

*Pilcharv, Clupanochun pilchardus. No teeth in the jaws; flesh preserved with salt, also pressed for oil : young firy used for anchovies.

*Barier, Cyprinus barbus. Spawn sometimes violently cathartic.-*Dace, C. leuciscus ;-* Roach, C. rutilus ;-Bleak, Bley, C. alburmus. Scales used to make oriental essence.

Isinglass, Fish glue, Ichthyocolla. Principally prepared from the sounds or air bladders of the beluga, by scraping, steeping in lime water, to remove the grease, washing, drying, twisting into staples, bending into a book, or rolling into a ball; used to fine wine and beer, and to make jelly for food; gr. vj grow solid with half a pint of water ; imported from Russia, short staple, (S. S.)

Cavialie. The spawn of sturgeon and some other fishes, 
broken by the hand, mixed with salt, and dried; used as sauce; imported from Russia. - Red caviare. The spawn of various fish salted and smoked.

\section{MOLLUSCA.}

Cuttle fish, Sepia, S. officinalis. Bone, os sepia, astringent, used by calf farmers, also in tooth powders ; for polishing metals, and to make moulds for small gold and silver work, as it is tender, and takes a grood impression by being pressed together with the pattern placed between them.

Sueve Fish, Hose fish, Anchor fish, Calamary, Poor cuttle, Sepia loligo, Loligo vulgaris. Flesh washed, after the ink is let out, is white, and, being dressed, has the taste of veal.

Beche de mer, Doris . . . . . Collected on the west coast of New Holland; dried and used for making a rich soup.

*Vineyard sxail, Escargot, Helix pomatia. Flesh used as a restorative food.

*Turbo pullus, Phasianella pullus. 'The shelly operculum, Guernsey eye-stone, put into the inner corner of the eye, works its way out at the outward corner, and brings out any strange substance with it.

MuREX BRANDARIs;-Purpura lapillus;-Scalaria clathrus; -Planorbis comeus. The yellowish juice reddens in the sun, and dyes woollen cloth scarlet.

*Eır, Omnier, Haliotis tuberculata. Flesh pickled in vinegar, and very highly spiced, imported as food from Guernsey.

Orstir, Ostren eclulis. Flesh eaten raw, or dressed, also pickled in vinegar and brine; shells, exposed to the air for months to bleach, testa ostreorum, testa, P. L. used as an absorbent, also burned for lime, calx e testis.

*Scallor, Pecten maximus. Flesh eaten dressed, also pickled in vinegar.

Peali oyster, Avicula maryaritifera;-A. hirundo. Shells, mother of pearl, moter perlurum, absorbent, also used as ornament; from the East Indies; blue edged; finest white edged, dearer ;concretions found between the membranes of the cloak, pearls, unimes, margarite, used for ornaments, very high priced if large.

Prisa NoBurs. Thread by which it adheres to the sand, lyyssus., used as silk; also produces pearls of considerable size, but tinged with brown.

"Muscre, Mytilus edulis. Flesh eaten raw, or dressed; frequently poisonous.

"Pearl muscre, Mya margariliferu, Unio margaritifcra. Pro- 
duces pearls, Scotch pearls, mostly irregular in shape, useless for ornaments; ground and washed over, margaritce preparatce.

*Cockle, Cardium edule. Flesh eaten raw, or dressed, also pickled for sauce.

*Mya pictorum. Shells, colour shells, used to spread colours upon.

\section{S. VERMES.}

*LeEch, Grey leech, Hirudo, H. officinalis, H. sanguisuga. Back brown, with six yellow lines and intermediate black lines; foot grey, with black spots; mouth three-cornered, anus round: bite used as a mode of bleeding, each leech sucks not quite $3 \mathrm{j}$ of blood, but much runs afterwards from the wounds : castor oil is a good application to leech bites when they are painful, or go into sores.

Green Leech, Foreign leech, Hirudo provincialis. Foot green, uniformly coloured; used for bleeding.

*Bastard leech, Hirudo carnivora. Foot becomes yellow in spirit of wine.

*Black LEech, Horse leech, Hirudo hæmopis sanguisuga. Teeth round, cannot penetrate the human skin.

\section{CRUSTACEA.}

* Craw FIsh, Cancer astacus, Astacus fluviatilis. Concretions in the stomach when about to change their shell, crabs' eyes, oculi cancrorum, concrementa cancrorum, C. P. absorbent.

*Large sea crab, Cancer pagurus. Black tips of the claws, crabs' claws, chela cancromim, absorbent.

Hog Lice, Wood lice, Millepedes, Aselli, Oniscus asellus. Alive no. 12 , or dried and powdered, $\mathrm{H}_{\mathrm{j}}$ to $3 \mathrm{j}$, diuretic, used in jaundice; a large variety imported from Russia.

\section{INSECTA.}

Used internally are mostly diuretic, and in excess produce strangury, or bloody urine; externally vesicatory.

Spanish Flies, Blistering flies, Cantharides, Meloe vesicatorius, Lytte, Cantharis. Used to raise blisters, and internally as stimulant and diuretic, gr. $\mathrm{j}$ to iv ; imported from South America.

Riband Cantharides, Telini fies, Meloe cichorii, Milabris cichorii. Used by the ancients, and now in China and Upper India.

Potatoe flies, Cantharides vittatc, P. U. S., Lytta vittata. Used in the United States. 
Meloe triantheare. Used in the East Indian hospitals.

Green canthalides. Carried from India to Egypt.

*OIl beft le, Meloe proscarabaus;-M. majalis, M. variegatus. Used as vesicatories, and also in hydrophobia.

Indra воvum, Mutella occidentalis. Used in snake bites, no. 5, with 12 scruples of the root of Bryonia epigea, dose gr. xij.

*LAdr BIrD, Lady cou, Coccionella septempnentata. Bruised on an aching tooth, as an odontalgic.-Coccionella bipunctata;Curculio anti-odontalgicus;-Carabus ferrugineus;-Chrysomela populi;-C. sanguinolenta, and many other eleuterata are used for the same purpose.

Bug, Cimex lectularius. Used as an emmenagogue.

Cochineal, Grana fina, Coccionella, Coccus, C. cacti, Cocci. Used as a cordial, gr. viij to Эj, but chiefly used as a red colouring drug for medicines, pickles, and in dyeing; $1,500 \mathrm{cwt}$ are annually consumed in the British islands; feeds on the Cactus cochinillifer, and perhaps C. tuna; imported in bags of 2 cwt. each, from South America: kermes grains and scarlet grains are mixed with it to reduce its price.

Grana sylvestria cochineal, Granilla. Sinaller than the grana fina, feeds voraciously on the Cactus ficus Indica, which it has nearly extirpated in India since it was first introduced from the Brazils in 1795 , by mistake; will not touch $C$. cochinillifer, nor C. tuna; colouring power inferior.

Kermes berries, Kermes, Vermeille, Coccus infectorius, $C$. baphicus, C. ilicis, C. quercus cocciferc. Dricd, alexiterial, colour syrups red.

*Scariet grains, Coccus Poloniculs. Found on the roots of strawberries, ryc, silver weed, and potentilla annua; used as a red dye.

Lac ixsect, Coecus laecu. Produces stick lac.

Cheraes manifera. Exudes manna.

*Plant lice, Aphides. Exude honey dew.

*Br.ss, Apes, Apis mellifica.-Dried $\mathrm{Jj}_{\mathrm{j}}$, diuretic; produces honey, bees' wax, and bee bread.

"Silk wora, Bombyx, 13. mori. Yield silk; broken in half when ready to spin, stretched out as far as possible, and dried, silk worm gut, used by anglers for their lines.

\section{1. 'ZOOPHY'Y'A.}

Red Corat, Corallium rubrum, Isis nolilis.

*White cor^r, Corallium, alhum, Madrepora oculata. Antacid. L 2 
Brack coral, Corallium nigrum, Gorgonium antipathes. Used in epilepsy.

\title{
UNKNOWN ANIMAL SUBSTANCES.
}

Trmpost. Similar to castor, used in the Celebes.

INDIAN GRass, Sea grass, Ladang, Laut. Used by anglers for the end of their lines next the hook; said to partake of the nature of a worm and a coralline. When alive, soft, and shrinks into the sand on the least touch; when dry, hard, straight, brittle. From Sumatra, kept oiled and in oiled gut skins to preserve its toughness.

\section{COMPOUND COMBUSTIBLES.}

\author{
NOT OF AN OILY NATURE.
}

OF VEGETABLE ORIGIN.

\section{SUGARS.}

Manna in tears, Mamna in lacrymis. Flows spontaneously from the manna ash trees, and dries upon the bark, in the months of June and July. Manna is mostly obtained from the Fraxinus rotundifolia, but is yielded, though in less quantity, by the $F$. ornus, $F$. excelsior, and $F$. parvifolia. It is also yielded by the plum, oak, and willow.-Flake manna, M. canulata. Hangs in stalactites from straw, \&c., bound round the tree in June and July. Manna is laxative, in a dose of $3^{\mathrm{ij}}$ to $\overline{3}$ ss for children, or $\equiv j s s$ for adults, in milk or any other liquid; from Sicily.-Common manna, M. pinguis, $M$. in sortis. Flows from incisions made after the 1st of August; Sicily._Briancon manna, M. laricis. Found on the leaves of the larch in Dauphiny; laxative, but weaker than that of the ash ; is probably a honey dew.-Arabian manna, Manna of Moses. Exuded in June from a species of tamarisk, growing in the deserts ; only to be collected at carly dawn, as the heat of the day melts it, and it runs into the sand; white, solid, if kept in a cool place, but melts even by the heat of the hand; sweet, aromatic : very scarce, only to be found in rainy years.-Persian manna, Wadi ennad, Terreniabin. Exuded from the Hedysarum alhagi ; used as a purgative.-Sarcocolla. Origin unknown : carried from Ethiopia to India, and hence to Europe; used as a slight astringent. 
White sugar, Cane sugar, Refined sugar, Sal Indus, Saccharum album, S. purissimum, S. purificatum. 'The essential salt of the sugar-cane, prepared by clarifying the juice with eggs or blood, getting rid of the superfluous acid by the addition of lime-water, and evaporating it till the sugar crystallises on cooling. The uncrystallisable portion (treacle) is then drained from the granular mass, and that which remains in the first instance got rid of by passing small portions of water, or, according to a late improvement, of saturated syrup, through the mass; 112 lbs. of raw sugar yield, on refining, 56 of refined lump, 22 of bastards, 29 of melasses, and 5 of dregs; used for making very light-coloured wine, and the best syrups: reduced in France by sugar of milk, that sold at Marseilles contains from 1 to $2 \bar{j} \mathrm{lb}$. of sugar of milk in each cwt.; sugar is nutritive, laxative, but griping; externally applied to ulcers, it is escharotic.

Browx sugar, Raw sugar, Moist sugar, Mel canne, Saccharum mibrum, S. non purificatum, Saccharum, P. L. since 1809. Cane sugar, from which the treacle has not been thoroughly separated; used for making wines, vinegar, and coarse syrups.

Chinese sugar. From Saccharum Sinense, richer than that of the East Indian cane.

Brown sugar Candy, Sacharum candum rubrum. From Germany.-White suyar candy, Saccharum candum allum. Sugar crystallised by the saturated syrup being left in a very warm place, from 90 to $100 \mathrm{deg}$. Fahr., and the shooting promoted by placing sticks, or a net of threads, at small distances from each. other in the liquor; it is also deposited from compound syrups, and does not seem to retain any of the foreign substances with which they were loaded: it may, however, be coloured red by means of cochineal. Being longer in dissolving than sugar, it is used in coughs to keep the throat moist; and is also blown into the eye, as a very mild escharotic in films or dimness of that organ.

'T'reacr.e, Melasses, Mel ustum, Theriaca communis. The black uncrystallisable portion of the juice of the sugar, used as a cheap sweet, also for making beer, rum, and the very dark syrups, as those of white poppies, and of buckthorn berries. Its taste may be amended by boiling with bone black and water. It preserves vegetable powders better than sugar; English.

PARSNEP SUga ; - Slirret sugar;-Carrot sugar ; - Bect sugar. Made from the ronts by decoction in water, expression, and evaporation, or by simple expression of the juice; one cwt. of beet yields only one ll). of sugar.-Cou-parsnep sugur. 'The stalks, when dry, exude sugar ; four lb. yield four oz.

Mapie sugar. Much used in Americu.-Walnut sugar. 
Made by the Tartars. - Birch sugar. Are all made by wounding the trees in the spring of the year, by boring a hole under a large arm of the tree, quite through the wood, as far as the bark on the opposite side, collecting the sap that flows from the wound, adding a little chalk to remove the acid in the juice, and evaporating it to a proper consistence. 'The sugar maple yields about six $l b$. from each tree in a season.

Pear sugar. Obtained by expressing the juice, adding chalk to saturate the superabundant acid, and evaporating it to a due consistence; it does not crystallise, and is a kind of white treacle.

Apple sugar. Onecwt. of apples yield about $84 \mathrm{lb}$. of juice, which produces nearly $12 \mathrm{lb}$. of a similar substance.

Todnies. Cocoa toddy. Procured by cutting off the tip of the spathe of cocos nucifera; drank while fresh to remove constipation. Palmyra toddy. From borassus flabelliformis; runs for about four months, each tree will yield about six pints of toddy, daily.-Malabar toddy. From caryota urens, flavour inferior to cocoa or palmyra toddy.-Mysore toddy. From elate sylvestris, pleasant tasted; runs for about three months; fifty trees will yield daily about seventeen gallons. - Nipa toddy. From cocos nypa; mostly made into wine. All these toddies are refreshing drinks when drank before sunrise, and are also used as yeast by the bakers; as the heat of the day comes on, they ferment and produce wine, which turns by eveningtide into vinegar.

JAGGeries. Cocoa jaggery, Ténné véllum. Raw sugar made from fresh cocoa toddy by evaporation.-Palmyra jaggery, Pannay véllum. From Palmyra toddy, six pints of toddy yield one 1b.-Malabar jaggery, Koondee panei véllum. From Malabar toddy.-Mysore jaggery. From Mysore toddy ; seventeen gallons will make about $46 \mathrm{lb}$. of jaggery. The jaggeries are used for the same purposes as the raw sugar of the cane.

Must, Mustum. The juice of ripe grapes.-First runnings, Lixivum, Procopum;-Last runnings, Circumcidaneum, Tortivum. Are all nutritive and laxative.-Carenum. Must boiled to twothirds.-Sapa. Must boiled to one-half.-Vin cuit, Defrutum. Must boiled to a fourth or third part; is much used in Palestine, Egypt, and other Mahometan countries as a sweetmeat.

Grape sugar. The brown sugar obtained from grapes as from pears, being previously freed from the acids and sulphate of lime that existed in the original juice; yields, by refining, $75 \mathrm{lb}$. in 100 of a white granular sugar, 24 of a kind of treacle, with a little gum, and some malate of lime.

Arbutus sugar. From the fruit of the strawberry-tree, which has been found to yield one-fifth of its weight of sugar, and rum may be made from the rape. 
Holces sugar. 'The large grass, Holcus Cafer, was brought from the South of Africa, and has begun to be cultivated in some parts of Italy, Bavaria, and Hungary. 'The sugar that it yields is said to be equal to that of the cane.

Dulse sugals. Extractible from fuci, is analogous to the sugar extractible from onions, and the crystallisable sugar of manna: they do not form wine, but change at once to vinegar.Sugar may also be made from many other plants.

Starcir segar. One hundred parts of starch are to be mixed with 200 of water, and added gradually to another 200 of water, previously mixed with one of oil of vitriol, and brought to a boiling heat in a timned copper vessel: the mixture is kept boiling for thirty-six hours, water being occasionally added to keep up the original quantity: some bone black is then added, and also some chalk to get rid of the acid : it is afterwards strained and evaporated by a gentle heat to the consistence of a syrup, and set by to crystallise. This sugar resembles that of grapes. If the quantity of oil of vitriol be increased to five or six parts, a few hours' boiling will suffice.

Potato sugali, Sirop de pommes de terre. From the washed pulp of potatoes, by the same process; used to make beer, and potato whiskey.

RAG sugar. Sugar has lately been obtained by treating linen rags with water acidulated with oil of vitriol, in the same manner as starch for starch sugar.

SPANish IIquorice, Black sugar, Succus glycyrrhizce simplex, S. Hispanicus. By boiling liquorice root in water, straining the decoction, and evaporating to dryness, but is usually imported; a common demulcent, taken ad libitum: reduced by adding the pulp of plums.

Extractur gLYcyrrhiz. The same, but evaporated only to a consistence fit for rolling into pills; demulcent, $3 \mathrm{j}$ to $3 \mathrm{iij}$; frequently used to cover the taste of aloes and other medicines, in draughts or mixtures. The root yields about half its weight of this extract.

Cassia ivup, Pulpa cassice extracta, Cassice pulpa. 'The pods of cassia fistula are broken, the pulp washed out with cold water, strained, and evaporated to a pilular consistence; laxative, $35 s$ to $\mathrm{ij}$, but seldom used separate. Four $\mathrm{lb}$. new pods yicld about one Ib. pulp.

Tamarind reup, Pulpa tamarindi extracta, Tamarindi pulpa. Prepared like cassia pulp; cooling, laxative, 3 ss, to $3 \mathrm{j} s \mathrm{~s}$, or from żij to ziij may be added to lbj of water for a cooling drink.

Pulp of Proxis, Prunorum Gallicorum pulpa. Prepared in 
the same manner from French prunes, but they require boiling in a small quantity of water to soften them; use the same.

Rob of ELDER BERRIEs, Rob baccarum sambuci sine saccharo. Succus bacce sambuci inspissatus. Juice of the berries evaporated by a gentle heat; sudorific, diuretic.

Rob of BLACK currants, without sugar. Rob de ribes. As the preceding; diluted with water, it is used in cleansing gargles. -The pulps or juices of other sweet fruits may be prepared in a similar manner.

\section{GUMS.}

The word gum is also used as an adjective to signify any exudation from plants, whether gummy, gumny resinous, or even resinous, which is in a lump, as gum opium, powdered opium, ammoniac in tears, gum ammoniac, and the like.

White gum Arabic, Gomme Turique, Gummi Arabicum, G. Turicum, Acacice gummi, Mimose Nilotica gummi. In small lumps, principally white: Turkey. The officinal preparations are very numerous.-The principal are Mucilago acaciæ, L. E. D. Emulsio Arabica, D. Mist. cretæ, L.D. Confect. amygd. L. D. Pulv. cret. comp., L.D. Pulv. tragac. comp., L. D.

Yellow gum Arabic, Brown gum Arabic, Grum babul, Gum barbara, Gomme de Jedda, Karoovelum pisin. In small lumps, from Mimosa Arabica, yellower or darker than that of M. Nilotica, not so soluble in water, and covers its surface with a pellicle, which in making pastes and syrups is apt to fall to the bottom and burn too.

Gum Senegal, Gomme Arabique, Gummi Senegalense, G. Seneca, G. Senegce. In large lumps, round, brown, from Mimosa Senegalensis. These gums are nutritive, and used as food by some negro nations; demulcent, $3 \mathrm{j}$ to $3 \mathrm{ij}$, ad libitum ; also used as a cement: to reduce them to a fine powder they must be previously dried, or the operation performed in a heated mortar, with a hot pestle.

Marrons, G. Turicum. Gum Senegal concreted together in large masses by moisture.

Bead-tree gum. St. Helena gum. Very dark, nearly black, from the Melia azedarachta; used by the dyers.

Cashew gum, Brazil gum, Gomme d'acajou. Reddish yellow, astringent ; its mucilage scarcely adhesive.

Larch gum, G. Orenburgense. P. Ross, exuded from the larch, is reddish, nearly transparent, not so glutinous as gum Arabic, tasting rather resinous.

Cherry-tree gum, G. cerasi;-Peach gum, G. amygdala 
Persice ;-Plum-tree gum, G. pruni. Substituted for gum Arabic by country practitioners; differ, however, in their chemical qualities from that gum, being what the chemists call cerasine or tragacanthine.

East Ixnia gum, Bengal gum, Fullam pisin. From the wood apple tree, Feronia elephantum: answers better for mixing colours than gum Arabic.

Ausa, Kumarkuni. Opaque; sold in Upper India : used in ozana.

Cotton-tree gum. From Bombax pentandrum: used with spices in bowel complaints.

Orive-tree gui, G. olive. Contains olivile.

Liches gum. Several species of lichen yield, by infusion, or decoction in water and evaporation, a gum similar to gum Arabic, and which may be applied to the same uses; as Lichen coralloides, which yiclds alout 14l1b. by the cwt.; L. esculentus about $13 ; \mathrm{L}$. pulmonarius, and I. farinaceus.

Hyacintu gum. May be obtained from the roots of Hyacinthus non scriptus, common wild hyacinth or harebell; formerly used by fletchers to glue feathers to arrows.

Locwoon Gus. In drops, often the size of a hen's egg, deep red, appearing black, sweet, very brittle.

Gus kuteera, Gomme Bassora, Gunmi vermiculatum. In loose wrinkled drops, from the Sterculia urens, without smell or taste, whitish, mostly transparent, forms a soft jelly in water; but if reduced to powder and boiled in water for a quarter of an hour, it is entirely dissolved; a tea-spoonful of the powder gives three pints of water the consistence of a syrup; used as a varnish.

Gum тragacastu, G. kuteera, Gummi tragacanthe, Tragacantha, Astragali tragacantha gummi. Exuded from Astragalus verus. From Aleppo, in cases; $\supset j$ of this renders water as thick as would be done by $\overline{3} j$ of gum Arabic ; demulcent, and from its viscidity used in sheathing the fauces, and in allaying tickling coughs: used also to dress ribands, laces, and in calico-printing. Officinal preparations.-Mucilago astrag. tragacanthæ, E. D. Pulv. tragac. comp., $L$.

Gü a сату. From Eschinomene grandiflora.-Thoa gum. From Thoa urens.

Gum of Pitcairnia crystullina;-Gum of Actinopluyllum anyulutum:-Gum of Actinophlyllum pedicellatum. Scarcely known.Gum may also be obtained from many other plants.

Britisi gus. Made by heating starch to the temperature 
of 6 or $\% 00 \mathrm{deg}$. Fahr. so that it may melt, exhale a peculiar scent, and become brown: used by the calico-printers.

Mrsachie. A gum, or gum resin, brought from Arabia, and used in India.

\section{GUM-RESINS.}

Natural exudations from plants, miscible with water, but neither saccharine nor gummy. Unless otherwise ordered, gum resins are purified by being softened by heat, or by a small quantity of water, and by pressing the softened mass through a canvas cloth.

Gum alouchi. From Wintera canella? very odoriferous, soft, dark-coloured.

Gum ammoniac, Gummi ammoniacum, Ammoniacum. Obtained by incision of a plant like fennel, or from Heracleum gummiferum : internally stimulant, expectorant, gr. $\mathrm{x}$ to 3 ss diffused in water $z_{\mathrm{j} j}$. Officinal preparations.-Mistura ammoniaci, L. D. Pil. scill. comp., L. E. Emplast. ammoniaci, L. Emplasti. Ammon. cum Hydrargyro, $L$.

Artichoкe gum, Kunkirzud, From Cynara scolymus; emetic.

Assa fetida, Devil's dung, Hing, Assafoetida gummi-resina, Ferulce assafcetidce gummi-resina. Exudes from the fresh cut surfaces of the root of Ferula assafoetida, from which it is scraped off when dry, and a fresh surface made by paring the remaining root till it is exhausted : purified as gum ammoniac ; expectorant, stimulant, and antispasmodic, gr. x. to 3 ss in water ${ }^{3} \mathrm{ij}$; used also in clysters. Imported in cases and casks of various weights. The principal officinal preparations. - Mist. assafoetidæ, $L$. $D$. Tinct. assafœetid., L. E. D. Spirit. ammon. fotid., L. E. D. Pil. galb. comp., $L$.

Gum bdellidm, Bdellium, Bd. ex Oriente, Dale's Pharm.

Mrrnha imperfecta. Exudes from a nondescript Amyris, called by Adanson niottout; has most of the properties of myrrh, used indiscriminately with it. Brought inixed amongst gum Arabic and myrrh from India and Turkey.

Bdellium ex Guinea, Dale, Gummi rubrum astringens, Kino P.D. Yielded by the Butea frondosa? ruby coloured, brittle, contains a very small proportion of resin.

Arabian bDelíum. From Borassus flabelliformis.

Italian bDELlium. From Chamærops humilis.

Opocalpasum. A kind of bdellium yielded by some unknown Amyris; tough like wax, dark brown, bitter. 
Euphor вич, Euphorbice gummi-resina. Exuded from incisions made in the Euphorbia officinarum, E. antiquorum, and E. Canariensis; a most violent drastic hydragogue, formerly used, to gr. $\mathrm{v}$ or $\mathrm{x}$, corrected with vinegar or lemon juice; externally stimulant, ulcerating. Imported from Barbary in serons of 100 to $150 \mathrm{lb}$.

Galbaxum, Galbani gummi-resina, Bubonis gallbani gummiresina. Exudes spontaneously, but generally from incisions made in Bubon galbanum: inported from Turkcy; emmenagogue and antispasmodic, gr. $\mathrm{x}$ to $\mathrm{\partial j}$; externally resolvent. Principal officinal preparations.-Pil. galb. comp., $L$. Tinct. galb., D. Emplastr. galb. comp., $L$.

Red galbanum. Analogous to sagapenum; produced from Bubon gummiferum.

Gomi gatda. Greyish; has the appearance of dark gum hock.

Ceylon Gambooge, East Indian picked gambooge, Gummi gutte gambice, Gambogia, Cambogia. From Stalagmitis cam. bogioides: hydragogue, useful in dropsy, gr. iij or iv, horâ quâque tertiâ, until it operates; makes an elegant yellow colour. - Gambonge in sorts. From Cambogia gutta.-Siamese gambooge. In tears; from Garcinia morella? - Mexican gamborge. From Vismia guttifera and V. sessiliflora. Officinal preparation.--Pil. cambogix comp., $L$.

Gum ivr, Gumm hederc. Produced by wounding the tree; reddish brown, burning with an aromatic odour, acrid, exulcerating; used dissolved in vinegar as a depilatory and odontalgic; and in substance to rub over baits to render them attractive to fish.

Gum nоск. Some specimens of this gum resemble elemi, others are dark-coloured.

Prraso Peruvianum, (Coll. of Phys. collection,) Fast India kino, Amboynce kino, Kino P. L. Yielded by Ptero-carpus erinaccus. Solution in water is rendered clear and of a deep brown colour by potash ; astringent, but uncertain.

Botaxy bay Kino, Broun gnem of Botamy bay, Kino P. E. Obtained frum the brown gum tree, Eucalyptus resinifera. Its tincture is not rendered turbid by water.

LetTcos oplum, Lactucarium. Obtained by incision from the flowering stems of the garden lettuce, Lactuca sativa; recommended by Dr. Duncan, senior, as a substitute for opium, as possessing its anodyne without some of its injurious effects; it has been used with advantage in allaying the pain of chronic rheumatism and colic; in checking diarrhor, and in allaying cough. 
MYrRh, myrRha. Origin unknown; attenuant, antiseptic, tonic, vermifuge, and emmenagogue, gr. $\mathrm{x}$ to $3 \mathrm{ss}$.- Liquid myrrh, Myrrha liquida, Stacte. Obtained by decoction? similar to myrrh in its qualities, differing only in consistence. Officinal preparations.-The principal are 'Tinct. myrrhæ and pil. aloes cum myrrha, D. L. E. Pil. ferri comp. D. L. Pil. galb. comp., D. $L$. Mist. ferri comp., $D$. Tinct. aloes et myrrhæ, $E$.

Cumbi Gum. Not unlike myrrh, and used for it in India, but in smaller doses, as being stronger; also in stopping the progress of sphacelus : origin not known.

- Villey bolum. A coarse kind of myrrh, used in Lower India : origin unknown.

Gum sassa. From an Abyssinian shrub, mixed with myrrh.

TURKey opium, Opium, Meconium, Papaveris somniferi succus spissatus. From the capsules of the white poppy by incision; but Miller thinks the Turkey opium is from a different plant, as the capsule is not of the same shape: one of the principal instruments of physicians; anodyne, narcotic, gr. ss to gr. ij, or even more, as the person is accustomed to its use or not, and also according to the disease that is present; so that it can only be exhibited with due effect, or even with safety, by a person who is not only skilful, but also acquainted with the constitutional habits of the patient as to this drug; some prefer a full dose at once, others repeated small doses: it is thought to be anodyne, even when used externally. The effect of opium taken improperly is best obviated by a copious exhibition of lemon juice, with stimulants, and the affusion of cold water on the head. Officinal preparations, very numerous.-The principal are, 'Tinct. opii, D.E.L. Tinct. opii camph., D. L. Acetum and vinum opii, D. Pulv. ipecac. comp. D.E.L. Pulv. cornu usti cum opio, D. L. Confectio opii, $L$.

Opium purificatum molle, P. L. Picked opium softened with water to the consistence for making pills.-Op. pur. durum, P. L. Picked opium dried in a water bath until fit for powdering.

Strained opium, Extractum Thebaicum, Opium colatum, $O$. purificatum, Laudanum opiatum. Soften the gum in a small quantity of water, not exceeding its own weight, press through canvas, and reduce by evaporation to a proper consistence, for pills.

Extractum opir. Rub opium $3 v j$ with water lbiij added by degrees, lest the mixture settle; then strain, and evaporate to a proper consistence.

Extractum opir aquosum. Rub 3 ij of opium with a pint of boiling water, for ten minutes, and pour off the solution; repeat 
this a second and third time; mix the liquors and expose them to the air in a broad vessel, for two days, then strain through linen, and evaporate.

Homberg's purified ol'ium. Baume's purified opium. Extract all the part that is soluble, by repeated decoction of $4.1 \mathrm{lb}$. in three or four gallons of water, until no more is taken up; then mix all these decoctions, evaporate to one gallon and a half, and keep boiling for two, three, or even six months, adding fresh water fron time to time; strain the decoction and evaporate to the consistence for making pills.

CoRnetTe's PURIFIEd oriun. Separate the resin by redissolving the common extract in water, strain the solution, and again reduce it by evaporation to an extract; repeat this process several times.

JosSE's PURIFIED OPIUM. Work opium under water, to separate the glutino-resinous part which remains in the hand: filter the water and evaporate to an extract. It still contains some resin, but is much less disagreeable in its smell, and considerably improved as an antispasmodic.

Accarik's purified opruar. Digest opium with charcoal powder in water for some days; strain the liquor, clarify with whites of egg, and cvaporate in a water-bath to an extract. Very mild in its effects, like the former.

Powel's FURIFIED opicm. Boil opium in water, as long as any thing is taken up by it ; then digest the residuum in spirit of wine, mix the two solutions, and evaporate them to a proper consistence.

Fist Indian opium. In round masses; black, smooth, like an extract, totally soluble in water, and the solution is precipitated by acetate of barytes, by which the solution of 'Turkey opium is not altered; and more copiously by oxalic acid; it also leaves no glutinous residuum on solution; is considered weaker than that of Turkey.

Exgish opium, Opium Anglicum. Has the same extract-like appearance as the East Indian; light-coloured, but is said to be equal if not superior in quality to the 'Turkish: Buckinghamshire.

Wrs.1) cemix opius. Yiclded by the Hypecoum procumbens and H. pendulum ; narcotic, and similar to opium.

Cinerris. From Cannabis jeea, most powerfully narcotic.

Момеа. The gum cherris purified.

Gua opopanax, Opoponax, Pustinuce opopanacis gummiresina. Exudes from incisions made in the roots of Pastinaca 
opopanax, or of Daucus gumrnifera; carminative, emmenagogue, and purgative, gr. $\mathrm{x}$ to $\mathrm{3j}$.

English opopanax. From Cornish lovage, Ligusticum Cornubiense.

CATRIghondoo. Origin unknown; sold in India, in small irregular lumps, light coloured, slightly acid taste; tonic, stomachic.

Sagapenum. From Ferula Persica, or some nondescript species of that genus, or of laserpitium; used as assafoetida and galbanum; dose gr. $\mathrm{x}$ to 3 ss. Officinal preparation.-Pil. galb. comp., L. D. Conserva rutæ, D. L.

Aleppo scammony, Scammonium Aleppense, Diagridium, Scammonice gummi-resina, Convolvuli scammonice gummi-resina. From the root of Convolvulus scammonia, the tops being cut off for that purpose; when reduced to a very fine powder, by trituration with loaf sugar or tartarum vitriolatum, it is the best vegetable purgative that is known at present, as its effects can be exactly calculated; dose from gr. iij to $\mathrm{xv}$, or more: Turkey. Officinal preparations.-Extract. colocynth. comp., I). Pulv. scammonii comp., L. D. E. Electuar. scammonii, D. Confectio scammonii, $L$.

French scammony. The juice of Cynanchum Monspeliacum; weakly cathartic.

Smyrna scammony, Scammonium Smymense. The juice of the Periploca scammonium, coarser than the Aleppo scammony, and very sandy; more violent in its operation; imported in cakes packed in chests, 11 . the $1 \mathrm{lb}$.

Ротато slip scammony. From Convolvulus Brasiliensis.

Hog-tennel gum, Gummi peucedani. From Peucedanum officinale by incision; opening, diuretic.

Elm tree gum, Ulmine, Gummi ulmi. Black, hard, shining, a few drops of nitric acid change it to a rosin.

\section{WATERY JUICES OF PLANTS.}

Acacra. The juice expressed from the pods of Mimosa Nilotica, inspissated to dryness.

German acacia, Acacia Germanica, Succus prunorum syluestrium. The juice of unripe sloes, inspissated; astringent, substituted for acacia.

Italinan acacia, Acacia Italica. The inspissated juice of Spartium spinosum; astringent.

Extractum aconiti, Succus spissatus aconiti napelli. From the juice of monkshood leaves, evaporated, without separating the 
sediment, to the consistence of thick honey; anodyne, sudorific, gr. ss to gr. v, bis terve die.

Socotrine aloes, Turkey alocs, East India aloes, Aloe Socotrina, A. lucida, A. spicate extractum. Reddish brown, glossy as if varished, affording a bright gold-yellow powder; obtained by incision from various species of aloe, and subsequent evaporation ; cathartic, gr. $\mathrm{x}$ to $\mathrm{\partial j}$; stomachic, aperient, emmenagogue, gr. ij to iiij, twice a day ; in clysters $3 \mathrm{j}$ as a cathartic or to destroy ascarides; to horses $\bar{s} \mathrm{ss}$ to $\bar{z} \mathrm{j}$ as a cathartic: from Socotora and Melinda in South Africa Officinal preparations very numerous. - The principal are, Decoctum aloes comp., $L$. Extract. aloes, L. D. Extr. colocynth. comp., L. D. Tinct. al. and tinct. al. comp., L.E. D. Tinct. benzoini, L. E. D. Vinum aloes, L. E. D. Pil. aloes cum myrrha, L. E. D.

Hepatic aloes, Bombay aloes, Aloe hepatica. Contains more rosin than the Socotrine; of a duskier colour, extremely bitter, smell unpleasant; affords a dull olive yellow powder : from Yemen in Arabia, in casks, and sometimes in skins.'

Cape aloes, Aloes Capensis. From the same plant as the Socotrine, but prepared with less care; produces a greenish yellow powder; from Melinda.

Barbadoes aloes, Aloe vulgaris extractum. Resembles aloe hepatica; from Barbadoes in gourd shells, holding from 6 to Tolb.

Purified aloes, Aloe lota, Gummi aloes, Extractum aloes, E. al. purificatum. Soak Socotrine aloes in warm water, pour off the clear liquid, and evaporate; more purgative than crude aloes, and less irritating; dose gr. $v$ to $x v$.

Agave aloes. From Agave Americana; sudorific.

Extractum anemonis pratensis. The undepurated juice bniled down; resolvent, in chronic diseases.

Yeroocus PAwL. The inspissated juice of Asclepias gigantea, used in lepra, gr. $v$ in a day, continued for weeks.

Extractum belladonye, Succus spissatus atrope belladonnc. From the leaves of deadly nightshade, narcotic, diaphoretic, resolvent, gr. ss to gr. iij, bis terve die. It yields 1-9th of extract.

Succ. sprs. CICUT,e, Extr. conii, Succ. spis. conii maculati. From hemlock leaves; alterative, resolvent, used in obstinate disorders; beginning with a small dose, say gr. ij, bis terve die.

J'ICE OF HYPocistrs, Succ. Rypocistidis. From the berries of asarum, or Cytinus hypocistis.

Extr. Hyoscyami, Succ. spis. hyoscyami, Succ. spis. hiyosc. 
nigri. From henbane leaves; anodyne, antispasmodic; gr. ss to 3 ss a day; 1 cwt. $\frac{3}{4}$ of the green herb yielded $111 \mathrm{~b}$. of extract.

Rob diacaryon sine melle, Extr. juglandis immaturi. The juice of unripe walnuts boiled down; vermifuge, its taste being covered with cinnamon water.

Thridace, Extr. lactuce, Succ. spis. lactuce sativa. From the expressed juice of common garden lettuce; narcotic, used as a substitute for opium: gr. $\mathrm{jj}$ to gr. $\mathrm{x}$, bis terve de die.

Extr. stramonir. From juice of thorny apple: narcotic and antispasmodic, gr. i to gr. viij, bis terve de die.

Succ. spis. LACTUC.E viros... From strong-scented wild lettuce, laxative, diuretic, gr. iij to $\mathrm{xv}$ daily, in obstinate dropsies.

Concrentrated orange JuICE, Succ. spis. aurantiorum.Concentrated lemon juice, Succus spissutus limonum. From the juice of oranges, or lemons; for use where the fruit cannot be obtained.

Learon Júre. From the lemons which get spoiled before they can be sold.

Citron JuICE, Acetositas citri. Exported from Italy in large casks.

Veruurce, Omphacium. The juice of unripe grapes, the juice of crab apples; distilled vinegar is sold for it.

A number of juices of plants are kept by the French druggists in flasks, covered with oil, but they are not called for in England: even citron juice has ceased to be kept in our shops.

\section{WATERY EXTRAC'TS.}

Prepared by boiling plants in water, straining the decoction, and evaporating it to a proper consistence. Barry's extracts differ from the common by the evaporation being carried on in a vacuum produced by admitting steam into the apparatus, which resembles a retort with its receiver; the part containing the liquor to be evaporated being a polished iron bowl. As the temperature is much lower than in the common way, the virtues of the plant are less altered, the extracts are generally green, and contain saline crystals, but some of them will not keep. Extracts are mostly used for the same purposes as the plants themselves, but in a smaller dose. To make extracts smooth, chemists sometimes add to each quarter of a cwt. 1lb. of gum Arabic, and a pint of olive oil; or to every $3 \mathrm{lb}$. add a little gum, 3 ij of olive oil, and $3 \mathrm{j}$ of rectified spirit, which will give it a gloss.

Extractum cacuminum absinthil. From wormwood tops, gr. $\mathrm{x}$ to $3 \mathrm{ss}$, ter die. 
Exтr. Acori. From Calamus aromaticus.

Horse aloes, Musambrium, Aloe caballina. From the decoction of the leaves of aloes; dark coloured, fœetid, used only for inferior horses and other cattle.

E. radicis bryoxia alb.e. From a decoction of the root : in doses of $\overline{3}$ ss to $3 \mathbf{j}$.

E. caluab.e. From the root.

E. Axthemidis, E. florum chamameli, E. chamameli, E. anthemidis nobilis. From chamomile flowers; $\mathrm{gr} . \mathrm{x}$ to $Э \mathrm{j}$, bis terve die.

Casir cotri, Catechu. From Acacia catechu, almost black, hard, very bitter, slightly astringent and tonic ; used as an astringent masticatory: brought from Acheen and Pegu.

Cuтta caмвоо, Gutta gambir. From Nauclea gambir; also from the Funis uncatus of Rumpl, and another tree; of a light brown colour, slightly bitter, powerfully astringent; in lozenges, balls, and flat cakes; used as a masticatory, to fasten the teeth and sweeten the breath; from Pegu.

JaPax earti, Bengal cutch, Terra Japonica, Gummi Lycium? Ligni mimosce catcchu extr., Catechu extr. From the wood of the Mimosa, or Acacia, catechu; in round masses, of a dark choco. late colour, solid, resinous and shining; appears to be prepared by decoction and evaporation by heat; it is imported mixed with catechu; astringent and tonic, gr. $\mathrm{x}$ to $3 \mathrm{j}$; also used in dyeing and tanning.

Catecir, Bombay cutch. In small squares, of a pale reddish brown, texture lamellated, grain rough; appears to be prepared by cold infusion, and drying in the sun; imported by itself, or mixed with terra Japonica.

E. Colocyxthids Molle. From the pulp of bitter apples; actively purgative, gr. $\mathrm{v}$ to $3 \mathrm{j}$.

Essentral Sat.t of bark. Bruise bark, and infuse in cold water, strain, and evaporate by a very gentle heat.

E. of BARK, E. corticis Peruviani, E. cinchonce molle. Boil lb $\mathrm{j}$ of bark three times, in a gallon of water, filtering each decoction while hot; add the several decoctions together, and evaporate to a proper consistence for pills ; $56 \mathrm{lb}$. of bark yielded $13 \frac{\mathrm{l}}{2} \mathrm{lb}$.

Hard extract ol bark, Li. corticis Peruviani dumm, E. cinchone durum. Reduced by drying to a state fit for being jowdered.

E. ов YELLOW вавк, E. cinchone flava, E. of red burh, I. cinchonce rubre. 


\section{E. CENTAURII MINORIS.}

E. of saf fron, Polychroite, E. croci.

Buack extract, Hard multum, E. cocculi Indici. Used in brewing ale.

E. Digrtalis.

E. Dulcamare.

E. Radicum enUle campane. From elecampane root.

E. FUMARIE.

Gaub. From Embryopteris glutinifera ; very astringent, used in dyeing and tanning: imported from the East Indies.

E. Cacuminum Geniste. From broom tops: 3 ss to $3 \mathbf{j}$ or more in dropsy.

E. of gentan, E. gentiance molle, E. radicis gentiance, E. gentiance lutece. From gentian root; tonic, gr. $\mathrm{x}$ to $3 \mathrm{ss}$, bis terve die : $\frac{1}{2}$ a cwt. of gentian yielded 25lb. of extract.

E. GENTIANE DURUM.

E. Ligni gUaIACi Molle. From lignum vitæ shavings.

E. LIGNI GUAIACI DURUM.

E. ligni Campechensis, E. hrematoxyli. From logwood; gr. $\mathrm{x}$ to $3 \mathrm{ss}$ in cinnamon water, two or three times a day, or after every stool : $80 \mathrm{lb}$. of logwood yielded $14 \mathrm{lb}$. of extract.

E. RADicum hellebori NigRi, $E$. hellebori nigri. From black hellebore root; alterative, gr. iij to viij, bis terve in die; cathartic, resolvent, gr. $\mathrm{x}$ to $\mathrm{\exists j}$ : 28lb. of the root yielded $11 \mathrm{lb}$. of extract.

E. oF Hops, E. humuli. From hops, anodyne in cases which

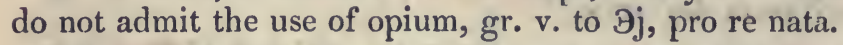

Extrart de lupurine, $E$. lupulini. From lupuline, matière jaune de houblon, by infusion in cold water; bitter, aromatic, dose not determined.

E. DE LUPUline AVEC LE Decoction, E. lupulini coctione paratum. Bitter, slightly aromatic; contains some of the resin of the lupuline.

E. radicis Jalap.e. Prepared by water only, is much milder in its operation than those with spirit; purgative, diuretic.

'Theriaca Germanorum optima, E. baccarum juniperi optimum. Soak juniper berries in cold water, and evaporate the infusion carefully poured off from the sediment; sweet tasted, semitransparent, and amber-coloured.

Ther. Germ. vulgaris, E. bacc. junip. sine contusione. Boil juniper berries in water, and evaporate the decoction; agreeable 
to the taste, aromatic, and diuretic : about 1-8th of extract is obtained.

Theriaca paulerum, E. bacc. junip. contusamum. The berries are bruised previous to decoction; is dark brown, thick, sharp tasted, and by no means agreeable; diuretic.

E. hellebori albi. Emetic and purgative.

Coccoloba kino.' From sea-side grape, coccoloba uvifera; its infusion is precipitated of a blue black by the oxysulphate of iron; astringent, useful in loosenesses, internal hæmorrhages, and the whites, gr. $\mathrm{x}$ to $Э \mathrm{j}$ : from Jamaica, sold for kino.

E. of lily of tile valley. Cathartic.

E. of mahogany. Prepared by decoction; sold for kino, and used in tanning.

Concextrated extract of lettuce. From the outward bark of the stem, and old leaves of garden lettuce, after the flowering, when the leaves begin to grow yellow, by cold infusion, straining without pressing, and evaporation on plates with a very gentle heat; anodyne, gr. v to 3 ss.

Grouтs. Ground malt, 6 or 8 slb., water 1 gallon and a half, kept covered and warm until in full fermentation, stirring it six times a-day, then evaporated to the consistence of a thick paste; used in Devonshire to make white ale.

E. milefoli. Astringent and tonic.

E. of mimosa ватк. Used for tanning leather; one cwt. equal to four or five of oak bark; from New South Wales.

E. OSMUND.F REGALIS. Used in rickets.

E. papaveris, F. capitum papaveris somniferi. From broken poppy-heads, the seed being taken out; by decoction and evaporation; anodyne, dose gr. ij to $\mathrm{j}$ : $28 \mathrm{lb}$. of broken heads yielded 5lb. and a quarter of extract.

E. QUassi.e. From the wood; substituted for hops, in brewing.

E. OF OAK ВАRK, E. cort. quercus. From oak bark: astringent, gr. $v$ to $\partial \mathrm{j}$, or more; from Turkey and the Black Sea; used in tanning: retail, for medicine.

E. OF PEPPER, L. piperis ni.gri. From the decoction; much stronger tasted than pepper. Úsed in agues.

E. PYROLE UMBELLATE.

E. of ratania. Resembles kino, and is sold for it; astringent and tonic ; is fusible, produces a reddish sediment in a solution of sugar of lead, and very slowly produces a sediment in a solution of ensetic tartar; from Brazil; used to colour wines red. 
F. Folionum rute, $E$. fol. rute graveolentis. By evaporating a decoction of rue leaves; stomachic, carminative, and emmenagogue: gr. $\mathrm{x}$ to $\mathrm{\Theta j}$, bis terve in die.

E. of SAvine, E. sabince, $E$. fol. sabince. As the former, stimulant, emmenagogue, gr. $x$ to $\mathrm{J}_{\mathrm{j}}$, bis terve in die.

E. SARSA PA Rille. From sarsaparilla root; gr. $x$ to $3 j$, in pills; 20lb. of fibres yielded 6lb. of extract.

E. senne, E. fol. cassia sennce. From senna leaves, serves as a basis for purgative pills, having scarcely any power of its own.

E. stramonir, P. L. 1824. Sem. stram. lb. j, water Oviij soak for four hours, bruise, boil to four pints; strain while hot and evaporate; anodyne and narcotic : dose, gr. $\frac{1}{4}$ to $\mathrm{gr}$. ijj.

Essence of spruce. From the twigs of Scotch fir ; stimulant and tonic: used to flavour treacle beer instead of hops.

Extractum stramonir. Prepared from the juice and decoction mixed together; $158 \mathrm{lb}$. of fresh stramonium yielded $3 \% \mathrm{lb}$. of juice; the cake was boiled in water, and the decoction added to the juice; the whole yielded, by evaporation, $3^{\mathrm{r}} \mathrm{lb}$. of extract, which was full of particles of nitre ; narcotic, in doses of gr. $j$ to $\mathrm{v}$, bis in die.

E. tanaceti, tonic and vermifuge.

E. taraxaci. From bruised fresh dandelion roots in boiling water; resolvent, diuretic, laxative, gr. $x$ to $3 j$, with vitriolated tartar.

E. Fol. Taraxacr. From the herb, a cwt. an $\frac{3}{4}$ yielded, by expressing the juice and then evaporating, 8lb. and a half of extract.

E. of TEA. Dry, solid, blackish, shining, and very brittle; it has a very weak smell and taste of tea, mixed with a styptic flavour, is easily dissoluble in the mouth, and tinges the spittle green; the solution in boiling water is brownish green, of a rough taste, and rather disagreeable smell; brought from China.

E. valerianfe. From the root, in a covered vessel; antispasmodic, gr. $x$ to $3 \mathrm{ss}$, or more.

\section{MIXED EXTRACTS.}

Prepared partly by water, and partly by spirit of wine, or by a mixture of both.

Extractum RHei. Soak 1lb. of rhubarb in seven pints and a half of water, mixed with half a pint of rectified spirit, for four days ; strain, let it settle, and evaporate the clear liquor; cathartic, gr. $x$ to 3 ss, but principally used as a basis for purging pills.

E. corticis Peluviani cum Resina, Extr. cinchonce officinalis, 
Extr. cinch. resinosum. Soak lb. jof bark in rectified spirit lb. iiij, for four days, and pour off the tincture; boil the residumm in water ; filter, and evaporate to the consistence of new honey; then add the tincture, previously brought to the same consistence by distilling off the spirit, and evaporate the whole in a gentle heat to a proper consistence. Astringent, tonic; dose $\mathrm{gr} . \mathrm{x}$ to $\mathrm{xxx}$, in pills.

E. cascarille resinosum. From cascarilla as the extr. cort. Peruv. c. resina ; tonic, gr. $v$ to $9 \mathrm{j}$, bis terve in die; 28lb. yielded $5 \frac{\mathrm{s}}{4} \mathrm{lb}$. of extract.

E. Jalapir molle, $E$. jalaya resinosum, $E$. convolvuli jalape. From jalap, as the extr. cort. Peruv. c. resinâ above mentioned; purgative, gr. $x$ to $3 \mathbf{j}$; it ought to be well ground, with a little sugar or potassæ sulphas to hinder it from griping; 18lb. of jalap yielded $16 \mathrm{lb}$. of extract.

E. JALAP.E DURUM.

E. podophyll, P. U. S. Cathartic.

\section{FARINAS AND FECUI.AS.}

\section{FARINAS.}

Fine wheat flour, Ador, Farina, $F$. tritici. The finest flour obtained by sifting the meal produced in the first grinding of wheat between sharp stones by a sieve of 64 wires to the inch; used for pastry.-Middlings. The remainder of the flour of the first grinding that will pass through a coarser sieve; used for making household bread, but is mostly reground.-Seconds. The finest part of the flour, obtained by grinding middlings over again, between blunt stones; used for making bakers' fine wheaten bread. - Pollard. 'The coarse flour, from whence the seconds has been sifted: used for making sea biscuits and gingerbread, and to fatten poultry and hogs. According to Accum, 32 pecks of wheat in the London mills yield $38 \frac{1}{3}$ of flour, 8 of pollard, and 12 of bran; the bulk of the wheat being doubled by grinding. Country houseliold flour. Is usually ground only once, and sifted to 4.5ths of the weight of the wheat.-Ammunition flour. Is required to be ground and sifted to $1960-2280$ ths, or very nearly 5-6ths the weight of the wheat.-Baked flour, Farina tosta. Astringent; used to make food for infants that are purged.

Wheat flour is distinguished by its coliesiveness, which is so great, that on being squeezed in the hand, the lump will be some time before it loses its shape. Liquid ammonia (aqua ammonix pura) turns it yellow; and, if any other corn has been ground with it, pale brown; or if peas or beans have been ground with it, a darker brown. 
Rye flour, Farina secalis. Used to make either a sweet bread, raising the dough by yeast, or an acid bread by using leaven for that purpose; this last is cooling, not so nourishing as the former, but more suited to an animal diet.

BArley flour, Farina hordei. When made into bread with yeast, it requires the dough to be baked very soon after it is made, as it grows sour almost immediately: a paste of barley-meal and water is used to take the hair off skins, previous to their being tanned.-Scotch barley-meal. From big, or bear, dark coloured. - Prepared pearl-barley. Pearl barley, highly dried, and then ground; used to make barley-water and gruel.

OAtmeal, Farina avenacea. Used to make gruel and bread, resolvent when employed as a poultice.

BEECH MAST MEAL. Is made into bread, but is affirmed to produce hydrophobia. Smiedel. de hydrophobia ex usu fructum fagi, Erlangen, 1762.

German rice flour. From German rice, or naked barley, Hordeum zeocriton; used to thicken soups; potato starch is sold for it.

\section{FECULAS.}

Wheat starch, Anıylum tritici. From wheat, by treading it in sacks in a current of water ; the water being received in troughs is left to ferment, which, decomposing the saccharine substance, renders the starch that is deposited on standing, very pure and white: friable, easily pulverised, crimp between the fingers, without smell or taste; demulcent, perhaps astringent; used for glysters in diarrhœea, dysentery, \&c.-Foreign starch. From the pollard and bran of wheat left after sifting away about half its bulk of the finer flour : Lubeck.

RYE starch. Floury, greyish white, scarcely crimp, retains the smell and taste of the grain; yields about half its weight of starch.

Barley starch. Powdery, greyish white, scarcely crimp, retains the smell and taste of the grain; yields rather more than half its weight of starch.

OAт sтARch. Floury, greyish, not crimp, with a weak smell and taste of water gruel. Yields half its weight of starch.

Arrow noot, Fecula sagittaria, F. marante, Maranta, P.U.S. From the root of Maranta arundinacea, by pounding or grating it in water, and letting the fecule settle; when rubbed up smooth with a little cold water, and boiling water poured upon this paste, it dissolves easily, by stirring, into a transparent jelly, without requiring to be boiled; nutritive: from the West Indies : 
potato starch is sold for it.-East Indian arrow root. From Curcuma angustifolia.

Potato starch. From raw potatoes, especially those which have been spoiled by frost; very white, globular, crimp, friable, heavy : when held towards the light it has shining particles in it; dissolves in boiling water as easily as arrow-root: 100lb. of potatoes, yicld 10lb. to $14 \mathrm{lb}$. of starch; sold for arrow-root, and German rice flour.-Potato flour, Potató farina. From boiled potatoes, not soluble in water; manufactured into sago, salep, maccaroni, vermicelli, semolina, tapioca.

Portland island sago, Gersa serpentarice, Cerussa serpentaria, Fecula ari maculati. From the root of Arum maculatum; prepared in the isle of Portland, and sold to the sick at Weymouth.

China-root starci. From Smilax China, reddish.

Aloe starch. From some species of aloes. lily.

Watelliliy starcir. From the root of the yellow water

Licts. A kind of starch procured from the roots of several species of Alstromeria, in Peru.

All the above species of starch are prepared in a manner similar to that of wheat or potatoes, and others may be made from different roots or seeds; they are all nutritive.

INULix. A white farinaceous powder that settles as the decoction of elecarnpane roots cools: dissolves in water, but does not remain united, separating again as the water grows cold.

SAGo. Prepared from the trunk of the sago tree, and several other kinds of palm trees, by splitting it, bruising the logs in water to separate the fecule, pouring off the water, letting it stand to settle: when the sediment is half dried in the air, it is granulated by being passed through a coarse sieve, and the drying finished first in the sun, and then by fire: a single tree yields from three to four cwt. of sago : from the East Indies, dark red; highly restorative.

Yam sago, West Indian sago. From the roots of Dioscorea sativa.-Mungo sago. From the seeds of Phaseolus mungo.White sayo, French sago. From kidney beans, or haricots.

Cassava bikad. From the root of Jatropha manihot, by expression of the juice, and baking the cake that is left; also from Y ucca gloriosa.

TArloca. From the root of Jatropha manihot, by washing the root, and thus preparing a fecule from it, which, when dried, is sprinkled with a little water and steamed, so as to form viscid 
irregular masses. These are dried in the sun until quite hard, and then broken into small grains. It is also made in the East Indies.

Potato taproca. From potato starch: by boiling it before it is dried, stirring it to break it into lumps.

Linseed oil cake, Lini placente, Ground linseed cake, Linseed powder, Farina lini placentarum. Used for poultices, but requires some oil or fat to be added to keep it from drying up too hard ; used for manure.

Cochin China rock-soy, Gummi ex oryza arte facta. Rice boiled to a kind of paste, and drawn out into threads; trans. parent; used to thicken soups.-China lock-soy. Opaque, and less esteemed.

\section{MEDICINAL FECUI.ES.}

Erateriua album. The half-ripe fruit of spurting cuciumber cut in pieces, so that the juice may drain out, which is left to settle, the liquid part poured off, and the sediment dried in the sun ; hydragogue, gr. ss. to $\mathrm{ij}$.

Elaterium NigRUM, Extractum elaterii, Succus spissatus momordica elaterii. From the nearly ripe spurting cucumber, by expressing its juice, and proceeding as before, drying the fecule with a gentle heat. Dr. Clutterbuck has ascertained that the active principle of wild cucumber is contained almost exclusively in the juice around the seeds, and that genuine elaterium is the matter which subsides spontaneously from this juice obtained without pressure. The chemical constitution of the elaterium of British conmerce has been investigated by Dr. Paris. Its constituents, as ascertained by him, are water 4 , extractive 26 , fecula 28, gluten 5, woody matter 25 , elatine and bitter principle 12 . The bitter principle, though not in itself purgative, quickens the action of the elatine by being combined with it. He considers elatine as a new principle, of a green colour, soft, heavier than water, not at all bitter, insoluble in water, soluble in alcohol. Half a grain or a grain of elaterium acts as a certain drastic hydragogue purge. Officinal preparation.-Extractum elaterii, L. D.

Feculf of briony, Fecula bryonice albce. From the root of white briony; cathartic.

Terra makemakey. A dark brown fecule, origin not known; used to cure ringworms, in New Spain.

\section{COLOURING FECULES.}

Woad, Glastum. From woad leaves, by grinding them to a paste, of which balls are made, placed in heaps, and occasionally sprinkled with water, to promote the fermentation; when this is 
finished, the woad is allowed to fall down into large lumps; used as a blue dye-stuff.

Indigo, Anil. Indicum. From the leaves and young shoots of several species of Indigofera and Nerium, by soaking them either in cold water, or still better in water kept warm, and at about 106 deg. Fahr. till the liquor becomes deep green; it is then drawn off, and beat or churned till blue flakes appear, lime-water is then added, the yellow liquor drawn off, the blue sediment dried, and formed into small lumps; used as a blue dye and colour.

\section{SPIRITUOUS LIQUORS.}

The strength of these liquors is technically denominated by numbers, referring to an arbitrary strength, called proof, a gallon of which was, in 1762 , to weigh $7 \mathrm{lb} .11 \mathrm{oz} .3$ drachms avoir. When spirit is said to be one to three over proof, it is meant that one gallon of water added to three gallons of the spirit will reduce it to proof; on the contrary, one in three under proof signifies that in three gallons of that spirit there is contained one gallon of water, and the remaining two gallons are proof spirit. As a gallon of water then weighed by law $8 \mathrm{lb} .7 \mathrm{oz} .5$ drachms avoir., the specific gravity of this proof spirit was to that of water as 910 to 1000. Of late, by a new regulation, the sp. grav. of proof spirit is to that of water as 12 to 13 , or 923 ; and the use of a hydrometer has been introduced, which shows the number of hundred parts of spirit that any liquor will require to be taken from it, or added, to reduce it to proof.

All these spirits are stimulant, but more employed as luxuries than as medicines; used externally in burns, and, when diluted, in ophthalmia; used also in chemistry as a solvent of rosin, and many other substances. Great improvements have of late been made in the apparatus for distillation on the Continent.

Common buandy, Eau de vie ordinaire, Aqua vitce, A. vitis. From high-coloured white wine, or pale red wines, by distillation in well-tinned stills, until the distilled liquor is no longer inflammable, or is less than 18 deg. Baume, equal to sp. grav. 0.9.4.

Cogniac braxdy, Ean de vie supérieure. From the palest white wines, by very gentle distillation, so as to bring over as little of the volatile oil of the wine as possible. It is sometimes kept in glass or stone-bottles, white Coyniac brandy, to prevent its acquiring taste and colour from the cask, and to preserve its musky flavour.

Eav de vil: dr: Marc: From dark red wines, as also from lees of wines, scrapings of wine casks, cake left in pressing grapes for wine ( 80 to 100lb. of which yield 1lb. of eau de marc), and from the lees left in making vinegrar, mixed with water, and distilled in untinned copper vessels, with a quick fire to bring over 
the oil of the wine, and thus give it the strong flavour required by the lower class of people, and by the English and other northern nations. It sells for $\frac{1}{4}$ or $\frac{1}{3}$ less price than that of ordinary brandy.

Eau de vie seconde, Repasse. The weak spirit that passes over after the stronger spirit has been taken away, and the receiving-can changed. There is collected of this about $\frac{1}{4}$ of the quantity obtained of stronger spirit. In manufactories this is redistilled; but for family use the worm is not cut, but the distillation is continued until this weak spirit is come over, and the whole mixed product kept for drinking : the residue, vinasse, left in the still, is used as a weak acid.

Eau de vie a preuve de Hollande. Brandy of any kind that forms a chaplet of beads when shaken; it varies from 18 to 20 deg. Baume, but is usually reckoned as 19 : it is the strength at which common brandy is retailed in France.-Eau de vie $\frac{5}{6}$ (cinq six). Brandy of any kind, five measures of which will, by the addition of water, make six measures of eau de vie à preuve de Hollande. It is generally reckoned equal to $22 \mathrm{deg}$. Baume, and is the strength at which the best brandy is usually retailed in France.-Eau de vie à preuve de huile. Brandy of any kind in which olive oil will just sink; it is at $23 \mathrm{deg}$. of Baume, and is the strongest brandy usually drank.

Eau de vie fort. From brandy of any kind redistilled, and the spirit that comes over saved in several separate portions: twelve strengths are usually made in France, the weakest being $\frac{5}{6}$ (cinq six, not cinq sixièmes), and the strongest $\frac{3}{9}$ (trois neuf, not trois neuvièmes); meaning that three measures of this spirit will make, by adding water, nine of eau de vie à preuve de Hollande ; it is equal to $38 \mathrm{deg}$. Baume.

Esprit de vin, Spiritus vini. All brandy stronger than 28 deg. Cartier, or $28 \mathrm{deg} \cdot \frac{x}{2}$ of Baume, or $\frac{4}{7}$, is esteemed in France as spirit of wine. The Paris Codex uses spirit of three strengths for its tinctures, 22, 32, and $36 \mathrm{deg}$. Baume.

Spinitus vinosus rectificatus, P. D. From brandy, rectified to the sp. gra. 0.84. -S. vin. tenuior, P. D. Sp. vin. rect. four pints, water 3 pints, mix ; the sp. grav. should be 0.93 .

ROUELLE'S SPIRIT OF WINE. Distil off half the quantity of brandy in a water-bath ; rectify this twice more, drawing off two thirds each time: mix the last spirit with water, to separate the oil, distil the spirit from the water, and rectify it once more ; produces $\frac{1}{8}$ the original quantity.

BAUME'S SPIRIT of wiNe. Distil off $\frac{1}{4}$ the quantity of brandy, and put it by; continue the distillation, and draw off another $\frac{1}{4}$; rectify this last portion in the same manner, and mix the first $\frac{3}{4}$ 
with the former first running ; rectify the second $\frac{1}{4}$ as before, and mix the first $\frac{1}{4}$ with the other; lastly, distil these first runnings, and draw off one-half : produces $\frac{1}{8}$ the original quantity.

Payfy and Chevallier's alcool. Mix a little caustic magnesia with the strongest spirit of wine to be bought of the distillers, and put it by for some time that the magnesia may absorb the acetic acid that is usually contained in their spirit, filter and distil the spirit twice in a water-bath from $\frac{x}{10}$ its weight of very high-dried chlorure of lime. The alcool ought to be $40 \mathrm{deg}$. Baume strong, or of the sp. grav. 0.823 ; and a piece of caustic barytes should not break down in it.

RAisin spirit. From raisins fermented with a proper quantity of water, and distilled with a quick fire, in order to bring over as much as possible of the flavour, this spirit being used to mix with malt spirit: 10 gallons are sufficient to give a brandy flavour to 1600 of common malt spirit.

Malt spikit, Spiritus frumenti. Made by mixing 60 quarters of barley meal, ground low, and 20 quarters of coarse ground pale malt, with 2:0 barrels of water, at about $170 \mathrm{deg}$. Fahr., taking out 30 barrels of the wort, and adding to this 10 barrels of porter yeast, and when the remaining wort is cooled down to $55 \mathrm{deg}$. adding 10 quarters more malt, previously mixed with 30 barrels of warm water, stirring the whole together, and putting it to ferment along with the reserved yeasted wort; this wash should be of the sp. grav. 1.084 to $1 \cdot 111$, or brought up to it by adding a strong infusion of ground malt. In the course of 12 or 14 days, the yeast head will fall quite flat, and the wash will have a vinous smell and taste, and be of the sp. grav. 1.002 when it is distilled, and on being redistilled should produce 1440 gallons of spirit, 1 to 10 over proof. 'The residue left in the still, distillers' wash, used to feed pigs.

Hollands, Brandewyn von koorn. Ten quarters of rye meal are mixed with a small quantity of cold water, and then as much boiling water added as is necessary to make a thin mash, and set to ferment with a small quantity of yeast; about the third day three quarters of ground malt, previously mixed with warm water, are added, and as much yeast as at first, stirring the whole well together. As suon as the head begins to fall, the whole is put into the still, and the spirit drawn off, rectified by a second distillation to $20 \mathrm{deg}$. Haume.

Best Holdands, Brandeugn von koorn voorloof drie quart. From wheat and malt, as the common Hollands; but the spirit is rectified to $2 \mathrm{t}$ deg. Baume; so that three measures of this spirit will, by adding water, make four of the same strength as the common. 
Dantzic bRANDy. From rye ground with the root of Calamus aromaticus, which gives it a mixed flavour of orris and cinnamon.

Rux. From the refuse of the raw sugar-manufactories, by taking equal quantities of the skimmings of the sugar-pans, of lees or returns, as they are commonly called, and of water; and to 100 gallons of this wash are added 10 gallons of molasses; this affords from to 10 to 17 gallons of proof rum, and twice as much low wines.-Double-distilled rum. Is rum rectified to a strength approaching to spirit of wine.

Sugar spirit. From the washings, skimmings, and other waste of the sugar-boilers : it is a very pure spirit, and used to mix with brandy.

Cane spirit. From the juice of the sugar-cane.

Molasses spirit, Spiritus ex syrupo, P. L. 1745. Is obtained from molasses, or treacle, by mixing 2 or 3 gallons of water with each gallon of molasses, and to every 200 gallons of this mixture adding a gallon of yeast; once or twice a day the head as it rises is stirred in, and in three or four days, 2 gallons more of water is added to each gallon of molasses originally used, and the same quantity of yeast as at first: four, five, or six days after this, there is added a third portion of yeast, as before, on which the fermentation proceeds with great violence, and in three or four days the wash is fit for the still : 100 gallons of this wash is computed to yield 22 gallons of spirit, 1 to 10 overproof.

Spiritus rectificatus, P. L. Molasses spirit, sp. grav. 0.835. - Proof spirit, S. tenuior, P. L. Molasses spirit, sp. grav. 0:930.-2. Sp. rect. half the quantity ordered, water the same, mix.

Alconor, P. L. Spiritus vini tartarisatus. Alcohol alcalisatum, grad. 42. Molasses spirit, sp. grav. 0.835, 1 gallon, add subcarb. of potash, heated to $300 \mathrm{deg}$. Fahr., 1lb. ; set it by for twentyfour hours; pour off the spirit, add 2ll). more of heated subcarbonate, and distil in a water-bath: the sp. grav. ought to be 0.815. - Alcoh. alcalisatum, gr. 46. Alcoh. alcal. gr. 4.2, lb. v, muriate of lime $\mathrm{lb} . \mathrm{j}$, mix, and distil to dryness.

VARNISII-MAKERs' SPIRIT, Extract spirit of wine for varnish. Obtained from molasses spirit by rectification to the highest possible strength; it has been prepared as high as 0.820 , by taking only the first gallon from 20 gallons distilled in a waterbath.

Ротато spirit. From $8 \mathrm{cwt}$ of steamed and mashed potatoes, $\frac{1}{2}$ a cwt. of malt, hot water added in three portions, in sufficient quantity to make 300 gallons of mash, and, lastly, 2 pints of yeast. As scon as the fermentation is finished, the wash is put into the still. 
2. Raw potatoes pulped 8 cwt., water 200 gallons, which is run off in half an hour, and malt $\frac{x}{2} \mathrm{cwt}$. added, with 120 gallons hot water. In three or four hours this wort is drawn off into the working tun, 50 gallons more lot water is added, and on being drawn off another 50 gallons is added, drawn off, and the whole fermented with yeast and distilled.

3. 150 gallons of water is put into a covered working tun of 500 gallons, lined with lead, and is heated by steam to $176 \mathrm{deg}$. Fahr.; 6 cwt. of potato starch is mixed in another tub, lined with lead, with $12 \mathrm{cwt}$ of water, and $12 \mathrm{Jb}$. of oil of vitriol, and mixed in threc portions with the water in the working tun, the heat being carefully kept up. In about six hours the starch will be changed into sugar, when the acid is to be neutralised with about $20 \mathrm{Jb}$. of whiting; the liquor is then drawn off, fermented with yeast, and distilled.

4. Steamed potatoes reduced to pulp are changed into sugar by oil of vitriol in a similar manner, and then fermented and distilled.

Swedish potatoe spirit, Danish potato spirit. Potatoes steamed and pulped are mixed with hot water into a mash; to each ton weight of potatoes is added $1 \mathrm{lb}$. of potash rendered caustic by quicklime; it is then cooled, and to each 3 tons of potatoes is added half a ton of malt, and the whole fermented and distilled as usual. A large quantity of yeast is obtained in this fermentation. The green taste of potatoe spirit is removed by rectifying the spirit with oxymuriate of lime, or bleaching-powder, ahout an ounce to each 10 gallons of spirit. $38 \mathrm{cwt}$. of potatoes, with 200 gallons of malt, yield about 225 gallons of spirit. Beet roots or carrots steamed and mixed with the potatoes improve the flavour.

Cirna arrack. From the toddy of Borassus gomutus, rice, and millet.

INDIAN ARRACK. From cocoa-nut toddy and rice. The Batavian, kneip, is esteemed the best ; then the Madras, the Goa, and Columbo are inferior.

Kullo charayum, Gungasir. From cocoa-nut toddy: the best of the pariah arracks drank in India.

Common pariah arRack. From any kind of toddy, or jaggery, rendered more intoxicating by adding hemp leaves, the juice of stramonium, and poppy heads.

Puttay charayem. From any kind of toddy, or jaggery, distilled with several kinds of barks; as Mimosa ferruginea, Acacia Arabica, etchum puttay, a species of phonix, and various others. 
African arrack. From the berries of the brandewyn bosch, Grewia flava. Very inferior to the Indian.

Apple whiskey, Cider spirit. Obtained from cider.-Shirret spirit;-Carrot spirit. Are obtained in the north of Europe from those roots.

Scotcif whisкey. From barley and oats, carelessly distilled, and suffered to burn to; the smoky flavour being by habit rendered agreeable.

Peach brandy. From that fruit; much drank in some parts of the United States.

Kirschenwasser. From common cherries.

Marasquina. From morello cherries.

Hollands gin, Jennever brandewyn, Spiritus juniperi. Corn spirit rectified twice over juniper berries.

ENGLISI Gin. Malt spirits 300 gallons, spirit of turpentine 4 pints, bay salt $20 \mathrm{lb}$; d distil.

MaLt Brandy. Malt spirit, flavoured with sweet spirit of nitre, and coloured with terra Japonica.

SPirit from faints. In rectifying spirits, and in distilling compound spirits, after the first strong portion has been drawn off, the weaker, and in some cases discoloured, spirit that arises is saved, under the name of faints; and when a sufficient quantity has been collected, it is rectified; the spirit thus obtained is principally used to make aniseed-cordial, as the strong flavour of the aniseseed will overpower any other flavour the spirit may have acquired.

Spirit of wine, Copying-liquid, Alcohol, P. E. All spirit, from whatever material produced, above 1 to 10 over proof, is thus deemed in the English laws: the Edinburgh College order it, for medical use, to have the specific gravity of $\cdot 835$. It renders paper transparent, and soon evaporating, the paper becomes opaque again.-Alcohol dilutum, P. E. Alcohol, P. E. and water, of each equal ineasures: the sp. grav. is about 0.935 .

\section{FERMENTED DOUGHS AND FERMENTS.}

The farina of the seeds of the grasses, mixed up into a paste with water, and exposed to a warm atmosphere, enter into fermentation; the paste becomes cellular, and its taste is much improved: but as some part of the mass is apt to become acid before the other is properly fermented, it has been found necessary, to promote the simultaneous fermentation of the whole, to add either a large proportion of a similar dough already in a state of fermentation, or of the frothy head and thick bottoms of liquors in the state of fermentation. 
Another kind of fermentation is excited in the manufacture of gingerbread, by the gradual evolution of carbonic acid gas within the mass; and a third, of a spurious nature, by the addition of subcarbonate of ammonia, the expansion of this salt by the heat of the oven rendering the dough cellular, and the bread nearly similar to that which has been regularly fermented.

\section{FERMENTED DOUGH, OR BREAD.}

ENGLish BREAD. Is made by dissolving $4 \mathrm{lb}$. of salt and half a gallon of yeast in about $36 \mathrm{lb}$. of warm water, making this into dough with flour; and when this has risen, adding another $36 \mathrm{lb}$. of warm water and more flour, and in about five hours the remainder of a sack, or $280 \mathrm{lb}$. of flour, with the necessary quantity of warm water, generally $10 \mathrm{~s} \mathrm{lb}$, and after some time baking it. This produces, when well baked, 80 quartern loaves, or $347 \frac{1}{2} 1 \mathrm{~b}$. of good serviceable bread; or if slack baked, 86 loaves, or 381 1b. $10 \mathrm{oz}$. of crumbling bread. 'The London bakers put in $\frac{1}{2} \mathrm{a}$ pound of alum, and take out the same weight of salt, that the loaves may part easier. The consumption of bread in London is, on an average, about $13 \frac{1}{2} \mathrm{oz}$. per head daily.

Paris white bread. Is made by diluting $80 \mathrm{lb}$. of dough reserved from the last baking, before any yeast was added, with a sufficient quantity of warm water to make a French sack, or $320 \mathrm{lb}$. of flour, into a dough much thinner than usual in England. When this has risen, $80 \mathrm{lb}$. of it is taken out, and covered up for leaven for the next baking, and then a lb. of dry yeast is diluted in water, and the solution added to the dough, which is immediately made into loaves and baked: the loaves being placed some distance apart, that they may be crusty all round. In general, a French sextier of wheat, or $284 \mathrm{lb}$, is computed to yield 176 lb. of flour, which, with $110 \mathrm{lb}$. of water, produces 286 of bread. - French country white bread. Has no yeast put into it. - French soup brear. Has a lb. of salt to each sack, in the place of yeast, to promote its solution in the soup, and is baked in thin loaves, so as to be nearly all crust. - The usual consumption of bread in a French family is estimated at $9 \mathrm{lb}$. of soft bread, and $7 \mathrm{lb}$. of soup bread for each person in a week, or nearly $2 \frac{1}{4} \mathrm{lb}$. for each daily.

Gixger виеad. Fine pollard $1 \mathrm{lb}$., treacle $\frac{3}{4} \mathrm{lb}$, potash, $\frac{1}{2}$ or., butter $10 \%$, warm water sufficient to make up the dough, $10 z$. of mixed spice, principally ginger, to which is added cinnamon, nutnieg, allspice, Cayenne pepper, and, in the inferior kinds, black pepper. Requires to be kept for several days, sometimes a fortnight, before it is fit for the oven; the rising being produced by the slow action of the acid in the treacle upon the subcarbonate of potash. 
2. Flour and treacle, each $1 \mathrm{lb}$., butter $1 \mathrm{oz}$., subcarbonate of magnesia $1 \mathrm{oz}$., or $1 \frac{1}{2} \mathrm{oz}$., with the usual spices: is fit for baking in a few hours' time.

3. Flour 2 lb., subc. of magnesia $\frac{1}{2}$ an oz., treacle $1 \frac{1}{2}$ lb., butter $2 \mathrm{oz}$., spices to the palate, tartaric acid $\frac{1}{4} \mathrm{oz}$., water a sufficient quantity. This is ripe for the oven in half an hour.

4. Flour $4 \frac{1}{4} \mathrm{lb}$., subc. of magnesia $1 \frac{1}{4}$ oz., the usual spices, treacle $2 \frac{3}{4} \mathrm{lb}$., butter $4 \frac{\mathrm{z}}{2} \mathrm{oz}$., water, in which $6 \mathrm{oz}$. of cream of tartar has been dissolved, a sufficient quantity. This may be baked in less than an hour: the bread has a slightly acid taste.

5. Volatile salt, being used for potash, or a small quantity added to the gingerbread, not yet ripe, enables the bread to be baked immediately : the upper surface of this bread is very dark and glossy.

Ammonjacal bread. Wheat flour 1 peck, or $14 \mathrm{lb}$, sub. carbonate of ammonia $2 \mathrm{oz}$, more or less, water sufficient to make the dough, which may be baked immediately: used when good yeast cannot be procured, or there is a sudden demand. This bread has small cells nearly all of a size, and a slight yellowish tinge.

\section{FERMENTS.}

Yeast, Barm, Fermentum cerevisic, Flores cerevisice. The frothy head that forms on the surface of fermenting liquors; used to promote the fermentation of other liquors and of dough: when it turns sour in summer time, a little subcarbonate of magnesia will remove the acidity; used also as a poultice to foul ulcers.

Artificial yeast. Boil malt, a quarter of a peck, in 3 pints of water; pour off 2 pints, and put it in a warm place for 30 hours; add 4 pints of a similar decoction, stir it well in, again ferment, and repeat this addition of 4 pints until a sufficient quantity of yeast is obtained: 10 pints will yield yeast sufficient for a brewing of 40 gallons; it is preferable to brewers' yeast, particularly when used for raising dough.

Dry yEAst. Obtained by spreading moist yeast upon canvas cloths spread upon a table or frame.

Levure. The yeast and lees of beer put into canvas bags to drain, and some water added to assist in carrying off the bitter flavour of the hops. Exported from Flanders to Paris for the use of the bakers.

\section{ROAS'IED VEGETABLE SUBSTANCES.}

RoASTED COFFEE. The seeds of the coffee shrub roasted by a gentle fire; used to make an infusion, which, being poured off or strained, and sugar added to it, is a grateful drink, with or without milk. 
Consica coffex. From the seeds of knee-holly, Ruscus aculeatus.-Rosetta coffec. From the seeds of fenugreek, adding a little lemon juice.-Egyptian coffee. From chick peas.-Holly coffee. From the berries. - Broom coffee. From the seeds.Gooseberry coffee. From the seeds washed out of the cake left in making gooseberry wine.-Currant coffee. From the seeds washed out of the cake left in making currant wine.

Rice corree. From the husked seeds: this is esteemed as the best substitute in India, where it is sometimes found that these substitutes agree better than the Turkey coffee.

RYe corfex, Dillenius's coffee, Hunt's economical breakfust poider. Rye roasted along with a little butter, and used as coffee. It is a good substitute, and can scarcely be distinguished from it.-Succory coffee, German coffee. Succory root roasted with a little butter or oil; but this wants the agreeable aroma of the Turkey.

Iris coFfeE, Sylvester's coffec. The seeds of the yellow water flag, Gladiolus luteus, or Iris pseudacorus, which is frequently found by the sides of pieces of water: this is the best of the European substitutes.

Patent cacao. Cacao or chocolate nuts bruised and roasted; is much richer than coffee, affording considerable nourishment.

CAcAo. The roasted husks of the cacao bean, or chocolate nut, used to make a poor kind of coffee drink.

Patent mat.t. Malt kept heated to $430 \mathrm{deg}$. Fahr. until it acquires a dark chocolate colour: used to colour becr; 11b. with $\tau 9$ of pale malt gives the colour and flavour of porter.

Roasted RUASSIA. Sold ground to embitter becr, and give it colour, but the beer soon grows turbid.

BrowN IIAIR POWDER. Flour roasted in an iron pan over the fire till it is brown.

OF ANIMAT, ORIGIN.

\section{ANIMAL SECRETIONS AND EXCRETIONS.}

Whiт: оF ес:(;, Allumen ovi. Nutritive, coagulates like blood by heat, and therefore used to clarify turbid liquors, and also as a varnish.

YeLK of EGit, Vitellus ori. Nutritive, coagulable the same as the whites, and used along with them for that purpose, as also to render oily substances miscible with water.

PotDRE CLARIFIANTE. The white and yelk of eggs beat together and dried by a very gentle heat, used to clarify wines, 
and exported to the French sugar islands, to clarify the cane juice.

Drien white of egg, Albumen. dried, used to form a test liquor.

Cuttue Fish INk, Sepia. When fresh taken from the cuttle fish, is a black glairy liquid, of a viscid consistence, a peculiar fishy smell, and very little taste; is preserved for use by being spread round saucers, so as to dry before putrefaction commences, or by evaporation on plates by a very gentle heat, or by being inclosed in an exhausted receiver with oil of vitriol: used for writing ink, and for a paint, much superior in ease of working to Indian ink, which latter dries so quickly, that it is difficult to colour a large pale shadow with it, and when once dry, some part always adheres to the paper, and cannot be removed; whereas cuttlefish ink may be washed almost clear off.

Melaina. Mix cuttlefish ink with very dilute nitric acid, and keep it warm until it becomes yellowish, then wash the powder well at first with water slightly alkalised with subcarb. of potash, and afterwards with plain cold water. Melaina is tasteless, black, powdery, insoluble in cold water, but soluble in hot water; used as a pigment, superior to Indian ink.

Human urine, Urina hominis, P. Sicil. Aperient; used in jaundice, $z^{\mathrm{j}}$ to $\mathrm{ij}$, omni mane.

Dried goats' blood, Sanguis hirci siccatus. Sudorific, antipleuritic.-Hogs' blood. Eaten with oatmeal.-Sheep's blood;$O x$ blood. Also eaten, and used instead of eggs to clarify liquids. -Dried blood. Neat cattle or sheep's blood, dried by a gentle heat, regulated by water baths placed one within another, so as not to be coagulated: exported for clarifying sugar-cane juice.

UREA. This substance in its purest form is exhibited in the form of elongated, brilliant pearly scales ; it is colourless, transparent, of a cool and sharp taste, and has an odour similar to that of urine. According to M. Thenard, the following is the best mode of obtaining it : urine evaporated to the consistence of a syrup, is to be treated with its own volume of nitric acid at 24 deg.; the mixture is to be shaken and immersed in an ice-bath to solidify the crystals of supernitrate of urea; these are washed with water at 0 , drained and pressed between sheets of blotting paper. When they are thus separated from foreign matters, they are to be dissolved in water, to which subcarbonate of potash is added, whereby the nitric acid is taken up, and the urea set at liberty. 'This new liquor is evaporated at a gentle heat, nearly to dryness; the residue is treated with pure alcohol, which only dissolves the urea, the solution is concentrated, and the urea 
crystallises. This is said to act as a diuretic. It has been given internally in solution in sugared water, in the dose of a gros.

Cow's URINe, Urina vacca. Used as a deobstruent, aperient, and purge; half a pint drank warm from the cow.-All-flowerwater. An infusion of recent cow's dung in cold water, in the dose of half a pint, is also used as a deobstruent and tonic aperient.

Ox gall, Fel tauri, Fel bovis. Cosmetic, detergent, used in earach, also as a collyrium, and gtt. $x x$ to $x \times x$ in wine as an emmenagogue, and to facilitate labour; used with oil to take off oil paint, and to wash greasy cloth.-Prepared ox gall, Fel taurimum inspissatum. The fresh gall is left for a night to settle, the clear fluid poured off, and evaporated in a water-bath; used to destroy the greasiness of some water colours, and to wash over tracing paper, that it may be written upon with ink.

White bear GaLL, Fel ursi. Antiepileptic.-Hare's gall, Fel leporis;-Gall of the silurus. Used as a collyrium, in cataract. Gall of eels, Fel anguillarum. Used to facilitate labour.

Asses' MrLK ;-Goats' milk;-Ewes' milk ;-Mares' milk;Woman's milk, Lac mulieris. Principally composed of sugar of milk dissolved in water; highly nutritive, laxative; popular remedies in atrophy and consumption. Mare's milk expels worms, especially the tænia.

Cow's muk, Lac vaccinum. Nutritive, the fattest of those usually employed; turns sour and curdles, but does not putrefy; boiled with sugar will keep some time; a little calcined magnesia will also prevent its turning sour, even in hot summers. Shows $4 \frac{1}{2}$ to $5 \mathrm{deg}$. Baume, but, if mixed with water, not more than 4 deg. at most.-Skimmed milk. Sits easy on the stomach; used as a varnish, and vehicle for painting in distemper: shows $5 \mathrm{deg}$. or more, Baume.

RENNet whey, Serum lactis. Milk 2 pints, rennet $35 s$, infused in a little hot water, mixed and kept in a gentle heat for some hours, then strained.

Butter MLK, Lac ebutyratum. By straining churned cream, the butter being left on the strainer, and the butter milk passing; allays the irritability sometimes produced by tea.

Frangipank. Skimmed milk, evaporated to dryness by a gentle heat; used to form artificial milk.

Sugar of milk, Saccharum lactis. Obtained in a crystalline form from whey clarified with white of eggs and evaporated: it is not so sweet as the vegetable sugars; used to make artificial whey, as a refreshing and laxative drink, to reduce cane sugar: not soluble in alcohol of $25 \mathrm{deg}$. Baume. 
Tyre. Made by adding a little butter milk to warm fresh milk, and letting it stand all night; much used in India, being eaten with rice; it is slightly acid and laxative; it is also churned for butter, either entire, but more commonly only the top or richest part.

Scotch sour cream. Put skimmed milk over night in a wooden tub with a spigot at bottom, and put this tub into another filled with hot water; in the morning take out the small tub and draw off the thin part of the milk, wigg, until the thick sour cream begins to come. This process requires practice as to the heat of the water; when it succeeds, skimmed milk yields nearly one half of this cream, which is eaten with sugar as a delicacy; it is only distinguishable from cream by its taste, and sells for double the price of fresh milk.-Buffalo milk. Thinner than that of the cow.

Honey, Mel Anglicum. Collected by bees, and deposited in the cells of their nests as food in store for winter; being chiefly collected from furze and broom, it is more waxy than the foreign honey from the south of Europe.-Narbonne honey, Mel Narbonense. Chiefly from rosemary and other labiate flowers.-Italian brown honey;-Minorca honey, Mel Minorcense;-East country honey. From pines, birch, \&c., only fit for making mead, ointments, and oxymels, on account of its strong taste and bad colour ; when heated, this last sort passes almost entirely into scum.

Honey is nutritive, laxative, but apt to gripe; it covers the taste of salts, \&c., better than sugar; used externally or in gargles, detergent. Officinal preparation.-Mel despumatum, L. D.

Poisonous honey. Found near Trebisond in Asia; also in South America; produces delirium, and sometimes death.

Coromande honey, Georgian honey, Stone honey. As hard as sugar-candy, the shape of the cells, brittle, not viscid, originally white, but becomes yellow by age; pleasant tasted.

Clarified honey, Mel despumatum. The best kind of honey is clarified by melting it in a water-bath, taking off the scum; the middling kind by dissolving it in water, adding the white of an egg to each pint of the solution, boiling it down to its original consistence, and scumming it ; the inferior kind requires solution in water, boiling the solution with 1lb. of bone black to each $25 \mathrm{lb}$. of honey, adding, when an excess of acid is apprehended, a small quantity of chalk or oyster-shell powder, straining and evaporating: it has not the agreeable smell of crude honey, but does not ferment so soon, nor is it so apt to gripe. Officinal Preparations.-Mel boracis, L. D. E. Mel rosæ, E. L. Oxymel simplex, $L$. $E$. Oxymel colchici, $D$. Oxymel cupri subacetat, $D$. Oxymel scillæ, D. L. Conserva rutæ, D. L. 
Hoxey DEw, Ros melleus. Found upon the upper side of leaves of trees in hot weather: dropped from the abdominal processes of the aphides, or plant lice, on the under side of the leaves over them; melts and evaporates by the heat of the sun.

Louristan maxna, Guz. A honey dew deposited upon leaves of trees in Persia and Armenia by the chermes mannifera, from its feathery abdominal processes: very white, resembling snow.

Edible birds' nests, Nidi esculenti. The nest of a species of swallows inhabiting the Indian Archipelago; these nests are formed of a mucous slime secreted in the stomachs of these birds, and flung up for that purpose: they are added to soup to render it thicker; the feathers sticking to them are separated by straining.

Cow dUNG, Fimus vacca. Used as a cataplasm in erysipelatous swellings, mixed with some unctuous matter to prevent its growing hard, and in the gout; also used very largely in calico printing as a cheap mucilage.

SheEp's DUNG. Used in dyeing, for the purpose of preparing cotton and linen to receive certain colours, particularly the red of madder and crosswort.-Poudrette. Human excrements, dried to a powder and sold in sacks, for manure.

\section{MORBID CONCRETIONS IN ANIMALS.}

BorNeo bezoar, Monkey bezoar. From the stomach of an unknown species of monkey, obtained by giving an emetic; bright green, with a fine lustre : in the highest esteem as a cordial.

Persiax bezoar, Oriental bezoar, Lapis bezoar Orientalis. From the stomach of the capra gazella; dark green, or olive; smooth, marking a green line upon paper; sp. grav. 2.233. From Persia.

Common Oriental bezoan, Snake stone. From the stomach of the Capra ægragus; applied to places bitten by snakes.Occidental bezoar, Lapis bezoar Occidentalis. From the antelope oryx; surface rough; grey, brittle, spongy; specific gravity 1.666; used instead of the Orièntal for cheapness' sake.-Hoy bezoar. From the stomach of the wild hog.

Pifdra nel porco, Lapis Malaccensis, L. hystricus, L. porrinus, Bez. hystricum. From the gall bladder of the porcupine; yellowish green, smooth, bitter.

Camel, bezoar, Wootay horashanum. From the gall bladder; used as a ycllow pigment. - Buffulo bezoar. From the gall bladder.-Ox bezour, Indian yellow? From the gall bladder of bos zebu; brought from Nepaul; used as pigments. 
Gall stone, Calculus cysticus bovinus. From the gall bladder of neat cattle in winter, when fed upon dry food; used, gr. $j$, in indigestions; also as a yellow pigment.

\section{GEI،ATINOUS EXTRACTS.}

Cake glue, Colle forte, Gluten commune. Prepared from the skins of animals, by soaking them for two or three weeks in lime water, boiling them with water, adding a little alum, down to a thick jelly, which is then poured out into shallow boxes, and, when cold, cut into squares, and dried in the air upon nets; used as a cement.

Flemish glue, Dutch glue. The skins are rinsed in several waters, and left to soak for some time, that they may require less boiling to be dissolved; cakes very thin, transparent; used by cabinet-makers in fine work.

Frfinch gLUe, Simmered for a long time with a small fire, until the skins are dissolved; then made to boil, and alum gr. $\mathrm{ij}$. to the pint added, to clear it for moulding; transparent and very brittle.

Hatmakers' grue. From the tendons of the legs of neat cattle and horses; brown, opaque, soft; grows moist in damp weather, but it does not render the felt brittle.

Bone glue, Gelatine sec. From gelatine brut, pp. 136 and 138 , by boiling it in water until dissolved, then moulding the decoction into cakes to suit the market.

Double size, Colle à baquet, Gelatine humide. Is made from skins, mostly rabbit skins ; also old gloves, parchment, and gelatine brut, in the same manner as glue, but is not boiled down so low, only so far that it is a tremulous jelly when cold. Single size. Is not boiled down so low.

Fish glue, Colle de poisson. Is made in like manner from various membranous and solid parts of cetaceous animals.

\section{OF MINERAL ORIGIN.}

Cologne earth, Cullen's earth, Umber, Terra Coloniensis. Black, or blackish brown, mixed with brownish red, fine grained, earthy, smooth to the touch, becomes polished by scraping, very light, burns with a disagreeable smell; found near Cologne; used in painting, both in water-colours and in oil; used also to render snuff fine and smooth; very. different from the brown ochre umber. 


\section{COMPOUND COMBUSTIBLES,}

OF AN OILY NATURE.

OF VEGETABLE ORIGIN.

\section{MUCILAGINOUS OILS.}

THEsE oils, unless it be otherwise directed, are obtained from the kernels of the plants by pressing them. As the retailers mix several of these oils together, the best method of obtaining them is from the oil-crushers, or brokers, as samples.

OIL OF SWEET ALMONDS, Oleum amygdalarum, O. amygdalinum, O. amygdalce, $\mathrm{O}$. amygdalce communis. From bitter almonds, or from old Jordan almonds, by heat; soon grows rank. $1 \mathrm{cwt}$. of bitter almonds unblanched produces $46 \mathrm{lb}$. of oil; the cake pays for pressing.-Cold-drawn almond oil. From fresh Barbary almonds; very fine, and keeps longer fiesh than the common. The old druggists kept an almond-press in the shop, and pressed the oil as they wanted it, by the lb. or $\frac{x}{2} l b$. of almonds at the time : the lb. yielded about $4 \mathrm{oz}$. This is demulcent and emollient, and has been found serviceable in catarrh and coughs, united with water by means of mucilage and sugar, or a few drops of liquor ammonix.-Dose. From half an oz. to an oz.

OIL OF STAR-ANISE SELDS, by expression, Ol. anisi stellati. Is of an agreeable fragrancy.

Ground-PEA ort. From Arachis hypogra; eatable, but strong-tasted; burns well, makes good soap.

Or of Ben, Ol. de ben. From Guilandia moringa; scentless, colourless, keeps long without growing rank.

Camellia orl. From Camellia oleosa; used for the table.

Java Armond ort. From Canarium commune; eaten while fresh, burned when stale.

INUIAN ALmoNd oll. From Terminalia carappa; pleasant tasted; used with salads.

Carappa orl. From the nuts of Carappa Guaianensis.

Argemonf orl. From-Argemone Mexicana; used as a liniment for the headach, also purgative, and burned in lamps.

Barbadoes cotton-seed oil. From Gossypium Barbadense; used to clear the skin of spots and freckles. 
OII, of wheat. By pressing the grain between heated plates.

Cucunber-séd oll. Used for the lamp.

Stinking trefoll ort. From Psoralia bituminosa; used for the lamp.

Orl of Cacao, Oleum cacao. From chocolate nuts, by expression; yield about $\frac{x}{8}$ th their weight of oil; used for the table.

Pinhoes oil, French physic-nut oil. From Jatropha multifida; purgative and emetic.

Jatropha glaUca oll. Used externally in rheumatism and palsy.

Grey nickar oil. From Guilandina bonducella; used in convulsions and palsy.

Mastich-Berry oll. From the berries of Pistachia lentiscus; used in cookery.

Hewp orl, Ol. cannabis. From hemp-seed; used for frying, by the painters as a drying oil, for soft soap and the lamp.

NetruE-Tree 01L. From the seeds of Celtis australis: excellent for the lamp.

Cornel oil. From the seeds of Cornus mascula and C. sanguinea: answers for lamps, but not for the table.

Physic-nut oil. Ol. cicinum, Ol. jatrophe curcadis. Used as castor oil for a purge, also externally in chronic rheumatism, and for the lamp.

Nut ort, Ol. nucum coryli. From the hazel nut, very fine; substituted for oil of ben; used by painters as a vehicle for their colours.

BeEch Mast oll, Ol. fagi. Very clear, keeps well; used with salads.

Buck-wheat oil. From the seeds of buck-wheat.

Hemp-nette oit. From the seeds of Galeopsis tetrahit: yielded ver'y plentifully.

Gingko orl. From the seeds of Gingko biloba: used for the table.

Sun-Flower seed oil. From Helianthus annuus; used for the lainp.

Walnut ort, Ol. nucum juglandis. Makes good plaisters ; will not keep; used by painters, is very drying: 90lb. av. of kernel yield 20 to 24 quart bottles of oil.

Cold-Drawn walnut orl. Eaten with salads. 
Expressed oll of bays, Ol. laurinum. From bay-berries; very fluid, insipid.

LINSEED oIt, Ol. lini. Viscous, bitter; miakes but a soft soap; used in lamps, but chiefly in painting, is very drying; also to make varnishes and printers' ink. Officinal Preparation.Linimentum aquæ calcis, $E$.

Cold-DRaW L Linseed oll, O. lini sine igne, O. lini usitatissimi. Used in medicine, laxative.

OrL of Mace, Ol.macis in ollis, O. moschate, O. nuciste, $O$. myristica nuclei expressum. From nutmegs by the press; buttery, smell and colour of mace, grows paler and harder by age : $2 \mathrm{lb}$. yielded 6 oz. From Banda.

OIL of BarabeE. From a wild nutmeg in Madagasear; stomachic.

TrUe oll of Mace, by expression, Ol. macis expressum verum. Red, remains always liquid or soft, has a strong smell of mace, subacid taste, imported in jars or bottles, the lower part being rather thicker than the top: 1lb. and a half of mace yielded in Europe $\tilde{3}$ jss. of oil.

MADI olL. From the seeds of Madia sativa; very fine; used for the table.

Otl. of stone-pine kernels, Ol. nucis pini. From the Pinus pinea; grows rank very soon; $16 \mathrm{lb}$. of kernels yield 5lb. of oil.

Cemrro nut oil. From Pinus cembra; used for the table.

Pistachia Nut ori.. Sweeter than almond oil; forms a green emulsion.-Cochin China pistachia oil. From P. oleosa; yellow; used for the table.

OIL of rhus Javanicus. From the berries by boiling; used to make Chinese varnish.

Bastard saffrow oil. From Cnicus tinctorius; used in rheumatism, palsy, and foul ulcers.

Poox xut oir. From Calophyllum inophyllum, well scented; used in rheumatism, and for lamps.

Kanart net olz. A delicious oil for the table, also used in medicine.

Maracca beas ors. Obtained by boiling, very acrid, raising blisters, but when diluted used in rheumatism and palsy.

Cashew nut oir. Obtained by boiling, very acrid.

Best saraid oli., Oleum maturum, O. completum. From the flesh of Italian olives, fine yellow, perfectly inodorous. - Salad oil, Siveet oil. From French olives; grass green, inodorous; imported 
from Marseilles: 12 bottles in a basket.-Both these olive oils are used with salads, and for frying, also to soften the hair, and to anoint the body all over as a preservative from the plague. They become concrete when poured upon a solution of 6 drachms of quicksilver in 7 drachms of nitric acid at $38 \mathrm{deg}$. Baume. They are reduced by poppy oil ; and that oil, as also argan oil, cold-drawn walnut oil, and beech mast oil, are sold for them.

Olive oIL, Oleum olivarum, Oliva oleum, O. fixum fructûs olive Europece. Imported from Sicily, Naples, Candia; but all are rank, being made from olives which have been left in heaps to sweat. Its quality is estimated by the quantity of foot or lees that separates on standing, the less the better; used for plaisters and ointments, the lamp, as it yields scarcely any soot, and largely in the woollen manufacture.

Oreum омрнасілum. From the cake left on pressing olives, pouring hot water on it, and again submitting it to the press; or from unripe olives; thick, deposits much sediment.-Droppings of sweet oil, Fax olei, Amurca. The foot deposited by olive oil; used instead of the preceding for oiling iron-work.

Poppy orl, Huile d'oeillette, Oliete, Oleum papaveris. Used as a salad oil; is not narcotic, as has been supposed; has a slight odour; keeps well, is drying, does not burn well, and smokes very much, makes a soft soap, but very good plaisters; works with colours more freely than nut oil, does not coagulate with acid nitrate of quicksilver.

Apricock ort, Huile de marmotte, Oleum chrysomelinum. Agreeable to the taste, used for that of almonds.

Argan oll. From the seeds of Rhamnus siculus: sold for olive oil.

Cold-Drawn Castor orl, Oleum de kerva, O. kervinum, $O$. palma liquidum, O. ricini. From the R. communis, not less than six months old, blanched with cold water, and pressed; $10 \mathrm{lb}$. yield 3lb. of oil.

Foreign CAstor oll. From the seeds ground with water in a mortar; two bushels and a half yield 4 gall. of oil; also obtained by bruising the seeds, tying the mass in a bag, and boiling in water; 10lb. yield 1lb. of oil.-Purgative, in doses of 3ss. to 3jss., floated on some distilled water or on wine; or, if it does not usually stay well on the stomach, on some tincture of senna, or made into an emulsion with yelk of egg, and a little distilled water, with gtt. xx. of lavender drops, and a teaspoonful of simple syrup: it may also be used in clysters : is particularly useful where a stimulant would be hurtful, as it operates quickly without disturbing the system; externally in swelling pains. Contrary to most medicines, on frequent repetition a less dose is 
sufficient; used to reduce essential oils, and balsam of capivi, as it dissolves in alcohol.-Oil of the embryos of ricinus communis. Very mild, sweet, and not purgative.

BapenNah lamp orl. From Ricinus viridis, the seeds being roasted and boiled; dark coloured, thick.

Croton oun, Tiglii oleum. From Molucca grains; extremely cathartic; when good, a drop is a sufficient dose. The acridness of some parcels of castor oil seems owing to an admixture of this oil, rather than that of the physic nut.

Oil of trichilia spinosa. From the berries, warm, pleasant smell, used in rheumatism.

Garden spurge oil, Oleum lathyris. From Euphorbia lathyris; cathartic, gutt. iv to viij; $14 \mathrm{oz}$. seeds yield $6 \mathrm{oz}$. oil.

Brown rapf, ort, Huile de colsa, Oleum rapa. From rape seed, Brassica campestris oleifera, dries slowly, makes a softish soap, is fit for ointments, but does not make good plaisters; smokes much when burned.

Pale rape oir, Refined rape oil. From brown rape oil, by inixing 2lb. of oil of vitriol with each cwt. of the oil, and twice as much water, beating the whole well together, letting it stand for eight or ten days in a warm place, pouring off the oil, and filtering it through flannel, or felt ; used for the lamp.

Turntp seed oit, Huile de navette de Dauphine. From Brassica rapa oleifera; used for the lamp.

Huile de vavette d'hiver. From Brassica napus oleifera.

RADISH SEEv oIL, O. raphani. From radish seed, used for salads.

Gingeluy oil, Benne oil, Sweet oil, Oleum sesami, P. U. S. From the seeds of the Sesamum orientale; used for food, and in painting.

Hute df cameline, Oell, Oleum sesami. From the seeds of gold of pleasure, Myagrum sativum; used for burning in lamps, and in ointments.

Mustard un, Oleum sinapis. From the hulls of black mustard seed, after the flour has been sifted from them; smells like rank linseed oil mixed with horse radish: used in rheumatism.

Sweet mustard orr. From Sinapis dichotoma, S. ramosa, S. glauca, S. Sinensis, and S. tori; used for the table.

Kuterara orl. From the seeds of Sterculia platanifolia.

TEA-SEED OIL. From the seeds of 'Thea oleosa, very limpid.

Hutserta or.. From the seeds of Verbesina sativa, very fine; used in cookery, and for the lamp. 
Oit of vernicia montana. From the kernels, yellow, used as a varnish.

Oil of bryonia callosa. Used for the lamp.

Margosa oil. From the fruit of Melia azederachta, bitter, vermifuge.

Huile D'oor. From ooli, a plant that grows in the Antilles; sold for oil of ben.

\section{VEGETABLE BUTTERS.}

BoILED OIL OF BAYs, Oleum laurinum verum, O. lauri nobilis. From bayberries, by boiling, thick like butter, green: from Italy.

Butter of laurus glauca. Used for candles, obtained by expression.

Orl of a vocado pear. Stomachic.

Myrtie oil, Myrteum. From myrtle berries; concrete, odoriferous, astringent.

Java tallow? Mava butter. Expressed from Bassia butyracea, white, used for making soap.

Butter of bassia loxgifolia. Greenish yellow.

MaCKaW Fat. From the nuts of Cocos fusiformis.

Tallow of lits.ea sebifera. Used for candles.

Butter of the choorie tree. Used as butter in India.

NutMeg butTer. Floats on the surface of the water in the still when nutmegs are distilled for their oil, insipid.

Palm ori, Oleum palma, O. palma sebaceum, O. cocois butyracece. Yellow, butyraceous, sweet scented, does not change colour when mixed with an alkali; used for food, and in emulsions as a demulcent; externally it is peculiarly emollient, and well adapted for ointments.

Oil of MACE in CAKes, Banda soap, Oleum macis in massis. Is cut out of the jars of oil of mace when it is discoloured and grown solid by age.

Bankara butter. From a not well-known nut.

Butter of cacao, Butyrum cacao. From the kernels of the chocolate nut by boiling; keeps well; used for food: $4 \mathrm{lb}$. of nuts yield about $11 \mathrm{~b}$.

American green wax, Cera viridis. Obtained from Myrica cerifera, and other species of myrica; by boiling the berries in water, they yield one-fourth of their weight of wax ; used to make sweet-scented candles, and also for the darker ointments and plaisters, instead of bees' wax : from the United States. 
Chinese vegetable tallow. From the seeds of Croton sebiferum.

\section{Bencoolen nut oil. From Croton Moluccanum.}

Guy amadou. From the fruits of the Virola sebifera or Myristica sebifera. The four preceding are all used to make odoriferous candles.

P.enoe ta l.Low. From the fruit of Vateria Indica by boiling, white, sometimes yellow, greasy with a waxiness, burns with an agrecable odour.

Sassafras nut ol , Oleum fabarum pichurim, P. Belg. White, butter-like, smelling like sassafiras, becomes yellowish and tallowy by age : $1 \mathrm{lb}$. yields about one oz. and a half of oil.

Coco A NuT olL, $O$. cocois nuciferce. By the press, white, used for lamps, and to make gas for lights ; makes a stinking soap.

Fine cocoa nut oil. By boiling, used in cookery.

Cabbage palm oil. From Areca oleracea.

\section{ESSENTIAL OILS.}

These oils, unless it be otherwise directed, are obtained by distilling the articles with an equal weight of water to prevent them from adhering to the still, and the oil and water acquiring a burnt taste; some, as those of the peels of fresh fruits, are obtained by rasping them, and pressing the raspings; a few by distilling the articles with twice their weight of water, adding $11 \mathrm{lb}$. of salt to each gallon of water, using a quick fire, and when half the water has come over, pouring it back again into the still, and thus cohobating it on the article. When rectificd for the purpose of rendering them fincr, they are distilled without water in a retort, and one half the oil is drawn over; that left in the retort is mixed with raw oil intended for sale in that state; they are all stimulant, in doses of gtt. ij to $\mathrm{x}$ upon sugar, but are mostly made into cordial waters, by distilling with spirit of wine, or water.

DisTiLled OIL of WORMWOOD, Oleum essentiale absinthii. From the herb; stomachic: $25 \mathrm{lb}$. of green wormwood yielded from six to ten drachms of oil ; 4.lb. of dry yielded an ounce, and 1slb. only j̈jss.

OIL OL Acows, Oleum acori, O. calami aromatici. 50lb. yielded $2 \mathrm{oz} ., 1 \mathrm{lb}$. yielded $\mathrm{j} \mathrm{ij}$; sweet scented.

Ginger grass oil. From Andropogon nardus, pleasant tasted.

OH, of amyris rrotium. Aromatic.

ESSENTIAL OIL OP BITTER ALMONDS, O. amygdalarum ama- 
rarum athereum. From ground almond cake, by distillation, with twice as much water and half as much salt, after having been left to soak for some days, and when half the water is come over, pouring it back into the still : 25lb. of cake yields $2 \mathrm{oz}$.; contains prussic acid; used to communicate flavour to confectionary, and as an ingredient in mixtures in phthisis and spasmodic diseases, instead of prussic acid; when rectified, its strength is prodigiously increased.

Orl of ANise seeds, Oleum anisi, $O$. volatile pimpinelle anisi. From the seeds ; congeals at 62 deg. Fahr.; poisonous to pigeons, so that, as Vogel has observed, if they are forced to breathe air impregnated with it by rubbing it on their bill, or head, it is fatal ; 1lb. yields $3 \mathrm{ij}$.- Oil of star anise seeds, Oleum anisi stellati. From the capsules; liquid, very fragrant, has the scent of anise. This is carminative and used in flatulent cholic. Dose mv. to $\mathrm{mxv}$. rubbed up with sugar and camphor mixture.

\section{Orl of DILl SEen, Oleum anethi. Carminative.}

Neroli, Oleum florum aurantiorum. From the flowers of the orange tree; 6 cwt. of flowers yield only one oz. of oil.

Oleum florum citri. From the flowers of the citron tree; amber-coloured, slightly fragrant: $60 \mathrm{lb}$. yield $1 \mathrm{oz}$.

Essence of bergamotte, Oleum limonis Bergamottce. From the peels of the Bergamotte orange ; by pressure, very fragrant: from Italy.

Huile d'orange. From orange peel by pressure; very fragrant:- Huile de petit grain. From small unripe oranges, by distillation, gold colour.

Oleum stillatitium radicis carline. From the root of the carline thistle; fragrant, sinks in, water.

Kyaputтy o1L, Cajeput oil, Oleum cajuputi, O. volatile melaleuce leucadendri. From the leaves; cooler than that of peppermint, but smells of turpentine; dissolves gum elastic, stimulant, antispasmodic, gtt. iij to $\mathbf{v}$, on sugar, and externally in rheumatism : from the East Indies, generally in large copper flasks.

O1L of Carui, Oleum carui. From the seeds, carminative; 2lb. yielded more than $1 \mathrm{oz}$, and $1 \mathrm{cwt}$. only $83 \mathrm{oz}$.

Distirled oil of cacao. From the chocolate nut; thick, reddish, rather buttery.

Orl of Cloves, Essence d'aillettes, Oleum caryophyllorum aromaticorum, O. caryophilli. From cloves, soaked and distilled with salt water, the distilled water being returned two or three times into the still; very heavy, acrimonious; supposed to contain some part of the rosin of the clove; stimulant, added to purgative pills to prevent griping; externally applied to aching teeth: $1 \mathrm{lb}$. of cloves yields from 3 jss to $\xi$ ijss : 1 cwt. yields $18 \mathrm{lb}$; $7 \mathrm{lb}$. and 
a half yield 1lb. of oil.-Expressed oil of cloves. From fresh mother cloves, antophylli.

Orl of wormwed, Oleum chenopodii, P. U. S. From C. anthelminticum.

Oil of Virginian pennyroyal, O. cunile, P. U. S.

Orl of Cassia, O. cassia. From cassia buds; stimulant, stomachic ; 30lb. yield $4 \mathrm{oz}$.

Distilled oil of camomle flowers, O. essentiale chamcemeti florum, $O$. anthemidis caruleum. From the flowers, stomachic dose mv. to mx. ; 1lb. yields a drachm, 82lb. yield 3 xiij, and at another time $3 \times$ viij ; it is of a fine blue, even if distilled in glass vessels.

Distilled orl of CAMomile, $O$. anthemidis viride. From the herb, green, stomachic.

Orl of cinnamon, Oleum cinnamomi. From the fresh bark, distilled with sea water; $11 \mathrm{lb}$. yield $1 \mathrm{oz}$. of oil ; from Ceylon.

Exglish oil of cinnamon. From the bark of inferior cinnamon, imported under the name of cassia, distilled with salt water, and cohobated: $11 \mathrm{~b}$. yields from $3 \mathrm{j}$ to $3 \mathrm{jss}$.

Essexce of cevrat, Oglio del cedro, Oleum cedri, O. citri finum. From the yellow part of citron peel; colourless, very thin and fragrant. - 2. The second oil obtained by the distillation of the yellow part of citron peel; greenish; 100 citrons yield $1 \mathrm{oz}$. of the white essence, and half an oz. of the greenish.3. From the yellow part of citron peel by expression.

Essence of citroxs, Oleum citri. From the lees left in the casks of citron juice ; clear, fragrant, greenish : $50 \mathrm{lb}$. of lees yield, by distillation, 3lb. of essence,-2. From whole citron peels by expression; very fragrant, but does not keep so well as the distilled oil.-3. From the cake left on pressing citron peels, by distillation with water; thick.

Rectifizd oil or citrons. The pressed oil of the whole peels, distilled until $3 \mathrm{oz}$. out of 5 are come over, white, very fragrant.

OIL OF CUMMIN SEED, O. cymini.

OrL OF Cl.ARY Flowers. 130lb. fresh yield $3 \mathrm{oz}$. and a half; used in perfumery for soap?

Oii. of partridge berry, Oleum gualtharia, P. U. S.

OlEus FENicul. From sweet fennel seeds; carminative: 1 bushel yielded $18 \mathrm{oz}$.

O11 OF HOPs. Collected during the boiling of hops in beer; used to increase the flavour of other hops by rubbing it amongst them. 
Orl of Hyssop Leaves, Oleum hyssopi. 2 cwt. yielded 6 oz., 30lb. yielded 3ix.

Essence des violettes, Oleum iridis. From the root of Florentine orris; smells like violets.

Essence of Jasmine, Oleum jasmini. From the flowers of J. grandiflorum, not picked from their cups; yielded in very small quantity, highly fragrant: brought from the East Indies.

Oleum JUNiperi, O. baccamm juniperi communis. From the berries; diuretic : 1lb. yielded 3iij, and 48lb. yielded $6 \mathrm{oz}$.

Essence of Lavender, English oil of lavender, O. lavandula, O. lavandula spica. From the flowers of narrow-leaved lavender, very fine scented, unites with strong acetic acid, sp. grav. 0.898; at $68 \mathrm{deg}$. Fahr. dissolves copal; 24 bundles produced $144 \mathrm{oz}$.

Foreign oll of lavender, O. lavandula llatifolice, O. lav. exoticum. From the flowers and seeds of broad-leaved lavender; sweet scented: Italy and south of France.

'True oll of spike, Huile daspic, O. spica verum, O. lav. stcechadis, O. lav. spica. From the flowers and seeds of French lavender, Lavandula stæchas, with a quick fire; inferior in scent to those of lavander: from Languedoc and Provence.

Rectified orl of I.AVExder. Drawing off $3 \mathrm{oz}$. in 5 ; sp. grav. 0.877 ; at $68 \mathrm{Fahr}$. used for choice perfumery ; the residue contains camphire.

True Riga balsam, Baume de Carpathes, Balsamum Libani. From the shoots of Pinus cembra, previously bruised and macerated for a month in water; pellucid, very liquid, whitish, smell and taste of oil of juniper, vulnerary, diuretic.

Essence of lemons, Essentia limonum, O. limonis, Citri medice oleum volatile. From the fresh peels of lemons; limpid, watery, fragrant; used in perfumery : from Italy.

Distilled oIr of MACE, Oleum macis stillatitium. From that spice; liquid, pale citron, smelling of the mace.

Oil of sweet malijoran, Oleum marjorana. 85lb. fresh yield $3 \mathrm{oz} \cdot 3 \mathrm{vj}$.

OrL of BALM, Oleum melissc. 961b. yield $\bar{j}$.

Oil of pepperaint, Oleum menthe piperite, O. herbe menthe piperit. florescentis. From the dried plant; $4 \mathrm{lb}$. of the fresh herb yielded $3^{\text {iij }}$; used to flavour spirit.

Rectified oll of peppermint. Used for peppermint lozenges and drops; very warm.

Oil of mint, Oleum menthe viridis, O. menthe vulgaris, $O$. menthce sativa. From the dried plant; 33 doz. yielded $8 \mathrm{oz}$. and 
a half; 6lb. of fresh leaves yielded Jiijss; and 4lb. dried yielded $1 \mathrm{oz}$. and a half. This is stimulant and carminative, and has been recommended in flatulence and anorexia. The dose is from 2 to 4 minims on a lump of sugar. Officinal preparation.Infus. menthx comp., $D$.

Orl of muforl flowfrs, Oleum millefolii. 18 baskets yield 4 oz. Jiiij ; 14lb. dry yield 5iij.

Oreum Moxakd. P. U. S. From M. punctata.

Volatife oll of black mustame seed. Mix 10 kilogrammes of the best black mustard powder with fiom 50 to 5.5 kilogrammes of water, and place them in an alembic, which is connected with a double-balled receirer: then distil. The volatile oil condenses at the bottom of the receiver in the form of brownish flakes. When six litres of water have passed over, change the receiver, or after that no volatile oil is deposited. Pour off the superabundant distilled water, and rarefy the oil by a naked fire in a small alembic. Thus it is obtained almost colourless. When diluted with its own weight of alcohol, at $40^{\circ}$, it is an excellent rubefacient, and acts almost instantaneously. It may be substituted for the ammoniacal ointment.

Essexce of MYrte, Oleum essentiale myrti. From the flowers and leaves; fragrant.

Essexce of Josquil, Oleum murcissi. Used in perfunery.

OrL OF митми, Oleum mucis moschata stillatitium. From that spice; liquid, pale yellow: from Banda.

Oil of тнуме, Oleum origani. From the plant; 2 cwt. fresh yield $50 \%$ and a half, $3 \frac{1}{16}$. dried yield 3 jss; stimulant, makes the hair grow, caustic, used in toothach: from France.-O. petroselini.

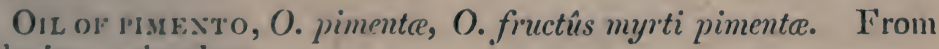
allspice; stimulant.

O. PISPINELL.F. From the roots of pimpernel; blue.

Orl of pexxy-Royat, $O$. pulegii. From the herb when in flọwer; 13lb. yielded $3 \mathrm{vj}$.

Ori of ravientsara, Oleum rancutsarce. From the leaves; sold in Europe for oil of cloves.

Ori, of RHODies, Oleum e ligmo rhodii. From Levant lignum rhodium : 80lb. yielded 3 ix ; 80lb. very resinous old wood yielded 207. : light, yellowish, but by keeping grows red: from the Levant; the orl of sandal-wood is sold for it.

OiL or wosls, Ol. rosce. From the flowers of musk roses in the cups split open, suaked in twice their weight of salt water for several days, then distilled, and the water colobated once or twice 
on them : 1 ewt. yields from half an oz. to an oz. of oil; the oil of sandal-wood is sold for it.

Orl of rosewont, Ol. rhodiole rosece. From the root; yellowish : $1 \mathrm{lb}$. yields $3 \mathrm{j}$; sold for oil of rhodium, and the water for rose-water.

Butter of roses, Adeps rosarum. From the flowers of damask roses; white, solid, melts at 94 deg. Fahr. separating slowly from the rose-water: having but little scent of its own, it is used to dilute the scent of musk, civet, and ambergris.

Aтtar, (itur, utr,) gul, or guhl, otto of roses, Oil of roses, $O$. rose. From the evergreen rose and the musk rose, new-distilled rose-water being exposed to the night air; a highly-esteemed perfume; freezes at $50 \mathrm{deg}$. Fahr.; melts at $85 \mathrm{deg}$. : from the East Indies and the Barbary coast.

OIL of Rosemary, O. rosmarini, O. rorismarini officinalis. From the flowering tops; sweet scented; $1 \mathrm{cwt}$. yields $8 \mathrm{oz}$; $11 \mathrm{lb}$. of dry leaves yields from $3 \mathrm{j}$ to $3 \mathrm{iij}$; $70 \mathrm{lb}$. of fresh leaves yield $5 \mathrm{oz}$. Stimulant, and given in nervous complaints, the dose being from two to six minims rubbed up with sugar.

RECTified oll of Rosemary. By redistilling until one half of the oil is come over. Used for fine perfumery ; the residuum contains camphire.

Distillen oil of RUe, O. rutce. From the dried plant; carminative, antispasmodic : $10 \mathrm{lb}$. of leaves yield 3 ij to 3 iiij ; $4 \mathrm{lb}$. in flower yield $3 \mathrm{j} ; 60 \mathrm{lb}$. yield $2 \mathrm{oz}$. and a half; $\tau 2 \mathrm{lb}$., with the seeds, yield $3 \mathrm{oz}$. Antispasmodic, and externally rubefacient in hysteria, and the convulsive affections of infancy attendant on dentition. Dose from 2 to 5 drops rubbed with sugar or mucilage.

OIL of SAGE, O. salvice.

Orr, of savine, O. sabince. From the dried plant; stimulant, powerfully emmenagogue; externally rubefacient.

Orl of SaNDal wood, O. santali albi. 1 lb. yields 2 drachms; sold for oil of rhodium, and oil of roses.

Oil of sassarras, O. sassafras, O. lauri sassafras. From the root of sassafras by distillation with salt water, and cohobation : 24lb. yield 9 oz. ; $30 \mathrm{lb}$. yield $7 \mathrm{oz} .3 \mathrm{j}$; and $6 \mathrm{lb}$. yield $2 \mathrm{oz}$. Stimulant, sudorific and diuretic, and given in scorbutus, chronic rheumatism and cutaneous diseases, the dose being from 2 to 10 minims rubbed up with water.

Oil of lemon thyme, Huile de tain, Oleum serpylli. 104lb. a little dried yield $3 \mathrm{oz}$; $98 \mathrm{lb}$. fresh yield $2 \mathrm{oz}$. and a half; $5 \mathrm{llb}$. yield 1 oz. 3 vj ; used to scent soaps. 
OIL of TANSEY, O. tanaceti. From the herb.

OrL of THYME, Oleum thymi. $2 \mathrm{cwt}$. fresh flowers yield $5 \mathrm{oz}$. and a half.

Essential oil of turlentrive. O. terebinthing, P. L. before 1809. From rough turpentine distilled with an equal weight of water, very slightly soluble in alcohol, does not contain succinic acid, the residuum is yellow rosin.

Ethereat, oli, of t'RPENTiNe, $O$. terebinthince athereum, P. I. 1716. From essential oil of turpentine, distilled without water in glass.

O. тЕвев. RECTIFicatua, P. L. 1788. Essential oil of turpentine, distilled with four times as inuch water._2 O.t.r., P.L. since 1809, O. volatile pini purissimum. Spirit of turpentine distilled with four times as much water.

Purifilid oil of turpentine. O. tereb. 8 oz. alcohol 1 oz., shake them together, pour off the alcohol, add a fresh quantity and repeat this, a third or a fourth time, until the oil becomes nearly tasteless and inodorous; but it soon recovers its own taste and smell. Oil of turpentine is stimulant, diuretic, diaphoretic, anthelmintic and rubefacient; and has been found serviceable in chronic rheumatism, lumbago and sciatica. It has also been used, either alone, or united with honey, against the tænia solium; for this latter purpose the dose is from half an ounce to two ounces; whilst in the former from ten minims to a drachm is usually prescribed. Officinal preparation.-Linimentum terebinthinæ, $L$.

\section{DISTILLED VEGETABLE OILS.}

Spirit of turPentine, Turps, Spiritus terebinthince, Oleum terehinthinn, P. I. since 1809. O. pini volatile. Distilled from rough turpentine, without any water; what is left in the still is colophony, or brown rosin, reddens litmus, contains succinic acid. Used by painters as a dryer, and also to make spirit varnishes. Town drawn in carboys. Hull or Liverpool in puncheons.

Hurle DE RAzE. Distilled from galipot or barras, without water. Sold for spirit of turpentine.

Kвсмиог, or., Oleum templinum. By distillation from Hungarian balsam.

BALsAM OF TUBPENTINe, Dutch drops. By distilling rosin, and collecting the oil in separate portions as it comes over; first a white oil, then yellow; lastly, a thick red oil, which is the balsam; stimulant, diuretic, suppurative.

Swedrsu tar, Russiun tar, Cedrin, Pix liquida. From logs of Pinus sylvestris, by distillation in a kiln; the heat produced by the combustion of one part of the wood being managed so as to 
carry on the distillation of the other part. Used as a powerfully antiseptic but coarse varnish, to light fires, and as a summer fuel.

American grefin tak. From Pinus palustris, which has been exhausted of its rough turpentine by incisions for three or four years.

American Light wood tar. From pini palustres that have fallen in the woods through age.

French tar, Goudron de Bordeaux. From P. maritimus.

Huir. de cade, O. cadinum. From Juniperus oxycedrus; used as tar.

Orl of tar, Jeran, Oleum pini, O. tadce. Obtained by distilling tar; soon thickens of itself, almost to a balsan.

OIL of BRICKs, Oleum lateritium. From olive oil, mixed with brick-dust, and distilled; very resolvent, useful in palsy and gout.

Orl of wоod-soot, O. fuliginis. Fetid, used in epilepsy.

Orl of вox, Oleum buxi, P. L. V. From box-wood, by distillation, without addition; resolvent.

Pyroligneous tar, Wood tar. Obtained in distilling and rectifying pyroligneous acid; will not unite with common pitch and tar. Used as a varnish.

Orl of Benjamin, Oleum benzoini. Obtained by distilling by a strong fire the residuum left after making flowers of benjamin, used in making an imitation of Russia leather.

Cпеолоте. The following observations have been abridged from Dr. Gully's translation of Magendie's Formulary.

This is an oily, colourless, transparent liquid, of a penetrating odour, resembling that of smoke, or snoked meat, and of a burning and exceedingly caustic taste; its sp. grav. is 1.03\%. Preparation.-In the diy distillation of tar from wood, the fluid collected in the receivers contains an empyreumatic acid water, which is rejected, and oil of tar, which is placed in glass retorts and rectified. In these two distillations the oil of tar is at first light, but as the heat is increased its gravity augments. At one period of the process the oil sinks to the bottom, and a fluid which is poor in creosote, and consists mostly of eupione, and other substances that interfere with the purity of the creosote, floats above it. This is poured off, and the pale yellow tar-oil is heated; carbonate of potass is added, until the carbonic acid is no longer disengaged on shaking. The mixture is decanted, in order to separate the acetate of potass, and the oil is again distilled in a glass retort, and all the first products that float on the water are rejected. 'The oil is then dissolved in a 
solution of caustic potass of the specific gravity $1 \cdot 12$; heat is thereby developed, and a portion of the materials composed of eupione, etc., not being dissolved, floats on the surface, and is removed. The alkaline solution is poured into an open capsule, and regularly heated to boiling. It rapidly absorbs the oxygen of the atmosphere, whereby a peculiar oxidizable principle in it is decomposed, and the mixture then turns brown. After cooling. in the open air, diluted sulphuric acid is added until the oil is set at liberty. It is then distilled with water holding a little caustic potass, and the whole is kept boiling until the quantity of oil which passes from the retort becomes dininished; at this point the distillation should cease. The oil and water in the receiver are again distilled with potass, and the same treatment with sulphuric acid repeated, as in the former instance. A third distillation is then made, and a little phosphoric instead of sulphuric acid is added, in order to take up some ammonia retained in the oil. The oil is then for the third time dissolved in caustic potass, and if the preceding processes have been carefully managed, they combine without leaving any residue of eupione, and the mixture, on exposure to the air, does not turn brown, but takes on a slightly reddish tint. As long, however, as any eupione remains, and the mixture turns brown, the solution in potass should be repeated. In this state the creosote is not entirely purc, but it may be used for medicinal purposes.

It may be obtained perfectly pure by distilling it with water alone, then rectifying the product of the distillation repeatedly until no water passes over when the heat is raised to $203^{\circ} \mathrm{C}$. The last product is creosote unalloyed by eupione, picamare, water, or other matters.

With respect to the therapeutic properties of creosote, it has been found beneficial in burns, in several skin diseases, in obstinate syphilitic ulcers, and in improving the condition of cancerous ulcers; it facilitates the expectoration in phthisis and bronchitis ; chronic glandular tumors have been dispersed by frictions or fomentations of creosote; it has been often found to afford temporary relief in toothach; it arrests capillary hemorrhage with certainty, but fails in that from the large vessels; it has been found an almost effectual remedy in atonic rheumatisin.

Morle of arlministering C'reosote.-In the treatment of ulcers creosote is to be applied in the concentrated form. At first it occasions more or less of inflammation, which however quickly subsides; as soon as this inflammation appears, the remedy should be discontinued for a few days. It may he applied to the surface of the sore by means of a camel hair brush, or from 6 to 12 drops may be placed on a poultice, and this applied to the ulcer.-When the object is to arrest external hemorrhage, it may be poured by drops into the wound; or, what scems more effectual, cotton or 
lint soaked in it may be applied.-When the object is to employ frictions, from two to eight drops are added to each ounce of water. The proportions for creosote ointment are 10 drops of creosote to 1 ounce of lard. For internal administration it may be given either in pills or draught, the former being made of one or two drops of creosote combined with some absorbent powder and mucilage, the latter of the same quantity, and some camphor mixture. Creosote may be inhaled either by steeping paper in it, and placing this close to the nostrils, or a portion of it may be poured into hot water in a Mudge's inhaler, and the creosoted vapour inspired in the usual way. When its internal use is continued for too long a time, it is apt to produce irritation of the system, and pains in the stomach and bowels. Demulcents should always accompany it.

\section{CAMPHIRE.}

Rovgh Camphire, Laurel camphire, Camphora. Obtained from the roots and shoots of the Laurus camphora, L. cinnamomum, and Capura curundu, by distillation with water. From China and Japan.

Dryobalanus camphire. Very little of this camphire comes to Europe, it being carried to China, where it sells for about 30 times the price of their own laurel camphire. Obtained by merely splitting the Dryobalanus camphora; the heart of this tree containing camphire mixed with oil of camphire. From Sumatra and Borneo.

REFined CAMPHIRE, by sublimation with one sixteenth its weight of lime in a very gentle heat. Camphire is stimulant, narcotic, and diaphoretic, gr. $v$ to $3 \mathrm{j}$, in pills or a bolus; too large a dose occasions vomiting and convulsions, counteracted by opium; suspended in liquids, by means of mucilage, yolk of egg, or almonds. Camphire is put into boxes to keep insects from them, and is used in fireworks ; it renders copal soluble in some essential oils.

Liquid CaMPhire, Oil of camphire, Camphora liquida, Oleum camphorce. From Dryobalanus camphora, by piercing the tree.

Caratte camphire. In tears, from the caratte. From Brazil.

Rosemary camphire. From the oil by a careful redistillation, without addition, of one third of the oil; the residuum affords crystals of camphire ; on separating which, and redistilling the remaining oil two or three times, the whole of the camphire, $1 \mathrm{oz}$. from 10 of the oil, may be obtained.

SWeET MarJoraM CAMPHIRE, about 1 oz. from 10 of the oil; not volatile; when set on fire it soon goes out.-Sage camphire, $1 \mathrm{oz}$. from 8 . 
LAVENDER CaMpHRe, 1 oz. from 4 , or even less, of oil.

Thyмe самтнine, crystals cubical, does not form a liquid solution either with nitric or sulphuric acid; is precipitated from nitric acid in a glutinous mass.

Margaric acid. From oils by distillation, washing the solid sublimate, pressing it to separate the liquid oleine; used to make candles, but is rather too fusible, melting a little below $60 \mathrm{deg}$. Fahr.

SoAP CAMPHIRE. From soaps, by solution in water, adding muriatic acid, collecting the curd, washing it with boiling water, and pressing it to separate the liquid oleine. Is a mixture of stearic and margaric acids; used to make candles, which are very white, as neat as was candles, and give a brighter light, but do not last so long.

TurpentiNe camphine. From spirit of turpentine, by passing muriatic acid gas through it, by which means it will yield about its own wcight of a kind of artificial camphire, not dissolved by dilute nitric acid, and when dissolved by strong nitric acid not separated by the addition of water.

Citrox campinze. From the white rectified oil of citrons, exposed to muriatic acid gas it absorbs 286 times its bulk, or nearly half its weight, and yields about 9-10ths of camphire.

\section{E'THERS.}

Hydrocisic fther. Prepared by exposing equal parts of sulpho-vinate of baryta and cyanuret of potassium to a gentle heat in a glass retort, to which a tubular matras is adapted. The product of the distillation is an almost colourless fluid, which separates into two parts, the lighter one being hydrocyanic æther; its action similar to that of prussic acid.

Etmer sulphuricus. Mix gradually equal weights of oil of vitriol and rectified spirit in a retort, and make the liquor boil as soon as possible; continue the distillation until a heavier liquor begius to appear under the ether in the receiver. If half the former quantity of rectified spirit is added to the residue left in the retort, more ether will be obtained.

ETnk: Aither rectificatus. Nith. sulphurici fl. 3xiv ; potassæ

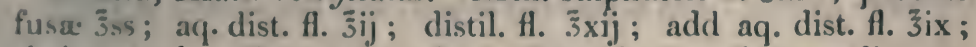
slake together, decant the ether. Stimulant, antispasmodic, gtt. $x x-3 j 54$, in water or wine; externally refrigerant, used in headach, and in burns, and dropped into the ear in earach. - Officinal Preparution. Spiritus setheris sulphurici, $L$.

NA PнтиA vixi, Ether vitriolicus. Spir. sther. vitriolici, P. L. 1788 , Ib. ijss, aq. kali puri 3 j; distil. 3 xiiij.

Nitrots Eтиед, Rither nitrosus. Put 3xxiv of nitre into 
a retort, placed in a pan of cold water, and pour upon it, by degrees, a mixture of $\overline{3}$ xij of oil of vitriol with zxix by measure of spirit of wine, which has been made gradually and grown cold; let the vapour, the evolution of which must be regulated with great caution by the addition of warm or cold water to that in the pan, pass through a pint of spirit of wine. To the ethereal liquor thus obtained, add about $3 \mathbf{j}$ of subcarbonatc of potash to neutralise the acid, the ether will swim on the surface : if it be required very pure, it may be rectified to one half, by distillation in a water bath, at about 140 deg. Fahr.; scarcely ever used.

Etrier muriaticus. Obtained by distilling, by a very gentle heat, a mixture of equal parts of alcohol and liquid concentrated hydrochloric acid. Is extremely volatile, and is decomposed by water. Its action is nearly that of sulphuric ether.

Arher muriaticus alcoholicus. (Phar. Par.) Dry salt žviij, ground black oxide of manganese $\bar{z}^{\mathrm{iij}}$, mix, add alcohol zxxiv, rectified oil of vitriol $\bar{\xi} \mathrm{vj}$, distil into a cooled receiver ${ }_{3} \times \mathrm{vj}$. It should show 22 deg. Baume.

Ether aceticus. Put acetate of potash $\bar{z} x v j$ into a retort ; mix alcohol इxvj with rectified oil of vitriol $\bar{j} \mathrm{vj}$, pour it on the acetate and distil to dryness. To the distilled liquor add lime water to separate the ether.

OIr of wine, Oleum vini. Mix equal measures of spirit of wine and oil of vitriol, distil by gentle heat, taking care that the black scum does not pass over into the receiver; separate the oily portion that passes over, add liquor potassæ to saturate the acid, then distil it by a gentle heat; ether passes over, and the oil remains floating on the liquor.

Oleum ethereum. Continue the distillation of the ingredients for sulphuric ether, with a less degree of heat, after the ether is come over, until a black froth begins to rise, then remove the retort from the fire, adding sufficient water to the liquor in the retort, that the oil may float on the surface; separate this oil, and add lime water, q. s. to neutralise the adherent acid, upon which the oil will separate itself ; antispasmodic ; used as an ingredient in the compound spirit of æther.

Pyroligneous etrike. From wood very copiously: more volatile than alcohol: has a peculiar odour, but burns well in lapms.

\section{TURPENTINES AND BALSAMS.}

Barsamum Junaicum, B. de Mecha, Opobalsamum. Exudes from incisions made in Amyris Gileadensis, or Amyris opobalsamuin, and is at first turbid, yellow, becomes clear, gold colour, of a very penetrating sweet turpentiny smell, and has a sharp, bitter, astringent taste: a drop of it let fall on warm water spreads over the whole surface, and on the water cooling, again contracts itself. 
Bala of Gilead, Balsamum Gileadense, Amyridis Gileadensis balsamum, Balsamcleon, Oleum balsami. Obtained by boiling the twigs and leaves in water; thin and oily, or, by a longer continued decoction, is thicker and less odoriferous; antiseptic, vulnerary; its fumes are said to be useful against barrenness; used also as a cosmetic, stimulating the skin so as to cause redness and swelling.

Caxada B.r.sam, Balm of Gilead, Resina strobilina, P. L. Balsaman Canalense, Terebinthina Canadensis, Pini balsamea. resina liquicla. From Pinus balsameæ; from America; used for balm of Gilead.

Balsam of capivi, Balsamum copaibre, Ol. capivia, Copaiba, Copaiferce officinulis resina liquida. Flows from the Copaifera officinalis; detersive, vulnerary, diuretic, and astringent ; may be given tu gtt. lx, or more, if the stomach will bear it, in leucorrhœa and gonorrhoa. By taking about gtt. $\mathrm{xxx}$ of elixir of vitriol in a glass of water, twice a day, the stomach may be made to retain gtt. Ixx to $\mathrm{c}$ of the balsam night and morning; a good dressing for fresh wounds. Reduced by castor oil, which is equally soluble in alcohol, and by rape oil. From Brazil.

Hungarian balsam, Resina strobilina. Exudes from the extremities of the branches of Pinus pumilio, and is also obtained by expression from the cones.

Strasmurg turpentine, Terebinthine de Venise, Resina abietis, P. L. before 1809, Oleum abietis, 'Terebinthina Argentoratensis. Obtained by piercing the tubercles of the bark of Pinus picea. A shepherd boy can collect only $4 \mathrm{oz}$. in a day.

Fir turpentixe, Resina abietina, P. L. 1720. From Pinus picen by incision; is not so fine as the Strasburg turpentine.

Venice turpentre, Terebinthine fine, Ter. Teneta, P. I. 1720. The fine clear part of rough turpentine that collects on the top by standing, or drains from the barrels exposed to the sun.

Scio turpentine, I'enice turpentine, Resina terebinthini, TereLintlina vera, $T$. Chiu. Obtained by incision from the Pistacia terebinthus, very clear and fine.

Cypres turpfontine, Ter. Cypria. From the Pistacia terebinthus, but collected with less care than at Scio; foul.

Lanch тurpentinz, Terelinthine de Sirisse, Resina luricis, Terelsinthina Veneta, Pini luricis resina liquida. From the larch, by boring it nearly through.

Rovcin turpentive, Horse Turpentine, Resina pini, Terebinthine vulyaris, 'T'. communis. From Pinus sylvestris, by cutting a bollow in the tree to entch the turpentine, and taking off the bark for a space of about eighteen inches above it. From Sweden and New England. 
Carolina rough turpentine. From the Pinus palustris. Imported from Wilmington.

French turpentine, Terebinthine commune de Bordeaux. From Pinus maritimus, the turpentine being melted and strained through straw.

Briançon turpentine, Terebinthina Brianzonica. From the Pinus cembro.-All the turpentines are stimulant and diuretic; dose $3 \mathrm{j}$ to $3 \mathrm{j}$ in pills, or made into an emulsion with yelk of egg or almonds; used externally, they are vulnerary and suppurative.

White balsam of Peru, Natural balsam, Balsamum album, Styrax alba. Obtained by incision from Myrospermum Peruifera.

Red balsan of Peru, Balsam of Tohe in gourds, Tolu, Balsamum Tolutanum, B. de Tolu, Toluiferce balsami balsamum, Tolutanum, P. U. S. Colour reddish, agreeable sweetish taste, a middle consistence between liquid and solid, very glutinous, the fragrancy of lemons ; anti-phthisical, vulnerary, anti-arthritic, nervine; dose, gtt. $\mathrm{x}-\mathrm{xxx}$; balsam of Tolu in cakes is sold for it.

Black balsay of Peru, Common balsam of Peru, Balsamumi Indicum nigrum, B. Peruvianum, Myroxyli Peruiferi balsamum, Myroxylon, P. U.S. Obtained by boiling the bark and branches in water. From South America. The balsams of Peru all contain benzoic acid, which gives them a very fragrant smell; taste sharp and bitter; are nervine, cephalic, stomachic, antiasthmatic, externally vulnerary; dose gtt. $\mathrm{x}$ to $\mathrm{xxx}$; used also in perfumery.

Balsamum populi. From the buds of the Populus balsamifera pressed between heated plates; buttery, brown, reddish, rather fragrant; $4 \mathrm{oz}$. of buds yield $3 \mathrm{ij}$ of balsam.

Rackasira balsamum. Transparent, brownish, red, thick, drawing in threads, balsamic smell and taste, rather bitter when tasted, and glues the lips together; brought to England in gourds.

Lrquin storax, Styrax liquida. Obtained by boiling the young shoots of the Liquidambar styraciflua, or Altinga excelsa, in water.

Liquid ain в r, Huile de copalme, Liquidambra, Ambra liquida. Obtained by incision from the Liquidambar imberbe? resolvent, suppurative, and used in perfumes, as it has the smell of benzoin.

Balsamum Mariz, Bals. tacamahaca, C.P. Oleum sancteMaria, Bals. calaba, Bals. Sancti Thome? Calaba. Yielded by the Calophyllum apetalum; yellowish, becomes thick and green by drying, sweet scented. 
Rosins.

Balsamum viride. From the Chloroxylon verticillatum of Peru.

GaNdah BIrosa. From Boswellia serrata; clear, greenish, hardens into pinky olibanum.

P.enoe varnish, Peynia varnishi, Liquid copal, Pundum. From Vateria Indica, or Elæocarpus copalliferus.

Birci orL, Ol. betulce. Obtained by heating birch bark in an earthern pot with a hole in its bottom, so that the rosin of the bark, as it melts out, flows down into another jar sunk in the ground, and luted to the upper jar; used in Russia to curry leather, preserving it from mouldiness and the attacks of insects.

Balsam acouchi. Flows from the Amyris ac'ichini ; odorous, vulnerary, nervine.

Clusia tulipentine. From Clusia alba and C. rosea ; used as pitch.

Wooraroo polsox, Balsam arouarou. Flows from the Icica hetaphylla pitch; smells like citron; used to poison weapons.

Sunflower turpentine. From Helianthus annuus.

Jerusalem artichook turpentiNe. From Helianthus tuberosus. Obtained by boiling the heads and skimming off the turpentine; very pale and clear. Sold for Strasburg turpentine.

Balsam houmiri. Flows from the Myrodendron houmiri ; red, transparent, balsamic ; used for torches.

JapAN TURPENTINe. By incision from Rhus vernix : used in varnishing.

Wood oIL. From the trunk of Dipterocarpus turbinatus.

Soft мastich, Mastich oil. Obtained from mastich trees, which have been grafted upon the turpentine tree.

\section{ROSINS.}

Flag axxotro, Orleana, Terra orleana, Orleana in foliis. In square cakes of 2 or 3 lbs. each, beat up with oil, either linseed, nut, or whale.

Egc axNotro, Orleana in ovulis. By steeping the seeds of Bixa orellana in water for seven or eight days, stirring the liquid, passing it through a sieve, and boiling it; when the colouring matter is scummed off, and made up while soft with oil into cakes; cathartic and then astringent, discussive, febrifuge, but little used in medicine, chiefly in dyeing. From the West Indies.

Roll axinotro, $O$. in rotulis, $O$. in buculis. In small oblong cakes, internally bright red. By rubbing the seeds with the 
hands, previously dipped in oil, till the red pellicles come off, and are reduced into a clear paste, which is scraped off and dried in the shade: used by females as a paint. From South America and the East Indies.

Gum Anmw, Gummi anime. From Hymenæa courbaril: used to make spirit varnish; soluble in alcohol. Gum cancame and Jamaica-birch rosin are sold for it. From Brazil and the East Indies.

Head benjamin, Benzoinum, Assa dulcis, Styracis benzoini balsamum. By incision firom Styrax benzoin; odoriferous, fragrant, balsamic, anti-asthmatic: used in perfumery and odoriferous fumigations. From Borneo and Sumatra.

Caffre's head benjamin. Inferior in quality.-Foot benjamin. From 'Terminalia benzoin? or Laurus benzoe; brownish, hard, impure.

JAMAicA-BIRch rosin, Resina clibou. From the Bursera gummifera; white or yellowish; used for varnishes; sold for gurn anime.

Caranna, Gummi caragna, Tacamahaca caragna. Origin not well known; brought from New Spain in masses, covered with broad leaves; resolvent, dark olive.-Fetid caranna. Has a fetid smell when burnt : from a chamerrops?

Gum chandra, Gum kikekanumala, Moschat rosin, East Indian copal, Gomme copal, Gummi chandetros, G. chanderros Copal, C. P. From Vateria Indica; used in varnishes; resembles yellow amber, and is sold for it. From Madagascar, and also aniong Sumatra camphire.

Gum copal, Copal. From 12hus copallinum: used as a cement in fumigations, as it diffuses an agreeable scent when burned, and in hard varnishes; not soluble in alcohol without the help of camphire or ammonia, and scarcely in oils, except oil of rosemary.-Melted copal. Obtained by holding the gum before a good fire, so that as soon as the copal inelts, it may drop into a pan of water: a kind of oil separates from it, and the copal becomes soluble in spirit of wine, and still more so if the melting is repeated.

GuM Elemi, Icica, Elemi, P. I. since 1720. By incision from Amyris elemifera; yielding a sweet odour when burnt. From South America.

East India rexir, Gum cancame, Gomme elemi, Elemi, P. L. I. and C. P. Cancamum, Balsamum cancamum. From Gardenia elemifera; whitish, clear, resembles white amber; antiseptic, detergent: sold for gum anime, but alcohol only dissolves 6 oz. out of 10. From Arabia and Ceylon. 
Gum gualacum, Gummi guaiacum, Guaiaci resina. By incision, from Guaiacum officinale ; tonic, antiscorbutic, diaphoretic, in doses of gr. $\mathbf{v}$ to $\mathrm{Yj}$, in pills or in emulsion; purgative in doses of gr. xv. to $9 \mathrm{ij}$ : Manchineal gum is sold for it. From the IVest Indies.

Ixcexse, Frankincense, Encens, Looban, Thus in guttis, Olibanum in guttis, Juniperi Lycice gummi resina;-the larger grains, Encens mâle, Thus masculum; - the smaller grains, Encens femelle, Thus fremininum; - the grains from which the dusty crust has been rubbed off in carriage, leaving them transparent, Manna thuris crystallina; - the dust of the crusts collected at the bottom of the sacks, Manna thuris. In small, pale, yellow drops, like mastich, rather hard, transparent, bitterish, sweet-smelling, not easily melted, takes fire easily, and burns with a sweet odour, leaving white ashes: sialogogue, stimulant Эss to $Э \mathrm{ij}$; also used to fumigate sick-rooms, and in religious ceremonies. From some thorny tree, Juniperus Lycia? J. Phœnicia? J. thurifera? Amyris kataf? or some undescriber amyris. Brought from the Levant; pink olibanum and fir rosin are sold for it.

Pink olnbanum, Avul (best) coondoor, Paringhi sumbrani, Looban, Sukkn lirosa, Olibanum, P. L. since 1805. In senitransparent tears, pink colour, brittle, adhesive to the teeth when chewed, bitterish, pungent, aromatic, burning with an agreeable odour, and clear steady light, leaving a black coal. By incision from the sala or birosa tree, Boswellia serrata, or Libanus thurifera: used in India as a medicine, but not as incense.

Brown ormanum, Koondricum, Coondoor, Googil, T7us in massis. In pretty large agglutinated masses, composed of light brown and yellowish tears, a stony hardness when pressed between the teeth, slightly pungent and bitter, more perfectly soluble in alcohol and ether than pink olibanum, and not burning with such a brilliant light. Obtained from Boswellia glabra by incision: used in the East Indies as incense in religious ceremonies, and, when inelted with some cheap oil, used as pitch. From Madagascar, Arabia, Sumatra, and the other eastern islands.

Lanancm, Lubdumm. Exudes from the Cistus creticus, obtained by lashing the tree with leather straps, to which it ad. heres, and is scraped off. - Ladamum in sortis. By boiling the twigs of Cistus ladaniferus in water : digestive, tonic, astringent; also used in toothach.

Mastucn, Masticlor, Resina lentiscina, Pistacice lentisci resina. By incision, from Pistacia lentiscus; in small, round, yellow drops ; tonic, detersive, and chewed to sweeten the breath and fasten the teeth. From the Levant.-Barbary mastich. From the Pistacia Atlantica. 

America.

Orampi gum, Gummi olampi. Of unknown origin. From

Burgundy PITch, White pitch, Pix Burgundica, Pix alba, Resina abietis humida, Resina alba humida, Pini abietis resina sponte concreta, Pix arida, P. L. 1809, Pix abietina. By incision, from Pinus abies, becomes solid immediately : it is melted with water and strained through coarse cloths : of a close consistence, rather soft, reddish brown, smell not unpleasant: very adhesive to the skin, rubefacient, used in colds, and short breath. From the North.

Fir rosin, Per-rosin, Frankincense, Thus fomininum, T. vulgare, Olibanum vulgare, Resina abietis sicca, Abietis resina, L. P. since 1809. Exudes from Pinus abies, compact, opaque, deep yellow; not so adhesive as Burgundy pitch, sold for incense, $10 \mathrm{~d}$. the $\mathrm{lb}$.

Natrve Rosin, Resina pini nativa. Exudes from Pinus sylvestris, the turpentine drying upon the wound, and forming a white crust over it.

White rosin, Resina pini communis, Resina alba, P. D. and P. E. Prepared from native rosin by melting and straining through a cloth; used indifferently with Burgundy pitch; adheres to the fingers.

Barras, Galipot de Bordeaux. Exudes from Pinus maritima; yields by distillation huile de raze.

American elemt. Exudes from Pinus palustris.

Gum sandarach, Gum Juniper, Sandaraca, Gummi juniperi. Yielded by the Thuya articulata, and 'T. quadrivalvis, astringent and tonic, used also in making varnishes, and in powder, pounce, to prevent ink from sinking in parchment, bad paper, or where they have been scraped.

Dragon's blood IN THE TEAR, Sanguis draconis in lacrymis. From the Dracæna draco, by incision; very pure, used in varnishes and dentifrices; powder a bright red, cinnabris.Dragon's blood in sticks, Sang. drac. in cannis, Pterncarpi draconis resina. From Pterocarpus draco, P. Indicus, and P. santalinus. In small masses, wrapped in leaves, dark red, breaks smooth; powder crimson. From the East Indies.-Dragon's blood in balls, Sang. drac. in placentis. Obtained by macerating or steaming the fruit of the Calamus draco; in round masses wrapped up in leaves of reeds, coarse grained; powder brownish red. Are all astringent. Used in tooth-powders, and to stain marbles red. From the East Indies.-Surinam dragon's blood. From Dahlbergia monetaria.

Gum storax, Red storax, Thus Judcorum, Styrax in massis, S. rubra, Styracis balsamum, Balsamum styracis officinalis. Ob- 
tained, by incision, from Styrax officinale, and perhaps from Liquidambar orientalis, in round cakes, hard, brownish red, mixed with whitish or yellowish fat grains, breaking under the finger, smells like balsam of Peru, bitter, stimulant, expectorant, gr. $x$ to $3 j$ jss. From the Levant.

Strrax calamita, $S$. in vesicis, Scobs styracina. In bladders, unctuous, marbled on the inside, easily melted, smells like benjamin ; used in perfumes. From the Levant.

Drop stonax, Storax en grains, Styrax in granis. In white, transparent grains, softening between the fingers, smells very agreeable but slight.-Strained storax, Styrax colata. Storax heated till it softens, and then passed between heated iron plates; 1lb. storax, warmed in bags, and pressed between iron plates, so hot, that they are nearly sufficient to make water hiss, yields two oz. and a half of strained storax.-Storax purificata. Storax dissolved in spirit of wine, the solution strained and evaporated to a proper consistence.

Tacamanac in the sheld, Tacumahaca. From Fagara octandra: imported in gourds, greenish, soft, smells of lavender, taste aromatic, cephalic, nervirie, externally suppurative, astringent; used in fumigations.

Tacamanac in the rump, Balsamem Focot. From Populus balsamifera; greenish yellow, in tears run into a mass; sweet scented: stomachic.-Bourbon tacamahaca, 'T. Mauritiana, T. vera, C. P. ; from Calophyllum inophyllum, now C. tacamahaca.

Balsam of 'Tolu in cakes, Baume de Carthagene, Balsamum Tolutanum in placentis. Red, solid, having been dried in the air; nervine, cephalic, anti-asthmatic: used for balsam of Tolu in gourds or jars. From Peru.

Dark yellow gum, Botamy bay gum, Gummi flavum, N. S. II: Gummi resinu ucrorriclis; from the base of the leaves of $\mathrm{X}$ an. thorrhcea hastilis, or Acarois resinifera of New South Wales: antidysenteric, and employed to unite the lips of wounds, however large or dangerous; also to compose a ccment ; resembles gambonge, but darker, not entirely soluble in alcohol, the remainder not woluble nor diffusible in water.

Liснт YEIMW GUM. Resembles yellow arsenic, gives water the smell of storax, but is not soluble in it; $20 \%$ out of 3 are soluble in alcolool, the solution is glutinous, what remains is astringent and soluble in water, taste pleasant. Both burn as freely as rosin, and smell, when burning, like balsam of Peru.Blue gum. From the Livania resinifera of Botany bay.

Tré varsisn resis. Yielded by the Terminalia vernix; used by the Chinese in varnish. 
Manchinel gum. Yielded by the Hippomane mancinella; sold for gum guaiacum.

Canarium gUm. Yielded by C. balsamiferum; sweet scented, used for incense.

Clove gum. Resina caryophyllorum. Reddish brown, found among cloves.

Ava dammer. From Pinus dammar. - White Malabar dammer.-Black Malabar dammer.-Coarse Malabar dammer. All from Chloroxylon chupada.-Nepaul dammer. From Shorea robusta. All these dammers are used in India for all the purposes of turpentine, rosin, and pitch.

Tecanez sandal resin. From the sandal tree of Tecamez. -Volkameria rosin. From the V. inermis of India.-New zealand rosin. From Avicennia resinifera. Both are red and astringent.

Ho; Gum. Exudes from Rhus metopium. Is black, very adhesive : called hog gum because the wild hogs, when wounded, rub themselves against the tree.

Taberne nontana resin. From T. arcuata.-Mombin rosin. The produce of Spondias myrobalanus.-Bursera rosin. The produce of B. Orientalis; is tonic, styptic.-Escallonia rosin. From E. resinifera, purplish.-Uvaria gum. From U. tritapeloidea, very odoriferous: all these are tonic, astringent, and aromatic.

Augra rosin. From A. Sinensis; black, used in China for varnish, and medicinally as a purgative.

Barbadoes cedar rosin, Gummi cedrinum, Col. of $\mathrm{Ph}$. Col.

Peruvian mastich. From Schinus molle; white, smelling like fennel and pepper.

Coumia resin. From Amyris ambrosiacia; used as incense, and in chronic diarrhœa.

Ticuna. From Amyris toxifera; used to poison weapons for war and hunting.

Kina-kina rosin. Yielded by Myrospermum pedicellatum: used by gouty persons to hold in the hand.

Lovace rosin, Resina ligustici. Exuded by Cornish lovage.

Guarana. From Brazil. Col. Ph. Col. Origin not known.

Boiled pitcil, Stone pitch, Pix sicca, $P$. atra, $P$. navalis, $P$. arida, P. L. before 1809. Obtained by boiling or distilling tar to the desired consistence; in medicine used only as a resolvent in plasters.-Fired pitch. By letting tar burn until about half, or 
2 cwt. out of 3 are consumed.-Poix noir, Poix grasse. From the dregs of resin and the straw by which it has been strained, run down in a pitcli-kiln.

Yellow rosin, Poix resine, $R$. flara, R. pini oleo volatile deprivatum. Obtained by boiling or distilling rough turpentine with water, or by boiling or distilling turpentine, and pouring the residuum, while yet fluid, into water, of which it absorbs about 1-Sth of its weight: suppurative externally, used in ointments and plasters.

Borled turpentine, Terebinthina cocta, P. L. V. Venice turpentine $1 \mathrm{lb}$. boiled in 20 pints of water, until as brittle as glass ; made into small cakes, for rubbing fiddle-sticks.

Brown rosix, Black rosin, Greek pitch, Brai sec. Colophane, Pix Grceca, Colophonium, Resin anigra. Obtained by boiling or distilling rough turpentine without water; suppurative externally.

\section{RESINOUS EXTRACTS.}

Rosix of calanus aromaticus, Resina calami.

Rosix of scammony, Resina scammonii.

Rosin of Jalap, Resina jalapa. 10lbs. yielded 1lb.: not soluble in ether.

Rosin of guatacum, Resina guaiaci. Dissolves in ether.

Rosin of turbitr. Resina turpetlii. Eight oz. yield $3 \mathbf{v}$.

Resina corticis Peruviani. Digest rectified spirit upon the substances repeatedly, till the last portion is not tinged; distil off the spirit till but a fourth part remains, add water to cause the rosin to settle, which is then to be washed and dried.

Extractum cinchox.e resinosum. Soak 2lbs. bruised bark in 4 llss. spirit of wine for four days, filter and distil off the spirit.

BARRY'S RESINOUS EXTRACT OF BARK. Distil tincture of bark, made with rectified spirit, nearly to dryness, remove the rosin on its surface, and evaporate slowly the remaining liquid to a fine extract.

Rosis of aloes, Resina aloes. The insoluble residuum left in making washed aloes.

Opium Pleificatem molle, P. D. Digest lb. $j$ of sliced opium in 1 b. xij of proof spirit; and after filtration, distil off the spirit till the inass is reduced to a consistence fit for pills.

Op. pur. dumum. Made sufficiently hard to powder.

Arcoholic extract of nux vomoa. Digest rasped nux vomica in alcohol $\mathrm{lb}$. $\mathrm{j}$ at $40 \mathrm{deg}$. Baume, in a cool place, strain and evaporate to an extract; if weak alcohol be used, the extract is not so powerful. 


\section{DRY ALCOHOLIC EXTRACT of nUX vomica. Make a tincture} of nux vomica with alcohol at $36 \mathrm{deg}$. Baume; filter, and evaporate on shallow plates with a very gentle heat; acts strongly as an excitant of the nervous system; in pills, gr. $j$ to $i j$, increased gradually and cautiously to Oss, or until the tetanic symptoms become considerable: used in palsy.

BRUCINE. Digest ether on powdered bark of Brucea antidysenterica, to separate a fatty matter; strain, add alcohol at 36 deg. Baume; digest, filter, evaporate to dryness; dissolve the mass in water, add liquid subacetate of lead; filter, pass sulphuretted hydrogen gas through the clear liquor; filter again, and add calcined magnesia: filter again, wash the sediment very slightly with cold water, dry, digest in alcohol, filter, and distil off the spirit. To purify the brucine, add a solution of oxalic acid, crystallize, add a mixture of alcohol at $40 \mathrm{deg}$. Baume, and ether at $60 \mathrm{deg}$, to extract the colouring matter, then dissolve the oxalate of brucine in water, add calcined magnesia, filter, digest the sediment in alcohol, filter, and let the spirit evaporate by exposure to the air. Brucine is crystalline, very bitter, scarcely soluble in water; acts strongly on the nervous system, gr. ss gradually to gr. vj. Nitric acid turns it deep crimson.

Cinchonine. Boil Peruvian bark in alcohol until all the bitterness is extracted; distil to dryness; dissolve the extract in boiling water, rendered very acid with muriatic acid; add calcined magnesia, boil for a few minutes till the liquor is clear; when cold, filter, wash the sediment left on the filter with cold water, dry it, boil alcohol upon it until all the bitterness is extracted; pour off the alcohol, and, as it cools, the cinchonine will crystal. lize. It may be purified by solution in a very weak acid, and the addition of an alkali; white, crystalline, scarcely soluble in water, or in ether: used in combination with sulphuric or acetic acid.

Derphine. Blanch stavesacre seeds, beat them to a paste, boil with a little water, strain, add calcined magnesia, boil for some minutes, filter, wash the sediment with water, and digest it in alcohol at 40 deg., decant the tincture and distil off the spirit; the delphine is left as a white powder; scarcely soluble in water, but soluble in alcohol or ether. Not yet tried medicinally.

2. Bruise unhusked stavesacre seeds, add weak sulphuric acid, filter, add ammonia to separate the delphine; dissolve in alcohol, distil off the spirit, dissolve the extract in muriatic acid, add calcined magnesia to saturate the muriatic acid, and throw down the delphine purer than before; redissolve in alcohol, filter, and distil off the spirit.

Digitaline. Supposed to be the active principle of digitalis. 
Sufficient researches have not, however, been yet made, to sanction the introduction of this substance into medicine.

Emetine. Pour ether at $60 \mathrm{deg}$. $3 \mathrm{ij}$ on powdered ipecacuanha $\bar{j}$, digest, decant, distil, and repeat this as long as any fatty odorous matter is extracted from the root; then digest the pow. der in alcohol of $40 \mathrm{deg}$. $3 \mathrm{iv}$, repeat this three times with fresh alcohol; distil gently to dryness, dissolve what is left in cold water; add subcarbonate of magnesia to separate the gallic acid it contains, dissolve again in alcolol, filter, and evaporate to dryness; produces 70 or $\$ 0$ grains. In reddish brown scales, easily running in the air, not crystallizable; emetic in doses of a quarter of a grain, or rather more.

Pore emetine. Digest powdered ipecacuanha first in ether, and then in rectified spirit; distil off the spirit, and dissolve the remainder in water, add calcined magnesia in sufficient quantity ; pour off the liquor, wash the remainder with a little very cold water to separate the colouring matter, and dry it, digest alcohol on it, filter, distil off the spirit ; dissolve the remainder in diluted acetic acid, clarify the solution by bone black, and add ammonia to throw down the emetine, which is white, scarcely soluble in water; emetic in doses of a sixteenth of a grain.

Gextranive. Digest gentian root in powder in ether for two days and nights, filter, evaporate nearly to dryness; add alcohol to the yellow crystalline mass thus obtained until it no longer becomes coloured; evaporate to dryness, redissolve in weak alcohol, filter, evaporate again to dryness; dissolve in water, add some calcined magnesia, boil, filter, digest the sediment in ether, and evaporate to dryness. Gentianine is yellow, scarcely soluble in water, very soluble in alcohol or ether; a strong aromatic bitter, in doses of gr. $\mathrm{ij}$; the tincture is mostly used.

Glaiadixe. Pub fresh-made gluten of wheat flour with alcohol, evaporate to dryness: the glaiadine thus obtained may be purified by extracting the colouring matter by means of sulphuric ether, which does not dissolve the glaiadine; used to form a test liquor.

LUPINIXE, prepared by boiling the lupinus terminis in alcohol of the specific gravity 936, filtering the solution, and then evaporating to dryness. The residuuni has a yellowish-green colour, is very solid, and transparent. This is dissolved in water, the colour removed by animal charcoal, the solution evaporated to the consistence of syrup, by which small white crystals are obtained. The liquid is then evaporated to dryness, the extract heated anew with boiling alcohol, and again evaporated, and then a bitter principle is obtained to which the name of lupin?ne has been given. This is a solid substance of a yellowish colour. Its 
taste is exceedingly bitter: it is soluble in water, as also in alcohol of sp. grav. 936 ; but insoluable in ether or pure alcohol. This has been considered capable of curing intermittent fever.

Morpira, Morphium, Morphine. Opium ziij, water $\overline{5} x$, soak for five days; filter, add calcined magnesia $3 \mathrm{j}$ gr. xij: or rather quicklime 3 jss ; boil for ten minutes, filter, wash with cold water till the water passes off clear, dry, and digest in warm alcohol of $22 \mathrm{deg}$. as long as it becomes coloured: boil the residuum in alcohol of $32 \mathrm{deg}$. for a few minutes; filter while hot, and as it cools, crystals of morphia will separate. These crystals may be purified by boiling them in alcohol, and recrystallizing them. Bone black may also be used to separate the colouring matter; extremely bitter, narcotic, used in the form of an acetate or sulphate.-The residuum, Extract of opium exhausted of morphine, is also used ; gr. iij are equal to gr. jof extractum opii aquosum, or to $\frac{x}{4} \mathrm{gr}$. of morphine.

Narcotine, Sel d'opizm, Matière de Derosne. Exhaust opium of whatever water will separate from it, dry the remainder, add muriatic acid at $4 \mathrm{deg}$. Baume, or rather pyroligneous acid at 4 or 5 deg., strain with pressure: to the liquor add ammonia, wash the precipitate with boiling alcohol at $36 \mathrm{deg}$., the narcotine taken up will separate as the alcohol cools, and may be purified by bone black: narcotic.

Extract of opium exhausted of narcotine. Evaporate the washings of the opium nearly to dryness, add ether to dissolve any narcotine which may be left in them, lecant, and evaporate to an extract: superior to the ordinary watery extract of opium. - Codeine. In treating solution of opium with muriate of lime a muriate of morphia is precipitated, in combination with codeine. 'This latter substance forms, with the acid and morphia, Gregory's salt, or the double muriate of morphia and codeine. From this the latter is separated by ammonia, the major part of the morphia precipitating. The supernatant solution of codeine and ammonia, with some non-precipitated morphia, is concentrated until the chlorohydrate of ammonia begins to crystallize, and with it the double salt of morphia and codeine. The crystals are to be dissolved in water, filtered through charcoal, and a slight excess of caustic potash added, by which means the codeine alone is precipitated, and is then taken up by alcohol or ether. Codeine combines with acids, forming salts; its action similar to that of morphia, but is not so powerful, one grain of it being equivalent to half a grain of morphia. Some say that it possesses a specific influence over the ganglionic system of nerves. It may be given either in a julep, or in pills. The hydrochlorate is more active than the simple codeine.

Piperine. Digest bruised black pepper $\mathrm{lb}$. ij in alcohol at 
36 deg. Baume, lb. iij, boil, when cool, decant and pour on fresh alcohol lb. iij, mix the tinctures, add distilled water lb. ij, and muriatic acid $3 \mathrm{oz}$; take away the fatty matter that is separated, and the piperine will be found collected on the filter and sides of the vessel in fine crystals.

2. Digest black pepper in alcohol as long as any thing is taken up, evaporate the tinctures, wash the fat that is obtained with boiling water, dissolve it in alcohol, leave the alcohol to evaporate spontaneously, and crystals of piperine will be obtained.

Quinine. Made from yellow bark, in the same manner as cinchonine from common Peruvian bark; white, scarcely soluble in water, very soluble in ether, by which it may be separated from cinchonine, if they are mixed together.

Salicine. The principle on which the febrifuge properties of the willow-bark depend. M. Leroux obtained it by the following process:-Boil three pounds of the willow-bark (salix helix) in 15 pounds of water, holding 4 ounces of subcarbonate of potash in solution; strain, and add to the cold decoction 2 pounds of fluid subacetate of lead; filter, add sulphuric acid, and precipitate the whole lead by sulphuretted hydrogen gas; saturate the excess of acid by chall; ; filter again, evaporate and neutralize it by dilute sulphuric acid; remove the colouring matter by charcoal, and filter it hot; crystallize twice if the salt is coloured after the first crystallization, and dry in the shade. This process gives about one ounce of salicine. M. Leroux obtains five per cent. of the weight of the bark. It exists in the bark of many species of salix, as the common willow, Salix monandra, S. incana, S. fissa, sic. Salicine thus obtained is in small silky groups of pearly white crystals, is very soluble in water and alcohol, insoluble in ether, is extremely bitter, and smells like willow bark. This substance possesses febrifuge qualities, but not in a degree equal to sulphate of quinia. May be given in the dose of 6 or 8 grains between the paroxysms of intermittents.

Soldxixf. Filter the juice of nightshade berries, quite ripe, add aminonia; filter, wash the sediment, boil in alcohol; filter, and distil off the spirit; the solanine is left as a white powder; not soluble in water, bitter; cmetic, narcotic.

Strycunise. Boil rasped nux vomica three times in water, adding at last a very little muriatic acid, evaporate the decoction to the consistence of syrup; add fresh quick lime, $1 \mathrm{o}$. to each 5 0\%. of the nux vomica, strain through cloth, wash the sediment with alcohol at 92 deg. to dissolve the brucine, dry the remaining precipitate, add alcoliol at $36 \mathrm{deg}$. to dissolve the strychnine, boil and evaporate about $4-5$ ths, the strychnine crystallizes as the alcohol cools, and may be rendered purer by dissolving again in alcolol, evaporation, and crystallization; the brucine, being more soluble in spirit, remains in solution. White, crystalline, or 
granular; scarcely soluble in water; acts still more strongly on the nervous system than rosin of nux vomica; in pills, containing 1-12th or 1-8th of a grain each, cautiously and gradually increased. Magendie gives the following formula for pills of strychnia; take of strychnia 2 grains, conserve of roses $\frac{1}{2}$ gros., mix carefully, and divide the mass into 24 pills.

Veratrine. Digest the seeds of Veratrum sabadilla in boiling alcohol, filter while hot; distil nearly to dryness; dissolve in cold water, filter, evaporate slowly; add a solution of acetate of lead, filter to pass sulphuretted hydrogen gas through the clear liquor, filter, evaporate a little; add calcined magnesia, filter, digest the sediment in boiling alcohol, filter and evaporate till a yellowish substance is left, which may be purified and rendered white by dissolving it in alcohol, and adding water to throw down the pure white veratrine. Errhine produces a very abundant salivation; cathartic, in doses of a quarter of a grain ; in larger doses emetic, producing tetanus. Dr. Turnbull has lately published a series of cases of heart affections, various forms of neuralgia, rheumatism, paralysis, dropsy, gout, \&c., in which the external application of veratria in form of ointment seemed to be followed by the most beneficial results. He directs from 10 to 20 grains of veratria to the ounce of lard, of which the size of a large nut is to be rubbed in night and morning.

\section{GLUTINOUS MATTERS.}

Brack Elastic GuM, Indian rubber, Caoutchouc, Gummi elasticum. From Jatropha elastica? the milky juice being spread upon clay moulds, and dried over a fire, or torches, and formed into water-proof boots and pormanteaus, as also bottles used for holding liquids, and for syringes; very easily expanded, and becomes almost transparent by extension.

Brown elastic gum. Dried by the air, stiff, does not expand easily.-Elastic gum softens by heat, dissolves in oils, petroleum, and ether; and is used for varnish, to make elastic catheters, bougies, and probes; and for rubbing out the traces of blacklead pencils.

Urchola elastic gum. Very elastic, brought from China.

Ficus Indica GUM. Soft.-Jack-tree gum;-Castilla elastica gum. Are all elastic.

Brrd-tIME, Viscus aucupum. By boiling missletoe berries in water till they break, pounding them in a mortar, and washing away the branny refuse with fresh water.

Holly BIRD-LIME. From the bark, stripped in June or July, and boiled in water for six or eight hours, until it becomes tender; the water is then separated from the bark, which is laid in layers with fern, and left to ferment for two or three weeks, until it 
forms a mucilage, which is pounded in a mortar into a mass, and well rubbed in the hands in running water, till all the refuse is worked out; the bird-lime is then put into an earthen vessel, and left for some days to purge itself. It may also be made from the bark of the wayfaring tree, and other vegetables; discutient externally; used to rub over twigs for catching birds or small animals.

SAPIUM AUCUPÁRIUM BIRD-LIME;-Hippomane biglandulosa bird-lime. Both used to eatch parrots.-Pittosporum tobira birdlime. Surrounds the seeds.-Schozolana-bird-lime. Covers the fruit.

Gloten of wheat flour. Mix flour with a little water into a stiff paste as for pastry, kneading this paste in water until the starch and saccharine matter are washed out. Grey, extensible, while fresh and moist, like elastic gum : the superiority of wheat flour depends upon this substance, which turns blue when mixed with guaiacum.

OF ANIMAL ORIGIN.

\section{ANIMAL OILS AND FATS.}

Are more emollient than the vegetable oils.

Goose greasf, Adeps anseris. From roasted geese; white, strong scent, taste agreeable, emollient, used in clysters; also an emetic, of very easy action.

Eer. Fat, Adeps anguilla. Collected from eels while roasting; used to preserve steel from rusting.

Human pat, Adepshominis. Very emollient, yellow, scentless, used in the Russian hospitals.

Vipers' f.st, Pinguedo vipera, Axungia viperina. Used in eye ointments, and to anoint the back in consumptions.

Bears' grease, Pinguedo ursi. Yellow, strong smelling, nearly liquid, much used to make the hair grow.

Vear. Fat, Pinguedo vitulina. Now preferred by the perfumers, as it will keep a long time without growing rank.

Hogs' I.and, Barrous' grease, Sain doux, Arvina, Axunge, Axungin, Adeps suilla praparata, A. praparata, A. porcina. From the raw lard, by chopping it fine, cr sather rolling it out to break the cells in which the fat is lodged, then melting the fat in a water bath, or other gentle heat, and straining it while warm: in bladders.-2. By boiling in water, and skimming it off when cold; contains water, grows rank much sooner than when melted by itself. 
Mutton Suet Rendered Down, Sevum ovillum curatum, S. praparatum;-Beef suet rendered down. Yellow tallow, Soap tallow, Sevum bovinum curatum, S. vaccinum curatum, S. preparatum.

White tallow. Yellow tallow melted, and a little alun mixed with saltpetre added to it, or a small quantity of nitric acid.

Kitchen stuFf. 'The refuse fat of the kitchen; it is generally melted and pressed from the graves, or membranes.

Currifrs' fat. Melted stuff, boiled until it is very hard and blackish when cool.

Bone GREASE. From the refuse bones of the kitchen and slaughter-house, bruised, boiled; used to make cart grease.

Hors e rat, Axungia ex equi juba. Used by enamellers for their lamps, gives out more heat than oil.

Beef marrow, Medulla bovina. Used by perfumers to make the hair grow.

Deer's suet, Sevum cervinum. Used by the gilders to put into gold size. - Yelk of wool, CEsypus. Obtained by washing raw wool in warm water.

Neats' foot ort, Nerve oil, Trotter oil, Oleum nervinum, Axungia pedum tauri. By boiling neats' feet and tripe in water; taste agreeable, does not grow hard by keeping; used to soften leather, and keep it in that state, also for frying fritters.

Pork grease, Flambard. The fat collected in boiling pork; grey, softer than hog's-lard; used in making soft soap.

Guacharo oil. From the guacharo bird: half liquid, transparent, scentless, and may be kept a year without becoming rank; used in cookery.

Carolina pigeon oil. From Carolina pigeons in large quantities.

Sturgeon fat, Axungia sturionis. Eaten as butter.

Greenland whale oil, Thran, Train oil, Oleum cetaceum. From the Balæna mysticetus, coarse, strong smelling.

ICEland whale orl. From the Balæna nordcaper.-Finfish oil. From the Balænoptera gibbar.-Sea unicorn oil. From the Monodon vulgaris; finer than any other kind of whale oil.

Great spermaceti whale oir, Southern fistery whate oil. From the Physeter macrocephalus, superior to the Greenland whale oil, pleasant tasted.

Blunt-headed cacholot oil. From the Physeter trumpo : finer than the Greenland whale oil.-Small-eyed cacholot oil. From the Physeter microps.-Porpoise oil. From the Delphinus pho- 
crena; of a fine quality.-Sword-fish oil. From the Delphinus gladiator; of excellent quality.

Sea-lion orl. From the Phoca leonina.-Sea-lion fut. From the Phoca jubata; resembles mutton suet.

Sear. or L, Axungia phoca, P. Suec. From the Phoca vitulina; brown.

SEA-cow oIt, Elephant oil, Morse oil. From the Trichechus rosmarus.

Fisir oir, of various Kinds. - Shark oil. Imported from Iceland.-Cod oil, Liver oil, Leber thran, Oleum jecinoris aselli. From the liver of the Gadus morhua.-Herring oil. By pressing the fish when plentiful; $2 \mathrm{cwt}$. of herrings yield rather more than a gallon.-Conger oil. Drained from the fish before they are salted.-Pilchard oil. By pressing the fish.-Father-lasher oil. From Cottus scorpio.-Stickleback oil. From Gasterosteus aculeatus; cbtained occasionally when the fish are very plentiful. - Loggerhead oil. From the Mediterranean turtle.

HeAd Matter. From the great spermaceti whale, principally lodged in a cavity below the snout, also from the bluntheaded and the small-eyed cacholot; composed of spermaceti mixed with oil.

Spermaceti oil, Sperm oil. From head matter, by filtering through flannel, or felt. The fincr kinds of whale and seal oils, forced through animal charcoal, are sold for it : used for chamber lamps, burning with but little smell.

Spermaceti, Blanc de baleine, Cetine, Cetaceum. The white fatty matter left in filtering spermaceti oil from head matter, further purified by boiling a short time in a ley of subcarbonate of potash, melting it, and pouring it out into moulds, crystalline, with a cavity in the centre, lined with crystals; used as a pectoral, mixed with sugar.

Fuesh Butter, Butyrum insulsum. Obtained from cream by agitation; used for food, and in ointments : by keeping it acquires a certain degree of rancidity, after which it remains unaltered; some nations prefer it in this state rather than to salt it.

Clarified butter, Butyrum purificatum. Melt fresh butter in a gentle heat, let it settle, and pour off the clear into a vessel set in cold water, to cool it immediately, without letting it crystallize: keeps long without becoming rank.

OrI. OF Y Y.LKS OF EGgS, Oleum e vitellis ovorum. Obtained by boiling eggs hard, roasting the yelks, first broken in two or three pieces each, in a frying-pan over the fire till the oil begins to exude out of them, and then pressing them with great force; fifty eggs yield about five o\%. of oil. Old eggs yield the greatest quantity. 


\section{BEES' WAX.}

Bees' wax, Cera flava. Forms the partitions of the cells in which bees store their honey; obtained by melting the comb; demulcent, used in diarrhœa and dysentery, made into an emulsion $9 j$ ter quaterve in die; from North America, Russia, Africa, Hamburgh, and the East Indies.

Ceva flave purificata. Common bees' wax melted, scummed, and left to settle.

B Lock white wax, Cera alba in massis. From bees' wax, by exposing it in thin flakes to the action of the sun, wind, and rain, frequently changing the surface thus exposed by remelting it, and reducing it again to thin flakes; used in making candles, and in white ointments, for the sake of its colour.

Virgins' wax, Cake white wax, Cera alba in offis. In round thin cakes.

Bé bread, Propolis. Collected or formed by bees, for the purpose of covering the bottom of the hive, and everything in their way which is too heavy to be removed by them; it is a mixture of rosin with wax; fume antiasthmatic.

White lac, Pela? Ambra alba, Coll. Phys. Coll.; resem. bles white wax, but is secreted by insects in the same manner as lac : from China.

\section{ANIMAL RESINS.}

Ambergris, Ambra grisea. Found in the sea and in the intestines of the spermaceti whale, Physeter macrocephalus, mixed with the beaks of the cuttle fish; appears to be a secretion of the animal when in a morbid state, has been found in the human intestinal canal, though some still suppose it to be a fossil substance, oozing out into the sea, where, swimming about, it is sometimes swallowed by that whale; aphrodisiac, gr. iij to $\mathrm{x}$; used in perfumery; when burned, smells agreeably, whence it is useful in pastilles.

Black amber, Ambra nigra. Of a darker colour than ambra grisea, but in other respects the same.

GraIn musk, Moschus in granis. From musk pods, stimulant, antispasmodic, gr. ij to Oss every three or four hours in a bolus. Has the strongest smell of any natural substance hitherto known, and when used in a very small quantity, augments the smell of other substances, without imparting its own; when burned, smells disagreeably.

Russian castor, Castoreum Rossecum. From Russia castor pods ; orange brown, bitter, acrid, with a peculiar strong and unpleasant smell; antispasmodic, perhaps emmenagogue, gr. $x$ to $\exists j$, in a bolus. 
2. New England castor, Custoreum novce Anglice. Very different smell from the former, but sold for it.

Civer, Zibethum. From civet bags, yellowish white, soft, unctuous, like honey, smell unpleasant, unless diluted : antispasmodic, but scarcely ever used alone internally; used in perfumery to augment the smell of other substances; when burned smells disagrecably; entirely soluble in oils.-Pole-cat civet. Sold for civet, dark colour.

Raw silk, Sericum. Secreted by the Phalena bombyx, for its security while in the state of a pupa or grub; cordial, restorative, $3 j$ in powder.

Coвweb, Tela aranearum. Secreted by spiders to form their nets; externally styptic, internally febrifuge; used in quartan agues, dose gr. $\mathrm{x}$; the cobwebs of the different kinds of spiders appear, however, to differ in their effects.

STick Lac, Lacca in ramulis, Lacca in baculis. Deposited by the coccus lacca on the branches of trees.

SEED LAC, Lacca in granis, $L$. in seminis. Stick lac which has been broken off the branches, and digested in warm water by the dyers for the extraction of its colour; brownish. East Indian.

Lump LAC, L. in massis. Seed lac melted into cakes. - Shell lac, L. in tabulis. Seed lac boiled in water, by which its colour has been extracterl, and then poured upon a wet slab; transparent, lightish red. East Indian light orange, retail.-Calefacient, attenuant, aperitive, diaphoretic, diuretic ; used in dentifrices, in varnishes, and to form sealing-wax.

Cexzos rac, L. Zeylanica. Deposited upon the Croton lacciferum; is in red sticks, purer than that deposited by the coccus lacca, astringent, dyes silk red.-Charon. A black lac, used in the Burmah dominions for lacquer.-Awel urruk. A coarse lac, used in India for cement.-Erythina lac. Deposited upon Erythina monosperna.

Carmine, Carminum, Purpura vegetabilis. Boil zj of cochineal, finely powdered, in 12 or $14 \mathrm{lb}$. of rain or distilled water in a tinned copper vessel for three minutes; then add alum gr. xxv, and continue the boiling for two minutes longer, and let it cool; draw off the clear liquor, as soon as it is only blood warm, into shallow vessels, put them by for a couple of days, by which time the carmine will have settled. In case the carmine does not separate properly, a few drops of muriate of tin, i. e. dyers' spirit, or of a solution of green vitriol, will throw it down immediately; the water being then drawn off, the carmine is dried in a warm stove, and should be entirely soluble in liquid anmonia. The first coarse sediment serves to make Florence lake; the water drawn off is liquid rouge. 
2. Boil lb. j of cochineal powdered, and $3 \mathrm{vj}$ of alum in $40 \mathrm{lb}$. of water, strain the decoction, add 3 ss of dyers' spirit, and after the carmine has settled, decant the liquid and dry the carmine: this process yields about 3 jss ; used as a paint for the ladies, and also by miniature painters.

Chesse, Caseus. Separated from milk by the addition of rennet, or the juice of rubiaceous and some other plants, and subsequent straining; for the purpose of keeping it, it is generally salted and pressed. There are many varieties of it, arising from the addition of cream to the milk, or its subtraction from the milk, the separation of the whey with or without compression, the salting of the curd, the breaking of the curd, or not, before pressure, the making with pressure or without, the colouring with saffron or annotto, the keeping, \&c.

\section{DISTILLED ANIMAL OILS.}

Orl of inartshors, Oleum cornu cervi. From harts' horns.

Dippel's oil, Animal oil, Rectified oil of hartshorn, Oleum Dippelii, 0 . animale, $O$. cornu cervi rectificatum. From oil of hartshorn, by a slow distillation, in a retort no bigger than is necessary, and saving only the first portion that comes over; very fine and thin, and must be kept in an opaque vessel, or in a drawer or darker place, as it is quickly discoloured by light; antispasmodic, anodyne, diaphoretic, gtt. $\mathrm{x}-\mathrm{xxx}$ in water; externally stimulant.

Oil of rones, Oleum ossium. Very fetid, burnt in lamps for making English lamp-black, and also used for lighting mines.

Butter of wax, Butyrum cerce. Distilled from bees' wax: concrete.

Orl of wax, Oleum cerce. From butter of wax, by redistillation: liquid.

\section{OF M NERAL ORIGIN.}

\section{MINERAL OILS.}

NaFta, Naphtha, Oleum petrce album. Pale yellow, fine, thin, very inflammable; found in Persia, Italy, and other places.

Artificiaid nafta. From coal tar, by distillation; used for lamps.

Oil of petre, Rock oil, Huile de Gabian, Petroleum, Oleum petrce. Red or brown; found in Persia, France, and other places.

Cost orr, Petrol. Floats on the water in which coal-gas gasometers are placed; from coal-tar by distillation; used for lamps. 
Barbadoes tari, Pisselcon Indicnum, Petroleum Barbadense, Bitumen, Petroleum. Dark, very thick, semi-liquid; found in 'Trinidad and other places.

JEw's PIтch, Asphaltum. Pitch black, hard, strong-scented; found in Syria and other places; used in varnishes.

Artificial asphaltum. Left in distilling Barbadoes tar, or coal tar.

Amber, Succinum, Carabe. Found in Prussia. The whitest, being the cheapest, is preferred for medical use; balsamic in powder, $9 \mathrm{j}$ to $3 \mathrm{j}$ in gonorrhœa and the whites: the transparent hinds are used in jewellery, and the coarser are distilled for oil of amber; also used to make oil varnish.

OrL of AyBer, Oleum succini, P. L. before 1809. Distilled from coarse pieces of amber, which are not fit for jewellery; stimulant, antispasmodic, externally discutient, rubefacient ; used in rheumatism, hooping-cough, and paralytic limbs. The following is recommended as a friction in tic doloureuxt-Olei succini f. unciam, tinct. opii fl. semunciam. Misce. Officinal preparations.-Spiritus ammonix succinatus.

Rectified oll of aMBER, Oleum succini rectificatum, O. sucrini, P. L. since 1809. Oil of amber redistilled twice.

Baisam of aмвER, Balsamum succini. 'The thick oil left in rectifying oil of amber.

Oleum petrolin Batbadensis. Distilled from Barbadoes tar by the retort, in a sand heat; blue when viewed with the back to the light, and orange when placed between the eye and the light.

Coal tar. Distilled from fossil coals; used as a coarse cheap varnish.

Artificiar, musk, Mosclus fictitius, Resina succini. Rectified oil of amber one part, nitric acid four parts ; digest, a black matter is deposited, to be well washed in water : smell similar to that of inusk or anbergris, and may be used for them in medicine.

\section{SIMPLE COMBUSTIBLES.}

\section{CHARCOALS.}

Charcos $\mathrm{t}$ varies in its qualitics according to the substance from which it is prepared; that of the soft woods, as the willow or alder, is best for crayons, and for making gunpowder; that of the harder 
woods is used for fuel, or for a support for substances exposed to the flame of a blowpipe. Charcoal of animal substances has the greatest clarifying power. Charcoal made by a low red heat, not exceeding cherry red, has a dull surface, and is best for clarifying liquids, and probably for making gunpowder, or for fuel. If the heat is carried beyond this point, the charcoal acquires a brilliant surface, and is considerably inferior for clarifying, and, probably, for every other use.

Oá charcoar, Beech icharcoal, Hazel charcoal. Pile-burned are those commonly sold in London for fuel.

Willow chancoar, Carbo ligni. Pile-burned is sometimes found mixed with the common charcoal, and picked out for crayons, to polish copper plates, tooth powder, and to put into poultices to correct fetid ulcers: also as an alterative in chronic costiveness.

Alder charcoal;-Dog-wood charcoal ;-Spindle-wood charcoal. Distilled in iron cylinders for making gunpowder: they must not be allowed to absorb the vapour contained in the receiving-vessels.

Chestrut charcoal. Burns slowly, and if blown, deadens immediately upon the blast being stopped; used by smiths for forging.

Areca net charcoal. Vaunted as a dentifrice; willow charcoal is sold for it.

Charcost DUst. The dust collected from the scuttles, used to reduce metallic oxides and similar purposes.

Vegetable charcoal, Charbon vegetable. Charcoal dust ground with water; used to clarify liquids.

BEECH BLACK, Blue black. Beech wood burned in close vessels; ground with white lead and oil produces a bluish-grey colour; used as paint.

Frankrort BLACK. Made of the lees of wine, or argol, well washed and ground with water: used to make printers' ink.

Noir D'Espagne, Suber ustum. Made of cork burnt in close vessels; used as a colour in painting.

Peach-stone Black. Peach stones, and the nuts of other stone fruits, as cherries, burnt in close vessels; ground with white lead and oil it produces the colour called old gray.

VINE-TWIG BLACK. Vine twigs burnt in close vessels; bluishblack; ground, mixed with white lead and oil, it produces a silver white colour.

RICE BLACK. From burnt rice; is deficient in colour. 
SUgAR BLACR. From sugar burned to a coal; deficient in body, but a warm colour for washing; works very free, and equal in mellowness to Indian ink.

Why. BLAck. From wheat burned to a coal; superior to lamp black, and equal to ivory black; dries well and hard in eight hours with boiled oil only; covers the ground well in one colouring.

Burxt sponge, Spongia usta. The sponge being cut to pieces, is well beaten to separate the sand it contains, and which makes up the far greater part of its weight, and is then burnt in a close vessel until it is black and friable; used in bronchocele and scrofulous complaints ; $3 j-3 i i j$ in an electuary, or in lozenges held under the tongue.

Vegetable ethiops, Pulvis quercus marince. From fucus vesiculosus, or bladder wrack, burned in a close vessel till it is black and friable: in bronchocele, \&c., as the preceding; also prepared from the pila marina.

Ivory BlACK, Cologne black, Cassel black, Ebur ustum nigrum, Spodium. From ivory shavings, or dust, heated in covered iron pots; used as a dentifrice and a paint; with white lead forms a beautiful pearl-grey colour.

Haвtshokx вLACK, Cornu ustum nigrum. Left in distilling hartshorn for the spirit.

Bone black, Animal charcoal, Charbon animal, Noir animal. The residuum left after the distillation of bone; reddish ; used for making blacking for leather, for moulding delicate founders' work, for clarifying liquors, and for abstracting the lime used in making sugar from the syrup.

Fine воле вLacк, Noir de Paris. From turners' bone dust, burned in covered iron skittle crucibles, and ground dry. Sold for ivory black, and, when finally levigated, for burnt lamp black.

Frnz charcoal. From finks; used for clarifying.

Prussian blue Makris' black, Noir de composition. The residuum from whence the prussiate of potash has been alixiviated; that of the manufactories which use dried blood clarifies far better than bone black, or than that of the manufactories that use houfs.

KILN-MADE COKE, Stifled cohe. From coal burned in a pile or open kiln; dull black; used as fuel, produces a very strong heat.

Gas сокв, Distilled coke. The remains of the coals used in making gas for lights; bright-grey, produces only a weak heat, not sufficient to smelt iron.

Charbos mineral. From bituminous slate, burned in 
covered iron pots, black, easily friable; used to clarify liquids, but is considerably inferior to bone black, and does not abstract the lime from syrup.

- Russian lamp black, Noir d Allemagne. Made by burning the chips of resinous deals, made from old fir trees, in tents, to the inside of which it adheres; mixed with linseed oil, is apt to take fire by itself; used as a paint.

BURN LAMP BLACK. Lamp black heated in a covered iron pot to get rid of its greasiness : used as a water-colour; fine bone black is sold for it.

LaM в васк, Fuligo lampadum. From distilled oil of bones burnt in lamps, with a long smoking wick : does not take fire with drying oils.

Woov sоoт, Fuligo ligni. Collected from chimneys, under which wood is burnt for fuel; contains sulphate of ammonia; bitter, antispasmodic.

Bistre. From wood soot, or peat, by pulverization and washing over ; an excellent brown water-colour, superior to Indian ink for drawings, when they are not intended to be tinted with other colours.

Cow-Dung soor. 26lb. yield, by sublimation, 6lb. of grey sal ammoniac.

Soот вLA'к. The soot of coal fires, sifted, used as a coarse black colour for making grey mortar.

\section{SULPHURS.}

\section{BRIMSTONE.}

Native sulphur. Rock sulphur, Prismatic sulphur, Sulphur nativum, Sulphur vivum citrinum. Found near volcanoes, fine yellow colour, burning away entirely, leaving no faces; used by silversmiths.-S. vivum, S. nativum griseum. Found near Mount Vesuvius, grey, burns with a blue flame when heated, but the flame soon goes out, earthy; principally used for the manufacture of brimstone and alum.

Rough brimstone, Brimstone, S. factitium, S. citrinum. Obtained by sublimation or by eliquation from pyrites and the other minerals containing sulphur; yellow; sold for S. vivum citrinum: from Italy.-S. v.griseum. Grey, impure.

Roll bRimstone, $S$. in rotulis, $S$. rotundum. Brimstone, purified by redistillation, and poured into moulds; from Italy. :-

HoRse BRImstone, Dregs of sulphur vivum, S. caballinum, Sulphuris vivi recrementa. The fæces left in the purification or sublimation of sulphur ; very impure; used in external application to the inferior cattle : sold for $\mathrm{S}$. vivum griseum. 
Flowers of sulphur, Flores sulphuris, Sulplur sublimatum. From brimstone, by sublimation, into large chambers built for the purpose ; pulverulent.

Washed rlowers of sulruer, Flores sulphuris loti, Sulphur sublimatum lotum. The common flowers washed with water to get rid of the acid.

Sulphur is laxative, propelling the faces with very little stimulus to the system; useful in piles, 3 ss to $3 \mathrm{j}$, nocte maneque; diaphoretic, communicating its peculiar smell to the sweat; used internally, and externally in ointments, as a specific in the itch and other cutancous affections; its suffocating fume, while burning, is used to whiten linen, straw bonnets, \&ce, and to kill bees and other insects ; equivalent, 2 .

Mirk of sulpuor, Lac sulphuris. Sulphur 1lb., quicklime or subcarb. of potash 3lb., boil in a sufficient quantity of water, add dilute sulphuric acid q. s., and wash the sediment.-S. precipitatum. Sulphur 1lb., fresh burned lime 이․, boil in water 4 gall., filter, adding muriatic acid $q$. s., and wash the sediment till it is insipid ; used internally in preference to the flowers, probably contains water.

Liver of surpur, Hepar sulphuris. Brimstone in powder $1 \mathrm{lb}$., subc. of potash 3lb.; melted together in a covered vessel.

Sulphunet of potasir, Kali sulphuretum, Potassce sulphuretum, P. L. 1809. Flowers of sulphur $\overline{3}$, subc. of pot. $\overline{3} \mathrm{v}$; melt together the proper proportion according to theory, 2 sulph. with 5 potassium, (from 11 subcarb). potash) equiv. 7-P'otassa sulphuretum, P. L.1815. Fl. sulph. इj, subc. of pot. 3 ij, melt.-Sulplucretum kali, Sulphurctum potassa, P. Li. Fl. sulph. subc. pot. ana p. acq. : mix and melt : expectorant, diaphoretic; used in catarrh and cutaneous affections; dose gr. $\mathrm{x}$ to $\mathrm{xv}$; proposed as an antidote to arsenic, but of doubtful utility.

Lintin river of surphur, Aqua sulphureti kali. Flowers of sulphur इ̇ss, liq. potassæ $\overline{3} \mathrm{ix}$; boil for ten minutes, filter, and keep in well-closed vials; used as an antidote to mineral poisons : externally in tinea and the itch.

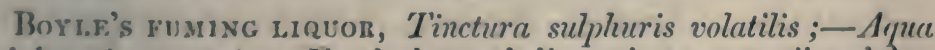
sulphureti ammonia. Fresh burned lime ziv, water $=$ ij; slake, and when cold, add sal ammoniac 3 iv, Howers of sulphur 3 ij; distil; used as a proof liquor for wine, but it requires the precipitate to be examined, by fusion, whether it be really lead.

Inneret of sulpuer. Take of iodine four parts, sublined Fulphur one part, mix and heat gently in a bottle: the excess of irxline is separated, and the ioduret remains as a grey, needled unass which rapidly absorbs moisture and soon decomposes. Mr. 
Biett used an ointment formed of this and lard in tubercular affections of the skin.

\section{PHOSHHORUS.}

Phosphorus of urine, Kunckel's phosphorus, Phosphorus urince, $P$. Kunckelii. From urine putrified and distilled in an iron pot, with a glass or stoneware head ; the residuum taken out, ground, put into small earthen retorts, and distilled with a very violent heat into water.

2. By pouring a solution of sugar of lead into urine, which precipitates a white powder, to be mixed with charcoal powder, and distilled with a violent heat into water.

3. Mix bone-ash $15 \mathrm{lb}$, with 3 gall. of water, add oil of vitriol 6lb.; the next day add more water, strain through a sieve, and wash the sediment well with hot water; evaporate the waters mixed together to the consistence of a syrup, add charcoal dust sufficient to absorb it, and distil into water.- Inflainmable at a very low heat, and therefore it must be kept under water ; purified by being kept in fusion in a glass tube under water until the impurities have settled; principally used as an easier and speedier method of procuring fire than the common; also used to analyse atmospheric air, and to form phosphoric ether : equivalent 1.5 .

\section{METALS.}

\section{METALLIC SULPHURETS AND SIMILAR COM. BINATIONS.}

\section{ANTIMONY.}

Crude antrimony, Eyes medicine, Prismatoidal antimony glance, Surmach, Antimonium crudum. Found in mines, in long needles, formerly preferred for medical and chemical use.

Smelted antrmony, Antimony, Sulphuret of antimony, Antimonium fusum, Antimonii sulphuretum. From crude antimony, by fusion and pouring into conical moulds; diaphoretic, used in rheumatism, scrofula, and cutaneous diseases as an alterative, $\vartheta_{j}$ to $3 \mathrm{j}$; given largely to horses, mixed with their food, to smooth their coats; used in the arts to purify gold, and by the ladies, to paint their eyebrows and eyelashes black; composed of 5.5 antimony with 2 sulph. equi. $\% \cdot \check{\text { s. }}$

Medicinal regulus of antimony, Antimonium medicinale, 
Regulus antimonii medicinalis. Common antimony $5 \mathrm{oz}$, subcarb. of potash 1 oz., common salt 4 oz.; powder, mix, melt; when cold, separate the scorix at top, powder the mass, and wash it well : more active than common antimony ; used_in some unknown nostrum.

A.struoniua medicamentosum. Common antimony $5 \mathrm{oz}$, commion salt $4 \mathrm{oz}$, nitre and argol ana $1 \mathrm{oz}$. mix, melt, grind, and wash well; used in some unknown nostrum.

Liver of antimony, Hepar antimonii. Common antimony 2lb., potash 4lb. ; mix and melt ; emetic, in doses of gr. iij to vj, but mostly used as a violent purge for grease in horses' heels, and for preparing sulphur baths for disorders of the skin, by adding an acid.

2 Antimony, saltpetre, ana 1lb., deflagrate and melt together.

Kermes mineral. Common antimony finely ground, 4lb., subcarb. of potash $1 \mathrm{lb}$, , soft water $\approx$ gall., boil for half an hour, filter, cools very slowly; the kermes settles as it cools; the antimony left upon the filter may be boiled again several times with fresli subc. of potash and water. Composed of 6.5 protox. ant. with $2 \cdot 125$ sulphuretted hydrogen, equiv. 8.625.

2. Common antimony $16 \mathrm{oz}$., subcarb. of potash $8 \mathrm{oz}$, flowers of sulphur $1 \mathrm{oz}$; mix, melt together, pour out; when cold, reduce the mass to powder, and boil in water q. s., filter while hot; the kermes precipitates as the water cools, and is to be well washed.

Cluzer.l's Kermes. Prepared common antimony ऊ̄ss, subcarb. of soda $\overline{3} \mathrm{x}$, distilled water a gallon; boil for half an hour, filter, let it settle, wash the precipitate with cold water which has been recently boiled, dry the precipitate by a heat of $90 \mathrm{deg}$. Fahr. folded up in glazed paper to keep the air and light from it; produces a very dark criuson powder, of a smooth velvety appearance. This preparation occupies in foreign practice the place of our James's powder, in doses of gr. ss to iij, as a diaphoretic, cathartic, and emetic.

Goldix sulphur of axtriony, Sulphur auratum antimonii. After the alkaline liquor has deposited the kermes mineral, add any acid, generally the acetic, to throw down the golden sulphur; by adding the acid in separate portions, the precipitate may be obtained of different colours and strength, the first being redder and stronger, the latter yellow and weaker. It may be used as kermes mineral, but requires a double or treble dose.

Selpher antmonir peacipitatum, P. L. 1788, Antimonii miphuretum precipitatım, P. L. 1809. Common antimony powdered $21 \mathrm{lb}$, subcarb. of potash water $4 \mathrm{lb}$., water $3 \mathrm{lb}$; ; boil for three 
hours, strain while hot, and add immediately dilute sulphuric acid to precipitate the sulphur; wash and dry.

Sulphur antim. Fuscun. Common antimony, subcarb. of potash ana $1 \mathrm{oz}$. ; melt together, powder, and dissolve in water 4lb.; let it cool; when cool, add dilute sulphuric acid q. s. to precipitate the remainder of the sulphur, agitate the mixture, that this last precipitate, which is yellow, may be mixed with the other; wash and dry. Both these are mixtures of kermes mineral with golden sulphur of antimony, and, therefore, to be esteemed inferior to the former: dose, gr. $\mathrm{j}$ to v.

\section{ARSENIC.}

Orpiment, Prismatoidal sulphur, Sesquisulphuret of arsenic, Hurtall, Yellow sulphuret of arsenic, Auripigmentum. Found in mines, yellowish green, with brilliant gold-coloured spangles; used by painters; caustic, composed of 4.75 black arsen., with 3 sulph. equiv. 7.75.-King's yellow, Hartal. From orpiment, by sublimation; from China, Japan, and the Burman empire.

Yeliow a RSE Nic, Yellow sulphuret of arsenic, Arsenicum flavum, A. citrinum. Made of 75 to $901 \mathrm{~b}$. white arsenic, rough brimstone $10 \mathrm{lb}$, by sublimation, or by distilling $100 \mathrm{lb}$. arsenical pyrites with 10lb. of iron pyrites. From Germany.

REAIGar, Red arsenic, Chinese vermition, Munsil, Hemiprismatic sulphur, Red sulphuret of arsenic, Resigallum, Sandaracha Gracorum, Auripigmentum rubrum. In mines; fine red colour, like vermilion; used also by painters; composed of 2 sulphur and 4.75 of black arsenic, equiv. $6 \cdot 75$. Made into cups, in which the juices of acid fruits being left become cathartic. From Japan and the Burmah dominions.-Manocillei. A coarse red orpiment, sold in Lower India for a paint.

RED ARswic, Red sulphuret of arsenic, Arsenicum rubrum factitium. From arsenical and sulphureous pyrites distilled together, or from powdery white arsenic, $3 \frac{1}{2} \mathrm{cwt}$. sublimed with $\frac{\mathrm{x}}{2} \mathrm{cwt}$. rough brimstone; the sublimate is afterwards melted and ladled into moulds. From Germany.

Magnes arsenicalis. Sulphur, white arsenic, and common antimony, of each 1lb.; mix by fusion: corrosive.

\section{IRON.}

Inon pyrites, Brass balls, Horse gold, Copperas balls, Hexahedral iron pyrites, Bisulphuret of iron. Native sulphuret of iron, Pyrites ferri. Brass yellow, in balls or crystallized; collected for the manufacture of green vitriol. By exposure to the weather they are decomposed into a saline powder, from whence the vitriol 
is extraced by elixiviation and crystallization. Comp. of $3 \cdot 5$ iron, with 4 sulph., equiv. $7 \cdot 5$.

CHALYBS CUM SULPHURE PREPARATUS. With a red hot bar of steel melt a roll of brimstone, so that it may fall into a vessel of water; separate the brimstone which falls at the same time into the water, and reduce the chalybs into a fine powder.

Sulpuuret of irow. By melting iron filings, or scales of iron and brimstone, p. xq. in a covered crucible; melts casily, and takes sharp casts.

Sulphuretum Fenri. Iron filings $6 \mathrm{oz}$, flowers of sulphur 2 oz. ; mix together, and melt in a covered crucible. Used in preparing hepatized ammonia.

BLACK LEAD, Rhombohcedral graphite-mica, Carburet of iron, Per carbure de fer, Plumbum nigrum, Cerussa nigru, Phumbago, Graphites. Found in mines; derives its name from its colour, composed of 92 parts iron and 8 charcoal; used for pencils, crayons, and the coarser sort to give a metallic lustre to other bodies, or to diminish the friction, in cases where grease or oil would be improper.

\section{L.EA D.}

Potrer's Lead ork, Sulphuret of lead; Galena. Found in mines, breaks in cubes; used by the potters in glazing earthen vessels.

\section{QUICKSILVEIR.}

Native cinnabar, Peritomous mulyblende, Bisulphuret of pricksilver, Durdar, Cimabaris. Found in mines; liable to be confounded with realgar, or red arsenic ; composed of 25 quicksilver, with 4 sulph., equiv. 29. From Surat, China, and Batavia.

Dutcir venurion, Sulphuretum hydrargyri rubrum, P. E. Cinnalsaris factitia. By grinding 170lb. of quicksilver and 50lb. of brimstone together, throwing the mixture by ladlesful into heated earthen sublimers, where it takes fire; the superfluous sulphur being consumed, the mouths of the vessets are then covered with tiles, which stops the conflagration, and the sublimation commences, which is continued until the whole is risen "p. From Holland.

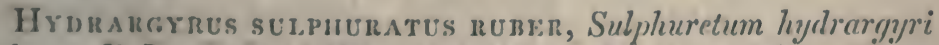
rul,rum, P. D., P’. I., 1809. Quicksilver $4.0^{\circ \% ., ~ s u l p h u r ~} 8$ oz., sublime: diaphoretic; used in cutancous discases and gout, also as a vermifuge, gr. $x$ to 5 ss: externally, 5 ss, thrown upon a red hot iron, is used as a fumigation to cleck the progress of venereal ulcers in the throat, nose, or mouth; totally volatile by heat, communicates no colour to spirit of wine. 
Strlphuret of QUICKsilver? Cinnabaris antimonii. Obtained as a secondary product in the making of butter of antimony, by raising the fire after the butter has come over.

2. Quicksilver $15 \mathrm{lb}$, rough brinstone, $5 \mathrm{lb}$, common antimony 1lb. and a half; mix and sublime: brown red. Perhaps composed of 25 quick. with 2 sulph., equiv. 27.

TIN.

Aurum musivum, Bisulphuret of tin, Aumum mosaicum. Quicksilver, tin, sulphur, sal ammoniac, ana p. æq., the tin being first melted, the quicksilver poured into it, and then the whole ground together, and sublimed in a bolt head: the Aurum musivum lies at the bottom; composed of 7.25 tin, with 4 of sulph., equiv. 11:25.

2. Dissolve tin in muriatic acid, precipitate by subcarb. of soda, mix the precipitate with half its weight of sulphur, and sublime.

3. Tin filings, sulphur, sal ammoniac, ana p. æq.; sublime. In these sublimations, if the fire is too great, only a grey sulphuret of tin is obtained. Used as a metallic gold colour in varnish work and sealing-wax.

\section{ME'TALS.}

GOLD.

Grain gold, Aurum. Cupelled gold melted with sufficient silver to form only 1-4th of the mass, granulated by being poured from on high in a small stream into water, the silver dissolved away by nitric acid, and the grains heated to give them their proper lustre. Used to make preparations of gold; equivalent 25.

Grold leaf, Aurum foliatum, Aurum in libellis. Used to gild pills and other substances.-Party gold. Gilt silvor hammered into leaves.

Sheld gold, Aurum in musculis. Grind the cuttings of gold leaf with thick gum water, and spread the ground gold on colour shells.

GoLd POWDER, Aurum pulveratum. Grain gold, 1 oz., quicksilver, nearly boiling, $6 \mathrm{oz}$.; rub together; distil off the quicksilver, or corrode it away with spirit of nitre, and heat the black powder that is left to redness.

2. Grain gold $\mathbf{1} \mathrm{oz}$. dissolve in aqua regia; add to the clear soiution green vitriol $4_{1} \mathrm{Oz}$. dissolved in water: wash the precipitate, and heat it to redness. Used in painting, gilding, \&c. 


\section{SILVER.}

Refixed sirver, Argentum cupellatum. Silver cupelled with a sufficient quantity of lead to scorify the copper mixed with it. Used to make preparations of silver.

Pure silver. Dissolve refined silver in nitric acid, add a solution of salt as long as any sediment falls; boil the sediment while still moist, along with water in a bright iron vessel; wash and dry the silver. Equiv. 13.5.

Silver leaf, Argentum foliatum. Used to cover pills and other substances.

Shell silver, Argentum in musculis. Grind the cuttings of silver leaf with strong gum water, and spread it in muscle shells. Used for writing silver-coloured letters, but tarnishes, and is inferior to argentum musivum, unless varnished over.

Silvell dust, Crocus argenti. Add slips of copper to a solution of silver in spirit of nitre, and wash the precipitated metal witl spirit of wine: used in japanning.

QUICKSII,VER.

Quicksirver, Quik, Mercury, Argentum vivum, Mercurius, Hydrargyms, Hyclrargyrum. Found native, but mostly extracted from the native sulphurets. Given in obstinate costiveness to the extent of lbj or lbjss, in hopes of forcing a passage by its weight. Used by water-gilders to dissolve their gold, by looking-glass makers to soften their tinfoil, lyy barometer and thermometer makers for their instruments, and in some other arts. Inported from Idria through Holland and Italy; from Spain, Nepaul, and Japan.

Punifind Quicksinger, Argentum vivum purificutum, $H y$ stargyrus purificatus, Hydrargymem purificatum. Distil it from an iron ressel. The imported quik is so pure, and any adulteration, if attempted, so readily discoverable by workmen accustomed to handle it, that this operation is superiluous.

2. Sirain the quik that has been used by looking-glass makers through chanois leather. Used by apothecaries, when it can be got cheap, to make blue pill and mercurial ointment.

S. Distil Dutch vermilion and iron filings of each 1lb. into watcr ; cquiv. 25.

\section{Coprer.}

Suret coppro, Cipmun. This, like pewter, is used for making many pharmaceutical vessels, which are generally tinned on the inside: these ressels have been proscribed by the colleges upon issufficient grounds, since, like lead, it cannot be dissolved while 
tin is co-existent in the mixture. When acids are boiled in vessels, part of whose tin lining is abraded, the acids take up some of the tin, and deposit it on the abraded part, thus repairing the damage in the same manner as brass pins are tinned, by boiling with tin filings and cream of tartar. Acid syrups and stews are and have been prepared for centuries in untinned copper vessels without any ill effects, although in gentlemen's houses and elegant inns they have occasionally produced of late direful effects : but the common cooks use only pewter spoons for stirring, and by leaving them in the liquid, render the acids ineffective upon copper, which effect is not produced by the silver spoons of superior establishments. Although the salts of copper are violent emetics, yet $3 j$ of filings has been taken against the rheumatism; and Rouelle used to exhibit in his lectures a lock of green hair he had himself cut from the head of an aged founder, who had much used that remedy. Equiv. 4.

BEAN-SHot copper. In small lumps, like peas or kidneybeans. Made by pouring a thin stream of melted copper into boiling water.

Feather-shot copper. In small thin rounds, with a feathered edge; by pouring the copper into cold water. Both are used for making solutions of copper.

Bronze powder, Aurum sophisticum. Verdigris 8 oz., tutty 4 oz., borax, nitre, ana 2 oz., corrosive sublimate $3 \mathrm{ij}$, made into a paste with oil, and melted together: used in japan work as a gold colour.

\section{IRON.}

Inon filmas, Ferri limatura. Tonic and astringent; used in chlorosis, gr. $\mathbf{v}-\mathrm{x}$, bis terve in die.-Iron turnings, Fierri ramenta, F. scobs.-Iron wire, Ferri fila. Only used in preparations, being the purest, which alone can be drawn into wire; equiv. 3.

Srees, Chalybs, Mars. Made from iron, by stratifying or melting it with charcoal, of which it takes up a minute portion: the filings are sometimes used as a stimulant and tonic; also in fireworks.

LEAD.

Granulated Lead. By melting new lead, pouring it in a small stream, from an iron ladle with a hole drilled in its bottom, into a pail of water ; equiv. 13.

Lead dust, Pulvis Plumbi. By melting new lead, adding bruised charcoal, and diffusing the lead among it, then pounding and washing away the charcoal; used by potters.

Pewter. I_ead hardened with tin, and in the best kinds with 
ant:mony. Used for making ressels, which have been proscribed by the colleges. Proust, however, has shown (Journ. de Phys. for 1SO6) that acids boiled in pewter vessels took up none of the lead, which they will not touch while tin is present; that when even a solution of sugar of lead was boiled in a pewter vessel, the lead was precipitated in its metallic state, and tin extracted from the ressel: lemon juice, diluted with water, left for a day and a night in the coarsest pewter vessels, did not dissolve an atom of lead, but acted only on the tin.

TIN.

Gissin tix. From the native oxide of tin collected in the Cornish strean works; equiv. 7:25.

Trxforl, Stanmum foliatum, Stanniolum. In thin leaves; used for ornament and to cover the hind surface of looking-glasses, being softened with a small quantity of quicksilver, which is afterwards pressed out of it by heavy weights.

Tin filixgs, Limature stanni;-Powder of tin, Pulvis stani. Melt grain tin in an iron mortar, and stir it, while cooling, until it becomes a powder, then sift it.

Graxusated tix, Stannum granulatum. Melt grain tin, and pour it into a wooden box rubbed on the inside with chalk, put on a cover that fits close, and shake it violently, till the metal is reduced to powder; wash off the chalk, and dry the grain. Vermifuge, in doses of $\bar{j}^{\mathrm{i} j} \mathrm{j}-\overline{\bar{j}} \mathrm{ss}$.

\section{SFELTER.}

Syelter, Zinc, Zincum. From lapis calaminaris, mixed with charcoal and distilled; or sublimed, as a secondary product, in the fusion of some German ores; used to produce galvanism, and in fireworks; equiv. 4.25.

Amalgam of zinc, Amalyama zinci. 'T'o zinc $2 \mathrm{oz.}$, heated in a crucible, add quicksilver 5 oz., also heated. Used to spread upon the rubbers of electrical machines.

\section{BISMUंTH.}

'Trs cisass, Bismuth, Eituin de glace, Marcasitu argented. Eliquated from its ores. Used in metallie mixtures to communicate fusibility; also in powder, as an imitation of silver for writing and painting; equiv. 9.

Fusine, mital. Bismuth 2 oz., lead 5 o\%, tin 3 o\%, melted together; melts in boiling water. Used to write on asses' skin, or paper prepared by rubling lurnt hartshorn into it; also for toy-spoons, to surprise children by their melting in hot liquors. 
Smith's solder for TIN. . Lead, tin, of each 4 oz., bismuth $8 \mathrm{oz}$; will melt in boiling water.

Onion's fusible metal. Lead 3 oz., tin 2 oz, bismuth 5 oz.; melts at $19 \%$ deg. Fahr.

Argentum musivum. Bismuth, tin, ana 2lb.; melt together, and add quicksilver $1 \mathrm{lb}$. : brittle; used as a silver colour.

\section{ANTIMONY.}

Regulus of antimony, Regulus, Antimony, Stibium, Regulus antimonii. From common antimony, saltpetre, and argol, ana $\mathrm{p}$. æq., pulverized, injected by degrees into a red hot crucible, and melted; the regulus settles at the bottom; equiv. $5 \cdot 5$.

2. Common antimony $16 \mathrm{oz}$. , tartar $12 \mathrm{oz}$, nitre $6 \mathrm{oz}$.; melt, and pour out into a melting-cone; when cold, separate the regulus, and if required to be very pure, remelt it once or twice; throw upon it, whilst in fusion, $1 \mathrm{oz}$. of nitre, and keep it melted for a quarter of an hour.

3. Common antimony, $16 \mathrm{oz}$, calcine in a shallow vessel till no sulphurcous vapour arises from it, taking care it does not melt, which requires 10 hours at least; it yields $12 \mathrm{oz}, 3 \mathrm{dr}$., $24 \mathrm{gr}$., of calx; mix this with as much soft soap, and melt: produces $9 \mathrm{o} z$., $6 \mathrm{dr} .54 \mathrm{gr}$. of regulus.

Martial regulus of antimony, Regulus antimonii martialis, R. a. stellatus. Upon 1lb. and a half of small nails heated to redness in a crucible, throw a mixture of $11 \mathrm{~b}$. common antimony, 4 oz. nitre, and 2 oz. tartar: melt and pour out, separate the regulus, and remelt it three or four times, throwing upon it each time 2 oz. nitre.-Regulus is used to form small cups, in which wine, being let to stand for a night, becomes emetic, or balls are made of it, which are infused in wine for the same purpose; also to harden lead, and thus make a compound metal fit for the best kind of pewter and for printers' types.

REgulus Jovis. Made by melting regulus of antimony with tin, generally in equal quantities, and casting it into the form of a cup, for rendering wine emetic; is less brittle than the pure regulus. These metals, mixed in various proportions, are used for making mirrors, medals, \&c.

\section{COBALT.}

Cовацт, Regulus of cobalt. Wash zaffre $11 \mathrm{~b}$., by which means about 5 or $6 \mathrm{oz}$. of calcined quartz, or sand, may be separated from it; mix the washed zaffre with soft soap, and melt it with a violent heat ; produces about 3 or $4 \mathrm{oz}$. ; equivalent 3.25.

2. Roast Cornish bright white colbalt ore, then smelt the oxide with twice as much soft soap. 


\section{ARSENIC.}

Bu.cK Arsexic, Metallic arsenic, Regulus of arsenic, Arsenic, Arsenicum nigmum, Regulus arsenici. From powdery white arsenic distilled with charcoal dust and some iron or lime to hinder any sulphur from rising. Used to whiten copper; equivalent 4.75 .

CoBalt, Mort à mouches, Fliegen stein. A mixture of black and white arsenic collected in the neck of the distilling vessels in making black arsenic: sold to poison flies.

\section{NICKEL.}

Spiess. A metallic compound that collects at the bottom of the pots in making smalt; used to make nickel.

White copper, Pak fong, Tutenague. A compound metal brought from China; contains 15 nickel, 28 spelter, and 21 copper, malleable.

\section{METALLIC OXIDES.}

GOLD.

Peritue precipitate, Cassius' purple, Precipitatum Cassii. Solution of gold in aqua regia, 1 oz., distilled water 1lb. and a half; mix, and hang in the liquid slips of tin.

2. Precipitate a dilute solution of gold by a dilute solution of muriate of tin, with a slight excess of acid. Used to communicate a purple colour to glass, when melted in an open vessel: in a close vessel the glass receives no colour.

Croces of Gorn, Oxide of gold, Crocus solis. Dissolve gold in aqua regia made of common salt, add subcarb. of potash $q . s$. to precipitate the whole. Used in venereal and scrofulous complaints : also to colour glass purple, but it is difficult to produce by either of these means an equable colour. If heated strongly, it recovers its metallic lustre, and may be used for true gold powder. 'The gold that remains in the solution being nearly onehalf, is separated loy adding a solution of green vitriol.

\section{QUICKSII.VHR.}

ETHIOPS PER SE. 13y shaking quicksilver in a large bottle, or by triturating it with water; pulverulent, black.

Hrinangres oxynum cixereum, P. I. Boil calomel aj in a gallon of lime-vater; wash the grey sediment with water, and dry it. Comp. of 25 quicks. and 1 oxyg.; equiv. 26.

Protoxine: of Quicksuver, P'ulvis liydrargyri cinereus. Quicksilver $\overline{3} \mathrm{ij}$, dilute nitric acid $\tilde{3} \mathrm{jj}$, distilled water 3 viij, aqua 
subcarbonatis ammonix q. s. (about $\bar{j} j s s$ ), to precipitate the oxide: wash and dry.

Oxidum hydratgeyr cinereun, P. E. Quicksilver 3 iv, dilute nitric acid $\overline{3} v$, distilled water $\overline{3} \times v$, aqua subcarbonatis ammoniæ q. s. Dissolve the metal in the acid, dilute the solution with the water, precipitate with the alkali: wash and dry the precipitate. Totally different from the London oxide of the same name: all these are used in syphilis, and are not apt to disorder the stomach and bowels. Dose gr. $\mathrm{j}$-iij, bis in die.

Calcined mencury, Precipitate per se, Peroxide of quicksilver, Mercurius pracipitatus per se, Mercurius calcinatus, Hydrargyrus calcinatus, Hydrargyri oxidum rubrum, Oxidum hydrargyri. By exposing a thin stratum of quicksilver to the action of heat sufficient to keep it boiling, in a flat-bottomed matrass, called Boyle's hell, contrived to admit air without letting the vapour of the quicksilver escape. In red scales, darker than red precipitate; may be used for the same purposes. Comp. of 25 quicks., 2 oxyg.; equiv. $2 \%$.

RED PREcipitate, Mercurius corrosivus ruber. Quik, aq. fortis composita, ana $\mathrm{lb} . \mathrm{j}$; dissolve, decant, and evaporate on a sand heat, until it becomes red.

Hydrargyrus mitratus ruber. Quik, nitric acid, ana zxij, acid muriat. $3 \mathrm{j}$; dissolve and evaporate to dryness.

Mercurius precipitatus conrosivus, Hydrargyri nitricooxidum, Oxidum hydrargyri nitricum, Oxidum hydrargyri rubrum per acidum nitricum. By dissolving quicksilver in nitric acid, with heat, and evaporating till a dry mass is left, which is then calcined in a broad, shallow vessel, until it no longer emits red vapours.

2. Quik $36 \mathrm{oz}$., dissolve in aquafortis $60 \mathrm{oz}$., digest two days to clear it, distil to dryness in a gallon retort, pour on a similar solution, and distil again to dryness: for this, six retorts are required, set in a sand heat: calcine the mass in three retorts, with receivers, set in separate furnaces. In the first three hours, flowers should settle in the arch of the retorts; in the next three, they should be driven into the neck; in the last three, the matter in the retorts should become first yellow, then orange, lastly vermilion red; the fire being then stopped, the residuum will be a shining red scaly mass, of a proper marketable quality. The aquafortis that comes over may be used over again, adding a quarter of fresh acid. Anti-syphilitic, gr. ss -ij nocte maneque, but principally used externally, as an escharotic and stimulant to foul ulcers, for which purpose it must be very finely pulverized.

Green preciprtate, Mercurius pracipitatus viridis, Lacerta viridis. Dissolve quicksilver $\tilde{3} \mathrm{j}$ in nitric acid q. s.; at the same 
time dissolve also copper $\overline{3} \mathrm{j}$ in another pared of nitric acid; mix the two solutions, evaporate to dryness, and calcine the residuum in a shallow vessel till no more red fumes appear; caustic.

LE $A D$.

Dross of LEAD, Plumbum ustum. Melt lead, and rake off the scum till it is entirely reduced to dross.

Massicot, Protoxide of lead, Ochra plumbaria factitia. Roast potters' lead ore, or dross of lead, until it acquires a yellow colour. Used as a paint; comp. of 13 lead, 1 oxyg.; equiv. 14.

LithaRGE OF GOLD, Lithargyrus aner. Ýcllow, impure.

Lituarge of silver, Lithargyrus argenti. White; obtained in the extraction of silver; from Germany.

Exglish mitharge, Lithargyrus, Plumbi oxidum semivitreum. Made by melting red lead; used in making plaisters, being more convenient than red lead, and from its peculiar scaly appearance it cannot be adulterated. In grinding litharge, 1\% oz. of olive oil are usually added to each cwt. to prevent dust.

Red lean, Minium, Plumbi oxidum rubrum. By roasting litharge in a flaming fire; used in making plaisters, and as a paint; reduced by red earths, a mixture of the protoxide and deutoxicle of lead.

Orange red, Sandix. Made by calcining white lead; is a brighter colour than red lead.

\section{N.}

Lonnstonf, Mregnes. Found in iron mines; astringent; used externally to draw iron out of wounds, also as an anulet against the grout, and to draw over or stroke certain parts in painful dis. cases, as a magical remedy.

Broon-stonls, Lapis hamatitis, Hamatitis. Found in mines; marke into polishers, and when prepared, used also as a polishingpowder ; drying, astringent, agglutinating.

Scales of Iron, Black oxide of iron, Protoxide of iron, Squama frri, Oxidum ferri nigrum. The scales of iron beaten off by the blacksmith in his work, separated fiom the dirt by means of a magnet, reduced to powder in a mortar, and washed over; do not occasion flatulence. Composed 3.5 iron and 1 ox.; equiv. 4.5 .

EтHops Martiatis. Keep iron filings under water, shaking them necasionally; wash the black powder, and dry quickly to prevent its rusting.

Cinaybs proparatus cum aclito. Wet steel dust with white wine vinegar, expose it to the sun; repeat this often, then levigate. 
Crocus martis, Peroxide of iron, Potée d'acier, C. martis astringens, Oxidum ferri rubrum. Calcine iron or steel filings till they become of red colour. Composed of 3.5 iron and 1.5 ox.; equiv. 5.

Crocus martis aperitivus, P. L. 1790, C. M. sulphuratus. Melt together equal parts of iron filings and sulphur, and calcine the mass till all the sulphur is driven off.

Rough colcothar, Brown red, Common Indian red, Rouge d'Angleterre. By recalcining green vitriol (previously calcined to whiteness, or distilled for its oil,) until it becomes very red.

Washed colcotuar, Indian red, Trip, Terra dulcis vitrioli. Wash rough colcothar, or the residuum left in the distillation of aquafortis, till all the saline matter is abstracted; scarlet.

Crocus. Calcine washed colcothar in a violent heat, until it becomes purplish or bluish ; very hard; used for polishing.

Fine crocus. Green vitriol and salt, of each 1lb., grind together, heat to a cherry red for some hours, and wash; violet brown, soft to the touch; spread with soap upon razor-strops.

JEweLLers' nouge. Precipitate a solution of green vitriol in water, by a solution of pearl ash, and calcine till of a scarlet colour.

All these are tonic, stimulant, gr. v. to x. Used in the composition of astringent drying and strengthening plaisters and ointments ; employed also for polishing metals, and as pigments.

TIN.

Stannum pulveratum, P. L. 1\%88. 'Tin 6lb., melt, and stir till it becomes covered with a powder, which take off, and when cold sift.

Poter D'Etain, Polisher's putty, Calcine, Cineres stanni. Melt tin, rake off the dross as it is formed, and calcine this dross till it becomes whitish.

2. Melt tin with an equal weight, or one ounce and a half of lead, and then raise the heat so as to render the mixed metal red hot, when the tin is immediately flung out in the state of putty. Both are very liard, used for polishing glass and japan work, and to colour opaque white enamel.

Bezoalidicum Joviale, Peroxide of tin. Tin 1 oz., nitre $3 \mathrm{oz}$., flung into a red hot crucible, and the calx well washed: composed of $\% \cdot 25$ tin with 2 oxyg., equiv. 9.25.

Antrchecticum Poterir. Tin, regulus of antimony, ana $p$. æq. melted together, then deflagrated with three times as much nitre, and well washed; are astringent, $\mathrm{\partial j}_{\mathrm{j}}$ to $\mathrm{ij}$; used in phthisis. 
Oxune of TIs, Oxidum stanni. Dissolve tin in aqua regia nuade of nitric and muriatic acid, in a small vessel covered to prevent the absorption of air; and immediately pour it into a solution of subcarbonate of potash sufficient to saturate the acid; filter and wash.

\section{SPEIT EIR.}

Lapis calaminaris, Calamina, Carbonas zinci impurus. Found in mines; drying, astringent: used in ointments; but cawk, sulphate of barytes, coloured, has been lately sold for it; used also to furnish zinc, and for making brass.

Turty, Tutia, Tuthia, Oxidum zinci impurnem. The sublimate collected in the chimneys of furnaces in which ores mixed with lapis calaminaris are snielted, this sublimate being mixed with clay on cylindrical moulds and baked; or it is collected during the roasting of blende, attaching itself to the upper part of the furnace: drying, astringent; used in eye-waters and eye-ointments.

Flowers of zrNc, Oxide of zinc, Flores zinci, zincum calcinatum, zinci oxidum, P. L. before 1824. Procured by burning zinc in a long deep crucible, placed sideways in a furnace, so as to collect the flowers conveniently as they form: antispasmodic; used in epilepsy, gr. $\mathrm{v}$ to $\mathrm{x}$; also in painting, as a substitute for white lead; dries very slowly, requires white vitriol to be added; comp. of 4.25 zinc and 1 oxyg., equiv. 5.25.

Diaphoretic calaminanis. Lap. calam. 4oz., nitric acid lbj:; dissolve, decant, distil to dryness, powder, and wash the residuum; sudorific, gr. $x$ to 1 .

Posipuorix, Nihil album. Collected in the smelting furnaces, wherein zinc ores or brass are melted; used in ointments for tutty.

Magistery of lapis calaminaris, Hydrated oxide of zinc. Dissolve lapis calaminaris in muriatic acid, and add subcarb. of ammonia water to precipitate it: wash and dry; emetic, cathartic, gr. iij to viij.

Zrscr oxrous, P. L. 1824. Sulphate of zinc 3 xij, aq. dist. $\mathrm{Oj}$; dissolve, add liquor ammonix $q . \mathrm{s}$, wash the precipitate, and dry.

\section{ANTIMONY.}

Protoxidz of antrmony, Powder of Algaroth, Mercurius vila. Pour butter of antimony into distilled water, wash the precipitate, and dry it by a gentle heat: comp. of 5.5 ant. with J oxyg., equiv. 6:5.

2. Digest 1lb. of liver of antimony for a day in three pints of 
water, to which $1 \mathrm{lb}$. of oil of vitriol and $1 \mathrm{lb}$. of common salt has been previously added: decant the clear solution and pour it into hot water, wash and dry.

Oxidum antimonir nitro-muriaticum. Mur. acid jaj, nitric acid $3 \mathrm{j}$, common antimony $3 \mathrm{j}$, dissolve, pour the clear solution into a gallon of water, and wash.

Oxidum antimonir, P. L. 1815. Dissolve emetic tartar $3 \mathrm{ij}$ in distilled water, and subcarb. of ammonia $3 \mathrm{ij}$ in another portion of water, mix the two solutions, boil till the precipitation is complete, and wash the precipitate.

Peroxide of antrmony, Diaphoretic antimony, Antimonium diaphoreticum, Calx antimonii, Antimonium calcinatum. Common antimony $11 \mathrm{~b}$., purified nitre 3lb., inject by spoonsful into a red hot crucible, powder and wash; the flowers that stick to the side of the crucible must be carefully separated, otherwise they render it emetic; comp. of 5.5 ant. with 2 oxyg., equiv. $7 \cdot 5$.

Bezon aineral, Bezoarticum minerale. Upon butter of antimony drop slowly as much nitric acid, distil it off; and pour it on again, adding one-third fresh acid; repeat this operation, and calcine the residuum.

Magistery of diaphoretic antimony, Matcria perlata. To the water that was used in washing the diaphoretic antimony add spirit of vitriol, or some other acid, as long as any precipitate is produced, which is to be washed.

Cerussa antimonir. Regulus of antimony 2lb., purified nitre 3lb.: grind together, and proceed as for diaphoretic antimony; produce $21 \mathrm{~b}$. $130 z$. In this operation and similar ones, the admixture of the emetic flowers may be avoided by sinking the crucible deep in the coals, so that the sides, up to the very top, may be too hot for them to settle on; or they may be collected by using a tubulated earthen retort.

Carix antrionil nitratis: To 4oz. of regulus of antimony, finely powdered, add by degrees $12 \mathrm{oz}$. of nitric acid, distil to dryness; powder the mass and wash it.-Diaphoretic, in doses of gr. ij to $\mathrm{x}$; but Wilson, Course of Chemistry, p. 106, says he has known diaphoretic antimony given with good success by half an ounce at a dose, and repeated two or three times a day, and that for several days successively.

Flowers of antrmony, Flores antimonii. Throw into an ignited tubulated retort powdered common antimony by spoonsful, till as many flowers come over into the receivers as are wanted: the bottom of the retort must be very hot, and the fire kept up steadily; emetic, in doses of gr. $\mathrm{j}$ to $\mathrm{ij}$.

Argentine flowers of antriony, Flores antimonii argentei. 
Keep regulus of antimony melted in vessels which admit the air, but prevent the escape of the flowers, and afford them a cool place on which they may settle.

Grass of antimony, Vitrum antimonii, Antimonium vitrifactum, Oxidum antimonii cum sulphure vitrificatum. Roast powdered common antimony in a shallow vessel over a gentle fire, till it is of a whitish grey, and emits no fumes in a red heat, then melt it in a quick fire into a clean brownish-red glass. If the antimony has been calcined too much, it will require a litkle common antimony to be added to render it trausparent : composed of eight parts of protoxide, united with one of common antimony ; violently emetic, in doses of gr. $j$ to $i j$, and very uncertain in its operation; used in making antimonial wine and emetic tartar.

Liver of antimony, Hepar antimonii. Roast common antimony to a dull grey, and melt it; $3 s .8 d$. the $\mathrm{lb}$.

Crocus metallonum, Crocus antimonii, P. L. 1745. Common antimony and saltpetre, ana, equal weights; mix and melt.

Crocus axtrmoxis, P. L. 1788. Calx antimonii illota. Common antimony and saltpetre, of each $1 \mathrm{lb}$., common salt 1oz.; mix and melt.

Panacea antimoxir. Sulphuret of antimony $\bar{z} \mathrm{vj}$, nitre $\overline{3} \mathrm{x}$, common salt $\overline{3} j s s$, charcoal dust $\overline{3} j ;$ mix in fine powder, throw into a red-hot crucible, and keep it in the fire for a quarter of an hour, take the crucible out and let it cool, break it carefully, separate the uppermost spongy scoria, powder and wash it: when washed it should be of a fine golden colour. This panacea is the basis of Lockyer's pills.

Crocus antimonir lotus, Oxidum antimonii cum sulphure per nitratem potassa. Common antirnony and saltpetre, of each equal weights ; mix and melt, pour out, separate the reddish part from the whitish crust, reduce the former to powder, and wash it as long as it communicates any taste to the water.

These four preparations are emetic, in doses of gr. ij to viij, but uncertain and sometimes violent; used for making emetic wine, \&c., and a purge for cattle: the yellowish-red varieties contain four parts of protoxide and one of antimony ; the dark-red two parts of protoxide to one of antimony.

Purging axtrmoxy, Antimonium catharticum. Glass of antimony $40 \%$, oil of vitriol $120 \%$, digest two days, distil to dryness, wash the residue, and add to it as much Glauber's salt, and twice as much sal enixum ; melt together, powder, and wash: the most certain of all the antimonial purges, gr. ij to Jss. Used now in some nostrum.

Schwanberg's fever powder. Common antimony $1 \mathrm{lb}$, heat 
it, when ready to melt add, by degrees, hartshorn shavings 4oz., stirring it, and keep it in a red heat for some time.

Antrmonial rowner, Pulvis antimonialis, P. L. 1788. Oxidum antimonii cum phosplate calcis. Common antimony in gross powder, hartshorn shavings, ana 2lb. ; roast in an iron pot until they form a grey powder, put this into a skittle pot, with a small hole in the cover, keep it in a red heat for two hours, and grind it to a fine powder.

Dr. James's powder, Pulvis antimonialis, P.L. since 1809. Common antimony $1 \mathrm{lb}$, hartshorn shavings 2lb.; proceed as in the former. Both uncertain preparations.

Chenevix's antrmonial powder. Mercurius vitæ and phosphate of lime (obtained by dissolving burnt bones in muriatic acid, and precipitating the solution by subcarb. of ammonia water), ana, equal weights; dissolve in muriatic acid, and pour the solution into water alkalized with subcarbonate of ammonia.-Febrifuge and diaphoretic, gr. iij to viij; in larger doses, gr. $\mathrm{x}$ to $9 \mathrm{j}$, emetic and purgative; used also as an alterative in cutaneous diseases.

\section{BISMUTH.}

Magistery of bismuth, Pearl white, Fard Spanish white, Dinitrate of bismuth, Magesterium marcasitce, Bismuthi subnitras. Dissolve bismuth in nitric acid, and pour it into river or distilled water, which throws down a white poivder, to be washed and dried in the shade, and kept from the light: comp. of $20 \mathrm{ox}$. bism. 6.95 acid, and 2.25 water, equiv. 29.

OXIDE of BISMUTH, Bismuthi oxidum album. Bismuth 4lb., nitric acid q. s. about 2lb.: dissolve and precipitate by subc. of potash $4 \mathrm{lb}$., in water $6 \mathrm{lb}$.; wash the precipitate well; used as an antispasmodic, and as a cosmetic paint ; grows yellow by keeping; comp. of 9 bism, with 1 oxyg., equiv. 10.

Flores bismuthi. Bismuth lb. ss, nitre lb. j ; grind together and inject by degrees into an ignited tubulated earthen retort, with receivers annexed to catch the flowers.

\section{MANGANESE.}

Manganese, Peroxide of manganese, Tritoxide of manganese, Magnesia nigra. Found in mines; used in a small proportion to render glass colourless, or in a large proportion to colour it purple; and in chemical processes to furnish oxygen gas by distilling, or to supply oxygen to the species for muriatic acid, and thus convert it into oxymuriatic acid: comp. of 3.5 mang. with 2.5 oxyg., equiv. $5 \cdot 5$.

BLACK WAD. Found in mines; earthy; used as a paint. 
COBALT.

Cóalt BLack, Oxide of cobalt. Boil powdered bright-white cobalt ore, found in Cornwall, in nitric acid; dilute with a large quantity of water; add subcarbonate of potash water, in small successive portions, letting the solution settle, and decanting off the clear each time until it becomes of a rose colour: then add subcarbonate of potash water as long as any sediment falls, which wash and dry: used to make blue colours for painters and potters.

2. Dissolve cobalt in muriatic acid, and add subcarb. of potash water; filter and wash: used in rheumatism.

\section{METALLIC SUB-SALTS.}

GOLD.

Aurum fulminans, Oxidum auri ammoniatum. Dissolve a few grains of grain-gold in aqua regia made with common salt, or by the mixture of the acids, and add liquid ammonia, to preci. pitate the gold.

2. Dissolve gold in aqua regia made with sal ammoniac, and precipitate the gold with subcarb. of potash water; requires much care, as it explodes with the utmost violence on the least friction, or a very slight heat: its fulminating quality may be destroyed, and the gold recovered, by boiling it in oil of vitriol or oil of tartar, as also by mixing it with sulphur, and exposing it to a gentle fire, which burns the sulphur away; it first becomes purple, and then appears in its metallic form. Aurum fulminans is sedative, antispasmodic, and carminative; used in spasmodic colic, in doses of gr. iij-vj.

\section{SILVER.}

Fulminating silver, Brugnatelli's fulminating powder. Dissolve silver gr. $\mathrm{xl}$, in nitric acid $3 \mathrm{ij}$, or lunar caustic $3 \mathrm{j}$, in distilled water $\xi_{i j}$; to this solution add spirit of wine $3 \mathrm{ij}$, and boil the mixture in a retort, or flask, so that the condensed steam may run back into the boiling liquid; a white crystalline powder forms at the bottom; when no more seems to form, let it cool ; wash the fulminating silver with river water, and dry it between bibulous paper, but without heat. Explodes with the slightest friction: a small portion, about 1-3d of a grain, being put in the middle of a bit of silver paper, the edge of which is smeared with paste, a bubble of glass is then wrapped up in this paper; the bubble thus loaded will explode, if thrown upon the ground or trod upon; is a good alarm, if put in places where it may be trodden upon by thieves, \&ic. 
QUICKSILVER.

Mineral turbith, Queen's yellow, Turpethum minerale, Mercurius emeticus flavus, Hydrargyrus vitriolatus, Oxidum hydrargyri sulphuricum, Subsulphas hydrargyri flavus. Corrode quicksilver by boiling it in about an equal weight of oil of vitriol to dryness; the white mass is then flung into a large quantity of boiling water, it immediately changes to a yellow powder, to be well washed and dried; emetic in doses of gr. $\mathrm{ij}$-viij; useful in inveterate gonorrhœa; as a preservative against hydrophobia; alterative, gr. $\mathrm{j}$-ij, in leprosy and obstinate glandular obstructions; as an errhine, diffused among other powders; and a fine yellow pigment. Contains 27 peroxide of quik and 5 sulph. acid; equiv. 32.

Sweet sublimate, Calomel, Protochloride of mercury, Mercurius dulcis sublimatus, Calomelas, Hydrargyri submurias, Murias protoxydi hydrargyri, Submurias hydrargyri sublimatum. Grind 40lb. of corrosive sublimate with $30 \mathrm{lb}$. of quicksilver, sublime the grey powder; powder and wash the sublimate with boiling water. Sold for calomel and panacea mercurialis.

Calomer, Mercurius dulcis sexies sublimatus, Calomelas. Repeat the sublimation six times.

Panacea mercurialis. Repeat the sublimation nine times, that the Mercurius dulcis may be rendered still milder.

Sweet Precipitate, Protochloride of mercury, Mercurius dulcis prccipitatus, Hydrargyrus muriatus mitis, Submurias hydrargyri pracipitatum, S. hydrargyri pracipitatus. Dissolve quicksilver in nitric acid by boiling, observing to have more quicksilver than the acid will take up, pour off the solution into a boiling brine, composed of common salt equal to half the weight of the quicksilver, dissolved in water in the proportion of about half an oz. of salt to a pint: the precipitate thus produced is to be well washed and dried.

Flowers of calomel.' Distil calomel in a low retort, having a very short and wide neck, so disposed in the furnace that the neck of the retort, being too hot for the calomel to settle there, it may be driven over into a large receiver half filled with hot water, and kept so as to steam: the sublimate is in the form of a fine white powder.-Dose, as alteratives, gr. $\mathrm{j}$ - $\mathrm{ij}$ nocte maneque; if they do not pass through the bowels, they affect the mouth, which may be avoided by joining purgatives with them ; as cathartics, $\mathrm{gr} . \mathrm{v}$ to viij or $\mathrm{x}$; but calomel was formerly, and still by some persons, given in doses of $9 \mathrm{j}$; contains quik 25 , with chlorine $4 \cdot 5$; equiv. $29 \cdot 5$. 
White precipitate, Mercurius prcecipitatus albus, Calx hydrargyri alba, Murias hydrargyro-ammoniacale, Hydrargyrus pracipitatus albus, the Hydrargyrum pracipitatum album of the London Pharmacopœia, and the Hydrargyri submurias ammoniatum of the Dublin. Dissolve corrosive sublimate and sal ammoniac, ana $\overline{3} \mathrm{vj}$, in half a gallon of water, add half a pint of liq. potas. subcarb., wash the precipitate and dry.

Hydrargirum prefcipitatum albun. Corrosive sublimate $\tilde{3} \mathrm{vj}$, sal ammoniac 3 iiij, liq. potass. subcarb. half a pint, distilled water four pints, proceed as above.

SUBMURIAS HYDRARGYri AMMONIATUM. Add to the liquor poured off from the sweet precipitate in its manufacture, liq. ammonix q. s. to throw down a new precipitate; wash this with cold distilled water, and dry it on blotting-paper; confounded with sweet precipitate, does not become black when rubbed with lime water; externally, to make a detergent ointment, in scabies and other cutaneous affections.-Officinal preparations. Unguent. Hydrargyri præcip. albi., L.D.

Furminating mercury. Dissolve $100 \mathrm{gr}$. of quik in nitric acid 3 jss by meas.; pour the solution into 2oz. by meas. of alcohol, heat till an effervescence takes place; the fulminating quicksilver gradually forms as a white powder, to be well washed and dried. Used as priming for fowling-pieces.

Protophosphate of Quicksilver, Phosphas protoxydi hydrargyri. Dissolve quik in nitric acid, add a solution of phosphate of soda as long as a sediment falls, wash and dry the white sediment ; contains 26 protoxide of quicksilver, and 6.75 phosphoric acid, equiv. 32.75 ; dose, gr. ss to gr. j.

Iodate of Quicksilver, Iodas hydrargyri. Add a solution of iodate of potash to the nitric solution of quicksilver, the iodate of quicksilver falls down; resembles 'Turpethum minerale; contains 190 quik, 7.5 oxygen, and 112.5 iodic acid.

Borate of QUicksitver, Boras hydrargyri. Borax saturated with soda 265 gr., calomel 222 gr.; grind together, adding, when well mixed, a little water; then fill the mortar with water, and let the red precipitate settle, wash and dry.

2. Precipitate the solution of quik in nitric acid by a solution of borax ; white.

Nitras IIYDrargyri ammoNiato-Nitricum. Dilute nitric acid $\mathrm{lb} . \mathrm{j}$, add carbonate of ammonia-water $\mathrm{z}_{\mathrm{z}} \mathrm{vj}$; when the effervescence is over, add quik 3 viij, dissolve, evaporate, and crystallize.

Protoiodide of quicksilver, Protoiodure de mercure. Protonitrate of quicksilver $100 \mathrm{gr}$., dissolve in water $400 \mathrm{gr}$., filter, 
add solution of hydriodate of potash as long as any sediment falls, wash and dry; yellow; used to make an ointment, tincture, and pills; contains 15.5 iodine, with 25 quik ; equiv. 40.5 This preparation should be preserved in a well-stopped bottle, and kept out of the solar light. It is used for making the ointment of the protoiodurets of mercury. There are pills also of the protoioduret.

Deutolodide of quicksilver, Deutoiodure de mercure. Dissolve corros. sublim. $70 \mathrm{gr}$. in water; dissolve also hydriodate of potash, $100 \mathrm{gr}$. in water; mix the two solutions by degrees, filter, wash and dry ; crimson, contains 31 iod. with 25 quik; equiv. 56. Used to make an ointment, tincture, and pills.

COPPER.

Green bice, Malachite, Viride montanum optimum, Chrysocolla, Hemiprismatic habroneme-malachite, Green carb. of copper. Composed of 10 perox copp. 75 carb. ac. and 1.25 water; equiv. $13 \cdot 875$.

Copper gréen, Cendres bleues cuivrées, Viride montanum vulgare, Uncleavable staphylinc-malachite, Dicarb. of copper;Blue bice, Cceruleum montanum, Lapis Armenus praparatus, Prismatic azure-malachite, Blue carbonate of copper. Contains 15 carb. of copp. and $6 \cdot 125$ protohydrate of copper ; equiv. $21 \cdot 625$. All are found in mines, and prepared, by grinding and washing, for paints.

Refiners' verditer, Sander's blue, Cendres bleues, Azurum cinereum. From the solution of copper obtained in precipitating silver from nitric acid by heating it with copper; this solution is heated and poured upon whiting moistened with water; the mixture stirred for several hours every day, till the liquor. loses its colour, when it is poured off', and a fresh portion of the solution poured on, until the proper colour is obtained.

Verditer blue, Cendres bleues superfins en pâte. Solution of blue vitriol at $35 \mathrm{deg}$. Baume, 240 pints ; solution of muriate of lime, at $40 \mathrm{deg}$. Baume, 180 pints ; mix, decant the clear liquor, and wash the sediment with the washings of a former operation at 8 or $10 \mathrm{deg}$. : add the first washings to the clear muriate of copper, until it begins to fall below $20 \mathrm{deg}$. Baume, the produce will be about 670 pints. Mix $100 \mathrm{lb}$. of quicklime with $300 \mathrm{lb}$. of water, and add 70 to $85 \mathrm{lb}$. of this lime cream to the muriate of copper; trying the liquor with ammonia-water whether it gives the proper shade; if too blue, more lime cream must be added: then wash the green sediment, of which there will be about 500lb.; saving these washings. Dry a parcel of this sediment to find how much dry material it will yield. To as much moist green paste as con- 
tains 2\%lb. of dry stuff, add $11 \mathrm{~b}$. of the lime cream, and 7-10ths of a pint of peart-ash water, at 15 deg: Baume, and grind it as quick as possible in a colour mill. Dissolve $\frac{1}{4} \mathrm{lb}$. of grey sal ammoniac in 4 pints of water, and $\frac{1}{2} l \mathrm{lb}$. of blue vitriol in another 4 pints of water; put the ground colour into a stone bottle, and add at the same time the blue-vitriol-water, and the sal-ammoniac water, cork well, wax, and leave it for four days. Turn out four of the bottles into a brandy hogshead, fill it up with water, which renew once a day in winter, and twice a day in summer, for eight times, stirring up the sediment whenever fresh water is added; then stir up, and strain.-Cendres bleues fin en pâte. Put in $\frac{x}{2} l b$. lime cream, and $\frac{1}{+} \mathrm{lb}$. white sal ammoniac.-Cendres bleues no. 1 en pâte Use 2lb. of lime cream, and $\frac{1}{2} \mathrm{lb}$. of white sal ammoniac. Used in painting paper-hangings, mostly for the ground colour, but is soon altered by the sun.-Cendres bleues superfins en pierre. Dry the moist superfine blue on white wood trays.-Cendres bleues fins en pierre. The dried fine moist blue, used as a watercolour. The washings above $10 \mathrm{deg}$. Baume, are boiled to 40 deg. and, being almost entirely muriate of lime, are mixed with it. Those below 10 deg. are used to wash the first sediment, or sulphate of lime.

Verditer green. The process for refiners' verditer often miscarries, and a green colour is produced instead of a blue.

Brexswre GreEN. Dissolve blue vitriol in a large quantity of water, and add spirit of urine, or rough bone spirit, as long as any sediment falls; decant, wash and dry the sediment; the liquor is used to make sal ammoniac.

Rougn vernigris, Vert de Gréce, Diacetate of copper, AErugo, Viride eris, Cupri subacetas. Prepared by putting plates of copper into a cask between layers of vine twigs, and moistening them with sour wine; emetic internally, in very small doses; externally caustic; much used as a paint: from France, composed of 10 ox. copp. 6.25 ac. and 6.75 water; equiv. 23.

ExGisis vernigris. By corroding copper with rough pyroligneous acid and tartar.

Frugo preparata. Rough verdigris q. p. grind with water; add more, and pour off the coloured water into another vessel, where let it settle; then pour away the water, and dry the sediment, repeating this washing with the remainder, until all is either dissolved or washed over.

Scurnz.'s cirfin, Arseniate of copper. Precipitate a solution of blue vitriol 2/b. in water 6 gallons, by a solution of white arsenic $11 \mathrm{oz}$, and pearl-ash $2 \mathrm{~b}$., in boiling water 2 gallons, and wash the precipitate; produce $11 \mathrm{~b}$. $80 z$. : used as a paint. 
Schwernfurt green, Vienna green, Vert de mitis. Dissolve verdigris $1 \mathrm{lb}$. in vinegar, and pour into it a solution of $1 \mathrm{lb}$. white arsenic in water; add more vinegar to dissolve the sediment; evaporate and crystallize. The crystals are a fine bluish green.

2. Boil 10lb. of the crystals with a solution of $1 \mathrm{lb}$. of potash; this will take off the blue tinge.

Es ustum. Copper, rough brimstone, ana p. æq. laid in strata, common salt, a small quantity sprinkled on each layer, exposed to the fire till the brimstone is burned out: when one piece is rubbed against another, it ought to have a red colour like cinnabar; caustic.

LEAD.

Flake white, Fine white, Carbonate of lead, Cerussa vera, Plumbi carbonas, $P$. subcarbonas, $P$. oxidum album. Made by suspending rolls of thin sheet-lead over malt vinegar, or pyroligneous acid, in close vessels, the evaporation from the acid being kept up by the vessels being placed in a heap of dung, or a steam bath.

Nottingham white. Made with alegar; does not discolour so soon as the common.

Newcastle white. Made with molasses vinegar.

Grace's white Lead. Made with the refuse water of the starch-makers, the phlegm obtained in distilling rough turpentine, brewers' grains, and exhausted hops, and any other similar matters.

French white lead, Blanc de plomb. Dissolve litharge in dilute acetic acid, and pass carbonic acid gas through the solution. Fine white lead is astringent, cooling; used externally, or employed as paint, mixed with nut or old poppy oil; it should be completely soluble in nitric acid, and the solution should not yield a precipitate when added to a solution of sulphate of soda ; contains 14 protox. lead, with $2 \cdot 75$ carb. acid; equiv. $16 \cdot 75$.

Wiluminson's white. Grind litharge with sea water, until its whiteness does not improve.

Mineral white. Dissolve lead or litharge in nitric acid, add a solution of subcarb. of potash, as long as any sediment falls; wash and dry.

White precipitate of Lean, Sulphate of lead. Litharge $1 \mathrm{lb}$., strong nitric acid 4oz., water 8oz.; after some time decant, add oil of vitriol as long as a sediment falls : pour off the liquor back on the litharge. A fresh solution will take place, and this may be continued until the whole of the litharge is changed into the white precipitate. Used as a white colour in miniature painting, being both beautiful and durable. 
Patent yer.low, Muriate of lead, Chloride of lead.' Common salt $1 \mathrm{cwt}$., litharge $4 \mathrm{cwt}$, ground together with water, kept for some time in a gentle heat, water being added to supply the loss by evaporation, the subcarb. of soda then washed out with more water, and the white residuum heated till it acquires a fine yellow colour: used as a paint.

NAPLES ret.low. Lead llb. and a half, common antimony 1lb., alum and common salt of ea. 1oz.: calcined together.

2. Flake white 12oz., diaphoretic antimony 2oz., calcined alum half an oz., sal ammoniac loz., calcine in a covered crucible, with a moderate heat, for three hours, so that at the end of that it may be barely red-hot: with a larger proportion of diaphoretic antimony and sal ammoniac, it verges to a gold colour. Used as a yellow colour.

\section{InON.}

Prussian blue, Cyamuret of iron, Hydrocyanate of iron, Caruleum Berolinense. Argol and saltpetre, 2lb. of each, throw by degrees into a red-hot crucible. Dry bullock's blood over the fire, in an iron pan, mix 2lb. of this dry blood with the prepared salt, calcine it in a crucible till it no longer emits a flame; then dissolve common alum $4 \mathrm{lb}$. in water 26 pints, and strain the solution; dissolve also dried green vitriol $11 \mathrm{~b}$. in water 4 pints, and strain while hot; mix the two solutions together while boiling-hot; dissolve the alkaline salt calcined with blood in 30 pints water, and filter through paper supported upon linen; mix this with the other solution, and strain through linen: put the sediment left upon the linen, while moist, into an earthen pan, and add spirit of salt $11 \mathrm{~b}$. and a half, stir the mass, and when the effervescence is over, dilute with plenty of water, and strain again; lastly, dry the sediment. Used for preparing the cyanuret of mercury.

2. Mix 1lb. of Dantzic potash with 2lb. each of dried blood and horns, put it into an iron pot, and keep it in a red heat till it no longer flames or smokes; take out the pasty mass, when cold dissolve it in water, filter, evaporate, crystallize, and redissolve the crystals in a pint and half of water. Then take green vitriol 1lb., common alum 1lb. to $4 \mathrm{lb}$, nix and dissolve them in a good quantity of water, by boiling, and filter while hot; precipitate this solution by the solution of prepared alkali, and filter. 'The precipitate will be the darker the less alum is added; but at the same time it will be greener from the great admixture of the oxide of iron which is precipitated, and which must be got rid of by adding, while it is moist, spirit of salt, diluting the mixture with water, and straining.

3. Precipitate a solution of green vitriol with the solution of prepared alkali, and purify the precipitate with spirit of salt; pre- 
cipitate a solution of common alum with a solution of subcarb. of potash: mix the two sediments together while diffused in warm water, strain and dry: a fine blue colour, but apt to turn red.

Prussian green. The sediments of the two first processes for making Prussian blue, before they have had the muriatic acid added to them.

2. Pour oxymuriatic acid upon fresh precipitated Prussian blue.

Burnt Prussian blue. From Prussian blue heated in a crucible; it is as good a colour as mummy, and dries so well as to require no drying oil to be mixed with it.

Borusstas ferri. Prussiate of iron. Calcine together dried blood 3 xij, subcarb. potash 3 iiij, and iron filings $\overline{3} s s$; dissolve the calcined mass in hot water, add vinegar as long as any sediment falls; filter; add a solution of green vitriol as long as any borussiate is precipitated; filter and dry. Used in intermittent fevers, gr. iv to vj, ter quotidie.

Phosprias ferri. Dissolve iron turnings in muriatic acid, and precipitate by adding phosphate of soda as long as any sediment falls, which wash and dry: blue.

Oxyphosphate of iron, Phosphas tritoxydi ferri. Dissolve colcothar, or any red oxide of iron, in dilute muriatic acid, and precipitate by phosphate of soda: white. Both are given from $\mathrm{gr} \cdot \mathrm{x}$ to gr. $\mathrm{xv}$, in cancer and scrofula.

Chalybs preparatus cum aceto. Steel filings wetted with white wine vinegar, dried in the sun, and this frequently repeated; then levigated.

Rust of IRon, Ferri rubigo, Limaturce ferri praparatce Chalybis rubigo, Carbonas ferri praparatus. Iron filings, or iron wire, exposed to the air, and frequently moistened with water, to which a small quantity of vinegar may be added; then ground to powder and washed over.

Ferr r carbonas, $C$. ferri precipitatus. A solution of $40 z$. of green vitriol in water is precipitated by another solution of 5 oz. of subcarb. of soda in water, the precipitate is washed with warm water, and dried without exposure to the air, that it may retain its green colour.

2. By precipitating the solution of green vitriol with subcarb. of potash, performing the process in hot water, and drying it by steam. The preparations of iron are used as tonics in cancer, scrofula, and in neuralgic affections.

Ioduret AND Hydriodate of IRoN. Mix 126 parts of iodine, and from 40 to 50 parts of clean iron filings in a flask with 1500 parts; let heat be applied till the mixture becomes clear, after which filter. The liquor is a solution of bydriodate 
of protoxide of iron. By evaporating the solution nearly to dry: ness, the acid and oxide are decomposed, water is formed, and a solid combination of iodine and iron remains, containing 126 parts, or one atom, of the former, and 28 parts, or one atom, of the latter. The ioduret of iron is deliquescent; when pure it is of an iron-grey colour, brittle and crystalline in texture like antimony; when dry, it is inodorous, and when moistened, it exhales the odour of iodine. Dr. Thomson, who was the first to use this preparation medicinally, administers it in those cases in which the capillary system requires to be stimulated, and the tone of the habit to be brought up to the healthy standard. The dose is 2,3 , or 4 grains in distilled water, three or four times daily. It is stimulant, tonic, and aperient; it has been found serviceable in amenorrhœa and leucorrhœa; from its supposed influence in improving the hematosis, it has been given in phthisis.

Ferri subcarbonas, P. L. 1815. Precipitate a solution of $80 z$. of green vitriol in water, by a solution of $60 z$. of subcarb. of soda.

\section{COBALT.}

Cobalt BLeE. Wash llb. zaffre to separate as much of the sand as possible; pour on it 8oz. nitric acid, diluted with an equal weight of water; digest for some hours, pour off the solution, and add fresh acid to the zaffre as long as it seems to extract any colour from it; mix the coloured solutions, evaporate nearly to dryness, dissolve in warm water, filter the liquor, add to the filtered nitric solution of the zaffre a solution of phosphate of soda as long as any sediment falls. Wash this violet subphosphate of cobalt, and mix it while still wet with 8 times as much alumine fresh precipitated (from alum-water by a more than sufficient quantity of liquid ammonia), well washed and still wet. Stir till the colour is yuite uniform, then dry, and lastly, heat it cherry-red in a crucible.

2. Dissolve regulus of cobalt, or bright white Cornish cobalt ore previously roasted, in nitric acid, and proceed as already prescribed.

3. Precipitate the nitrate of cobalt by a solution of arseniate of potash ; and mix this precipitated arseniate of cobalt with sixteen times as much moist alumine.

4. Mix the nitric solution of cobalt or zaffre at once with freshmade alumine; this is of a good blue colour.

5. Precipitate the nitric solution of cobalt or zaffre with a solution of ammonia alum; this is paler than the rest.

\section{CHROMIUM.}

Criromate of iron. Found in masses in the Shetland Isles, 
and in mines, black, hard enough to cut glass, with an imperfect metallic lustre. Used for making chrome yellow.

Chrome yellow, Chromate of lead. Frepared from chromate of iron, by heating it with nitre or pearl-ash; washing the mass, and mixing the ley with a solution of lead in nitric acid, or of sugar of lead in water; it should not effervesce with nitric acid; used as a gold-colour paint.

\section{METALLIC SALTS.}

GOLD.

Muriate of gold, Chloride d'or, Murias auri, Chloruretum auri. Grain gold $3 \mathrm{j}$, nitric acid at $36 \mathrm{deg}$. Baume $3 \mathrm{j}$, muriatic acid at 22 deg. Baume ziij; dissolve with heat until the smell of chlorine gas is perceivable, then set it by to crystallize. Used in venereal complaints, and as a caustic in cancerous affections.

Solution of Muriate of GoLD, Hydrochlorate d'or en solution. Dissolve the muriate of gold in water. Used to discover oil in distilled waters.

Soda muriate of gold, Chloruretum auri et sodii, Aurum muriaticum natronatum.' Grain gold $z^{\mathrm{ij}}$ make into muriate of gold, dissolve the crystals in water $3 \mathrm{x}$; add a solution of decrepitated salt 3 ss in water $3 \mathrm{vj}$, evaporate and crystallize. Dose gr. 1-8 to gr. ij rubbed into the gums, in syphilis; very uncertain in its action; it has recently been found serviceable in scrofulous affections, either by frictions or internally in the form of pastilles or pills, or mixed up with extracts.

\section{PLATINUM.}

Soda muriate of platinum, Chloruretum platini et sodii. Dissolve platinum $3 j$ in aqua regia, q. s. and crystallize; dissolve the crystals in water, and add a solution of decrepitated salt $3 \mathrm{ij}$ in water; evaporate and crystallize. In syphilis gr. $\mathrm{lj}$ rubbed into the gums.

Nitro-muriate of platinum, Hydrochlorate of platinum. Platinum in small granules $3 \mathrm{j}$, add nitric acid $3 \mathrm{j}$, and muriatic acid 3 iij: when the reaction has ceased, pour off the acid, and pour on fresh; repeat this until the whole of the platina is dissolved, which will require about $20 \mathrm{oz}$. of the aqua regia; evaporate and crystallize.

Solution of nitro-muriate of platinum. Dissolve the crystallized nitro-muriate in water; used to distinguish solutions of potash from soda. 


\section{SILVER.}

Lunar crystals, Nitrate of silver, Crystalli henares. Dissolve silver $\overline{3}^{\mathrm{ij}}$ in nitric acid at $33 \mathrm{deg}$. Baume, 亏3iiij, and crystallize; tonic, antispasmodic, and hydragogue: sometimes causes the skin to turn purple, or black, even after the use of the medicine has been left off for some time; administered in chorea and epilepsy ; externally to cicatrize ulcers; as an application to erysipelas, and as a gargle in ulccrations of the fauces. The dose gr. $\frac{1}{6}$ to gr. 1, in a pill with crumb of bread.

Solution of nitrate of silver. Crystallized nitrate $3 \mathrm{j}$, water $\overline{3} \mathrm{v}$; dissolve. Used as a test for muriatic acid.

Lunar caustic, Causticum lunare, Argentum nitratum, Argenti nitras. Formed by dissolving pure silver in spirit of nitre, evaporating to dryness, melting and pouring the melted mass into moulds, which may be made by thrusting a greased stick into a piece of clay; deliquescent. Used as a caustic; as an astringent wash in solution, and as a tonic and antispasmodic internally, in doses of $1-4$ to iij grains; cont. 6.75 nitric acid, with 14.75 of silver; equiv. $21 \cdot 5$.

\section{COPFER.}

Bue vitriol, Blue stone, Couperose bleu, Sulphate of copper, Vitriolum caruleum, Cupri subhas. Made by roasting copper, boiling the oxide in oil of vitriol, washing the residuum, evaporating and crystallizing. This substance is tonic, emetic, astringent, and escharotic; and has been found of use in epilepsy, hysteria, and intermittent fever; and also to produce vomiting in incipient phthisis : externally as a stimulant to ulcers, and to take down fungus. A weak solution is sometimes used as a collyrium in ophthalmia. Dose, gr. $\frac{1}{4}$ to gr. ij in a pill $=\mathrm{gr}$. ij to gr. $\mathrm{x}$ in f. 3ij of water vomits. The incompatibles are alkalies, earths, and their carbonates; salts of lead, acetate of iron; astringent vegetable infusions and tinctures.

2. By moistening plates of copper, covering them with rough brimstone, calcining, washing out the salt, evaporating and crystallizing. In large blue crystals; tonic, astringent, in doses of gr. ss to $\mathrm{ij}$; emetic, gr. ij to $\mathrm{x}$; externally escharotic. Used in dyeing, to increase the brilliancy of yellow browns: liquid gallic acid will show if it contains iron. Contains 5 perox. copp., 5 sulph. acid, with $5 \cdot 625$ water; equiv. $15 \cdot 625$.

Pale riug vitroo.. By mixing a little nitric acid with the oil of vitriol and twelve times as much water, the solution of the copper is easily performed, but the crystals are pale.

Toonuswoo, Cyprische vitriol von der Compagnie, $V$. Cyprium ex India, $V$. Cyprium, $\mathrm{Ph}$. Bat. In very large sky-blue crystals. 
From Pegu; used in India, and brought to Europe by the Dutch.

Roman vitriol, Cyprian vitriol, Vitriol de Chypre, $V$. Cyprium. Made by letting the water of copper-mines evaporate in shallow ponds. From Cyprus, in small sky-blue crystals.

Swedische vitriol, Faln viktril, $V$. triplum. Made by evaporating the water of the copper-mine at Fahlun; blue rather than green. Contains iron, copper, and zinc; does not copper iron by being rubbed upon it: nine shades of colour are made. -

Goslar blue vitriol, $V$. cupratum. Pale blue-green crystals, very large and transparent, having the form of those of pure sulphate of iron. Contains both copper and zinc.

Hungarian blue vitriol, $V$. Hungaricum. By evaporating the water of copper-mines.

Solution of Sulphate of Copper, Bhe vitriol water. Blue vitriol purified by repeated solutions and crystallizations $\overline{3}$, water $3 \mathrm{v}$; dissolve. Used as a test for arsenic.

Ammonia sulphate of copper, Cuprum ammoniatum, Ammoniuretum cupri. Blue vitriol 3 iv, subcarb. of ammonia $3 \mathrm{vj}$; grind together, and dry by means of filtering paper ; tonic, antispasmodic. Used in epilepsy and chorea, gr. ss, gradually increased to gr. v.

Solution of ammonia sulphate of copper. Pour into a solution of blue vitriol as much subcarbonate of ammonia-water as is necessary, first to precipitate the oxide of copper, and then to redissolve it again; add to the liquor its own weight of alcohol, to throw down the crystals of the ammonia sulphate; dry, and dissolve in water. Used as a test-liquor for arsenic.

Blue eye-water, Aqua sapphirina, Aqua cupri ammoniati, P. L. Lime-water $\mathrm{lb}$. j, sal ammoniac $3 \mathrm{j}$; mix, and let them stand upon a small piece of clean copper till they acquire a fine blue colour.

Liquor cupri ammoniati. Cuprum ammoniatum 3j, water $\mathrm{lb} . \mathrm{j}$; dissolve and filter.

Aqua cupri ammoniati, P. D. Lime-water žviij, sal ammoniac $3 \mathrm{ij}$, verdigris gr. iiij; digest for a day, and pour off the clear; a slight stimulant and escharotic; used to ulcers, and diluted to remove specks on the cornea, also as a show-liquor in chemists' windows.

Frencil verdigris, Distilled verdigris, Acetate of copper, Atrugo crystallisata, Crystalli Veneris. Dissolve verdigris in distilled vinegar, and crystallize; 3ss daily to a glandered horse produced no visible effect or inconvenience. From France. 
ENGLISH vERDIGRIS. Blue vitriol 24oz. dissolved in water, sugar of lead $30 \mathrm{oz}$. and a half, also dissolved in water; mix the solutions, filter, crystallize by evaporation; yields about $10 \mathrm{oz}$. of crystals: a superior paint to rough verdigris.

Solution of acetate of copper. Dissolve French verdigris in water to saturation. Used as a test-liquor for sulphur and gold.

\section{InON.}

Protosulphate of rnon, Sal Martis, Ferrum vitriolatum, Ferri sulphas. Dissolve iron turnings in dilute sulphuric acid, eraporate and crystallize; tonic, emmenagogue, anthelmintic, gr. $\mathrm{j}$ to $\mathrm{v}$. Used in glysters against ascarides; contains 4.6 protox. iron, 5 sulph. acid, with $7 \cdot 875$ water; equiv. $17 \cdot 3 \% 5$.-Officinal preparation. Mist. ferri comp, $L$. Pil. ferri comp., $L$.

Copperas, Commercial sulphate of iron, Green vitriol, Conperose verte. Vitriolum viride, $V$. vulgare Anglicanum, $V$. ferri, Ferri sulphas venale. Made by allowing martial pyrites to effloresce, washing out the salt, boiling along with old iron, evaporating and crystallizing. Contains muriate of iron; crystals small, pale green, become covered with a yellow efflorescence by drying: this is prevented by dipping them into treacle-water, which covers them with a kind of varnish: colour darkened by dipping in a decoction of Turkey berries. Used in dyeing black, making ink, and in various trades.

Vitriol de Rome, Vitriolum Romanum, P. Bat. In large crystals, deep green. From the residuum of pyrites distilled for brimstone, or set on fire.

Pisax vitriol. Resembles the Roman, but the crystals are smaller and greener; preferred by black dyers and hat-makers; probably the basis of the Genoa black. Made near Pisa.

Goscar vitriol, $V$. ferratum. Sulphate of iron and zinc, pale, greenish.

Saltzbuigir vitriol, $V$. hermaphroditicum. Bluish green, of several shades; contains both copper and iron; coppers iron.

Huxgalian vitriol, $\boldsymbol{r}$. Hungaricum, P. Bat. Deep green; contains copper.

Daxtzic viturol. Green, not quite so deep as the Hungarian; contains copper and iron, but no muriatic acid; coppers iron.

Solutrox of protosulphate of mon, Copperas-uater. Protosulphate of iron 3 drachms, distilled water 10 drachms; dissolve. Used as a test for gold, oxygen gas in water, prussic acid, and gallic acid: it is speedily altered by the air: also to blacken leather. 
Persulphate of iron, Tritosulfate de fer, Persesquisulphate of iron. Calcine copperas in the open air, moistening it with a small quantity of nitric acid: wash the powder, and keep the red solution as a test for prussic acid, gallic acid, and boletic acid.

Vitriol calcined white, Vitrioleum ad albedinem calcinatum, Sulphas ferri exsiccatum, Sulphas ferri exsiccatus. Green vitriol heated in an unglazed pot, or spread upon the top of a furnace, or in a sunny place, until it is white, and grows red at the edges; astringent, drying.

Ferrum tartarizatum. Rub iron filings 1 lb, with cream of tartar 2lb., and water 1lb. ; expose to the air for a week, dry, powder; add water $1 \mathrm{lb}$, expose again to the air for a week, dry, and powder.

Tartarum ferri. Carbonas ferri (or rust of iron) 1 oz., cream of tartar, 2oz., water 1lb.; boil, filter, cool, filter again, evaporate to a pellicle, cool; it will form a saline mass, which is to be powdered: tonic and diuretic, $g r . x-3$ ss.

LIQUOR FERRI ALKALINI. Iron 3ijss, dissolve in spirit of nitre $3 \mathrm{ij}$, distilled water $3 \mathrm{vj}$; add by degrees aqua subcarb. pot. $\overline{\xi j}$; let it stand, and pour off the clear: these are tonic and emmenagogue, 3ss-3j, bis terve die.

Tinctura martis Glauberi. Iron filings, crude tartar, ana $\mathrm{lb}$. iij, boil in water lb. xxxvj to 2 gall.; filter while hot, and evaporate to $\mathrm{lb} . \mathrm{v}$; tonic, emmenagogue, and deobstruent.

Acetas ferri. Protoxide of iron ziv, distilled vinegar ziij; dissolve and strain : tonic, astringent.

Iron LIQUOR, Acetate of iron. Leave old iron in a cask of vinegar or sour beer.

2. Leave old iron in rectified pyroligneous acid at $3 \mathrm{deg}$. Baume, for three or, four days, or till it comes to $10 \mathrm{deg}$; ; then draw off and evaporate the solution to $14 \mathrm{deg}$. : the tar deposited on the remaining iron may be burned off whenever it hinders the solution.

3. Mix a solution of acetate lime with a sol. of copperas. Used in dyeing black and browns.

Ens Martis, Flores salis ammoniaci Martialis, Flores Martiales, Murias ammonice et ferri. By subliming with a quick sudden heat sal ammoniac, rubbed with twice its weight of iron filings or colcothar, and repeating the sublimation with fresh salt, as long as the flowers are well coloured.

Ferrum ammoniatum, P. L. since 1819. Subcarbonate of iron $\mathrm{lb} . \mathrm{j}$, dissolve in muriatic acid $\mathrm{lb} . \mathrm{j}$; evaporate to dryness, add sal ammoniac lb.j, and sublime.

2. Dissolve iron in spirit of salt, and water and sal ammoniac, 
then evaporate to dryness; gr. iij-xv; useful in glandular enlargements of the breasts, chlorosis, \&c. This is a muriate of ammonia and iron, is of an orange-yellow colour, and has an odour resembling that of saffron. It is very soluble; an ounce of water dissolving four drachms of it; it is also very soluble in alcohols. Alkalies and their carbonates, as also lime water, are incompatible with it. It is tonic, emmenagogue, and aperient. - Officinal preparation. T'inct. ferri ammoniat.

\section{QUICKSILVER.}

Hydrargyrus acetatus, Acetas hydrargyri, Acetis hydrargyri. Quicksilver 1lb., diluted spirit of nitre q. s. to dissolve it ; precipitate with subcarb. of potash-water, wash and dry the precipitate; then dissolve it in spirit of verdigris q. s.; filter, evaporate to a pellicle, and crystallize; antivenereal, gr. j, nocte maneque, increasing the dose gradually.

2. Quicksilver, diluted spirit of nitre q. s.; dissolve it without heat; dissolve also Kali acetatum ziij, in boiling water 1 gall.; mix the two solutions, set them to crystallize, and wash the crystals.

Corrosive sublimate, White mercury, Oxymuriate of quicksilver, Perchloride of quicksilver, Mercurius corrosivus sublimatus, M. c. albus, Hydrargyrus muriatus, Hydrargyri oxymuirias, Murias hydrargyri corrosivus, Hydrargyrum muriaticum corrosivum. Quik 1lb., dissolve in nitric acid about $1 \frac{1}{2} l \mathrm{lb}$.; evaporate to dryness, add decrepitated salt and vitriol calcined white, of each 1lb.; mix and sublime; or, which is still better, distil from a very low retort, having a wide short neck, into a large receiver: the greater part will come over in the form of a fine white snow. In a bolt head, the newly-condensed sublimate, being liquid, runs down to the bottom, and has got to be raised over again. It took twelve hours to sublime $31 \mathrm{lb}$. in a bolt head; but in a retort $6 \mathrm{lb}$. came over in two hours. Composed of 25 quik and 2 chlorine; equiv. 34.-Officinal preparation. Liquor hydr. oxymuriatis, L.

2. Boil quicksilver 2lb. in oil of vitriol 2lb. to dryness; when cold, add common salt 3lb. and a half, and sublime.

3. Boil quik 1lb., with oil of vitriol 7lb. to dryness; weigh, and add salt and black oxide of manganese, of each the same weight ; sublime.

4. Quicksilver 2lb., spirit of salt 2lb, spirit of nitre $11 \mathrm{~b}$.; distil.

5. Dissolve red precipitate in spirit of salt, and crystallize; antisyphilitic, acting quickly, but not permanently, gr. 1-8th to j, twice a day; in gargles, gr. iij to water 1lb., or as a wash in itch; $3 i j$ a day to a horse, diuretic, enlarging the kidneys, and 
rendering them diseased: in some salivation was produced, in others inflammation, in all debility.

Venetran sublimate, Dutch sublimate. Green vitriol calcined red $400 \mathrm{lb}$, nitre and common salt ana 200lb., quicksilver $280 \mathrm{lb}$, residuum of a preceding operation, or of aquafortis, 50lb., impure corrosive sublimate of a preceding operation 20lb.; moisten with a portion of the acid that distilled over in a former process, and sublime.

Solution of corrosive sublimate, for testing. Corr. subl. $3 \mathrm{ij}$, distilled water $3 \mathrm{x}$, dissolve, and keep in the dark. Used to discover albumen, and also lime and ammonia.

Sal alembroth, Sal sapientice. Corrosive sublimate, sal ammoniac ana p. æq., water q. s. to dissolve them; evaporate and crystallize.

Protonitrate of Quicksilver. Quicks. $1 \mathrm{oz}$. dissolve in nitric acid diluted five times its weight of water; dry the crystals between filtering paper, redissolve in water, and keep a globule of quik at the bottom of the bottle: a test for ammonia, muriatic acid, phosphoric acid, sulphuric acid, gold, and platinum.

Prussiate of Quicksilver, Cyanure de mercure. Red precipitate $1 \mathrm{oz} .$, Prussian blue $2 \mathrm{oz}$., distilled water, $6 \mathrm{oz}$.; boil for half an hour, filter, pour on fresh water, boil, and filter; mix the two solutions, evaporate and crystallize: antisyphilitic, $Э \mathrm{j}$, taken in distilled water.

\section{LEAD.}

SugAR of LEAD, Lead saccharum, Saccharum Saturni, Cerussa acetata, Acetis plumbi, Plumbi acetas, Superacetas plumbi. Fine white lead 1lb., distilled vinegar 12lb. ; boil, filter, evaporate to 50 deg. Baume, and crystallize: the manufacturers use litharge, and the Dutch use distilled cider vinegar, as the least oily; internally, gr. iij-vij, as a specific in hooping cough; and also in visceral hemorrhages, in which cases it is combined with opium. Dose in this latter case is gr. ss. to gr. jss. made into a pill with gr. ss. of opium and crumb of bread. Externally, gr. iij to water $3 j$, as an eye-water; $3 j$ to water $z v$, as a strong lotion, or $3 \mathrm{x}$ for a weak: $12 \mathrm{oz}$. given to a horse was slightly diuretic, without any inconvenience.-Officinal preparation. Ceratum plumbi acetatis, L. E. D. Acidum acetosum forte, $E$. Solutio acetatis zinci, $E$.

2. Purified pyroligneous acid at $80 \mathrm{deg}$. Baume 65lb., litharge 58lb., water q. s. produces $75 \mathrm{lb}$. of fine saccharum; the mother water retains $25 \mathrm{lb}$, and may be used for another operation with advantage. Contains 14 protox. of lead, 6.25 acid, and 3.375 water; equiv. $23 \cdot 635$.

Goulard's extractum Saturni, Aqua lithargyri acetati, 
Liquor plumbi acetatis, Liquor subacetatis lithargyri. Litharge $\mathrm{lb}$. ij, distilled vinegar 1 gall., boil to $\mathrm{lb}$. vj; let it settle, and pour off the clear; fouls the bottles very much, cannot be cleared off with subcarb. of potash, requires oil of vitriol or aquafortis; cooling, astringent: used to make white-wash.

Saturnus acetosus, Pulvis extracti Saturni. Extract of lead eraporated to dryness. - Subacetate of lead. Sugar of lead $3 \mathrm{x}$, litharge $3 \mathrm{xv}$, water $3 \mathrm{xxv}$; boil to a half, and crystallize. Used to separate colouring matter from fermented liquors, and set free the alcohol.

Nitrate of Lead. Dissolve litharge, or fine white lead, in nitric acid, sp. gr. 1.3, and crystallize. Used for preparing nitrous acid.

TIN.

LAC SPIRIT. Muriatic acid (sp. gr. 1·19) 60lb., tin 3lb.; dissolve. Used in dyeing with lac dye.

Dyers' spirit. Dyers' aquafortis 28lb., tin 4lb.; dissolve gradually, stirring frequently. Used in dyeing with lac dye; if for cochineal less tin is used.

2. Nitric acid 20lb., sal ammoniac 10lb.; dissolve, add tin q.p. which dissolves without effervescence. Used by the French dyers for cochineal.

MURIATE: of tin, Ifydrochlorate of tin. Muriatic acid at 25 deg. Baume $4 \mathrm{oz}$. , grain tin $1 \mathrm{oz}$; dissolve, evaporate, crystallize, redissolve, recrystallize, and redissolve. Used as a test for molybdic acid, platinum, corrosive sublimate, albumen and tannin.

SPELTER.

White vitriol, Galitzen stein, White copperas, Vitriolum allum, Zincum vitriolatum. Obtained at Goslar, by quenching the roasted silver ores in troughs of water, evaporating this water, setting it by to crystallize, melting the crystals, skimming off the impurities, pouring the melted mass into wooden boxes, and disturbing the regular crystallization by frequent stirring. Contains $5 \% 25$ ox. of zinc, 5 acid, and 3.875 water; equiv. 13.625. Used as a dryer of oil paint.

Vitrlolum albem depuratum, Sal vitrioli, Zincum vitriolatum purifucatum, Zinci sulphas, Sulphas zinci. Dissolve zinc in oil of vitriol much diluted with water, and crystallize.

2. White vitriol q. p. dissolve in water, add oxide of zinc, digest for some hours; filter, evaporate, and crystallize : tonic, astringent, and antispasmodic, gr. $\frac{1}{2}-\mathrm{ij}$; emetic, and operating very quickly, gr. $x$ to 3 ss; externally astringent. Contains $5 \cdot 25$ 
ox. of zinc, 5 acid, and $7 \cdot 875$ water; equiv. to $18 \cdot 125$; does not dry oil colours.

Solutio acetitis zincr. White vitriol $3 \mathrm{j}$, dissolve in distilled water $\overline{3}$; sugar of lead Эiiij, dissolve in distilled water $\overline{3}$; mix and filter; astringent; used as a collyrium and injection.

\section{ANTIMONY.}

Butter of Antrmony, Butyrum antimonii, Oleum antimonii, Murias antimonii, Causticum antimoniale. Common antimony, corrosive sublimate, ana p. æq.; grind together; distil in a widenecked retort, and let the buttery matter that comes over run in a moist place to a liquid oil.

2. Antimony calcined to greyness, or powdered glass of antimony $9 \mathrm{oz}$., common salt $32 \mathrm{oz}$., oil of vitriol $24 \mathrm{oz}$., water $16 \mathrm{oz}$; distil : this yields $40 \mathrm{oz}$. of butter of antimony.

3. Common antimony, or glass of antimony $1 \mathrm{lb}$, common salt 4lb., oil of vitriol 3lb., water '2lb.; distil.

Antrmonium muriatum. Liver of antimony 1lb., dry common salt 2lb.; mix, and add them to oil of vitriol 1lb.; distil. Caustic, but apt to spread; used, however, largely by the farriers.

Emetic tartar, Emetique, Tartarus emeticus, Tartarum emeticum, Tartras antimonii. Crocus metallorum, white tartar, ana 4lb.: boil them in water, filter, evaporate to a pellicle, and crystallize.

2. Boil $8 \mathrm{lb}$. of common antimony with $16 \mathrm{lb}$. of oil of vitriol in an iron pot to dryness, wash the grey mass until the uncombined sulphuric acid is carried off; mix it with an equal weight of crude tartar, boil in water, and crystallize.

Antimonium tartarizatum. Crocus of antimony 3lb., cream of tartar 4lb., water 4 gallons: proceed as usual.

Tartarum antimoniatum. Oxyd. antim. nitro-muriat. $3 \mathrm{ij}$, cream of tartar $\overline{3} i j s s$, distilled water 3 xviij : proceed as before.

Antmonium tartarizatum. Glass of antimony, cream of tartar, ana 1lb., water 1 gallon; boil, filter, and crystallize. This is emetic, sometimes cathartic, diaphoretic, expectorant, alterative, and rubefacient. As an emetic, the dose is gr. $\mathrm{j}$-iv. in solution; as a diaphorctic and expectorant, gr. $\frac{1}{8}$ to gr. ${ }^{\overline{2}}$. Alkalies, earths, and their carbonates, as also strong acids, decoctions of bitter and astringent vegetables are incompatible with $i$ t.-Officinal preparation. Liquor antimonii tartarizati, $L_{0}-$ Vinum tartratis antimonii, $E$. 


\section{EARTHS AND ALKALIES.}

\section{EARTHS AND CLAYS.}

Terra lemia alba. Dirty white, with a grey cast, very heavy, rough, harsh, not colouring, burns very hard, outwardly dark brown, inwardly brownish yellow; used in dysenteries and malignant fevers.

Bolus Armfna alBa. Bright white, compact, very smooth and soft, not colouring, burns very hard, and at last forms a whitish grey glass; sudorific.

Bolus candida, Axungia lune. Pearly white, light, smooth, not unctuous nor colouring; burns to a very pale whitish yellow; astringent, cordial.

Tobacco-pipe clay, Argile d’Abondant, A. de Montereau, Cimolia alba. White, smooth, unctuous, slightly colouring, burns rather hard, and very white: used to make tobacco-pipes and white stone-ware.

Waite lumber stone, Terra sigillata alba, Terra Samia vulgaris. Tobacco-pipe clay, made into cakes with a stamp; used as an astringent, and to take grease out of woollen cloth.

Sonp-rock, Spanish chalk, Paratonium, Creta Hispanica, C. sartoria. White, firm, compact, weighty, hard, smooth, unctuous, not colouring, burns to a stone; writes upon glass, and if rubbed off, the marks become again visible by breathing upon the place: used by tailors to draw their patterns, to take out grease spots, and to engrave upon, the engraving being afterwards hardened by fire.

KAor.1s, Porcelain clay. Dry, friable, infusible. That of Cornwall used to make English china and fine pottery; that of Limoges to make Sevres china, and exported to Copenhagen for the same purpose; that of Passau, to make Vienna china.

Terra Cimolia. White, compact, smooth, colouring, burning rather harder; found in the island Argentiere: used to wash clothes.

Cимгк, Creta, C. argentaria. White, soft, marking lines; when newly burned, it grows hot with water, and falls into powder; antacid: used in heartburn, gr. $x$ - $3 i j$; externally absorbent, and as a crayon.-Hard chalk. Coarss.

Wniтsis, Spanish white, Blanc d'Espagne, Blanc de Troyes, Calcis carbonas preparata, C'reta praparata. From soft chalk, 
by washing and making into large balls for cheap white paint, or into small drops for medical use.

Creta precipitata. Precipitate a solution of muriate of lime by a solution of subcarb. of soda in water, and wash the sediment.-Officinal preparation. Mistura cretæ, L. E. ; Hydrargyrum cum creta, $L_{\text {. }}$; Pulvis cretæ compos., L. E. ; Pulvis opiatus, $E$.

Magnesia alba, Subcarbonate of magnesia, Magnesia, P. D. Magnesia carbonas, M. subcarbonas. Obtained by precipitating the bittern, or liquor, left in the boiling of sea-water after the common salt has been separated, by a ley of wood ashes or subcarb. of potash. With respect to its use, it is antacid, and laxative when it meets with an acid, and may be given in the dose of 3 ss to $3 \mathrm{ij}$ in water.-Officinal preparation. Magnesia, L. E. D.; Hydr. cum magnesia, $D$.

2. Epsom salt 12 oz., potas. subcarb. 9 oz., water 3 gall. ; mix: is a mixture of the hydrate and carbonate of magnesia.

Hrinry's Magnesia. Epsom salt 56lb., dissolve in water, and precipitate with subcarb. of soda, q. s. dissolved in water; wash the sediment well, and finish the washing with rose-water. Subcarbonate of magnesia is made up while drying, either into large cubes with the edges bevelled, or in small dice : is powdered by being rubbed through a sieve; antacid, laxative, lithontriptic, 3ss-3ij; mixes well with milk, but not with water, sometimes occasions flatulence.

Calcined inagnesia, Oxide of magnesium, Magnesie caustique, Magnesia usta, Magnesia, P. L. and P. E. Expose subcarb. of magnesia to a red heat for two hours, or until it exhibits a peculiar luminous appearance: produces about half its original weight ; antacid, laxative, $3 \mathrm{ss}-3 \mathrm{ij}$; does not occasion flatulence, but is not so soluble in the stomach as the other; it absorbs scarcely any carbonic acid by exposure to the air; equivalent $1 \cdot 5$.

Magistery of Alum, Earth of Alum, Pure alumine, Oxide of aluminium. Dissolve alum in water, and add to the solution ammonia water sufficient to precipitate the earth; wash it well, and dry.

2. Dry ammoniacal alum, rub it to powder, and keep it red hot in a crucible for some hours.

Gelatrnous alumine, Hydrate of alumine. Pure alumine, not dried, but in a moist state : used to mix with oxide of cobalt and other colouring oxides as a basis for the colour.

Baume's aLUM white. Roman alum 1lb., honey half a $1 \mathrm{~b}$.; dry, powder, and calcine in a shallow dish to whiteness; wash and dry: a beautiful white, even with oil. 
Itamian white chalk, Gesso, Bianchetto di pittori. Dull white, hard, compact, regular texture, colouring, burns rather harder; used for a crayon.

Blaxc DE Bougival. White marle, composed of two parts clay and one of chalk, made up in oblong cakes.

Blanc DE Rouen. White marle, made up in masses of $11 \mathrm{lb}$. each.

Buanc DE Moudon, Blanc de Morat, Gera Earth? Silvery, silky, white, very fine, effervescing with acids; used as whiting.

Strigau earth, Bole, Terra sigillata Silesiaca, Axungia solis. Deep dull yellow, smooth, coarse but compact, heavy not colouring, burns very hard, and to a fine red. From Strigau; astringent and alexiterial.

Yellow ochre, French ochre, Spruce ochre, Powder ochre, Light oche, Sphragis. Fine dusky yellow, compact, firm, smooth, unctuous, slightly colouring, when moist very viscid, burns very hard, and to a fine bright red; Shotover Hill, Oxfordshire, and elsewhere : used in painting.

Light red rouge de Prusse. Light ochre burnt: produces flesh colour with white lead and nut oil.

Venice Tripolr, Terra Tripolitana vera. Whitish yellow, or pale straw, firm, harsh, dry, colouring, burns rather harder and to a pale rose colour ; used for polishing and cleaning metals.

Tripoli. The septarix, ludi Helmonti, or waxen veins, found on the east coasts of England calcined.

2. The clunch, or curl stone, of the Staffordshire mines calcined: gives gold and silver a beautiful black lustre.

Clay ocure, Stone oclire. Deep yellow, heavy, close, firm, smooth, not colouring, burns to a fine deep colour, without any hardness. From Mendip hills; used in painting.-Burnt stone ochre. Deep red.

Yeliow earti, Argilla lutea. Pale yellow, very fine, loose, friable, colouring greatly, astringent taste, burns to a fine rose colour, but not harder. From Saxony : used for polishing, and as a paint.-Burnt yellow earth, Englischer rod. Fine rose red; used in Holland as a paint.

Italias ochre, Janene d'Italie. Fine yellow, firm, compact, very light, colouring, astringent; burns very hard, and to a dull red.

Conrse оснrr. Fine bright, yellow, heavy, hard, firm, irregular texture, harsh, dusty, colouring, very impure; burns to a very pale ashen red, but no harder: Mendip hills. 
Roman ochre. Hard, heavy, very deep or brown yellow; firm, regular, harsh, dusty, colouring very much; burns rather hard, and to a fine purplish red: Somersetshire, also near Rome; all used as paints.

Founders' loam. Deep yellow, fine, soft, with spangles of mica, slightly colouring : burns to a pale red, but not harder; Thrup, in Northamptonshire, also near Highgate Archway : used by founders for moulding.

Red Armenian bole, Bolus Armena rubra. Deep red, hard, heavy, close, rough, colouring the hands; burns rather harder, and to a brighter red; astringent and alexiterial.

Common Lemnian earth, Terra Turcica. Pale flesh red, not very close, heavy, slightly unctuous; burns very hard, and to a dusky yellow.

German bole, Bolus Bohemica rubra. Pale yellowish red, compact, but unequal, heavy, smooth; burus rather harder, without changing colour; astringent.

Terra Lemnia rubra. Pale red, variegated with yellow, close, very heavy, rough, but scrapes smooth, not colouring; burns very hard, and to a fine deep red: Lemnos; astringent, sudorific.

Bole of Blors, Bolus Blesensis, Bolus Armena hutea. Pale red with an orange cast, close, hard, heavy, not colouring, effervescing violently with acids, very astringent taste, burns to a stony hardness and a dark red; astringent, sudorific; highly commended in the plague.

French bole, Bolus rubra Gallica. Pale red, with white and yellow veins, heavy, close, slightly unctuous, not colouring, slightly astringent; burns very hard, but of the same colour; astringent in powder.

Barros, Bucaros, Terra Portugallica. Fine florid red, heavy, harsh, colouring, strongly astringent, burns brighter but not harder : used in dysentery and in dentifrices.

Bradwall-hall clay. Brick-red.-Hallfield colliery, clay. A marle, burning to a light red of four different shades : both are used in making Staffordshire pottery.

Mahogany carth. Pale red, sometimes darker, compact, heavy, smooth, but neither glossy nor unctuous, not colouring, burns very hard without change of colour; Isle of Wight : used in painting, and to stain wood of a mahogany colour.

SoFt RUDDLE, Clay iron-ore, Rubrica fabrilis mollis. Dusky red, loose, very heavy, extremely unctuous, with an oily gloss, colouring very much; burns very hard, externally little altered, 
but internally resembles iron : in iron mines; used as a colour, and also as an iron ore.

Hard rudde, Red chalk, Sanguine, Crayon rouge, Rubrica fabrilis. Deep red, hard, heavy, solid, smooth, rather unctuous, colouring very strongly ; burns very hard and darker: used as a crayon, also as an astringent.

Red lember stone, Terra sigillata rubra. Red chalk ground, made into small cakes and sealed.

Сомsоn воLе, Bolus communis. Red chalk ground and made into large round cakes : astringent: used for cattle, and in tooth powders.

RED stone-ochre, Ochra rubra. Fine deep red, solid, harsh, very dusty, colouring, not altered by burning : Warkwickshire.

RED ochre, Ochra friabilis rubra, Sil Syriacum. Fine strong red, heavy, loose, rough, dusty, colouring very much; burns very hard and much paler.

INDIAN STONE-RED. Fine purplish red, very solid, hard, rough, dusty, colouring; burns rather darker : all used as paints.

Spaxish brown, Almagra, Ochra Hispanica. Fine deep red, with a purple cast, heavy, not hard, rough, colours very much; burns very hard and paler: used as a colour, and as a polishing powder.

Indan red, Rouge Indienne, Terra Persica, Oclira purpurea Persica. Fine purple, extremely heavy, very hard, solid, with glittering particles, colours very much, burns very hard, with no change of colour; from Ormuz; used as a paint, does not glaze well.

Venetian red, Bolus Veneta. Dull red, not very heavy, firm, but dusty, colouring, burns very hard, and of a duskier colour; from Venice.

BRowN RED ochre. Very deep brown red, extremely heavy, firm, very rough, colours very much, slightly altered by burning.

Ruxga matta, Terre de Patua. Deep red, loose, friable: imported from the banks of the Ganges. All these are used as pigments.

Terra di Sienna. Deep brown or coffee colour, fine, compact, very light, very smooth and glossy, does not colour, when wetted marks a fine yellow upon paper; burns to a pale reddish brown, but does not liarden; from Italy, and an inferior sort from Wycomb.

London blue cray, Gluise, Argile de Gentilli, Argile d'Issy. Dark bluish; used for luting vessels in distilling acids, but 
requires another luting over it to keep it moist, and prevent its cracking; also for pottery, for lining ponds, and for modelling.

Devonshire blue clay. Makes white solid pottery, but is expensive.

Devonshire BLAck Ciay. Fat, tough; makes cream ware.

Devonshire cracking clay. Grey, burns to a beautiful white, but is apt to crack in the firing.

Common ClAy, Argilla lateritia. Drying, astringent, used for artificial stones, as bricks, \&c. and common pottery.

Fulcers' earth, Cimolia purpurescens, Smectis, Terra saponaria, Terra fullonica. Greyish brown, but varying greatly, hard, very compact, rough, but scrapes glossy, does not colour, burns hard and yellowish brown; being very fine, and absorbing grease very readily; used to full woollens.

Rotten stone, Terra cariosa. Ash brown, very light, moderately hard, dry, colouring, burns to a deep ash, but no harder; Derbyshire; used as a polishing powder.

Umber, Terra Umbria, Creta Umbria. Fine pale brown, close, very light, dry, colouring, burns deep reddish brown, but no harder; used as a colour, and to give porcelain the shining ground called ecaille. From Turkey.-Burnt umber. Used for paint; makes a good shade for gold: both are excellent dead colours, having a good body.

Windsor LoAM, Hedgerly loam. Yellowish brown, very hard, heavy, harsh, colouring slightly, burns very hard and fine deep red; from Hedgerly near Windsor; used for setting the bricks of wind-furnaces, glass-house furnaces; also for making lutes, and coating glass and earthen vessels to be exposed to a strong fire.

BАтн BRICKs. Windsor loam made into bricks; used for a coarse polishing powder.

Founders' clay, Penny earth. Dusky brown, very hard, heavy, harsl, not colouring ; Woolwich, also Northamptonshire ; used for moulds in large founderies.

Cheam cray. Very light ash-colour, nearly white, compact, fine, very smooth, not colouring, burns pale white and very hard; used for the body of glazed gallipots.

Bohemian tripoli, Polier schiefer, Creta cinerea, Schistus mollis, Terra Melia. Light ash-colour, heavy, moderately hard, open, harsh, dusty but not colouring, not altered by burning; used for polishing, and as a plate powder.

Terlie verte, Terra viridis. Deep bluish green, very heavy, 
hard, smooth, glossy, not colouring but marking a green line, coppery taste, burns very hard and to a dusky brown; from near Rome, also near Woolwich: used as a lasting, but not bright green paint.

Argile de Savirignes. Blue, very tough, sandy; used to make the French poterie de gres, or stone ware.

Argile des Forges-I.es-Eaux. Blue ; used to make glasshouse pots, and stone ware.

StOURBRIDGE CLAY. Dark grey, made into bricks for building glass-house furnaces, and also into crucibles for violent heats.

WeLSH CLAY. Used to make Welsh fire clumps for building the fire-rooms of steam-engine furnaces.

French chalk, Creta Brianzonica, C. Gallica, Morochtos, Leucogæa. Greenish, semitransparent, compact, smooth, unctuous, glossy, not colouring, scrapes white, marks an unctuous silvery line; burns very hard and white; astringent, used to mark woollen cloth, to take out grease, and cause boots to slip on easily; frequently confounded with Spanish chalk.

Mrrsen, Meer schaum, Keffekil, Marga viridescens. Pale greyish green resembling tallow dropped upon brass, close, heavy, smooth, unctuous, glossy, not colouring, burning extremely hard and pale white; used as soap, and to make the large bowls of German tobacco-pipes.

Brack chalk, Drawing slate, Pierre d'Italie, Crayon noire, Schistus pictorius. Fine black, compact, laminated, slightly smooth, colours and writes, burns white and friable, some burns red; in coal mines; used as a crayon.

Kıllow, Nod dû, Killoia molliuscula. Fine black with a bluish cast, slightly smooth, friable, colours very much, tastes astringent, burns hard and grey; Wales: made into balls or sticks, used in painting.

Hard Knulow, Marking stone, Common black chalk, Black shale, Schistus carbonarius. 'Fine black, firm, slightly flaky, dusty, colouring, burns to a fine white suft ash; used as a paint.

Bernt hartshors, Cornu ustum album, Cornu ustum. Burn hartshorn until nearly white, grind, and wash.

Sponies preparatum. Burn ivory, grind, and wash.

Ввоом аsнеs, Cineres geniste. From brom stalks burned, diuretic, in dropsy.

DaUlakif. Farti. Used in India to make sherbet; contains one-fifth of acidulous sulphate of iron. 


\section{STONES AND GLASSES.}

The five precious stones. Garnet, hyacinth, sapphire, cornelian, emerald : cordial!

Crystal powder. Heat quartz red hot, quench it in water, then grind in an agate mortar, or chert mill; used in making glass, and is a good dryer for paints.

Flint powder. Heat flints, quench in water, then grind to powder; used in making fine pottery.

Maidstone sand, Arena rotunda. Fine, white, used to dry up ink, and to filter acid and corrosive liquors.-Lynn sand. White, used to make flint glass.

SEA SAND. Coarse; when washed and dried used for scouring, and sand heats.

Powdered glass, Vitrum pulverisatum. Powdered as crystal, or flints ; used to filter acids ; also glued upon paper as a polishing powder, and to wear down corns upon the feet, after the feet have been well soaked and dried, likewise to blow into the eyes to wear down any excrescence.

Emery, Smyris, Smerillus. Extremely hard; ground in mills, and sorted by being stirred with water, the water left to settle for a determinate number of minutes, then drawn off into another vessel, and left finally to deposit the powder with which it is loaded; used for polishing, either in the state of powder, or glued upon paper for scouring: emery stones from Jersey and Naxos.

Pothee D'emery. The sludge that falls from lapidaries' mills, made into balls for polishing.-Moule. The sludge of the grindstones used in grinding cutlery.

Pierre a l'eau tendre. Greenish or brownish grey, easily rubbed to powder in water, powder used to polish metals.

WAter-of-Ayr stone. Used for polishing mathematical instruments.

Pumice stone, Lapis pumex, Pumex. Spongy, swims upon water; used whole as a kind of file, in powder as a polishing powder, and added to some dentrifices.

LANCET STONE. A green soft hornstone, found in some parts of the old pavement in London: the only known material on which lancets can be set; said to come from Germany.

Hone, Pierre a rasoir. Yellow, with a bed of black slate clay, used with oil, but soap is much cleaner; from Namur. 
Orl stone. Dark greenish grey, from Turkey.

PierRe a I'Eau DUR. Greenish, compact, scaly, paler than lancet stone: all are used to sharpen cutlery.

Muscovy glass, Isinglass, Talc, Talcum. From Russia, in square lumps, separable into flakes of amazing thinness; used to glaze ships' windows, as not liable to break when great guns are fired; also in microscopes to confine objects.

TaLc, Ubruc. Imported from the East Indies, in round pieces, separable into scales; used to silver paper.

Isish sLate, Alum slate, Lapis Hibernicus. Sweetish, agglutinant in bruises, fractures, a spoonful in beer.

Exglish talc, Asbestus. Fibrous; used to make wicks for lamps, and cloth which is incombustible by a modern heat; also to absorb oil of vitriol and prevent its being accidentally spilled from the bottles sold with chemical matches.

Lime-stone, Lapis calcarius; Marble, Marmor. Both are used in coarse powder to ascertain the strength of acids, to yield carbonic acid gas while dissolving in them, $100 \mathrm{gr}$. yielding about J00 cub. in., or to make lime: marble powder.

Stone ltme, Oxide of calcium, Calx viva, Calx. From limestone, or marble, by a red heat ; corrosive, antacid, depilatory : used for cements, to make lime-water, and render the alkalies caustic: composed of 2.5 calcium, and 1 oxygen; equiv. 3.5 .

Osteocolla. Agglutinant; used in fractures, $9 \mathrm{j}$, night and morning.

Gypsus, Sulphate of lime. Used as a cement; also as a forcing manure: composed of 3.5 lime, 5 acid, and 2.25th water.

Raw plaster of Paris. Differs from gypsum in containing carbonate of lime, which causes it to set firmer in moulding, and also fits it for slowly absorbing the acid of wine; it renders cloudy white wines transparent.

Bolled plaster of Paris, Burned Gypsum. Used as a cement, and to make models of statues.

CAwx, Heavy spar, Derbyshire white, Spathum ponderosum, Sulphas baryta. Found in mines; used to mix with flake white, to make muriate of barytes, and lately sold for lapis calaminaris, but it is not soluble in spirit of vitriol.

Permanext white, Artificial sulphate of barytes. Precipitate muriate of barytes by oil of vitriol, or a solution of Glauber's salt ; used to mark jars in laboratories, as it is affected by a very few substances. 
Rat's stone, Witherite Terra ponderosa, Carbonas baryta. Found in mines; used as a poison for rats, and to prepare muriate of barytes.

KемP's white, Precipitated carbonate of barytes. Witherite q. p., spirit of salt q. s., dissolve, add subcarbonate of ammonia to precipitate the white, wash, and dry in cakes for use.

Morveau's white. Dissolve cream of tartar in water, and add lime-water as long as any sediment falls, wash and dry.

ZAFFrE, Safflor, Saffra. One part of roasted cobalt, ground with two or three parts of very pure quartzose sand; used as a blue colour for painting glass; from Saxony.

Smalt, Powder blue, Smalta, Azurum. From roasted cobalt, melted with twice or thrice its weight of sand, and an equal weight of potash; used in painting, and getting up linen : from Saxony.

Ultra-marine blue, Caruleum ultramontanum. Lapis lazuli 1lb. is heated to redness, quenched in water, and ground to a fine powder; to this is added yellow rosin $6 \mathrm{oz}$., turpentine, bees' wax, linseed oil, ana $2 \mathrm{oz} .$, previously melted together, and the whole made into a mass; this is kneaded in successive portions of warm water, which it colours blue, and from whence it is deposited by standing, and sorted according to its qualities : a fine blue colour with poppy oil; East Indian lapis lazuli.

Ultramarine ashes, Sander's blue. The remains left after the extraction of ultramarine, the wax and oil being burned away, and the ashes washed; inferior in colour.

Egyptian azure. Carbonate of soda $15 \mathrm{oz}$. , calcined flints $20 \mathrm{oz}$, copper filings $3 \mathrm{oz}$., mix and heat together for two hours: a fine sky blue.

Fluxes for enamel colours. Flint powder 4 oz., flint glass $12 \mathrm{oz}$., red lead $16 \mathrm{oz}$., calcined borax $3 \mathrm{oz}$. Melt in a Hessian crucible; keep it melted for several hours in a steady heat, then pour it out into water, and grind it in a white biscuit-ware mortar.

2. Flint glass $10 \mathrm{oz}$, white arsenic and nitre, of each $1 \mathrm{oz}$.

3. Flint glass $3 \mathrm{oz}$, red lead $1 \mathrm{oz}$.

4. Flint glass $16 \mathrm{oz}$, red lead $19 \mathrm{oz}$, borax (not calcined) $11 \mathrm{oz}$.

5. Flint glass 6 oz., red lead 8 oz., flux, No. $2,4 \mathrm{oz}$.

Yeliow examel. Red lead $8 \mathrm{oz}$, oxide of antimony $1 \mathrm{oz}$, oxide of tin $1 \mathrm{oz}$, calcined together; of this take $2 \mathrm{oz}$., flux, No. 4 , $3 \mathrm{oz}$.

Orange enamel. Red lead $12 \mathrm{oz}$, red sulphate of iron $1 \mathrm{oz}$. , 
oxide of antimony $1 \mathrm{oz}$, flint powder $3 \mathrm{oz}$.; calcine and melt with flux $50 \mathrm{oz}$.

DARK RED ENAMEL. Sulphate of iron, calcined dark, 7 oz., flux, No. 1, 18 oz., colcothar 1 oz.

Light Red enamel. Red sulphate of iron 2 oz., flux, No. 1, $6 \mathrm{oz}$, white lead $3 \mathrm{oz}$.

Brown enamel. Manganese $10 \mathrm{oz}$, red lead $32 \mathrm{oz}$, flint powder $16 \mathrm{oz}$.-Used to cover watches and other toys.

Paste, Strass. Rock crystal 6 Troy oz., red lead 9 oz. 5 dwt., fine pearl ash $3 \mathrm{oz} .7 \mathrm{dwt} . \frac{1}{2}$, boracic acid $7 \mathrm{dwt} . \frac{\mathrm{x}}{2}$, oxide of arsenic 5 grains: to be kept in quiet fusion for at least 24 hours, in a Hessian crucible, and cooled gradually. Used to imitate diamonds in jewellery, and as a basis for making artificial gems.

False topaz. Paste 1 Troy oz. 15 dwt., glass of antimony $1 \mathrm{dwt} . \frac{\mathrm{x}}{2}$, Cassius' purple precipitate $1 \mathrm{gr}$.

False roby. Paste 5 oz., oxide of manganese $2 \mathrm{dwt} . \frac{\mathrm{I}}{2}$.

False emerald. Paste 5 oz., oxide of copper $1 \mathrm{dwt} 15 \mathrm{gr}$., oxide of chrome $2 \mathrm{gr}$.

False sapphire. Paste $8 \mathrm{oz}$, oxide of cobalt $2 \mathrm{dwt} .9 \mathrm{gr}$.

False ametuyst. Paste 16 oz., oxide of manganese 15 to 24 gr., oxide of cobalt $1 \mathrm{gr}$.

False oriental galnet. Paste $17 \mathrm{dwt} .19 \mathrm{gr}$., glass of antimony $8 \mathrm{dwt} .18 \mathrm{gr}$., oxide of manganese $2 \mathrm{gr}$.

All used as false gems: many other compositions are made, almost every artist having his own receipts.

CHina blue, Royal smalt. Oxide of cobalt, melted with felspar and a little American potash. Used to paint pottery ware, and as a pigment.

Tabasheer, Tabaxir. A stony concretion formed in the joints of the bamboo cane. Used in diseases arising from obstructions.

Suer.t lime, Calx e testis. From oyster or other shells, by calcination : corrosive, antacid, depilatory ; used for cements, to make lime water and render the alkalies caustic. Used the same as stone lime.

Limf-water, Aque calcis, Liquor calcis. Fresh burned lime $8 \mathrm{uz.}$ pour upon it boiling water a gallon, cover up close, and, when cold, keep the whole in a glass bottle, pour off the clear when wanted: astringent, antacid, 3 iv to $\mathrm{lb}$. $\mathrm{j}$, in small draughts; its taste is best covered with 1-5th of milk; also externally to ulcers. 


\section{ALKALIES AND THEIR CARBONATES.}

As the two subcarbonates of soda and of potash are sold in a solid form, their strength is attempted to be ascertained by the quantity of sulphuric acid that a solution of $100 \mathrm{gr}$. of either of them requires for its saturation: this operation is called alkalimetry, and tubes graduated into 100 parts, and containing the necessary quantity of acid to saturate 100 grains of the pure subcarbonates are used, called alkalimeters; but as the sulphuric acid acts upon the sulphates and sulphurets of these alkalies, and which are usually present, the essay is not a whit more accurate than the method of the German soap boilers, who merely pour a quart of water upon a pound of ashes, and then putting in a piece of Dutch soap, add water in small portions until the soap sinks. The ashes are the stronger as they require more water before the soap sinks.

\section{POTASH。}

Asm balls, Cineres herbarum. Principally the ashes of fern, made up into balls : used for washing instead of soap, and to clean paintings.

Pot-Ash, Alumen catinum. From land plants burned to ashes, the ashes elixated with water, and the ley evaporated to dryness. From America.

Pearl-ash, Potasse de New Yorck, Potasse rouge d'Amerique, Cineres perlati. From pot-ash, by calcination, by a gentle heat to avoid melting, solution in water, filtration, and evaporation, stirring it all the time to granulate the salt. From America.Burnt lees of wine, Cendres gravellées, Cinis infectorius, C. facum, Cineres clavellati, Alumen facum, Potasse subcarbonas impurus, Potassa impura. From the ashes of lees of wine, grape cake, and vine twigs, very pure; preferred by the continental dyers. From France. This is used for preparing the subcarbonate for medical uses.

Salt of tartar, Sal tartari, Kali ppm. e tartaro, Kali e tartaro, Subcarbonas potassa purissimus, Potassa subcarbonas e tartaro. Burn argol in a crucible, powder and calcine till it is nearly white; dissolve in water, filter and evaporate. Composed of 6 pot-ash, 2.75 carb. ac., with $2 \cdot 25$ water : equiv. $11 ; 100$ gr. saturate $\mathbf{7 0}$ of oil of vitriol.

SALt of wormwood, Sal absinthii. Wormwood burned to ashes, dissolved in water, the solution filtered, and evaporated to dryness. 
Товассо Asнes. The smuggled tobacco seized by the English government is all burned, and the ashes alone sold.

Treves potash, Potasse de Treves, is as strong as pearl-ash.

Vosges potash, Potasse de Vosges. Used in France, the weakest of those usually sold.

Dantzic potash. Resembles Russian potash, but is rather weaker.

Russian potasi, Cineres Russici. From beech, birch, poplar, or alder, burned to ashes, part of the ashes elixated with water, and the ley used to moisten the remainder of the ashes, covering fresh billets of wood with the moistened ashes, and setting the pile on fire. From Russia and Sweden, in large black lumps as hard as a stone, with a sulphureous smell: solution green, tinging silver dark purple. Petersburg.

Travancore potash. From cocoa-nut branches.-Mara oppoo. From cocoa-nut and plantain leaves.

Subcarbonate of potash, Kali preparatum, Subcarbonas kali, Carbonas potassa, Potasse subcarbonas. Pour upon burnt lees of wine an equal weight of boiling water; filter and evaporate until the liquor grows thick, then remove the fire, and stir the salt continually, until it concretes into small grains. As burnt lees of wine are now with difficulty procurable in England, pearlash is used for them. 'This is used in acidities of the primæ vire, and in glandular obstructions. Dose from gr. $\mathbf{x}$ to 3 ss properly diluted. The incompatibles are, the mineral acids, muriate and acetate of ammonia, sulphate of magnesia, lime, and lime water, all the metallic salts. - Officinal preparation. Liquor potassæ subcarbonatis, $L . D$.

Nitre: Fixed by charcoal, Subcarbonate of potash, Nitrum a carbonibus fixalum. Nitre 16 oz., charcoal powder 4 oz.; melt the nitre, and throw into it the charcoal powder, until it ceases to take fire: produces 13 or $\mathbf{1 4} \mathrm{oz}$. of subcarbonate of potash, equal to salt of tartar.

Wuite rlux, Cornish flux, Fluxus albus. Nitre and tartar ana p. æq.: deflagrate as before.-All these alkalies are diuretic, in doses gr. v. to $3 \mathrm{j}$, cathartic in larger doses; they are used in making glass, in bleaching and scouring cloth, and to precipitate alum.

Saline oli, of tartar, Oil of tartar, Oleum tartari per doliquium, Aqua kali. Spread salt of tartar, pearl-ash, or potash thin, on plates, in a damp cellar, and when it has run into water, strain through linen; used in scouring.

Liquor potass.e slbcarbonatis, Aqua subcarbonatis kali. Subcarbonate of potash $\overline{3} \times \mathrm{ij}$, distilled water $\overline{3} \times \mathrm{jj}$; dissolve and 
filter. - Henry's carbonate of potasse water, is made up to the spec. grav. of 1.248 , that it may saturate an equal measure of sulphuric acid, spec. grav. 1.135, or of nitric acid, spec. grav. 1.143, or of muriatic acid, spec. grav. 1.074. Used in assaying mineral waters.

Bicarbonate of potash, Kali aératum, Potassce carbonas, P. L. 1824. Dissolve subcarbonate of potash $11 \mathrm{lb}$., in water 3lb., and pass through the liquor the gass expelled by adding pounded marble to dilute sulphuric acid; the carbonate of potash crystallizes as fast as it is formed: preferable, as being milder tasted than the subcarbonate; used to form effervescent mixtures. Composed of 6 potash, 5.5 carb. acid, and 1.125 water; equiv. $2 \cdot 625$. Use the same as that of the Subcarbonas potassæ already noticed.

2. Dissolve pearl-ash in water, add bran, or saw-dust, to soak up the liquor, put it into a crucible, cover, lute the joint, and heat the crucible till it is red hot. When cooled, wash out the salt, evaporate and crystallize, until no more crystals can be obtained; then heat the remaining liquid with fresh bran, and proceed as before.

Lixivium saponarium, Pure potash water, Solution of potash prepared with lime, Eau seconde, Aqua kali puri, Liquor potassa. Upon quick lime $3 \mathrm{vj}$, pour boiling distilled water $\mathrm{lb}$. vj, and add subcarbonate of potash $\mathrm{lb}$. $\mathrm{j}$, dissolved in water 2lb. : cover the vessel, and when cool filter through cotton cloth; if it effervesce with a dilute acid, it must be treated again with fresh lime. A pint should weigh exactly $\overline{3} \times v j$; if it weigh more, for every drachm of excess add $3 s s$ of distilled water to each lb. Troy; if less, evaporate some part of it. Used in calculous complaints.

AQUa kali caustici, Aqua potassce. Lime 8 oz., add water $24 \mathrm{oz}$., when cold add subcarb. pot. $6 \mathrm{oz}$.; strain, adding fresh water, so as to get $36 \mathrm{oz} .-$ Henry's pure potash water. Is made up to the spec. grav. $1 \cdot 1$; two measures of it have the same effective strength as one measure of his carbonate of potash water. Used in analyzing substances.

Potash pREPARED With alcoHol. Evaporate a solution of salt of tartar, nitre fixed by charcoal, or the white flux, made caustic by quicklime, to the consistence of syrup, cool to about 130 degrees of Fahrenheit, add three times its weight of alcohol, and keep for some days, draw off the clear, wash the bottoms with fresh alcohol, and add to it the other. Distil off $2 \mathrm{oz}$. out of 3 of the alcohol used, evaporate the remainder in a silver basin, taking off the scum; when nearly red hot, pour it out on a very dry marble slab, or silver basin, and break it up as soon as it fixes. To be kept in small parcels, in very dry, well-stopped vessels. 
Caustic potash, Pure potash, Hydrate de deutoxide de potassium, Lapis infernalis, Lapis septicus, Kali purum. Potassa, $P$. fusa, Kali causticum. Evaporate pure potash water till the boiling ceases, and the salt melts smoothly like oil, then pour it out on an iron plate, and cut it into picces : caustic, but is apt to spread. Composed of 6 potash, and $1 \cdot 125$ water; equiv. $7 \cdot 125$.

Nitre fixed By metals, Nitrum a metallis fixatum. Regulus of antimony $4 \mathrm{oz}$. , melt in a large crucible, add purified nitre $20 \mathrm{oz}$. at three separate times, an hour apart ; keep the matter in fusion for some time. Very caustic.

MINERAL ALKALI OR SODA.

British barilla. The ashes of Salicornia Europæa calcined into a porous mass. Very poor in subcarbonate of soda.

Kelp, Varecq. Soude de Normandie. The ashes of Fucus vesiculosus, and several other species; contains scarcely any subcarbonate of soda, never more than 3 in the 100 .

Smyrna barilla, Cendre du Levant. From Mesembryanthemum Copticum and Salsola kali; contains about 40 in the 100 of subcarbonate of soda.

Barilla ashes, Spanish barilla, Alicant barilla, Soda Alican. tina, S. Alonensis, Sal alkali, Soda impura, Carbonas snde impura. From Mesembryanthemum nodiflorum burned with Salsola sativa; contains about 25 in the 100 of subcarbonate of soda.

East Indian barilla ashes. From Salsola Indica, S. nudi flora, and S. elata.

Cape barilla. From Salsola aphylla and S. soda.-Marseilles barilla. From Salsola soda. - Sicily barilla. From Salsola tragus. - Teneriffe barilla.

Branquette, Soude d'Aigues mortes. The ashes of Salicornia Europaca, Salsola tragus, Atriplex portulacoides, Salsola kali, and Statice limonium: contains about 3 to 8 in the 100 of subcarlonate of soda.

Salicon. Soude de NArbonve. The ashes of Salicornia annua: contains about 14 or 15 in the 100 of subcarb. of soda.

Alexandria barilua, Roquette, Rochetta Alexandrina. From Salsola Arabica, with Mesembryanthemum nodiflorum, and Plantago squarrosa.-Soude de Bourde. Very bad, stinking.

PooN HЕER. A whitish earth, containing much subcarb. of soda, found in the East Indies.

Natros: From lakes dried up by the summer's heat. Is a sesquicarbonate of soda mixed with salt, and sulphate of soda. Imported from Egypt.-Trona. A similar mineral, imported 
from Tripoli. Both are washed for the sesquicarbonate of soda they yield.-Over munnoo. Resembles trona; East Indies.

SEsquicarbonate of SODa. Obtained from natron and trona; composed of 4 soda, $4 \cdot 125$ carb. ac. and 2.25 water; equiv. $10 \cdot 375$. Used in making soda water.

UnREFINED minerat, alkali, Gaz oppoo. In regular very thin whitish cakes; having been dried in ponds: imported from the East Indies.

Subcarbonate of soda, Salt of soda, Salt of barilla, Sal alkali, Natron praparatum, Soda subcarbonas, Carbonas soda, P. E. and D. Dissolve Spanish barilla ashes $1 \mathrm{lb}$. in water 1 gall., filter and evaporate to $2 \mathrm{lb}$., set it aside to crystallizc; antacid, deobstruent, gr. $\mathrm{x}-3 \mathrm{ss}$, bis terve in die. - Officinal preparation. Sodæ subcarbonas exsiccata, $L . D$.; sodæ carbonas, $L$.

2. By calcining 180lb. ea. of Glauber's salt and chalk, with 110lb. of charcoal dust, washing out the salt and crystallizing; produces $300 \mathrm{lb}$. of salt, of which $100 \mathrm{lb}$. is pure subcarbonate of soda.

3. By mixing a solution of Glauber's salt with a solution of lime in pure pyroligneous acid, boiling for some time, filtering, evaporating to dryness, calcining the acetate of soda thus obtained, redissolving in water, and crystallizing.

4. Is obtained as a secondary product in making mineral yellow. Composed of 4 soda, 2.75 carb. ac. and 11.25 water; equiv. 18. Used largely in making hard soap, glass, and dyeing.

Henry's carbonate of soda water. Dissolve subcarbonate of soda in water, so that the solution may have the sp. gr. of 1.11: 2 meas. are equal in saturating power to one of his carbon. of potash water.

Sode subcar bonas exsiccata, Carbonas sodce siccatum. Melt subc. of soda until it becomes dry, stirring it continually: antacid; used also in calculous complaints, in small doses frequently repeated, so as to take $\mathrm{Bj}$ to $\mathrm{ij}$ in the day.

Bicarbunate of Soda, Sodce carbonas, P. L. 1824. Pass the gas from pounded marble dissolving in diluted sulphuric acid through a solution of subcarb. of soda in water, as in making bicarbonate of potash ; antacid, gr. $x$ 3j.

2. Calcine subcarb. of soda with bran, as in making bicarbonate of soda; comp. of 4 soda; 5.5 of carb. acid, and 1.125 of water ; equiv. 10.625

Caustic soda, Pure soda, is prepared by acting upon sub. carb. of soda with quicklime, as in making caustic potash.

Soda PREPAREd with alcohol. Also prepared in a manner similar to potash. 
Potasse d'Asrerique, Petite potasse blene. Caustic soda melted with salt, lime, and oxide of copper; sold to the Paris laundresses for American potash, as they object to using soda.

SOAP I.EY. From barilla ashes mixed with one-third their weight of quicklime, and the caustic soda and salt washed out with water. Is very various in its strength; and weak leys are afterwards drawn from the same ashes, by pouring on more water, and draining it off, for three or four times.

Henry's pUre soda-water. From pure caustic soda dissolved in water, so as to have the sp. gr. of 1.07 ; is of the same effective strength as his carbonate of soda-water.

\section{VOLATIIE ALKALI OR AMMONIA.}

Carbonate of ammonia, Subcarbonate of ammonia, Volatile sal ammoniac, Bakers' salt, Sesquicarbonate of ammonia, Sal vola. tilis salis ammoniaci, Ammonia preparata, Ammoniae carbonas, Ammonice subcarbonas. Sal ammoniac 1lb., powdered chalk $2 \mathrm{lb}$.; mix accurately, and sublime. This is stimulant, antacid, diaphoretic, and antispasmodic, and is used in hysteria, dyspepsia, and chronic rheumatism. Dose gr. $\mathrm{v}$ to $\mathrm{xv}$ in pills, or in any bland fluid. Officinal preparation. -Ammonix bicarbonas; Liquor ammoniæ acetatis; Cuprum ammoniatum, L. E. D.

2. Sal ammoniac, subcarb. of soda, ana lb. $\mathrm{j}$; sublime. P. D. Stimulant, and used as an errhine, like the spirit. Much used by the bakers, to make bread in a hurry : the bread is yellowish, and the cells very small, but it may be baked as soon as the dough is mixed. When fresh-made is composed of $2 \cdot 125 \mathrm{amm}$. $4 \cdot 125$ carb. acid, with $1 \cdot 125$ water; equiv. $7 \cdot 375$. By keeping the outer surface loses a portion of its ammonia, and is changed into bicarbonate, which has not the pungency or volatility of the sesquicarbonate.

Spikit of hartshors, Spiritus cornu cervi, Liquor volatilis cornu cervi. From hartshorn, by distillation; when rectified, has a pleasant refreshing odour.

Salt of Hartshorn, Volatile salt, Smelling salt, Sal comu cervi, is obtained in the same process with spirit of hartshorn, and is purified by mixture with 1-8th of chalk and sublimation with a gentle heat : pleasant smell. Salt of oxteeth is sold for it, in France.

Spirit op oxtzetr, Salt of oxteeth. Nearly equally pleasant as spirit of hartshorn, for which they are sold.

ROUGII BONE SPIIIT, Liquor volatilis ossium. From bones which have been boiled for their grease by distillation in iron pots or cylinders; separating the oil and salt by filtration; 1-5th more 
alkali is obtained in unluted vessels than in luted. Hales says, subcarb. of ammonia heated absorbs air.

Rectified bone spirit, Salt ofbones, Sal ossium. The rough spirit, distilled from 1-8th of wood ashes, or charcoal powder ; the salt of bones first arises; when it begins to melt by the spirit that succeeds, the distillation is stopped for the present, the salt taken out, and then distillation begun again, till nearly the whole of the liquor has come over.

Spirit of urine, Spiritus urince, Salt of urine. Obtained largely from urine which has been kept a little while; for if fresh, the water must be distilled off before the spirit will appear.

Spirit of woon soot, Spiritus fuliginis, Salt of wood soot, Sal fuliginis. From wood soot; strongly scented, anti-epileptic.

Liquid mild volatile alkali, Spirit of sal ammoniac, Spiritus salis ammoniaci, Aqua ammonia, P. L. Aqua carbonatis ammonia. Subcarb. of potash 3lb., sal anmoniac $21 \mathrm{lb}$., water 8lb. ; distil to dryness.

Liquor amMonie carbonatis, Liquor ammonice subcarbonatis. Subcarb. of ammonia 3iiij, distilled water $\mathrm{lb}$. $\mathrm{j}$; dissolve and filter : stimulant, gtt. $\mathbf{x x}$ to $3 \mathrm{j}$, also as an errhine.

Henry's carbonate of ammonia-water. Dissolve subcarbonate of ammonia in water, so that the sp. gr. may be 1.046 : two measures are equal in saturating acids to one of his carbonate of potash-water. Used in analysis.

Ammoniacal liguor. From coals; obtained in those gasworks that use coals; a chaldron yielding about 200 gallons. Used to make sal ammoniac.

Caustic volatile alikali, Spirit of sal ammoniac with lime, Aqua ammonice purce. Lime, water ana $\mathrm{lb}$. $\mathrm{ij}$; slake and add sal ammoniac $\mathrm{lb}$. $\mathrm{j}$, boiling water $\mathrm{lb}$. vj, cover the vessel immediately; when cold pour off the liquor, and distil with a gentle heat $\mathrm{lb}$. j.

Aqua ammonie caustice. Lime $\mathrm{lb}$. $\mathrm{ij}$, water lb. $\mathrm{j}$, slake and cover it up: the next day add sal ammoniac $3 \times$ xyj, water lb. v, distil $\overline{3} \times \mathrm{x}$. The specific gravity ought to be 934 ; or a bottle holding 3 xij of water should hold 3xj-3iijss of this fluid.

Aqua Ammonie, P. E. Lime lb. jss, water zix, slake, when cool add sal ammoniac $\mathrm{lb}$. $\mathrm{j}$; distil into distilled water $\mathrm{lb}$. $\mathrm{j}$, until the retort becomes red hot.

Liquor ammonie, Lime 3̈ $\mathrm{vj}$, water lb. j; slake, and cover up for an hour, then add sal ammoniac 3ैviij, boiling water $\mathrm{lb}$. iij, and cover till cold, then strain and distil $3 \times$ xij. Specific gravity should be 960 ; or a bottle holding $3 x i j$ of water should hold $3 x j s s$ of this fluicl. This is seldom given internally-externally, 
as a rubefacient, or vesicant. - Principal officinal preparation. Ammonia hydrosulphuratum, D. E.; Linimentum ammoniæ, D. L.; Liniment. camph. comp., D. L.; Liniment. hydrargyri, $L$.

Henry's pure ammonia-water. Made up to the sp. gr. of 970 ; one measure is equal in saturating acids to one measure of his carbonate of potash-water. Used in testing liquors.

Liquor volatilis cornu cervi cum calce. Spirit of hartshorn 4lb., fresh slaked lime 1lb., distil into water kept cool, and, if necessary, adjust its specific gravity by the addition of distilled water, or by repeating the distillation: antacid, stimulant.

\section{NEUTRAL SALTS.}

Water, when saturated with any one salt, will dissolve another or even several other salts; hence a small quantity of water, poured upon a large mass of impure salt, saturates itself with the most abundant, and then, dissolving the other salts which render it impure, leaves the remainder in a state of purity.

\section{SALTS OF ALUMINE.}

Alum, Lump alum, Sulphate of alumine and potash, Rock alum, Alun de roche, Alun de glace, Alumen vulgare, Sulphas alumine. In large lumps, formed by pouring a solution at $50 \mathrm{deg}$. Baume into barrels, where it forms a nearly solid mass. Obtained from different minerals by elixation and crystallization, previously adding potash or potash and urine: tonic, astringent, gr. v. - xx; in gargles, 3 ss to water $\bar{z}^{\mathrm{iv}}$; in eye-waters and injections, gr. xij to water $3 v j$ : used largely by the dyers, also to harden tallow for mould candles, and many other purposes in the arts.

Roаси alum, Alun fin, Alumen crystallinum, A. rupeum. Crystallized from a solution at 25 or $30 \mathrm{deg}$. Baume. In pyramidal lumps of crystals; preferred by the dyers in certain processes.

AI.UN DE LIEGE. Impure, but by solution and recrystallization is rendered very pure.

Italian roach alum, Alun de Rome, Alumen Romanum, $A$. rubrum. In crystals, pale red when broken, and covered with a reddish efflorescence: not refined; used by the dyers; contains no ammonia nor iron.

T'urkey alum, Alun de Smyme, Alumen de Rochi. From the original manufactory of Rocha, in Syria ; in pieces the size of an almond to that of an egg, covered with a reddish efflorescence.-The potash sulphates of alumine are composed of 20 
sulph. acid, 6.75 alumine, 6 potash, and 28.125 water: equiv. $60 \cdot 875$.

Ammonia alum, Sulphate of alumine and ammonia, Alun ammoniacal. From the same minerals as potash alum, but crystallized by means of urine or sulphate of ammonia. In small scaly crystals, rather less soluble in water than potash alum; lose their ammonia in time. Used in dyeing certain colours. Composed of 20 sulph. acid, .6.75 alumine, 2.125 ammonia, and 28.125 water; equiv. $5 \%$.

Burnt alum, Alumen ustum, A. exsiccatum, Sulphas alumince exsiccatum. By melting common alum, and keeping it on the fire until it cease to boil: used in colic, $Э \mathrm{j}$ for a dose; externally escharotic: $5 \mathrm{lb}$. yield $31 \mathrm{lb}$.

\section{SALTS OF BARYTES.}

Muriate of Barytes, Chloride of barium, Hydrochlorate of barytes, Murias barytc. . Dissolve carbonate of barytes, or rat's stone, 1lb., in spirit of salt $1 \mathrm{lb}$., previously mixed with water 3lb.; filter and crystallize by repeated evaporation.

2. Mix sulphate of barytes, i. e. cawk, 2lb., with charcoal $4 \mathrm{oz}$; keep it red hot in a covered vessel for six hours, boil the mass in water 8lb., strain, and to clear the liquor add spirit of salt as long as it produces any effervescence; lastly crystallize by evaporation. Vermifuge, alterant; used gr. $j$, bis terve in die, in cancer and scrofula.

Solutio muriatis baryte. Murias barytæ $\bar{j}$, distilled water $3 \mathrm{iij}$; dissolve : deobstruent, gtt. $\mathrm{v}$-viij, bis terve die, in cancer and scrofula: externally escharotic, to fungous ulcers and specks on the cornea.

Acetate. of Barytes. By dissolving carbonate of barytes in pure acetic acid, evaporating and crystallizing.

Nitrate of Barytes. By dissolving carbonate of barytes in nitric acid, evaporating and crystallizing.

The solutions of both the acetate and nitrate of barytes are used to discover sulphuric acid, and the crystals of the nitrate to discover, by fusion, potash, soda, or lithium in minerals.

\section{SALTS OF LIME.}

Hydrosulphate of lime, with sulphur (liquid). One part of sulphur, two parts of subcarbonate of lime, and nine of water: these are to be added together, and boiled in an earthen vessel, until completely saturated; the liquid is then to be decanted and filtered. It is of a deep brown colour; has been found useful in psora: $1 \mathrm{oz}$, and a half to be rubbed in three times a day. 
Muriate of lime, Hydrochlorate of lime, Murias calcis. Dissolve the mass left in the distillation of lime with sal ammoniac in water; filter and evaporate to dryness.

2. Dissolve white marble or chalk in muriatic acid, and evaporate to dryness. Used for preparing the liquid muriate employed as a substitute for muriate of barytes.

Liquid shell, Liquor calcis muriatis. Murias calcis zij, distilled water $\frac{3 i j}{3}$; dissolve and filter.

A(rua calcis Muriatis. Chalk z̃j, diluted muriatic acid $30 \mathrm{j}$; dissolve and filter.

Solutio muriatis calcis. White marble 9 oz., muriatic acid $16 \mathrm{oz}$, water $8 \mathrm{oz}$., dissolve, evaporate to dryness; dissolve the dried mass in an ounce and a half its weight of distilled water, and filter: deobstruent, in scrofulous and glandular diseases, gtt. xl to $3 \mathrm{j}$, diluted, bis terve die : seems to be the most active ingredient in mineral waters.

Purifring I.IQuid, Solutio oxymuriatis calcis. Com. salt $4 \mathrm{oz}$., black oxide of manganese in powder $1 \frac{\mathrm{r}}{2} \mathrm{oz}$, oil of vitriol $3 \mathrm{oz}$., water $6 \mathrm{oz}$., mix, distil, and pass the gas into a bottle containing quicklime $2 \mathrm{oz}$, water $62 \mathrm{oz}$; strain the liquor. Used as a lotion in venereal sores, also diluted with water, $\frac{1}{4}$ pint to a gallon, to destroy the odour of sick rooms, manufactories using animal entrails, and houses of office; and still weaker to sweeten game.

\section{SAI.TS OF MAGNESIA.}

Epsom salt, Sal Epsomensis, S. catharticus umarus, Magnesia vitriolata, Magnesia sulphas. Obtained from sea.water, after the common salt has been crystallized.

2. From magnesian limestone, by washing out the lime with rough pyroligneous acid, or other acid, then dissolving the magnesian residuum in oil of vitriol, and crystallizing: Epsom salt is purgative, $\overline{3} j-\overline{3} \mathrm{ij}$; allays the pain of the colic; also used in purgative clysters.

\section{SALTS OF AMMONIA.}

Grey sat. ammoniac, Sal ammoniacus, Muriate of ammonia, Hydrochlorate of ammonia, Murias ammonia, M. ammoniacus. By subliming the soot formed by burning cows' or camels' dung: $26 \mathrm{lb}$. of dung yield $6 \mathrm{lb}$. of salt. Used in preparing cendres bleues and other colours. From Egypt direct, and through the East Indies.

Sal amsoniaces purificatus. By dissolving grey sal ammoniac in water, evaporating and crystallizing. 
White sal amioniac. By adding oil of vitriol to bone spirit, crystallizing the product, mixing it with common salt, and subliming. In this process the residuum, by solution in water and crystallization, yields Glauber's salt.

2. By.adding ground gypsum to bone spirit, straining, pouring the liquor upon common salt, and subliming.

3. By mixing the bittern of sea-water with putrid urine or bone spirit: diuretic, stimulant, and tonic : used internally, in doses of 5 to 20 grains, frequently repeated against agues; also added to Peruvian bark to increase its febrifuge power; externally stimulant, $\ddot{3} \mathrm{j}$ to water $\bar{z}$ viij, as a lotion in gangrene, indolent tumours; and chilblains. Used to give pungency to snuff, in dyeing to brighten certain colours, and by other artists for various purposés.

Flowers of sat ammoniac, Flores salis ammoniaci. Grey sal ammoniac broke into pieces, and sublimed either from an earthen body into aludels, or from a wide-necked retort into a large receiver: this mode of obtaining sal ammoniac in fine powder was adopted on account of its toughness and the difficulty of pounding it.

Benzoate of Ammonia. By saturating subcarbonate of ammonia-water with benzoic acid; in crystals.

Succinatr of ammonia. By saturating subcarbonate of ammonia-water with succinic acid; in crystals. Both are used in analyses to separate iron from manganese.

Oxalate of ammonia. By saturating liquid oxalic acid with ammonia-water, evaporating, and crystallizing.

Oxalate of ammonia-water. By dissolving oxalate of ammonia in ten times its weight of water. Used to ascertain the presence of lime in waters.

Sulphate of ammonia, Sal secretus Glauberi. By adding dilute sulphuric acid either to sal ammoniac or ammoniacal liquor, evaporating and crystallizing; diuretic, aperitive.

Spiritus Mindereri, Aqua ammonice acetata, Liguor ammo. nice acetatis, Aq. acetatis ammonia. Subcarb. of ammonia $2 \mathrm{oz}$, distilled vinegar q. s. (about lb. iij) as long as any effervescence is produced, or rather more: diaphoretic $\bar{\jmath} s \mathrm{~s}$; externally as a collyrium in ophthalmia.

Hydrosulphate of ammonia, Hydrosulphuret of ammonia, Ammonia hepatizata, Hydrosulphurelum ammonia, Ammonium hydrosulphuratum. Pass the gas from artificial sulphuret of iron ऊiv, while dissolving in muriatic acid $\overline{3}$ vij previously diluted with $2 \frac{x}{2}$ pints of water, into a bottle containing pure ammoniawater 3iv. Dose gtt. v, gradually augmented: used in diabetes, 
2. Pass the gas through three bottles; the first containing a little water to absorb any muriatic acid that may come over; the second the ammonia-water; and the third filled with lime and water to absorb the superfluous gas, and prevent its getting into the laboratory, it being both highly deleterious and of a very disagreeable smell. Used as a test liquor for metals.

Succinas ammonie liquidum pYroanimale. Unréctified salt of hartshorn $\overline{3} \mathrm{j}$, water $\overline{3} \mathrm{vj}$; dissolve, add succinic acid sufficient to saturate it; then filter; antispasmodic.

\section{SALTS OF POTASH.}

Rotgh saltpetre, Sal petre, Nitrum. Found naturally efflorescing from the earth and certain stones, also from the rub. bish of old buildings : obtained by elixiviation, adding, if necessary, wood ashes to supply the alkaline basis: East Indian.

Refined saltpetre, Nitre, Sal nitri, Kali nitratum, Potasse nitras. Obtained from rough saltpetre, by redissolving it in water and crystallizing.

2. By adding only a small quantity of water to the rough nitre, letting it remain sone time, and draining it off.' A cooling diuretic in small repeated doses of gr. $v-x$ each, every two hours; taken to $\overline{3} j$ it occasions blnody stools, and even death: a small piece dissolved slowly in the mouth frequently stops a sore throat in the beginning; used also in gargles: employed in artillery and fireworks.

Sore-throat salt, Lapis prunella, Sal prunelle. Melt nitre 1lb., inject upon it gradually flowers of sulphur 2 oz., and pour it out into moulds, either balls or cakes.

Crystal mineral. Melt nitre 16 oz., and when it flows smooth, pour it into warm moulds; yields about $8 \mathrm{oz}$.

Maceuer's neutral arsenicat salt, Arsenate of potash, Kali arsenicatum, Arsenias kali. Distil white arsenic and nitre ana p. æq.: dissolve the residuum in water, evaporate and crystallize : tonic, gr. 1-16th to 1-4th in pills; used also in preparing cobalt blue.

Muriate of potasir, Iyydrochlorate of potash, Sal febrifugus Sylvii, Spiritus salis marini coagulatus. By saturating spirit of salt with pearlash, evaporating and crystallizing.

2. By heating or distilling sal ammoniac and pearlash, dissolv ing the residuum in water, evaporating, and crystallizing: aperient, diurctic.

Oxymuriate of potash, Chlorate of potash, Potassce oxymurias. Mix common salt 3lb., manganese 2lb., and add oil of vitriol 2lb., previously diluted with water q. 8.; distil into a 
receiver containing pearlash $6 \mathrm{oz}$. dissolved in water 3lb.; when the distillation is finished, evaporate the liquid in the receiver slowly in the dark; the oxymuriate will crystallize first in flakes: stimulant, gr. j-iij ; explodes when struck, or dropped into acids. Used for making matches for instantaneous lights, and for procuring oxygen gas.

Bleaching Lrquid, Eau de Javelle, Aqua alkatina oxymuriatica. Common salt $\mathrm{lb}$. $\mathrm{ij}$, manganese $\mathrm{lb}$. $\mathrm{j}$; water $\mathrm{lb} . \mathrm{ij}$, put into a retort, and add gradually oil of vitriol $1 \mathrm{~b}$. $\mathrm{j}$; pass the vapour through a solution of subcarb. of potash jiij in water $3 \times x i x$, applying heat towards the last. Specific gravity is $1.08 \%$; stimulant, antisyphilitic. Used to bleach linen, take out spots, and to purify air impregnated with putrid exhalations.

SALT OF sorREL, Quadraxalate of potash, Sal acetosella verus, Potasse oxalas. From the leaves of wood sorrel bruised and expressed; the juice is then left to settle, poured off clear, and crystallized by slow evaporation : $1 \mathrm{cwt}$. of wood sorrel yields 5 or 6 oz.

2. From the leaves of sheep's sorrel, treated in the same manner.

3. By dropping subcarbonate of potash-water into a saturated solution of oxalic acid in water, when it precipitates, and may be separated by filtration: if two much alkali is added, it is taken up, and will require an addition of the acid to throw it down again; cooling. Used to make lemonade and whey.

Vitniolated tartar, Tartarum vitriolatum. Dissolve green vitriol in water, precipitate with oil of tartar, wash the precipitate, filter, evaporate, and crystallize.

Nitrom vitriolatum, Kali vitriolatum, Potassa sulphas. Dissolve the residuum left in distilling Glauber's spirit of nitre in water; add subcarb. of potash, if necessary, to saturate any superfluous acid, evaporate and crystallize.

2. Evaporate the liquid that is left in making magnesia alba, and crystallize: aperient and deobstruent, $3 j$ to $3^{\text {ss }}$; cathartic, 3iiij to $3 \mathrm{vj}$ : useful in visceral obstructions. Being very hard, it is used in compound powders to divide jalap or scammony while triturating with them.

Sal Enixum. Boil the residuum left in the distillation of saltpetre with green vitriol, strain and evaporate to dryness. Used as a flux by silversmiths and platers; also to adulterate cream of tartar, and being powdered and rubbed into the wood with a hard brush, to stop the ravages of the dry rot.

Potass.e supersulphas. Dissolve the salt that remains in 
distilling nitre with oil of vitriol in water, evaporate, crystallize, and dry the crystals: a cooling purgative, $\mathrm{Jj}_{\mathrm{j}}$ to $\mathrm{3ij}$.

Sulphas potass.e cuM surphure. Mix nitre and flowers of sulphur ana p. æq.; throw them by small portions into a red hot crucible, and let the mass cool. Aperient, deobstruent, and depurative; in cutaneous affections and obstructions of the viscera. In its medical effects it agrees with sulphureous mineral waters, which contain a proportion of neutral salt. A saline solution analogous in operation to that of the Harrowgate waters may be made, by dissolving two drachms of this salt, one drachm of cream of tartar, and one ounce and a half of sulphate of magnesia, in two pounds of water. Dose $3 \mathrm{ij}$ to $3 \mathrm{iv}$.

Sal polychrestus Glaseri. Proceed as before; but as soon as the deflagration is over, raise the heat, keep the mass in fusion for some time, pour it out, dissolve it in water; filter, evaporate, and crystallize.

RED ARgol, Tartarum rubrum. From red wines.

White ARgol, Tartarum album, Supertartris potasse impurus. From white wines; the essential salt of the grape deposited during the fermentation of the wine, especially in the northern wine countries, where the fruit does not ripen thoroughly. Used as fluxes, for preparing the best subcarbonate of potash, in dyeing, and many arts.

Crystals of taletar, Crystalli tartari, Potasse supertartras. Obtained by boiling white argol in water, with some white clay ; filtering, evaporating, and crystallizing.

2. By clarifying the solution with white of eggs and woodashes, instead of white_clays, as in the former: from Venice and Montpellier.

Cream of tartar, Cremor tartari. Formerly the skin of crystals that formed un the surface of the ley during evaporation; now used for the crystals reduced to powder: cooling, laxative, may be taken ad libitum; used as a diuretic in dropsy.

Solcblf tartan, 'T'artarum solubile, 'T. tartarisatum, Kali tartarisatum, Tartris potassa, Potassa tartras, Tartaras hali. Dissolve pearlash 1lb. in a gallon of water, add cream of tartar as long as any effervescence arises, i. e., rather less than 3lb.; evaporate and crystallize: purgative $\overline{3} \mathrm{j}$; laxative $3 \mathrm{j}$ to $\mathrm{iij}$; also added to senna and resinous purgatives $3 \mathrm{j}$ to $\overline{3} \mathrm{j}$, to prevent their griping.

Butisn crғaм of тARтAR. Argol $3 \mathrm{cwt}$, sal enixum 1 cwt.; dissolve in water and crystallize: sold for cream of tartar.

SOlUble cheas of tartak, Tartarum boraxatum, Tartris 
boraxata potassa et soda. Borax 2lb., potassæ supertartras 5lb., dissolve in water q. s., evaporate to dryness: is soluble in an equal weight of water.

Chromate of potash. Heat chromate of iron with an equal weight of saltpetre in a strong blast fire, wash out the salt, filtel the leys, evaporate, crystallize, redissolve and recrystallize two or three times, then dissolve the crystals in five times their weight of water. Used as a test liquor for metals, particularly lead.

TrIPLE PRUSSIATE of potasi, Ferruretted hydrocyanate of potash. Digest Prussian blue 1lb. in oil of vitriol 1lb., previously mixed with five pints of water: boil, filter, and wash the sediment well; then put it into a sufficient quantity of pure potash-water to turn the blue to a yellowish brown, filter, evaporate, crystallize, and redissolve the crystals. Used as a test liquor for metals.

Cyanuret of potassium and Hydrocyanate of potash. Obtained by exposing ferruginous prussiate of potash for some time to a well-sustained heat in a stone crucible, taking care to stop the mouth of it during the period of its cooling. By this means the cyanuret of iron is completely decomposed, and that of potash remains unaltered. The residue of this calcination is a blackish lamellar mass, which is the cyanuret of potassium rendered dark by the iron and carbon belonging to the cyanuret of iron. This mass is to be washed in water; it deposits iron and carbon, whilst the cyanuret of potassium dissolves, and is transformed into hydrocyanate of potash. 'The solution should be perfectly colourless; when well prepared cyanuret of potassium is white and transparent. The action of cyanuret of - potassium and of hydrocyanate of potash resembles that of Prussic acid. By dissolving cyanuret of potassium in eight times its weight of distilled water, we obtain what may be called medicinal hydrocyanate of potash. This solution should always be extemporaneous. It may be given in the same dose as medicinal Prussic acid, and under the same circumstances.

Hydrosulpiate of POTAsh, Hydrosulphuret of potash. Prepared as hydrosulphate of ammonia, putting pure potash-water into the second bottle. Used as a test liquor for metals.

IoDATE of Potash. Dissolve iodine in pure potash-water, evaporate to dryness, separate the hydriodate by spirit of wine; then dissolve the iodate in water, and crystallize. Used in bronchocele.

Hrdriodate of potash. Obtained from the mixed mass in the preceding process; by washing with spirit of wine, filtering, and distilling off the spirit. Used in bronchocele and in chronic rheumatism, commencing with two grains and a half three times a day in solution, gradually increased to ten grains. 
Solution of HYdriodate of POTASH. Hydriodate of potash gr. xxxvj, distilled water $3 \mathrm{j}$ : in scrofula and bronchocele; gtt. $\mathbf{x}$ to $x x$, ter die, in syrop: will not keep.

S.ı diuneticus, Terra foliata tartari, Kali acetatum, Acetis potassa, Potassce acetas, A. hali. Saturate subcarb. of potash with distilled vinegar, and evaporate to dryness; redissolve the salt in distilled water, and evaporate until it concretes on cooling; diuretic or cathartic, as it is managed, dose Эss to $3 \mathrm{ij}$.

\section{SALTS OF SODA.}

Trincar, Rough borax, Chrysocolla, Borax cruda. Found upon the edges of lakes; used in soldering, and for a flux. From the East Indies.

Refined bokax, Borax raffinata, Soda boras, S. subboras. Dissolve tincar in water, boil for some time, filter and crystallize; diuretic, emmenagogue, $3 \mathrm{ss}$ to $\mathrm{g} \mathrm{ij}$; externally as a gargle in thrush, or to stop excessive salivation; used also in soldering.Glass of borax. Borax dried by a gentle heat, breaking down the frothy mass as it rises; then melted by increasing the heat: the crucible should be cither of silver, gold, or platina. Used as a flux in blowpipe experiments.

Cosmon salt, Muriate of soda, Chloride of sodium, Sal communis, Sal culinaris, Soda murias, Murias natricus, Chloruretum sodii. Is found native, and also prepared, in a variety of forms, from the sea water and salt springs, by evaporation either by the sun's heat, called bay salt; or by boiling, called white salt.

Rock salt, Sal gemma, S. fossilis. Found native; when pure does not decrepitate, nor lose weight in a low red heat: it sometimes contains from 1 to 4 in the 100 of marl with some sulphate of lime; hence the excise-laws allow 65lb. to be a bushel, instead of 56lb., as in bay salt and boiled salt. Used to make builed salt, and for the same purposes.

London's patent solid salt. Cheshire rock-salt melted in a reverberatory furnace and ladled out into moulds. Used for preserving pickled provisions, as it dissolves very slowly in the brine as it becomes weak.

Bay salt, Sal marinus, Sal niger. Sea water slowly evaporated in shallow ponds by the sun; dark grey, in square hoppers; contains iodine : imported from France, Portugal, and Spain.

Cheshire stoved salt, Lump salt, Basket salt. By quick boiling the brine of salt springs until only so much water is left as merely to cover the small flaky crystals in the boiler, which are then put into conical wicker baskets, drained, and dried in stones : 100 tons of saturated brine will yicld 23 tons of salt. 
Cheshire common salt. By evaporating brine at 160 or 170 deg. Fahr. and draining the crystals, which are close, hard, and in square hoppers. Used for striking, and salting provisions intended for cool climates.

Cheshire large grained faky salt, British bay salt. From brine, evaporated at 130 or $140 \mathrm{deg}$. Fahr., harder than the common salt, and in crystals approaching to a cubical form. Used for salting provisions for warm climates.

Cheshire fishery salt. From brine evaporated 100 or only 110 deg. Fahr. in large nearly cubical crystals. Used for salting provisions intended for very hot climates, or long voyages.

Lymington common salt. By spontaneously evaporating away in shallow ponds five parts out of six of sea water, and quick boiling of the remainder to a nearly solid mass, which is drained in troughs.

Lymington salt cats. The salt deposited upon stakes by the bittern which drains from the Lymington common salt; is in lumps of 60 or $8: 1 \mathrm{lb}$. 100 tons of sea water yield only 2 tons $17 \mathrm{cwt}$. of salt. The usual proportion at the Lymington works are to each 100 tons of common salt, 1 ton of cat salt, and 4 or 5 tons of Epsom salt.

Scotch common salt. By quick boiling of sea water : is in small crystals.

Scotch Sunday salt. By making up the fires late on Saturday nights, and leaving the boiling to itself all Sunday ; is in considerably larger crystals, which are taken out on Monday morning.

Salt upon salt. From bay salt dissolved in brine and recrystallized.

Saltpetre salt, Sal salis petre. The salt that adheres to the sides and bottoms of the settling tubs, in refining saltpetre.

Decrepitated common salt, Sal communis decrepitatus, Murias soda siccatus. Heat the salt in a covered vessel till it ceases to crackle.

All these muriates of soda are stimulant, antiseptic, and hence used as seasoning for food both for man and beast. They are also employed in preserving animal substances, and occasionally in medicine, $\bar{j} j$ in clysters as a purge, and $\bar{j}$ to two pints of water as a stimulant and absorbent lotion in wens and bruises.

Sulphate of soda, Sulphas soda. Glauber's salt dried 8oz., charcoal dust $2 \mathrm{oz}$., sulphur $1 \mathrm{oz}$; grind together, heat in a crucifor half an hour, cool, dissolve in water, filter and separate the sulphite from the sulphate, crystallization. 
2. Pass sulphureous acid gas through a solution of caustic soda. Used to bleach straw hats.

Acetate of soda, Socla acetata. Saturate acetic acid with subcarbonate of soda, filter, evaporate, and crystallize; milder to the taste than acetate of potash.

Arseniate of soda, Arsenias soda. White arsenic 9oz., dry nitrate of soda 16oz.; mix and heat together in a bolt head or a sandbath, until the nitric acid is dissipated; dose one-sixth of a grain.

Nitrate of soda, Nitras soda. Saturate a solution of subcarbonate of soda with nitric acid, evaporate and crystallize. Lised to prepare arseniate of soda.

Subriospifate of soda. Saturate a solution of subcarb. of soda with liquid phosphoric acid, evaporate, and crystallize. Used as a test in blowpipe experiments, and also dissolved to discover silver in saline solutions.

'Tasteless purging salt', Soda phosphata, Phosphas soda. Dissolve phosphoric acid in water, add subcarb. of soda q. s. to saturate the acid: evaporate and crystallize.

2. Dissolve well-burnt bones in nitric acid; dissolve also Glauber's salt in water, and pour it into the nitrous solution, as long as a precipitation takes place; filter, and distil the liquor to recover the nitric acid, wash, evaporate and crystallize; purgative $5 \mathrm{rj}$ to $5 \mathrm{x}$, in broth: used also to prepare cobalt blue.

Ginuber's salt, Sulphate of soda, Sal mirabilis Glauberi, S. catharticus Glauberi, Natron vitriolatum, Soda sulphas. Dissolve the residuum left in distilling sulphuric acid upon salt, in water, saturate the excess of acid, either with subcarb. of soda, or powdered chalk ; filter, evaporate and crystallize.

2. To common spirit of bones or ammoniacal liquor add oil of vitriol, crystallize the sulphate of ammonia thus made, mix this with common salt, sublime the sal ammoniac from it, and the Glauber's salt remains, which is to be dissolved and crystallized.

Lymingtox Glaunen's sart, Sulphate of magnesia and sodu. Obtained from the mother liquor of sea water, crystallizing in rhomboids.

2. By dissolving Fipsom salt in a solution of Glauber's salt.

Rocheld.x sal.t, Sal Rupellensis, Natron tartarisutun, Soda tartarisutu, 'Turtris potussa et sodla, T'artras potassa et sodce. Dissolve subcarb. of soda $20 \%$. in water $10 \mathrm{lb}$.; add, while boiling, cream of tartar $210 \%$ : filter, evaporate to a pellicle, and crystallize. 
2. Dissolve cream of tartar lb. iij, in water 3 gall., add pearlash q. s. to saturate the superfluous acid, as in making soluble tartar, filter, add common salt $\overline{3} x j$, evaporate and crystallize. A more agreeable purgative than Glauber's salt, but rather weaker.

Sandiver, Sel de verre, Glass gall, Fel vitri. The saline scum that swims on the glass when first made; used in tooth-powders.

BLACK ASH. The waste ley of the soap-maker, pumped out of the boiler, evaporated in large iron boilers, and the salt separated as it falls down. "It consists of the sulphate, muriate, and sebate of soda, and of potash, and, being put into a reverberatory furnace, it is heated so as to partially decompose these salts, and bring it to a pasty kind of fusion, at which time it is let to run out of the furnace into an iron pan to grow cool and solid; it is then sold to the yellow soap-maker, or to the alum-maker.

\section{SALTS OF THE ALKALINE ROSINS.}

Sulphate of Quinine, Sulphas cinchonce. Digest yellow bark in weak sulphuric acid, made by adding 50 grains by weight of oil of vitriol to each $1 \mathrm{~b}$. $j$ of water : add hot lime to render the liquor clear, and wash away the extra lime from the precipitate; drain this precipitate and digest in rectified spirit, decant and distil off the spirit, dissolve the rosin in hot water rendered sour with sulphuric acid, and as the liquor cools, the sulphate of quinine crystallizes.

2. Powdered bark 2lb., water 2 gall., oil of vitriol 2 oz., measures; strain, add lime 8 oz., or enough to render the decoction dark brown, with a reddish brown sediment; proceed as above: produce 5 or 6 drachms. Febrifuge, gr. viij equal to bark $\mathbf{z j}$.

Quine hydro-ferro-cyanas. Prepared by boiling a mixture of pure quina and Prussian blue in distilled water, and then evaporating to dryness. One grain of this salt given one hour before the accession of an intermittent, is stated by $\mathrm{Dr}$. Gouzel, of Antwerp, to have perfectly cured the disease.

Quince phosphas. This may be obtained by the decomposition of the hydro-chlorate of quina by the phosphate of ammonia. This phosphate may be procured by saturating a given quantity of pure phosphoric acid with ammonia, and driving off the excess by means of gentle heat. 480 parts of the crystallized sulphate of quina are then to be rubbed together with 1200 of the hydrochlorate of barytes in crystals, and then eight times their weight of distilled water is to be added, filtered, and the residuum washed. The liquids are next to be mixed together, and diluted with four times their weight of distilled water, after which the diluted solution of the phosphate of ammonia is to be added by degrees, carefully shaking it. When a precipitate no longer 
ensues, the liquid must be filtered, and the phosphate of quina must be speedily washed with cold distilled water.

IoDATE of sTRYChNia. Obtained by saturating a concentrated solution of powdered strychnia with iodic acid, on which the mixture swells, absorbs the water, and becomes thick : treat the mass with boiling alcohol, filter and leave to evaporate: the result is a beautiful crystallization of iodate of strychnia. It may also be got by the double decomposition of a salt of strychnia, and some soluble iodate-muriate of strychnia and iodate of soda for instance. Iodate of strychnia is white, crystallized in beautiful prismatic needles, is slightly soluble in cold water, very soluble in hot water and in alcohol. Has been found serviceable in paraplegia; it may be given in pills of one eighth of a grain each, one at night and the other in the morning, and the dose is increased gradually until eight are taken in twenty-four hours.

Sulpirate of strychisine. Dissolve strychnine in dilute sulphuric acid, evaporate and crystallize; proposed to be employed, or any other salt of strychnine, when the system is accustomed to the action of pure strychnine, but not in use.

Sulpuate of brucine. Prepared in the same manner, and as well as other salts of brucine for the same purpose; not used as yet.

Selphate of morphia. Dissolve morphia in oil of vitriol, previously diluted with a considerable quantity of water; evaporate and crystallize : narcotic, a quarter of a gr. to gr. $\mathrm{j}$, in a day and night.

AcEtate of Morphia. Dissolve morphia in acetic acid q. s. and evaporate to dryness; narcotic, a quarter of a gr. to gr. $\mathrm{j}$, in a day and night.

\section{ACIDS.}

THE strength of liquid acids is usually expressed in England by the enunciation of their specific gravity, water being considered as unity; and in France and the neighbouring countries, by the degrees of Baume's hydrometer, on account of its easy construction: but this does not answer for all acids, for the experiments of Molerat, a manufacturer of acetic acid, showed that the strength of acetic acid cannot be determined by the mere consi. deration of its specific gravity; and the case is probably the same with some other acids formed in or from organic bodies.

Hence the French chemists have introduced a fictitious standard, founded upon the capability of the acid to saturate a determinate weight of well-crystallized subcarbonate of soda: the 
quantity of pure sulphuric acid (36 parts) necessary to saturate 100 parts of subcarbonate of soda, being esteemed as 100 acidimetric degrees. Then if upon trial 88 grains of any other acid be required to saturate 100 grains; or, for the sake of using smaller quantities, 22 grains should saturate 25 of subcarbonate of soda ; then, as 88 (22) of the acid is equivalent in force to 36 (9) of sulphuric acid, so by inverse proportion are 100 acidimetric degrees to $40 \mathrm{deg}$. $\cdot 99$, the conventional strength of the acid assayed, which may be quoted as 4.1 acidimetric degrees strong.

There are other modes of calculating the strength of acids in this mode of valuation, which is substituted for the equivalents of Dr. Wollaston, with a view of rendering the calculations more adapted to the habits of practical men.

As the power possessed by 36 parts of oil of vitriol to saturate 100 parts of dry subcarbonate of soda is taken to represent 100 degrees of strength, so if 36 parts of any other acid liquor are taken, the number of the parts of subcarbonate that it will saturate is at once the expression of its acidimetric strength: thus as a solution of 36 grains of crystallized acetic acid will saturate 90 grains of the subcarbonate of soda, this 90 is the expression of its acidimetric strength. The acidimetric strength of an acid may also be estimated from the saturation of any determinate weight of subcarbonate by a determinate weight of acid: for example, 100 grains of the acidum nitricum of the London Pharm. ought to saturate 212 grains of subcarbonate: then as 100 grains of acid are to 212 grains of alkali, so are 36 grains of acid representing $100 \mathrm{deg}$. of strength to the strength of the nitric acid, which will be found to be $76 \mathrm{deg} .32$; and in like manner as 100 grains of the acidum muriaticum are required to saturate 124 grains of subcarbonate of soda, its strength expressed in the French mode will be found to be $14 \mathrm{deg}$. 64 .

If the strength of any acid be given in acidimetric degrees, the quantity of subcarbonate of soda that any assigned weight of it will saturate is thus found. As 36 , the standard quantity of oil of vitriol taken to represent 100 degrees of strength, is to the quoted strength of the acid, so is the weight of the acid intended to be used to the weight of the subcarbonate that it will saturate. For instance, let it be required how much subcarbonate of soda 100 grains of acetic acid, from wood at $31 \mathrm{deg} \cdot \cdot 32$, will saturate: then as 36 are to 31.32 so are 100 to $8 \%$, the number of grains of subcarbonate that the acid will saturate. And this is the number quoted by the London college as the power of saturation that their acidum aceticum fortius ought to possess.

The use to be made of this mode of valuation may be thus exhibited. Having $1500 \mathrm{lb}$. of rectified pyroligneous acid 8 acidimetric degrees strong, how much crystallized sulphate of soda will be required to be added to the pyrolignite of lime formed 
by this quantity of acid to convert it into pyrolignite of soda? It is known that every $20 \mathrm{lb}$. 25 of sulph. of soda contains $5 \mathrm{lb}$. of dry sulphuric acid, which with $11 \mathrm{~b} .125$ of water would form 6lb. 125 of oil of vitriol at $66 \mathrm{deg}$. Baume, or 100 acid deg. Now 1500lb. of pyroligneous acid multiplied into $8 \mathrm{deg}$. of strength, will give for its total strength $12,000 \mathrm{deg}$. and $6 \mathrm{lb}$. $\cdot 125$ of oil of vitriol multiplied into $100 \mathrm{deg}$. will give for the total strength of each $20 \mathrm{lb}$. 25 of sulphate of soda $612 \mathrm{deg} . \cdot 5$. Hence, if 12,000 , the total strength of the pyroligneous acid, be divided by $612 \cdot 5$, the quotient 19,595 , or say $19 \cdot 6$, will show how many times 20lb. 25 of sulphate of soda must be employed; which will be found equal to $3981 \mathrm{lb}$.

OF VEGETABLE ORIGIN.

Malt vinegar, Common vinegar. Convert 20 quarters (160 bushels) of malt, with at least $56 \mathrm{lb}$. of hops, into at most 100 barrels of good serviceable ware. Put this ware into sweet casks, (oil butts are the best,) laid upon scantlings in the sun, filling them within three inches of the bung. Let the bungs stand open when the sun shines hot upon the cask; but in close or wet weather, and at nights, let the bungs be stopped and covered from the rain. Let not the head work out at the bungs, and it will sink to the bottom: when the first head of the liquor has fallen, draw it from the lee into another clean sweet cask, and so afterwards from cask to cask, till it come to perfection; then draw it off into a store cask. If the ware grow long and ropy, put in a fit quantity of alum, work it well together, and it will grow short again. The largest casks are the fittest to house and keep these wares in for store.-Statutes of the Distillers of London. The use of afterworts, or brewers' wash, is forbidden by these statutes.

Pickling vinegar, White wine vinegar. Make 4 bushels of malt into 130 gall. of wort; when cooled to about 75 deg. Fahr. add 4 gall. of yeast; let it stand 36 hours; then take two casks, having false bottoms pierced with holes one foot from the bottom, upon which place a considerable thickness of the bottoms of the British wine manufactories, or of low-priced raisins. Fill one of these casks two-thirds full, and the other only sufficient to moisten the rape; draw off every day the liquid material that is above the rape in the full cask into the other, and repeat this alternately until the vinegar is made.

Alfagl:, Acetum cererisia. Work strong ale upon the cuttings of the vine, unripe grapes, or cheap raisins, in the same manner as wine vinegar, with three casks, or as pickling vinegar.

WiNe visegar. Number thrce sweet casks 1, 2, 3, and fill No. 1 with good sound white rape (that is, the foot-stalks and skins of grapes left in making white wine) to within six inches of the bung; stop it close, and let it stand to gather heat, for two or 
three days in summer, but in winter it will require more time. When conveniently hot, fill up the cask within three inches of the top with wine of any kind, being well conditioned, not musty, and without dregs. Stop the cask close, and at the same time fill No. 2 with rape to gather heat; when sufficiently hot, draw off No. 1, put it into No.2, stop both close, and fill No. 3 with rape. When No. 1 and 3 have gathered heat sufficient, fill up No 1 with fresh liquor, draw off No. 2, put it into No. 3, and so let No. 2 gather sufficient heat again. Then draw off No 1, put it into No. 2; draw off No. 3, and put it into a store cask; for, having passed three times through the rape, it is become good merchantable ware. Proceed in this manner, supplying one cask from another, until all the wine to be converted into vinegar is spent. The working casks must be left nearly full, until more wine vinegar is to be made; for if the rape stand dry, it will wax hot, soon decay, and be utterly spoiled.-Statutes of the Distillers of London.

Best French wine vinegar, Vinaigre d'Orleans. Fill a cask of about 50 gallons' content a quarter full of good vinegar; put the wine intended for vinegar into a cask half-filled with beech shavings well pressed down. In eight days' time, draw off the clear wine into a clean cask, and put $2 \frac{x}{2}$ gall. into the vinegar cask. In another eight days, add $2 \frac{\pi}{2}$ gall. more wine, and so a third and fourth time: the vinegar cask should be kept in a room exposed to the mid-day sun, and the temperature kept up to about $25 \mathrm{deg}$. Reaum. or $90 \mathrm{deg}$. Fahr. by a fire if necessary. Then with a wooden spoon bring up some of the froth; if this is thick, white, and pearly, draw off 10 gall. of the vinegar, and proceed as before, until the tartar and lees of the wine accumulate so as to hinder the fermentation, and render the vinegar muddy. If the froth is red, another $2 \frac{1}{2}$ gall. of wine must be added, and the heat of the room increased. Each cask yields about 100 gall. of vinegar yearly, for ten years. Muddy vinegar is cleared by straining it through beech shavings pressed together, letting it remain on them a few days before drawing off: weak wines generally become muddy. Sometimes a cask suddenly stops working without any apparent cause; in this case draw off its contents, wash it with hot vinegar, fill it a quarter full with good vinegar, and proceed as with a new cask.

French household wine vinegar. Bring a small cask of Orleans vinegar, keep it in a cool place, and as the vinegar is drawn off for use, fill it up with wine.

Cyder vinegar. From cyder, worked as malt vinegar.

Sugar vinegar. To each gallon of water add 4lb. of brown sugar, and work it either as wine or malt vinegar.

GooseberRy vinegar. To each quart of bruised gooseberries add three quarts of water, and to each gallon of liquor 
1lb. of coarse sugar, or more; expose to the sun as in making malt vinegar.

Raisix vinegar. After making raisin wine, lay the pressed raisins in a heap to heat ; then to each cwt. put 15 gall. of water, and a little yeast, and work it as pickling vinegar.

Crystal vinegar. Pickling vinegar 1 gall., fresh burned bone black 6oz., stir together, let it stand two or three days, decant off the clear, and filter the bottons: used for pickles which require a clear colourless vinegar.

Acetum purificatum, P. U.S. Vinegar 1 gall., charcoal powder loz.; boil up and strain, or let it settle and decant off the clear.

Algol vinegar, Acetum ex tartaro. Warm water lb. xvj, white argol lb. j, dissolve, when cold add spir. vini $O \mathrm{jss}$ : keep it in a warm place in a slightly covered vessel, until the fermentation is completed, decant, and keep it well stopped.

German household vinegar. Soft water $7 \frac{x}{2}$ gall., honey 2lb., dissolve, add corn spirit 1 gall., keep it stopped up in a warm place for three months, then decant into bottles.

2. Soft water $7 \frac{1}{2}$ gall., corn spirit 2 pints, cream of tartar $1 \frac{x}{2} \mathrm{oz}$., dry yeast the size of a goose egg, ferment for three months, then decant into bottles.

Vinegar is used principally as a sauce, and to preserve vegetable substance; but it is employed externally as a refrigerant and repeller: useful also internally when an over-dose of strong wine, spirit, opium, or other narcotic poison has been taken. A false strength is given to it by adding oil of vitriol, or some acrid vegetable, as peflitory of Spain, grana Cnidia, or capsicum, which may be discovered by its leaving a sense of heat upon the lips, whereas pure vinegar leaves on the contrary a sense of cold.

Quass, Posca? Mix rye flour and warm water together, keep it by the fireside till it has turned sour : much drunk in Russia; looks thick and unpleasing at first, but becomes agreeable by use.

Vinasse. 'The bottom left in the still, in distilling wine: used in some manufactories as a weak acetic acid.

Distilllers' wasir. The grounds left in the still in distilling corn spirit: used to fatten swine.

Distulied vinegar, Acetum distillatum. Common vinegar 16 gall., distil in a copper still with a copper worm, drawing off 12 gall. A pewter worm renders it milky: sold for verjuice.

2. Vinegar 8 gall., water 8 gall., mix and distil off 8 gall.

Vinegais distilleis in glass, Acidum aceticum, P. L. and C. P. A. acetosum distillatum, A. aceticum dilutum, P. L. 1824. 
Pickling vinegar 1 gall., distil in a glass vessel 1 pint, which keep separate for perfumes or cosmetics, then draw off 6 pints, being the material required by the colleges for medical purposes.

Acidum acetosum, P. Bat. A. aceticum dilutum, P. Belg. Wine vinegar 16 pints, charcoal powder 1lb., distil in glass or stone ware 2 pints, which keep separate; then draw off 8 pints; continue the distillation, keeping each pint separate until the distilled vinegar has a burnt flavour; mix the others with 8 pints : $3 j$ of this acid should saturate $3 j$ of subcarbonate of soda, if it does not, add some stronger acid, or some of that which came over first: its spec. grav. is usually 1.00\%. Distilled vinegar is used when the mucilage of raw vinegar would be prejudicial, or its colour.-Sapa aceti. The bottoms left in distilling vinegar, with. out the addition of water.

Concentrated vinegar, Acetum concentratum, Acidum aciticum forte. Sapa aceti 1 gallon, charcoal powder 1lb., distil.

Badollier's strong acetous acid, Acidum acetosum forte, P. E. Vitriol calcined to whiteness $\mathrm{lb} . \mathrm{j}$, sugar of lead $\overline{5} \mathrm{x}$; rub together and distil.

Dollfuss' concentrated acetous acid. Sugar of lead 12oz., oil of vitriol $6 \mathrm{oz}$; distil \%oz., used to make aromatic vinegar, and as a very active errhine.

Spirit of verdigris, Radical vinegar, Esprit de Venus, Spiritus Veneris, Acidum acetosum, A. aceticum purum, C. P. Crystallized verdigris 2lb., dry it in a water-bath, distil it in a sand heat, re-distil the produced liquor: produces $1 \mathrm{lb}$.: sp. gr. 1.050. Dissolves camphire and oils.

Acidum ACETicum, P. D. Kali acetatum „s vj, add gradually oil of vitriol ziij, allowing the mixture to cool between each addition; distil to dryness: produces $z_{i i j}$.

Cuystallized acetic acid, Acidum aceticum glaciale. Acetate of soda dried, and melted by a gentle heat $10 \frac{1}{4} \mathrm{oz}$., oil of vitriol $5 \mathrm{oz}$. , mix gradually, and distil ; dry the crystals with filtering paper; produces about $6 \mathrm{oz}$.

LowITz's ACETIC ACID. Sulphate of potash 120z., oil of vitriol 6 oz., diluted with $18 \mathrm{oz}$. water ; evaporate to dryness; add acetate of soda gently dried $9 \mathrm{oz}$., black oxide of manganese ground very fine $\frac{1}{2}$ Oz., distil in glass, in a sand heat.

Rovgh pYroligneous acid, Vinegar of wood, Spirit of wood, Acetum ligni. From woods not of a resinous nature, as beech, birch, oak, or ash, by distillation in cast iron cylinders. $8 \mathrm{cwt}$. of wood yields about 35 gallons or $3001 \mathrm{lb}$. of spirit and phlegm, and leaves about 18lb. of charcoal, so that nearly half the wood passes off in gas, which being inflammable, is conducted by pipes to the fire-room of the furnaces, and aids in the supply of
heat. 
2. As a secondary product in the distillation of alder, willow, or dog-wood, in making charcoal for the manufacture of gunpowder.

Rectified Pyolig neous acrd, Smoking liquor, Spiritus acidus lirni, Essentia fuliginis. 'The rough acid redistilled in a copper' still. 100 gall. usually leave 20 gall. of viscid tarry matter in the still. Transparent, brown, a strong smoky flavour, sp. gr. 1.013 half as strong again as the best common vinegar. Used to preserve and smoke meat and fish by their being dipped in it for at most two or three minutes, or to give them a smoky flavour by rubbing them orer with it by means of a feather or sponge.

Spiritus buxi, P.L. 1745. From box wood.

Acetic acid from wood, Purified pyroligneous acid, Acidum aceticum ligni. Saturate rectified pyroligneous acid with lime, or chalk, evaporate to dryness, gently heat it, stirring it all the time, then dissolve it in water so as to mark $15 \mathrm{deg}$. Baume, mix the solution with a saturated solution of sulphate of soda; sulphate of lime falls down, and the liquid is pyrolignite of soda : evaporate to 27 or $28 \mathrm{deg}$. and set by to crystallize; evaporate the remaining liquid again, and crystallize, (whel) no more crystals can be obtained, the remainder is to be evaporated to dryness, and calcined for carbonate of soda); gently heat the rough pyrolignite in flat iron pans, until it flows quite smooth: the heat must never be so great as to occasion the least fume: hence $8 \mathrm{cwt}$. will require about 24 hours to effect this. Dissolve the roasted pyrolignite in water so as to mark $15 \mathrm{deg}$, decant and crystallize: add at once oil of vitriol sufficient to saturate the soda, decant the liquid from the sulphate of soda that is formed, and distil until the drops come over coloured, then change the receiver. The clear acid is usually 40 acidimetric degrees strong, and its specific gravity $1 \cdot 05 \%$.

2. Dissolve sulphate of soda in rectified pyroligneous acid, saturate the solution with chalk, strain, wash the sediment, add the washings to the solution, and proceed to crystallize the pyrolignite of soda as in the former process. Used to preserve animal substances, and for the purposes to which acetic acid is applicable.

Acidem ACETicum fortius, P.L. Acetic acid from wood, $100 \mathrm{gr}$. of which will saturate $87 \mathrm{gr}$. of erystallized subcarbonate of soda, or 30 acid. deg. 32 strong: used by the I.ondon college to make sugar of lead.

Honey watel for tue han, Aqua mellis. Honey 4lb., very dry sand 2lb., put into a retort or body that will hold five times as much, distil with a very gentle heat: a yellowish acid water. Used to encourage the growth of hair. 
SPIrit of rye bread, Spiritus acidus panis secalince. Cut rye bread in slices, fill a retort with it, distil, rectify the aqueous liquor. Used to extract the colour from garnets, and other stones, which it does quicker than any other acid.

Flowers of benjamin, Flores benzoini, Flores benzoes, Acidum benzoicum. Melt benjamin with a very gentle heat in a glazed earthen pot, to the neck of which a paper cone or chamber is annexed; if the flowers are tinged with oil, press them between bibulous paper, mix with white clay, and sublime again: $1 b . j$ of benjamin yielded $3 \mathrm{ij}$ of flowers.

Scheele's BeNzoIC Acid. Benjamin lb. jss, lime ziiij; rub together, boil in water 1 gall., decant, boil the sediment in water lb. iiij; decant, mix the two liquors, and boil down to a half, filter, add muriatic acid as long as any thing is thrown down, decant, dry and sublime the flowers: $1 \mathrm{lb}$. $\mathrm{j}$ of benjamin yields $3 \mathrm{j} 3 \mathrm{vj} \mathrm{Oij}$ of flowers.

Green's Benzoic acid. Benjamin 3xxiv, subcarb. of soda 3 viij ; rub together, boil in water $1 \mathrm{~b} . \mathrm{xvj}$, strain, boil the grounds in water lb. vj, strain, mix the two liquors, boil to $\mathrm{lb}$. $\mathrm{ij}$; filter and precipitate with dilute sulphuric acid q. s.; dissolve the precipitate in boiling water, strain and crystallize; $1 \mathrm{~b}$. $\mathrm{j}$ benjamin yielded $3 \mathrm{j} 3 \mathrm{j} \mathrm{O} \mathrm{j}$ of flowers. Obtained also from the urine of neat cattle and horses: a manufactory of sal ammoniac, near Magdeburgh, which uses urine, is able to supply flowers of benjamin by the cwt. Expectorant ; used in chronic coughs, gr. $x$ to 3 ss.

Concrete acid of Lemons, White citric acid, Acidum citricum, Acidum citricum crystallis concretum. Saturate lemon or limejuice with powdered chalk, wash the sediment with cold water and dry it ; each gallon of lemon juice forms $8 \mathrm{oz}$. 1-4th to $12 \mathrm{oz}$. 3-4ths of this citrate of lime: upon this powder pour dilute sulphuric acid $f$. ऊix to each 3 of chalk previously used; or, if the imported citrate of lime is used, $15 \mathrm{lb}$. will require $40 \mathrm{lb}$. of a spirit of vitriol, whose specific gravity is $1 \cdot 15$; strain through a cloth and expose the liquor in shallow vessels, that it may crystallize by spontaneous evaporation: an agreeable acid, cooling, and antiseptic; $\bar{z}^{\mathrm{ss}}$ in water $\bar{\jmath}$, is equal to lemon juice. Gr. $x x v j$ saturate subcarb. of potash gr. lxj, or subcarb. of ammon. gr. xlij, or magnesia alba gr. xl.

Brown cITRIC ACID. The first crop of crystals when evaporated by heat; sold cheaper.

Crystallized aciv of tartar, Acidum tartari crystallisatum. Cream of tartar $30 \mathrm{oz}$, boil in water 2 gall.; add chalk till it ceases to effervesce (about 1lb.), let it settle, strain, wash; to the sediment add oil of vitriol $12 \mathrm{oz}$, diluted with water 1 gall., stir, 
strain and evaporate by a water bath, that it may crystallize: the mother water yields by evaporation and crystallization tartrate of potash. Tartaric acid is used as a substitute for lemon juice and citric acid.

Spirit of tartar, Spiritus tartari. Distil argol and separate the acid spirit from the oil by a funnel : the residuum yields, by burning in the open air, very pure subcarb. of potash. It may be used for distilled vinegar.

LActic Acid. This may be extracted both from milk and from the juice of beet root. If from the latter it should be left in a stove of a fixed temperature, between $25^{\circ}$ and $30^{\circ}$. After a few days, fermentation takes place, and hydrogen mixed with carburetted hydrogen is abundantly evolved. The fermentation ended, and the liquid restored to its former fluidity-which generally occupies two months-it is evaporated to a syrupy consistence: crystals of mannete then appear, and with them a sugar. The product of the evaporation is treated with alcohol, which dissolves the lactic acid, leaving a quantity of precipitate. The alcoholic extract is taken up by the water, wherefrom a fresh deposit is made; the fluid is then saturated with carbonate of zinc, and a copious precipitation again takes place. 'The lactate of zinc, when concentrated, crystallizes, is collected and heated with water, to which some animal charcoal previously washed with hydrochloric acid is added; the whole is then filtered, and the lactate of zinc, perfectly white, crystallizes: these crystals are again washed with boiling alcohol, in which they are insoluble. By successive treatment with baryta and sulphuric acid the lactic acid is separated and concentrated in vacuo. Finally, on shaking it with sulphuric æether which dissolves it, a flaky matter is separated-when concentrated in vacuo, lactic acid is a colourless fluid of a syrupy consistence; it is inodorous, and intensely acid to the taste-very soluble in water and alcohol, rapidly dissolves phosphate of lime. Has been found of use in dyspepsia or mere debility of the digestive organs, may be given in the form of lemonade or lozenges.

Oxalic acid, Acid of sugar, Acidum oxalicum. Starch 25 oz., put it into a retort, add first common nitric acid $75 \mathrm{oz}$. , and when the action is over add nitric acid $24 \mathrm{oz}$. ; heat, decant, leave it to crystallize, decant the mother water. Add fresh nitric acid to the mother water, and crystallize again 3 or 4 times until $200 \mathrm{o \%}$. or more nitric acid has been used. Produces about $12 \frac{1}{2} \%$ of crystallized oxalic acid; the crystals are purified by solution in water and recrystallization. From its resemblance to Epsom salts it has occasioned several accidents, but it has a strong acid taste. Used for cleaning boot-tops, and as a precipitant for lime, either free or in combination. 'The nitrous gas which is disengaged is used 
in the manufacture of oil of vitriol, so that it is seldom made on purpose.

Iodine, Iode, Iodium. Extract all the soluble part of kelp by water, and crystallize the soda by evaporation : to the mother ley add oil of vitriol to excess and boil the liquid, then strain it to separate some sulphur, and mix the filtered liquor with as much manganese as there was oil of vitriol used: on applying the heat, the iodine sublimes in the form of greyish black scales, with a metallic lustre; stimulant, gr. ss, daily; specific in bronchocele, and advantageously given, in order to remove morbid growths and tumours; also in paralysis; but its action must be carefully watched, as it produces gastric irritations, and emaciation. Several practitioners have derived benefit from its employment in the various species of scrofula, in tubercular affections of the chest and abdomen; also as an emmenagogue. Latterly iodine has been employed in the treatment of syphilitic buboes, and in gonorrhœa; in lucorrhœa; also some cases of cancer are said to have been cured by it. It may be administered in the form of tincture, or dissolved in water (iodated or iorduretted waters.)

Solution of Iodine. Iodine gr. j, distilled water 1 pint; dissolve : solution orange yellow. Used as a test for starch, with which it produces a purple colour, and as one of the best modes of prescribing the iodine.

Iodic ACID, Acidum iodicum. Diffuse iodine in water, and pass chlorine gas through the mixture, until it becomes clear and colourless; evaporate to a semitransparent white saline mass.

Tannin, Tannic acid. Nutgalls $11 \mathrm{~b}$., infuse in distilled water, strain, add hydrochlorate of tin as long as any sediment is produced, wash, diffuse the sediment in water, and pass hydrosulphuric gas, from artificial sulphuret of iron while dissolving in dilute muriatic acid, through the water; filter, evaporate to dryness, and dissolve in water. Used as a test for gelatine.

Fiedler's gallic acid. Blue nutgalls 1lb., water 2 gall., boil to 1 gall.; strain. Dissolve alum 2lb. in water, add subcarbonate of potash as long as any sediment falls, wash this sediment well, and add it to the decoction of galls; next day fiter, wash the sediment till the washing no longer strikes a black colour with copperas water, mix the washings with filtered liquor, evaporate and crystallize. The liquid acid used as a test for iron and titanium, and to distinguish strontian from barytes.

OF ANIMAL ORIGIN.

Acid of Ants, Acidum formicarum. Ants $1 \mathrm{~b}$. j, boiling water lb. iiij; infuse for three hours, press out the liquor, and strain: stimulant. Used as a lotion in impotency. 
Scheele's acid of Prussian blue, Acide hydro-cyanique, Acidum Prussicum. Prussian blue $2 \mathrm{oz}$., calcined mercury $6 \mathrm{oz}$., distilled water 6 oz.: boil till the blue colour is changed to a yellowish green, filter, add hot water $10 \mathrm{oz}$., to wash the sedinient perfectly, pour the liquor upon clean iron filings 3 iij, and add oil of vitriol $3 \mathrm{j}$; pour the liquid from the quicksilver that has separated, and distil till 1-4th part has passed.

La Planche's Prussic acid. Proceed as before, but draw off only 1-6th, and redistil upon chalk, gr. ij to the oz., drawing off only $3-4$ ths.

Gay Lussac's Prussic acid. To prussiate of quicksilver 3 oz., contained in a tubulated retort connected with two receivers surrounded with ice and salt, the first of which contains pieces of muriate of lime and chalk; add slightly-smoking spirit of salt $2 \mathrm{oz}$.; distil with a slight heat, until some water appears in the first receiver, then stop the distillation, and take away the freezing mixture of ice and salt from the first receiver only : the Prussic acid will distil over into the second smaller receiver, leaving the water with the dry muriate of lime, and the muriatic acid with the chalk.

Magendie's medicinal Prussic acid. Gay Lussac's Prussic acid $3 \mathrm{j}$, distilled water 3 viijss, by weight; or acid $3 \mathrm{j}$, distilled water Jvj, by measure; antispasmodic.

Schecle's Prussic acid as prepared by the Paris apothecarics. Gay Lussac's acid 3j, water 3xl.

Schecle's Prussic acid as prepared by Robiquet. Gay Lussac's acid $3 j$, water $3 \mathrm{jj}$.

Scheele's Prussic acid as ordered in the Paris Codex Medic. Gay Lussac's acid $3 \mathrm{j}$, water $3 \mathrm{j}$.- - Strong Prussic acid in very small quantity, gtt. $\mathrm{j}-\mathrm{ij}$, either applied to the tongue or even to the skin, kills instantaneously, and the body exhales for several days a strong smell of bitter almonds; gtt. $v j-x$ of Scheele's or La Planche's acid in water 3 iij to iv, taken by tea-spoonsful every two hours is beneficial in chronic cough and in phthisis.

Serious, and sometimes fatal, accidents have been occasioned by the want of uniformity in the strength of Prussic acid. For the purpose of obtaining such uniformity, Mr. Everitt, Professor of Chemistry to the Medico-Botanical Society, has proposed the following process:- "Into a phial capable of holding rather more than one fluid ounce, put 40 grs. of the cyanuret of silver, add 7o\%. 10 minims of water and 40 minims of the dilute of hydrochlorate acid, cork closely, shake several times for the first quarter of an hour, set aside to allow the chloride of silver to fall, decant the clear liquid into anotlier bottle, to be preserved for use; every fluid drachm will contain one grain of real hydrocy- 
anic acid." With respect to the medicinal use of this substance it may be remarked that several distinguished practitioners have found it serviceable in affections of a spasmodic nature, either of the lungs or stomach.

\section{OF MINERAI ORIGIN.}

1. White arsenic, Oxide of arsenic, Acide arsenieux, Deutoxide d'arsenic, Arsenicum album, Oxidum arsenici, Arsenici oxydum, Acidum arseniosum. Obtained in a powdery form by subliming some kinds of cobalt ore, and reduced to lumps, for convenience of carriage, by sublimation. Imported from Germany in casks of 2 to 5 cwt.

Arsenici oxydum prceparatum. From the former by a fresh sublimation: tonic, but scarcely ever used in medicine, although frequently for empoisoning or self-destruction; in metallic mixtures to whiten copper and in dyeing.

Tasteless ague drop. White arsenic gr. j, water 1oz. ; dissolve : dose a tea-spoonful night and morning. Used in the fen countries by private practitioners. In a book of travels through England, it is said to be common for the farmers in the marshy parts of Essex to fetch their wives from the uplands, who seldom live long in the low countries; so that most of the farmers there have had several wives, and many make much money by this system of wiving. Does this mortality arise from the ague, or from the use of this remedy?

Solution of deutoxide of arsenic for assaying Distilled water 3iv, white arsenic gr. xlviij ; dissolve by boiling. As a test for ${ }^{\mathrm{s}} \mathrm{ul}$ phuric acid, lime, and copper.

Boracic AcID, Sedative salt of vitriol, Acidum boracicum, Sal acidum boracis. Borax 3oz., water 2 pints; dissolve, add oil of vitriol $3 \mathrm{vj}$, evaporate to a pellicle, and crystallize.

2. From the water of some Italian lakes, by evaporation and crystallization in such quantities as to overstock the market: some left in the Custom-house, as not worth the duties laid on it. Used to make borax.

Muriatic acid, Hydrochloric acid, Marine acid, Acid of common salt, Acidum muriaticum, A. hydrochloricum, A. salis communis.-Lemeri's spirit of salt. Common salt 1lb., potters' earth 3lb. ; moisten, mix, make into balls, distil.

Acid water of salt, Aqua acida salis communis.-Oil of salt, Oleum salis. Redistil Lemeri's acid by a heat of about $100 \mathrm{deg}$. Fahr.; the acid water comes over, limpid, ungrateful to the taste; the oil of salt remains very rich, fragrant, gratefully acid, greenish yellow. 
Acidum muriaticum, P. L. Decrep. salt 3xxiv, oil of vitriol $\xi \mathrm{xx}$; distil into a pint of water; spec. grav. should be $1 \cdot 17$, and $100 \mathrm{gr}$. ought to saturate $124 \mathrm{gr}$. of subcarbonate of soda.-Officinal preparation. Murias Barytæ, $E$. Solutio muriatis calcis, $E$. D. Tinctura ferri muriatis, L. E. D. Hydrosulphuratum ammonix, $E$.

IHenry's muriatic acid for assays. Muriatic acid diluted to gr. $1.0 \% 4$, so that a measure of it will saturate an equal measure of subcarbonate of potash-water, or of pure ammonia-water, or two measures of pure potash-water, or of pure soda-water, or of subcarbonate of soda-water, or of subcarbonate of ammoniawater.

A. muriaticum, P. Bat. Water $6 \mathrm{oz}$, boiled German oil of vitriol $12 \mathrm{oz}$; mix, pour it upon decrep. salt $18 \mathrm{oz}$, in a retort connected with a receiver and two bottles; the first bottle containing water $4 \mathrm{oz}$; the second $6 \mathrm{oz}$; distil, mix the acid in the receiver and first bottle: that in the second bottle, being weaker, is kept for ordinary uses. If the strong acid brings over any sulphuric acid, it should be rectified upon salt $2 \mathrm{oz}$.

A. muriaticum, P. Belg. Water $9 \mathrm{oz}$, oil of vitriol 24 oz.; mix, pour upon decrep. salt $30 \mathrm{oz}$., in a large glass body, lengthen the nose of the head by a pipe passing nearly to the bottom of a long-necked receiver containing water $15 \mathrm{oz}$, and the joint merely secured by a roll of paper. Distil till the charge begins to grow solid; then take off the receiver, and apply another containing water $1 \frac{1}{8} \mathrm{oz}$. The first receiver contains a very pale, smoking, concentrated acid, of $22 \mathrm{deg}$. Baume, free from sulphuric acid; the second a very strong, but coloured acid, contaminated with a little sulphuric acid.

Muriatic acirl distilled in iron, Acide hydrochlorique des cylindres. 20 cast-iron cylindrical retorts, about 5 feet long, and 18 inches over, are usually placed in one stack of furnaces, with a fire-ronm to each pair. Each retort is charged with 160lb. of salt, heated, and then $128 \mathrm{lb}$. of oil of vitriol, at $66 \mathrm{deg}$. Baume; or, which is better, 1331b. at 64 deg. are poured in. The vapours are passed into $150 \mathrm{lb}$. of water, contained in 4 eight-gallon bottles connected by bent pipes, the first of which is set in a trough of running water. 'The produce is about 208lb. of yellow, smoking, austere acid, at 23 deg. Baume, equal to sp. grav. 1.19, from each retort: that collected in the first bottle contains sulphuric acid, and sometimes muriate of iron, and sulphate of soda.

Muriatic acid obtained in manufacturing subcarbonate of soda, Acide hydrochlorique des bastringues. Salt 2,400lb., oil of vitriol 2,640lb., at $54 \mathrm{deg}$. Baume, distilled in a leaden pan, covered with the cast-iron under plates of a flue passing over and then under the leaden pan; the vapour is passed into several series of 
large stone-ware jars, or aludels, placed one on the other, to the number of seven or eight. As the residuum must be drawn out while yet soft, there is only produced 1,920 , or $2,160 \mathrm{lb}$. of weak acid, at $21 \mathrm{deg}$. Baume: being about 2-3ds of the acid in the salt : the acid is yellow, and pleasanter to the taste than that distilled in iron.

Weber's marine acid. Bittern, or residuum of sea-water after the common salt has been obtained by evaporation, 5lb., oil of vitriol 1lb., previously diluted with water $21 \mathrm{lb}$; distil.

Acidum muriaticum dilutum, P. D. Spirit of salt, spec. grav. $1 \cdot 170$, distilled water, ana p. æq.; mix : the specific gravity should be $1 \cdot 080$. Muriatic acid is tonic, antiseptic, gtt. $\mathrm{x}-\mathrm{xx}$, well diluted in typhus, $3 \mathrm{ss}-3 \mathrm{ij}$ in water $\overline{3} \mathrm{vj}$ as a gargle in putrid sore throat, gtt. viij in water 3 iv as an injection in gonorrhœa. Used in the arts as a cheap acid : a small portion improves salted provisions : also as a test for silver, borax, ammonia.

Sprrit of Nitre with boLE, Spiritus nitri. Nitre 1lb., clay 4lb., moisten, make into balls, and distil.

Aqua fortis, $A$. f. simplex. Copperas 2lb., white rough petre 11b., mix and distil.

2. Spirit of nitre $20 \mathrm{lb}$, oil of vitriol $7 \mathrm{lb}$, water $30 \mathrm{lb}$; mix. Said (Elab. laid open) to be nearly the standard of the aqua fortis imported from Holland for the dyers.

Double aqua fortis, A. f. duplex. White petre, copperas, of each 6 blb., copperas calcined to redness $31 \mathrm{lb}$., distil.

2. Spirit of nitre $91 \mathrm{lb}$, oil of vitriol $11 \mathrm{~b}$.; mix : used by engravers and brass founders to clean their work.

Strong aqua fortis, Eau forte, Stark wasser. Copperas calcined to whiteness, white petre, of each $30 \mathrm{lb}$., mix and distil in an iron pot with a stone-ware head : very red, smoking, has sometimes an oil floating upon it.

Julin's aqua fortis. Rough nitre, and calcined Fahlun aqua fortis vitriol No. 3, of each 4lb., distil; a white inflammable substance comes over with the acid, the nature of which is unknown. Boerhaave's spiritus nitri Glauberi. Nitre 3lb., oil of vitriol 1lb.; distil : gold colour, deep red vapour, scarcely confinable.

Geoffroy's spirit of nitre, Nitrous acid, Spiritus nitri fumans, Acidum nitrosum, $A$. nitroso-nitriticum. Nitre $60 \mathrm{oz}$., oil of vitriol $30 \mathrm{oz}$; distil into a large receiver without water; yields about $30 \mathrm{oz}$ : : red, and very smoking, sp. gr. 1·53.

2. Nitre $24 \mathrm{oz}$., oil of vitriol $12 \mathrm{oz}$, distil into a receiver connected at top with two bottles, the first containing water $1 \frac{1}{4} \mathrm{oz}$., the second $6 \mathrm{oz}$. The receiver contains a concentrated acid, sp. 
gr. $1 \cdot 55$, the first bottle a weaker coloured acid, the second a pale acid slightly impregnated with nitrous gas.

Spirit of nitre. White petre $24 \mathrm{lb}$., oil of vitriol 12lb.; distil into 6 pints of water.

Acide nitrique jaune ambre. Nitre $170 \mathrm{lb}$., oil of vitriol $100 \mathrm{lb}$., distil in a cast-iron cylinder connected, by elbow pipes, with four 10 gall. bottles half-filled with water; the first elbow pipe should be of glass, to permit the colour of the vapour being seen. The acid collected in the first bottle is impure, and may be used to make single aqua fortis, that in the second and third bottles is purer, that in the fourth bottle is put into the first bottle in the next distillation. Iron pots with stone-ware heads are also used: the acid thus obtained is redder, and yields less pale acid. It is usually sold sp. gr. $1 \cdot 335$, so that a bottle holding $5 \mathrm{oz}$. of water shall hold $6 \frac{1}{2}$ oz. of this acid, or at $36 \mathrm{deg}$. Baume.

Nitric acid, Rectified spirit of nitre, Spiritus nitri decolor, Acide nitricum, P. E. Distil Geoffroy's spirit of nitre, in glass unluted ressels, until the acid in the retort becomes colourless. It must be kept in a dark place.

Acidum nitricum, P. Bat. Oil of vitriol and water of each $12 \mathrm{oz}$., mix, and when cool, pour upon nitre 24. oz., distil to dryness : if the acid is coloured, redistil it in unluted vessels until the acid becomes pale.

Acidum nitrosum dilutum, A. nitricum, P. Belg. Geoffroy's spirit of nitre lb. j, water $\mathrm{lb} . \mathrm{j}$, mix.

Acidum nitricum, P. L. Nitre very pure and dried, oil of vitriol, ana $24 \mathrm{oz}$. , distil till red fumes appear ; redistil from nitre $1 \mathrm{oz}$ : : produces $15 \frac{3}{4} \mathrm{oz}$. of white acid : the redistillation is useless; sp. gr. should be $1 \cdot 5$; an ounce measure of it, diluted with water, should dissolve 3 vij of limestone; or $108 \mathrm{gr}$. ought to saturate 212 gr. of crystals of subcarbonate of soda.-Officinal preparatiom. Acidum nitricum dilutum, $L$. Argenti nitras, $L$. Liquor ferri alkalini, $L$. Unguent. hydrargyr. nitratis, $L$. Hydrargyri nitrico-oxydum, $L$. Spiritus ætheris nitrici, $L$.

Acidum nitricum dilutum, P. L. Acid. nitricum $3 \bar{j}$ measure, distilled water $\tilde{z}^{i x}$ measure.

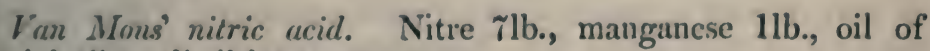
vitriol $4 \mathrm{lb}$.; distil into water $\mathrm{q} . \mathrm{p}$.

Assanyer's nitric acil, Proof aqua fortis, Aqua separataria. To pale nitric acid add a solution of nitrate of silver as long as any cloudiness is produced; let it settle for a few days, pour off the clear, and distil nearly to dryness. 
- Steinacher's purified nitric acid. Nitric acid $16 \mathrm{oz}$, litharge $2 \mathrm{oz}$, distil very slowly, leaving about $2 \mathrm{oz}$. in the retort.

Henry's nitric acid for assaying. Sp. grav. 1·143; has the same power of saturation as his muriatic acid at $1 \cdot 074$, or sulphuric acid at $1 \cdot 135$.

The stronger kinds of this acid are used as a caustic to warts, \&c. ; diluted so as not to injure the teeth, viz., of the strong acid gtt. $\mathrm{j}$ to $\mathrm{x}$, in a small tumbler of water, is useful in liver complaints, lues venerea, nausea from dyspepsia, sea-sickness, \&c. ; in the arts, to dissolve metals or cleanse the surfaces.

Lemeri's solvent for antimony. Spirit of nitre $10 \mathrm{oz}$. , oil of vitriol, muriatic acid, of each $4 \mathrm{oz}$; dissolves regulus of antimony and its oxides.

Agua fortis composita, P. L. 1745. Double aqua fortis $16 \mathrm{oz}$, common salt $3 \mathrm{j}$; distil to dryness: used to make red precipitate, and cause the scaly appearance.

Dyer's aqua fortis. Nitric acid perfectly freed from nitrous gas, sp. gr. $1 \cdot 1 \%$, 100lb. ; muriatic acid sp. gr. 1·19, 5lb.; mix : dissolves tin without oxidizing it.

Spiritus nitri bezoardicus. Precipitate butter of antimony by sp. nitre, and distil off the acid.

Aqua regia. Spirit of nitre $16 \mathrm{oz}$, common salt $4 \mathrm{oz}$.; dissolve.

Aqua regia made with sal ammoniac. Spirit of nitre 16 oz., sal ammoniac $4 \mathrm{oz}$.; dissolve: very expensive, and difficult to keep.

Nitro-muriatic acid, Hydrochloronitric acid. Nitric acid at $33 \mathrm{deg}$. Baume 1lb., muriatic acid at $20 \mathrm{deg}$. $3 \mathrm{lb}$.; mix. All are used to dissolve gold and platinum.

Acidum Nrtro-muriaticum dilutum. Acidi nitrici, Acidi muriatici, sing. Oss. Aqua distillat, $\mathrm{O}_{j}$. For the nitro-muriatic acid wash, or bath; three ounces of this acid being required to every gallon of the water for the bath, but double this quantity when used as a wash or lotion. In affections of the liver, and for internal obstructions.

Liquid Chlonine, Oxymuriatic acid, Dephlogisticated spirit of salt, Acidum oxymuriaticum, Aqua oxymuriatica, Chlorum aquâ solutum. Common salt 3lb., manganese $1 \mathrm{lb}$., oil of vitriol $1 \frac{x}{2} \mathrm{lb}$., water $1 \mathrm{lb}$. : distil, and pass the vapour through 3 or 4 bottles half filled with water; pale greenish yellow, scarcely heavier than water; used in syphilis and scarlatina, 3 ss to iij, in water $\overline{3}$ viii, taken, by small doses, in a day : bleaches linen, straw, and takes out fruit spots, iron moulds, or ink marks. 
Phosphoric acrd, Acidum phosphoricum. Bone ash in fine powder $48 \mathrm{oz}$., oil of vitriol $26 \mathrm{oz}$, water $16 \mathrm{oz}$; boil for two hours in a tin vessel, strain, add fresh water until all the acidity is extracted, mix the waters and boil to $36 \mathrm{oz}$., at first in a tin, and then in a porcelain ressel. Add subcarbonate of ammonia water as long as any sediment falls; filter, evaporate, remove into a porcelain crucible, and reduce it by evaporation and fusion in silver vessels to a clear glass, which weigh and dissolve in six times as much water.

2. By adding phosphorus gradually to nitrous acid in a pierced retort; when all the phosphorus is dissolved, the remaining nitrous acid is distilled off; used in caries of the teeth and bones, gutt. xv to $\mathrm{xl}$, in water $\overline{3} \mathrm{ij}$ every two hours; it has been also employed externally in caries ossium, compresses moistened with the acid diluted with eight parts of distilled water being applied over the ulcers, under which the bone was carious.

German oil of vitriol, Oleum vitrioli, Spiritus vitrioli fortis, Acidum sulphuricum Germanicum. Calcine copperas to redness, distil in small charges for about 18 hours, although it will contiuue to emit vapour for 10 days. Boerhaave from $81 \mathrm{lb}$. copperas calcined to 5lb., in 2 retorts, obtained $21 \mathrm{oz}$. of thick black smoking oil, and $52 \mathrm{oz}$. of light powdery colcothar were left, $8 \mathrm{oz}$. passed off uncondensed. Bernhard from $6 \mathrm{cwt}$. calcined to a yellowish red, distilled apparently in 12lb. charges, the phlegm collected in dishes until very acid, and white vapours began to appear, and then $\frac{1}{2} l b$. put into each receiver, which were luted on, obtained only 64lb.

Nordhausen oil of vitriol, Acide fumante de Nordhausen. From copperas calcined to redness, distilled in 3lb. charges in earthen cucurbites set slanting, to get out the colcothar without disturbing them, the phlegm allowed to drop into a dish until white vapours appear very copiously, receivers then applied and luted with $\frac{x}{2} l \mathrm{~b}$. water in each in the first distillation: 3 charges of each retort are distilled into each receiver before the acid is poured out; black, very smoking, sp. gr. 19, or $68 \mathrm{deg}$. Baume; by exposure to air, or boiling, it ceases to smoke, and becomes similar to the acid obtained from sulphur. Dissolves a larger quantity of indigo than the acid from sulphur; the solution requires no heat, and is of a beautiful purple colour. From Nordhausen in Saxony, also from Bleyl in Boliemia, where a manufactory of it has been established from time immemorial. Used in dyeing.

White smoking sulphuric acid. Copperas calcined to redness 20lb., distil and receive the vapours in oil of vitriol from sulphur $7 \frac{1}{2} l \mathrm{~b}$.; produces $10 \mathrm{lb}$. of sinoking acid, perfectly similar to the Nordhausen except in colour. 
2. Distil several successive charges of red sulphate of iron into a small quantity of distilled water.

Anhydrous sulphuric acid, Icy oil of vitriol, Oleum vitrioli glaciale. From calcined copperas, as the German oil, not putting on a receiver until the white vapours come out very copiously, and putting no water or phlegm into it. Bernhard from $6 \mathrm{cwt}$. of copperas obtained $50 \mathrm{lb}$.

2. By distilling Nordhausen oil of vitriol in luted vessels; the icy oil sublimes into the neck of the retort, while the hydrated acid passes over in a liquid form.

3. By distilling calcined copperas a number of times into the same portion of English oil of vitriol ; white, transparent crystals, smoking very much; melts at $66 \mathrm{deg}$. Fahr. and crystallizes at 77 deg.; contains no water.

Acidum sulphuricum depuratum, P. Belg. German oil of vitriol boiled in a bolt head on a sand bath, until it admits no watery vapours, and becomes pale.

Acidum sulphuricum purum, P. Belg. German oil of vitriol 2lb.; distil in a very large retort in a sand bath into an unluted receiver, by a heat not exceeding that of boiling water, as long as large drops of water form in the neck; then augment the heat even to boiling, and when oily streaks appear and the vessels are filled with the white vapours of sulphuric acid, apply another receiver previously warmed, and distil, at the rate of 4 drops in a minute, to dryness.

Oil of sulphur by the bell, Oleum sulphuris per campanam. Burn sulphur in a moist place and during moist weather under a glass, bell, or some similar vessel, previously moistened on the inside with the steam of water; collect what drops from the bell in a glass plate, and distil it until white vapours begin to appear, the oil of sulphur remains in the retort. The purest sulphuric acid; but it was esteemed good workmanship to obtain 5 oz. from each bell in 24 hours.

Common oil of vitriol, Sulphuric acid, Oleum vitrioli Anglicum, Acidum sulphuricum Anglicum. Mix sulphur 100lb. with saltpetre 100 or $120 \mathrm{lb}$., burn it by degrees upon a plate of hot iron, conduct the vapour into a chamber of 5000 or 10,000 cubic feet capacity, formed of sheet lead, having at the bottom a layer of two or three inches of weak sulphuric acid. A small hole, about two inches above the level of the burning sulphur, must be left to allow a draught of air to enter the chamber, and a chimney at the further end to let it pass off. Inject occasionally a shower of water, and draw off every morning the acid that was made during the preceding day, leaving the original depth on the floor of the 
chamber. Evaporate this acid in leaden pans to sp. gr. 1.532 or 50 deg. Baume; then distil it in glass retorts, or a platina still with a leaden head, until all the water has come over, and the acid is brought to sp. gr. 1.845 or 66 deg. Baume, so that a bottle holding $12 \mathrm{oz}$. of water should hold full $22 \mathrm{oz}$. of this acid; the produce is from 2500 to $2600 \mathrm{lb}$. of acid.

2. Upon an iron dish set on a furnace, and communicating with a leaden chamber 50 feet long, 27 wide, and 15 high, the bottom of which is covered with a sheet of sulphuric acid, sp. gr. 1.075 or $10 \mathrm{deg}$. Baume, throw $100 \mathrm{lb}$. of rough brimstone, which should take fire immediately: at the same time the vapour from the mixture of $11 \mathrm{~b}$. of treacle and 9lb. of smoking nitrous acid, heated in a bolt head, set on the sand bath of an adjoining furnace, is admitted about two feet above the burning sulphur. In two hours' time the steam of 10 gallons of water is to be admitted, and a small hole opened just above the burning brimstone to admit the air. When the steam is condensed, the door by which the brimstone was introduced, and two chimneys at the further end of the chamber, are opened to renew the air in the chamber for a fresh operation. Four operations may be made in 24 hours, but it is preferable to perform only three, or even two. The acid drawn off is about sp. gr. 1.381 or 40 deg. Baume; if less steam is injected and the sp. gr. raised to 1.53 .2 or $50 \mathrm{deg}$. Baume, it absorbs some of the nitrous gas, which cannot afterwards be separated from it, and which renders it unfit for making the solution of indigo used by the dyers. The acid thus obtained is then concentrated as before. This produces $300 \mathrm{lb}$. of acid, sp. gr. 1.845 or $66^{\circ} \mathrm{deg}$. Baume, from each $100 \mathrm{lb}$. of brimstone, which is only 12lb. less than the theoretical product. The abstraction of the nitric acid from the treacle produces oxalic acid, which saves the whole expense of the saltpetre.

Hill's patent oil of vitriol. The native sulphuret of iron, or martial pyrites, is distilled, and an imponderable substance, as the patent terms it, is to be injected into the chamber; this may be oxygen gas from black oxide of manganese.

Henry's sulphuric acid for assays. - Rectified oil of vitriol diluted to sp. gr. 1.135: it has the same power of saturation as his nitric acid and muriatic acid.

Rectified nil of vitriol, Oleum vitrioli rectificatum. Distil, in a sand pot, oil of vitriol $4.0 \%$ at a time in a large green-glass retort into an unluted receiver, fitting very loosely to the retort. 1) Bryan Higgins observed, that green glass was apt to crack, and that even flint glass retorts would crack if the sand rose up higher than the evaporable charge. Dr. Ure styys, he can distil a pint or nearly 2lb. of acid in a continuous stream, without heating the 
receiver in the least, by using a plain glass retort capable of holding 2 or 4 quarts of water, putting into the acid a few fragments of glass, and connecting the retort with a large globular receiver by a glass adapter 4 feet long, and from 1 to 2 inches in diameter, unluted and fitting very loosely at each end, that the vapours which rush forth occasionally may not burst the vessels; the retort is to be placed over a charcoal fire, and the flame made to play loosely on its bottom. Sulphuric acid is used as a caustic to warts or wounds, and in many trades, particularly dyeing, so that 3000 tons of it are consumed yearly in the British islands.

Spirit of vitriol, Spiritus vitrioli, Sp. vitrioli tenuis. The phlegm that comes over, in rectifying the acid distilled from green vitriol, sp. gr. 1·200.

Acidum sulphuricum dilutum, P. E. and P. D. Sulphur. acid 1 oz., water 7 oz., both by weight.

Vitriol to clean coppers, Acidum sulphuricum dilutum, P. L. Sulph. acid 1 oz., water 7 oz., both by measure.

Elixir of vitriol, Elixir vitrioli. Water q. p. add oil of vitriol q. s. to give a grateful acidity. Tonic, astringent, gtt. $\mathrm{xx}$ to $3 \mathrm{ij}$, in a cup of water; or $3 \mathrm{j}$ to 3 viij water for a gargle to check a salivation: used by workmen and servants to clean copper and iron work; also, as a cheap acid in punch or acid stews instead of lemons, and to give strength to poor vinegar.

Sulphurous acid, Aqua sulphurata, Gas sulphuris. Collected by burning brimstone $2 \mathrm{lb}$. under a glass jar, standing with its mouth downwards in a plate of water, holding two pints till the water is sufficiently acid.

2. Oil of vitriol $8 \mathrm{oz}$. , quicksilver $4 \mathrm{oz}$., boil in a retort, and pass the gas into a pint of water : the bottom will serve for making turbith mineral or corrosive sublimate.

3. Oil of vitriol $3 \mathrm{oz}$., charcoal in small pieces $1 \mathrm{oz}$., distil into 3 pints of water; cheap, but much carbonic acid gas is produced, which incommodes the operation, and the bottom is of no use.

4. Oil of vitriol $1 \mathrm{oz}$., sulphur $3 \mathrm{j}$, dissolve and add water $6 \mathrm{oz}$. Used to bleach silk, straw, take fruit-stains out of linen, to analyze iron and steel, and stop the fermentation of wine.

Spirit of Amber, Spiritus succini.-Volatile salt of amber, Succinic acid, Sal succini, Acidum succini: Obtained by distillation from amber, pressing the acid salt between blotting-paper, and either subliming it again, or dissolving it in water and crystallizing: antispasmodic, diuretic, gr. $\mathrm{v}$ to $\mathrm{gj}$. 


\section{WATERY LIQUIDS.}

\section{NATURAI, WATERS.}

THE salts obtained by the evaporation of a mineral water are not to be considered as its real contents, because new combinations are formed during the process, and the most insoluble compounds possible are separated first: whereas, in the original water there is good reason to suppose the real mode of composition is that of the most soluble compositions that are capable of being formed from the remote principles contained in the water. Hence those common products, sulphate of lime and muriate of soda, probably exist in mineral waters as sulphate of soda and muriate of lime, arid it is to the presence of the latter salt that much of the medical effects of mineral waters is to be ascribed.

River water, Aqua fluviatilis;-Rain water, Aq. pluvialis. Are the purest of the common waters.

Snow water, Aq. nivalis. Is also very pure.

Spring water, Aq. fontana. Generally contains sulphate of lime and muriate of soda: The purest spring waters hitherto discovered are the Malvern spring water of England, and the Madras spring water of India, which is even superior to the Malvern.

Acinulous waters, Acidula. Taste acid, sparkle on being pourcd out; contain an excess of carbonic acid, and almost constantly common salt, with some of the earthy carbonates.

Chatrbeate waters, Aqua chalybeate. Strike a black colour with oak bark or other vegetable astringents, sometimes are also acidulous; these deposit their iron upon boiling, as those of the Spa and Pyrmont; others vitriolic, and retain their power of striking a black colour after being boiled and filtered, as that of Westwood in Derbyshire.

Sulphureous waters, Aq. sulphurea. Stink like rotten eggs, blacken silver and lead, contain sulphuretted hydrogen, either uncombined or united to lime or an alkali. Harrowgate is well known.

Hard watras, Aq. fontana. Curdle soap even after boiling; contain sulphate of lime.

Sart watens, Aq. salina. Easily recognised by their saline taste, and the salt crystallizing in cubes; precipitate the solution of silver, lead, or quicksilver in spirit of nitre, forming a white cloud.

Purging waters, $A q$. cathartica. Bitter, purgative, preci- 
pitate the solution of silver, lead, or quicksilver in spirit of nitre, forming a yellow cloud; not affected by acids, but afford a precipitate with subcarb. of potash ; contain Epsom salt; the springs of Bagnigge Wells, Dulwich, and Epsom, are of this nature.

Alkaline waters, Aq. alkaline. Change blue vegetable colours to a green, effervesce with acids, yield a precipitate with alum water. Tilbury water is an example.

Copprer waters, Aq. cuprece. Turn blue with liquid subcarb. of ammonia, if not already of that colour ; cover iron left in them with a coat of copper; contain blue vitriol; found near copper mines, poisonous.

Aluminous waters, Aq. aluminosce. Change vegetable blue to a red, even after standing some time in the open air, effervesce with alkalies, and are decomposed, precipitating in flocculi.

Petrifying waters, $A$. lapidificantes. Deposit an earthy sediment on standing or by boiling; unwholesome.

Stygran water, Aqua Stygis. Corrodes glass and earthenware, contains fluoric acid: poisonous, reported to have been exhibited to Alexander the Great, and to have occasioned his death, the water being carried from the spring in Arcadia, in a horse's hoof : another spring of this kind has been lately found in Prussia, and closed up by the government.

Sea water, Aqua marina. Contains common salt and Epsom salt in large quantity; purgative, but should always be filtered through paper to separate the fine sand and invisible mollusca that it contains: the taste is best covered by mucilage of salep. It is the usual clyster on board ship. Many attempts have been made to obtain fresh water from it at sea.

MAYDEw, Ros majalis. Collected by sponges off the grass: used as a cosmetic.

Senna sura vinegar, Cadalay poolippoo neer. The night dew wrung out of muslin spread over horse gram while growing: used in India as the common vehicle for medicines; contains oxalic, malic, and acetic acids.

\section{ARTIFICIAL WATERS.}

Distilued water, Holy water, Aqua distillata, Aq. depurata. Rain or river water 10 gall. distil, throw away the first half gallon, and draw off 6 gall., which keep in glass or stone ware vessels, covered only with paper caps to admit the absorption of air. Used as a diet-drink in cancerous diseases, and in the religious ceremonies of the Catholic church. 9 parts of water are resolvable into 8 of oxygen and 1 of hydrogen by weight. 
Alitifial sha water, Aqua marina arte facta. Water 5 gall. muriate of soda $\overline{\tilde{j}} \mathrm{x}$, muriate of magnesia $3 \mathrm{x}$, muriate of lime 亏ैij, sulphate of soda and sulphate of magnesia of each $5 \mathrm{vj}$; dissolve: dose 今iv, or as a bath.

Water impiegnated with fixed arr, Carbonic acid, Aqua acidulata cum ucido carbonico, Acidum carbonicum. Put marble in coarse grains into a bottle wetted beforehand, and add by degrees a sufficient quantity of muriatic acid, at $10 \mathrm{deg}$. Baume, to dissolve the marble; pass the gas by means of elbowpipes through two or three bottles, the first having only a small quantity of water to absorb any muriatic acid that may come over, the others containing between them about a gallon of water for each half ounce of marble employed: an agreeable summer drink. The muriatic acid in the residuum may be obtained for future use, by adding oil of vitriol as long as any sediment falls.

Single soda water, Aqua acidi carbonici. Impregnate water by means of an apparatus made for the purpose, and which will allow considerable pressure to be applied, with five or ten times its bulk of carbonic acid gas (each ounce of marble yields nearly two gall. of the gas), and transfer the impregnated water into half-pint bottles, to be well corked and wired. The gas escapes as soon as the bottle is opened, and gives the water an agreeable piquancy.

Carbonated lime water, Aqua calcaria acidula. Lime water 1 pint, distilled water 2 pints; pass carbonic acid gas through it, until the water, which at first is rendered cloudy, becomes transparent again. Used in calculous complaints.

A rtificial. Spa water, Aqua carbonatis aciduli soda mixta. Water 5 gall. carbonate of lime $3 i j$, carbonate of magnesia $3 j$, subcarbonate of soda $\overline{5} \mathrm{vj}$, muriate of soda $\overline{3} \mathrm{j} s s$; dissolve, and pass through it the carbonic acid fiom marble $3 \mathrm{ij}$.

Amtificial chais brate water, Aqua carbonatis aciduli ferri. Water impregnated with fixed air 1 pint, iron filings $\tilde{3} \mathrm{j}$; keep in a cool place for 24 hours : pour off the clear.

Aqua supencarbonatis potass.z. Oil of vitriol ziij, water lb. iij ; mix, and add gradually marble powder $3 \mathrm{iij}$; pass the gas that is discharged through water 1 gall. with subcarb. of potash . $\mathrm{j}$ dissolved in it, in a proper apparatus, to secure considerable pressure, and enable the bottles containing it to be corked without letting the gas escape till drank.

Dotнi.: soda water, Aque suljcarbonutis sode. Prepared by putting 1 gall. water and subcarb. of soda 3 ij in bottles, and passing carbonic acid gas through it. Used largely as a cooling beverage in summer : beneficial in calculous complaints. 
Liquid magnesia, Aqua magnesia, P.U.S. Water 8 pints, carbonate of magnesia 3iij; mix, and impregnate with carbonic acid gas, as in making double soda water.

Hydrosulphuric ACID, Water impregnated with hepatic gas, Acidum hydrosulphuricum, Aqua hydrosulphurata, Aqua hepatica, Acidum hydrothionicum. Sulphuret of iron $\overline{3}$, dilute sulphuric acid 3iij; dissolve, and pass the gas into a large bottle inverted in a tub of water, until 2-3rds of the water that filled it is expelled; stop the bottle under water, and shake it well, loosening the stopper now and then, that the air may enter: when the water is saturated with the gas, it is to be kept in smaller bottles, well stopped. Used in gout, Devonshire colic, and diseases from quicksilver: a teacup daily, or as a bath.

Śdine sulphur water, Aqua sulphurata salina. Dissolve what salts appear necessary in water, and pass into the solution either sulphuretted hydrogen gas only, or a mixture of that and carbonic acid gas.

Hahneman's wine-test, Aqua hydrosulphurata acidula, Aqua sulphurato-acidula, Aqua hepatica acidula, Liquor probatorius Hahnemanni. Quicklime 3 j, flowers of sulphur 3 jss; heat in a covered crucible for 5 or 6 minutes; of this take $3^{i j}$, tartaric acid $3 \mathrm{ij}$; powder, mix, and shake in a stopped bottle with a pint of water; let it settle, pour off the clear, and add tartaric acid $j_{j}$ ss. Used as a test for discovering lead in wines; also in diseases arising from quicksilver.

\section{WINES.}

The purer kinds of fermented liquors are mixtures of spirit of wine, water, and extractive matter; the spirit may be separated by careful distillation, or, if the extractive matter be first got rid of by the addition of subacetate of lead and filtration, the spirit may be separated by adding very pure and dry subcarb. of potash, when it will swim upon the liquor: the spirit constitutes from 12 to 25 per cent. of the proper wines, and from 2 to 8 per cent. of the malt liquors.

Two chemists have examined the quantity of alcohol to be obtained from the fermented liquors mostly in use-Newmann and Brande. It appears from the comparison of their experiments, that the wines of the present day are much stronger than they were about 80 years ago, at least in England, probably owing to the addition of brandy: Two-bottle men now actually drink more alcohol than their six-bottle grandfathers.

The fermentation of these liquors is usually hastened by the addition of yeast, crude tartar, or bruised vine-leaves; but this is 
seldom necessary for wines, if the liquor be kept in a proper warmth, but malt liquors are more sluggish.

If the fermentation is in danger of proceeding too far, it may be stopped by drawing off the liquor clear into another vessel, in which some brimstone has been newly burned, or, in the case of red wine, some nutmeg powder upon a hot shovel, or which has been washed with brandy ; the sediment left in the old cask may be strained through flannel or paper till clear, and added to the other : instead of this, a part only may be drawn out of the cask, and some rags, dipped in melted brimstone and lighted, may be held by a pair of tongs in the bung-hole, slightly covered, so as to impregnate the liquor with the fumes, about $1 \mathrm{oz}$. brimstone to a hhd., then returning what had been drawn out, and bunging up very close: or a small quantity of oil of vitriol may be poured in: lastly, the addition of black manganese has been proposed on theoretical grounds.

If the fermentation has already proceeded too far, and the liquor become sour, the further fermentation must be stopped as above, and some lumps of chalk or burned oyster-shells, added to saturate the acid already generated.

If the liquors do not become clear soon enough, for each 36 gall. dissolve isinglass $1 \mathrm{oz}$. in water 2lb.: strain, and mix this with part of the liquor; beat it up to a froth, and pour it into the rest of the liquor; stir the whole well, and bung it up. Instead of isinglass, some use hartshorn shavings in rather larger quantity ; red wines are fined with eggs, No. 12 to the pipe, beaten up to a froth, mixed with the wine, and well stirred in.

If the liquor has acquired a bad flavour, the best way is to let the fermentation go on, aud convert it at once into vinegar.

Wines may also be made of blackberries and other English fruits, upon the same principles. The above are the methods generally employed; but most persons have peculiar ways of proceeding, which may indeed be varied to infinity, and so as to produce at pleasure a sweet or dry wine; the sweet not being so thoroughly fermented as the dry. The addition of brandy destroys the proper flavour of the wine, and it is better to omit it entirely (except for elder or Port wine, whose flavour is so strong that it cannot well be injured), and to increase the strength by augmenting the quantity of the raisins or sugar. In general, the must for wines ought to be made of raisins $6 \mathrm{lb}$., or sugar 4lb., to the gall., allowing for that contained in the fruit; and in most fruits, especially the black currant, it is advantageous to boil them previously to making them into wine, as this improves the flavour greatly.

Wines are ustally doctored, as it is called, in order to give 
them peculiar flavours, and render them similar to some celebrated grape wines. Thus bitter almonds are added to give a nutty flavour; sweet briar, orris root, clary, cherry, laurel water, and elder flowers, to form the bouquet of high-flavoured wines; alum, to render young and meagre red wines bright ; Brazil wood, cake of pressed elderberries and bilberries, to render pale faint Port of a rich deep purple colour ; oak sawdust, and the husks of filberts, to give additional astringency to unripe red wines; and a tincture of the seeds of raisins to flavour fictitious Port wine. Wine is coloured with red beet, but in this case it is rendered colourless by lime water. Genuine red wines yield a greenish grey precipitate, with a solution of sugar of lead; but those coloured with bilberries, elderberries, or logwood, give deep blue precipitates, and those coloured by Brazil wood, red sanders, and red beet, red precipitates. Gypsum is used to clear cloudy white wines, as also lime; and the size of a walnut of sugar of lead, with a table spoonful of sal enixum, is put to 4.2 gall. of muddy wine to clear it; and hence, as the sugar of lead is decomposed, it is changed into an insoluble sulphate of lead: the practice is not so dangerous as has been represented by those afflicted with the poison mania.

\section{GRAPE WINES.}

Maderra, Vimum Maderaicense. Rich, full-bodied, sweet, the acid being absorbed by adding raw plaster of Paris stone; by which means the wine is enabled to be sent to the East and West Indies to ripen it, and from thence to London, without turning sour during the voyage. Useful in bites of poisonous snakes, a bottle drank in two doses, a few minutes one after the other. Yielded to Newmann 6.59 in the 100 of spirit by weight, to Brande $22 \cdot 27$ by measure.

Canary sack, Palma sack, Vidonia, Fayal, Teneriffe, $V$. Canarium, Vinum, P. U. S. An inferior kind of Madeira. Newmann, Palma sack 6.59 ; Brande, Teneriffe $19 \cdot 79$; Vidonia 19.25 of spirit.

Sherry, Vinum Xeres, V. album Hispanicum, Vinum, P. L. Dry, well-fermented. Newmann 6.59; Brande $19 \cdot 1 \%$.

Mountain wine, Vinum album montanum, $V$. album Hispanicum. Sweet.

Rhenish, Hock, Vinum Rhenanum. Acerb, made from scarcely ripened grapes; when mixed with sugar has a fine perfume. Newmann 6.25; Brande 1208.

Lissa. Brande $26 \cdot 47$, being the strongest examined by him.

Burgundy, $V$. Burgundicum. Like most French wines made from selected grapes (the bad berries being cut off the stalks), 
pressed, and only the juice fermented; red: esteemed the best wine that is made. Newmann 6.25; Brande 14.5\%.

Claret, Vin de Bordeaux, Vinum Burdegalense. Thin, rather acid. Brande $15 \cdot 10$.

Champagre, Vinum Campanacense. White and red, mostly effervescent when the bottle is opened. Newmann $\% \cdot 29$; Brande $12 \cdot 61$.

Lrsbon, $V$. Olissoponense. Yielded to Brande 18.94 per cent.

Bucellas. 18.49 per cent of spirit.

Calcavella. $18 \cdot 65$ per cent.

Spaxish red, Tent, Vinum tintum. Newmann 8.33; Brande $13 \cdot 3$.

Malaga. Brande 18:94.

Frostiniac, Vinum Frontignacense. Newmann 8.33; Brande $12 \cdot 79$.

Marsala. Yielded to Brande 25.9.

Colares. $19 \cdot 75$.

Lacryma Christi. The best Italian wine; $19 \cdot \%$.

White Constantia. The best Cape wine; $19 \cdot 75$.

Red Constantia. 18:92.

Red Madeira. $20 \cdot 35$.

Cape Muschat. 18:25.

Cape Madeira. 20.51.

Alba Flora. $17 \cdot 26$.

MaLdGi. $17 \cdot 26$.

White Hermitage. Newinann 7.98 ; Brande $1 \% \cdot 43$.

RED Hermitage. Yielded to Brande 12.32.

Roussillon: $18 \cdot 13$.

Maumsey Madeira. Newmann $11 \cdot 11$; Brande $16 \cdot 40$.

LUNEL. Yielded to Brande $15 \cdot 52$.

Red Shrraz. A famous Persian wine; 15.52.

White Shira\%. Made in India from the small Kishmish grape; yiclds $19 \cdot 80$.

Syracuse. Imported in thin quart flasks; yielded to Brande $15 \% 28$.

Sauternk. 14.22.

NiCE. $14 \cdot 63$.

BARSAC. $13 \cdot 86$. 
Vin de Grave. Newmann 5.55 ; Brande 13.37.

Cote rote. Yielded to Brande 12.32.

Tокау, V. Tokayense. Newmann 6.25; Brande 9.88.

Al and, $V$. St. Helenii. Yielded to Newmann $4 \cdot 85$.

Alicant, $V$. Illicitanum. 10.41.

Muscadine, $V$. Moschatellinum. $8 \cdot 33$.

Neufchatel, $V$. Neocastrense. 9.02.

Monte Pulciano, $V$. de Monte Pulciano. $\quad \% \cdot 63$.

Moselue, $V$. Mosellanum. 6.25.

Pontac, $V$. Pontacense. $5 \cdot 55$.

Salamanca, $V$. Salamancense. 8.33.

Red Tyrol wine, $V$. Tyrolense rubrum. $4 \cdot 16$ of spirit in the 100 by weight.

East Indian grape wine. From small dried Kishmish raisins ; yields about 21 p. c. of spirit by measure.

Por t wine, Vinum mubrum Portugallicum, $V$. ex Portu Calensi. Dark red, made from grapes gathered without selection, flung into a cistern, trod, and their skins and stalks left in the mass, which separate during fermentation, and form a dry head over the liquid; when the head begins to fall, the liquor underneath is drawn out, and casked; before being brought to England it is mixed with 1-3rd of brandy to enable it to keep during the voyage, otherwise the carriage brings on the acetous fermentation, and the wine is converted into vinegar; acerb. Yielded to Brande 22.18 of spirit.

RAPE wine, Piquette, Leger, Lora. Water poured upon the cake of grapes, and fermented; used as a common drink for servants.

2. Pour water upon grapes, and replace what is drank every day, adding a little brandy when it grows weak.

$\mathbf{R}_{\text {AIsIN }}$ wine. Raisins $1 \mathrm{cwt}$, water 16 gall., soak for a fortnight, stirring every day, press, put the liquor in a cask with the bung loose, till it has done hissing, then add brandy 2 to $4 \mathrm{lb}$, and bung up close: some use little more than half, or 2-3rds of this quantity of raisins. The cake left on pressing will serve to make vinegar. Yields $25 \cdot 12$ in the 100 of spirit.

\section{MADE WINES.}

ENGLiSh grape WiNe. From the juice of out-of-door grapes, or from an infusion of about 50lb. of the young leaves or cuttings of the vine in 7 or 8 gall. of water, adding sugar about $31 \mathrm{lb}$. to each gallon of liquor. Yields $18 \cdot 11$ p. c. of spirit. 
Gooseberry wine. Ripe berries bruised 10 gall., water 30 gall., soak 24 hours, strain; to each gallon add Lisbon sugar 2lb., and ferment.

2. Bruised berries $80 \mathrm{lb}$, water 10 gall., soak for a day, strain; to each gallon add loaf sugar 6lb., and ferment.

3. Juice 10 gall., water 20 gall., sugar $\% 01 b$. ; ferment.

4. Berries $100 \mathrm{lb}$, brown sugar $\mathrm{Slb}$, water a sufficient quantity to fill a 15-gallon cask. Yields a good yellowish white, very transparent wine.

5. Green berries $40 \mathrm{lb}$, water 4 gallons, bruise together; the next day press out the juice; to every gallon add sugar 3lb.; ferment. Gooscberry wine yields on an average 11.84 in the 100 of spirit. The seeds left in the cake are washed and roasted for coffee.

Cumant wine. Red currants rolb., bruised and pressed, brown sugar 10lb., water sufficient quantity to fill up a 15-gall. cask. Yields a pleasant red wine, rather tart, but keeping well.

2. White currants 1 sieve, red currants 1 gall., press; to each gall. of juice add 3 gall. water; to 10 gall. liquor add $30 \mathrm{lb}$. sugar, and ferment; when you bung it up add brandy $2 \mathrm{lb}$. to each 10 gall. of wine.

3. Juice 11 quarts, i. c. the produce of a sieve, sugar 20lb., water sufficient quantity to fill up a 9-gall. cask; ferment, and when it has done working, add brandy 4.jb. ; for a half hogshead use currants 3 sieves, sugar $84 \mathrm{lb}$, brandy 1 gall. Yields about 20.55 in the 100 of spirit.

Black cunRant Wine. Berries $201 \mathrm{lb}$., brandy 2 to $4 \mathrm{lb}$, water 12 to 14 gall., yeast 2 spoonsful; fermented for eight days, then bottled and well corked; pleasant but thick, rather vinous, cooling, dark purple colour.

2. Made into wine like the common currants.

3. Juice of boiled fruit and water p. xeq. ; to each quart of liquor add sugar $\mathbf{l l b}$, and ferment.

Mixed fruit wine. White currants 3 sieves, red gooseberries 2 sieves, these should yield 40 pints of juice; to each gallon add water 2 gall., sugar $31 \mathrm{lb}$. and a half; ferment.

2. White, red, and black currants, cherries, especially blackheart, raspherries, ana p. aeq.; to each 4lb; of the bruised fruit add water 1 gall., steep for three days, press, and to cach gallon of liquor add yellow sugar 3lb.; ferment, and when finished add to each 9 gall. " 2 pints of brandy; if it does not fine soon enough, to each 9 gallons add half an $o z$. of isinglass dissolved in a pint of water. 
3. Fruit, any that is to be had quite ripe, press the juice, and if very rich in flavour, an equal quantity of water may be added; to each gallon of liquor add 4lb. of sugar, and ferment.

Cherry wine. Cherries 30lb., moist sugar 5lb., water suff. quantity to fill a 7-gallon cask; ferment.

Pine-apple wine. From the juice of the fruit; very pleasant, used to flavour rum.

Crder, Pomatium. From the juice of apples, Yields from $5 \cdot 21$ to $9 \cdot 87$ p. c. of spirit.

Water moil. Water poured upon the cake of apples, and fermented; used for farm-servants' drink.

Perry, Pyraceum. From the juice of pears, particularly the rough-tasted sorts: fermented in the open air. Yields 7.26 in the 100 of spirit.

Pont. Cider 24 gall., juice of elderberries 6 gall., Port wine 4 gall., brandy 1 gall. and a half, logwood 1lb., isinglass 12 oz., dissolved in a gallon of the cider: bung it down; in two months it will be fit to bottle, but should not be drank until the next year: if a rough flavour is required, alum 4 to $6 \mathrm{oz}$. may be added.

Soutrampton Port. Cider 36 gall., elder wine, damson wine, of each 11 gall., brandy 5 gall.

Raisin wine. Cider, not of a rough flavour, 36 gall., raisins 112lb. : ferment.

Colepress's cider. From apples and mulberries pressed together, well flavoured, and of a beautiful colour.

Post. From poppy heads and brown sugar: very intoxicating and narcotic : made in the East Indies. The English fruit wines differ from those made from the grape, by containing the malic acid instead of the tartaric.

Methrglin, Hydromel vinosum. Honey $1 \mathrm{cwt}$. boiling water suff. quant. to fill a half hogshead or 3 Z-gall. cask, stir it well for a day or two, add yeast, and ferment; some boil the honey in the water, with an oz. of hops to each gallon, for an hour or two, but this boiling hinders its due fermentation: yields about 7.32 in the 100 of spirit.

MEAD. Is made from the honeycombs, from which the honey has been drained out, by boiling in water, and then fermented; generally confounded with metheglin.

Cowslip mead. Honey 30 lb., water 15 gall. boil; when cold, add lemons sliced, No. 18, cowslip pips 14 gall., yeast 8 oz., and sweet briar one handful : ferment and bottle.

Champagne. Brown sugar 10lb., loaf sugar 12lb., water 9 
gall., concrete acid of lemons or crystallized acid of tartar $\mathbf{3} v \mathbf{j}$; dissolve by a gentle boil, before it grows cold add yeast about 1lb., and ferment: when the working is nearly over, add perry 1 gall., brandy $31 \mathrm{~b}$., and bung it up for three months, then draw out $2 \mathrm{lb}$. of the wine, dissolve isinglass $1 \mathrm{oz}$. in it, pour it again into the cask, and in a fortnight bottle it.

Pixk Champagxk. Add cochineal 1 oz., when the preceding is first bunged.

Muscadell, Clary wine. Sugar 45̃lb., water 15 gall., boil, add gradually to it a pint of yeast, infuse in it for three days clary flowers 3 gall., then strain; ferment as usual, and then add 1 gall. brandy.

Cowsulp wiNe. To each gallon of water add 3lb. of white sugar ; add yeast, and ferment a day and a half, then add cowslip flowers 1 gall., the rind and peel of 2 lemons or Seville oranges to each gallon, the third day strain, and continue the fermentation.

Eider WiNe. Juice of the berries 6 gall., water 12 gall., brown sugar 60lb., dissolve by boiling, add yeast, and ferment, then add brandy $4 \mathrm{lb}$., and bung it up for three months: disagreeable when cold, but is mulled with allspice, and drank warm in winter time as a stimulant: 100 meas. yield about 9.87 of spirit.

Funtiviac, White elder wine. Water 6 gall., white sugar $18 \mathrm{lb}$., raisins 6lb., flowers of white-berried elder half a gall., lemon juice $8 \mathrm{uz}$., yeast $6 \mathrm{oz}$.; ferment and bottle.

GiNGer wise. Bruised ginger 12 oz., water 10 gall., boil for half an hour, add sugar 2slb., boil till dissolved, then cool, and rask the liquor along with 14 lemons sliced, and $3 \mathrm{lb}$. of brandy, add a little yeast, and ferment; bung it up for three months, and then bottle it.

Oraxge wine. Sugar 23lb., water 10 gall., boil, clarify with the white of six eggs, pour the boiling liquor upon parings of oranges, No. 100, add the strained juice of these oranges and yeast $6 \mathrm{oz}$; let it work for three or four days, then strain it into a barrel, bung it up loosely ; in a month add brandy $4 \mathrm{lb}$., and in three months it will be fit to drink.

2. Loaf sugar 56/b., juice of 140 Seville oranges, peel of 40 of the oranges, water 15 gallons; ferment and add brandy 2 pints. 100 pints yicld about 11.26 of spirit.

LEMoN wisf. Raisins cut in half 2lb., brown sugar 2lb., boiling water 2 gall., rind of 2 lemons, ferment for two days, strain, bottle in half-pint stone bottles, wire the corks : it will be fit for use in a little more than a fortuight.

Gisger BEER. Lump sugar 3lb., bruised ginger $2 \mathrm{oz}$, cream 
of tartar $1 \mathrm{oz}$., lemons sliced No. 4 , pour on them boiling water 4 gall.; add yeast $8 \mathrm{oz}$., work for four days, then bottle in half pints, and tie the corks down.

2. Moist sugar $6 \mathrm{lb}$, ginger $5 \mathrm{oz}$., cream of tartar $2 \mathrm{oz}$., lemons No. 4, yeast 8 oz., water 7 gall.; work two or three days, strain, add brandy llb., bung very close, and in fourteen days bottle it: a cooling effervescent drink in summer.

IMPERIAI, POP. Cream of tartar 3 oz., ginger $1 \mathrm{oz}$, white sugar $1 \mathrm{lb} .8 \mathrm{oz}$., lemon juice $1 \mathrm{oz}$., water 1 gall. and a half, yeast $1 \mathrm{oz}$; bottle, and tie the corks down.

\section{MALT LIQUORS.}

Sugar 6lb. is esteemed equal in strength, and coriander seed 1lb. in intoxicating power, to a bushel of malt: the sugar employed is burnt to colour the beer instead of brown malt, and it has been proposed to employ roasted coffee for this purpose.

The desire of evading the duty on malt has occasioned the discovery of its being necessary to malt only l-3rd of the corn, as this portion will convert the other into its own nature during the process.

Capsicum and grains of paradise are used to give a pungent taste to weak beer, but, to avoid detection, concentrated tinctures are mostly used; and ginger, coriander seed, and orange peel are used to flavour it : besides these opium, cocculus Indicus, nux vomica, tobacco, and extract of poppies, are used to increase the intoxicating quality. Quassia is employed instead of hops as a bitter, but as this does not precipitate the mucilage, the beer soon grows muddy unless kept very cool.

Mild or new beer is made to taste like stale by adding a little oil of vitriol, or some alum; and, on the other hand, stale or sourish beer is made to resemble mild by neutralising the acid by oyster-shells or chalk.

When strong beer is reduced by adding small beer, publicans usually add melasses to enable it to form a head, and extract of gentian to keep up the flavour.

Ale, Barley-vine, Ala, Cerevisia alba. Pale malt 14 quarters, mashed at three times with 28,18 and 18 barr. of water, boiled with hops $112 \mathrm{lb}$., set with $36 \mathrm{lb}$. of yeast, cleansed with $4 \mathrm{lb}$. of salt ; produced 34 barr. or 1 gall. 1 pint of ale from each gall. of malt. Burton ale yields about 8.88, Edinburgh 6.20, Dorchester 5.56 of spirit in the 100 .

Draught porter. Pale malt 7 quarters, amber malt 6 quart., brown malt 3 quart., mashed at twice with 56 and 48 barr. 
of water, boiled with Kentish hops 1131b., set with 80lb. of yeast, salt 4lb., and flour $\frac{8}{2} \mathrm{lb}$; produced 56 barrels of porter, or $3 \frac{x}{2}$ gall. porter from each gall. of malt. A third mashing of the same grains produced 20 barr. of table beer. London porter yields only about $4 \cdot 2$ of spirit from 100 meas.

Botruing porter. Pale malt 4 quarters, amber malt 3 quart., brown malt 3 quart., mashed at three times with 25,12 , and 12 barr. of water, boiled with ordinary Kentish hops 100lb., set with yeast 52lb., and salt $2 \mathrm{lb}$; ; produced 34 barrels, or $1 \frac{x}{2}$ gall. of porter from each gall. of malt. Brown stout yields 6.8 of spirit from 100 meas.

Devosshike white ale. Pale ale wort 25 gall., hops 2 handfuls, yeast $3 \mathrm{lb}$., grouts 6 or $8 \mathrm{lb}$. When the fermentation is at its height, bottle in strong stone half pints, well corked and wired: effervesces when opened.

TABLE ALE. Very pale malt 12 quarters, mashed at three times with 46,32 and 32 barrels of water, boiled with hops 62lb., set with $114 \mathrm{lb}$. of yeast, cleansed by the yeast head being beat in, and let to work out; produced 100 barr. or 4 gall. ale from each gall. of malt.

Twopevny. Malt 1 bushel and a half, hops 1lb., liquorice root $1 \mathrm{lb} .8 \mathrm{oz}$., treacle 5lb., Spanish liquorice $2 \mathrm{oz}$, capsicum $3 \mathrm{ij}$; frequently drank the week after it is brewerl: used in cold weather as a stimulant. Produce 36 gall., that is, three times the malt.

Table: Beer, Cerevisia. Malt 8 bush., hops 8lb., sugar 8lb. made into colour, Spanish liquorice $8 \mathrm{oz}$., treacle $10 \mathrm{lb}$. Produce 10 barrels, that is, five times the malt.

Maderra. Pale malt ground 4 bushels, boiling water 44 gall., infuse, strain off this wort while warm, take 24 gall. sugar candy 14lb.; when dissolved, add yeast 2lb.; ferment, keep scumming off the yeast; when the fermentation is nearly finished, add raisin wine 2 gall. and a half, brandy, Port wine, of each 2 gall.; bung it down for six or nine months. A second infusion of the wort may be brewed for beer.

SHERrY. Loaf sugar 32lb., sugar candy 10lb., water 16 gall., boil, add pale ale wort (as for Madeira) 6 gall., yeast 1lb.: on the third day add raisins stoned 10lb., and in another two or three days brandy 1 gall.; bung it down for four months, draw it off into another cask, add brandy 1 gall, and in three months bottle it.-Imitations of foreign wines, but far inferior to our own fruit wines.

MuM. Brewed from wheat malt.

Wutte sPruck BEer. To water 10 gall. put sugar 6lb., × 2 
cssence of spruce $4 \mathrm{oz}$. (a $3 \mathrm{~s}$. pot), add yeast, work as in making ginger beer, and bottle immediately in half pints.

Brown spruce BeEr. As the white, using treacle in lieu of sugar.

Treacle BeEr. Hops $1 \mathrm{lb} .4 \mathrm{oz}$, boil in water 36 gall. for an hour, add treacle 14lb., a little yeast, and ferment.

2. Hops 1 oz., and half, water 1 gall., treacle $1 \mathrm{lb}$.

Malmsey, Parsnep wine. Cut the roots into thin slices, boil them in no more water than will just cover them, press out the liquor and ferment.

Elecampane wine, Vin d'aulnée. Is prepared in France, and considered as stomachic.

Pulque. From the sap of the leaves of Agave Americana: drank in South America.

Brnch wine. From the sap of the birch tree.

Tonny. From various species of palms, by cutting off the end of the flowering bud, collecting the sap, and letting it stand a few hours to ferment.

\section{GASES AND FUMIGATIONS.}

\section{GASES.}

Hydrogen gas, Gas hydrogenium. Zinc turnings jss, common water 4 pints put into a retort: add oil of vitriol $3 \mathrm{vj}$, and place the retort so that the gas may pass into inverted bottles filled with water, or into a gas-holder. Used in artificial fireworks, and to find the quantity of oxygen contained in gases.

Sulphuretted hydrogen gas, Hepatic gas, Gas hydrogenium sulphuratum. Lime $2 \mathrm{oz}$, sulphur $3 \mathrm{oz}$. mix, melt, pour out, and when cold put into a retort, add gradually oil of vitriol, and receive the gas in inverted bottles. Extremely fetid, poisonous, yet exhibited in olustinate cuugh after peripneumonia, requires great caution.

Oxrgen gas, Pure air, Dephlogisticated air, Vital air, Gas oxygenium. Heat black oxide of manganese $1 \mathrm{lb}$. in a retort or iron bottle, and collect the gas it yields, rejecting the first bubbles: produce about 3400 cubic inches, or more than 14 gallons. Stimulant when breathed, in doses of 6 to 30 cubic inches.

- Carbonic acid Gas, Fixed air, Gas acidum carbonicum. 
Marble in coarse powder $\frac{1}{2}$ oz., add muriatic acid, diluted with 1-3rd its weight of water, by degrees, until the marble is dissolved, collecting the gas: produce about 1 gallon. In small doses sedative; externally used in cancer and fetid ulcers.

\section{FUMIGATIONS.}

Nitrous fumigatron, Fumigatio nitrosa. Sal. nitri ziv', ol. vitrioli ij: in a saucer placed upon hot sand in the middle of the roon.

Disinfecting fumigation, Fumigatio oxymuriatica. Sal. comm. $3 \mathrm{oz}$, black manganese $1 \mathrm{oz}$., oil of vitriol $1 \mathrm{oz}$., water $20 z$ : in a cup carried through the apartments, or they may be shut up for an hour or two, and then opened.

Powders for making effervescent mixtures, pastilles for burning, and the like, act by the gas they produce; but they are referred to the forms in which the materials are sold.

\section{LIQUID COMPOUNDS.}

\section{NOT OILY.}

\section{DISTILLED WATERS.}

Sose of these are intended for medical purposes, mostly as vehicles, others for perfume. In respect to medicines, no great care is usually judged necessary, the herb just as collected, without any separation of decayed parts, or accidental mixture of dirt or other substance, is added to the water, distilled in a short. necked, wide still as quickly as possible, and spirit of wine $3^{i j}$, or even more, added to each pint. Many do not even take this trouble, but rub a drop or two of the oil, with a little magnesia, and add it to common water, or dilute the oil with ten times as much spirit of wine, and add, when it is wanted, a few drops of this essence to the water or other vehicle.

But for perfumes, as rose water, elder-flower water, \&c., more care is requisite, as the buyers must be pleased with their sinell and appearance; hence the herb, \&ic., must be carefully picked, and the waters as carefully distilled in a high narrow-necked still, in order that no part of the infusion may lee thrown over wilh the distilled water, as this would render them liable to become mothery in a short time; if a superior article is required, the waters must be redistilled by a gentle heat. 
Waters which have acquired a burnt smell in the stilling lose it by freezing.

These waters must also be kept in a cool place, covered only with paper pricked with pin holes, for four montlís, to get rid of the herbaceous smell of fresh distilled waters. Distilled waters may be prevented from turning sour by adding a little calcined magnesia to them; and those which have begun to be spoiled may be recovered by adding to each pint a grain of each, borax and alum. A drop of muriate of gold added to these waters shows whether they contain any oil, by forming in that case a fine metallic film on their surface.

\section{FOR MEDICAL USE.}

Aqua alexiteria simplex. Green mint lb. ss, tops of sea wormwood, green angelica leaves, ana $\mathrm{lb} . \mathrm{j}$; draw three gallons: this is a pleasant compound water. tive.

Dill water, $A q$. anethi. Seeds $2 \mathrm{lb}$. to the gallon; carmina-

Aniseseed-water, Aq. anisi. Collected in the distillation of the oil ; carminative.

Orange peel water, Aq. cortic. aurant. simplex. Seville orange peel 3 iiij to the gallon.

2. Peel 2lb. to the gallon; an agreeable vehicle.

Caraway water, Aq. carui. Seeds $11 \mathrm{~b}$. to the gallon; carminative.

AQ. CASCARILld. Bark 1lb., water 6 pints; soak for some days, and distil 2 pints of a milky water. "It may be prepared while making the extract. Tonic.

Cassia water, Aq. cassia, Aq. lauri cassia. 1lb. to the gallon.

2. Cassia (parva) 81b; ; draw 12 yallons.

3. Cassia buds 1lb., cassia lignea 2lb.; draw 8 gallons.

4. Cassia (parva) 6lb., spirit of wine 2 gall., water q. s., draw 4 gall. of spiritus cinnamomi, and 10 gall. of aq. cinnam. Sold for cinnamon water.

BuAck ChERRY WATER, Aq. cerasorum nigrorum. The fruit with the stones bruised; lb. xij to the gallon.

2. Cake left after squeezing black cherries for their juice $3 \mathrm{lb}$, water 2 gallons; let them stand for a day, and distil 4 pints; antispasmodic, contains prussic acid; when drawn very strong, lb. vj of cherry-stones to the pint, is deleterious; expunged from the Pharmacopœia in 1745. 
Bitter aluond water, Aq. amygdalarum amararum. Almond (bitter) cake bruised 4lb., draw five gallons.

Aq. amygdalarum amararim concentrata, P. Bor. Amygd. amar. cont. lb. ij., S. V. R. 亏ij, aq. lb. vj; distil in glass. lb. ij.

Cinnamon water, Eau de canelle, Aq. cimnamomi tenuis, $A$. cinnamomi, A. lauri cinnumomi. $\mathrm{lb}$. $\mathrm{j}$ to the gallon.

2. Cinnamon $\mathrm{lb}$. j, or oil $\mathrm{Gv}$, to the gallon. P. L. 1824 .

3. Bruised cinnamon lb. j, water 2 gall, simmer in a still for half an hour, put what comes over into the still again; when cold strain through flannel. Cassia must be distilled, as its infusion is yellow.

4. Water 2 pints, cinnamon $2 \mathrm{oz}$; distil in a water bath: stomachic, tonic, and covers the disagreeable taste of some medicines. Cassia water is sold for it.

Aq. Corticis Penuviane. Bark 1lb., water 6 pints; soak for some days, and distil 3 pints of a milky water. It may be prepared while making the extract. Tonic.

Cumin water, Aq. cumini. From the seeds; carminative.

AQ. CYmbalanie. From the herb; used in Italy as the vehicle for exhibiting arsenic as a poison, but has no power of its own.

Spearwort water, Aq. flammula. From the herb; acrid, vomits instantly, and, in cases of poison being taken, is preferable to any medicine yet known, as it does not excite any contraction of the upper part of the stomach, and thus defeat its own intention, as white vitriol sometimes does.

SWeEt fexner. Water, Aq. foeniculi. Seeds $11 \mathrm{~b}$, to the gallon; a weak carminative.

Arsfi-smart Water, Aq. hydropiperis. From the herb; acrid, lb. j-lb. jss, drank in a day, esteemed very effectual in nephritic cases.

Hyssop water, Aq. hyssopi. From the herb; pectoral, stomachic.

Juntper water, Aq.juniperi baccarum. Stimulant.

Laurel water, Aq. lauro-cerasi. From the leaves, lb. viij to the gall.; contains prussic acid, is stronger than black-cherry water; has been used for poisoning, and therefore labours under an ill name, although doubtless one of the most efficacious of this sort of medicines, and of great use in consumption.

2. P. Boruss. Fol. lauri cerasi lb. j; S. V. R. 3̈ij; aquæ Ib. vj, distil in glass. $1 \mathrm{~b}$. iij. 
LemON-per. water, Aq. e corticibus citri, $A$. citri medica. Fresh peel $2 \mathrm{lb}$. to the gallon.

Bavlm water, $A q$. melissa. From the herb, cephalic, cordial.

Perpermint water, $A q$. mentha piperitidis simplex, $A$. menthe piperite. Green herb lb. viij to the gallon; P. L. before 1745.

2. Dried herb lb. jss, or green lb. iij, to the gallon; P. L. since 1745. P. D.

3. Herb in flower $\mathrm{lb}$. ij to the gallon, P.E.

4. Green herb lb. iij, or dried lb. jss, or oil ziij to the gallon; P. L. 1824 .

5. Oil of peppermint $1 \mathrm{oz}$., water q. s. ; draw 10 gallons.

6. Oil 2 oz.; draw 9 gallons.

7. Oil 1lb.; draw 30 gallons; stimulant, carminative; and covers disagreeable flavours.

Mint water, $A q$. menthe, $A$. mentha vulgaris simplex, $A$. mentha sative, $A$. menthe viridis. Green herb $\mathrm{lb}$. viij to the gallon; P. L. before 1745.

2. Dried herb $\mathrm{lb}$. jss to the gallon; P. L. since 1745. P. D.

3. Dried herb $\mathrm{lb}$. jss, or green $\mathrm{lb}$. iij, or oil $3^{\mathrm{iij}}$ to the gallon. P. L. 1824.

4. Oil of spearmint 1 oz., draw 10 gallons; antispasmodic, allays vomiting.

Nutmeg watei, Aqua mucis moschata. Nutmegs 1 oz., water q. s. ; distil a gallon; used in incipient phthisis.

White POPPY watrR, $A q$. papaveris albi. From the flowers; narcotic, much used in some parts of Lincolnshire, every cottager growing the plant for his own consumption in making this water.

Ar.tspice water, $A q$. piperis Jamaicensis, $A$. pimento, $A$. pimenta, A. myrti pimente. Half a lb. to a gallon : stimulant; used in hospitals as a cheap spicy vehicle. blue.

Pimpernel water, Aq. pimpinella. From the roots; acrid,

Pennymoyal water, $A q$. pulegii, $A$. pulegii simplex, $A$. menthce pulegii. Green herb lb. viij to the gallon; P. L. before 1745.

2. Dry herb $\mathrm{lb}$. jss to the gallon; P. L. since 1745. P. D.

3. Fresh herb lb. iij to the gallon; P. E.

4. Dry herb lb. jss, or green lb. iij, or oil $3^{\mathrm{iij}}$ to the gallon. P. L. 18\%4.

5. Oil of pennyroyal $1 \mathrm{oz}$; draw 12 gallons. 
6. Oil of pennyroyal $11 \mathrm{~b}$.; draw 30 gallons. Emmenagogue.

Rue watek, $A q$. Rutce. From the herb; stimulant, emmenagogue.

AQ. Castorei. Russian castor $\tilde{3} j$, water q. s. ; distill lb. ij.

AQ. Lactis alexiteria. Leaves of the meadow-sweet, carduus benedictus, goats' rue, ana M. vj ; of mint, wormwood, ana M.v ; of rue M. iij; of angelica M. ij ; milk gall. iij : distil in a water bath to dryness: diaphoretic.

A Q. oMvium Florum. From cows' dung, collected in May and distilled in a balneum; used in phthisis.

\section{FOR PERFLUERY AND COSMETICS.}

Eau dange distillée. Benj. 2 oz., stor. 1 oz., cinnam. 1 dr., cloves $2 \mathrm{~d}$., calam. a stick, coriander seeds whole a pinch, water 2 pints.

Eau d'ange distillée et musquée. Water 2 pints, benjamin 4 oz., storax $2 \mathrm{oz}$., cinnam. half an ounce, cloves $3 \mathrm{ij}$, calamus a stick, musk bags $3 \mathrm{j}$ : distil; save the residuum.

Carline thistle water, Aq. carline. From the root.

Slaranise water, Aq. anisi stellati. Very fragrant.

Orange-flower water, Eau de fleurs d'oranges, Aq. napha, $A$. aurantiorum florum. lb.iij to lb. iv of water; from Italy.-2. Ib.iij to $\mathrm{lb}$. vj of water. -3 . Water 4 pints, orange flowers $2 \mathrm{lb}$.; distil in B. M. ; fine scented: if wanted only to purify tobacco for snuffs it may be drawn much lower.

Bean-flower vater, Aq. fabarum florum. Fragrant, cooling to the face and hands.

Strawberry water, Aq. fragaric. Fruit bruised 20lb., water q. s.; draw 2 gall. and a half: very fragrant.

Simple lavender water, Aq. lavandula florum. Collected in the distillation of the oil ; mostly used to scent soaps.

Aqua ledi palustris. Very fragrant; sold for rose water.

Lily of the valley water, Aq. lilii convallium. Fragrant ; used as a perfume to scent soaps.

Eau de millefleurs. Eau d'ange 2 pints, musk 12 or $20 \mathrm{gr}$., or musk bags $\overline{3} \mathrm{j}$ : if not strong enough, add a thread of essence of ambergris.

Eau d'ceillet. Water two pints, cloves 2 oz.; distil in a water bath.

Myrtle-flower water, Aq. myrti florum. Fresh flowers lb. iij; draw a gall.; very fragrant ; used as a perfume. 
Rose water, Aq. rosarum Damascenarum, A. rose, $A$. rosce centifolice. Petals of the flowers 6lb. to the gall.-2. Petals 8lb. to the gall.-3. Petals 10 bushels; draw 14 galls.-4. Salted roses 60lb., yellow sanders 8 oz.; draw 16 galls. -5 . Attar of roses $1 \mathrm{oz}$., spirit of wine cong. j, aq. distil q. s. ; distil 40 gallons.6. Water 4 pints, roses 3lb.; distil in B. M. When much rose water is wanted to purify tobaccu for snuff, it may be drawn weaker.-Yellow sandal wood water, rose root water, aqua ledi palustris, are sold for it.

Rose root water, Aq. rhodia radicis. From rose root; sold for rose water.

Rosemary water, Aqua rorismarini. From the tops; fragrant.

Raspberry water, Aqua rubi Idai. From the fruit; fragrant. - Elder-flower water, Aq. sambuci florum. From the fresh flowers. -2. Salted flowers 501b.; draw 20 gallons : agreeably aromatic, cooling to the face and hands.

- Yellow sanders water, Aq. santali citrini. From yellow sanderș; sold for rose water.

Water of camels' hay, Aq. schænanthi. From the herb; fragrant.

Germander water, Aq. scordii. From the herb; fragrant, although no oil comes over with it.

Eau de tain. Water 2 pints, lemon thyme 2 handf, ; distil in a water bath. Other sweet-scented herbs may be distilled the same.

Lime-flower water, Aq. tilia. From the flowers when fresh gathered ; fragrant.

Meadow-sweet water, Aq. ulmarice. From the flowers; has a fine flavour, but the flowers must be infused in warm water as soon as gathered.

Vanilla water, Aq. vanillarum. From the pods : fragrant.

USED IN COOKERY.

Marjorum water, Aq. marjorance. Fresh herb 8lb. to the gallon; strong-scented.

USED IN THE ARTS.

Eau distillée d'anserine, Aq. potentilla: From the herb; used in the dressing of French gauzes, and, although it has neither taste nor smell, common water will not supply its place. 


\section{INFUSIONS.}

The infusion of most vegetable substances may be kept unchanged, in a cool place, for a long time, in long narrow-necked ressels, if a little sweet oil is poured upon it; the oil may be taken off by a syringe, or a little tow.

FOK MEDICAL USE.

TAB watek, Aq. picis liquida. Tar 3 pints, boiling water 1 gallon; strain: stimulant, one or two pints in a day.

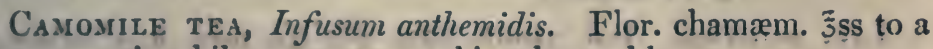
pint; emetic while warm, stomachic when cold.

INF. ARMORACI COMPOSITUM. Rad. raph. rust., sem. sinapis, of each $\overline{3} \mathrm{j}$ to a pint, add spir. armor. comp. $\ddot{3} \mathrm{j}$ : diuretic to $\overline{3} \times \mathrm{ij}$, in die.

INF. AURANTII COMPOSITUm. Cort. aurant. sic. 3ij, cort. limon. rec. $3 j$, caryoph. arom. 3 ss to half a pint : stomachic $3 \mathrm{j} i j$ omni bihorio.

INF. CALUMB.e. Rad, colombo $3 i j$, to half a pint ; tonic.

INF. BERBERIS. Berberis cort. contus. 3ss, aqua ferventis Oss, macera per horas duas; dose $3 \mathrm{j} \mathrm{i}-\mathrm{z}_{\mathrm{ij}} \mathrm{j}$, with subcarb. of soda. or potash, and tinct. of calumba; in jaundice, \&c.

INF. CAlami. Calami rad. contus. ड̄ss; aq. ferventis Oss, with a cordial tincture, as a stomachic.

Inf. CONII MACUi.ATI. Dried leaves of conium, coriander seeds, bruised, ana $3 \mathrm{ij}$; boiling water Oss ; infuse for two hours. Combined with liq. ammon. acet., tinc. hyosciami, and syrup. papaveris; in pulmonary diseases.

Inf. GUAI aci cumposit Us. Guaiaci ligni ras.lb. ss; glycyrrh. rad. cont. $3 j$; sassafras corticis concis. З̌ss; coriand. sem. cont. Ovj; infunde per dies tres, dein cola: dosis $3 i j-\overline{3} v j$, bis die : in scrofula, rheumatism, cutaneous eruptions, \&c.

INF. CARYophillonum. $3 \mathrm{j}$ to half a pint: stimulant.

IN $F$. CASCARILLA. Cort. $3 \mathrm{j}$ to a pint : tonic.

INF. catkcuU, I. c. compositum. Catechu 3ijss, cinnam. 3ss, to half a pirit.

IxF. of вавк, Inf. cinchona. Cort. Peruv. 3̈ss to half a pint : tonic.

IsF, cusparr.e. Cort. angusturxe $3 \mathrm{jj}$ to half a pint: tonic.

INF. Digitalis. Fol. dig. sicc. $3 j$ to half a pint; and add 
亏ैss of spir. cinnam. : diuretic $\overline{3}$ j every eight or ten hours, till it has a sensible effect upon the body.

InF. gentrane compositum. Rad. gentianæ, cort. aurant. sicc. ana $3 \mathrm{j}$, cort. limon. rec. $3 \mathrm{ij}$, aq. ferv. $3 x i j$.

Linseed tea, Inf. lini, I. l. compositum. Sem. lini $3 j$, rad. glycyrrh. 亏iv, aq. ferv. lb. ij.

INF. JUNIPERI compositus. Junip. bac. contus. z̧ij, aq. ferventis $O j$, macera per horas binas, cola et adde spirit. juniperi comp. $3 j$, potassæ supertart. 3 jss. (Sprague.)

INF. MARRUBIr. Marrub. herb. exsic. $5 s s$, aq. distil. ferven. Oss; $\overline{3} s s-3 \overline{i j}$, ter in die.

INF. MENTHE. Fol. menth. sicc. $3 i j$, aq. ferv. q. s. to strain 亏ैvj; when cold, add sach. albi 3ij, oil. menth. sat. gtt. iij dissolved in tinct. cardam. comp $\overline{3} s s$; diaphoretic.

Inf. Menthe compositus. Menth. virid. exsic. et cont. jiss, $^{\circ}$ rosæ gall. petal. exsic. 3 jss, aq. ferventis $O_{j}$, acid. sulph. dil. $3 \mathrm{ij}$, saccl. purif. j.jss. Pour the boiling water with half the acid on the mint and rose leaves; then strain the liquor and add the other half and the sugar. Powerfully anti-emetic. (Sprague.)

InF. MENYanthidis. Fol. menyanth. zss, zingib. rad. con is. Эij, aq. fervent. Oss, macera horas per binas. In doses of $3 j-3 i j$, with spirit. æther. nit. $3 \mathbf{j}-3 \mathbf{i j}$ : in rheumatism, gout, and cutancous affections.

INF. QUASSIE. Jj to half a pint : tonic.

INF. оF внUваRв, Inf. rhei. $3 j$ to half a pint: $3 \mathrm{iv}$, with neutral salts, as a purgative, 3 ss with tinct. cinnam. as a stomachic.

Ixf. rhei boraxatum. ( $P$. Pol.) Rhub., 6 ; borax, 1 ; cinnum. water, 8 ; boiling water, 48 .

Inf. rhei alkalinum. ( $P$. Aust.) Rhub., 3 ; carb. potass., 1 ; boiling water, 48 .

INF. Ros.e, I. $r$. compositum, Tinctura rosarum. Rosæ rubræ 3iv, aq. ferv. lb. jjss, spir. vitıioli 3iij, sacch. alb. ßjjss : cooling ; also as a vehicle for Epsom salt, whose taste it covers very well.

INF. SENxe, I. s. compositum. Sennæ 亏jss, rad. zingib. 3j, aq. ferv. lb. $\mathrm{j}$; purgative $\mathrm{J} \mathrm{ij}$ to iv; but generally given as a vehicle.

INF. simaroub.e. $3^{\text {ss }}$ to half a pint; bitter, tonic.

INF. TABACI. $3 \mathrm{j}$ to a pint; as an antispasmodic clyster.

Inf. Tamarindi cum senna. Tamar. $\bar{j} j$, sennæ $3 \mathrm{j}$, sem. coriand. 3ss, sacch. rubr. $\bar{s} s s$, aq. ferv. $\overline{3} v i i j$; laxative $\overline{3} i j$ to ziv.

INF. valerianse. $3 \mathrm{ij}$ to aq. 3 vij; antispasmodic, to $3 \mathrm{jj}$. 


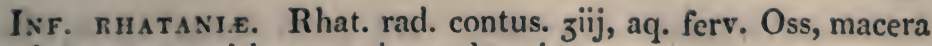
per horas sex; with aromatics and tonics.

Cathartic infusions. Inf. senna $\overline{3} j$, tinct. sennæ, tinct. jalapa, ana $3 \mathrm{j}$, potass. tartr. $3 \mathrm{j}$, syr. sennæ $3 \mathrm{j}$.

2. Inf. sennæ 3jos, sal Epsom 3rj, tinct. jalap. 3j, tinct. opii m. $\mathrm{x}$, tinct. castor. $3 \mathrm{j}$ : both for one dose. doses.

3. Inf. seunæ $\overline{3} i j$, sodx tartr. $\overline{\overline{3}} v j$, aq. cinnam. $\overline{3}$ ss, for two

4. Fol. sennæ 3iij, sal. Glaub. इj, aq. ferv. lb. j; strain, for a clyster.

Dieretic infusions. Bacc. junip. cont. $3 \mathrm{ij}$, sem. anisi $3 \mathrm{ij}$, aq. ferv. lb. $\mathrm{j}$ : to strained liquor $\overline{\bar{J}} \mathrm{xij}$, add sp. junip. comp. $\overline{3} \mathrm{ij}$, tinct. scillæ כj, sal nitre Эij. Dose a tea-cupful frequently.

2. Inf. digit. $\overline{3} \mathrm{iv}$, tinct, digit. 3 ss, potass. acetat. $3 \mathrm{j}$, tinct. opii m. v. Dose coch. maj. j, twice or thrice a day.

3. Cacum. spartii $\bar{j}$, aq. lb. $\mathrm{j}$, boil to onc-half: strain : diuretic, 今j, with spr. ath. nitr. m. x, every other hour.

Iacerial drink, Potus imperialis. Cream of tartar žss, white sugar 3 iiij, orange peel 3 iij, boiling water 3 pints, for common drink in fevers.

INF. SERPENTARIE COMP. Serpentariæ rad. cont., contrajerræ rad. cont. ana $3 \mathrm{ij}$, aq. ferventis $\mathrm{O}$ ss, macera per horas binas, cola et adde tinct. serpentarix, $3 \mathbf{j}$. Doses $\overline{3} s-\overline{3} \mathrm{j}$, with liq. ammon. acet., in diseases of debility.

Inr. Spigelie compositus. Spigel. rad. concis. J̄ss, senna foliorum 3ij, aurantii cort., santonici. semin. cont., faniculi sem. contus. ana $3 \mathbf{j}$, aq. ferventis $\overline{3} x i j$, macera per horas binas. A wine-glass full every morning, fusting, to expel lumbrici. (Sprague).

INF. Uve URs. Uvre ursi fol. 3ij, aq. ferventis O ss. Macera per horas tres. With the alkaline carbonates, hyosciamus, or opium, in affections of the urinary organs; and with dilute sulphuric acid and digitalis in affections of the respiratory organs.

IxF. VALERIAN.e Fortius. Valerian. rad. cont. ऊ̌ss, aq. ferventis () ss, macera per horas duas, cola et adde spirit. lavand. comp., syrup. aurantii, ana $\bar{s} s s:-\overline{3} i j$ ter die. In hysteria and other nervous affections.

Astringent INFusions. Cort. querc. 3 ss, aq. lb. ss; to the strained liquor $3 j \mathrm{ss}$, add pulv. gallarum gr. $x$, tinct. catechu, tinct. cardam. comp., syr. cort. aurant., ana 3ss, for one dose.

2. Inf. cusparix $3 \mathrm{j}$, tinct. catechu $3 \mathrm{j}$, pulv. ipec. gr. iij, opii gr. ss, for one dose. 
Strengthening infüsions. Inf. gent. comp. $3 j$, aq. kali 3ss, tinct. cascar. $3 \mathrm{j}$, for one dose.

2. Inf. cascar. 3jss, tinct. ejusd., tinct. $z z$, ana $3 \mathrm{j}$; for a dose, in loss of appetite from drinking.

Stimulant infusion. Sem. sinap. nigr. cont, rad. raphan. sylv. ana 3 ss, aq. ferv. $l b_{0} \mathrm{j}$; strain when cold, and add spir. amm. arom. 3j, spir. pimentæ $3 s s$; dose coch. maj. ij, three a day, praised by Dr. Paris in palsy.

Fotus cicuta. Fol. cicutæ rec. lb. ss (or sicc. ziij), aquæ lb. ij.

\section{DECOCTIONS.}

Decoctum Gallie. Gallarum contus. 3ैss, aq. distil. O ijss, decoque ad oct. ij et cola; dein adde tinc. Gallæ $3 j$. As a fomentation, enema or injection, for prolapsus ani, hæmorrhoids, and in leucorrhæa.

Dec. santonicr. Santon. semin. cont. 亏3ij, aq. distil. 亏3xx, coque leni igne ad $\mathrm{O} j$, dein cola. As an injection against ascarides.

Dec. Spartir cacumniuir. Spartii cacum. concis. $3 j$; aq. distil. $\mathrm{O}$ j, decoque ad octarium dimidium, et cola. Diuretic; combined with diuretic salts and the æethers in dropsies.

Dec. taraxaci. Taraxaci rad. recent. concis. 3 3ij, aq. distil. $\mathrm{O} \mathrm{ij}$, coque ad $\mathrm{Oj}$, et cola; with the alkaline carbonates, extract of taraxacum, \&c., in glandular obstructions.

Dec. tormentile.e. Tormentillæ radicis contus. $\overrightarrow{3} j$, aq. distil. $\mathbf{O}$ jss, coque ad octarium, et cola. In colliquative diarrhœa.

Dec. Althee officinalis. Rad. althææ sicc. 3̋iv; uvar. pass. sij, aq. lb. vij.

Dec. chamemeli compositum. Flor. cham. sicc. ऊ̄ss, sem. fœnic. 3 ij, aq. lb. j.

Dec. Ballote ranate. Fol. et Flor. ballot. lanatæ 3 jij, aq. $\mathrm{lb}$. $\mathrm{ij}$. coque ad lb. $\mathrm{j}$; dose $3 \mathrm{ij} 4$ tis horis. In dropsies, as a diuretic, when there is no active organic disease.

DEc. of BARK, Dec. cinchonce, $3 \mathrm{j}$ to a pint ; boil for ten minutes: tonic, $z_{j} \mathrm{j}$ to $z^{\mathrm{iv}}$, in die.

Mucilago seminum cydoniarum, Dec.cydonice. Sem. cyd. 3ij, aq. lb. ij.

Dec. daphnes mezerei. Cort. rad. mezerei $3 \mathrm{ij}$, rad. glycyrrl. ऊss, aq. lb. iij ; diaphoretic, $3 \mathrm{j}$ to iv, in die, by small doses.

Dec. digitalis. Fol. digit. sicc. 3 j, aq. q. s. to strain 3 viij.

Dec. dulcamare: Caul $3 \mathrm{j}$ to a pint and a half, and boil to a pint. 
Dec. Geoffre.e INERMis. Cort. $3 j$, aq. lb. ij, coque ad lb. j.

DEC. GUAIACr Composites. Lign. guaiaci żiij, uvar. pass. šij, rad. sassfr., rad. glycyrrh. ana $\overline{3}$, aq. lb. x. coque ad dimidium; alterative, $\mathrm{lb}$. ss to $1 \mathrm{~b}$. $\mathrm{j}$, in die.

Dec. LICHevis. $\overline{3} \mathrm{j}$ to aquæ $\mathrm{lb}$. jss; boil to lb. $\mathrm{j}$; nutritive.

Dec. Pro enemate, D. malva compositum. Malvæ sicc. $ろ$ j, fl. chamæm. ¿ss, aq. lb. j.

Popry liquor, Dec. papaveris. Heads $3 \mathrm{j}$ to a pint; emollient, as a fomentation.

Dec. quercus. Cort. quercus $3 \ddot{j}$, aq. lb. $\mathrm{ij}$, coque ad $\mathrm{lb} . \mathrm{j}$; an astringent injection or lotion in gleets and the whites.

Dec sarsasparille. $3 \mathrm{j}$ to a pint; boil to one half.

LISBON DIET DRINK, Dec. sarsaparille compositum. Rad. sars. jvj, cort. rad. sassafras, cort. guaiaci, rad. glycyrrh. ana $3 \mathrm{j}$, cort. rad. mezerei 3 iij, water 10 pints, boil to 5 ; are both alterative, to lb. jss in die.

DEC. SENEG.E. Rad. $\bar{j} \mathrm{j}$ to aq. $\mathrm{lb}$. $\mathrm{ij}$; boil to $\mathrm{lb} . \mathrm{j}$; acrid, in rheumatism.

Dec. usur. Cort. $\tilde{j} \mathrm{j}$ to aq. $\mathrm{lb}$. $\mathrm{j}$; boil to $\mathrm{lb}$. ss; in herpetic eruptions, to $\mathrm{lb}$. jss in die.

Dec. Helreborri, Dec. veratri. Rad. $3 \mathrm{j}$ to $\mathrm{lb}$. ij ; boil to lb. j, when cold, add spir. vini $\tilde{3} \mathrm{ij}$.

Diaphoretic deccction. Dec. cort. Per. 3x, liq. amm. acet., tinct. cinch. $3 \mathrm{ij}$, conf. aromat. 3 ss, for a dose every three hours.

Coolrng decoction. Dec. hord. lb. j, acid. muriat. $3 j$, syr. simpl. 3ij; for common drink in putrid fevers.

Strengthening decoctions. Cort. Peruv. cont. 3̈ss, serpént. $3 \mathrm{ij}$, aq. Ib. $\mathrm{j}$; boil to a half, and strain; then add spir. cinnam. 3ैjss, acidi sulph. diluti 3 jss; dose $3 \ddot{i j}$ every six hours.

2. Dec. cort. Peruv. 3 jijs, inf. gent. comp. 3 j, tinct. cascar., aq. kali, ana $3 \mathrm{ij}$; dose coch. maj. ij, frequently.

3. Dec. cort. Peruv. 亏̄vj, tinct. ejusd. 3 ss, conf. aromat. Эj, spir. amm. arom. $3 \mathrm{j}$; dose coch. maj. ij, daily.

Hartsion d drink, Mistura cormu usti. Cornu usti 3̈ij, gunı Arab. $3 \mathrm{j}$, aqua lb. $\mathrm{iij}$; boil to $\mathrm{lb}$. $\mathrm{jj}$; strain ; demulcent, merely mucilaginous.

\section{FOR KITCHEN USE.}

Plain barley water, Aq. hordeata, Dec. hordei. Pearl barley 2 oz., water $4 \frac{1}{2}$ pints, boil to 2 pints and strain. 
Barley water, Ptisana communis, Dec. pectorale, D. hordei compositum. Plain barley water 2 pints, figs $2 \mathrm{oz}$., liquorice $\frac{1}{2} \mathrm{oz}$., raisins stoned $20 z$., water 1 pint, boil to 2 , and strain; demulcent, ad libitum.

Raisin drink, Potus uvarum siccarum. Stoned raisins 4 oz., water 3 pints; boil, strain 3 pints.

Rice drink, Dec. oryzce. Rice 2 oz., water 2 pints, boil to strain a pint; a little lemon peel may be added.

Tisane de ris, Eau de ris. Rice half an oz., water sufficient to strain 3 pints, boil.

FOR USE IN THE ARTS.

Infusion of Brazil wood.-Inf: of logwood.-Inf. of nut galls. Are all three prepared by pouring boiling water on the chips of the woods, or the bruised galls.

Inf. of turmeric. - Inf. of dried red cabbage. - Inf. of violet blue dahilia petals. - Inf. of red roses. - Inf. of periwinkle petals. - Inf. of blue flag flowers. - Inf. of mallow flowers. Are prepared in the same manner; but as the infusion of red cabbage, nutgalls, and Brazil wood are often in use, $1 \mathrm{oz}$. meas. $\frac{x}{2}$ of spirit of wine is added to a pint of the first, and $3 \mathrm{oz}$. measures to the two last, to preserve them.

Inf. of litmus. Made from the cakes of litmus.

Red inf. of turmeric.-Red inf. of blue dahlia petals.

Red inf. of litmus.-Reddish violet inf. of litmus. Are made by adding weak acetic acid to the ordinary infusions until the desired colour is obtained. All of these infusions are used to discover slight traces of acids, or alkalies, in mineral waters, or ¿queous liquids, or to ascertain when saline mixtures are neutralized.

\section{MUCILAGES AND JELLIES.}

\section{FOR MEDICAL USE.}

Mucilago acacie, M. gummi Arabici, ziv to half a pint; demulcent.

Boiled starch, Muc. amyli. 3iij to a pint, boiled; as a restringent clyster; does not become stiff by adding calcined magnesia.

MUC. gummi tragacanthe. $\overline{3}$ jo half a pint, soak for 24 hours, then rub, and press through a cloth; principally used to make lozenges. - 2. Gum $\overline{3}$, water $\overline{3}$ iv. 
JeLly of ICEIAND suoss, Gel. lichenis. Iceland moss 4 oz., water q. s. to strain a pint and a half, add white sugar $4 \mathrm{oz}$. nutritive and tonic in phthisis.

SAIEP JET.LY. Salep ground 2 oz., water 12 pints, add calcined magnesia $3 \mathrm{oz}$, to prevent it from growing mouldy.

FOR KITCHEN USE,

Biscuit jelly, Gelutina panis. White biscuit 4 oz., water 4 pints; boil to a half, strain, evaporate to a pint, add white sugar $1 \mathrm{lb}$., red wine $4 \mathrm{oz}$. . cinnamon water $1 \mathrm{oz}$. ; in dysentery, and weakness of stomach.

Hartshorn jelly, Gel. cormu cervi. Hartshorn shavings 1 oz., water 4 pints, boil to $\stackrel{2}{\sim}$ strain; warm again with orange juice 1 oz., white sugar 6 oz., sherry $\tilde{j} \mathrm{oz}$.

2. Hartshorn shavings 8 oz., water 4 pints, boil, strain, add white wine and sugar ana $4 \mathrm{oz}$., or if a very clear jelly is required, syr. of vinegar $6 \mathrm{oz}$., clarify with the white of $2 \mathrm{eggs}$, strain, putting cinnamon or lemion-peel on the strainer to flavour the jelly; nutritive.

Sago jelly. Soak sago in water for an hour, pour it off, and adding more, boil till the sago is transparent, then add wine and sugar, or clear broth.

Arrow root jelly. Arrow root 1 oz., stir in boiling water sufficient to form a thick jelly, which may be flavoured at pleasure.

Tapioca jelly. Soak it in water for a night, then boil it gently till quite clear, and add lemon-juice, lemon-peel, wine, sugar, and cinnamon, at pleasurc.

Almond jelly, Gicl. amiyggdulumum. Sweet almonds blanched I oz., white sugar $5 \mathrm{vj}$, water $40 \%$, rub into an emulsion, strain, and add melted hartshorn jelly $\mathrm{S} 0 \%$, orange-flower water $3 \mathrm{j}$, essence of lemon gtt. iij.

Créme de riz. Rice 3 spoonsful, boil in water 2 pints to 1 , strain, add sweet almonds No. 10, bitter almonds No. 5 ; make an emulsion, with sugar, a little cinnamon or orange-flower water, and drink it warm in the morning.

Isingluss jelly. Isinglass? oz., water? pints, boil to 1, strain, and add milk $\mathrm{I}$ pint, white sugar candy $1 \mathrm{oz}$; nutritive.

I'arlable soup, Glaze. Leg or shin of beef, break the bones, put it into a digester that will merely hold it, covered with cold water, hoil it gently for eight or ten hours, strain, let it cool, take off the fat, pour into a shallow stewpan, add whole black pepper t oz., boil away to about a quart, pour it into a smaller stewpan, and simmer gently till it is reduced to the thickness of a 
syrup; then either pour it into small upright jelly-pots, with covers, and when cold, paste the joints over with paper; or pour it out upon flat dishes, to lie about $\frac{1}{4}$ inch deep, when set divide it in pieces and dry them. A shin of beef of 9lb. produced $9 \mathrm{oz}$. of portable soup, and $2 \frac{1}{4} \mathrm{lb}$. of meat fit for potting.

\section{USED IN THE ARTS.}

Solution of Isinglass. Isinglass gr. $\mathrm{x}$, water $3 \mathrm{j} \mathrm{j}$, boil and strain; used as a test for tannin : if for keeping, add spirit of wine 3jss.

Carpenters' glue. Cake glue $8 \mathrm{oz}$., water 2 pints; soak for a night, and boil to a proper consistence.

Flour paste, Colle de pâte. Wheat flour and water rubbed together smooth, and then boiled until dissolved, adding a little alum.

Hard paste. A little powdered rosin is added in the boiling; aloes is sometimes used to deter insects from eating it. A few drops of any essential oil, or a little camphire, prevents it from growing mouldy ; in a covered jar, it may then be kept for a year ; using a brush with plain water when dry.

Potatoe paste. Potatoes grated fine $1 \mathrm{lb}$., water 2 pints and a half; boil, add powdered alum half an oz.

Chinese paste. Bullocks' blood 10lb., quicklime 1lb., beat together ; it becomes a stiff jelly, in which state it is sold, and will keep in cool weather for three weeks; when used, it is beat down with water to a proper consistence.

Vernis de colle forte. Carpenters' glue and alum; used for varnishing furniture to render it less liable to take fire.

Mucilage of flea-wort seeds. Used to dress muslin.

French cement. Gum water, thickened with starch powder; used by the naturalists and French artificial flower makers; keeps for a long time; lemon-juice is sometimes added.

Mouth glue, Indian glue, Colle à bouche. Best cake glue, dissolve in a little water, add brown sugar a small quantity, and some essence of lemons, pour it into greased moulds, dry it. When used, it is wetted with the tongue, and rubbed on the paper to be joined.

Liquid glue. Melted glue, vinegar, of each 1 pint, spirit of wine $4 \mathrm{oz}$; ; used as a cement.

Solution of starch. Starch 5 gr., water $1 \mathrm{oz}$. ; used as a test for iodine.

Sol. of albumen. White of eggs strained $1 \mathrm{oz}$., water $10 \mathrm{oz}$ 2. Dried white of eggs $1 \mathrm{oz}$., water $20 \mathrm{oz}$; ; both are used as a test for tannin. 


\section{EMULSIONS AND LOHOCHS.}

A new laid egg weighs about 3 jijss, the white $\overline{3} \mathrm{j} 3 \mathrm{vj}$; yelk $3 \mathrm{x}$; shell $z^{i v}$; an oz. of blanched almonds are usually 26 in number; mucilage of gum Arabic $5 j$, made of equal parts, gum and water, will form $3 i j$ of any oil into an emulsion with water $3 j$.

Almond mik, Emulsio amygdalina. Amygd. dulc. 3 j, amygd. amar. No. 3, sacch. albi lb. ij, aq. dist. lb. ij, aq. fl. aurant. $3 \mathrm{ij}$ : the bitter almonds improve the flavour.

Mistura amgdale. Conf. amygd. $\bar{j} j$, aq. distil. $1 \mathrm{lb} . \mathrm{j}$; pectoral.

Euvisio Arabica. Gum Arab. 3ij, amygd. dulc. sacch. albi ana sss, decoct. hordei lb. j.

Em. самғноват. Camph. Эj, amygd. dulc. 3ij, sacch. albi 3j, aq. 亏̌ j.

2. Camph. gr. $\mathrm{x}$, vitellum unius ovi, sacchari albi $\overline{3}$., aq. $\overline{3} \mathrm{vj}$. Commodious methods of giving camphor.

EM. OLEI AMYGDALARUM. Ol. amygd. $\overline{3}$ j, gum Arab. pulv. $3 j$, syr. simp. $\bar{j} j$, aq. rosæ $\overline{3} s s$; in coughs.

EM. oleI ricini. Ol. ricini $\overline{3} s s$, vitelli unius ovi aq. dist. $\overline{3}$, spir. lavand, comp. gtt. $\mathrm{xl}$, syr. Tolut. 3ss; as an opening draught.

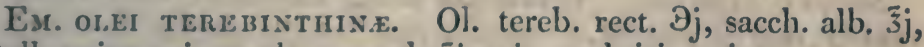
vitell. unius ovi, emuls. amygd. 亏̄iv : in nephritic pains.

Es. теrebintus.e. Tereb. Chiæ $3 \mathrm{ij}$, sacch. albi $3 \mathrm{j}$, vitellum unius ovi, emuls. amygd. 3iv; in gleets.

EM. pro goNorRuea chronica. Bals. copaibæ, syrup. Tolutan., gum Arabic, ana $3 \mathrm{j}$, spirit. æther. nit. 3ijss, aq. rosæ $3 \mathrm{vj}$, mist. ว̌ss ad $\tilde{j} \mathrm{j}$; bis ter in die.

Ex. Effervescexs. Mist. amygdala $\overline{3} j$, vini ipecac. gtt. $x$, potas. carbon. gr. $\mathrm{x}$ : add succ. limon. 3iij, and take it while it effervesces : cxpectorant.

2. Mist. amygd, 3̂j, pot. carbon. gr. x, syr. papav. rubri $3 \mathrm{j}$, succ. limon. 3iij; detnulcent.

Lorocir alium. Amygd. dulc. No. 16, anygd. amar. No. 2, aqua rosa $3 \mathrm{iv}$, make an emulsion, add gum tragacanth. gr. xvj, kacch. albi $33 \mathrm{j}$, ol. amygd. $3 \mathrm{iv}$, aq. flor. aurant. $3 \mathrm{ij}$; spcrmaceti or ipecac. may also be added.

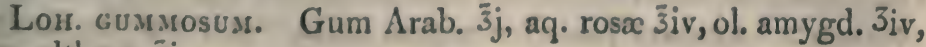
syr. althax $\overline{3}$. 
Lor. ov.. Vitellum unius ovi, ol. amygd. $3 \mathrm{j}$, syr. althææ $3 \mathrm{j}$, aq. rosæ 3̈ij.

Lor. Troverr. Ol. amygd., syr. capilli Ven., mannæ, pulpæ cassæ, ana $3 \mathrm{ij}$, gum. tragacanth. gr. xvj, aq. fl. aurant. $3 \mathrm{ij}$ : is sufficient for two days, beyond which it will not keep.

Lor. viride. Syr. violar. $\ddot{3}$, pistach. 3iv, infus. croci gt.t. $\mathrm{xv}$, aq. rosæ $3 \mathrm{iv}$, gum. tragacanth. gr. xvj, ol. amygd 3iv, aq. fl. aurant. $3 i j$.

\section{ICED CREAMS, ORGEATS, \&c.}

Cream for icing. New milk 2 pints, yelk of $4 \mathrm{eggs}$, white sugar 4 oz. ; rub together, strain, heat gently, and cool gradually ; ice as wanted: used also to make flavoured ices. - To ice cream and other liquids, put 2 pints into a covered icing pot, capable of holding twice as much, keep cool in a pail of ice; bruise ice 6lb., mix it in a deep pan, with salt $2 \mathrm{lb}$; throw some of this mixture into the hollow made by the the icing pot, and every five or six minutes open the pot, break down the ice that forms on the inside of the pot, that the whole may be converted into ice : as the ice and salt melt, add fresh.

Coffee for icing, Sorbet au caffé.-Tea for icing, Sorbet au thé. Cream for icing 2 pints, strong coffee or tea 2 oz., sugar $1 \mathrm{oz}$., yelk of 4 eggs : ice as wanted.

Chocolate for icing, Sorbet au chocolat. Chocolate 2 oz., rub 1 down with cream for icing 2 pints; and ice as wanted.

Sorbet a la vanille. Cream for icing, flavoured with syrup of vanilla: ice as wanted.

Sorbet ì la pistache.-Sorbet, aux amandes ordinxircs. Beat blanched almonds, or pistachia kernels $4 \mathrm{oz}$, into a paste, add cream for icing 2 pints, sugar $2 \mathrm{oz}$. ; ice as wanted.

Sorbet à la pistache de Provence. Provence almonds blanched 2 oz., apricot kernels blanched $\frac{1}{4} \mathrm{oz}$., white sugar 2 oz., cream for

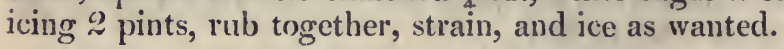

Orgeat, Sirop d'orgeat, Symupus hordeatus. Amygd. dulc. 1b.j, amygd. amar. 3ij; make an emulsion by adding barley water 2 pints ; strain, to the strained liquor $\overline{3} x$, acld sacch. alb. lb. jss, and when the sugar is dissolved, aq. flor. aurant. $3 \mathrm{j}$.

Syrupus amygdalinus. Jordan almonds $8 \mathrm{oz}$, bitter almonds 4 oz., water $q$. s. to make a very thick emulsion, strain, add the remainder of 2 pints of water, sugar $31 \mathrm{lb}$, orange-flower water 2 oz. ; sp. limon. cort. $3 \mathrm{vj}$; strain through Hannel.

9. Bitter almonds $8 \mathrm{oz}$, rose water a pint, orange-flower water $1 \mathrm{oz}$, make an emulsion, strain, and add white sugar $2 \mathrm{lb}$.

Orgea ${ }^{\circ}$. Almond paste for orgeat $6 \mathrm{oz}$., water 2 pints, strain, flarour with orange-flower water. 


\section{WATERY MIXTURES.}

FOR MEDICAL USE.

Aqua alumixosa of Falliopus. Corr. sublim., ana $3 \mathrm{ij}$, rose water, plantain water, ana $\mathrm{lb} . \mathrm{j}$, boil to a half and fiter.

AQ. alumisis Batrana, Aq. aleminis composita, Liquor aluminis compositus. Alum, white vitriol, ana sss, water $\mathrm{lb}$. iij; dissolve and filter : astringent; used in washing ulcers and eruptions, or as an injection in gonorrhœa and the whites.

Mineral solvent, Fowler's solution of arsenic, Solvens minerale, Liquor arsenicalis. White arsenic, kali ppi., ana gr. lxiv, distilled water lb. j: boil, and when cold, add lavender drops ziiij, distilled water q. s. to make an exact pint : tonic, febrifuge ; used in agues; doses to adults gtt. xij, ter in die: stout boys, gtt. $x-x i j ;$ young boys and girls, gtt. vij-x; children under seven, gtt. v-vij; from two to four, gtt. ij-v.

Sydenhay's styptic water, Aqua vitriolica cerulea. Blue vitriol 亏̈iij, alum, oil of vitriol, ana żij, water 3 viij : dissolve and filter.

Solutio solphatis cupri composita. Blue vitriol, alum, ana $3 \mathrm{oz}$. , water $24 \mathrm{oz}$., oil of vitriol $2 \mathrm{oz}$. and a half : dissolve and filter; used to stop blceding at the nose, applied with dossils of lint.

LIQUOR HYDRARGYRI OXYMURIATIS. Corrosive sublimate gr. viij, distilled water $\tilde{3} \times v$, spirit of wine $\overline{3} j$; dissolve : alterative, $3 i j-3^{v j}$, bis terve in die; $3 \mathrm{j}$ contains gr. ss of corrosive sublimate.

Gowland's rotion. Bitter almonds 1 oz., sugar 2 oz., distilled water 2lb.; grind together, strain, and add corros. sublim. aij, previously ground with S. V.R. $3 i j$; used as a wash in obstinate eruptions.

Lotio antíl一ogistica. Liquoris plumbi subacetatis $3 \mathrm{vj}$, liquoris ammonix acetatis $3 \mathrm{iv}$, aqux puræ $\mathrm{lb}$. $\mathrm{ij}$. Misce.

Lotio evaporans astringexs. Ammonix muriatis 3ij, liquoris ammoniæ acet. 33iij, aquæ puræ 3̋xij. Misce.

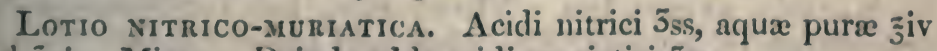
rel 3 vj. Misce. Deinde adde acidi muriatici 3̌ss.

Lotio ol eosa. Liquoris calcis, olei olivæx, āā partes æquales.

YeLlow wash, Aq. phagedenica. Lime water lb. j, corrosive sublimate 3 ss; rub together: shake up when used as a wash for foul ulecrs, particularly the syphilitic. 
White wash, Royal preventive, Aq. lithargyri acetati composita, Liquor plumbi acetatis dilutus, Liq. subacetatis lithargyri compositus. Extr. Saturni, proof spirit, ana j, distilled water $\mathrm{lb} \mathrm{j}$ : cooling, astringent; used as a lotion in inflammations and burns.

-Young's PURGING DRINk. Carbon of soda 3ijss, crystals of tartar 3iij, water 3viij, corked up immediately in stone bottles and wired; a pleasant cooling laxative in summer.

WARD's white Drops. Quicksilver 12 oz., spir. nitre 2lb.; dissolve, add ammonia ppa. 14 oz., evaporate so as to form a light salt, which drain and dissolve in rose water 3lb. and a half.

2. Quicksilver 4 oz., spir. nitre $1 \mathrm{lb}$. j; dissolve, add ammonia ppa. $\%$ oz., evaporate and crystallize, then dissolve each pound of salt in three pints and a half of rose water.

3. Corrosive sublimate 3 jss, spirit of salt $2 \mathrm{oz}$, water $1 \mathrm{lb}$. jss: very inferior.

Liqueur de Pressavin. Dissolve quicksilver in spirit of nitre and precipitate it with subcarb. of potash, then take this precipitate and cream of tartar ana $1 \mathrm{oz}$., distilled water $40 \mathrm{oz.}$; dissolve: two spoonsful of this liquor is diluted with two pints of distilled water, and a wine glass, i. e. 2 oz. taken quaterve die, avoiding the use of common salt in the food: used in syphilis.

Alum whey, Serum lactis aluminosum. Cows' milk. lb jss, alum 3ijss; boil together and strain.

- Mustard whry, Serum lactis sinapinum. Cows' milk lb ij, sem. sinapeos cont. $2 \mathrm{oz}$.; boil together and strain.

Collyrium astringens. Vini opii 3ij, zinci sulphatis $9 s s$, aquæ rosarum, aquæ puræ, āā ̌̌̀j. Misce.

Collyrium aNTIPHLOGISTICUM. Liquoris plumbi subacetatis ऊss, aquæ rosarum jij, aquße distillatæ $\mathrm{lb}$. ss. Misce aquam tepidam, partibus æqualibus, tempore utendi.

Collyrium acetosum. Aceti dist. '̌̉j, spir. vini $3 \mathrm{jj}$, aq. rosæ $3 x i j$ : in ophthalmia.

DE Brun's col. Aloes. Aloes hep. 3j, vini albi, aq. rosar. ana $\overline{3}$ jss : in ulcerated eyelids.

Bates's Eye-water. Vitriol cær., bol. Gall. ana gr. xv, camph. gr. iv, æq. ferv. 3̈iv ; when cold add aq. lb. iv.

Common eye-WATer, Aq. ophthalmica, Aq. vitriolica camphorata. White vitriol 3 ss, camphire $3 \mathrm{ij}$, boiling water $1 \mathrm{lb}$. ij; dissolve and filter.

AQ. zinci vitriolata cUM camphora. White vitriol $3 \mathrm{ss}$, spiritus camphoratus 3 ss, boiling water $1 \mathrm{~b}$. $\mathrm{ij}$; dissolve ard filter: 
discutient; used as a lotion for ulcers, or diluted with water $p$. æq. as a collyrium.

Col. amMonis acetatis. Opii gr. $x$, aquæ ferv. $\tilde{z} v j$; solve, cola et adde liq. ammon. acet. $3 \mathrm{jj}$ : when ophthalmia is very painful.

2. Liq. ammon, acet. $30 \mathrm{j}$, mist. camph. $\tilde{3} \mathrm{vj}$ : when ophthalmia has left the eyes relaxed and weak.

Goulard's eye-water, Col. Goulardi. Extr. Saturni gtt. $x$, aq. rosar. З̌vj.

2. Extr. Saturni gtt. $x$, spir. camph. gtt. xx, aq. rosar. З̌viij: in the inflammatory stage of ophthalmia.

Col. opır. Opii gr. x, camphoræ gr. vj, aq. ferv. 3 xij, coletur : if ophthalmia is very painful.

Col. Sacchari Saturni. Gr. vj to aq. rosar. 3̌jj.

Col. vitrioli albi. Gr. $x$ to aq. rosar. 3̄viij.

2. Vitrioli albi $3 j$, spir. camph. 3 jss, aq. fervent. 3 ij, aq. rosar. siv: in the weak state of the eyes after ophthalmia.

3. Vitr. alb. 3 ss, album unius ovi, aq. rosar. $3 i v$; the same, but much stronger.

Col. vitrioli cerules. Vitr. cærul. gr. iij, mist. camph. $3 \bar{v}$, in the purulent ophthalmia of infants.

Liquor ziNCr acktatis. Zinci sulph. gr. xxiv, aquæ distill. 亏iv, solve: plumbi superacetat. gr. xxxij, aquæ distillat. ऊiv, solve. Mix the solutions, let them rest a little, and then filter. In ophthalmia and gonorrhoea.

Emmocatio amaoniz aceтатis. Liq. amm. acet. lb.j, spir. vini Ӟij; ; for sprains and bruises.

Eмв. сазтио re. Camph. 3̌ss, spir. vinilb. ss, aceti dist. 3̋vj, aquæ 3 iij.

Eмв. saronis. Sapon. alb. 3iij, spir. vini 3 xij, spir. corn. cervi 3 iv, camph. $3 \mathrm{j}$; as the former.

Purginc clyster, enema catharticum. Mannæ $3 j$, dec. chamæm. 3 x, ol. olivar. 3̋j, sal. Epsom 3ैss.

Exema foridus. To the former add tinct. assefotidx $3 \mathrm{ij}$; antispasmodic.

Exrsa op1. Inf. lini $\xi$ viij, tinct. opii $3 j$ : in pains from calculi.

Tовасco clyster, Enema tabaci. Fol. tabaci Эij, aq. ferv. ¿xiij; as soon as sufficiently cool, throw up one half, and the remainder half an hour afterwards if necessary, in strangulated hernia. 
Enema terebinthines. Tereb. comm. 予ss, vitellum ov unius, inf. lini $3 \mathrm{x}$ : in calculus.

Common clyster, Enema domestica. Mutton broth strained, linseed oil, of each a quarter of a pint, brown sugar an $\mathrm{Oz}$.

Encma catharticua. Dec. malyæ c. $3 x$, magnes. sulph. $3 j$, ol. oliv. $3 \mathrm{ij} ; \mathrm{m}$.

Es. Fetıdu. Dec. malvæ c. $\approx$ x, assæfœt. $3^{\mathrm{ij}}$, spir. ammon. comp. 3 jss, tinct. opii $3^{\text {ss }} ; \mathrm{m}$.

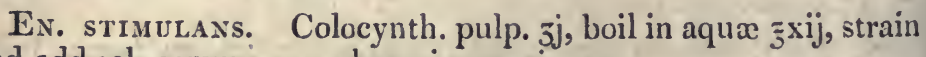
and add sal. comm., syr. rhamni, ana $3 \mathrm{j} ; \mathrm{m}$.

Es. opiatum. Mucilag. amyli žj, tinct. upii $3 \mathrm{i}$; misce.

En. ol. terebinthin ж. Ol. terebinth. zss, vitelli ovi No. 1, grind and add gruel $\overline{3} x$.

Ex. Anticolicum. Inf. chamæm. $3 x$, add ol. cajeputi gtt. iiij, dissolved in spir. nitri dulc. gtt. $x l$.

Capsicum garge, Gargarisma capsici. Capsici pulv. $3 \mathrm{j}$, sal. comm. $\exists j$, aceti $j \mathrm{iv}$, aq. ferv. $\jmath j$, strain; used in ulcerated sore throat and scarlet fever.

OAK bark gargle, Gargarisma quercûs. Alum $\ni^{\text {ss, }}$ cort. querc. $3 \ddot{i j}$, ol. vitriol. gtt. $\mathrm{xxx}$, aq. ferv. ${ }_{3} \mathrm{vj}$; in relaxation of the uvula.

Gargarisma eruginis. Linim. æring. $3 \mathrm{jj}$, mell. $3 \mathrm{j}$, aq. $\tilde{\mathrm{j}} \mathrm{j}$. Galr. boracis. Boracis $3 \mathrm{ij}$, mell. $3 \mathrm{j}$, aq. rosar. $3 v i j$ : in thrush.

Gar. Nıtri. Sal nitri 3ij, mell. 3iv, aq. rosar. $3 v j$ : in inflammatory sore throat; used frequently.

Gargarisma comande. (Inf. for child.) Aquæ puræ 亏̈xxij, sub-boracis sodæ $3 \mathrm{x}$, tinct. catechu $\bar{j} \mathrm{j}$, tinct. capsici annui $3 \mathrm{ij}$, mellis rosæ - jjss.- Misce. Interdum adde, loco boracis sodæ et tinct. catechu, acidum muriaticum, vel acidum sulphuricum.

Gar. Spiritus salis. Spir. salis gtt. $x x$, mell. $3 j$, aq. $z^{i v}$ : in inflammatory sore throat.

Gar. sublimati corrosivi. Subl. corr. gr. iij, aq. dist. lb. j: for venereal ulcers in the throat.

Gargarisma astringens. ” Infus. rhatanhiæ इvjss, acid. sulph . dil: $3^{i j s s, ~ s y r u p . ~ m o r i ~} j \mathrm{j}$. In relaxation of the uvula and fauces (Sprague.)

Gutta Fellis. Fell. bov. 3iij, bals. Peruv. 3j, to be dropped in the ear, after syringing with soapy water: in abscess of the ear. 
Injectio caustici Lunaris. Caust. Lun. gr. ij, aq. dist. इj; for fistulous sores.

Linimexters calcis, $L$. aqua calcis. Linseed or common olive oil, lime water, ana p. æq., shake them together.

Lis. oprr. Linim. camph. comp. $3^{i x}$, tinct. canthar. 3 j, tinct. opii 3 ij; stimulant and anodyne.

Lotio Acidi Nitrici. Aq. fortis $3 \mathrm{j}$, aquæ $\mathrm{lb}$. $\mathrm{j}$; in mortification.

Lotiox of Prussic acid. Magendie's medicinal Prussic

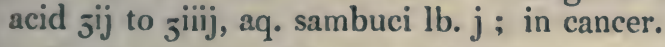

L. Alumisis. Alum., aceti distil,, vitrioli alb. ana $3 s s$, aquæ lb. ij ; for chilblains.

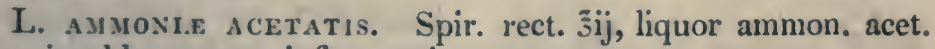
$5 \mathrm{v}$ : in phlegmonous inflammation.

L. Gocr.andr. Extr. Saturni 3 j, S. V. R. 3 jij, aquæ rosæ lb. j.

2. Extr. Saturni 亏̈ij, acet. dist. 亏亏iv, S. V. R. 亏̄ss, aquæ rosæ lb. $\mathrm{j}$ : as the former.

Black wash, L. hydrargyri nigra. Calomelanos $3 \mathrm{ij}$, aq. calcis $\mathrm{lb} . \mathrm{j}$ : in syphilis.

L. мувин.е. 'linct. myrrhæ, aq. calcis, ana zij : in scorbutic ulcers.

L. opı. Opii 3 ij, aq. distil $\mathrm{lb}$. $\mathrm{j}$ : for painful and irritable ulcers.

L. Salis ammoniaci. Sal. ammon. zjj, aceti, spir. rect. ana lb. $s$; in circocele.

L. vitrololi certier. Vitriol. cxerul., boli Gall. ana 3 ss, eamphoræ $\mathrm{j}$, aq. ferv. lb. iv : in phagedænic ulcers.

Haustus ammonife acetatis. Liq. ammon. acet. ziij, mist. camph. 3 xij, liq. antim. tartar. gtt. $x \mathrm{x}$, syr. croci $3 \mathrm{j}$; every four hours, in low fevers, as a diaphoretic.

Hatstes acidi xitrici comp. Acidi nitrici dil., spirit. wther. nitrici, āa $3 j$, infus. digitalis $3^{\mathrm{iij}}$, aq. distill. $3^{i x}$, syrup zingiberis 3 ij. Misce. Ter die sumendus. In dropsies.

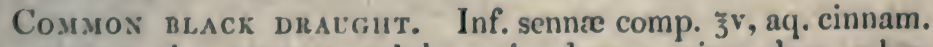
$\tilde{3}$, mannæ $j^{i r}$, magnes. sulph. $3 v j$; dose a wine glass, when necessary.

Havstes вisмutur. Oxydi bismuthi gr.v, pulv. tragacanth.

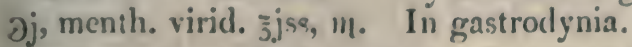

H. sat.ısts. Kali ppi. jaj, succi limon. žss (vel acid. citrici gr. xv), aq. cinnam $3 \mathrm{ij}$, aqua 3 viij, syr. aurant. $z_{\text {j }}$ : as the former. 
H. salines effervescress. Kali ppi. Эj, aq. cinnam. $3 \mathrm{ij}$, aq. 3 j, syr. aurant. 3 jss: when taken, add a table spoonful of lemon juice, and drink it immediately, in putrid sore throat.

Mistura alkalina anodyna. Tincturæ opii $3 i j$, liquoris potassæ 3ijss, spiritus myristici 3̌ss, aquæ puræ 3 xjss: Misce.

Mistura ammoniaci. Gum. ammon. $3 \mathrm{ij}$, aq. lb. jss: expectorant.

Mist. ammonie acetatis. Liq. ammon. acet. そjss, sal.

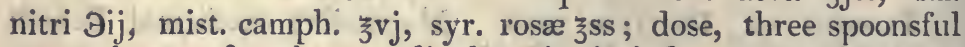
every three or four hours: diaphoretic, in inflammatory fevers.

Mist. AsSAFEtide. 3 ij to half a pint of water; antispasmodic.

Mist. assafoet. millari. Assafot. 1, liq. ammon. acet. 4, aq. pulegii 12; a table-spoonful every three hours.

Astringent mixture, (Hosp. Par.) Rose water jiv. extr. of rhatanhia root $3 j$, syrup of diacodium $3 j$.

- Mist. Camphore. Camph. 3ss, spir. rect. gtt. x, aq. lb. j; as a vehicle.

Mistura Carminativa. (Inf. for child.) Magnesiæ sulphatis $३ j s s$, magnesiæ carbonatis 3 ijss, tincturæ cardamomi comp. zjss., tincturæe castorei $m x l$, olei anisi $m x$, aquæ anethi $z x i j$, aquæ

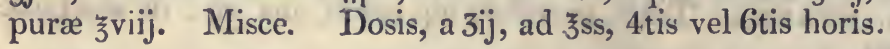

Mist. cosmetica. Ol. amygd. jiv., ol. tart. p. d. 弦, ol. rhodii gtt. iij, mix : clears the skin, but makes it smart.

Mist. Crete. Cretæ ppæ. zss, sacch. puri ziij, gum Arab.

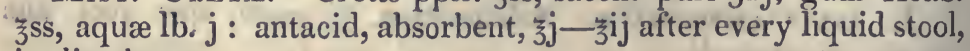
in diarrbœa.

Mistura Febrifuga. (Inf: for child). Misturæ camphoræ そxxiij, antimonii tartarizati gr. iij, potassæ nitratis $3 \mathrm{vj}$, spiritus ætheris nitrici そsss, syrupi limonum 3 ss. Misce. Dosis, a $3 \mathrm{j}-$ §ss. Interdum adde, vinum ipecacuanhæ, vel tincturam digitalis, vel tincturam opii, vel syrupum papaveris.

Mist. Ferri composita. Myrrhæ $3 \mathrm{j}$, subc. potassæ gr. Xxv, sacch. puri $3 j$, aq. rosæ $亏$ vijss; rub together, add spir. nuc. mosch. そss, sal Martis $\not j$; pour im mediately into draught phials, so as to quite fill them, and keep them close stopped till re-

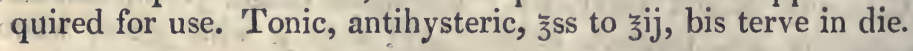

Mist. Guaiaci, P.L. Gum guaiaci zjss, sacch. albi zij̣,

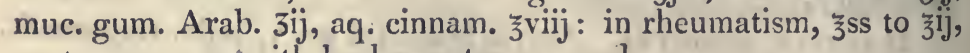
nocte maneque, with barley water or gruel.

Mist. Guaiaci Ammoniat. (Guy's Hosp.) Gum guaiaci

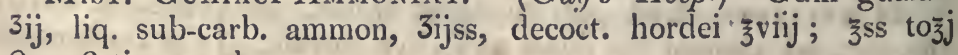
2 or 3 times a day. 
F Mist, Rhei comp. (Guy's Hosp.) Rhub. zi, sub-carb. of soda

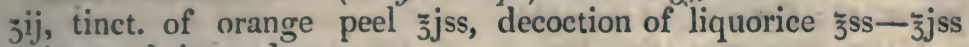
twice or thrice a day.

Mrst. моoschi. Moschi, gum Arab., sacch. pur. ana 3j, aq.

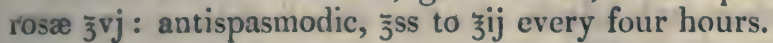

Mist pro diarrhos. Olei cinnamom. gtt. viij, sacchar. albi $j^{\mathrm{ij}}$. Misce. Dein adde decoct. tormentillæ $\_$vj, pulv. cretæ comp. cum opio $3^{\mathrm{ij}}$, tinct. rhatanhiæe `ss. Misce, žss ter die.

2. Copaibæ $3 \mathrm{ij}$, mellis despum. $3 \mathrm{vj}:$ misce, et adde gradatim decocti tormentillæ $z$ zj, tinct. rhatanhiæ ${ }_{3}$, tinct. opii. gtt. $\mathrm{xl}$;

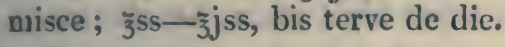

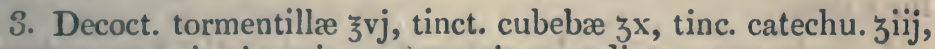

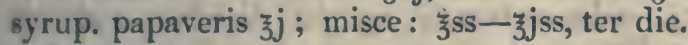

These three preparations are very useful in colliquative diarrhœa and leucorrhæa.

Mist. tartari emetici. Liq. antim. tart. 3̌ss, salis nitri

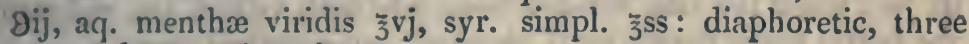
spoonful every three hours.

Mist. eмetica. Vin. ipecac. 3 j, tart. emet. gr. j, aq. 3 jss : for à dose.

2. I pecac. $3 \mathrm{ss}$, tart. emet. gr. j, tinct. scillæ 3 j, aq. 3 viss.; dose coch. maj. iiij at first and two more every fifteen minutes till it operates.

3. Tart. emet. gr. ij, aq. ziv : dose coch. med. ij every quarter of an hour.

4. Vitrioli cæerul. gr. $x$, aq. zij, for a dose.

Mist. antispasmodica. Tinct. castor. $3 \mathrm{j}$, æther. sulph. gtt. $x$, tinct. opii gtt. vij, aq. cinnam. zjss : for a dose, thrice a day.

2. Moschi $3 \mathrm{j}$, gum Arab. 3ss, aq. rosæ $3 \mathrm{j}$, æther. sulp. $3 \mathrm{j}$ : for one dose, pro re nata.

3. Assafoet. 3 j, aq. menth. pip. 3 j, tinct. valer. amm. $3 \mathrm{ij}$, tinct. cast. 3 iij, reth. sulph. $3 \mathrm{j}$ : dose coch. maj. j every two hours; in hysteria.

4. Rad. valer. $3 \mathrm{j}$, tinct. valer. amm., tinct. castor. ana $3 \mathrm{j}$, mist. camph. 3 xij, for a dose thrice a day.

Mistulia Sedativa. (Inf. for child.) Magnesise subcarbonatis, cretæe præparatæ, pulv. acáciæ, āa jij, spiritus ammoniæ

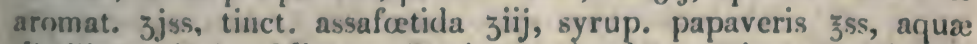
distillata $\mathrm{O}$ j. Misce. Dosis, î $3 \mathrm{j}$ ad 3 ss, stis, vel 4 tis, vel 6tis horis. Interdum adde tinct. catechu. \&ic. Sec.

Mist. narcotica. Tinct. opii gtt. xv, syr. papav. zij, spir. cinnam. $3 . j$, aq. $3 j$; for a duse, at the commencenent of the lot fit of an ague. 


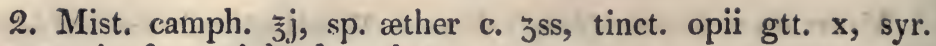
papav. $3 \mathrm{j}$ : for a night draught.

Mist. purgans. Sal. Epsom, sal. Glaub. ana ziij, aq. menth. vir. $z_{s s}$ liq. antim. tart. $3 \mathrm{j}$ : dose coch. maj. ij, thrice a day.

2. Sal. Epsom, sal. Glaub, ana $\xi_{\text {ss, }}$, vitrioli virid. gr. v, mist camph. ¿vijss: dose cochl. maj. ij, twice a day, for a continuance.

3. Ol. ricini そsss, vitelli ovi q. s, syr. papav. 3 ij, tinct. opii gtt. v, aq. $\jmath_{j}$; for a dose, every three or four hours, in Devonshire or painters' colic.

4. Rad. rhæi gr. xviii., potas. supersulph. gr. x., aq. cinnam $气$, for a dose.

5. Sodæ tartar. 3 j, sodæ carbon. Эj, aq. ३jjss, dissolve, and add when about to be taken succi limon. coch. $\mathrm{j}$ maj. to cause an effervescence; for a morning draught, daily.

6. Sodæ carbon. $3 i j$, ferri sulph. gr. iij, magnes. alb. 3 , aq. 1b. jss : when the salts are dissolved, add spir. vitrioli $3 \mathrm{x}$, and stop the bottle immediately until required; an excellent tonic.

Mist. Diuretica. Inf. gentianæ comp. ̌̋jss, potas. subcarb. gr. x., spir. æther. comp. 3 ss, tinct. cinnam. $3 \mathrm{j}$; for one dose.

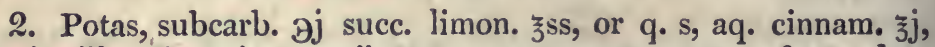
aceti scillæ 3 jss, tinct. opii gtt. v, syr. aurant. $\jmath^{s s ;}$ for a dose twice a day, frequently.

3. Potas. acet. $3 \mathrm{j}$, oxym. colchici zij, aq. $\jmath_{j}$, spir. junip. c. そss ; for a dose.

4. Liq. ammon. acet. $\stackrel{\jmath}{3} \mathrm{j}$, potas. acet. $3 \mathrm{j}$ : for a dose, thrice a day.

5. Sal. nitri 3 j, mist. ammon. $3 v j$, sp. junip. c. ऊjss, aceti scillæ $\zeta v j$; dose coch. ampl. j, every four hours.

6. Tinct. lyttæ gtt. $x$, sp. æhther. nitr. $3 j$, mist. camph. $3 x i j$, syr. zz. $3 \mathrm{j}$ : for a dose, thrice a day.

Mist. Diuretica Fortion. Infus. digitalis zvss, tinct. digi-

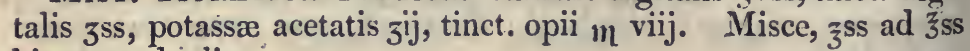
bis terve de die.

Mist. Diuretica ex tunica. Infus. gentianæ comp. $3 \mathrm{vj}$, acetatis potassæ 3 jss, spir $\mathrm{it.}$ junip. comp., spir. armorac. comp. ana $\bar{s}$ ss, spirit. æether. nit. $3^{\mathrm{j} j s s .}$ Misce.

Mist. antihysterica. Assafœetid. $3 j$, tere cum aq. menth. piper. $\bar{\jmath} v j$, dein adde tinct. valer. ammon. 3 ij, tinct. castoræ $3^{i i j}$, æther. sulph. 3jss. Misce. Dose $\frac{z}{3} \mathrm{ss}, 2$ dis horis.

Mist. ammonicici compos. Ammoniaci zjss, aq. cinnamon. $\tilde{\jmath} \mathrm{v}$, tinct. castoræ $3 \mathrm{j} s \mathrm{~s}$, tinct. opii $\mathrm{m} \mathrm{x}$, syrup. tolutan, $\mathrm{z}_{\mathrm{j}}$. Misce, ऊss ad $う$ j; subinde. 
Mist. Cakminativa. Magnes. ustæ gr. xxxv, pulv, rhei gr. viij, sacchar. albi $3 j s s$, olei anisi gtt. v, tinct. castorei gtt. $\mathrm{xw}$, tinct. opii gtt. iv, aq. fontan. ऊ3ij. Misce. Dose, $3 \mathrm{j}$ ad 3iij, infantibus.

Mist. ANodyna, (pro infantibus). Testæ præpar. 3ij, syrup. papav. alb. ...j, spirit. ammon. fortid. $3 \mathrm{js}$, olei. anethi. āă gtt. iij, aq. distil. 3iij. Dosis, $3 \mathbf{j}-3 \mathrm{ij}$, 4 tis horis.

Mist. expectorass. Assafot. Эij, aq. menthæ sat. 3 iij, syr. Tolu.. $\mathrm{j}$; dose coch. maj. j, every three hours.

2. Mist. ammon., aq. cinnam. ana ว̌jss, syr. Tolu. ǰss, tinct. castor. 3 ij, tinct. opii gtt. $\mathbf{v}$; dose coch. maj. j, when the cough is troublesome, in pertussis.

Mist. diaphonetica. Mist. camph. Jjjss, liq. ammon. acet. 3 ss, liq. antin. tart. gtt. $\mathbf{x x}$, tinct. opii gtt. $\mathbf{x}$; for one dose.

2. Potas. carbon. gr. $\mathrm{x}$, mist. camph. $\overline{\mathrm{J}} \mathrm{j}$; for a dose, to be taken with lemon juice, while effervescing.

Mistura diaphoretica, (Inf. for child.) Liquoris ammoniz acetatis $\tilde{3} \mathrm{iv}$, vini antimonii tartarizati $\tilde{3}$ ss, vini ipecacuanhæ $3 \mathrm{ij}$,

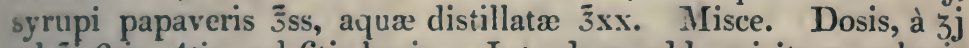
ad $3 \mathrm{j}$ Stis, 4 tis, vel 6 tis horis. Interdum adde spiritum retheris nitrici, vel tincturam opii.

Mistera diaphoretica anodyan. (Inf. for child.) Liquoris ammonix acetatis $\tilde{3} i v$., vini antimonii tartarizati, vini ipecacuanhæ, 3ij, àā spiritûs ætheris nitrici ̌sss, syrupi papaveris $\overline{3} j$, extracti conii gr. xiv, aqua distillata $3 x i j$. Misce. Dosis, à $3 \mathrm{j}$ ad jss 4 tis, vel 6 tis horis.

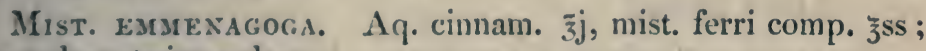
for a dose, twice a day.

2. Tinct. ferri mur. tinct. aloes c. ana $\overline{5}$ ss, tinct. castor. $3 \mathrm{ij}$; dose cochl. minimum $\mathrm{j}$, in a cup of camomile tea, three times a day.

Mist. demulcexs. Sperm. ceti $3 i j$, vitel. ovi dimid., syr.

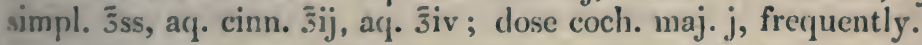

Mist. axtacid... Liq. potassa 3ij, liq. calcis $\overline{3} \mathrm{vj}$; dose one or two spoonsful pro re nata, in beef tea.

2. Magn. albse 5ss, aq. menth. pip. 3 ijss, spir. lavand. c. 5ss, syr. carui sir, syr. \%\%. $3 i j$; dose coch. med. j, pro re nata.

Mist. balsam Penevianir. Balsam. Perus. 3ij, mellis despumati $3 \mathrm{ij}$, misce ct adde gradatim, decocti glycyrrh. ¿vij, acid. sulphur. arcm. gtt. sx, tinct. aurantii co. $\overline{5} \mathrm{ss}$. Misce. In doses of 3 ss, and $3 j s s$, in diseases of debility. (1. C.)

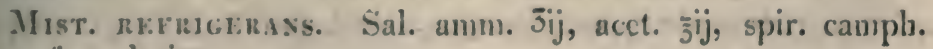
3 ss ; for a lotion. 

lotion.

2. Extr. Saturn, $3 \mathrm{j}$, acet. $3 \mathrm{ij}$, S. V. R. $3 \mathrm{ij}$, aq. 3 viij; for a

Mist. stimur.ans. Ammon. carb. 3ss, aq. menth. pip. ऊँvij, syr. aurant. ऊ̌ss, dose coch. med. when the patient is faint.

2. Mist. camph. 3 j, sp. æth. sulph. 3 ij, tinct. cardam. c. $3 i v$, sp. anisi $3 v j$, ol. carui gtt. xij, syr. zz. 3ij, aq. menth. pip. 亏̄vss; dose coch. maj. ij, pro re nata, in windy colic.

Mist. Roborans. Infus. rosar. co. З̌vss; quininæ sulphatis gr. xij, acidi sulph. arom. $\mathrm{m}_{\mathrm{L} x \mathrm{xv}}$, tinct. aurantii co. $3 \mathrm{iij}$. In doses of Зss- Zjss, bis ter die.

Mistura tonicA. Infusi cascarillæ lb. $\mathrm{ij}$, tinct. aurant. comp. ऊij, acidi sulphurici aromat. $3 \mathrm{ij}$. Misce. Dosis, à cochlear. $\mathrm{j}$ ad cochl. iij, magna ter die.

Mixture of hydrocyanate of fotash. Hydroc. of potash $3 \mathrm{j}$, distilled water 1 pint, sugar jjss ; coch. med. $\mathrm{j}$, nocte maneque, or in divided doses.

2. Hydrocyan. potassæ gtt. $x v$, aq. distill. $\check{3} \mathrm{ij}$, syr. simp. $\jmath_{j}$; coch. min. j. omnibus tribus horis.

Mixture of Cyanuret of POTASh. Cyanur. potassæ gr. ss, aq. dist. $3 \mathrm{ij}$, syr. simp. $\bar{\jmath}_{\mathrm{j}}$; coch. med. j. omnib. duobus horis.

Mixt. OF BRUCiNE. Brucine gr. v, sach. alb. 亏̌ij, aq. dist. 3ij; coch. maj. j, nocte maneque.

ANodyne DRops. Acetate of morphia, gr. xvj, acid. acet. gtt. iij, S. V. R. 3 j, water $3 \mathrm{j}$; anodyne, gtt. 6 to 24 : the sulphate may be used for a change.

Mixture of coloured emetine. Emetine gr. iij ss, simple syrup 3 ss, water $3 \mathrm{ij}$; coch. med. j, every half hour; emetic.

Mixt. of pure emetine. Pure emetine gr. j, dissolve in a drop or two of nitric acid, simple syrup $\overline{3} j$, water $3 \mathrm{iij}$; mix ; coch. med. $\mathrm{j}$, every fifteen minutes till vomiting is produced.

Mixt. of strychnine. Strychnine gr. j, sacch. alb. 3ij, acet. gtt. $\mathrm{ij}$, aq. dist. $3 \mathrm{ij}$; in palsy, coch. min. $\mathrm{j}$, nocte maneque.

Mixt. of Prússic ACıD. Magendie's medicinal Prussic acid $3 \mathrm{j}$, water $\mathrm{lb}$. j, sugar 3 jss ; coch. med. j, morning and evening, up to coch. vj or viij in a day and night.

2. Magendie's medicinal Prussic acid gtt. xv, simple syrup $\overline{5}$, water $3 \mathrm{ij}$; cochl. med. $\mathrm{j}$, every eight hours.

ACIDUM HYDRocyanicum Vegetabile. Ol. amygda. amar. æther. fresh made $3 \mathbf{j}$, alcoholis, aq. distil. ana $3 \mathrm{iv} ; \mathrm{m}$.; dose gtt. ij, gradually increased. 
AQUA HYDROC. vEGET. Ol. amygd, amar. fresh made 3 j, alcoholis $\bar{\jmath}$ jss, aq. distil $\overline{3} \mathrm{xvjss.}$

Mistura arsexicalis. Liquor. arsenicalis $3 i i j$, tinct. car-

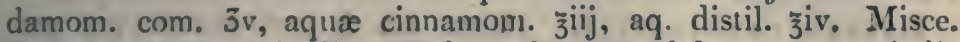
Dosis $3 . \mathrm{j}$, bis terve in die. Taken after a meal for agues, periodic cephalalgia, lepra, chronic rheumatism, \&c.

Mist. conir composita. Extracti conii 3 ss, sodx sub-carbon. gr. xlv. Decocti glycyrrh. 3 vss, spiritus pimentæ 3iij. Misce. Dosis, $\check{\jmath}^{\mathrm{ss}} \mathrm{j} \mathrm{j} \mathrm{ij}$, in pertussis, and pulmonary irritation.

Mist. cinchone aperiens. Confectionis rosæ gallicæ $3 j$; contere cum decoct. cinchonæ ferventis, 亏̌iij, stent simul per horam et cola.,-liquori colat. adde acidi sulphur. dil. 3j, magnesiæ

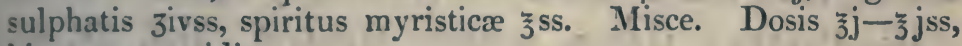
bis terve quotidie.

Mistura cathartica ammoniata. Olei menth. virid, mxij, sacchari purif. 3iij, tere simul, tum adjice infus. sennæ co. $3 v i j$, sodæe sulphatis $\xi_{3}$, tinct. sennæ $3 \mathrm{v}$, spirit. ammon. aromat. $3 \mathrm{iij}$. Dosis $\bar{\jmath} \mathrm{j}$ - $\mathrm{j} \mathrm{j}$.

Mist. olibani compos. (Sprague). Gum res. olibani 3ij, bals. copaibæ 3 jss, mucilag. acaciæ $\tilde{3}$ jss, mellis despumati $\bar{\jmath} j$, aquæe cinnamom. $\bar{\jmath} \mathrm{v}$, tinct. cantharidis $3 \mathrm{ij}$. Misce. $\tilde{z}_{\mathrm{ss}}-\bar{\jmath} \mathrm{jss}$, bis ter in die. In gleets, leucorrhœa, \&c.

Mist. myrrhe. (Spraque). Myrrhæ 3jss, decoct. glycyrrh. ferventis $\overline{3}$ vss; tere simul, et cola. Dosis $3 \mathrm{j}$ bis terve quotidie; with either sub-carbonate of soda, or a little mineral acid, or camphorated tincturc of opium.

Mist. Ruei compos. (Sprague). Thei radicis pulveris 3ss,

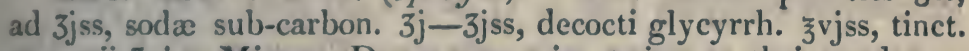
aurantii $3 v j$. Misce. Doses $\_s s-\xi j s s, t w i c e$ or thrice a day as a stomachic, or aperient.

Mist. infus. uve ursi cum pigitale. Infus. uvæ ursi zvijss, acidi sulph. dil. $3 \mathrm{ij}$, tinct. digitalis $3 \mathrm{j}$, syrup. papaveris, $3 \mathrm{iij}$. Misce. In chronic inflammation of the larynx, trachea, and mucous membrane of the urinary organs.

Mrxtere with INFusion of UVA URsi. Mist. infus. uva ursi comp. Infus. uvæ ursi $\frac{3}{\text { vijss, }}$ potassa carbon. 3 ij, extracti conii gr. xx, extract papaveris gr. xxv, syrup. zingiberis 3iij. Misce. $3 j-3$ jss. In chronic diseases of the urinary organs.

HADEx's liquor opit sedativur. Extract a tincture from the bottoms of tinctura opii, by means of tartaric acid dissolved in water.

Oxyrnodixus. Ol. rosati $\overline{3} \mathrm{j}$, aceti rosati $\overline{3} \mathrm{j}$ : used as a liniment in herpes and erysipelas. 
Soot nRops, Fit drops, 'Tinctura fuliginis. Wood soot zij, kali ppm. Ib. ss, sal. ammon. 亏j, aq. fluvial. lb. iiij; digest for threc days, and strain : antispasmodic.

Datroy's carminative. Magn. alb. Đ ij, ol. menth. pip. gtt. j, ol. nuc. mosch. gtt. iij, ol. anisi gtt. iij, tinct. cast. gtt. xxx, tinct. assaf. gtt. xv, tinct. opii gtt. $v$, spir. pulegii gtt. xv, tinct. cardam. c. gtt. $x x x$, aq. menth. pip. $3 i j$.

Mistura guataci alkalina. Guaiaci, calcis vivæ, ana $\overline{3} \mathrm{j}$; grind together, and add water $\mathrm{lb}$.

Tuncture of balk with lime water. Cort. Per. 3 ij, calcis vivæ $\overline{3} \mathrm{j}$; grind together, and add aq. calcis $\mathrm{lb}$. ij ; filter: dose 3̈iij thrice a day. Mixes well with watery liquids.

Dr. Porter's liquor molihil citratis. Opii Jiv, ac. citrici cryst. $\overline{3} \mathrm{ij}$; grind together; add aq. bull. $1 \mathrm{~b}$. j, digest for a day, and filter: milder than the usual opiates.

Fly water. White arsenic $3 j$, water a pint: dissolve by boiling and sweeten with treacle: used to destroy flies.

\section{VETFRIXARY MEDICINES.}

Tincture of euphonbium made with oll of tartar. Tinctura euphorbia alkalina. Gum euphorbium 8 oz., aq. kali ppi. 3lb. ; caustic, much used by the farricrs.

IVIITE's solution of potash. Subc. of potash $2 \mathrm{oz}$, lime water $8 \mathrm{oz}$. ; dissolve; used to correct the acidity of the stomach in calves.

Anodye clyster for horses. Opium 1 to 2 drachms, (or tincture of opium $1 \mathrm{oz}$. to $1 \frac{1}{2} \mathrm{oz}$.), water gruel 2 to 3 pints.

Strmulate clyster fok horses. Common salt 8 oz., linseed oil 4 oz., water 8 or 10 pints ; mix ; useful in stomach staggers.

Camphine clyster for horses. Camphire 3 to $1 \mathrm{dr}$, olive oil $1 \mathrm{oz}$., kali ppm. $1 \mathrm{dr}$., rub together and add tinct. of opium $1 \mathrm{oz}$., warm water 2 pints; as a diuretic, in stoppage of water.

Optate clyster fol horses. Opium $1 \mathrm{dr}$. to $1 \frac{1}{2} \mathrm{dr}$, warm water $8 \mathrm{oz}$, dissolve, and add it to about 2 pints of boiled starch.

Purgatuve ciryster lol horses: Common salt 4 to $8 \mathrm{oz}$, warm water $\delta$ or 12 pints; dissolve.

Chrster for cows. Common salt 1lb., water 10 or 12 pints; to be given after the laxative drenches, to assist their opcration.

Cordial for calves. Caraway seeds powdered $\frac{x}{2}$ oz., ginger powder $\frac{x}{2} \mathrm{dr}$., subcarb. of soda 1 dr., brandy or gin $1 \mathrm{oz}$, water $80 z$. 2. Brandy $\frac{x}{2} \mathrm{oz}$., cows' urine 4 oz. 
ANODYNE DRENCH FOR Horses. Tinct. of opium $2 \mathrm{dr}$. to $1 \mathrm{oz}$., sweet spir. of nitre 1 to $2 \mathrm{oz}$., essence of peppermint 1 to 2 dr., water a pint ; mix.-2. Anodyne ball dissolved in warm alc. -3. Gum Arabic $\mathcal{O}$ oz., dissolve in a pint of warm water, and add oil of peppermint 20 drops, tinc. of opium $\frac{1}{2}$ oz.; useful when horses have been purged too inuch.

Astringent drench for honses. Ppd. chalk and gum Arab. of each $1 \mathrm{oz}$, mint water $12 \mathrm{oz}$., tinct. of opium $\frac{\mathrm{r}}{2} \mathrm{oz}$; ; mix for a dose. - 2. Powdered opium $\frac{1}{2} \mathrm{dr}$., natrum ppm. $1 \mathrm{dr}$. powdered ginger $1 \frac{\mathrm{t}}{2} \mathrm{dr}$, water gruel 1 pint ; mix.-3. Opium $\frac{1}{2} \mathrm{dr}$., ginger powd. 2 dr., oak bark powd. 1 oz., decoction of oak bark or strong camomile tea, a pint ; for diabetes.

Drencil For botTS in IIORSEs. Common salt 4 to $6 \mathrm{oz}$, water 2 pints; dissolve: the horse to be kept fasting for 10 or 12 hours, then have 2 pints of milk sweetened with honey given, and about five minutes afterwards the drench.

Carminative drink for horses. Rum, brandy, or gin 4 to $6 \mathrm{oz}$., water $12 \mathrm{oz}$; mix fully equal to Daffy's elixir in effect.

Colic drinch ror horses. Ven. turp. 1 to $3 \mathrm{oz}$, oil of juniper 2 or $3 \mathrm{dr}$., sweet spir. of nitre $1 \mathrm{oz}$., water 1 pint ; mix for a close.-2. Tinct. of opium $6 \mathrm{dr}$. to $1 \mathrm{oz}$., sweet spir. of nitre $1 \mathrm{oz}$. to $12 \mathrm{dr}$., water or peppermint water 1 pint ; mix for a dose. -3 . Sal Epsom $\overline{\bar{j}} \mathrm{v}$, sap. Castil. ऊ̈jjss, tinct. opii $3 \mathrm{ij}$, dissolve in aq. cinnam.

COEGH DRENCH FOn HORses. Fresh squills 3 oz., (or garlick 4 or 5 oz.,) vinegar 1 pint; soak for a few hours, squeeze out the liquor, and add treacle $11 \mathrm{~b}$. : for 4 doses.

Drexcy fol Dropsy of the Belty in horses. Strong ale 10 pints, wormwood one handful, boil gently to two pints; add long pepper and grains of Paradise of each $1 \frac{1}{2} \mathrm{o} \%$, treacle $3 \mathrm{oz}$., Castile soay, 2 to $4 \mathrm{oz}$; for a dose, and the horse exercised immediately till he sweats.

Garlick drexch for horses. Garlick 1 to 2 oz, boil in milk 2 pints; used in chronic coughs.

I.AXATIVE, DREXch for honses. Barb. aloes $3 \mathrm{dr}$., canella alba $1 \frac{\mathrm{x}}{2} \mathrm{dr}$, salt of tartar $1 \mathrm{dr}$, mint water $8 \mathrm{oz}$.; mix for a draught. - 2. Barbad. aloes 3 dr., kali ppm. $1 \frac{1}{2}$ dr., castor oil 4 to $6 \mathrm{oz}$., mint water and plain water of each $4 \mathrm{oz}$ : : in fevers if contive. -3. Epsom salt 6 to $12 \mathrm{oz}$, whey or gruel 2 pints, castor oil 6 to $120 \%$; mix. -4. Castor, olive, linsed, or rape vil, or hog's lard, of either $8 \mathrm{oz}$. , warm water $\frac{8}{2}$ pint; mix. -5. Barbad. alnes 2 to $3 \mathrm{dr}$., kali ppm. $2 \mathrm{dr}$, castor oil and warm water of each $\frac{1}{2}$ pint; $\operatorname{mix}$ for a dose. -6 . Barbad. aloes to $3 \mathrm{dr}$., salt of tartar 1 dr., mint water and castor oil of each $\frac{1}{2}$ pint ; mix.- 7 . 
Common salt 4 oz., cream $\frac{x}{2}$ pint, water 2 pints; mix : used by farmers. - 8. Barbad. aloes $6 \mathrm{dr}$, common salt $6 \mathrm{oz}$., flour of mustard $1 \mathrm{oz}$., water 2 pints; mix: used in the staggers. -9 . Epsom or Glauber's salt 6 to $8 \mathrm{oz}$, whey 2 pints ; mix: useful when the animal is feverish, as a cooling purge after bleeding, in influenza or chills.-10. Barbad. aloes $\frac{\pi}{2}$ oz., salt of tartar $2 \mathrm{dr}$., Glauber's salt 6 oz., water 2 pints ; mix : used in the mad staggers, after very plentiful bleeding.

Purging drench for horses. Barbad. aloes 1 oz., Castile soap 2 dr., kali ppm. 1 dr., water 1 pint; dissolve for one dose.

Stimulant Drench, for stomach staggers. Common salt 1 oz., water $\frac{\mathrm{r}}{2}$ pint; dissolve, and add spirit of sal volatile 1 to $2 \mathrm{dr}$.2. Tinct. of cardamoms $2 \mathrm{oz}$., mint water $12 \mathrm{oz}$. ; mix. -3 . Barb. aloes $6 \mathrm{dr}$. to $1 \mathrm{oz}$, calomel 1 to $2 \mathrm{dr}$., cascarilla $2 \mathrm{dr}$., oil of

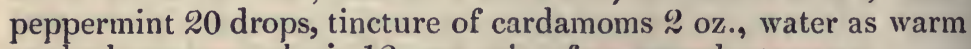
as the horse can take it $12 \mathrm{oz}$; ; mix : for stomach staggers.

Turpentine drencil For horses. Ven. turp. 1 oz., yelk of eggs No. 2; rub together, and add mint water 1 pint; used in stoppage of water.

Worm Drenches. Common salt 4 oz., aloes 2 dr., water 2 pints ; mix.-2. Oil of turp. 4 oz., oatmeal gruel 1 pint; mix.3. Oil of turp. $4 \mathrm{oz}$, castor or linseed oil $8 \mathrm{oz}$, gruel $8 \mathrm{oz}$; mix.

Cordial astieingent drench for cows. Powdered catechu and allspice of each ' 2 drachms, caraway seeds powd. $\frac{x}{2}$ oz., table beer or water $\frac{1}{2}$ pint, simmer a few minutes over the fire, and then add strong beer or ale $\frac{x}{2}$ pint; used in all loosenesses and scouring of cattle: for sheep this will make four doses.

LAXative DRENCH For cows. Common salt 4 to 6 oz., flour of mustard a table spoonful, grated ginger or ground pepper of eitluer a tea spoonful, gin or other spirit a quarter of a pint, water 2 pints.-.?. Barbadoes aloes 4 drachms, common salt 4 oz., ginger $1 \mathrm{dr}$, , anodyne carminative tincture 2 oz., water 2 pints; useful in red water, gorged choking, loss of cud, or whenever purging is useful.-3. Epsom salt 6 to 8 oz., castor or olive oil 6 or 8 oz., water a pint, mix : this is more proper when fever is present, and the animal feels hot, and the pulse is quick.

Drexch for the Chill in cows. Flour of mustard, a little salt, and a quart of water. The chill is the dyspepsia of medical writers ; the milk becomes Haky and of a yellowish colour, hence it is also called the yellows; the appetite goes off sometimes entirely, and the animal is dull and heavy.

Carminative drench for cows. Common salt 4 oz., Barb. aloes 4 drachms, ginger powd. $1 \mathrm{dr}$., water 2 pints, anodyne carminative tincture $2 \mathrm{oz}$; $\mathrm{mix}$ : used in blasting, hoving, or 
blowing of cattle, that is, in over feeding; also in the yellows. If the wind threaten to burst the animal, it must have a passage made for it by a probang. This purgative drench is usually succeeded by a clyster immediately afterwards.

Drench For hoven cattle. Natron ppd. 4 oz., castor oil $\frac{x}{2}$ pint, water a pint ; for a dose.

Drench for scouring rot in horsed cattle. Mutton suet boiled in milk.

Purging drFacil for calves. Epsom salt 6 to 8 oz, water 4 pints; if they appear griped, add castor oil $2 \mathrm{oz}$., anodyne carminative tincture 2 drachms.

LAXATIVE DRENCh For CaIses. Epsom salt 2 oz., ginger powder and natrum ppd. of each $\frac{x}{2}$ drachm, water 4 oz.-2. Cows' urine $\frac{1}{2}$ pint.

Alkaline drench for calves. Thin gruel 4 oz., Epsom salt $\frac{1}{2}$ oz., White's solution of potash one or two tea spoonsful ; mix ; used to prevent diseases in calves. If the calf seems griped, add tincture of opium a tea spoonful, or anodyne carminative tincture a table spoonful.

PURGiNg dReNCh Fol sheEP. Épsom or common salt 1 or $2 \mathrm{oz}$., water a pint, a drachm of aloes, a little ginger powder, and if the sheep appears in pain, tinct. of opium $3 j$ may be added.

Clater's drexch for sheep. Nitre 6 oz., ginger powder 4 oz., colcothar $2 \mathrm{oz}$, common salt $3 \frac{1}{2} \mathrm{lb}$, boiling water 3 gall., when cold add oil of turp. $36 \mathrm{oz}$; ; dose $2 \mathrm{oz}$., if weakly only half, to be given once in four days for a fortuight.

PuRgin drench ror nogs. Gruel 4 oz., Epsom salt $\frac{1}{2}$ oz. ; if the dog appears griped, add tinct. of opium 20 drops. -2 . Castor oil 1 oz., to which tinct. of opium 20 drops may be added if necessary.

Embrocatjons for buUises. Soap liniment 5 o\%, aqua ammonia $1 \mathrm{oz}$. ; mix.-2. Soap liniment $3 \mathrm{oz}$. , oil of turpentine 2 o7., camphire 1 o\%. ; mix.-3. 'Tinct. of cantharides $1 \mathrm{oz}$, camphorated spirit of wine 6 drachms, oil of origanum $\mathcal{Q}$ drachms ; mix.-4. Distilled vinegar $80 \%$, spirit of wine $6 \%$ o., sal ammoniac 1 oz. ; dissolve. -5 . Sugar of lead $\frac{t}{2}$ an oz., vinegar and water of each 8 oz. ; dissolve.

Simple emizion of Farmins. Salad oil $20 \%$, honey 3 oz., s)ft water 1 pint, salt of wormwood 2 drachms ; mix.

Pectorai, facusiox of palumirs. Camphire one to two drachms, rubbed to a powder by adding a few drops of spirit of wine, oil of anisesed lo to 1.5 drops; simpre emulsion $1: 0 \%$ to a pint ; mix. 
Eye-Water for horses. Sugar of lead 2 drachms, vinegar 2 to 4 oz., soft water to fill up a pint bottle; dissolve.-2. White vitriol $1 \frac{1}{2}$ dr., oil of vitriol $\frac{1}{2}$ a dr., water a pint ; mix.-3. Sugar of lead $3 \mathrm{dr}$., white vitriol 4 scrup., water a pint; mix and strain.

Liquid caustic for canker in Horses. Corros. sublim. powd. $1 \mathrm{dr}$., spirit of salt $\frac{x}{2}$ an oz., spirit of wine and water of each 2 oz. ; mix.

Liquor For FLY IN sHEEP. Bacc. lauri 1 oz., arsen. alb. $\frac{x}{2}$ an oz., water 2 gall.; boil and strain.

Astringent lotions. Muriate of iron 1 oz., water $8 \mathrm{oz}$; mix.-2. Blue vitriol $q$. p. water just sufficient to dissolve.

Lotion For TENDER MOUTHED Honses. Alum powdered $1 \mathrm{oz}$, honey $4 \mathrm{oz}$. , infus. of roses a pint; to be used with a syringe.

Astringent lotion for grease. Alum 1 oz., oil of vitriol $1 \mathrm{dr}$, water 1 pint; mix.-2. Alum 4 oz., blue vitriol $\frac{x}{2}$ an oz., water 1 pint and $a \frac{x}{2}$; mix.-3. Sugar of lead $4 \mathrm{oz}$., vinegar $6 \mathrm{oz}$., water 1 pint and $\mathrm{a} \frac{\mathrm{x}}{2} ; \mathrm{mix}$. When the heels are very inflamed and irritable these lotions must be weakened by more water.-4. Corrosive sublimate $2 \mathrm{dr}$., spirit of salt $6 \mathrm{dr}$., water 1 pint; to be used when the discharge is very fetid.

LOTION FOR SADDLE GALLS oR WARBLES. Distilled vinegar $3 \mathrm{oz}$, sugar of lead $3 \mathrm{dr}$., spirit of wine $4 \mathrm{oz}$. , water $8 \mathrm{oz}$. ; dissolve.-2. Sal ammoniac $\frac{x}{2}$ an oz., spirit of salt $2 \mathrm{dr}$., water 8 to $12 \mathrm{oz}$., dissolve.-3. Soap liniment and liquor of acetated ammonia of each $2 \mathrm{oz}$; mix.

Saturnine lotion for strains. Ext. of lead 2 oz., vinegar and water of each 1 pint; mix.

Lotion for THE MANGE IN HoRses. Corrosive sublimate $1 \mathrm{dr}$., spirit of salt $3 \mathrm{dr}$., water 1 pint; mix.-2. Corrosive sublimate $1 \mathrm{dr}$., sal ammoniac $\frac{x}{2}$ an oz., water 1 pint; mix. - 3 . White hellebore root $4 \mathrm{oz}$., boil in 3 pints of water to 2 , strain, and add corrosive sublimate $2 \mathrm{dr}$., previously dissolved in spirit of salt $3 \mathrm{dr}$.

Lotion For MANGe IN cows. Corrosive sublimate $2 \mathrm{dr}$., spirit of salt $\frac{1}{2}$ an oz., water 1 pint ; mix: useful in case the sulphur ointment will not do.

\section{IERFUMES AND COSMETICS.}

MruK of Roses. Kali ppi. gr. vj, ol. amygd. 1 oz., ess. Bergam. 3ij, aquæ rosæ 3 oz., aq. flor. aurant. 3ij. M.

2. Jordan almonds $8 \mathrm{oz}$, oil of almonds, Castile soap, white wax, ana $\frac{x}{2}$ an oz., spermaceti $3 i j$, ol. lavand. Angl. 3 ss, rose water 3lb., S. V. R. 1lb., M. 
3. Bitter almonds 8 oz., distilled water $6 \mathrm{oz}$, elder-flower water 4 oz., make an emulsion, and add ol. tart. p. deliq. 3iij, tinct. benz. $3^{i j}$. M. : used as a cosmetic wash.

French milk of roses. Rose water lb. jss, tinct. of benz., tinct. of storax, of each $1 \mathrm{oz}$., spirit of roses $3 \mathrm{ij}$.

German milk of roses. Extr. Saturni 3vj, spir. lavand. 3̄j, aq.

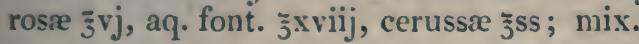

Liquid soap, Lotio saponacea. Ol. olivæ §iv, ol. tartari p. del. ¿ss, rub together, then add aq. rosar. $\mathrm{x}_{\mathrm{xij}}$ : cosmetic.

Eau dunge bouillée. Rose water and orange flower water of each 3 pints, benzoin $11 \mathrm{~b}$., storax 8 oz., cinnam. 1 oz., cloves $\frac{1}{2}$ an oz., a musk bag, calamus two or three sticks, boil away a pint and a half: boil a fresh parcel of water on the residuum, and add to the former. mine.

Liquid rouge. The red liquid left in the preparation of car-

2. Dissolve carmine in subcarbonate of potash water, and dilute with more water.

3. Dissolve pure rouge in a mixture of alcohol and weak acetic acid.

Almond bloom. Brazil dust $1 \mathrm{oz}$, water 3 pints; boil, strain, add isinglass $3 \mathrm{vj}$, grana sylvestria $2 \mathrm{oz}$ (or cochineal $3 \mathrm{ij}$ ), alum 1 oz., borax ziij; boil again and strain through a fine cloth.

Pink dye. Washed safflower $3 \mathrm{ij}$, subc. of potash gr. xviij, spirit of wine 3 vij, digest for two hours, add distilled water $3 \mathrm{ij}$, digest for two hours more, add distilled vinegar or lemon juice q. s. to reduce it to a fine rose colour : used as a cosmetic, and to dye silk stockings.

\section{FOR KITCIEN AND TABLE USE.}

Pickle for meats. Brown sugar, bay salt, common salt, ana 2lb., saltpetre 8 oz., water 2 gall. Used to pickle meats, to which it gives a fine red colour, while the sugar renders them mild and of an excellent flavour.

Essence of anchovies. Anchovies 2lb. to 4lb. and a half, pulp through a fine hair sieve, boil the bones with common salt $7 \mathrm{oz}$. in water (jlb.: strain, add flour 7 o\%, and the pulp of the fish; boil, pass the whole through the sieve, colour with bole to your fancy; it should produce 1 gallon.

2. Anchovies 5 double barrels, bay salt 211 b., brown salt 7lb., starch powder 3lb., powd. bole 1lb., Cayenne pepper $8 \mathrm{oz}$, water 20 gall.; produces 42 doz. and 6 pots. 
3. Use young pilchards, which are richer than young herrings ; and herring liquor, from the white or pickled herrings.

Quintessence of anchovy. Anchovies 1lb., pulp them through a sieve, add vinegar $1 \frac{x}{2}$ oz., Cayenne pepper $\frac{3}{4}$ av. dram., and a roll of lemon peel.-2. Sherry, Madeira, or mushroom catsup may be used instead of vinegar.

Quin's sauce. Walnut pickle, Port wine, of each 1 pint, mushroom catsup 2 pints, anchovies, eschalots, of each 2 doz., soy $\frac{1}{2}$ pint, Cayenne pepper 2 av. drachms ; boil gently for ten minutes ; strain and bottle.

2. Soy 8lb., walnut catsup, mushroom catsup, of each 2 gall., sprats $8 \mathrm{lb}$., Cayenne pepper $8 \mathrm{oz}$., garlic $11 \mathrm{~b}$.

3. Distilled vinegar 1 gall., soy $1 \mathrm{lb}$, allspice $8 \mathrm{oz}$.

4. Walnut pickle $\frac{x}{2}$ a pint, catsup $\frac{x}{2}$ a pint, anchovies No. 6 , garlick 6 cloves, Cayenne pepper 3 j.

Soy. Seeds of dolichos soja (peas or kidney beans may be used for them) 1 gall., boil till soft, add bruised wheat 1 gall., keep in a warm place for 24 hours, then add common salt 1 gall., water 2 gall., put the whole in a stone jar, bung it up for two or three months, shaking it very frequently, press out the liquor: the residuum may be treated afresh with water and salt, for soy of an inferior quality.

2. Strong purl boiled to a half, add red herrings, anchovies, Spanish liquorice, and garlick: when shaken it should leave a yellow brown colour on the sides of the ressel.

Lemon pickle. Lemon juice, vinegar of each $\mathbf{3}$ gall., ginger 1lb., allspice, pepper, grated lemon peel of each $8 \mathrm{oz}$., common salt glb. and a half, cloves, bird pepper of each $2 \mathrm{oz}$, mace, nutmegs of each 1 oz.-2. Lemons cut, No. 6 , salt 1lb., garlick 6 cloves, horse radish scraped, mustard flour of each 2 oz., cloves, mace, nutmegs, Cayenne pepper, ana $5^{\mathrm{ij}}$, vinegar $4 \mathrm{lb}$.

Coratch. Mushroom catsup $6 \mathrm{lb}$., walnut catsup 1lb., Ind. soy, tchillie vinegar, of each $4 \mathrm{oz}$., ess. anch. $1 \mathrm{oz}$.

Tomato sauce. Bruised tomatoes 1 gall., salt $8 \mathrm{oz}$., in three days squeeze out the juice, to each half gall. of juice add shallots 4 oz., black pepper $\frac{x}{4}$ oz., boil for half an hour, strain, add mace, allspice, ginger, nutmegs, of each $\frac{1}{2}$ an oz., coriander seed and cochineal, of each $\frac{1}{4}$ of an oz., simmer gently for half an hour, strain, and when cold bottle.

Mushroom culsup. Sprinkle full-grown flaps gathered in September with salt, stir them often for two days, squeeze with a spoon only, to each pint of juice put whole black pepper $\frac{x}{2}$ an oz., heat in a close stopped stone jar set in a stewpan of boiling water 
for two hours, strain, and to each pint add brandy $\frac{x}{2}$ an oz., let it stand till next day, again strain, and bottle; if any mouldiness appears boil up with half the quantity of whole black pepper; the grounds freed from the pepper serve to make mushroom powder. -2. Mushroom juice 8 gall., pimento $8 \mathrm{oz}$., pepper $4 \mathrm{oz}$., cloves $4 \mathrm{oz}$, ginger $4 \mathrm{oz}$, shallots $12 \mathrm{oz}$, long pepper $2 \mathrm{oz}$., salt $4.1 \mathrm{~b}$.; boil for an hour: strain and bottle.

Oyster catsup;-Cockle catsup;-Muscle catsup. Pound the fish, adding to each pint, Sherry wine a pint, salt $1 \mathrm{oz}$, powdered mace 2 av.drams., pepper 1 drachm ; boil up, skim, strain, add to each pint brandy 2 ten spoonsful, then bottle : to flavour sauces when the fish are out of season.

Walnut catsup. Green walnut shells 6 half sieves or 16 gall., salt $3 \mathrm{lb}$, beat together for a week, drain off the liquor: to 6 quarts, the general produce, add ginger, allspice, of each $4 \mathrm{oz}$., long pepper, cloves, of each $2 \mathrm{oz}$., boil for half an hour, cool and bottle, dividing the spices equally.

2. Juice of walnut shells 15 gall., salt half a bush., ginger, shallots, garlick, horse-radish, ana 3lb., ess. anch. 6 quarts.

3. Juice of young walnuts 1 gall., add anchovies $21 \mathrm{lb}$., shallots llb., clove, mace, black pepper, ana $1 \mathrm{oz}$., and a clove of garlick, boil a little, and bottle.

4. Walnut juice 6 gall., vinegar 12 pints, sprats $24 \mathrm{lb}$, pimento 1lb., ginger 2 oz., long pepper 3 oz., cloves 6 oz., shallots 12 oz. ; boil, and bottle.

Kitchiner's relish. Ground black pepper, salt, of each $1 \mathrm{oz}$, ground allspice, scraped horse-radish, minced shallots, of each $\frac{1}{2}$ an oz., walnut pickle 1 pint; steep fourteen days and strain.2. Use mushroom catsup instead of walnut pickle.

Sance superlative. Port wine, mushroom catsup, of each 2 pints, walnut pickle 1 pint, anchovies pounded $\frac{1}{2} \mathrm{lb}$., lemon peel, minced shallots, scraped horse-radish, of each $2 \mathrm{oz}$, allspice, black pepper powdered, of each $1 \mathrm{oz}$. Cayenne pepper 2 av. drachms, or curry powder 6 av. drachms, bruised celery seed 2 av. drachms; steep fourteen days, and strain.

Kitchiner's double relish. Sauce superlative 4 pints, add $\frac{s}{2}$ a pint of soy or thick browning.

Essence of turtle. Essence of anchovy $2 \mathrm{oz}$., meas. shallot wine $8 \mathrm{nz}$., basil wine $8 \mathrm{oz}$., mushroom catsup $4 \mathrm{oz}$, citric acid $1 \mathrm{av}$. drachm, thin paired lemon peel $\frac{3}{4}$ oz., curry powder ${ }_{4}^{3}$ oz., steep for a week: used to give the flavour of turtle to soups and the like.

Fish suuce. Port wiue 1 gall., mountain 2 pints, walnut 
catsup 4 pints, anchovies and liquor 2 lb., lemons No. 8, shallots 3 doz., Cayenne pepper q. p. scraped horse-radish root $2 \mathrm{lb}$., mace $1 \mathrm{oz}$. , flour of mustard $8 \mathrm{oz}$.; boil up gently, strain and bottle.

2. Anchovies No. 24, shallots No. 10, horse-radish root scraped 3 spoonsful, mace, cloves, of each $3 \ddot{i j}$, lemons sliced No. 2, anchovy liquor $8 \mathrm{oz}$., Hock or Rhenish wine $2 \mathrm{lb}$., water 1lb., boil to $2 \mathrm{lb}$., strain, add walnut catsup $6 \mathrm{oz}$, and bottle.

Browning. White sugar in powder $2 \mathrm{lb}$., fresh butter $8 \mathrm{oz}$. , fry gently until of a fine dark brown, add by degrees strong purl 1 gall., then put Jamaica and black pepper, of each 4 oz., shallots 6 oz., mace 1 oz., catsup $8 \mathrm{lb}$., salt at pleasure, peel of 8 lemons, boil gently, when cold skim and bottle the clear: used to colour and flavour animal food.

Whey, Serum lactis. Cows' milk lb. jss, crem. tart. $\frac{3}{2}$ an oz., boil the milk, add the salt, and strain.

Wine whey, Ser. lactis vinosum. Cows' milk lb. ij, spring water lb. j; boil, and add white wine half a pint.

Clarified whey, Ser. lactis clarificatum. Cows' milk 6 pints, rennet q. s.; let it stand in a warm place for some hours, strain, add the whites of $3 \mathrm{eggs}$, and cream of tartar half a drachm; boil and filter through paper.

Lemonade for icing;-Orangeade for icing. Rub off the yellow peel of 3 or 4 fruits with hard loaf sugar 1 oz., add sugar 4 oz., water 2 pints; cut the fruits in half, and squeeze the juice into the syrup : ice as wanted.

Strawberry water for icing;-Raspberry water for icing ; -Berberry water for icing. To every $5 \mathrm{oz}$. of the fruit rubbed gently in a mortar to avoid breaking the kernels add water 2 pints, and after some time sugar 5 oz., strain, squeezing the grounds, and keep cool in ice till used: ice as wanted.

Gooseberry water for icing. To each lb. and a half of fruit add sugar 6 oz., and water 2 pints, sometimes 4 oz. of the gooseberries are taken out and replaced by as much strawberries: ice as wanted.

Cherry water for icing. Stone the fruit, crack the stones, rub the kernels in a cloth to get off the rough-flavoured skin; to each lb. and a half of juice, flesh, and kernels, add sugar 6 oz., water ? pints, and strain : ice as wanted.

Verjuice water for icing. Choose the largest, juciest, and best flavoured unripe grapes, stone them, to each $20 \mathrm{oz}$. of fruit rubbed down add sugar 6 oz., water 2 pints, milk 1 table spoonful, strain ; spices may be added at pleasure : ice as wanted.

Lemonade, Lemon sherbet. White sugar 5 oz., flavoured by rubbing off the yellow peel of a lemon, dissolve in 2 pints of 
spring water, add juice of three lemons: apt in hot countries to produce cholera.-Orange sherbet. Use oranges for lemons; more wholesome than lemonade.

Tea punch. Hot tea 2 pints, arrack $\frac{1}{2}$ a bottle, about $13 \frac{\pi}{2} \mathrm{oz}$., white sugar 4 oz., flavoured by rubbing off the yellow peel of 4 lemons, add juice of $\mathrm{S}$ lemons.

Wine punch. Arrack 2 pints, juice of 12 lemons, white sugar 1lb., hot tea 6 pints, Port wine 2 pints.

2. White sugar $\frac{3}{4} \mathrm{lb}$., flavoured by rubbing off the yellow peel of 3 lemons, Port wine 1 gall., boil, adding at the end cinnamon $\frac{1}{3}$ an oz., strain, add arrack 1 pint, and juice of 9 lemons.

Cold punch. Arrack, Port wine, and water, of each 2 pints, juice of 8 lemons, white sugar $1 \mathrm{lb}$.

Iced punch. Champagne wine, or Rhenish wine, 2 pints, arrack 1 pint, juice of 6 lemons, white sugar $1 \mathrm{lb}$., flavoured by rubbing off the yellow peel of 6 lemons; ice as cream.

\section{USFD IN THE ARTS.}

Refined ox gall, Fel bovis purificatum. Fresh ox gall. 1 lb.; boil, skim, add alum $1 \mathrm{oz}$, and keep it on the fire for some time; to another pint add common salt $1 \mathrm{oz}$., in the same manner; keep them bottled up for three months, then decant off the clear: mix them in an equal proportion; a thick yellow coagulum is immediately formed, leaving the refined gall clear and colourless : used by limners, enabling them to lay several successive coats of colours upon drawings, to fix chalk and pencil drawings so that they may be tinted, to remove the greasiness of ivory, and even allowing them to paint with water colours upon oiled paper or satin.

Liquirl pounce. Subscarb. of soda $1 \mathrm{oz}$, water a pint ; colour with syr. rhamni $3 \mathrm{jj}$, or a little sap green. If potash is used instead of soda the ink will spread.

Marking ink. Lunar caustic $3 \mathrm{ij}$, distilled water $3 \mathrm{vj}$; dissolve and add gum water $3 i j$ : wet the linen where you intend to write with liquid pounce, dry it, and then write upon it with a clean pen.

Suxnn blue, Iiquid blue. Indigo 1lb., oil of vitriol 4. 1b. ; dissolve, by keeping the bottle in boiling water, then add water 12 Il)., or q. p.

Chemic, Sulpliate of indigo. Indigo 1lb., oil of vitriol perfectly free from nitrous gas $9 \mathrm{lb}$.: used in dycing greens.

Solution of indign. Rub Guatimala flora indigo $5 \mathrm{j}$ with rectified vil of vitriol 3 iv, dilute with water 3 iij; add whiting to neutralize the acid, and filter the liquid: used to measure the discolouring power of chlorine and chloride of lime. 


\section{LIQUID COLOURS.}

Lacca fluida. Gamboge, dissolve in water with gum Arabic and alum; yellow; used for colouring maps, writing, and staining paper.-2. Steep French berries in water, strain, add gum Arabic and alum; yellow.-3. Steep round zedoary in spirit of wine; clear yellow.-4. Steep turmeric in spirit of wine; deep yellow : both are used for artificial flowers.-5. Steep Brazil chips in vinegar, add alum ; red.-6. Dissolve litmus in water, to $5 \mathrm{oz}$., meas. add 2 of spirit of wine; red.- $\%$. Steep cochineal in water, strain, add alum and gum Arabic; red.-8. Dissolve carmine in subcarbonate of potash water; red.-9. Dilute Saxon blue with water; blue.-10. Add distilled vinegar to the solution of litmus till the proper blue colour is obtained.-11. Steep litmus in water, strain ; purple.-12. Dissolve crystallized verdigris in water, and add gum; green.-13. Dissolve sap green in water, and add alum; green.-14. Render the solution of litmus green by adding subcarbonate of potash to its solution.-15. Crystallized verdigris, cream of tartar, of each $4 \mathrm{oz}$., dissolve in water, add gum Arabic; green.

Colours for show bottles. - Yellow. Dissolve iron in spirit of salt and dilute.-Red. Spirit of hartshorn q. p. dilute with water and tinge with cochineal.--2. Dissolve sal ammoniac in water and tinge with cochineal.-Blue. Blue vitriol, alum, ana $2 \mathrm{oz}$, water $2 \mathrm{lb}$., spirit of vitriol q. s. - 2. Blue vitriol $4 \mathrm{oz}$., water $3 \mathrm{lb}$. Green. Rough verdigris $3 \mathrm{oz}$, dissolve in spirit of vitriol, and add water $4 \mathrm{lb} .-2$. Add distilled verdigris and blue vitriol to a strong decoction of turmeric.-Purple. Verdigris $3 \mathrm{ij}$, spirit of hartshorn $4 \mathrm{oz}$., water $1 \frac{x}{2} \mathrm{lb} .-1$. Sugar of lead $1 \mathrm{oz}$, cochineal $\ni$ $\mathrm{j}$, water q. p.-3. Add a little spirit of hartshorn to an infusion of logwood.

Boot-top liquid. Sour milk $3 \mathrm{lb}$, oil of vitriol $2 \mathrm{oz}$, compound tincture of lavender $3 \mathrm{oz}$. g gum Arab. 1 oz., lemon juice 2 oz., white of 2 eggs. M.-2. Sour milk 3 lb., spirit of salt, spirit of vitriol, ana $\%$ oz., compound tincture of lavender $1 \mathrm{oz}$. M. M. Sour milk 3 pints, butter of antimony, cream of tartar, ana $2 \mathrm{oz}$., citric acid, burnt alum, common alum, ana $1 \mathrm{oz}$.

Blacking. Lamp black 6 lb., sugar 6 llb. dissolved in water 2 lb., sperm oil 1lb., gum Arabic 3 oz. dissolved in vinegar $2 \mathrm{lb}$, vinegar 3 gall., oil of vitriol $1 \mathrm{lb}$. and a half: mix.-2. Bone black, common treacle, ana 1\% oz., sperm oil, oil of vitriol, ana 3 oz., vinegar No. 18, 4 pints: mix.-3. Bone black, treacle, ana $2 \mathrm{lb}$, neat's foot oil $8 \mathrm{oz}$., oil of vitriol $1 \mathrm{oz}$, gum tragacanth 2 oz., vinegar 6 pints : mix. -4 . Bone black $6 \mathrm{lb}$., vinegar, water, ana 2 gall., treacle $8 \mathrm{lb}$., oil of vitriol $1 \mathrm{lb} .-5$. Bone black $1 \mathrm{oz}$., 
small beer or water $1 \mathrm{lb}$, brown sugar, gum Arabic, ana half an oz., or, if required to be very shining, the white of an egg.-6. Bone black $4 \mathrm{oz}$., treacle $8 \mathrm{oz}$, vinegar $1 \mathrm{lb}$.: used to black leather.

Water-proof liquor. Roche alum $4 \mathrm{oz}$., sugar of lead $3 \mathrm{ij}$, powd. gum Arab. $3 \mathrm{j}$, water $8 \mathrm{oz}$ : : used for soles of shoes.

Nankeen dye. Arnotto, subc. of potash, ana p. æeq. boiled in water: the proportion of subcarb. is altered as the colour is required to be deeper or lighter: used to restore the colour of faded nankeen clothing.

Black ink, Atramentum. Galls in sorts $2 \mathrm{lb}$., logwood, green vitriol, ana $1 \mathrm{lb}$, water $8 \mathrm{lb}$., gum Arabic q. p.: very good.-2. Bruised galls $1 \mathrm{lb}$, green vitriol 8 oz., gum Arabic 4 oz., water 2 gall., for common sale.

Patent ink. Logwood shavings, powdered galls, ana $2 \mathrm{lb}$., pomegranate bark 4 oz., green vitriol 1 lb., gum Arabic common 8 oz., water 1 gall.

Ink used in the Prerogative office. Galls 1 lb., gum Arab. 6 oz., alum 2 oz., green vitriol 7 oz., kino 3 oz., logwood in powder $40 z$., water 1 gall. Used for writing, but is destroyed by acids and even by age; its restoration may be attempted by wetting the place with an infusion of galls, or with the solution of alkali calcined with blood, as in making Prussian blue, alternately with diluted muriatic acid.

Japan ink. Dry the green vitriol by heating it until yellow, or sprinkle it with a little nitric acid; this renders the ink of a full blackness immediately on being mixed.

Marking ink, Boues d'encre The sediment left on making ink : used by the packers for marking.

Solution of picromel. To bullock's gall add a solution of sugar of lead, as long as any sediment falls; filter, add subacetate of lead; wash the sediment, dissolve in weak acetic acid, and pass through the solution hydro-sulphuric acid gas; filter, and evaporate the liquor nearly to dryness, redissolve in water, and add a small quantity of strong alcohol to make it keep: used to distinguish the acetate of lead from the subacetate of lead.

Solution of alcoholic extruct of malva sylvestris. Dry the petals of the wild mallow, steep them in alcohol at $40 \mathrm{deg}$. Baume : distil off the alcohol, and dissolve the extract left in water: the deep purplish violet solution is used as a test for acids and alkalies, and to stain test papers for the same purpose: it is discoloured by the sulphites and sulphurets of the alkalies, which renders it very useful in assaying kelp and barilla ashes.

Brine of red cablage. - Brine of .violets. Steep red cabbage, or 
the petals of blue violets, in a strong solution of salt: used as a test for acids and alkalies.

Sol. of hematine. Steep powdered logwood in water, temp. 120 to 130 deg. Fahr. for about 6 hours, filter, evaporate to dry. ness, steep the extract in alcohol for 24 hours, filter, evaporate till thick, add water, leave it to dry of itself, the hematine will crystallize: wash the crystals with spirit of wine, and dissolve them in water: used to distinguish the various acids and alkalies by the different shades.

\section{IMPREGNATED WINES.}

Although some of the wines are obscurely ordered by their mere colour and country, of which, however, many sorts are sold ; yet this is of less consequence, as the retailers usually employ raisin or currant wine instead of more expensive foreign ones. The P. L. 1745 was the only one that determined the exact sorts the college wished to have employed, until 1809, when the college rejected all wine but Sherry, to which alone they restricted the generic term of vinum, as the Pharmacopœia of the United States has restricted the term vinum to Teneriffe. In the present Pharmacopœia they have changed all the wines into weak tinctures, but left their names unaltered.

FOR MEDICINE.

wine of Alovs, Tinctura hierce. Spec. hieræ picræ §j, white wine $\mathrm{lb} . \mathrm{j}$ : digest.

Tinctura sacra. Aloes そ̌viij, canell. alb. そ̌jj, white wine lb.x; digest: use white sand to divide the aloes, and prevent its clogging.

Vinum aloes. P. L. before 1824. Aloes žviij, white sand q. s., canell. alb. zij, Sherry lb. vj, proof spirits lb. ij : dig. 14 days.

Vinum aloes Socotrine. Soc. aloes $3 j$, cardam. min., ging. ana $\mathrm{jj}$, white wine $\mathrm{lb}$. $\mathrm{ij}$ : digest 7 days.

Elixir proprietatis Helmonti, Vinum aloeticum alkalinum. Aloes Socotr., croci, myrrh. ana zj, sal ammon. 3 vj, kali pp. 3 viij, white lb. ij: digest 7 days. - Helmont's original process was more complicated; some put in only croc. $3 \mathrm{ij}$ : stomachic $3 \mathrm{j}$ to $3 \mathrm{iij}$, bis terve die; in larger doses to 3 jss, purgative.

Antrmonial wine, $V$. benedictum, $V$. antimoniale. Croc. metallor $3 \mathrm{j}$, mountain $\mathrm{lb}$. jss : digest, strain.

Vinum antimonir. Vitr. antim. $3 \mathrm{j}$, Sherry lb. jss.

Vinum antimonil tartarisati, P. L. 1788. Tart. emetic.

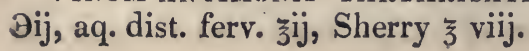


Liquor antimonit tartarizati. Tart. emetic Эj, aq. dist. ferv. 亏iv; dissolve and add Sherry 3 vj.

Vinum tartritis antimonir. Tart. emetic gr. xxiv, Sherry lb. $\mathrm{j}$; dissolve: emetic, but uncertain $\tilde{\jmath}^{s s}$ to $\bar{\jmath} \mathrm{j}$; alterative $\jmath^{\text {ss }}$ to jjss.

Tinctura croci vixosa, $V$. croceum. Croci jaj, Canary wine $\mathrm{lb} . \mathrm{j}$; digest without heat 6 days and strain; cordial $3 \mathrm{j}$ to $3 \mathrm{ij}$.

Vinum martiaxum. (Ph. Pruss.) Iron filings 2 parts, cinnam. 1, Rhenish wine 24; doses $3^{\mathrm{ij}}$ to $\check{s}$ ss.

Steel wine, Vinum Chalybeatum, P. L. 1720. Limat. ferri $\tilde{j} \mathrm{j}$, croci ${ }_{j} \mathrm{ij}$, white wine $\mathrm{lb} . \mathrm{j}$; digest 3 days and strain.

Vinem chalybeatua, P. L. 1745. Limat. ferri ziiij, cinnam., macis, ana ǰss, ${ }^{\circledR}$ Rhenish wine $\mathrm{lb}$. iiij : digest one month.

VINUM FEIRI, P. L. 1788. Limat. ferri zij, Sherry lb. ij: digest one month.

Vixem Ferm, P.D. Fer. fil. „̧iv, Rhenish lb. iiij; digest 7 days: tonic, astringent, 3 ij to $3 \mathrm{vj}$, bis terve die.

WiNe BITTERS, $V$. amarum. Rad. gentian. flav., cort. limon, recent. ana $3 \mathrm{j}$, piper. long. $3_{\mathrm{ij}}$, mountain $\mathrm{lb}$. $\mathrm{ij}$; digest.

Vinum gramtiane compositum. Rad. gen. 3 ss, cort. Peruv. $\bar{j}$ j, cort. aurant. sicc. $3 i j$, canell. alb. $3 \mathrm{j}$, proof spir. $\tilde{5}^{i i i j}$, Malaga lb. ijss; digest 7 days.

2. Gentian llb. orange peel 10 oz., cardam. 4 oz. cimnam. 4 oz., currant wine 3 gall. and a half; tonic, stomachic, zij to $3 v j$ or more.

Vinum cinchone. (Ph. Par.) Peruvian bark 1 part, alcohol 2, claret 12; dose 3 ij to ziv.

Vinuas cinchonse comp. (P/. Par.) Peruvian bark 123, quassi, Winter's bark, and rind of bitter oranges, ana 8 ; alcohol 250, wine 1500 .

Vinus amarum. (Pll. Batav.) Peruvian Bark 8, Gentian 4, orange peel 2, canella alba 1, alcohol 32, Spanish wine 384.

Vixum antiscor ветісим. (Ph. Par.) Horse radish 4 parts, scurvy-grass, water-cress, mustard, buck-bean, ana 2 , muriate of ammonia 1, white wine 1.25, spirit of scurvy-grass 12; dose 3 j to 3 ss.

Vinum extel: campaxi. (Ph. Pruss.) Elecampane wine. Elecampane $3 \mathrm{j}$, red wine $\mathrm{ll}$. ij ; doses $3 \mathrm{ij}$ to $\mathrm{j}^{\mathrm{i}} \mathrm{v}$.

Vines nellebolatum, P. L. 1680. Rad. helleb. albi jiv., Sherry lb. ij; anti-arthritic, $3 j$ to 3 iij. 
IPECACUANHA wINe, Vinum ipecacuanhe, P. L. 1745. Rad. ipecac. $₹$ ij, flav. aurant. Hispal. sicc. $̌ s s$, Canary lb. ij.

Vinum ipecacuanhe, P. L. 1788. Rad. ipecac. 腼, Sherry lb. $\ddot{j j}$; emetic 3 j.

Laudanum, L. liquidum Sydenhami. Opii §̌ij, croci そj, cinnam., caryophyll. ana $3 \mathrm{j}$, white wine lb. $\mathrm{j}$; digest 3 days : contains 1.8 th of opium.

Tinctura Thebaica, P. L. Opii colati 3 ij, cinnam., caryoph. ana 3 ij, white wine $\mathrm{lb} . \mathrm{j}$; digest a week; the same strength.

Vinum opII, P. L. 1809. Extract opii 3 j, cinnam. caryoph. ana $3 \mathrm{j}$, Sherry lb. $\mathrm{j}$; digest 8 days: only half the strength of the former ; anodyne, narcotic, gtt. v. to lxviij or more.

Rhubarb wine, Tinctura rhabarbari vinosa. Rhabarb. そij, cardam. minor. $z_{3} s s$, croci $3 \mathrm{ij}$, Mountain $\mathrm{lb}$. $\mathrm{ij}$ : digest.

Vinum rhabarbari. Rhabarb. žjjss, cardam. min. ̌̌ss, croci zij, Spanish white wine lb. ij, proof spir. 3 viiij.

Vinum rhei palmati. Rhabarb. 3 ij, canell. alb. $3 j$, proof spir. $\zeta_{\mathrm{ij}}$, white wine $\xi \mathrm{xv}$; digest 7 days: laxative, tonic, $\xi^{\mathrm{ss}}$ to zjss. The saffron is frequently omitted.

Vinum amarum. (M. Dubois.) Vini alb. Madeirensis lb. xviij, cinchonæ ₹viij, canellæa albæ $\jmath_{j}$ ss ; baccæ juniperi, cort. citri medicæ, cort. Winterani, āä zix, carbon sodæ zivss.

WINE of squILLs, Vinum scilliticum. Rad. scill. alb. lb. j, old French white wine 1 gall.: digest 14 days: emetic in a large dose, expectorant in small doses.

Vinum scilliticum comp. White wine lb. jss, oxymel of squills $3 \mathrm{ij}$, squill roots $3 \mathrm{j}$, rind of oranges and calamus aromaticus, $\bar{a} \bar{a} z \mathrm{ij}$; digest for 3 days, then add of oxymel of squills $z_{3} \mathrm{ij}$ : doses 3 ij to 3 ss.

Vinum nicotian.e tabacr. Fol. tabaci sicc. $\breve{j}$, white wine ¿xij; digest 7 days : antispasmodic, diuretic, gtt. $\mathrm{x}$ to $\mathrm{xxx}$.

Viper wine, Vinum viperinum, P.L. before 174.5. Viperæ sicc. No. 6, Spanish wine $\mathrm{Ib}$. ij : digest 3 days.

Vinum viperinum, P.L. since 1745 . Vip. sicc. zij, Mountain lb. iij; digest for a week : restorative, stimulant.

Vinum radicum colchici. Rad. colch. sicc. zij, zin. alb. Hisp. lb. ij; infuse, filter, and add S. V. R. $3 \mathrm{ij}$; used in gout, gtt. $\mathrm{xx}$. at night.

Vinum florum colchici. Flor. colch. žjij, vini albi Hisp. lb. j.

Vinum seminum colchici. Sem. colch. sicc. zij, vin. albi. Hisp. lb. j; infuse for 10 days, and filter: $3^{\text {ss }}$ to $3 \mathrm{jij}$, bis in die, in rheumatism. 
WINE of CINCHONINE. Sulphate of cinchonine gr. xviij, Madeira (or other) wine lb. ij.

2 Wine lb. ij, tincture of cinchonine $\bar{z}^{\mathrm{j} j}$; febrifuge.

WINE oF QUININE. Sulphate of quinine gr. vj, Madeira wine lb. $\mathrm{j}$; Malaga or any other wine may be used.

2. Wine lb. $\mathrm{j}$, tincture of quinine $\tilde{3}_{\mathrm{j}} \mathrm{j}$.

FOR THE TABLE AND KITCHEN.

Yellore essence of orange. Orange peel, S. V. R., and water, ana $6 \mathrm{oz}$; ; digest, strain, and add Sherry wine 2 pints.

Basil wine. Float the green leaves (which are in perfection the middle of August) with Sherry wine, steep for 10 days, then strain : gives the turtle flavour to soup, and even to turtle itself. Celery leaves, and the dried leaves of other sweet herbs, may also be used to flavour wine, for those with whom acids do not agree.

Cayenne wine. Cayenne pepper 1 oz., Sherry 1 pint ; steep 11 days, and strain.

Currie wine. Currie powder 6 oz., Sherry wine 1 gall. ; infuse 10 days, strain.

Shallot wine. Shallots 3 oz., peel and pound to a pulp, Sherry wine 1 pint; steep for 10 ten days, strain, add 3 oz. more shallot pulp, steep again, and strain for use. 'The best preparation for giving the shallot flavour, as it is not apt to rise.

Ragout wine. Ragout spice 6 oz., Sherry wine 1 gall.; steep 10 days.

\section{IMPREGNATED VINEGARS.}

\section{FOR MEDICINE.}

Acetum opii selativum, introduced by Mr. Horne as a succedaneum for the liquor opii sedativus of Mr. Battley. The following is Mr. Horne's formula for his sedative - "Take three times the quantity of the best opium, reduced to fine powder, that is ordered by the London pharmacopocia for two pints of tincture: add to the opium two pints of dilute acetic acid. After they have digested a few hours, add six or eight pints of rectified spirits of wine. Macerate about seven days, and then carefully filter, in order to separate the insoluble parts of the opium; then introduce the liquor into a retort, accurately closerl, and distil off the spirit. The product in the retort, after the spirit has all passed over, is the required acetum opii sedativum. If the distillation be carefully conducted, the result will always prove of uniform strength. One minim will be equivalent to three of the tincture 
of opium, free from spirit, and it will keep without changing for an indefinite time."

Seuill vinegar, Acetum scilliticum, P. L. before 1745. Rad. scill. sicc. $1 \mathrm{~b} . \mathrm{j}$, aceti $\mathrm{lb}$. vj; bottle up and expose to the sun for a month.

A. scilliticum, P. L. 1788. A. scilla. Scill. sicc. lb. j, aceti lb. vj, proof spirit lb. ss.

A. scilla maritima. Rad. scillæ sicc. $3 i \mathrm{ij}$, acet. dist. lb. ijss, S. V. R. 3iij; expectorant, diuretic, 3ss to 3j.-2. Use common vinegar.

Acetum colchicr. Rad. colchici 3 j, acet. distil. $1 b$. j; digest for three days, and express, add proof spirit $3 \mathrm{j}$; diuretic, $3 \mathrm{ss}$ to $3 j$, bis die.

Common bLACK jnop, Guttce nigrce. Opium 8 oz., distilled vinegar $2 \mathrm{lb}$.; infuse; milder than tincture of opium.

BATtLEy's LiquOR oriI sedativus. 'This is supposed to be a solution of opium in vinegar; it will not keep without an addition of spirit of wine, but this takes away the mildness of its action.

Acetate or solanine. Dissolve solanine in acetic acid; emetic, in quarter grain doses.

Vinegar of the four thieves, Acetum theriacale, A. proplyylacticum. Summit. rorismar. sicc., fol. salviæ sicc. ana ziiij, flor. lavand. sicc. $3 \mathrm{ij}$, caryophyll. $3 \mathrm{j}$, acet. dist. 1 gall. : digest for seven days, press, and filter : used as a corrector of bad smells: sometimes garlick is added.

Aromatic spirit of vinegar, Acetum aromaticum, Acidum aceticum camphoratum, $A$. acetosum camphoratum. Acid. acetos. fort. $\jmath^{\mathrm{vj}}$, camph. ¿ss, reduced to powder by S. V. R. q. s.

ACET. ARom. Forte. Strong acetous acid (No. 4) 2lb. and a half, camphire 2 oz., ol. carph. ver. 3 ji, S. V. R. 8 oz. M.

Extemporaneous aromatic vinegar. Acet. potassie 3j, ess. lim. gtt. iij, ol. vitrioli gtt. $x x$.

Acetum opir. (Ph. U. S.et Dr. Paris). Black drop. Opium lb. ss, vinegar, or verjuice, $\mathrm{O}$ iij, nutmeg $\bar{j}$ jss, saffron $\xi_{3}$ ss: boil down to a proper consistence, and add sugar $\bar{j}$ iv, yeast $\xi \mathrm{j}$.

Acetum Rure, Rue vinegar. (Ph. Pruss. et Aust.) Rue 1, vinegar 8 ; dose $\xi$ ss to $亏 j$ in an enema.

Acetum Berlinense. White wine vinegar $\mathrm{lb}$. vj, roots of angelica, valerian, and mint, of each $\xi$ ss, camomile flowers, juniper berries, and laurel berries, of each $z \mathrm{ss}$, safforn and camphor, of each $3 \mathrm{j}$ : digest and filter. In diseases of debility, in doses of 1 or 2 drachms. 
Spielmay's camphorated vinegar. Camphor $3 \mathrm{j}$, powder with $\mathrm{xx}$ gtt. of alcohol, and then triturate, with $3 \mathrm{ij}$ of sugar, and add $\overline{3} \mathrm{x}$ of white wine vinegar; shake until all is dissolved: dose jij to $\tilde{j} s s$.

\section{FOR, PERFUMERY AND COSMETICS.}

Vinaigre rosat, Acetum rosatum. Petal. ros. rubr. sicc. lb. j, acet. apot. lb. xij; infuse eight days, strain, and repeat the infusion with fresh roses.

Vinaigre de rosmarin, Acetum anthosatum. From rosemary flowers, as the vinaigre rosat.

Vinaigre distille de lavande. From the flowering tops by infusing them in vinegar, and then distilling 3-4ths.

2. Vinegar, distilled in glass lb. j, oil of lavander q. p. M. Many other vinegars of this kind may be made from odoriferous plants or their oils; they are used as cooling odoriferous cosmetics.

Vinaigre dentifrique. Rad. pyrethri $\overline{3} \mathrm{ij}$, cinnam., caryoph., guaiac. ana $3 \mathrm{ij}$, spirit. cochlear. $3_{\mathrm{ij}}$, aq. vulner. rubr. ziv, acet. opt. alb. lb. iiij; used to wash the mouth in tooth-ache, or carious teeth, either by itself or diluted.

\section{FOR KITCHEN AND TABLE USE.}

Cucumber vinegar. - Capsicum vinegar.-Garlick vinegar.Shallot vinegar. - Onion vinegar. - Caper vineyar. - Cress seed vinergar.-Celery seed vinegar. - Truffle vinergar.-Seville orangepecl vinegar.-Ginger vinegar.-Black pepper vinegar.-White pepper vinegar.-Chillie vinegar.-Horse-radish vineyar. Are all made by steeping about an oz. of the articles in each pint of vinegar for fourteen days, and straining.

Tarragon vinegar. - Basil vinegar. - Green mint vinegar.Eller flower vinegar.-Celery vinegar.-Cherville vinegar.-Burnet vinergar. Float the leaves with vinegar, steep for fourtecn days, then strain, and keep in half-pint bottles.

Currie vinegar. Curric powder $6 \mathrm{oz}$, vinegar 1 gall.; infuse ten days, strain. The French vinaigriers make no less than sixtyfive sorts of different flavoured vinegars.

Compound horse-raslish vinegur. Scraped horse-radish gathered in November 3 oz., minced shallots 1 o\%, Cayenne pepper 1 av. drachm, vinegar 2 pints, steep for a week, and strain: black pepper, mustard sced bruised, celery seed, and cress sced may be added.

Camp yinger. Garlick sliced 8 o\%., Cayenne pepper, soy, walnut catsup, of each $40 \%$, anchovies chopped No. 36, vinegar 1 
gall., cochineal suff. to colour it a deep red; infuse six weeks, then strain.

2. Cayenne pepper 1 av. drachm, soy 4 oz., measures, walnut catsup 8 oz., 6 chopped anchovies, garlick minced fine 1 clove, vinegar 1 pint, steep for a month, strain for use.

Parmentier's salad vinegar. Dried tarragon, savory, chives, shallots, 3 oz. of each, tops of dried mint and of balm a handful each, vinegar 1 gall., steep for a fortnight in a warm place, strain and squeeze. days.

Ragout vinegar. Ragout spice 3 oz., vinegar 1 gall., steep ten

Raspberry vinegar. Red raspberries $1 \frac{1}{2}$ pint, white wine vinegar 3 pints, steep for a day and night, strain, add fresh raspberries, and do so a third time : to each pint add white sugar 1lb.; boil, skim, when cold add to each pint brandy $2 \mathrm{oz}$.

Raspberry sherbet. Raspberry vinegar 1 oz., water 8 oz. ; mix ; an agreeable summer drink.

Artificial lemon juice. Pyrolignous acid 1 pint, white sugar $\frac{3}{4} \mathrm{oz} . ;$ dissolve, and add quintessence of lemon peel 30 drops.

USED IN THE ARTS.

Black reviver. Galls 3 oz., logwood, green vitriol, iron filings, sumach, ana $1 \mathrm{oz}$., vinegar 2 pints.

Red ink. Lign. Brazil $8 \mathrm{oz}$, vinegar 10 pints, boil to a half, and add roche alum $8 \mathrm{oz}$.

2. Stale beer 1 pint, coccin. 3 j, gum Arab. 1 oz., Brazil wood, roche alum, of each $2 \mathrm{oz}$.

\section{A M M ONIA TA.}

\section{FOR MEDICINES.}

Spiritus salis ammoniaci dulcis, Sp. ammonice, P. L. 1788 and 1815. Sal ammoniac $\bar{\jmath}$ iv, pearlash $\overline{3} \mathrm{vj}$, proof spr. lb. iij; mix and distil lb. jss. P. D. draws off lb. ij. Stimulant, antispasmodic, in fainting and nervous debility. Dose 3 ss to $z i$ in water. -Officinal preparation. Spir. ammon. aromat. and spir. ammon. fœtid. L. E. D.

Sp. Aммоnie, P. L. 1809. Liquor ammoniæ lb.j, S.V.R. lb. ij; $M$.

Axcohol ammoniatum. Lime $\check{x} \mathrm{ij}$, water $\xi v j$, slake, when cold add sal ammon. $̌$ viij; distil into S. V. R. ऊxxxij.

Sal volatile drops, Sp. salis volatilis oleosus. Cinnam. 3̈j, 


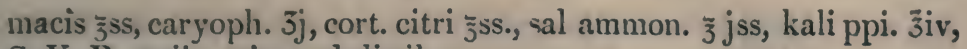
S. V. R. 3 xij; mix and distil.

Sp. volatilis aromaticus. Spir. sal. ammon. dulc. lb. ij, essen. limon., ol. dist. nucis mosch. ana $3 \mathrm{ij}$, ol. dist. caryoph. arom. zss; distil.

Sp. ammoni. composites, P. L. 1788. Spir. sal. ammon. dulc. lb. ij, ess. limon., ol. dist. nuc. mosch. ana $3 \mathrm{ij}$; mix.

SP. Amovie compositus, P. L. 1809. Spir. ammon. lb. ij, ess. limon., ol. dist. caryoph. ana $3 \mathrm{ij}$; nix.

SP. Ammoxie aromaticus, P. L. 1815. Cinnam., caryoph. ana $3 \mathrm{ij}$, cort. limon. ǰiv, kali pp. lb. ss, sal. ammon. ${ }_{j}^{z} v$, S. V. R. lb. v. aquæ cong. j; distil. lb. vj. Stimulant, diaphoretic; used in the same cases as spir. ammoniæ. Dose the same.-Officinal preparation. Tinct. guaiaci ammoniat. and tinct. valerian. ammoniat. L. D.

Sp. amoniz aromaticus, P. L. Spir. ammon. lb. ij, ess. amon. $3 \mathrm{ij}$, nuc. mosch. contus. 3 ss; digest for three days and distil lb. jss.

Alconol ammoniatum a romaticum, T. aromatica ammoniata. Alcohol ammon. ₹viij, ol. dist. rorismarini zj jss, ess. limon. $\mathrm{j} j$; dissolve : stimulant, diaphoretic 3 ss to $3 \mathrm{j}$.

Sal volatile drups. Olea mixta 3 jij, sal. vol. ammon. $20 \mathrm{oz}$., S. V.R. 2 gall. ; draw off 18 or 19 pints.

Fit drols, Sp. volatilis foetidus, Sp. ammonia foetidus, P. L. 1788. Sal. ammon. lb. j, kali pp. lb. jss, proof spir. lb. vj, assæfœtidæ Ӟiv ; distil lb. $v$.

2. Spir. ammoniæ lb. j, tinct. assæfort. 亏̄ss ; mix.

3. Sal ammonice 1lb., potash 2lb., gum fœtid. 6 oz., S. V.R. 1 gall., water q. s., distil 10 pints; antispasmodic, in hysteric disorders.

Sp. AmMоnif, Fשтidus, P. L. 1809, P. D. Alcohol ammoniatum foetidum, ' 1 : asscefuetida ammoniata. Spir. ammoniæ lb. ij, assafoct. $3 i j$ (P. D. 3 j $3 i j)$; digest and distil lb. jss (P. E. lib. ij). Stimulant, antispasmodic; useful in hysteria, spasmodic asthma; dose $j^{\text {ss }}$ to $j^{i}$, in water.

'T. conticis Peruviani volatilis. Cort. Peruv. z̈iv, sp. sal. amm. Ib. ij; steep and strain.

T. cinchone ammoniata. Cort. Peruv. $\overline{3}$ iv, spir. ammon. lb. ij ; steep ten days; stimulant, tonic, 3 ss to $3 \mathrm{ij}$.

Sp. солснге Аммолiatus. Colchici sem. cont. $\overline{3} \mathrm{ij}$, spir. anmon. arom. $\mathrm{O} \mathrm{j}$; digest and strain.

Volatile tincture of guaxac, T.guaiacina volatilis. Gum. В в 2 
guaiaci 3 iv, spir. volatilis aromat. lb. jss ; digest fourteen days ; stimulant, diaphoretic, in rheumatism, 3 ss to $3 \mathrm{ij}$, bis die.

T. gUAIACI, P. L. 1788. Gum. guaiaci $\zeta$ iv, sp. ammon. comp. lb. jss.

T. guaraci ammoniata. Tinct. guaiaci $z$ iv, sp. amm. aromaticus lb. jss.

T. valerianæ volatulis. Rad. valer. offic., spir. volatilis arom. lb. ij ; digest; to give a sweet scent to a solvent intended for a fotid plant seems a mistake.

T. valeriane ammoniata, P. L. Rad. valer. $z$ iv, sp. am. arom. lb. ij; stimulant, antispasmodic; useful in nervous and spasmodic affections; dose 3 ss to $3 \mathrm{i}$; in some bland fluid.

2. Rad. valer. 1 lb., spir. corn. cervi 7 lb., S. V. R. 1 lb. ; digest ; antispasmodic, $3 \mathrm{j}$ to $3 \mathrm{ij}$.

T. Fœtida volatrlis. Assæfœtidæ 3 iv, spir. ammon. $1 b . \mathrm{jj}$.

T. valeriane ammoniata, P. D. Rad. valer. 3 iv, spir. ammon. lb. ij ; digest.

Orl and hartshorn, Linimentum volatile. Aq. amm. carb. $3 \mathrm{ij}$, ol. amydg. $\overline{3}$; mix.

Lin. AmMonis, P. L. L. ammonia carbonatis, L. ammonia subcarbonatis. Aq. ammon. carb. $\overline{3}$ ss, ol. olivæ $\overline{3}$ jss, M.

Lin. ammonia fortius. Aq. ammon. puræ $\overline{3}$ j, ol. oliv. 3 ij, M. ; stimulant, rubefacient, in cynanche tonsillaris, spread on a piece of flannel, and applied round the throat; a larger proportion of oil is added where the skin is very irritable.

Lin. ammonia, P. D. Oleum ammoniatum. Aq. ammon. puræ 3 ij, ol. oliv. $\overline{3}$ ij. M.

2. Cleanse greasy phials and bottles with bone spirit, and save the milky liquor, adding oil if necessary ; externally stimulant, rubefacient, in rheumatic pains, tooth-ache.

WARD'S ESSENCE FOR HEAD-ACHE, Lin. camphorce compositum. Aq. ammon. puræ $\overline{3}$ vj, spir. lavand. lb. $\mathrm{j} ;$ mix and distil lb. j, add camph. 3 ij.

2. Spir. ammon. arom. $\overline{3}$ xij, spir. lavand. simp. $\overline{3}$, camph. 亏 $\mathrm{ij}$; dissolve.

3. S. V. R. 4 oz., spir. ammon. 2 oz., campl. 2 oz., M.

4. S. V. R. 2 lb., aq. ammon. pur. 5 oz., camph. 4 oz., ess. limon. 3 ss, roche alum $2 \mathrm{oz}$, mix and decant: stimulant; used externally in local pains, as head-ache or colic.

T. Castorei composita. Castor. Russ. $\bar{j} \mathrm{j}$, assæfotid. $\overline{3} \mathrm{ss}$, spir. ammon. lb. $\mathrm{j}$; digest ; antispasmodic, in hysteria $3 \mathrm{ss}$ to $3 \mathrm{j}$. 
Edinbergit paregoric elixir, $T$. opii ammoniata. Flor. benz., croc. ana 3 iij. opii 3 ij, ol. anisi $3 \mathrm{ss,} \mathrm{alcohol.} \mathrm{ammon.}$ $\tilde{z} \times v j$; digest: anodyne, diaphoretic, $z$ ss to $z j$ : is four times as strong as London paregoric elixir, $3 \mathrm{j}$ containing opii gr. $\mathrm{j}$.

Potestates succini. Oil of amber $\xi j$, subcarb. of ammon. 亏 ss, alcohol P. L. lb. ss ; digest four or five days, and decant, gtt. $\mathrm{x}$ to $\mathrm{xl}$, externally in hooping-cough.

VETERINARY MEDICINE.

Horse cordial. Balsam. traumatici 1 pint, spir. ammon. comp., spir. nitri dulc. ana $8 \mathrm{oz}$.; put up in Bateman's phials, and sealed.

\section{FOI PERFUMERY.}

Common eau de luce, Spiritus ammonice succinatus, P. L. 1788. Sapo Cast. gr. $x$, ol. succ. rect. 9 j, S. V. R. 3 j; dissolve and add aq. ammon. puræ $\xi$ iiij.

2. Scio turp. true 2 oz., S. V. R. 2 lb.; dissolve; add, when wanted, a few drops to aq. ammon. puræ q. p.

3. Mastich 2 oz., S. V. R. 2 lb. ; dissolve, and use as the former.

4. Mastich 3 ij, musk gr. xij, S. V. R. oz. ; dissolve, and add it to aq. ammon. puræ q. p.

5. Aq. ammon. puræ lb. j, ol. succ. rect., ol. lavand., ol. rorismar. ana $3 \mathrm{ij}$; dissolve.

6. S. V. R. lb. ij, ol. succ. 1 oz. ; digest, decant, and add ammon. ppæ. 4 oz., dissolved in water lb. $\mathrm{j}$ : a drachm of oil of lavander or rosemary, or both, may be added to the spirit, if thought proper.

7. Ol. succ. rect. gtt. $x l$, S. V. R. $३$ ij, aq. ammon. puræ $\lesssim$ xij ; distil with a very gentle heat.

Spir. ammon. succ., P. L. 1809. Mastiches 3 iij, S. V. R. 3 ix ; dissolve, decant, and add ol. lavand. min. xiv, ol. succ. rect. min. iv, aq. ammon. purae $\xi \mathrm{x}$. - These either will not retain the milky appearance for any length of time, or the sweet scented oils are contrary to the intention of the medicine.

Eau de luce veritable, Aq. lucice. Kali pp. 3 iij, ol. succ. fœt. 3 jss; rub together, and add by degrees S. V. K. 3 iv, digest 15 minutes, decant; gtt. $x l$ of this liquor, poured into aq. ammon. pura 3 jss, forms eau de luce of the true milky cloudy appearance, and not settling.

2. S. V. R. 3 iv, ol. succ. foet. 3 j; dissolve, decant, and pour into aq. ammon. purse lb. ij, or rather more. 1 . Strec. Antispasmodic: used in hysteric fits, and bites of venomous serpents, $3 \mathbf{j}$ in water or wine. 
Ammoniacal lavender water. Ol. lavand. Angl. $̧$ ij, ess. ambr. gr. $\jmath_{j}$, eau de luce $\mathrm{Oj}, \mathrm{S}$. V. R. Oij; a superior article.

\section{COMPOUND SPIRITS.}

When these liquors are intended for the toilette, or for retail sale, care must be taken to choose a spirit that has no ill scent; the distillation must be made in a balneum, and the distilled spirit kept for some time in a cool cellar. or rather in an ice-house; but as the apothecaries use these spirits for medicines they do not consider this care to be necessary, and their usual method is to mix a small quantity of essential oil with proof spirit, and thus avoid the trouble of distilling. The usual dose is $3 \mathrm{ij} ;$ to $\bar{z}$, and they are universally stimulant.

Sprrit of worm-wood, Aqua absinthii minus composita. Fol. absin. sic. lb. ij, cardam. min., sem. coriand., ana lb. ss, proof spir. 4 gall., distil 4 gall.

2. Absinth. 2 lb., sem. coriand., calam. aromat. ana 1 lb., S.V.R. 2 gall., distil 4 gall. ; stomachic.

Elixir of Garlick. Rad. ali. contus. No. 80, S. V. R. $\mathrm{lb} . \mathrm{j}$; distil to dryness, and repeat the distillation upon fresh cloves of garlick a second and third time, then add camph. $3 \mathrm{ij}$; diaphoretic, 3 ss bis die.

Sp. of ANgelica, Aq. angelica. Leaves $1 b . j$ to the gall. of proof spirit.

Sp. rad. angelica. Dried roots $\mathrm{lb}$. ij to the gall.

AQ. ANISI Fortis. Seeds lb. $\mathrm{j}$ to the gall. proof.

Sp. anisi. The same, lb. ss to the gall. proof.

Aq. Seminum anisi conposita, $S p$. anisi compositus. Sem. anisi, sem. angelicæ, ana lb. ss to the gall. proof.

2. Sem. anisi 4 llb., sem. angel. 1 lb., S. V. R. 4 gall., draw 8 gall.; carminative. Dose 3 ss to 3 iv.

Sp. of star-anise seed. Is more pleasant than the common.

Aq. corticis aurantiorum fortis, Sp. aurant. corticis. From the yellow part of the peel, $\mathrm{lb}$. $\mathrm{j}$ to the gall. proof.

Aq. corticis aurantiorum spirituosa. The same, lb. ss to the gall. proof.

2. Cort. aurant. sicc. 3 lb., S. V. R. 1 gallon and a half; draw 3 gallons: stomachic.

Hysteric water, Aq. bryonice composita. Succ. rad. bryon. lb. iiij, succ. rutæ, succ. artemis. ana lb. ij, fol. sabinæ m. iij, matricariæ, nepetæ, pulegii, ana $\mathrm{m} . \mathrm{ij}$, ocimi, dictam. Cret. ana $\mathrm{m}$. 
j ss, cort. aurant. flav. rec. $\check{3}$ iiij, myrrh. $气$ ij, cast. Russ. $う$ j, proof spirit lb. viij; distil lb. xij.

2. Rad. bryon. rec. $7 \mathrm{lb}$., mugwort $\mathrm{m}$. 6, rue $\mathrm{m}$. 24, savine $\mathrm{m}$. 48 , motherwort m. 6, pennyroyal m. 12 , cat mint, sweet basil, ana m. 6, S. V. R. 5 gallons: draw 10 gallons.

3. Tinct. valerianæ 3 ss, ol. pulegii gtt. xij, ol. rutæ gtt. iij, S. V. R., aquæ, ana lb. j: M. Antispasmodic, emmenagogue, generally sold lowered with aq. pulegii.

Cardamom water, Aq. cardamomi fortis, A. seminum cardamoni. Seeds unhusked $\overline{3}$ iiij to the gallon proof.

SP. of CLoves, Sp. caryophyllorum aromati. lb. ij to the gallon proof.

Caraway cordial, Strong caraway water, Aq. seminum carui fortis, A. sem. carui, Sp. carui, P. L. 1788, P. D. Spir. cari carui. Seeds lb. ss to the gallon proof.

2. Seeds, bruised, 2 lb., S. V. R. 2 gall.; draw 10 gall.

Sp. carui, P. L. 1809. Seeds lb. jss to the gall.

Essence of caraway seeds. Oil of caraway $\precsim$ j, S. V. R. $\lesssim$ iiij; mix.

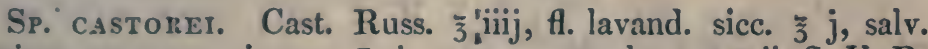
rorism. ana $z$ ss, cinnam. 3 vj, mac., caryoph. ana 3 ij, S. V. R. lb. $v j$, distil to dryness in B. M. ; antispasmodic, in hysteria.

Camojile drops. S. V. R. lb. j, ol. chamæm. 弓j.

Compound camomile water, Aq. florum chamameli composita. Fl. cham. sicc. lb. j, flav. aurant. $3 \mathrm{ij}$, absinth., puleg. ana m. ij, sem. anisi, cymini, foniculi, bacc. lauri, juniperi, ana $\bar{\jmath} j$, proof spirit 1 gallon; draw two gallons; but it is usually made proof.

Strong cinnamon water, Aq. cinnamomi fortis. Cinnam. lb. $\mathrm{j}$, proof spirit 1 gallon; draw $10 \mathrm{lb}$.

Aq. cinnamomi spirituosa, Sp. cinnamomi, P. L. 1788, Sp. lauri cinnamomi. $1 \mathrm{lb}$. to the gallon proof.

Sp. cinnamomi, P. L. 1824. Ol. cinnam. v, S. V. R. Oivss, aqua q. s.; distil a gallon.

Spir. cassie. Cassia buds 1 lb., cass. lign. 2 lb., S. V. R. 10 gallons; draw 20 gallons: sold for strong cinnamon water.

Spirit of lemon peei, Aq. citri corticum fortis. Peel lb. ij to the gallon proof; distil.

SP. OF CORIANDER, Sp. coriandri. Seeds $1 \mathrm{lb}$. to the gallon proof.

Sr. crocr. Croc. $३$ iiij, proof spirit lb. iiij; distil lb. ijss.

Plague water, $A q$. epidemica, Aq. alexiteria spirituosa, $S p$. 
alexiterius. Fol. menth. rec. lb. ss, fol. angel., summ. absinth. mar. ana $\zeta$ iiij, proof spir. lb. viij, distil lb. viij.

Compound gentian water, Aq. gentiance composita. Rad. gent. lb. jss, fol. et flor. centaur. min. ana $亏$ iiij, proof spir. lb. vj; distil 1 gall.

SP. of HYSsop, $S p$. hyssopi. Tops lb. $\mathrm{j}$ to the gallon proof.

Aq. Junlperi composita, Sp.juniperi compositus. Bac. junip. lb. j, sem. carui, sem. fœnic. dulc. ana $\bar{\jmath}$ jss, proof spir. 1 gallon ; distil 1 gallon.

2. Gin, not sweetened, is usually sold for it, as, unless the other is drawn stronger than the colleges order it, the spirit will not be bright enough for retail sale: stimulant, diuretic.

Sp. of peppermint, Aq. menthe piperitidis spirituosa, $S p$. mentha piperitidis, $S p$. menthe piperita, P. L. 1809. Herb in flower lb. jss to the gallon proof.

Sp. menthe piperite, P. L. 1824. Ol. menth. pip. 9 vjss, S. V. R. 4 pints and a half, water q. s.; draw 1 gallon.

Essence of peppermint. S. V. R. 1 pint, put into it kali pp. 1 oz., previously heated, decant, and add ol. menth. pip. half an oz., M.

2. Ol. menth. pip. 1 lb., S. V. R. 2 gall., colour with herb. menth. pip. sicc. 8 oz., M. mix.

3. Ol. men. pip. 3 oz., S. V. R. coloured with spinage 2 pints;

Cordial mint water, Aq. menthe vulgaris spirituosa, Sp. menthe sativa, Sp. menthe viridis, P. L. 1809. Dried herb lb. jss to the gallon proof.

Sp. Menthe viridis, P. L. 1824. Ol. menth. vir. gvjss., S. V. R. Oiiijss, water q. s. ; draw 1 gall.

AQ. mirabilis. Caryoph. arom., galang., cubeb., macis, cardam. min., nuc. mosch., zz, ana $3 \mathrm{j}$, succ. chelidonii maj. lb. ss, proof spirit lb. ijss; distil lb. ijss.

2. Cass. lign., cort. lim. ana 4 oz., sem. angel. 2 oz., fol. menth. pip. 6 oz., rad. galang. 2 oz., sem. cardam. min. 1 oz., pimentæ 4 oz., S. V. R. 2 gallons; draw 4 gallons.

Sp. PImento, P. L. Sp. pimente. Pimento 2 oz. to the gallon proof.

Sp. pimento, P.D. $3 \mathrm{oz}$. to the gallon proof; a cheap stimulant; used in hospitals.

Sp. myrti pimente. $8 \mathrm{oz}$. to the gallon proof.

Nutmeg water, Aq. nephritica. Flor. spinæ albæ rec. lb. iiij, nuc. mosch. 3 iij, white wine 2 gall., distil 12 pints. 
Aq. nucis moschate, Sp. nucis moschate, Sp. myristica, Sp. myristica moschata. Nutmegs $\check{j}$ ij to the gallon proof. The druggists draw it overproof, because they want it bright : stimulant, carminative.

Riga Balsay, Sp.turiomem pini. Shoots of the Scotch fir collected early in the spring, $\mathrm{lb} . \mathrm{j}$ to the gallon proof; stimulant, diuretic; externally vulnerary.

Сompolid piony waten, Aq. epileptica, Aq. peonice composita. Flor. lil. convall. lb. j, proof spirit cong. ij ss, fl. tiliæ lb. ss, fl. proniæ $\bar{j}$ iiij, rad. pron. mar. $\check{z}$ jjss, rad. dictam. alb., rad. aristol. long. ana $j$ ss, fol. visci, fol. rutre, ana m. $i j$, sem. pron. decort. $3 x$, sem. ruta jiiijs, cast. Russ., cubeb., macis, ana $3 i j$, cinnam. $\bar{z}$ jss, fl. rorism. pug. vj, fl. stœech. Arab., fl. lavand. ana pug. iij, ft. beton., H. tunica, fl. paraly seos, ana pug. viij, succ. ceras. nigr. lb. iiij; distil 4 gallons: used as a general vehicle.

Sp. pexwyoral water, Aq. pulegii spirituosa, Sp. pulegii, P. L. 1788. Dry herb lb. jss to the gallon proof; emmenagogue.

Sp. pulegii, P. L. 1824. Ol. pulegii Э vij, S. V. R. Oiiijss, aquæ q. s.; distil a gallon.

Essence of pennyroyal. S. V. R. 2 pints, colour with spinage, strain, and add ol. pulegii $3 \mathrm{oz}$.

Sp. of scurvy grass, Aq. raphani composita, P. L. 1720. Fol. cochlear. hort., fol. coch. mar. ana $\mathrm{lb}$. vj, express the juice and add succ. beccabungx, succ. nasturt. aquat. ana $\mathrm{lb}$. jss, rad. raphari rustic. $1 \mathrm{~b}$. $\mathrm{ij}$, rad. ari. rec. $亏 \mathrm{vj}$, cort. Winteri, nuc. mosch. ana 3 iiij, cort. limon. sicc. $3 \mathrm{ij}$, proof spirit lb. iiij; distil 1 gallon.

Aq. raphani composita, P. L. 1745. Fol. coch. hort. lb. iv, rad. raph. rust., flav. cort. aurant. Hisp. ana $1 \mathrm{~b}$. ij, nuc. mosch. 亏̈ix, proof spirit 2 gall., water q. s.; distil 2 gall.

$S q$. raphani compositus. Same as the last, but using nuc. mosch. З̌j.

Sp. armoracia compositus. Same as the last, but omitting the scurvy grass.

Sp. cochlearia simplex. Fol. cochl. rec. 32lb., rad. raph. 4lb., S. V. R. 5 gall.; draw 3 gall.; antiscorbutic.

Treacle waten, Aq. theriacalis, Aq. alexiteria spirituosa cum aceto. Fol. menth. vulg. rec., fol. angel. rec. ana lb. ss, summ. absinth. mar. rec. zis., proof spirit 1 gall. ; distill 1 gall., and add aceti lb. j. The old process was inore complicated.

2. Aq. bryonix comp. $12 \mathrm{oz}$, acet. dist. $4 \mathrm{o} \%$, M. ; cordial, stimulant.

Hengary water, Eau de la Reine de Hongrie, Aq. Hungarica. Fresh rosemary flowers $1 \mathrm{~b}$. ij, rectified spirit lb. iij; distil. Also imported fiom France. 
Sp. rosmarini, P. L. 1809. lb.ij to the gall. proof.

Sp. rosmarini, P. L. 1815. lb. ij to the gall. rectd.

Sp. rosmarini, P. L. 1824. Ol. rosm. ऊ̌j, S. V. R. 1 gall., water q. s.; distil 1 gall.

2. Ol. rorism. ver. 6 oz., ol. lavand. gall. 1 oz., bacc. cassiæ 6 oz., pimentæ 4 oz., S. V. R. 2 gall.; draw 3 gall.

3. Ol. rorism. ३jjss, ol. lavand. Angl. zij, ol. cinn. gtt. j, proof spirit 10 pints ; mix.

4. Ol. rorism. 3iv, ol. lavand. Gall. 3j, S. V. R. 3 pints, aq. 1 pint; mix : fragrant; used as a cosmetic, and with sugar as a liqueur.

Sp. rosmarini, P. D. Flowering tops lb. jss to the gall. proof.

Sweet spirit of vitriol, $S p$. vitrioli dulcis, $S p$. etheris vitriolici, P. L. 1788. Oil of vitriol, S. V. R. ana pond. æq.; mix and distil till a black scum begins to rise, then suddenly stop the distillation.

Sp. atheris sulphurici, P. L. since 1809. AEther sulphuricus cum alcohole. Ether 8 oz., S. V. R. 1 pint; mix ; antispasmodic, stimulant, $3 \mathrm{j}$ to $3 \mathrm{iij}$ in water.

Swe ET Spirit of nitre, Nitre dulcis, Nitre drops, Sp. nitri dulcis. Spirit of nitre lb. ss, S. V. R. 2 pints: distil as long as what comes over does not effervesce with subcarb. of potash.

Sp. etheris nitrosi, P. L. Acid nitros. lb. ss by wt., S. V. R. lb. ij: distil そxxj.

2. Spir. nitri $11 \mathrm{lb}$., S. V. R. 1 gall., water 4 pints; distil 10 pints : stimulant, diuretic, antispasmodic, gtt. $x x \times$ to $3 \mathrm{j}$, or more.

Sp. etheris Nitrici. Spir. nitri ziij by wt., S. V. R. lb. ij, add gradually and distil zxxvj.

Sp. ethereus nitrosus. Add to the residuum of nitrous ether the spirit of wine that collected the rapour; distil to dryness in B. M.; mix the distilled liquor with the alkaline ley used in preparing the nitrous ether, and also with kali pp. q. s. to neutralize the acid; lastly, distil in B. M. ; the specific gravity should be 850 .

Sp. atheris nitrosi, P. E. Spir. nitri lb. j, S. V. R. lb. iij; distil in B. M. as long as anything comes over.

Sweet spirit of salt, Sp. salis dulcis. Spir. salis 弓jiv, S. V. R. $ろ v j$; distil $气 v$ : diuretic.

Hoffman's aNodyne liquor, Liquor anodynus Hoffmanni, Sp. etheris vitriolici compositus. Oleum vini ziv, spir. æther. vitr. lb. ij; mix. 
Sp. atheris sulphurici compositus. Ol. ætherei zij, 'spir. æth. sulph. lb. $\mathrm{j}$; mix. $\operatorname{mix}$.

2. Ether 12 oz., S. V. R. 1 gall., ol. vini $3 \mathrm{ij}$, water 2 pints;

3. Oil of vitriol 2lb., S. V. R. 1 gall.; distil 7 pints.

4. Spir. æther. vitrioli, spir. vitrioli dulcis, ana p. æq.; mix; stimulant, antispasnodic, $\bar{\jmath}^{s s}$ to $\mathfrak{j}$ j.

Clutton's febrifuge spirit, Sp. febrifugus Cluitoni. Spir. æther. vitriol. 4 pints, spir. salis. dulc. 1 pint ; mix.

2. Spir. vitrioli dulc., spir. salis dulc. ana p. æq. ; mix.

3. Ol. vitrioli $11 \mathrm{~b} .12$ oz., spir. salis $11 \mathrm{~b}$., S. V. R. 1 gallon ; distil.

Double distilled lavander water, Eau de lavande, $A q$. lavandula, Sp. lavand. simplex. Picked flowers lb. vj, S. V. R. lb. xriij; steep, and distil. Also imported from France and Italy.

Sp. lavandula, P. L. 1788. Flor. lavand. lb. jss to the gall. proof.

Sp. lavandula, P. L. 1809. Flor. lb. ij to the gall. proof.

Sp. I.Avandule, P. L. 1824. Flor. lb. ij to the gall. rectified spirit._2. Ol. lavand. Angl. ટllb., ess. ambr. gris. こ̌ss, S. V. R. 12 gall.-3. Ol. lav. Angl. 5 oz., S. V. R. 3 gall., distilled water 2 gall., fine with burnt alum. -4 . Flor. lavand. 14lb., S. V. R. 5 gall., draw 10 gall.; but if the flowers are fresh, the spirit may be drawn a little lower.-5. Ol. lavand. exotic 2 oz., ol. rorism. 1 oz., ol. cinnam. ver. gtt. iv, proof spirit 1 gall.-6. Ol. lavand. Angl. 3 oz., ess. Bergam. 1 oz., ess. amb. gris. 3v, S. V. 1 . 14 pints, aq. rosæ opt. 2 pints.-7. Ol. lavand. 3ij, ess. Berg. $3 \mathrm{j}$, ess. ambr. gr. gtt. xxx, ol. rhodii gtt. vj (mosch gr. j?) S. V. K. lb. j.-8. Ol. lavand. $3 \mathrm{ij}$, ol. rorismar. $3 \mathrm{j}$, ess. ambr. gris. $3 \mathrm{j}$, S. V. R. lb. ij.

Sp. lavandula spica. Flor. lb. ij, S. V. R. lb. viij by wt., distil lb. vij by wt.

FOR PERFUMERY AND COSMETICS.

Sp. of oranges. S. V. R. 8 o\%., ess. of oranges 3ss. -Lemeri's double distilled orange flower water, Ean du naphe, Aq. napha. Orange flowers 6llb., yellow peel of Seville oranges $60 \%$, white wine 1 gall., steep for two days in a warm place, distil._-2. For white wine use spirit of balm 4 pints, melasses spirit 4 pints.

Esprit de Bergamotte. Peel, fresh, ll). ij to the gall. proof.2. S. V. R. 1 gall., ess. Bergam. 亏̌, ess. aubergr. ऊij; M. 
Eau de bouquet. S. V. R. lb. jss, spir. rosemary and ess. violet of each $3 \mathrm{ss}$, spir. lemons $3 \mathrm{j}$, rose water $8 \mathrm{oz}$.

Sp. calami aromatici. $\xi$ viij to the gall. proof.

Eau de Cologne. Essence de Bergam. ziij, ess. of neroli 3 jss, ess. de cedrat zij, ess. limonum ziij, ol. rorismar. $3 \mathrm{j}, \mathrm{S}$. V. R. lb. xij, spir. rorism. lb. iijss, aq. meliss. compos. lb. ij ziv ; mix ; distil in B. M. and keep it in a cold cellar or ice-house for some time; used externally as a cosmetic, and made with sugar into a ratatia.

2. Winé spirit at $32 \mathrm{deg}$. Baume, 4 pints, neroli, ess. of cedrat, orange, citron, Bergamotte, rosemary, of each 24 drops, less cardamom seeds 3 ij, distil in glass 3 pints.

3. Wine spirit at $32 \mathrm{deg}$. Baume 2 pints, ess. of citron and Bergamotte $3 \mathrm{ij}$, ess. cedrat $3 \mathrm{j}$, ess. lavand. $3 \mathrm{ss}$, ess. fl. aurant. tinct.

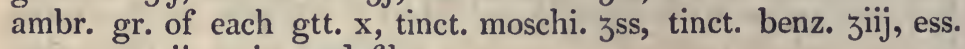
rosar. gtt. ij; mix, and filter.

Eau de framboises. Strawberries bruised lb. xvj, S. V. R. lb. viij; distil to dryness in B. M.

Sp. of jasmin. S. V. R. 8 oz., ess. of jasmine 3ss.

Essence of jasmine. Ess. violet 1 oz., ess. of Bergamotte 1 drachm.

Smith's British lavander. Ol. lavand. Angl. 2 oz., ess. ambr. gr. 1 oz., eau de Cologne 1 pint, S. V. R. 2 pints.

Sweet-scented honey water, Aq. mellis odorifera. Ess. Berg. zss, ess. limon. $3 i j$, ol. caryoph. gtt. xij, mosch. gr. xij, S. V. R. 1 gall., aq. flor. aurant., aq. ros. opt. ana 2 pints, crocus in fœno about gr. xviij to colour it, but very yellow honey is better, and communicates a clamminess that retains the scent longer; it should be very bright ; some add a little brandy colouring: an agreeable perfume, and is also made into ratafia by adding sugar. Usually confounded with honey water for the hair.

Eau de millefleurs. S. V. R. lb. jss, sp. of jasmine zij, ess. of lav. 3 ss, ess. Bergam. $z^{\mathrm{ij}}$, orange $\mathrm{fl}$. water $8 \mathrm{oz}$.

Essence de myrte. Myrtle in flower $1 \mathrm{~b} . \mathrm{j}$ to the gallon.

Sp. of balm, Sp. melissa. Tops $\mathrm{lb}$. $\mathrm{j}$ to the gall. proof: fragrant cosmetics.

Eau de melisse des Carmes, Aq. melissce composita. Fol. meliss. sicc. 4 oz., cort. lim. sicc. 2 oz., nuc. mosch. - sem. coriand. ana 1 oz., caryoph. arom. - cinn. - rad. angel. opt. ana ziv, S. V. R. lb. $\mathrm{ij}$, brandy lb. ij ; steep, distil in B. M., redistil, and keep for some time in a cold cellar. The published receipt. 
2. Spir. melissa 8 pints, spir. cort. citror. 4 pints, spir. nuc. mosch. - sp. coriand. ana 2 pints, sp. rorismar. - sp. thymi, - sp. cinn. - sp. anis. virid. sp. majoran. - sp. hyssopi. - sp. salvia, - sp. rad. angelicie, - sp. caryoph. arom. ana 1 pint; mix, distil, and keep it for a twelvemonth in an icc-house: supposed to be the original receipt of the barefooted Carmelites, now in possession of the Company of Apothecaries of Paris, who sell a great quantity of this celebrated water: cosmetic, stimulant.

Eau sans pareille. Ess. Bergam. zijss, ess. limon. ziv, ess. citri. $3^{i j}$, spir. rorismar. 亏viij, S. V. R. lb. vj: mix and distil in B. M. ; a fragrant cosmetic.-2. S. V. R. 1 gall., mosch. gr. $x x$, ess.

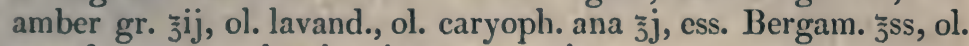
sassafr. gtt. xv, ol. origani gtt. xx : mix.

Esprit de la rose, Sp. rosa. Petal. rosarum lb. viij, S. V. R. 1b. iv; steep and distil to dryness in 13. M.-2. Attar of roses $3 \mathrm{j}$, S. V. R. 1 gall.; distil in B. M. It may be made either more or less scented, at pleasure.

Essence of roses. S. V. R. 2 pints, attar of roses ziij.

Sp. of sage, Sp. of salvia. Tops lb. $\mathrm{j}$ to the gall. proof.

Esprit de tain, $S p$. of lemon thyme, Sp.thymi. Tops lb. $\mathrm{j}$ to the gall. proof.

Eau Carquebusade, Aq. vulnararia, Aq. sclopetaria. Sum. sicc. salviæ, absinth., fœnic., hysop., rutæ, majoran., origan., scrpilli, saturejæ, menth. piper., meliss., thym., rorism., calamenth., scordii, fol. angelicæ recent., fol. basil., flor. lavand. ana $4 \mathrm{oz}$, proof spirit 2 gall.; stcep for a fortnight, distil $1 \frac{x}{2}$ gall.

2. Summ. millefolii lb. jss, fol. rorism., fol. thym. ana lb. ss, proof spirit 2 gall. : distil 1 gall.

3. Fol. rorism. lb. jss, summ. millef., fol. thym. ana lb. ss, proof spirit 2 gall.; distil 1 gail.; stimulant, also cosmetic, vulnerary.

Essence de tuberemes. - Essence de jasmin. The flowers are stratified with wool or cotton, impregnated with oil of ben, or nut oil, in an earthen vessel closely covered, and kept for some time in a warm bath; and this repeated with fresh flowers, until the oil is well scented; the wool, \&c. is then put into spirit of wine, q. s., and distilled in a balneum.

HOL THE KITCHEN.

Spirit of swcet basil.-Sp. of swect marjoram. T'ops 1lb., proof melasses spirit 1 gall., water $\frac{1}{2}$ gall. ; steep and distil off' 1 gall. : used to flavour sauces and stews.

Essence of bitter almonds. Essential oil of bitter almonds $\mathrm{lb} . \mathrm{j}$, S. V. R. lb. vij; used by confectioners to make noyeau. 
FOR USE IN THE ARTS.

Guyot's spirit. French brandy 5 gall.; distil 10 pints : add to that left in the still well-water 30 pints, lavander flowers or leaves $1 \mathrm{lb}$; distil all off. Take of the spirit first drawn off $11 \mathrm{oz}$, measures, well water $69 \mathrm{oz}$. measures ; of the second spirit $80 \mathrm{oz}$. measures: mix. Used for preserving animals and vegetables; contains 1 part of alcohol to 13 water.

Substitute for Guyot's spirit. Spirit of lavander 1 pint, very clear spring water 6 pints; if it grows thick, filter through white filtering paper.

\section{TINCTURES.}

\section{FOR MEDICAL USE.}

Tinctura aconiti. Fol. acon. 艿, proof spirit §vj; anodyne, deobstruent, gtt. $\mathrm{x}$, gradually increased.

Tinct. absintuir. (Ph. Den. et Pruss.) Wormwood 1 part, alcohol 6. Doses 3 ss to 3 ij.

Tinct. absinthil comp. (Par.) Large and small wormwood, of each 8, cloves 8, sugar 4, alcohol 125 .

Essentia amara. (Ph. Den.) Wormwood 4, blessed thistle, bitter orange peel, and gentian root, ana 1, alcohol 45 . Doses $z^{\text {ss }}$ to 3 ij added to mixtures.

Tinct. aloes, P. L. 1788, P. D. Aloes Soc. そ̌ss, extr. glycyrr. 亏j, proof spirit, water, ana lb. ss.-T. aloes, P. L. 1809.

Tinct. aloes Socotrine. Al.j Soc. ̌ss, ext. glyc. そjss, S. V. R. そiv, water lb. j; purgative, stomachic, §̌ss to §jss.

Vinum aloes, P. L. 1824. Al. spic. extr. ̌̌viij, canellæ cort. зij, proof spirit and water, ana $\mathrm{O}$ iv.

Elixir aloes saponaceum. Al. Soc., kali acet., fell. bovis

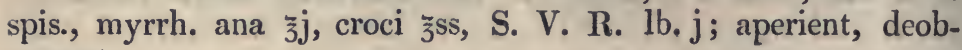
struent.

Balsum of LIFE, Dec. aloes compositum. Extr. glycyr. §̌ss, kali ppi. Эij, aloes Soc., myrrh., croci, ana $3 \mathrm{j}$ water $\mathrm{lb.j}$; boil to $\zeta x i j$, strain, add tinct. cardam. comp. $३ \mathrm{iv}$; its taste improves greatly by keeping; stomachic, aperient, $\jmath^{5 S}$ to $\xi \mathrm{ij}$; also externally to wounds and ulcers.

Asthmatic elixir. Opium 1 oz., camphire 5 drachms, ol. anisi $1 \mathrm{oz}$. proof spirit 1 gall. 
Trinct. Aloes etherea. Myrrh. §jss, æther. sulph. c. alco. lb. $\mathrm{j}$; digest, add aloes Soc. そjjs, croci ̌̃j, digest again : more stimulant than the spirit tincture.

Spirit bitters, T. amara, T. gentiane composita, P. L. et D. Rad. gentian. $\bar{z}^{i j}$, cort. aurant. sicc. $\check{\jmath}_{j}$, sem. card. minor. $\bar{z}$ ss, proof spir. lb. ij.

2. Rad. gent. 1lb., cort. aurant. 8 oz., gran. Parad. 1lb., coccin. 3 ij, raisin wine 4 pints, proof spir. 12 pints.

3. Rad. gent. 8 o\%., cort. aur. 4 oz., gran. Par. 1 oz., cocc. 3 ij, proof spirit 1 gall.

4. Rad. gent. 8 oz., coccin. ziv, S. V. R. 4 gall., water 6 gall.

'Tinct. gentiane composita, P. E. Rad. gent. ऊ̌ij, cort. aur. $3 \mathrm{j}$, canel. alb. $\bar{s} s s$, cocc. 3 ss, proof spir. lb. ijss.

Essentia Anetur. Spir. anethi $3 x i i$, ol. anethi $3 i j$, extr.

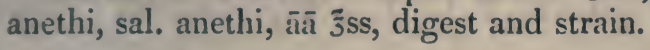

Tinct. AnthF.nedis.

Tinct. of antimony, $T$. antimonii. 'Take crude antimony $1 \mathrm{oz}$. , salt of tartar and saltpetre, of each $2 \frac{1}{2} \mathrm{oz}$., mix and throw them into a red hot crucible: when melted, pour them out into an iron mortar, powder the mass while hot, and before it grows cold put it into a bottle with $\mathrm{lb}$. iv of spirit of wine; digest and decant.

Tinct. angusture, T. Bomplandice trifoliatce, 'T. cusparia. Cort. ang. $\overline{3} i j$, proof spirit lb. $\mathrm{jj}$; stomachic, tonic, $3 \mathrm{j}$ to $\overline{3} s s$.

Vinum antimonit tartarizati, P. L. 1824. Antim. tart. aj, dissolve in water 3 3ैiij, filter and add S. V. R. $z_{3 j}$; emetic.

Spilsbury's antiscorbutic dirops. Sublim. corr, rad. gent., cort. aurant. sicc. ana $3 \mathrm{jj}$, antiinon. crudi, sant. rubri, ana jj, S. V. R., aquæ ana żiij.

2. Corros. sublim. Эiv, antim. tartar. $3 x$ Эij, coccincl. $3 v$ $3 j$, rad. gent. 4. oz., aq. fontance 4 pints, ol. vitrioli q. s.

'Tinct. gumm anime. Gum anime $3 \ddot{j}$, S. V. R., water, ana $80 \%$; used as an alterative.

BATES'S ANODYNE BALSAM, Balsamum anodymum, T: saponis

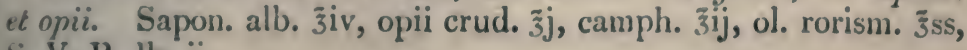
S. V. R. Ib. ij.

2. Sapio. Cast., camph. ana 6 oz., opii 3 iv, croci $3 j, \mathrm{~S} . \mathrm{V} . \mathbf{R}$. $18 \mathrm{oz}$.

3. Sap. alb. 12 oz., op. crud. 3 oz., camph. 1 oz., 3iv, ol. rorism. 3iij, S. V. R. 1 gall. : anodyne gtt. $\mathrm{xx}$ to $\mathrm{xl}$; also externally to sprains. 
Antivenereal drops. Corr. sublim. and mur. ferri, dissolved in S. V.R.

Tinct. aromatica, T. cinnamomi composita, P. L. et D. Cinn. 3vi, sem. card. min. ziij, piper. long., zz. ana zij, proof spirit lb. ij.

2. Bac. cassiæ 3 oz., sem. card. min. 1 oz. 3iv, pp. long. brev. 1 oz., zz. 1 oz., proof spirit 1 gall.

8. Cinn., canel. alb., galang. ana $3 s s$, card. min. ̌̌ij, S. V. R. lb. $\mathrm{j}$; stimulant, astringent, $3 \mathrm{j}$ to $3 \mathrm{ss}$.

Tinct. cinnamomi composita, P. E. Cinnam., sem. card. min. ana $३ j$, piper. long. $3 \mathrm{ij}$, proof spirit lb. ijss.

Tinct. balsami Peruviani. Bals. Peru. ziv, S. V. R. lb. j: pectoral $3 \mathrm{j}$ to $\mathrm{ij}$, quater in die; also as a perfume, and to drop into rose water to make milk of roses.

Tinct. balsami Tolutani, P. L., T. Toluiferce balsami. Bals. Tol. 3jss, S. V. R. lb. j.

T. balsami Tolutani, P. D. Bals. Tol. jj, S. V. R. lb. js; used in making pectoral syrup.

Tinc. Balsami sulphuris. Bals. sulphuris terebinth. boiled in B. M. to dryness, $3 \mathrm{ij}$, proof spirit lb. $\mathrm{j}$ : digest ; pectoral.

Freeman's bathing spirits. Sapo. mollis 6 lb., campl. 8 oz., S. V. R., water, ana 3 gall. : colour with Daffy's elixir.

2. Sapon. mol. 12 oz., camph. 2 oz., kali ppi. 3ss, proof spirit 14 pints, Daffy's elixir $4 \mathrm{oz}$; mix : this will give 122 dozen bottles.

JACKson's BATHING spirits. Sapon. moll. 2lb., camph. 12 oz., ol. rorism., ol. organi, ana 1 oz. ziv, S. V. R. 2 gall. : are both similar to opodeldoc.

Alcohol de brucine. Brucine gr. xv, wine spirit at $36 \mathrm{deg}$. Baume $3 \mathrm{j}$, dose gtt. vj to xxiv.

Brodum's nervous cordial. Tinct. gent., t. calumb., t. cardam., t. cort. Peruv, with spir. lavand. c. and vin. ferri.

Tinct. Calanir. Calami rad. contusi żiv, spirit. tenuior, Oij; digere per dies quatuordecim et cola: tonic in bitter infusions.

Tinct. centauriu cacuminum. Centaurii cacumin. ziij, spirit. tenuior. vij: digere per dies quatuordecim et cola: tonic combined with bitter infusions.

Colombo bitters, T. columbe, P. L. T. calumbe. Rad. col. 亏̈ijss, proof spirit lb. ij.

2. Rad. colomb. 2lb. 4 oz., cort. aurant. 1lb., sem. card. 8 oz., S. V.R. 4 gall.; tonic, $3 \mathrm{j}$ to $\overline{3} \mathrm{ss}$, in bilious complaints. 
Tinct. columba, P. E., T. columbo. Rad. col. ${ }_{3} \mathrm{ij}$, proof spirit lb: ij.

Essexce of camomile. Lign. quassiæ 8 oz., S. V. R. 1 gall., ol. chamæm. q. s. to scent it.

Spirit of WiNe and camphire, $S p$. vini camploratus, $S p$. vinosus camphoratus, T. camphore. Camph. ij., S. V. R. lb. ij.

Sp. camphoratus, Sp. camphora. Camph. 气̌iv, S. V. R. lb. ij ; stimulant, anodyne, in pains, numbnesses.

Tinct. of cantinarides, T. cantharidum, P. L. before 1745 . Rhabarb. jiij, guaiac. 3jss, laccæ $3 \mathrm{j}$, cantharid. 3 ij, coccin. 3ss, S. V. R. lb. jss.

Tinct. cantharidum, P. L. 1745, T. cantharidis, F. L. 1788. Canth. 3ij, coccin. 3ss, proof spirit lb. jss.

Tinct. lytte, T. cantharidis, P. L. 1824. Canth. 5iij, proof spirit lb. jj.

2. Canth. (crass.) 1 oz., coccin. 5 ij, proof spirit 6 pints : stimulant, -diuretic, in gleets, seminal weaknesses, 3 ss to $3 \mathrm{j}$, bis terve

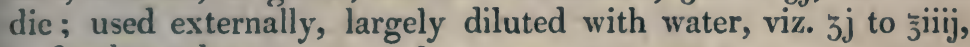
to fistulous ulcers.

Tinct. meloes vesicatorii. Canth. $3 \mathrm{j}$, proof spirit $\mathrm{lb} . \mathrm{j}$.

Tinct. capsicr. Capsic. $3 j$, proof spirit $1 \mathrm{lb} . \mathrm{ij}$; stimulant, $3 \mathrm{j}$ to $3 \mathrm{ss}$, in atonic gout.

Tinct. of cardamoms, T. cardamomi, P. L. before 1745 . Cardam. min. lb. ss, proof spir. lb. ij.

Tinct. cardamomi, P. L. since 1745, P. D. Sem. card. min. ̧̌iv, proof spirit lb. ij.

2. Sem. card. min. 1lb., proof spirit 1 gall. : carminative, stimulant, 3 j to $\bar{s} \mathrm{ss}$; used to prevent grịping.

Tinct. amomi repentis. Sem. card. min. ร̌iv, proof spirit lb. jss by weight.

Tinct. cascarill.e, 'T. crotonis eleutheria. Cort. cascar. żiiij, proof spirit lb. ij; stimulant, in debility of the stomach and bowels $3 j$ to 3 ss, ter quaterve die.

Tinct. of caston, T. castorei, P. L. before 1745. Cast. Russ. 3 ss, spir. cast. Russ. lb. ss.

Tinct. castorei, P. L. since 1745. Tinet. cast. Russ. Cast. Russ. 3 ij, proof spirit lb. ij.

Tinct. castorei Canadensis, T. c. Nova Anglia. Cast. Canad. 3ij, proof spirit lb. ij.-2. Cast. Nov. Angl. 8 oz., S. V. R. 5 pints, water 3 pints; antispasmodic, in female diseases, 3 j. to 3 iij.

Tinct. castorei, P. E. Cast. Russ. そjjss, S. V. R. lb. j. . 


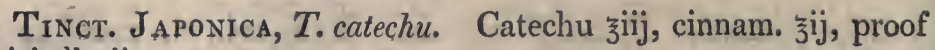
spirit lb. ij.

2. Terr. Japon. 6 oz., bacc. cassæ 4 oz., proof spirit 5 pints ; astringent, $3 \mathrm{j}$ to $\xi s s$, in diarrhœea, menorrhagia, fluor albus.

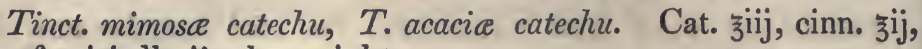
proof spirit lb. ijss by weight.

Tinct. of the bark, T. corticis Peruviani simplex, T. cort. Peruviani, T. cinchona, P. D. Cort. Peruv. žiiij, proof spirit lb. ij.

Tinct. cinchone, P. L. Cort. Peruv. $3 v i j$, proof spirit lb. ij.2. Cort. Peruv. 2lb., proof spirit 2 gall.-3. Extr. cort. (Hispan.) $6 \mathrm{oz} .$, S. V. R. 10 pints, water 1 gall.; tonic, stomachic, $3 \mathrm{j}$ to 乡ss.

Tinct. cinchone officinalis. Cort. Peruv. 亏iiij, proof spirit lb. ijss by weight.

Concentrated tincture of bark. Extract. resinos. cort. flavæ 2lb., tinct. cort. aurant. 2 pints, S. V. R. 12 pints.

2. $24 \mathrm{lb}$., cort. cinch. $6 \mathrm{lb}$., cort. casc. $4 \mathrm{lb}$., serp.Virg. $16 \mathrm{lb}$., cort. aurant. 8 oz., croc. in fono 4 gall., S. V. R. $28 \mathrm{lb}$. proof spirit.

Alcohol de cinchonine. Sulphate of quinine gr. viij, wine spirit at $34 \mathrm{deg}$. Baume $\bar{\jmath} \mathrm{j}$; febrifuge.

Huxham's compound tincture of bark, T. corticis Peruviani composita, T. cinchone composita. Cort. Per. $3 \mathrm{ij}$, cort. aurant. sicc. 3 jss, rad. serpent. Virg. $3 i \mathrm{ijj}$, croc. 3 j, coccin. $引 \mathrm{ijj}$, proof spirit $3 \mathrm{xx}$.

2. Cort. Per. 3lb., cort. aurant. 2lb. 4 oz., rad. serp.Virg. 8 oz., croc. in fœno 2 oz., coccin. 1 oz., S. V. R. 2 gall. 2 pints, water 2 gallons.

3. Cort. Per. 2lb., cort. aurant. 1lb., rad. serp.' 4 oz., croci 2 oz., coccin. 3 ij, S. V. R. 12 pints, water 2 pints.

4. Cort. Per. 12 oz., cort. aurant. 8 oz., rad. serp. 2 oz., croc. in fœeno 1 oz., spir. nitri dulcis 4 oz., S. V. R. 1 gall.

5. Cort. Per. 5lb., cort. aur. 3lb. 8 oz., rad. serp. 8 oz., croc. in fœno 4 oz., cocc. 2 oz., proof spirit 6 gall. ; produce 40 pints.

6. Extr. cort. Hisp. 6 oz., cort. aur. 12 oz., rad. serp. 2 oz., croc. in fœno 2 oz., proof spirit 2 gall.

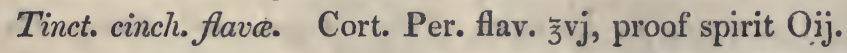

Tinct. cinch. rubrce. Cort. Per. rub. ̌vij, proof spirit Oij.

Tinct. cinnamom, P. L. Cinn. ziij, proof spirit lb. ij.

Tinct. of cassia, T. cassice bacca. Cassia buds 4 oz., proof spirit 4 pints, sold for t. cinnamomi : stomachic, astringent, $3 j$ to 3iij 
Tinct. cinnamomi P. D. Cinn. ₹iijss, proof spirit lb. ij.

Tinct. lauri cinnamomi. Cinn. ziiij, proof spirit lb. ijss by weight.

VINUM. colchicr, P. L. 1824. Colehici rad. rec. lb. j, proof spirit `iiij, water 3 viij.

Tinct. colchici seminuar.

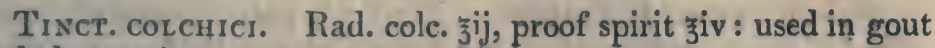
and rheumatism.

Trnct. contrayerve. (Par. H.) Dose $j \mathrm{j}$ to $3 \mathrm{ij}$ in a mixture.

'TrNct. cubeb.e.

Tincture of copper ammoniacal. Prepared by taking one drachm twelve grains of copper filings, liquor of ammonia one ounce and a half. When the liquid has assumed a blue colour, it is decanted, and set aside. This tincture is used in making Kochlin's liquid in the following manner:-Take of ammoniacal tincture of copper two ounces, hydrochloric acid five drachms twelve grains, distilled water five pounds. This has been found serviceable in cases of scrofula. The dose for a child of from three to eleven years old is a tea-spoonful once a day.

Ciramberlain's bilious cordial. From the inner bark of the Juglans cinerea, with spices; much used in America.

Dalbeic's tincture of coloquintida. Pulp. colocynth. §jss, sem. anis. stell. $3 \mathrm{j}$, proof spirit $3 \mathrm{xx}$; purgative, gtt. $\mathbf{x v}$, ter quaterve die, augmenting the dose by gtt. $\mathrm{j}$ each time until a stool is obtained.

Trict. conir maculati. Fol. conii žij, card. min. 3 s, proof spirit 乡zij.

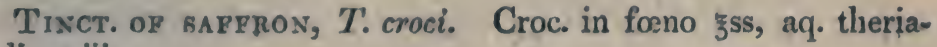
calis そ̌iij.

Tinet. croci cum spiritu vini. Croc. §ss, proof spirit §viij. 3iij.

2. Croc. 4 oz., coccin. 3iiij, proof spir. 1 gall.; cordial, $3 j$ to

Tinct. Belladonse. Belladon. fol. exsiccat. žij, spirit. tenuior. $\mathrm{Oj}$; macera per dies quatuordecim et cola: doses gtt. $\mathrm{x}$ to $\mathrm{xxv}$.

Tincture of вт ramonium, $T$. dature siramonii. Sem. datura stramonii $3 i j$, proof spirit $\mathrm{lb}$. $\mathrm{j}$; is said to be superior to laudanum: dose gtt. viij.

Tinct. dictamisi albr. Rad. dictam. alb. rec. zij, S. V. R. 1 pint; tonic, antispasmodic, gtt. $\mathbf{x x}$ to 1 , bis terve in die, in epilepsy and chlorosis. 
Tinct. of Foxglove, $T$. digitalis. Fol. digit. sicc. 3 iv, proof spirit lb. ij; diuretic, gtt. $x$, cautiously increased.

Tinct. of euphorbium, T. euphorbii. Gum. euph. 3 oz., S. V.R. 1 pint; externally stimulant.

Trnct. of gali, T. fellis. Dried gall $2 \mathrm{oz}$., proof spirit 1 pint; removes freckles.

VINUM FERRI, P. L. 1824. Ferri zj, potas. supertartr. 3vj; grind together and moisten with water occasionally for six weeks; then dry, grind, and add water $\xi x x x$, strain and add proof spirit sxx.

Tinct. Martis Mrasichti, T. florum Martialium, T. ferri ammoniata. Flor. Martial. §iiij, proof spirit lb. j.

Tinct. of steel, T. Martis cum sale ammoniaco. Residuum in subliming iron filings with sal ammoniac q. p., S. V.R. q. s. to extract the tincture, evaporate to one half, and add a little spirit of salt.

Tinct. Martis in spiritu salis. Iron filings lb. ss, spir. of salt lib. iij : dissolve, decant, evaporate to a pint, and add S. V. R. lb. iij.

Tinct. FerRi muriati, T. ferri muriatis, P. L. \& D. From the rust instead of the filings of iron.

2. Colcoth. vitriol. 2 oz., spir. salis 8 oz., S. V. R. 2 gall., water 4 pints; it will look well in time, but if for immediate sale add a little brandy colouring.

T. muriatis ferri, P. E. Blacksmiths' scales of iron „̌iij, spir. salt q. s. to dissolve them, add S. V. R. to make up the weight of lb. ijss.

Tinct. acetatis Ferri. Kali acet. žjij, sal Martis $\bar{\jmath}$; grind together, add S. V.R. lb. ij ; digest seven days, and decant: are astringent, tonic, gtt. $\mathrm{xx}-3 \mathrm{j}$, bis terve die.

Tinct. fetida, T. assefeetida, T. assafoetida, P. I. Ass. fœt. 今̌iiij, S. V. R. lb. ij.

Tinct. asscefotida, P. D. Ass. fœet. 亏̌iiij, S. V. R. lb. ij, water 亏viij.

Tinct. fervile assafœetida. Ass. fœet. 亏iiij, S. V. R. lb. ijss by

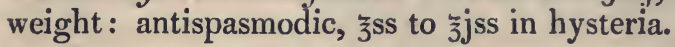

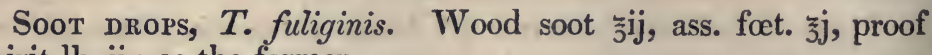
spirit lb. $\mathrm{ij}$; as the former.

Tinct. galbani. Galb. 亏̌jij, proof spirit lb. $\mathrm{ij}$; less nauseous than the two former, but also less effectual.

Teinture de gentianin. Gentianin gr. jv, wine spirit at 24 deg. Baume 3 . 
Tixcture of Galls, $T$. Gallarum. Galls ziiij, proof spirit lb. $i j$ : astringent $j j-z i j j$; used as a test liquor for iron, with which it grows black.

Gout cordial. Rad. rhei, fol. sennæ, sem. coriand., sem. fœnic., coccinellæ ana $\tilde{j} \mathrm{ij}$, rad. glycyrh., croci ana $\tilde{j} \mathrm{j}$, raisins $2 \frac{x}{2}$ lb., S. V. R. 2 gall.

RefCE's EAU DE Husson, T. gratiola. From the dried herb of hedge hyssop: used in gout and rheumatism.

Tincture of gualacum, T. guaiaci, P. L. 1809. T.guaiaci officinalis. Gum guaiaci lb. ss, S. V. R. lb. ij, digest fourteen days; stimulant, diaphoretic, in rheumatism 3 ij to sss. $^{2}$

Hatfield's tincture. G. guaiaci, saponis ana $3 \mathrm{ij}, \mathrm{S}$. V. R. b. jss.

Hill's essence of bardana. G. guaiaci $\check{j}, \mathrm{~S}$. V.R. aquæ ana కij.

Tincture of black hellebore, T' hellebori. Rad. helleb. nig. 3 ij, sal. tart. $3 \mathrm{j}$, coccin. $3 \mathrm{j}$, proof spir. lb.j.

Tinct. melampodii, T. hellebori nigri, P. L. before 1809, P. D. Rad. helleb. nig. 亏iiij, coccin. $\mathrm{g}^{\mathrm{ij}}$, proof spir. lb. ij.

Tinct. hellebori nigri, P. L. 1809. Rad. helleb. nig. siiij, proof spirit lb. ij.

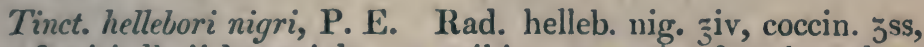
proof spirit lb. ij by weight; a striking example of uscless alterations: attenuant, emmenagogue, $35 s-3$ jss, bis terve die.

Hill's balsam of hoNey. Bals. Tolu 1lb., honey lib., S. V.R. 1 gallon.

2. Bals. Tolu opt. 2 oz., gum. styrac. 3 ij, opii pur. zss, mell. opt. 8 oz., S. V. R. 2 pints; pectoral, used in coughs and colds.

Ford's balsam OF hoREHound. Horehound, liquorice root ana $31 \mathrm{lb} .8 \mathrm{oz}$, water $\mathrm{q}$. s. to strain 6 pints, infuse: to the infusion add proof spirit or brandy 12 pints, camphire $1 \mathrm{oz}$. $3 \mathrm{ij}$, opium pur., benjamin ana $1 \mathrm{oz}$. , dried squills $2 \mathrm{oz}$., oil of anise seed 1 oz., honey 3lb. $8 \mathrm{oz}$.

EAU IDE Hussos. Is thought to be a mixed tincture or wine of henbane and colchicum; a tincture of colchicum has been proposed for it by Want; a tincture of hedge hyssop is said to be sold for it by Reece; and a wine of white hellebore proposed by More : but neither of them is possessed of the same cliaracters as the Parisian medicine.

Tinct. of St. John's wort, $T$. hyperici. From the tops: useful in maniacal and melancholic cases.

Tinct. OF hops, T. humuli. Hops $\xi \mathrm{v}$, proof spirit lb. $\mathrm{ij}$; tonic, narcotic, 3 ss to $3 \mathrm{ij}$. 
Tinct. of heniane, T.hyosciami, P. L. T.hyosciami nigri. Fol. hyosc, nigr. sicc. ziiij, proof spirit lb. ij.

T: hyosciami, P. D. Fol. hyos. sicc. sij zij, proof spirit lib. j; narcotic, sometimies purgative, gtt. $x \times$ to $3 \mathrm{j}$.

'Tinct. ipecacuanhz. Rad. ipecac. 2 oz., S. V. R. á pint: is less emetic than the root in substance; used in dysentery.

VINUM tPecactuanhis, P. L. 1824. Ipec. rad. 3 ij ; proof spirit $\mathrm{fl}$. $3 \times \mathrm{xij}$, water $\mathrm{fl} .3 \times x$. A goood emetic for infants. Dose siv tô $3 \mathrm{x}$ in divided doses.

Tinct. JaĹapir, T. jälape, P. L. Rad. jalap. žviij, proof spír. lb. ij. Purgative; generally added to purgative dratights to promote their effects

Tinct. jalapœ, P.D. Rad. jalap. 3 w, proof spirit lb. ij.

Tinct. convolvuli jalape. Rad. jalap. ३iij, proof spirit $3 x v$ by weight; purgative, $3 \mathrm{j}$ to 3 ss.

Elixir jalape composituin. Rad. jalap. 4 oz., scam. Alep. zî̀, G. G. G. 3ij, S. V. R. 2 pints.

Tinct. кino, P. L. 1809. Kino 3 ij, proof spirit lb. ij.

Tinct. kino, P. L. 1824. Kino siij, S. V. R. Oij.

Tinct. kino, P. D. Kino iij, proof spirit lb. jss.

Tinct. kino, P. E. Kino sij, proof spirit lb. jss by wt. ; astringent $3 \mathrm{j}$ to 3 ss in diarrhœa.

Tinct. Lacce. Gum. lacc. 4 oz, gum. myrrh. 2 oz., spir. cochlear. 6 pints; to wash spongy gums.

Tincr. of opium, Laudanum liquidum tartarizatum. Opii

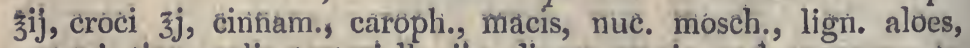
ană $3 \mathrm{j}$, tinct. salis tartari $\mathrm{lb}$. ij; digest, strain and evaporate to one half.

Tinct. opii, P. L. 1788. Hard purif, opium $3 \mathrm{x}_{3}$ proof spirit lb. ij.

Tinct. opiz, P. L. and D. Opii zijss, proof spirit lb. ij; the sediment is usea to make Haden's liq. opii sedativus.

Tinct. opii, P. E. Opii zij, proof spirit lb. ij by wt. : anodỳne, narcotic, gtt. $\mathrm{xx}$ to $\mathrm{xl}$, or more; externally anodyne, antispasmodic.

Vinum opii, P. L. 1824. Extr. opii $\jmath_{j}$, cinnam., caryoph. ana $3 j$, proof spirit $z v j$, water $z x$; anodyne, narcotic, gtt. v. to $3 j$.

Ford's laudianum. Opii 3 j, cinnam., caryoph. ana 3 j, S. V. R. aq. ana 3 viij

Lavander Drops, Red hartshorn, Spiritus lavandule compositus, P. L. before 1809. Spir. lavand. simp. lb. iij, spir. rorism. lb. j, cinnam., nuc. mosch. ana $\overline{3}$ ss, santal. rubr. ziij. 
Tinct. lavandula composita, Sp. lavand. comp. P. L. 1809. The same, but with $1 \mathrm{oz}$. of red sanders.

2. Ras, sant. rubr. 1lb., piment., cass. lign. ana 8 oz., S. V. R. 12 pints; digest, strain, and add ol. lavand. 4 oz., ol. rorism. 2 oz., proof spirit 4 galls.

3. Ras. sant. rubr. 1lb., cass. lign. 2 oz., nuc. mosch. 1 oz., croci in f. 3iij, pisar. aurantiar. 1 oz., fol. ros. rubr. 2 oz., S. V.R. 1 gall.; make a tincture, it will produce 6 pints, to 4 pints of this tincture add ol. lavand. exot. 14 oz., spir. vol. aromat. 6 oz., S. V. R. 5 gall., distilled water 10 pints.

4. Red sanders 4 oz., S. V. R. 4 pints; digest, strain, and add ol. lavand. ziv, ol. rorism. 1 oz., ol. cass. gtt. viij, ol. caryoph. gtt. iv, spir. ammon. comp. q. s. about $3 \mathrm{vj}$, to produce the proper colour. Stimulant, antispasmodic, $3 \mathrm{ss}-3 \mathrm{ij}$, in nervous languors.

Sp. lavandula compositus, P. D. The same as the last, with cloves 3 ij added.

Sp. lavandula compositus, P. E. Spir. lavand. Ib. iij by weight, sp. rorism. lb. $\mathrm{j}$ by weight, cinnam. $3 \mathrm{j}$, caryoph. $3 \mathrm{ij}$, nuc. mosch. $3 \mathrm{ss}_{\text {, }}$ sant. rubr. $3^{i i j}$.

T'eixture de r.upuline. Magendie's lupuline $\bar{j}$ j, S. V. R. jij; digest, add S. V.R. to make $3 \mathrm{oz}$; press out the liquid.

Tinct. i.actucarir.

Tinct. mastichis. Used to make eau de luce.

Simple tincture of MYrRi, $T$. myrrha simplex. Myrrh jss, salt. tart. $j^{i j}$; keep in a moist place for a week, add S. V. R. گँviij.

Tinct.myrrha, P. L. 1745. Myrrh ziij, proof spirit lb. ij.

Tinct myrrhice, P. L. 1788 and P. D. Myrrh ziij, proof spirit lb. jss., S. V. R. lb. ss.

Tinct. myrrha, P. L. 1809. Myrrh §iij, S. V. R. そxij, water lb. ss.

Tinct. myrrha, P. L. 1815. Myrrh 3ij, S. V. R. lb. ij, water Ib. j.

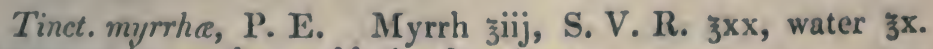
Detergent in gargles, and lotion for ulcers.

COMPOUND TINCTURE OF MYRR, Tincture of myrrh and aloes, T. myrrhace composita. Alocs, myrrh, ana $3 \mathrm{j}$, proof spirit $\mathrm{lb} . \mathrm{j}$.

2. Aloes, myrrh, ana 12 oz., proof spirit 3 gall.

3. Gum. myrrh 1lb. 4. oz., aloes Barbad. 4 oz., proof spirit 1 gallon. 
- 4. Gum. myrrh 1lb. 2 oz., aloes B. B. 6 oz., S. V. R. 7 pints, water 5 pints. Detergent, prevents suppuration in green wounds.

- Euxir myrrhe compositum, T. sabince composita. Extr. sabinæ $\mathrm{J}_{\mathrm{j}}$, tinct. castor $\mathrm{lb}$. j, tinct. myrrh lb. ss : emmenagogue.

Teinture de myrrhe. Myrrh 3 oz., eau de Rabel 1lb. by weight ; stimulant.

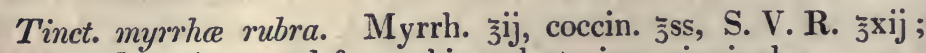
digest and strain: used for making electarium gingivale.

Tincture of nux vonica. Rosin of nux vomica gr. iij, S. V. R. $3 j$; in palsy.

Paregoric elixir, Elixir paregoricum. Opii pur., - fl. benz. ana $3 j$, camph. $\vartheta^{i j}$, ol. sem. anisi jss, S. V. R. lb. ij.

2. Pulv. opii, fl. benz. ana 12 oz., gum. benz. 6 oz., campl. 1 oz., ol. anisi zxij, proof spirit 3 gall.

3. Extr. opii 2 oz. $3 i \mathrm{j}$, camph., fl. benz. ana $1 \mathrm{oz}$. jiv, ol. anisi §vj, S. V. R. 2 gall., water 10 pints.

4. Gum opium 1 oz., gum benz. 2 dum 8 oz., camph. 1 oz., ol. anisi ziv, S. V. R. 12 pints, water 2 pints. Anodyne 3 ss-3ij ; useful in recent coughs.

Tinct. camphorata. The same, but with proof spirit.

Tinct. camphorce composita. The same, with proof spirit, and omitting the oil of anise seeds.

Nonris's DRops. Tart. emet. dissolved in S. V. R. and then coloured.

Tinct. Pinr. Essence of spruce žj, spir. turion. pini lb. $\mathrm{j}$; stimulant, antiseptic.

Tinct. piperis. Pip. nig. 亏iv, S. V. R. žzvj ; digest.

Rateman's pectoral drops. Sem. fonic. dulc. 2lb. 8 oz., sem. anisi $1 \mathrm{lb}$., proof spirit 4 gall., water q. s.; distil 10 gall., to which add opium 7 oz. ziv, camph. 6 oz., kali pp. 1 oz., coral. rubr. $4 \mathrm{oz}$.

2. Castor. N. A. 2 oz., opium, ol. anisi ana 1 oz. ziv, camph. $8 \mathrm{oz}$., sem. fœnic. dulc. 2 oz., tinct. antim. $4 \mathrm{oz}$., proof spirit 10 pints, add rad. valerian and cochineal in powder.

3. Castor., camph. ana 4 oz., coccin. 1 oz., S. V. R. 2 gall., water 1 gall.

4. Opii, camph. ana $11 \mathrm{~b}$., castor. ol. anisi, santal. rub. ana 4 oz., treacle 10lb., S. V. R. 5 gall., water 4 gall.

5. Opii, camph. ana $3 \mathrm{x}$, coccin. $3 \mathrm{j}$, kali ppi. giv, ol. fœnic. dulc. $3 \mathrm{j}$ (or seeds $3 \mathrm{oz}$ ), proof spirit 14 pints, water 2 pints; produces 15 pints. 
6. Castor 1 oz., ol. anisi $3 j$, camph. $3 \mathbf{v}$, coccin. $3 j s s$, opii $3 v j$, proof spirit 1 gall.

7. Rad. glycyrrh., sem. anisi ana 2lb., water 5 gall., boil to 3 gall. ; strain, add sacchar. ust. 1lb., opii うjss, castor N. A., rad. valerianæ ana $3 \mathrm{x}$, camph. $\mathrm{j}_{\mathrm{j}} \mathrm{j}, \mathrm{S}$. V. R. 2 gall., digest, strain, and add to the above. This will fill 22 doz. bottles.

Tinctere of psychotria sulphurea. P. U S. Yellow, very bitter; used as a tonic.

JEsurts' DROPS, Balsamum polychrestum, Elixir antivenereum. Gum guaiaci. žvij, bals. Peruv. ziv, rad. sarsæ žv, S. V. R. lb. ijss.

Bals. gualacinum. Gum. guaiaci. lb. j, bals. Peruv. jiij, S. V. R. lb. ijss ; diaphoretic $3 j$ to $j i j$; externally prevents suppuration.

Elixik prophietatis dulce. Myrrh, aloes, croci ana j̃ij, S. V. R. lb. ij.

Elixir aloes, Tinct. aloes composita. Tinct. myrrh lb. ij, aloes croci ana ऊ̌ij.

Tinct. aloes cum myrrha. Myrrh žij, S. V. R. lb. jss, water

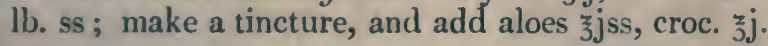

2. Gum. myrrh 12 oz., croc. in fono 1 oz., aloes Soc. 8 oz., S. V. R. 5 pints, water 3 pints; the compound tincture of myrrh is frequently sold for it. Stimulant, stomachic, emmenagogue, $z^{\text {ss }}$ - zjss, bis terve die.

Elixir proprietatis cum acido. 'To elixir proprietatis add spirit of vitriol till gratefully acid; stomachic 3 ss- 3 jss.

Elixir proprietatis tartarizatum. Myrrh, aloes, croci, ana lb. j, tinct. salis tartari lb. xij: for patients with whom acids do not agree.

Tincture of poppy, $T$. papaveris. Poppies, every part except the root, dried in the shade and powdered ziv, proof spirit $\mathrm{OJj}_{3}$; ligest a week, and strain: produces about $亏$ viij or $\mathrm{x}$; is about half the strength of tincture of opium.

Ratciff's puncing elixir. Rad. jalap. 6 o\%, aloes Cap. $5 \mathrm{oz}$, rad. gent. 2 oz., cancll. alb. $1 \mathrm{oz}$. jiv, cort. aurant. $1 \mathrm{oz}$, gr. Parad. ziv, proof spirit 2 gall., steep for three weeks, strain, and add scam. Alep., jalap., fol. senna in powder ana $1 \mathrm{oz}$. ziv.

2. 'T'inct. aloes 2 pints, tinct. jalap., tinct. gent. ana 8 oz., proof spirit 2 pints, scamm., r. jalap., fol. sennæ ana ziv.

3. Proof spirit, tinct. aloes ana 4 pints, tinct. gent., tinct. jalap. ana 2 pirsts, add pulv. jalap. $6 \mathrm{oz}$. 
4. Aloes Soc. $3 \mathrm{vj}$, cinnam., zedoariæ ana $3 \mathrm{ss}$, rad. rhei $3 \mathrm{j}$, coccin. $3 s s$, syr. rhamni $3 \mathrm{ij}$, spir. ten. $1 \mathrm{~b} . \mathrm{j}$, aq. $z^{\mathrm{v}}$.

5. Hiera picra 1lb., S. V. R. 10 pints, water 14 pints, syr. spin. cerv. 4lb., coccin. $1 \mathrm{oz}$ : : an inferior sort.

Tinct. PYRETHRI. Rad. pyrethri zj, sp. rorism. ̌̌viij; used as a wash for the mouth, diluted with about twice as much water; sialogogue in toothach.

Oxley's tinct. of pyrethrum. Rad. pyrethri $3 x$, spir. æether. sulphur. Oj, digest ten days, strain, add camph. 3 j, ol. rorism. $\xi^{\mathrm{ss}}$, tinct. opii zij. M. Apply with lint to the painful tooth.

Tincture of quassia, T. quassia, $T$. quassice excelsce. Quas. ऊj, proof spirit lb. ij ; bitter.

Alcohol ne QUININE. Sulphate of quinine gr. v; winè spirit at $43 \mathrm{deg}$. Baume $\bar{\jmath}$ : febrifuge, used to prepare the wine.

EAU DE RABEL, Elixir vitrioli. Ol. vitriol. 4 oz., S. V. R. 12 oz., both by weight; tonic, astringent, diuretic.

Tincture of rhubarb, T. rhabarbari, P. L. before 1788. Rhabarb. $j$ jss, sem. cardam. min., croci ana $3 \ddot{j}$, rad. glycyrrh. 3 j, proof spirit lb. j.

Tinct. rhabarbari spirituosa, T. rhabarbari, P. L. since 1788.

Tinct. rhei, P. L. Rhabarb. 3 ij, sem. cardam. min. ${ }_{3}^{5 s}$, croci 3ij, proof spirit lb. ij.

2. Rad. rhei 2lb., sem. cardam., gr. Parad. ana 6 oz., croc. in f. $3 \mathrm{oz}$, proof spirit 3 gall.

3. Rad. rhei 1lb., rad. glyc. 6 oz., zz. 2 oz., cardam. 1 oz., croci ziij, S. V. R. 5 pints, water 3 pints.

4. Rad. rhei comm. 3lb.; sem. cardam. 10 oz., croci 6 oz., S. V. R. water ana 3 gall., will strain about 44 pints.

5. Rad. rhei opt. 3lb., sem. card. 8 oz., croci 2 oz., S. V. R. 6 gall.; a superior article for retail sale.

Tinct. rhabarbari, P. D. The same as the London, but with rad. glyc. §̌ss.

Tinct. rhei palmati, T. rhei, P. E. Rhabarb. ziij, sem. card. min. $3 s s$, proof spirit lb. ijss by weight.

Bates's tincture of rhubarb. Rhad. rad. glycyrrh. ana zij, uvæ passæ stoned No. 40, sem. anisi $\xi j$, sacch. candi $\mathrm{vj}_{\mathrm{j}}$, S. V. R. ib. ij; much the pleasantest in taste.

Tinct. rhabarbari composita, T. rhei composita, P. L. 1809. Rhabarb. $z i j$, rad. glycyrrh. $3 \mathrm{ss}, \mathbf{z z}$. croci ana $3 \mathrm{ij}$, proof spirit lb. xij, water lb. j. 
Tinct. Thei composita, P. L. 1815. Species as the former, proof spirit $\mathrm{lb}$. j, water 3 xij.

Tinct. rhei et aloes, Elixir sacrum. Rhabarb. 3x, al. Soc. 3 vj, sem. card. min. 3 ss, proof spirit lb. ijss by wt.

Tinct. rhei et gentiana, T. rhei amara. Rhabarb. $3 \mathrm{ij}$, rad. gent. §̊ss, proof spirit lb. ijss by wt.

All these preparations of rhubarb are stomachic, $3 \mathrm{j}-3 \mathrm{iij}$, and purgative in doses of $3 \mathrm{vj}$, producing costiveness after their operation is over; favourite remedies with spirit drinkers.

'Tinctura Piscidice Erythrine. Tincture of the Jamaica dugwood, prepared with an ounce of the bark to twelve ounces of rectified alcohol. It is said by Dr. Hamilton, who introduces it, to be a powerful narcotic, anodyne, and diaphoretic. He considers it to be superior to the tincture of opium in its medicinal effects, and at the same time it does not produce those unpleasant symptoms, which frequently prevent our using the last-mentioned drug. In the West India islands it is employed to intoxicate the fish, in order that they may be more readily caught. $-M e d$. Bot. Trans.

Tinct. of rilatany root, Tinctura rhatanic. Rad. rhataniæ $2 \mathrm{oz}$, proof spirit 1 pint: used in diarrhœa.

Tinct. mintanis aromatica. Rhatan. rad. cont. 腌, canellæ cort. cont. $\frac{\xi}{3} \mathrm{j}$, spirit. tenuior. $\mathrm{O} \mathrm{ij}$, digere per dies decem. et per chartam cola. As a stomachic and astringent, with a tonic infusion.

TINCT. RHodis. Rhodii ligni ras. ziv, spirit. rect. $\mathrm{O}$ j, macera per dies quatuordecim et cola. $\xi \mathrm{ss} \xi j$ ter die in mucilaginous mixtures.

Tinct. Ricini. Sem. ricini q. p. S. V.R. sufficient to drown the seeds; dost $1 \mathrm{oz} .$, purgative.

2. Dissolve castor oil q. p. in spirit of winc.

Rraen's cardiac tincture. Capsicum, camphire, lesser cardamoms, rhubarb, aloes, and castor, in proof spirit, with a few drops of oil of vitriol.

DAFFY's Elrxir, Dicey's Daffy, Elixir salutis. Fol. senn. ziv, ras. lign. guaiac., rad. enulre sicc., sem. anisi., sem. carui, sem. coriand., rad. glycyrrh. ana zij, uvar. pass. (stoned) zviij, proof sp. lb. v.j.

Swixtox's Daffy. Rad. jalap $8 \mathrm{lb}$., fol. sennx 12 oz., sem. coriand., sem. anisi, rad. glycyrrh., rad. enula ana $4 \%$., S. V. R., water, ana 1 gallon. 
2. Fol. senn., rad. rhei, sem. anisi ana 2 lb., rad. jalap., sem. carui ana $1 \mathrm{lb}$, sant. rubr. $8 \mathrm{oz}$., proof spirit 10 gall., brown sugar $4 \mathrm{lb}$.

3. Rhabarb. E. Ind. 40 lb., sennæ 15 lb., sant. rubr. 5 lb., sem. carui, sem. anisi, sem. coriandri ana 5 lb., cineres Russici 8 oz., S. V. R. 10 gall.; digest three days, then add proof spirit 80 gall., treacle $46 \mathrm{lb}$.

4. Rad. rhei 14 lb., sem. anisi 10lb., sennæ parvæ 8lb., rad. jalap. 4 lb., sant. rubr. 3 lb. 8 oz., ciner. Russ. 2 lb., S. V. R. 38 gall., water 18 gall.

5. Rad. enulæ, ras. guaiaci, sem. coriand., rad. rhei, rad. glycyrrh., sem. anisi ana $3 \mathrm{oz}$., raisins $1 \mathrm{lb} .8 \mathrm{oz}$., proof spirit 10 pints.

6. Rad. jalap. 3 lb., fol. sennæ 1 lb., sem. anisi 6 oz., sem. coriand. $4 \mathrm{oz}$., cort. aurant. sicc. $2 \mathrm{oz}$., proof spirit 2 gall.

7. Fol. sennæ 7lb., rad. jalap. 5lb., sem. anisi 14lb., sem. carui 4lb., sem. fœnic. dulc. 4lb., brandy colouring 2 gall., S. V. R. 26 gall., water 24 gall. ; let it stand three weeks, strain, washing out the last portions with water 2 gall., then add treacle $281 \mathrm{~b}$.

Trnct. senne, T. sennce, P. L. Fol. sennæ lb. j, sem. carui

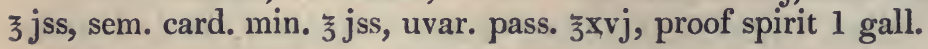

Tinct. sennce, P.D. As the London, omitting the raisins.

Tinct. sennce composita. Fol. sen. $亏$ ij, rad. jalap. $ろ$ j, sem. coriand. $亏$ ss, proof spirit lb. iijss by weight; when made, add white sugar ziv.

A common remedy in flatulent colic, and used as a purge by those accustomed to spirit drinking : dose one, two, or three table spoonfuls.

Tinct. Saturnina. Sugar of lead, green vitriol ana $z^{i j}$, S. V. R. lb. ij ; used in phthisis.

Opodeldoc, Soap liniment, Balsamum saponis, Linimentum saponaceum, L. saponis, L. saponis compositum. Sapo. Castil. ziij, camphor. $\xi \mathrm{j}$, spir. rorismarini lb. j.

Tinct. saponis composita, T. saponis camphorata. Sapon. Cast. $३$ iv, camph. 3 ij, ol. rorismar. $₹$ ss, S. V. R. lb. ij.

2. Sapo. moll. 16lb., water 1 gall. : dissolve, add camph. 1lb., dissolved in S. V.R. 1 gall., proof spirit 4 gall., ol. rorism. 8 oz.

3. Sap. moll. 5lb., camph. 12 oz., ol. rorism. 2 oz., S. V. R. 10 pints, water 6 pints. Rubbed on the part in rheumatism ; internally, gtt. lx, in gout.

Steer's opodeldoc. Sap. Cast. 3lb., S. V. R. 3 gall., camph. 14 oz., ol. rorism. 3 oz., ol, origani 6 oz., aq. ammon. pur. 2lb. 
2. Sap. alb. 1lb., camph. 2 oz., ol. rorism. ana 3iv, S. V. R. 2 pints.

3. Sap. alb. 1lb., camph. 4 oz., ol. origani, ol. rorism. ana 3iv, S. V. R. q. v. : it will bear near 6 pints.

4. Sap. alb. 3lb., camph., ol. rorism. ana 6 oz., spir. am. comp. 4 oz., S. V. R. $4 \frac{x}{2}$ gall.

5. Sap. alb. 4 oz., camph. 1 oz., ol. rorism. $3 \mathrm{ij}$, ol. origani gtt. $\mathrm{xxx}$, S. V. R. 1 pint, water half a pint.

TrNct. of salt of tartar, $T$. salis tartari. Melt 6 oz. of salt of tartar in a crucible ; powder it while hot, and immediately pour upon the powder a quart of spirit of wine, digest it for several days, and decant.

TiNct. of squills, T. Scilla. Fresh squills $\bar{j}$ iv, proof spirit lb. $\mathrm{jj}$; expectorant, diuretic, gtt. $\mathrm{x}$ to $\mathrm{xxx}$.

Tinct. of SNake root, $T$. serpentarice Virginianc. Rad. serp. $\overline{\mathrm{j}} \mathrm{ij}$, tinct. salis tartari lb. j.

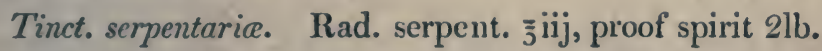

Tinct. aristolochice serpentarice. Rad. serpent. $\cong \mathrm{j}$, coccinel. $3 \mathrm{j}$, proof spirit lb. ijss by weight. Diaphoretic, tonic, $3 j-3 i v$.

Stomaci tructure, $T$. stomachica, $T$. cardamomi composita, P. L. Cinnam. う̌ss, sem. cardam. min., sem. carui, coccinel. ana $3 \mathrm{ij}$, uvar. passar, stoned, $\mathrm{j}$ iv, proof spirit lb. ij.

2. Use cassia budsfor cinnamon, and only put half the cochineal ; stomachic, $3 \mathrm{j}-3$ iij.

Tinct. cardamomi compositu, P. D. The same, onitting the raisins.

Tryct. sarsaparill...

SQurae's elrxin. Opium 4 oz., camphor 1 oz., coccinel. 3 j, fœniculi dulc. $3 \mathrm{ij}$, tinct. serpent. 1 pint, spir. anisi 2 gall., water 2 pints, and add aur. musiv. $6 \mathrm{oz}$.

2. Rad. glycyirh. $1 \mathrm{lb}$, kali pp. $4 \mathrm{o} \%$, coccincl. 1 oz., water 12 pints; boil till reduced to 1 gall., then add tinct. opii $12 \mathrm{oz}$, camph. $10 \%$, S.V.R. 4 pints, aur. musiv. $12 \mathrm{oz}$.

3. Opii $1 \mathrm{oz} .3 \mathrm{iv}$, camph. 1 oz., coccin., kali pp. ana $3 \mathrm{j}$, burnt sugar 2 oz., tinct. serpent. 1 pint, sp. anisi 2 gall., aur. musiv. $8 \mathrm{oz}$.

Alconor, di: strychink. Strychnine gr. jjss, wine spirit at 36 deg. Baume, $\tilde{3} \mathrm{j}$; in palsy, gtt. vj to xxiij.

Stoughtox's elixir. Rad. gent. 2lb. 4 o\%,, rad. serpent. Virg. 1lb., cort. aurant. sicc. 1lb. 8 oze, cal. aromat. 4 oz., S. V. R. water ana 6 gall. 
2. Rad. gent. $4 \mathrm{lb}$, , cort. aurant. $2 \mathrm{lb}$., pis. aurant. 1lb., coccin. 3 ij, sem. cardam. min. 1 oz., S. V. R. 8 gall.

Eaton's styptrc, Tinct. styptica. Green vitriol calcined $3 \mathrm{j}$, proof spirit, tinged yellow with a little oak bark, lb. ij.

2. Galls, crocus Martis ana $4 \mathrm{oz}$, proof spirit 1 gall.

3. S. V. R. coloured yellow with oak bark.

Trixct. of sulphur, T. sulphuris. Hepar. sulph. 3 ij, proof spirit lb. $\mathrm{j}$; pectoral in coughs.

Trnct. Therracalis. Venice treacle, Mithridate ana $\mathbf{l b} . \mathbf{s s}$, proof spirit, strong vinegar ana lb. ij.-2. Aq. theriac. 2 gall. syr. croci 4 lb.

Friar's Balsam, V'ervain's balsam, Wade's drops, Jesuits' drops, Wound balsam, Balsam for cuts, Baume du Commandeur, Balsamum traumaticum, T. benzoes composita, T. benzoini camposita. Benz. 3 iij, stor. colati $3 \mathrm{ij}$, bals. Tolu $3 \mathrm{j}$, aloes Socotr. ss, S. V. R. lb. ij.

Tinct. benzoin composita. Benz. 3 iij, bals. Peru. 3 ij, al. hepat. 3 ss, S. V. R. lb. ij by weight.

2. Benz. 20 oz., styr. col. 12 oz., bals. Tolu 8 oz., gum guaiaci 1lb., aloes Cap., olibani, tereb. Venet. ana 8 oz., pulv. curcum. 1 oz., S. V. R. 2 gall., water 4 gall.

3. Benz. ziij, al. Socotr, $\overline{3}$ ss, S. V. R. xxxij; digest for two days, then add bals. Peru. 3 ij.

4. Benz. 8 oz., gum. styr., gum. guaiaci (parv.) ana 6 oz., bals. Tolu, aloes ana 2 oz., bals. Peru. 1 oz., S. V. R. 1 gall.

Baume's vulneraire. Scio turpentine 3 oz,, S. V. R. $12 \mathrm{oz}$.

Thibaut's Balsam. Myrrh, aloes, sang. dracon. ana $3 \mathrm{j}$, S. V. R. $6 \mathrm{oz}$; dissolve, add flor. hyperici perfor. pug. j, steep twenty-four hours, strain with expression, to the strained liquor add tereb. e Chia 3 ss. In common use for cuts and slight wounds ; internally diuretic $3 \mathrm{ss}-3 \mathrm{j}$, in gonorrhœa.

'TAYLOR'S RED BOTTLE, Whitworth doctor's red bottle. British brandy coloured with cochineal, and flavoured with ol. origani.

Usquebaugh flavum. Pimento, sem. anisi, sem. carui ana 3 oz., mace, cloves, nutmegs ana 2 oz., sem. coriand., rad. angel. ana 8 oz., croci, annotto ana 2 oz., sugar 6 oz., S. V. R. 6 gall.

Usq. viride. The same, using sap green in lieu of saffron and annotto. 
Tinct, of valerian, $T$. valeriance. Rad, valerian. $\xi$ iv, proof spirit ll. $\mathrm{ij}$; antispasmodic, $3 \mathrm{ij}-\tilde{\Sigma}$ ss.

Alcohol de veratrine. Veratrine gr. iv., wine spirit $\xi j$; dose gtt. $\mathrm{x}$ to $\mathrm{xxv}$.

Tinct. of White helleborf, $T$. hellebori albi, T. veratri, T. veratri albi. Rad. helleb. albi § viij, proof spirit lb. ij. Sold in large quantities to make some unknown nostrum.

Vinum veratri, V. hellebori albi. Veratri rad. 3 viij, proof sp. $\mathrm{Oj}$, water Ojss.

TiNct. of GiNger. T. zingiberis, P. L. before 1824. $T$. amomi zingiberis. $\mathrm{Zz}$. ऊj, proof spirit $\mathrm{lb} . \mathrm{j}$.

Oxley's concentrated essence of Jamaica ginger, T. zingiberis, P. L. 1824. Made with rectified spirit instead of proof.

The devil's erryxir." (P. P.) Pods of capsicum bruised

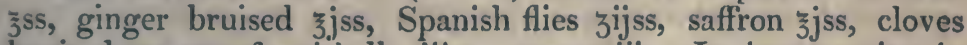
bruised 3 ss, proof spirit lb. iijss. 3 ss- 3 iij. In impotentia; in mixtures.

Mrxsicht's elixir of vitriol, Acid elixir of vitriol, Elixir vitrioli Mynsichti. Cinnam., zz., caryoph. ana ziij, cal. aromat.

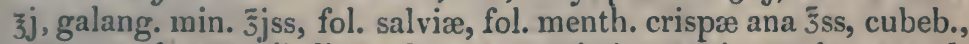
nuc. mosch. ana $3 \mathrm{ij}$, lign. aloes, cort. citri ana $3 \mathrm{j}$, sacchar. cand. ziij, S. V. R. lb. jss, ol. vitrioli lb. j; digest twenty days.

Elixir vitrioli acidum. Tinct. arom. lb. j, ol. vitriol. $\overline{3}^{\mathrm{iv}}$ by weight.

Acidum sulpluricum aromaticum. S. V. R. lb. ij, ol, vitrioli

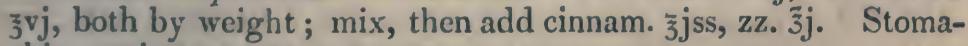
chic, astringent, gtt. $\mathrm{x}$ to $\mathrm{xxx}$.

Vatedelin's T. of spirit of turpentiNe. Sp. tercb. $5 \mathrm{oz}$. meas., wine spirit at $36 \mathrm{deg}$. Baume, $1 \mathrm{oz}$. by meas: does not become turbid on adding water.

Vigani's elixir of vitriol, Sweet elixir of vitriol, Elixir vitrioli dulce. 'Tinct. aromat, lb. j, spir. vitrioli dulce, 3 viij.

Sp. eтheris яromaticus. Cinnam. 3 iij, sem. cardam. min. 3jss, piper. longi, $z z$. ana $3 \mathrm{j}$, spir. æther, sulphurici $l b . j$.

Ether sutphericus cum alcohole aromaticus. Species for tinct. cinnam. comp, P. E., æther. sulphur. c. alcoh. lb. ij: diuretic, diaphoretic, antispasmodic 3ss to 3ij.

WARNER's CORDIAY. Rhabarb. 3 j, fol. sennæ 3 jss, croc. 3j, rad. glycyrrh. 3ir, uvarum pass. lb. j, spir. vini Gallici lb. iij.

Gouttes AMEres. St. Ignatius's beans, or in their stead, nuces romicæ, rasped, $1 \mathrm{~b}$. $\mathrm{j}$, aq. kali $38 \mathrm{~s}$, bistre $3 \mathrm{j}$, aq. absinth. min. comp. lib. ij; stomachic, gtt. $j$ to viij, in any bitter infusion. 
Golden sPIRIts of sCURVY-Grass, Sp. cochlearia purgans Spir. coch. simpl. 1 gall., G. G. G. 8 oz.

Essence of coltsfoot. Tinct. bals. Tolut., bals. traumat. ana 2 oz., S. V. R. $4 \mathrm{oz}$.; used as a pectoral for coughs.

DE LA MotTE's GoLdEx DRops, Bestucheff's nervous tincture, Elixir d'or de M. le Général de la Motte. Muriate of iron (obtained by distilling pyrites $6 \mathrm{lb}$. with $12 \mathrm{lb}$. of corrosive sublimate) ziij, alcohol $\zeta v j$, exposed for some time to the rays of the sun ; much used in gout, hypochondriasis, and nervous diseases. They have the remarkable property of losing their yellow colour in the sun, and recovering it in the shade.

Trncture of Iodine, $T$. iodii, $T$. iodinis. Iodine gr. xl, S. V. R. $3 \mathrm{j}$ : used in bronchocele, dose gtt. $\mathrm{x}$, in syrop and water, thrice a day; the dose is to be gradually increased to gtt. xv. and $\mathrm{xx}$. It will not keep, being soon converted into ioduretted hydroiodic acid, which however is perhaps equally effective.

Ether sulfurique Iodure. Iodine gr. v, ether sulf. $3 \mathrm{j}$ : dose at most gtt. $x$.

Alcoholic solution of iodine for testing. Iodine $3 \mathrm{j}$, alcohol $5 \mathrm{iiij}$ : used to discover starch in vegetables.

Sol. AlCoholique de DeUto-IOdure DE MERCuRE. Deutoiodure of mercury gr. xvj. wine spirit at $36 \mathrm{deg}$. Baume: dose $\mathrm{gtt}$. $\mathrm{x}$. to $\mathrm{xx}$.

Ether sulfurique avec le deuto-iodure de mercure. Deuto-iodure of mercury gr. xvj, ether sulf. 3jss: stronger than the alcoholic tincture.

Tinct. antimonir diaphoretici. Antim. diaph. lb. $\mathrm{j}$, salis petræ lb. iij, mix, keep in a strong melting heat for half an hour, pour into a mortar, powder, add while warm spir. vini tartarizati (alcohol, P. L.) lb. iij; digest three days: more elegant and fragrant than any of the other antimonial tinctures.

SALMON's Drops of LIFE, Gutte vite. Opii ziiij, water lb. viij, dissolve, simmer for three days, strain, evaporate to lb. $\mathrm{ij}$. Take croci in fœno $\bar{j}$, cast. Ross. 亏̈jss, coccinellæ, - rad. serp. Virgin. ana $\overline{5}$ ss, nuc. mosch., -zedoariæ ana $3 \mathrm{ij}$, camphoræ $3 \mathrm{j}$, tinct. antim. diaphoretici lb. $\mathrm{j}$; digest three or four days, then add the solution of opium, digest two days and decant : may be given from $\mathrm{gtt}$. $\mathrm{x}$ to $\mathrm{xl}$. A most excellent opiate.

2. T. castor ב̈viij, vini antim. aq. ana lb. j, opii, croci, ana $\tilde{\jmath}^{\mathrm{ss}}$, cocci 3 ij ; very inferior.

Tinct. succrin. Amber ziiij, in very fine powder, S. V. R. sxviij; digest in hot sand for several days, distil off half the spirit. 
Tixcr. Tabaci. Tabaci foliorum concisi jjss, camphoræ pulv. $3 \mathrm{j}$, spirit. rectificat., aq. destillat. āā 亏̄iv ; digere per dies octo et cola : as an anodyne; chiefly employed externally in painful affections and in inflammations of the eye.

FOR VETERINARY MEDICINES.

TINCTURE of Allspice. Jamaica pepper 8 oz., proof spirit 3 pints; dose half a pint diluted with 1 pint of water, in the gripes of horses.

\section{FOIR PERFUMERY AND COSMETICS.}

Essexce of AMBERgrise, Essentia ambra grisece, T. ambrce grisea. Ambr. gr. jj, S. V. R. žiij.

2. Amb. gr. $j^{s s}$, empty musk bags 3 ss, S. V. R. a pint.

3. Amb. gr. mosch. ana $3 i v$, sacch. alb. $3 j$; grind, add ol. caryoph. gtt. $\mathbf{x}$, bals. Peruv. gtt. $\mathrm{xx}, \mathrm{S}$. V. R. 2 pints; used as a perfume, and to add in small quantity to sweet scented spirits.

Tinct. of benjamin, Pectoral balsam of honey, T. benzoes. Benj. zij, S. V. K. lb. j; digest. - 2. Benz., styr. calam. ana 3 j S. V. R. zviij. -3. Benz. (or flor. benz.), styr. calam. ana $3^{\mathrm{ij}}$, essent. jasmini 3ss, ol. lign. Rhod. Эss, mosch., zibeth. ana gr. iiij, S. V. R. lb. ss ; used to perfume clothes, or evaporate in sick rooms, or to mix with rose water, \&c., to form extemporaneous milk of roses, as a cosmetic wash. fune.

Essence of circtte. Civette $\overline{3}$, S. V. R. lb.j; used as a per-

Essence royale. Ambergrise Gij, musk $\mathrm{ej}$, civette gr. $\mathrm{x}$, ol. cinnam. gtt. vj, ol. lign. rhod. gtt. iiij, kali pp. $3 \mathrm{ss}$; rub together, and add esprit de la rose, orange flower water ana $\bar{z} j s s$; aphrodisiac, a few drops in syrup of capillaire.

V'egetable extract. S. V. R. lb. jss, honey 4 oz., ess. of Bergam. jij, eau de melisse des Carmes lb. j.

Eau de Maréchuale. Mosch. gr. xx, ess. Berg., ol. lavand., ol. caryoph. ana $1 \mathrm{oz}$., ess. ambr. gr. 2 oz., ol. sassafr. gtt. xv, ol. origani gtt. xx, S. V. R. 4 pints. -2. S. V. R. lb. jss, ess. of violet 1 oz., ess. of Bergam., ess. of oillets, of each 3ij, orange-flower water $8 \mathrm{oz}$.

Eau de millefleurs. S. V. R. 4 pints, musk gr. x, ess. lemons

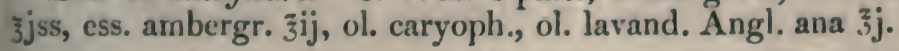

Essence of mush, T. moschi, Mosch. in gran. 3 ij, S. V. R. lb. j; used to scent other bodies.

Ess. of neroli. S. V.R. 8 oz., orange peel 6 oz., orrice root $3 \mathrm{ij}$, ambergris $\mathrm{gr}$. inj. 
Ess. d'aillettes. S. V. R. 8 oz., cinnam. 3 drachms, cloves 1 drachm.

Esprit de violettes. Flor. orrice root 4 oz., S. V. R. 2 pints; fragrant.

Ess. of violets. S. V. R. $8 \mathrm{oz}$, orrice root $2 \mathrm{oz}$.

Greenhough's tincture for the teeth. Amygd. amar. 2 oz., lign. Brass., bacc. cass. ana $3^{i v}$, ireos Florent. 3ij, coccin., sal. acetosel. ver. alumin. ana 3 j, S. V. R. 2 pints, spir. cochlear. 3iiij.

Ruspinis tincture for the teeth. Rad. ireos Flor. 8 oz., caryoph. arom. 1 oz., S. V. R. 2 pints, ess. ambr. gris. $1 \mathrm{oz}$.

Hudson's preservative for the teeth and gums. Tinct. myrrh.,

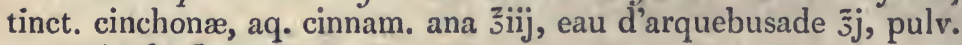
gum. Arab. ऊ̌ss.

Shaving liquid, shaving oil. Sap. moll. 4 lb., S. V. R. 5 pints.

Essence royale pour faire la barbe. Sap. Cast. 8 oz., proof spirit 1 pint.

Esprit de savon, Sp. saponis. Sap. Venet. ऊँvj, sal. absinthii §j. gum benzoes sss, S. V. R. Oviij,

2. Sapon. Aloensis rasi žviiij, sal. absinthii ziiij, aquæ q. s., dissolve, filter, evaporate nearly to dryness; add S. V. R. Ib. j, digest six days and filter : used for shaving.

\section{FOl TIE KITCHEN AND TABLE.}

Essence of celery seed. Bruised celery seed $2 \mathrm{oz}$., brandy a pint, steep for 14 days.

Ess. of allspice;-Ess. of cinnamon; Ess. of nutmeg;-Ess. of clove;-Ess. of mace; Ess. of marjomum. Oils of the spices $\frac{x}{2}$ an oz., spirit of wine 1 pint: used to flavour gravy or mulled wine.

- Ess. of ginger. Ginger, fresh grated, $3 \mathrm{oz}$., lemon peel $1 \mathrm{oz}$., brandy 2 pints; steep ten days.

Ess. of Cayenne pepper with brandy. Cayenne pepper $1 \mathrm{oz}$, brandy 1 pint; steep for 14 days, and strain.

Tincture of allspice; $-T$. of cinnamon;-T. of cloves; $T$. of nutmeg. Bruised spice $1 \frac{\mathrm{T}}{2} \mathrm{oz}$., proof spirit 1 pint; steep 14 days.

Tinct. of savory spice. Black pepper $1 \mathrm{oz}$., powdered allspice $\frac{r}{2}$ an oz., grated nutmeg $\frac{i}{4}$ of an ounce., proof spirit 1 pint ; steep 10 days.

Kitchiner's spirit of soup herbs. Lemon thyme, winter savory, sweet marjoram, sweet basil, of each $\frac{x}{2}$ an ounce., grated lemon peel, eschallots] 2 av. drachms, bruised celery seed 1 av. drachm, proof spirit a pint; steep 10 days. 
Essence of lemon peel. Lemon peel $6 \mathrm{oz}$., spirit of wine $8 \mathrm{oz}$; steep.-Several other essences are used partly as medicines, partly in cookery. See the Index.

Quintessence of lemon peel. Spirit of wine 1 pint, ess. of lemons $\frac{1}{2}$ an oz.; dissolve: used to flavour punch, soups, jellies, and the like.

Tincture of orange peel. Orange peel $3 \mathrm{oz}$, proof spirit 2 pints: makes a fine ratafia with sugar.

Brandy bitters. Gentian 3lb., orange peel 2lb., cardamoms llb., cinnamon $8 \mathrm{oz}$, cochineal 2 oz., spirit of wine 6 gall., water 5 gall.

Mock arrack, Vauxhall nectar. Rum 2 pints, flowers of benjamin 20 grains.

Peppermint cordial. Oil of peppermint 75 drops, sugar 1 oz., grind together, add spirit of wine 1 pint, then mix it with spirit of wine 10 pints, water 10 gall., and fine with alum $\frac{x}{2}$ an $\mathbf{o z}$.

USED IN THE ARTS.

Common varnish. Sandarac 8 oz., tereb. Venet. 6 oz., S. V. R. 2 pints.

Transparent varnish. Gum. junip. 8 oz., tereb. Venet. 4 oz., mastich 2 oz., S. V. R. 2 pints; used upon wood.

White rarnish. Gum. junip. 1 lb., Strasburgh turpentine 6 oz., S. V. R. 2 pints; used upon paper, wood, and linen.

White hard vamish. Mastich 4 oz., gum. juniper., ter. Venet. ana 3 oz., pounded glass (to prevent the gums from forming an impenetrable mass) 3 oz., S.V.R. 2 pints; used upon cards, sheaths, \&r.

White polishing varnish. Mastich in tears 2 oz., gum. juniper. 8 oz., gum. elemi 1 oz., tereb. Argent. 4 oz., S. V. R. 2 pints used upon metal, polished with pumice powder.

Transparent copal varnish. Spirit of wine, fully charged with camphire, 4 oz., cupal in fine powder 1 oz., dissolve, filter, add the filtered liquor to S. V. R. 1 pint, in which gum. elemi 1 oz. has been previously dissolved.

2. S. V. R. 1 pint, camphire $\frac{1}{2}$ an oz.: dissolve, pour it upon copal in small pieces $4 \mathrm{oz}$; ; heat it so that the bubbles that rise up may be counted; when cold, pour it off, and add more spirit to the residuum; used for pictures.

3. Copal, melted and dropped into water, 3 oz., gum. sandarac, $6 \mathrm{oz.}$, mastich 3 oz., tereb. Argent. $2 \frac{2}{2}$ oz., pounded glass 4 oz., S. V. R. 2 pints; used for metals, chairs, \&:c. 
. French polish. Shell lac 3 oz., mastich 1 oz., sandarac 1 oz., S. V. R. $40 \mathrm{oz}$; ; dissolve in a gentle heat, making up the loss by evaporation.

Crystal varnish. Gum. mastich 3 oz., S. V. R. 1 pint.

Mauger's varnish. Spirit of wine $4 \mathrm{oz}$. meas., camphire 3 ss, white resin and oil of rosemary, of each $3 j$; dissolve : both are used to fix pencil drawings.

Silver wash. Gum. sandarac 1 oz., mastich half an oz., gum. benzoin $3 \mathrm{ij}, \mathrm{S}$. V. R. half a pint.

Indian varnish. Shell lac, seed lac, of each 5 oz., S. V. R. 2 pints; dissolve with a gentle heat and strain.

Hard spirit varnish. Seed lac, yellow resin, of each $1 \frac{x}{2} \mathrm{lb}$, S. V. R. 2 gallons.

Soft spirit varnish. Common resin 3lb., seed lac 12 oz., S. V.R. 2 gallons.

Soft brilliant varnish. Gum. sandarac 6 oz., gum. elemi 4 oz., gum. anime 1 oz., camphor 3iv, S. V. R. 2 pints; used upon wood and pasteboard.

Reddish varnish. . Gum. sandarac 8 oz., laccæ in tabulis $2 \mathrm{oz}$, resinæ nigr. 4 oz., tereb. Venet. 6 oz., S. V. R. 2 pints; used upon wood and metals.

Lacquer. Seed lac, dragon's blood, annotto, gamboge ana 4 oz., saffron $1 \mathrm{oz}$., S. V. R. 10 pints.-2. Turmeric 1lb., annotto 2 oz., shell lac, gum juniper, ana 12 oz., S. V. R. 12 oz.-3. Seed lac $3 \mathrm{oz}$., amber, gamboge ana $2 \mathrm{oz}$., extract of red sanders $z_{\mathrm{ss}}$, dragon's blood 3 j, saffron 3 ss, S. V. R. 2 pints 4 oz.-4. Turmeric jvj, saffron gr. xv, S. V.R. 1 pint 4 oz.: draw the tincture, add gamboge $3 \mathrm{vj}$, gum. sandarac, gum. elemi ana 2 oz., dragon's blood, seed lac ana $1 \mathrm{oz}$.; used upon metals and wood to give a golden colour.

Red varnish. Sandarac 4 oz., seed lac 2 oz., mastich, choice benjamin ana 1 oz., turpentine 2 oz., S. V. R. 2 pints; used for violins and cabinet work.

Black varnish. Gum. sandarac 8 oz., resin fl. 4 oz., lamp black 2 oz., S. V. R. 4 pints.-2. Spir. of wine 1 pint, black sealing wax suff. to colour it.

Varnish for iron or wood. Wood tar 1 gallon, spir. of wine half a pint; dissolve.

White copal varnish. Spir. of wine half a pint, copal in powder $3 \mathrm{oz}$, white resin half an oz.; in another bottle put spir. of wine three quarters of a pint, larch turp. 3 oz., head benzoin half an oz.; in a third bottle put spir. of wine three quarters of a pint, sanda- 
rac $8 \mathrm{oz}$. mastich $1 \mathrm{oz}$; ; in a fourth bottle spirit of wine one quarter of a pint, and elemi an oz.: keep warm for two or three days, then strain off the clear tinctures and mix them together.

Black copal vamish. Mix the bottoms of the tinctures for white copal varnish together for black or dark work.

Tincture of Brazil wood, Stain for crocus. Ground Brazil 3lb., aq. kali 8 oz., melasses spir. 15 gall.; used as a dye.

Tinct. of red sanders, Spirit stain. Santal. rubr. 6 oz., melasses spirit 1 gall.; used as a dye.

Tinct. of turmeric, T. curcuma. From the root; used in dyeing the imitation Indian shawls yellow.

\section{SYRUPS.}

Syrups in general require $2 \mathrm{lb}$. av. of sugar to the pint. They are judged to be sufficiently boiled when some taken up in a spoon pours out like oil ; and when a thin skim appears on blowing upon the syrup, it is judged to be completely saturated; a bottle that holds $4 \mathrm{oz}$. Troy of water, ought to hold $4 \mathrm{oz} .3$ drachms of syrup, equal to spec. gr. $1 \cdot 321$, or 35 degrees Baume.

Most syrups should be kept in small bottles, capillaires, in a cool place, and only a small quantity brought into the shop for present use; the larger serving bottles of the syrups in common use may have conical corks, with a wire passing through them, and having a ring at top; this would be far better than the mere tin cover now used, which seldom prevents the access of the flies.

To make clear syrups, the sugar must be in a single lump, and be taken from the bottom or broad end of the loaf, for if powdered or bruised the syrup will be cloudy. In boiling syrups, if they appear likely to boil over, a little oil will prevent it, or rubbing the edges of the pan with soap. The heat of syrup when sufficiently boiled down is $221 \mathrm{deg}$. Fahr., and its density $32 \mathrm{deg}$. Baume. 'The whites of 2 eggs, with the shells, will clarify 2 or 3 pints of a decoction for making syrup; the shells are put in, not to lose the white that adheres to them.

FOR MEDICAI, USL.

Simple syrup, Syrupus simplex. Sugar $30 \mathrm{oz}$. Troy to the pint. This serves as a general formula for making syrups when no proportion of sugar is expressly given.

Syibup of Garlick, Syr. allii. Rad. allii lb. j, water lb. ij, sugar q. s.; expectorant, diuretic, $3 j$-3iij.

Syrup of marsh-mallows, Syr. ex althea, Syr. althea. 
Fresh roots $11 \mathrm{~b}$,, water 1 gall.; boil to one half, press out the liquor, let it settle, add white sugar lb. iiij, and boil to lb. vj.

Syr. althece officinalis. Fresh roots $\mathrm{lb}$. $\mathrm{j}$, water $\mathrm{lb} . \mathrm{x}$; boil to one half, add white sugar lb. iiij, and boil to a syrup; demulcent, ad libitum, in tickling coughs.

SYr. of HoRSE-RADISH JuIce, Syr. armoracice. Juice or horse-radish q. p., sugar q. s. to make a syrup; a spoonful swal lowed slowly, removes hoarseness immediately; a more simple and efficacious medicine than the syrupus de erysimo of the old editions of the $\mathbf{P}$. $\mathbf{L}$.

Syr. of MaIdenhaIr, Sirop de capillaire, Syrupus capillorum Veneris. Maidenhair $\overline{3} \mathrm{v}$, stick liquorice $\bar{z}^{\mathrm{ij}}$, boiling water $\mathrm{lb} . \mathrm{vj}$; steep for six hours, strai $n$, add white sugar $1 \mathrm{~b}$. $i j$.

Syr. pectoralis. Maidenhair $\tilde{3} \mathrm{v}$, stick liquorice $\tilde{\jmath}^{\mathrm{iiij}}$, boiling water lb. v, sugar q. s.

2. Maidenhair $1 \mathrm{oz}$, water 6 pints; steep, strain, add white sugar $8 \mathrm{lb}$,' boil to a syrup, adding, when cold, orange flower water $2 \mathrm{oz}$. Common capillaire is sold for it.

SYr. of crove PINKs, Syr. infusionis flomum caryophyllorum; Syr. caryophyllorum mubrom, Syr. caryophylli rubri, Syr. dianthi caryophylli. Fresh petals of clove pinks, the white points being cut off, lb. ij, boiling water 6 pints; infuse for 12 hours, strain, and add white sugar q. s.

2. Clove pinks 1 peck, white sugar $24 \mathrm{lb}$.; produces syrup $40 \mathrm{lb}$. and a half. Syrup of cochineal is sold for it.

SYr. of cochineat, Syr. coccinella. Cochineal $3 j$, sugar 2lb. $1 \mathrm{oz}$., water a pint; used as a red colouring syrup. Sold for syrup of clove pinks.

SYR. OF CLOVES, Syr. caryophyllorum aromaticorum. Caryoph. 亏iij, white wine $\mathrm{lb}$. $\mathrm{j}$; infuse, strain, and add sugar q. s.: stomsachic.

Srr. of crnnanon, Syr. de cinnamomo. Cinnam. ziij, boiling water $\mathrm{lb} . \mathrm{j}$; infuse, strain, and add sugar q. s.: stomachic.

Syr. corallin simplex. Red coral in powder 3iiij, juice of berberries lb. iiij ; filter, to each pint add white sugar lb. jss; to each lb. add syr. caryoph. rubr. (e. coccin.) ziv ; astringent $3 i j-$ $\xi \mathrm{j}$, in looseness.

Syr. of saffron, Syr. croci, P. L. before 1788. Croci 3 j, vin. Canar. lb. $\mathrm{j}$; infuse three days, press, and add sugar q. s. wine.

Syr. croci, P. L. since 1788. Made with water instead of

2. Croci $4 \mathrm{oz}$, coccin. $3 \mathrm{ij}$, boiling water 1 gallon; strain and add white sugar $12 \mathrm{lb}$. 
3. Croci 3 oz., coccin. jiv, boiling water 1 gallon, sugar $16 \mathrm{lb}$.

4. Croci in fono 6 oz., water 12lb., white sugar 28lb., produced 40lb.; cordial, but since it has been made with water, used only to colour medicines.

SYr. of QUINCEs, Syr. cydoniorum. Succ. cydon. defæcati lb. iij, cinnam. $3 j$, caryoph. arom., $2 z$. ana $35 s$; digest for six hours, then add vini rubri $l b . j$, sacch. albi $l b . x v$; astringent in looseness.

SYr. of LIqUorice. Rad. glycyrrh. §ij, adianth. alb. $3 j$, hyssop. 亏ss, boiling water lb. iij; steep for twenty-four hours, press, add mell. opt., sacch. alb. ana $\overline{3} x$, boil to a syrup; demulcent, ad libitum in coughs.

SYr. OF LEMON JUICE, Syr. e succo limonum, Syr. succi limonis, Syr. limonis. Juice, rendered clear by settling and subsequent filtering, 1 pint, white sugar lb. $\mathrm{ij}$.

Syr. citri Medice. Juice, rendered clear as before, 3lb., sugar 5lb.; cooling, expectorant, pleasanter than oxymel.

Syr. of MUlberries, Syr. e succo mororum, Syr. succi mori, Syr. mori. Is made in the same manner as the syrup of lemon juice.

2. Juice $7 \mathrm{lb}$., water $11 \mathrm{~b}$. , coccin. $3 \mathrm{j}$, sacch. alb. $16 \mathrm{lb}$.

3. Fruit 18 gall. produced juice $30 \mathrm{lb}$, sugar $35 \mathrm{lb}$.: produced 56lb. of syrup: grateful, cooling. Syrup of red poppies rendered blue by sulphuric acid is sold for it.

SYr. OF OPICM, Syr. opii. Extr, opii aquosi gr. xviij, boiling water $\overline{3}$ viij ; dissolve, add sugar q. s. -2. Opium pur. 2 oz. ziiij, water $201 \mathrm{lb}$., sugar $24 \mathrm{lb}$. ; boil to a proper consistence.-3. Extr. opii 3 iv, white sugar 10lb., water 6lb.-4. Extr. opii gr. xvj, sim. ple syrup $11 \mathrm{lb} .-5$. Simple syrup 3 j, tinct. opii gtt. xxv. Narcotic, 3ैss to $3 j^{j}$. Sold for the syrup of poppies.

Syr. OF Popples, Syr. de meconio, Diacodion, Syr. papaveris albi, Syr. papaveris, P. L. Poppy heads, without the seeds, 3xiv, boiling water $2 \frac{1}{2}$ gall.; boil to one half, press out the liquor with great force, boil again 2 pints, strain while hot, boil down to a pint, and dissolve in it white sugar lb. $\mathrm{jj}$.

2. Poppy heads, broken, 5!b. 4 oz., water q. s., sugar 35 lb.

3. Broken heads $12 \mathrm{lb}$., sugar $48 \mathrm{lb}$, produced $67 \mathrm{lb}$. : narcotic, 3 ij- $-\frac{2}{3} 5 s$, or more. As the preparation is so troublesome, syrup of opium is sold for it: beng dark-coloured many make it of treacle instead of sugar.

Syr. papaveris, P. D. Poppy heads lb. j, water lb. iij; boil, express, and evaporate to $\mathrm{lb}$. J, strain, add sugar q. s. to make a syrup. 
Syr. papaveris somniferi. Poppy heads lb. ij, water lb. xxx, sugar $\mathrm{lb}$. iiij.

Syr. of cowslips, Syr. efloribus paralyseos. Is made as the syrup of clove pinks; slightly narcotic.

Syr. of PEACH nlossoms, Syr. e floribus malorum Persicarum. Peach blossoms lb. j, warm water lb. iij; soak for a day, press out, and repeat the infusion with fresh flowers four times more; strain, and to three pints of the liquor add sugar $\mathrm{lb}$. ijss, boil to a syrup; mildly cathartic: used for infants.

Syr. of horehound, Syr. de prassio, Syr. marrubii. White horehound man. j, boiling water q. s. to strain a pint; infuse, strain, add sugar q. s. Is sold for any syrup of herbs that is demanded, and which is not in the shop.

Syr. of RED poppies, Syr. of corn roses, Syr de papavere erratico, Syr. papaveris erratici, Syr. rhceados. Scald and steep wild poppy flowers $\mathrm{ll}$. $\mathrm{j}$, in boiling water $3 \times$ viij, press out the liquor, let it settle, decant, and add white sugar lb. ijss.

2. Flowers $14 \mathrm{lb}$., water $48 \mathrm{lb}$., sugar $91 \mathrm{llb}$., produced 132lb.; narcotic, but principally used to colour medicines.

SÝr. of rhubark, Syr. de rhabarbaro. Rhabarb., fol. sennæ

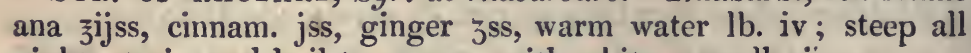
night, strain, and boil to a syrup with white sugar lb. ij.

2. Rhabarb. E. Ind., fol. sennæ, raisins ana 4 oz., ginger ziv, white sugar 9lb., water 1 gall.; cathartic.

SYr. of PALE Roses, Syr. rosaceus solutivus, Syr. rosarum solutivus. Liquor left in distilling 6lb. of damask roses, boiled down to 3 pints; let it settle for a night, decant, add white sugar $\mathrm{lb}$. $\mathrm{v}$, and boil it till it weighs $\mathrm{lb}$. viijss.

Syr. rosa, P. L. before 1809. Damask rose petals dried žvij, boiling water $\mathrm{lb}$. iiij; infuse, evaporate to $\mathrm{lb}$. $\mathrm{ijss}$, add sugar lb. vj.

Syr. rosa, P. L. since 1809 . The same, but made with pale rose petals.

Syr. rose centifolia. . Fresh petals $\mathrm{lb}$. $\mathrm{j}$, boiling water $\mathrm{lb}$. iv; infuse, add sugar lb. iij ; slightly purgative : used for children.

Syr, of red roses, Syr. de rosis siccis. Dried petals lb. ss, boiling water $\mathrm{lb}$. iv; infuse, strain with expression, add sugar $\mathrm{lb}$. $\mathrm{j}$, boil to a syrup.

Syr. rosa Gallice. Dried petals §̌vij, boiling water lb. v, sugar $\mathrm{lb} . \mathrm{vj}$; is slightly astringent, but more used as a red colour.

-SYr. of RUE, Syr. ruta. Rue man. j, boiling water q. s., to strain a pint, add sugar q. s.; antispasmodic. 
Syr. sarsaparille. Rad. sars. lb. j, aquæ 1 gall.; boil to 4 pints, and add sugar $\mathrm{lb}$. $\mathrm{j}$.

Syr. nosaceus solutivus cum sfinsa. Fol. sennæ zrj, sem. carui, sem. fœenic. dulc. ana jiij, infusion of damask roses lb. iij, sugar lb. ij.

SYr. sExx.E, P. L. 1815. Sennæ 亏̌ij, sem. foen. d. ろj, boiling water $\mathrm{lb} . \mathrm{j}$; infuse, strain, add manna $\tilde{z}^{\mathrm{iij}}$, sugar $\mathrm{llb}$ : purgative ; used for children $\jmath^{\mathrm{ij}}$ to $\mathrm{\jmath ss}^{\mathrm{s}}$.

Balsamic syrop, Syr. balsamicus, Syr. Tolutanus, P. L. 1788. Balsam of Tolu ǰviij, water lb. iij; boil for two hours in a still, and return what comes over; strain, and add sugar $31 \mathrm{xxx}$ : syrup of benzoin, or storax is sold for it.

Syr. Tolutanus, P. L. 1809. Bals. Tolu そj, water lb. j; boil in a close vessel, strain, add sugar lb. ij.

Syr. Toluiferce balsami. Simple syrup lb. ij, tinct. bals. Tolu วิj: M.

SYR. OF GINGER, Syr. zingiberis, P. L. before 1745. Root bruised ziij, white wine $1 \mathrm{lb} . \mathrm{j}$; infuse warm for three days, strain, add sugar $\mathrm{l} b$. jss.

Syr. zivgiberis, P. L. since 1809. Root sliced jij, boiling water $\mathrm{lb}$. ij, sugar lb. ij.

Syr. amomi zingiberis. Root sliced ziij, boiling water lb. iv, sugar lb. vijss ; carminative, stomachic.

SYr. of ciNCHONINE. Sulphate of cinchonine gr. xxxviij, simple syrup lb. $\mathrm{j}$; febrifuge.

Srr. of Magendie's Prussic acid, Sirop cyanique. Medicinal Prussic acid jj, simple syrup lb. j.

Syr. of EMETINe. Emetine gr. xiij, simple syrup lb.j; used as a syrup of ipecacuanha.

Syr. of pure emetine. Pure emetine gr. iij, simple syrup lb. j; dose a teaspoonful: emetic.

Syr. of gentianine. Gentianine gr. xiij, simple syrup lb. j.

SYr. OF LUPULINE. Tinct. of lupuline $\xi j$, simple syrup $\xi$ vij; the lupuline separates, hence the syrup must be well shaken when used.

Syr. or monphia. Acetate of morphia gr. iij, simple syrup Ib. j; narcotic, coch. min. $\mathrm{j}$, every three hours.

SYr. of QuiNine. Sulphate of quinine gr. iij, simple syrup lb. $j$; febrifuge, coch. vj, usually stops an intermittent.

SYr. of sUlphate of Morphia. Sulphate of morphia gr. iij; simple syrup lb. j; narcotic, taken alternately with syrup of morphia, for a change. 
Sinop D'HYDROCYANATE DE POTASSE.- Medicinal hydrocyanate of potash $3 \mathrm{j}$, simple syrup $\mathrm{lb} . \mathrm{j}$; used to form pectoral mixtures.

Syr. volatilis. S. V. R. 1 pint, white sugar as much as it will dissolve; stimulant, anti-emetic.

Syr. of GAIL, Syr. fellis. Tincture of bullock's gall 1 oz., simple syrup 1lb.; mix: stomachic, promotes digestion, in doses of $3 \mathrm{j}$.

Syr. of IPecacuanha, Syr. ipecacuanhe. Tincture of ipecacuanha in S. V. R. made as strong as possible, 1 oz., simple syrup $11 \mathrm{~b}$. ; mix : antidysenteric, expectorant, $3 \mathrm{j}$ to $3 \mathrm{ij}$, in larger doses $\xi_{j}$ to $\xi j s s$, emetic.

2. Ipecacuanha 1 oz., boiling water 1 pint; infuse, strain, add sugar $\mathrm{lb} . \mathrm{ij}$ : this is much weaker.

Sirup de cuisiniere. Rad. sarsap. lb. ij, rad. chinæ, lign. guaiaci ana lb. ij, aq. q. s. to strain lb. ij, add sacch. rubri, mellis ana $\mathrm{lb} . \mathrm{ij}$; to which some add corrosive sublimate, which is useless, as it is immediately changed to mercurius dulcis and precipitated.

Laudanum liquidum cydoniatum. Opii živ, croci $3 \mathrm{ij}$, succi cydonix lb. ijss, fermenti coch. iv. Ferment till the opium and saffron separate, then express and filter: to the liquor add cinnam. 3 ij, caryoph. arom., lign. aloes, santali flavi ana $3 \mathrm{j}$, digest fourteen days, filter and evaporate to one half : narcotic and anodyne, gutt. $\mathrm{x}$ to $\mathrm{xxx}$.

Braithwaite's genuine black drop. Opium sliced $8 \mathrm{oz}$, juice of crab apples 3 pints, nutmegs $1 \frac{x}{2}$ oz., saffron 3 jij; boil till smooth, add sugar 4 oz., yeast 2 table spoonsful; keep it near the fire for six or eight weeks, and then place it in the open air till it becomes a syrup; decant, filter, and put it into small bottles, adding a little sugar to each bottle: these quantities should produce about 2 pints : one drop is equal to four of tincture of opium, and does not affect the head nearly so much.

Abre Rosseau's drops, Guttce seu laudanum Abbatis Rosseau, Vinum opiatum fermentatione paratum. Mel. Narb. そxij, aq. calidæ lb. iij, set it in a warm place, and as soon as it ferments, add opii ziv dissolved in aq. $\zeta$ xij, let it work for a month, then evaporate to $\bar{x}$, strain, and add S. V. R. ̌̌ivss.

Neuman's liquid raudanum. Opium fermented with water, and not evaporated farther than to the consistence of honey. See his laudanum amongst Electuaries.

GodFrEX's condrat. Venice treacle, ginger ana 2 oz., S. V. R. 3 pints, ol. sassafr. $3 \mathrm{vj}$, water 3 gall., treacle $14 \mathrm{lb}$, tinct. Theb. 4 pints. 
2. Sassafras lb. j, zz. 4 oz., water 3 gall.; boil gently to 2 gall., add treacle $16 \mathrm{lb}$, S. V. R. 7 pints, tinct. Theb. 1 pint.

3. Opium 8 oz., ol. carui, ol. sassafr. ana 5 oz., treacle $56 \mathrm{lb}$, S. V. R. 1 gall., water $S$ gall.

4. Opium jiv, treacle $4 \mathrm{lb}$., boiling water 1 gall.; dissolve, add S. V.R. 2 oz., ol. sassfr. gtt. xl.

5. Sem. carui, sem. coriandri, sem. anisi ana 4lb., water q. s. ; distil 16 gall., to which add opium 12 oz., ol. sassafr. 4 oz., dissolved in S. V. R. 2 gall., proof spirit 5 gall., treacle 84 lb.: this is a good article.

6. S. V. R. 1 pint, tinct. opii 2 o\%,, ol. sassafr. „j jss, water 10lb., treacle $7 \mathrm{lb}$.

7. Sassafr. $\mathrm{j} i x$, sem. carui, sem. coriand., sem. anisi ana $\jmath_{j}$, aq. lb. vj; boil to lb. iv, strain, add treacle lb. vj, boil a few minutes, and when cold add tinct. opii ziij: anodyne, narcotic; chiefly used to prevent the crying of children, when in pain or starving.

Dalby's carminative. Tinct. opii zivss, tinct. ass. foet. 3ijss, ol. carui Эiij, ol. menth. pip. Эvj, tinct. castor. zvjss, S. V. R. $3 \mathrm{vj}$; put $3 \mathrm{jj}$ into each bottle with magnesia $j \mathrm{j}$, and till up with simple syrup and a little S. V.R.

Oxrack, Oxymel simplex. Honey lb. jj, white wine vinegar lb. j; dissolve.

Syr. acetosus. White wine vinegar $\mathrm{lb}$. $\mathrm{jj}$, white sugar $\mathrm{lb} . \mathrm{v}$; dissolve.

Syr. acidi acetosi. White wine vinegar lb. ijss, white sugar lb. iijss; boil to a syrup: diluted with water forms acidulous drinks and gargles.

Oxymer ex allio. Vinegar lb. ss, sem. carui, sem. fœn. dul. ana $3 i j$; boil, add garlick $\xi s s$, cuver, and when cold strain, then udd honey $\tilde{3} x$.

Oxyarel colcuici. Fresh roots $\xi j$, distilled vinegar $1 b . j$, soak for two days, press, to the liquor add honey lb. ij, and boil to a syrup; in asthma and dropsy $3 \mathrm{j}$, bis die, gradually increased.

Mec scill.e. Mel. lb. iij, tinct. scilla lb. ij.

OxyMer of squri.r.s, Oxymel scilliticum, O. scilla, Syr. scille. Honey lb. iij, aceti scillæ lb. ij; boil to a proper consistence.

STr. scrLi. Maritra.e. White sugar lb. iijss, aceti scilla lb. $i j$; expectorant, detergent, $3 i j$ to $3 i j j$; or in larger doses to clildren as an emetic.

OXYMEt, z. cremorf. tartari. Crem. tart. zij, mellis jxxiv, aqua Ovj; boil, in stone ware or glaśs, to the consistence of a syrup: for making electuarium gingivale. 


\section{FOR VETERINARY MEDICINE.}

Syrop of buckthorn, Syr. de spina cervina, Syr. spince cervina. Juice of buckthorn berries full ripe lb. iv ; steep ginger and allspice, ana jiv in 1 pint of it, then strain, boil the rest to lb. jss, mix the two liquors, and add sugar lb. iijss.

Syr. rhamni catharticr. Juice clarified by settling 2lb., white sugar $3 \mathrm{lb}$.

2. Juice 1 gall., brown sugar $12 \mathrm{lb}$.

3. Juice 3 gall., brown sugar 28lb., piment. 6 oz. zz. 4 oz., produced $381 \mathrm{lb}$; ; cathartic, but apt to gripe, $\xi s s$ to $\xi$ jss, seldom used but in clysters, except by the farriers, who employ it very liberally.

FOR THE KITCHEN AND TABLE.

Capillaire, Clarified syrup. White sugar 24lb., water 16 pints, boil nearly to a syrup, clarify with white of 3 eggs, scum, and finish the boiling, adding, while warm, orange flower water 1 pint.-2. Gum. tragacanth. 3 oz., water 2 gall.: boil, strain, and make it up 3 galls. ; add white sugar $24 \mathrm{lb}$., clarify with the white of 5 eggs, and then add orange flower water $2 \frac{x}{2}$ pints: this does not mix well with wine.-3. Lump sugar $8 \mathrm{lb}$., water 1 gall.; boil, scum, and clarify with the white of an egg, when nearly cold add rose water 1 pint, put it up in very dry warm bottles; it may be coloured with brandy colouring if desired: nutritive, restorative, an elegant addition to pump water in summer time; sold for sirop de capillaire.

Capillaire. Simple syrup 1 pint, curaçoa a wine-glassful.

Syr. of berberries, Syr. de berberis. Juice, cleared by settling, lb. ij, white sugar lb. jss, boil to a syrup.

Syr. of raspberries, Syr. rubi Idai. Juice lb. ij, sugar lb. iv zij ; dissolve: a grateful acid cooler.

Syr. of elderberries, Syr. sambucinus. Juice of the berries q. p. sugar q. s. to make a syrup.

Syr. of black currants, Syr. e ribis nigris. As syrup of lemon juice ; cooling.

Syr. of red currants, Syr. e ribis rubris. Press out the juice; strain, put it into a glass or china vessel, cover with paper in which holes are pricked, expose it to the sun for a fortnight, take off the crust at top, add to each $4 \mathrm{lb}$. of the clear liquor, 7lb. of sugar, and give it a quick boil : this preparation prevents any further fermentation.

Syr. of orange peel, Syr. e corticibus aurantiorum, Syr. corticis 
aurantii, Syr. aurantii, Syr. citri aurantii. Yellow part of Seville orange peel ${ }_{3} \mathrm{ij}$, boiling water $\mathrm{lb} . \mathrm{j}$; steep for a night, decant and add refined sugar $\mathrm{lb}$. $\mathrm{ijj}$. -2 . Orange peel $1 \frac{1}{2} \mathrm{lb}$., white sugar 24lb., water 2 gall.; stomachic.

Syr. of orange juice, Syr. e succo aurantiorum. Juice of oranges, strained and clarificd, lb. j, white sugar lb. ij : stomachic, drank in water; also used for making punch, and mixing with melted butter for puddings.

Syr. of lemons. Lemon juice 1 pint, white sugar $1 \frac{3}{4} \mathrm{lb}$, thin pared lemon peel 1 oz. -2 . Clarified syrup 1 pint, citric acid $\frac{8}{4} \mathrm{oz}$, lemon peel j oz.-3. Syrup of lemon peel $\frac{x}{2}$ pint, simple syrup $\frac{x}{2}$ pint, citric acid $\frac{x}{4} \mathrm{Oz}$.

Syr. of lemon peel. Lemon peel 3 oz., boiling water $1 \frac{1}{2}$ pint, steep for a night, strain, and add white sugar $2 \mathrm{lb}$.

Syr. of nutmegs, Syr. nucum moschatarum. Nutmegs ziij, white wine $1 \mathrm{~b} . \mathrm{j}$; infuse three days, strain, add sugar lb. jss; stomachic, stimulant.

Syr. of kermes, Syr. alkermes. Juice of kermes 1lb., white sugar $4 \mathrm{lb}$. : dissolve.

Alkermes. Bay leaves $1 \mathrm{lb}$., mace $11 \mathrm{~b} .4 \mathrm{oz}$., nutmeg and cinnamon of each $2 \mathrm{oz}$., cloves $3 \mathrm{vj}$, white cogniac brandy 28 pints, steep three weeks, strain, distil 24 pints, add syrup of kermes 18lb.: much used in Italy; every distiller's has a different flavour: this approaches very near to that of alkermes de Santa Maria novella.

Confectio alkermes. Sugar lb. j, rose water ${ }_{3} \mathrm{vj}$; dissolve, add juice of kermes $\mathrm{lb}$. iij, ol. cinnam. $\mathrm{Oj}$; the older recipes ordered a little gold leaf to float about in it, also musk and ambergris; stimulant.

Ratafia d'angelique. Angelica seeds $3 \mathrm{j}$, stalks of angelica, bitter almonds blanched ana $4 \mathrm{oz}$., proof spirit 12 pints, white sugar 2lb. ; digest, strain and filter : carminative.

Ratafia d'anis. Anise seed 2 oz., proof spirit 4 pints, sugar 10 oz. : it may be made of star anise seed.

Huile d'anis. Anise seed 2 oz., S. V. R. 4 pints, simple syrup 4lb.: tincture of vanilla may be added.

Anisette de Bourdenux. Sugar $9 \mathrm{oz}$., oil of anise seed gtt. vj; rub together, add by degrees S. V.R. 2 pints, water 4 pints: filter.-2. Cogniac brandy 6 pints, simple syrup 1lb., anise seed water $\frac{3}{4}$ pint.

Eau de vie d'Andayje. 'The same ingredients as the former, but less sugar and oil.

Ratafue de cuffé. Roasted coffce, ground 1lb., proof spirit 1 gall., sugar $20 \mathrm{oz}$; digest for a week. 
Ratafia de cassis. Ripe black currants 6lb., cloves 355 , cinnamon $3 j$, proof spirit 18 pints, sugar $31 \mathrm{lb} .8 \mathrm{oz}$; ; digest for a fortnight.

Ratafia des cerises. Morello cherries with their kernels bruised 8lb., proof spirit 8 pints; digest for a month, strain with expression, add sugar $11 \mathrm{~b} .8 \mathrm{oz}$.

Ratafia de Grenoble. Small wild black cherries with their kernels bruised 12lb., proof spirit 6 gall.; digest for a month, strain, add sugar 12lb., a little citron peel may be added at pleasure.

Ratafia de cacao, $R$. de chocolat. Caracca cacao nuts roasted 1lb., West India cacao nuts roasted $8 \mathrm{oz}$., proof spirit 1 gall.; digest for a fortnight, strain, add sugar $11 \mathrm{~b} .8 \mathrm{oz}$., tinct. of vanilla gtt. $\mathrm{xxx}$.

Clairet, Rossalis des six graines. The seeds of anise, fennel, dill, corriander, carui, and daucus Creticus of each 1 oz., proof spirit 4 pints, sugar 1 llb.

Ratafia de coings. Juice of quinces 6 pints, cinnam., 3iij, coriander seed bruised $3^{i j}$, cloves bruised $\mathrm{gr}$. xv, mace $3 \mathrm{ss}$, bitter almonds ziv, S.V.R. 3 pints; digest for a week, add sugar $21 \mathrm{~b} .8 \mathrm{oz}$.

Escubac, Usquebaugh. Saffron $1 \mathrm{oz}$, juniper berries jiv, dates without their kernels, raisins ana $3 \mathrm{oz}$., jubebs $6 \mathrm{oz}$, anise seed, mace, cloves, coriander seed ana $\bar{\jmath}$, cinnam. 3 ij, proof spirit 12 pints, simple syrup 6lb.; pectoral, emmenagogue.

Ratafia de framboises. Raspberries 8lb., proof spirit 4 pints, sugar $12 \mathrm{oz}$.

Ratafia de genièvre. Dried juniper berries not bruised 2 oz., proof spirit 4 pints, sugar $10 \mathrm{oz}$.

Ratafia de brou de noix. Young walnuts, whose shells are not yet hard, no. 60 , brandy 4 pints, sugar 12 oz., mace, cinnamon, cloves, ana gr. xv; digest for two or three months, press out the liquor, filter, and keep it for two or three years: stomachic.

Ratafia de noyaux. Peach or apricot kernels, with their shells bruised, no. 120 , proof spirit 4 pints, sugar $10 \mathrm{oz} .-2$. Reduce the S. V.R. to proof, with the juice of apricots or peaches, to make this liqueur.

Crême de noyaux. Bitter alnonds blanched 4 oz., proof spirit 2 pints, sugar $\mathrm{j}$ lb. - 2. Bitter almonds $4 \mathrm{oz}$., coriand. seed $3 \mathrm{ij}$, cinnam. $3 \mathrm{j}$, mace $3 \mathrm{j}$, linseed half an oz., gin or proof spirit 4 pints, white sugar 1lb. 8 oz., ginger $3 \mathrm{j}$, boiling water $2 \mathrm{lb}$., alum $3 \mathrm{ij}$.

Ratafia d'aillets. Clove pinks, the white heels pulled off, $4 \mathrm{lb}$., cinnamon, cloves ana gr. xv, proof spirit 1 gall., sugar $11 \mathrm{lb}$.

Ratafia à la Provençale. Striped pinks 1lb., proof spirit 2 pints, sugar $8 \mathrm{oz}$., juice of strawberries $11 \mathrm{oz}$., saffron $\mathrm{gr}$. xv. 
Ratafia d'écorces d'oranges. Fresh peel of Seville oranges 4 oz., proof spirit 1 gall., sugar 1lb. ; digest for six hours.

Ratifia de fleurs doranges. Fresh flowers of the orange tree 2lb., proof spirit 1 gall., sugar $1 \mathrm{lb} .8 \mathrm{oz}$. : digest for six hours only.

Huile de vanille. S. V. R. 2 pints, simple syrup 2lb., tincture of vanilla $\mathrm{q}$. s.

Syr. of vanilla. Vanilla $2 \mathrm{oz}$, in small pieces, powdered sugar $17 \mathrm{oz}$., water $10 \mathrm{oz}$., spirit of wine $\frac{3}{4} \mathrm{oz}$. ; rub down, add the white of an egg, cover the pot with a paper that has a pin hole in it, and keep it in a vessel of warm water for a whole day, let it stand 24 hours, and strain ; used to flavour liqueurs, and ices: $1 \mathrm{oz}$. is equal to ss of vanilla.

Vespetro. Angelica seed 2 oz., coriander seed 1 oz., fennel seed, anise seed ana $3 \mathrm{ij}$, lemons sliced, no. 2, proof spirit 4 pints, sugar $11 \mathrm{lb}$.

Ratafia à la violette. Flor. orrice root $3 \mathrm{ij}$, archel $1 \mathrm{oz} ., \mathrm{S} . \mathrm{V} . \mathbf{R}$. 4 pints: digest, strain, and add sugar $4 \mathrm{lb}$.

Fenouillette de Tíle de Rhé. Fennel seed 2 oz., herb of the same 8 oz., S. V. R. 2 pints, water 4 pints, sugar $10 \mathrm{oz} .-2$. White wine 60 gall., fennel seed bruised a handful, or a whole plant of fennel ; distil.

Elephant's milk, Urine d'éléphant. Benjamin 2 oz., S. V. R. 1 pint, boiling water $2 \frac{x}{2}$ pints; when cold, strain, and add sugar llb. 8 oz.

Ratafia de baume de Tolu. Balsam of Tolu 2 oz., S. V. R. 1 pint, boiling water 3 pints, sugar 1lb. $8 \mathrm{oz}$.

Citronelle, Eiau de Barbades. Fresh orange peel 2 oz., fresh lemon peel $4 \mathrm{oz}$., cloves $3 \mathrm{ss}$, coriander $3 \mathrm{j}$, proof spirit 4 pints; distil in B. M. and add white sugar p. æq.

Crême des Barbades. Orange peels, lemon peels, ana no. 3, cinnamon $4 \mathrm{oz}$., mace $3^{\mathrm{ij}}$, cloves $3 \mathrm{j}$, rum 18 pints ; distil in B.M. and add sugar p. æq.-2. Lemons sliced, no. 24, citrons sliced no. 6, S. V. R. 2 gull. 4 pints, fresh balm leaves 8 oz., water 3 gall. 4 pints ; digest for a fortnight, strain.

Ccdrat. Lemon peels no. 12, S. V. R. 2 gall.; distil in B. M. and add simple syrup p. req.

Parfait amour. The same, coloured with a little cochineal.

Marasquin de groseilles. Gooseberries quite ripe 100lb., black cherry leaves $12 \mathrm{lb}$.; bruise and ferment; distil and rectify the spirit : to each pint of this spirit add as much distilled water, and sugar $1 \mathrm{lb}$. 
Huile de Venus. Flowers of the wild carrot, picked, $6 \mathrm{oz}$., S. V. R. 10 pints; distil in B. M.; to the spirit add as much syrup of capillaire; it may be coloured with cochineal.

Eau divine. S. V. R. I gall., ess. of lemons, ess. of Bergamotte ana $3 \mathbf{j}$; distil in B. M. add sugar $4 \mathrm{lb}$, dissolved in pure water 2 gall., and lastly, orange flower water $5 \mathrm{oz}$.

Brandy shrub. Brandy 9 pints, lemon juice, orange juice ara 1 pint, orange peels no. 4 , lemon peels no. 2 , sugar $21 \mathrm{lb}$, water 5 pints.

Rum shrub. The same, using rum instead of brandy.-2. Concrete acid of lemons 8 oz., water 5 gall., raisin wine 4 gall., rum 10 gall., orange flower water 4 pints, honey 6lb.-3. Orange juice 2 pints, rum 8 pints, sugar 1lb. $8 \mathrm{oz}$.

Punch shrub. Lemon juice or lime juice $1 \frac{x}{2} l b$. ; strain, and add white sugar 4lb., rubbing part of it upon 12 of the lemons to get off the yellow peel before squeezing them, rum 4 pints: used to make punch by putting half a pint into 2 pints of hot infusion of tea; it will take about 25 lemons, or twice that number of limes.

Lemonade shrub. Juice of 8 lemons, juice of berberries $3 \mathrm{oz}$., white sugar half an oz., white wine half a pint; may be diluted at pleasure to make lemonade or sherbet. In hot countries use orange juice, as lemoh or lime juice is apt to produce cholera.

Curaçoa. Melasses spirit 1 gall., Seville orange peel cut thin, dried, and powdered, $1 \mathrm{lb}$., steep fourteen days; strain, add simple syrup 1 gall.

Creme d’orange. Oranges sliced no. 36, S. V. R. 2 gall., sugar $18 \mathrm{lb}$, water 4 gall. 4 pints, tincture of saffron $1 \mathrm{oz}$. jiv, orange flower water 4 pints; digest for a fortnight, strain.

Sportsman's cordial, Eau de chasseurs. Peppermint water, S. V. R. of each 1 pint, white sugar $8 \mathrm{oz}$.

All the above liqueurs are stimulant, and taken ad libitum for pleasure.

Liqueurs are also made by adding Hungary water, honey water, eau de Cologne, and several other spirits, to an equal quantity of simple syrup, or common capillaire.

Hippocras. Canary, Lisbon ana 12 pints, cinnam. 2 oz., canel. alb. 3iv, caryoph., macis, nuc. mosch. zingib., galang. ana $3 \mathrm{j}$; digest three days, strain, add white sugar $40 \mathrm{oz}$.

Elixir de Garus. Myrrh, aloes ana 3 jss, cloves, nutmegs ana 3 iij, saffron 3 j, cinnamon 3 vj, S. V. R. 1 gall.; distil 9 pints, then make an infusion of maidenhair $4 \mathrm{oz}$, liquorice root 3 iv, figs 3 oz., in boiling water 1 gall.; strain with expression, dissolve in it 
white sugar $12 \mathrm{lb}$, add orange flower water $12 \mathrm{oz} .:$ to each pound of this syrup add half its weight of the distilled spirit, and keep it for some time in a cellar.

2. Myrrh. jiv, aloes, croci ana $3 \mathrm{ij}$, cinnam., caryoph., nuc. mosch. ana $3 \mathrm{j}$, proof spirit 2 pints; make a tincture, strain, add syr. capilli Veneris lb. ij, aq. flor. aurant. 3 xij.

Huile liquereuse des fleurs d'oranges. Orange flower water, simple syrup ana p. æq.

Huile liquereuse de la rose, Julepum rosatum. Rose water, simple syrup ana p. æq.

Colour for brening, Brandy colouring, Essentia bince. Brown sugar melted until it begins to grow bitter, and then made into a syrup with lime water: used to colour liquors.

Brozning. Lump sugar 8 oz., water a table spoonful; heat it to a brown colour; add salt $1 \mathrm{oz}$., and dilute with water to the thickness of Japan soy: used to colour sauces.

Raspberry vinegar, Oxysaccharum mubi Idai. . Raspberries 3lb., vinegar 2 pints, white sugar $3 \mathrm{lb}$. : produce 3 pints of vinegar.

FOR USE IN THE ARTS.

Solution of burnt sugar. Burn white sugar until the vapours are copiously disengaged, and the brown, almost black, matter sticks to the vessel; add warm water to form a solution, to every oz. measure of which add spirit of wine 3 jss to keep it : when used, dilute it with more water that the shade of colour may be perceived: used as a measure of the discolouring power of charcoal.

Syr. of red cablage, Syr. brassica rubra. Juice of red cabbage lb. ij, sugar lb. v, make a syrup; some steam the leaves before they press them.-2. Leaves q. p. boiling water q. s. to cover them ; infuse, strain, add sugar q. s.; pectoral, much used in some places.

Syr. of violets, Syr. violarum, P.L. before 1745. Fresh flowers lb. j, boiling water lb. ijss; infuse for a day, press out the liquor ; in every 2 pints dissolve sugar lb. iv ; scum, and boil to a syrup.

Syr. e succo violarum. Juice expressed from the flowers $1 \mathrm{~b} . \mathrm{j}$, sugar lb. ij, or rather more ; boil to a syrup.

Syr. violarum, P. L. since 1745, Syr. viola, Syr. viola odorata. From the infusion strained through a fine cloth, carefully avoiding the least pressure.

The syrups of logwood, columbine flowers, purple flag, bluebottle, litmus, red cabbage, and even indigo scented by iris root, 
are sold for it : that of indigo does not strike red with acids. $\mathrm{L}_{\text {s }}$ ed as a colouring syrup, or gentle laxative for infants; but mostly as a test for acids.

\title{
XII. COMPOUNDS,
}

\author{
NEITHER LIQUID NOR OILY.
}

CONSERVES.

IN making conserves, the sugar requires the same attention as in making syrups; and when made, the conserves should be put into a stone pot, covered only with a paper, and let to stand two or three weeks in the sun, stirring them once or twice a week.

\section{FOR MEDICAL USE.}

Mec hexceboratum, Rad. helleb. alb. lb. j, water lb. iv ; soak, boil, press out the liquor, strain again, add honey lb. iij, and boil to a proper consistence; cathartic, in mania.

Honey of Roses, $\mathrm{Mel}$ rosatum, $M$. rosaceum, $M$. rosa. Dried red roses §iv, boiling water $\mathrm{lb}$. ij ; infuse, strain, add honey lb. $\mathrm{y}$, and boil down : used in cooling detergent gargles.

RoB DYACARYoN. Juice of green walnut husks $4 \mathrm{lb}$, honey 2lb.; boil down : stomachic 3 j to 3 ss: about 50 walnuts yield 2 pints of juice.

Ron dramorum. Juice of mulberries $4 \mathrm{lb}$, honey $2 \mathrm{lb}$.; boil down : cooling.

Conserve of Wormwoop, Conserva absinthii maritimi. Leaves lb. $\mathrm{j}$, sugar lb. iij ; heat or grind into a conserve : tonic stomachic.

Cons. cochla stimulant, antiscorbutic.

Cons. of Hirs, Cons. cynosbati, Cons. fructus cynobasti, Confectio rose canince. Fruit carefully separated from the seeds and their down lb. j. sugar $5 x x$.

Cons. rose canrase. Fruit pulped lb. j, sugar lb. iij; cooling.-2. Hips $231 \mathrm{lb}$., before pulping, after being pulped and beat up with white sugar $216 \mathrm{lb}$, produced $388 \mathrm{lb}$.

Cons. of mint, Cons. menthe foliorum, Cons. menthe sativa. Leaves lb. j, sugar lb. iij; allays vomitting.

Cons. of red roses, Cons. florum rosarum rubrarum, Cons. florum rosa rubra, Cons. rose rubre, Confectio rosa Gallica, Cons. rosa Gallica. Petals lb. j; sugar lb. iij; astringent. 
Cons, of rosemary, Cons, roris marini.

CoNs. OF RUE, Cons. rute foliorum,

Cons. of orange PEEL, Cons. corticum aurantiorum, Cons. flacedinis corticum aurantiorum Hispalensium, Cons. corticis exterioris aurantii Hispalensis, Confectio aurantiorum, Cons. aurantii, Cons. citri aurantii. Yellow part of the peel of Seville oranges Ib. j, sugar lb. iij ; stomachic.

MarMalade of slozs. Pulpa prunorum sylvestrium condita, Cons. prunorum sylvestrium, Cons. prunce sylvestris. Soften the sloes by simmering them over the fire in a little water, taking care they do not burst, pulp them through a sieve, add to the pulp three times its weight of sugar; astringent.

Cons. ari. Fresh roots lb. ss, sugar lb. jss ; diuretic, attenuant.

Cons. scilla. Fresh squills $\tilde{3} j$, sugar $气 x$; diuretic, attenuant.

FOR THE TABLE.

BARBERRY JELLY, Rob de berberis. Juice of barberries strained 1 pint, sugar ${ }_{3}^{z} \mathrm{vj}$; boil down to a jelly.-2. Juice and sugar ana p. æeq.; boil down: refrigerant.

Kentish cherry jelly, Rob de cerasis. Kentish cherry juice, strained, 1 pint, sugar $\_\mathrm{vj}$; boil down: refrigerant.

Cornelian cherry jelly, Rob de cornis. Cornelian cherries lb. j; boil in a little water, pass through the sieve, add sugar $\tilde{3} \mathrm{vj}$, and boil down.

Quince jelly, Rol cydoniorum. Juice of quinces, cleared by settling a while, lb. vj; boil to lb. ij, add sugar $̧ v j$, and boil down.

Quince marmalade, Diacydonium. Flesh of quinces, boiled soft in water, lb. viij, white sugar lb. vj, boil to a jelly, and pour into moulds.

Rob prunorum acidorum. Unripe plums $8 \mathrm{lb}$, white sugar $7 \mathrm{lb}$.

Currant jelly, Rob de ribes. Juice of red currants lb. j, sugar 3vj; boil down; a sieve of currants produced 12lb. of juice,-2. Juice of red currants, white sugar ana p. xq., stir it gently and smoothly for three hours, put it into glasses, and in three days it will concrete into a firm jelly.

Rob of elderberries with sugar, Rob baccarum sambuci cum saccharo. Juice lb. iiij, sugar lb. j; boil down: detergent, used in, gargles._2. Juice 16 gall., sugar 87., produced $130 \mathrm{lb}$.

Apple jelly. Apple juice strained lb. iiij, sugar lb. ij; boil to a jelly.

Strawherry jelly. Juice of strawberries lb, iiij, sugar lb. ij; boil down. 
Gooseberry jelly. Dissolve sugar in about half its weight of water, boil; it will be nearly solid when cold : to this syrup add an equal weight of gooseberry juice, and give it a boil, but not long, for otherwise it will not fix.

Gooseberry jam. A sieve of red gooseberries, picked, weighed 22lb., which with 12lb. of white sugar, produced 26lb. of jam.

Damson cheese. Boil the fruit in water q. s. to cover it, and pulp through a very coarse sieve, to each pound add sugar $4 \mathrm{oz}$., boil till it begins to candy on the sides, then pour it into tin moulds. Other kinds of plums may be treated in the same way, as also cherries and several kinds of fruit.

Raspberry jam. Picked raspberries, white sugar, of each 14lb., produced $27 \mathrm{lb}$. of jam; 24 gall. of raspberies produced $17 \mathrm{lb}$. of juice.

Apricot jam. Flesh of apricots, white sugar, of each $2 \frac{1}{2} \mathrm{lb}$., produced $4 \frac{x}{2} \mathrm{lb}$. jam: 6 doz. apricots, stoned and pared, produced $2 \frac{\mathrm{r}}{2} \mathrm{lb}$. of flesh.

Scotch marmalade. Juice of Seville oranges 2 pints, yellow peel of the oranges cut small, yellow honey $2 \mathrm{lb}$. ; boil to a proper consistence.

Marmalade of hips. The hips of Rosa systyla and R. arvensis make a fine flavoured conserve, that may be used as an excellent sweetmeat.

Marmalade of wood sorrel, Cons. foliorum lujula, Cons. lujula. Leaves of wood sorrel Ib. j, sugar lb. iij; gratefully acid, of an elegant red colour, cooling.

Essence of lemon peel.-Ess. of Seville orange peel. Rub off the yellow rind of these fruits with hard white. sugar, and press the essence into a pot.

\section{ELEC'TARIES.}

Under the name of electaries physicians include all solid or pulpy mixtures of different substances which are not of an oily nature, but more or less soluble or diffusible in water. The name electarium has been usually written electuary ; but Cælius Aurelianus, the most ancient author who uses the word, writes it electarium. Gum tragacanth does not answer for electaries, as it renders them slimy when long kept.

\section{FOR MEDICAL USE.}

Electarium e baccis lauri. Fol. rutæ sicc., sem. carui, sem. petrosel. vulg., bacc. lauri ana §̌j, sagapeni zss, piper. nigri, castor. Russ. ana $3 \mathrm{ij}$, mel. $̧ \mathbf{x v}$. 
Confectio rute. Fol. rutæ sicc., sem. carui, bacc. lauri ana $\jmath_{j} \mathrm{ss}$, sagapeni $\mathrm{j}^{\mathrm{ss}}$, pip. nigri $3^{\mathrm{ij}}$, mell. $3 \mathrm{x} \mathrm{xj}$ : antihysteric, $j^{\text {ss }}$ to $3 \mathrm{ij}$; in clysters carminative, $\varsigma_{3} \mathrm{j}$ to $\mathrm{z}_{\mathrm{j}} \mathrm{ij}$, in flatulent colic.

Diacorallion. Corall. albi. - coral. rubri. - boli Armen. veræ - sang. draconis ana $3 \mathrm{j}$, margaritarum 3 ss, lign. aloes. - rosar. rubr. - gum. tragacanthæ, - cinnam. ana $3^{i j}$, ligni santali albi et rubri ana $\exists_{j}$, sacchari in aq. cinnam. tenui soluti four times the weight of the species; an elegant absorbent.

Diascordium, Electarium e scordio. Species e scordio cum opio lb. j, syr. papav. alb. lb. iij; alexiterial, antispasmodic, astringent $3 \mathrm{j}$ to $3 \mathrm{iij}$.

Mithridatium, Confectio Damocratis. Cinnam. 3xiv, myrrhæ, - agarici, - nardi Indicæ, - zz., - croci, - sem. thlaspis, - thuris, terebinth. Chiæ ana $3 \mathrm{x}$, junci odorati,- costi (or zedoar.), fol. malabathri (or macis), stoech. - piper. long. - sem. seselis, - succ. hypocist. - styr. colati. - opopan. - galbani col. - opobalsami (or ol. nuc. mosch. expr.), castor. Russ., ana $\jmath_{j}$, polii, -scordii, -carpobalsami (or cubeb.), pip. alb. - sem. dauci Cret. bdellii aua 3 vij, nardi Celticæ, - rad. gent. - fol. dictam. Cret. - ros. ros. rubr. - sem. petrosel. Macedon. - sem. cardam. min. - sem. fœenic. dulc. - gum. Arab. - opii colati (dissolved in wine) ana $3 \mathrm{v}$, rad. calam. arom. rad. valer. sylv. - sem. anisi, - sagapeni ana 3 iij, mei athamant. hyperici, - acaciæ (or terr. Jap.), ventrium scincorum ana 3 ijss, honey three times the weight of the species : astringent, narcotic,

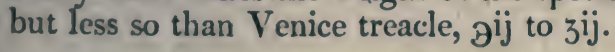

2. Cass. lign. 2 oz, gum. thuris,-zz. - croci ana 1 oz. $z^{i v ., ~ m y r r h . ~}$ - galbani, - styr. fol. scordii, sem. fœnic. dulc. - opii, - cal. aromat. - sem. anisi, - pip. longi, - cubeb. - castor. - valerianæ, - cardam. min. ana 1 oz. gum Arab. 3 oz., catechu 3 ij, honey q. s.

3. Species for mithridate $7 \mathrm{lb}$., honey $21 \mathrm{lb}$., S. V. R., water ana 1 pint.

Philonium Romanum. Piper. albi,-sem. hyoscyami albi

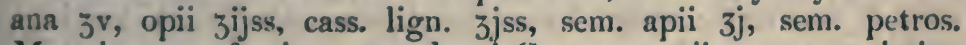
Maced. - sem. fœenic. - sem. dauci Cret. ana $9 \mathrm{ij}$, gr. v, croci $3 j \mathrm{ss}$, spicæ Ind. - pyrethri, - zedoar. ana gr. xv, cinnam. 3jss, myrrhæ, castorei ana $3 \mathrm{j}$, syr. papav. alb. q. s.

Philonium Loxdinexse. Piper. albi, - zz. - sem. carui ana ३ij, opii colati $3 \mathrm{vj}$, syr. papav. alb. boiled down to the consistence of honey $3 \times x 3^{i j}$.

Conf. opiata. Opii pur. duri $3 v j$, pip. longi, $-7 . z .-$ sem. carui ana $z^{3 j}$, syr. papav. alb. boiled down to the consistence of honey $3 \times x 3 \mathrm{ij}$.

Conf. opii, P. L. 1809. Opii duri 3vj, pip. longi $3 j$, zz. $z^{i j}$, 
sem. carui ziij, simple syrup $\mathrm{lb} . \mathrm{j}$ : stimulant, dose of philonium $3 j$ to $3 j s s$, of the confection only gr. $x$ to 3 ss.

Conf. opii, P. L. 1824. Add tragac. 3ij.

Venici. treacle, Theriaca Andromachi. Trochisci de scillâ lb. ss, piper. longi, - opii col. - viper. sicc. ana $\check{3}$ iij, cinnam. - opo balsami (or al. nuc. mosch. expr.) ana jij, agarici,-radicis iridis Flor. - herb. scordii., - flor. ros. rubr. - sem. napi, - extr. glycyrrh. ana 3 jss, nardi Ind. - croci, - amomi, -myrrhæ, - costi (or zedoariæ), junci odor. ana $\jmath_{j}$, rad. pentaph. - rhabarb.-zz, malabathri fol. (or macis), fol. dictam. Cret.-fol. marrub.-fol. calaminthæ,-stœech. -piper. nigri,-sem. petrosel. Macedon.-olibani,-terebinth. Chix.rad. valerian, sylv. ana $3 \mathrm{vj}$, rad, gent.-nardi Celt.-mei athamant.fol. polii,-fol. hyperici,-fol. chamæpityos,-sum. chamædryos cum semine,-carpobals. (or cubeb.), sem. anisi,-sem. fœnic. dul.sem. cardam. min. - sem. ammeos, - sem. seselis, - sem. thlaspis, succ. hypocist. - acaciæ (or catechu), gum. Arab.-styr. colati, : sagapeni colati, -terræ Lemn. (or bol. Armen., or bol. Gall.), vitrioli virid. calc. ana $\mathrm{ss}_{\mathrm{s}}$ rad. aristol. ten. (or arist. long.), summ. cent. min. - sem. dauci Cret. - opopan. - galbani col.-castor. Russ.bitum. jud. (or succin. alb.), rad. calam. arom. ana $3 \mathrm{ij}$, honey three times the weight of the species; stimulant, carminative, narcotic, $3 \mathbf{j}$ to $\xi s s$.

2. Pip. long. - cass. lign. ana 2 oz., croci, - zz. - gum thuris, sem. anisi, - sem. cardam. miri. - gum. stor. - sal. Martis, - gum. myrrh. - cubeb. - sem. foenic. dulc. - bol. Armen. ana 1 oz., fol. scordii. - castor, - calam. arom. ana 1 oz. ziiij, succ. Hispan. 3 oz., gum. Arab. 4 oz., opopan. - galban. ana 3iij, honey $6 \mathrm{lb}$.

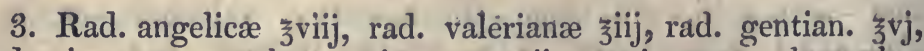
zedoariæ, - sem. cardam. min. - ana $3 \mathrm{j}$, croci, - succ. glycyrrh. myrrh-opii ana $\xi j$, honey $\xi l x x v$; the opium is to be dissolved in Sherry q. s.

4. Opii zij, piment. 4 oz., rhæi 1 oz., zz. 2 oz., gent. 8 oz., anisi 8 oz., fœnic. dulc. 8 oz., vitriol. vir. calc. ziv, ol. lauri $3 j$, mellis q. s.

5. Ext. bacc. junip. ziiij, myrrhæ (in vino Sherry solut.) rad. angelicæ, - rad. helenii, - rad. aristol. rotund. ana $3 \mathrm{ij}$, syr. cort. aurant. - syr. papav. albi ana $̧$ siij; mix.

Electarium opiatum, E. thebaiacum. Pulv. aromatici $z$ vj, rad. serpent. Virg. 亏iij, opii $\varsigma^{s s}$, syrop. zz. lb. j: the opium to be dissolved in Sherry q. s.

Confectio Paulina, C. Archigenis. Costi (or zedoar.), cinnam. - pip. longi, - pip. nigri, - styr. col. - galban. col. - opii col. castor Russ. ana そij, simple syrup boiled to the consistence of honey 亏xlviii. 
Sir Walter Raleigh's cordial, Confectio Raleighana, C. cardiaca. Sum. rorism. recen. - bacc. junip. ana 1lb., sem. card. min. - zedoar. - croci ana lb. ss, proof spir. cong. jss; make a tincture, strain, evaporate to lb. ijss, then add pulv. e chel. cancr.

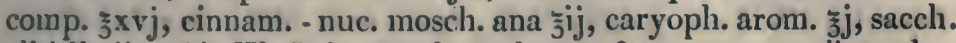
albi lb. ij. Sir W. R.'s own formula was far more complicated.

Conf. aromatica, P. L. Cinnam. - nuc. mosch. ana $3 \mathrm{ij}$,

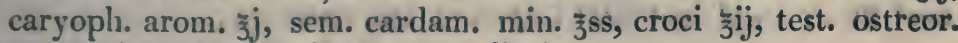
pp. ${ }_{3}^{3} \times v j$, sacch. alb. lb. ij, water lb. j.

2. Turneric 6lb., cass. (parvæ) 3lb., cardam. min.1lb. 8 oz., nutmegs 1lb., cloves 1lb., chalk ppd. 7lb.; grind together; to each $4 \mathrm{lb}$. of these species add saffron, $11 \mathrm{lb} .60 \mathrm{z} ., \mathrm{S}$. V. R. 3 pints, chalk ppd. 10lb., true oil of cloves $2 \mathrm{oz.}$, tinct. stomach. $8 \mathrm{oz}$., syrup of saffron 10lb.; the saffron should be the best Spanish, and infused for a week in the spirit of wine; when good, it will bear 14 or $16 \mathrm{lb}$. of chalk, and yet be of a good colour.

3. Rad. zedoar. 2lb., water 1 gall.; evaporate to 6 pints, add sugar 12lb., and when cold add gum. Seneg. $4 \mathrm{lb}$., rad. curcum. Chin. 8lb., nuc. mosch. 4lb., cassiæe parvæ 8lb., gran. Parad. 1lb., sem. cardam. min. 1lb., starch 6lb., chalk ppd. 21lb., corall. rub ppd. $7 \mathrm{lb}$, as also S. V. R. 2 pints, aloes, - cassix,-sem. cardam. min. ana 4 oz., nuc. mosch. 8 oz., croci in fono 1lb., pulv. chel canc. comp. $4 \mathrm{oz}$. : if the colour is not good, add kali ppd. 1 oz.

Conf. aromatica, P. D. Cinnam., nuc. mosch. ana $3 i j$, sacch. alb., croci ana $\jmath_{j}$, sem. cardam. min. caryoph. ana $3 \not j$, cretæ præecip. sij, syr. aurant. cort. q. s.

Elect. aromaticus. Pulv. aromat. p. j. syr. aurantii p. ij.

Diacassia cum Mania, Elect. e cassia, Elect. e casia, Confectio cassice. Pulp of cassia fistula lb. ss, mannæ 3 ij, pulp. tamarind. 3 ij, syr. rosarum lb. ss.

Elect. cassice. Syr. cort. aurant. used for syr. rosarum.

Elect. cassia fistula. Pulp. cass. fist., pulp. tamarind., mannse ana p. j., syr. rosar. Dam. lb. iij.

Syrupus senc.e, P.D. Sennæ $z$ ss, boiling water $l b . j$; infuse, strain, add manna, sugar ana lb. j.

Syr. senna, P. L. 1809. Senna қj, sem. fonic. dul. зj, aq. ferv. lb. $\mathrm{j}$ : infuse, strain, add manna, sugar ana $\mathrm{lb}$. $\mathrm{j}$.

These are of the consistence of soft manna, and not syrups.

Et.ect. ex meleboro. Rad. elleb. albi lb. j, aquar lb. xij; boil to lb. vj, strain, add honey lb. iij, and boil to the consistence. of honey; cathartic.

Lenitive electary, Elect. lenitivum, E. e scnna, Conf. senna. 
Sennæ zviij, figs lb. j, pulp. tamarind., pulp. cassiæ., pulp. prun. Gall. ana lb. ss, sem. coriand. ऊiiij, glycyrrh. ३iij, sacch. alb. lb. ijss; laxative $3 i j$ to $̧ s s$, or more.

2. Senna (parva) 4lb., coriander seed $2 \mathrm{lb}$., raisins 10lb., stick liquorice $1 \mathrm{lb} .8 \mathrm{oz}$., prunes $10 \mathrm{lb}$., tamarinds $10 \mathrm{lb}$., treacle $28 \mathrm{lb}$.

3. Figs $20 \mathrm{lb}$., prunes $14 \mathrm{lb}$., tamarinds $14 \mathrm{lb}$., cass. fistula $20 \mathrm{lb}$., white sugar $50 \mathrm{lb}$., stick liquorice $4 \mathrm{lb} .8 \mathrm{oz}$., senna $12 \mathrm{lb}$,, coriander seed 8lb.; produced 124lb. of elect. len. optimum.

4. Figs $49 \mathrm{lb}$., tamarinds $28 \mathrm{lb}$, treacle $56 \mathrm{lb}$., jalap $1 \mathrm{lb}$. ivory black 2lb., senna (parva) 10lb., coriander seed 7lb.; produced 140lb.

5. Tamarind. rubr., prunes ana 4lb., treacle 20lb.; boil well together, and add species made of senna 3lb., coriander seed $2 \mathrm{lb}$.

Elect. senna. Senna šiij, pulp. prun. Gall. lb. j, pulp. tamarind. zij, common treacle lb. jss, ol. carui zij.

Elect. cassia senna. Fol. sennæ 弓viij, sem. coriand. そiiij, rad. glycyrrh. zijj, figs, pulp. prun. ana lb. j, pulp. tamarind. lb. ss, sacch. alb. lb. ijss. - The pulp of apples is used for the others, and coloured with walnut rinds.

Contracting apothecaries' lenitive electary, Elect. lenitivum pro pauperibus. Fol. sennæ, - crem. tart. ana 3 jss, pulp. prun. 3 jss, syr. q. s. M.

Confect. senne comp. Sulphuris sublimati, potassæ super-

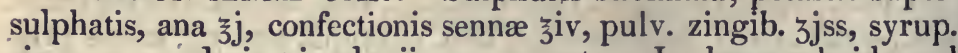
simp. q. s. ; dosis $3 j$ ad $3 \mathrm{ij}$, pro re nata. In hæmorrhoids and affections of the large bowels.

Confect. Menth. virid. Fol. recent. menthæ virid. jiv, sacchari purificat. そxii ; anti-emetic, in bolus and mixtures.

Caryocostinum. Scamm., hermodact., caryoph. arom., zz. ana $3 \mathrm{vj}$, ol. carui $3 \mathrm{j}$, honey lb. j.

Elect. e scammonio, P. L. 1745. Scammon. jjss, caryoph. arom., zz. ana $3 \mathrm{vj}$, ol. carui $3 \mathrm{ss}$, honey lb. ss.

Elect. e scammonio, P. L. 1788, Confectio scammonea. The same with syrop of roses instead of honey.

2. Scamm. Alepp., piment., rad. glyc. ana 12 oz., zz. $1 \mathrm{lb} .8$ oz., ol. carui 1 oz. jiv, ol. caryoph. ver. 3 ij honey $12 \mathrm{lb}$.

3. Rad. jalapæ, zz. ana 1 oz. 3iiij, scamm. 3vj, ol. carui $3 \mathrm{ij}$, ol. caryoph. ver. gtt. xvj, honey $1 \mathrm{lb} .8 \mathrm{oz}$. : purgative, $\mathrm{Jj}_{\mathrm{j}}$ to $3 \mathrm{j}$.

Elect. scammonii. Scamm., zz. ana 3j, ol. caryoph. arom. $3 \mathrm{j}$, syr. aurant. cort. q. s.

Confectio AMYGDALe, C. amygdalarum. Sweet almonds, blanched, $3 \mathrm{j}$, gum Arabic $3 \mathrm{j}$, white sugar $3 \mathrm{ss}$; used to make 
emulsions when required, by merely rubbing down with distilled water.

WARD's PASTE, Conf. piperis nigri. Piper. nigri, rad. enulæ camp., ana llb., sem. fonic. dulc. 3lb., honey, white sugar ana 2lb. ; for piles, and fistula in ano; dose the size of a nutmeg, three or four times a day.

Plukenet's ointment for cancer. Arsenic. alb. $-f$. sulph. - fl. ranunculi flammulæ, - $\mathrm{fl}$. contulæ fœtidæ, made into a paste with white of egg.

Conf. Japonica, Elect. mimosce catechu. Catechu 亏iiij, gum. kino 3̈iij, cinnam. - nuc. mosch. ana $\overline{3} j$, opii $3 \mathrm{j}$ (dissolved in Sherry q. s.), syr. rosar. rubr. boiled to the consistence of honey lb. ij žiij.

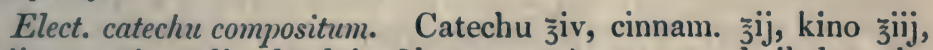
opii pur. jjss (dissolved in Sherry q. s.), syr. zz., boiled to the consistence of honey lb. ij 3 iij.

2. Catechu llb., cassiæ, pulv. nuc. mosch. comm. ana 4 oz., opii ziiij, syr. rosæ $7 \mathrm{lb.}$; astringent.

Fox Lungs, Lohoch e pulmone vulpium. Sperm. ceti, succ. glycyrrh. ana $8 \mathrm{oz}$., water q. s. to soften the liquorice and make an electary, add honey $3 \mathrm{lb}$., ol. anisi q. s. to flavour it rather strongly ; pectoral; used in coughs, although omitted by the college for more than a century, still retains its place in the public opinion : the druggists have substituted spermaceti for fox lungs.

MeL boracis, Mel subboracis. Borax $3 \mathrm{j}$, mel despum. $̧ \mathbf{j}$; detergent: used as a gargle in aphthx.

Unguentum Rgyptacum. Rough verdigris ppd. $\mathrm{v}^{\mathrm{v}}$, honey $\zeta$ xiv, vinegar $\jmath^{2} \mathrm{vij}$; boil to a proper consistence.

Mel Aiyyptiacum. Is the thin portion that separates from unguentum Egyptiacum by keeping.

Oxyser erugras, Linimentum aruginis. Verdigris $3 j$, vinegar žii ; dissolve, strain, add honey zxiv ; boil to a proper consistence; detergent, and used to keep down fungous flesh ; diluted, is used in gargles.

Smelis, olntment for the itch, T'apsimel, P. L. before 1745. Succ. chelidonii, - succ. tapsi barbati ana lb. ij, honey lb. ij ; boil down, add vitriol. virid. - alum. ust. q. s. to make an ointment ; used to cure the itch, by being exhibited as a suppository, or by merely smelling to the medicine.

MEL solutivum. Liquor left on distilling 6lb. of damask roses, cummin seed $\jmath_{j}$, moist sugar $1 \mathrm{~b}$. iv, honey $\mathrm{lb}$. $\mathrm{ij}$; boil down.

Eleosaccharus anisi. Ol. anisi gtt. xvj, sacch. albi mag. 
nesiæ albæ ana 1 oz.; rub together; to make extemporaneous anise seed water, by adding a few grains to a pint of water.

Er.zos. CARUi;-Elcos. cinnamomi;-Elcos. menthe viperite;-Elaos. pulegii. Are all made the same way.

Chelsea pensioner. G. guaiaci $3 j$, rhabarb. $3 \ddot{j}$, crem. tart. そj, fl. sulph. $३ \mathrm{jj}$, nuc. mosch. no. j, mellis lb. j: dose coch. maj. ij, night and morning in rheumatism.

NeUManN's oprum. Opii q. p. soak in water, scumming it carefully, then strain, add a little sugar, and set it in a warm place to ferment; when the fermentation slackens, it may excited again by stirring up the lees; continue this for some months until the fermentation can no longer be excited, then strain and evaporate to a pilular consistence; but it answers better given in a liquid than in a solid form: hypnotic and anodyne.

Extractuí seu raudanum cydoniatum. Opii lb. ss, succ. cydon. lb. vj, digest, filter, evaporate to an extract, adding ol. cinn., ol. caryoph., ol. macis ana gtt. $x$.

LANGelotT's PREPARED opium. Opii $1 b . j$, succ. cydoniorum lb. x., kali ppi. 弓jj, sacchar. ऊiv; ferment for some time, filter, and evaporate to the consistence of loney, upon which digest S. V.R.; filter, and distil off the spirit.

Extractum opit, (P. Wurtemberg, ) Opii 亏̌iv, aquæ comm. c. succo citri acidulatæ $1 \mathrm{~b}$. iv; boil, filter, and evaporate,

LUdoLPH'S MAGISTERY of opIUM, Magisterium opii Ludovici. Dissolve opium in vinegar, strain, and add subc. of potash water until the precipitation ceases; filter, and dry the precipitate.

Quercetan's opium. Dissolve opium in vinegar, filter and evaporate the liquor to the consistence of an extract. This electary is recommended by Horst, Sylvius, Langley and others, as milder than crude opium.

Graser's prepared opium. Digest opium in May-dew, filter and evaporate.

Opium pREPared with vinegar. Dissolve opium in vinegar; filter and distil off the acid, repeating this three times.

Glauber's prepared oplưm. Opii ऊiv, spir. salis zjss', cremor. tartari $\overline{3}$; mix, digest with S. V. R., filter, and distil off the spirit.

Electarium anthelminticun. Stanni pulv. ziij, conf. rosæ Gall. ऊss, syr. simpl: q. s.; dose a table spoonful every morning for three days; to be succeeded by a cathartic.

El. Catharticum. Conf. sennæ そjss, lact. sulph. そss, syr. rosæ q. s.; dose 3 j, three or four times a day, in piles. 
Ec. Demulcens. Sperm. ceti 3ij, pulv. trag. c. 3j, syr. papav. syr. Tolu. ana $3 i j$, conf. rosæ $3 v j$, sal nitri $3^{\text {ss }}$; dose size of a nutmeg frequently.

Ez. emmenagogicuir. Myrrhæ Эj, ferri ammon. gr. vj, syr. 22. q. S.; size of a nutmeg to be taken twice a day.

Er. strmolans. Gum. ammon. zj, aceti scillæ q. s. ut fiat emplastrum; to be applied to the pit of the stomach.

El. Dolicios. Pods scraped into syrop, till the hairs render it as thick as honey; dose a tea spoonful in the morning fasting, as a vermifuge, a purge being given a day or two afterwards.

Er. sulphuris. Fl. sulph. sss, elect. lenit. zij, salis nitri ziij, syr. cort. aurant. q. s.; in piles, dose $3 j$ to $3 i j$, bis terve die.

El. sulprurıs comp. Flor. sulph. 3̄ss, potass. supertart. 3 j, confectio sennæ $\bar{j}$ ij. confect. piperis nig. そjss, syrop. zingib. $3 \mathrm{j}$; dose $3 \mathrm{j}-3 \mathrm{ij} \cdot(. J . C$.)

El. sulphuris cum borace. ( $J . C$.) Flor. sulph. 3 j, pot.

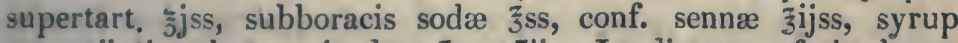
aurantii $3 j$, vel. q. s., in dose 3 ss $-3 i j$. In diseases of the lower bowels, and uterine organs.

El. terebintinise. Ol. tereb. rect. $3 j$, mellis 3̊ss; dose, coch. min. $\mathrm{j}$ to $\mathrm{ij}$, bis in die, in gonorrhœa.

Epithema ammoniaci. Gum ammon. ziij, solve in acetum scillæ q. s., cui adde extr. cicutæ $3 i j$, extr. Saturni $3 j$; for white swellings.

Ep. Goulardi. Cons. rosar. $ј$, mellis rosar., extr. Saturni, tinct. opii ana $3 \mathrm{ij}$; for painful and irritable ulcers.

2. Cremor. lactis $3 j$, extr. Saturni $3 j$; for erysipelatous inflammations.

Er. terebintuñ. Mellis, tereb. vulg. ana żj, far. tritici, q. s. : for chilblains.

2. T'ereb. comm. $3 j$, vitellum unius ovi; as a digestive to wounds.

Causticum comune c. opio. Potasse c. calce zij, opil pulv. jss, sapon. moll. q. s. to fungous ulcers.

Pasta epispastica. Canthar., farina tritici ana p. aeq., acet. q. 8. superior to blistering plaster.

Linctus demurcens. Sperm. ceti, pulv. trag. comp. ana 亏̌ss, syr. papar. q. s. ut f. linctus; dose a tea spoonful occasionally.

L. ExPECTORans. Oxym. scillæ, syr, althrese, mucil. gum. Arab. ana 3̄ss. 
L. strmulans. Mellis 3 j, ol. terebinth. $3 \mathrm{ij}$; dose a tca spoonful night and morning, with a draught of any weak drink.

L. potasse nitratis. Potas. nit. contrit. §jss, mellis rosæ そj, oxymellis simp, $z_{\text {ss. }}$ Misce. $3 \mathrm{j}$, subinde.

L. AcIDI MURIATICI. Mellis rosæ $z x$, syrop. rheados $3 i j$, acidi múriatici $\mathrm{m} \mathrm{xx}$.

L. oleosus. Olei amygdal.; syrup. mori, ana $z j$, conf. ros.

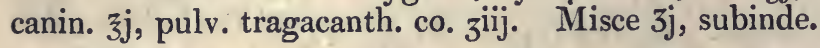

2. Olei olivæ, oxymellis scillæ syrup., papaveris, ana $3 j$. Dosis $3 \mathrm{j}$, subinde.

L. opratus. Syrup. papav. zij, mucilag. acaciæ ver. $3 \mathrm{j}$, confect. ros. canin. $3 \mathrm{j}$, acid. sulph. dil. $3 \mathrm{ij}$.

Cathartic suppository. Sapo dur. 3j. elaterii gr. ij; used when a powerful action is required.

Narcotic suppository. Soap $3 \mathrm{j}$, opium $9 \mathrm{j}$ ss; useful in nephritic pains.

Suppositorium vermifugum. Saponis duri $3 j$, aloes Socotr. gr. $\mathrm{x}$; to be introduced immediately after a stool.

Depilatory orntuent, Linimentum depilatorium. Calcis vivæ $3 j$, auripigmenti $3 j$, albumin. ovorum q. s. ; mix.

Sinafism. Horse-radish root fresh, flour of mustard, water; beaten into a mass.

Electarium ex carbone. Carb. lign. ziij. gum Arab. 3ij; sacch. albi 3j, aq. q. s.; a table spoonful added to clysters of bran, in dysentery and windy colic.

Opiatum antituberculosum, of Lepecq de la Cloture. Sperm. ceti,-ocul. cancr. - sulphur, ana $3 \mathrm{ij}$; conserv. rosar. $\xi^{s s}$; agarici

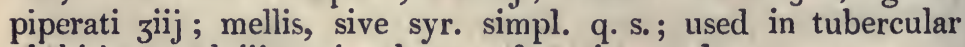
phthisis, gr. xlviij to 3 jss three or four times a day.

Moschus Reductus. Nuc. mosch., macis, cinnam., caryoph. arom., spicæ nardi ana p. æq. blood q. s.; beat it into a paste, dry in the sun, moisten it with musk water, and add 1-4th of pure musk.-2. Toasted bread, goat's blood, of each $2 \mathrm{oz}$., pure musk $1 \mathrm{oz}$; ; beat well together, and fill the bags.-3. Styrax, labdanum, lign. aloes pulv. of each $4 \mathrm{oz}$., musk, civette of each 3 iv ; mix. - 4. Musk, rad. angelicæ, goat's blood of each p. æq. - 5. Mosch, Chin. 4 oz., chocolate half an oz., ivory black quarter of an oz., sal tartari 3 j.

Ambra-grisea reducta. Ben nuts 3 oz., sperm. ceti 3 oz., benjamin, Flor. orrice root, starch of each $7 \mathrm{oz}$., asphaltum $1 \mathrm{oz}$., musk 3iv, ambergrise $6 \mathrm{oz}$., mucilage of gum tragacanth q. s. 
ZibeTHUM REDUCTUM. Civette q. p.; mix it with ox gall and storax.-2. Civette $18 \mathrm{oz}$., pulp of raisins $8 \mathrm{oz}$., musk $1 \mathrm{oz}$.; mix, and keep it in a warm place for three weeks or a month.3. Civette $20 \mathrm{oz}$., styr. liquid., honey, ox gall. pulp of figs of each $2 \frac{x}{2}$ oz., musk $1 \mathrm{oz}$.

Extr. cort. Perur. reductum. Cort. fraxini 30lb., gum. Arab. lb. j, cort. Peruv. small and gruffs from tinctures $30 \mathrm{lb}$.

Axsotto Reductum. Flag annotto 3lb., gum. trag. $2 \mathrm{lb}$. dissolve in water q. s. add soap, red bole of each 2 oz.

\section{VETERINAAY MLEDICINHS.}

CONFECTIO OPII FOR HORSES. Opium $1 \frac{1}{2}$ oz., macerate in warm water till it forms a thin paste, then add ginger powder 3 oz., carui seeds powd. allspice powd. of each 6 oz., treacle $24 \mathrm{oz}$.; mix. This is a good cordial for cattle; the above' will make about 20 doses of $2 \mathrm{oz}$. each, to be given in warm beer or an infusion of peppermint.

Theriaca Londinensis, Cataplasma e cymino. Sem. cymini lb. ss, bacc. lauri. - fol. scord. - rad. serp. Virg. ana żiij, caryoph. arom. $\jmath_{j}$, honey $\tilde{\jmath}_{\mathrm{j}} \mathrm{x}$ viij ; the old formula had opium in it, and was made up with syrup of poppies.

2. For cloves, put in twice the weight of allspice: at present mostly used by the farriers as an alexipharmic ; formerly given $3 i j$

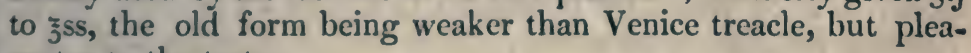
santer to the taste.

Mustard liniment for horses. Flour of mustard $2 \mathrm{oz}$, aqua ammonix $1 \mathrm{oz}$., water q. s. to give it the consistence of thin cream; mix, and rub on the belly in inflammation of the bowels.

Escharotic liniment, for farriers. Honey 4 oz., spirit of salt and verdigrise of each $10 \%$; mix.

\section{PERFUMERY AND COSMETICS.}

Coral dentifrice, El. gingivale. Oxym. e crem. tart. §xij, tinct. myrrh. rub. 亏̈iij. ol. cajep. gtt. $x$, ol. cinnam. gtt. $x x$; mix : for scorbutic gums. -2. Laccæe in glob. 3 ij, alum. Biiij, rad. irid. Flor., rad. bistortæ, flor. rosar, rubr., myrrhæ ana $3 i j$, mellis $q . s$. to make an electary.

El. dentifricium. Myrrh. $3^{\mathrm{iij}}$, crem. tart., cochin. ana $3 \mathrm{jss}$, caryoph. arom. $3 \mathrm{j}$, mellis ziiij; mix.

El. gingivale antiscorbuticum. Gum. lacc. in baculis, myrrhæ ana $3 \mathrm{j}$, mellis q. 8 .

El. ad stomacacen Spielmanni. Pulv. rad. ireos. Flor., pulv. 
sang. drac. of each ziij, alum. zij, myrrhæ, mastichis of each $3 j$, syr. Tolutanus q. s. to make an electary; in foul gums.

Almond paste. Almonds blanched 4 oz., lemon juice $2 \mathrm{oz}$, oil of almonds $3 \mathrm{oz}$., water $1 \mathrm{oz}$. proof spirit $6 \mathrm{oz} .-2$. Bitter almonds blanched 1lb., white of 4 eggs, rose water, S. V. R. ana q. s.

Brown almond paste. Bitter almonds blanched, pulp. of raisins of each 1lb., proof spirit q. s.: cosmetic, softens the skin, and prevents chaps.

FOR THE KITCHEN AND TABLE.

Almond paste for orgeat. Boil the almonds in water until the skin parts easily, strain, throw the almonds into cold water, blanch them, and dry either in the sun or stove till they are brittle; to each half pound of blanched almonds add as much Italian melon seed, steep in cold water 4 pints for five or six hours, strain off the water except about 4 or $5 \mathrm{oz}$., reduce them to a fine paste, adding powdered sugar $1 \frac{\mathrm{I}}{2} \mathrm{lb}$. This paste may be dried in a stove, that it may be kept for some time.

Almond paste, Pasta regia, P. amygdalina. Amygd. dulc. decort. lbj, amygd. amar, decort. $35 s$, sugar lb. j, aq. flor. aurant. q. s.; beat to a paste sufficiently stiff not to stick to the fingers.

Quince marmalade, Miva vel gelatina cydoniorum. Juice of quinces $\mathrm{lb}$. xij, boil to a half, add white wine lb. v; simmer away about 3 or 4 pints, let it settle, strain, add white sugar lb. iij, and boil till it fixes when cold.

Ready made mustard. Flour of mustard 3lb., salt 1lb.; make it up with raisin wine, and add 3 or 4 spoonsful of sugar to each pint. Must, i. e. grape juice, was formerly used, whence its name; used as a sauce._-2. Flour of mustard 8lb., wheat flour, bay salt, of each $1 \frac{x}{2}$ lb., Cayenne pepper $2 \frac{x}{2}$ oz., water q. s.3. Salt $1 \frac{\mathrm{x}}{2} \mathrm{lb}$, boiling vinegar 2 gall., scraped horse radish $11 \mathrm{~b}$., cover, and let it stand a day and night ; strain, and add flour of mustard q. s.

Patent mustard. Black ginger 12lb., common salt 18lb., water 15 gall., boil, strain; to each gall. add flour of mustard 5lb.

Moutarde à lestragon. Black mustard seed, dried until friable and then finely powdered, 1lb., salt $2 \mathrm{oz}$., made up with tarrigon vinegar. The French make about twenty-four other different flavoured mustards by mixing up the ground seed with different vinegars, but this is that mostly used; they are dark coloured, as being made from the powder of the whole seed, but in other respects far superior to the mustard made with the mixed powders sold for flour of mustard in England, in which a bright yellow colour is required. 
Solid essence of sprats, Extract of sprats. Essence of sprats 7lb., wheat flour, well dried, q. s. to give the consistence of cream, adding a little common bole to colour it, then evaporate in a steam bath to the consistence of butter.

Bittern. Extract of cocculus Indicus, extract of quassia, Spanish liquorice, calcined sulphate of iron; sold in large casks to brewers.

Multum. Extract of quassia, and liquorice root; used by brewers in licu of hops and malt.

Bitter balls, for brewers. Pulv. rad. gent. 8lb., extr. gent. 4lb., treacle q. s. to roll up in balls.

Flash. Extract of capsicum with sugar, but sold as burnt sugar and isinglass; used to colour brandy and rum, and make them appear stronger.

\section{USED IN THE ARTS.}

Composition for encaustic painting. Gum Arabic 9 oz., water a pint ; dissolve, add mastich in fine powder $14 \mathrm{oz.}$, boil to a paste, add white wax $10 \mathrm{oz}$., in small pieces, and whilst hot, add by degrees cold spring water 2 pints, then strain the composition, which will be like cream.

2. Mix mastich $24 \mathrm{oz}$, with the gum water, leaving out the wax, and when sufficiently heated and mixed over the fire, add by degrees cold water $24 \mathrm{oz}$., and strain.

3. Dissolve gum Arabic 2 oz., in water 24 oz., add 1lb. of white wax, boil over a slow fire, pour it into a cold vessel, beat it well together; when this is mixed with the colours, it will require more water than the others.

Used in painting, the colours being mixed with these compositions as with oil, adding water, if necessary ; when the painting is finished, melt some white wax, and with a hard brush varnish the painting, and when cold rub it to make it entirely smootl.

Blacking paste. Rape oil $3 \mathrm{oz}$, oil of vitriol $3 \mathrm{oz}$, mix ; the next day add treacle, ivory black, of each $3 \mathrm{lb}$., stone blue $6 \mathrm{oz}$., vinegar q. s. to form a thick paste: this will fill 1 doz. tin boxes. -2. Rape oil $3 \mathrm{oz}$., treacle, brown sugar ana $9 \mathrm{oz}$; mix, add ivory black 3lb., flour paste 2lb.; when the paste is quite smooth, thin it to the consistence of honey, with vinegar q. so: used for making blacking for leather.

Armenian cement. Soak isinglass in water until it is soft, then dissolve it in rect. spirit. In $2 \mathrm{oz}$. of this dissolve gum galbanum or gum ammoniac, of either gr. $x$, add 5 or 6 large tears of mastich reduced to a liquid state by rectified spirit. The cement must be kept closely stopped, and when wanted for use melted 
by putting the bottle in some warm water: used to cement stones to watch cases, also broken glass and china ; resists moisture very well.

\section{CATAPLASMS OR POULTICES.}

Cataplasma aluminis. Alum $\ni \mathrm{j}$, cons. rosar. $气$ jss, white of an egg; in ophthalmia.

Cat. car bonis lignt. Farinæ lini lb. ss, ligni carb. ppæ. žij, aq. ferv. q. s. ; in gangrene and fetid ulcers.

Cat. cicute. Cicutæ fol. m. ij, coque in aq. $1 b . j$, adde farinæ lini, vel avenæ q. s. ; in open cancer.

Cat. Dauci. Rad. dauci lb. ss, coque in aquæ q. s. ut sit mollis; in scorbutic ulcers.

Cat. Digitalis. Fol. digitalis sicc. そ̋ij (or fol. dig. rec. そiv), aquæ $\mathrm{lb}$. $\mathrm{ij}$, coque ad dimidium; strain, and with the decoction and linseed meal make a poultice for irritable painful ulcers.

Cat. efFervescens. Far. tritici lb. j, cerev. fermenti lb. ss; mix, expose to a gentle heat until it begins to ferment: in gangrene.

Cat. Goulardr. Extract. Saturni jjss, spir. vini rect. 3 ij, aquæ $\xi x i j$, micæ panis q. s.; in inflammations.

Cat. farine lini. Far. lini q. p. aquæ ferv. q. s.; smcar the surface with oil before it is applied: to promote suppuration.

Cat. panis. Micæ panis, far. lini ana p. æeq., lactis ferventis q. S.; for the same purpose.

CAt. rosæ. Cons. rosar. $\_$ij, alum $z_{\text {ss }}$ to $z j$; for weak eyes or chronic ophthalmia.

Cat. salis communis. Pulv. lini, micæ panis ana p. æq. aquæ sale communi saturatæ $q . s . ;$ in enlarged glands or wens.

Catr. salis Glauberi. Sal. Glauberi 3 j, aq. ferv. q. s. ; dissolve, add micæ panis q. s.; in inflammation of the eyes.

Cat. emeticum. Tabaci fol. $3 j$, aq. q. s. to beat up into a poultice; to be applied to the epigastric region.

\section{FOR VETERINARY MEDICINE.}

Cleansing poultice. Black soap 1lb., honey 8 oz., burnt alum $4 \mathrm{oz}$., verdigrise powdered half an oz., wheat flour q. s.; for the sore heels of horses, which are very foul.

1. Discutient poultice. Root of briony $3 \mathrm{oz}$, boil in water till soft, add gum ammoniac $4 \mathrm{dr}$., clissolved in vinegar q. s., sal ammoniac 3 dr., camphire 2 dr., dissolved in S. V. R. q. s. ; for hardness of tendons: superior to blue ointment. 
Emollant poultice. Linseed meal made into a poultice by pouring boiling water on it; when cold add a little lard or oil to prevent it from growing hard.

Healing poultice. Beut up 1 or 2 eggs with wheat flour to a proper consistence; for sores.

Repellent poultice. Vinegar, rape oil, of each p. xq., oatmeal q. s. to form a poultice; for fresh strains or bruises in horses.

2. The same, with a little alum dissolved in the vinegar, about 1oz. to the pint.

Resolvent Poultick. Vinegar, beer, of each p. æq., sal ammon. $2 \mathrm{oz}$., dissolve, and add oatmeal q. s.; to resolve coagulated blood in bruises.

\section{PILLS.}

These differ from the electaries as being solely designed for medicines, which are of a powerful nature, and whose doses must be determined with some accuracy. Although called pills, the greater number of them are kept in the shops in mass, and are only made into pills when wanted for use, or sale by retail. Boluses and the horse-balls, usually kept in the shops, are also included under this title, as they in fact differ only in magnitude. Pills are frequently ordered in old prescriptions to be gilt or silvered, which is easily done by placing them, as soon as made, at convenient distances upon a leaf of gold or silver, then cutting off the requisite portion, letting the pills and leaf fall into a very dry gallipot; and after covering it with a slip of paper and the hand shaking the whole for a moment or two; the leaf will thus adhere to the pills, but this ornament retards their solution in the stomach. - The size of pills varies in different countries : in England they are of the size of small peas, and about gr. $v$ each; the Germarıs make them very small, ordering 30 or 40 in common for a dose, so that they are nicknamed mice-turds, which, in fact, their pills resemble; the French, on the other hand, make them so large that they rescmble our boluses.

Horse balls should not exced the size of a pigeon's egg; they are often rolled in cylinders about one inch wide, and two inches and a half long; they should be wrapped up in the thinnest paper that can be procured.

FOIR MEDICAL USE.

A romatic: pills, Pilula diambre sine odoratis, $P$. aromatica. Aloes Soc. $\tilde{j}$ jss, gum guaiaci $̋$ j, species aromat., bals. Peruv. ana $\xi$ ss: in small doses diaphoretic ; in larger, purgative. Now 
mostly kept in powder, by the name of pulv. aloes comp. and pulv. aloes cum guaiaco.

Pil. coccie minores, P. ex colocynthide cum aloe. Al. soc., scammon. ana $亏$ ij, pulp. colocynth. $\zeta \mathrm{j}$, ol. caryoph. arom. $3 \mathrm{ij}$.

2. Aloes, pulp. colocynth., pulv. jalapii, ana 1lb., ol. caryoph. 2 oz., syr. spin. cervi q. s.

3. Scammon. Alep., jalapii, ana 1lb., pulp. colocynth., aloes Soc. ana 8 oz., kali vitriolati 2 oz., ol. caryoph. 2 nd. 1 oz., syr. spin. cervi 2lb. 12 oz. : cathartic, gr. $v-x$, or more.

Pil. aloes cum colocynthide. Aloes Soc., scammon. ana そ viij, colocynth. そiiij, ol. caryoph. arom., sulph. potassæ cun sulphure, ana $̋ j$.

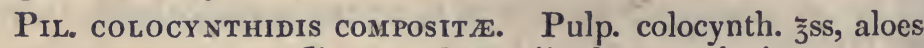
hepat., scammon. ana $3 \mathrm{j}$, sapo. Cast. $3 \mathrm{ij}$, ol. caryoph $3 \mathbf{j}$.

Aloe pills, Family pills, Antibilious pills, Aloe rosata. Aloes Socotr. 4 oz., succ. rosar. Damasc. $\mathrm{lb}$. $\mathrm{j}$; evaporate to a proper consistence.

Pil. ex aloe. Aloes Socotr. 3 j, extr. gentian. 3 ss, syr. zz. q. s. - Pil. aloes composita. Instead of the syr. zz. of the last, use ol. carui min. $x l$, and syr. simp.

Pil. aloes cum zingibere. Aloes hep. $३$ j, rad. zingib. 3 j, sapo. alb. $3 \mathrm{ss}$, ol. menth. pip. 3ss.

Pil. aloetica. Al. Socotr., sapon. allb. ana p. æq., syr. simp. q. s. ; cathartic, gr. $\mathrm{v}$ to $\mathrm{xv}$.

Coloquintida pills, Pil. $e$ duobus. Pulp. colocynth., scammonii, ana $\zeta \mathrm{j}$, ol. caryophill. arom. 3 ss, syr. de spin. cerv. $q$. s.

Pil. ex colocynthide simpliciores. The same, with a double proportion of oil of cloves. .

Female pills, Pil. ephractice. Pil. aromat. žiij, rhabarb., extr. gentian., sal Martis, ana $\bar{\jmath}$ j, sal absinth. $̌ s s$, syr. rosar. solut. q. s.

Pil. Bene dict Aloes Soc. 6 oz., galbani, assæfœtidæ, myrrh. ana $1 \mathrm{oz} . z_{\mathrm{iv}}$, macis, croci, ana $3 \mathrm{vj}$, sal Martis $9 \mathrm{oz}$, fol, sennæ 3 oz., ol. succin. rect. 1 oz. Emmenagogue, gr. v. to xv.

Fetid pilis, Pil. foetida, Pil. gummosce Pil. e gummi. Galbani, myrrhæ, opoponacis, sagapeni, ana $j^{j}$, asșæfœetidæ そss, syr. croci q. s.

Pil. galbani compositce. Omit the opoponax, and put in an extra そss of myrrh and sagapenum.

2. Galbani, myrrhæ, sagapeni, ana 12 oz., opoponacis 8 oz., gum. fœtidæ 6 oz., syr. croci llb. 8 oz. ; antispasmodic, gr. $x-3 s s$, bis terve die, in hysterics and nervous complaints. 
Pil. argenti nitratis. (Paris $H$.) Nitrate of silver gr. iij, gummous extract of opium 3 ss ; musk $3 j$, camphor $\ni^{i j}$, for 48 pills: two or three pills a day.

Pil. Balsamic.e. (Copland.) Balsam. Peruvian. jjss, myrrhæ Эij, assæfœtid., Galban., ana $9 \mathrm{j}$, pulv. capsici annui gr. xvj, magnesia ustæ q. s. Divide in pilulas xxxvj. 2 vel 3 bis terve in die. Diseases of debility, leucorrhæa, hysteria, \&c.

PiL. DE BRUCINe. Brucine gr. $x$, cons. rosar. 3 ss; fiant pil. xxiv, silver them.

Pil. de strycrinine. Strychnine gr. ij, cons. rosæ canin. jss ; fiant pil. xxiv, silver them.

Pil. DE veratrine. Veratrine gr. ss, gum. Arab. or syr. gum. Arab. q. s. ; ut fiant pil. vj: dose pil. j to iij, in a day.

Pil. de deutoiodure de mercure. Deutoiodure de mercure gr. j, extr. junip. gr. x, glycyrrh. rad. tritæ, q. s. ; ut fiant pil. viij ; dose pil. ij to iv morning and evening.

Pil. de protolodure de mercure. Protoiodure of mercury gr. j, extr. junip. gr. $x$, glycyrrh. rad. tritæ, q. s. : ut fiant pil. viij : dose pil. ij to iv morning and evening.

Pil. Avec l'oxide d'or. Oxid. auri per potassum gr. v ; extr. cort. mezerei 3 ij; fiant pil. lx.

2. Muriat. trip. auri gr. j; extr. cort. mezerei $3 \mathrm{ij}$; fiant pil. $\mathrm{lx}$. In scrofula pil. $\mathrm{j}$ to viij in a day.

Pil. ass.eføtide composite. Assæfoctidx; galbani, myrrhæ, an $\bar{j}$, ol. succini rect. $3 \mathrm{j}$, syr. simp. q. s.

Pil. aloes et asseffoctide. Aloes Socotr., assæfotidæ, sapon. alb. ana p. æq., mucilag. gum. Arab. q. s.

Gamboge pills, Pil. de guttu gamandra. Resinæ jalap., scammonii, gutt. gam., calomel. ana .̌ss, gum. ammon. วiij (dissol ved in succ. irid. nostr.), tartar. vitriol. $3 \mathbf{i j}$, mastich. $3 \mathrm{j}$, croci əj, ol. terebinth. gtt. xl, syr. spinæ cervinæ q. s.

Pil. cambogie composite. Gutt. gamb., aloes Socotr., comp. pulv. cinnam., ana $3 \mathrm{j}$, sapon. cast. $3 \mathrm{ij}$; dose gr. $\mathrm{x}$ to $\mathrm{xx}$.

Pil. hydragoge. Gum. ammon. žij, aloes Socotr., G. G. G. ana $3 \mathrm{ij}$, elaterii contriti $3 s s$, tinct. gentianæ $q$. s. to form pills of gr. ij each : violently cathartic; used in dropsy.

Rhubar bills, Pil. de rhaluarbaro. Rhabarb. jj, resin. jalap., tartar. vitriol. ana 3 ijss, ol. dist. nuc. mosch. 3 ss, extr. gentian. liq. q. s.

2. Rhabarb. 3 j, aloes Socotr. 3vj, myrrhae $3 s s$, ol. menth. pip. 39s, औyr. cort. aurant. q. s. ; stomachic, laxative,, $\mathrm{j}$, bis in die.

Rufus's PIL.s, Common pills, Pil. Thufi, P. L. lefore 1745 , 1.F2 


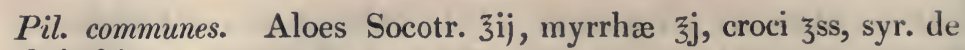
absinthio q. s.

Pil. Rufi., P. L. 1745. Pilula ex aloe cum myrrha. Aloes Socotr. $\zeta_{\mathrm{ij}}$, myrrh., croci $3 \mathrm{j}$, syr. croci q. s.

Pil. aloes cum myrrha. The same, but with simple syrup.

2. Aloes 1lb., myrrhæ $8 \mathrm{oz}$, , croci in fœno $2 \mathrm{oz}$., syr. croci $1 \mathrm{lb}$. $8 \mathrm{oz}$.

3. Aloes 1lb., myrrh. 6 oz., croci, pulv. curcuma veri, ana 3 oz., syr. croci q. 's.; stomachic, purgative, gr. $\mathrm{x}-$ Эj.

Pil. aloes et myrrha, P. E. Aloes hepat. $3 \mathrm{j}$, myrrh. $3 \mathrm{ss}$, croci 3ij, ol. carui $3 \mathrm{ss}$, syr. simp. q. s.

Pil. aloes et myrrhæ, P. D. Aloes Soc. ziiij, myrrh. zij, croci $\xi$ j, syr. simp. q. s.

Rudius's Pilts, Pil. Rudii. Pulp. colocynth. $3^{\mathrm{vj}}$, ras. agarici, rad. helleb. nigri, rad. turpethi, ana $̌$ ss, cinnam., macis, caryoph. arom. ana $3^{i j}, S$. V. R. $3 x$; digest four days, strain with strong pressure, add scammonii $\zeta$ ss, aloes Soctr. $3 j$; distil off the spirit till the remainder is left of the consistence of honey, and reduce this to a mass by farther evaporation. Cathartic, gr. $\mathrm{v}-\mathrm{xxx}$, ter die, till it operates : the original formula, esteemed one of the most certain purges known, and used when evacuation was difficult to be procured, but yet absolutely necessary.

Extractum catharticum. Pulp. colocynth. $3 \mathrm{vj}$, cardam. min. $\jmath_{s s}$, proof spirit lb. ; digest, express, and dissolve in the tincture aloes Socotr. 3 jss, scammon. $3 s s$, draw off the spirit, and reduce the remainder to a proper consistence.

Extr. colocynthidis compositum. P. L. before 1809. Pulp. colocynth. 3vj, proof spirit lb.j ; digest, press out the tincture, add aloes Socotr. 3jss, scammon. そss, distil off the spirit, adding towards the end cardam. min. 3 j.

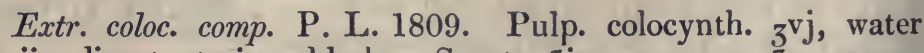
lb. ij ; digest, strain, add aloes Socotr. 3 jss, scammon. 3 ss, sapon. duri ziij, evaporate, adding as before, cardam. min. 3j.

Extr. col. comp. P. L. 1815. As the last, omitting the soap.

Extr. col. comp. P. L. 1824. As the formula in 1809, using proof spirit lb. $\mathrm{j}$ instead of the water.

Extr. col. comp. P. D. As the London 1809, using only lb. j of water, and adding the soap, reduced to a jelly by water, along with the cardamoms towards the end.

2. Colocynth. 15 oz., aloes Soc. 3lb., gum. scam. 10 oz., sem. coriand. 2 oz., dr. 4, proof spirit 2 gall.

3. Pulv. coloc. lb. jss, card. min. 4 oz., scamm., aloes hepat. ana $6 \mathrm{o}$. 
Storax pills, Pil. e styrace, P. L. before 1745. Styr. calam., olibani, myrrhæ, succ. glycyrrh., opii, ana §ss, croci 3 j, syr. papav. alb. q. s.

Pil. e styrace, P. L. since 1745 . Styr. calam. colati そ̌jij, croci $3 \mathrm{j}$, opii colati $j \mathrm{v}$.

Pil. e styrace, P. D. Styr. purif. ziij, opii pur. moll., croci, ana jj; $\mathbf{M}$.

Anodyne, gr. iij- $\mathrm{x}$; used in the coughs of aged persons as a night pill.

Common vight Pilis, Anodyne pills, Nepenthes opiatum, P. I. 1688. Extr. opii (made first with distilled vinegar, and then with proof spirit) $3 \mathrm{j}$, extr. croci (made with proof spirit) $3 \mathrm{j} s \mathrm{~s}$, castor. $3 \mathrm{j}$, tinct. spec. diambræ sine odor. (made of spec. 3 iv in S. V. R. q. s.) ol. nuc. mosch. gtt. $\mathrm{x}$; evaporate to a mass for pills.

Laudanum, P. L. 1720. The same, omitting the extraction of the opium with distilled vinegar.

Prl. Saponaces. Opii colati (moistened with wine) zss, sapon. alb. $3^{\mathrm{iv}}$, ess. limon. $3 \mathrm{j}$.

PIL. Ex opıo, Pil. opii. Opii purif. duri 3 ij, extr. glycyrrh. jj.

Pil. saponis cum opio, Pil. sapon. compositce. Opii sicc. pulv. $̌ s s$, sapon. alb. $\check{3} \mathrm{j}$; twice the strength of the pil. saponacere of the older pharmacopoir.

Pir. opinte, Pil. Thebaice. Opii žj, extr. glycyrrh. そviij, soften with proof spirit, add pip. Jamaica $\xi j$.

All these are anodyne, narcotic, gr. $\mathbf{v - x x}$; but the very different strength of the several formulæ must be considered : dissolve quicker in the stomach than storax pills, and better adapted for occasional exhibition : the omission of the extraction of the opium with vinegar, renders their action not so mild as the original prescription.

East Inda prids, Tanjore pills. Arsen. alb. $3 \mathrm{j}$, pip. nigri j.j; mix : used in confirmed lues, as a preventive of canine madness, and in elephantiasis.

Mercurial pill, The blue pill, Pil. mercuriales. Hydrar. $3 \mathrm{v}$, terebinth. argent. $3 i j$; grind together, add extr. cathart. iij 3 , rhabarb. $3 \mathrm{j}$.

Pil. EX hydRakgyro. Hydrarg. pur., extr. glycyrrh. ana 3ij, rad. glycyrrh. 3 j.

PIL. Hydargyri, P. L. and I). Hydrarg. pur. 3 ij, conserv. rosar. 3iij, rad. glycyrrh. 3j. 
2. Hydrarg. 12 oz., tereb. comm. q. s., rhabarb. 2 oz. 3ij, pulp. colocynth. $4 \mathrm{oz}$. Deobstruent, alterative, gr. $\mathrm{v}-\mathrm{xx}$, bis terve die, in syphilis, and most little known complaints.

Pil. hydrargyri, P. E. Hydrarg. pur., conserv. rosar. ana $う$ j, amyli zij, mucil. gum. Arab. q. s., and make the whole into 480 pills.

Belloste's PIlls. Hydrarg. 1lb., sacch. 4 oz., scammon. rad. jalap. ana 1lb., vini alb. q. s.: some use cream of tartar instead of sugar.

Calomel pills, Plummer's pills, The red pill, Pil. hydrargyri submuriatis, P. L: 1809. Calomel, sulph. antim. præcip. ana 3j, gum. guaiaci $3 \mathrm{jj}$, bals. Copaibæ q. s.

Pil. hydrar. subm. P. L. 1815. As the former, substituting mucil. gum. Arab. for balsam Copaibæ.

Pil hydrar. subm. compositce. Calom., antim. sulph. præc. ana 3ij, gum. guaiaci 3̌ss, S. V. R. そ̌ss.

James's analeptic pills. Pil. Rufi llb., calc. antimonii lotæ 8 oz., gum. guaiaci 8 oz.; M. and make 32 pills from each drachm.

2. Pil. Rufi, pulv. antimonialis, gum. guaiaci, ana $9 \mathrm{j}$; make into 20 pills with tincture of castor.

Anderson's Scots pills. Aloes Bbds. 1lb., rad. helleb. nigr., rad. jalapii, kali ppi. ana 1 oz., ol. anisi ziv, syr. simp. q. s.

2. Aloes B. B. 2 lb. 8 oz., water $8 \mathrm{oz}$; soften, add jalap., sem. anisi pulv., ebor. usti, ana $8 \mathrm{oz}$, ol. anisi $1 \mathrm{oz}$.

3. Aloes (Bermudas) 1lb., rad. jalap., flor. sulph., ebor. usti, rad. glycyrrh. ana 2 oz., ol. anisi 3j, G. G. G. zij, sap. Castil. 4 oz., syr. sp. cervin. q. s.

Hooper's pills. Vitriol. virid., aquæ, ana 8 oz. : dissolve, add aloes Barb. 2lb. 8 oz., canellæ albæ 6 oz., gum. myrrh. 2 oz., opoponacis 3 iv.

2. Sal. Martis 2 oz., pulv. aloes c. canella $1 \mathrm{lb}$, mucilag. gum. tragacanthæ, tinct. aloes, ana q. s. ; cut each drachm into 18 pills, put 40 in a box.

ScotT's Pills. Aloes B. 9 lb., pulv. jalap. 3lb., pulv. zingib. $8 \mathrm{oz}$., ol. anisi $\xi \mathrm{j}$, treacle $21 \mathrm{oz}$.

2. Aloes 1lb.; colocynth. 4 oz., scamm. half an oz., helleb. nigr. half an oz., G. G. G. half an oz., syr. q. s.

3. Res. jalap. そss, scamm. 3ij, aloes そ̌iv, ol. anisi gtt. $x x x$, pills $5 \mathrm{gr}$. each.

Matthew's pills, Pil. Matthai. Extr. opii, - rad. helleb. nigri. - rad. glycyrrh, - sapon. tartari, ana گiv, croci Anglici $\overline{3}$ viij : 
beat it up often, and if it becomes dry moisten it with ol. tereb. rect. Anodyne, gr. iij to gr. $x$.

Starkey's pills, Pil. Starkei. Extr. opii jiv, nuc. mosch, - bezoard. mineral, ana $\overline{3} \mathrm{ij}$, croci, - rad. serpent. Virgin. ana $3 \mathrm{j}$, sapon. tartari lb. ss, ol. sassfr. „̃ss, tinct. antimonii zij. Anodyne, superior to Matthew's pills, but not so much in use.

LockyeR's PILls. Panacea antimonii gr. $x$, sacchar. cand. alb. $\tilde{j}$ j, fiant pil. 100 ; one, two, or three taken at a time will work gently by vomit and stool. The formula for panacea antimonii is omitted in its place, and will be found in the corrections and additions.

IVard's antimonial pill. Glass of antimony, finely levigated, $4 \mathrm{oz}$., dragon's blood $1 \mathrm{oz}$., mountain wine q. s. make into pills of gr. jss each.

Dinner pills. Lady Crespigny's pills, Lady Webster's pills, Pil. stomachica Mesues, P. L. 1635, P. ante cibum. Aloes 3vj, mastiches, rosæ rubræ, ana $3 \mathrm{ij}$, syr. absinth. q. s. ; produce a bulky and copious evacuation.

Dixon's antibilious pills. Aloes, scammony, rhubarb, and tartar emetic.

Fothergill's pills. Aloes, scammony, coloquintida, and diaphoretic antimony.

Peter's pills. Aloes, jalap, scammony, gamboge, ana §̌jij.

2. Pulv. jalapii, aloes Barb., cambogiæ, scamm. ana $3 \mathrm{ij}$, calomel ppti. $\jmath_{j}$, S. V.R. q. s. to form a pill mass.

Speenraax's pills. Aloes, myrrh, rhubarb, extr. chamæm., ol. chamæm.

Barclay's antibilious pills. Exxtr. coloc. 3 ij, resin. jalapx $3 \mathrm{j}$, sap. amygd. 3 jss, guaiaci 3 iij, tart. emet. gr. viij, ol. junip., ol. carui, ol. ror. marince, ana gtt. iv, syr. rhamni q. s. to form 64 pills.

Barclay's antibilous mass. Extr. guaiaci žxxuj, sap. amygd. $\overline{3} x v i i j$, res. jalapii, scamm. Alepp., pulp. colocynth. ana ऊxij, tart. emet. $3 \mathrm{j}$, 3 vj, gr. viij, ol. caryoph. $3 \mathrm{j}$, ziij, ol. junip., ol. carui, ol. rorismar. ana $3 \mathrm{vj}, \partial_{j}$, gr. iiij, syr. e spin. cerv. q. s. to make a mass.

Pil. ARSEnicr. Arsen. alb. gr. j, sacch. albi gr. $x$, micæ panis q. s., fiant pil. $x$; tonic in periodical headachs, agues.

Pil. arsenici, P. U.S. Acid. arsenicosi gr. ij, opii gr. viij, saponis gr. xxij.

Prl. caromelanos. Calomel. gr. iij, jalapa gr.ix, muc. gun Arab. q. s., fiant pil. iij: to be taken at night. 
2. Merc. corros. subl. $Э \mathrm{j}$, hydrarg. $\xi \mathrm{j}$, gum. tragac. gr. xij, scammonii, jalapæ, ana $3 \mathrm{v}$, syr. simpl. q. s.; make into pills of gr. iv each: usually employed in syphilis, two or four pills every night. The sublimate is changed to calomel.

Pil. conir. Calomel. gr. ix, extr. conii 3 j, camphoræ zss, spir. rect. gtt. $v$, fiant pil. xxiv: two to be taken every three or four hours; in spasmodic difficulty of urine.

Pil. Ferri cum myrrha, Pil. ferri composite. Myrrhæ 3 ij, natri ppi., sal. Martis, sacch. albi, ana $3 \mathrm{j}$; tonic, emmenagogue, two or four thrice a day.

Pil. e scilla, Pil. scille composite. Scillæ rec. 3 j, zingib., sapon. duri, ana ziij, gum. ammon. $3^{\mathrm{jj}}$, syr. simp. q. s.

Pil. scillitic.x. Scillæ sicc. Эј, gum. ammon., sem. cardam., extr. glycyrrh. ana $3 \mathrm{j}$, syr. simp. q. s.

Pil. scilla cum zingibere. Scillæ pulv. 3 j, zingib. 3 ij, ol. anisi gtt. $\mathrm{x}$, saponis in gelatinam reducti q. s.; expectorant, two or four thrice a day.

Pil. terebinthine. Tereb. Chiæ $3 \ddot{j}$, Эj, rbarb. $3 \mathrm{j}$, bals. Copaibæ q. s.

2. Tereb. Chiæ, olibani, ana $3 \mathrm{j}$, sal. Martis j, bals. Copaibæ q. s. ; tonic, astringent, three or six, bis terve in ie, in gonorrhæa.

Bolus aluminis. Alum. gr. $x v$, cons. rosar. $Э j$, syr. cort. aurant. q. s., in fluxes.

Boz. моsch I. Moschi gr. xv, camph. gr. v, syr. q. s. ; in convulsive affections and in typhoid fevers.

2. Moschi, ammoniæ carb. ana Эss, cons. rosar. q. s.; every three hours in mortifications accompanied with spasms.

Bol. vitrioli ALBI. Vitr. albi pur. gr. xxv, cons. rosar. q. s. ; in camomile or green tea, when poison has been swallowed.

Pilule anthelmintice. G. G. G. gr. viij, calomel, gr. v, muc. gum. Arab. q. s. for one morning dose.

Prl. astringentes. Sacch. Saturnii gr. iij, opii gr. j, f. pil. iij; one to be taken twice a day; drinking draughts acidulated with vinegar after it.

Pil. cathartice. Extr. coloc. c. 3 j, opii gr. iij, ol. nuc. mosch. gtt. iv., f. pil. xij; dose ij every hour until two stools have been obtained.

2. Aloes Soc. Эj, scammonii gr. xij, extr. rhabarb. żij, capsici gr. vj, ol. caryoph. gtt. v ; f. pil. xvj : dose 2 at bed time. occasionally.

3. Pulv. al. c. 3 j, pulv. antim. gr. v., sapon. duri gr. $\mathrm{x}$, dccoct. alc. omp. q. s. ut f. pil. $\mathrm{xx}$ : dose 2 , when costive. 
4. Pulv. al. c. myrrh. 3 j, extr. coloc. c. gr. xxiv, calomel. gr. $\mathrm{xv}$; f. pil. $\mathrm{xx}$; dose 1 or 2 occasionally.

5. Calomel. gr. x, pil. cambog. c., extr. colocynth. c. ana gr. xv, syr. zz. q. s. ut f. pil. xij; dose 2 at night or morning when costive. dose.

6. Rad. jalap. gr. xv, calomel. gr. v, cons. cynosb. q. s. for one

Pil. diaphoretice. Potassa sulphureti gr. xv, sapon. duri 3 j, bals. Peru. q. s. ut f. pil. xxx ; duse iij, every four hours, in juniper-berry tea: useful in eruptions.

2. Pulv. antimonialis `̌ss, opii Эjss, calomel. gr. v, confect. opii q. s. ut f. pil. $x$; dose $j$, at bed-time.

3. Guaiaci gr. x, pulv. ipecac. comp. gr. v, conf. rosæ $q$. s. for a dose.

4. Guaiaci gr. $x$, tart. emet., opii, ana gr. j, syr. simpl. q. s. ut f. bolus.

5. Camphoræ, pulv. antim. ana gr. iij, opii gr. j, conf. aromat. q. s. ut f. bolus.

Pil. diunetice. Rad. scillæ sicc. gr. iv, fol. digital. gr. x., calomel. gr. vj, myrrhæ $Э j$, assæfœt. $3 s s$, extr. gent.q. s. ut f. pil. $\mathrm{xv}$; dose $\mathrm{j}$, night and morning.

2. Pil. scillæ 3j, calomel. gr. v, f. pil. $x v$; dose ij, every night.

3. Sodæ carbon. sicc. 3 j, sapon. duri Điv, ol. juniperi gtt. $x v$, syr. zz. q. s. ut f. pil. xxx; dose iij, every day, in calculi in the kidneys.

4. Scillæ sicc. gr. ij, pil. hydrarg. gr. v, opii gr. ss, ut f. pil. j, for a night pill, to be taken three or four nights successively.

Pil. emetic.. Vitriol. albi Эj, cons. ros. caninæ q. s. ut fiat bolus; for one dose, to be taken with camomile tea.

Pr.. fumenagoge. Pil. aloes c. myrrha, pil. galbani c. ana 3 j, f. pil. xxiv ; dose ij twice a day.

2. Pil. aloes c. myrr., pil. ferri c. ana $3 \mathrm{j}$, sodæ subcarb. $\ni_{\mathrm{j}}, \mathrm{f}$. pil. $x x x$, dose $\mathrm{ij}$, twice a day.

Pir. expectorantes. Myrrha 3 jss, scilla sic. 3 ss, extr. hyoscyami Әij, aq. q. s. ut f. pil. xxx; dose 2, night and morning.

Pil. Narcotice. Extr. hyoscyami gr. xviij, camph. gr. xij, f. pil. xij ; dose iij, every night.

2. Extr. conii zss, fol. conii q. s. ut f. pil., each weighing gr. ij, to begin with pill $\mathrm{j}$, night and morning, then $\mathrm{ij}$, iij, and as far as the patient can bear: in cancer, scrofula, and other obstinate diseases. 
3. Opii gr. iv, extr. hyos., extr. conii, ana gr. xv, f. pil. vj ; dose $\mathrm{j}$ every night.

Pil. stimulantes. Canthar. gr. j, ammon. subcarb., conf. aromat. ana gr. v, syr. simpl. q. s.; for a dose every four or six hours, in horse-radish tea.

2. Myrrhæ 3 jss, vitrioli albi gr. x, conf. rosæ q. s. ut f. pil. xx ; dose $\mathrm{ij}$, twice a day.

Pil. Tonice. Ferri ammon. 3 j, extr. gent., aloes Soc. ana 3ss, f. pil. $x x x$; dose $\mathrm{ij}$, thrice a day.

2. Ferri carbon. gr. v, rad. valerianæ 3ss, syr. zz. q. s. ut f. bolus.

Worm PILls. Calomel 1 oz., sugar 2 oz., starch 1 oz., mucil. gum. tragac. q. s. to make 248 pills ; dose no. 1, night and morning, for children.

Keyser's pills. Hydrarg. acetat. 4 oz., mannæ 30 oz., starch 2 oz., mucil. gum. tragac. q. s., make into pills of gr. vj each ; dose no. 2 , nocte maneque, increasing the dose to no. 25 or more; a box of 1000 or 1200 pills is usually sufficient for the cure of a common case of syphilis.

\section{FOR VETERINARY MEDICINE.}

Alterative balls. Emetic tartar 5 oz., powd. ginger 3 oz., opium 1 oz., syrop q. s. to make 16 balls.

Alt. laxative Ball. Barbad. aloes 1 oz., Castille soap $1 \frac{\mathrm{x}}{2} \mathrm{Oz}$., powdered ginger half an oz., syrop q. s. to make six balls; for grease.

Alt. ball for strangles. Barbad. aloes $1 \frac{\pi}{2}$ dr., emetic tartar and Castille soap of each 2 drachms; make a ball.

Alt. ball for weak horses. Calomel 1 scr., aloes $1 \mathrm{dr}$, cascarilla and rhubarb of each in powder $2 \mathrm{dr}$., Castille soap $3 \mathrm{dr}$., syrop q. s. to make a ball.-Alterative powders may be made into balls with flower and treacle.

Anodyne Ball. Opium half a drachm to $1 \mathrm{dr}$, Castille soap 2 to $4 \mathrm{dr}$., ginger powder 1 to $2 \mathrm{dr}$., anise seed powd. half an oz. to $1 \mathrm{oz}$., oil of caraway-seeds half a dr., syrup q. s. to form a ball.

Astringent ball. Powdered opium half a drachm, natron ppm. $1 \mathrm{dr}$., powd. cassia or ginger $1 \frac{\mathrm{x}}{2} \mathrm{dr}$.; wheat flour and syrup to form a ball.

Astringent balls for looseness. Opium half a drachm to $1 \mathrm{dr}$, ginger powd. $1 \mathrm{dr}$. and a half, ppd. chalk $3 \mathrm{dr}$., flour $2 \mathrm{dr}$; make into a ball with treacle, syrup, or honey. 
2. Gum kino $2 \mathrm{dr}$, aromatic powder $1 \frac{\mathrm{r}}{2} \mathrm{dr}$., Castille soap and flour of each 2 dr., honey q. s. to make a ball.

BALL FOR BLOODY URINe. Powdered catechu half an oz., alum half an oz. to $1 \mathrm{oz}$., cascarilla bark 1 to $2 \mathrm{dr}$., liquorice powder and treacle q. s. to make a ball.

Camphire balls. Camph. 2 dr., liquorice powder and syrup q. s. to make a ball.

2. Camph. 2 dr., nitre 1 oz., liquorice powder and syrup q. s. to make a ball.

Colick ball. Powd. opium half a dr., Castille soap and camphire of each $2 \mathrm{dr}$., ginger $1 \frac{\mathrm{x}}{2} \mathrm{dr}$.; make into a ball with liquorice powder and treacle : to be kept in a bladder for use on a journey.

Cordial ball. Caraway seeds fresh powdered $3 \mathrm{dr}$., Winter's bark and ppd. chalk of each 2 dr., opium half a dr., oil of aniseseed 20 drops, syrup q. s. to form a ball.

2. Ginger $2 \mathrm{dr}$, liquorice root powd. half an oz., oil of caraway and of anise seeds of each 12 drops, treacle q. s. to make a ball.

Cordial diuretic balls. Strained turpentine $8 \mathrm{oz}$. , yellow rosin $4 \mathrm{oz}$., soap 6 oz., sweet oil 2 oz.; meit together, and add oil of anise seed 2 oz., oil of caraway half an oz., previously rubbed with ginger $4 \mathrm{oz}$ : : make into 16 balls with linseed powder.

Corvial diuretic ball. Hard soap and common turpentine of each $4 \mathrm{dr}$., ginger powder $1 \mathrm{dr}$., opium powder half a dr., caraway seed powder $q$. s. to make a ball.

Cordial balls for journeys, Globuli cardiaci. Cumin sced, anise seed, caraway seeds, all powdered, of each $4 \mathrm{oz}$., ginger $2 \mathrm{oz}$., treacle q. s. to make into balls: dose $2 \mathrm{oz}$.

2. Anise seed, caraway seed, sweet fennel seed, stick liquorice, all powdered; of each $4 \mathrm{oz}$., ginger and cassia of each $1 \frac{x}{2} \mathrm{oz}$., loney q. s. to make into balls: dose $2 \mathrm{oz}$.

3. Cumin seed, coriander seed, caraway seed, all powdered, of each $4 \mathrm{oz}$., grains of Paradise $1 \mathrm{oz}$., cassia half an oz., cardamom sceds and saffron of each 2 dr., syrop q. 8 . to form into balls: dose $20 \%$.

4. Powd. ginger $4 \mathrm{oz}$., powd. caraway seed $8 \mathrm{oz}$., oil of caraway and oil of anise seed of each $2 \mathrm{dr}$, liquorice powder $8 \mathrm{oz}$, treacle q. s. to form into balls : dose $2 \mathrm{oz}$.

CoUgh BaLl. Gum ammon. 3 to $4 \mathrm{dr}$., soap $2 \mathrm{dr}$., ginger $1 \frac{1}{2} \mathrm{dr}$., powder squills and camphire of each $1 \mathrm{dr}$, oil of anise seeds 20 drops, syrup q. s. to make a ball.

2. Gum ammoniac $3 \mathrm{dr}$., powdered squills $1 \mathrm{dr}$., opium half a dr., syrup q. s. to make a ball. 
Diaphoretic alterative balls. Antimonial powder $2 \mathrm{dr}$., camphire $1 \frac{1}{2}$ dr., flour $3 \mathrm{dr}$., syrup q. s. to make a ball.

2. Emetic tartar, camphire, of each 1 to $2 \mathrm{dr}$., liquorice powd. 3 dr., syrup q. s. to make a ball.

Diuretic balls, Globuli diuretici. Castille soap 4 oz., nitre and rosin of each $2 \mathrm{oz}$, oil of juniper half an oz., linseed meal and syrup of each q. s. to make 6 balls for strong horses, or 8 for delicate.

2. Castille soap 4 oz., Venice turp. 2 oz., powd. anise sced q. s. to make 6 balls.

3. Castille soap, strained turpentine, of each $3 \mathrm{dr}$., liquorice powder q. s. to make a ball.

4. Hard soap and common turpentine, of each half an oz., caraway seed powder q. s. to make a ball.

Diuretic alterative balls. Yellow rosin $4 \mathrm{oz}$, Castille soap $3 \mathrm{oz}$., Venice turp. $2 \mathrm{oz}$, caraway seed powd. q. s. to form into balls.

2. Saltpetre $4 \mathrm{oz}$, rosin and flour of each $2 \mathrm{oz}$, oil of juniper half an oz., treacle q. s. to make into balls.

Farcy balls. Corrosive subl. 10 to 20 grains, powd. anise seeds half an oz., syrup q. s. to make a ball; if sickness, much purging or staling is produced, diminish the dose of sublimate.2. The same, with half a drachm or a drachm of opium.-3. Blue vitriol $1 \mathrm{dr}$., liquorice powder $3 \mathrm{dr}$., syrup q. s. to form a ball, to be given twice a day. -4. Blue vitriol $1 \mathrm{dr}$., corrosive sublimate 10 grains, liquorice powder $3 \mathrm{dr}$., syrup q. s. to form a ball. -5 . Blue vitriol $1 \mathrm{dr}$., white arsenic and corrusive sublimate, of each 10 grains, liquorice powder $3 \mathrm{dr}$, syrup q. s. to form a ball. If any of these produce a purging, they must be discontinued immediately.

Fever balls. Emetic tartar 2 dr., nitre 1 oz., liquorice powd. 3 dr., syrup q. s. to make a ball.

Balls for epidemic fever. Powders for epidemic fever, made up into balls with flour and syrup, or treacle.

Garlick BaLls. Garlick 1 to 2 oz., pound into a paste, liquorice powder $\mathrm{q}$. s. to make into a ball; used in chronic coughs.

Gripf. Ball. Cayenne pepper half a dr., made up into a ball with powd. anise seed, liquorice powder, and syrup.

Laxative ball. Barbad. aloes and hard soap of each $3 \mathrm{dr}$., syrup q. s. to make a ball.

Laxative alterative Balls. Barb. aloes 10 to $12 \mathrm{dr}$, 
Castille soap $21 \mathrm{dr}$, anise seed powd. 12 to $16 \mathrm{dr}$., ginger $4 \mathrm{dr}$, syrup or treacle q. s. to form 4 balls. -2 . Barb. aloes 10 to $12 \mathrm{dr}$., calomel 2 to $4 \mathrm{dr}$., caraway seed powd. $12 \mathrm{dr}$., ginger $4 \mathrm{dr}$., oil of cloves 40 drops, syrup q. s. to make 4 balls.-3. Flowers of sulphur 6 oz., emetic tartar 6 or $8 \mathrm{dr}$., corrosive sublimate $10 \mathrm{gr}$., syrup q. s. to form 6 balls.

MANGE BaLls. Corrosive sublimate half an oz., emetic tartar $3 \mathrm{oz}$., anise seeds powdered $6 \mathrm{oz}$., ginger $2 \mathrm{oz}$., syrup q. s. to make 16 balls; one to be given every morning, unless they purge.

Mercurial. ball. Calomel half a dr., Barbadoes aloes $2 \mathrm{dr}$., rhubarb, Castille soap, of each 3 dr., syrup q. s. to make a ball; used in inflammation of the liver.

Physic Ball. Barbad. aloes 5 to $8 \mathrm{dr}$. hard soap $4 \mathrm{dr}$., ginger $1 \mathrm{dr}$; melt together in a slight heat: if made for keeping add a little sweet oil. The best ball that can be made.-2. Barb. aloes $5 \mathrm{dr}$., natron ppd. $2 \mathrm{dr}$., aromatic powd. $1 \mathrm{dr}$., oil of caraway 10 drops, syrup q. s. to make a ball.-4. Barbad. aloes 7 dr. to 1 oz., natron ppd. $2 \mathrm{dr}$., aromatic powder $1 \mathrm{dr}$., oil of anise seeds 10 drops, syrup q. s. to make a ball.

Stomachic balls. Gentian powd. $4 \mathrm{dr}$, ginger powd. $1 \frac{1}{2} \mathrm{dr}$., ppd. natron $1 \mathrm{dr}$., treacle q. s. to form a ball.-2. Cascarilla powder $2 \mathrm{dr}$., myrrh powd. $1 \frac{\mathrm{r}}{2} \mathrm{dr}$, Castille soap $1 \mathrm{dr}$., treacle q. s. to form a ball.-3. Quassia powd. $2 \mathrm{dr}$, aromatic powder $1 \frac{x}{2} \mathrm{dr}$., ppd. natron $1 \mathrm{dr}$., treacle q. s. to form a ball.-4. Columbo powd. half an oz., cassia powd. $1 \mathrm{dr}$., rhubarb powd. $2 \mathrm{dr}$. to $4 \mathrm{dr}$., syrup q. s. to form a ball.

Stomach laxative ball. Barbad. aloes 3 to $5 \mathrm{dr}$, white soap $3 \mathrm{dr}$., ginger powdered $2 \mathrm{dr}$,, oil of caraway 20 drops, syrup q. s. to make a ball.

Stomachic pURGative BALL, for washey horses. Barbad. aloes $3 \mathrm{dr}$., rhubarb $2 \mathrm{dr}$., ginger and cascarilla of each $1 \mathrm{dr}$., oil of camomile 20 drops, carbonate of soda $2 \mathrm{dr}$., syrup q. s. to make a ball.

Stomachic purgative Ball for thin ill-conditioned horses. Barbadoes aloes half an oz., rhubarb $2 \mathrm{dr}$., calomel $1 \mathrm{dr}$., ginger $1 \frac{1}{2} \mathrm{dr}$., oil of caraway 10 drops, Castille soap $2 \mathrm{dr}$., syrop q. s. to make a ball.

Strencituening ball. Columbo root powd. 2 dr., cascarilla powd. $1 \mathrm{dr}$., natron $\mathrm{ppm}$. $2 \mathrm{dr}$., syrup q. $\mathrm{s}$. to make a ball. The horse to have gruel made of wheat flour or arrow-root: sometimes half a drachm of opium may be added, which will generally stop the looseness for some time.

SUlpuU R BaL.. Flower of sulphur 1 to 2 o., emetic tartar 
1 to $2 \mathrm{dr}$., calomel 1 to 2 scruples; mix, for a dose to be given daily in mange and skin diseases.

Tonic BaLls. White arsenic 5 to $10 \mathrm{gr}$., anise seed powd. half an oz., opium half a dr., treacle $q$. s. to form a ball.-2. White arsenic 5 to $10 \mathrm{gr}$., opium half a dr., white vitriol, or blue, or green, $2 \mathrm{dr}$., caraway seeds powd. $\frac{x}{2} \mathrm{oz}$., treacle $q$. s. to form a ball.-. 3. Peruv. bark powd. $1 \mathrm{oz}$, opium half a dr., ginger $1 \frac{1}{2} \mathrm{dr}$., oil of caraway 20 drops, treacle q. s. to form a ball. -4. Cascarilla and gentian root powd. each $2 \mathrm{dr}$., opium half a dr., oil of caraway 20 drops, treacle q. s. to form a ball.-5. Quassia and canella alba of each $2 \mathrm{dr}$., opium half a dr., ginger $1 \mathrm{dr}$., treacle q. s. to form a ball.-6. Gentian root powd. 3. dr., opium half a dr., cascarilla, myrrh, and ppd. natron, of each $1 \mathrm{dr}$., treacle q. s. to form a ball. -7. Colombo powd. 3 to $4 \mathrm{dr}$., opium $1 \mathrm{dr}$., cassia $1 \mathrm{dr}$., allspice powd. 2 dr., treacle $q$. s. to form a ball. -8 . Yellow bark 6 dr., cascarilla $1 \mathrm{dr}$., powd. opium half a dr., salt of tartar 1 scrup., syrup q. s. to make a ball ; if the horse is costive, the opium must be omitted.

Tonic ball, for washey horses. Salt of steel 2 to $4 \mathrm{dr}$., Columbo root $3 \mathrm{dr}$., cascarilla bark $2 \mathrm{dr}$., opium 1 scrup., syrop q. s. to make a ball.-2. Blue vitriol $1 \mathrm{dr}$., liquorice powder $3 \mathrm{dr}$., treacle q. s. to make a ball.-3. Salt of steel 2 to $4 \mathrm{dr}$., powdered myrrh $2 \mathrm{dr}$., ginger $1 \mathrm{dr}$., syrop or treacle q. s. to make a ball.

Tonic ball, for excessive staling in horses. Gentian root half an oz., ginger $2 \mathrm{dr}$., opium half a dr. to $1 \mathrm{dr}$., oil of caraway 20 to 30 drops, syrop q. s. to make a ball.

Tonic ball, for incontinence of urine in horses. Blue vitriol $1 \mathrm{dr}$, Venice turp. 3 to $4 \mathrm{dr}$., ginger $2 \mathrm{dr}$., liquorice powder q. s. to make a ball.

Worm Balls. Aloes 4 to 6 dr., Castile soap 3 dr., calomel, ginger powd., of each 1 to $2 \mathrm{dr}$., oil of cloves 10 drops, syrop q. s. to form a ball. -2 . Aloes 4 to $6 \mathrm{dr}$., powdered tin 3 to $4 \mathrm{dr}$., Castille soap $3 \mathrm{dr}$., ginger powd. 1 to $2 \mathrm{dr}$, , oil of cloves 10 to 20 drops, syrop q. s. to form a ball.

Purging bolus for Dogs. Jalap and rhubarb of each 10 to $20 \mathrm{gr}$., ginger 3 or $4 \mathrm{gr}$., soap $10 \mathrm{gr}$., water q. s. ; if this does not open the bowels, add aloes half a dr., or 3 or $4 \mathrm{gr}$. of calomel. In the distemper it must be preceded by a copious bleeding, and abstinence from food for a day and a night.

\section{HARD CONFECTIONS; OR, DRY COMPOSITIONS PRINCIPALLY COMPOSED OF SUGAR.}

Two methods are generally followed in making hard confections. Some are made with sugar, of which one half in fine 
powder is dissolved in an infusion or decoction in a brass or iron ladle lipped to the right; and when dissolved, the other half of the sugar, previously warmed, and any essential oil, is added, well stirred in, and the grouty mass dragged out by a wire to form drops on a slab sprinkled with sugar or starch. In others the sugar is not dissolved, but the mass is made to cohere by a mucilage, generally of gum tragacanth, or by white of eggs.

Ambergris is the only perfume that can be properly used for perfumed lozenges and tablets for the nrouth.

\section{FOR MEDICAL USE.}

Marsh-mallow Lozenges, Trochisci althce. Rad. althææ, in powder, 1lb., white sugar 4lb., muc. g. tragac. q. s.

Starcu lozenges, Trochisci bechici albi, T. amyli. Amyli z jss, rad. glycyrrh. ३̌vj, rad. iridis Flor. ${ }_{3} s s$, sugar lb. jss, muc. g. trag. q. s.

T. amyli sine iride. As the other, but without the orrice.

Morsuli a romatici. Sugar 1lb. j, water q.s. ; dissolve, boil to a full candy height, when half cold add amygdal. dulc. decort.,

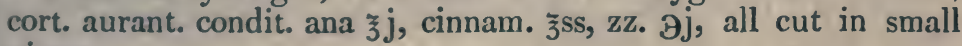
pieces.

Morsur. Acetr. White sugar 1lb., dissolve, evaporate, and form into lozenges, which imbibe with acetic acid 2 oz.

Antimony Lozenges, Morsuli stibii Kunkelii. Sulph. antimon. ppi., - anıygd. dulc. excort. ana ̌̌ss, citri cort. cond. zij, syr. simp. q. s.; make into 8 cakes; dose one a day: the best mode of exhibiting sulphuret of antimony as an alterative.

Troсн. веснісг albi, (P. Belg.) Gum. Arab.-sacch. alb.

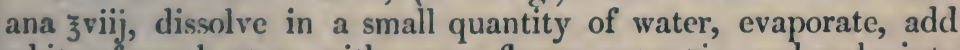
white of egg beat up with orange flower water 3 iv, and make into troches.

Yellow pectoral lozenges, Tr. bechici flavi. Rad. irid. Flor. 3vj, rad. glycyrrh. ziij, amyli $3 s s$, croci pulv. ij, sugar žviij, muc. g. trag. q. s.

Lozenges for the heartiurn, Tab. cardialgice Cret. ppx. ziv, chel. cancr. ppm. з3ij, bol. arm. $3 \mathrm{j}$, nuc. mosch. $9 \mathrm{j}$, sugar ziij, water q. s.

Tro. \&. creta. Cret. ppa. ziv, chel. canc. ppm. $3 \mathrm{ij}$, cinn. ऊss, sugar ziij, muc. g. Arab. q. s.

'Tro. carbonatis calcis. Cret. ppa. ziv, gum. Arab. そj, nuc. mosch. 3 j, sugar 3 vj, water q. s.

Cougn Lozenges., T'ablettes anticaturrhales de T'ronchin. Gum Arab. §viij, kermetis miner. - sem. anisi ana $g^{i v, ~ s u c . ~ g l y-~}$ 
cyrrh. $\xi^{i j}$, extr. opii gr. xij, sacch. albi lb. $i j$ : make into small lozenges.

Clove lozenges. Cloves $3 \mathrm{v}$, sugar 1lb. 8 oz, muc. g. tragac. q. s.; make 150 lozenges, containing gr. ij of cloves each ; used as restoratives after fatigue, or added to chocolate to render it stomachic.

2. Sacch. alb. 7lb., gum. tragac. $3 x i v$, ol. caryophyl. そss.

Catechu lozenges. Catechu in powder ziij, powdered cinnamon $z i j$, oil of cinnamon gtt. $v$, white sugar $z x i v$, mucilage of tragacanth q. s. In relaxations of the uvula, and in irritation about the larynx.

Cachou rozenges. Catechu 3 oz, sugar 12 oz, muc. g. trag. q. s.-Cachou à lambre gris. The same, with ambr. gris. gr. viij.-Cachou musqué. The same, with mosch. gr. viij.-Cachou à la fleur d'oranges. The same, with ess. neroli gtt. vj.

Cachou à la reglisse. Catechu 2 oz., ext. glycyrrh. pur. 1 oz., sugar 10 oz., muc. g. trag. q.s.-Cachou à la violette. The same, with rad. irid. Flor. 3 jss.

Cachou à la canelle. Catechu 3 oz., cinnamon 3 jss, ol. cassiæ gtt. v, sugar 14 oz., muc. g. trag. q. s.

All of these are used to fasten the teeth, and disguise a stinking breath.

Cinnamon tozenges. Cinnamon 7 oz., sugar 12 oz., muc. g. trag. q. s. : stomachic. -2 . Sacch. alb. 8 lb., ess. cinnam. 3 oz., muc. trag. $18 \mathrm{oz}$.

Saffron lozenges. Hay saffron, dried and powdered, $1 \mathrm{oz}$., sugar 1lb., muc. g. trag. q. s. : anodyne, pectoral, emmenagogue.

Black pectoral lozenges, Tr. bechici niyri, P. L. before 1745. Extr. glycyrrh., sacch. ana $\xi x$, gum. tragacanth., amygd. dulc. decort. ana $\xi \mathrm{vj}$, inuc. sem. cydon., made with rose water q. s.

Tro. Bechici NIGRI, P. L. since 1745. Extr. glycyrh., sacch. ana $\xi x$, gum. tragac. 1lb. ss, water q. s.

Tro. Glycyrrhize. Extr. glycyrrh., sacch. ana $z x$, gum. tragac. ziij. water q. s.

Tro. glycyrrhiza glabre. Extr. glycyrrh, gum. Arab. ana $11 \mathrm{~b}$. j, sacchari 1lb. ij, warm water q. s.; dissolve, strain, and evaporate.

Tro. glycyrrhiza cum opio. Opii zij, dissolved in tinct. bals. Tolut. そss, syr. simp. そ̌viij, extr. glycyrh., gum Arab. ana §̌v, made into troches of gr. $x$ each. 
IPECaCUania lozenges. Ipecac. ziv, sugar 2lb., muc. g. trag. q. s.; make 480 lozenges, containing each gr. ss of ipecacuanha; expectorant; used in coughs, also stomachic.

2. (P. Belg.) Cort. rad. ipec. $3 \mathrm{j}$, sacch. albi žviij, muc. g. trag. q. s.

Orrice lozexges, Violet lozenges. Rad. irid. Flor., gum. Arab. ana $3^{\mathrm{ij}}$, rad. glycyrrh. 3 vj, sugar $11 \mathrm{lb} .8$ oz. muc. g. trag. q. s.

Gum lozenges, Tro. gummosi. Gum Arab. 4 oz, starch 1 oz, sugar $12 \mathrm{oz}$, aq. rosæ q. s.

LEMON DROPS. Sugar llb. in very fine powder, dissolve one half along with salt of sorrel 3 iij, in the smallest quantity of water ; as soon as it boils add the other half of the sugar, and css. limon. gtt. viij, drag it out immediately by a crooked wire in drops upon a slab.-2. Use concrete acid of lemons, or acid of tartar, instead of the salt of sorrel.-3. Colour with turmeric.

Lemon sugar. Concrete acid of lemons $3 \mathrm{oz}$, sugar $4 \mathrm{lb}$, essence of lemons 3 ij.

Morsuli citri. Sugar $16 \mathrm{oz}$, citron or lemon juice $2 \frac{\mathrm{r}}{2} \mathrm{oz}$, eleosacch. citri $4 \mathrm{oz}$; dry.

Steer lozenges. Sugar $3 \mathrm{lb} .8 \mathrm{oz}$, iron filings, or rust of iron, $8 \mathrm{oz}$, cinnamon $2 \mathrm{oz}$, muc. g. trag. q. s. ; stomachic, tonic.

Aromatic lozenges of steel. Are prepared with vitriol. vir. and a little tinct. canthar.

Candied horehound. Marrubium conditum. Juice of horehound 1 pint, white sugar $4 \mathrm{lb}$., brown sugar $6 \mathrm{lb}$.

Magnesia lozenges, Tro. e magnesia. Magnes. usta živ, zz. Эj, sugar $3 \mathrm{ij}$, muc. g. Arab. q. s.

2. Magnesia $1 \mathrm{oz}$, sugar $4 \mathrm{oz}$, muc. g. trag. made with aq. flor. aurant. q. s.

Purple tablets. Magnesiæ 3lb., sacch. alb. $1 \frac{1}{2} l \mathrm{lb}$., drop lake $1 \mathrm{oz}$, gum. tragac. $3 \mathrm{oz}$; mix.

Nutmeg nozkxges. Sacch. alb. $8 \mathrm{lb}$., gum. tragac. $2 \frac{1}{2} \mathrm{oz}$, ol. nuc. mosch. $1 \mathrm{oz}$.

PePpermint drops. Sugar 2lb., peppermint water $4 \mathrm{oz}$, made into drops, as those of lemons: essence of peppermint may be added, if they are required to be very warm.

Peppermint lozenges. Sugar 2lb., starch $20 \%$, essence of peppermint q. p. muc. gum. trag. q. s. -2. Use plaster of Paris instead of starch, to give a body to these lozenges; stimulant.3. Sacch. alb. 4lb., muc. g. tragac. q. s., ol. menth. pip. 3 vj.4. White sugar 3 xivss, melt in a ladle, add white sugar $3 \mathrm{jss}$ mixed 
with oil of peppermint gr. xlv, and drop on a slab rubbed with oil of sweet almonds. -5. Manus Christi lb. ss, imbibe it with ol. menth. pip. 3 ss, dissolved in alcohol 3 jss. -6 . Ichthyoc. $3 \mathrm{j}$, water 亏 iij, dissolve, add eleosacch. menth. pip. lb. j. -7. Sacch. albi $\xi$ vj, ol. menth. pip. gtt. xxxvj, white of 2 eggs; rub together, and form into troches.

Nitre props. Sal. nitri 4 oz., sugar 1lb., water $2 \mathrm{oz}$.

Nitre lozenges, Tro. nitri. Sal. nitri 4 oz., sugar 1lb., muc. g. trag. q. s. ; diuretic internally, held in the mouth to remove incipient sore throats.

Pastilles de rose. Sugar 2lb., rose water 4 oz., made into drops.

Manus Christi. The same, made into a flat cake.

Pâte de rose lozenges, Patirosa lozenges. Sugar 2lb., starch 4 oz., ol. rhodii gtt. vj, muc. g. trag. made with rose water coloured with cochineal q. s.; pectoral.

Troc. spongre uste. Sacchar. albi 3 oz., spong. ust. 1 oz., extr. glycyrrh. 3 iij, pulv. amyli ¡ij, mucil. g. Arab. q. s.

Rhubarb Lozenges. Rhubarb, 1 oz., sugar 6 oz, muc. g. trag. made with aq. cinnam. q. s. ; cathartic.

Sulphur lozenges, Tro. sulphuris. Flor. sulph. 1 oz., sugar 8 oz., muc. g. trag. q. s.; pectoral ; used in asthma and piles.

Pectoral rozenges. Fl. sulph. 3vj, fl. benz. 3ss, gum. Arab. rad. irid. Flor. ana 3iij, balsam. sulph. anis. 3j, sugar 18 oz., muc. g. trag. q. s.

Tolu Lozenges. Sugar 2lb., cream of tartar 3 oz., starch 1 oz., tinct. bals. Tolu 3iv, muc. g. trag. q. s.; pectoral.

Pate de tussilage a l'anis. Extr. glycyrrh. dissolved in a strong decoction of the flowers of coltsfoot and cudweed, strained and evaporated to a paste, adding a little ol. anisi towards the end; pectoral.

Vanilua lozenges. Vanilla in powder $3 \mathrm{oz}$, sugar $18 \mathrm{oz}$, muc. g. trag. q. s. : each lozenge ought to contain gr. ij of vanilla; odoriferous, stomachic.

Zinc Lozenges. Sulphate of zinc 3iv, refined sugar lb. $i j$, mucilage of tragacanth q. s. ; divide into lozenges, so that each may contain gr. $\frac{x}{2}$ of the zinc.

Ginger lozenges, Zz. 1 oz., sugar 1 lb., muc. g. trag. q. s. ; stimulant, stomachic.-2. Pulv, zingib. $10 \mathrm{oz}$. , sacch. alb. $8 \mathrm{lb}$, muc. trag. $18 \mathrm{oz}$.

Ginger candy. Zz. 2 oz., boiling water q. s. to strain a pint, white sugar 6lb., brown sugar $8 \mathrm{lb}$. 
Ginger drops. Sugar 2lb., strong infusion of ginger $4 \mathrm{oz}$.

Tablettes de Spitslait. Raisins $1 \mathrm{lb}$, pearl barley $1 \mathrm{lb} .8$ oz., water q. s. ; boil for a short time, dissolve opii `ss, gum. Arab. $4 \mathrm{oz}$., Spanish liquorice $1 \mathrm{oz}$. in water ; mix the two liquors, strain, add brown sugar 4lb., clarify the syrop with white of eggs, evaporate to a paste, adding anise seed, in powder, ziij, towards the end, pour it out upon a slab, divide and dry; pectoral in obstinate coughs.

Worm cakres. Scamm. Alepp. 2 oz., calomel ppd. 3 oz., res. jalapii 2 oz., crem. tartari 4 oz., white sugar 3lb., muc. g. trag. q. s.

2. Calomel 1 oz., res. jalap. 2 oz., white sugar 2 lb., muc. g. trag. made with rose water q. s. ; make 1960 lozenges, weighing gr. viij., and containing calom. gr. 1-4th. res. jalap. gr. ss. each.

3. Scammon. and crem. tart. ana $\jmath_{j}$, calomel ppt. $\frac{3}{3}$ ss, sacchar. alb. 3 j, muc. g. trag. q. S.; will make 80 .

Storey's sorm cakes. Calomel $Э \mathrm{j}$, jalap. $3 \mathrm{j}$, zz. Эij, sacch. 1 oz., cinnabar. antim. q. s. to colour them, syr. simp. q. s. to make into cakes.

Ching's yellow worm lozenges. Saffron 3 iv, water 1 pint; boil, strain, add calomel 1lb., white sugar 28lb., muc. g. trag. q. s.: each lozenge should contain gr. $\mathrm{j}$ of calomel.

Ching's bruzn worm lozenges. Calomel 7 oz., extr. jalapii resinos. 3lb. 8 oz., white sugar 9lb. muc. g. trag. q. s.; each lozenge should contain gr. ss. of calomel.

Lozenges of pUre emetine. Pure emetine gr. vj, sugar 3 iv ; make into 260 lozenges; emetic.

Emetic lozenges of emetine. Emetine gr. $x x v j$, sugar 3 ij; make into 66 lozenges : emetic, no. $\mathrm{j}$ for a child, iv for an adult.

Pectoral lozenges of emetine. Emetine gr. xxvj, sugar $\bar{\jmath}$ iv, carmine q. s. to colour them red; make into 260 lozenges; occasionally in chronic coughs, hooping cough, and chronic diarrhoca: more than one in an hour will excite nausea.

\section{FOR CONEECTIONART.}

Pâte de gomme Aralique. Very white gum Arabic, white sugar, of each $21 \mathrm{~b} .8 \mathrm{oz}$. , boiling water 5 pints ; dissolve, strain, evaporate without boiling to the consistence of honey; beat up the whites of $12 \mathrm{eggs}$ with orange flower water $4 \mathrm{oz}$. measures, which mix gradually with the paste, and evaporate over a slow fire, stirring it continually till it will not stick to the fingers or wooden slice: it should be very light, spongy, and extremely white; pectoral: sold for Pâte de guimauve.-2. Add starch towards the end: this is an inferiorarticle. 


\section{XII. CONSISTENT AND DRY COMPOUNDS.-}

Pâte de gomme de Senegal. White sugar 5lb., washed gum Senegal $6 \mathrm{lb}$, water 30 pints, make into a paste, add orange flower water $9 \mathrm{oz}$. by weight ; essence of lemons and citric acid may be added to flavour it: sold for Pâte de dattes, and Pâte de jujubes.

Pâte de guimauve, Pasta althree. Rad. althææ decort. $亏$ iv, water 5 pints ; boil to 4 pints, strain, add gum. Arab., sacch. a lb., of each lb. ij, evaporate to an extract, then take from the fire, stir it quickly with the white of 12 eggs, previously beat to a froth, add, while stirring, aq. flor. aurant. $f l z$ iv.-Pâte de gomme Arabique is sold for it.

Pâte de dattes. Dates $1 \frac{\mathrm{x}}{2} \mathrm{lb}$., white sugar 5lb., washed gum Senegal 6lb., water 30 pints, orange flower water $9 \mathrm{oz}$. by weight; prepare as the Pâte de gomme Arabique: produce about $9 \mathrm{lb}$.Pâte de gomme de Senegal is sold for it.

Pâte de jujubes. Raisins stoned 1lb., currants picked, jujubes opened, of each $4 \mathrm{oz}$, water q. s. ; boil, strain with expression, add sugar 2 lb. 4 oz., gum. Arab. $21 \mathrm{~b} .8 \mathrm{oz}$., previously made into a mucilage with some water, and strain; evaporate gently, pour into moulds, finish the drying in a stove, and then divide it: expectorant in coughs.-Pâte de gomme de Senegal is sold for it.

Refined juice, Refined liquorice. Spanish liquorice 4lb., gum. Arab. 2lb., water q. s. ; dissolve, strain, evaporate gently to a soft extract, roll into cylinders, cut into lengths, and polish by rubbing them together in a box ; expectorant in coughs, \&c.-2. Spanish liquorice, carpenter's glue, of each $\mathrm{lb}$. j, water q. s.

Pâte de reglisse noire. Refined liquorice 8 oz., gum Arabic 2lb., sugar 1lb., water q. s. : dissolve, and evaporate till it forms a very thick syrop, add rad. enulæ camp., rad. irid. Flor. ana $₹$ ss, ess. de cedrat a few drops, put into tin moulds, and dry in a stove.

Pâte blanche de reglisse. From the roots of liquorice, in the same manner as pâte de guimauve; pectoral.

Barley-sugar, Saccharum hordeatum. Sugar 1lb., saffron 12 grains, water q. s. ; boil to a full candy height, pour it out upon an oiled slab, and roll it in cylinders: formerly a decoction of barley was used.-2. Use mucilage of gum Arabic, and flavour with lemons.

White barley-sugar, Penides, Alphenic. Sugar q. p., decoction of barley q. s.; boil to a full candy height, add a few drops of ess. Bergamotte or ess. of lemons, and twist it together, that the air may render it white.-2. Add starch to give the whiteness.

Chocolate, Chocolada, Chocolat de Santé. Caraccas cacao 8lb., Island cacao $2 \mathrm{lb}$, roast them, and while warm add white sugar 10lb., make into a paste on a heated slab; produces $22 \mathrm{lb} .-2$. Caraccas cacao 8lb., sweet almonds q. s. to relieve the dryness of 
this cacao: some add butter.-3. Island cacao 8lb., starch powder q. s. to absorb the fatness of this cacao.-4. Cacao cake from whence the oil has been pressed, mutton suet q. s.

Spanish chocolate. Use seeds of ground peas for cacao, and add maize flour.

Chocolat à la vanille. To $201 \mathrm{lb}$. of the best chocolate paste add cinnamon, Mexican vanilla, of each $3 \mathrm{oz}$., cloves $\mathrm{\ni} \mathrm{j}$ : used as a nourishing and restorative food.

\section{POWDERS AND STONES.}

FOR MEDICAL USE.

'True Gascoigne's Powder, Pulvis e chelis cancrorum compositus, P. L. before 1745. Margarit. ppm., ocul. cancr., corall. rubr., succin. alb., corn. cervi calc., lap. bezoard. Orient. ana $弓 j$, chel. canc. $\bar{\jmath} \mathrm{vj}$; make into balls.

Lady Kent's Powder, $P$. bezoarticus, Globuli bezoardicus. Chel. cancr. $\zeta$ viij, marg. pp., coral. rubr. ana $\lesssim \mathrm{ij}$, lap. bezoar. Orient. $3 \mathrm{j}$; cordial, in great esteem, although few will go to the price of it.

Cephalic snuff, $P$. cephalicus. Fol. asari, fol. majoran., fol. lil. convall. ana p. æq.

P. sternutatorius, $P$. asari compositus, P. L. Fol. sicc. asari, fol. majoranæ, fol. mari Syr., flor. lavand. ana p. æq.

P. asari compositus, P. D. Fol. sicc. asari 3 j, flor. lavand. 3 ij.

$P$. asari compositus, P. E. Fol. asari 3 oz., fol. majoran., flor. lavand. ana $1 \mathrm{oz}$.

P. Cornachini. Scammon. $z x$, antim. diaphoret. $z$ vj, crem. tart. $\zeta$ ijss ; cathartic, febrifuge, $\ni$ j : an excellent medicine.

Diaceltatesson Paracelsi. Antim. diaph. gr. xviij, res. scamm. gr. xvj, crem. tart. gr. vij. M.

Eari. of Warwick's Powder, P. comitis Wamicensis. Scammonii $\xi$ ij, antimonii diaph. 3 j, crem. tartari 3 ss.

SPecies diambre sine odoratis, Spec. aromatica, $P$. aromaticus, P. L. et D. Cinnam. $̧$ jij, sem. card. min., zz., piper. long. ana $\xi \mathrm{j}$; the old receipt was more compounded.

P. Cinnamomi compositus. Cinnam. 3 ij, sem. cardam. min.

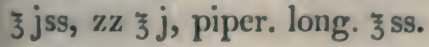

P. aromaticus, P. E. Cinn., zz., piper. long. ana p. xq.; stimulant, carminative, stomachic, gr. $\mathrm{v}$ to $\mathrm{X}$.

Plummer's alterative powder, Rethiops Plummeri. Calomel, sulph. antim. ana 3 ij. 
Spec. Diatragacanthi Frigide, $P$.e tragacantha compositus, P. L. before 1788. Gum. tragac., gum. Arab., rad. althææ ana

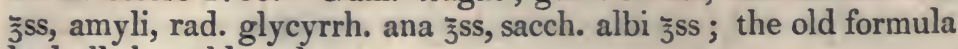
had all the cold seeds.

P. e tragacantha compositus, P. L. since $1788, P$. tragacantha compositus. Gum. tragac., gum. Arab., amyli ana 3 jss, sacch. alb. 3 iij ; demulcent, 3 ss to $3 \mathrm{j}$; used in tickling coughs.

Species hiere PICRe. Cinnam., zedoar., asari, sem. cardain. min., croci ana jvj, coccinel. Эj, aloes Socotr. ǰxij.

Hiera picra. Gummi aloes $\mathrm{lb}$. j, canel. alb. joij.

$P$. aloeticus. Aloes Socotr. lb. j, canel. alb. §iij.

$P$. aloes cum canella. Al. hep. lb. j canel. alb. そ̋ij.

2. Aloes Barbad. 7lb., aloes Cap. 2lb., canel. alb. 3lb., pimento 1lb., turmeric 1lb. 8 oz. : cathartic, gr. $x$ to $Э \mathrm{j}$.

Pulvis aperiens. Pulveris jalapre Oss, submuriatis hydrargyri gr. v, pulveris zingiberis gr. v for a single dose.

Mead's Powder against the bite of a Mad nog, $P$. anty-

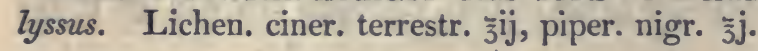

P. DIASENE. Fol. senæ, crem. tart. ana $3 \mathrm{j}$, caryoph., ciunam., galangæ, sem. ammeos ana $3 \mathrm{ij}$, scammonii $\bar{z}^{\mathrm{sS}}$.

$P . e$ sena compositus. Omit the ammi and galanga, and put in zz. 3 ij.

P. e sena compositus, P. senve compositus. Fol. sennæ, crem. tart. ana $\tilde{3} \mathrm{ij}$, scammon. $\overline{3} s \mathrm{~s}, \mathrm{zz}$

P. DIaturpethi compositus. Rad. turpethi, rad. jalapii, rad. hermodactyli, tartar. vitriol. ana p. æq.

P. Jalape compositus. Rad. jalap. $j$ j, crem. tart. $\jmath^{i j}$; purgative, $\partial_{\mathrm{j}}$, to $\mathrm{Bij}$.

Ethiops mineralis, Hydrargyrus cum sulphure, Hydrargyri sulphuretum nigrum. Argent. vivi, fl. sulphuris ana lb. j.

2. Argent. viv. 7lb., fl. sulph. 14lb.; vermifuge, alterative Эj to $3 \mathrm{j}$, bis terve in die; also used by the ferriers and farmers.

P. I Bolo compositus sine opio. Boli armen. (or bol. Gall.) lb. ss, cinnam. ziiij, rad. torment. gum. Arab. ana ziij, pip. long. 弥s.

P. E creta comfositus, $P$. cretce compositus. For bole use ppd. chalk.

P. carbonatis calcis compositus, $P$. cretaceus. Cret. pp. ३iiij, nuc. mosch. $3 \mathrm{ss}$, cinnam. 3 jss; absorbent, stomachic, carminative $\mathrm{Oj}$ to $\mathrm{Oij}$. 
P. E воlо composites cux opio. Species for pulv. e bol. comp. s. opio as before, add opii colati ziij.

P. E creta compositus cum opio. Pulv. e creta comp. jriiij, opii purif. duri $j$ jss.

$P$. crete compositus cum opio. Pulv. cretæ comp. žjjs, opii duri Эiiij; astringent, stomachic, gr. $\mathrm{xv}$ to $\mathrm{Oij}$, which last dose contains gr. $j$ of opium.

Pulvis cauphorx. Camphoræ 3 ss, spir. rectif. q. s., tere cum sacch. purificat. jjss, pulv. acaciæ jüj; misce bene et in chartulis $x i j$, distribue.

One of these rubbed up with a little water forms an excellent emulsion, especially when a little extract of conium or syrup of poppies is added, in dentition and diseases of irritation.

P. E cerussa composites, $P$. e cerussa. Cerussæ $3 \mathrm{v}$, sarcocol. 亏̈jss, gum. tragacanth. 亏̈ss: cooling, astringent; used externally in excoriations.

Сомmon Gascoigne's Powder, $P$. e chelis cancrorum compositus, P. L. since 1745. Chel. cancr. ppm. lb. j, margarit. ppm. (or cret. ppæ. as in P. L. 1788), corall. rubr. pp. ana 亏iij; absorbent, 3is to 3 j.

Contrayerva ralls, Lapis contrayerca, Globuli contrayerva, $P$. contrayerva compositus, P. L. since 1809. Chel. cancr. ppm. lb. j, cretæ ppæ., corall. rubr. ppi. ana jiij, rad. contrayervæ $z v$; the original formula had amber in it.

P. contrayerve compositus, P. L. since 1809 . Test. ppm. lb. jss, rad. contrayervæ ${ }_{3}^{z} v$; diaphoretic, $\partial_{j}$ to $\vartheta_{i j}$.

P. E succino cospositus, vice Trockisci de carabe. Succin. pp., gum. Arab. ana $j \mathbb{x}$, succ. hypocist., balaust., terræ Japon. ana $j r$, olibani $j s s$, opii colati $j \mathrm{j}$.

P. xıso composıres. Kino $5 x v$, cinnam. jiiij, opii duri jj; astringent; dose of the latter ss to $Э \mathrm{j}$, which last contains opi gr. j.

P. E MYRRA composites, P. L. before 1788. Fol, sicc. rutæ, fol. dict. Cret. myrrhæ ana §js, assafœtidæ, sagapeni, cast. Russ., opopon. ana jј.

P. e myrrha compositus, P. L. since 1788. Myrrhæ, sabinæ, ruta, cast. Russ. ana j.

SPEC. E scordio sixe opio. Boli Arm. (or boli Gall.) รiv, scordii $3^{i j}$, cinnam. jjss, styr. calam. col., rad. torment., rad. bistort., rad. gentian., fol. dict. Cret., galban. col., gum. Arab. rosor. rubr. ana 3 j, piper. long., $2 \%$. ana ${ }_{3} \mathrm{SS}$.

Spec. e scordio cum opio. Add to the former, opii col. 3ijj. 
Euphorbium prieparatum. Euphorbium 2 oz., lemon juice a pint; dissolve, strain, and evaporate to dryness.

- Diagrydum, Diacrydium. Scamm. lb. j, juice of quinces $\S$ viij; infuse 12 hours, and evaporate to dryness.

P. e scammonio compositus, $P$. scammonece compositus. Scammonii, extr. jalap. duri ana $z \mathrm{ij}, \mathrm{zz}$. 3 ss ; cathartic, gr. $\mathrm{x}$ to xv.

$P$. scammonii compositus. Scammon., crem. tart. ana $1 \mathrm{oz}$.; cathartic, weaker : dose Эss to Эss.

$P$. e scammonio cum aloe. Scammon. 3 jj, extr. jalap. duri, aloes Soc. ana 3 jss, zz. 3 ss.

$P$. basilicus. Scammon., crem. tart., calomel., cerus. antimonii ana p. æq.

$P$. E scammono cum calomelane. Scammonii zss calomel., sacch. alb. ana žj ; cathartic, vermifuge, gr. $v$ to $\mathrm{x}$, or more.

Pulvis Calomelanos cum Digitale. Hydrargyri submuriatis, sacchari albi, āā $\jmath_{j}$, pulveris digitalis $\bar{\jmath} \mathrm{ss}$; misce; dosis, à $\mathrm{gr} . \mathrm{j}$ ad gr. v.

P. aloeticus cum guataco, $P$. aloes compositus, $P$. aloes cum

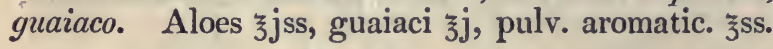

P. aloeticus cum FerRo. Aloes Soc. §jss, myrrl. そ̋ij, extr. gent. duri, sal Martis ana 3 j.

Dover's powder, $P$. sudorificus Doveri. Tartar. vitriol., sal. nitri ana ziiij; throw into a red hot mortar, stir them with a spoon until they have done flaming, powder very fine, and add opii, rad. ipecac., rad. glycyrrh. ana $3 \mathbf{j}$; dose gr. $x l$ to $\mathbf{l x x}$ in wine whey. The red hot mortar must decompose the nitre and produce a ferruginated alkali, and therefore different from the college formula.

2. Tart. vitriol., sal. nitri ana 4 oz., opii, ipecac., rad. glycyrrh. ana $1 \mathrm{oz}$; diaphoretic, sudorific, gr. vj to $\mathrm{xx}$ : used in rheumatism.

P. IPeCacuanhe compositus, $P$. ipecacuanhe et opii. Ipecac., opii ana $3 \mathrm{j}$, tartar. vitriol. $3 \mathrm{j}$.

Pulvis ipecacuanhe cum calomelane. Hydrargyri submuriatis $3 \mathrm{j}$, pulveris ipecacuanhæ $3^{\mathrm{ij}}$, pulveris cinnamomi ${ }^{\mathrm{ss}}$, sacchari albi zjss; misce; dosis, à gr. ij ad gr. v.

P. opiatus, P. L. Opii 3j, corn. cerv. usti zix.

$P$. cornu usti cum opio. Opii 3 j, corn. cerv. usti $ろ$ j, coccinel. $3 \mathrm{j}$.

P. opiatus, P. E. Opii $\jmath j$, cret. ppæ. $3^{\mathrm{ix}}$; absorbent, anodyne, gr. $v$ to $x$, which last contains opii gr. j.

AlKalised QUicksilver, Athiops alcalisatus, Hydrargyrus cum creta, P. L. Argent. vivi Ӟiij, cretæ $\xi \mathrm{v}$. 
Powders, \&c.

Hydrargyrus cum creta, P. D. Argent. vivi, mannæ ana $3 \mathrm{j}$; rub till the quicksilver disappears, then add creta $3 \mathrm{j}$, rub again, wash out the manna with a pint of warm water, add cretæ 3 iij more to the sediment while moist, and dry upon blotting paper.

HydrargYrUS CUM magnesia. Argent. vivi, mannæ ana $う$, magnesiæ albæ ${ }_{j} \mathrm{ss}$; proceed as in the last.

Potential cautery, Common caustic, Cauterium potentiale, Lapis septicus, Causticum commune mitius. Quick lime, soft soap ana p. æq.

Causticum commune fortius, Calx cum cali puro, Potassa cum calce, Cali causticum cum calce. Soap ley made of potash q. v. boil to a third or fourth part, and add lime q. s. to soak up the remaining liquor; caustic, not so liable to spread as pure potash, but much weaker.

Lapis medicamentosus. Alum., lithargyri, boli Arm. ana lb. vj, colcoth. vitrioli aceti opt., ana $\mathrm{lb}$. iij; boil to a stony consistence; astringent, detergent, externally, $3 \mathrm{j}$, to a pint of water.

LApis ophthalmicus, $L$. divinus. Vitr. cærul., alumin., nitri ana $\tilde{3} \mathrm{j}$; melt together, adding at the end camph. $3 \mathrm{j}$ : used to make an eye water, $3^{\mathrm{ij}}$ to water $4 \mathrm{oz}$.

Pierre divine. Roche alum burnt 3 oz., add liquid ammonia $3 \mathrm{j}$; mix, and add vermilion $\mathrm{Jj}$; for toothache, a piece to be put into the tooth.

P. DE TRIBUS. Scammon., crem. tartari, antimon. diaphor. ana p. æq. ; cathartic, gr. $x v$ to $3 \mathrm{j}$.

P. strptrcus, $P$. sulphatis alımince compositus. Aluminis ziv, kino $3 \mathrm{j}$; styptic, gr. $\mathbf{x}$ to $\mathbf{x v}$, or externally to bleeding wounds.

Mercurius saccharatus. Hydrarg., sacch. albi ana žss, ol. tanaceti gtt. xvj: rub till the quicksilver disappears : vermifuge, $3 \mathrm{j}$ in a day.

Poudre de lupuline. Lupuline $3 \mathrm{j}$, white sugar $3 \mathrm{ij}$.

Pate arsenicale. Cinnab. gr. lxx, sang. dracon. gr. xxij, arsen. albi gr. viij ; used in cancer, being made into a paste with spittle when used.

Pulvis emmenagogicus. Fol. sabinæ sicc., zz. ana $y^{\text {ss, }}$ potas. sulphatis $3 \mathrm{jss}$; to be taken twice a day.

P. BaLsamicus. Mastich, myrrhæe, sarcocolla ana 3 j; mix ; to be sprinkled on bared bones, tendons, and ligaments.

Pulvis rientericus. Pulveris tragacanth. comp., pulveris rhei, ana $3^{i i j}$, pulveris ipecacuanhæ comp. $3 \mathrm{j}$, hydrargyri cum 
creta 3j. Misce. Dosis à gr. v ad 3ss, 3tis, 4tis, vel 6tis horis. Interdum adde extract. catechu, \&c.

Mochlique des Freres de la Charite. Vitr. antim. very finely ground $3 \mathrm{j}$. sacch. albi $z^{\mathrm{ij}}$; dose $\ni_{\mathrm{j}}$ to $z^{s s}$, as a specific in colic from lead.

Vitrum antimonir ceratum. Celæ flavæ $3 \mathrm{j}$, melt and add vitr. antin. in extremely fine powder $气 \mathrm{j}:$ mix well, and keep in the fire for an hour, or till it acquires the appearance of Spanish snuff; cool, and powder; in diarrhœa and dysentery gr, vj twice a day.

P. Diaphoreticus. Pulv. antimonialis gr. viij, crem. tartari gr. vj.-2. Pulv. antimonialis gr. vij, salis nitri gr. v; diaphoretic, in fevers.

P. Jalape. Jalapæ 马j, crem. tartari $3 \mathrm{j}$.

P. rhabarbari. Rhabarb. gr. $x x v$, crem. tart. $3 \mathrm{j}$; purging.

P. sabins. Fol. sabinæ pulv. そjij æruginis, Merc. præcip. rubri ana $气 s s$; to stimulate and consume fleshy tumours.

Duke of Portland's gout powder, $P$. Ducis Portlandia. Rad. aristol., rad. gentianæ, summ. chamædryos, summ. centaur. min. ana p. æq. ; used in gout.

Herrenschwand's worm specivic. G. G. G. gr. x, sal. tartari 马j.

Tonquin nemedy, P. Tunchinensis, P.alexipharmicus Sinensis. Rad. valer. sylv. pulv. $Э \mathrm{Jj}$, moschi gr. xvj, camph. gr. vj ; mix ; antispasmodic, alexiterial, to gr. $x i j$, in hooping-cough; to $3 \mathrm{j}$ in hydrophobia and exanthemata; to Эijss, in mania.

P. vermifugus. Sal. comm. $3 \mathrm{ij}$, coccinellæ $\ni_{\mathrm{ij}}$; dose $3 \mathrm{ss}$, every morning. - 2. Ferri carbon. $Э \mathrm{j}$, in any vehicle, early every morning.

Pulvis cinchone cum soda. Pulveris cinchonæ, sodæ subcarbonatis, ana partes æquales. Dosis à gr. v ad Đss, bis terve in die.

Pulvis tonicus. Ferri sulphatis exsiccati 3iij, potassæ sulphatis 亏̌ij, pulveris cascarillæ ziijss. Misce. Dosis à gr. iij ad gr. $\mathrm{x}$, bis terve in die. (Infantibus.)

P. Tonicus. Cort. Peruv. ̌̌ss, sal. Epsom. zvj ; for four doses, one every other hour, in agues,

2. Ferri ammon. gr. v, rhabarb. gr. iij; once a day.

3. Ferri tartar. gr. $x$, rad. calumbæ gr. xv; for a dose every four hours.

Pulvis calumbe compositus. Pulveris calumbæ $\lesssim$, pulv. rhei $\xi_{s s}$, sodæ subcarbonatis 3iijss. Misce. Dosis à gr. vj ad ३ss, bis de die. 
Chelteniam salts. Glauber's salt, Epsom salt, common salt, of each 28lb. ; dry in an oven, and powder ; purgative, $3 v \mathbf{v j}$ to žjss.

2. Sal. Glaub. 3ij, sal. Epsom. gr. lxvj, sal. comm. gr. x, sal. Martis gr. ss.

3. Common salt, Epsom salt, Glauber's salt, of each $1 \mathrm{lb}$; dissolve, filter, and evaporate to dryness, then add green vitriol 3ss.

Poudre de Muriate D'or-ET-De-sodde. Mur. auri-et-sodæ crystal. gr. j, pulv. lycopod. gr. ij, M.-2. Use pulv. rad. iridis flor. deprived of all its soluble parts by alcohol and water, pulv. lycopodii.

P. Diureticus. Rad. scillæ sicc. gr. iij, opii gr. ss, cinnnam. gr. $x$; for a dose twice a day.

2. Rad. scill. sicc. gr. xij, sal. nitri $3 j$, sacch. albi, cinnam. ana 3 j, f. pulv. no. vj; dose one, twice a day.

3. Crem. tart. 3 j, rad. scill. sicc. gr. iij, zz. gr. v; for a dose, every six hours.

P. PURgans. Rhabarb. gr. xv, scamm., ammoniæ subcarbon. ana gr. v; for a single dose.

2. Rad. jalap. gr. xv, rad. ipecac. gr. v, ol. cinnam. gtt. ij; for one dose.

3. G. G. G. gr. iij, sacchari $Э \mathrm{j}$; for a dose, every three hours until a stool is obtained.

Pulvis catharticus. Submuriatis hydrargyri, pulveris cambogiæ, pulv. jalapx, pulv. rhei, pulv. cinnamomi, ana 3ij. Misce. Dosis, à gr. v ad Эj.

P. Antacidus. Pulv. creta c. cum opio $\mathfrak{j} j$, catechu gr. $x v$; for a dose, to be taken after each liquid stool, in loosenesses arising from acidity.

P. REFRIgerans. Salis nitri gr. xv, in a teacup of water, immediately upon its being dissolved.

P. expectorans. Myrrha $z_{\text {SS, sacchari }}$ ss; to be taken in divided doses, daily, in any convenient vehicle.

2. Scillæ sicc. gr. viij, ipecac. gr. v, camphore jj, pulv. antim. gr. vj, sacch. pur. $3 \mathrm{j}$, f. pulv. iv; dose $\mathrm{j}$, twice a day, in barley water.

3. Myrrhæ gr. xij, ipecac. gr. vj, salis nitri 3ss, f. pulv. iv ; dose $\mathrm{j}$, every four hours.

MARRIOTT'S DRY VOMIT. Tartar. emetic, vitrioli car. ana p. aq. ; to be taken without any liquid. 
Alumen saccharinum. Common alum made up into small sugar loaves, with white of egg and rose water: used by females to make an astringent wash.

P. Diaphoreticus. Pulv. ipecac. c. gr. xv, pulv. tragac. comp. $\Im^{i j}$, f. pulv. iv ; dose $j$, every hour.

2. Pulv. ipecac. c. gr. $x v$, pulv. antimon. gr. $\mathrm{j}$, f. pulvis ; to be taken at bedtime.

3. Antim. sulphureti præcip., extr. aconiti ana gr. j, magnes. carb. $\mathrm{g}^{\mathrm{ss}}$, f. pulvis.

4. Pulvis antimon. gr. iij, potas. subcarbon. gr. v, flor. chamæm. Эj. f. pulv.; dose j, every six hours, for two or three days.

5. Pulv. ipecac. gr. ij, opii gr.j, sal. nitri gr. xvj, f. pulv. to be taken at bedtime.

Tartarum solubile extemporaneum. Crem. tart. 3lb., kali pp. $11 b$.

Extempore smeling salts. Sal. ammon. ¡jj, kali pp. $3 j$, ess. limon. gtt. v.

Sal volatile oleosum. Subcarb. of potash, sal ammoniac ana $\xi v j$, powder, mix, add leaves of Marum Syriacum $\varsigma_{s s}$, alcohol, P. L. Ojss, (impregnated with ol. caryoph. $3 \mathrm{ss}$, ol. cinnam. $3 \mathbf{j}$, ol. nuc. mosch. Эij, ol. marjoranæ, limon., and aurant., of each $3 \mathrm{j}$ ), water Oij; distil with an extremely gentle heat, and as soon as the liquid that rises begins to dissolve the salt that has sublimed, take the vessel from the sand, and collect the salt; extremely fragrant.

SMElling salts, Sal ammoniacum volatile cum lavandulâ. Subcarbonate of ammonia そviij, grind with ol. lavand. exot. $३$ jss ; sublime with a gentle heat.

Pulvis sode compositus. Sodæ subcarbon. exsiccat. $3 \mathrm{vj}$, hydrargyri submuriatis $3 \mathrm{j}$, pulv. cretæ comp. $亏$ j. Misce. Dosis, à gr. v. ad Ӭj.

Aerated soda powders. Sodæ carbonatis $z$ ss, in each blue paper; acid of tartar gr. xxv, in each white paper; for half a pint of water: pleasant, cooling beverages in summer.

Seidlitz powders. Soda tartar. $3 i \mathrm{jj}$, sodæ carb. $\mathrm{j}^{\mathrm{ij}}$, in one paper ; acid. tart. gr. $\mathbf{x x x v}$, in the other; for half a pint of water. -Aërated soda powders, in a single bottle, will not keep effervescent more than a month, the acid and alkali uniting. If sugar is added, the same combination takes place: white barley sugar does better, but it will not keep good more than two months.

Midgeley's sodarc powders. To each paper of acid add 1-8th gr. tartarized antimony. 
VAKAKA. Vanilla $1 \mathrm{oz}$., white sugar $4 \mathrm{oz}$; grind together: analeptic.

SPECIES Pro CONFECTIO oriI.-Species pro mist. crete.

Pulvis sudorificus. Sulphuret of antimon. $12 \mathrm{lb}$, cream of tartar 4lb.

Pulvis rhei compositus. Pulveris rhei 3 iijss, hydrargyri cum creta $3 \mathrm{j}$, potassæ subcarbon. 3 jss, pulv. cinnamomi 3 ss. Misce. Dosis, à gr. v ad $3 \mathrm{j}$, bis vel ter die.

P. stani factitius. Polisher's putty 4 lb., ivory black $4 \mathrm{oz}$. The ill effects sometimes arising from tin as a vermifuge, are owing to the substitution of this powder for the filings.

RAdIX GLYCYRRHIZ.E TRITA REDUCTA. Rad. glycyrrh. ras., guaiaci, far. tritici ana p. æq.-2. Rad. glycyrrh. 7lb., brown sugar 14lb.-3. Box dust $28 \mathrm{lb}$., fabarum 36lb., curcumæ 3lb., succ. liquoritia 14lb.-4. Far. trit. 56lb., succin. 2lb., P. D. $6 \mathrm{lb}$., sacch. rub. $7 \mathrm{lb}$.

Rad. ENUle trita REDUCTa. Rad. enulæ, barley meal ana p. æq.-2. Fabarum 56lb., box dust 14lb., rad. enulæ $28 \mathrm{lb}$. -3. Fabarum 56lb., rad. enulæ 56lb.-4. Pulv. enulæ camp. 40lb., ivory black 12lb., cret. ppæ. 6lb., flour 22lb., yellow ochre $1 \frac{1}{2} l b$.

Semina fenugreci trita reducta. Sem. fonugræc, pea meal, ana p. æq.-2. Sem. fœnug. $56 \mathrm{lb}$, rad. curcumæ $7 \mathrm{lb}$., fabarum 36lb., whiting 14lb., box dust 14lb.

Sem. anisi trita reducta. Sem. anisi, ras. guaiaci ana $p$. æc. -2. Sem. lini 32lb., pulv. lini 36lb., ras. guaiaci $20 \mathrm{lb}$., ebor. 4lb., Dutch pink 7lb.-3. Sem. anisi, 21lb., sem. foenic. dulc. $7 \mathrm{lb}$., ras. guaiaci $28 \mathrm{lb}$., turmeric $1 \mathrm{lb}$., pale rape oil 4 pints. -4 . Sem. anisi 56lb., ras. guaiaci $70 \mathrm{lb}$. - 5. Stone blue 2lb., cucuma 2lb., sago 4lb., sem. anisi 65lb., far. trit. 65lb.

Piper nigrum tritum reductum. P. nig. $\mathrm{lb}$. j, hulls of black mustard seed $\mathrm{lb}$. vj.

RAD. CURCUMæ TRITA REDUCta. Rad. curcumæ, ras. guaiaci ana p. æ氏. - 2. Rad. curcumæ 12lb., fabarum 12lb., lign. rubri 4lb.

Cortex Peruvianus tritus factitius. Rad. bistortæ, calami aromatici ana p. seq. -2 . Cort. quercus, rad. gentiance, in different proportions.-3. Herb. lycopi Europæi.-4. Rad. gei montani.- 5. Cort. fraxini, rad. torment., zz. ground together.Bugle, ajuga reptans; self heal, prunella vulgaris; yellow loosestrife, lysimachia vulgaris; the bark of the slue bush, prunus spinosa; the bark of the horse-chesnut tree, asculus hippocastanum; the bark of several species of willows and sallows, salix : are all substituted for cort. Peruvianus. 
Cort. Peruv. tritus reductus. Cort. Peruv., mahogany sawdust, oak sawdust, ground together.

Radix RHEI TRITa REDUCta. Mix the powder with that of the root of meadow rue, or of monks' rhubarb: used for tinctures.

Gum kino factitium. Lign. Camp. 48lb., rad. torm. 16lb., rad. rub. tinct. $12 \mathrm{lb}$., water q. s. ; boil, add catechu 16lb., strain and evaporate to dryness : it will produce $24 \mathrm{lb}$.

Common Smyrna scammony, Scammonium Smyrnense factitium. Scamm. Alepp. 8 oz., rad. jalap. 4lb., fol. sennæ, ebor. usti ana 1lb., zz. 2 oz., mannæ comm. 3lb., G. G. G 2lb., syr. spinæ cervi 2lb.-2. Rad. jalap. 2lb., fol. sennæ, scamm. Alep. G. G. G. ana 8 oz., eboris usti, zz. ana 4 oz.-3. Scamm. Alep. 1lb., extr. jalap 5lb., gum. guaiac. 10lb., sago 10lb., ivory black $4 \mathrm{lb}$.

Cremor tartari reductus. Cryst. tart. 3lb., sal. enixi 11 b.

Turpethum minerale reductum. Turbith mineral, lowered in price by massicot.

Lapis bezon factitius. Bol. Armen., dried blood ana p. æq. muc. g. tragac. q. s.

Atriops mineralis Reductus. Ethiops mineral and antimony of each 1lb.; grind together: used in diseases of the skin, $3 \mathrm{j}$ in the horse's corn.

Aloe Socotrina trita factitia. Al. Capens, at hepat. ana p. æq.

RAd. IRIDIS TRITA REDUCta. Rad. irid. 84lb., farinæ $12 \mathrm{lb.}$

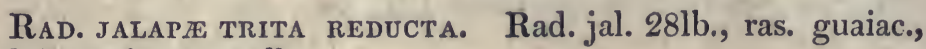
rad. bryoniæ ana $14 \mathrm{lb}$.

Rad. salop trita reducta. Pulv. salop. ver. 10lb., amyli, sago dust ana $2 \mathrm{lb}$. ; mix.

RAd. SAlop trita FACTITIA. Starch and sago dust ana p. æq.

RAD. ziNzIBERIS tRITA REDUCTA. Rad. zinz. 56lb., fabarum 28lb., box dust 28lb., capsici $1 \mathrm{lb}$.

P. antimonialis factitius. Antimon. diaphor. 10 oz., tart. emetic. $1 \mathrm{oz}$.; some put only $6 \mathrm{oz}$. of ant. diaph.-2. Corn. cervi usti $18 \mathrm{oz}$. , tart. emet. $1 \mathrm{oz}$.

Ladanum spurium. G. anime, g. copal, g. lac. g. mastiche ana 2lb., g. Arabic 3lb., catechu, Span. liquorice ana 1lb., syr. Tolut. $8 \mathrm{oz}$, , ess. ambergrise, ess. moschi ana $2 \mathrm{oz}$.; melt together. 
Rad. ipecacuanhe trita ReDUCta. Mix the ipecacuanha with the seeds of narrow-leaved wild orache, atriplex patula; those of garden orache, a. hortensis : the root of primrose, primula veris vulgaris; or the root of oxlip, $\mathrm{p}$. veris elatior.

Pulpa colocyntuidis factitia. Sem. colocyth. 3lb., rad. bryonix 1lb. ; sold for the ground pith.

BatTley's GREeN SENNA powder. This nostrum is supposed to be senna leaves heated until they become yellow, and then reduced to a greenish hue by the addition of powdered charcoal.

\section{FOR VETERINARY MEDICINE.}

Horse spice, Species equinus. Rasur. guaiaci 1lb., zz. nigri, pimentæ, scm. cymini ana $21 \mathrm{lb}$, rad. curcumæ, canellæ albæ ana 1lb.-2. Rad. curcumæ, sem. cymini ana 5lb. zz. 2 lb. 8 oz.3. Piper. Cayennæ 2 oz., faloarum $45 \mathrm{lb}$, mustard hulls $45 \mathrm{lb}$., sem. cumini $15 \mathrm{lb}$., pulv. carui $15 \mathrm{lb}$., pulv. curcumæ 9lb., bacc. lauri 3lb., ivory black $1 \mathrm{lb}$.

Cow spice. Rad. curcumæ, sem. anisi, rad. glycyrrh., pul. diapente ana p. æeq.

Dinpente. Rad. aristol. longi, myrrhæ, bacc. lauri, ras. eboris, rad. gentiana ana lb. $\mathrm{j}$; used by farriers as a tonic.-2. Bacc. lauri 3lb., rad. gentianæ 2lb., rad. curcumæ 4lb. sinapis $3 \mathrm{lb}$.

Absorbent powders for horses. Natron ppd. $2 \mathrm{dr}$, columbo root powd. 3 to $4 \mathrm{dr}$., ginger $1 \mathrm{dr}$.; mix for a dose.2. Ppd. chalk 4 dr., gentian root powd. 2 to $3 \mathrm{dr}$., pulvis aromaticus 1 to $2 \mathrm{dr}$.; mix for a dose. -3 . Aloes 2 to $3 \mathrm{dr}$., rhubarb 3 to 4 dr., natron ppd. 2 dr., ginger 1 to $2 \mathrm{dr}$; mix for a dose.

Alterative powders for horses. Prep. antimony 6 oz, flowers of sulphur $8 \%$.; mix for eight doses.-2. Rosin $4 \mathrm{oz}$., nitre $3 \mathrm{oz}$, emetic tartar $1 \mathrm{oz}$.; mix for eight doses.

Arsenichl powder for norses. White arsenic gr. j, cream of tartar gr. $\mathrm{x}$; rub well together for a dose, to be given three times a day, unless it produces loss of appetite.

Astringent powner. Alum 4 oz., bole Armenian $1 \mathrm{o} \%$; mix; for grease and running sores.-2. White vitriol $2 \mathrm{oz}$., flowers of zinc $1 \mathrm{oz}$; mix; for external use.-3. White vitriol and bole of each $2 \mathrm{o \%}$; mix.-4. Sugar of lead $2 \mathrm{oz}$., bole $1 \mathrm{oz}$; mix.

Cacstic powden, for canker in horses. Corros. sublim. powd. $1 \mathrm{o}$. , blue vitriol 2 oz., ppd. chalk $4 \mathrm{oz}$; mix.

Cordial diurfic powder, for horses. Nitre, yellow rosin, and carui seeds powdered, of each $1 \mathrm{oz}$.; mix, for one dose. 
Diafhoretic alderative powder, for horses. Ppd. antimony 1 oz., caraway seed powd. half an oz.; mix.-2. Ppd. antimony 2 dr., precipitated sulphuret of antimony half a dr., caraway seeds powd. half an ounce; mix for one dose.

Diuretic POWDERS For Horses. Rosin and salt petre of each half an ounce; mix for a dose, once or twice a day.

Diuretic alterative powder. Yellow rosin and salt petre of each $4 \mathrm{oz}$.; mix for six or eight doses, one to be given daily.

Diuretic alterative powder for grease. Powdered rosin and nitre of each $4 \mathrm{oz}$; mix, and divide into eight doses.

Fever powder for horses. Nitre half an oz. to $1 \mathrm{oz}$., camphire and emetic tartar of each 1 to $2 \mathrm{dr}$.; used after their bowels have been opened.-2. Nitre half an oz to $1 \mathrm{oz}$., antimonial powder $2 \mathrm{dr}$., camphire $1 \mathrm{dr}$. to $2 \mathrm{dr}$. ; mix. -3. Powdered rosin $3 \mathrm{dr}$., emetic 1 dr., nitre half an oz.; mix.

Laxative alterative powders. Flowers of sulphur 6 oz., emetic tartar 6 to $8 \mathrm{dr}$, , calomel $3 \mathrm{dr}$.; mix for six doses.

Purging powder for pigs. Jalap $1 \mathrm{dr}$., to which may be added scammony 10 or $12 \mathrm{gr}$, , or calomel $10 \mathrm{gr}$.

German paste for birds. Pea meal 2lb., sweet almonds blanched 1lb., fresh butter $3 \mathrm{oz}$. ; beat all up together, add a little honey and cake saffron shred, pass it through a colander to granulate it. Some put in the yelks of $2 \mathrm{eggs}$, but this makes it too expensive, and too fattening for the birds : it will keep good six months: used for feeding nightingales, larks, and other insectivorous birds.

RAT POWDER. Rad. ranunculi bulbosi dried and powdered.

Powder for destroying Mick. Rad. helleb. nigri, sem. staphisagriæ ana 1 oz., oatmeal 2lb., ol. carui gtt. xxx.

FLY POWder. Arsen. alb. 4 oz., white sugar 6lb., rose pink $1 \mathrm{oz}$. : put $z$ vj in each paper.

\section{FOR THE KITCHEN AND TABLE.}

Currie powder. Coriander 18 oz., black pepper 2 oz., Cayenne pepper 1 oz., turmeric, cumin seed, of each $3 \mathrm{oz}$, fœenugr. seed 3 iv.

2. Sem. coriandri $13 \mathrm{oz}$, pip. nigri $5 \mathrm{oz}$, pip. Cayenne $1 \mathrm{oz}$, sem. fœnugr., sem. cymini ana 3 oz., rad. curcumæ $6 \mathrm{oz}$.

3. Sem. coriandri llb., rad. curcumæ 8 oz., zz. 6 oz., sem. cumini, pip. Indic. ana 4 oz., pip. nigri 3 oz., cinnam., sem. cardam. min. ana $1 \mathrm{oz}$, tamarind. nigr. $2 \mathrm{lb}$.

4. Sem. coriand., rad. curcumæ ana 4lb., zz., pimentæ, pip. Cayenne, capsici bacc. ana 1lb., sem. cardam. min. 4 oz., macis, caryoph. arom., cinnam. ana $1 \mathrm{oz}$. 
5. Coriander seed, turmeric of each $3 \mathrm{lb}$., black pepper, mustard, ginger, of each $1 \mathrm{lb}$., lesser cardamoms 8 oz., Cayenne pepper, cummin seed, of each 4 oz.; powder and mix: used as a sauce.

Red pepper, Cayonne pepper, Piper Cayenne. Capsicums, salt, of each lb. j, grind together, and colour with bole; from the West Indies. mill.

2. Capsicums dried 1lb., salt 4 oz. ; pound or grind in a pepper

3. English chilies $1 \mathrm{lb}$., salt 4 oz.; 100 chilies will make about $2 \mathrm{oz}$. of Cayenne, the Havour of which is superior to that of capsicum, or the imported.

Reduced Cayenne pepper. English chilies, bury in flour, bake for two hours and a half, or till they are dry enough to powder, then cut them in small pieces, to each $o z$. add flour $1 \mathrm{lb}$., water q. s. to make them into small biscuits, bake, powder the biscuit and sift it.

Prepared black pepper. Black pepper $1 \mathrm{llb}$., ground and soaked in 3 pints of vinegar for some days, the vinegar strained off, and the pepper dried; milder than raw pepper.

Prepared Cayenne pepper. Cayenue pepper ground, soaked in vinegar, the vinegar strained off, and the pepper dried; milder than raw Cayenne pepper.

Pickling salt. Brown sugar, foreign bay salt, common salt, of each 2lb., saltpetre $8 \mathrm{oz}$; mix: renders meat or butter salted with it very finely flavoured, and red.

Kidder's swcet spice. Cloves, mace, nutmegs, cinnamon, sugar, of each $1 \mathrm{lb}$.; mix : used in pastry.

Kidder's saroury spice. Cloves, mace, nutmegs, pepper, salt, of each $1 \mathrm{lb}$.; mix: used in cookery.

French sansayje spice, Fipices fines. Black pepper 5lb., cloves and nutmegs of each $1 \frac{1}{2} \mathrm{lb}$., ginger $2 \frac{1}{2} \mathrm{lb}$., anise seed and coriander seed of each three quarters of $\mathrm{alb}$.; powder them together : used by the forcign sausage makers.

Kitclen pepper. Ginger $1 \mathrm{lb}$., cinnamon, black pepper, nutmegs, Jamaica pepper, of each 8 oz., cloves $3 \mathrm{jj}$, salt $6 \mathrm{lb}$.; grind together.

Raymut spice. Salt $1 \mathrm{lb}$., flour of mustard, ground black pepper, grated lemon peel, of each half a lb., allspice, ginger, grated nutmegs, of each a quarter of an oz., Cayenne pepper $20 \%$; mix, and powder fine.

English spice. 'The roots of cyperus longus, root of calamus aromaticus, leaves of sweet willow, myrica gale, or root of avens, 
geum urbanum and g. rivale, ground together ; for in all cases a mixture of several spices is more agreeable than any one used singly.

Powder of coriander. Sem. coriandri, nux vomica, quassia, ground together: used by the ale brewers.

Sharp whites. Wheaten flour ground with alum.

Stuff. Alum in small crystals lb. j, common salt $31 \mathrm{lb}$, to mix with flour for baking.

Heading for beer. Alum, green vitriol, ana p. æq.

Mushroom powder. Mushrooms, blewits, champignons, or any other wholesome kind, half peck, 2 onions, cloves, and mace, of each a quarter of an 0z., white pepper $1 \mathrm{oz}$.; expose to a gentle heat till the liquor the mushrooms yield be dried up, then dry on tins in a slow oven till they can be powdered or ground in a mill. -2. The squeezings left in making plain mushroom catchup, mix with dried flour, roll out, dry and powder.

Oyster powder, Preserved oysters. Oysters 3 doz., salt three quarters of an oz., pound, press through a hair sieve, add dried wheat flour suff. quant. to make a paste, about $7 \frac{x}{2}$ oz., roll out to the thickness of half a crown, dry, pound, sift, put into bottles, and seal the corks: 3 av. drachms will make half a pint of sauce.

Cockle powder, Muscle powder. May be made the same way.

Anchovy powder. Pound the fish, rub through a sieve, make into a paste with dried flour, roll out thin, dry, and reduce to a fine powder.

Sprat powder. Head and gut the sprats, float them over with vinegar, add, a little salt and allspice, bake for two hours, rub them through a hair sieve, and proceed as in making anchovy powder.

Flour of mustard, Durham mustard, Farina sinapis. The seeds of black mustard dried until they form a powder when bruised, then ground and sifted to separate the hulls or black skin of the seed, which does not form so fine a powder : yellow, and must not be confounded with powdered black mustard seed, sem. sinapis trita, which is very black coloured, and used to make the foreign mustard sauces. When flour of mustard is made up into mustard sauce, and taken in too large a dose, it stops the respiration, and draws tears from the eyes; the spasm is relieved by smelling.

Reduced flour of mustard. Flour of mustard, ground white mustard seed, salt, ana p. æq.

2. Flour of mustard 14lb., ground white mustard seed, turmeric, Cayenne pepper, and common salt, in various proportions: does not affect the breath. 
Ginger beer powders. White sugar $3 j \mathrm{j}$ ij, zz. gr. v, natr. pp. gr. xxvj, in each blue paper; acid of tartar $3 j s s$, in each white paper: these quantities are for half a pint of water.

Spruce beer pozders. White sugar $3 \mathrm{j}$ эij, natr. pp. xxvj, ess. of spruce gr. x. in each blue paper; acid of tartar $3 \mathrm{ss,} \mathrm{in} \mathrm{each}$ white paper: for half a pint of water.

Portable lemonade. Acid of tartar 1 oz., sugar 6 oz., ess. limon. 10 drops; rub together, divide into 24 papers, for a tumbler of water each.

2. Concrete acid of lemons $1 \mathrm{oz}$, white sugar $4 \mathrm{lb}$, ess. limon. $\mathrm{jij}$.

Whey powder, Petit lait en poudre. Sugar of milk 2 oz., white sugar 8 oz., gum Arabic half an oz.: dose an oz., in 2 pints of water.

\section{PERFUMERY AND COSMETICS.}

Rouge, Rouge d'Espagne. Wash safflower until the water comes off colourless, dry the washed petals, and soak them in subcarb. of soda water; pour the yellow liquor upon fine white carded cotton, add lemon juice, citric acid, or acetic acid, the cotton takes a yellowish red dye; wash the cotton to take away the jellow tinge, then soak the cotton in fresh subcarbonate of soda water, decant the liquid upon some French chalk, levigated very fine, again add the acid to throw down the pure red matter, and grind the coloured chalk with a few drops of olive oil.

2. Separate the colour from the cotton by the acids; and then grind the sediment with French chalk and oil.

Pure rouge, Vert rouge d'Athenes. Separate the colour from the cotton by the acids, and dry the sediment, which becomes of a copper bronze colour when dry, but reassumes its red colour when wetted.

Pink sancers. Safflower, previously washed in water until it no longer gives out any colour, and dried, $8 \mathrm{oz}$, subcarb. of soda 2 oz, water 2 gall.; infuse, strain, add French chalk $4 \mathrm{lb}$., scraped fine with Dutch rushes, and precipitate the colour upon it with citric acid or tartaric acid.

Perfumed pouder for scent boxes. Sem. coriandri, rad. irid. Flor., fol. rosar., rad. calam. arom. ana 4 oz, f. lavand. 8 oz., moschi Эj, lign. rhodii 3 j.

2. Sem. coriandri, rad. irid. Flor., fol. rosar. rubr. ana 1 oz., macis, caryoph. arom. ana $3 \mathrm{j}$, flor. lavand. $1 \mathrm{oz}$. ziv, rad. calam. arom. 1 oz., moschi gr. iij, if agreeable.

Spec. odoriferc, for wash balls. Amyli 20 oz., rad. irid. Flor. 12 oz., ol. rorisin., ol. lavand. Angl. ana $3 \mathrm{j}$, sem. bamiæ moschatæ 2 oz. 
Pearl powder. Magistery of bismuth, French chalk scraped fine by Dutch rushes, ana p. æq. ; cosmetic.

Plain hair powder. Starch powdered, and sifted very fine.

Poudre de roses communes. Starch powder 25lb., rose leaves 1lb.; stir them with your hand every four hours, to prevent heating: the next day sift them out, and put in fresh leaves; repeat this three times; the box should be open all the time.

Poudre de roses musquées. Starch powder 3lb., musk rose leaves $1 \mathrm{lb}$.; they do not require stirring as they do not heat: the next day sift, and put in fresh for three times; the box should be close.

Poudre de jonquille. As poudre de roses musquées, but with - jonquilles for roses.

Poudre de fleurs doranges. Starch powder 25lb., orange flowers $1 \mathrm{lb}$.; stir up twice a day : repeat this three times, keeping the chest close during the making and after.

Poudre de jasmine. Starch powder 20lb., jasmine flowers no. 10,000 , laid in beds together for twenty-four hours; they do not heat : repeat this for three or four days.

Poudre de violette. Orrice, powdered and sifted.

Violet powder. Starch powder $28 \mathrm{lb}$, pulv. iridis $15 \mathrm{oz}$., ess. Bergam. 3iij, ol. rhod. ver. gtt. xxv.

Poudre blanche melangée. Add $2 \mathrm{oz}$ of parfum à parfumer les autres poudres to $1 \mathrm{lb}$. of poudre de jasmin, or de fleurs d'oranges.

Poudre de chipre. Wash oak moss for three days in running water, dry it in the sun very well, otherwise it will not powder fine; then perfume it once or twice with jasmine or musk rose flowers, which will make it take other scents better.

Pouclre de chipre de Montpellier. Poudre de chipre perfumed with Howers as before, 2lb., civette gr. xviij, musk 3 ss, ground with a little sugar.

Poudre fine à la Mareschalle. Oak moss in powder 2lb., plain powder $11 \mathrm{~b}$., cloves $1 \mathrm{oz}$., calamus arom. in powd. $1 \mathrm{oz}$., cyperus in powd. 2 oz., rotten wood in powder $2 \mathrm{oz}$; ; mix all well together. Rotten oak wood should be used, because it is red and gives a fine colour. 28lb.

Mareschale powder. Pulv. caryoph. arom. $10 \frac{x}{2}$ oz., starch powd.

Poudre de frangipane. Poudre de fleurs d'orange 6lb., poudre de chipre $61 \mathrm{lb}$.; pour $1 \mathrm{oz}$. essence of amber into a very hot mortar, rover it with powder, and beat well together; mix this with the whole by sifting, then put half a drachm of civette and a little 
sugar into the mortar, and proceed as before. The mortar and pestle should be sufficiently hot to make spittle hiss. This powder is ash grey, which agrees well with every coloured hair.

Poudre de frangipane de musquée. Instead of 3 ss civette put in only 18 grains, and add 5 ss of musk.

Poudre de fiangipane parfiumée. Mix poudre de chipre with as much plain powder, perfume it with flowers, and then add ambergris and civette, of each q. p.

Poudre dambrette. Poudre de jasmin 5lb., poudre de roses musquées Jlb. ; mix : put some in a sieve, and add 2 drachms ess. of ambergris; mix, sift, break the clots, mix them with more of the powder, and sift the whole several times to mix them well.

Musk pozder. Hair powder 28lb., musk a quarter of an oz.

Species for scenting hair powder. Pulv. irid. Flor. 1lb., ess. berg. 2 oz., ol. neroli $3 \mathrm{j}$, moschi $Э \mathrm{j}$.

Parfum pour parfumer les autres poudres. Poudre d'ambrette 12lb.; grind 12 drachms of civette with a little sugar, add to it some of the poudre d'ambrette on the sieve, and sift till you have mixed it with the powder, then get a drachm of musk into the powder by the same means.

Pâte parfumé pour chapelets et medailles. Beat up poudre fine à la Mareschalle with muc. of tragac. made with eau de millefleurs, then mould it, rubbing the moulds with an essence or huile antique of some flower: this pâte is coffee coloured.-2. Parfum pour parfumer les autres poudres $q$. p. Leat up with muc. of tragacanth. made with orange flower water, adding a thread of ess. of ambergris: this pâte is white, but may be coloured red by vermilion, or yellow by fine yellow ochre.-3. Poudre de chipre parfumée, and poudre de frangipane, each an equal quantity beat up with muc. tragac. made with eau de millefleurs : this is grey.-4. Poudre fine it la Mareschalle and cake of eau d'ange of each an equal quantity beat up with muc. of tragac. made with eau de millefleurs. - 5. Poudre de chipre parfumée, poudre de frangipane, parfum à parfumer les autres poudres, of each an equal quantity, beat up with mucil. tragac. made with orange flower water and a thread of ess. of ambergris : this pate is ash grey.

French almond pourder, Pulvis manualis. Amygd. amar. blanched 48 oz., far. oryza 26 o\%, pul. rad. Flor., cretæe ppre. ana 2 oz., far. fabarum 12 o\%, sal. tartari, benz., sperm. ceti, ana 1 o\%., ol. lavand., ol. caryoph. ana gutta $\mathrm{xxx}$, ol. jasmini per infus. Oj: mix. -2. Amygd. amar. blanched $\xi x i j$, benz, irid. Floren., far. oryza, ana $\xi_{j}$, sal tartari $3 i j$, ol. lavanil., ol. rhodii, ana gtt. $\mathrm{x} x$; mix.

Rose pearls, Rose beads. Beat the petals of the red rose in an 
iron mortar, for some hours, until they form a black paste, which is to be rolled into beads and dried. They are very hard, susceptible of a fine polish, and retain all the fragrance of the flower.

Sweet balls, Pomambra. Rad. iridis Flor. そjss, cinnam. そss, caryoph. arom., lign. rhodii, flor. lavand. ana zij, ambr. gris., mosch. ana gr. iij, muc. g. tragac. made with rose water q.s.: some cover the ball with spirit varnish, but this keeps in the scent; worn in the pocket as a perfume.-2. Plaster of Paris 3 ij, lign. santali. citr., rad. cyperi rot., caryoph. arom. ana $3 \mathrm{ij}$, benz., styr. calam.

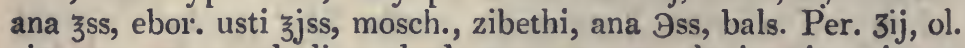
cinnam. gtt. $v$, ol. lign. rhod. gtt. $x v$, ess. de jasmine $3 j$, ess. neroli $\exists j$, muc. g. tragac. made with rose water $q$. s.: make into beads, and pierce them while yet soft.

Tooth powder, Pulvis dentifricus. Rad. irid. Flor. 4 oz., oss. sepiæ 2 oz., crem. tart. 1 oz., ol. caryoph. gtt. xvj, lake 16 drops. -2. Catechu 1 oz., cort. Peruv. Hav., crem. tart. cassiæ, bol. Armen. ana $3^{i v, ~ s a n g . ~ d r a c o n ., ~ m y r r h æ, ~ a n a ~ 3 i j .-3 . ~ R o s e ~ p i n k ~}$ 20 oz., bol. Armen., oss. sepiæ, crem. tart. ana 8 oz., myrrh 4 oz., rad. i id. Flor. 2 oz., ess. Bcrgam. 3ss.-4. Oss. sepire 4 oz., crem. tart., rad. irid. Flor. ana $2 \mathrm{oz}$, alum. usti, rose pink, ana $1 \mathrm{oz}$.5. Magnesiæ, rad. irid. Flor., rose pink, cretæ ppæ. ana 2 oz., natr. ppi. $3 v j$, ol. rhodii gtt. ij.

Lardner's prepared charcoal. Chalk coloured grey with charcoal; used as a tooth powder.

Green tooth powder. Fol. salviæ sicc., crustæ panis tostæ, salis comm. ana 3.j, nuc. mosch., caryoph. arom. ana $3 \mathrm{j}$.

Grosvenor's tooth powder. Rose pink 3lb., pulv. irid. Flor. half a lb., test. ostreor. 3lb., ol. rhodii gtt. $\mathrm{xxv}$.

Asiatic dentifrice. Coral. rub. ppr. 8lb. 4 oz., Venetian red 12 oz. $3 \mathrm{dr}$., ochre and pumice stone of each 1lb. 2 oz. $6 \mathrm{dr}$, moschi Chinæ 3ss; mix.

Hemet's dentifrice. Oss. sep. lb. jss, crem. tart. 4 oz., irid. Fl. 2 oz.

Ruspini's dentifrice. Oss. sep. 8 oz., alum rup. 1 oz., crem. tart. 2 oz., irid. Fl. 1 oz., c. c. usti 2 oz., ol. rhodii gtt. 6 .

Opiate en poudre. Brick $8 \mathrm{oz}$., China ware $4 \mathrm{oz}$. , red coral $1 \mathrm{oz}$.; powder fine, and add cinnamon and cloves, of each 1 drachm.

Depilatory. Quicklime 1 oz., orpiment $3 \mathrm{dr}$., orrice $2 \mathrm{dr}$., saltpetre $1 \mathrm{dr}$., sulphur $1 \mathrm{dr}$., soap lees half a pint; evaporate to a proper consistence.

Roseate powder. Lime 12 oz., starch $10 \mathrm{oz}$, orpiment $1 \mathrm{oz}$; mix. Both are used to take off hair. 


\section{FUMIGATING PASTILLES.}

In compounding fumigating pastilles, only those ingredients should be used that yield a sweet scent upon being burned, as ambergris, cascarilla, copal of rhus copallinum, calamus aromaticus, yellow sanders, wood aloes, gum ivy, star anise seed: musk, so commonly employed, is worse than useless, as it yields a very disagreeable sinell when burned, as does also civette--Benzoin jij, cascarillæx jj, myrrh. jss, ol. nuc. mosch., ol. caryoph. ana gtt. xv, sal. nitri jj, carb. lign. 亏̈jss, muc. g. trag. q. s.

2. Benz., oliban., styracis, gum thuris, mastic. ana 1 oz., carb. lign. 1lb. 8 oz., gum. tragac. 3iiij, water q. s.; camphire may be added if for a sick chamber.-3. Benz. 3 iij, mastich., oliban., ana jss, cascarillæ, ol. caryoph., bals Peru. ana jj, carb. lign. 2 oz. 3ij, ol. lavand. gtt. $x$, campl. $3 i j$, moschi gr. x, gum. tragac. ziv, -4. Benz. 8 oz., styr. calam. 3 xij, labdani, olibani, mastiches, caryoph. arom. ana jjss, carb. lign. 2 lb. 4 oz., muc. g. trag. q. s. -5. Styracis, benz. ana 4 oz., santal. citr. 1 oz., carb. lign. 24 oz., labdani jij, set on fire, and burnt to correct bad smells.-6. Pulv. sandal. $1 \mathrm{oz}$., pulv. cascar. $1 \mathrm{oz}$., pulv, caryoph. $1 \mathrm{oz}$, gum thuris 1 oz., olibani jiv, g. benzoin ziv, p. carbon. ziijss, styr. colat. zjss, moschi gr. v, camph. 3ij, fl. benzuin $Э \mathbf{j}$, ess. limon. gtt. $\mathrm{xx}$, ess. bergam. gtt. xv, ol. lavand. Angl. gtt. xv.-7. The cake of eau d'ange made without citrons, beat it up with muc. of tragac. made with orange flower water q. s. -8 . Benz. 1lb., storax half a lb., cinnam. half an oz., cloves $3 \mathrm{ij}$, Provins roses $2 \mathrm{oz}$., calamus a stick; beat up with muc. of tragacanth. made with rose and orange flower water.

Pastilles de roses à bruler. Cake of eau d'ange by decoctious (taking out the citrons) 1lb., rose petals fresh gathered a handful, mucilage of g. tragac. made with rose water q. s.; beat all together.

Pastilles communes à bruler. Bej. comm. 1lb., cloves half an oz., cinnam. 2 dr., calamus a stick, mucilage of tragac. q. s.

Pastilles de Portugal. Cake of eau d'ange beat up with muc. of tragac. made with orange flower water; then dissolve ambr. gris. $\mathrm{gr} . \mathrm{xx}$, in eau de mille fleurs $\xi \mathrm{ijj}$, and add this to the former.

\section{SNUFF.}

While powdering the tobacco sift often, that the tobacco may not be beaten to too fine a powder; soak in three or four waters and strain, the last time with strong expression, then dry in the sun: moisten the snuff again with rose water, orange flower water, 
or eau d'ange, which are the only waters fit for snuff; then dry, and repeat this perfuming again.-It being necessary that the dried leaves of tobacco should undergo some kind of fermentation to render them agreeable to smokers and snuff-takers, the best kinds are moistened with treacle and water during the process of drying. Tonca beans are put into snuff-boxes to scent the snuff: the leaves of Orchis fusca and those of several other species of orchides that have the scent of the Tonca bean, are used to scent snuff. French snuff is scented with the root of calamus aromaticus.

Tabac de cedrat. Is perfumed by dropping the ess. into snuff: $-T$. de Bergamotte. The same.-T. de neroli. The same. Scented snuff must be kept in close vessels.

T. parfumé aux fleurs. Put orange flowers, jasmine, common or musk roses, or tuberoses, with the snuff, for a day and a night, and sift them out; repeat this as often as necessary. Snuff does not heat with the flowers.-2. Lay paper, pricked with a large pin, between the flowers and snuff: this is better.

T. musqué. Snuff scented to your pleasure 1lb., musk 20 gr., sugar q. s. to grind the musk; mix.

$T$. en odeur de Malthe. Snuff scented with orange flowers 1lb., ambergr. 20 gr., civette 10 gr., sugar q. s.

T. à la pointe d' Espagne. Scented snuff aux fleurs 1lb., musk 20 gr., civette 6 gr., sugar q. s.

T. ambre. Scented snuff aux fleurs 1lb., ambergr. $24 \mathrm{gr}$.

$T$. en odeur de Rome. Snuff scented aux fleurs, ambergr. 20 gr., musk 6 gr., civette 5 gr., sugar q. s.

Yellow snuff. Yellow ochre the size of an egg, add chalk to lower the colour, grind with $4 \mathrm{dr}$. of oil of almonds till fine, then add water by degrees, and two spoonsful of mucil. of tragacant. till you have about a quart ; mix this with purified snuff q. v. and dry it; then grind some gum tragac. with some scented water, and moisten your snuff with it, and when dry, with a very fine sieve sift out the colour that does not adhere to the snuff.

Red snuff. Use red ochre.

Tabac de Pongibou. Yellow snuff scented with orange flowers 1lb., civette 12 gr., sugar q. s. to grind the civette to a powder, ess. of orange flowers $4 \mathrm{dr}$. Snuff will not bear more than this quantity of essence without being greasy; other essences may be used, the snuff being previously scented with the same odour.

T. fin, façon d'Espagne. Red snuff perfumed with flowers. 
USED IN THE ARTS.

Venetian cenuss, Cerussa Veneta, Plumbum album. Flake white, cawk, ana p. $x q$.

Hamburgh white lead. Flake white $1 \mathrm{cwt}$., cawk $2 \mathrm{cwt}$.

Best Dutch white lead. Flake white $1 \mathrm{cwt}$., cawk $3 \mathrm{cwt}$.

Common Dutch white lead. Flake white $1 \mathrm{cwt}$., cawk $7 \mathrm{cwt}$.

English uchite lead. Flake white reduced in price by chalk, inferior to the preccding.

Ink powder. Green vitriol 1lb., galls 2lb., gum. Arab. 8 oz. : 2 oz. nake a pint of ink. - 2. Vitriol. calc. 3 vj, pulv. g. Arab. 3 ij, indigo $j s s$, gallæ, sacch. albi, ana $\check{j}^{\mathrm{iij}}$; $\mathrm{mix}$.

Granu sylvestria. A dry powder, with many small fragments of something that has been made into a dry uniform cake; it has only 1-6th of the colouring power of fine cochineal, and is in general about 1-8th of its price; it is probably composed of the white downy substance left by the wild cocci upon the plants on which they feed, along with fragments and dust of the insects themselves, with perhaps some vegetable substance. Cochineal itself seems formerly to have been nade into a paste and dried.

Indian ink, Indicum, Atramentum Indicum. The best kind is made of real lamp black, procured by burning oil under shades, mixed up with glue made of an ass's skin, to which is added a little musk ; astringent $3 \mathrm{j}-\mathrm{ij}$, dissolved in water or wine, in hemorrhages, also stomachic.-2. Russian lamp black made up with glue. -3. Honey $11 \mathrm{~b}$., yelk of eggs no. 2, gum. Arab. half an oz., lamp black q. s.; beat into a mass. - 4. Horse beans burnt perfectly black, ground fine, and made up into sticks with gum water; is very inferior to the others.-5. Seed lac $3 \mathrm{j}$ 3ij, borax $3 \mathrm{j}$, aquæe jiiij : lamp black q. s. to form into cakes.

Lump archel, Tournesol en pains, Laccacarulea, Lacmus tinctorius. Prepared from Canary archel, ground archel, and some other lichens, by reducing them to powder, adding half as much pearl ashes, and moistening the whole with urine or bone spirit; a small proportion of lime is then added, and the archel cut into cubes and dried.

Litmus, Lacmus tinctorius albo-crerulcus. Like the former, with a large proportion of whiting at the end, which renders it light blue; some add infusion of Brasil wood.

Cudbear. Canary archel soaked with urine or bone spirit, and ground to powder. All are used in dyeing violet colours, which, however, do not stand well; also as very delicate tests for acids 
and alkalies, the infusion or tincture being reddened by acids, and rendered green by alkalies.

Florey black, Florée d'Inde. The dried scum of the dyer's woad bath, which is prepared by diluting woad with water, adding some slaked lime, and keeping the liquor warm when it ferments and throws up a blue froth. It is remarkable, that although the fermented bath is red, cloth dipped in it comes out of a green colour, which turns, as it dries, to a blue.

Florence lake, Lacca Florentina. Pearl ashes 1 oz. 3iv, water q. s., dissolve; alum. Rom. $2 \mathrm{oz}$. 3iv, water q. s., dissolve : filter both solutions, and add the first to the alum solution while warm, strain, mix the sediment upon the strainer with the first coarse residuum obtained in boiling cochineal with alum for making carmine, and dry it. This lake is an excellent glazing colour ground with linseed oil, and used with drying oil; having little body it may be mixed with Indian red.

Drop lake, Lacca in globulis. Make a magistery of alum, as in making Florence lake; boil Brasil dust $1 \mathrm{oz}$. 3iv, in water 3 pints ; strain, add the magistery or sediment of alım to the strained liquor, stir it well, let it settle, and dry the sediment in small lumps.

Fine madder lake, Lacca columbina. Dutch grappe madder, (that is, madder root ground between two millstones a small distance apart, as in grinding pearl or French barley, so that only the bark, which contains the most colour, is reduced to powder, and the central woody part of the root left) $2 \mathrm{oz}$., tie it up in a cloth, beat it in a pint of water in a stone mortar, repeat with fresh water, in general 5 pints will take out all the colour, boil, add alum $1 \mathrm{oz}$., dissolved in a pint of water, then add oil of tartar $1 \mathrm{oz}$. and a half, wash the sediment, and dry; produces half an oz.

Lac lake, Lac colour, East Indian cochineal. Fresh stick lac, boil in water impregnated with subcarbonate of soda, and add a solution of alum, which throws down the lake equal to 1-5th of the lac. It requires about four times the quantity to produce a dye equal to cochineal.

Lac dye. Preparation unknown, softens in water, and contains less colouring matter than lac lake.

Orange lake. Best Spanish annotto 4 oz., pearl ashes 1lb., boil in 1 gall. of water for half an hour, strain, dissolve, alum $11 \mathrm{~b}$. and a half in water 1 gallon and a half, strain, and add the coloured liquid as long as any sediment falls, strain, and dry the sediment.

Red and purple lakes may be prepared from red dulse, cochineal, and kermes berries, and yellow lake from turmeric, by boiling them in water, or steeping them in spirit of wine, straining, mixing the 
liquor in white precipitate of lead, oxide of tin, or Baume's alum white, to furnish a body to the colour, and drying.

Iris green. Juice of the petals of blue flag, iris nostras, ground with quicklime.

Cork, Corker. Lichen omphalodes made up into balls; used to dye wool.

Weld yellow. Fine whiting $4 \mathrm{lb}$., water 4 pints, boil together into a suiooth paste, add gradually alum half an oz. in fine powder. Boil weld in water for a quarter of an hour, strain, and add the liquor to the pap of whiting and alum until the desired shade of colour is obtained; pour into earthen pans, and dry on chalk : used by the paper-hanging makers.

Brown pink. French berries $1 \mathrm{lb}$., fustic in chips half a $\mathrm{lb}$., pearl ashes $11 \mathrm{lb}$., water $1 \frac{x}{2}$ gall., boil in a tin or pewter caldron, strain through flannel while hot: dissolve alum $1 \frac{x}{2} \mathrm{lb}$., in water $2 \frac{x}{2}$ gall., pour it into the strained tincture as long as a sediment falls, wash the sediment, drain on paper or cloth and dry.-2. French berries $2 \mathrm{lb}$., water 2 gallons, boil for two hours, strain through flannel; add levigated soft part of the cuttle fish bone $1 \frac{1}{2} \mathrm{lb}$., evaporate in a water bath to a stiff consistence, grind on a stone, cut into cakes and dry on a board. Is a fine glazing colour ground with linseed oil and used with drying oil.

Dutch pink. Prepared from French berries in the same manner as brown pink, but turmeric is used instead of fustick, and whiting, starch, or white lead to give the body. It should be of a fine golden yellow and very bright.

Schult gell. Prepared from birch leaves.

English pink, Light pink. Prepared like Dutch pink, but with more whiting.

Rose pink. Whiting coloured with a decoction of Brasil wood and pearl-ashes; very fine colour, but does not stand.

Stone blue, Fig blue, Crown blue, Mecklenberg blue, Queen's blue, Indicum vulgare. Indigo reduced in price by adding starch.2. Indigo and whiting.

Sap green. Juice of buckthorn berries, black alder, or of evergreen privet, 12 pints, lime water 8 pints, gum Arabic $6 \mathrm{oz}$; evaporate till quite thick, then pour into bladders.

English verdigrise. Blue vitriol 24lb., white vitriol 16lb., sugar of lead 12lb., alum $2 \mathrm{lb}$; ; all coarsely powdered, put in a pot over the fire, and stirred until they are united into a mass.

Cake water colours. Extracts of colourcd flowers, or the usual colours made up with gum water and a little isinglass jelly, and put into greased moulds. 
Crayons. Spermaceti 3 oz., boiling water 1 pint, add bone ashes finely ground 1lb., colouring matter, as ochre, \&c. q. p. roll out the paste, and when half dry cut it in pipes. - 2. Pipeclay, coloured with ochre, \&c. q. p. make it a paste with ale wort.

Parolic cement, Universal cement. Curdle skim milk, press the whey out of it, break the curd into small pieces, and dry it until it becomes fit to grind, in a coffee mill, to a coarse powder; $100 \mathrm{oz}$. of fresh curd by drying is reduced to about 30 . Take perfectly dired curd $10 \mathrm{oz}$., strong quicklime in powder $1 \mathrm{oz}$., camphire also powdered Эij; mix, and fill wide-mouth ounce phials therewith: to be kept carefully stopped. When used, mix with a little water, and apply it quickly.

Clothes powder. Pipeclay $1 \mathrm{lb} .8$ oz., pip. alb., amyli, ana $1 \mathrm{oz.}$ rad. irid. Flor. 1 oz. jiv, S. V. R. 2 oz.

Clothes ball. Pipeclay 2lb., Fullers' earth, whiting, ana 4 oz., pip. alb. 2 oz., fel bovis $4 \mathrm{oz}$; ; used for cleaning clothes.

Breeches ball. Bath brick 1lb., pipeclay 2lb., pumice stone powder $4 \mathrm{oz}$., ox gall $6 \mathrm{oz}$.; they may be coloured with rose pink, yellow ochre, umber, Irish slate, \&c., to any desired shade.

Essential salt of lemons. Crem. tart. $4 \mathrm{oz}$, sal. acetosellæ $8 \mathrm{oz}$., used to take iron moulds out of linen.

Silvery boiling pouder. White argol, common salt, alum, of each llb.: plate boiled in water with a little of this powder acquires a brilliant whiteness.

Plate powder. Hydrarg. c. cretæ 1 oz, cretæ pp. 4 oz.-2. Polisher's putty, corn. cerv. ust. ana $8 \mathrm{oz}$., whiting $1 \mathrm{llb}$.

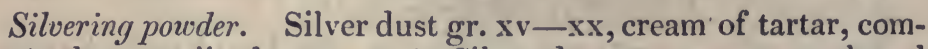
mon salt, ana 3 ij, alum 3 ss.--2. Silver dust $z s s$, common salt, sal ammoniac, ana $3 \mathrm{jj}$, corros. sublimate $3 \mathrm{j}$; make into a paste with water: used to silver copper, which is to be cleaned by boiling with argol and alum, then rub it with either of these powders, and polish with soft leather. 


\section{OILY OR GREASY COMPOUNDS.}

\section{COMPOUND OILS.}

FOR MEDICAL USE.

OIL OF Roses BY INFusiox, Oleum rosaceum, Ol. rosa. Rose petals, not fully blown, picked, heeled, and beat to a pulp, 4 oz., olive oil 1 pint ; expose to the sun for a week, press out the oil, repeat the insolation with fresh roses twice more, then leave the roses in the oil for use.

Orl of camomile by infusion, Oleum chamamelinum. From the flowers, as that of roses; used in sprains.

Ort of St. Johx's wort, Oleum hyperici, Bals. hyp. simp.

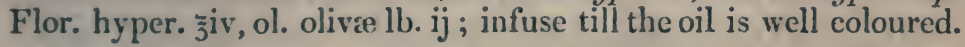

B. hyp. fact. Ol. viride, rendered paler by adding rape oil.2. Ol. oliv. comm. 1 gall., rad. anchusæ $8 \mathrm{oz}$; vulnerary.

Orl of white lilies, Oleum lilionum. As oil of roses; emol: lient : Ol. oliv. is usually sold for it.

OrL of еARтн woras, Oleum lumbricorum. Lumb. terr. lb. ss, ol. oliv. lb. ij, vini albi lb.ss; boil till the wine is consumed, then press.

Or. L. Fаст. Ol. olivæ com., ol. lini, ana lb. j.

Oil of elder ýowers, Oleum sambucinum. Fl. sambuci lb. j, ol. oliv. lb. ij; boil till crisp, press out the oil, and let it settle: emollient.

Grean elder oix, Ol. samibuci viride. Elder leaves, fresh, lb. $j$, olive oil 2 pints, boil till the leaves are crisp, press out the vil, and put it on the fire again until it acquires a fine green colour.

Exetik oll, Ol. Excestrense. Ol. viride lb. xvj; euphorb. - sinapeos, - castor, pyrethri, of each $j^{j}$.

On, of muchlaces, Ol. e mucilaginilus. Rad. althæe rec. lb. ss, sem. lini, sem. feeni Graxci, ana ziij, aquae lb. ij; boil for half an hour, add ol. olive lb. iv, continue boiling till the water is nearly consumed, pour off the oil. -2 . Rad. althxae rec. $4 \mathrm{lb}$., sem. foenugr., sem. lini, ana $2 \mathrm{lb}$., a mixture of common olive oil, sperm oil, and seal oil, in equal parts, 4 galls. - 3. Sem. focnugr. 8 oz., ol. lini 2 pints; infuse for a week, strain : very cmollient. 
Green oil, Ol. viride. Fol. lauri, fol. rutæ, fol. majoran., fol. absinth. mar., fol. chamæmeli, all fresh, ana ziij, ol. oliv. lb. $i j$; boil till crisp, press out the oil and let it settle; emollient.

Ort of scoliplons, Ol. scorpionum. Live scorpions, no. 30, ol. amygd. lb. $\mathrm{ij}$; expose to the sun for forty days : centipedes are usually substituted for scorpions, as being more easily procurable; externally emollient, internally diaphoretic, occasioning a prickly heat on the skin.

Campholzated orl, Linimentum camphorce, Ol. camphoratum.

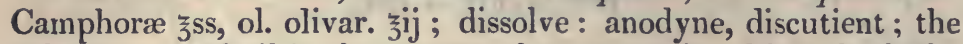
only compound oil in the present pharmacopoia, although all the preceding are in esteem with private practitioners.

BALSAM OF sUlPHUR, Balsamum sulphuris simplex, Ol. sulphuratum, P. L. Fl. sulph. 亏iv, ol. olivæ 3 xvj.

Or. sulphuratum, P. E. Fl. sulph. žij, ol. olivæ žxvj; dissolve.-2. Fl. sulph. 3lb., ol. lini 4 galls.; dissolve by boiling.

Balsamum sulphuris Barbadense. Petroleum sulphiratum. Petrol. Bbd. 弓xvj, fl. sulph. 亏iij ; detergent to ulcers.

Bals. SUlpir. Anisatum. Fl. sulph. 1 oz., ol. anisi 4 oz. ; dissolve.-2. Bals. sulph. simp. scented with ol. anisi; pectoral, gtt. $\mathrm{x}$ to $\mathrm{xxx}$.

Common Dutch props, Bals. sulph. terebinthinatum. Fl. sulph. 4 oz., ol. terebith. 8 oz.; dissolve.-2. Bals. sulph. simp. $4 \mathrm{oz}$, ol. tereb. 1 pint ; dissolve: diuretic, detergent.

Gurstonian embrocation for rheumatism. Ol. oliv., ol. terebinth. ana $乡$ jss, spir. vitrioli ziij.

Huile acostique. Olive oil lb. ss, bullocks' garlick, bay leaves of each $4 \mathrm{dr}$.; boil fifteen minutes, strain: for earach, a little on cotton to be put into the ear.

TAYLOR's REMEDY FOR DEAFNEss. Ol. amygd. lb. j, rad.

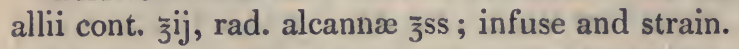

LYNCH's EMBROCATION. Ol. olivæ scented with essential oils, and coloured with alkanet root.

WhiteheAD's ESSENCE OF MUSTARD. Ol. terebinth., camph., spir. rosmarini, to which is added flour of mustard.

Roche's EMBRocation For the HOOPING COUGH. Ol. olivæ ¡xvj, ol. succ. ఓviij, ol. caryoph. q. p. to scent it strongly.

Balsamum Saturni. Sacch. Saturni 8 oz., ol, terebinth. q. s.; dissolve, and pour off.

Mixed olls for sal volatile drops, Olea mixta. Ess. berg., ess. limon. ana $\zeta j$, ol. lavand. exot., ol. piment. ana $\xi^{s s .}$

Oleum anisi reductua. Ol. anisi 1lb., almond oil $8 \mathrm{oz}$, 
sperm. ceti $1 \mathrm{oz}$., to make it candy in winter.-2. Ol. anisi 3lb., ol. olivæ opt. 1lb.

Or. CARYOPHYloRUM REDUCTUM. Ol. caryoph., ol. ricini ana $q \cdot p$.

Balsamum Peruvianum reductum. Bals. Peru. 3lb., benz. Ilb., S. V. R. q. s. to give it a proper consistence.

Bat.s. Peruv. Factitiun. Bals. Tolu 6lb., gum. ben7. 14lb., S. V.R. 2 gall.

Butyrum cere factitium. Sperm. ceti, ol. amygd., ol. lateritii, ana $\mathrm{lb} . \mathrm{j}$; mix.

Balsanum Copaibe reductum. Bals. Copaib. 6lb., pale rape oil 2lb., resin. fl. 1lb.-2. Res. flav. $7 \mathrm{lb} .8$ oz., bals Copaibæ 48lb., resin 2lb., rape oil 14lb. -3 . Copaib. 12lb., resin 4lb., Genoa oil a gallon.

Solution of copaiba, Supposed to be Frank's solution by Battley. Take $12 \mathrm{oz}$. of balsam of copaiba, and six of calcined magnesia, rub together, add a pint of proof spirit, filter, and then half an ounce of spirit of nitrous ether.

Copaiba Factitia. Nut oil $7 \frac{1}{2} l$ lb., res. fl. $2 \frac{1}{2} l b .$, ol. junip. 2 oz., Bals. Canad. 20 oz., ol. sabinx, ol. aurant. ana 1 oz.-2. Bals. Canad. 8lb., resin fl. 2lb., ol. lini 4lb., tereb. Ven. $2 \mathrm{lb}$.

Ol. succini reductum. Ol. succin. lb. j, petrol. Bbd. lb. ij.

Or. ricini redúctum. Ol. ricini 8lb., ol. amygd. $2 \mathrm{lb}$.

Balsamum terebintuin.e vulgare. Res. nigræ, ol. tereb. ana $11 \mathrm{~b}$.

Bals. Gilfadense factitium. Res. fl. 10lb., melt, and add tinct. benz. 2lb.; evaporate to a proper consistence, add css. limon. 3lb.; ol. roris. 2lb., ol. carui $2 \mathrm{lb}$.

Oz. lateritium Factitium. Ol. lini llb., ol. tereb. half a lb., ol. corn. cerv. 1 oz., petr. Bbd. 1 oz.

Ol. MENTIR PIPERITIS REDUCTUM. Ol. menth. pip. 3lb., S. V. R. $11 \mathrm{lb}$.

Ol. organi Reductum. Ol. origani 7lb., ol. terebin. 2lb., petrol. Bbd. q. s. to colour it.

Common oll of PETre, British oil, Ol. petra vulgare. Ol. tereb. 8 oz., petrol. Bbd. 4 oz., ol. rorism. ziv.-2. Ol. tereb. 5lb., asphalt. $12 \mathrm{oz}$, ol. lateritii $8 \mathrm{oz} .-3$. Ol. tereb. 5lb., ol. laterit. ver. $8 \mathrm{oz}$.

VETERINARY MEDICINES.

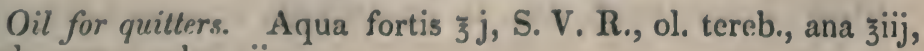
hydr. præc. rubr. $3 i j$. 
Embrocation for strains. Soft soap 1 oz., spir. of wine 4 oz., oil of rosemary and camphire of each $2 \mathrm{dr}$.; mix.-2. Soft soap, elder flower ointment, spir. of wine, and oil of turpentine, of each 4 oz. ; mix.

Liquid blister. Span. flies 1 oz., boiling water half a pint; soak for a day and night, add spir. of wine $4 \mathrm{oz}$., corrosive sublimate $1 \mathrm{dr}$., previously dissolved in 3 or $4 \mathrm{dr}$. of spirit of salt : may be either strained or used as it is. -2 . Spir. of wine and liquid ammonia of each $2 \mathrm{oz}$, , oil of turp., of origanum, or of rosemary, either of them $1 \mathrm{oz}$., Spanish flies powd. $6 \mathrm{dr}$. to $1 \mathrm{oz}$; mix.3. Blistering plaister of the College $2 \mathrm{oz}$., rub it down with half an oz. to an oz. of oil of turp.-4. Sweet oil 3 oz., oil of turpentine $1 \mathrm{oz}$. powdered cantharides lualf an oz.; mix.

Ointment for spavins. Euphorb. 1 oz., corros. subl. $3 \mathrm{j}$, arsenic. alb. $3 \mathrm{ij}$, ol. origan. $1 \mathrm{oz}$, ol. lauri $4 \mathrm{oz}$.

Liniment for thrushes and canker. Tar $4 \mathrm{oz}$; melt and add spirit of salt $6 \mathrm{dr}$., verdigris $4 \mathrm{dr}$. : mix.

Oil for worms in dogs. Oil of turp. $4 \mathrm{dr}$., castor oil 1 oz.; mix for a dose: in strong dogs the oil of turp. may be given alone first, and three or four hours afterwards the castor oil.

Oil of spike. Ol. tereb. coloured with rad. anchusæ q. s.2. Ol. tereb. 6 pints, petrol. Bbd. 4 oz., rad. anch. 2 oz.: used by farriers as a liniment.

Mixed oils, Nine oils, Oleum ex omnibus. Train oil 23lb., ol. terebinth. 6lb., ol. lateritii, ol. succini, ana 1lb., spir. vin. camph. 2lb., petrol. Bbd. 7lb., ol. vitrioli $2 \mathrm{oz}$.

The oils. Ol. vitrioli, ol. terebinth., ol. olivæ comm., ana p. æq.

Newmarket oil. Ol. lini, ol. terebinth., ol. hyperici, ana 3lb., ol. vitrioli 1 oz.; used in sprains, as also in lumbago and rheumatism.

Lord Stamford's mixed oils. Ol. origani 6 oz., ol. terebinth. 1lb. 8 oz., S. V. R. 1lb. 2 oz., ol. chamæm. or virid. 6lb., gum camphor. $3 \mathrm{oz}$.

Taylor's mixed oils. Ol. absinthii 2lb., spir. vitriol. dulc. 3lb., ol. origani veri $11 \mathrm{lb}$.

Radley's mixed oils. Petrol. B. B.'8 oz., ol. lini, ol. terebith., of each 4 pints, ol. vitrioli $4 \mathrm{oz}$; ; add, when cold, ol. origani $1 \mathrm{oz}$.

Marshall's mixed oils. Ol. lini, ol. olivæ, ana lb. j, ol. virid., ol. tereb., ana lb. ss, ol. vitrioli 3 jss. M.

Black oil. Ol. tereb. $4 \mathrm{lb}$,, ol. vitrioli 8 oz., ol. rapæ 1 gall., ol. Brit. 4 oz. 
Darby's oil. Ol. succini, bals. sulph., petrol. Barb. ana p. æq.

Mixture for bugs. Corros. sublimate $3 \mathrm{ij}$, S. V. R. 8 oz.; rub together, add ol. terebinth. 8 oz.

\section{PERFUMERY AND COSMETICS.}

Huile antique à la rose. $-H$. ant. à la tuberose.-H. ant. à la Acur dorange.-H. ant. au jasmin. Oil of ben nuts, scented with the essences of the different flowers, gtt. $x x x$ to $1 \mathrm{~b} . \mathrm{j} .-2$. Olive oil scented the same; keeps the hair moist. -3. Mix the flowers with ground blanched bitter alınonds, and then press for the oil ; dries the hair.

H. ant. à la violette. Oil of ben, olives, or almonds, scented with orrice, in the same manner as in making essence de jasmin, and then pressed out of the wool or cotton.

H. ant. aux mille fleurs. Oil of ben or almonds, mixed with different essences to the fancy of the perfumer, but so that none shall predominate.

$H$. ant. verté. Olive oil $\mathrm{lb}$. j, gum guaiacum $3 \mathrm{j}$; after some time strain, and scent to your pleasure.

$H$. ant. rouge à la rnse. Olive oil $\mathrm{lb}$. $\mathrm{j}$, alkanet root 3 ss; strain, and add attar of roses 15 drops.

Oil of roses. Attar of roses 3ss, O. O. 0.8 oz.

Micassar oil. Olive oil lb. j, oil of origanum $3 \mathrm{j}$.

Oil for the toothach. Ol. terebinth. $\xi \mathrm{j}$, camph. $3 \mathrm{ij}$.

Pomatum scent. Ol. lavand. exot. 14 oz., ol. caryoph. ver. 1 oz., ol. origani 2 oz., gum benzoin 20 oz.-2. Ess. Bergam., ess. limon. ana 12 oz., ol. caryoph., ol. origani, ana 3 oz., gum benzoin $20 \mathrm{oz}$. -3. Ess. Bergain. 1lb., ess. limon. 8 oz., ol. origan., ol. caryoph. ana 2 oz., ol. aurant. $1 \frac{1}{2}$ oz.

Scent for cowslip pomatum. Ess. Bergam. 1lb., ess. limon. half a lb., ol. caryoph. $4 \mathrm{oz}$.

Scent for jonquille pomatum. Ess. Bergam., ess. limon. ana half a llb., ol. caryoph. $2 \mathrm{oz}$, ol. sas afras, ol. aurant. ana $1 \mathrm{oz}$.

Scent for mille fleur ponnatum. Ess. limon. 3 oz., ess. ambergris 4 o\%., ol. caryoph., ol. lavand. Angl., ana 2 oz.

\section{USED IN THE ARTS.}

Drying oil, Boiled oil, Oleum desiccativum. Nut or linseed oil 8lb., white lead dried, sacch. Saturni dried, vitrioli albi dried, ana $1 \mathrm{o \%}$. , litharg. $12 \mathrm{oz}$. ; boil slightly and scum until a pellicle is formed, then cool, and let it settle.-2. Linseed or nut oil $16 \%$ o, litharge $1 \frac{1}{2} \mathrm{oz}$. , vitr alb. 3iij ; boil.-3. Linseed or nut oil $160 \%$., litharge 3 or $4 \mathrm{oz}$; boil. -4. Very old linseed or nut oil $16 \mathrm{oz.}$, 
litharge 3 or $4 \mathrm{oz.}$; mix, and let it stand for some time, shaking it often, then pour off. -5 . Nut oil $2 \mathrm{lb}$., water $31 \mathrm{lb}$., vitr. albi 2 oz. ; boil till nearly all the water is consumed, then expose to the sun for some time.-6. Oil, mix with snow or powdered ice, and keep it from thawing as long as possible; in two months the oil will have acquired the drying property: used to mix with colours to cause them to dry quickly.

Painters' cream. Nut oil $3 \mathrm{oz}$., mastich half an oz.; dissolve, add sacch. Saturni $3 j$, and then water gradually to the consistence of cream; used by painters to cover their work which they are obliged to leave for some time: when they begin again it is washed off with a wet sponge.

Furniture varnish. White wax 8 oz., ol. terebinth. 1 pint.

Picture varnish. Mastich 12 oz., Scio turp. 2 oz. ziv, camphire gr. xxx, pounded glass $4 \mathrm{oz}$, oil of turpentine $3 \frac{x}{2}$ pints; pour off the clear: used for oil paintings.-2. Japanner's copal varnish 2lb., heat it, and pour it into a mixture of turpentine $1 \frac{x}{2} \mathrm{lb}$., and drying oil half a lb. : it dries slowly, but never chills.

Gold varnish for leather. Turmeric, gamboge, ana $9 \mathrm{j}$ ss, oil of turpentine 2 pints, add seed lac, gum sandarac, ana $4 \mathrm{oz}$, dragon's blood ziv, turp. $2 \mathrm{oz}$., pounded glass $4 \mathrm{oz}$; ; pour off the clear.

Copal varnish. Oil of turpentine, thickened by keeping, 8 oz., copal $2 \frac{x}{2}$ oz. -2 . Oil of turpentine $6 \mathrm{oz}$, oil of lavander $2 \mathrm{oz}$, copal $1 \mathrm{oz}$.

Japanner's copal varnish. Copal 4lb., melt in a glass matrass till the water is evaporated, as will appear by the vapour condensed on any cold substance dropping quietly to the bottom; pour in boiling hot linseed oil 1 pint; take the matrass from the fire, and mix the varnish while hot with about its own weight of oil of turpentine.

Transparent japan for tin ware. Oil of turpentine $8 \mathrm{oz}$. , oil of lavander $6 \mathrm{oz}$., copal 2 oz., camphire $3 \mathrm{j}$.

Le Blond's varnish for prints. Balsam. Copaibæ 4lb., copal in powder 1lb.; add by single ounces every day to the balsam, keeping it in a warm place, or the sun, stirring it often; when all is dissolved add true scio turpentine q. p.

Sheldrake's copal varnish. Ol. terebinth. rectif. veri 1 pint, spir. sal ammon. $2 \mathrm{oz}$. ; mix, add copal in small pieces $2 \mathrm{oz}$. : stop the vessel with a cork cut in grooves, bring it quickly to boil, so that the bubbles may be counted as they rise, and keep it at that heat till the copal is dissolved: watch it constantly, for if the least stoppage or over-heating takes place, it is in vain to proceed: then 
leave the vessel till quite cold before you open it, otherwise the varnish will be blown out with violence.

Varnish for coloured dravings. Canada balsam 1 oz., oil of turpentine $2 \mathrm{oz}$. : size the drawings first with a jelly of isinglass, and, when dry, apply the varnish, which will make them resemble vil paintings.

Common turpentine varnish. Resin. flav. 3lb. 8 oz., ol. tereb. 1 gall.-2. Ol. tereb., ol. spica, sang. dracon., ana lb. j.

Italian varnish. Boil Scio turp. $8 \mathrm{oz}$. until it is brittle; powder very fine, and dissolve in ol. tereb.

Mastic varnish. Gum mastic 4 oz., ol. tereb. 2 pints.

Oil varnish for common work. 'Resin 3lb., turpentine 2lb., drying linseed oil 10 pints; dissolve by heating: if too thick, thin by a little oil of turpentine.

Gold size. Ol. lini $16 \mathrm{lb}$, asphalt. 2lb., brown umber 1lb., red lead 1lb., turp. 8lb.-2. Gum anime, gum asphaltum, of each $1 \mathrm{oz}$. , litharge, red lead, brown umber, of each half an oz., linseed oil 4 oz., drying oil $8 \mathrm{oz}$.; melt together, and strain.

Japan gold size. Gum. ammon. 4 oz., linseed oil $1 \mathrm{oz}$.; dissolve by boiling, and thin by adding oil of turpentine.

Sheldrake's oil for painting. Nut or poppy oil 1 pint; boil, add ceruss. 2 oz., when dissolved add a pint of his copal varnish, previously warmed, and stir till the oil of turpentine is evaporated: gives more brightness than common drying oil, but less than varnish; loses its drying quality in time, therefore only so much as is sufficient for a month or six weeks" consumption should be made at once.

Black japan for leather. Boiled linseed oil 1 gallon, burnt umber 8 oz.o, asphaltum 3 oz., boil, and add ol. terebinth. q. s.2. Ol. tereb. 2 oz., shell lac 1 oz., S. V. R. 3iiij, bone black q. s.

Varnish for grates, Brunswich black. Asphalt. comm. 4lb.; melt, add ol. lini 2lb., ol. tercbinth. 1 gall.

Norfolk fluid for preserving leather. Linseed oil 3 pints, res. flav. $40 \%$, fir resin 2 o\%., cer. flav. $12 \mathrm{oz.}$; melt, add neat's foot oil 2 pints, ol. terebinth. 1 pint : to preserve and soften leather.

IFexille varnish. Indian rubber dissolved in a sufficient quantity of petroleum, naphtha, or oil of coal tar ; used for varnishing balloons.

Vernis Martin. Put Scio turpentine $4 \%$. into a gallon stone ware pot on a clear fire, when fluid add $80 \%$ finely powdered yellow amber, in a quarter of an hour add copal in pieces $11 \mathrm{~b}$., scio turp. and warm spirit of turp.. of each $4 \mathrm{uz}$.; in half an hour 
add white resin $2 \mathrm{oz}$, keep it on the fire till it is as fluid as water, then take it off, and add of either nut, poppy, or linseed oil, hot, $24 \mathrm{oz}$., give it a boil up, add hot turpentine $2 \mathrm{lb}$., boil up and add another lb. of hot turpentine, boil up, cool, and strain; if too thick set the pot in warm water, and thin with spirit of turpentine: it grows better by age.

Meggellup. Mastich varnish 1lb., pale drying oil 2lb.: used by painters to apply their glazings with.-2. Turpentine, mastich varnish, linseed oil mixed in various proportions.

Amber varnish. Scio turpentine $8 \mathrm{oz}$., melt, add 1lb. of powdered amber, keep on the fire half an hour, take it off, and add $2 \mathrm{oz}$. of white resin quite warm, add 1lb. of hot linseed or poppy oil; when cold, strain.

Hard amber varnish. Melted amber 4 oz., ol. lini 2 pints; boil until dissolved.-2. Melted amber $4 \mathrm{oz}$., ol. lini and ol. tereb. of each 1 pint : the residuum left in distilling amber may be used.

Oil varnish for buildings. Wood tar 1 gall., tallow 1 oz., brown rosin 2 oz.; melt together.-2. Wood tar 1 gall., copperas in powder 2 oz. ; mix.

Prepared asphaltum. Melt Scio turp. 2 oz., add bruised asphaltum $1 \mathrm{oz}$., take it off the fire, thin with spir. turp.

Wilson's prepared asphaltum. Bals. of Copaibæ 2 oz., simmer, add bruised asphaltum $1 \mathrm{oz}$, take it off the fire and thin with spir. of turp. : an excellent glazing colour.

Scouring drops, Essence vestimentale. Spir. of turp. and essence of lemons, of each $1 \mathrm{oz}$. by measure : the oil must be fresh and the essence newly made, or the essence of lemons will leave a circle round the spot.

Oil of spike. Ol. tereb. 3 pints, ol. lavand. 1 pint: used by. enamellers to mix their colours.

Furniture oil, Oil stain, Mahogany stain. Ol. lini 1 gall., alkanet root $12 \mathrm{oz}$., rose pink $6 \mathrm{oz} .-2$. Linseed oil lb. jss, resin $4 \mathrm{oz}$.

Water proof liquid. Indian rubber $3 \mathrm{j}$, ol. tereb. $6 \mathrm{oz}$, and add ol. lini $8 \mathrm{oz}$.

\section{SOAPS.}

FOR MEDIC.AT, USE.

Almond orl soap, Sapo amygdalinus. Oil of almonds q. v., lixivii saponarii 3 times as much, simmer together for some hours, until the oil forms a jelly; when cooled, add common salt q. s., and 
continue the boiling until the soap is solid, when cooled skim it off the water and pour it into moulds. - 2. Soap ley made of barilıa or kelp (at 38 deg. Baume's hydrom., or so strong that a bottle holding $8 \mathrm{oz}$. water will hold 11 of the ley) 2lb., oil of almonds $4 \mathrm{lb}$.; rub them together in a mortar, and put the mixture in tin moulds for some weeks.-3. Ol. amygd. 7 pints, soap ley 13 pints, common salt q. s.; produces $11 \mathrm{lb}$.

Vexice so ap, White Castile soap, White Marseilles soap, Alicant soap, Sapo, S. Venetus, Sapo albus Hispanicus, S. Aloensis. From olive oil and barilha; white : are aperient, diuretic, detergent, gr. $x-\jmath$ ss, bis in die; also in calculous complaints, $̌ s s-z j$ daily.

Mottled Castille soap, Sapo Castilliensis marmoreus. From olive oil and barilha, white, with veins made by adding a solution of green vitriol to the soap; a detergent cosmetic.

Starkey's soap, Sapo tartari. Rub warm subcarb. of potash with oil of turpentine, adding a little water.

Macquer's acid soar, Sapo vitriolicus. Sapon. Ven. 4 oz., ol. vitrioli q. s.; add the acid by degrees to the soap rendered soft by a little water, continually rubbing the mass in a mortar; detergent: used when alkalies would be prejudicial.

Crotos oil soap. Croton oil $3 j$, aq. potassa 3 ss, rub together; purgative, dose gr. ij or iij.

\section{VETERINARY MEDICINE.}

Soft soap, Green soap, Sapo viridis, Sapo mollis. From rape, linseed, and other seed oils, and a ley of potash; transparent, yellowish, with small seed-like lumps of tallow diffused through it : used externally.

Black soap, Sapo niger. From fresh oil and a ley of potash, without any tallow, dark coloured, ill smelling.

2. Soft soap 7lb., train oil 1lb., water 7 pints; boil together, add common ivory black q. s. to colour it: used in ointments by cattle doctors.

\section{PERFUMERY AND COSMETIL'S.}

Shaving paste. White wax, sperm. ceti, almond oil, of each $3 \mathrm{j}$; melt, and while warm beat up with rose water q. s., and adil a square of Windsor soap.

Transparent soap. Dissolve almond soap in spirit of wine, filter, and distil off the spirit.-2. Soft soap $15 \mathrm{lb}$., dry and dissolve in S. V. R. 2 gall., succ. lim. $18 \%$ \% ; scent ad libitum.

White wash loalls. Sapon. alb. 6lb., amyli 3lb., aq. rosa 8 oz., aq. rorismar. 4 oz., camphorse ziv, species odorifer. 2 oz. -2. Sap. 
alb. Hisp. 1lb., aq. rosar. 3 pints, alburn. ovor. no. ij, aq. kali ppi. 1 oz.; boil till hard again, add ol. lign. rhod. $3 \mathrm{j}$, ol. caryoph. gtt. $x$, ess. jasmin. $\xi j$, ess. neroli 3 ss, and form into squares.3. White soap 5lb., rad. irid. Flor. 4 oz., amyli 3 oz., styrac. calam. 1 oz., aq. rosar. q. s.-4. Sap. alb. Hisp. lib., almonds blanched, beat up into a paste with rose water and orange flower water $3 \mathrm{oz}$., oxid. bismuthi 3 j, kali ppi. $3 \mathrm{ij}$, moschi gr. vj, zibethi gr. iij, ol. lign. rhodii $3 \mathrm{j}$, ess. jasmin. $3 \mathrm{j}$. -5 . White soap, starch, of each lib., ess. limon. ziv, aq. rosar. $8 \mathrm{oz}$; make into balls of $3 \frac{x}{2} \mathrm{oz}$. each.

Cream balls. White curd soap 7lb., amyli 1lb., water q. s.; beat it together, weigh into ounce balls, and roll in pulv. amyli.

Red mottled wash balls. Cut white soap into small square pieces, roll them in powdered common bole, and squeeze the pieces together into balls, without mixing them more than is necessary.

Blue moitled wash balls. In like manner, rolling the pieces in powder blue.

Windsor soap. Hard curd soap, melted and scented with ol. carui and ess. Bergamotte.-2. Hard curd soap scented with ol. carui only.-3. Soap half a cwt., ol. carui 1lb. 8 oz., tinct. moschi 12 oz., ol. lavand. Angl. 1 oz., ol. origani ziiij.

Purified soap. Cut a cake of soap small, add 5 or 6 quarts of water ; heat, stir, pour into pans, and leave it to grow hard, cut it very small, let it dry as hard as wood; pour on it brandy, adding a little salt, and turn the pieces over and over to moisten them equally; then dry it again.

Les meilleures savonettes de Bologne. Sav. de Bol. 3 packets, soften with eau d'ange, add French milk of roses 8 pints; divide it into two, to each of which add $2 \mathrm{oz}$. of bals. of Peru, a thread of neroli, a good handful of a powder composed of 1-3d pouáre fine à la Mareschale, 1-3d of elecampane root powdered, 1-3d labdanum, and a gallon of musked eau d'ange.

If savonettes de la pâte de Bologne cannot be procured, use 4lb. of purified soap in the place of each packet; and for the poudre composée you may use the cake of eau d'ange ground very fine. The musked eau d'ange is made of eau d'ange 4 pints, rose water the same quantity, musk 3 ij.

Savonettes fines de Bologne. Three packets of saron. com. de Bologne, soften with eau d'ange for 2 or 3 days; beat it well to get out the lumps, then part it in two. To one part of your soap add a good handful of powd. labdanum, sifted very fine, balsam of Peru half an oz., a thread of ess. of neroli, 8 pints of musked cau d'ange ; mix well together : do the same with the other parcel 
of soap; after a couple of days roll them.-2. Savonettes communes de Bologne 3 packets, soften as before, and part in two : to each half add a handful of powd. labdanum, a handful of the cake from eau d'ange, bals. Peru 1 oz., neroli half an oz., a gallon of eau de mille fleurs; mix.

Savonettes de Neroli. Dry purified soap 8lb., moisten with orange flower or rose water; stir it twice a day till quite smooth, leave it till sufficiently dry to beat, then add powder of fine labdanum 1lb., essence of neroli $2 \mathrm{oz}$.; beat well : if it grows too hard soften with orange flower water.

Sur. communes. Soap 5lb., starch 2lb., essence of orange or citron $1 \mathrm{oz}$., cau pour faire la barbe a gallon; beat together, and make it into balls. - 2. Soap 5lb., starch $21 \mathrm{~b}$., eau pour faire la barbe 1 gall., oil of spike a spoonful, oil of orange (Bergamot) or citron half an oz., liquid storax 2 spoonsful.-3. Soap cut small 5lb., eau de citron 2 pints, force it through a coarse cloth, add starch $2 \mathrm{lb}$, essence of orange or citron $1 \mathrm{oz}$, , ceruss. $2 \mathrm{oz}$., diluted with half a pint of water; beat it well together.

Sav. bien parfumées. Sav. de Bol. 3 packets, soften with eau d'ange and French milk of roses; then divide in two, and perfume each part thus :- grind 3.ss civette with bals. Peru 2 oz., add ess. of ambergris $3 i j$, a thread of oil of cinnamon, as much oil of cloves, and keep for use. 'To each half of soap add 2 handsful of poudre composée as above in 3-3rds: also, half your vils, a gallon of cau de mille fleurs, and half an $0 z$. of neroli.

\section{FOH USE IN TIIE AlTS.}

Furniture cream. Pearl ash $2 \mathrm{oz}$, water half a gallon, dissolve and filter; add white wax $50 z$, cut into shavings, dissolve with heat; to be diluted with water, spread upon the wood with a painter's brush, then polislied with a hard brush or cloth. It may be applied to statues and the like. -2 . River water 10 pints, soap? a quarter of a lb., bees' wax 1lb., boil together, add 2 o\%. of pearl ash; shake well: used for varnishing wood work.

Blıcking loalls. Adip. porc., cera fl. ana $1 \mathrm{oz}$, bone black, fulig. lamp., sacch. rubr. ana 8 oz., double glue size 4 oz. - 2. Bone black $80 z$,g gum. tragac. $10 \%$, sacchar. candi $20 \%$, water $8 \mathrm{oz}$ : used for blacking leather.

Scouring balls for taking greuse, ont of cloth. Curd soap $\frac{1}{2}$ lb., ol. tereb. 1 o\%, ox gall 4 spoonsful, lcmon juice q. s. to moisten the mass, starch (1. s. to make it into balls. 


\section{OINTMEN'TS.}

In neighbourhoods where customers require cheap rather than good articles, cera flava factitia is used for bees' wax, lard for oil or spermaceti, and tallow for mutton suet.

FOR MEDICAL USE.

White oIntment, Unguentum.album, P. L. before 1745. OI. rosacei そ̇ix, cerussæ 3 iij, cer. albæ 3 ij.

Ung. cerusse, Ung. subacetatis plumbi, Ung. album cum cerussâ. Unguent. ceræ albæ lb. $\mathrm{j}$, cerussæ $3 \mathrm{ij}$.

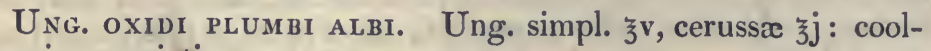
ing, in excoriations.

Ung. album (:amphoratum, P. L. before 1745. Species for unguent. alb. as before, camphoræ $3 \mathrm{ij}$, ground with a little ol. amygd.

Linimentum Arcei. Gum. elemi, ter. Argent. ana jjss, sevi ppi. $3 \mathrm{ij}$, adipis porc. $3 \mathrm{j}$.

- Ung. e gumm eleni. Sevi ovilli lb. ij, gum. elemi lb. j, tereb. comm. $\zeta x$.

Ung. eleMrI, P. L. Ung. elemi compositum. To the preceding add ol. oliv. 3 ij.

Ung. elemi, P. D. Elemi lb. j, ceræ albæ lb. ss, adipis ppi lb. iv.-2. Sevi 7lb., gum. elemi 3lb., tereb. comm. 2lb., ol. oliv. Genoa 1lb. : stimulant.

Black basilicon, Ung. basilicon nigrum, Ung. tetrapharmacum, Ung. resince nigra. Ceræ flavæ, res. flavæ, picis aridæ, i. e. resinæ nigræ, ana ३ix, ol. olivar. lb. j.

Yellow basilicon, Ung. basilicon favum. Ol. olivar. lb. j, ceræ fl., resina fl., pic. Burgund. ana lb. j, tereb. comm. 3iij.

UNG. RESINE FLAVE. Res. fl., ceræ fl., ol. oliv. ana lb. j.

Ceratum citrinum, P. L. before 1745 . Res. fl. lb. ss, sevi ovin. ३̌iv, tereb. Arg. క̌ij.

Cer. citrinum, P. L. 1745 . Ung. basil. fl. lb. ss, cer. fl. 3 j.

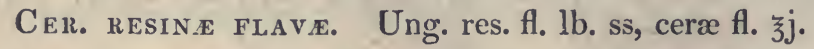

Cer. resine. Res. fl., ceræ flavæ, ol. oliv. ana lb j.

UnG. REsinosum. Axung. porc. lb. viij, resinæ albæ lb. ij, cer. fl. lb. ij.

UNG. Resine alb.e. Axung. lb. iv, resinæ albæ lb. ij, cer. fl. lb. j. 
Blee olntmext, Unction, Ung. caruleum. Argent. vivi lb. j, tereb. Venetæ 亏j, axung. porc. lb. iv.

UxG. C.ERULEUM Fortius. Axung. porc. lb. ij, argent. vivi lb. j, balsami sulph. simpl. §̌ss.

Ung. cenuleum mitius. Axung. porc. lb. iv, arg. vivilb. j, tereb. comm. 3 j.

Ceratum mercuriale. Ceræ fl, axung. porc. ana lb. ss, argent. vivi, 亏iij, balsam. sulph. simp. 3 j.

UNG. hydRARgYri fortius. Hydrarg. lb. ij, adip. suill. そxxiij, sevi ovilli $\bar{\jmath}$.

UNG. HYDRARGYRI mitiUs. Ung. hydr. fort. lb. j, adip. suill. lb. ij.

Ung. hydrargyri, P. E. Argent. vivi, sevi ovilli, ana lb. j, adlip. porc. lb. iij.

UnG. HYDRARGYRI, P. D. Argent. vivi, adip. porc. ana lib. j.

Strong mercurial ointment. Argent. vivi $6 \mathrm{lb}$, axungiæ $12 \mathrm{lb}$.

Weak mercurial ointment. Argent. vivi $2 \mathrm{lb}$., axungiæ 14lb. : alterative, $3 j$ to $3 j$ of the strong, rubbed into the inside of the thighs, omni nocte, in syphilis; the weak used to kill vermin on the body.

Donovan's mercurial ointment. Rub calomel with aq. potassæ, or dissolve quicksilver in nitric acid, and precipitate by adding aq. potass $x$, to obtain the protoxide of quicksilver. 'To each drachm of this oxide add lard zijss, rub them together, and then heat them to about 300 or $350 \mathrm{deg}$. Fahr., and keep stirring them for two hours. Each $0 \%$ of lard takes up about gr. xxj of the oxide, and becomes of a grey colour. The exact degree of heat is of consequence; at $212 \mathrm{deg}$. the ingredients do not unite, at 400 deg. or alove that heat the oxide is decomposed, and red oxide or even metallic quicksilver separates. If the lard contains common salt, calomel will be formed, and the operation will not succeed. Much more powerful than the common mercurial ointment; it being sufficient to rub in only $3 j$.

2. By melting common mercurial ointment in a water bath, letting it cool slowly, and separating the upper grey stratum. By rubbing the heavy residue with inagnesia alba, the greater part of the quicksilver in the blue ointment will be recovered, as it was never chemically united.

3. By exposing ung. oxid. hydr. cinerei to a heat of about 300 degrees for some hours.

Marshmathow orntment, Ung. ex althera. Ol. e nucilaginibus lb. iij, cera fl. It). ss, resina fl. It) ss, tereb. comm. 3ij- 
Ung. Nutritum. Litharg. lb. ss, rub it by degrees, and alternately, with aceti. $\xi v$, ol. rosati lb. $j$, by small portions of each until it is quite white.

Ung. tripuna Racum. Empl. comm. ziv, ol. oliv. zij, aceti $\jmath_{j}$; boil together.

Linim. tripharmacem. Empl. comm. ̌̌iv, ol. oliv. žjij, aceti §j; boil together: cooling, desiccative.

Eye sar.ve, Ung. ophthalmicum. Lap. tutiæ, lap. calamin. ana 3vj, plumbi usti, camph. ana $3 \mathrm{ij}$, myrrhæ, sarcocol., aloes, vitriol. albi, ana $3 \mathrm{j}$, butyri recentis $\xi \times \mathrm{ij}$, ceræ albæ $\mathrm{z}_{\mathrm{j}}$.

Ung. тuti:, P. L. before 1745. Tutiæ, ppæ. 3 ij, lap. calam. $\zeta \mathrm{j}$, unguenti rosacei $\mathrm{lb}$. jss.

Ung. tutia, P. L. 1745. Tutiæ ppæ. q. p. axung. viper. q.s.

Ung. tutia, P. L. 1788. 'Tutix ppæ. q. p. linim. ceræ alb. q. s.

Ung. zinci. Flor. zinci $̋$ j, adip. pp. ̌̌v.

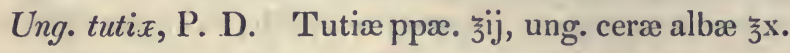

Ung. oxidi zinci impuri. Tutiæ ppæ. 3 j, linim. simp. ̌̌s.

Ung. oxidi zinci, P. D. Flor. zinc. ̌̌jss, ung. ceræ albæ lb. j.

Ung. oxidi zinci, P. E. Flor. zinci $ろ$ j, linim. simp. $气 \mathrm{vj}$ : used in ophthalmia.

UnG. simplex. Axung. porc. lb. ij, aq. rosar. ziij; beat up together, then melt, let it settle, separate the water, beat up again into a light mass, adding ess. limon. q. p.

Ung. adipis suille. The same without the ess. limon.

Ung. rubrum desiccativum. Ol. comm. lb. ij, ceræ $f$.

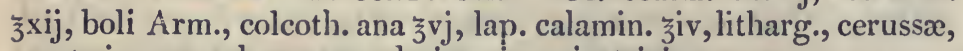
ana $̌ v j s s$, camphoræ $\bar{s}$ s ; desiccative, cicatrizing.

White elder ointarent, Ung. sambucinum, Ung. sambuci, P. L. before 1809. Flor. sambuci lb. iv, sevi ovill. lb. iij, ol. olivæ $1 \mathrm{~b}, \mathrm{j}$.

UNG. SAMBUCr FLoRUM. Fl. samb., adip. ppa. analb. ij.

2. Fl. sambuci $28 \mathrm{lb}$, axung. porc. $84 \mathrm{lb}$., sevi $28 \mathrm{lb}$.; produced when strained $98 \mathrm{lb}$.

3. Ung. sambuci comm. 1lb., ceræ albæ 1 oz., ol. lavand. exot. zij, for retail sale; emollient.

Uug. sambuci, P. D. Fl. samb. lb. iij, adip. pp. lb. iv., scvi ppi. lib. ij.

Batsamum Locatelut. Ol. oliva lb. j, tereb. Ven. lb. ss ; boil to an ointment, add santali rubri $3 \mathrm{vj}$; pectoral; used internally in coughs, with an equal quantity of cons. rosar. 
2. Use sang. drac. for sant. rub.; this has a hot taste.

Bats. virine. Ol. lini lb. ss, elemi $\check{\zeta}^{i j}$, ærug. jij.

UxG. DETERGENs. Resinæ fl., axung. porc., sevi ovilli, ana lb. j, ceræe flavæ, olibani, ana lb. jss, euphorbii, ærug. ana 亏̌jj, tereb. Argent. 亏̌iij.

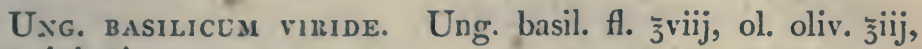
aruginis 3 j.

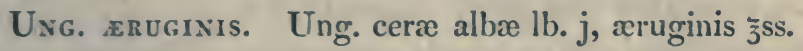

Ung. subacetatis cupri. Ung. resinosi $\check{5} \times \mathbf{x}$, xrug. $\check{\zeta}^{\mathrm{j}}$; detergent, and to keep down fungous flesh.

The green orntment, Ung. sambuci viride. Ol. viridis lb. iij, ceræ fl. $\overline{5}$.

2. Axung. porc. $1 \mathrm{cwt}$, fol. sambuci $56 \mathrm{lb}$., sevi $14 \mathrm{lb}$; ; boil together till the leaves are crisp, strain, put it again on a slow fire, and gently stir it till it is of a beautiful green colour; this is much better than adding ærugo to colour it, as is done by some.

Ung. Nervinum. Ol. laurini 3lb., ung. sambuci virid. 1lb., axungix $2 \mathrm{lb}$, ol. succini $4 \mathrm{oz}$. : the original ointment had a number of herbs, boiled in ol. nervini lb. v, sevi lb. ij, and was scented with ol. spicæ 3 jss.

UNG. POPULNEUM. This is another compound ointment of a number of herbs, boiled in lard, for which green elder ointment is now sold; emollient.

Spermaceti olntment, Ceratum album. Ol. oliv. ceræalbæ,

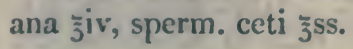

Usg. ацвUм, P. L. 1745, Ung. cerce. Ol. oliv. Ib. j, cere albæ 亏̌iv, sperm. ceti 亏iij.

Liмiм. ar,buм, Ung. spermatis ceti, Ung. cetacei. Ol. oliv. 3iij, ceræa alb. $3 \mathrm{ij}$, spern. ceti $3 v j$.

Ceratum spermatis cetr, Cer. cetacei. Ol. oliv. ̌jiv, ceræ albæe zij, sperm. ceti $̧$ ss.

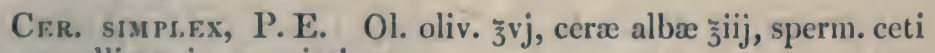
$3 \mathrm{j}$; emollient, in excoriations.

White precipitate ontment, Ung. e mercurio procipitato. Ung. simplicis ₹̋ss, sulph. precip. 3 ij, merc. prace. albi Đij, aq. kali ppi. q.s.

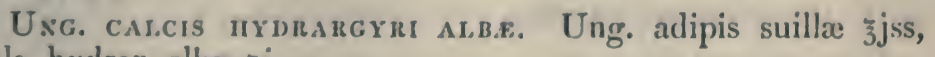
calc. hydrar. albæ $3 \mathrm{j}$.

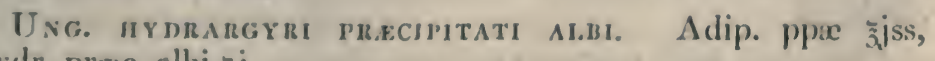
hydr. prac. albi 3 j. 
UNG. SUBMURIATIS HYDRARGYRI AMMONIATI. Ung. ceræ albæ lb. j, submur: hydrarg. ammon. そjjss.

Tar ointment, Ung. e pice, Ung. picis, P. L. Ung. picis liquida. Picis liquidæ, sevi ppi, ana p. æq.

Ung. picis, P. E. Picis liq. lb. v, ceræ fl. lb. ij; are detergent: used in cutaneous foulness.

Ointment of sugar of Lead, Ung. Saturninum, P. L. Ol. oliv. lb. ss, ceræ albæ §jss, sacch. Saturni zij.

Ung. cerussa acetate, Ung.plumbi superacetatis. The same, with ceræ albæ $३ \mathrm{ij}$.

Ung. acetatis plumbi, Ung. Saturninum, P. E. Ung. simp. $ろ x x$, sacch. Saturni jj.

Ung. acetatis plumbi. Ung. ceræ albæ lb. jss, sacch. Saturni §j ; cooling, desiccative.

Brimstone ointaent, Ung. e sulphure. Ung. simp. lb. ss, flor. sulph. §ij, ess. linıon. Эj.

Ung. sulphuris, P. L. before 1809. Ung. adip. suil. lb. ss, fl. sulph. そiv.

Ung. sulphuris, P. L. since 1809. Adip. ppæ. lb. ss, $\mathrm{A}$. sulph. ziij.

Ung. sulphuris, P. D. Adip. ppæ. lb. iv, fl. sulph. lb. j.

Ung. sulphuris, P. E. Axung. porc. lb. iv, fl. sulph. lb. j, scent with ess. limon. or ol. lavand. 3 ss.

Itch ointment, Unig. sulphuris compositum. Adip. ppæ. lb. jss, fl. sulph. Ib. ss, rad. helleb. albi $3 \mathrm{j}$, nitri salis $3 \mathrm{j}$, sapon. mollis lb. ss: are used in psora; the compound ointment is the most efficacious, but irritates.

Jackson's itch ointment. Adip. ppæ., ol. palmæ, sulph. vivi, rad. helleb. albi, ana p. æq.

Blister ointment, Ointment of Spanish flies, Ung. advesicatoria. Axung. porc., empl. vesicatorii, ana q. æq.

Ung. cantharidis, P. L. Ung. lytte. Canthar. zij, aquæ zviij; boil to one half, strain, add ung. resinæ $\mathrm{fl}$. $s$ viij; boil to an ointment.

Ceratum camphore. This is made with half an ounce of camphor and two ounces of ceratum cetacei, as an external application in the treatment of psoriasis.

Ceratum cantharidis, Cer. lytte. Cerat. sperm. ceti zvj, canth. 3 j.

Ung. cantharidis, P. D. Ung. ceræ f. lb. ss, canth. §j. 
Ung. pulveris meloes vesicatorii, Ung. epispasticum fortius. Ung. resinosi $\tilde{\jmath}$ vij, canth. $\tilde{\jmath}$ j.

UNG. INFUSI MELOES vesicatori, Ung.epispasticum miiius. Canth. $ّ j$, aquæ ferv. §iv ; infuse for a night, strain with impression, add axung. porc., tereb. Ven. ana §̌jj, resinæ, ceræ fl. ana §j : used to keep blisters open.

Uxci. album camphoratum, P.,L. $1745 . \quad$ Ol. oliv. lb. j,

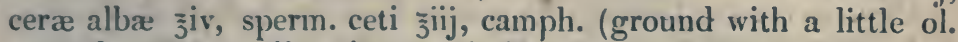
amygd.) 3jss; cooling, in excoriations.

Pile onsmext, Ung. linarice. Herb. linariæ c. flor., axung. porc. ana 1lb.; beat up, and boil together till the moisture is consumed.

UNG. opiatum. Pulveris opii $3 j$, unguenti cetacei ziij. Contunde gradatim.

UNG. PRo PoRrigiNe. Ung. picis, ung. hydrarg. nitrici mitioris, ung. cetacei, ana p. æq. Misce.

Turner's cerate, Healing salve, Ceratum epuloticum, Cer. lapidis calaminaris, P. L. Cer. calamina. Ol. oliv. Ib. j, ceræ fl. lb. ss ; melt, cool, and when it begins to set, add lap. calamin. lb. ss.

Ung. calaminare. Ung. ceræ fl. lb. v, lap. calam. lb. j.

Ceratum carbonatis zinci impuri, Cer. lapidis calaminaris, P. E. Cerat. simpl. lb. v, lap. calam. lb. j : drying, cicatrizing.

Ung. hellebori albi, P. L. Ung. veratri. Rad. helleb. albi zij, adip. ppæ. そ̌viij, ess. limon. Эj.

Ung. hellebori alli, P. D. Rad. helleb. albi siij, adip. ppæ. lb. $\mathrm{j}$ : used in itch for the upper ranks of society, who object to sulphur.

Ung. hydrargrri nitrati. Argent. vivi $\bar{j}$, acid. nitrosi zij ; dissolve, and while warm add adip. suillæ $\mathrm{lb}$. $\mathrm{j}$, previously meitted.

Ung. hydrargyri nitratis, P. L. 1809. Instead of lard only,

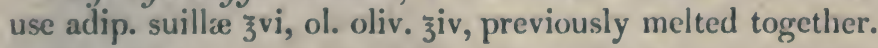

Ung. hydr. nitr. P. L. 1815. Instead of acid. nitrici $3 i j$, use only $3 \mathrm{xj}$.

Ung. supernitratis hydrargyri. Instead of lard only, use adip. suillæ $3 \mathrm{iv}$, ol. oliv. lb. $\mathrm{j}$, previously melted together.

Ung. nitratis liydrar!yyri fortius. Arg. vivi $3 \hat{j}$, acid. nitr. $3 \mathrm{ij}$, ol. oliv. З̌̉ix, adip. ppæe. 3iij.

Ung. nitr. hydr. mitius. As the ung. nit. hyd. fort, but with 
three times as much oil and lard: stimulant, detergent, in psora, herpetic eruptions, and in ulcerations of the tarsi. Only a small quantity should be made at a time, as it grows too hard for use by keeping.

Gounard's orntment, Ceratum lithargyri acetati, Cer. plumbi compositum. Lid. plumbi acet. 弓ijss, cera fl. ziv, ol. oliv. zix, camphoræ 3 ss.

Cer. saponis. Litharg. Ib. j, aceti lb. viij; boil till they unite, add sapon. Venet. $亏$ viij, ceræ $\mathrm{fl}$. $\xi \mathrm{x}$, ol. oliv. lb. $\mathrm{j}$ : cooling, defensive.

Oil and bees' wax, Ceratum, Cer. simplex, P. L. Ceræ fl. ¡iv, ol. oliv. ろiv.

UNG. Ceræe Flave. Ceræfl. lb. j, adip. ppæ. lb. iv.

UnG. Cere albe. Ceræ albæ lb. j, adip. ppæ. lb. iv.

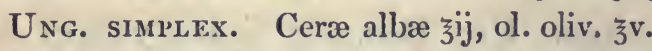

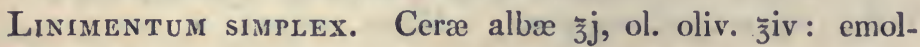
lient.

UNG. conIr. Fol. conii rec, adipis, ana ziv; well beat together, then melted and strained; in ophthalmia tarsi.

Weak ung. conii. To $\jmath_{j}$ of the former, add sperm. ceti $3 \mathrm{j}$, ceræ albæ 3 jss ; for painful and irritable ulcers.

UnG. ophthalmicum. Merc. prace. rubri, lap. calam. ppi. ana 3 jss, litharg. $3 \mathrm{j}$, tutiæ ppæ. $3 \mathrm{ss}$, cinnabaris $Э \mathrm{j}$, adipis suill. $3 \mathrm{ij}$, bals. Peruv. gtt. xv; in specks on the eyes, arising from small ulcers which have healed up.

Ung. rlumbi compositum. Camph. 3 ss, ol. oliva zix, ceræ

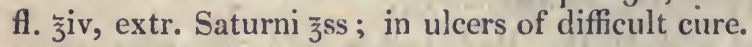

2. Ung. ceræ $3 j$, Mere. prace. rubri $3 j$, extr. Saturni $3 j$, extr. opii $3 \mathrm{ij}$; for ulcers that slough.

Smellome's eye ointment. Arug. 3 ss, ol. oliv. gtt. xxx, ung. basilic. $う$ j.

Marshall's cerate. Ol. palmæ $3 v$, calomel. $3 j$, saccl. Sat. 亏ss, ung. nitr. hydrargyri §̌jj.

Kirkland's neutral cerate. Diach. žiij, ol. oliv. ̌iv, cretæ ppæ. ziv; when nearly cool, add acet. dist. ziv, sacch. Sat. ziij.

UNG. hemonRHoidale. Ol. olivæ comm. 6 pints, ceræ albæ 2lb. 12 oz., sperm. ceti 1lb. 8 oz., pulv. gall:e 9 oz., pulv. opii 4 oz., extr. Saturni 2lb. $8 \mathrm{oz}$.

Ung. iodureti sulphuris. This is prepared by taking of ioduret of sulphur 5 parts, lard 96 part. It has been used in chronic cutancous diseases. 
Blue cerate, Cer. defensivum caruleum, P. Belg. Ceræ fl., ung. nutriti, ana jiv, ol. oliv. lb. ss, smalti pulv. ̌̌iij; M.

Lininurgh itch ointmext. Picis nig. 1lb., lac. sulph., adeps suil. ana $2 \mathrm{lb}$.

Le Mont's ointuent. Axung. porc. 7lb., tereb. Ven. 1lb., litharg. 1lb., cerus. 1lb., alum $6 \mathrm{oz}$, corros. subl. 1lb., vermilion $1 \mathrm{oz}$.

Singleton's golden ointment. Auripigmentum, lard, ana q. s. ; used as an eye-salve.

DUPUYTREN's EYE-salve. Red oxide of mercury gr. $x$, sulphate of zinc gr. $\mathrm{xx}$, axungia $3 \mathrm{ij}$.

Astringent ointments. Hogs' lard 6 oz., Venice turp. 4 oz. ; melt, and while liquid add sugar of lead powd. $2 \mathrm{oz}$.

2. Hogs' lard $4 \mathrm{oz}$., oil of rosemary $2 \mathrm{dr}$., flake white powd. $1^{\frac{1}{2}}$ dr.; mix.

3. Hogs' lard $4 \mathrm{oz}$, oil of turp. 2 dr., extract of lead half an o7. ; mix.

4. Strained turpentine $1 \mathrm{oz}$, hogs' lard $4 \mathrm{oz}$, alum fine powdered 1 oz.; mix.

5. 'Treacle $4 \mathrm{oz}$, powdered aluin $1 \mathrm{oz}$; mix.

6. Honey $8 \mathrm{oz}$., sugar of lead $1 \frac{3}{2} \mathrm{oz}$. , blue vitriol $1 \mathrm{oz}$.

RED PRECiPITATE oINTMENT, Ung. liydrargyri nitrico-oxydi.

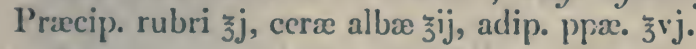

Ung. subitratis mydrargyri. Pracip. rubri žss, ung. cera albx lb. ss.

Uxc. oxidi mynargyri nubri. Pracip. rubri 3 j, adipis 亏̃viij ; stimulant; used to ill-conditioned ulcers, also weakened with lard as an eye-salve.

Linimentum irydramgym. Campl. 3 j, S. V. R. gtt. xv; grind, add adip. ppas., ung. hydr. fort. ana ziv, liquor ammonia 3iv; as the blue ointment; but quicker in its operation.

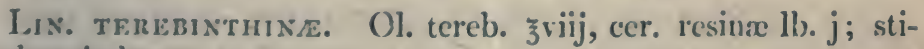
inulant in burns.

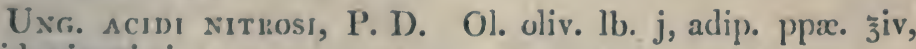
acid. nitrosi $\jmath_{j}$.

Oxygrised lann, Uny. acirli nitrosi, P. E. Adip. ppac. lb. j, ac. nitr. 3vj: stimulant, to foul ulcers; frequently sold for the ung. hydr. nitrati.

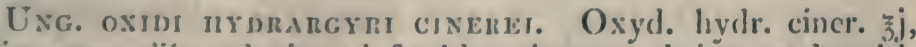
adip. ppac. 3iij; substifuted for blue ointment, being made with less labour, but seems inferior in operation. If exposed to a heat 
of about 300 degrees for some hours, it will be changed into Donovan's mercurial ointment, and thus augmented in power.

Perper salve, Ung. piperis nigri. Adip. ppæ. lb. j, pip. nigri 亏iv; stimulant, irritative.

Common itch ointment. Adip. suillæ 16lb, tereb. Ven. 1lb. 12 oz., Merc. corros. sublim., Sacch. Saturni ana, 2lb., sal. ammon. 1lb., alum. comm. 1lb., cinnab. q. s. to colour it, scent with ess. limon.

2. Adip. ppæ. 5lb., ol. palmæ 1lb, cerussæ 6 oz., alum rupei, Merc. corros. subl., lithargyri, ana 4 oz.

BaIley's IтCH oINTMENT. Ol. olivæ, axung. porc., with sal nitri, alum, vitriol. alb. and ciunabar, scented with ol. anisi, ol. origani, and ol. spicæ verum, and coloured with rad. anchusæ.

Dr. Bateman's iтch ointuent. Kali ppi. žss, aq. rosæ $\jmath_{j}$, cinnab. $3 \mathrm{j}$, ess. Bergam. $\zeta^{s s}$, fl. sulph. axung. porc., ana $3 x \mathrm{j}$.

Savine ointmext, Ceratum sabince. Fol. sabinæe rec. lb. j, ceræ fl. lb. ss, adip. ppæ. lb. ij.

Ung. sabine. Fol. sabinæ, ceræ fl. ana lb. ss, adip. ppæ. lb. $\mathrm{ij}$; used to keep open ulcers.

Ung. Ammonis. Ammoniæ carbon. 3 ss, cerati simpl. $3 s s$; for scrofulous ulcers.

Ung. lapidis calaminaris Saturninum. Cer. calam. 3 j, extr. Saturni $3 \mathbf{j}$; for burns.

E Ung. Catechu. Catechu ziv, alum zix, res. fl. ziv, ol. oliv. $\xi \mathrm{x}$, water q. s.: a good application to ulcers in warm climates, as the fat and resinous ointments of the colder countries have a bad effect.

Pommade de veratrine. Veratrine gr. iiij, prepared lard $\xi j$ : used in rheumatism and gout.

Pom. ave: L'Hydrodate de potasse. Hydriodate of potash $ろ$ ss, ppd. lard §jss: used in scrofula and swelled glands.

Pom. D'hydriodate iodure de potasse. Pom. d'hydriod. de potasse $\jmath_{j}$ ss, iodine gr. iij to xiij : stronger than the plain pommade.

Pom. Avec. L'iodate DE zinc. Iodate of zinc 3 j, ppd. lard ¡j: used also in scrofula.

Pom. de proto-iodure de mercure. Proto-iodure of quicksilver gr. xvj, ppd. lard §jss.

Pom. de deuto-lodure de mercure. Deuto-iodure of quicksilver gr. xvj, ppd. lard §jss.

Poм. D’on. Gold divided by quicksilver gr. j, ppd. lard zss. 
Pom. DE MURIATE D'OR-ET-DE-soude. Sodo-muriate of gold 1-10th of a grain, ppd. lard jss : used in venereal ulcers.

Common orl of mace, Unguent. macis. Macis, ol. palmæ, ana $11 \mathrm{~b}$; ; beat to a paste, add beef marrow melted 3lb.

Strrax colata factitia. Bals. Tolu 6lb., bals. Peruv. 11 b. 8 oz.-2. Gum. benzoin. 8lb., styr. liquidæ 6lb., bals. Tolu 3lb., bals. Peruv. 2lb., gum. flavi N. S. W. 7lb., S. V. R. 6 gall.; let them stand for a fortnight, strain, distil to a proper consistence: about 12 pints of the spirit is consumed; what comes over will serve for the same purpose another time: produces about $24 \mathrm{lb}$.

3. Gum. styr. 3lb., gum. benzoin. 6lb., bals. Tolu 2lb. 4 oz., aloes Socotr. 12 oz., S. V. R. 6 gall. ; digest three or four days, and add bals. Peruv. 6 oz., ol. olivæ opt. 4 oz.

Galbanum colatum reductum. Galbani col. veri 7lb., picis Burgund. 3lb., tereb. Venetæ 2lb.-2. Gum. galb. 2nd $14 \mathrm{lb}$, sagap. 7lb., ol. tereb. 10lb., tereb. Venet. 4 oz.-3. Galban., tereb. Ven., ana 12 oz., ass. fœtid. 5 oz., resin. nigr. 2lb., aquæ q. s. -4 . Galban. 50lb., tereb. venet. 5lb., resin. nigr. 1lb.; produces $491 \mathrm{lb}$.

Terebintina Chra factitia. Balsami Canad, resinæ flavæ, ana p. æq.-2. Tereb. Ven., res. fl. ana lb. ij, bals. Can. 12 oz.-3. Res. fl. 56lb., rape oil 1 gall., water 2 gall., ol. tereb. 2 gall.

Styrax liquida renucta. Styrac. liquidæ 1 oz., bals. Tolu 2lb., S. V. R. q. s.

Styrax calamita factitia. Ras. guaiac. 2lb., gum. benz. pulv. 6 o\%, sang. drac. 3 ij, tine bone black 3 jss, bals. Peruv., S. V. R. ana q. s.

Poix Jaune, Poix de Bourgogne. Melt perrosin, take it from the fire, and add spir. of turp. to reduce it to the proper consistence.

\section{FOR VETERINARY MEDICINE.}

Blistering orNTMENT for Honses, Ung. epispasticum equinum. Ung. laurini, ung. samb., ana 1lb., canthar., cuphorbii, ol. origani, ana 8 oz., Merc. corr. subl. 3j.-2. Pic. Burgund. 12 oz., tereb. comm. 5 oz., canthar. 10 oz., euphorbii 1 oz., axung. porc. 1lb. $8 \mathrm{oz}$., aceti comm. $8 \mathrm{oz}$ - -3. Ung. laurini $4 \mathrm{oz}$., ol. origani 1 oz.., canthar., euphorbii, ana $3 \mathrm{jj} .-4$. Ung. viridis $1 \mathrm{lb} .8 \mathrm{oz.}$, euphorb. $3 \mathrm{ij}$, ol. origani $1 \mathrm{oz}$, , canthar. $2 \mathrm{oz}$., tereb. comm. $1_{2}^{\mathrm{L}} \mathrm{oz}$. -5. Cantharides half an $0 \%$., oil of turpentine 1 oz., hogs' lard 4 oz. ; mix. - 6. Oil of turp. 1 oz., add gradually oil of vitriol 2 drachms, hog's lard 4 oz., cantharides 1 oz. ; mix.-7. 'Tar 4 oz., oil of vitriol 2 drachms, hogs' lard 2 oz., oil of origanum half an 
oz., cantharides $2 \mathrm{oz}$; ; mix very carefully.-8. Hogs' lard 4 oz., oil of turp. and Spanish flies powd., of each 1 oz., mix.-9. Hogs' lard $6 \mathrm{oz}$., oil of rosemary $4 \mathrm{dr}$., oil of origanum $2 \mathrm{dr}$., corrosive sublimate $1 \mathrm{dr}$., (dissolved in spirit of salt $2 \mathrm{dr}$.,) Spanish flies powd. 6 dr.; mix.-10. Hogs' lard 6 oz., Venice turp. 4 oz., bees' wax 2 oz., yellow resin 1 oz.: melt together, and when cooling add oil of origanum half an oz., cantharides $3 \mathrm{oz}$. : if it grow too hard in winter, soften with oil of turpentine on a slab.

Mild dRessing For CANKER in Horses. Tar 8 oz., oil of vitriol $1 \mathrm{oz}$.; mix. -2. Tar $8 \mathrm{oz}$., verdigris $1 \mathrm{oz}$; mix. -3. Honey $3 \mathrm{oz}$. , dist. verdigris $1 \mathrm{oz}$., alum and bole of each half an oz., vinegar $4 \mathrm{oz}$.; mix in a gentle heat.

Digestive ointment. Hogs' lard and strained turpentine of each $4 \mathrm{oz}$., verdigris or blue vitriol $1 \mathrm{oz}$; mix.-2. Yellow basilicon $4 \mathrm{oz}$., oil of turp. and red precipitate finely powdered, of each $1 \mathrm{oz}$. ; mix.-3. Ointment of nitrated quicksilver $4 \mathrm{oz}$., oil of turp. $1 \mathrm{oz}$.; mix.-4. Hogs' lard and common turp. of each 1lb. ; melt and add verdigris $2 \mathrm{oz}$ : : stir till cold.

Ointment for fistulas in Horses. Ointment of nitrated quicksilver 4 oz., oil of turpentine $1 \mathrm{oz}$; mix.-2. Yellow basilicon $4 \mathrm{oz}$., oil of turpentine $1 \mathrm{oz}$, verdigris half an oz.: mix.3. Oil of vitriol $1 \mathrm{oz}$., add cautiously oil of turpentine $2 \mathrm{oz}$. ; when mixed, add turpentine and hogs' lard of each $3 \mathrm{oz}$.

Ointment for grease. Hogs' lard 4 oz., white lead 1 oz.; mix.-2. Hogs' lard 4 oz., palm oil 2 oz.. olive oil 1 oz.; melt together, and when cold add extract of lead $1 \frac{x}{2} \mathrm{oz}$.

Ointment To gROW haIR, on broken knees. Wax ointment $2 \mathrm{oz}$., camphire 2 drachms, oil of rosemary $1 \mathrm{dr}$.; colour with ivory black or common bole.

Hoof ointment. Tar, tallow, of each 1lb.; melt together, for cracked heels.-2. Pitch, tar, hogs' lard, of each 1lb.; melt together.

Heel orntment. Axungire 3lb., mellis 2lb., tereb. comm. 1lb., vitriol. cærul., ærug. æris, alum. comm., ana 8 oz., train oil 8oz.; used by farries and grooms.

Ointment For low, or foot rot, in cows. Hogs' lard, common turp., of each $4 \mathrm{oz}$.; melt, and add blue vitriol $1 \mathrm{oz}$.

Ointment for mallenders and sallenders. Wax ointment $2 \mathrm{oz}$. , olive oil $1 \mathrm{oz}$. , camphire and oil of rosemary, of each $1 \mathrm{dr}$., extract of lead $2 \mathrm{dr}$.; mix.-2. Ointment of nitrated quick silver and olive oil, of each $1 \mathrm{oz} . ;$ mix.-3. Hogs' lard $1 \mathrm{oz}$., red precipitate 2 drachms; mix.

Ointment for the Mange, in horses. Hogs' lard 6. oz, 
sulph. vivum 4 oz., oil of turpentine 3 oz. ; mix. -2 . Oil of tar $8 \mathrm{oz}$, oil of turpentine $4 \mathrm{oz}$., sulphur vivum $2 \mathrm{oz}$.; mix.

Ointment for sitfasts. Camphire 2 drachms, oil of origanum 1dr.; dissolve.-2. Mercurial ointment $9 \mathrm{oz}$., calomel half a drachm, oil of turpentine $9 \mathrm{dr}$.; mix.

Strmulating oINTMENT For horses. Yellow basilicon $4 \mathrm{oz}$., sweet oil and red precipitate of each half an $\mathrm{oz}$.; mix.

LINIMENT FOR SUPPURATING INFLAMED GLANUS IN HORSES. Sperma ceti ointment $2 \mathrm{oz}$, camphire $2 \mathrm{dr}$, , oil of origanum $1 \mathrm{dr}$.; mix.

Charge For windgalls, or lamenes. Burgundy pitch $4 \mathrm{oz}$ : bees' wax 3 oz., Barbadoes tar 2 oz.; melt, and add red lead 4 oz. ; if too hard, soften with sweet oil or lard.

StopPING For the FeEt. Tallow 2lb., tar and common turpentine of each $1 \mathrm{lb}$; melt together.-2. Clay and cow dung mixed.

Orntment for mange. Train oil 12 oz., oil of turp. 4 oz. ; nix, and add sulphur vivum $4 \mathrm{oz}$.

Sevum Melilotr. Suet 8lb., melilot leaves 2lb.; boil till crisp: used in making melilot plaster.

Ointment of stavesacre. Stavesacre seed powdered, made into an ointment with lard and train oil; useful to kill lice in cattle.

Соммом оIL of ваYs, Ung. laurinum vulgare. Fol. lauri lb. j, bacc. lauri lb. ss, fol. brassica jiv, neat's foot oil lb. v, beef suet $\mathrm{lb}$. ij ; boil and express.

\section{FOR THE KITCHEN.}

Salted butter, Butyrum salitum. Fresh butter 16lb., salt 1lb, well beat together; used to keep the butter fresh: the salt may at any time be washed out, and the butter sold for fresh, or used in its salted state.

Fine salted butter. Butter $16 \mathrm{lb}$. , salt $14 \mathrm{oz}$. , saltpetre $1 \mathrm{oz}$, brown sugar or honey $1 \mathrm{oz}$; ; well beat together, and kept in a cool place for one or two months before it is used: eaten in its salted state, rich like marrow.

Honey butter. Rich butter 15lb., honey llb., beat up together ; as a delicacy for sick or aged persons.

\section{FOR PERFUMERY AND COSMETICS.}

Cold cream, Ceratum Guleni. Ol. anygd. 1lb., cerx albx 4 oz. ; melt, pour into a warm mortar, add by degrees aq. rosar. $1 b . j$ : it should be very light and white -2 . Trotter oil 1 pint, aq. rosix 
2 pints, sperm. ceti melted 1lb. 8 oz., ceræ albæ melted 1 oz., ol . amygd. 2 oz., ess. Berg. $1 \mathrm{oz}$.; beat it up together, and keep it floating upon some rose-water.-3. Lard 1lb., sperma ceti $4 \mathrm{oz}$.

Hudson's cold cream. Ol. amygd. ३̌ij, cer. alb., sperm. ceti, ana

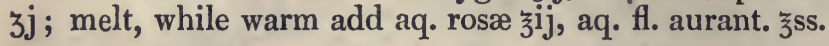

Red lip salve, Cerätum labiale rubrum. Ceræ alb. 4 oz., ol. oliv. 5 oz., sperm. ceti ziv, ol. lavand. gtt. xx, rad. anchusæ 2 oz. -2. Ol. oliv. opt. 2 oz., ceræ alb., sperm. ceti, ana 3 oz., rad. anchusæ $3 v j$; melt, strain, add ol. lign. rhod. gtt. iij. -3. Ol. amydg. $6 \mathrm{oz}$., sperm. ceti 3 oz., ceræ alb. 2 oz., rad. anchusæ 1 oz., bals. Peruv. 3ij.

White lip salve, Ceratum labiale album. Ol. amygd., sperm. ceti, ceræ albæ, sacch. candi albi, ana p. æ. .

Pommade de la jeunesse. Pomatum mixed with pear white, or magistery of bismuth; turns the hair black.

Pommade d'orange. Axung. porc. 1lb., ol. palmæ 8 oz., ess. neroli $1 \mathrm{oz} .-2$. White wax $2 \mathrm{lb}$, bees' wax $4 \mathrm{lb}$., lard $3 \frac{x}{2} \mathrm{lb}$., suet 6lb. 4 oz.; makes 3 doz. pots French orange pomatum.

Pommade divine. Beef marrow 1lb. 8oz., cinnam. $1 \frac{1}{2}$ oz., stor. calam., benzoini, rad. irid. Flor. ana 1 oz., caryoph., nuc. myrist. ana 3 j.-2. Sevi ovilli 1lb. 8 oz., stor. calam. benz., rad. irid. Flor., rad. cyperi, cinnam., caryoph. arom., nuc. mosch. ana zix ; keep melted in a gentle heat for some time, then strain.-3. Sevi ovilli 4 lb., ceræ alb. 1lb., ess. bergam., ess. limon. ana $1 \frac{x}{2}$ oz., ol. lavand., ol. origani, ana ziv. This last oil, by its stimulating power, promotes the growth of the hair.-4. Marrow $2 \frac{x}{2} \mathrm{lb}$., bals. Gilead. 3 oz., ol. caryoph. arom. 1 oz.

Pommade à la rose. Lard lb. j, suet $4 \mathrm{oz}$., rose water $1 \mathrm{oz}$, spirit of roses $1 \mathrm{oz}$ : : mix.

French rose pommade divine. Beef suet $4 \mathrm{lb}$., yellow wax $6 \mathrm{oz}$, thick honey 1 oz., rose leaves 1 peck, rose water 1 pint; melt, when chill, add extr. roses $1 \mathrm{oz}$, and mould it.

Common pomatum. Lard 12lb., suet 4lb., ess. lim. $8 \mathrm{lb}$.

East India pomatum. Suet 9lb., lard 8lb., bees' wax 1lb., ess. lim. 8 oz., gum. benz. 10 oz., musk Jiv.

Pommade à la jasmine. Same as $\mathrm{P}$. à la rose, but using spirit of jasmine.

Millefleurs pomatum. Same as East Indian, but made with white wax instead of yellow.

Rose pomatum. White wax $2 \mathrm{lb} .14 \mathrm{oz}$., bees' wax $2 \mathrm{lb}$., lard 6lb. 12 oz., suet 9lb., rose water 2 pints; makes 45 pots French rose pomatum. 
Soft pomatum. Suet 9lb. 8 oz., lard 9lb. 4 oz., bees' wax, benjamin powdered, scent, of each $8 \mathrm{oz}$.

Soft Mareschal pomatum. Lard 11lb. 8 oz., suet 12lb., bees' wax 6lb., scent $10 \mathrm{oz}$., Mareschal powder $12 \mathrm{oz}$.

French pommade. Wash pigs' flare in water, changed every three hours for four days, the last two days squeeze it with a spoon when you change the water; drain it well, melt it in a water bath, pour it into a basin of water, stir it together till cold, then beat it up to separate the water.-2. Pommade $4 \mathrm{oz}$., white wax, sperma ceti, of each half an oz, oil of almonds $2 \mathrm{oz}$.

Pommade aux fleurs. Spread pommade as thick as a finger on two pewter plates, cover one with flowers, and then turn the other plate upon it that the flowers may not be squeezed; leave them twelve or twenty-four hours, adding fresh flowers until your pommade is sufficiently scented. It is only pommade de jasmin, flcurs d'orange, and tubereuse, that can be made in this manner, other flowers are not sufficiently strong to scent the pommade.

Pommade pour rafraichir le teint et ôter les rongeurs du visage. Pommade lb. ss, rennet apples no. 2, cut in pieces without peeling, four cold seeds $1 \mathrm{oz}$.; melt; add oil of almorids $1 \mathrm{oz}$. , strain into spring water, when cold beat out the water.

\section{USED IN THE ARTS.}

Oil colours in bottles. Prepared with the spermaceti mixture like oil colour cakes, but the proportion of oil is larger.

Fish oil paints. The oil for grinding white is made by putting litharge and white vitriol of each 12lb., into vinegar 32 gallons, adding, after some time, a ton of whale, seal, or cod oil ; the next day the clear part is poured off, and linseed oil 12 gallons, oil of turpentine 2 gallons, are added.-The sediment, left when the clear oil is poured off, mixed with half its quantity of lime water, is also used under the name of prepared residue oil for common colours.

Pale green. Lime water 6 gall., whiting and road dust, of each 1 cwt., blue black 30lb., yellow ochre 24lb., wet blue previously ground in prepared residue oil $20 \mathrm{lb}$.; thin with ppd. residue oil 1 quart to each 8lb., and the same quantity of linseed oil.

Bright green. Yellow ochre $1 \mathrm{cwt}$, road dust $1 \frac{1}{2} \mathrm{cwt}$, wet blue $1 \mathrm{cwt}$, blue black 10lb., lime water 6 gall., ppd. fish oil 4 gall., ppd. residue oil and linseed oil, of each $7 \frac{x}{2}$ gall.

Lead colour. Whiting 1 cwt., blue black 5lb., white lead ground in oil $28 \mathrm{lb}$,, road dust $56 \mathrm{lb}$., lime water 5 gall., ppd. residue oil $2 \frac{1}{2}$ gall. 
Brown red. Lime water 8 gallons, Spanish brown $1 \mathrm{cwt}$, road dust 2 cwt., ppd. fish oil 4 gall., ppd. residue oil and linseed oil, of each 4 gall.

Yellow. Put in yellow ochre instead of Spanish brown, as in the last.

Black. Put in lamp black or blue black.

Stone colour. Lime water 4 gallons, whiting $1 \mathrm{cwt}$., white lead ground in oil 28lb., road dust 56lb., ppd. fish oil 2 gallons, ppd. residue oil and linseed oil, of each $3 \frac{x}{2}$ gallons. The cheapest of these paints, and the hardness and durability given to them by the road dust (i. e. ground gravel) has brought them into great use for common out-door painting.

Flexible paint. To each cwt. of oil paint is to be added yellow soap lb. $j$, dissolved in water $\mathrm{lb}$. vj, and mixed while still hot; used for painting canvas.

Glazicrs' putty. Whiting and drying oil.

Anti-attrition. Hogs' lard lb. x, camph. 4 oz., black lead q. s. to colour it; used to rub on iron to prevent rust, and diminish friction.

Dressing for leather to render it waterproof. Ol. lini 1lb., ceræe fl., tereb. comm. ana $2 \mathrm{oz}$., picis Burg. 1 oz.-2. Ol. lini $1 \mathrm{lb}$, sevi 8 oz., ceræ fl. 6 oz., resinæ fl. 1 oz.

Callot's soft varnish for etching. Oil of linseed $4 \mathrm{oz}$., gum benzoin, white wax, of each half an oz.; melt, and keep it on the fire till it is reduced to two-thirds: keep in a pot.

\section{PLASTERS.}

\section{FOR MEDICAL USE.}

Adhesive PLASTER, Emplastrum adhœsivum, E. commune adhasivum, E. lithargyri cum resina, P. L. E. resinc. Diachyl. simpl. lb. iij, resinæ fl. lb. ss.-2. Ol. oliv. 79lb., litharg. $46 \mathrm{lb}$. 8 oz., resinæ fl. $16 \mathrm{lb}$; used to bring together the edges of wounds, or confine other dressings.

Empl. lithargy Ri CUm Resina, P. D. Diachyl. simp. lb. iij, resinæ fl. lb. ss.

Emp. Resinosum. Diachyl. simp. lb. v, resinæ fl. lb. j.

Emplastrum ammoniaci. Gum ammoniac $\bar{z}$, distilled vinegar $\xi$ viij; evaporate to a proper thickness; discutient in scrofula and white swellings. The empl. ex ammon. P. L. 1720, was an unguent, containing ammon. $\xi v j$ in $\xi x x v j s s$.

Emp. ex ammoniaco cum Mercurio, $\boldsymbol{E}$. ammoniaci cum 
leydrargyro, P. L. Hydrarg. šiij, balsam. sulph. 3 j ; rub together, add gum. ammon. $1 \mathrm{~b} . \mathrm{j}$.

Emp. ammoniaci cum hydrargyro, P.D. Use tereb. com. zj, to kill the quicksilver.

Baynton's adhesive plaster. Diachyl. simp. 1lb., resinæ fl. $3 \mathrm{vj}$; used to roll up limbs with old ulcers.

Cephalic plaster, Empl. cephalicum, E. picis Burgundica. Picis Burgund. lb. ij, labdani lb. j, resinæ fl., ceræ fl. ana živ, ol. 3 j.

Eмpl. picis compositum. Picis aridæ, P. L. 1809, lb. ij,

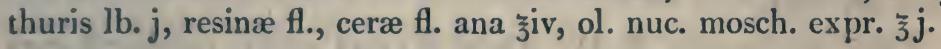

Empl. p. comp. P. L. 1824. To the preceding add ol. oliv. aq. ana 3 ij.-2. Pic. Burg. 6lb., ceræ fl. $3 \mathrm{lb}$., resinæ fl. 8lb., axung. porc. $7 \mathrm{lb}$., tereb. comm., ol. palmæ, ol. lini, ana 1lb.; rubefacient, stimulant; used in headach, applied to the temples or forehead.

Empl. е cymino, E. cumini, P. L. 1809. Pic. Burg. lb. iij, sem. cymini, sem. carui, bacc. lauri, ceræ fl. ana 亏iij.

Empl. cumini, P. L. 1824. To the preceding add ol. olivæ, aqur, ana 3 jss; discutient, to the stomach and belly in flatulence, also to indolent tumours.

White diachylon, Diachylon simplex, Empl. commune, $E$. lithargyri, P. L. E. plumbi. Litharg. lb. v, ol. oliv. lb. viij, water q. s. about 2 pints.

Empl. inthakgYri, P.D. Litharg. lb. v, ol. oliv. lb. ix, aquæe lb. ij.

Empl. oxidi plumbe shimitrei. Litharg. lb. v, ol. oliv. lb. $\mathrm{x}$ by weight; defensive, to keep the air from ulcers; also to repel milk in women weaning their children: has usually too little oil, and will not stick.

Yel.low diachyon, Gum diachylon, Diachylon cum gummi, Empl. commune cum gummi. Diachyl. simpl. lb. iij, galbani col. zviiij, tereb. comm., thuris, ana §iij.

Empl. lithargiri cum gummi, E. gallani compositum. As the former, but with only tereb. comm. $3 x$.

Eмrl. galbani. Diachyl. simpl. lb. ij, galbani lb. ss, ceræ fl. ziv.

Eupt. Gumsosum. Diachyl. simpl. lb. viij, gum. ammon., galbani, ccrse fl. ana lb. $\mathrm{j}$ : stimulant ; used in pains and weakness of the limbs.

Blistering plaster, Empl. cpispasticum primum. Empl. de melilot. lb. jss, cathar. §̧xij, sem. ammeos $\precsim$ jss, aceti lb. ss. 
Empl. epispasticum secundum. Pic. Burgund. zxij, tereb. Ven. そiv, canthar. $̌$ vj.

Empl. vesicatorium. Empl. attrah. lb. ij, cantharid. lb. j, aceti lb. ss.

Empl. cantharidis, P. L. 1809. Empl. ceræ lb. ij, cantharid. lb. j, adip. suillæ lb. ss.

Empl. lyttce. Empl. ceræ lb. jss, cantharid., adip. ppæ. ana lb. j.

Empl. cantharidis, P. L. Empl. ceræ lb. jss; adip. ppæ. lb. ss, canthar. lb. j.

Empl. cantharidis, P. D. Ceræ fl., sevi ovilli, cantharid. ana lb. j, resinæ $\mathrm{fl}$. živ.

Empl. meloes vesicatorii. Sevi ovilli, ceræ fl., resinæ, cantharid. ana $\mathrm{lb} . \mathrm{j}$.

Empl. meloes vesicatorii compositum. Tereb. Venetæ žxviij,

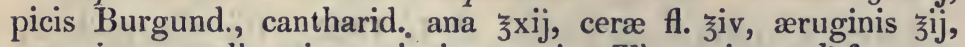
sem. sinapeos alb., piper. nigri, ana $3 \mathrm{j}$.- The resins and fats are first melted, and when nearly cold, the powdered flies are stirred in; ought to be softer than the other plasters, that it may be spread by the thumb: used to raise blisters; but as only the flies next the surface can act, it is generally necessary to sprinkle powdered flies on the face of it to secure its action, so that the plaster itself is a mere waste of flies, as they may be spread with equal effect upon basilicon, or warmed melilot plaster.

Empl. euphonir. Empl. picis comp. ziv, euphorbii zss; to bring encysted tumours to suppuration.

Empl. salis ammoniaci. Diachyl. simpl. $z^{i j}$, sapon. albi

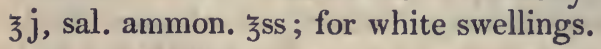

Diachylon compositum, Empl. e mucilaginibus. Gum. ammon. lb. ss, tereb. comm. 3 ij; melt, add ceræ fl. $\zeta x l$. previously melted with ol. mucilaginum $\zeta$ viij, and still fluid.

Flower of ointments, Empl. flos unguentorum dictum. Resinæ fl., tereb. comm., ceræ fl., sevi ovilli, ana lb. ss, olibani živ,

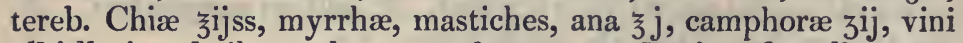
albi lb. jss; boil together to a plaster.-2. Resinæ $\mathrm{fl}$. 16lb., ceræ fl., sevi, ana 6lb., picis Burgund. 2lb. ; suppurative, warm.

Strengthening plaster, Empl. roborans, P. L. E. thuris, P.L. Diachyl. simpl. lb. ij, gum thuris lb. ss, sang. draconis 亏iij.

2. Diachyl. simp. 28lb., gum. thuris 8lb., boli comm. ppæ. 1lb.; astringent, strengthening; used as a mechanical support to the muscles, by public dancers. 
Plasters.

Empl. thuris, P. D. For sang. drac. use crocus Martis.

EMpl. oxidi ferri rubri, E. roborans, P. E. Diachyl.

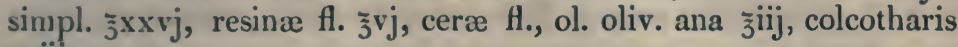
亏ेviij.

Mercurial plastri, Empl. mercuriale. Argent. vivi zviij, styr. liquidæ $\tilde{3}$ jss, tereb. Venet. $\overline{3}_{j}$; grind together, melt diachyl. simpl. lb. j, with gum ammoniac lb. jss and vitrioli albi そsss: pour this into the mortar, and mix all together.

Empl. Commune cum mercurio, E. lithargyri cum hydrargyro, E. hydrargyri, P. L. Diachyl.simpl. lb. j, argent. vivi ziij, balsami sulph. simpl. 3 j, or q. s.

2. Diachyl. simpl. 24lb., argent. vivi 3lb., ung. mercur. fortioris q. s. to divide the quicksilver; discutient : used to indolent tumours.

EMPL. HY DRARGYRI, P. E. Diachyl. simpl. lb. iv, argent. vivi lb. iij, ol. oliv., resinæ fl. ana lb. j.

Empl. de minıo. Minii ३̧ix, ol. rosat. lb. jss, aceti zvj.

Empl. e minio. Minii lb. ijss, ol. oliv. lb. iiij.

Empl. e minio fuscum. Ol. oliv. 2ndi. 24lb., minii 14lb., resina nig. 2lb.-2. Boil the red kind until it becomes brown.

Oxycroceum, Empl. oxycroceum. Picis nigræ, resinæ nig., ceræ fl. ana ziv, tereb. Chiæ, galbani, gum. ammon., myrrhæ, olibani, mastiches, ana $\check{z}_{j} z^{i i j}$, croci 3 ijss.

2. Picis Burg. comm. 4lb., picis nig. $7 \mathrm{lb}$., resinæ fl. $6 \mathrm{lb}$., tereb. Venet. 3lb., tereb. comm. 2lb., sang. dracon. 8 oz.; warm, discuticnt.

Soap plaster, Empl. de sapone. Ol. comm. lb. ij, minii lb. j, sapon. Venet. lb. ss.

EMPL. E SAPONE, E. saponis, P. L. et D. Diachyl. simpl. lb. iij, sap. Ven. lb. ss.

2. Diachyl. simpl. 12lb., sapon. alb. 1lb.: discutient, to indolent tumours, also to defend the skin from the contact of air, clothes, or bandages.

Empl. saponis, P. E. Empl. gummosi lb. ij, diachyl. simpl. lb. iiij, sap. Ven. lb. j.

Paracelsus's plaster, Empl. stipticum. Ol. oliv. $3 v j$, ceræe

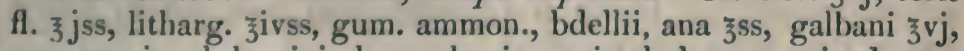
opoponacis, ol. laurini, lap. calamin., aristol. longa, aristol. rot., myrrha, thuris, ana $3^{\mathrm{ij}}$, tereb. Chiæ $3 \mathrm{j}$.

2. Diachyl. simpl. 28lb., diachyl. c. gum. 2lb., canel. albre, gum. thuris, ana llb. $80 z$. 
Stomach Plaster, Empl. stomachicum, E. labdani. Labdani

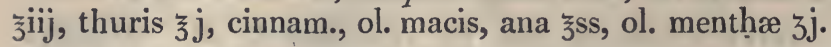

2. Labdani 1lb., ceræ fl. 10lb., ol. palmæ 8lb., resinæ nig. 5lb., picis Burg. 4lb., ol. macis per. expr. 2 oz., ol. carui ziv, ol. menthæ vulg. 3 jss.

EMPL. opIr, P. L. 1809. Diachyl. simpl. lb. j, thuris ziij, opii duri ऊss.

Empl. opii, P. L. 1824. To the preceding add. aq. §viij; anodyne, in rheumatism, and local pains.

Empl. aromaticum. Thuris žij, ceræ fl. ̌ss, cinnam. $3 \mathrm{vj}$, ol. pimentæ, ess. limon. ana $3 i j$; applied to the stomach in indigestion.

Empl. Asse FæTide. Diach. simpl., assæ fœtidæ, ana lb. ij, galbani, ceræ $\mathrm{f}$. ana lb.j; applied to the navel in flatulence and hysterics.

Empl. calefaciens. Empl. cantharidis, P. D. lb. j, picis Burgund. lb. vij; stimulant, more active than Burgundy pitch alone, and yet seldom raises a blister.

Issue peas, Pisa pro fonticulis. Ceræ fl. 1lb., rad. curcumæ 8 oz., rad. irid. Flor. 4 oz., tereb. Ven. q. s. ; make into peas.2. Ceræ fl. 6 oz., rad. irid. Flor. 2 oz., vermilion 4 oz., tereb. Ven. q. $s$; form into peas.-3. Ceræ fl. 6 oz., ærig. æris, rad. helleb. albi, ana 2 oz., cantharidum 1 oz., rad. irid. Flor. 1 $\frac{1}{2}$ oz., tereb. Ven. q. s. ; this last is caustic, and will open issues itself; the others are used to put into issues that begin to close up, to keep them open longer.

Factitious bees' wax, Cera flava factitia. Res. flav. 8lb., sevi ovill. 4lb., pulv. curcumæ 8 oz.; melt and strain; when cold rub the cake with a little hair powder.

SANGUIS DRAConis FActitius. Resinæ flav. 4lb., ol. olivæ 8 oz.: melt, add Venetian red and ground red sanders, of each $11 \mathrm{~b}$.

Labdanum factitium. Ceræ flav., adip. suil. ana $\xi v j$, eboris usti nigri 弓iv.

Resive. Perrosin, or galipot, 1 cwt., brown rosin 3 cwt., melt together, strain through straw, and pour it while hot into cold water.

Bra gras. Tar, brown rosin, poix grasse melted together.

Resine DE Boutique. Perrosin, or galipot, melt with only a small quantity of brown rosin, strain into cold water : a finer article than the common resine.

Melilot plaster, Empl. de meliloto simplex. Resinæ fl. 1 b. 
viij, ceræ $\mathrm{A}$. Ib. iv, sevi ovilli lb. ij, meliloti viridis, cut very small, lb. $\mathrm{v}$; melt, keep on the fire till the herb is crisp, strain.

Resinæ fl. 28lb., ceræ fl. 4lb., sevi meliloti 10lb.: stimulant; used in dressing blisters, but irritates more than basilicon; the strong smell of the melilot is disliked by most, but is required by farriers and some private practitioners.

Empl. attranens. Resinæ fl., ceræ fl. ana lb. iij, sevi ovilli lb. j._Empl. cerce. Ceræ fl., sevi ovilli, ana lb. iij, resinæ fl. lb. j.

E.mpl. simplex, E. cereum. Ceræ fl. lb. iij, sevi ovilli, resinæ fl. ana lb. ij.

\section{PERFUMERY.}

Roll pomatum. Suet 5lb., white wax 8 oz., sperma ceti 2 oz., ol. lavand., ess. Bergam. ana ziv.-2. Mutton suet 3lb., white wax 8 oz., ess. limon. q. p.-3. Suet 14lb., wax 4lb., scent 8 oz., benjamin powdered half an oz.

Hard Mareschal pomatum. White wax 2lb., suet $6 \frac{3}{4} \mathrm{lb}$., scent $4 \frac{\mathrm{t}}{2} \mathrm{oz} .$, Mareschal powder $6 \mathrm{oz}$.

\section{USED IN THE ARTS.}

Oil-colour cakes. Grind the colours first with oil of turpentine, and a varnish made of gum mastich in powder $4 \mathrm{oz}$, dissolved without heat in a pint of oil of turpentine; let them dry, then heat a grinding stone, by putting a charcoal fire under it, grind the colours upon it, and add an ointment made by adding melted spermaceti 3lb. to a pint of poppy oil, take a piece of the proper size, make it into a ball, put this into a mould and press it. When these cakes are used, rub them down with poppy oil, oil of turpentine, or any other convenient vehicle.

Furniture balls. Ol. lini 1 pint, rad. anchusæ 2 oz., heat together, strain, add ceræ fl. 18., resinæ fl. 2 oz.

Red sealing wax. Gum lac 2lb., vermilion 4 oz., ol. tereb., ol. olive, ana $3 \mathrm{oz}$; roll in cakes, and polish with a rag till quite cold.-2. Resinæ fl. 6lb., shell lac 2lb., tereb. Venet. 2lb., bole $8 \mathrm{oz}$.

Black sealing wax. As the red, using lamp black instead of vermilion, the coarsest lac and rough turpentine.

French sealing wax. Shell lac 2lb., Ven. turp. 1lb., Chinese vermilion 3lb., melt, and form into sticks 12 or 24 to the lb.

Gold sealing wax. 'T'o sealing wax melted, and beginning to grow solid, stir in' gold colour talc.

Marbled sealing wax. Melt each colour in a separate vessel, and just as they begin to grow solid mix together.

Common sereling uax. Brown rosin 19 o\%, becs' wax $1 \% \%$, melt together. 
Soft sealing wax. Bees' wax 4lb., Venice turpentine 1lb., levig. bole suff. to give the requisite colour.

Green soft wax. Colour with ppd. verdigris instead of bole: both are used for sealing official papers, and as a cement.

Wax lute. Bees' wax lb. j, melt and add linseed oil sufficient to render it pliable: used as a cement which can be easily removed.

Seal engraver's cement. Common rosin and brick dust; it grows harder every time it is melted, but always remains inferior to Botany Bay cement.

Botany Bay cement. Yellow gum and brick dust of each p. æq., used to cement china ware.

Gilders' wax. Ceræ fl. 1lb. 8 oz., ærug. æris, vitrioli albi, ana $8 \mathrm{oz}$. , colcothar. $2 \mathrm{lb} .12 \mathrm{oz}$.; the dry species must be powdered very fine : borac. $4 \mathrm{oz}$. may be added.-2. Ceræ fl. 15lb., colcothar. 7lb., ærug. æris, vitrioli albi, ana $3 \mathrm{lb.} 8 \mathrm{oz}$, , borac. $8 \mathrm{oz} .-3$. Ceræ fl., colcothar. ana 4 lb., ærug. æris 2lb., borac., alum. usti, ana $2 \mathrm{oz} .-4$. Colcothar. $18 \mathrm{lb}$., ceræ fl. 10lb. 8 oz., ærug. æris, vitrioli albi, ana $3 \mathrm{lb} .8 \mathrm{oz}$.

Mummy, Mumia Egyptiaca. The mixed resinous mass with which the Egyptian corpses have been preserved: used as a good glazing colour, but it is long in drying.

Callot's hard varnish for etching. Add to the soft varnish more wax, so as to form a solid ball.

Engraver's stopping out varnish, Petit vernis. Lamp black reduced to a thick consistence with spirit of turpentine.

Black ball. Bees' wax 8 or., tallow 1 oz., gum Arab. 1 oz., lamp black q. s.: : used for blacking leather.

\section{APPARATUS AND CHESTS.}

Issue PLAsters, Sparadrapum pro fonticulis. Ceræ fl. lb. ss, minii tereb., Chiæ, ana そiv, cinnab., rad. irid. Flor. ana $\zeta \mathrm{j}$, mosch. gr. iv; melted, spread upon linen, polished with a moistened calendering glass rubber, and lastly cut in small squares. -2 . Diachyl. simpl. lb. j, rad. irid. Flor. $\zeta \mathrm{j}$; spread, and polished. -3. Diachyl. simpl. 2lb., pic. Burg., sarcocollæ, ana 4 oz., tereb. comm. 1. oz.; spread and polished.

Coln plasters, Spar. viride. Ceræ fl. 2lb., pic. Burgund. 12 oz., tereb. comm. 6 oz., ærug. ppæ. 3 oz.; spread on cloth, cut and polished.-2. Bees' wax 1 oz., rosin 2 dr., Venice turpentine, blue vitriol, of each $4 \mathrm{dr}$., arsenic 3 ss ; mix. 
KenNedy's corn plaster. Ceræ fl. lb. j, tereb. Ven. zij, ærug. æris $\tilde{3} \mathrm{j}$; put 12 bits in each box.

Defensive prasters, Spar. seu Tela Gualteri. Ol. oliv.

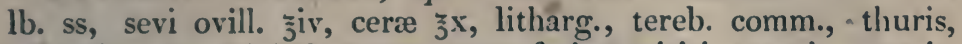
mastiches, ana $\overline{3} \mathrm{j}$, boli Armen. ppæ. farinæ tritici, ana $\bar{z}_{\mathrm{j}} \mathrm{j}$ : pour it, while liquid, upon cloth, and spread it : used for issues, and to keep on dressings.

Adhesive plasters, Strapping, Spar. adhasivum. Diachyl. llb., resinæ fl. 4 oz., tereb. comm. half an oz., or in summer time only 3 ij; melt, pour upon cloth, and spread it rather thick: much used by surgeons to close the lips of wounds, and retain dressings.

\section{Spread diachylon plaster, Spar. diachyli.}

Bougies, Candele probatorice, Cereoli simplices. Catgut, of different thicknesses, dipped in emplastr. hydrargyri, and rolled up smooth upon a slab.-2. Pieces of old linen about a foot long, wide at one end, and tapering to the other, dipped in emplastr. hydrargyri, emplastr. saponis, or diachyl. simpl. and rolled up while the plaster is yet warm, upon a heated slab.

Elastic gum bougies. Catgut dipped repeatedly in a solution of elastic gum or Indian rubber, in ether or naphtha, until a sufficient thickness of gum is deposited upon the catgut.

White вougies. Ceræ fl. lb.j, sperm. ceti ziij, cerussæ acetat. $3 \mathrm{v}$, spread upon cloth, cut in slips, and roll the spread side outwards.

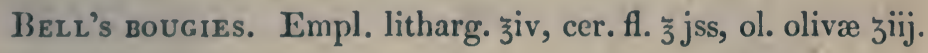

Elastic gum catheters. A bougie, made of fine catgut, very thickly coated with wax, bent to the proper curve, is dipped repeatedly in the ethereal solution of elastic gum, until a sufficient thickness of gum is deposited upon the bougie: it is then dried perfectly in a warm room or stove; and finally boiled in water to melt out the wax and allow the catgut to be withdrawn.

2. A wire bent to the proper curve is wrapped round spirally, the turns overlapping each other, with a thin riband of elastic gum, whose surface has been softened by dipping in boiling water, or still better in ether, or in a solution of camphire in spirit of nitre to which some spirit of wine has been added; over this is wound a silk riband, and over that another worm of packthread to bind down the whole: when the gum is judged to be dry enough, the packthread and riband are removed, the catheter dipped for a moment in boiling water to expand it, and allow the wire to be withdrawn, and one or two holes are then made at the close end.

3. A fine tissue of silk is wove upon a wire properly hent; and 
the wire thus clothed is dipped in the ethereal solution of elastic gum, and treated as in the first method; when properly covered and dried the wire is withdrawn, and the apertures at the closed end made.

Emetic curs, Antimonial cups. Cast from regulus of antimony in a mould.-2. Cast from regulus Jovis; is easier made and less brittle: used to prepare emetic wine, by leaving wine in it for 12 hours.

Chinese purging cup. Made of risigallum, or red arsenic ; wire is left in them all night, and drank in the morning as a purge.

Anodye necklaces. Are formed of the roots of hyoscyamus, Job's tears, allspice steeped in brandy, jumble beads, or elk's hoof, to suit the fancies of the prescribers; used to procure easy dentition in children, and sleep in fevers.

ApPEnSA. Root of vervain hung round the neck by a yard of white satin riband for scrofula; but the usual medicines must be exhibited during the same period.-2. A root of the peony suspended to the neck in epilepsy; its use to be accompanied with that of the most active cathartics.-3. Magnes arsenicalis, or camphire, hung to the neck so as to reach the pit of the stomach, to guard against contagion, act probably by inspiring courage.

Sponge tents, Turunde intumescentes. Soft sponge is dipped in melted wax, and squeezed in a press while warm, when cold it is taken out, and cut into the required form; used to dilate fistulous ulcers by its expanding force when softened by warmth and moisture.

Vaccine matter. Collected either upon lancets, or by opening the pustule, and applying a small glass ball and tube (like those called by the boys in London candle pops, or fire pops) to the opening, expelling part of the air in the ball by bringing a lighted taper near it, then withdrawing the taper the matter is drawn into the ball, in which it may be sealed up hermetically or cemented, and thus kept for a length of time; used lately for an absolute preventive of the small pox, but now with a view of diminishing the susceptibility of acquiring that disease, and to render it milder if required.

Smat. pox matter. Collected from the pustules upon lancets, or the scales of the pustules are preserved ; used to communicate the disease under favourable circumstances, instead of hazarding its being acquired when circumstances are unfavourable.

Court Plaster, Sticking plaster. Black silk is strained and brushed over with a solution of isinglass $1 \mathrm{oz}$. , in proof spirit 12 oz., to which tinct. benz. $2 \mathrm{oz}$. is added: when dry this is repeated 
five times more, after which, two coats are given it of a solution of tereb. Chia $4 \mathrm{oz}$., in tinct. benz. $6 \mathrm{oz}$., which renders it less liable to crack; but some finish it with a simple tincture of black bals. of Peru.-2. Isinglass $4 \mathrm{oz}$, tinct. benz. comp. $1 \mathrm{oz}$, water $2 \mathrm{oz}$. -3. Ichthyoc. finely shred, benzoin, styr. bals. ana żj, S. V. R. jviij ; dissolve, and while warm spread over the strained silk three or four times: if it become too thick add a little S. V. R.-4. Mucil. g. tragac. $3 \mathrm{ij}$, Bals. Peruv. $3 \mathrm{j}$; mix, and spread as before. -5. Instead of black silk, spread the composition upon goldbeaters' skins.

Bleached sponge, Spongia dealbata. Soak the sponge in very dilute muriatic acid to get rid of any chalky matter it may contain, then in cold water for five or six days, changing the water frequently, and squeezing the sponge well each time. Soak it in sulphurous acid for a week, changing the acid frequently, wash it well, and scent it with rose water or orange flower.

Spavish wool, Bezetta rubra, B. di Levante. Separate the colouring matter from safflower, as in making rouge: using white crape to take the colour from the second solution in subcarbonate of soda water: used to colour the cheeks by rubbing the wool upon them.

FOR THE KITCHEN.

Claret rags, Tournesol en drapeanx, Bezetta carulea. Linen coloured with Auvergne archel : used to colour jellies and confectionary.

Common claret rags. Linen dipped in juice of blood-red grapes, or in juice of mulberries, or in lees of red and claret wine; exported from France : used to colour the rind of Dutch cheeses.

FOR USE IN THE ARTS.

Litmus paper;-Turmeric paper; Reddened litmus paper;Perfumed cherry juice paper ;-Mallow flower paper;-Elderberry paper ;-Elderberry paper altered by ammonia;-Blue litmus paper ; -Brazil uood paper;-Brazil wood paper altered by alkalies ;Juice of buckthorn paper. Are all made by staining paper with the infusion of the several substances.

Paper stained with alcoholic extract of the yellow pouder at the bottom of dahlia petals; - Acetate of lead paper;-Subacetate of lead paper;-Proto-sulphate of iron paper. Are made by staining paper with the solutions of the several substances in water. All of these are used as tests for discovering acids, alkalies, sulphur and other ingredients in compounds, or for ascertaining the point of neutralization in compounding acids with alkalies or other bases: those of litmus, litmus reddened, and turmeric, are the most in use. 
Tracing paper. Nut oil, oil of turpentine, of each half a pint ; rub the paper with this oil, and dry it immediately by rubbing it with wheat flour; this may be used to copy drawings or writings as soon as made; if washed over with ox gall it will bear being written upon with ink.

Storm glass. Camphire 3 ij, saltpetre 3 jss, sal ammoniac $z^{s s,}$ S. V. R. そij ; dissolve, keep in a bottle or tube covered with a bladder : used to foretell changes of weather.

Lead tree. Sugar of lead $3 \mathrm{vj}$, distilled or rain water 2 pints; dissolve, and hang in it, by a thread, a small piece of zinc.

Tin tree. Muriate of tin ziij, nitric acid $10 \mathrm{drops}$, distilled water about 2 pints; mix, and hang in it a small piece of zinc.

Phosphorus bottles. Phosphorus z $\mathrm{ij}$, lime $3 \mathrm{j}$, mixed together, put into a loosely stopped phial, and heat it before the fire, or in a ladle of sand, for about half an hour.-2. Pliosphorus $3 \mathrm{j}$, cera alba gr. xv, put it into a bottle under water, and melt them together, let the water cool, and as it begins to grow solid, turn the bottle round, that the sides may be coated, then pour out the water, and dry it in a cool place.

Matches for instantaneous light. Oxymuriate of potash, flowers of sulphur, of each $\mathrm{Sss}_{\mathrm{s}}$ vermilion gr. ij, oil of turpentine q. s. to make a paste, with which coat the ends of slips of wood, previously dipped in oil of turpentine and dried; when these matches are plunged into oil of vitriol and immediately withdrawn, they take fire instantaneously. To prevent the oil of vitriol from spilling, if the bottle should accidentally fall on one side, pounded asbestos or sand is put into the bottle to soak up the acid.

2. Oxymuriate of potash gr. ix, sugar gr. iij, flowers of sulphur gr. ij, vermilion gr. j, wheat flour gr. ij, spirit of wine $q . s . ;$ the wood to be previously primed with camphire dissolved in spirit of wine.

Glue wafers, Medallion wafers. Colour Salisbury glue by means of Brasil wood, turmeric, or the like : fill up the hollow part of a seal with gum water mixed with any coloured powder; leaving the flat part clear; then pour as much of the melted coloured glue on the seal as will lie upon it, and let it dry in a gentle heat; when used, wet the paper where the wafer is to be applice, 'and place the back of the wafer upon the wet paper.

Waxed paper. Cartridge paper placed on a hot plate, and rubbed with bees' wax : used to form steam pipes, gas pipes, or to close the joining of vessels by merely wrapping a slip of it round them, and tying it down with twine. 


\section{MEDICINE: CHESTS.}

Medicine chests for ships that carry a surgeon. Some idea of what ought to be shipped for a voyage may be formed from the following lists, which the physician of Greenwich Hospital, Dr. Blane, judges necessary for the service of 100 men for 12 months*; and by which the nary chests are fitted proportionally.

1. Pharmacentic articles. Cort. Peruv. 10lb., if for a warm climate 20lb.-Glauber's or Epsom salt 10lb. [15lb.]-senna 2lb. [4lb.]-ipecac. 4 oz. - tartar emetic $1 \frac{1}{2}$ oz.-calomel $2 \frac{x}{2} \mathrm{oz} .-$ opium 1 oz.-aloes half an oz.-gum ammoniac 2 oz.-bals. Copaibre 3 oz. - cantharides 1 oz. - capsicum 3 oz.-tinct. benz. comp. 4 oz. - camphire 3 oz. - castor $1 \frac{1}{2}$ oz.-camomile fl. or hops $2 \mathrm{lb}$. cinuamon $1 \mathrm{oz}$.-chalk ppd. or oyster shells $6 \mathrm{oz}$.- conserve of roses $8 \mathrm{oz}$. - confectio cardiaca $2 \mathrm{oz}$. - extract. cathart. half an oz. [3 oz.] - extract. conii $3 \mathrm{oz}$.- extract hæmatoxyli $1 \mathrm{oz}$.- - gentian root $5 \mathrm{oz}$. - ginger 3 oz.-gum Arabic 4 oz. - gum guaiacum 3 oz.-jalap $1 \frac{1}{2}$ oz. [2 $\frac{1}{2}$ oz.] -laudanum (tinct. op.) 4 oz.--linseed 1lb.-magnesia (subcarbonate) $6 \mathrm{oz}$.-manna $8 \mathrm{oz}$.-mustard seed whole $8 \mathrm{oz}$. -myrrh 4 oz. - quicksilver 2 oz.-corrosive sublimate $1 \mathrm{oz} .-$ sal nitri 8 oz.-almond oil 1 pint-castor oil 8 o\%. [2lb.]-linseed oil 3 pints-oleum menthæ 1 oz.-Jamaica pepper 4 oz.-quassia 8 oz. - volatile salts $2 \mathrm{oz}$. [1lb] - salt Martis half an oz.- kali ppd. $10 \mathrm{oz}$. - Venice soap $8 \mathrm{oz}$. - sarsaparilla $31 \mathrm{lb}$. - Virginia snake root 4 oz. - spermaceti 4 oz.-spirit of wine 1 pint-spirit of vitriol 8 oz.-ammoniæ acetas, or materials for preparing it, 2 pintsoil of turpentine $4 \mathrm{oz}$. [4lb.] -dried squills half an $\mathrm{O} z$. - flowers of sulphur 1 oz. [1lb.]-golden sulphur of antimony half an oz.cream of tartar 1lb. [3lb.] - vinegar 6 pints - white vitriol $10 z$. wormwood 1lb. - flowers of zinc $3 \mathrm{ij}$.

2. Surgical applications. Simple cerate 6lb.-spermaceti ointment $6 \mathrm{lb}$.- - red precipitate $1 \mathrm{lb}$.- - blue vitriol $8 \mathrm{oz}$.- - blister plaster 6lb.--extr. Saturni 4lb. - sugar of lead $4 \mathrm{lb}$.- - cantharides in powder 11 b. - strapping, lint, tow, rags, at discretion.

3. Dirtrticurticles. Barley $3 \mathrm{cwt}$ - $\mathrm{cggs}$ greased and packed in salt 20 doz.- - extract of spruce 1211$\}$. - Cemon juice clarified and rum added to make it keep 5 gall. [10 gall.] -raisins 50lb.-rice 2 cwt.-coarse sugar 2 cwt.- sago 20lh. - salep powder 10lb.prtable soup 50ll. - tamarinds 10lb. - white wine 300 gall. - red wine 100 gall.

Merlicine chests for plantation service. Dancer, in his Medical Assistant, gives the following list of medicines as necessary, along with indigenous remedies, for 100 negroes for a year. Aloes $80 \%$.

* The quantities put within brackets are those which are recommended by the Editor of this Edition. 
-alum 8 oz.-Peruvian bark 4lb.- balsam Copaibæ 8 oz.-cantharides 8 oz.-calomel 1 oz.-camphire 3 oz. [ 6 oz. $]$ - catechu 1lb., [2 lb.] - camomile flowers 1lb. - elixir of vitriol 8 oz.-paregoric elixir $8 \mathrm{oz}$.- extr. cathart. half an oz.-flowers of sulphur 1lb.--flowers of zinc 1 oz.-gamboge 1 oz.-gum ammoniac $4 \mathrm{oz}$. - gum Arabic 8 oz.-ipecacuana 4 oz.-iron filings ppd. 2lb.jalap 4 oz.-linseed 2lb.--liquorice $8 \mathrm{oz}$.-magnesia alba 4 oz.mezereon $4 \mathrm{oz}$.- myrrh $4 \mathrm{oz}$.- -sal nitri $4 \mathrm{oz}$.- -spirit of nitre $4 \mathrm{oz}$. -opium $4 \mathrm{oz}$.- - oil of anise seed $2 \mathrm{oz}$.-olive oil 4 pints-oil of peppermint $1 \mathrm{oz}$.- - oil of turpentine 1lb.-yellow basilicon 1lb.simple cerate $1 \mathrm{lb}$.-mercurial ointment $4 \mathrm{oz}$.- -gum plaster $8 \mathrm{oz}$. - mercurial plaster $4 \mathrm{oz}$.- sumach $2 \mathrm{oz}$.- sal ammoniac $4 \mathrm{oz}$.Glauber's salt 10lb.-kali ppd. 8 oz. - sal Martis 2 oz. - senna $4 \mathrm{oz}$. - snake root $4 \mathrm{oz}$. - spirit of sal ammoniac 6 oz.-ammoniæ acetas 2 pints - double distilled lavander water $4 \mathrm{oz}$.- Hoffmann's anodyne liquor $4 \mathrm{oz}$. - sweet spirit of nitre $4 \mathrm{oz}$.- -emetic tartar half an oz.-rhubarb 4 oz. - Strasburgh turpentine $4 \mathrm{oz}$.- vinegar 2 gall. - extractum Saturni 8 oz. - white vitriol 2 oz.-blue vitriol 4 oz. - verdigris $8 \mathrm{oz}$.- red precipitate $4 \mathrm{oz}$.- corrosive sublimate half an $\mathrm{oz}$.

2. Necessaries.-1 large clyster syringe, 1 small ditto, 6 for injections, 4 lancets, 1 tooth instrument, 3 or 4 eye cups, 1 doz. bougies in sorts, 3 doz. phials with corks, 3 doz. pill boxes, 1 set of scales and weights, lint and tow.

Medicine chests for small ships, or families in the country.-These are usually made up to some book of directions, of which three are in general use in London, viz.-1. A Companion to the Medicine Chest, by Savory, which, being well written, is adapted for chests ordered by persons of education, for whose diseases also the medicines are selected. It were to be wished that the cabinet-makers would adapt the bottles, \&c. to this book. By a singular error, the words laudanum and opium are throughout used as synonymous to each other, while at the same time the tincture of opium is probably meant by both.-2. Directions for the Use, \&c. published by Shaw, the druggists' printer. These directions and medicines are principally intended for the diseases of the lower classes, hence this is the book by which druggists generally make up medicine chests for small ships which do not carry a surgeon, unless they have books of their own, as is the case with most of the druggists in sea ports, or the eastern part of London, because Shaw's Directions require the generality of the medicines ordered to be made up when wanted from the different simple articles contained in the chest, whereas sea commanders prefer a chest of medicines ready prepared for use, and which at most require only to be weighed or measured, and even that operation not to require great accuracy, previous to their exhibition.-Among the many books of this kind I have found in the chests brought to me to 


\section{APPARATUS AND CHESTS.}

refit, most of which are copies, with slight variations of each other, one appeared far superior to the rest. It was written by Lot Trip, and published by Hull and Browne, No. 145, Pearl Street, of what town or city is not mentioned; but I understand they are store-keepers at New York, and belong to the Society of Friends. It had this striking advantage, that there was given at the end the composition of the several compound medicines used in it, so that it could be refitted, as at first, at any port ; and if a medical man happened to be a passenger on board, he could use the medicines with more confidence than if he had to guess at their composition from their appearance, and the directions given for their use.-3. The Family Medicine Chest Book, published by Cox, mostly used by country druggists.

Besides these three books, which contain what may be called sets of medicines for ordinary cases until regular assistance can be obtained, there is a fourth, called An Index to the Portable Dispensary, published by Phillips, which describes the uses and doses of the most common medicines, and is adapted for small cabinets, containing only a few articles, for which purpose it may in some cases be cut up, and used as descriptive labels. 



\section{N D E X.}

A.

Agatu, 120

Abele, 30

Abies, 28

A brotannm, 70

Abrus, 97

Absinthinm, 70

Abuta, 122

Acacia, 92, 93, 95, 103 gum, 152

Acanthacese, 45

Acanthium, 66

Acanthus, 45

Acarna, 65

Acarnus, 65

Acaroides, 20

Acer, 109

Acerinex, 109

Acetas ferri, 256

hydrangri, 257

kali, 287

plumbi, 258

potasser, 287

Acetate of barytes, 280

of copper, 255

of iron, 256

of morphia, 291

of soda, 289

of solanine, 368

Acetis hydrangyri, 257

potasser, 287

plumbi, 258

Acetosella, 42, 111

Acetositas citri, 160

Accturn, 293, 296;

anthoeatum, 369

aromaticum, 368

Berlinense, 368

cerevisise, 293

colchici, 368

-concentratum, 296

$\checkmark$ dlatillatum, 295

ligni, 297

opiii, 368

prophylscticum, 368

punficatum, 295

rosatum, 369

rute, 368

scillix, 368

theriacale, 368
Achillea, 71

Achras, 60

Achryanthes, 44, 85

Acid, acetic, 295, 296

$\sim$ acetous, 296

of ants, 300

benzoic, 298

boracic, 302

carbonic, 313

citric, 298

gallic, 300

hydrochloric, 302, 303

hydrochloronitric, 306

hydrosulphuric, 314

iodic, 300

ioduretted hydr., 400

lactic, 299

of lemons, 298

margaric, 199

marine, 302

muriatic, 302

nitric, 305

nitro-muriatic, 306

nitrous, 305

oxalic, 299

oxymuriatic, 306

phosphoric, 307

of Prussian bluc, 301

Prussic, 301

L pyrolignous, 297

of salt, 302

succinic, 310

of sugar, 299

sulphuric, 307

sulphurous, 310

tannic, 300

of tartar, cryst., 298

arsénicux, 302

fumante do Nordh, 307

hydrocyaniquo, 301

bydruchlorique, 303

nitrique, 305

Acids, 291

Vegetable, 293:

Acidule, 311

Acidum aceticum, 297

- camphor, 368

- fortius, 297

- ligni, 296

acclosum, 295

arscniosum, 302
Acidum benzoicum, 298

boracicum, 302

carbonicum, 313

citricum, 298

formicarum, 300

hydrochloricum, 302

hydrocyan. veget. 350

hydrosulphuricum, 314

hydrothionicum, 314

iodicum, 300

muriaticum, 302

- dilut. 304

nitricum, 319,305

nitroso-nitricum, 304

nitrosum, 305

oxalicum, 299

oxymuriaticum, 306

phosphoricum, 307, 320

Prussicum, 301

salis communis, 302,316

succini, 310,324

sulphuricum, 24, 307, 310

- aromatic. 399

tartari cryst. 298

Acinos, 47

Acipenser, 143

Aconitum, 126

Acorn, 30

Acorus, 19, 24

Actra, 125

Actinophyllum gum. 153

Adamaram, 86

Adansonia, 121

Adder's tongue, 13

Adenanthera, 95

$\Lambda \mathrm{deps}, 140,215$

rosaruus, 194

Adiantum, 12

Adjownen, 82

Adonis, 125

Ador, 15, 165

Adoxa, 83

Adruc, 15

Aigopodium, 78

Kirugo, 247

crystallisata, 254,268

Tis ustum, 248

Aisclinomene, 99

Aisculus, 110

Fither aceticus, 200 muriaticus, 200 
Ather muriaticus alcoholi-' Alkanet, 54 cus, 200

nitrosus, 199

rectificatus, 199

sulphuricus, 199

-c. alcoh. 378

Fthusa, 79

Ethiops alcalisatus, 456

martialis, 237

mineralis, 454

— red. 462

per se, 235

Plummeri, 453

vegetable, 223

Agal agal, 127

Agaric, 9

Agaricus, 9

Agathis, 28

Agathophyllum, 118 .

Agave, 22

aloes, 161

Ageratum, 71

Aghilcultay, 92

Agnus castus, 45

Agrimonia, 89

Agrimony, 67, 89

Agrostemma, 118

Anguilla, 143

Air, dephlogisticated, 324

fixed, 324

pure, 324

vital, 324

Ajuga, 49

Ala, 322

Alangium, 87

Albina, 26

Albumen, 177

Alcea, 121

Alchemillạ, 89

Alchornia, 57

Alcohol, P. L. 172

alcalisatum, 172

ammoniat. 370

— aromat. 371

- fœetid, 371, 387

de brucine, 384

de cinchonine, 386

de quinine, 394

de strychnine, 397

de veratrine, 398

Alcool, 172

Alcornocco cabarro, 57

Alder, 30, 104

Ale, 322

Alegar, 293

Alexanders, 79

Alga, 14

Algæ, 7

Alhgi, 99

Alisma, 27

Alismaceæ, 27

Alkali, unref. mineral, 275 volat. 277

Alkalies, 72
Alkekengi, 52

Alkermes, 413

Allantoides, 135

Alleluja, 111

Allgood, 42

Allheal, 48

Alliaria, 107

Allium, 23, 24

Allseed, 43

Allspice, 86

Almagra, 265

Almond, 92

burnt, 92

Java, 102

Guiana, 109

Alnus, 30, 104

Aloe, 22, 159

rosata, 434

Socotr. trita fact. 462

Aloes, starch, 167

wood, 37,92

Aloexylum, 92

Alpinia, 26

Alphenic, 469

Alsine, 117

Alstonia, 59

Alstrœmeria, 22

Althæa, 121

Altingia, 29

Alum, 279

ammonia, 280

burnt, 280

root, 83

Alumen, 279

catinum, 272

fæcum, 272

saccharinum, 477

ustum, 280

Alumine, gelatinous, 262 hydrate of, 262 pure, 262

Alysson, 108

Alyssum, 51, 108

Amadou, 9

Amalgam of zinc, 233

Amaracus, 53

Amaranthace, 43

Amaranthus, 43

Amarelle, 91

Amber, 221

black, 218

gris, 218,230

liquid, 202

powers of, 373

Ambra, alba, 218 grisea, 218

- reducta, 428

liquida, 202

nigra, 218

Ambrosia, 53, 72, 108

Ammi, 79, 80, 82

Ammonia hepatizata, 282 ppa. 277

sulphate of copper, 254
Ammoniacal tincture of copper, 387

Ammoniacum, 154

Ammoniata, 370

Ammoniated iron, 256

Ammonium hydrosulphuratum, 296

Ammoniuretum cupri, 254

Amomum, 25, 53, 80, 86

Amsa, 153

Amurca, 186

Amygdaleæ, 91

Amygdalus, 92

Amylum tritici, 166

Amyris, 101

Anabasis, 43

Anacardium, 100

Anagallis, 44, 49

Anagyris, 95

Ananas, 21

Anas, 141

Anchor fish, 145

Anchovies, 144

Anchovy powder, 466

Anchusa, 53

Andrachne, 60

Andromeda, 61

Andropogon, 18

Androsace, 45

Androsæmum, 110

Anemone, 124

Anethum, 78

Angelica, 80

tree, 78

Angustura, 102

bark, 118

Anil, 98, 169

Animals, 131 preserving of, 131

Anise, 78, 123

Anizette de Bourd. 413

Anisum, 78, 83, 123, 132

Annona, 122

Annonaceæ, 122

Annotto, 120, 203

reductum, 42.9

Anonis, 96

Anser, 141

Antelope, 138

Anthemis, 70

Anthericum, 22

Anthora, 126

Anthos, 46

Anthoxanthum, 17

Anthyllis, 96

Antiaris, 33

Anti-attrition, 502

Antidesma, 91

Antihecticum Poterii, 238

Antimonium, calcinat. 240

catharticum, 241

crudum, 226

diaphoreticum, 240

fusum, 226 
INDEX.

Antimonium medica. 2 구

nedicinale, 226

muriatum, 260, 273

tartarisatum, 260

vitrifactum, 240

Antimony, 234

crude, 226

purging, 241

smelted, 226

sulphurets of, $226,22 \pi$, 228

Antirrhinum, 50

Antithora, 126

Antopbylli, 87

Aparine, 72

Apes, 147

Aphanes, 89

Aphides, 147

A pios, 35, 97

A pium, 79

A pocynez, 57

A pocynum, 57

Aponogeton, 20

A ppensa, 510

Apple, 52, 61, 66, 88, 89, $95,105,123,150$

Apricock, 32

Aqua absin thii, 374

acet. ammon. 282

acida sal. comm. 302

acidi carbonici, 313

acidulata c. a. carb. 313

alexiteria simp. 326

— spirit. 375

- spir. c. aceto, 377

alkalina oxymur. 284

aluminis, 341

aluminosa, 341

ammonix, 278,282

- caustice, 278

- purse, 278

amygd. amar. 327

anethi, 326

angelicax, 374

snisi, 326

- fortis, 374

- stellati, 329

aursnt. cort. 326

- cortici, 374

aurant. flor. 329

bryonize composita, 374

calcaris scidula, 313

caleis, 271

carb. acid. sod. mixta, 313

- ferri, 313

- amm. 282

cardamomi, 375

carlinge, 32 ?

carni, 326,375

cescarillim, $32 f$

cassiax, 326

castorei, 329

ceras. nigror. 326

rhalybeata, 311
Aqua chamæineli, 375

cinnamoni, 326, 375

citri cort. 328,375

cort. Peruv. 327 .

cumini, 327

cupri amm. 254

cymbalarix, 326

depurata, 312

distillata, 312

epidenica, 375

epileptica, 377

fabarum flor. 329

flammulx, 327

florum omnium, 329

fluviatilis, 311

fœniculi, 327

fontana, 311

fortis, 306

fragarix, 329

gentianæ, 376

hepatica, 314

- acid. 314

hordeata, 335

Hungarice, 377 v

hydroc. veget. 350

hydropipcris, 327

hydrosulphurata, 314

hydrosnlph. acid, 314

hyssopi, 327

juniperi, 327

- compos. 376

kali, 273

- caustic, 274

- puri, 274

lactis alexiteria, 329

lavandulæ, 329, 379

laurocerasi, 327

ledi palustris, 329

lilii convall. 329

lithargyri acet. 258

c. 342

lucix, 373

magnesix, $314 \mathrm{r}$

marina, 313

marjoraur, 330

mellis, 297

- odorifera, 380

melisser, 328,380

menthre, 328, 376

- piper. 328,376

mirabilia, 376

muriatis calcis, 281

myrti, 329

naphre, 329, 379

nephritica, 376

nivalis, 311

nucis mosch. 328,377

ophthalmica, 342

oxymuriatica, 306

preonix composita, 376

papaver, albi, 328

pliagedenica, 341

piris liquidxe, 331

pimentse, 328
Aqua pimpinellæ, 328

piper. Jamaic. 328

pluvialis, 311

potass 2,274

potentillx, 330

pulegii, 328,377

raphani, 377

regia, 306

rhodiæ rad. 330

rorismar. 330

rosæ, 330

rubi Idxi, 330

ruta, 329

salina, 311

sambuci flor. 330

santali citr. 330

sapphirina, 254

scœenanthi, 330

scordii, 330

sclopetaria, 381

subcarb. kali, 273

sulphurata, 310

sulphurea, 311

sulph. acidula, 313

sulphureti ammon. 225

- kali, 225

superb. potassæ, 313

— sodæ, 313

Stygis, 312

theriacalis, 377

tiliæ, 330

ulmarix, 330

vanillarum, 330

vitæ, 169

vitis, 169

vitriolica, 341

vulneraria, 381

zinci vitr. a. camph. 342

Aqux alkalin $x, 312$

aluminosæ, 312

catharticx, 311

clialybeat $x, 311$

cupreæ, 312

fontanæ, 311

lapidificantcs, 312

salin $x, 311$

sulphurcæ, 311

Aquilaria, 92

Aq̣uilegia, 126;

Arabis, 107

Arachis, 96

Aralia, 78

Araliacere, 78

Arbur vito, 28

Arbutus, 60

sugar, 150

Arcell, 11

Archangcl, 48

Archel, 11

lump, 473

Arctium, 6.5

Areca, 20

Arena, 268

Arenaria, 81 
Arenga, 20

Argemone, 105

Argentina, 90

Argentum, 231

musivum, 234

nitratum, 253.

vivum, 231

Argilla, 265, 279

lutea, 263

Argillæ, 261, 265, 266

Argol, 285

Arisarum, 14

Aristotelia, 104

Aristolochia, 37

Aristolochiæ, 37

Armeniaca, 92

Armoracia, 108

Armour, 137

Arnica, 69

Aroideæ, 14

Arrack, 173 mock, 403

Arrow head, 27 root, 166

Arsenias kali, 283 sodæ, 289

Arseniate of copper, 247 of potash, 283 of soda, 289,383

Arsenic, 228, 235

black, 235

red, 228,240

white, 302 yellow, 228, 240

Arsenicum album, 302 citrinum, 228 flavum, 228 nigrum, 235 rubrum, 228

Arse smart. 42

Artanita, 45

Artedia, 82

Artemisia, 70

Artichoke, 65, 71 gum, 154

Artocarpex, 32

Artocarpus, 33

Arum, 14

Arundo, 18

Arvina, 215

Asarabacca, 37

Asarum, 37

Asbestus, 269

Asclepias, 57

Ascyron, 110

Aselli, 146

Ash, 59, 88, 118 balls, 272 \%

Ashes, barilla, 275 black, 290 tobacco, 273

Asimina, 122

Asinus, 139

Aspalathus, 95
Asparagi, 23,

Asparagus, 23

Aspen, 30

Asperugo, 53

Asperula, 72

Asphodel, 22

Asphodeli, 22

Asphodelus, 22

Asphaltum, 22I prepared, 484

Asplenium, 12

Ass, 139

Assa dulcis, 204 foetida, 154

Asses' milk, 179

Astacus, 146

Aster, 67, 71

Astragalus, 97

Astrantia, 79, 82

A thamanta, 79, 81

Athanasia, 70

Atractylis, 66

A tragene, 124

Atramentum, 363

Indicum, 473

Atriplex, 42

Atriplices, 42

Atropa, 51

Attar gul. 194

Augia, 110

Aurantium, 113

Auricula, 45

Judac. 10

leporis, 82

muris, 64

Auricularia, 47

Auripigmentum, 228

Aurum, 230

foliatum, 230

fulminans, 243

in libellis, 230

Mosaicum, 230

muriat. natronat. 252

musivum, 230

pulveratum, 230

sophisticum, 230

Autour bark, 127

Avellana, 30, 36

Avena, 16

Avens, 90

Averrhoa, 102

Aves, 141

Avicennia, 46

Avicula, 145

Avocado pear, 39

Avul coondoor, 205

Awel urruk, 219

Awl, 76

Axunge, 227

Axungia, 215, 216

Lunæ, 261

Solis, 263

viperarum, 215

Ayapana, 67
Ázapana, 62

Azalea, 61

Azarole, 88

Azedarach, 112

Azure, Egyptian, 270

Azurum cinereum, 246

Azurum, 270

B.

Babul, 93

Baccæ aurantiæ, 113

Baccharis, 67, 71

Bachelors' button, 117

Bacon, 140

Bactris, 19

Bagassa, 33

Bajora, 18

Balanus, 94

Balæna, 140

Balænoptera, 140

Balaustix, 87

Ball, black, 508

breeches, 476

clothes, 476

Ballote, 48

Balls, alterative, 442

ash, 272

astringent, 442

bitter, 431

blacking, 487

brass, 228

colick, 443

contrayerva, 455

copperas, 228, 241

cordial, 443

cough, 443

cream, 486

deers, 9

diuretic, 444

fever, 444,461

furniture, 507,525

horse, 442, 446, 459

laxative, 444

mange, 445

puff, 9

purging, 444, 445

scouring, for grease, 487

stomachic, 445

sweet, 470

tan, 31

tonic, 446

wash, 486

Balm, 47

of Gilead, 201

- tree, 101

Balsam, 47, 111, ]18, 201 acouchi, 203

of amber, 221

anodyne, 383

arouarou, 203

Canada, 201

of capivi, 201

friars', 398 
INDEX.

Balsam of honey, 389

- pectoral, 401

of horehound, 389

houmiri, 203

Hungarian, 201

of life, 382

natural, 202

of Peru, 202

Riga, 192, 392

of sulphur, 377

Thibaut's, 398

of Tolu, 202, 207, 213, 219

of turpentine, 195

Vervain's, 398

wound, 398

yellow, 111

Balsamaria, 110

Balsamseleon, 201

Balsamum al bum, 202

amyridis, 201

anodynum, 383

calaba, 202

Canadense, 201

cancamum, 204

copaibre, 201

- red, 479

focot, 207

Gileadeuse, 201

- fact. 479

graiacinum, 409

byperici, 477

Indicum, 202

Judaicum, 200

Libani, 193

Locatelli, 490

Mariæ, 202

Mecha, 200

myroxyli, 202

I'cruvianum, 202

- factitium, 479

- red, 479

polychrestum, 393

populi, 202

rackasiri, 202

Sancti Thomæ, 202

saponis, 396

Saturni, 478

styracis, 202, 206

succini, 222

sulph. anisatum, 478

- Iarbadense, 478

- nimp. 478

- terebinth. 478

taramshara, 202

terebinth. vulg. 479

toluiferw, 202

Tolntanum, 202, 207

tmumaticum, 414

viride, 203,491

Balsams, 201

Bambusa, 18

Pamia, 12]

Banana, 25
Bancudus, 76

Bane berries, 125

Banilloes, 27

Bankara, 188

Baobab, 121

Bar wood, 128

Barabee, 39

Barba Aaronis, 14

Barbados nut, 36 pride, 95

Barbarea, 107

Barbaty, 97

Barbel, 144

Barbura, 93

Bardana, 65, 72, 76

Bark, 73, 76, 81

Barks, 127

Barilla, 275

Barleria, 45

Barley, 16, 20

pearl, 16

flour, 166

prep. pearl, 166

starch, 166

wine, 322

Barm, 175

Barras, 206

Barren wort, 104

Barringtonia, 111

Barros, 264

Barrow's grease, 215

Baryosma, 99

Basella, 42

Basil, 47

Basilicon, black, 506 yellow, 506

Basilicum, 47

Bassia, 60

Bast, 120

Batatas, 52

Baudruches, 137

Baume de Carpathes, 192

Carthagene, 207

commandeur, 413

vulnéraire, 314

Bay, 24, 39, 57, 60, 77

Bdellium, 154

Bead tree, 112

- gutn, 152

Beads, rose, 487

Bean, 56, 97, 101

Irazilian, 40

Bear, 139

berry, 60

IBear's breech, 4.5

foot, 89, 125

grease, 215

ear, 45

Beaver, 139

Beccabunga, 49

Bèclse de mer, 14.5

Bedeguar, 89

Bedstraw, ladies, $7: 2$

I3eech, 3 !
Beech mast meal, 166

Bcef, 134

Beer, 3:3, 324

Bees, 147

Bees' wax, 218

Bcetle, 147

Beet, 42 sugar, 149

Behen, 44, 66, 117, 127

Bela-aye, 57

Bell flower, 63

Belladonna, 51

Bellis, 68

Beluga, 143

Ben, 66 nuts, 94

Bengalee, 25

Benjamin, 204

Beuzoate of anımonia, 282

Benzoinum, 204

Bcrberideæ, 104

Berberis, 104

Berberigo, 104

Bere, 17

Bcrries, straw, 90

Besleria, 50

Beta, 42

Betel, 32 nut, 20

Betonica, 47, 49

Betony, 47, 49

Betula, 30

Betulideæ, 30, 31

Bczetta corulea, 511 di Levante, 511 rubra, 511

Bezoar, 181 mineral, 240

Bezoardicuin minerale, 240 joviale, 238

Bhoot, 98

Bhoota, 17

Bianchetti, 8 di pittori, 263

Bicarb. of potash, 274 of soda, 276

Bice, 246

Bidens, 71

Bifolium, 27

Bigg, 17

Jiguonia, 55

Billerry, 61

Billardicra, 103

Bina, 17

Bindweed, 24, 42, 55,

Birch, 30, 10' sugar, 150

Bird-lime, 214

Bird's oye, 125 font, 98

Birth wort, 37

Biahop's weed, 79

Bislingun, 24, 25

Bismalva, 121 
Bismuth, 233, 242

Bistort, 42

Bistorta, 42

Bistre, 224

Bisulphuret of iron, 228 quicksilver, 229 tin, 230

Bittern, 431

Bitter sweet, 52 wood, 119

Bitters, brandy, 403 colombo, 384 spirit, 383 wine, 364

Bitumen, 221

Bixa, 120

Black, 222, 223, 236 ash, 290

berry, 90

Brunswick, 483 cobalt, 243

florey, 474

lamp, 224

lead, 229

reviver, 370 varnish, 404

Blacking, 362

Bladder wrack, 7 nut tree, 103 ox, 136

Blanc, 261 de baleine, 217 de Bougival, 263 de Moudon, 263 de Rouen, 263

Blanquette, 275

Blattaria, 51

Bleak, 144

Blechnum, 12

Blewits, 118

Bley, 144

Blister, liquid, 480

Blistering flics, 146

Blite, 43

Blitum, 43

Blood, 178 root, 105

Blood stone, 237 wort, 42

Bloody dock, 42

Bloom, almond, 357

Blubber, 140

Blue bottle, 66

China, 271

cobalt, 251

liquid, 361

powder, 270

Prussian, 250

Sanders, 284, 216

Saxon, 253, 361

stone, 253,476

ultramarine, 270

verditer, 246

vitriol, 253
Bocconia, 105

Boerhavia, 44

Bog bean, 56 moss, 12

Bohon upas, 58

Bois d'Angleterre, 33 d'aloes, 37 de calambac, 137 de Cham. 107 de chandelle, 109 de la Chine, 128 de Chypre, 128 d'Inde, 94 jaune, 33 de palixandre, 128 de rose, 128 tapire, 128 violet, 128

Bol, 15

Bole, 263

Boletus, 9

Bolus aluminis, 440 Armena, 261, 264, 278 Blesensis, 264

Bohemica, 264 candida, 261 communis, "265 Gallica, 264 moschi, 440 purging, for dogs, 463 Veneta, 245, 259 vitrioli albi, 440

Bombax, 121

Bombyx, 147

Bonduc tree, 94

Bone. glue, 182 grease, 216

Bones, refuse, 135

Bonnets, Scotch, 9

Bonplandia, 118

Borage, 54

Boragineæ, 53

Borago, 53

Boras hydrargyri, 245 sodx, 287

Borassus, 20

Borate of quicksilver, 245

Borax, 287

Borussias ferri, 250

Bos, 134, 136

Boswellia, 102

Botany Bay wood, 128

Botargo, 143

Botrys, 43

Bottle, phosphorus, 512 red, 398

Boues d'encre, 363

Bougies, 509

Box tree, 35

Brai gras, 506 sec, 209

Brains, 135

Brakes, 12

Bramble, 90
Bran, 16

Branca ursina, 45

Brance, 15

Brandewyn bosch, 120 von koorn, 172

Brandy, 169, 172, 174 cherry, 91 shrub, 416

Brank ursine, 45 "

Brass balls, 228

Brassica, 55, 106, 107

Brazil, 95, 101, 112 beef wood, 128

Brazil gum, 152 nuts, 87, 109

Brazilletto, 91, 95, 100

Bread, 168, 175, 176 bee, 218

fruit, 33 nut, 27

Breakfast powder, 177

Bresil, 95

Bresille, 99

Bresillet, 94

Briar, 89

Bricks, 266

Brimstone, 224

Brine of red cabbage, 363 of violets, 364

Brionia, 24

Briony, 24 fecule, 168

Briza, 15

Brochettes, 135

Brocimum, 27

Brocoli, 106

Bromelia, 21

Bromeliæ, 21

Bromus, 19

Bronze powder, 232

Brook lime, 49

Broom, 95 ashes, 267 coffee, 177 rape, 50

Brossæa, 61

Brouquichons, 9

Brown gum tree, 87 Spanish, 265

Browning, 360, 417

Brucea, 102

Brucine, 210

Bruguiera, 76

Bruscus, 23

Bryonia, 62

Bryony, 62

Bubon, 80, 82, 88

Bucaros, 264

Buck, J38 eyes, 110

Buckho, 118

Buckthorn, 38, 103, 111

Buck wheat, 42

Buckia, 26 
INDEX.

Buenos Arres, 135

Buffalo, 136

bezoar, 181 milk, 180

Bufo, 142

Bug, 147

Bugula, 49

Bugle, 49

Bugloss, 53

Buglossum, 53

Bulbocastanum, 82

Bulbus vomitorius, 22

Bull fists, 8 hoof, 116

Bull's liver, 9 tongue, 9

Bunias, 108

Bunium, 82

Buphthalmum, 70

Bupleurum, 82

Burdock, 65, 72, 76

Burnet, 89

Bursa pastoris, 108

Bursera, 102

Butchers' broom, 23

Butea, 95

Butonica, 111

Butter of antimony, 260 Iaurus Glauca, 188

bassia, 188

bur, 68

cacao, 188

choorie, 188

clarified, 217

cups, 124

fresh, 217

honey, 499

milk, $] 79$

nut, $19,60,102$

nutmeg, 188

roses, 194

salted, 492

tree, 60

of $\operatorname{wax}, 220$

wort, 45

Butters, vegetable, 188

Buttneria, 121

Butterfly, 57 weed, 57

Butyrum antimonii, 260 cacao, 188

cers, 220

- fact. 480

insulsum, 217

purifiratnm, 217

Buxun, 35

Bysuns, 145

C'.

Caspian, 33

Cabatha, 122

Cabbage, 14, 106, 108

tree, 99
Cabob, Chiua, 40

Cacalia, 66

Cacatin, 118

Cacao, 14, 121, 177

Cachen, 56

Cacholot, 140

Cachou, 448

Cachrys, 81

Cactus, 84

Cada pilava, 76

Cadalay poolip. necr, 312

Cresalpinia, 94

Caiaca, 35

Cake, almond, 92 linseed, 117

Cakes, oil-colour, 507 water-colour, 475 worm, 451 -

Calaba, 202

Caladium, 15

Calaguala, 13

Calamary, 145

Calabash trce, 53

Calambac, 92

Calamina, 239

Calamint, 46

Calamintha, 46

Calamus, 19, 20

Calavanches, 98

Calbigia, 15

Calias, 14

Calcine, 238

Calcitrapa, 66

Calculus bovinus, 182

Calchash, 53, 62

Calendula, 69

Caleza de negro, 20

Calibash, 116

Calla, 13

Calleloc, 43

Callicocca, 73

Calomel, 244

Calomelas, 244

Calomelanos, 244

Calophyllum, 110

Caltha, 125

Caltrops, 85, 119

Calumba, 122

Calves' mawes, 13.5 snout, 50

Calycanthus, 92

Calypectun, 88

Calx antimonii, 240 - nitratis, 240 cum kali puro, 457 e testin, 14.5, 271 viva, 269 hydrangyri alba, 245

Cam wood, 100

Camhogia, 111, 15.5

Camel, 138 bezoar, 180

Cameln' hay, 18

Camellia, 115
Camelina, 107

Camelus, 138

Cammock, 96

Camomile, 70

Campanula, 63

Campanulaceæ, 63

Camphire, 198, 199

dryobalanus, 198

liquid, 198

tree, 39

Camphora, 198

Camphorata, 43

Camphorosma, 43

Campion, 118

Canagna, 122

Canards, 135

Canarium, 102

Canary grass, 18

Cancamum, 204

Cancer, 146

weed, 46 ,

Candelæ probatorix, 509

Candy, ginger, 450

Candy, sugar, 149

Cane, 14, 18, 26 spirit, 172

Canella, 86, 112

Canelle, 40, 86

Canelo, 123

Cancpin, 137

Canna, 25

Cannabis, 34

Cannæ, 25

Cantabrica, 55

Canterbury bells, 63

Cantharides, 146

Cantharis, 146

Canthium, 73

Caoutchouc, 214

Caper, 109, 119

Capillaire, 412

Capillus Veneris, 12

Capparidex, 109

Capparis, 109

Capra, 138

Capraria, 50

Caprifoliacen, 77

Caprifolium, 77

Caprimulgus, 140

Capsicum, 53

Carabe, 221,

Carabouca wood, 128

Carabus, 147

Caragna, 204

Caranna, 204

Caraway, 78

Carbo ligni, 221, 222

Carbonas ammonia, 277

baryte, 270

calcis, 261

ferri, 250

magnesia, 261, 275)

plumbi, 248

potassse, 273,274 
Carbonas sodæ imp. 275 - siccat. 276 zinci, 239

Carbonate of ammonia, 277 of barytes, 270,284 of copper, 246 of lead, 248 of soda, 276

Carburet of iron, 229

Cardamine, 107

Cardamoms, 26

Cardamomum, 26

Cardiaca, 48

Cardinal flower, 63

Cardiospermum, 109

Cardium, 146

Cardoon, 65

Carduus, 65, 66, 72

Carenum, 150

Carex, 15

Carica, 33, 116

Carlina, 65

Carmin. Dalby's, 352, 411

Carmine, 219

Carnations, 95

Carob tree, 93

Caroba, 93

Carolinea, 121

Carpapiga, 32

Carpobalsamum, 86, 101

Carrot, 82 spirit, 174 sugar, 149

Carthamus, 66

Carui, 78

Carum, 78

Caruru, 38

Caryocar, 109

Caryota, 19

Caryocostinum, 424

Caryophillata, 90

Caryophillex, 117

Caryophyllus, 87, 117, 126

Cascarilla, 36, 79, 80

Cascola, 16

Caseus, 220

Cash cutti, 161

Cashew gum, 152 nut, 100

Cashioberry bush, 77

Casia, 39, 40

Cassada, 36

Cassamunar, 25

Cassava, 36 bread, 167

Cassia, 39, 40, 86, 93

Cassia pulp, 151

Cassine, 77, 103

Cassuvium, 100

Castanea, 30

Castilla gum, 214

Castor, 139, 218 seeds, 35

Castoroum, 139, 218
Catananche, 64

Cataplasma e cymino, 429 salis comm. 432 salis Glauberi, 432 emeticum, 432

Cataplasmata aluminis, 432 carbon. ligni, 432 cicuts, 432

digitalis, 432

effervescens, 432

extemporanea, 452

Goulardii, 432

farinæ lini, 432

panis, 432

rosæ, 432

veterinaria, 432

Cataputia, 35

Catchfly, 117

Catechu, 161

Catgut, 137-139

Cathartocarpus, 93

Catheters, elastic gum, 509

Catrighondoo, 158

Cat's claw, 93

- foot, 67 tail, 15

Caucalis, 82

Cauda equina, 13, 14

Cauliflower, 106

Caulis, 106

Caustic for canker, 356 common, 457

Causticum antimon. 260 commune, 457 - c. opio, 427 lunare, 253

Cauterium potentiale, 474

Cavalam, 120

Caveach, 143

Caviar, 144

Cawk, 269

Ceanothus, 104

Cedar, 28, 55, 112, 120

Cedrat, 431

Cedrela, 112

Cedria, 195

Celandine, 105, 124

Celastrineæ, 103

Celastrus, 103

Celery, 78

Celtis, 31

Cembro nuts, 28

Cement, Armenian, 431

Botany Bay, 508

French, 338

parolic, 476

seal engravers', 508

universal, 476

Cendres du Levant, 275 bleues, 246 gravellées, 272

Centaurea, 66

Centaurium, 56, 66

Centaury, 56
Centinodia, 42

Centory, 56, 66

Cepa, 22

Cepatelli, 9

Cephalis, 73

Cera alba, 218

Cera flava, 218

- factitia, 506

- viridis, 188

Cerasse, 62

Cerasus, 91, 110

Cerastum, 117

Ceratia, 93

Ceratonia, 93

Cerate, blue, 495

Kirkland's, 494

Marshall's, 494

Turner's, 493

Ceratum, 494

album, 491

calaminæ, 493

camphoræ, 492

cantharidis, 493

carb. zinci imp. 493

cetacei, 491

citrinum, 488

defensivum cœrul. 495

epuloticum, 493

Galcni, 499

labiale, 500

lapid. calaminaris, 493

litharg. acetati, 494

lyttæ, 493

mercuriale, 489

plumbi comp. 494

resinæ, 488

- flavæ, 488

sabine, 496

saponis, 494

simplex, 491, 492

spermaceti, 491

Cerbera, 58

Cereis, 95, 100

Cereoli simplices, 509

Cerevisia, 322

Ceroxylon, 20

Ceruss, Venetian, 472

Cerussa acetata, 258

antimonii, 240

nigra, 229

serpentariæ, 167

vera, 248

Cervus, 138

Cetaceum, 216

Ceterach, 12

Cetine, 216

Cevadilla, 21

Ceylonian plant, 47

Chærefolium, 79

Chærophyllum, 79

Chalk, 261

black, 266

French, 267

red, 264 
Chalk, white, 262

Chalybs, 232 prop. c. aceto, 237,250 c. sulph. prep. 229

Chamsecissus, 47

Chamsecrparissus, 70

Chamsdaphne, 38

Chamsedrys, 48

Chamelrea, 38

Chamæleon, 65

Chamæmelum, 70

Chammmorus, 90

Chamsepitys, 48

Chamæriphes, 20

Chamærops, 20

Chameerubus, 90

Chamæsyce, 35

Champac, 123

Champagne, 317, 321

Champignon, 9, 10

Chanterelle, 9

Chappungham wood, 94

Char, 144

Chara, 108

Charbon, 221, 222

Charcoal, 222

Lardner's, 470

Chardoon, 65

Charge for windgalls, 499

Charlock, 106

Charon, 219

Cheese, 220

renning, 72

Cheeses, confection, 420

Cheiranthus, 107

Cheiri, 107

Chela cancrorum, 146

Chelonia, 141

Chelidonium, 105, 124

Chemic, 361

Chenopodium, 43

Chermes, 147

Cherries, 157

Cherry, 52, 77, 91, 110 tree gum, 152

Chervil, 79

Cheatnut, 31, $110^{\circ}$

Chests, medicine, 513

Cherrette, 9

Chick weed, 49, 84, 117

Chien de mer, 143

Chilidonium, 105

Chimaphylla, 61

China, 24

China root starch, 167

Chinininchs bark, 122

Clinna, 18

Chinolia, 143

Chinguapin, 31

Chinney weed, 11

Chirayit, sf;

Chironia, 56

Chlenceen, 121

Chlora, 56
Clilorate of potash, 283

Chloride of barium, 280 of lead, 249

d'or, 251

of sodium, 287

Chlorine liquid, 306

Chloromyron, 41

Chlorum aqua solutum, 306

Chloruretum auri, 252

— et sodii, 252

platini et sodii, 252

— sodii, 287

Chocolada, 452

Chocolate, 452

for icing, 340

nut, 121

Chondrilla, 64

Chota chia, 113

Chouan, 128

Chrème des Barbades, 415 de noyaux, 414 d'orange, 416

Christophoriana, 125

Chromate of iron, 251 of lead, 252 of potash, 286

Chrome, ycllow, 252

Chromium, 252

Chrysanthemum, 69

Chrysobalanus, 91

Chrysocolla, 246, 287

Chrysocoma, 67 .

Chrysocome, 67

Chrysogonum, 104

Chrysomela, 147

Chrysophyllum, 60

Chrysosplenium, 83

Cicea, 35

Cicely, 79

Cicer, 98

Cichorace $x, 63$

Cichorium, 63

Cicuta, 79

Cicutaria, 79

Cider, 320 spirit, 174

Cimex, 147

Cimicifuga, 126

Címolia, 261, 266

Cinara, 65

Cinarncephalex, 65

Cinchona, 74, 77

Cinchonine, 210

Cineraria, 71

Cineres elavellati, 272

genists, 267

herbarum, 272

- perlati, 272

Ruvici, 272

stanni, 238

Cinis, 272

Cinnabar, 229

Cinnabaris, 229

Cinnamomum, 40
Ciunamon, 40, 118, 126

Cinq-foil, 90

Circrea, 85

Circumcidancun, 150

Cirsiun, 65

Cissampelos, 122

Cistineæ, 116

Cistus, 61, 203

Citron, 112, 113

Citronelle, 415

Citrul, 62

Citrullus 62

Citrus, 113

Cires, 23

Civet, 219

Civet cat, 139

Cladonia, 10

Clairet, 414

Claret, 317

Clary, 46, 321

Clavaria, 9

Clavelli, 130

Clay, 264-266, 281

founders', 266

iron ore, 264

porcelain, 261

tobacco pipe, 261

Clays, 260-266, 281

Claytonia, 85

Cleavers, 72

Clcmatis, 124

Cleome, 108

Clerodendrum, 46

Clinopodium, 48

Clompanos, 120

Clove berry tree, 86 tree, 86

Cloves, 86

Cloud berry, 90

Clupea, 144

Clupanodum, 144

Clusia, 110

Clutia, 35

Clymenum, 110

Clysters, 343,344

veterinary, 352

Cncorum, 38, 54, 101

Cnicus, 66

Coagulum, 135

Coak, 223, 235

Coal oil, 220 tar, 221

Cobweb, 219

Cobalt, 234, 243

Cobolt, 235

Cocci, 147

Coccionella, 147

Coccoloba, 42

Cocenon, 93 snticlote, 62

Cocenlus Indicus, 121

C'occus, 147

Corhineal, 147 
Cochlcaria, 108

Cockle, 118, 146 powder, 466

Cock's combs, 49

Cockshead, 99

Cocoa, 19

Cocos, 19

Cocus wood, 128

Cod, 143 oil, 217.

Codaga pala, 57

Codeine, 212

Cœruleum Berolinen. 249 montanum, 246 ultram, 270

Coffea, 76

Coffe, 76

Coffce, 177

for icing, 340

shrub, 76

Cogruee, 17

Coissi, 119

Coix, 19

Coke, 223

Colchicacex, 20

Colchicum, 20

Colcothar, 238

Cole wort, 55, 106, 108

Colle, 102

à bouche, 338

forte, 338

de pate, 338,352

Collinsonia, 46

Collyria, 342

Collyrium, astringens, 342 acetosum, 342 aloes, 342

ammon. acet. 343

Goùlardii, 343 ।

opii, 343

sacchari sat. 343

vitrioli, 343

Colocasia, 14

Colocynth, 62

Colocynthis, 62 .

Colombo, 57, 122

Colophane, 209

Colophonium, 209

Coloquintida, 62

Colour for brewing, 417 ; lac, 474

Colouring, brandy, 417

Colours, cake water, 475 — oil, 507

liquid, 362

oil, in bottles, 501

show bottle, 362

Colsa, 107

Colt's foot, 68

Coluber, 142

Columba, 57, 122

Columbine, 126

Colutea, 98

romarum, 90
Combretaceæ, 86

Combustibles, 221

Comfrey, 53

Commelineæ, 20

Comocladia, 101

Composition, encaustic, 431

Concrementa cancro. 146

Concretions, morbid, 181

Condoms, 137

Conessi bark, 57

Confectio alkermes, 413 amygdalarum, 424

Archigenis, 422

aromatica, 423

aurantiorum, 419

cardiaca, 423

cassiæ, 423

Damocratis, 421

- Japonica, 425

menthæ, 424

opiata, 421

opii, 422,428

Paulina, 422

piperis nigri, 425

Raleighana, 423

rose, 418

rutæ, 419

scamnoneæ, 424

sennæ, 423, 424

Conferva, 8

Conger, 143

Coniferæ, 29

Conium, 80

Conserva absinthii, 418

ari, 435

aurantior. 419

citri aurantii, 419

cochlearim, 418

cynosbati, 418

lujulæ, 420

menthæ, 418

prunorum, 419

roris marini, 419

rosæ rubræ, 418

rutæ, 419

scillæ, 419

Conserve of hips, 418

lemon peel, 419

of mint, 418

of orange peel, 419

of roses, 418

of rosemary, 419

of rue, 419

of wormwood, 418

Conserves, 418,419

Consolida, 54, 69, 126

Consound, 54

Contrayerva, $33,37,57,96$, 116

Convallaria, 23

Convallium, 23

Convolvulaceæ, 54

Convolvulus, 54

Conyza, 67
Cool thi, 97

Coondoor, 205

Copaiba, 201

factitia, 279

solution of by Franks, 479

Copaifera, 99

Copal, 204

liquid. 203

varnishes, 403, 404

Copper, 231, 232

green, 246

white, 235

Copperas, 255, 268

white, 259

Coptis, 125

Coral, 148

Corallina, 8

Coralline, 8

Corallium, 148

Coratch, 143, 358

Corchprus, 120

Cordia, 53

Cordial, bilious, 403

for calves, 352

caraway, 375

Godfrey's, 410

gout, 389

horse, 373

nervous, 384

peppermint, 403

Sir W. Ralcigh's, 423

sportsman's, 416

Warner's, 399

Coriaria, 101

Coriander, 79

Coriandram, 79

Coris, 110

Cork, 11, 30, 475

Corker, 11, 475

Corn, 17

Guinea, 18

rose, 105

salad, 72

Cornel, 77

Cornillons, 135

Cornu cervinum, 44

unicornu, 141

ustum, 223, 267

Cornua, 138

Cornus, 77

Coronilla, 98

Coronopus, 108

Corrigiola, 84

Corruda, 23

Cortex angelinæ, 127

aurantiorum, cond. 113

caryophylloides, 40

citri condita, 113

cuspariæ, 118

flavus, 74

granati, 87

limonum condita, 113

Peruv. trit. fact. 461

red. 462 
INDEX.

Cortex pallidus, it pocgereba, 127 ruber, 74 simaroubre, 119 thuris, 36 unguentarius, 127 Winteranus, 123

\section{Cortnsa, 45}

Corrus, 141

Corvlidere, 30

Corylus, 30

Corrmbifere, 66

Corypha, 20

Cosmibuena, 75

Costmary, 69

Costus, 26

Cotonea, 88

Cotton, 70,121 tree gum, 153 weed, 70

Cottus, 144

Cotula, 70

Cotyledon, 83

Couch grass, 16

Coumarouna, 99

Conperose bleue, 253 verte, 255

Courou moelli, 120

Couscous, 18

Coutoubrea, 56

Coventry bells, 63

Cow dung, 181 parsnep sugar, 149 tree, 60 weed, 80 wheat, 49

Cow's milk, 179

Cowbage, 97

Cowslips, 4.5, 53

Crab, 88, 146

Crambe, 108

Cranberry, 61

Crane's bill, 111

Crassula, 83

Crastulacese, 83

('ratagus, 88

Cratapongonum, 49

Craw fish, 146

Crayon noir, 267

Crnyon rouge, 26:

Crayons, 476

Cream, 180

cold, 500

furniture, 486

for icing, 340

pinters', 482

of tartar, 28.5

of tart. solub. 28.5

Creata, 45, 56,

Creme do ris, 337

de Iarhades, 415

de Ninyaux, 415

d'orange, 416

Cremor tartari, 285
Cremor reductus, 462

Creosote, 196

Crepis, 64

Crepitus lupi, 9

Crescentia, 53

Cress, 107, 108

Creta, 261, 262

præcipitata, 262

preparata, 262

Crista galli, 49

Crithnum, 81

Crocodilion, 66

Crocus, '25, 237, 251

antimonii, 241

argenti, 231

of gold, 235

Martis, 238

metallorum, 241

in placenta, 129

Solis, 235

Cross wort, 73

Croton, 36

Crottles, 10, 11

Crow foot, 124, 125 quills, 151

Cruciata, 73

Crueiferæ, 106

Crustacea, 146

Crystal, 268 mineral, 283

Crystalli lunares, 253 tartari, 28.5

Veneris, 254

Crystals of tartar, 285

Cubeb, 32

Cubeba, 32

Cuckow flower, 117

- pint, 14

Cucumber, 62

Cucumis, 62

Cucurbita, 62

Cucurbitacex, 61

Cudbear, 491

Cudweed, 67, 69

Culilaban, 40

Culilawan, 40

Cumin, 80, 105 opium, 157

Cuminum, 80, 105

Cunila, 48

Cunoniacear, 83

Cupressus, 28

Cupruin, 2.31

amtroniatum, 254

Cups, antimonial, 510 emetic, 510 purging, 510

Cupula, 30

Curaçoa, 416

Curatoc, 21

Curculio, 147

Cureuma, 26

Currants, 84, 112, 120 coffee, 177
Cusparia, 118

Cusparieæ, 118

Cuscuta, 55

Cutch, 161

Cutta camboo, 160

Cuttle fish, 145

Cyanure de Mercure, 258

Cyanuret of iron, 249

of potassium, 286

Cyanus, 66

Cyathea, 13

Cycadeæ, 27

Cycas, 20, 27

Cyclamen, 45

Cyclopteris, 13

Cydonia, 88

Cymbalaria, 50

Cyminum, 80

Cynanchum, 57

Cynocrambe, 34

Cynoglossum, 54

Cynomorium, 43

Cynorrhodon, 89

Cynosbatos, 89

Cynosorchis, 27

Cynosurus, 17

Cyperus, 15

Cypress, 28

Cyprinus, 144

Cytini, 87

Cytinus, 37

Cytisus, 96

D.

Daberlocks, 7

Dædalea, 9

Duffodil, 24

Dahn, 17

Daisy, 69

Dalea, 96

Daunner, 208

Damson, 119

Danais, 73

Dandelion, 65

Daplune, 38

Date, 19

Datura, 51

Daucus, 82

Daulakic carth, 267

Day's eye, 69

Deafness, Taylor's remedy, 478

Decoction of lark, 334

cooling, 335

diaphoretic, 33.5

Decnetions, 334,348

strengthening, 33.5, 3.50)

Decoctum alocs compositum, 382

althare, 3.34

ballota lan. 334

chamremeli, 334 
cinchonæ, 334

cydonire, 334

daphnes mez. 334

digitalis, 334

dulcamaræ, 334

pro encmate, 334

gallæ, 334

geoffrææ in. 335

guaiaci comp. 335

hellebori, 335

hordei, 335

lichenis, 335

malva comp. 335

oryzæ, 335,350

papaveris, 335

pectorale, 336

quercus, 335

santonici, 334

sarsaparillæ, 335

senegæ, 335

spartii cacum. 334

taraxaci, 334

tornentillæ, 334, 349

veratri, 335,350

ulmi, 335,350

Deer, 138

Defrutum, 150

Delphine, 210

Delphinium, 126

Delphinus, 140

Dentelle des boutoun. 135

Demidovia, 85

Dens caninus, 21

elephantis, 139

leonis, 65

Dentaria, 44, 107

Dentifrices, 429,470

Dentillaria, 44

Depilatory, $48 x y 0$

Derris, 99

Devil in a bush, 126

Devil's bit, 72

Deuto iodure de Merc. 246

Deutoxide d'arsenic, 302

Dew berry, 90

may, 312

Diacassia cum manna, 423

Diaceltatesson, 453

Diacetate of copper, 247

Diachylon, 503

compositum, 503

gum, 503

spread, 509

Diacodion, 407

Diacorallion, 421

Diacrydium, 456

Diacydonium, 419

Diagridium, 158, 456

Dianthus, 117

Diapente, 463

Diaphoretic antimony, 253 calaminaris, 240

Diascordium, 421

Dicera, 120
Diceros, 50

Dictamnus, 48, 118

Dietrichin, 26

Digitaline, 210

Digitalis, 50

Dill, 78

Dills, 7

Dillenia, 124

Dilleniaceæ, 124

Dimocarpus, 109

Dinitrate of bismuth, 242

Diodon, 143

Dioscorea, 24

Dioscoreæ, 24

Diosma, 118

Diosmex, 118

Diospyros, 60

Dipsaceæ, 72

Dipsacus, 72

Dipterix, 99

Dircæa, 38

Dittander, 108

Dittany, 48, 118

Dock, 41

Dodder, 55

Dog fish, 143

stones, 27

wood, 77,97

Dog's bane, 58

Dolichos, 97

Doronicum, 69

Dorstenia, 33

Dorycnium, 54

Doughs, fermented, 175

Dove's foot, 111

Draba, 107

Dracæna, 23, 142

Draco, 20

Dracocephalum, 48

Dracontium, 14

Dracunculus, 70

Dragon, 142

root, 14

Dragons, 14

blood, 206

Drank, 18

Draught, black, 345

Dregs of sulph. viv. 224

Drenches, 353, 354, 355

Dressing for can. mild, 498 for leather, 502

Drink for can. madness, 335 carmin. for horses, 353

hartshorn, 335

imperial, 333

Lisbon diet, 335

purging, 342

raisin, 336

riee, 336

Dromedary, 138

Drop wort, 80, 91

black, 368,410

Droppings of sweet oil, 186

Drops, Abbé Rousseau's, 410
Drops, anodyne, 350

antivenereal, 384

camomile, 385

de la Motte's golden, 400

Dutch, 195, $4804 \%$

fit, 352,371

ginger, 451

jesuits', 393, 397, 413

lavander, 390

lemon, 449

of life, 400

nitre, 378,450

Norris's, 392

pectoral, 392

peppermint, 449

sal volatile, 370

scouring, 484

soot, 352, 404

Spilsbury's, 383

tasteless ague, 302

Wade's, 398

Ward's white, 342

Drosera, 109

Droseraccæ, 109

Dross of lead, 237

Dryınis, 123

Dryobalanops, 111

Dryopteris, 13

Duck's meat, 27

Dugong, 140

Dulcamara, 52

Dulesh, 7

Dulse, 7 sugar, 151

Dung, devil"s, 154

Durdar, 229

Durra, 18

Dust, charcoal, 222

lead, 232

silver, 231

Dwale, 51

Dye, berry, 61

lac, 474

Dye, nankeen, 363

pink, 357

Dyers' wee d, 108

E.

Eagle wood, 37, 92, 99

Ear, 145

wort, 47

Earth of alum, 262

Cologne, 182

Cullen's, 182

mahogany, 264

nuts, 83

peas, 96

Strigeau, 263

Farths, 261

Eau d'ange, 329, 357

d'anserine, 330

d'arquebusade, 381 
INDEX.

Eau de Barbades, 415

de bouquet, 380

de canelle, 327

de chasseurs, 416

de Cologne, 380

divine, 416

de fl. d'oranges, 329

forte, 304

de framboises, 380

de IIusson, 404, 405

de Javelle, 284

de lavande, 379

de luce, 373

de Maréchale, 401

de mel. des Carm. 350

de mil. fl. 329, 380, 396,

417

du naphe, 379

d'cillet, 329

de Rabel, 394

d. L R. d. Hongric, 377

de ris, 336

sans pareille, 380

scconde, 874

de tain, 330

de rie, 160,170

de rie d'Andaye, 413

Ebenaceae, 60

Ebenus, 19

Ebony, 19, 55

Ebulus, 78

Ebur, 139

ustum, 223

Echinope, 66

Fchites, 57

Febium, 53

Erlipta, 71

Fildoes, 14

Fel, 143

fat, 215

gall, 179

Fgg, white of, 177

Filnagni, 38

F.largnus, 38

Elaris, 19

Elacocarpene, 120

Flarocarpus, 120

Flasodendrum, 104

F.Jaesacchara varia, 442

Elastic gurn tree, 37

Flate, 20

Filaterium, 168

Elatine, 50

E.duler, $32,77,82,83$

Electaria extemp. 437-44i

Flectaries, $137-43$

Filectarium snchclminticum, $4: 26$

aromst. $4 \cdot 23$

cassiar, 423

catechil compon. $42 \%$

catharticum, 426

demulcens, 427

dentifricium, 429
Electarium dolichos, 426

ellebore, 423

emmenagogicum, 427

ex carbone, 428

gingivale, 429

lauri, 420

lenitirum, 423

mimosec cat. 425

opiatum, 422

scanmonii, 424

scordii, 421

sennæ, 424

stimulans, 427

ad stomacacen, 429

sulphuris, 427

- comp. 427

- cum. bor. 427

terebinthinæ, 427

Thebaicum, 422

Electary, lenitive, 423

Elemi, 204, 206

Eleoselinum, 78

Elephant, 139

wood, 123

Elephas, 139

Elettaria, 26

Eleuteria bark, 36

Elicampane, 68

Elixir aloes, 393

- saponac. 382

antivenereum, 393

asthmatic, 382

Daffy's, 395

the Devil's, 399

of garlick, 374

de Giarus, 416

jalape compositum, 390

myrrhae composit. 391

d'or, 400

paregoric, 408

proprietatis, 40 ?

- dulce, 409

purging, 409

sacrum, $44.223^{-}$

salutis, $4+34.5$

Squires', 397

Stoughton's, 397

of vitriol, 310, 394, 393

acidum, 399

- dulce, 399

Elk, 139

Ellcborus, 21, 124

Fim, 31

gum, 158

Finbroc. for bruises, 3.5 .5

for boop. cough, 480

Lynch's, 480

for rhenmatism, 480

for strains, 480

Embroc. cxtersp. 343

Einbryopteris, 60

Findlia, 2f;

Fimery, 268

Fimetine, 211
Emetique, 260

Emplastrum adliøsiv. 502

anımoniaci, 502

ammon. c. hyd. 503

aromaticum, 506

assæ fretidæ, 506

attrahens, 507

calefaciens, 506

cantharidis, 504

cephalicum, 503

ceræ, 507

cereum, 507

commune, 503

- c. mercurio, 505

cumini, 503

epispasticum, 504

euphorbii, 504

flos. unguent. 504

galbani, 503

— com. 503

gummosum, 503

hydrargyri, 505

ladani, 506

lythargyri, 503

lythargyri c. gum, 503

- c. hydrargyro, 505

- c. resina, 502

lyttæ, 504

de meliloto, 506

meloes vesic. 504

mercuriale, 505

minio, 505

e mucilaginibus, 504

opii, 506

oxidi ferri rubri, 505

- plumb. seniv. 503

oxycroceum, 505

picis Burgundica, 503

- compositæ, 503

plumbi, 509

rсsinx, 502

roborans, 504

salis ammoniaci, 504

saponis, 505

simplex, 507

stipticum, 505

stomachicun, 506

thuris, 505

vesicatorium, 504

Emulsions, ferricrs', 35.

Emulsiones, 339

Enameln, 270, 271

Encens, 205

lindive, 63

linema, catharticum, 3.:3 344

Jomesticum, 344

spticolicum, 3.14

fretidum, 34.3, 3.44

ropintum, :344

opiii, 343

stimulang, 344

tatiari, 34 ?

trerelinth. 344 
Encmata, 343, 344

Ens Martis, 256

Enula, 68

Ephedra, 29

Epibaterium, 122

Epices fines, 483

Epidendron, 26

Epilobium, 85

Epimedium, 104

Epithema ammoniaci, 427 Goulardi, 427

terebinthinæ, 427

Epithymum, 55

Equisetaceæ, 13

Equisetum, 13, 14

Equus, 139

Ergot, 17

Erica, 60

Ericu, 57

Ericineæ, 60

Erigeron, 68

Ervum, 98

Eruca, 107

Eryngium, 83

Eryngo, 82

Erysimum, 107

Erythina, 97

Erythronium, 21

Escallonia, 85

Escargot, 145

Eseourgeon, 17

Escubac, 414

Esprit de Bergamotte, 379 de Ia Rose, 38]

de savon, 402

de tain, 381

de Venus, 296

de vin, 170

de violettes, 402

Essence of allspice, 402

of ambergrise, 401

of anchovies, 357

of bardảna, 368

of Bergamotte, 190

of bitter almonds, 381

of camomile, 385

of curaway seeds, 375

of cedrat, 191

of citrons, 191

of civette, 401

of coltsfoot, 400

of ginger, 399, 402

for the head-ache, Ward's, 372

of jasm. 192, 381

of jonquil, 193

of lavender, 192

of lemons, 192

of lemon-peel, 403

of musk, 401

of mustard, 496

of myrtlc, 193

de myrte, 380

of ncroli, 401
Essence of orange, 367

d'œillettes, 190, 401

of orange-pecl, $4.36,420$

of pennyroyal, 377

of peppermint, 376

royale, 401

roy. p. f. la barbe, 402

of roses, 381

of sprats, 431

of spruce, 164

de tubercuses, 381

of turtle, 359

des violettes, 192, 402

vestimentale, 484

Ess. for kitchen use, 402

Essentia ambr. griseæ, 401

amara, 382

anethi, 383

binæ, 417

fuliginis, 297

limonum, 192

Esula, 35

Etain de glace, 233

Fternal flower, 67

Ether, 199, 200

muriatic, 200

nitrous, 200

pyroligneous, 200

sulfuriq. iodure, 400

av. deuto-iod. de Merc. 400

Eucalyptus, 87

Eugenia, 87

Eupatorium, 67, 71, 89

Euphorbia, 34

Euphorbiaceæ, 34

Euphorbium, 155

præeparatinm, 456

Euphoria, 109

Euphragia, 49

Euphrasia, 49

Evodia, 118

Evonymus, 103

Ewes' milk, 179

Excoecaria, 37

Excretions, 177

Exostemma, 75

Extract of bark, 161, 210

- resinous, 210

black, 162

of gentian, 162

of hops, 162

of lettuce, 163

of lily of the valley, 163

of mahogany, 163

of mimosa bark, 163

of nux romica, 209, 210

of oak bark, 163

of opium deprived of narcotine, 212

of pepper, 163

of rhatania, 163

of saffron, 162

of savine, 164
Extract of sprats, $421,+47$

of tea, 164

vegetable, 417

Extracts, gelatinous, 182 . mixed, 164

watery, 160

Extractum absinthii, 160

aconiti, 158

acori, 161 ?

aloes spicatæe, 159

anemonis p. 159

anthemidis, 161

belladonnæ, 159

bryoniæ a. 161

calumbæ, 161

Campech. lign. 162

cascarillæ resin. 165 ?

cassiæ sennæ, 164

catechu, 161

catharticnm, 4.1436

centaurii $\mathrm{m}, 162$

chamæmeli, 162

cinchonæ, 161, 164, 177

- resin, 165, 210, 222

cocculi, Ind. 162

colocynthidis, 161

- comp. 436

conii, 159

convolvuli jal. 165

cort. Peruv. 161

- cum resina, 164 reductum, 445

croci, 162

cyloniatum, 443

digitalis, 162

dulcamarxe, 162

elaterii, 168

enulæ crmp. 162

fumariæ, 162

genistæ cac. 162

gentiasæ, 162

glycyrrhiza, 151

guaiaci lign. 162

hæmatoxyli, 16 ?

hellebori $n$. 162

humuli, 162

hyosciami, 159

jalapæe, 162

- resin, 165

jugland. imm. 160

juniperi, 162

lactucæ, 160

lupulini, 162

millefolii, 163

mimosæ c. 163

opii, 156

osmundæ reg. 163

papaveris, 163

piperis n. 163

podophylli, 165

pyrolæ umb. 163

quassiæ, 163

quercus, 163

rhei, 164 
INDEX.

Fxtractum rutee, 164 sabinæ, 164 sarsaparillı, 164

Saturni. 258

sennæ, 164

stramonii, 160-164

tanaceti, 164

tarasaci, 164

Thebaicum, 156

valeriana, 164

Eve bright, 49

stone, 145

water, blue, 254

Eyes medecine, 228

F.

Faba, 40, 56, 97, 104

Fabaria, 83

Frex olei, 186

Fagara, 118

Fagopyrum, 42

Fague, 31

Falauna, 123

Far, 16

Fard, 241

Farfara, 68

Farina, 165

avenacea, 166

hordei, 166

lini placentarum, 168

secalis, 166

sinspis, 160

tosta, 165

tritici, 165

Farinae resolventes, 123

Farro, 16, 17

Fat, curriers', 216

mackaw, 188

cea-lion, 216

Father lasher, 144

Fats, animal, 213

Faufel, 20

Feculs, 166

ari mac. 167

bryonia, 168

marantar, 166

agittariae, 16,6

Fel snguillarum, 179

bovia, 179,361

- inspis. 179

leporia, 179

tauri, 179

ursi, 179

vitri, 290

wort, 56

Fennel, 78

flower, 126

giant, 81

Fenouilletce de lilo de Rbe, 431

Fenugreek, 96
Fermentum cen visie, 116

Ferments, 176

Fern, 12

Ferrum ammoniatum, 256 tartarizatum, 256

vitriolatum, 255

Ferula, 81

Festuca, 18

Feuillea, 63

Feve, 97

Fever few, 69 root, 79

Ficarium, 37

Ficoideæ, 85

Fieus, 33 Iudica gum, 214

Fig, 33, 84 wort, 50

Fila ferri, 232

Filago, 67

Filandre, 137

Filices, 12

Filipendula, 91

Filix, 12

Fimus vacex, 181

Finfish, 140

Finks, 140

Finocchio, 78

Fir, 28

moss, 13

Fish glue, 1, 4

oil, 217

skin, 143

Fistularia, 9

Five-leaved grass, 90

Flacourtia, 120

Flag, 19, 25

Flambard, 216

Flare, 142

Flash, 431

Flax, 38, 116

Flea bane, 68

wort, 44

Fleur de luce, 24

Fliegen stein, 235

Flint, 268

Flix weed, 107

Florteo d'Inde, 474

Flores antimonii, 240

aurantior. cond. 113

benzoini, 293

bismuthi, 242

carminativi, 129

cerevisise, 176

cordisles, 129

Martiales, 256

salis ammon. 282

sal. ammon. Mart. 256

sulphuris, 225

zinci, 239

Flos amoris, 43

unguentorum, 604

Mour, baked, 16.5

Flom, stce, 166
Flower, cardinal, 63 fence, 95

- preserving of, 3

gentle, 43

of nntimony, 240

of benzoin, 298

of calomel, 244

carminative, 129

cordial, 129

of sal ammon. 282

of sulphur, 225

of zine, 239

Fluellin, 49

Fluid, Norfolk, 483

Fluviatiles, 14

Flux, white, 273

Fœniculum, 78, 81

Fœnum Græcum, 96

Folia de bunkood, 127

Folium Indicum, 40

Folliculi sennæ, 94

Fools' stones, 27

Formentone, 17

Fotus cicutæ, 334

Fowl, 141

Foxglove, 50

Fragaria, 90

Frangipane, 179

Frangula, 63

Frangulacex, 103

Frankincense, 205

Frank's solution of copriba, 479

Frasera, 57

Fraxinella, 118

Fraxinus, 59, 88

French berries, 103

Friar's cowl, 14 crown, 65

Frog, 142

bit, 27

fish, 142

Froment, 15

Frontiniac, 317, 321

Fruits, prescrving of, 3

Frumentum, 16

Fucus, 7

Fuligo, 224

Fuller's earth, 266

Fulminating mercury, 245 silver, 243

Fumaria, 105

Fumarider, 10\%

Fumigatio nitrosa, 325 oxymuriatica, 325

Fumigation, disinfect. 32.5 nitroug, 325

Fumitory, 165

Fungi, 8

Fungen, 9, 10

Funis felleus, 75, 122

Furfur, 16

Furzo, 95

IPuanin, 103 
F'usses, 86

Fustick, 33, 100

G.

Gadus, 143

Galanga, 26

Galangale, 26

Galbanum, 155

colatum red. 497 red. 155

Gale frutex, 31

Galega, 98

Galena, 229

Galeopsis, 48

Galinsoga, 72

Galipot, 206

Galium, 72

Gall, 179

refined ox, 361 stone, 182

Galla, 30

Gallæ, 30

Gallinæ, 141

Galls, 30

Gallus, 141

Galuchat, 143

Gambogia, 155

Gamboge, 155

Ganda birosa, 203

Ganistrum, 120

Ganja, 34

Garcinia, 111

Gardenia, 73

Gargarisma æruginis, 344 astringens, 344

boracis, 344

capsici, 344

commune, 344

nitri, 344

quercus, 344

sub. corros. 344

spirit. salis, 344

Gargarismata, 344

Gargles, 344

Garlic, 23

Garnet berries, 84

Gas acid. carbonicum, 324 carbonic acid, 324

hepatic, 324

hydrog. sulph. 324

oxygen, 324

oxygenium, 324

sulphuris, 316

sulphur. hydrog. 324

Gases, 324

Gasterosteus, 144

Gatter tree, 77

Gaub, 162

Gazoppoo, 276

Gazelle, 138
Gee, 91

Gelatina amygd. 337

cornu cervi, 337

cydoniorum, 419

lichenis, 337

panis, 337

Gelatine brut, 136, 138

humide, 182

Gelb. schutt. 475

Geldres rose, 77

Genipa, 73

Genip tree, 109

Genista, 95

Gentian, 56, 82

Gentiana, 56, 82, 128

Gentianeæ, 56

Gentianel, 56

Gentianella, 56

Gentianine, 211

Geoffræa, 98

Gera earth, 263

Geranieæ, 111

Geranium, 111

Gerkins, 62

Germander, 48

Gersa serpentariæ, 167

Gesso, 263

Geum, 90

Gillenia, 91

Gilly-flower, 106

Gilt-head, 144

Gin, 174

Gingelly, 55

Ginger, 24

bread, 175

grass, 18

Gingidium, 82

Gingko, 29

Ginoria, 87

Ginseng, 78

Girdle and hangers, 8

Girofle, 86

Gith, 126

Gladiolider, 25

Gladiolus, 25

Gladwyn, 25

Glaiadine, 211

Glaise, 265

Glandes, 30

Glans, 94

Glass of antimony, 241

borax, 287

gall, 290

Muscovy, 269

powdered, 268

storm, 512

wort, 43

Glasses, 268, 269

Glastum, 108, ]68, 180

Glaze, 337

Glechoma, 47

Gleditisia, 93

Glob berries, 29

Globularize, 44
Globuli bezoardicí, 453

cardiaci, 443

contrayervæ, 455

diuretici, 443

Gloves, chicken skin, 137

Glue, 337

Gluten commune, 182 of wheat, 215

Glutinous matters, 214

Glycine, 97

Glycyrrhiza, 98

Glyster, common, 343, 344

purging, 343, 344

tobaceo, 343

Flysters, veterinary, 352

Gnaphalium, 67,70

Goat, 138

stones, 27

Goat's beard, 9, 65

blood, dried, 178

milk, 178

Gold, 230

beaters' skin, 135

horse, 228

of pleasure, 108

thread, 125

Golden locks, 12, 67

rod, 67

Gom, 15

Gomme d'acajou, 152

Arabique, 152

Bassora, 153

copal, 204

elemi, 204

de Jedda, 152

Turique, 152

Gompbrena, 44

Googil, 205

Goose, 141

berives, 84

berry coffce, 177

foot, 43

grass, 53,72

grease, 215

Gorgonium, 148

Gorse, 95

Gossypium, 28

Go-to-bed-at-noon, 65

Goudron, 196

Gourd, 62

Gout wort, 78

Gouttes amères, 399

Grains, 17 d'ambrette, 121

Grains of Paradise, 26 scarlet, 147

de zelim, 122

Gram, 98

Gramen, 16, 18

Parnasai, 109

Gran farro, 16

Grana actes, 77

Avenionensia, 103

fina, 147 
INDEX.

Grana sylvestria, $14 i, 4 i 3$ tiglia, 36

Granadilla, 116

Granata, 86

Granilla, 147

Grape, 42, 111

sugar, 150

vine, 111

Graphites, 229

Grappe, 73

Grass, 18

ginger, 18

of Parnassus, 109

tree, 20

Gratia Dei, 111

Gratiola, 50

Gravel root, 67

Graves, 216

Gravelle, 130

Grease, 227, 216

Green, Brunswick, 247

bright, 501

copper, 246

iris, 475

oyster, 8

pale, 501

I'russian, 250

$\operatorname{sap}, 475$

sauce, 118

venditer, 247

Scheele's, 24i

Schweinfurt, 247

weed, 95

Gregory's salt, 212

Girewia, 120

Grias, 111

Griffes de girofle, 87

Grits, 16

(irouts, 163

Gromwell, 54

Groseularia, 84

Ground iry, 47 nuts, 96 pine, 43,48

Groundsel, 69

Gruan, 16

Grudum, 16

Girutellum, 16

Guacharo, 141

Gueco, 67

Gitsiacum, 93, 119

Ginal theria, fil

fiuana, 142

Finarana, 208

(ivarea, 112

Ohava, 85

Guenvina, 39

Guertardia, 73

Guiana alenonds, 109

Giviggiolana, 5.5

Givilandina, 94

(ivilno, 18

Gnines graius, 26

porls, :3 3
Gum agaty, 153

alouchi, 154

ammoniac, 154

anime, 204

Arabic, 152

Babul, 152

Barbara, 152

Bdellium, 154

Bengal, 153

blue, 207

Botany-bay, 207

British, 153

brown, 155

Canarium, 208

cancanie, 204

chandra, 204

clove, 208

copal, 204

cumbi, 155

East India, 153

elastic, 214

elemi, 204

guaiacum, 205

hock, 155

hog, 208

ivy, 155

juniper, 206

kino fac. 462

kikekanumala, 204

kuteera, 153

manchineel, 208

olampi, 206

opopanax, 157

St. Helena, 152

sandarach, 206

sassa, 156

Senegal, 152

storax, 206

tragacanth, 153

tree, 87

uvaria, 208

yellow, 207

Gummi aloes, 159

ammoniacum, 153

amygdalx P'ersicie, 152

anirue, 204

Arabicum, 152

astrag. trag. 153

caragua, 204

cedrinum, 208

ceragi, 152

clanderros, 204

chandetros, 204

clasticum, 214

flavum, N.S.W. 207

galda, 154

gutts gambise, 155

heders, 155

juniperi, 205, 206

kino factitium, 462

1 ycium, 161

olampi, 206

oliver, 153

Oreubungense, 152
Gummi ex oryza, 168

peucedani, 158

pruni, 153

rubrum astr. 154

Senegr, 152

Senegalense, 152

senica, 152

tragacantha, 153

Turicum, 152

ulmi, 158

vermiculatum, 153

resina acaroidis, 207

— assæ fæt. 154

- bubonis g. 155

- euphorbix, 155

- convolv. scam. 158

- ferulæ a. 154

- galbani, 155

- past. opop. 157

- scammoneæ, 158

- juniperi, 205

Gum resins, 154

Gums, 152

Gungasir, 173

Gur' ellu, 71

Gut, silk-worm, 147

Guttæ Abbatis Ross, 410

fellis, 344

nigræ, 368

vitax, 400

Guttiferæ, 110

Guy amadou, 189

Guz, 181

Gypsopliila, 117

Gypsum, 269 .

II.

Haddock, 143

Hrematites, 237

Hxmatoxylon, 94

Hæver, 37

Hair, 134 powder, 469

Halicacabum, 52

Haliotis, 145

Hams, 136, 140

Hanchinol, 89

Hard hack, 91

Haro, 139

bells, 22

Hare's car, 82

foot, 96

gall, 179

Haricot, 97

Harmel, 119

Hart, 138

Hart's tongue, 12 wort, 7!9, 81

Hartall, 228

Hartshorn, burnt, 267

red, 390

shaving", 138 
Hasta regia, 22

Haustus acid. nit. co. 345 amm. acet. 345 bismuthi, 345 salinus, 345 - effervescens, 345

Hawkweed, 64

Haws, 88

Hawthorn, 88

Hazel, 30

Head matter, 140, 217

Heading for beer, 466

Heart's ease, 116

Heaths, 60

Hedera, 48, 77

Hedycarya, 34

Hedycroa, 91

Hedysarum, 99

Helenium, 68

Helianthemum, 116

Helianthus, 71

Heliotropium, 36, 54

Helix, 145

Hell weed, 55

Helleboraster, 126

Hellebore, 21, 27, 125

Helleborine, 27

Helleborus, 125

Helmet flower, 126

Helminthocorton, 8

Helonias, 21

Helvella, 9

Helxine, 34

Hemerocallis, 21

Hemimeris, 50

Hemionites, 12

Hemlock, 79, 80

Hemp, 34, 48

Henbane, 51

Henna, 88

Hen's foot, 82

Hepar antimonii, 227, 241 sulphuris, 225

Hepatica, 11, 124

Heptaphyllum, 90

Heracleum, 81

Herb Bennet, 90

Christopher, 125

Gerard, 79

impious, 67

mastich, 47, 48

Paris, 23

Robert, 111

twopence, 45

Herba costa, 64

Doria, 68

Paris, 23

purgativa, 43

Sancti Petri, 81

Herbæ capillares, 129

emollientes, 129

pro enemate, 129

pro fotu, 129

Herbe aux charpentiers, 43
Herbe au Diable, 44

Herbs, preserving of, 2 capillary, 12, 129

emollient, 129

fomentation, 129

glyster, 129

Hermodactyles, 21

Hernandia, 40

Herniaria, 84

Herring, 144

Hesperideæ, 112

Hesperitis, 107

Heuchern, 83

Hibiscus, 121

Hiccory, 102

Hides, 135

Hieracium, 64, 69

Hiera picra, 454

High taper, 50

Hind berry, 90

Hing, 154

Hippocastanum, 110

Hippocastanideæ, 110

Hippocras, 416

Hippocratea, 110

Hippocraticeæ, 110

Hippocrepis, 99

Hippoglossum, 24

Hippomane, 37

Hippophar, 38

Hippopetamus, 140

Hipposelinum, 79

Hips, 89

Hirundinaria, 57

Hirudo, 146

Hock, 316

Hog, 140

bezoar, 181

fennel gum, 158

gum-tree, 101

lice, 147

plum, 102

Hog's-lard, 215

Holcus, 18 sugar, 150

Hollands, 171, 174

Holly, 23, 82, 103 coffee, 177

hock, 121

Holoschænos, 15

Holosteum, 117

Holostium, 44

Homo, 134

Hone, 268

wort, 80

Honesty, 107

Honey, 180

butter, 419

dew, 181

suckle, 77

of roses, 418

Hoofs, 135

Hop, 34,48

Hopea, 59
Hordeum, 16, 17

Horehound, 49, 67 candied, 449

Hore-strange, 81

Horminum, 46

Horns, 138

stink, 9

Horse, 139 balls, 442

- cordial, 443

- diuretic, 444

fat, 216

tail, 13, 29

tongue, 24

Hose fish, 145

Hound's tongue, 54

Hovenia, 104

Huaco, 67

Huanuco, 75

Huile acoustique, 478

d'anis, 413

d'aspic, 192

de eade, 196

de cameline, 187

de colsa, 187

de copalme, 202

de Gabian, 220

de marmotte, 187

de navette, 187

d'œillette, 186

d'ooli, 188

d'orange, 190

de petit grain, 190

de raze, 195

de tain, 194

de vanille, 415

de Venus, 416

Huiles antiques, 481

liquereuses, 417

Humulus, 34

Hurr nut, 86

Hurtall, 228

Huts' ellu, 71

Hyænanche, 36

Hyacinth gum, 153

Hyacinthus, 22

Hydnum, 9

Hydrargyrum, 231

acetatum, 257

calcinatum, 236

eum ereta, 457

cum magnesia, 457

muriatum, 257

- mite, 244

muriaticum corros. 257

nitratum rubrum, 236

nitrico-oxidum, 236

præcipitat. album, 245

cum sulphure, 454

sulphur. rubrum. 229

- sulphuret. nig. 454

vitriolatum, 244

Hydrastis, 125

Hydrate de deut. de pot. 275 
Ilydrocharides, 28

IIydrocharis, 28

IIydrochlorate of awiu. 281 of barytes, 280

of lime, 281

d'or, 25:2

of platinum, 252

of potash, 253

of $\operatorname{tin}, 259$

Hydrocotyle, 82

Iydrocyanate of iron, 249

Hydro-ferro-cyanate of Quinis, 290

of potash, 286

of potash ferruret, 286

Hydrogeton, 20

Hydriodate of iron, 250 of potash, 286

II ydrolapathum, 41

Hydromel vinosum, 320

1 ydrophylax, 76

Hydrosulphate of am. 282 of lime, 230 of potash, 286

11 ydrosulphuret of am. 282 of potash, 286

Hydrosulphuretum amm. 202

Hyla, 142

II lopia, 123

IIymenia, 95

IIyosciam us, 5 I

11 yuseris, 64

Hipecoon, 10 ذ

Hypccoum, 105

Iyporanthera, 94

Hypericiuese, 110

Hy[ericum, 110

Hrpnum, 12

Hypobseris, 61

Hypocistus, 37

Hypodrys, 9

Iyseop, 47, 50

H) ssopus, 47

\section{J.}

Iberie, 108

I biscus, 121

Icaco, 91

Ice plant, 85

Ichitbyocolla, 144

Icica, 101,204

Ictordes, 14

Ignatia, 58

Iguana, 142

Ikan, 128

llex, 103

Ilicidex, 103

Illecebra, 83

Illecebrum, 81

Illicium, I23

Imbricaria, 60
Iupatiens, 111

Imperatoria, 79

luperial drink, 333

Incense, 205

Indian bread, 21

grass, 148

physic, 91

pickle, 139

shot, 26

spikenard, 18

tobacco, 63

Indicum, 169, 473, 474, 491. 493

Indigo, 98, 169

Indigofera, 98

Indrabovum, 147

Infusion of bark, 331

blue flag, 336

Brazil wood, 336

dahlia, 336

litmus, 336

logwood, 336

mallow, 336

nut galls, 336

periwiukle, 336

red cabbage, 336

- roses, 336

rliubarb, 332

turmeric, 336

Infusions, astringent, 333

cathartic, 333

diuretic, 333

stimulant, 334

strengthening, 334

Infusum anthemidis, 331

armoracis com. 331

aurantii com. 331

berberis, 331

calami, 331

calumbx, 331

caryophyll. 331

cascarilla, 331

catechu, 331

cinchonse, 331

conii macul. 331

cusparion, 331

digitalis, 331

geutianæ comp. 332

guaiaci com. 331

lini, 332

menthre comp. 332

quassire, 332

rhatania, 333

rhei, $33 \% 2$

- nlkal. 332

- borsx, 332

rose, 332

enna, 332

eerpentar. co. 333

simnrouba, 332

spigclis co. 333

tabaci, 332

tamariud, c. menna, 332

uธa "
Infusum valeriauæ, 332,333

Inguinalis, 71

Injectio caust. lunaris, 345

Ink, black, 363

cuttle fish, 178

Indian, 473

marking, 361,363

nut, 86

red, 370

Inocarpus, 60

Inodium, 116

Insecta, 146

Intestines, 135

Inula, 68

Inulin, 167

Iodas hydrargyri, 245

lodate of potash, 286 of quicksilver, 245

Iodine, 300

Iodium, 300

ioduret of iron, 250

- of sulphur, 225

Ipecacuanba, 24, 57, 73, 91, 116

Ipo, 33

Ipomea, 55

Irides, 24

Iris, 25

colfee, 177

Iron, 232

liquor, 256

pyrites, 228

wood, $76^{\circ}$

wort, 48,49

Isatis, 108

Isinglass, 144

Isis, 147

I va, 48

Ivory, 139

Ivy, 77

\section{J.}

Jaborand, 32

Jacaranda, 55

Jacea, 66

Juck in a box, 40

by the liedge, 107

treo, 33

- gum, 214

Jackic, 142

Jacobrea, 68

Jacob's laulder, 55

Jaggery, 150

Julap, 54

Jalapium, 54

Jambos, 87

Jamgornas, 120

Jams, 420

Japan earth, 161 for leather, 483

transparent, 482

Japans hout. 128 
Jasione, 63

Jasmine, 59

Jasmineæ, 59

Jasminum, 59

Jatropha, 36

Jaune d'Italie, 263

Java almonds, 102

Jeea, 34

Jeffersonia, 105

Jellies, 337

from fruits, 410,420

Jennever brandewyn, 174

Jeran, 196

Jesuits' bark, 74, 99 .

Jews' ear, 10

Job's tears, 18

Jovar, 18

Jow, 16

Jubaba, 127

Judas tree, 95

Jugeoline, 55

Juglandeæ, 102

Juglans, 102

Juice, citron, 160

hypocistus, 159

lemon, 160

orange, 160

refined, 452

Juices of plants, 158

Jujubæ, 104

Jujubes, 104

Julcpum rosatum, 417

Jumble beads, 97

Junceæ, 18

Juncus, 18

Juniper, 28

Juniperus, 28

Jussiæa, 85

Justicia, 45

K.

Kachoo, 14

Kxmpferia, 25

Kaki, 60

Kale, 14

Kali, 43

acetatum, 287

aeratum, 274

arsenicatum, 283

causticum, 275

- c. calce, 457

nitratum, 283

ppm. 274

- e. tart. 272

purum, 274

sulphuretum, 225

tartarisatum, 285

e tartaro, 272

vitriolatum, 284

Kalumb, 122

Knari nuts, 128
Kaolin, 261

Karil, 120

Karoovelum pisin, 152

Katchup, 358

Keessari, 98

Kelp, 275

Kenkerig, 11

Kermes, 147

berries, 147

mineral, 227

$\mathrm{Ki}, 60$

Kiffekil, 267

Kilirorum puttay, 127

Killoia, 267

Killow, 267

Kinakina, 74, 99

Kine, 134

King wood, 128

King's spear, 22 yellow, 228

Kino, 174

Kirschenwasser, 174

Kishmish, 112

Knap weed, 66

Knawell, 84

Kncip, 173

Knot berry, 90

Knot grass, 42, 84, 91

Knowltonia, 126

Kæchlin's liquid, 387

Kœmpferia, 25

Kola, 120

nut, 120

Koleho, 59

Koondee panei vellum, 150

Koondricum, 205

Koula, 112

Kramcria, 99

Kullo charayum, 173

Kumarkuni, 153

Kunkirzud, 154

Kya putty tree, 86

L。

Labdanum, 205

factitium, $\mathbf{5 0 6}$

spurium, 462

Labiatæ, 46

Laburnum, 96

Lablab, 97

Labrum Veneris, 72

Lac animantium, 179

white, 218,219

insect, 147

spirit, 259

sulphuris, 225

Lacca, 219

cœrulea, 473

columbina, 474

Florentina, 474

fluida, 362
Lacerta viridis, 236

Lacmus, 473

Lachryma, 18

Lacquer, 404

Lacryma Christi, 317

Lactuca, 64

Lactucarium, 155

Ladang, 148

Ladanum, 205

Ladies' mantle, 89

smocks, 107

spur, 462

Lady bird, 147 cow, 147

Lady's traces, 27

Lagoecia, 80

Lagopus, 96

Lake, drop, 474

Florence, 474

lac, 474

madder, 474

orange, 474

Lamb's lettuce, 44

Laminæ balænarum, 140

Lamium, 48

Lamp black, 224

oil seeds, 36

Lamprey, 143

Lampsana, 63

Lapathum, 41

Lapis Armenus, 246

bezoar, 181

- factitius, 462

calaminaris, 239

calcarius, 269

contrayervæ, 455

divinus, 457

hrematites, 238

Hibernicus, 269

hystricus, 181

infernalis, 275

Malaccensis, 181

manati, 140

medicamentosus, 457

ophthalmicus, 457

porcinus, 181

prunellæ, 283

pumex, 268

septicus, 275,457

Lappa, 65, 72 .

Lapsana, 64 .

Larch, 28

gum, 152

Lard, oxygenised, 495

Lardizabala, 122

Larix, 28

Larks spur, 126

Laserpitium, 81

Lathræa, 49

Lathyris, 35

Lathyrus, 98

Laudanum, 426

Abbé Rosseau, 410

Dutchman's, 116 
INDEX.

Laudanum Ford's, 390

liquid, 410

cydoniatum, 410

liquid, Sydenham's, $366^{\circ}$

- tartarisatum, 390

opiatum, 156

Lauraster, 40

Lasurel, 30, 59, 91, 110

Lasureola, 39

Lauri, 39, 40

Iaurocerasus, 91

Laurus, 24, 39

tinus, 77

Laut, 148

Lavender, 44

British, 380

Lavendula, 46

Iavatera, 128

Laver, 7

Lawsonia, 88

Lead, 232

black, 229

ore, 229

oxides of, 237

red, 237

saccharum, 258

trec, 512

white, 473

Leaf gold, 230 silver, 231

Ieather, 136, 138

oak, 10

wood, 38

L.eaves, park, 110

Lecania, 91

Ixccino, 9

Lecythis, 87

Jedun, 61

Ieech, 146

Jeeks, 22, 83

Jees of wine, burnt, 272

Loger, 318

Leguminose, 92

Iemna, 28

Iemnian earth, 264

Lemon, 113, 115

grass, 18

jusce, artificial, 370

Lemonade, 360

for iciug, 360

portalle, 467

shrub, 416

I. ens, 27, 98

Ienticula, 17

Ientils, 7, 98

Lentiscus, 102

Lentodon, 6.4

Ientopetalon, 101

Ireonurus, 48

Iewparl's bane, 62

I. çídium, 108

Leptospermum, 87

J.epus, 13 .

Isekia, 12
Letchicutty elley, 127

Lettuce, 64

Leucogæa, 267

I.eucojum, 107

Levisticum, 81

Levure, 176

Ley, soap, 277

Liane, 109, 122

Libanus, 102

Libidibi, 95

Libby tree, 20

Lichen, 8, 10

gum, 153

Ligna sudorifica, 130

Lignum aloes, 37

aquilinum, 37

aspalathi, 92

Brasiliense, 95

Campechense, 94

colubrinum, 59

hæmatoxyli, 94

nephriticum, 94

pavans, 36

pterocarpi, 99

quassix, 119

rhodium, 95, 101, 128

sanctum, 119

vita trec, 119

Ligusticum, 81

Ligustrum, 59

Lily, 21, 23, 56, 104

Lilium, 21, 23

Limaturæe ferri, 232

ferri $\mathrm{pp} .250$

stanni, 233

Lime, 114, 120

shell, 271

stonc, 269

Limctta, 114

Limon, 114

limonium, 44

Limonum cortex, 113

Linaria, 50

Lincti extemporanei, 427

Linctus acidi nuriat. 427

demulecrs, 427

expectorans, 427

oleosus, 427

opiatus, 427

potasse nit. 427

stimulans, 427

Linden, 120

Lines, 116

ling, 143

Lingua cervina, 12

Liniment, escharotic, 429 muntard, 429

soap, 396

for supp. glands, 499

- thrushes, 460

linimenta extemp. 343

Jinin. oruginin, 425

album, 491

ammonix, 372
Linim. am. carbon, 372

- subcarb. 372

Arcæi, 488

calcis, 345

camphore, 478

- compos. 372

depilatorium, 428

hydrargyri, 495

opii, 345

sapon. 396

simplex, 494

tcrebinthinæ, 495

tripharmacum, 490

volatile, 372

Linkea, 39

Linnæa, 77

Linseed, 116

powder, 168

oil cake, 168

Linum, 116

Liqueur de Pressavin, 342

Liquid, bleaching, 284

boot top, 362

blister 480

colours, 362

copying, 174

purifying, 281

shaving, 402

soap, 357

water-proof, 484

Liquids, watery, 311

Liquidambar, 31

Liquidambra, 202

Liquiritia, 96

Liquor aluminis, 341

ammoniacal, 278

ammonix, 278

- acct. 282

anodynus Hoffm, 378

antimonii tartar. 365

arsenicalis, 341

calcis, 271

- muriatis, 281

carbon. amm. 278

cupr. ammon. 254

ferri alkalini, 256

for fly in sheep, 356

fuming, 225

liydrargyri oxym. 341

morphii citrat. 352

opii sedativ. 351,367

plumbi acet. $25 ?$

- superac. 258

- acet. dil. 342

poppy, 335

potasser, 274

- subcarb. 273

probatorius. 314

smoking, 297

sulacet. lith, comp. 342

sulcarbon. ammon. 278

vol. curn. cerv. 277

$$
\text { c. calcc, } 279
$$

- nssium; 277 
Liquor waterproof, 363 zinci acet. 343

Iiquorice, 94, 96, 151 refined, 452

Liquors, malt, 322

Liriodendron, 123

Lisbon wine, 317

Litharge, 237

Lithargyrus, 237

Lithospermum, 53

Litmus, 473

Litsæa, 40

Lit schi, 109

Linta, 167

Live long, 83

Liver of antimony, 227, 241 of sulphur, 225

Liverwort, 10, 11

Lixivium, 150 saponarium, 274

Lizari, 72

Load-stone, 237

Loam, 266 founders', 264

Lobelia, 62

Lobeliaccæ, 62

Lobia, 97

Lockcr gowlons, 126

Locksoy, 168

Lodicea, 20

Logwood, 94 gum, 153

Lohoch pulmon. vulp. 425

Lohochs, 339

Loligo, 145

Lonchites, 12

London pride, 83

Lonicera, 77

Lontarus, 20

Looban, 205

Loose strife, 45

Lopeza jaar, 127

Lora, 318

Loradilla, 12

Lorantheæ, 76

Loranthus, 76

Lotio acidi nitricl, 345

aluminis, 345

ammon. acet. 345

antiphlogistica, 341

evaporans astr. 341

Goulardii, 345

hydrarg. nig. 345

myrrhæ, 345

nitro-muriatica, 341

oleosa, 341

opii, 345,360

salis ammoniaci, 345

saponacea, 357

vitrioli coer. 345

Lotion, Gowland's, 341 of Prussic acid, 345

Lotions, 341, 356 astringent, 356 .
Lotions, ferricrs', 356

for grease, 356

mange, 356

for strains, 356

Lotiones extempor. 94

Lotus, 95, 97, 104

Louse wort, 42

Lovage, 81 opopanax, 157

Love apple, 52

Loxa, 74, 75

Lozenges, antimony, 447

cachou, 448

catechu, 448

Ching's worm, 451

cinnamon, 448

clove, 448

cough, 447

emetic, 451

emetine, 451

ginger, 450

gum, 449

heartburn, 447

ipecacuanha, 449

magnesia, 449

marsh-mallow, 4.47

nitre, 496

nutmcg, 449

orrice, 449

pate do rose, 450

patirosa, 450

peppermint, 449

poctoral, 447, 450, 451; 467,468

rhubarb, 450

eaffron, 448

starch, 447

steel, 449

sulphur, $450^{\circ}$

Tolu, 450

vanilla, 450

violet, 449

zinc, 450

Lucerne, 96

Lujula, 111

Lunaria, 13, 107

Lunar caustic, 253 crystals, 253

Lung wort, 10, 54, 57, 69

Lungs, fox, 425 oak, 10

Lupine, 96

Lupinus, 96

Lupuline, 34

Lupulus, 34

Lupulinum, 34

Lute, wax, 508

Luteola, 109

Lychnis, 117

Lycoperdon, 8, 9

Lycopersicon, 52

Lycopodinex, 13

Lycopodium, 13

Lycopsis, 53
Lycopus, 48

Lysimachia, 45, 49, 87

Lysimachix, 44

Lythrum, 88

Lyttæ, 146

M.

Macanet grains, 91

Macaw trees, 19

Mace, 39

Macis, 39

Mackaw fat, 188

Macrocneun, 73, 75

Mad wort, 48, 53

Madar, 57

Madder, 72, 73

Madeira, 316, 323

Madi, 71

Madia, 71

Madrepora, 147

Maduca, 60

Magisterium marcas. 242 opii, 426

Magistery of alum, 262

of bisunuth, 242

of diaphor. antim. 240

of lap. calaminaris, 239

of opium, 426

Magnes. 237

arsenicalis, 228

Magnesia, 262

alba, 262

calcined, 262

Henry's, 262

liquid, 314

nigra, 242

usta, 262

vitriolata, 281

Magnesie caustiquc, 262

Magnolia, 123

Magnoliaceæ, 123

Mahogany, 112

stain, 484

Maidenhair, 12

Maize, 17

Mala Armeniaca, 82 insana, 52

Persica, 92

Punica, 87

Malabar nut, 45

Malabathruu, 40

Malacca bean, 100

Malachite, 246

Malacorium, 87

Mallo, 120, 121

Malunsey, 317

Malpighia, 110

Malpighiaceæ, 110

Malt, 17, 176

brandy, 174

liquors, 322

spirit, 171

Maltum, 17 
Malus, 88 aurantia, 113 citria, 112 limonia, 113 Persica, 92

Malva, 121

Malracea, 120

Maramaa, 111

Mammalia, 134

Man, 134

Manati, 140

Manatus, 140

Manchineal, 37

Mandragora, jl

Mandrake, 51

Manganese, 243

Mangel wurzel, 42

Mangifera, 100

Mangoe, 100

Mangrove, 76

Mauna, 148 grass, 17 Louristan, 181 seeds, 17 thuris, 205

Manocillei, 228

Mansil, 228

Manus Christi, 450

Maple, 109 sugar, 149

Mara oppoo, 273

Maranta, 26, 166

Marasquina, 174 de groseilles, 415

Marble, 269

Marcasita argenten, 233

Marchantia, 11

Maro's milk, 179

Marga viridesccus, 267

Marmarite, 143

Marjorate, 47

Marjorana, 47

Marlow, 47

Marmor, 269

Marmelades, 418, 419

Marrons, 1.52

Marrow, 216

Marrubinen, 48 conditum, 449

Mars, 232

Martagon, 21

Marum, $47,48,53$

Marvel of l'cru, 44

Marygold, 69, 125

Mash cally, 97

Massicot, 237

Mast, beech, 30

Massoy hark, 127

Master wort, 81,82

Mastich, 203, 205, 208

tree, 102

Matalista, 128

Matclies for inst. light, 512

Mater prerlarum, 145
Materia perlata, 240

Matfellon, 66

Methuskea, 32

Matiere do Derosne, 212

Matricaria, 69

Matrisylva, 77

Matter, head, 141

small-pox, 510

vaccine, 510

Matters, glutinous, 214

Mattia, 51

Maudlin, 71

Mava, 60

butter, 188

Maw sced, 104

May, 88

apple, 105

weed, 70

Maycril, 143

Maydew, 312

Maytee, 96

Mead, 320

Meadow-sweet, 91 rue, 124

Meal bark tree, 27

Meals, resolvent, 129

Meat fruit, 33

Mecaxochitle, 32

Mechoocan, 54

Mechoacana, 54

Meconium, 156

Medeola, 24

Medicago, 96

Medium, 63

Medlar, 88

Medulla, 216

Meek rappe, 73

Meer schaum, 267 .

Meesia, 119

Megrellup, 494

Mcl, 180

AEgyptiacum, 425

boracis, 425

canna, 149

belleboratum, 418

roste, 418

scill $x, 411$

Golutivum, 425

Bubboracis, 425

ustum, 149

Melaina, 178

Mclalenca, 86

Melainbo bark, 123

Melampodium, 125

Melampyrum, 49

Melandro, 143

Melasecs, 149 spirit, 172

Melnatoma, 87

Melastomex, 87

Melengris, 141

Melia, 112

Meliacer, 112

Melicoccu, 109
Melicone, 17

Melilot, 96

Melilotus, 96

Mclissa, 47

Melittis, 47

Mellaghoo, 31

Melo, 62

Meloe, 146, 147

Melon, 62

Melongena, 52

Menispermex, 122

Menispermum, 122

Mentha, 46

Menthastrum, 46

Menyanthes, 56

Mercurialis, 34, 42

Mereurius, 231

calcinatus, 236

corrosivus ruber, 236

- albus, 257

- sublim. 257

dulcis præcip. 244

- sublimatus, 244

cmeticus flavus, 244

præcipitatus, 236

- albus, 245, 258

saccharatus, 457

vitx, 239

Mercury, 34, 42, 244

calcined, 236

fulminating, 245

white, 257

Merulius, 9

Mesembryanthemum, 85

Mespilus, 88

Metal, fusible, 233

Metals, 226

Metel, 51

Metlieglin, 320

Methonica, 21

Metrosileros, 87

Meu, 79

Mcum, 78

Mexico seeds, 35

Mezereon, 38

Mezorcuin, 38

Michelia, 123

Microcos, 120

Middlings, 165

Miglio, 17

Milabris, 146

Milfoil, 71

Milium, 17, 54

Milk, 179

almond, 339

elephant's, 415

of roses, 357

of sulpliur, 225

wort, 100

Mill mountain, 117

Millefolium, 71

Millepedes, 146

Millet, 17, 18

Milt waste, 12 
Milzadella, 48

Mimosa, 92, 93 . gum, 152

Mimusops, 60

Minium, 250

Mint, 46

Mioschilos, 41

Mirabilis, 44

Misseltoe, 76

Mistura alkalina anod. 346 ammon. acct. 346 ammoniaci, 346 — comp. 348 amygdalæ, 339 anodyna, 349 antacida, 349 antihysterica, $\mathbf{3 4 8}$ antispasmodica, 347 arscnicalis, 351 assæfotidæ, 346 - Millari, 346 bals. Peruv. 349 camphoræ, 346 carminativa, 346,348 cathart. ammon. 351 cinchonæ aper. 351 conii comp. 351 cornu usti, 335 cosmetica, 346 cretæ, 346 demulcens, 349 diaphoretica, 349 - anodyna, 349 diuretica, 348 diuret. et tonic. 348 emetica, 347 emmenagoga, 349 expectorans, 349 febrifuga, 346 ferri composita, 346 guaiaci, 346

- alkal. 352

guaiaci ammon. 346 infus. uva ursi, 351

- com. 351

moschi, 347 myrrhæ, 351 narcotica, 347 olibani co. 351 pro diarrhœe, 347 purgans, 348 refrigerans, 349 rhei com. 351 rhei comp. 346 roborans, 356 sedativa, 347 stimulans, 350 tartar. emet. 347 tonica, 350

Misturæ extemporaneæ, 345 $-352$

Mithridatium, 421

Miva cydoniorum, 430

Mixture, astringent, 346
Mixture of brucine, 850 0 infus. uvæ ursi, 351 for bugs, 481 of cyanure of pot. 350 of emetine, 350 of hydroc. of pot. 350 of Prussic acid, 350 of strychninc, 350

Mixtures, watery, 341

Mochlique des Fr. de la Charité, 458

Mohair, 138

Moil water, 320

Mollinedia, 123

Mollipuffs, 9

Mollugo, 72

Mollusca, 145

Molucca grains, 35

Moly, 22

Mombin, 102

Momea, 151

Momordica, 62

Monarda, 48

Money wort, 45

Monkey, 134 bezoar, 181

Monk's hood, 126

Monodon, 141

Monophyllon, 23

Moog, 97

Moon wort, 13, 107

Moorhungliy root, 94

Moot, 97

Morchella, 8

Morell, 8

Morhua, 17

Morinda, 76

Moringa, 94

Morochtos, 267

Morphia, 212

Morphine, 212

Morphium, 212

Morse, 140

Morsuli aceti, 447 aromatici, 447

citri, 449 stibii Kunkelii, 447

Morsus diaboli, 72 ranæ, 27

Mort à mouches, 235

Morus, 33

Moschatel, 83

Moschus, 138 fictitius, 221 in granis, 218 reductus, 428 in vesica, 138

Moss, 13 cup, 11 dead man's skull, 12 Iceland, 10 tree, 10

Mother of pearl, 14

Motor, 98
Moulc, 216

Mouse ear, 64, 192 tail, 125

Mousse de Corse, 8

Mousseron, 10

Moutarde à l'estragon, 430

Moxa, 70

Muchucunda, 121

Mucilage, 336 of flearwort seeds, 333

Mucilago acaciæ, 336 amyli, 336

g. Arab. 336

-tragacanth, 336

sem. cydon. 334

Mudar, 57

Muddi, 76

Mug wort, 70

Mugil, 144

Mugaaio, 10

Mukka, 17

Mulberry, 33

Mule, 139

Mullein, 48, 50

Mullet, 144

Multum, 161, 431

Mum, 338

Mummiæ, 134, 508

Mummy, 134, 508

Mungo, 97

Munjeet, 73

Murena, 144

Muretta, 57

Murex, 145

Murias ammoniacus, 281 ammonix, 281

- et ferri, 256

antimonii, $26 \mathrm{U}$

auri, 252

barytæ, 280

calcis, 281

hydrargyri amm. 341

- corrosivus, 557

hydr. protoxydi, 244

natricus, 287

sodæ; 287

- siccatus, 288

Muriate of ammonia, 281

of barytes, 280

of gold, 252

of lead, 249

of lime, 281

of platinum, 252

of potash, 283

of soda, 287

of tin, 259

Musa, 25

Musæ, 25

Musambrium, 161

Musc, Kebardine, 138

Muscadell, 321

Musci, 12

Muscle, 146

powder, 466 
INDEX.

Muscus, 10 clavatus, 13

Mushroom, 9, 10, 43 powder, 466

Musk, artificial, 221 bags, 138 grain, 218 grape, 22 in poc, 138 seeds, 121

Mussoor, 97

Must, 150

Mustard, 106, 107 Durham, 466 flour of, 466 patent, 430 ready made, 430 reduced fl. of, 466

Mustela, 139

Mustum, 150

Mutella, 147

Mutton, 136

Maya, 146

Myagrum, 108

II yosotis, 53

Myosurus, 125

Myrica, 31

Myriceæ, 31

Myristica, 39

Myristicæ, 39

Mrrobalani, 86, 129

Myrobalans, 40, 129

Myrobalanus, 34, 86

Myrodendrum, 101

Mrrospermum, 99

M yroxylon, 99, 213

Myrrh, 156 liquid, 156

Myrula, 156 imperfecta, 154 liquida, 156

Myrrhis, 80

Myrsen, 267

Myrteum, 188

Myrtillus, 61

Myrtinese, 86

Myrtle, 31, 86 oil, 188

Mytta, 93

Myuachic, 154

Mytilus, 145

Myxa, 53

Nafta, 113

N.

Naphx, 113

Naptha, 220 vini, 199

Napus, 107

Narcaphte, 36

Narcissi, 25

Narcissus, 24

Narcotine, 212

Nard, 18, 72
Nardus, 18, 72

Narwhal, 141

Nasturtium, 107, 108, 111

Natchenny, 17

Natre, 53

Natron, 275

ppm. 276

tartarisatum, 289

vitriolatum, 289

Nauclea, 73

Navel wort, 45,83

Navette, 107

Navew, 107

Neat cattle, 134

Necklaces, anodyne, 510

Nectar, Vauxhall, 403

Nectarine, 92

Nees berry, 60

Nelumbium, 104

Nepenthes opiatum, 437

Nepeta, 47

Nephrodium, 13

Nerf de bœuf, 134

Nerinm, 57

Neroli, 203

Nests, edible birds', 181

Nettle, $31,34,48$

Nicaragua wood, 95

Nickar, 94

Nickel, 235

Nicotiana, 51

Nidi esculenti, 181

Nigella, 126

Nightshade, 51, 52, 85

Nihil album, 239

Nin sing, 80

Nipa palm, 19

Nipple wort, 63

Nisi, 80

Nitras, argenti, 253 hydrarg. am. nit. 245 potassee, 283 sodx, 289

Nitrate of barytes, 280 of lead, 259

of silver, 253

of soda, 289

Nitre fixed by metals, 275

Nitro-muriatc of plat. 252

Nitrum, 283

carbon fix. 273

metal fixat. 275

vitriolatum, 284

Nod dá, 267

Noclatali, 91

Nirelenshena, 14

Noir d'Allemagne, 224 animal, 223

decomposition, 223

d'Faragne, 222

do Paris, 223

Nonatclia, 76

Nopalem, 84

Nontrock, 8
Nuces aquaticæ, 85 behen, 94 cupressi, 28

Nummulari, 45

Nut, earth, 82 galls, 30 haugh, 82 hazel, 30 kipper, 82 pig, 82

Nutmeg, 39

Nuxahouai, 58 moschata, 39 vomica, 58

Nyctageneæ, 44

Nyctago, 44

Nymphæa, 56, 104

Nymplıaceæ, 104

o.

Oak, 30,43, 100

Oats, 166

meal, 166

starch, 166

Ochnaceæ, 119

Ochra, 121, 265 plumbaria, 237

Ochre, 263, 264, 265

Oculi cancrorum, 146

Oculus Christi, 46

Ocymum, 47

Oehl, 187

Gillet, 117

Ginantlie, 80

Enoplia, 194

Enothera, 85

Oisypus, 216

Oglio del cèdro, 191

Oko corn, 30

Okra, 121

Oil of acorns, 189

almonds, 183

amber, 221

amyris, protium, 189

animal, 220

anise seeds, 190

apricock, 186

argan, 186

argemonc, 183

avocaulo pear, 188

balm, 192

Bapennah lamp, 187

Larabec, 185

bastard saffron, 186

bays, 185, 188, 499

becch mast, 18.5

ben, 183

Bencoolen nut, 189

benjamin, 196

benne, 188

birch, 203

bitter almonds, ess. 189

black, 480 


\section{2}

Ofl bolled, 481

bones, 232

boxwood, 209

bricks, 209

British, 479

bryonia, 200

buck wheat, 197

cabbage palm, 202

cacao, 196, 203

cajeput, 203

camellia, 196

camomile, 204, 495

camphire, 209

camphorated, 496

carappa, 196

caraway, 203

cashew nut, 198

cassia, 204

castor, 199

cinnamon, 204

clary, 204

cloves, 203

coal, 232

cocoa nut, 202

cornel, 196

cotton seed, 196

croton, 199

cucumber, 196

cumin, 204

Darby's, 498

dill, 203

Dippel's 232

drying, 499

earth worms, 477

elder flowers, 477

Exeter, 477

fish, 228

furniture, $502 \& \mathrm{c}^{\mathrm{t}}$

gardon spurge, 199

gingelly, 200

ginger grass, 202

gingko, 197

green, 477,478

ground pea, 196

guacharo, 227

hartshorn, 232

Oil and hartshorn, 372

hemp, 183

hemp nettle, 184

hops, 191

hutsella, 187

hyssop, 191

Indian almond, 183

Jatropha, 184

Java almond, 183 .

kanari nut, 185

Krumholz, 195

kuteera, 187

kyaputty, 190

lavander, 192 .

lemon thyme, 194

linseed, 185

liver, 217

Macasear, 481

INDEX.

Oil and mace, $185,188,497$ - dist, 192

madi, 185

Malacca bean, 185

marjoram, 192

margosa, 188

mastich, 184, 203

milfoil, 193

mint, 193

mucilages, 477

mustard, 187

myrtle, 188

neat's foot, 216

nerve, 216

nettle tree, 184

Newmarket, 480

nickar, 184

nut, 184

nutmeg, 193

olive, 186

palm, 188

pariritge berry, 19]

penuy royal, 193

- Virgin, 191

peppermint, 192

petre, 220, 479

physic nut, 184

pigeon, 216

pimento, 193

pinhocn. 184

pistachia, 185

poon nut, 187

poppy, 186

prepared residuo, 501

for quitters, 479

radish seed, 187

raventsara, 193

rape, 187,195

rhodium, 193

rhus. Jav. 185

rock, 220

roses, 193, 194, 477,481

rosemary, 194

rosewort, 194

rue, 194

sage, 194

St. John's wort, 477

salad, 185

Oil of salt, 302

sandal wood, 194

sassafras, 189

— nut, 189

savine, 194

scorpion, 478

shaving, 402

Sheldrake's, 483

soot, 196

spermaceti, 216

spike, $192,80,484$

star anise, 183,190

stinking trefoil, 184

stone pine, 185

sulphur, by the hell, 308

sunflower, 184
Oil, sweet. 185, 187

tausey, 195

tar, 196

tartar, 273

tea seed, 187

thyme, 193,195

for the tooth-ache, 481

train, 216

trichilia, 187

trotter, 216

turnep, 187

turpentine, 195

vernicia, 187

vitriol, 307, 310, 324

walnut, 184

wax, 220

whale, 216

wheat, 184

white lilies, 477

wine, 200

wood, 203

for worms, 480

wormweed, 191

wormwood, 189

yelk of eggs, 217

and becs' wax, 494

bush, 35

Oils, the, 477

animal, 215

compound, 477

distilled vegetable, 195

essential, 189

fish, 217

mineral, 220

mixed, 460

- for sal. v. drops, 478

mucilaginous, 183

nine, 480

vegetable, 183

Ointment, blister, 491, 492, 493,511

blue, 489

brimstone, 692

for cancer, 425

depilatory, 428

digestive, 498

Edinburgh, 495

elder, white, 490

Goulard's, 494

green, 491

itch, $422,496^{4}$

- smelling, 425

Le Mort's, 495

marshmallow, 489

Mercurial, 489

- Donovan's, 489

pile, 4.93

red precipitate, 495

savine, 496

Spanish flies, 492

for spavins, 480

Singleton's, 495

Smellome's, 494

spermaceti, 491 
Ointment, staresacre, 499 sugar of lead, \$9:2 tar, 492 white, 483 white precipitate, 491

Ointments, astringent, 495 flower of, 504

for fistulas, 498

for horses, 497

for mange, 499

01, 14

Old wires tow, 12

Oldenlandia, 77

Olea, 59 mixta, 480

Oleines, 59

Oleum abietis, 201 absinthii, 189

acori, 189

ashereum, 200

ammoniatum, 372

amygdalarum, 183

anyg. amar, ether. 189

ancthi, 190

animale, 220

anisi, 190

— reductum, 478

- stellati, 183, 190

anthemidis, 191

antimonii, 260

aurantiorum flor. 190

lalsami, 201

hen, 183

benzoini, 196

Bergamotta, 190

betulx, 203

buxi, 196

cacao, 184

cadinum, 196

crije putt, 190

calami arom. 189

camphorat, 196

camphoratum, 478

cannabis, 184

carlina, 190

estri, 190

caryophyllor, 120

- rel. 497

casian, 191

celri, 19 I

cerae, 220

cetaceum, 216

chameweli, 191

chamaemelinom, 477

ehenopodii, $|y|$

cicinurn, 184

cinnamomi, 191

ritri, 191

chrysomarlinum, 186

citri florum, 190

cocois but. 188

- nucir. 18 ?

completum, 185 ,

coniu cervi, 220
Oleum coryll, 184

cunilæ, 191

cymini, 191

desiccativum, 481

Dippelii, 220

Fixcestrense, 477

fagi, 184

fæniculi, 191

fuliginis, 196

Gual threrix, 191

hyperici, 477

hyssopi, 192

iridis, 192

jasmini, 192

jatrophæ curc. 184

juglandis, 184

juniperi, 192

do kerva, 186

kervinum, 186

lateritium, 196

— fact. 479

lathyris, 187

lauri nobilis, 188

— sass. 194

laurinum, 185

la vandulæ, 192

e lingo rhodii, 193

liliorum, 477

limonis, 192

lini, 185

lumbricortım, 49.5

macis, 185, 1.88, 192

marjoranæ, 192

maturum, 185, 198

melalcucæ. 190

meliseæ, 192

mentbr, 192

- piperitx, 192

- piper. red. 497

millefolii, 193

monarda, 193

moschate, 185

e mucilaginibus, 49.5

nyristicæ expr. 165

myrti, essent. 193

narcissi, 193

ncrvinum, 216

nucis moschaten, 193

— pini, 185

nucists, 18.5

olivarum, 186

ex omuibus, 498

omphacinuin, 186

origani, 206

- red, 479

omiun, 220

palmer, 188

- liq̨uidum, 186

papraveris, 186

petre, 220

- vulgare, 479

petrolei, 2:0, 221

potroselini. 193

pichurim, 189
Oleum,plmeuter, 193

pimpinelle, 193

- anisi, 190

pini, 195, 196

pulegï, 193

rapæe, 187

raphani, 200

ravenstarx, 193

rhodiolx, 194

ricini, 186

— red, 479

rosaceum, 477

rosx, 194,477

rosmarini, 194

rutx, 194

sabinæ, 194

salis, 302

salvi, 194

sambuci viride, 477

sambucinum, 477

Sanctæ-Mariæ, 202

santali albi, 194

sassafras, 194

scorpionum, 478

serpylli, 194

sesami, 187

sinapis, 187

spicæ, 192

stæechadis, 192

succini, 221

sulphuratum, 478

sulphuris p. camp. 308

succini red. 479

tædæ, 196

tanaceti, 195

tartari p. deliq. 273

templinum, 195

terebinthine, 195

thymi, 195

tiglii, 187

vini, 200

viride, 478

e vitellis ovor. 217

vitrioli, 307,309

Olibanum, brown, 205

in guttis, 205

jink, 205

vulgare, 208

(O)icte, 186

Olive, $33,5.9$

tree gum, 153

Omphaciusn, 160

Onagrarier, 8.5

Oncorlizz, 24

Onens, 24

One berry, 23

blasle, 23

Onion, 22

Oniecus, 146

Onobrichis, 99

Onions, 96

Oncpordum, 66

()กอะเนก, 54

Ophinglossum, 13 
Ophiorrhiza, 56

Ophioxylon, 57

Oplirys, 27

Opiate en poudre, 470

Opiatum antituberc. 428

Opium, 156

Anglicum, 157

colatum, 156

East Indian, 157

English, 157

Glaser's, 426

Glauber's, 426

Langelotte's, 426

lettuce, 155

Neumann's, 426

prep. with vinegar, 426

purificatum, 156, 209

purified, 156

Quercetan's, 426

strained, 156

Turcicum, 156

Opobalsamum, 200

Opocalpasum, 154

Opodeldoc, 396

Opopanax, 157

Opuntia, 84

Orache, 42

Orange, 87, 113

Orangeade for icing, 360

Orchides, 26

Orchis, 27

Orgeat, 340

Origanum, 47

Orlcana, 203

Ormier, 145

Ornithugalon, 22

Ornithopus, 98

Orobanche, 50

Orobanchideæ, 49

Orobus, 98

Orontium, 50

Orpiment, 228

Orpine, 83

Orrice, 24

Orror, 96

Oryza, 17

Ossa sepiæ, 145

Osmunda, 13

Osteocolla, 269

Ostrea, 145

Ostrich, 141

Osyris, 41

Otto of roses, 194

Ouvirandra, 209

Over munno, 276

Ovis, 136

Ovum gallinaceum, 141

Ox bezoar, 181

eye, 70

gall, 179, 361

lip, 45

tongue, 53

Oxalas potassæ, 298

Oxalate of ammonia, 296
Oxalis, 111

Oxide of aluminum, 262

antimony, 239

of arsenic, 315

of bismuth, 242

of calcium, 269

of cobalt, 242

of gold, 235

of iron, 237

of lead, 237

of magnesium, 262

of quicksilver, 235

of tin, 238

of zinc, 239

Oxides metallic, 235

Oxyacantha, 104

Oxycedrus, 29

Oxycoccus, 61

Oxycroceum, 505

Oxydum antimonii, 239

antim. nitro. mur. 239

- c. sul. p. nit. pot. 241 vitrif. 241

arsenici, 302

auri ammon. 243

bismuth, 242

ferri, 237

hydrargyri ciner. 235

- nitricum, 236

- rubrum, 236

sulphuricum, 244

plumbi, 248

- semivitr. 237

stanni, 238

zinci, 239

Oxymurias hydrarg. 257 potassæ, 283

Oxymuriate of quicks. 257

of potash, 283

Oxylapathum, 41

Oxymel, 41]

æruginis, 425

allii, 411

colchici, 411

e crem. tart. 411

scillø, 411

simplex, 411

of squills, 411

Oxyphosphate of iron, 250

Oxyrrhodinum, 351

Oxysaccharum rubi Id. 417

Oyster, 145

powder, 466

Oysters, preserved, 466

Ozier, 29

\section{P.}

Pachera, 121

Pacourina, 66

Paddy, 17

Pænæ, 120

Pæonia, 125

Pagils, 45

Paint, flexible, 502
Paints, fish-oil, 501

Pak fong, 235

Palisanten hout, 128

Palm, 19, 20

Palma, 19

Christi, 35

Palmæ, 19

Palmyra, 20

Pampelmus, 114

Panacæea antimonii, 241

Mercurialis, 244

Panax, 48, 78

Pandaneæ, 27

Pandanus, 27

Panic, 17

Panicum, 17, 18

Pannay, vellum, 150

Pao aquila, 128

gaban, 100

Papaver, 105

Papaveraceæ, 105

Papaw, 116

Paper, tracing, 512

waxed, 512

Papers, test, 511

Parætonium, 261

Paralysis, 45

Parfait amour, 415

Parfum pour parf. les autr. poudres, 469

Pariera, 297

Parietaria, 34

Paringhi sambrani, 205

Paris, 23

Parnassieæ, 109

Paronychia, 83, 108

Parrot's corn, 66

Parsley, 79, 81 pier, 89

Parsnep, 79, 80 sugar, 149

Parthenium, 69

Partridge berry, 61

Party gold, 230

Paspalum, 18

Pasque flower, 124

Passerina, 38

Passiflora, 116

Passifloreæ, 116

Passion flower, 116

Pasta althææ, 452

amygdalina, 430

epispastica, 427

regia, 430

Paste, almond, 430

blacking, 431

Chinese, 338

- for fistula, 425

flour, 338

German, 464

hard, 338

potato, 338

shaving, 485

Ward's, 425 
Pastes, 271

Pastilles a bruler, 471 fumigating, 471 de rose, 450

Pastinaca, 84, 86,

Pâte arsenicale, 457 de dattes, 452 de gomme Arab. 451 de Senegal, 452 de guimaure, 452 de jujubes, 452 parfumee, 469 de $r$ Églisse, 4.52 de tussilage à l'anis, 450

Patience, 41

Patientia, 41

Patins, 135

Pattibea, 76

Pau de merda, sujo, 127

Paullinia, 109

Pant, 120

$\mathrm{Pe} l 2,218$

Pea, 96, 98

Peach, 92 brandy, 174 gum, 152

Pear, 84,88 sugar, 150

Pearl ash, 272, 273

Pearls, 146 rose, 469

l'eas, issue, 506

Pecten, 79, 145

Pediculareæ, 49

Pedicularis, 49

Peepul mul, 127

P'caulina, 125

P'eganum, 119

I'ckea, 109

Pellitory, 34, 79

P'cnea, 45

l'enides, 452

J'ennicillaria, 18

Pennisctum, 18

P'ennyroyal, 46 wort, 82

Pensece, 116

Pentioner, Chelses, 426

P'entopetez, 121

Pentaphyllum, 90

Peperomia, 32

Peplun, 35

P'epo, 62

Pepper, 32

Eithiopian, 122

bark, 40

black, prep., 46:5

Cayenne, 46.5

- red, 465

clove, 86

English, 108

kitchen, 465

Jamaira, 86
Pepper, Japan, 118

monkey, 122

red, 465

Spanish, 53

wort, 108

Peraso, 155

Percarbure de fer, 229

Perchloride of quicks, 257

Perfoliata, 82

Pergulea, 58

Periclymenum, 77

Periploca, 58

Periwinkle, 58

Peroxide of antimony, 240 of iron, 238

of manganese, 242

of quicksilver, 236

of tin, 238

Per rosin, 206

Perry, 320

Persica, 92

Persicaria, 42

Persimmon, 60

Persoonia, 39

Persesquisulphate of iron, 256

Persulphate of iron, 245

Peruvian bark, 74, 75

Perygua, 77

Pes anserinus, 43 columbinus, 111

leporinus, 96

Petasites, 68

Petrol, 232

Petroleum, 220 sulphuratum, 478

Petromyzon, 142

Petroselinum, 80, 81

Petum, 51

Peucedanum, 81

Pewter, 232

Peziza, 10

Phalangium, 22

Phalaris, 17

Phallua, 9

Phaseolus, 97

Phasianellus, 145

P'hasianus, 141

Pheasant 's cye, 125

Phillandrium, 79

Philadelphus, 87

I'hillyrea, 59

Philonium, 421

Phlomis, 48

Phoes, 140

Phonix, 19

I'honphas ferri, 250

- tritoxidi, 250

hydrar. protox., 245

Quince, 290

sorde, 289

Phosphorus, 226

Phu, 72

Phyllanthus, 3.5

Phyllites, 12
Phyllon, 34

Physalis, 52

Physeter, 141

Physic nut, 36

Phrtelephas, 20

Phyteuma, 63

Phy tolacca, 43

Piccalilly, 130

Pickle, lemon, 358

for meats, 357

Pick-tooth, Oriental, 82

Picramnia, 91

Picria, 50

Picris, 64

Picroxylon, 123

Piedra de porco, 181

Pierre divine, 474

à l'eau, 261

à rasoir, 282

d'I talie, 281

Pig's flare, 140

Pigeons, 141

Pilchard, 144

Pilcorn, 16

Pilewort, 124

Pill. 16

blue, 437

Mercurial, 437

red, 438

Pills, 433

aloe, 434

analeptic, 438

anodyne, 437

antibilious, 434

aromatic, 533

Barclay's, 439

Belloste's, 438

blue, 437

calomel, 438

coloquintida, 434 .

common, 435

dinner, 439

Dixon's, 439

Fast Indian, 437

extempore, 440

family, 434

female, 434

fetid, 434

Fothergill's, 439

gamboge, 435

Hooper's, 438

Keyser's, 442

Lady Crespigny's, 439

Lady Webster's, 439

Lockyer's, 439

Matthews's, 433

Mercurial, 437

night, 437

Peter's, 439

Plummer's, 436

rhubarb, 435

Rudius's, 436,

Rufue's, 4.35

Scott's, 438 
Pills, Speediman's, 439

Starkey's, 439

storax, 437

Tanjore, 437

Ward's antimonial, 434 worm, 442

Pilulæ ex aloe, 434

aloeticæ, 434

aloes et assæ foet., 435

- c. colocynthide, 434

- compos. 434

—et myrrhæ, 436

- c. zingib., 434

ante cibum, 439

anthelminticæ, 440

argenti nit., 435

aromaticæ, 433

arsenici, 439

assæ fœtidæ comp., 435

astringentes, 440

balsamicæ, 435

benedictæ, 434

calomelanos, 439

cambogix compos., 435

catharticæ, 440

cocciæ minores, 434

colocynth. 434

ex coloc. c. aloe, 434

colocynthidis comp., 450

communes, 435

conii, 440

diambre sine odor. 433

diaphoreticæ, 441

diureticæ, 441

e duobus, 434

ecphracticæ, 434

emeticæ, 441

cmmenagogæ, 441

expectorantes, 441

extemporaneæ, 440

ferri compositæ, 440

- cum myrrha, 440

fœtidæ, 434

galbani comp., 434

e gummi, 434

gummosæ, 434

de gutta gamandra, 435

hydragogæ, 435

hydrarg†ri, 437

- submuriatis, 438

—_ comp., 438

Mathæi, 438

mercuriales, 454

narcoticx, 441

opiatæ, 437

ex opio, 437

de rhabarbaro, 435

Rudii, 436

Rufi, 436

saponaceæ, 437

saponis compositæ, 437

- c. opio, 437

e scilla, 440

scillæ compositæ, 440
Pilulæ scillæ c. zingib., 440 scilliticæ, 440

Starkei, 439

stimulantes, 442

stomachicæ, 439

e styrace, 437

terebinthinæ, 440

Thebaicæ, 437

tonicæ, 442

Pilules de brucine, 435 deuto-iod. de Merc. 435

de proto-iod. de Merc., 435

avec l'oxide d'or, 435

de strychnine, 435

de veratine, 435

Pimenta, 86

Pimpernel, 44

Pimpinella, 78, 89

Pimple mool, 127

Pindars, 96

Pine, 28

apple, 21

nuts, 27

Pinguedo ursi, 215

viperæ, 215

vitulina, 21

Pinguicula, 45

Pink, 56, 117

brown, 475

Dutch, 475

dye, 357

English, 475

light, 475

root, 90

saucers, 467

Pinknea, $7^{\circ}$

Pinna, 145

Pinus, 28

Piony, 125

Pipcr, 32, 53, 86, 118, 122

Cayenne, 465

nigr. tritum red., 461

Piperidex, 31

Piperine, 212

Piperitis, 108

Pipla more, 127

Pipperidges, 104

Piquette, 318

Pisa pro fonticulis, 506

Piscidia, 97

Pisces, 143

Pishamin, 60

Piss-a-bed, 65, 93

Pisselcon, 221

Pistachia, 102

Pistia, 27

Pisum, 98

Pitcairnia, 21 gum, 153

Pitch, 208

Burgundy, 206

Greek, 209

Jews', 221

tree, 28
Pitch, white, 206

Pittosporeæ, 103

Pittosporum, 103

Pivoulade, 10

Pix abietina, 206

alba, 206

arida, 206,208

atra, 208

Burgundica, 206

Græca, 209

liquida, 195

navalis, 209

sicca, 208

Placenta amygdalæ, 92

lini, 117,168

Placus, 71

Plane-tree, 31

Planorbus, 145

Plant lice, 147

Plantagineæ, 44

Plantago, 27, 44

Plantain, 25, 27, 44

Plants, parts of unknown, 126

Plaster, adhesive, 502

Baynton's, 503

blistering, 503

cephalic, 503

court, 510

diachylon, spread, 509

melilot, 506

Mercurial, 505

Paracelsus's, 505

of Paris, 269

soap, 505

sticking, 510

stomach, 506

strengthening, 504

Plasters, 502

adhesive, 509

corn, 509

defensive, 509

issue, 508

Platanideæ, 31

Platanus; 31

Platinum, salts of, 252

Plegorrhiza, 40

Pliant mealy tree, 77

Plum, 86, 91, 102

tree gum, 153

Plumbagineæ, 44

Plumbago, 44, 229

Plumbum album, 473

nigrum, 229

ustum, 237

Podalyria, 95

Podophyllum, 105

Pods, castor, 139

musk, 138

pepper, 53

Poinciana, 95

Pois queniques, 94

Poison-oak, 101

Poison, hyæna, 36

wooraroo, 203 
Poix de Bonrygne, 49 ;

I'oix grasse, 209 de jaune, 497 noir, 200 resine, 203

Poke weed, 43

Pole, 19 cat, 179

Polemonidex, 55

Polemonium, 55

Polish, French, 404

Polium, 49

Pollard, 15, 165

Poly, 49

Polyanthes, 24

Polycarpon, 84

Polychroite, 161

Polygala, 98, 100

Polvgalea, 100

Polygonatum, 23

Polygones, 41

Polygonum, 42

Poly mountain, 48, 49

Polrpodium, 12

Polyporly of the oak, 13

Polytrichum, 12

Poma, 88, 113

Pomacer, 88

Pomambra, 470

Pommade de deuto-iod, de Merc. 496

divine, 500

aux fleurs, 501

French, 501 avec l'hydr. de pot. 496

— liod. de zinc, 496

— ind. de pot. 496

aे la jasmine, 500

do la jeunesse, 500

de muriate d'or et de sonde, 497

d'or, 496

d'orange, 500

de proto.iod. de Merc. 496

ponr mar. le teint. 501

à la rose, 50)0

de veratnue, 496

Pomatum, common, :500

Eant India, 50()

bard Mareachal, j07

millefleurs, 5019)

roll, 507

rome, 500

sof, 501

Pombolia, 116

Pornegranate, 87

Pompholix, 239

I'ompora, 27

P'ond weed, 14

P'onna maram, 110

Pooda carapan puttay, 127

Poollughon shuttum, 139

Poon heer, 275
Poon wood tree, 110

Poonag, 37

Pop, imperial, 322

Poplar, 29

Poppy, 105, 118

Populus, 29

Porc, 143

Porcelia, 123

Pork, 140 grease, 216

Porliera, 119

Porpoise, 141

Porrum, 22

Port, Southampton, 320

Porter, 322, 323

Portulaca, 42, 85

Portulaceæ, 85

Posca, 295

Post, 320

Potalia, 57

Potamogeton, 14

Potash, 272, 273

caustic, 274,275

ppd. w. alcohol, 274

Potassa, 275

c. calce, 457

fusa, 275

impura, 272

Potusse, 272, 273

d'Amérique, 277

bleues petites, 277

de N. Yorcke, 272

Potato, 47, 52, 55

slip, 55

farina, $16 \bar{\imath}$

flies, 146

flour, 167

spirit, 173

starcli, 167

sugar, 151

tapioca, 167

Potée d'acier, 238

d'emery, 268

d'étain, 238

Potentilla, 90

Potentillex, 90

P'oterium, 89

I'otestates, succini, 373

Pothos, 14

P'otus inuperialis, 334 uvarum sice. $336^{\circ}$

Poudre it la Mareachale, 468 de Chipre, 468

clarifiante, 177

de fleurs d'orange, 468

de frangipane, 468

de jaenine, 468

de jonquille, 468

de Inpuline, 457

de mur. dior e. d. snude, 459

de roser, 468

Poudrette, 181

Youltires, veterinary, 432
Pounce, 206

Pounce liquid, 361

Pouretia, 21

Powder, aer. sodn, 460

absorbent, 463

of Algorath, 392

almond, 469

alterative, 463

antimonial, 242

arsenical, 463

astringent, 463

clothes, 476

cordial, 463

coriander, 466

crystal, 268

currie, 464

diaphoretic al. 464

diuretic, 463

Dover's, 456

D. of Portland's, 4.58

E. of Warwick's, 4.5.3

fever, 255,464

flint, 268

fly, 464

fulminating, 2.57

Gascoignc's, 453, 455

gold, 230

green senna, 463

hair, 468

ink, 473

James's, 242

Lady Kent's, 453

laxative, 464

mad dogs', 454

mushrooms, 466

musk, 469

pearl, 468

for scent boxes, 467

plate, 476

J'lummer's alter. 4.53

purging, 464

rat, 464

roseate, 470

salop, 52

Benua, 463

silvoring, 476

silver boiling, 476

of tin, 233

tooth, 470

vinlet, 468 .

whey, 467

Powders, ginger beer, 467

Dr. James's, 242

Sicidlitz, 460

sodaic, 460

spruse heer, 467

veterinary, 463, 464

Precocia, 92

P'rassium, 48

I'recipitato, green, 236

per se, 236

purple, 23.5

red, 236

swert, 244 
Precipitate, white, 245

Præcipitatum Cassii, 235

Prenanthes, 64

Preservative for the teeth, 402

Preserving, the modes of, 2 of animals, 131

Preventive, royal, 342

Prick madam, 83 wood, 103

Pride, 142

Primrose, 45, 85

Primula, 45

Prinos, 104

Privet, 59, 104

Procopum, 150

Propolis, 218

Prosopis, 100

Proteæ, 39

Proto-chlor. of Merc. 244 iodide of quicksilv. 245 iodure de Mercure, 245 nitrate of quicksilver, 258

phosphate of quicksilver, 245

sulph. of iron, 255

oxide of antimony, 239

— of iron, 237

- of lead, 237

— of quicksilver, 235

Pruna, 91

Prunella, 49

Prunelloes, 91

Prunus, 91

Prussiate of potash, triple 286 of iron, 250 of quicksilver, 258

Pseudacorus, 24

Pseudo brasilium, 91 cytisus, 96 rhabarbarum, 124

Psidium, 86

Psoralia, 96

Psychotria, 73

Psyllium, 44

Ptarmica, 71

Ptelea, 118

Pteris, 12

Ptisana communis, 336

Pterocarpus, 99

Puccoon, 105

Pulegium, 46

Pulicaria, 68

Pulmonaria, ]0, 53, 54

Pulp of prunes, 151

Pulpa cassiæ, 151 colocynthidis fact. 463 prunorum, 151

- condita, 419

tamarindi, 151

Pulque, 21, 324

Pulsatilla, 124

Pulveres extemporanei, 453 $-462$
Pulvis alexipha. Sinen, 458 aloes, compos. 456

- c. canella, 454

- c. guaiaco, 456

aloeticus, 454

- c. ferro, 456

-c. guaiaco, 456

antacidus, 459

antilyssus, 454

antimonialis, 242

- factitius, 462

aperiens, 454

aromaticus, 453

asari comp. 453

balsamicus, 457

Basilicus, 456

bezoarticus, 453

e bolo comp. 454

- c. opio, 455

calomel. c. digit. 456

calumbæ comp. 458

camphoræ, 455

carb. calcis comp. 454

catharticus, 459

cephalicus, 453

cerussæ compos. 456

e. ch. cancr. c. 453,455

cinchonæ c. soda, 458

cinnam. comp. 453

Com. Warwiciensis, 453

contrayervæ c. 455

Cornachini, 453

cornu usti c. op. 456

cretæ comp. 454

- - cum opio, 455

cretaceus, 454

cum calom. 456

dentifricus, 470

diaphoreticus, 458,460

diasenæ, 454

diaturpethi comp. 454

diureticus, 459

Ducis Portlandiæ, 458

emmenagogicus, 457

enulæ trit, red. 451

expectorans, 459

extr. Saturni, 259

hydr. ciner. 235

ipecac. compos. 456

- et opii, 456

jalapæ, 458

- comp. 454

glycyr, rad. trit. red. 461

kino comp. 455.

lientericus, 457

manualis, 469

myrrhæ comp. 455

opiatus, 456

plumbi, 232

purgans, 459

quercus mar. 223

rhabarbari, 458

refrigerans, 459

rhei comp, 461
Pulvis, sabinæ, 584

scamm. c. aloe, 456

- - calomelane, 456

- comp. 456

sennæ comp. 454

sodæ comp. 460

stanni, 233

- factitius, 461

sternutatorius, 453

stypticus, 457

succini comp. 455

sudorificus, 461

- Doveri, 456

sulph. alum. comp. 457

tonicus, 458

tragacanthæ, c. 454

de tribus, 457

Tunchinensis, 458

vermifugus, 458

Pumex, 268

Pumpion, 62

Punch, 361

shrub, 416

Punica, 87

Pundum, 203

Purging nuts, 36

Purple, Cassius', 235

Purpura, 146

vegetabilis, 219

Purslane, 42, 85

Put chuck, 127

Puttay charayam, 173

Putty, glaziers', 502 polishers', 238

Pyraceum, 320

Pyrenacex, 45

Pyrethrum, 70

Pyrites, 228

Pyrola, 61

Pyrus, 88

Q.

Quadria, 39

Quadrox. of Potash, 284

Quail, 141

Quass, 295

Quassia, 119

roasted, 177

Queen of the meadows, 91

Quercitron, 7, 30

Quercus, 30

Quick, 231

Quicken, 88

Quicksilver, 229, 231

alkalised, 456

Quills, 141 .

Quince, 88

Quinine, 213

Quinoa, 43

Quinquefolium, 90

Quinquina, 74, 75

Quinsey berries, 84 
INDEX.

Quintess. of anchory, 357

Quintess. of lemon-peel, 403

R.

Rabbit, 139

Radices aperientes, 129

Radish, 94, 106, 108

Radix curcum. tr. red. 461 Columba, 122

enulæe tr. red. 461

hellebori nigri, 125

Indic. Lopez, 127

ipecac. tr. red. 463

iridis tr. red. 462

jalapee tr. red. 462

mustelæ, 57

pefaulina, 128

rhæi tr. red. 462

salop tr. fact. 462

- - red. 462

Santre Helenæ, 128

zingib. tr. red. 462

Rag sugar, 151

wort, 68

Rags, claret, 511

Rai, 106

Raia, 143

Raising, 111, 112

Raisin spirit, 171

Ramenta ferri, 232

Rampions, 63

Ramosons, 23

Rana, 142

Ranunculacea, 123

Ranunculus, 124, 125

Rape, 107, 112

oil cake, 165

Raphanus, 106, 108

Rapum, 106

Rapunculus, 63

Raupberry, 90

Rasura cornu cervi, 138 eboris, 133

Rats' otone, 270

Ratafias, 413, 414, 415

Rattle, 49

Rattlennake root, 100

Raven, 141

Raventeara, 118

Ray, 143

Realgwr, 228

Reanmuria, 85

Recrementa sulph. viv. 224

Red, brown, 238, 520

Indian, 238

head, 57

light, 263

moroces, 12.5

orange, 237

stone, 265

tan, 83

varnish, 420
Red, Venetian, 265

wood, 100

wood tree, 112

whorts, 57

Redingcotes Ang. 137

Reed, 15, 18

mace, 15

Regina prati, 91

Regulus, 234

antimonii, 234

of antimony, 226, 234

of arsenic, 235

arsenici, 235

of cobalt, 234

Jovis, 234

Relish, Kitchener's, 359

Rennet, 135, J 42 whey, 179

Repasse, 170

Reptilia, 141

Reseda, 109

Resedaceæ, 109

Resina abietina, 201

abietis, 201, 206

- humida, 206

alba, 206

- humida, 206

aloes, 209

calami, 209

caryophyllorum, 208

chibou, 204

cort. Peruv. 209

flava, 209

guaiaci, 205, 209

jalapse, 209

laricis, 201

lentiscina, 205

ligustici, 208

liq. copaiferæo, 201

- pini bals. 201

- lar. 201

nifra, 209

pini, 2()1, 206

coinm. 206

- nativa, 206

- ol. vol. dep. 209

jistaciso 1. 20.5

pterocarpi dr. 206

scammonii, 209

strohilina, 201

succini, 221

terebinthi, 201

turpethi, 209

Reaino, 506

Kesins, snimal, 218

Rest harrow, 96

Revcille matin, 35

Reviver, black, 38.5

Rhabarbarum, 41

Rhamnus, 104

Rhapontic, 41, 66

Rhaponticum, 41,66

Rhatania, 100

Rheum, 41
Rhenish, 316

Rhinanthus, 49

Rhizobolus, 109

Rhizophora, 76

Rhodia, 83

Rhodiola, 83

Rhododendron, 61

Rhœas, 105

Rhubarb, 41, 124

Rhubarbe, 41, 66

Rhus, 101

Rib grass, 44

wort, 44

Ribes, 84

Ribesia, 84

Rice, 17

coffee, 176, 177

paper, 127

Riche's support, 61

Ricinus, 35

Rindera, 57

Ring-worm bush, 94

Rinuzzo, 9

Risagon, 25

Risigallum, 240

Ritro, 66

River-horse, 140

weed, 8

Rivinia, 43

Roach, 145

Roan, 88

Rob. bac. samb. 152,436

bl. currant, 152

berberidis, 435

ccrasi, 435

do cornis, 435

cydonior, 435

dyacaryon, 160, 424

diamorum, 434

elderberry, 152, 436

prunorum, 436

ribes, 152,436

Robinia, 97

Robinsonia, 37

Rocambole, 32

Rocella, 11

Rochetta Alexand. 289, 290

Rocket, 107, 108, 109

Rood caliatour hout, 99

eben hout, 128

Englischer, 277

hout, 99

Root of scarcity, 42

Roots, 127

opening, 129

preserving of, 12

Roquette, 289, 290

Rosa, 89, 109 mala, 29

Rosacem, 89

Rose, 38, 54, 57, 77, 89, 125

Rose Bay, 57

Rosella, 109 
Rosemary, 38, 44, 46, 64

Rose roof, 83

wood, $53,54,55,95$, 101

wort, 83

Rosetti, 8

Rosin of aloes, 209

augia, 209

Barbadoes cedar, 208

black, 209

brown, 209

bursera, 208

calamus, 209

coumia, 208

escallonia, 208

fir, 206

guaiacum, 209

jalap, 209

Jamaica birch, 204

kina-kina, 208

lovage, 208

mombin, 208

Moschat, 204

native, 206

New Zealand, 208

sandal, 208

scammony, 209

tabernæm. 208

turbith, 209

varnish, 207

volkameria, 208

white, 206

yellow, 209

Rosins, animal, 218

Ros majalis, 312

melleus, 181

Solis, 109

Rosmarinus, 46

Rossalis de six gr. 414

Rottleria, 37

Rouge, 467

d'Angleterre, 238

d'Espagne, 467

Indienne, 265

Jeweller's, 238

liquid, 357

de Prusse, 263

vert d'Athènes, 467

Rough bound, 143

Rousette, 143

Rubber, Indian, 214

Rubia, 72

Rubiaceæ, 72

Rubigo chalybis, 250 ferri, 250

Rubrica fabrilis, 265

Rubus, 90

Ruby-blende, 229

Ruddle, 265

Rue, 12, 98, 119, 124

Ruellia, 45

Rum, 172

shrub, 416

Rumex, 41
Rumphal, 14

Runckel, 143

Runga matta, 279

Runnings, 150

Rupture wort, 84

Ruscus, 23

Rush, 13, 15, 18 nut, 15

Russia seeds, 18

Rust of iron, 250

Ruta, 12, 98, 119

Rutaceæ, 119

Rye, 17

coffee, 177

flour, 166

starch, 166

\section{S.}

Sabbatia, 56

Sabina, 29

Saccharum, 15, 149, I50 candum, 149

hordeatum, 452

lactis, 149,179

Saturni, 258

Sack, 316

Sacradaans hout, 128

Safflor, '270

Safflower, 66

Saffra, 270 .

Saffron, 20, 25, 66 cake, 129

Sagapenum, 158

Sage, $46,48,53$

Saggina, 18

Sagitta, 27

Sagittaria, 27

Sago, 167

Sagou, 19

Saguaster, 19

Sagus, 19

Sain doux, 215

foin, 99

St. John's bread, 93

- wort, 110

Lucie wood, 91

Marten's hout, 128

Peter's corn, 16

- wort, 110

Sal absinthii, 272 acetosellæ, 284 acid. boracis, 302

alembroth, 258

alkali, 276

ammoniac, 281

— volatile, 277

- - lavandulæ, 460

cathart. amarus, 281

— Glaub. 289

communis, 287, 288

com. decrep. 288

cornu cervi, 277
Sal diureticus, 287

enixum, 284

Epsom, 281

febrif. Sylvii, $28 \%$

fossilis, 287

fuliginis, 278

gemmæ, 287

Indus, 149

Martis, 255

mirab. Glaub. 289

nitri, 283

ossium, 278

petræ, 283

polych. Glas. 285

prunellæ, 283

Rupellensis, 289

sal petræ, 288

sapientix, 258

secr. Glaub. 282

succini, 310

tartari, 272

vitrioli, 252

vol. oleosum, 460

- sal. amm. 278

Salep, 27, 52

Salsafy, 65

Salicariea, 87

Saliceæ, 29

Salicine, 213

Salicor, 275

Salicornia, 43

Salix, 29

Sallow, 29

thorn, 38

Salmo, 144

Salmon, 144

Salmoni hout, 128

Salsola, 43

Salt, amber, vol. 310

baker's, 277

barilla, 276

bark, ess. 173

of bones, vol. 277

common, 287,288

decrepitated, 288

Epsom, 281

Glauber's, 289

hartshorn, 277

lemons, essential, 476

Loudon's solid, 287

neutr. arsen. 283

ox teeth, 277

petre, 283

pickling, 465

Rochelle, 289

rock, 287

smelling, 277

upon salt, 288

salt petre, 288

of soda, 276

sorrel, 284

sore throat, 283

of tartar, 272

of urine, 278 
Salt, tasteless purring, 289 vitriol sed. 302 volatile, $27 i$ wood soot, 278 wormwood, 272

Salt cats, 288 fish, 144 wort, 33

Salts, Cheltenham, 459 neutral, 279 smelling, 460

Salve, eye, 490 Dupuytren's eye, 495 healing, 493 lip, 500 pepper, 496

Salvia, 46, 48

Sambac, 59

Siambucus, 77

Samolus, 45

Samphire, 43, 81

Sampsucus, 47

Sanamunda, 38

Sand, 268 wort, 117

Sandal tree, 38

Sandaraca, 206 Greec. 228

Sanders, 38, 99

Sandiver, 290

Sandix, 237

Sanguinaria, 105

Sanguine, 265

Sanguis draconis, 206 — fact. 506

birei sice. 178 hominis, 178

Sangnisorba, 89

Sanguisorbese, 89

Sanicle, 45,82

Sanicula, 82

Santa Maria leaf, 32 - trec, 110

Sintalsces, 38

Sintaliun, 38, 99

Soutallara, 70

Siantonica, 70

Sontonicum, 70

Sapa, 150) areti, 290 ,

Sapindace, 109

Sapindus, 10?

Sapium, 36, 37

Sapo, 484, 48,5 alt. UIsp. 485 Alenais, 48.5 amygdalinus, 484 Cast. marm. 183 mollis, 48.; niger, 48.5 tartari, 485 Venetus, 48.5 vitriolirus, 485 Sapodilla, 60
Saponaria, 109, 117

Sapoteæ, 60

Sappan, 94

Surcocolla, 45, 148

Sarmentacere, 111

Sarsaparilla, 15, 24, 78

Sassafras nuts, 40

Satin flower, 107 wood, 128

Satureja, 47

Saturnus acetosus, 259

Satyrion, 27

Satyrium, 27

Sauce alone, 107 fish, 359

Quin's, 358

superlative, 359

tomato, 358

Saul-tree, 28

Saumah, 17

Saur kraut, 106

Saururus, 20, 32

Sausages, 134, 136

Savine, 29

Savonettes, 486, 487

Savory, 47

Saw wort, 66

Saxifrage, 79, 83, 117

Saxifrageæ, 83

Scabiosa, 63, 72

Scabious, 63, 72

Scalaria, 145

Scales of iron, 237

Scallop, 145

Scammonium Alepp. 158

Smyra. 158

- factit. 462

Scammony, 62

Aleppo, 158

French, 158

plant, 55

potato slip, 158

Smyrna, 158

Scandix, 79

Scaphu, 59

Scariola, 64

Scarlet grains, 147

Scents, poinatuin, 481

Scloenanthus, 18

Schageri cottan, 120

Schiefer, polier, $266^{\circ}$

Schinus, 102

Schistus carbonarius, 267 nollis, 266 pictorius, 267

Scilla, 22

Scincus, 142

Scirpus, 15

Sclarea, 46

Scleranthus, 84

Scobs styracina, 207

Scolopendrum, 12

Scolymus, 64

Scomber, 144
Scordium, 48

Scorodonia, 48

Scorodoprasum, 22

Scorpioides, 99

Scorpien grass, 53 wort, 99

Scorzonera, 65

Scotia, 93

Scrophularia, 50

Scrophularex, 50

Scurvy grass, 55, 108

Scutellaria, 48

Sea bear, 140

calf, 140

cow, 140

dog, 140

grass, 8, 149

holly, 82

horse, 140

lion, 140

moss, 8

sword, 141

Seal, 140

Sebestenex, 53

Sebestens, 53

Sebifera, 40

Secale, 17

Scconds, 165

Secretions, animal, 177

Securidaca, 98

Sedge, 15

Sedum, 83

Seeds, cold, $1: 29$ hot, 129

Seggrum, 68

Sego, 19

Sel d'opium, 212 de verie, 304

Selago, 13

Self heal, 48

Selinum, 82

Semecarpus, 100

Semen cina, 70 contra, 70

Semilla, 131

Scmina anisi trit. red. 479

fœenugræeci t. r. 473

calida, 129

frigida, 129

tschischim, 94

Semola, 16

Semoletta, 16

Semolino, 16

Sempervivum, 84

Senceio, 68

Sencza, 100

Seneka, 100

Senellip, 883

Sengreen, 27

Senna, 58, 93, 94, 99

Sensitive plaut, 93, 94, 99

Sepia, 145, 178

Septfoil, 90

Scrapias, 27 
Sereque, 95

Seriana, 109

Sericum, 219

Seris, 63

Serjeant, 121

Serpentaria, 14, 37

Serpentes, 142

Serpyllum, 47

Serratula, 66

Sersoon, 106

Serum lac, $179,342,360$

Service-tree, 88

Sesama, 18

Sesamum, 18, 55 seeds, 110

Sesbon, 99

Seseli, 79, 81, 82

Sesquicarb. of ammo. 291 of soda, 290

Sesuvium, 85

Setaria, 17

Setter wort, 126

Sevum, 136, 216 meliloti, 499

Shaddock, 114

Shagreen, 143

Shale, black, 281

Shallots, 23

Shark skin, 143

Sheep, 136

Sheeps' dung, 181 scabious, 63

Shell, liquid, 281 tooth, 143 tortoise, 141 turtle, 141

Shepherds' purse, 108 needle, 79

Sherardia, 73

Sherbet, 360,370

Sherry, 316, 323

Sheta, 106

Shorea, 28

Shrub, 416

Sida, 121

Sideritis, 48, 49

Siderodendrum, 76

Sigillum Salomonis, 23

Sil, 265

Silene, 117

Siler, 81

Siligo, 15

Siliqua, 97 dulcis, 93

Silk, 219

crow, 8

weed, 57

worm, 147

Silurus gall, 179

Silver, 231

weed, 90

Simarouba, 27, 119

Simaroubeæ, 119

Simovia, 145
Simplocineæ, 59

Sinapis, 106

Sinapism, 428

Siphonia, 37

Sirium, 38

Sirop de capillaire, $\mathbf{4 0 6}$ de cuisinière, 410

cyanique, 409

d. hyd. cya. d. pot. 410

Syrop d'orgeat, 340 de pomme de terre, 151

Sisarum, 80

Sison, 80

Sisymbrium, 46, 107

Sium, 80

Size, 185 gold, 483

Skate, 142

Skink, 142

Skins, basil, 136 druggists' gut, 136 sausage, 136

Skirret, 80 spirit, 174 sugar, 149

Slate, alum, 270 drawing, 267 Irish, 269

Sleeve fish, 145

Sloc, 92

Smallage, 78

Smalt, 270, 271

Smectis, 266

Smerillus, 268

Smylax, 24

Smyris, 268

Smyrnium, 79

Snail, 145

Snake root, 37, 46, 126 stone, 181 weed, 38,82 wood, 59,128

Snap dragon, 50

Sneeze wort, 71

Snuff, 471, 472 cephalic, 453

Soap, Alicant, 485 almond oil, 484

Banda, 188

black, 485

Castille, 485

croton oil, 485

ley, 277

liquid, 3.57

Macquer's acid, 485

Marseilles, 485

purified, 486

soft, 485

Starkey's, 485

transparent, 485

Venice, 485

Windsor, 486

berries, 109

rock; 261
Soda, 275

acetata, 239

caustic, 275

impura, 275

phosphorata, 289

ppd. with alcohol, 276

pure, 276, 277

tartarizata, 289

gold, muriate of, 252

Solaneæ, 50

Solanine, 213

Solanum, 51

Soldanella, 45, 55

Solder for tin, 234

Solidago, 68

Solomon's seal, 23

Solutio acet. zinci. 260 mur. barytæ, 280

- calcis, 281

oxym. calc. 281

sulphat. cupri c. 341

alcohol de deuto iod. de Merc. 400

Solution of albumen, 338 of arsen. Fowl. 341

of burnt sugar, 433

of hematine, 364

of hydroiod. potash, 287

of indigo, 361

of iodine, 300

— alcoh. 400

of isinglass, 337

of malva, 363

of picromel, 363

of potash, 273

- White's, 352

of starch, 338

of subl, corr. 258

Solvens minerale, 341

Solvent for antimony, 306 mineral, 341

Sonchus, 64

Soojee, 16

Soot, 224

Sop, 123

Sope wort, 117

Sophia, 107

Sorb, 88

Sorbets, 340

Sorbus, 88

Sorgho, 18

Sorghum, 18

Sorrel, 41, 111, 121

Soude, 275

Soup, portable, 337

Sour cream, 180

Southern wood, 70

Sow bread, 45

Soy, 358

Spanish flies, 147

Spar, 269

Sparadrapum adhæs. 509 diachyli, 509

Gualteri, 509 
Sparadrapum, pro fonticulis, 508

viride, 508

Sparganium, 15

Sparrow grass, 23

Spartium, 95

Sparus, 144

Spatham ponderos. 269

Spear-worh 124

Species aromaticæ, 470

for bitters, 129

pro conf. opii, 461

diambre, s. od. 453

diatragac. frig. 454

for diet drink, 130

equinus, 463

for hair powder, 469

hieræ picræ, 454

pro mist. cretæ, 460

for wash balls, 467

scordii c. opio, 455

- sine opio, 455

sternutatoria, 130

Specific, worm, 458

Speed well, 49

Spelta, 16

Spelter, 233, 239

Spergula, 117

Spermaceti, 217 oil, 217

Sphagnum, 12

Sphondylium, 81

Sphragis, 263

Spica, 46

Spice, cow, 463

English, 465

horse, 463

ragouth, 465

sausage, 465

sevoury, 465

sweet, 465

Spider wort, 23, 28

Spielman's camph. vin. 369

Spices, 235

Spigelia, 56

Spignel, 79

Spikenard, 18, 48, 67

Spilanthus, 71

Spina, 120

albe, 83

cervina, 103

Spinachin, 42, 143

Spinage, 42

Spindle tree, 103

Spirzea, 91

Spirit of amber, 310

angelica, 374

balm, 380

boue, 277

cloves, 375

Clutton's febrif. 379

coriander, 375

dyers, 2.59

from faints, 186
Spirit, Guyot's, 382

of hartshorn, 277

of hyssop, 376

of jasmin, 380

lac, 259

of lemon pecl, 376

nitre, 305 thyme, 381

- swect, 378

oranges, 379

ox-teeth, 277

pennyroyal, 377

peppermint, 376

proof, 172

rye-bread, 298

sage, 381

sal. ammon. 278

— with lime, 278

salt, 302

— dephlog. 306

- swcet, 378

scurvy grass, 377

- golden, 400

soup herbs, 402

star anise-seed, 374

sweet basil, 381

- marjoram, 381

tartar, 299

turpentine, 195

urine, 278

verdigris, 296

of vinegar, 368

of vitriol, sweet, 378

of wine, 170,174

- for varnishes, 172

— and camphire, 385

wood soot, 278,296

wormwood, 374

Spirituous liquors, 169

Spiritus æther. arom. 399

- nitr. 378

- sulph. 378

— vitr. 378

comp. 379

alexiterius, 375

smmonix, 370

- aromat. 371

- compos. 371

- foetid. 371

- succinatus, 373

anisi, 374

angelicar rad. 374

armoracite, 377

aurantii cort. 374

buxi, 297

calami arom. 380

camphore, 385

camphoratus, 385

cassixe, 375

caryoph. aroin. 375

castorei, 375

carui, 375

cinnamomi, 375

cochlearix purg. 415
Spiritus, coch. simp. 377

colchici amm. 371

coriandri, 375

cornu cervi, 277

croci, 375

febrifugus Clut. 379

frumenti, 171

fuliginis, 278

hyssopi, 376

juniperi, 174

- compos. 376

lavandulæ, 379

— comp. 391

ligni, 297

melissæ, 380

menthæ, 376

- piper, 376

Mindereri, 282

myristicæ, 377

nitri, 304-306

- dulcis, 378

nuc. mosch. 377

pan. secal. 298

pimento, 376

pulegii, 377

raphaui c. 377

rectificatus, 172

rosæ, 381

rosmarini, 378

salis, 302

— ammon. 278

- dulc. 370

— dulc. 378

— mar. coag. 283

— volat. oleosus, 370

salvix, 381

saponis, 402

succini, 310

syrupo, 172

tartari, 299

tenuior, 172

terebinthinæ, 195

thymi, 381

turion. pini. 377

urinæ, 278

Veneris, 296

vini, 170

- camphoratus, 36.5

vinos. rect. 170

- tenuior, 170

vitrioli, 307,310

- dulcis, 378

volatilis arom. 371

- fort. 371

Spirits, bathing, 384

compound, 374

Splcen wort, 12

Sponndias, 102

Sprodium, 223

proparatum, 267

Sponge, 8

bleached, 511

burnt, 223

Spongia, 8 
Spongia, dealbata, 511

rosæ, 89

usta, 223

Sprats, 144

powder, 466

Spruce beer, 323, 32t

Spunk, 9

Spurge, 35, 38

Spurry, 117

Squalus, 143

Squamæ ferri, 237

Squamaria, 49

Squash, 62

Squill, 22

Squinancy wort, 72

Stachys, 48,49

Stag, 138

Stain for crocus, 405

oil, 484

spirit, 405

Stalagmitis, 111

Stanniolum, 233

Stannum, 233

granulatum, 233

pulveratum, 238

Stapelia, 58

Staphisagria, 126

Staphylea, 103

Star of Bethlehem, 22 shoot, 8

thistle, 66

wort, 67,71

Starch, 166, 167

boiled, 336

sugar, 151

Statice, 44

Staticeæ, 44

Stave wood, 119

Staves acre, 1:0

Steel, 232

Stein, galitzcn, 259

Stellaria, 117

Sterculia, 120

Stcrculiaceæ, 120

Stibium, 234

Stickleback, 144

Stissera, 26

Stigmarota, 120

Stinking weed, 83, 93

Stitch wort, 117

Stizolobium, 99

Stock fish, 144 gilliflower, 107

Stockvisch hout, 95

Stæchas, 46, 67

Stone, lancet, 268

Stone-crop, 83

lime, 269

lumber, 261, 265

marking, 267

ochre, 263

oil, 269

pumice, 268

rotten, 266
Stone, water-of-Ayr, 268

Stones, 268

five precious, 268

Stopping for the feet, 517

Storax, 206

tree, 59

liquid, 202

Stramonium, 51

Strapping, 527

Strap wort, 84

Strass, 271

Stratiotes, 27

Strawberry, 60, 90

Strigau earth, 263

Struthio, 141

Strychneæ, 58

Strychnine, 213

Strychnos, 58, 59

Stuff, 466

Sturgeon, 143 fat, 216

Styphelia, 61

Styptic, Eaton's, 398

Styrax, 206, 207

alba, 202

calam. fact. 497

colata, 207

- fact. 497

liquida, 202

— red. 497

tree, 59

Subacetas cupri, 247

Subboras sodæ, 287

Subcarbonas amm. 277

ferri, 251

kali, 273

magnesia, 262

plumbi, 248

potas. imp. 272

— pur. 272

- e tart. 272

sodæ, 276

- exsíc. 276

Subcarbonate of am. 277 of potash, 273

of soda, 276

Suber, 31 ustum, 223

Sublimate, corrosive, 257 sweet, 244

Submurias hydrarg. 244 — ammoniac, 245

- præcipit. 244

Subnitras bismuthi, 242

Subphosphate of soda, 289

Substances, roast. veg. 176

Subsalts, metallic, 242

Subsulphas hydr. flav. 244

Succada, 62

Succinas am. liq. pyr. 283

Succinate of ammon. 282

Succinum, 221

Succisa, 72

Succory, 63
Succory coffee, 177

Succus glycyrrhizæ, 151

Hispanicus, 151

hypocistidis, 159

prun. sylvestr. 158

spis. acon. nap. 158

- atropæ b. 159

— aurantii, 159

- cicutæe, 159

- conii, 159

- hyoscy. 159

- lactucæ, 160

- limon. 160

- momordicæ, 168

- pap. somn. 156

samb. bac. 152

Sudia, 91

Suet, 136, 216

Sugar, 148

barley, 452

black, 151

cane, 18

of lead, 258

lemon, 449

milk, 179

spirit, 171

Sugars, 148

Sugre, 143

Sukka birosa, 205

Sula, 141

Sulphas aluminæ, 279

- exsiccat. 280

barytæ, 269

cinchonæ, 290

cupri, 253

ferri, 255

magnesiæ, 281

potassæ, 284

- c. sulph. 285

sodæ, 389

zinci, 259

Sulphate of alum. and am. 280

— and pot. 279

of ammonia, 296

barytes, 269

brucine, 291

copper, 253

indigo, 363

iron, 255

lead, 248

lime, 269

magn. and soda, 289

morphia, 291

quinine, 290

soda, 289

stryclunine, 291

Sulphis sodæ, 283

Sulphite of soda, 288

Sulphur, 224, 225

of antim. gold, 227

auratum antim. 227

nativum, 224

præcipit. 225

sublimatum, 225 
Sulphur vivum, 224 water, sal. 314 wort, 81

Sulphuret of antim. 226 arsenic, 228

irou, 229

lead, 229

potash, 225

quicksilver, 2.29, 230

Sulphurets, metallic, 226

Sulphuretum ant. fus. 228 - pracip. 227

ferri, 229

hydr. nigr. 471

- rubr. 229

kali, 2:25

potasser, 225

Sulphurs, 224

Sumach, 100

Sun dew, 109

flower, 76, 125

Superacetas plumbi, 258

Supersulphas potasse, 284

Supertartria potassa, 285

Suppositorium vermif. 428

Suppository, cathart. 428 narcotic, 428

Surahwah nut, 117

Surmach, 226

Sus, 140

Swallow wort, 57

Sweet William, 117 wood, 50

Swieteria, 112

Sycamore, 33, 110

Symphytum, 54, 69

symplocarpus, 14

Simplucos, 59

Siringa, 87

Syrop of berberries, 412 balsamic, 409

buck thorn, 412

cinchonine, 409

cinuamon, 406

clarified, 412

clove pinks, 406

cloves, 406

cochineal, 406

corn roses, 408

cow-lipg, 40's

currants, 412

elder berries, 412

emethe, 409

gall, 410

parlick, 40.5

gentiasin, 409

ginger, 409

horchound, 408

liorse radish, 40f;

ipecacusaha, 410

kcrmes, 413

of lemon juice, 407

- peel, 413

lemons, 413
Syrop liquorice, 407

lupuline, 409

maidcuhair, 406

marsh mallows, 405

morphia, 409

mulberries, 407

nutmegs, 413

opium, 407

orange juice, 413

- peel, 413

peach blossoms, 408

poppies, 407,408

Pruss. acid, 409

quinces, 407

quinine, 409

raspberries, 412

red cabbage, 417

rhubarb, 408

roses, 408

rue, 408

saffron, 406

simple, 405

sulph. of morphia, 409

vanilla, 415

violets, 417

Syrupus acetosus, 411

acid. acet. 411

alkermes, 413

allii, 405

althæx, 405

amomi zing. 409

amygdalinus, 355

aruioraciæ, 406

aurantii, 413

balsamicus, 409

de berberis, 412

brassicæ rubra, 417

capill. Ven. 406

caryoph. arom. 406

- rub. 406

citri aur. 413

- med. 407

coccincllæ, 406

cinnamomi, 406

corallii, 406

croci, 406

cydoniorum, 407

dianthi car. 406

fellis, 410

hordeatus, 340

ipecacuasha, 410

limonis, 407

mal. Persic. 408

martubii, 408

meconio, 407

inororum, 407

nuc. mosch. 413

opii, 407

papaveris, 407,408

paralyscos, 408

pectoralis, 406

prassii, 408

rhabarbari, 408

rherados, 408
Syrupus rhamni cath. 412 ribis, 412

rosaceus, 408

roser, 408

rubi Idæi, 412

rutæ, 408

sambucinus, 412

sarsaparillæ, 409

scillæ, 411

sennx, 409, 423

simplex, 405

spinæ cervinæ, 412

toluif. bals. 409

Tolutanus, 409

violarum, 417

volatilis, 410

zingiberis, 409

T.

Tabac, 472

Tabacnm, 51

Tabasheer, 271

Tabaxir, 271

Tabelle card. 446

Tabernæmontana, 58

Tablettes anticat. 447

- de Spitzlait, 451

de Tronchin, 447

Tablets, purple, 449

Tacamalıaca, 215, 219

Tagetes, 68

Talcum, 269

Talinum, 85

Talc, 269

Tallow, 216

Java, 188

litswa, 188

pœnoc, 188

tree, 36

vegetable, 189

Tamarind, 93 pulp, 151

Tamarindi, 93

Tamarindus, 93

'Taunariscince, 8.4

Tamariscus, 84

'Tamarisk, 84

'Tamus, 24

'Tanacetuu, 69

'Tan-balls, 30

'Tanner's bark, 30

'Tamnin, 314

Tunsey, 69, 90

Tupioca, 167

'Tupsimel, 425

'Tapsus, 50

'Tar, 195, $196^{\circ}$

Barbadocs, 2:21 coal, 221

T'araxacum, 65

Tare, 98

Targorium, 59

Tarragon, 70 
Tartar, emetic, 260 soluble, 285 vitriolated, 284

Tartarum, 284 album, 285 antimoniatum, 260 boraxatum, 285 emeticum, 260 ferri, 256 rubrum, 285 solubile, 477,285 tartarisatum, 285 vitriolatum, 284

Tarton-raira, 41

Tartras antimonii, 260 kali, 285

potass - et sodæ, 289

Tartris borax. pot. et sod. 285 potassæ, 285 , - et sodx, $289^{\circ}$

Taxidæx, 29

Taxus, 29

Tea, Apalachian, 104 Bowles's herb, 130 camomile, 331 China, 114, 115 for icing, 340 imitation, 130 Labrador, 61 linseed, 332 Mexican, 43 Mongul, 130 New Jersey, 104 Oswego, 48 Paraguay, 96, 163 Russian, 130 in tiles, 131 Toolsie, 47

Teas, Chinese kinds of, 114, 115

Teasel, 72

Tectonia, 45

Teeth, 135, 143

Teinture de gentianin, 388 de lupuline, 391 de myrrhe, 391

Tela aranearum, 219 Gualteri, 411

Telephium, 83

Tellicherry bark, 57

Tellinum, 85

Tenne vellum, 150

Tent, wine, 317

Tent wort, 12

Tents, sponge, 510

Terebintaceæ, 100

Terebinthina argent, 201

Brianzonica, 202

Canadensis, 201

Chia, 201

— fact, 497

cocta, 209

communis, 201
Terebinthina Cypria, 201

Veneta, 20]

vera, 201

vulgaris, 201

Terebinthine comm. 201

fine, 201

de Suisse, 201

de Venise, 201

Tereniabin, 148

Terminalia, 86

Ternstromiex, 63

Terra cariosa, 266

cimolia, 261

Coloniensis, 195

dulc. vitr. 238

fol. tartari, 287

fullinoca, 266

Japonica, 161

Lemnia, 261, 273

makemakey, 168

Melia, 266

merita, 26

Orleana, 203

Persica, 265

ponderosa, 270

Portugallica, 270

Samia, 261

saponaria, 261, 266

sigillata, 263,265

Tripolitana, 263

Turcica, 264

Umbria, 266

viridis, 266

de Patna, 265

de Sienna, 265

verte, 266

Tespesia, 100

Testudo, 141

Tetranthera, 40

Tetragonia, 95

Tetrao, 141

Tetraodon, 143

Tencrium, 48

Thalia, 26

Thalictrum, 124

Thapsia, 79

Thea, 114

Theacea, 114

Theobroma, 121

Theophrasta, 58

Theriaca Andromachi, 422 communis, 149

Germanorum, 162

Londinensis, 429

pauperum, 162

Thesium, 38

Thistle, 65, 66, 71, 105

Thlaspi, 108

Thoa, 34

gum, 153

Thora, 124

Thorn, 88, 92, 104

apple, 51

back, 142
Thorough root, 67

wax, 82

Thran, 217

Thridace, 160

Throat wort, 63

Thrymba, 47

Thuja, 28

Thus in guttis, 205

Judæorum, 206

in massis, 205

vulgare, 206

Thyme, 47

Thymelex, 38

Thymelæa, 38

Thymiama, 36

Thymus, 47

Ticuna, 208

Tilia, 120

Tiliaceæ, 120

Tillandsia, 22

Timac, 122

Timpost, 148

Tin, 230, 233

foil, 233

glass, 233

tree, 530

Tincar, 287

Tinct. absinthii, 382

- comp. 382

acaciæ catechu, 386

acet. ferri, 388

aconiti, 382

aloes, 382

— ætherea, 383

- composita, 393

- c. myrrha, 393

amara, 383

ambr. gris, 401

amomi rep. 385

- zing. 399

Angusturæ, 383

an themidis,

antimonii, 383

— diaph. 400

aristol. serp. 397

aromatica, 384

- amm. 371

assæ fœet. 388

-

bals. Peruv. 384

- sulph. 384

- Tolut. 384

belladonnæ, 387

benzoes, 401

- comp. 398

Bonpland, trif. 383

calami, 384

camphoræ, 385

- comp. 392

camphorata, 392

cantharidum, 385

capsici, 385

cardamomi, 385

- comp. 397 
INDEX.

Tinct. cardiac, 395

cascarillse, 385

cassize bac. 386

castorei, 385

- comp. 372

catechu, 385

centaurii cacum. 384

cinchonæ, 386, 402

- 2mm. 471

cinnamomi, 386

- comp. 384

colchici, $38 \mathrm{j}$

colombæ, 384

conii mac. 387

contrayerva, 387

convolv. jalapee, 390

corticis Peruv. 386 volat. 371

croci, 397

vinosa, 365

crotonis eleuth. 385

cubebxe, 387

curcumæ, 405

cusparize, 383

datura stramonii, 403

dict. albi, 387

digitalis, 388

euphorbii, 388

- alkalina, 352

fellis, 388

ferulæe asere foet. 388

ferri amm. 388

flor. Mart. 388

foetida, 388

- volat. 371

fuliginis, 352,388

galbani, 388

gallarum, 389

gent. comp. 383

gratioles, 389

guaiaci, 372,389

- smm. 372

- vol. 371

gummi animc, 383

flavi, 389

hellebori, 389

— albi, 399

- nigri, 389

hicra, 364

humuli, 389

hyoscismi, 390

hyperici, 389

iodii, 400

iorlinis, 400

ipecac. 390

jalapee, 390

jalapii, 390

Japonica, 386

kino, 390

laccer, 390

lactucarii, 391

laur. cinn. 387

lavand. comp. 391

lytto, 385
Tinct. Martis, 256

- Myns. 399

-c. sal. amm. 388

— in spir. sal. 388

mur. ferri, 388

mastichis, 391

melampodii, 389

meloes ves. 385

mimosæ cat. 386

moschi, 401

myrrhs, 391

opii, 390

— amm. 373

papaveris, 393

pini, 392

piperis, 392

psychotriæ sulph. 393

pyrethri, 394

quassix, 394

rhabarbari, 394

rhabarbari vinosa, 36

rhataniæ, 395

rhæi, 394

— et aloes, 395

- amara, 395

- et gent. 395

rhodii, 395

ricini, 395

rosarym, 332

sabinæ comp. 391

sacra, 364

salis tartari, 397

saponis comp. 396

— et opii, 383

sarsaparillæ, 397

Saturnina, 396

scillæ, 397

sennæ, 396

serpentarix, 397

stomachica, 39 ?

styptica, 398

succini, 400

sulphuris, 398

- volat. 225

tabaci, 401

Thebaica, 366

theriacalis, 398

Toluiferæ bals. 384

valcriansc, 399

- amm. 272

- vol. 372

veratri, 399

zingiberia, 399

Tincture of allnpice, 402

antimony, 383

bark, 385

- with lime water, 352

henjamin, 401

IBestucheff's nerv. 400

hlack hellebore, $\$ 89$

Brazil woorl, 40.5

cantharides, 38.5

cardamoms, 385

cardine, 395
Tincture of cassia, 386

castor, 385

coloquintida, 387

euphorbium, 388

- alkaline, 352

foxglove, 388

gall, 388

ginger, 399

guaiacum, 389

- volatile, 371

Hatfield's, 389

henbane, 390

hops, 389

iodine, 400

myrrh, 391

— and aloes, 391

nut galls, 389

nux vomica, 392

opium, 390

orange peel, 463

piscidiæ Erythrinæ, 395

poppy, 393

psychotria sulph. 393

- of spice, 402

peryth, 394

quassia, 394

red sanders, 405

rhatany root, 395

rhubarb, 394

saffron, 387

St. John's wort, 405

salt of tartar, 397

snake root, 397

sp. of turpentine, 399

squills, 397

stecl, 388

stomach, 397

stramonium, 387

sulphur, 398

for the tecth, 402

turmeric, 405

valerian, 399

Tinctures, 382, et seq.

for kitchen use, 402, 403

Tinder, German, 9

Spanish, 67

Tisane de ris, 336

Titan cotte, 59

Tithymalus, 35

Toad, 142

flax, 50

Tobacco, 51, 63

British herb, 130

Tococa, 87

Torddy, 150, 324

Tolu, 202

Toluifera, 99

Tolutanum, 202

Tomatoes, 52

Tonea bean, 99

Tongues, 13.4

Tonq̨uin remedy, 458

Toona, 112

Toorushoo, 253 


\section{8}

Tooth-ache tree, 118 pick, 82

wort, 44,49

Tordylium, 82

Tori, 106

Tormentil, 90

Tormentilla, yo

Tortivum, 156

Tortoise, 142

Tota bona, 42

Touch me not, 111

Touchwood, 9

Tournesol en drap, 511 en pains, 473

Touroulin, 87

Toxicodendron, 36,100

Toyes, 14

Tradescantia, 20

Trachelium, 63

Tragacantha, 153

Tragopogon, 65

Tragorchis, 27

Trapa, 85

Traveller's joy, 124

Treacle, 149

Venice, 422

Trefoil, 56, 96, 118

Tramella, 8

Tribulus, 85, 119

Tricheeus, 140

Trichilia, 112

Trichomanes, 12

Trichosanthes, 62

Trifolium, 36, 96, 119, 124

Trigonella, 96

Trilliaceæ, 23

Trillium, 23

Triopteris, 110

Triorehis, 27

Triosteum, 77

Trip, 238

Tripe, 134

Tripoli, 263, 266

Tripolium, 67

Trissago, 48

Triticospeltum, 17

Triticum, 15

vaccinum, 49

Tritoxide of manganese, 242

Tritosulphate de fer, 256

Troschisci althæx, 447 amyli, 447

- sine iride, 447

bechici albi, 447

- flavi, 447

- nigri, 448

carb. calcis, 447

e creta, 447

glycyrrhizæ, 448

- cum opio, 448

gummosi, 449

magnesiæ, 449

nitri, 450
INDEX.

Troschisci spongiæ ustæ, 450 Ulva, 8, 18 sulphuris, 450

Trollius, 126

Trona, 275

Tropæolum, 111

Trubs, 8

True love, 23

Truffles, 8

Tsi Xu, 110

Tsin-y, 123

Tsinaw, 24

Tschillie, 53

Tschischim, 94

Tuber, 8

Tuberose, 24

Tulip, 22

tree, 123

wood, 128

Tulipa, 21

Tulipaceæ, 21

Tunny, 144

Turbeth, 44, 54

mineral, 244

Turbo, 145

Turkey, 141

berries, 104

Turk's cap, 21

Turmeric, 26

Turnip, 14, 104, 106

Turnsol, 36, 54

Turpentine, 195, 199, 201, 202,203

tree, 102

Turpethum, 54

minerale, 244

- red, 462

Turps, 195

Turritis, 107

Turtle, 142

Turund intumescent, 510

Tusk, 143

Tussilago, 68

Tutenague, 235

Tuthia, 289

Tutia, 239

Tustan, 110

Tutty, 239

Tway blade, 27

Two penny, 323

Trpha, 15,18

Typhaceæ, 15

Tyre, 192

\section{U}

Ubruc, 269

Ulex, 95

Ulmaria, 9]

Ulmarieæ, 91

Ulmide $x, 31$

Ulmine, 158

Ulmus, 31

Ultramarine, 270

maeis, 497
Umbelliferæ, 78

Umber, 182, 266

Umbilicus Veneris, 83

Umbria, 266

Uncaria, 73

Unction, 507

Unguentum acet. plumbi, 492

acidi nitrosi, 495

adipis suillæ, 490

AEgyptiacum, 442

æruginis, 491

album, 488, 481

camphor. 488,493

- c. cerussa, 488

ex altliæa, 489

ammonix, 496

basilicon flavum, 488

- nigrum, 488

- viride, 491

calaminare, 493

calcis hydr. albæ, 491

canthar. 492

catechu, $496^{\circ}$

ceræ, 491

- albæ, 494

- flavæ, 494

cerussæ, 488

- acetatx, 492

cetacei, 491

cœeruleum, 489

conii, 494

detergens, 491

elemi, 488

- comp. 438

epispasticum, 493

- equinum, 497

hæmorrhoidale, 494

helleb. albi, 4.93

hydrargyri, $48 ?$

- nitrati, 493

nitrico-oxydi, 495

— præe. albi, 491

iodureti sulphuris, 494

lap. cal. Saturn. 496

laurinum, 499

linarix, 493

lyttx, 492

meloes, 493

e Merc. præcip. 491

nervinum, $49 \mathrm{l}$

nitr. hydr. 494

nutritum, 490

ophthalm. 490, 494

opiatum, 493

oxidi hydr. cin. 495

- - rubri, 494

— plumbi albi, 488

- zinci, 490

picis, 492

- liquidæ, 492

piperis nigri, 496 
Unguentum plumb. c. 494

- superacet. 492

populneum, 491

pro porrigine, 493

resinæ albee, 488

- flave, 488

- nigræ, 488

resinosum, 488

rubr. desicc. 490

sabinx, 496

sambuci florum, 490

- riride, 491

Saturninum, 492

simplex, 490, 494

sperm. ceti, 491

subacet. cupri, 491

- plunbi, 488

subm. hydr. am. 492

subnitr. bydr. 495

sulphuris, 492

— compos. 492

supernitr. hisdr. 493

tetrapharm. 488

tripharm. 490

tutiæ, $\mathbf{4 9 0}$

veratri, 493

ad resicat. 492

zinci, 490

Ungula alcis, 139

Unicorn fish, 141

Unicorn's horn, 141

Lnio, 145

Uniones, 145

Unona, 122

Upas antiar. 33

Uríneola, 58

gum, 214

Urea, 178

Urena, 16

Urina, 178

Urine d'Elephant, 415

Ursus, 133

Urtica, 34, 48

Urticexe, 34

Usnea, 11, 12

Caquebaugh, 414

flavum, 398

viride, 398

Iva criepa, 84

ursi, 60)

Uva, 111

Uvaria, 122

V.

Vaccaria, 117

Vacrinia, 61

Vaccinice, 6,1

Vaccinum, 61

Vahea, 58

Vakaks, 461

Valantia, 73

Valerian, 5.5, 72
Valeriana, 72

Valcrianex, 72

Vallea, 120

Valonia, 30

Vangloc, 55

Vanilla, 26

Vanillon, 27

Vaquois, 27

Varecq, 289

Varnish, amber, 502

for col. drawings, $50 \mathrm{l}$

common, 501

copal, 419,500

for etching, 520,526

flexible, 501,423 .

furniture, 500

for grates, 501

Indian, 420

for iron, 420

Italian, 501

japanner's copal, 500

for leather, $500 \mathrm{kd} 3$.

mastic, 500

Mauger's, 419

oil, copal, 500

peyna, 203

picture, 500

ponoe, 203

for prints, 500

reddish, 404

spirit, 404

stopping out, 508

nuaker's spirit, 172

tree, 86

white, 403

Varnishes, oil, 484 spirit, 403

Vateria, 120

Vaugeria, 73

Vaybadum puttay, 127

Veal, 134

fat, 216

Vegetable marrow, 62

Vegetables, I modes of prescrving, 2

Vejuco, 64

Velvet leaf, 122

Venison, 138

Venus' comb, 79

Veratrine, 214

Ventrum, 2I

Verbascum, 51

Verbena, 45, 46

Verbesina, 71

Verdigris, 247

distilled, 254

English, 247, 254, 47.'

French, 254

Verditer, refiner 8,246

Verjuice, 160

Vermeille, 147

Vermes, 146

Veruilinn, Chinesr, 220

Dutch, 229
Verncllo, 15

Vernicia, 37

Vernis de colle, 38, 338

Martin, 501

petit, 526

Veronica, 49, 50

Vert de mitis, 261

Vervain, 45, 46

Vespetro, 415

Vetch, 96, 99

Viburnum, 77

Vicia, 98

Victorialis, 23

Vicnna green, 247

Vicktril, Faln, 254

Villarsia, 56

Villey bolun, 156

Vin d'aulnée, 321

cnit, 150

Vinacea, 112

Vinaigre dentrifrique, 369 dist. de lavande, 369

d'Orleans, 294

rosat. 369

de rosmarin, 369

Vinasse, 170, 275

Vinca, 58

Vinegar, 293

aromatic, 368

camp. 369

concentrated, 296

currie, 369

distilled, 295

four thieves, 363

radical, 295

raspberry, 370, 417

rue, 368

salad, 370

squill, 368

of wood, 297

Vinegars for cookery, 369 impregnated, 367

Vinum, P. L. 314

I. U. S. 314

albuin IIispan, 316

- montanum, 316

aloes, 364,382

aloct. alkal. 364

amarum, 365

antimoninle, 364

antin. tartar. $365,3.99$

antiscorbuticum, 36.5

benedictum, 364

Burgunticum, 316

Burilegalense, 317

Champanamecine, 317

Canarinum, 316

chalybentum, 365

cinchonse, 36.5

- comp. 36.5

colchiri, 387

- florum, 366

- radicum, $366_{5}$

- scminum, 356 
Vinum croceum, 365

enulæ camp. 365

ferri, 365

Frontignacense, 317 gentianæ comp. 365

helleboratum, 365

— albi, 399

ipecacuanhæ, 366, 390

Madeiracense, 316

Martianum, 365

nicotianæ, 366

Olissopanense, 317

opiatum, 410

opii, 366,390

rhabarbari, 366

rhei palm. 366

Rhenanum, 316

rubr. Port. 318

scilliticum, 366

- comp. 366

tart. antim. 365

tintum, 317

veratri, 399

viperinum, 366

Xeres, 316

Viola, 63, 116

Violaceæ, 116

Violet, 21, 107, 116

Violet wood, 122

Viper, ] 43

Vipera, 143

Viper's fat, 215 garlic, 23

grass, 65

Virga aurea, 68

Virgin's bower, 124

Viride æris, 247 montanum, 246

Virola, 39

Viscum, 76 aucupum, 215

Vismia, 110

Vitellus ovi, 177

Vitex, 45

Vitis, 7,111

Vitriol, blue, 253

calc. white, 256

to clean coppers, 3

de Chypre, 254

Cyprian, 253

Cyprische, 253

Dantzic, 255

Goslar, 254

green, 255

Hungarian, 254

Pisan, 255

Roman, 254

de Rome, 255

Saltzburgh, 255

Swedische, 254

white, 259

Vitriolium, album, 259

ad albed. calc. 256

cœruleum, 253 cupratum, 254

Cyprium, 253

ferratum, 255

ferri, 25.5

hermaphr. 255

Hungaricum, 254, 255

Romanum, 255

triplum, 254

viride, 255

vulgare, 255

Vitrum antimonii, 241

- ceratum, 458

pulverisat. 268

Viverra, 139

Volkameria, 46

Volubilis, 42

Vomit, Marriot's dry, 459

Vullam pisin, 153

W.

Wad, black, 242

Wadi ennad, 148

Wafers, glue, 512

Wake Robin, 14

Walkera, 119

Wall flower, 107

Wall, pepper, 83

Walnut, 102

sugar, 16

Walrus, 140

Warroogo, 18

Wartwort, 35

Wash, black, 345

distillers', 172, 295

silver, 404

white, 342

yellow, 341

Wasser, stark, 304

Water, acidulous, 313

allflower, 179, 329

allspice, 328

aniseed, 326

arse-smart, 327

barley, 336

Bate's eye, 342

baulm, 328

bean-flower, 329

bitter almond, 327

black cherry, 326

blue vitriol, 254

camel's hay, 330

camomile, 375

carraway, 326,375

carb. of amm. 278

- of potash, 273

— of soda, 276

carbonated lime, 213

cardamom, 375

carline thistle, 329

cassia, 326

chalybeate, 311

cinnamion, 327,375 copperas, 255

cordial mint, 376

cumin, 327

dill, 326

distilled, 312

elder-flower, 330

eye, $342,343,356$

fennel, 327

fly, 352

fruits, for icing, 360

gentian, 376

germander, 330

hepatic gas, 314

holy, 3 । 2

honey, 297

Hungary, 377

hyssop, 327

hysteric, 374

impreg. fixed air, 313

juniper, 327

laurel, 327

lavander, 374

— double distil. 379

- simple, 329

lemon peel, 327

lily of the valley, 329

lime, 271

- flower, 320

marjoram, 330

meadow-sweet, 330

mint, 328

myrtle flowcr, 329

nutmeg, 328,376

orange flower, 329

- peel, 326

oxal, of ammon. 282

pennyroyal, 328,377

peppermint, 328

pimpernel, 328

piony, 377

plague, 375

poppy, 328

potash, 273

pure ammonia, 279

— soda, 276

rain, 311

raspberry, 330

rose, 330

- root, 330

rosemary, 330

rue, 329

acid of salt, 302

saline-sulphur, 314

sea, 312

soda, 313

soldier, 29

spear-wort, 327

Spa, 313

star-anise, 329

lily starch, 179

strawberry, 329

Stygian, 312

sw. scent. honey, 380

Syden. styptic. 341 
W ater, tar, 331

treacle, 377

vanilla, 330

yellow sanders, 3.30

Waters, alkaline, 312

aluminous, 312

artificial, $31: 2$

copper, 312

distilled, 3.2.5

hard, 311

for icing, 360

natural, 311

petrifying, 312

purging, 311

salt 311

sulphureous, 311

War, bees', 218

- factitious, 506

gilders', 506

green, 188

sealing, $50 \pi, 508$

- soft, 508

white, 218

Waybreal, 44

Way-faring tree, 77

Webera, 73

Weed, 7

Weinmannia, 75,83

Weld, 109

Whale, 140, 141

bone, 140

fins, 140

oil, 217

Wheat, 15, 17, 50

flour, 16.5

gluten, 21.5

starch, $166^{\circ}$

Whey, 179, 342, 360 powier, 466

Whin, 96

Wlina, 96

Whirkey, 174

White, alum, 262

bean tree, 88

bear gall. 179

bottle, 117

Derbyshire, 269

of $\mathrm{egg}, 177$

ne, 248

R. ke, 248

Keinp's, $2 \pi 0$

lead, 248

mineral, 248

Morvean's, 270

permanent, 269

pearl, 242

rot, 82

Spanish, 24:2, 261

Wilkinson's, 248

Whites, sharp, 466

Whiting, 144, 253
Whitlow grass, 83, 108

Whortle berries, 61

Widow wail, 101

Willow, 29, 85, 91

herb, 45,49

W'ine, 316

of aloes, 364

antimonial, 364 .

Cayenne, 367

basil, 367

bitters, 365

cinchonine, 367

currie, 367

elecampane, 365

English grape, 316

ipecacuanha, 366

Port, 317

of quinine, 367

ragout, 367

raisin, 318

Rhenisb, 316

rhubarb, 366

shallot, 367

squills, 366

steel, 365

test, 313

viper, 366

Wines, grape, $316-319$

impregnated, 364

made, 318

Winter green, 61

Wintera, 112

Winterana, 123

Winter's bark, 123

Wiserpukki, 61

Wishecompuoware, 61

Witherite, 270

Woad, 108, 168

Wolf's bane, 126

Woman's milk, 179

Womum, 78

Wontay, 32

Woolbine, 77

Wood, drying of, 2

Wood, bitter, 122

lice, 146

roof, 72

sage, 48

waxen, 95

Woorls, sudorific, 114

Wonginon, 102

Wool, Spanish, 51]

Wooraroo, 203

Wootay korashanum, 181

Worm bark tree, 99

drenclice, 354

grass, 56

seed, 43,70

Worm wood, 70

Wound wort, 69

Wrack, 7, 14
X.

Xanthium, 72

Xanthorrhea, 20

Xylobalsamum, 101

Xylocasia, 40

Xylopicrum, 123

Xylostroma, 10

Y. and \%.

Yam, 24

Yarrow, 71

Yeast, 174, 175

Yelk of egg, 1,7

of wool, 216

Yellow, 502

chrome, 252

Indian, 181

Naples, 249

patent, 249

qucen's, 244

weld, 475

earth, 263

root, 125

weed, 109

wood, 118, 122

Yeroocum pawl, 159

Yew, 29

Yucca, 21

Yu-lan, 123

Zacintha, 64

Zaffre, 270

Zamia, 20

Zanthophyllex, 118

Zanthorrliza, 125

Zanthoxylon, 118

Zea, 17

Zeocriton, 16

Zedoaria, 2.5

Zedoary, 25

Zeopyrum, 17

Zerumbet, 25

Zibethum, 219

reductum, 429

Ziegel thee, 130

Zinc, 233

Zincum, 233

calcinatum, 2.37

vitriolatum, 2.59

Zingileer, 14, 25, 26

Zirbel nuts, 27

Zivet perfume, 139

Zizunia, 18

Ziziphora, 48

Znophyte, 147

Zosiera, 11

Zosterere, 14

\%sgophylles, 119

Kignhisllum, 11!?

TIE FNI). 
I.ONDON :

BRADBLRY AND EVANG, PRINTFRS, WIITEFRIAKS

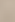




\section{A P P E N D I X,}

Containing the alterations which have been introduced into the London Pharmacopoia of 1836 . According to the edition of the Pharmacopoia Londinensis of 1836, the values of the liquid measures have all been changed, and are at present as follow:-

$\left.\begin{array}{ll}\text { Congius or Gallon } & \mathrm{C} \\ \text { Octarius or Pint } & \mathrm{O} \\ \text { Fluid ounce } & \mathrm{f} z \\ \text { Fluid drachm } & \mathrm{f} z \\ \text { Minim } & \mathrm{m}\end{array}\right\}$ Contains $\begin{cases}\text { Eight Pints } & \text { O viii. } \\ \text { Twenty fluid oz. } & \text { f zxx. } \\ \text { Eight fluid drachms } & \text { f zviii. } \\ \text { Sixty minims } & \text { m lx. }\end{cases}$

Aconitina. Aconitine.-Take of the root of aconite, dried and pounded, two pounds; rectified spirit three gallons, dilute sulphuric acid, solution of ammonia, purified animal charcoal, of each a sufficient quantity; boil the aconite with a gallon of the spirit for an hour in a retort to which a receiver is annexed; pour off the liquor, and what remains again boil with another gallon of the spirit and the recently-distilled spirit, and pour off this liquor. Let the same thing be done a third time. Then express the aconite; and all the liquors being mixed and strained, let the spirit distil: evaporate what remains to the proper consistence of an extract. Dissolve this in water, and filter. Evaporate the liquor by a gentle heat, so that it may acquire a consistence not unlike syrup. To this add of dilute sulphuric acid mixed with distilled water, a sufficient quantity to dissolve the aconitine. Lastly, drop into it the solution of ammonia, and dissolve the precipitated aconitine in dilute sulphuric acid, mixed with water as before. Then add the animal charcoal, occasionally shaking the vessel every quarter of an hour. Then strain, and again dropping in the solution of ammonia, in order to throw down the aconitine, wash and dry. 
Use. - This is too dangerous a preparation for internal exhibition. An ointment has been made of it in the proportion of one grain to a drachm of hog's lard in neuralgic affections.

Carbo Animalis purificatus. Animal Charcoal purified.-Take of animal charcoal one pound; hydrochloric acid, water, of each twelve fiuid ounces: mix the hydrochloric acid with the water, and pour it gradually on the charcoal; then digest for two days with a gentle heat, occasionally shaking it. Set aside, and pour off the supernatant liquor; then wash the charcoal with water frequently renewed, until no acid can be perceived; lastly dry.

Use.-This is employed to deprive the alcaloids, \&c., of foreign colouring matter.

Argenti Cyanidum. Cyanide of Silver.-Take of nitrate of silver two ounces and two drachms; dilute hydrocyanic acid, distilled water, of each a pint; dissolve the nitrate of silver in water, and add the dilute hydrocyanic acid, and mix. Wash the precipitate with water, and dry.

Use.-Sometimes used for the preparation of hydrocyanic acid.

Hydrargyri Bicyanidum. Bicyanide of Mercury.-Take of percyanide of iron eight ounces, binoxide of mercury ten ounces, distilled water four pints; boil together for half an hour, and strain. Evaporate the liquor, that crystals may form. Wash the residue frequently with boiling distilled water, and, the liquors being mixed, evaporate again, that crystals may form.

Hydrargyri Iodidum. Iodide of Mercury.-Take of mercury one ounce, iodine tive drachms, alcohol as much as may suffice; rub together the mercury and the iodine, the alcohol being added gradually, until the globules are no longer seen. Dry the powder as soon as possible by a gentle heat, excluding the light, and keep it in a well-stopped vessel.

Use.-This is used in making an ointment for inveterate venereal ulcers. The proportions are 20 grains of the iodide to $1 \frac{1}{2}$ ounce of lard.

In preparing the biniodide of mercury double the quantity of iodine is used with the same quantity of mercury, and it is employed in the same cases. An alcoholic solution of it is also employed in the treatment of scrofulous affections combined with syphilis. The proportions are, alcohol at $36^{\circ}$ one ounce and a half, biniodide of mercury 20 grains. The dose of the solution is 10,15 , or 20 drops in a glass of distilled water.

Plumbi Iodidum. Iodide of Lead. - Take of acetate of lead nine ounces, iodide of potassium seven ounces, distilled water 
APPEXDIX.

one gallon. Dissolve the acetate of lead in six pints of water, and strain, and to them add the iodide of potassium previously dissolved in two pints of water. Wash the precipitate thrown down, and dry.

Use.-It is used in the form of an ointment.

Liquor Potassce effervescens. Effervescing Solution of Potass.Take of bicarbonate of potass one drachm, distilled water one pint; dissolve the bicarbonate of potass in the water, and transmit through it a quantity of carbonic acid, forcibly compressed, more than is sufficient for saturation. Keep the solution in a well-stopped vessel.

Liquor Potassii Iodidi Compositus. Compound Solution of Iodide of Potassium. - Take of iodide of potassium ten grains, iodine five grains, distilled water one pint ; mix that they may be dissolved.

Use.-This has been found serviceable in cases wherein iodine is indicated. Its dose is from miij to $m v i j$.

Morphice Acetas. Acetate of Morphia.-Take of morphia six drachms, acetic acid three fluid drachms, distilled water four fluid ounces; mix the acid with the water, and pour it on the morphia until it is saturated. Let the solution be evaporated by a gentle heat, so that crystals may form.

Use.-This is used where opium is indicated. It may be given in the dose of from gr. $\frac{1}{4}$ to $\mathrm{ij}$. It is considered to be the basis of Battley's Liquor Opii Sedativus.

Morphia hydrochloras. Hydrochlorate of Morphia.-Take of opium, cut up into bits, one pound; crystals of chloride of lead two ounces, or a sufficient quantity; purified animal charcoal three ounces and half; hydrochloric acid, distilled water, solution of ammonia, of each a sufficient quantity. Macerate the opium in four pints of the distilled water for thirty hours, and pound it ; then, when it has been digested for twenty hours more, express it. Macerate what remains for a second and a third time in water, so that it may be tasteless, and pound it and express it each time. Evaporate the mixed liquors by a heat of $140^{\circ}$ to the consistence of syrup. 'I'hen add three pints of distilled water, and, when all the faces have subsided, pour off the supernatant liquor. To this add gradually two ounces of chloride of lead, previously dissolved in four pints of boiling distilled water, or a sufficient quantity, until nothing more is thrown down. Pour off the liquor, and wash the residue repeatedly with distilled water. Then, having mixed the liquors together, evaporate, as before, by a gentle heat, and set aside, that crystals may form. Press these in a linen cloth; then dissolve in a pint of distilled water, and digest with one 
sunce and half of animal charcoal, at a temperature of $120^{\circ}$; then strain. Then, having washed away the charcoal, cautiously evaporate the liquors, that pure crystals may form. Into the decanted liquor from which the crystals were first separated, previously adding a pint of water, gradually drop a quantity of solution of ammonia, sufficient to throw down all the morphia, shaking the vessel occasionally. To this, when washed with distilled water, add the hydrochloric acid, so that it may be saturated; then digest with two ounces of animal charcoal, and filter. Lastly, all the charcoal being washed away, evaporate the liquors cautiously, that pure crystals may form.

Use, \&c.

Acetum Cantharidis. Vinegar of Cantharides.-Take of powdered cantharides two ounces, acetic acid one pint; macerate the cantharides in the acid for eight days, shaking them occasionally; then express and strain.

Use, \&c.-As an extemporaneous blister. 


\section{,}







\section{THE LIQRARY FACULTY OF PHARM 9 CY UNIVERSITY OF TORCNTC}




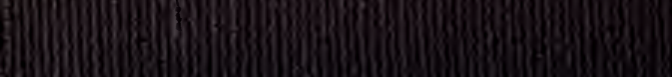

8,

(5)

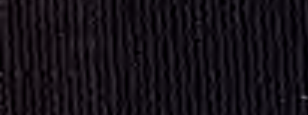

stens 